\title{
2. SITE 462: NAURU BASIN, WESTERN PACIFIC OCEAN, DEEP SEA DRILLING PROJECT LEG $61^{1}$
}

\author{
Shipboard Scientific Party ${ }^{2}$
}

\section{HOLE 462}

Date occupied: $1550 \mathrm{Z} 28$ May 1978

Date departed: 0700Z 8 June 1978

Time on hole: 10 days, 14 hours, $12 \mathrm{~min}$.

Position (latitude; longitude): $7^{\circ} 14.25^{\prime} \mathrm{N} ; 165^{\circ} 01.83^{\prime} \mathrm{E}$

Water depth (sea level; corrected $\mathbf{m}$, echo sounding): 5181

Water depth (rig floor; corrected m, echo sounding): 5191

Bottom felt (m, drillpipe): 5189

Penetration (m): 617.0

Number of cores: 69

Total length of cored section $(\mathrm{m}): \mathbf{6 1 6 . 5}$

Total core recovered $(\mathrm{m}): 376.8$

Core recovery $(\%)$ : 61

Oldest sediment cored:

Depth sub-bottom (m): 599

Nature: Brown clay, chert

Age: Cenomanian

Measured velocity $(\mathrm{km} / \mathrm{s}): 2.5$

Basement:

Depth sub-bottom (m): 617.0

Nature: Basaltic sill

Velocity range $(\mathrm{km} / \mathrm{s}): 4-5.9$

Principal results: Hole $462\left(7^{\circ} 14.25^{\prime} \mathrm{N}, 165^{\circ} 01.83^{\prime} \mathrm{E}\right)$ was drilled as a re-entry pilot hole from 28 May to 8 June at a water depth of 5181 corrected meters. Total length of continuously cored section was

\footnotetext{
1 Initial Reports of the Deep Sea Drilling Project, Volume 61.

2 Roger L. Larson (Co-Chief Scientist), Lamont-Doherty Geological Observatory, Palisades, New York (now at Graduate School of Oceanography, University of Rhode Island Kingston, Rhode Island); Seymour Schlanger (Co-Chief Scientist), Hawaii Institute of Geophysics, University of Hawaii at Manoa, Honolulu, Hawaii; Rodey Batiza, Department of Earth and Planetary Sciences, Washington University, St. Louis, Missouri; Robert E. Boyce, Deep Sea Drilling Project, Scripps Institution of Oceanography, La Jolla, California; Patrick De Wever, Département des Sciences de la Terre, Université des Sciences et Techniques, Villeneuve d'Asq. France; Hugh Jenkyns, Department of Geology and Mineralogy, Oxford University, Oxford, United Kingdom; Ralph Moberly, Hawaii Institute of Geophysics, University of Hawaii as Manoa, Honolulu, Hawaii; Isabella Premoli Silva, Istituto di Paleontologia, Università di Milano, Milan, Italy; Volkher Riech, Bundesanstalt für Geowissenschaften und Rohstoffe, Hannover, Federal Republic of Germany; Sergey A. Shcheka, Far East Institute of Geology, U.S.S.R. Academy of Sciences, Vladivostok, U.S.S.R.; William V. Sliter, U.S. Geological Survey, Menlo Park, California (now at U.S. Geological Survey, Branch of Paleontology and Stratigraphy, Reston, Virginia); Maureen Steiner, Division of Geology and Planetary Sciences, California Institute of Technology, Pasadena, California (now at The University of Wyoming, Department of Geology, Laramie, Wyoming): Hans Thiersten, Geological Research Division, Scrips Institution, La Oce, ography, La Jolla, California; and Hidekazu Tokuyama, Ocean Research Institute, Univer sity of Tokyo, Nakano, Tokyo, Japan. Two week extension: Roger L. Larson, Seymour Schlanger, Pavel Čepek, Bundesanstalt für Geowissenschaften und Rohstoffe, Hannover, Federal Republic of Germany; Naoyuki Fujii, Department of Earth Sciences, Kobe University, Rokkodai, Kobe, Japan; Vladimir 1. Koporulin, Geological Institute, U.S.S.R. Academy of Sciences, Moscow, U.S.S.R.; Isabella Premoli Silva; David Rea, Department of Atmospheric and Oceanic Science, University of Michigan, Ann Arbor, Michigan; William Sayre, University of Southampton, Southampton, Unired Kingdom (now at Department Sayre, University of So State Unicersity, Amp, Jent Sciences, lowa State University, Ames, lowa); William V. Sliter; Jörn Thiede, Institutt fur Geologi, Universitetett Oslo, Blindern, Oslo, Norway: Tracy Vallier, U.S. Geological Survey, Menlo Park, California; and Ken Windom, Department of Earth Sciences, Iowa State University, Ames, lowa.
}

616.5 meters. Total core recovered was 376.8 meters. Core recovery was $61 \%$. The section is divided into units. Unit I extends from 0.5 to 297 meters: calcareous and radiolarian oozes and chalks, mainly of turbidite origin, containing shallow-bank to reef skeletal debris of Eocene age, and planktonic microfossils as old as Late Cretaceous, in deeper-water strata of Oligocene age; at 50 meters depth, several meters of late Miocene-Pliocene ooze is rich in air-borne volcanic ash; age of Unit I ranges from Pleistocene to early Oligocene or late Eocene. Unit II extends from 297 to 447 meters: cherts, chalks and limestones of early Oligocene or late Eocene to middle Maestrichtian age. Unit III extends from 447 to 560 meters; volcanogenic and zeolitic sandstone, mudstone, and limestone of Maestrichtian to Cenomanian age, containing locally abundant shallow-bank skeletal debris of Maestrichtian to Campanian age. Unit IV extends from 560 to 617 meters (total depth); hyaloclastic mudstone layers, one of which contains undatable fish teeth and radiolarians intercalated with seven altered basalt and diabase sills. Total basalt recovery was approximately 35 meters from six sills 0.5 to 9 meters thick, and one sill at least 30 meters thick which was not fully penetrated at 617 meters. This deepest sill is diabase and displays granophyre facies. All sedimentary units are characterized by abundant contributions of sediment transported and redeposited at Site 462.

Six Uyeda-temperature-probe runs were made, three good, two questionable, and one without usable results. Based on these data and shipboard porosity and conductivity measurements, a geothermal gradient was plotted that gave a surface value of $1.1 \mathrm{HFU}$, which is consistent with other measurements in the area.

Six logging runs were made: (1) temperature and natural gamma, which was successful; (2) sonic and gamma, which failed; (3) induction and gamma, which succeeded; (4) sonic, which failed; (5) density, gamma, and temperature, which succeeded; and (6) guard, neutron, and gamma, which failed. Failures were due to hole conditions, particularly in the Eocene chert section.

The vessel moved 1553 feet to re-entry Hole $462 \mathrm{~A}$, on a bearing of $16.6^{\circ}$ from Hole 462 .

\section{HOLE 462A}

Date occupied: 0305Z 9 June 1978

Date departed: 0524Z 27 July 1978

Time on hole: 47 days, 2 hours, $19 \mathrm{~min}^{3}$

Position (latitude; longitude): $07^{\circ} 14.50^{\prime} \mathrm{N} ; 165^{\circ} 01.90^{\prime} \mathrm{E}$

Water depth (sea level; corrected $\mathrm{m}$, echo sounding): 5177

Water depth (rig floor; corrected $\mathrm{m}$, echo sounding): 5187

Bottom felt (m, drill pipe): 5186

Penetration (m): 1068.5

Number of cores: 92

Total length of cored section $(\mathrm{m}): 629.0$

Total core recovered $(\mathrm{m}): 348.7$

Core recovery $(\%): 55.5$

${ }^{3}$ Includes Majuro port call and steaming between $462 \mathrm{~A}$ and Majuro and return. 
Oldest sediment cored:

Depth Sub-bottom (m): 994

Nature: Brown-red clay, volcaniclastic sandstone and siltstone

Age: Barremian

Measured velocity $(\mathrm{km} / \mathrm{s}): 2.93$

Basement:

Depth sub-bottom (m): 1068.5

Nature: Basaltic sill

Velocity range $(\mathrm{km} / \mathrm{s}): 5.40-6.25$

Principal results: Hole $462 \mathrm{~A}$ was a multiple re-entry hole programmed to penetrate and sample Mesozoic sediments and the underlying oceanic crust of anomaly M-26. The upper 617 meters of Hole $462 \mathrm{~A}$ virtually duplicated Hole 462 . From 617 meters down to the total depth of 1068.5 meters, the drill penetrated an igneous complex of single and multiple diabase sills and extrusives. A few datable horizons were cored. The deepest of these, taken in Core 80 at a sub-bottom depth of 994 meters, contained a bathyal fauna of radiolarians, fish debris, and agglutinate foraminifers.

Also obtained in Hole 462A were (1) neutron and gamma-ray logs in the pipe and bottom-hole assembly, and (2) a sonic log in the open hole. Difficulties prevented further logging.

\section{BACKGROUND AND OBJECTIVES}

\section{Introduction}

Our goal at Site 462 was to study the paleontologic, sedimentary, petrologic, tectonic, and magnetic histories of that area through Recent to Late Jurassic time by drilling a deep re-entry site into the Nauru Basin west of the Ralik Chain of the Marshall Islands (Fig. 1). This area formed at a fast-spreading Pacific Plate boundary 145 to 155 m.y. ago, in the Late Jurassic (Fig. 2). Cores from this locale would allow us to better understand biostratigraphic evolution and sedimentary processes in a Mesozoic open-ocean environment, the petrologic nature of fast-spreading oceanic crust, the tectonic history of the Late Jurassic Pacific Plate, and the nature of the Jurassic magnetic quiet zone.

\section{Sedimentological and Paleoenvironmental Objectives}

The basement, or plate, age at Holes 462 and $462 \mathrm{~A}$ in the Nauru Basin should be approximately 145 to 155 m.y., giving us an opportunity to core sediments possibly as old as Oxfordian. The section there should therefore encompass these stratigraphic intervals: late Barremian-Aptian-early Albian, and Cenomanian-Turonian, occupied by organic-carbon-rich "black shales" or sapropels, cored at many DSDP sites. These blackshale sections are thought to be the result of the development of a widespread and thick oxygen-minimum layer in the world ocean during relatively short and welldefined times (Schlanger and Jenkyns, 1976).

Sedimentological, geochemical, and paleontological studies of strata deposited during the above-mentioned stages at Holes 462 and $462 \mathrm{~A}$ would enable us to compare the effects of an oxygen-minimum buildup in a relatively closed basin such as the Atlantic Ocean and Tethys Sea, where terrestrial carbonaceous input was high, with effects in a relatively open basin such as the Pacific, where terrestrial carbonaceous input presumably was low. The Nauru Basin sediments should contain a clear record of a deep-water oxygen-minimum event-one without the complicating factor of a heavy terrestrial organic-carbon overprint.
Geochemical and isotopic studies of Holes 462 and $462 \mathrm{~A}$ material should resolve some of the questions posed concerning the correlation of oxygen-minimum expansions and global climatic changes. Further, since the development of oxygen minima may be linked to variations in upper-water-layer fertility, the fossil record at Holes 462 and $462 \mathrm{~A}$, which should contain information on the range and extension of new groups, will help in establishing such a linkage. Recovery of a complete fossiliferous section down to the Oxfordian will in itself be valuable in refining zonations and deciphering paleoenvironmental events.

The Cenozoic section at this site may, according to the site surveys, consist of interbedded pelagic sediments and turbidites. It is in a deep basin surrounded by atolls of the Marshalls and volcanic islands of the Caroline chain (Fig. 1). Further, Kana Keoki seismic records (Fig. 3) and the detailed bathymetric chart (Fig. 4) show levees and channels indicative of probable distal turbidite regimes. Therefore, we should be able to identify events such as the onset and cessation of volcanism that built the edifices in the Marshalls and eastern Carolines. Turbidite-debris analysis should also give us information on reef build-up and, probably, island emergence in the area, as was done in the Line Islands area on Leg 33 (Schlanger, Jackson, et al., 1976).

\section{Petrologic Objectives}

It has been a top priority to obtain relatively deep sections from oceanic crust formed at both slow- and fastspreading ridges. Three DSDP Legs $(51,52,53)$ involved drilling such sites on 110-m.y.-old, slow-spreading crust in the western Atlantic Ocean. The Nauru Basin site was meant to sample fast-spreading, Mesozoicage crust. The Nauru Basin formed at $4.7 \mathrm{~cm} / \mathrm{yr}$, halfrate, and is an area of smooth oceanic crust, characterized by a well-defined magnetic-lineation pattern.

The results from Atlantic Ocean drilling indicate that the construction of upper Layer 2 is largely by extrusives, with many pillow lava sequences separated by abundant glass-lined fragments. Is this also true for fast-spreading crust? This is an especially interesting question in the Nauru Basin, because the seismic-profile records show many smooth layers that may be indicative of significant intrusive activity.

Almost all of the Atlantic Ocean samples show alteration of basalts by cold water, and abundant production of smectite. Very few high-temperature-metamorphosed samples have been recovered. Much relatively fresh glass was recovered from one of the deep sites on the 110 m.y. old Atlantic crust. Is this also typical of fastspreading crust, indicating a similar distribution of ridge-crest isotherms and hydrothermal-circulation history? Magnetic-anomaly patterns, although subdued in amplitude, in the Nauru Basin are remarkably well defined, indicating that alteration has had little affect on the magnetic-anomaly source layer.

\section{Tectonic Objectives}

The history of horizontal motion of the Pacific Plate back through the Early Cretaceous is relatively well 


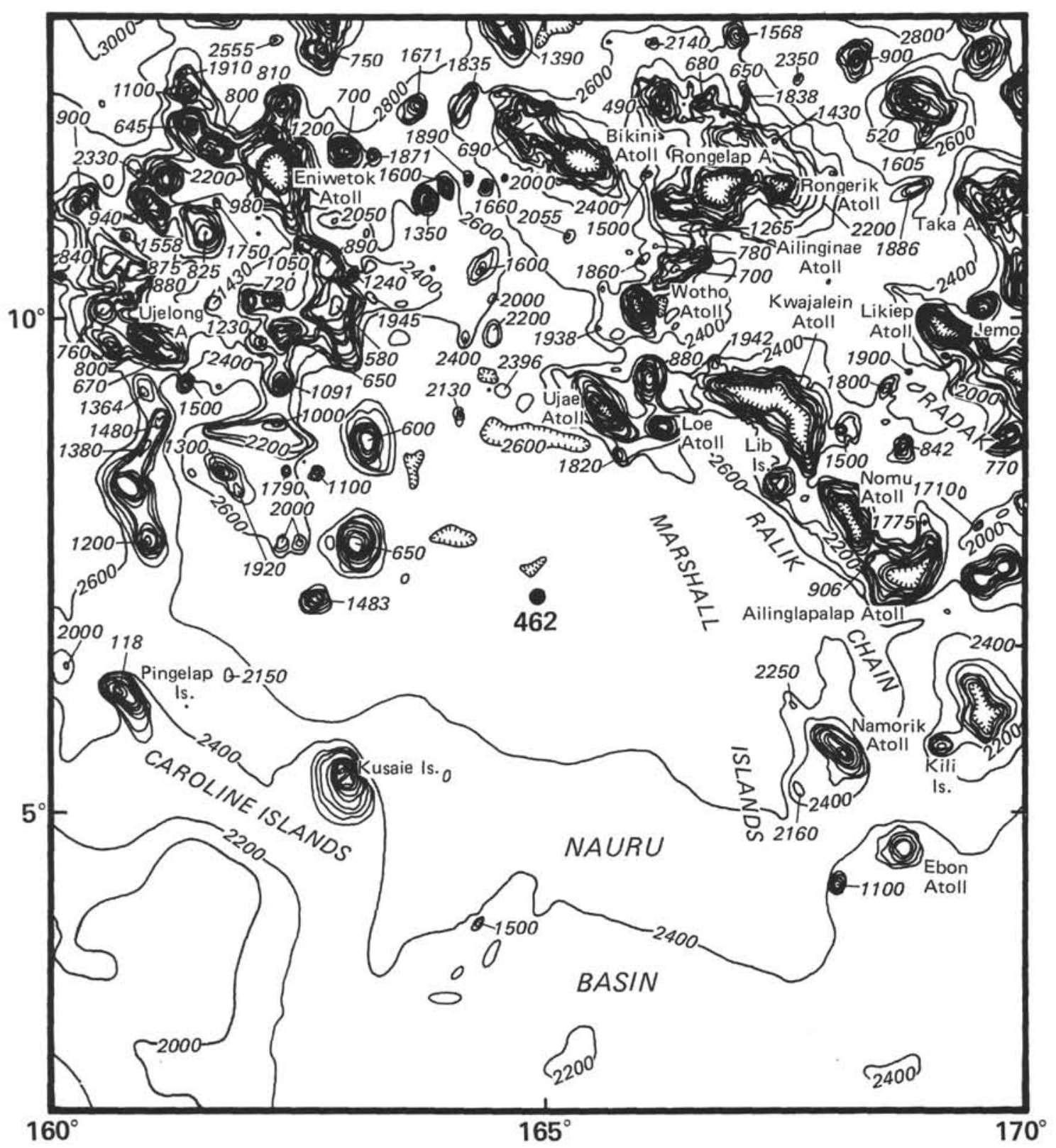

Figure 1. Regional bathymetric setting of Site 462 in the Nauru Basin, fringed to the north, east, and west by seamounts, guyots, and the Marshall and eastern Caroline Islands.

known from studied magnetic-lineation patterns, magnetic studies of seamounts, and facies studies of sediments. The preceding Jurassic history is relatively unknown, because no Jurassic seamounts have been reported, magnetic-lineation information is very limited, and no sediments of unequivocal Jurassic age have been recovered from the western Pacific. Tentative studies of Jurassic magnetic-lineation patterns suggest a moreequatorial paleolatitude for the Late Jurassic Nauru Basin than the Early Cretaceous Central Pacific Basin just to the east (Fig. 2). This raises the possibility that in the Late Jurassic the Pacific Plate was initially moving south, or at least had a dominant counterclockwise rotational component. Sometime in the Late Jurassic or Early Cretaceous, this retrograde motion reversed, perhaps by rebounding off eastern Gondwanaland, and the Pacific Plate began the steady northward motion that persists today.

Studies of Mesozoic sedimentary facies coupled with paleomagnetic studies of the sedimentary and volcanic rocks of the Nauru Basin should confirm or deny the above hypothesis. An equatorial sedimentary sequence at the base of the Nauru Basin section, overlain by higher-latitude sediments, in turn overlain by a second equatorial sequence, would support the retrogrademotion hypothesis. Paleomagnetic-inclination information should reveal the corresponding history of latitudinal motion, although nothing can be inferred concerning rotation of the Mesozoic Pacific Plate from the relative paleomagnetic declinations. 


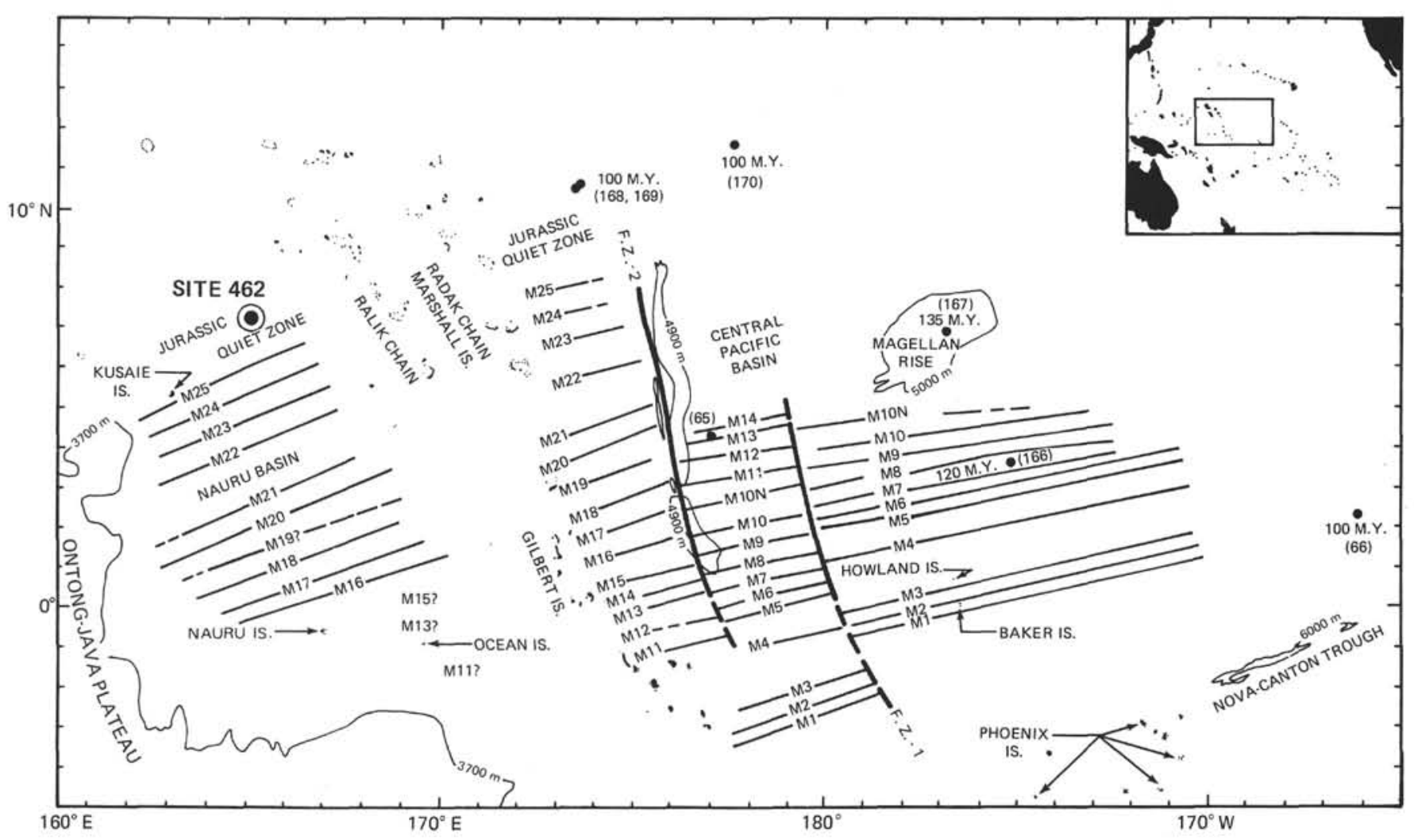

Figure 2. Mesozoic magnetic-lineation patterns of the Nauru and Central Pacific Basins, showing the location of Site 462 in the Jurassic quiet zone (from Larson, 1976).

\section{Magnetic Objectives}

Studies of the remanent-paleomagnetic-inclination information should contribute to our understanding of the Mesozoic tectonic evolution of the Pacific Plate, as described above. In addition, paleomagnetic and rockmagnetic studies of Jurassic sedimentary and volcanic rocks should be of great interest in understanding the history of the Earth's magnetic field at that time.

The M-sequence of magnetic anomalies is always bounded on its old (Jurassic) end by an "envelope" of anomaly amplitudes that taper down from "normal" values at about $145 \mathrm{~m} . \mathrm{y}$. to very small anomalies by 155 m.y. This latter portion of the record, nominally from 153 to 160 m.y., is called the Jurassic magnetic quiet zone (Fig. 2) and was the target of our drilling program in the northern Nauru Basin. In this area, very small but coherent magnetic anomalies (M26, M27, M28) imply remanent magnetizations nearly an order of magnitude lower than Lower Cretaceous magnetic anomalies. Obtaining a significant Jurassic volcanic section should test the hypothesis that these low-amplitude anomalies result from fluctuations of the Jurassic dipole-field intensity, field reversals during a time of generally low magnetic intensity, local variations in petrology, or a large increase in reversal frequency.

\section{Site Survey Results}

A detailed survey of the vicinity surrounding Site 462 was conducted from the Hawaii Institute of Geophysics vessel Kana Keoki from 9 April to 17 April 1977. Bathymetric relief is less than 150 meters (Fig. 4), and is dominated by two turbidity-current channels in the southwestern region of the survey. The transition between discrete, leveed channels and an extremely flat turbidite plain occurs near the center of the survey. Site 462 is about $10 \mathrm{~km}$ east of the southeastern leveed-channel system, on a very flat turbidite plain characterized by many flat-lying internal reflectors that comprise an upper and lower sedimentary sequence. A further seismic characteristic of the Nauru Basin is an unusual lack of refracted arrivals observed on sonobuoy stations (Larson, 1976; Houtz, 1976). However, many of the normalincident reflections also produce prominent wide-angle reflections on air gun-sonobuoy (ASPER) seismic records. Wide-angle reflection solutions from seven ASPER measurements were averaged to characterize the average thickness and velocity of the sediments in the area. The upper sedimentary sequence consists of the material between the sea floor and the reflector at 7.3 seconds on Figure 3. This material has an average interval velocity of $1.68 \mathrm{~km} / \mathrm{s}$ and an average layer thickness of 417 meters; it is probably Cenozoic. The lower sequence is the lower-frequency set of flat-lying reflectors between 7.3 and 7.6 seconds. The base of this sequence is harder to pick than the upper unit, but the average interval velocity of this material is $3.59 \mathrm{~km} / \mathrm{s}$, and the average layer thickness is $\mathbf{5 3 4}$ meters. It is probably much more lithified Mesozoic sediments, and may contain interbedded volcanic units. The scientific objec- 


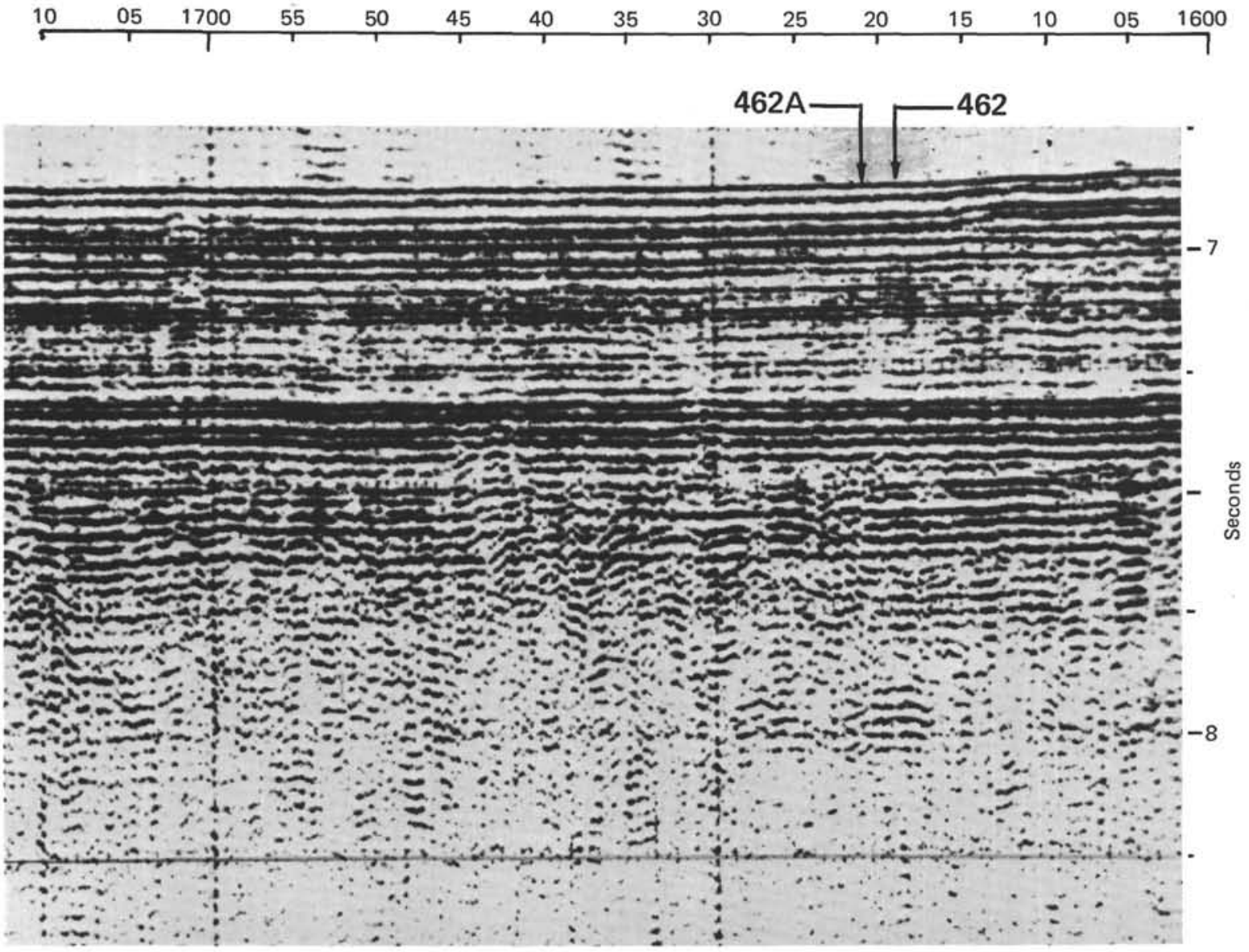

Figure 3. Seismic-reflection profile made by Kana Keoki on 11 April 1977, during her site survey of the area. East is to the left and west to the right. Holes 462 and $462 \mathrm{~A}$ are slightly south of this profile.

tives of this site were mainly concerned with the lower sedimentary sequence and the basement beneath it; however, we hoped that the upper sedimentary unit would provide a soft bed in which to spud the bottomhole assembly and the re-entry cone and casing.

Core MP-1 is a piston core recovered by the Kana Keoki about $17 \mathrm{~km}$ north-northwest of Site 462. Two lithologies are present in the core. The uppermost 2 meters is pelagic clay, and the remainder is calcareous ooze. The clay is moderate brown, slightly mottled grayish-orange at a few intervals, with 12 to $20 \%$ radiolarian remains. Other components are a trace to a few per cent of volcanic glass (light and dark), globular golden-brown palagonite, zeolite, pyroxene, diatoms, radiolarians, sponge spicules, and silicoflagellates. The calcareous ooze in the remainder of the core is all very pale-orange. At several intervals are suggestions of horizontal bedding, but only in the lowest part of the core $(113-150 \mathrm{~cm}$, Section 7) is the lamination sufficiently distinctive to record on the visual core description. There are a few black specks, possibly pyrite, in midcore.

The core below Section 1 and part of Section 2 is a sequence of turbiditic layers, in which the size fractions increase downward along with the planktonic-foraminifer content. In Sections 3 and 4, the washed residues are relatively rich in small manganese nodules (between $20 \mathrm{C}$ and $44 \mu \mathrm{m}$ ). Foraminifers are present only in the 150- to $44-\mu \mathrm{m}$ fraction. Assemblages are very mixed, including species characteristic of the Pliocene, late Miocene, and rarely the middle Miocene. The most abundant forms belong to the biserial genus Streptochilus (Brönnimann and Resig, 1971). Few diatoms, rare sponge spicules, and fish debris are also present.

The upper $111 \mathrm{~cm}$ in Section 7 are very similar to the upper part of the core. Radiolarians are still the dominant forms of the washed residues; however, planktonic foraminifers are common to abundant, and present also in the fraction larger than $150 \mu \mathrm{m}$. A few benthic foraminifers also occur. The highly reworked planktonicforaminifer assemblages contain forms of the following ages: early Pliocene; late, middle, and early Miocene; and late Oligocene. The Quaternary species Globorotalia truncatulinoides is recorded for the first time. From 112 to $150 \mathrm{~cm}$ in Section 7, the turbidites become coarser, and the foraminifer content represents about $50 \%$ of the washed residues. The reworked planktonic assemblages also include forms of middle Eocene and Late Cretaceous ages, along with the other intervals mentioned above. Still, the most abundant assemblages belong to the late Miocene and early Pliocene. Along with the increasing size fractions, benthic foraminifers 


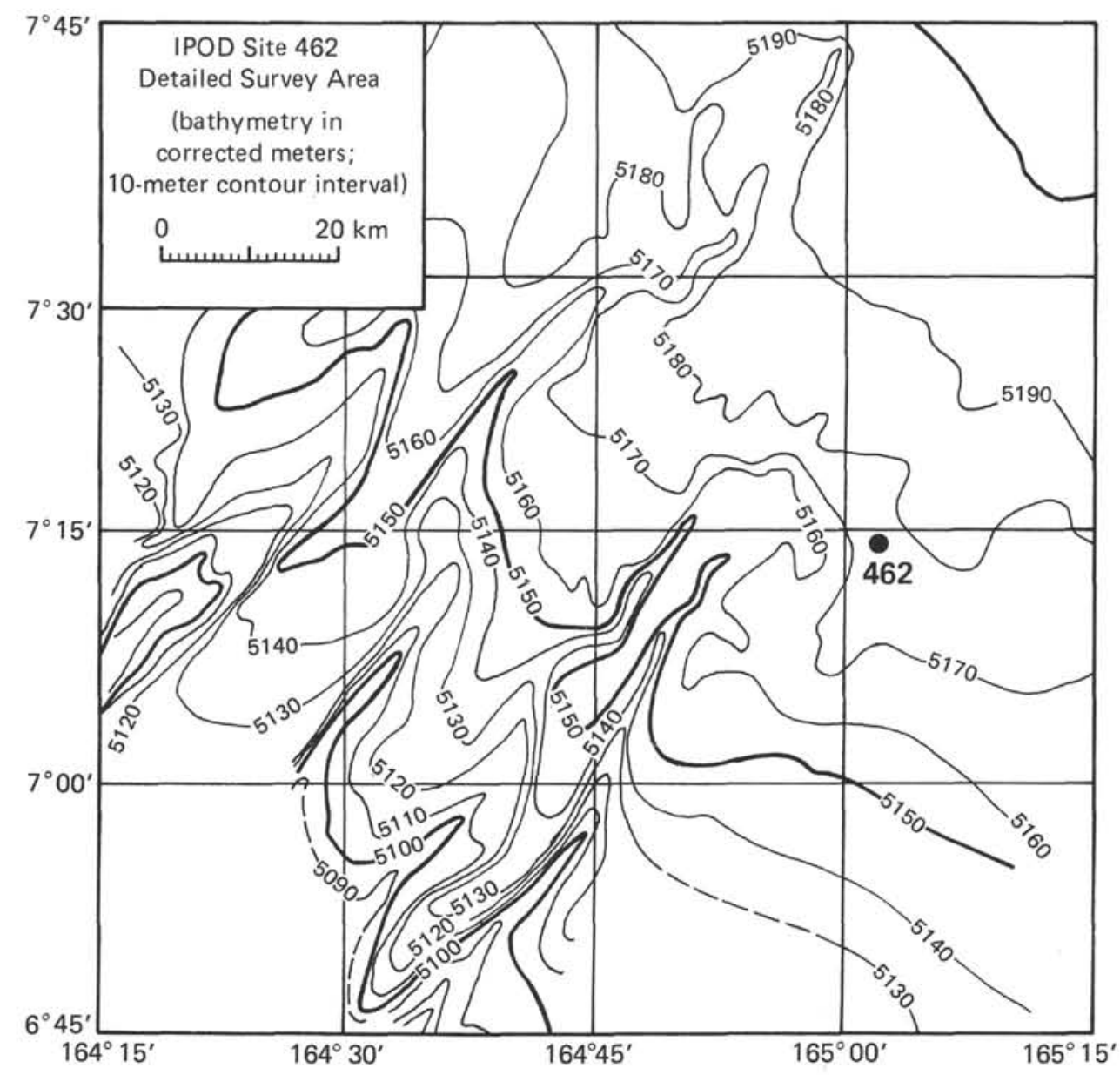

Figure 4. Detailed bathymetric chart of the Site 462 area, based on Kana Keoki survey that outlines the channel-and-levee system that channels sediment to this area from the Ontong-Java Plateau.

become more frequent and diversified. They possibly belong to the upper bathyal zone, and on the basis of the good preservation, they are probably Quaternary in age. Ostracodes, echinoid fragments, and sclerites are also recorded in this part of the section, along with volcanic glass(?).

It seems exceptionally unlikely that all of this is one calcareous turbidite, because the overall grain size suggests a distal setting, which the thickness belies. Probably there are several turbidites whose tops and bottoms cannot be detected. The sequence was of coarser flows followed by finer ones, perhaps related to slight changes in the turbidite processes in the leveed distributary channels shown in the detailed bathymetric chart of the site area. Presumably the distant source was the OntongJava Plateau during the middle or late Quaternary.

Four ocean-bottom seismometers were deployed within a kilometer of each other near the center of the detailed survey area. Two $150-\mathrm{km}$-long explosion refraction lines were run, one parallel and one perpendicular to the magnetic lineations. For the purposes of drilling, the principal results of this study are as follows: (1) depth to velocities greater than $5.0 \mathrm{~km} / \mathrm{s}$ range between 5.9 and $6.2 \mathrm{~km}$; (2) depth to velocities greater than $6.0 \mathrm{~km} / \mathrm{s}$ range between 8.4 and $9.9 \mathrm{~km}$; (3) sedi- ment thickness ranges between 700 and 1000 meters; (4) Layer 2 is abnormally thick. For an expanded discussion of this study, see Wipperman et al. (this volume).

The Site 462 survey is located in the Jurassic magnetic quiet zone and centered on Late Jurassic magnetic anomalies M26, M27, and M28 (Fig. 5). The anomalies in this survey area are of very low amplitude ( $~ 80$ gammas), but they are strongly lineated parallel to the Late Jurassic magnetic anomalies to the south (M20-M25; see Fig. 2). There are no volcanic peaks or fracture-zone offsets within the area, and the amplitudes and crosssectional shapes of the anomalies are all very uniform. The time scale used to model the anomalies in Figure 5 was derived by Cande et al. (1978), to match a similar set of anomalies in the Japanese Jurassic quiet zone. The extremely low amplitudes require a magnetization intensity of $\pm 0.002 \mathrm{emu} / \mathrm{cm}^{3}$ for a 500 -meter-thick layer, which is a value 5 to 10 times smaller than magnetizations used to match other Cenozoic and Mesozoic magnetic sequences. A skewness parameter of $\theta=$ $-160^{\circ}$ was used in the model, which corresponds to a paleolatitude of 20 to $30^{\circ} \mathrm{S}$. This value is not well determined, because the very low magnetization intensity and relatively great depth of the model results only in small changes in the shapes of the model profiles with changes 


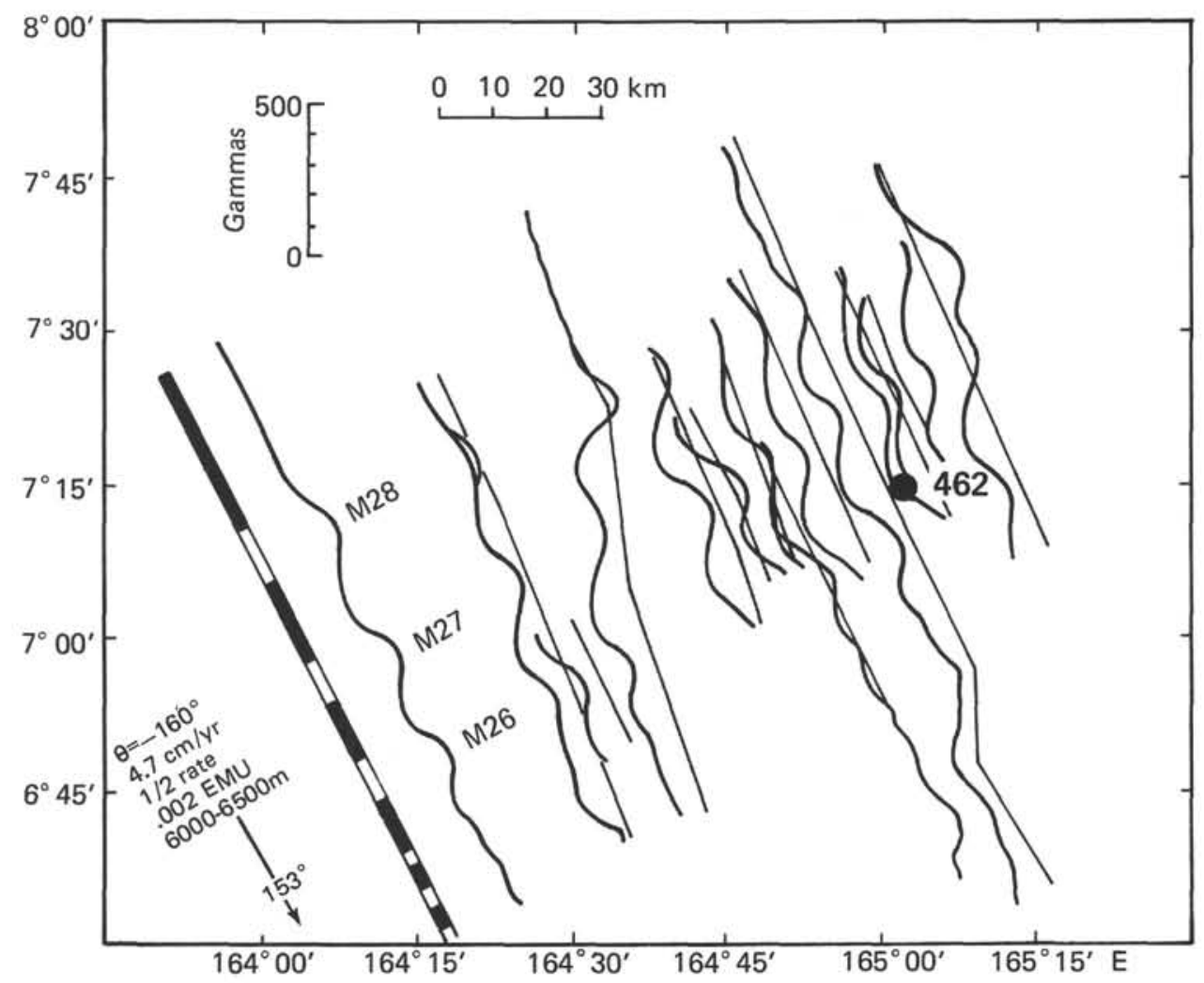

Figure 5. Cross-strike magnetic-anomaly profiles across anomalies M26, M27, and M28, in the Jurassic quiet zone of the northern Nauru Basin. Data are from the Kana Keoki survey and a model profile based on the revised Late Jurassic magnetic time scale of Cande et al. (1978).

in $\theta$. Skewness measurements on Late Jurassic anomalies M20 to M25 from the Japanese, Hawaiian, and Phoenix lineations suggest that this is approximately the correct value for the Nauru Basin (S. C. Cande, pers. comm., 1977). A further consequence of not knowing exactly the skewness value for anomalies M26, M27, and M28 is that the locations of the model block boundaries are not well fixed. Site 462 is very close to the nor$\mathrm{mal} /$ reversed transition that forms the older boundary of magnetic anomaly M26, and our inexact knowledge of the location of that boundary makes it impossible to predict the polarity of volcanic basement at Site 462 . This location was chosen deliberately in the hope that the transition zone might be sampled. This would allow a test of the hypothesis that the low-amplitude anomalies result from field reversals during a time of low intensity, which would be supported by the recovery of basalts with similar magnetic inclinations, but opposite polarities. The alternate hypothesis is that the anomalies result from fluctuations of the dipole or non-dipole field during a uniform polarity interval, which would be supported if basalts with varying magnetic inclinations that all have the same polarity were recovered.

\section{OPERATIONS}

We profiled from Guam to Site 462 in 6 days, 13.3 hours, via Heezen Guyot, a $27-\mathrm{km}$ diversion from a rhumb-line track that allowed a crossing of this alternate shallow-water site (Fig. 6) on the northern edge of the Nauru Basin. Our approach to Site 462 was from the northwest, generally on course $115^{\circ}$ that took us over the northern and presumably oldest part of the Nauru Basin (Fig. 7). This track shows a very flat sea floor about 5150 meters deep, and crossings of magnetic anomalies M29, M28, and M27 (Figure 5) that should be mid- to Late Jurassic in age (Cande et al., 1978). At $1025 \mathrm{Z}$ on $28 \mathrm{May}$, we changed course to $153^{\circ}$ and slowed to 6 knots to make our approach down a previous Kana Keoki track to the site.

This track took us across at least one channel-andlevee system that feeds sediments to the Nauru Basin from the Ontong-Java Plateau to the southwest. This system is well outlined in the detailed bathymetry of the site-survey area (Fig. 4), and on our $3.5-\mathrm{kHz}$ records, which show the channel floored with reflective, probably somewhat winnowed sediment that sits between levees of relatively transparent, unlayered material. Profiles of the $3.5-\mathrm{kHz}$ records away from the modern channel-and-levee systems show many flat-lying reflectors in the upper several tens of meters of section. Site 462 is on this type of $3.5-\mathrm{kHz}$ profile, southeast of the main channel-and-levee system outlined by the site survey. The sediment distributary system has channeled the carbonate-rich turbidites into this area; they are interbedded with radiolarian oozes in the 300 to 400 -meter thick section of uppermost sediments. This section corresponds to the upper 0.4 to 0.5 seconds of relatively high-frequency reflectors apparent on seismic-reflection profiles (Figs. 3 and 8). Our objectives lay generally below the middle Eocene chert layer that shows clearly 


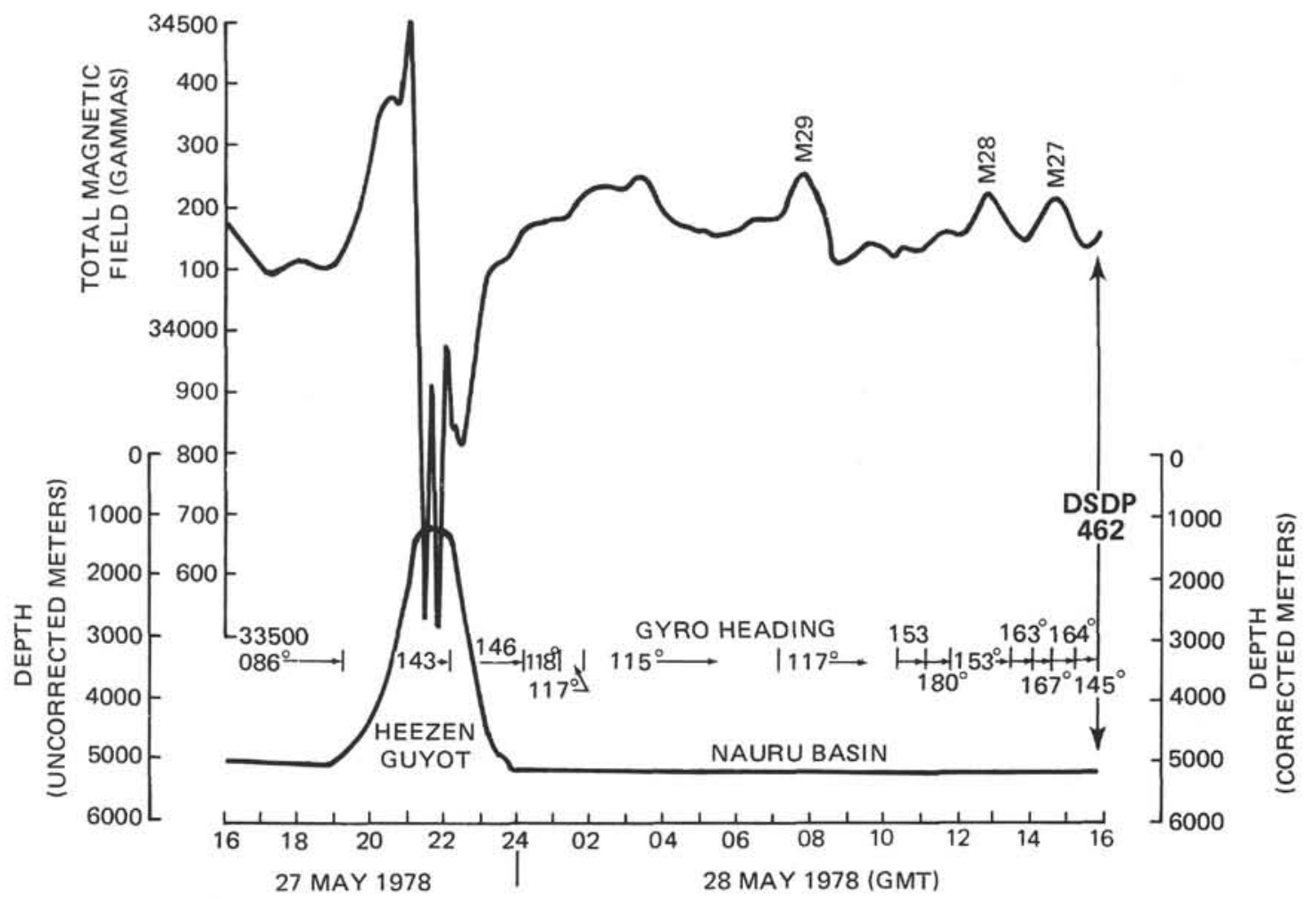

Figure 6. Bathymetric and magnetic profiles made by Glomar Challenger, Leg 61, on the approach to Site 462 across Heezen Guyot and the northern Nauru Basin.

at 7.3 seconds on the Kana Keoki profile (Fig. 3) in the relatively low-frequency, flat-lying reflectors that correspond to Mesozoic sedimentary and igneous rocks.

A number of well-timed satellite fixes and precise maneuvering of the vessel allowed us to navigate exactly to the planned drop site. At $1550 \mathrm{Z}$ on $28 \mathrm{May}$, we launched the beacon for Site 462 in 5152 (uncorrected) meters of water (5191 m corrected to the rig floor). We turned, retrieved our running gear, positioned ourselves over the beacon with a 200 -foot offset to the west, and began running in pipe at about $1745 \mathrm{Z}$ on 28 May.

Since this was to be a re-entry site, we measured the water depth as precisely as possible by measuring the drill string as it was run in, and then we took a punch core from 5189.5 to 5199 meters. No weight indication of contact was noted, but the core barrel was retrieved almost completely filled with sediment. One joint of drill pipe was set back and the punch-core procedure was repeated. No core was recovered, but some sediment was found in the core catcher and coating the lowest 0.5 meters of the core liner. Water depth from the rig floor was set at 5189.0 meters.

A jetting test was then conducted to determine the length of the re-entry conductor casing string to be set. With the exception of a fairly resistant stratum at 45 to 47 meters sub-bottom, the bit was washed easily through the soft ooze to 86 meters, with only minimal pumping. This depth was considered to be in excess of the length of casing required to provide adequate support for the re-entry cone. The bit then was pulled clear of the mud line, the inner core barrel was tripped, and continuous coring was begun at 5199 meters.
We continuously cored the upper 314 meters of the section in the first 33 cores, with few problems and generally high recovery percentages (Table 1). Cores 9 and 15 were nearly all lost, because the core catcher sock carried away and jammed in the check valve on Core 9, and was inadvertently left out on Core 15 . Six attempts to measure sediment temperature at the bottom of the hole, and thus construct a very accurate "base-level" heat-flow measurement for oceanic crust, were made at $133.5,181.0,219.0,257.0,295.0$, and 314.0 meters. Measurements were limited to this interval because soft sediments above 133.5 meters would not bear the weight of the lower drill collars, and hard chert stringers below 314.5 meters might bend the temperature probe and cause us to lose the hole. The first three measurements were obviously successful, but the latter three have peculiar-looking equilibration curves and occasional bad readings that indicate instrument malfunction.

The first cherts, of late Eocene age, were found in Core 34 from 314.0 to 323.5 meters, but heavy cherts and slow drilling were not encountered until Core 40, from 371.0 to 380.5 meters. We believe that this level correlates with the top of the $\mathrm{B}_{1}$ seismic reflector, because the interval velocity of $1.7 \mathrm{~km} / \mathrm{s}$ for the overlying sediment yields 380 meters of section corresponding to the 0.46 seconds of two-way travel time on the profiler records above $B_{1}$.

Recovery was uniformly poor from Cores 40 to 46 $(371.0-437.5 \mathrm{~m})$, below which the Eocene and possibly Paleocene chert sequence gave way to volcanogenic turbidites, limestone, and conglomerate of probable Cretaceous (late Campanian-early Maestrichtian) age. We 


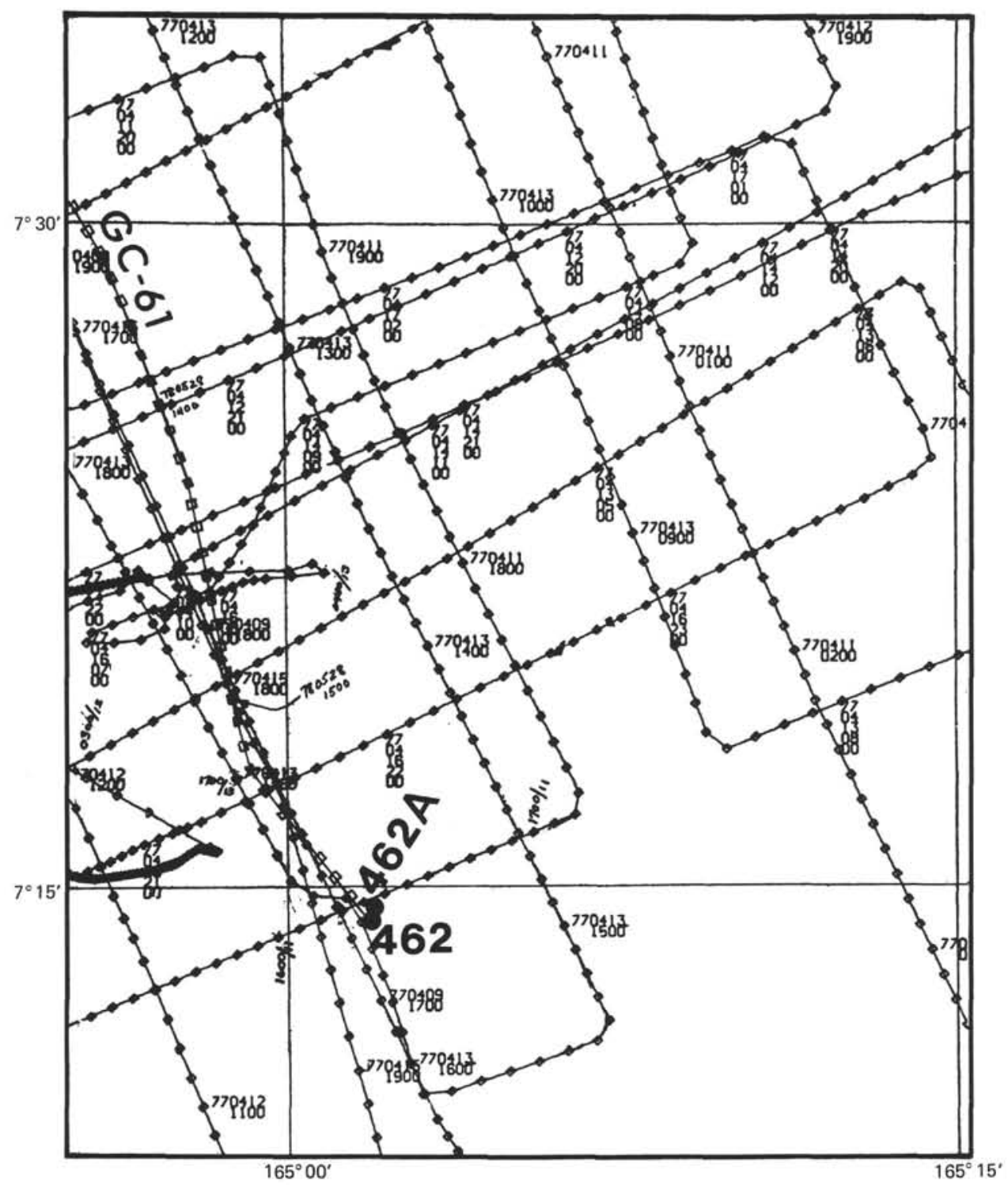

Figure 7. Chart of Site 462 area, showing Kana Keoki and Glomar Challenger Leg 61 tracks.

tried hard-formation core catchers and very slow penetration with minimum pump pressure, but these modifications did not improve recovery until the major cherts disappeared at about Core 47.

Cores 48 to 60 are a Late Cretaceous sequence of claystones, limestones, volcaniclastics, conglomerates, and very minor cherts that cored and recovered well. They were re-cored on the re-entry hole, because they are too lithified to wash ahead without a center bit in place. After retrieving Core 53, we found the bit partially plugged and had to run an extended core barrel to dislodge the obstruction.

Cores 60 to 69 contain a series of Cenomanian or younger basaltic sills, with some thermally altered claystones in Core 64 . In general, we had good recovery but a very slow rate of penetration in the basalt sequence. Often, penetration rates dropped to $1 \mathrm{~m} / \mathrm{hr}$, probably because of the density of the basalts, and possibly because of bit damage suffered during the chert drilling. Sometimes cores were pulled before a full 9 meters of penetration, because of the slow rate of penetration. Often we discovered a piece of basalt jammed in the core catcher of these cores and the plastic core liner collapsed above it. Although the bit was still cutting full-gauge core, we decided to terminate the hole at Core 69 because the rate of penetration was very slow, and because we had decided to stay in this area and attempt to penetrate the sill with the re-entry hole.

On 5 June 1978, we attempted to shoot three on-site sonobuoys with the 120 -in ${ }^{3}$ air gun tethered to floats. Only the third buoy was successful. All buoys were Select International (Aquatronics) sonobuoys (model SB76-1), and were rigged and deployed in accordance with procedures developed on Vema 3405 . The first buoy failed because of a bad hydrophone or faulty electronics in the buoy. No reasonable transmitted signal was received. The second buoy sank because of the addition of too much ballast weight and a poorly secured flotation collar. The third buoy was successful in that it yielded a high signal-to-noise level, but no wide-angle- 

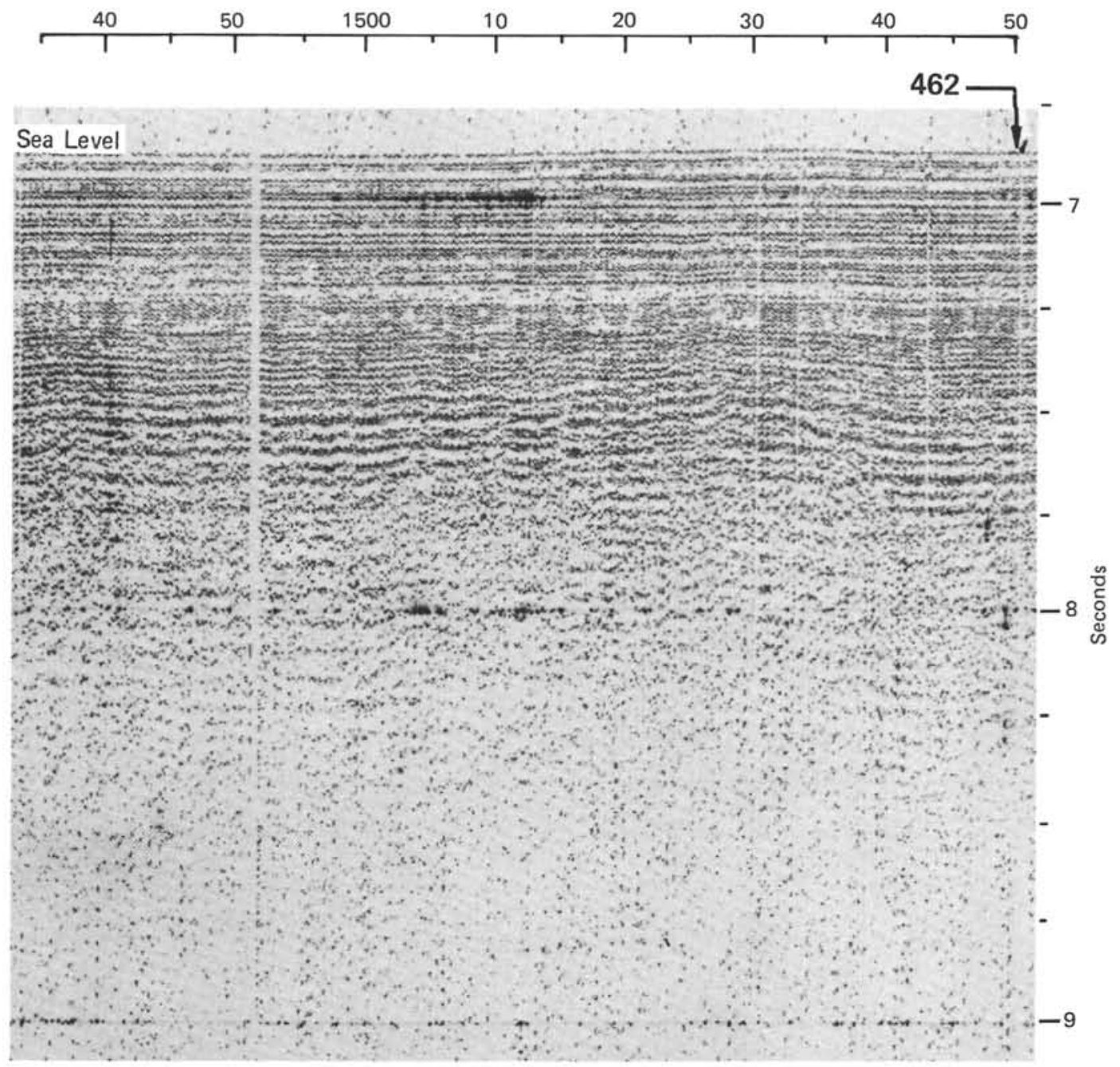

Figure 8. Seismic-reflection profile made by Glomar Challenger during Leg 61, on her approach to Site 462 across the northern Nauru Basin.

reflection information was received, because the experiment was cut off after only about an hour of recording, owing to a shift in the wind.

After Core 69, we released the bit and pumped freshwater mud into the upper part of the hole, in preparation for logging operations. The hole was logged with Gearhart-Owen Corp. equipment which allows realtime display of the logging data via their computer and laser camera system. We first attempted the temperature $\log$, but met a bridge at 5338 meters. We pulled out the tool, ran in two stands of pipe to knock out the bridge, and then re-ran the temperature log, this time in the density tool, with the gamma-ray source removed. We successfully logged temperature going down the hole, and natural gamma radiation coming up. We obtained a maximum temperature of $15.4^{\circ} \mathrm{C}$ with 5796 meters of logging cable out.

We next attempted to run the sonic and natural gamma-ray log, which failed because we could not get the tool down past the chert sequence. The run was terminated when the sonic log shorted out, probably because of an open connection generated by banging the sonde on the chert ledges.
We then hooked up the induction (electrical-conductivity) $\log$ with the natural gamma-ray log and worked our way to the bottom of the hole. We successfully logged conductivity up the hole, but the lower 200 meters of logging cable was snarled when retrieved from the pipe. The depth during logging is probably reasonably accurate, and it is likely that the tool floated at a point on the way up the hole. It required several hours to re-terminate the logging cable.

In a second attempt to obtain a velocity log, we hooked up the backup sonic tool and again could not get down through the chert sequence. This is probably due to two things: first, the hole is 3 to $4^{\circ}$ off vertical, and, second, the sonde is not rigid, so that when the tip of the sonde encounters a chert ledge, the sonde bends and hangs up instead of running by.

Next we ran what proved to be our most successful log: density (gamma-ray back-scatter), natural gammaray, and temperature. We had some problem working past the cherts, but got the tool well down into the basalt sequence. There we measured a maximum temperature of $17^{\circ} \mathrm{C}$ and successfully logged up the hole, the density and natural gamma-ray logs doing a beauti- 
Table 1. Coring summary, Site 462.

\begin{tabular}{|c|c|c|c|c|c|c|c|}
\hline $\begin{array}{l}\text { Core } \\
\text { No. }\end{array}$ & $\begin{array}{c}\text { Date } \\
\text { (1978) }\end{array}$ & Time & $\begin{array}{l}\text { Depth from } \\
\text { Drill Floor } \\
\text { (m) } \\
\text { Top Bottom }\end{array}$ & $\begin{array}{l}\text { Depth below } \\
\text { Sea Floor } \\
(\mathrm{m}) \\
\text { Top Bottom }\end{array}$ & $\begin{array}{l}\text { Length } \\
\text { Cored } \\
\text { (m) }\end{array}$ & $\begin{array}{l}\text { Length } \\
\text { Recovered } \\
\text { (m) }\end{array}$ & $\begin{array}{c}\text { Recovery } \\
(\%)\end{array}$ \\
\hline \multicolumn{8}{|l|}{ Hole 462} \\
\hline 1 & May 2 & 2025 & $5189.5-5199.0$ & $0.5-10.0$ & 9.5 & 9.3 & 98 \\
\hline 2 & 3 & $0 \quad 0328$ & $5199.0-5208.5$ & $10.0-19.5$ & 9.5 & 5.0 & 53 \\
\hline 3 & 3 & $0 \quad 0445$ & $5208.5-5218.0$ & $19.5-29.0$ & 9.5 & 8.4 & 88 \\
\hline 4 & 3 & 0605 & $5218.0-5227.5$ & $29.0-38.5$ & 9.5 & 7.6 & 80 \\
\hline 5 & 3 & $0 \quad 0735$ & $5227.5-5237.0$ & $38.5-48,0$ & 9.5 & 9.8 & $100+$ \\
\hline 6 & 3 & $0 \quad 0854$ & $5237.0-5246.5$ & $48.0-57.5$ & 9.5 & 8.8 & 93 \\
\hline 7 & 3 & $0 \quad 1020$ & $5246.5-5256.0$ & $57.5-67.0$ & 9.5 & 8.6 & 91 \\
\hline 8 & 3 & $0 \quad 1144$ & $5256.0-5265.5$ & $67.0-76.5$ & 9.5 & 5.7 & 60 \\
\hline 9 & 3 & $0 \quad 1310$ & $5265.5-5275.0$ & $76.5-86.0$ & 9.5 & 0.1 & 1 \\
\hline 10 & 3 & $0 \quad 1435$ & $5275.0-5284.5$ & $86.0-95.5$ & 9.5 & 8.6 & 91 \\
\hline 11 & 3 & $0 \quad 1556$ & $5284.5-5294.0$ & $95.5-105.0$ & 9.5 & 5.6 & 59 \\
\hline 12 & 3 & $\begin{array}{ll}0 & 1722\end{array}$ & $5294.0-5303.5$ & $105.0-114.5$ & 9.5 & 9.2 & 97 \\
\hline 13 & 3 & $0 \quad 1912$ & $5303.5-5313.0$ & $114.5-124.0$ & 9.5 & 9.3 & 98 \\
\hline 14 & 3 & $0 \quad 2050$ & $5313.0-5322.5$ & $124.0-133.5$ & 9.5 & 9.0 & 95 \\
\hline 15 & 3 & $1 \quad 0037$ & $5322.5-5332.0$ & $133.5-143.0$ & 9.5 & 0.7 & 7 \\
\hline 16 & 3 & 10216 & $5332.0-5341.5$ & $143.0-152.5$ & 9.5 & 7.1 & 75 \\
\hline 17 & 3 & i 0350 & $5341.5-5351.0$ & $152.5-162.0$ & 9.5 & 9.7 & $100+$ \\
\hline 18 & 3 & i $\quad 0530$ & $5351.0-5360.5$ & $162.0-171.5$ & 9.5 & 9.4 & 99 \\
\hline 19 & 3 & 10700 & $5360.5-5370.0$ & $171.5-181.0$ & 9.5 & 8.0 & 84 \\
\hline 20 & 3 & i 1015 & $5370.0-5379.5$ & $181.0-190.5$ & 9.5 & 6.9 & 73 \\
\hline 21 & 3 & 11155 & $5379.5-5389.0$ & $190.5-200.0$ & 9.5 & 9.0 & 95 \\
\hline 22 & 3 & i 1330 & $5389.0-5398.5$ & $200.0-209.5$ & 9.5 & 9.5 & 100 \\
\hline 23 & 3 & 1500 & $5398.5-5408.0$ & $209.5-219.0$ & 9.5 & 8.9 & 94 \\
\hline 24 & 3 & i 1835 & $5408.0-5417.5$ & $219.0-228.5$ & 9.5 & 6.9 & 73 \\
\hline 25 & 3 & i 2015 & $5417.5-5427.0$ & $228.5-238.0$ & 9.5 & 9.5 & 99 \\
\hline 26 & 3 & 12200 & $5427.0-5436.5$ & $238.0-247.5$ & 9.5 & 7.9 & 83 \\
\hline 27 & 3 & $1 \quad 2332$ & $5436.5-5446.0$ & $247.5-257.0$ & 9.5 & 9.9 & $100+$ \\
\hline 28 & June & i 0255 & $5446.0-5455.5$ & $257.0-266.5$ & 9.5 & 9.7 & $100+$ \\
\hline 29 & & 10420 & $5455.5-5465.0$ & $266.5-276.0$ & 9.5 & 9.2 & 97 \\
\hline 30 & & 10545 & $5465.0-5474.5$ & $276.0-285.5$ & 9.5 & 3.8 & 40 \\
\hline 31 & & i $\quad 0720$ & $5474.5-5484.0$ & $285.5-295.0$ & 9.5 & 3.2 & 34 \\
\hline 32 & & i 1050 & $5484.0-5493.5$ & $295.0-304.5$ & 9.5 & 5.3 & 56 \\
\hline 33 & & $1 \quad 1228$ & $5493.5-5503.0$ & $304.5-314.0$ & 9.5 & 2.8 & 29 \\
\hline 34 & & 11645 & $5503.0-5512.5$ & $314.0-323.5$ & 9.5 & 1.2 & 13 \\
\hline 35 & & $1 \quad 1825$ & $5512.5-5522.0$ & $323.5-333.0$ & 9.5 & 0.5 & 5 \\
\hline 36 & & i 2020 & $5522.0-5531.5$ & $333.0-342.5$ & 9.5 & 5.3 & 56 \\
\hline 37 & & 12215 & $5531.5-5541.0$ & $342.5-352.0$ & 9.5 & 9.0 & 95 \\
\hline 38 & & $1 \quad 2353$ & $5541.0-5550.5$ & $352.0-361.5$ & 9.5 & 7.3 & 77 \\
\hline 39 & & $2 \quad 0133$ & $5550.5-5560.0$ & $361.5-371.0$ & 9.5 & 6.7 & 71 \\
\hline 40 & & 20310 & $5560.0-5569.5$ & $371.0-380.5$ & 9.5 & 0.1 & 1 \\
\hline 41 & & 20440 & $5569.5-5579.0$ & $380.5-390.0$ & 9.5 & 0.3 & 3 \\
\hline 42 & & 20640 & $5579.0-5588.5$ & $390.0-399.5$ & 9.5 & 0.7 & 7 \\
\hline 43 & & 20835 & $5588.5-5598.0$ & $399.5-409.0$ & 9.5 & 0.4 & 4 \\
\hline 44 & & $2 \quad 1040$ & $5598.0-5607.5$ & $409.0-418.5$ & 9.5 & 0.8 & 8 \\
\hline 45 & & 21235 & $5607.5-5617.0$ & $418.5-428.0$ & 9.5 & 0.3 & 3 \\
\hline 46 & & $2 \quad 1428$ & $5617.0-5626.5$ & $428.0-437.5$ & 9.5 & 0.1 & $i$ \\
\hline 47 & & $2 \quad 1723$ & $5626.5-5636.0$ & $437.5-447.0$ & 9.5 & 0.1 & $i$ \\
\hline 48 & & $2 \quad 1918$ & $5636.0-5645.5$ & $447,0-456.5$ & 9.5 & 2.8 & 29 \\
\hline 49 & & $2 \quad 2100$ & $5645.5-5655.0$ & $456.5-466.0$ & 9.5 & 7.8 & 82 \\
\hline 50 & & $2 \quad 2255$ & $5655.0-5664.5$ & $466.0-475.5$ & 9.5 & 9.8 & $100+$ \\
\hline 51 & & 30025 & $5664.5-5674.0$ & $475.5-485.0$ & 9.5 & 5.0 & 53 \\
\hline 52 & & $3 \quad 0234$ & $5674.0-5683.5$ & $485.0-494.5$ & 9.5 & 5.4 & 57 \\
\hline 53 & & 30545 & $5683.5-5693.0$ & $494.5-504.0$ & 9.5 & 2.8 & 29 \\
\hline 54 & & $3 \quad 1230$ & $5693.0-5702.5$ & $504.0-513.5$ & 9.5 & 4.7 & 49 \\
\hline 55 & & 31445 & $5702.5-5711.5$ & $513.5-522.5$ & 9.0 & 7.0 & 78 \\
\hline 56 & & $3 \quad 1645$ & $5711.5-5720.5$ & $522.5-531.5$ & 9.0 & 2.4 & 27 \\
\hline 57 & & 31900 & $5720.5-5729.5$ & $531.5-540.5$ & 9.0 & 4.4 & 49 \\
\hline 58 & & $3 \quad 2100$ & $5729.5-5738.5$ & $540.5-549.5$ & 9.0 & 6.8 & 76 \\
\hline 59 & & $3 \quad 2315$ & $5738.5-5747.5$ & $549.5-558.5$ & 9.0 & 3.3 & 37 \\
\hline 60 & & $4 \quad 0425$ & $5747.5-5756.5$ & $558.5-567.5$ & 9.0 & 4.2 & 47 \\
\hline 61 & & $\begin{array}{ll}4 & 1127\end{array}$ & $5756.5-5765.5$ & $567.5-576.5$ & 9.0 & 2.4 & 27 \\
\hline 62 & & $4 \quad 1550$ & $5765.5-5768.5$ & $576.5-579.5$ & 3.0 & 2.4 & 80 \\
\hline 63 & & $4 \quad 2046$ & $5768.5-5774.5$ & $579.5-585.5$ & 6.0 & 4.1 & 68 \\
\hline 64 & & $5 \quad 0053$ & $5774.5-5783.5$ & $585.5-594.5$ & 9.0 & 5.7 & 63 \\
\hline 65 & & $5 \quad 0400$ & $5783.5-5788.0$ & $594.5-599.0$ & 4.5 & 3.2 & 71 \\
\hline 66 & & $5 \quad 0942$ & $5788.0-5795.0$ & $599.0-606.0$ & 7.0 & 7.5 & $100+$ \\
\hline 67 & & $5 \quad 1410$ & $5795.0-5798.0$ & $606.0-609.0$ & 3.0 & 2.5 & 83 \\
\hline 68 & & $5 \quad 2010$ & $5798.0-5803.0$ & $609.0-614.0$ & 5.0 & 5.8 & $100+$ \\
\hline 69 & & 60005 & $5803.0-5806.0$ & $614.0-617.0$ & 3.0 & 1.6 & 53 \\
\hline & & & & Totals & 616.5 & 376.8 & 61 \\
\hline Hole $462 A$ & & & & & & & \\
\hline $\begin{array}{c}1 \\
\text { (washed) }\end{array}$ & s & $9 \quad 1740$ & $5264.5-5274.0$ & $78.5-88.0$ & 9.5 & 9.7 & $100+$ \\
\hline $\begin{array}{c}2 \\
\text { (washed) }\end{array}$ & & 2040 & $5435.5-5445.0$ & $249.5-259.0$ & 9.5 & 8.3 & 87 \\
\hline $\begin{array}{l}\mathrm{H} 1 \\
\end{array}$ & & 2345 & $5445.0-5559.0$ & $259.0-373.0$ & - & - & - \\
\hline $\begin{array}{c}\text { (washed) } \\
\mathrm{H} 2\end{array}$ & & & & & & & \\
\hline $\mathrm{H}_{3}$ & 1 & $\begin{array}{ll}0 & 0230\end{array}$ & $5559.0-5587.5$ & $373.0-401.5$ & - & $\overline{04}$ & $\overline{4}$ \\
\hline 3 & $i$ & $0 \quad 0435$ & $5587.5-5597.0$ & $401.5-411.0$ & 9.5 & 0.4 & 4 \\
\hline 4 & 1 & 0 & $5597,0-5606.5$ & $411.0-420.5$ & 9.5 & 0.7 & 7 \\
\hline 5 & 1 & $0 \quad 0845$ & $5606.5-5616.0$ & $420.5-430.0$ & 9.5 & 0.2 & 2 \\
\hline 6 & 1 & 0 & $5616.0-5625.5$ & $430.0-439.5$ & 9.5 & 0.1 & 1 \\
\hline 7 & 1 & $0 \quad 1255$ & $5625.5-5635.0$ & $439.5-449.0$ & 9.5 & 1.4 & 15 \\
\hline (washed) & & & & & & & \\
\hline $\mathrm{H}_{3}$ & 1 & $0 \quad 1600$ & $5635.0-5673.0$ & $449.0-487.0$ & - & $\bar{A}$ & - \\
\hline $\begin{array}{c}8 \\
\text { (washed) }\end{array}$ & i & 0 & $5673.0-5682.5$ & $487.0-496.5$ & 9.5 & 4.6 & 48 \\
\hline $\begin{array}{l}\text { (wasnec } \\
\text { H4 }\end{array}$ & 1 & 0135 & $5682.5-5701.5$ & $496.5-515.5$ & - & - & - \\
\hline 9 & 1 & 0550 & $5701.5-5711.0$ & $515.5-525.0$ & 9.5 & 7.8 & 82 \\
\hline
\end{tabular}

Table 1. (Continued).

\begin{tabular}{|c|c|c|c|c|c|c|c|c|}
\hline $\begin{array}{l}\text { Core } \\
\text { No. }\end{array}$ & $\begin{array}{c}\text { Date } \\
\text { (1978 }\end{array}$ & & Time & $\begin{array}{l}\text { Depth from } \\
\text { Drill Floor } \\
\text { (m) } \\
\text { Top Bottom }\end{array}$ & $\begin{array}{l}\text { Depth below } \\
\text { Sea Floor } \\
\text { (m) } \\
\text { Top Bottom }\end{array}$ & $\begin{array}{l}\text { Length } \\
\text { Cored } \\
\text { (m) }\end{array}$ & $\begin{array}{l}\text { Length } \\
\text { Recovered } \\
\text { (m) }\end{array}$ & $\begin{array}{c}\text { Recovery } \\
(\%)\end{array}$ \\
\hline Hole 46 & (Cont & & & & & & & \\
\hline 10 & & 10 & 0740 & $5711.0-5720.5$ & $525.0-534.5$ & 9.5 & 4.8 & 51 \\
\hline 11 & & 10 & 0930 & $5720.5-5730.0$ & $534.5-544.0$ & 9.5 & 2.0 & 21 \\
\hline 12 & & i 1 & 1155 & $5730.0-5739.5$ & $544.0-553.5$ & 9.5 & 2.1 & 22 \\
\hline 13 & & 11 & 1405 & $5739.5-5749.0$ & $553.5-563.0$ & 9.5 & 3.2 & 34 \\
\hline 14 & & 11 & 1722 & $5749.0-5752.5$ & $563.0-566.5$ & 3.5 & 1.8 & 51 \\
\hline 15 & & 12 & 2052 & $5752.5-5758.0$ & $566.5-572.0$ & 5.5 & 1.6 & 29 \\
\hline 16 & & 20 & 0010 & $5758.0-5760.0$ & $572.0-574.0$ & 2.0 & 1.8 & 90 \\
\hline 17 & & 20 & 0810 & $5760.0-5762.0$ & $574.0-576.0$ & 2.0 & 2.3 & $100+$ \\
\hline 18 & & 21 & 1525 & $5762.0-5764.0$ & $576.0-578.0$ & 2.0 & 2.3 & $100+$ \\
\hline 19 & & 22 & 2020 & $5764.0-5767.0$ & $578.0-581.0$ & 3.0 & 2.7 & 90 \\
\hline 20 & & 31 & 1645 & $5767.0-5772.0$ & $581.0-586.0$ & 5.0 & 2.9 & 58 \\
\hline & & 4 & $\begin{array}{l}\text { (first re } \\
2315\end{array}$ & e-entry completed) & & 20 & & \\
\hline 21 & & 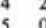 & 2315 & $57740-57830$ & $\begin{array}{l}586.0-388.0 \\
588.0-597.0\end{array}$ & 2.0 & 7.8 & $\begin{array}{l}90 \\
81\end{array}$ \\
\hline 22 & & 50 & 0935 & $5783.0-5792.0$ & $597.0-606.0$ & 9.0 & 4.6 & S1 \\
\hline 24 & & 5 & 1420 & $5792.0-5801.0$ & $606,0-615.0$ & 9.0 & 4.6 & 51 \\
\hline 25 & & 52 & 2010 & $5801.0-5810.0$ & $615.0-624.0$ & 9.0 & 0.9 & 10 \\
\hline 26 & & 60 & 0520 & $5810.0-5812.0$ & $624.0-626.0$ & 2.0 & 0.0 & 0 \\
\hline B1 & & 61 & 1630 & - & - & - & 1.5 & - \\
\hline & & $\begin{array}{ll}7 \\
8 & 5 \\
8 & 0\end{array}$ & (second & $\begin{array}{c}\mathrm{d} \text { re-entry complet } \\
58120-58160\end{array}$ & ted) & & & \\
\hline $\begin{array}{l}27 \\
28\end{array}$ & & $8 \quad 0$ & 0825 & & $\begin{array}{l}6260.0-030.0 \\
630.0-636.0\end{array}$ & $\begin{array}{l}4.0 \\
6.0\end{array}$ & $\begin{array}{l}3.7 \\
5.9\end{array}$ & $\begin{array}{l}93 \\
98\end{array}$ \\
\hline 29 & & $8 \quad 1$ & 1750 & $5822.0-5831.0$ & $636.0-645.0$ & $\begin{array}{l}0.0 \\
9.0\end{array}$ & 7.1 & 79 \\
\hline 30 & & $\begin{array}{lll}9 & 0\end{array}$ & 0315 & $5831.0-5840.0$ & $645.0-654.0$ & 9.0 & 8.4 & 93 \\
\hline 31 & & 90 & 0630 & $5840.0-5841.5$ & $654.0-655.5$ & 1.5 & 0.9 & 60 \\
\hline 32 & & 91 & 1000 & $5841.5-5849.0$ & $655.5-663.0$ & 7.5 & 2.4 & 32 \\
\hline 33 & & 91 & 1558 & $5849.0-5858,0$ & $663.0-672.0$ & 9.0 & 0.1 & 1 \\
\hline 34 & & 91 & 1920 & $5858.0-5867.0$ & $672.0-681.0$ & 9.0 & 0.0 & 0 \\
\hline 35 & & 92 & 2135 & $5867.0-5871.0$ & $681.0-685.0$ & 4.0 & tr & 0 \\
\hline 36 & & 00 & 0240 & $5871.0-5876.0$ & $685.0-690.0$ & 5.0 & 0.3 & 6 \\
\hline 37 & & 00 & 0647 & $5876.0-5877.0$ & $690.0-691.0$ & 1.0 & 0.0 & 0 \\
\hline B2 & & 01 & 1935 & - & - & - & 0.7 & - \\
\hline & & 14 & (third $\mathrm{r}$ & re-entry completed & & & & \\
\hline 38 & & 12 & 2113 & $5877.0-5878.0$ & $691.0-692.0$ & 1.0 & 2.6 & 260 \\
\hline 39 & & 200 & 0450 & 5878.0-5888.0 & $692.0-702.0$ & 10.0 & 5.5 & 55 \\
\hline 40 & & 20 & 0830 & 5888.0-5897.0 & $702.0-711.0$ & 9.0 & 2.0 & 22 \\
\hline 41 & & 21 & 1410 & $5897.0-5906.0$ & $711.0-720.0$ & 9.0 & 9.4 & $100+$ \\
\hline 42 & & 21 & 1618 & $5906.0-5909.0$ & $720.0-723.0$ & 3.0 & 2.6 & 87 \\
\hline 43 & & 21 & 1818 & 5909.0-5915.0 & $723.0-729.0$ & 6.0 & 3.8 & 63 \\
\hline 44 & & 22 & 2240 & $5915.0-5919.0$ & $729.0-733.0$ & 4.0 & 3.0 & 75 \\
\hline 45 & & 30 & 0300 & $5919.0-5924.0$ & $733.0-738.0$ & 5.0 & 3.7 & 74 \\
\hline 46 & & 31 & $\begin{array}{l}1030 \\
1736\end{array}$ & $\begin{array}{l}5924.0-5933.0 \\
59330-5942\end{array}$ & $738.0-747.0$ & 9.0 & 6.5 & 72 \\
\hline $\begin{array}{l}47 \\
48\end{array}$ & & $\begin{array}{ll}3 & 1 \\
4 & 0\end{array}$ & $\begin{array}{l}1736 \\
0130\end{array}$ & $5933.0-5942.0$ & $\begin{array}{l}747,0-756.0 \\
7560-7650\end{array}$ & 9.0 & $\begin{array}{l}4.1 \\
6.7\end{array}$ & $\begin{array}{l}46 \\
74\end{array}$ \\
\hline $\begin{array}{l}48 \\
49\end{array}$ & & $\begin{array}{l}440 \\
4\end{array}$ & $\begin{array}{l}0130 \\
0555\end{array}$ & $\begin{array}{l}5942.0-5951.0 \\
5951.0-5960.0\end{array}$ & $\begin{array}{l}756.0-765.0 \\
765.0-774.0\end{array}$ & 9.0 & $\begin{array}{l}6.7 \\
4.3\end{array}$ & $\begin{array}{l}74 \\
48\end{array}$ \\
\hline 50 & & $4 \quad 1$ & 1150 & $5960.0-5964.5$ & $774.0-778.5$ & $\begin{array}{l}9.0 \\
4.5\end{array}$ & 8.2 & $\begin{array}{l}48 \\
182\end{array}$ \\
\hline 51 & & $4 \quad 1$ & 1921 & $5964.5-5973.5$ & $778.5-787.5$ & 9.0 & 5.4 & 60 \\
\hline & & 54 & (fourth & re-entry complete & & & & \\
\hline 52 & & 60 & 0310 & $5973.5-5978.0$ & $787.5-792.0$ & 4.5 & 4.4 & 98 \\
\hline 53 & & 60 & 0835 & $5978.0-5983.5$ & $792.0-797.5$ & 5.5 & 2.8 & 51 \\
\hline 54 & & 61 & 1150 & $5983.5-5987.0$ & $797.5-801.0$ & 3.5 & 2.1 & 60 \\
\hline 55 & & 61 & 1715 & $5987.0-5992.5$ & $801.0-806.5$ & 5.5 & 2.2 & 40 \\
\hline 56 & & 70 & 0255 & $5992.5-6001.5$ & $806.5-815.5$ & 9.0 & 3.2 & 36 \\
\hline 57 & & 70 & 0831 & $6001.5-6010.5$ & $815.5-824.5$ & 9.0 & 1.5 & 17 \\
\hline 58 & & 71 & 1254 & $6010.5-6019.5$ & $824.5-833.5$ & 9.0 & 5.4 & 60 \\
\hline 59 & & 72 & 2245 & $6019.5-6028.5$ & $833.5-842.5$ & 9.0 & 8.7 & 97 \\
\hline 60 & & 80 & 0434 & 6028.5-6037.5 & $842.5-851.5$ & 9.0 & 5.0 & 56 \\
\hline 61 & & 80 & 0940 & $6037.5-6046.5$ & $851.5-860.5$ & 9.0 & 7.5 & 83 \\
\hline 62 & & 81 & 1525 & $6046.5-6050.5$ & $860.5-864.5$ & 4.0 & 4.1 & $100+$ \\
\hline 63 & & & 1849 & $6050.5-6055.5$ & $864.5-869.5$ & 5.0 & 2.3 & 46 \\
\hline 64 & & 91 & $\begin{array}{l}1145 \\
\text { fifth }\end{array}$ & $\begin{array}{l}6055.5-6062.5 \\
\text { eentry completed }\end{array}$ & $869.5-876.5$ & 7.0 & 7.5 & $100+$ \\
\hline 65 & & & 1710 & $6062.5-6069.0$ & $876.5-883.0$ & 6.5 & 4.2 & 65 \\
\hline 66 & & 02 & 2340 & $6069.0-6078.0$ & $883.0-892.0$ & 9.0 & 8.9 & 99 \\
\hline 67 & July & 10 & 0515 & $6078.0-6087.0$ & $892.0-901.0$ & 9.0 & 9.8 & $100+$ \\
\hline 68 & & i i & 1256 & $6087.0-6096.0$ & $901.0-910.0$ & 9.0 & 7.9 & 88 \\
\hline 69 & & i 1 & 1940 & $6096.0-6105.0$ & $910.0-919.0$ & 9.0 & 3.3 & 37 \\
\hline 70 & & 20 & 0227 & $6105.0-6114.0$ & $919.0-928.0$ & 9.0 & 4.6 & 51 \\
\hline 71 & & 20 & 0550 & $6114.0-6117.0$ & $928.0-931.0$ & 3.0 & 0.5 & 17 \\
\hline 72 & & 20 & 0950 & $6117.0-6123.0$ & $931.0-937.0$ & 6.0 & 3.6 & 60 \\
\hline 73 & & 21 & 1450 & $6123.0-6132.0$ & $937.0-946.0$ & 9.0 & 3.1 & 34 \\
\hline 74 & & 30 & 0845 & $6132.0-6139.0$ & $946.0-953.0$ & 7.0 & 7.2 & $100+$ \\
\hline $\mathrm{x} 1$ & & 41 & 1115 & $6139.0-6139.0$ & $953.0-953.0$ & NA & 0.4 & NA \\
\hline 75 & & 922 & 2200 & $6139.0-6144.0$ & $953.0-958.0$ & 5.0 & 6.8 & $100+$ \\
\hline 76 & & $\begin{array}{llll}0 & 0 & \end{array}$ & 0900 & 6144.0-6153.0 & 958.0-967.0 & 9.0 & 0.5 & 06 \\
\hline 77 & & $\begin{array}{ll}0 & 1\end{array}$ & 1612 & $6153.0-6162.0$ & 967.0 & 9.0 & 4.0 & 44 \\
\hline 78 & & 10 & 0017 & $6162.0-6171.0$ & $976.0-5$ & 9.0 & 3.6 & 40 \\
\hline 79 & & 10 & 0615 & $6171.0-6180.0$ & $985.0-994.0$ & 9.0 & 6.8 & 76 \\
\hline 80 & & $\begin{array}{ll}1 & 1\end{array}$ & 1112 & $6180.0-6184.0$ & 994.0-998.0 & 4.0 & 4.3 & $100+$ \\
\hline 81 & & 11 & 1515 & $6184.0-6189.0$ & $998.0-1003.0$ & 5.0 & 3.5 & 70 \\
\hline & & & (sixth r & $\begin{array}{r}\text { re-entry completed } \\
61890-6690.0\end{array}$ & $1003.5-1004.0$ & 1.0 & 0.5 & 50 \\
\hline 83 & & 30 & 23545 & $\begin{array}{l}6189.0-6190.0 \\
6190,0-6191.5\end{array}$ & $1004,0-1005.5$ & 1.5 & 0.08 & 05 \\
\hline 84 & & 31 & 1325 & $6191.5-6200.5$ & $1005.5-1014.5$ & 9.0 & 7.5 & 83 \\
\hline 85 & & 32 & 2007 & $6200.5-6209.5$ & $1014.5-1023.5$ & 9.0 & 5.4 & 60 \\
\hline 86 & & 40 & 0300 & $6209.5-6212.0$ & $1023.5-1026.0$ & 2.5 & 0 & 0 \\
\hline 87 & & $\begin{array}{llll}4 & 0 & \end{array}$ & 0850 & $6212.0-6218.5$ & $1026.0-1032.5$ & 6.5 & 3.0 & 46 \\
\hline 88 & & $\begin{array}{lll}4 & 1\end{array}$ & 1558 & $6218.5-6222.5$ & $1032.5-1036.5$ & 4.0 & 4.3 & $100+$ \\
\hline 89 & & $\begin{array}{lll}4 & 2\end{array}$ & 2020 & $6222.5-6227.5$ & $1036.5-1041.5$ & 5.0 & 3.5 & 70 \\
\hline 90 & & $\begin{array}{lll}5 & 0\end{array}$ & 0735 & $6227.5-6236.5$ & $1041.5-1050.5$ & 9.0 & 6.1 & 70 \\
\hline 91 & & 50 & 0735 & $6236.5-6245.5$ & $1050.5-1059.5$ & 9.0 & 0.02 & 0 \\
\hline 92 & & 51 & 1115 & $6245.5-6254.5$ & $1059.5-1068.5$ & 9.0 & 0.02 & 0 \\
\hline & & & & & Totals & 629.0 & 348.72 & 55.4 \\
\hline
\end{tabular}


ful job of outlining the basalt sills with included sediment beds, and the overlying chert-chalk sequence.

Our final log was a combination of electrical conductivity for hard rocks (guard or Lateralog), porosity (neutron back-scatter), and natural gamma-ray, which we could not get to work past the chert sequence. We then retrieved the log, pulled the bottom-hole assembly out of the hole, and began to move the 1553 feet to Hole $462 \mathrm{~A}$ while the drill string was brought on deck.

A total of 376.8 meters of core were taken from Hole 462 , for a recovery rate of $61 \%$.

Hole 462 was drilled as the pilot hole for re-entry Hole 462A. Throughout drilling at Holes 462 and 462A, the weather was generally excellent and never hampered our operations. Trade winds of 10 to 20 knots from the east-northeast were experienced, accompanied by mild squalls that intensified at night but very seldom required alteration of our heading. The sea state was generally 2 or 3 , and the vessel rolled no more than one or two degrees.

Hole 462 was drilled to 616.5 meters sub-bottom and logged. The vessel was then offset 473 meters on a bearing of $16.6^{\circ}$ from Hole 462 and prepared to launch the re-entry system from Hole $462 \mathrm{~A}$. The re-entry assembly consisted of a 16-foot-diameter re-entry cone with mudskirt, 73 meters of 16-inch-diameter conductor casing, and a bottom-hole assembly 74.5 meters long. The cone was keelhauled under the ship, and the remainder of the re-entry assembly was lowered into place through the moon pool. The assembly was lowered to the mudline and washed in very easily with 5 to 10 strokes per minute of pumping. At a point that appears to be 3 meters above complete wash-in, the assembly took up weight and would not penetrate further with 40 strokes per minute of pumping and 30,000 pounds of weight on the bit. Either a hard layer was encountered at 72 meters sub-bottom, or the mudskirt actually was on the bottom and the mudline is 3 meters shallower than estimated. The pinger attached to the mudskirt was still transmitting, indicating that the former may have been the case; however, the pinger may have been jostled up to a level even with the mudskirt during the launching, so that it was transmitting from exactly on the sea floor. It seems unlikely that a hard layer, which was not present at Hole 462, was encountered so close to the mudskirton-bottom level at this location. Even if the mudskirt were off the bottom by 3 meters, the cone probably would sink in by that amount in. a few days.

After unlatching the bottom-hole assembly, the hole was drilled and spot cored to 400 meters sub-bottom. The chert, chalk, and limestone interval was re-cored continuously in an unsuccessful attempt to recover more carbonate sediments. The hole was then spot cored from 449 to 515 meters (Table 1), where continuous coring was begun in Late Cretaceous claystones and limestones. After Core 8, 10 stands of pipe were laid back in order to raise the bottom-hole assembly above the chert zone and ream out that level of the hole. The cherts cored easily and did not seem to present any hole problems at this point.
At 565 meters, in Core 14, the top of the basaltic sill encountered at 560 meters in Hole 462 was reached. The upper part of the sill cored very slowly, with penetration rates of less than $1 \mathrm{~m} / \mathrm{hr}$. The pipe was round-tripped after Core 20, at 586 meters, in order to change the bit and add more drill collars for additional drilling weight in the bottom-hole assembly. The bit, type F94CK, was in good shape, although 17 teeth were broken out of the drive rows. The other teeth had not suffered much wear, and all the bearings were still sealed.

A new bottom-hole assembly was made up, with three additional drill collars in the lower part of the assembly and a new F94CK bit. No trouble occurred until the sonar scanning tool was run in, which shorted out soon after it started to scan. It was retrieved and found to have a cracked plastic lead housing. That was repaired, and the tool was run in to 165 meters, where it jammed because of a backed-out set screw. On the third attempt, the cone was successfully re-entered and the bit was easily run down to the bottom of the hole.

Operations went well until after Core 25, at 624 meters sub-bottom. The core barrel for Core 26 would not seat, and repeated runs of an extended core barrel did not remove the obstruction. After running an extended barrel twice, a regular barrel was pumped down and a 2-meter interval was cut. The core barrel contained nothing, so we were then certain that there was a bit obstruction. On retrieving the bit, 10 broken drive teeth were found, but the bit was otherwise in good shape. We decided to run a type F99CK hard-rock bit on the next re-entry. It will cut well, and last a long time in basalt, but will not make much penetration in claystone.

The drill string was run in in record time, but the sonar scanning tool malfunctioned on its way down the pipe. The tool was retrieved, repaired, and run in, and we made a stab at the cone, using a new display scope for the sonar scanning tool on the bridge. This scope has a number of problems: (1) it does not hold an image long enough; (2) it seems to be miscalibrated; and (3) the mud-line image cannot be attenuated, leading to a confusing display when in the vicinity of the cone. This scope was replaced with the original scope.

On retrieval, the sonar tool jammed in the pipe at 650 meters below the sea surface. The logging cable parted at the weak-link joint that is also the cable termination. A conventional core barrel with new tungsten-carbide dogs was made up and run in as a fishing tool. A connection was made to the top of the sonar tool on the first try, but the shear-pin connection to the overshot parted on attempted retrieval. Considerable working of the sand-line tension on the second try proved successful, and the pipe was cleared of obstructions.

On lowering two stands of pipe, we determined that our stab missed the cone, probably because of the new display scope. The original display scope in place, we easily re-entered and ran in to the bottom of the hole.

The F99CK bit penetrated no faster than a F94CK in the basaltic sill, but cut beautiful cores, with individual sections 1 to 2 meters in length. Penetration was about 1 
$\mathrm{m} / \mathrm{hr}$. A new beacon $(13.5 \mathrm{kHz})$ was dropped during the cutting of Core 29 , because the original one was losing its signal strength. The new one had very small offsets relative to this hole. Cores 27 and 31 were recovered early, because erratic pump pressure indicated that the cored basalt was unseating the core barrel. Core 32 cut very quickly and contained basalt underlain by volcaniclastic sediments. Cores 33,34 , and 35 also drilled quickly, presumably through the same sequence, although only traces of the formation were recovered. Basalt was encountered again in Core 36 . Core 37 also drilled with hard-rock characteristics, but no core was recovered. The string was rotated for 1 hour after Core 37 , but no penetration was noted. Pump pressure was slightly erratic, but not too unusual; torque and bit weight were satisfactory, but the lack of recovery and penetration induced us to pull the string to inspect the bottom-hole assembly. Also, the pump pressure tended to go up when the bit weight was slacked off, indicating that the core barrel may not have been seated.

The drill string was retrieved, and all hardware was found to be in good condition. The F99CK bit was in excellent condition after 39 rotating hours. All teeth were intact, and the bearings were sealed. Basalt cobbles were found above the bit and flapper valve, which had prevented the core barrel from seating and blocked the coring process. Although we were uncertain of the next formation to be encountered, we ran another new F99CK hard-rock bit, because the first one performed so well.

The pipe was run in for re-entry \#3 without incident. After scanning for less than 1 hour, an apparently good stab was made, accompanied by audible clanging from the in-the-pipe hydrophone. However, a slight loss of weight and more-than-normal total-weight fluctuations indicated that the cone may have been missed. The pipe was pulled up above the level of the cone, and a second stab was made. All signs then indicated a successful stab, and running in of several stands of pipe verified it.

We began coring with Core 38 , which cut very slowly, after which the coring rate increased to 2 to $3 \mathrm{~m} / \mathrm{hr}$. Cores 39 to 51 were taken through a basalt sequence with extrusive characteristics increasing downwards. Cores 40 to 43 contained volcaniclastic siltstones and claystones. Very few problems were encountered in this coring sequence. The core diameter reduced, until Core 51 measured 5.4 to $5.6 \mathrm{~cm}$ in diameter and had a rather "lumpy" appearance. Because the bit had 48 hours on it at that point, we decided on a round trip for bit replacement.

Recovery of the F99CK bit showed one significantly but not dangerously loose cone. The other three cones were all tight, and the teeth were mainly intact, although there was quite a bit of tooth wear. Since the teeth held up better on these bits, we decided to run another F99CK (button-tooth) bit for re-entry \#4.

The drill string was run in for re-entry \#4 without incident, and an apparently successful stab was made after only a half hour of scanning. Running in several more stands verified a successful stab, and the drilling assembly was run in to the bottom of the hole to start cutting Core 52 . Core 53 required a second wire-line run, because the overshot shear pin sheared on the first one. Core 54 was pulled early because of a drop in pump pressure, indicating that the core barrel was coming unlatched. Core 57 recovered only 1.5 meters of a 9.0meter core, because of a jammed core liner and jammed core barrel. Core 59 was run experimentally without a core liner, and $97 \%$ of the core was recovered. Coring with liners again resulted in a jammed liner-catcher combination on Core 62 , which was pulled early because of a drop in pump pressure, indicating unlatching of the core barrel. Decreasing core diameter and 53 hours of bit life induced us to execute a round trip for a new bit after Core 64 . This bit suffered similar but more extensive wear than the previous F99CK. One cone was becoming dangerously loose, while the other three remained sealed. More teeth were broken, and about 3/16 of an inch of "shirttail wear" was noted.

Seven deviation surveys were made between Cores 49 and 63 , all but the last showing large $\left(5-10^{\circ}\right)$ deviations, although the measurements may be unreliable (the replicate measurement does not match the first one, and is not $180^{\circ}$ across the bull's-eye from it). The survey at Core 63,865 meters, showed an apparently reliable measurement of only $1.3^{\circ}$. During re-entry \#5, another survey was made at 801 meters, approximately in the middle of the previous large, but erratic ones. A reliable $1.5^{\circ}$ deviation proved that the previous results were due to a malfunctioning survey instrument.

In an attempt to make hole faster, we decided to use an F94CK (chisel-tooth) bit on re-entry \#5. The drill collars were magnifluxed for crack detection, and the lowest one was demagnetized during this pipe run-in. The pipe was run in without incident, and an apparently good stab was made, with only 15 minutes of scanning. The drilling assembly went down the hole easily, with only a minor hang-up on a previously encountered basalt ledge at 5791 meters. On picking up the Bowen power sub, the bearings in the supporting swivel failed, requiring three additional hours to change the swivel out for its spare. Because of many previously jammed core liners, we began this coring sequence at Core 65 , without using liners. This increased recovery, lowered the cutting and wire-line time, and lowered the danger of the core barrel unlatching and allowing basalt fragments to accumulate in the bit sub. These cores cut considerably faster than previously, possibly because of the chisel tooth bit, although the formation was more rubbly and less dense than before. This rubble reduced recovery from Cores 69 to 73, and caused the drill string to torque up somewhat. A round trip was decided on during Core 74, at 953 meters, because of slow penetration and drill-string torquing. The bit had been used only for 40 hours, but core diameters were hard to measure in the rubble sequence.

The bit was recovered with only three cones attached, the fourth one apparently having been left in the hole. One of the remaining cones was locked, and the other two were dangerously loose. Most of the teeth were worn off these cones as the result of drilling on the lost cone. The bottom of the hole was $3 / 16$ to $1 / 4$ of an inch 
undersized. Recovery for Core 74 was $103 \%$, consisting of 7.2 meters of sill-type basalt cut in about 30 - to $50-\mathrm{cm}$ lengths. Core diameter was uniform at 5.1 to $5.4 \mathrm{~cm}$. Heavy scratch marks were observed on the lowest 6 meters of the bottom drill collar, indicating that the lost cone was bypassed at some point. Probably at least Core 74 was drilled with only three cones, after the lost cone had been bypassed.

A junk basket consisting of a drill-collar-sized pipe (concave junk mill), with teeth and tungsten carbide at the bottom, was rigged to fish for the missing cone. Two sets of dogs that completely close the core barrel were rigged above the junk mill. These dogs were blocked open with 4-in.-diameter PVC pipe glued to a piece of plywood, to allow the EDO scanning tool access through the bit. This assembly should have over-cored the basalt rubble and loose cone at the bottom of the hole, then recovered the cone after the PVC pipe and plywood were crushed during the coring.

The pipe was run in without incident, the EDOscanning tool worked normally, and the re-entry was made after about 15 minutes of scanning. The drilling assembly was run to the bottom of the hole, and the drill string was rotated with about 12,000 pounds of weight for about 20 minutes. No drill-string torquing or bouncing was observed. The hole was reamed and flushed with mud, and the drill string was round-tripped.

The drill string was pulled up, and the PVC pipe-plywood arrangement had not been crushed, allowing the core dogs to close. A few basalt cobbles were wedged beneath the dogs, but the cone was not recovered. Small sections of polished surfaces on the bottom of the teeth, groove marks on the outside of the junk mill, and several chunks torn out of the teeth all indicated that the cone probably was still in the hole, although not necessarily on the bottom or in one piece. A second junk basket was made up, similar to the first one, but with a shorter piece of PVC pipe to block open the core dogs. In order for the dogs to close with this arrangement, it was only necessary that the PVC pipe be pushed up the bit sub $2 \frac{1}{2}$ inches.

The fishing assembly was made up and run in without incident. Re-entry was temporarily hampered by a minor electronic console malfunction, which was quickly cured, and the re-entry was made in the usual short time, without further incident. The drill string was run to the bottom of the hole and rotated for 2 hours with 12,000 pounds of weight on the junk mill. The drill string first rotated smoothly, then exhibited moderate torquing, then ran smoothly again. After drilling, weighted drilling mud was pumped into the hole, and the circulation was reversed in an attempt to pick up any loose fragments on the bottom of the hole. The weighted mud was then flushed out of the hole, and the drill string was retrieved.

The junk mill was brought on deck, and all the core dogs but one had been torn or milled out of the core catcher. The last dog was badly milled, apparently from coring a solid piece of basalt for too long a time. The junk mill teeth were dulled, but it was not obvious that the missing cone was encountered at the bottom of the hole. We decided to run down a regular drilling assembly with a F99CK button-tooth bit, to determine if we could drill ahead. This assembly was made up and run into the re-entry cone, where re-entry was made to a new $16-\mathrm{kHz}$ beacon dropped in the meantime. Re-entry took about 2 hours, because new beacon offsets were determined.

The drilling assembly was run in to the bottom of the hole, where mud was pumped, and about 2 meters of fill were encountered. Repeated attempts to rotate the bit on bottom with 5000 to 12,000 pounds of drilling weight resulted in moderate bouncing and serious torquing of the drill string. The drill string stalled several times, and no apparent progress was made down the hole. After stalling, the drill string could be freed by lifting it about 3 meters to open the bumper subs, indicating that the obstruction was on the bottom. After 45 minutes of drilling with no apparent progress, we decided to retrieve the drill string before the present bit was too badly damaged.

The drill string was pulled out of the hole and up to the rig floor. The core barrel was empty, and the bit cones were badly gouged and scarred. Twenty-five inserts were broken off. The bit-cone bearings were in good condition. We decided to run back in the hole with the concave junk mill blocked open with PVC pipe. A permanent magnet was run in after re-entry as a backup junk catcher. This magnet seated about $10 \mathrm{~cm}$ above the core dogs and was intended to retain bit-cone fragments passing through the core dogs. The magnet was an old tool, and not very powerful.

The drill string was run in, and re-entry was made with no problems. The drilling assembly was then run to the bottom of the hole, and the junk mill was rotated on bottom with about 5000 pounds or less drilling weight, for 5 to 10 minutes. Minor torquing was experienced at first, then the drill string turned smoothly.

The overshot was then run in, and the magnet was retrieved. The magnet collected only pipe scale. An attempt was made to re-energize the magnet by wrapping the magnifluxing cable around it and exposing it to about 10,000 amp-turns of magnetic flux. No appreciable difference in magnetic attraction was noted.

The Servco junk mill was then turned on bottom for another 10 minutes of light weight, and the drill string was retrieved; we discovered that all the core dogs had been torn from the junk mill after only 15 minutes of rotation. Nothing was recovered from the hole.

About the time this junk mill was brought on deck, the chief engineer reported that the $\# 2$ bow thruster had salt water flooded in the lube oil. Something in the system had failed to seal and repairs had to be made ashore. A crane is necessary to move the "ear muffs" that seal the thruster tunnels while the thrusters are being worked on. This could be done in Majuro, and we could maintain our position in the calm weather to finish one more round trip.

Only enough time remained to make one more round trip into the hole. It was decided to run the natural 
gamma-ray-neutron back-scatter logs in the pipe, and to conduct a junk run. We decided to run the Homco junk mill, which is similar to the Servco model, except that it has free-rotating core dogs and no way to land a core barrel with a magnet attached. Its core dogs are propped open with a wooden "sandwich" that also serves as a landing pad for the EDO scanning tool.

The drill string was run in without problems. Reentry took about 2 hours and was hampered by the lack of $\# 2$ bow thruster. The drilling assembly was run to the bottom of the hole, and the logging tool was run in through the pipe. The logging run was conducted coming up the hole, with a total expenditure of time for logging of about 5 hours.

The junk mill was then set down on bottom with about 10,000 pounds of drilling weight and rotated slowly for 1 to 2 minutes. The drill string was pulled out of the hole for the last time, and we had recovered two cobbles of basalt and got all the core dogs back intact, but the bit cone was not retrieved. The free-rotating core-dog assembly was less free-rotating than when it was lowered, because of sand-sized grit in the moving parts. The ship was got under way and run due west for 2 miles, where a sonobuoy was deployed, the ship was turned to head due east, and a run was made across Site 462. The sonobuoy malfunctioned, probably because of the hydrophone tangling in the magnetometer cable, but a good quality, normal-incidence seismic profile was obtained across the site. The ship then continued due east across the northern Nauru Basin, profiling at about 6 knots. All geophysical running gear and the electronics lab watch were secured when we came abeam of Ailinglapalap Atoll, about $300 \mathrm{~km}$ west of Majuro. The ship was docked at Majuro Atoll on the morning of 11 July 1978 for repairs to the bow thruster and crew exchange.

Because a freighter was occupying the only available space at Majuro wharf, the ship was anchored out, and work was begun on the bow thruster. This required a harbor tugboat and divers to manipulate into place the "ear muffs" that seal the thruster tunnel. Since the weather was calm, the work proceeded smoothly. After sealing and pumping out the thruster tunnel, the cause of the leak was determined to be hold-down bolts (studs) that had loosened from vibration. All 12 bolts were changed, but the gear box itself was not replaced. Thruster repair consumed 3 days, during which the ship could not be moved without endangering the sealed thruster tunnel. On July 12, during this period, the crew change was accomplished via a charter aircraft, a local freighter acting as a ferry, and a school bus. During the morning of July 14, thruster repair was completed, and the ship moved to the wharf to take on fresh water for drilling mud. About 40,000 gallons of fresh water was pumped on in about 20 hours. At approximately 0630 on July 15, we sailed from Majuro to re-occupy Site 462. The ship's party included eight people who departed the vessel in Majuro when the Site 462 work was completed. A corresponding eight of the Leg 62 crew waited on Majuro during this period. This ship track back to Site 462 was between Ailinglapalap and Namu Atolls, a deviation from a rhumb line track of about $25 \mathrm{~km}$, which allowed a different crossing of the archipelagic apron of the western Marshalls.

The ship proceeded without incident across the northern Nauru Basin to Site 462. Fifteen minutes after starting to listen for a beacon, the $16-\mathrm{kHz}$ instrument signal was received at a range of 12,000 feet off the port bow. The ship's course was altered, the running gear was retrieved, and the ship was positioned on site.

A junk grinder modified under the supervision of Mr. Arkie Slayton of the Midway Fishing Tool Co. was run in on a short bottom-hole assembly. This junk grinder consisted of a concave grinding surface built up from an existing "clover leaf" grinder. The $2 \frac{1}{2} 2$-in. throat for the scanning tool was designed to be filled with a center bit modified with tungsten-carbide chips on the head. The drill string was run in, and the re-entry stab was made after 2 hours of scanning. The scanning tool was retrieved, and two verification stands were run in. The logging sheaves were rigged down, and the drill string was run to the bottom of the hole. No bridges or filled sections were encountered. The grinder first took up weight at 6139 meters, the total depth of the hole.

The junk grinder was turned with 10,000 to 15,000 pounds of weight for about an hour. There was no bouncing, but severe torquing was observed, requiring us to lift the grinder off bottom when the drill string stalled out. Often the junk became wedged on the side of the grinder and "followed the grinder up the hole." After about an hour of this procedure, the torquing smoothed out, and more weight was applied to the grinder. The grinder was rotated another half hour, and the bottom of the hole was declared junk-free. The drill string was pulled out of the hole and retrieved to the ship. The grinder and center bit were recovered intact, the center bit being worn badly in the grinding process. The main surface of the grinder was still in good condition. Obvious milled surfaces and traces of PVC pipe were observed on the grinder.

The bottom-hole assembly was re-rigged with an F99CK button-tooth basalt bit and run in to a point above the re-entry cone. The scanning tool was run down, but would not fall to the bottom of the pipe. It was retrieved, and we discovered a backed-out screw that was jamming it in the pipe. The screw was torqued down, and the scanning tool was run to the bottom of the pipe. An electronic malfunction occurred immediately after beginning to scan, so the tool was retrieved. Two leads in the logging tool head were found to be shorted out because of a water leak. The logging-tool head was repaired, and the scanning tool was run down the pipe for the third time.

The scanning tool was run down the pipe, and scanning was conducted for 2 hours prior to a successful stab. The target on the scanning scope was very poor, because of the pipe dope coating the transducer head, discovered upon retrieval of the tool. This resulted from 
applying pipe dope to the interior pipe joint (the "box") instead of the exterior pipe joint (the "pin"), when running in pipe.

The pipe was run to the bottom of the hole, and drilling commenced at 953.0 meters. Moderate torquing was observed for the first 3.5 hours of drilling, then the torque level smoothed out. Mainly intrusive, sill-type basalts were recovered in Cores 75 to 79 , from 953 to 994 meters, although the core catcher of Core 79 contained brown claystone. Recovery of Core 76 was poor, because of a core-dog jam, and Core 80 was retrieved early because of slow progress, found to be caused by a jammed core liner. Core 80 contained 3 meters of gray volcaniclastic siltstone, overlying 1 meter of basalt. Core 81, from 998 to 1003 meters, contained fractured, sill-type basalt.

The drill string was pulled out of the hole to change the bit after Core 81 and 35 hours of bit life. This decision was based on the need to work with a new, multipurpose bit in the time remaining before the logging program commenced; the general feeling was that it would be safe to change the bit at that point. On retrieval, the bit was discovered to have three loose conesone dangerously loose-and a small piece of the cone body containing four inserts was missing from one cone. This piece may have been knocked off on reentry, and may have been the cause of the torquing during the initial coring. Alternatively, the torquing could have resulted from milling of junk in the hole that remained after the junk-grinder run.

The bottom-hole assembly was re-rigged with an F94CK chisel-tooth, multi-purpose bit and run in to a point above the re-entry cone. The core was successfully stabbed after scanning for 1 hour to a much improved target over the previous re-entry. The drill string was run to the bottom of the hole, and coring was begun with Core 82 . Core 82 was retrieved early, because of very slow penetration; it was found to contain 1 meter of basalt and 3 meters of cuttings. Apparently, either the flapper valve was jammed open or the spring was broken, so the center bit was run down twice in an attempt to clear the jam. Core 83 was another short core, to see if the flapper valve had been cleared. Only one small piece of basalt was retrieved after cutting a 1.5-meter core, but the core barrel appeared to have seated, so we proceeded with coring full-length cores. Coring appeared normal until Core 91, although Core 86 had no recovery for no apparent reason. Cores 91 and 92 recovered only a $2-\mathrm{cm}$ fragment of basalt each in the core catcher. The fragment in Core 92 was rotated sideways, giving the impression of extra space somewhere in the bit assembly, so we decided to trip out of the hole at that point with 37 hours of wear on the bit. Coring had been slow and continuous from Core 85 to 91 , but Core 92 had drilled very quickly. When the bit was recovered on deck, all four cores were found intact with the bearings sealed; however, all the drive-teeth inserts were worn off the middle of all the cones. The flapper-valve spring was broken, which may account for some of our earlier problems with an open flapper valve.
The used bit was removed from the pipe, and a special landing sub was installed for the scanning tool, which also allows logging tools to pass easily through the end of the pipe. The pipe was run in to the re-entry cone, the scanning tool was run down the pipe, and the stab was made after 15 minutes of scanning. The scanning tool was retrieved, the end of the drill string was run down to the bottom of the re-entry-cone casing, and the sonic-velocity and gamma-ray caliper tool was run down the pipe. This tool was run to the bottom of the hole without encountering any ledges, and the tool was retrieved up the hole while logging. The tool worked normally, and an excellent velocity log was obtained.

The tool was retrieved up the pipe and lost near the top of the pipe, apparently because it was two-blocked against the line wiper at the rig floor. We felt that the tool probably had fallen back to the bottom of the hole, so a guard tool was rigged to be run carefully down the hole. The guard tool encountered the velocity tool at 132 meters; on retrieval, it was found to have been jammed there because the caliper was open.

The five stands of pipe that had been laid down to retrieve the velocity tool were put back into the drill string, and the scanning tool was run down the pipe for re-entry. When the scanning tool reached the bottom of the pipe, it would not present a target or a bottom echo, so it was retrieved and found to have a water leak. An alternate scanning tool was run down the pipe, the target was scanned for about 1 hour, and the stab was made. On retrieving the scanning tool after the fifteenth successful re-entry at Hole $462 \mathrm{~A}$, a broken strand of armor wire was found on the logging cable at about 5000 meters. This jammed and balled up against the line wiper, requiring about 250 meters of loose wire to be cut off. The logging cable was no longer usable for logging or re-entries, so the scanning tool was retrieved, and the drill string was pulled out of the hole. At 0524 (local), 27 July, the ship departed the site and sailed due east toward Majuro. At 1400 (local), 29 July, Glomar Challenger rendezvoused with a small craft at the entrance to Majuro Lagoon, where a transfer of 10 people on and 10 people off the ship was accomplished. This terminated Leg 61.

\section{SEDIMENT LITHOLOGY}

\section{Introduction}

The stratigraphy of sediments and sedimentary rocks recovered from the Nauru Basin is as follows:

\begin{tabular}{|c|c|c|}
\hline Unit I & 0-297 meters & $\begin{array}{l}\text { Calcareous and radiolarian oozes and } \\
\text { chalks, mainly of turbidite origin, of } \\
\text { late Eocene and younger age. }\end{array}$ \\
\hline Unit II & $297-447$ meters & $\begin{array}{l}\text { Cherts, chalks, and limestones, pre- } \\
\text { sumably the diagenetically advanced } \\
\text { Eocene to Maestrichtian equivalents } \\
\text { of Unit I, above. }\end{array}$ \\
\hline Unit III & 447-996.5 meters & $\begin{array}{l}\text { Volcanogenic and zeolitic sand- } \\
\text { stones, mudstones, and limestones } \\
\text { (the lowest within sills and flows), } \\
\text { of Maestrichtian to Barremian age. }\end{array}$ \\
\hline
\end{tabular}


For the purpose of this report, the section can be divided into these three units. All units are characterized by abundant contributions of sediment transported to the site and redeposited. In brief, Unit I is ooze above about 220 meters, and mainly chalk below that depth.

The contact between Units I and II is placed at the first cherty rock recovered, a piece of porcellanite near the top of Core 32 . Unit II is chalk, with sparse porcellanite and chert above Core 41 , but Cores 42 through 47 were slow to drill, and recovery of chert and limestone was poor. Unit III has a upper section of redeposited volcaniclastic siltstones, sandstones, and breccias, interbedded with marls, limestones, and chalks. It was recovered as high as 447 meters, but may extend up to 440 meters (by interpretation of the density log through an uncovered interval). The section below about 487 meters, dominated by zeolitic mudstones and claystones, contains but minor amounts of limestone or volcanic sandstone. Basalt intrudes the zeolitic mudstone at 561 meters, but layers of mudstone lie between sills as deep as 599 meters. Whether these Cretaceous zeolitic sedimentary rocks continue deeper could not be determined at this site.

Two holes $(462,462 \mathrm{~A})$ were drilled; a graphic summary of their stratigraphy to a depth of 617 meters is given in Figure 9.

\section{Hole 462}

In Hole 462 the following units are recognized:

\section{Unit I: Calcareous and Radiolarian Oozes and Chalks (0-297 m)}

The sea floor of the Nauru Basin lies at 5181 meters Precision Depth Recorder, (PDR) at this site, well below the CCD. At these depths, we expected and found brown pelagic clay at the top of the piston core taken during the 1977 site survey, as well as in the top 2 meters of Core 1 . The clay, like most of the oozes and clays well into the section, is rich in radiolarians, perhaps owing to the proximity of this site to the equatorial belt of high productivity during much of the Cenozoic. The first several cores were moderately to strongly disturbed by the coring process, so that our inferences of the rhythmically bedded in situ appearance and redeposited origin of the bulk of the Neogene are based on (1) alternations of solution-prone and solution-resistant lithologies where least disturbed by drilling, the homogeneous disturbed portions combining the alternating lithologies; (2) abundant carbonate detritus reworked from sediments with microfossils as old as Late Cretaceous; (3) comparison with obvious turbidites from deeper levels, where recovery of preserved primary sedimentary structures improved; (4) the regional setting, a nearly flat-floored basin with leveed channels, sloping gently up to the southwest, where at about $400 \mathrm{~km}$ distance is the eroded edge of the Ontong-Java Plateau; and (5) continuous, "turbidite-appearing" reflectors on the site-survey seismic-reflection profiles.

The beds, colored in various shades of brown, contain abundant clay and radiolarians, and range from siliceous pelagic clays through radiolarian-rich clays to radiolarian oozes. Diatom remains and spicules of siliceous sponges are common locally, and trace amounts of phosphatic fish debris and opaline silicoflagellates may be present.

The layers of calcareous ooze are mainly composed of nannofossils, perhaps resulting from more-active dissolution of foraminifers in the source area or in the present basin of deposition. At many levels, however, foraminifer content is sufficiently high to give the ooze a sandy appearance and feel. A few per cent of radiolarians are present in many of the carbonate-rich layers. The ooze is very pale-orange to white; none of the cores displayed the pastel greens, blues, and purples common in freshly opened piston and DSDP cores in areas of present-day particle-by-particle pelagic carbonate sedimentation: such colors bleach rapidly as the original micro-environment of reducing pore waters is destroyed. This supports the overwhelming evidence discovered by the paleontologists that virtually all of the carbonate grains were redeposited.

The repetitions of carbonate and non-carbonate beds are on a scale from less than 0.1 meter to more than 8 meters. The percentage of $\mathrm{CaCO}_{3}$ in a bed about 1.2 meters thick in Core 16 is shown in Figure 10. Obviously, the thicker carbonates are not single turbidites, and probably most of the thinner ones are not; if they were, the volumes of individual density flows would have been enormous. Slight mottling, indistinct horizontal bedding in some units, and alternations of foraminifer-rich and foraminifer-poor layers suggest that the carbonate-bearing parts of Unit I represent repeated influxes of sediment, whereas at other times such processes were infrequent or nil. Perhaps the difference could be related to changes in tectonism or bottom currents in the source area, but more likely there were changes in the levee heights, locations, and pathways along the distributary channels fed from the OntongJava Plateau.

Toward the tops of the better-sampled carbonate units, the nannofossil ooze grades upwards into siliceous pelagic clay. Commonly, the siliceous, dominantly radiolarian component of a sequence of turbidites is sufficiently great that the succession is nannofossil ooze through radiolarian ooze to pelagic clay. Most of the radiolarian tests are fragmented and sizesorted. Perhaps these grains, with a high ratio of surface area to volume, are fractions of turbidites even more distal than the carbonate part. The pelagic clay represents the background sedimentation in the region. It may also in part represent a solution facies of the tops of the oozes.

Below about 250 meters, the recovered carbonate sediment becomes sufficiently lithified to earn the name chalk. The density log suggests that the transition is between about 228 and 241 meters; however, the hole is washed out in this area, so the density log is probably not reliable. In the lower part of Unit I and the upper part of Unit II, the appearance of several split cores is of pieces of chalk a few centimeters thick, separated by intervals of ooze-like soft sediment. This has been common at other DSDP sites in carbonate sections. The up- 


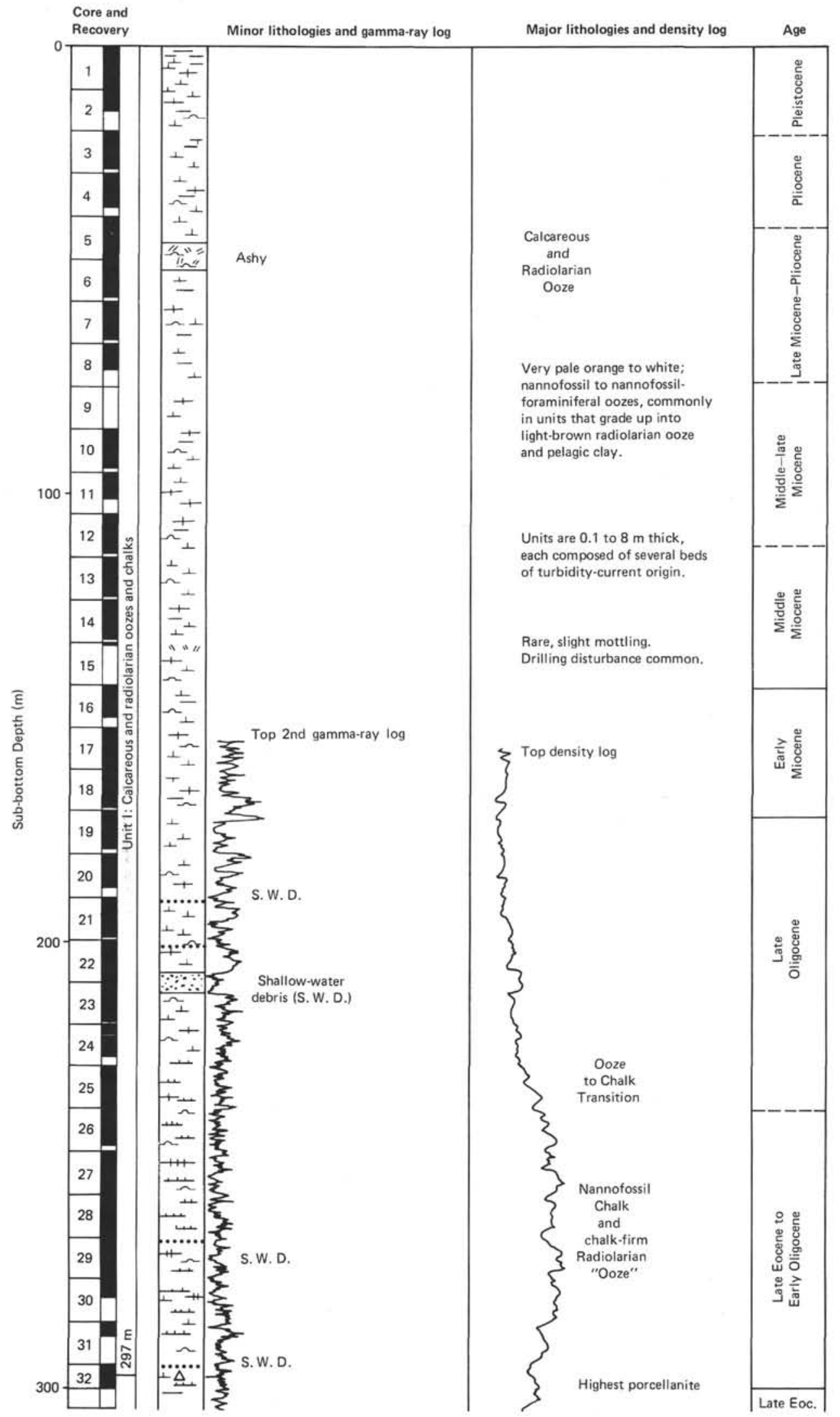

Figure 9. Lithologic summary, Site 462. 


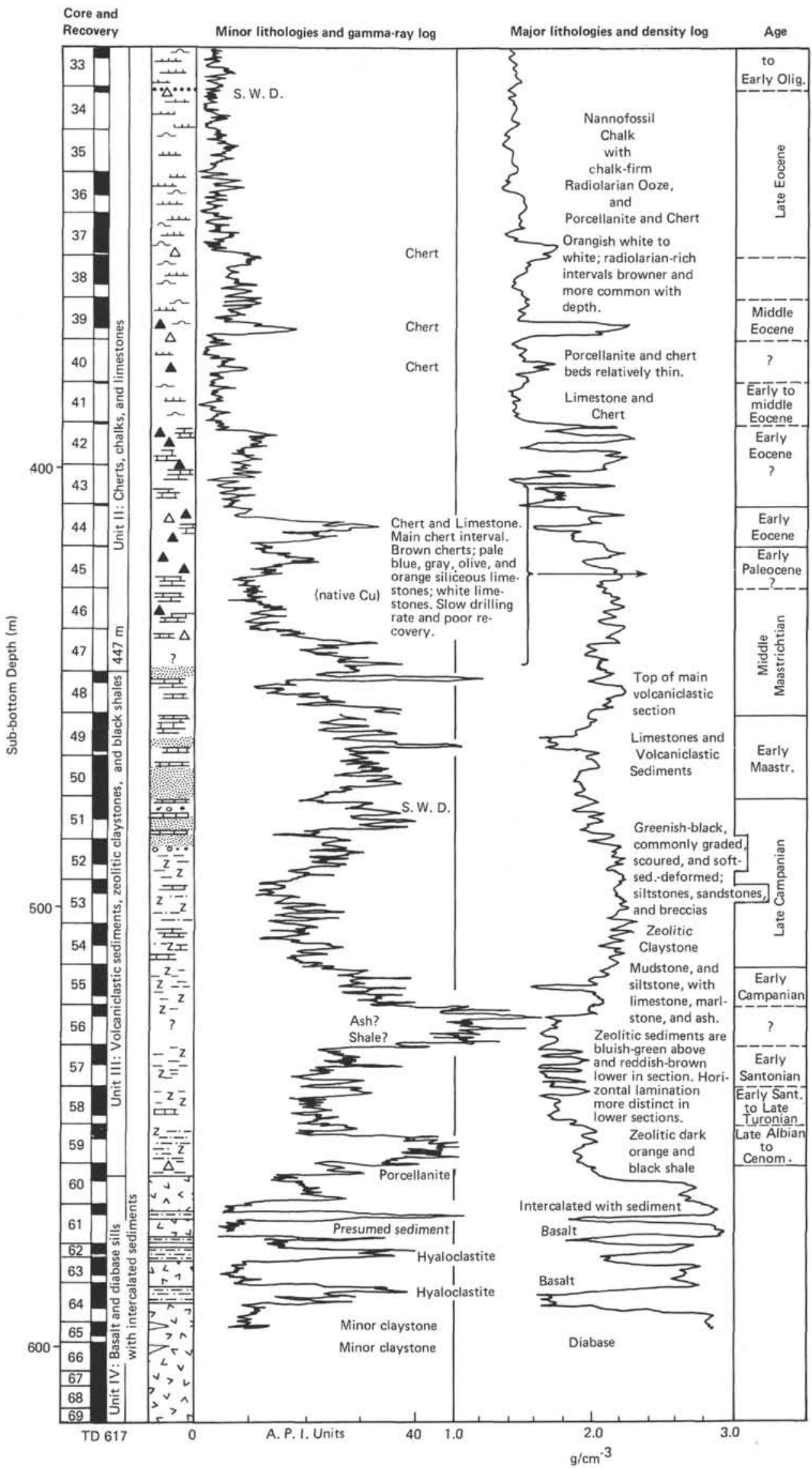

Figure 9. (Continued). 


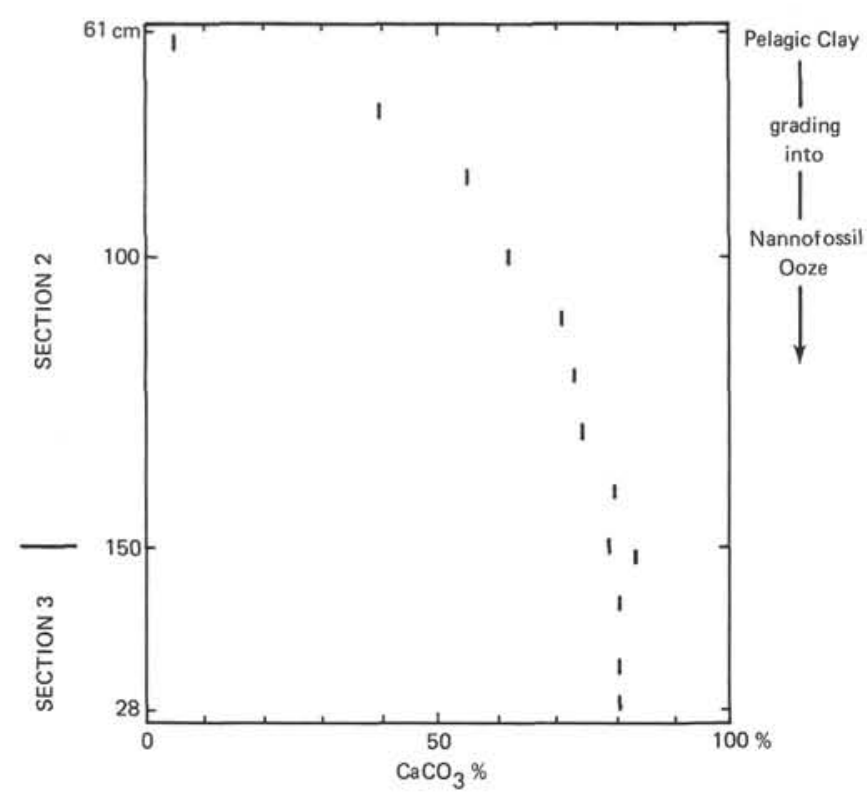

Figure 10. $\mathrm{CaCO}_{3}$ content of a 1.2-meter-thick turbidite interval in Core 16, Site 462 (J. Rutherford, analyst).

permost part may indeed represent a transitional inter$\mathrm{val}$, with layers of ooze interbedded with layers in which differences in texture or composition have allowed diagenesis to proceed to the chalk stage. The alternative explanation, which the density log suggests, certainly is the correct one farther down in the section, where small relict lumps of chalk as well as flakes of rusty scale from the drill pipe can be seen in the "soft" intervals. The larger, biscuit-like pieces of chalk represent sediment cored when the driller released the brake momentarily, whereas the sediment between the large pieces is chalk ground up by the bit, wetted with water circulated through the string of drill pipe, and then pressed up into the core barrel.

Sedimentary rock without a common name may be present in Unit I below about 200 meters, and is typical of much of Unit II. The rock is the siliceous equivalent of chalk, composed dominantly of radiolarians, with clay and sponge spicules, but so firm that the term ooze seems inappropriate. It behaves like chalk under a spatula or fingernail, and small lumps resist disintegration during modest washing. Yet certainly the rock is too friable to deserve the names porcellanite or chert. We have called it a very firm radiolarian ooze for lack of anything more appropriate.

Against this general background of turbidite oozes and chalks, two less common but significant lithologic contributions are found in Unit I, ash and shallowwater, sand-sized material. The ash is found in Cores 4 , 5 , and 6 , and also was indicated by a modest increase in the drilling rate at the bottom of Core 5. By inspection of the first-run gamma-ray log, the principal ashy inter$\mathrm{val}$ is between 44 and 50 meters.

Where the ashy component is contained in radiolarian ooze it is brown, whereas it is greenish-gray in carbonate ooze. Yellow-brown glass, glass partly altered and crowded with opaque dust, feldspar, pyroxene, and some amphibole are the components from volcanic activity nearby. The volcanism records the early late Miocene to Pliocene growth of Kusaie Island, the easternmost and apparently youngest of the Caroline Island Chain. Kusaie is the closest island to Site 462, lying about $260 \mathrm{~km}$ to the southwest.

Sands of shallow-water origin characterize parts of Cores 21, 22, 29, 32, and 34 and are thickest at about 210 meters depth. According to the gamma-ray and density logs, the principal interval lies at 207 to 212 meters depth. The carbonate component of the coarse fraction is a mixture of chalky-lustered, recrystallized, highly abraded fragments of large foraminifers, mollusks, echinoid spines, calcareous red algae, bryozoans, and, rarely, corals. Rare fragments of white to pale-yellow calcite spar are also present. Individual fragments range from 1 to $4 \mathrm{~mm}$ in diameter. Identified large foraminifers include nummulitids and discoclyclinids. The former include these genera, in decreasing order of abundance: Nummulites, Heterostegina, Operculina, Spiroclypeus, Cycloclypeus, and Assilina; the discoclyclinids are mainly represented by Asterocyclina. Also present is a primitive species of Miogypsinoides. Cores 22 and 32 are especially rich, containing, among other large foraminifers, alveolinids, Cycloclypeus, and lepidocyclinids.

This assemblage is Eocene in age, but also contains Paleocene and Cretaceous redeposited elements. The assemblage indicates an origin in a reef to shallow-bank environment. In thin section, intensely recrystallized and strongly calcite-cemented rock fragments containing the above-listed fossil elements are seen. This indicates that lithified reef rock, as well as individual skeletal fragments, of Eocene age were transported into the deeper-water Oligocene facies. A similar event took place during Oligocene time in the Line Islands (Winterer, Ewing, et al., 1973; see Premoli Silva and Brusa, this volume).

Volcanic grains make another component of the sand. They include lithic grains which are commonly vesicular and are opaque to transmitted light at their greatest thickness, as well as vitric and crystal (pyroxene) grains. Like the lime sand, they are detrital in origin. Probably they are the record of times in the Oligocene when the Marshall Islands were above sea level. Foraminifers of probable Eocene age and volcanic rock from the tops and submarine slopes of the islands were being eroded. The Ralak Chain of the Marshalls lies about 230 to $400 \mathrm{~km}$ to the northeast and east of the site, and the unnamed group of the Marshalls (containing Enewetak Atoll and numerous closer atolls, seamounts, and guyots) is the same distance to the northwest; Enewetak Atoll is known to have been emergent in the Oligocene.

\section{Unit II: Cherts, Chalks, and Limestones (297-447 m)}

As noted in the introduction, the top of Unit II arbitrarily is placed at the level of the highest recovered cherty rock within the chalk and firm radiolarian "ooze." These principal lithologies persist down to about 390 meters, but with a general increase in the pro- 
portion of the radiolarian intervals to the nannofossilchalk intervals between about 330 and 390 meters. The highest recovered porcellanite, from 297 meters, does not show on the logs (hole washed out), but intervals at 349 to 353,367 to 370 , and 376 to 378 meters show above the top of the main interval at 390 meters depth. The 367- to 370-meter interval showed the highest density, and chert sampled in Core $39, \mathrm{CC}$, at about 368 meters, may be a principal seismic reflector.

At Site 462, two different sequences of silica diagenesis and formation of authigenic silicates can be recognized, which reflect two different types of particle sources. The dominantly biogenic silica supply in the Cenozoic sequence led to chert formation in Cores 32 to 47, at burial depths exceeding 300 meters. Preliminary examination shows that diagenesis of the Cretaceous volcaniclastic sediments led to the formation of zeolites and authigenic clay minerals.

Dissolution of biogenic opal in the radiolarian and radiolarian-nannofossil oozes increases with depth: diatoms are preserved only above Core 20 , whereas below that level opal is limited to varying amounts of remaining radiolarians and sponge spicules. No alteration of biogenic opal-A to opal-CT (low-temperature cristobalite/tridymite) has been noted in non-silicified sediments, contrary to evidence from other sites, where alteration in individual skeletons was observed.

Porcellanites occur only sporadically in Cores 32,34 , 40,44 , and 47 , the majority of pieces recovered being quartzose cherts. Intercalated radiolarian oozes and calcareous turbidites are interpreted as host rocks.

Carbonate diagenesis, like silica diagenesis, had advanced in the lower part of Unit II. Limestones and siliceous limestones are the only other lithologies recovered with the chert from the main cherty interval between 390 and 450 meters. The more-siliceous limestones are colored pale tints of blue, grayish-yellow, light olive-gray, and very pale orange; the limestones are more nearly white. Nannofossils are common in the limestones, but the origin of most carbonate is not discernable in the shipboard smear slides scraped from the limestones. Some of the rhombs may have been sparry cement, and the various spindles and tiny irregular grains probably represent skeletal remains in various stages of dissolution or overgrowth. A very thin vein of native copper is present on a high-angle hair-line joint within Core 46.

\section{Unit III: Greenish-Black Volcaniclastic Sediments, Brownish-Red Zeolitic Claystones, and Black Shales (447-559 m)}

Unit III is separated from Unit II by the down-hole disappearance of major chert and the appearance of volcaniclastic material; its boundary with Unit IV is at the sediment/basalt contact. Unit III embraces the time interval between late Campanian/early Maestrichtian and Cenomanian. The top of the unit comprises lightolive-gray to pale-yellow nannofossil chalks and limestones, locally mottled; associated lithologies are darkgray to olive-gray nannofossil marls and claystones which are horizontally laminated at some levels. These sediments, which contain considerable percentages of unspecified carbonate, traces of volcanogenic grains, very sparse radiolarians, and sponge spicules, are interpreted as a pelagic product in which the amount of redeposition has been modest.

Interbedded and intermixed with these host lithologies are a series of greenish-gray to greenish-black volcaniclastic sediments. These deposits are perhaps the most striking feature of this unit and display a range of sedimentary structures: tabular and trough cross-lamination, horizontal and parallel lamination, angular and scoop-shaped scours and pebbly mudstone conglomerates whose clasts range up to $2 \mathrm{~cm}$ in length. Prominent vertical burrows are present in one cross- and horizontally laminated calcareous volcaniclastic level at the top of the unit (Core 48, Section 1): these organo-sedimentary features may be escape structures, the result of rapid and premature burial of the organism concerned (see Moberly and Jenkyns, this volume). This mixed calcareous volcaniclastic level is one of the few in the unit which contains a notable admixture of planktonic foraminifers. Grading is obvious in many of the volcaniclastic sediments, and one bed, attaining a thickness of 2.55 meters, fines upwards from a dark-greenish-gray, granular base to a greenish-gray, burrow-mottled, clayrich nannofossil limestone (Core 51, Sections 1-3). Slump structures, both within the scale of the core itself and, apparently, extending over several tens of centimeters, characterize particularly the basal levels of the volcaniclastic sediments; inclined bedding, up to $30^{\circ}$ from the horizontal, is present locally. A range of other styles of soft-sediment deformation (phacoidal structures) are also present, commonly involving horizontally and cross-laminated horizons. The basal part of the volcaniclastic section comprises a matrix-rich volcanic breccia (wackestone), where sparse altered mafic clasts are enveloped in bluish-gray clay. Volcanic glass, heavy minerals, radiolarians, sponge spicules, fish remains, and clay constitute the fine fraction.

Associated with these volcaniclastic sediments are a variety of shallow-water skeletal grains. In Core 48-2, of Maestrichtian age, the coarse-grained carbonate components are a poorly sorted mixture of chalky and abraded tests of large benthic foraminifers (including Pseudorbitoides, Vaughnina, and Asterorbus), subangular chips of mollusk shells, short segments of echinoid spines, and rare bryozoans. Small chips of white to yellow calcite spar are present, and some of the fossil remains show calcite cement adhering to their surfaces, suggesting that rock fragments as well as uncemented skeletal grains were redeposited within the upper levels of the volcaniclastic sequence.

In Core 51-3, of late Campanian age, the coarsegrained carbonate components are a poorly sorted mixture of small $(<1 \mathrm{~mm})$ unidentifiable calcite fragments, large foraminifers, echinoid spines (rare), fragments of white to yellow calcite spar, and mollusk shells. Many of the large foraminifers are relatively well preserved, but most, like the echinoid spines, are thickly coated with clear to white and yellow, subhedral calcite crystals. There is a striking contrast between well-preserved 
(slightly chalky), large foraminifers and calcite-coated forms that appear to have been broken out of a wellcemented rock. Identified large benthic foraminifers include Vaughnina sp., Pseudorbitoides sp., and amphisteginids. In Core 52, rudistid fragments were found.

These shallow-water fossils of Maestrichtian to late Campanian age indicate that banks within the photic zone existed during the Late Cretaceous, probably in the Marshall Islands, as noted above. The presence of calcite-cemented material mixed with the individual foraminifer tests suggests that these banks may have emerged and that subsequently fragments of these diagenetically mature limestones mixed with co-existing reef and forereef material in the turbidites.

The volcaniclastic sediments, with their associated fauna, are clearly redeposited, and, because many of them display features typical of Bouma sequences, they readily may be interpreted as turbidites. The matrix-rich volcanic breccias probably were formed by deposition from a plastic, mobile mass, possibly some kind of debris flow. It is possible that the original texture was more granular initially, and considerable in situ devitrification of glass to clay minerals has taken place. All these volcaniclastic sediments presumably reflect synchronous volcanism nearby.

Below the volcaniclastic sediments are light-olivegray claystones to limestones that typically occur in sequences that are calcareous and laminated at the base and pass upwards into more-clay-rich, burrowed tops. Above this burrowed level, zeolitic claystones, usually consisting of pale-bluish-green and pale-brown layers (2-3 cm thick), are typically developed. The olive-gray limestones to claystones here are interpreted as redeposited material, and the zeolitic claystones are interpreted as the product of background pelagic sedimentation. Farther down the section, the thickness of the zeolitic claystones gradually increases, and colors of grayish-red and reddish-brown dominate over the pale-bluish-green hues. Olive-green claystones die away downward, until the pale-reddish-brown zeolitic claystones to siltstones, locally evincing faint horizontal lamination, become the dominant lithology. Traces of radiolarians, sponge spicules, fish teeth, and nannofossils constitute the fauna and flora. Occasionally, beds of greenish-gray, horizontally laminated volcaniclastics are interbedded (Core 57, Section 3, and core catcher). Near the base of the section, green mottles and calcite veins occur, and horizontal lamination is common; a nannofossil marlstone is recorded from Core 58, Section 4. Core 59, also zeolitic mudstone (with nannofossils in Section 1), is dominantly reddish- to light-brown, but contains horizontal, millimeter-scale laminae colored dark yellowish-orange, moderate brown, and grayish-green. Most striking perhaps are interbedded reddish-brown and greenishbrown horizontal laminae, and a distinct black horizon. Zeolitic mudstone, containing a piece of moderatebrown, impure quartz chert, is in contact with basalt.

The zeolitic mudstones presumably represent the alteration products of fine-grained volcanic material which has undergone modest redeposition; the former presence of siliceous organisms, tentatively identified in smear slides, is supported by the presence of chert: an isolated nodule was recovered from the Cretaceous volcanogenic sequence $40 \mathrm{~cm}$ above basalt in Core 60 . This chert is isotropic under crossed nicols (opal-CT?), and shows a sound velocity $(5.292 \mathrm{~km} / \mathrm{s})$ higher than, for instance, a porcellanite from Core $47(4.290 \mathrm{~km} / \mathrm{s})$.

The grayish-brown to black sediments, dated at about the Cenomanian/Turonian boundary, are intriguing, in that similarly colored, coeval, but organic-rich sediments are recorded from a variety of locations within the major ocean basins and in pelagic sections on land. These sediments, however, are not organic-rich $(0.11 \%$ organic carbon maximum), and they apparently owe their color to enrichment in iron and manganese oxyhydroxides.

\section{Unit IV: Basalt and Diabase with Sedimentary Intercalations}

Unit IV is dominantly basalt and diabase, but it provided samples from four major sedimentary intercalations (63-1, 6-62 cm; 64-1, $30 \mathrm{~cm}$ through 64-3, $42 \mathrm{~cm}$; $65-1,0-20 \mathrm{~cm}$; and $66-1,0-16 \mathrm{~cm})$, here grouped as part of sedimentary Unit III. The first, stratigraphically highest of these horizons is a grayish-black to black, waxy claystone with relict hyaloclastite texture, containing abundant zeolites and fragments of dark material which is iron- and manganese-rich. Chemical analysis (XRF) of the material reveals a composition very similar to that of the enclosing sill, except for an elevated $\mathrm{Mg}$ content. The second and thickest of these sedimentary intervals comprises greenish-black claystones to hyaloclastic siltstones, horizontally and cross-laminated. The component particles are chiefly altered volcanic glass, set in a matrix of clay that probably resulted from terminal devitrification of an igneous precursor. The material at $65-1,0-20 \mathrm{~cm}$ is essentially identical to this; that at $66-1,0-16 \mathrm{~cm}$, however, is grayish-red and grayish-blue-green hyaloclastic claystones containing some fish debris.

The sediments above-described are presumably rafts caught up during emplacement of the basic sill; they are therefore likely to have undergone some thermal metamorphism. The stratigraphically highest intercalation, with its black, waxy character, is part and parcel of the dark Cenomanian sediments that lie above the sill. The grayish-red and grayish-blue-green hyaloclastic sediments probably formed as a by-product of extrusion of the Lower Cretaceous flows discovered in Hole 462A. Redeposition has clearly operated during formation of the cross- and horizontally laminated, greenish-black siltstones that constitute the two central intercalations.

According to interpretation of the density and gammaray logs, the top of the basalt is at 561 meters. Sedimentary intercalations logged at 570 to 571.5 and 575 to 576 meters were not recovered in Core 61 , nor was the bottom of the intercalation at 578 to 581.5 meters recovered in Core 62 , but its base is the hyaloclastite recovered in the top of Core 63. Most of the intercalation logged between 586 and 590.5 meters was recovered in Core 64. Logs were not started deep enough to identify clearly the actual depth of sediments recovered at 
the tops of Cores 65 and 66 within the diabase sill. It is possible that these pieces fell into the hole between periods of coring, and were thereby available for collection at the tops of the next cores, but the size of the pieces and bit-cut marks indicate that they are in place.

\section{Hole 462A}

The first part of this text is a comparison of sediments and sedimentary rocks recovered from the upper part of Hole 462A with those of Units I, II, and III recovered from Hole 462. The second part is a description and summary analysis of the Mesozoic section recovered below the total depth of Hole 462 .

To assign a particular lithology to a certain depth, the datum used for the purpose of comparing Hole 462 and $462 \mathrm{~A}$ is the length of the string of drill pipe plus the bottom-hole assembly hanging from the derrick floor, not in-hole depths below the sea floor. The reason for this is that the sea floor at Hole $462 \mathrm{~A}$ is listed as 3 meters less than at Hole 462 (actually, probably less than 3 meters, considering that the holes are merely about 500 meters apart on a turbidite-formed abyssal plain, and that the PDR readings are rounded-off upward. Thus, on Figure 9 the cores from Hole 462 are plotted 3 meters deeper than the sub-bottom depths of cores from Hole $462 \mathrm{~A}$.

We have followed the general DSDP convention in spacing or "hanging" the actual meters recovered from the top of the listed cored interval for a regular core. For washed cores $\mathrm{H} 2, \mathrm{H} 3$, and $\mathrm{H} 4$, the in situ location of the pieces of rock recovered from the washed interval is unknown, except that the largest hard pieces probably represent the hardest beds wherever they were penetrated in that interval, and that the softer sediment probably was almost totally washed away by the water pumped down the hole. Washed core H1, however, was almost certainly obtained between 363.5 and 371 meters. Finally, the bit core (B1) probably is the rock unrecovered by Core 26 .

\section{Unit I: Calcareous and Radiolarian Oozes and Chalks (at least 78.5-259 m sub-bottom)}

This unit extends from the sea floor to 297 meters in Hole 462. In 462A, Core 1 sampled the upper, or ooze, part of the unit, and Core 2 sampled the lower, or chalk, part. As in Hole 462, the ooze is present as alternating intervals of nannofossil, nannofossil-foraminifer, foraminifer, nannofossil-radiolarian, and radiolarian ooze. The carbonate oozes, which predominate and show no sedimentary structures, are very pale orange to white, whereas the siliceous oozes are browner and show slight to moderate mottling in some parts. Each of the carbonate intervals presumably is made of numerous turbidites, as deduced for the previous hole.

Chalk recovered in Core 2 resembles chalk cored at similar depths in Hole 462, shortly below the ooze-tochalk transition. It is very pale orange, with faint evidence of burrowing in some parts. The chalk contains several 1- to 6-cm intervals of dark-yellowish-brown, firm, nannofossil-bearing radiolarian ooze, which is faintly laminated and burrowed. Sediment in Core 2 is virtually identical with sediment of similar depth, age, and diagenetic stage from the first hole.

\section{Unit II: Cherts, Chalks, and Limestones \\ (at least in the interval 363.5 to $441 \mathrm{~m}$ )}

Washing, rather than coring, down across the equivalent depth in Hole 462A of the unit boundaries of Hole 462 precluded recovery of the highest cherty stringers marking the arbitrary top of Unit II, or the highest volcaniclastic sediments marking the arbitrary top of Unit III.

Foraminifer-nannofossil chalk is the dominant lithology of Core $\mathrm{H} 1$; this washed core spanned depths from 259 and 373 meters before the core barrel was pulled, but the recovery probably was between 363.5 and 371 meters, according to the drillers' interpretation of pump pressures and drilling rates. The chalk is very pale orange to white, and most was badly disturbed by drilling. Firm, calcareous radiolarian ooze (whose lithology, like that of the chalk, is described more fully in the report for Hole 462) is present in the chalk as burrowed, grayish-orange layers, of millimeter- to centimeter-scale. A piece of porcellanite jammed in the core catcher may be from the equivalent of the cherty interval at about 370 meters in Hole 462 .

Washed Core $\mathrm{H} 2$ and regular Cores 3 through 7 recovered a meager total of 4.2 meters of cherts and limestones of the 76 meters penetrated. The true proportion of these rocks, or of any other types of sediment in the section, is therefore unknown. The cherty rocks include light-gray, greenish-gray, and light- to moderate-yellowish-brown porcellanites, and light-gray to light-olivegray, siliceous limestones, as well as quartzose cherts in more varied and generally deeper shades, such as grayish-orange and grayish-orange-pink, pale olive-gray, and moderate- to dusky yellowish-brown. Zeolitic limestones, and two thin beds of claystone, are the only other represented lithologies.

\section{Unit III: Volcanogenic and Zeolitic Sandstones, Mudstones, and Limestones (about $450 \mathrm{~m}$, to within igneous rocks of Unit IV)}

The upper part of Unit III, as recovered from spot cores and washed cores, comprises pinkish-white through pale-brownish-gray to pale-yellowish-brown limestone, locally clay rich and nannofossil-bearing. Pale-bluegreen nannofossil marlstones are also present. A paleyellowish-brown chert is recorded from one core (H3-3). Faint horizontal lamination is present at some levels; burrow mottling is more common. Interbedded with these sediments in washed core $\mathrm{H} 3$ are beds of crossand horizontally laminated, greenish-gray, volcaniclastic sandstones, containing detrital carbonate. Disturbed ripple bedding is present in some of these volcaniclastic layers.

The volcaniclastic components decrease downward in Cores 8 and $\mathrm{H} 4$, and the host rock is mostly mediumbrownish-gray through light-olive-gray limestone and clay-rich nannofossil limestone. Increasingly, however, thin couplets of pale- to grayish-blue-green and grayishbrown, zeolitic volcanic claystones make their appear- 
ance. Varicolored claystones (medium gray, grayishbrown, pale yellowish-brown, pale blue-green) dominate in the lower parts of the unit. Increasingly also, the content of recognizable zeolites increases in the lower reaches of these claystones. Particularly notable is the presence at 462A-9-5 of native copper in several parts of the core. This occurrence is at a level considerably below that in Hole 462, and, unlike that example, is not in sub-vertical veinlets. Rather, the copper occurs in tiny strands surrounded by haloes or apparently bedded levels of blue-green zeolitic claystone which themselves are set in a brownish-red matrix. This latter color dominates through most of Core 10, and the lithology concerned, which locally carries Chondrites burrows, contains thin, grayish-blue-green interbeds of claystone and cross- and horizontally laminated volcaniclastic siltstone. Thicker layers of greenish-gray volcaniclastic siltstone to sandstone show graded units and horizontal and ripple bedding, locally evincing signs of soft-sediment deformation. Fucoid burrows are not uncommon. At some levels (see Core 11), the claystones are less obviously zeolitic; radiolarians, grossly recrystallized into siliceous globules, are common at certain horizons in Cores 12 and 13 , typically being better preserved in the grayishblue zones than in the light-brown claystones.

At the base of the sedimentary section, the varicolored claystones darken to brownish-black and black with light-brown smears. Faint lamination is present throughout these darker lithologies, and in Core 14-1 the laminae dip at approximately $20^{\circ}$. Resting directly on basalt is a piece of black chert.

As in Hole 462, sediments are also intercalated within the basalt. These sediments are chiefly gray, hyaloclastic siltstones and sandstones, locally showing grading, cross- and parallel lamination, and soft-sediment deformation. Pebbly conglomerates occur at some levels. A thin, quartzose radiolarian claystone, reddish-brown in color, is stuck to chilled basalt in Section 20-2. Several features of note are present in these intra-basalt sediments. First are distinct contact-metamorphic aureoles at 32-1 and 41-7, where sediments below the basalt contain spherical, magnetic porphyroblasts of millimeter scale. The coalescence of these spherules shows clearly that they have grown in place; they decrease in size but increase in number below the sediment/basalt contact, giving the appearance of inverse grading. The second important feature is the presence of abundant plant remains, apparently coated by a patina of pyrite in Section 40-1; these remains occur in a laminated sediment deformed into a phacoidal structure whose bedding dips some 5 to $10^{\circ}$. A sample of this core, dated as probable Aptian-Albian, contains approximately $0.25 \%$ organic carbon. Similar organic-rich sediments containing terrestrial plants occur in coeval sediments in other oceans.

Following a port call at Majuro, drilling was resumed on 19 July. At 993 meters below the sea floor, beneath 428 meters of almost continuous diabase, we recovered $239 \mathrm{~cm}$ of volcaniclastic sediment at 79-6, 80-1, and $80-2$. The uppermost part of this unit, at $79-6$, is grayish-red (5R 4/2), and the lower parts, in Core 80 , are various shades of dark gray (N3 and N4) and brownish-black (5YR 2/1 and rarely 5 YR 4/1). Sandy and rarely pebbly siltstone occurs above $42.5 \mathrm{~cm}$ in Section 80-1. This unit exhibits trough, parallel, and crosslaminations, and three obvious instances of normal graded bedding with fairly sharp basal contacts. Between 42.5 and $62.5 \mathrm{~cm}$ in Section $80-1$ is a conglomerate layer. The matrix of this unit is the same kind of sandy siltstone described above. The clasts are angular, oriented parallel to bedding, and average 5 to $8 \mathrm{~mm}$. The largest clast, at $55 \mathrm{~cm}$, measures about $20 \times 5 \mathrm{~mm}$. Rarely, basalt pebbles occur as clasts, but no carbonate material was observed. The coarsest material in this layer occurs near the middle, at 51 to $56 \mathrm{~cm}$, the grain size grading both up and down to coarse sand. Underlying the conglomerate is $117 \mathrm{~cm}$ of generally homogeneous sandy siltstone containing rare coarser and fine laminae. A second conglomerate, also containing angular clasts, occurs between 59 and $65 \mathrm{~cm}$ in Section 80-2. The clasts average about $5 \mathrm{~mm}$, and range up to $15 \mathrm{~mm}$. Boundaries of this unit are rather abrupt. The lowest unit in this sequence is $46 \mathrm{~cm}$ of sandy siltstone containing faint parallel lamination at $1-$ to $2-\mathrm{cm}$ intervals. At the base of this unit is a $1-$ to $2-\mathrm{cm}$ interval of lightergray material, and on one corner of the lowest piece $(80-2,101 \mathrm{~cm})$ is a small amount of black glass. These sediments consists almost entirely $(95 \%+)$ of very angular, clear to olive-colored grains altered to smectite, with trace amounts of glass, feldspar, and opaque minerals. No carbonate grains were observed. One thin layer $(80-1,18 \mathrm{~cm})$ contains a Barremian radiolarian assemblage, plus fish debris and agglutinate foraminifers.

The graded beds, parallel and cross-laminations, homogeneous intervals, and the thin pelagic layer suggest that all five intervals of the Bouma turbidite sequence may be present here. The siliceous sediments, the redeposited shallow-water grains, the volcaniclastic deposits, and the organic-rich horizons are discussed elsewhere in this volume.

\section{INORGANIC GEOCHEMISTRY}

Interstitial pore water was squeezed from 11 sediment samples taken at regular intervals down to a depth of 445 meters, 16 meters above the top of the sill complex. These water samples were analyzed for $p \mathrm{H}$, alkalinity, $\mathrm{Ca}^{2+}, \mathrm{Mg}^{2+}$, and $\mathrm{Cl}^{-}$by standard DSDP methods, previously described. The results are shown in Table 2 .

The variations of $\mathrm{Ca}^{2+}$ and $\mathrm{Mg}^{2+}$ with depth (Fig. 11), and $\mathrm{pH}$, alkalinity, $\mathrm{Cl}^{-}$, and salinity with depth (Fig. 12), show two major zones related to the major lithological units separated by the chert-rich layer concentrated between 365 and 448 meters sub-bottom. Unfortunately, recovery was too low within the chert zone to allow taking of interstitial-water samples. The sediments above the chert, basically turbidite flows, range downward from calcareous and radiolarian oozes into chalks between 220 and 255 meters sub-bottom. The increase in alkalinity and drop in $p \mathrm{H}$ above 365 meters suggest a very broad sulfate-reduction zone in the section above the cherts, related to the origin of the sediments and to the present environment. Deep-water 
Table 2. Summary of shipboard geochemical data, Leg 61 .

\begin{tabular}{|c|c|c|c|c|c|c|c|c|c|c|}
\hline Sample & $\begin{array}{l}\text { Core } \\
\text { No. }\end{array}$ & $\begin{array}{c}\text { Section } \\
\text { No. }\end{array}$ & $\begin{array}{c}\text { Interval } \\
(\mathrm{cm})\end{array}$ & $\begin{array}{l}\text { Sub-bottom } \\
\text { Depth (m) }\end{array}$ & $p \mathrm{H}$ & $\begin{array}{c}\text { Alkalinity } \\
(\mathrm{meq} / \mathrm{A})\end{array}$ & $\begin{array}{c}\text { Salinity } \\
(\%)\end{array}$ & $\begin{array}{l}\text { Calcium } \\
(\mathrm{mM} / \mathrm{i})\end{array}$ & $\begin{array}{l}\text { Magnesium } \\
(\mathrm{mM} / \mathrm{l})\end{array}$ & $\begin{array}{c}\text { Chlorinity } \\
(\%)\end{array}$ \\
\hline \multicolumn{5}{|c|}{ IAPSO (standard sea water) } & 7.88 & 2.54 & 35.8 & 10.55 & 53.99 & 19.34 \\
\hline \multicolumn{5}{|c|}{ SSW (surface sea water) } & 8.27 & 2.31 & 34.6 & 10.15 & 52.09 & 18.78 \\
\hline 1 & 1 & 6 & $144-150$ & $9.44-9.5$ & 7.55 & 2.94 & 35.3 & 10.47 & 52.42 & 19.68 \\
\hline 2 & 5 & 4 & $140-150$ & $44.4-44.5$ & 7.54 & 2.95 & 36.1 & 11.63 & 52.08 & 19.94 \\
\hline 3 & 10 & 4 & $140-150$ & $91.9-92.0$ & 7.42 & 3.44 & 36.0 & 12.20 & 50.57 & 19.61 \\
\hline 4 & 16 & 3 & $140-150$ & $147.4-147.5$ & 7.25 & 3.77 & 35.2 & 13.79 & 48.69 & 19.34 \\
\hline 5 & 20 & 4 & $140-150$ & $186.9-187.0$ & 7.22 & 3.97 & 35.4 & 14.82 & 47.89 & 19.58 \\
\hline 6 & 26 & 4 & $140-150$ & $243.9-244.0$ & 7.21 & 3.87 & 35.4 & 15.73 & 47.10 & 19.64 \\
\hline 7 & 30 & 2 & $140-150$ & $278.9-279.0$ & 7.23 & 4.18 & 35.5 & 16.59 & 46.53 & 19.51 \\
\hline 8 & 36 & 3 & $140-150$ & $337.4-337.5$ & 7.21 & 4.13 & 35.6 & 17.51 & 45.67 & 19.61 \\
\hline 9 & 48 & 1 & $90-100$ & $448.4-448.5$ & 7.33 & 0.72 & 35.7 & 55.04 & 10.67 & 19.61 \\
\hline 10 & 54 & 2 & $140-150$ & $506.9-507.0$ & 7.54 & 0.39 & 35.6 & 57.05 & 9.66 & 19.81 \\
\hline 11 & 58 & 3 & $140-150$ & $544.4-544.5$ & 7.58 & 0.88 & 34.2 & 58.01 & 10.70 & 19.14 \\
\hline
\end{tabular}

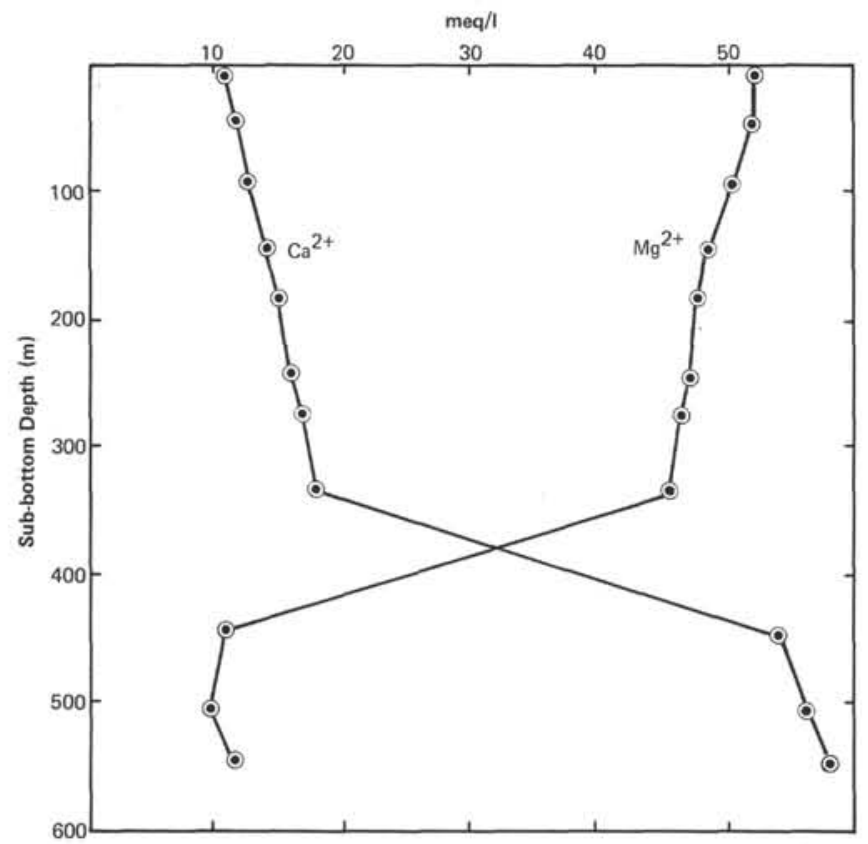

Figure 11. Variation of calcium and magnesium concentrations with depth.

pelagic sediments generally show either a continuous drop in alkalinity or a slight increase in the uppermost 50 to 200 meters in higher-productivity areas, because most of the organic matter is broken down during its descent through the water column.

The vertical anomaly in alkalinity and $p \mathrm{H}$ values at Site 462 can be explained best by the relatively high organic content of the turbidites, which originated in much shallower water and were transported into deep water. In deep water, the high hydrostatic pressure and low temperature would greatly slow the biochemical transformations responsible for this increase in alkalinity and decrease in $p \mathrm{H}$ (i.e., the oxidation of organic matter into $\mathrm{CO}_{2}$, coupled with the reduction of the anion of a strong acid $\left[\mathrm{SO}_{4}^{2-}\right]$ to the anion of a weak acid [HS-]), and would increase the time and depth at which these changes occur. Also the depth of the alkalinity maximum corresponds to the zone of highest sedimentation rate $(\simeq 2 \mathrm{~cm} / 1000 \mathrm{yr})$ in Hole 462 .

The slow increase in calcium and decrease in magnesium at nearly a 1:1 ratio (Fig. 13) is typical of the

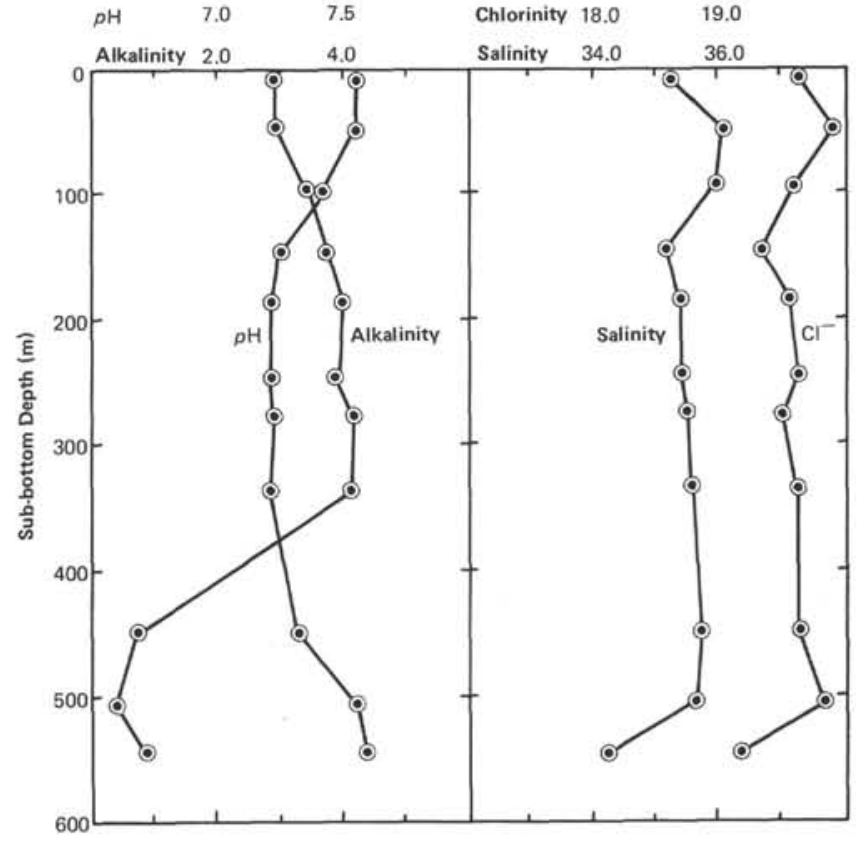

Figure 12. Variation of alkalinity, $p \mathrm{H}$, salinity, and chlorinity with depth.

diagenetic changes in biogenic oozes involving recrystallization accompanied by replacement of calcium by magnesium.

Below the chert layers the measured parameters strongly affected by diagenetic changes are quite different from those above the chert, reflecting both the nature of the chert layer and the sediments below it. The increase in $p \mathrm{H}$, decrease in alkalinity, and the high calcium and low magnesium are probably due to low organic content and the formation of clays from the volcaniclastic sediments, with solution of calcium and replacement by magnesium. The sharp gradients across the chert zone imply that this layer has porosity low enough either to block diffusion or to be very ratelimiting. Silicate diagenesis also can cause a decrease in $\mathrm{CO}_{2}$ and a rise in $p \mathrm{H}$.

The effect of the sill upon the gradients is difficult to assess, but circulation of interstitial water through the basalt may be responsible for the lower chlorinity and salinity in Core 58 (16 m above the sill), and also the high manganese content of the basal claystones. 


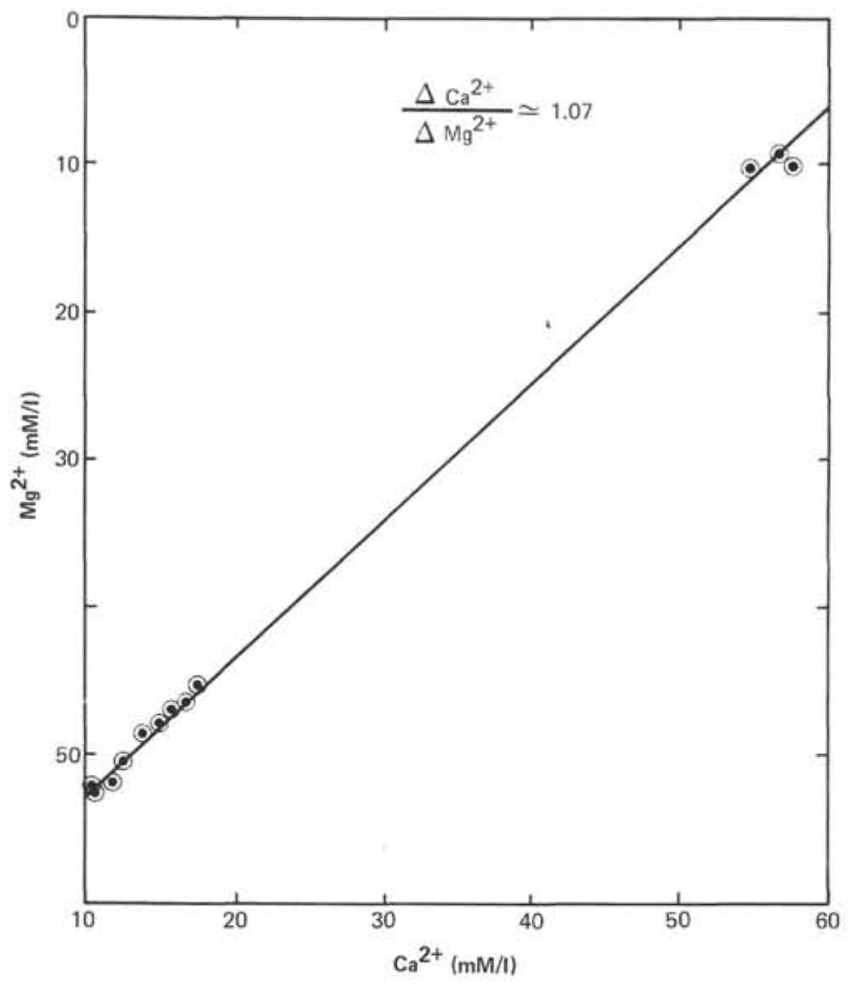

Figure 13. Co-variation of calcium and magnesium.

Calcium carbonate was determined with the carbonate bomb. These data are in Table 3 .

\section{BIOSTRATIGRAPHY}

\section{Summary}

Modern sediments at Site 462 deposited at a water depth of 5181 meters consist of red clays with manganese nodules. The washed residue of the $>63-\mu \mathrm{m}$ size fraction is limited to a few radiolarians, sponge spicules, and fish debris. The sediments are characterized by a lack of carbonates.

In Core 1, 3 meters of red clay were recovered. They are underlain by apparently homogeneous, white nannofossil-foraminifer ooze which yielded heavily mixed but well preserved planktonic-foraminifer assemblages, with forms at least as old as the late Miocene. Microscopic analysis reveals that the "homogeneous" oozes are finely graded, and ultimately can be subdivided into different units, the largest planktonic foraminifers occurring at the bottoms of the turbiditic sequences. In the upper part of the "pelagic" turbidite, planktonic foraminifers are present only in the smaller fraction (150-63 $\mu \mathrm{m})$, or even absent.

These patterns were already described from piston core MP1, taken by the Kana Keoki near Site 462 during the site survey.

The alternation of red clay with carbonate-rich and earlier of radiolarian "pelagic" turbidites represents the main feature of the lithologic succession recovered at
Table 3. Hole 462 calcium carbonate data determined aboard ship by the carbonate-bomb technique.

\begin{tabular}{lr}
\hline $\begin{array}{c}\text { Sample } \\
\text { (interval in cm) }\end{array}$ & $\% \mathrm{CaCO}_{3}$ \\
\hline $462-12-4,16-19$ & 24 \\
$12-4,75-77$ & 88 \\
$16-1,26-28$ & $\sim 2$ \\
$16-2,63-65$ & 5 \\
$16-2,74-76$ & 40 \\
$16-2,85-87$ & 56 \\
$16-2,99-101$ & 62 \\
$16-2,109-111$ & 71 \\
$16-2,119-121$ & 73 \\
$16-2,129-131$ & 74 \\
$16-2,139-141$ & 80 \\
$16-2,148-150$ & 79 \\
$16-3,1-3$ & 83 \\
$16-3,8-10$ & 81 \\
$16-3,25-27$ & 81 \\
$16-3,19-21$ & 81 \\
$23-2,58-60$ & 90 \\
$24-2,134-136$ & 78 \\
$24, \mathrm{CC}, \mathrm{CC}$ & 63 \\
$25-1,90-92$ & 89 \\
$26-2,97-99$ & 92 \\
$28-1,34-36$ & 91 \\
$33-1,130-132$ & 86 \\
$44-1,42-44$ & 24 \\
$48-1,113-115$ & 50 \\
$48-2,57-59$ & 62 \\
$53-1,25-28$ & 67 \\
\hline &
\end{tabular}

Site 462 , at least down to Core 39 , at a depth of 370 meters sub-bottom.

By analogy with the modern situation, it is assumed that the indigenous pelagic sediments at this site are the red clays and that the fine- and coarse-grained calcareous components are allochthonous and were carried downslope by turbidity and/or bottom currents from shallower areas well above the CCD, possibly even above the lysocline. As mentioned above, the turbidites contain a suite of Pleistocene through Miocene planktonic foraminifers, forms as old as the Cretaceous occasionally being represented. In some cases, the reworked forms are more abundant than those of the most recent age, completely masking the biostratigraphic signal. This sedimentary model is also confirmed by the presence of scattered coarser graded layers, described as volcaniclastic sandstones rich in shallow-water larger foraminifers, red algae, coral, and mollusk fragments, and more rarely lithic materials. These coarser layers surely originated in water shallower than that from which "pelagic" turbidites came-perhaps from a reef around a volcanic island. The age and composition of the two types of reworked materials are plotted against depth in Figure 14.

Because of the heterogeneity of sedimentation at Site 462 , for each sample the occurrence, abundance, and preservation of the main fossil groups (foraminifers, 
calcareous nannoplankton, and radiolarians from the $>63-\mu \mathrm{m}$ washed residues obtained during the cruise) are plotted against sub-bottom depth, age, zonal assignment, and $\mathrm{CaCO}_{3}$ content (Figs. 15-17). Moreover, the relative abundance of the minor fossil groups and the inorganic materials in the residues was estimated for all Mesozoic samples, as shown in Figure 17.

The primary observations resulting from those plots are (1) the negative correlation between foraminifer-and radiolarian-abundance curves; (2) the positive correlation between the amount of volcanic material and foraminifers; (3) the uniform distribution of the calcareous nannoplankton, compared to the spotty presence of both foraminifers and radiolarians during the Cenozoic; whereas (4) in the Cretaceous the abundance of calcareous nannoplankton fluctuates together with the other fossil groups in response to sediment type; and (5) the increased abundance of deep-water biogenic components in the Cretaceous section.

\section{Calcareous Nannofossils}

Age determinations of Cenozoic nannofossil assemblages from Holes 462 and $462 \mathrm{~A}$ are based on the zonal schemes of Martini (1971) and Bukry $(1973,1975)$. The Mesozoic biostratigraphic scheme is a slightly modified version of Thierstein's (1976). Estimates of absolute time for the biostratigraphic units are shown in Tables 4 through 6 and follow those by Berggren and Van Couvering (1974), Hardenbohl and Berggren (1978), and van Hinte (1976). Zonal assignments of cores, the abundance of nannofossils, and the state of preservation (i.e. etching and overgrowth) are shown in Figures 15 through 17. The precise positions of the examined samples and their estimated ages are indicated on the core-description sheets.

The Cenozoic, and at least parts of the Cretaceous, carbonate record at this site are largely allochthonous. Evidence for turbidite deposition is found in the scarcity of isolated nannoliths on smear slides through most of the Cenozoic sequence. The sediments often consist of fine radiolarian sands, nannoliths being preserved only within the radiolarian tests. Dissolution and overgrowth features persist throughout the sequence. Reworking of older specimens is observed throughout the Cenozoic. The abundance of reworked taxa decreases with increasing age difference compared to the autochthonous assemblage. Mixing of fossils from adjacent zones abounds and leads to uncertainty in delineating zonal boundaries, particularly in the Oligocene and late Miocene to Pleistocene.

No neritic taxa have been observed in any of the assemblages, with the exception of Braarudosphaera sp. in Cores 55 and A9, of early Campanian age.

The abundance and preservation of calcareous nannofossils in sediments below 520 meters sub-bottom deteriorate, making accurate dating extremely difficult. An age range of late Albian to latest Cenomanian for sediments overlying the highest sill complex is based on the presence of rare to few Cruciellipsis chiastia, Eiffellithus turriseiffelii, and Cylindralithus spp.; early
Turonian species are missing. Rare, poorly preserved Lithraphidites alatus make a Cenomanian age very likely.

An isolated, poorly preserved nannofossil assemblage was found in a thin layer of claystone intercalated in basalt sills in Core 40, Section 1, $92 \mathrm{~cm}$. This assemblage consists of Watznaueria barnesae (99\%), Lithastrinus floralis (rare), Rucinolithus irregularis, and several long-ranging Early Cretaceous species (Late Aptian to earliest Albian), possibly indicating a restricted environment of original deposition.

All other sediment samples from within the basaltic complex were barren, or of Campanian age, indicating down-hole contamination.

In the lower part of Hole 462A, at 993 meters below the sea floor, beneath 428 meters of almost continuous diabase, $239 \mathrm{~cm}$ of volcaniclastic sediment was recovered from $462 \mathrm{~A}-79-6$ to $462 \mathrm{~A}-80-2$. Twenty samples (Table 7) of this sediment were studied for calcareous nannofossils, but all were barren. The samples selected above, below, and from the radiolarian layer (Fig. 18), and from pebbles (claystone) in the sediment, also brought negative results.

After both re-entries (\#12 and \#13) the next cores contained cuttings in which Late Cretaceous nannofossils were recovered in (Cores 76 and 82). These occurrences represent down-hole contamination from the Cretaceous layers overlying the basalt.

\section{Foraminifers}

The type of sedimentation strongly biases the biostratigraphic signal, particularly that based on planktonic foraminifers. Frequently the age of the sequence was established on the basis of calcareous nannofossils or radiolarians, rather than planktonic foraminifers, which are distributed sporadically through the stratigraphic column (Figs. 14-17). The zonal scheme based on planktonic foraminifers used in the present report is shown in Tables 4 through 6 and is based mainly on correlational zonal schemes by Berggren and Van Couvering (1974) and Hardenbol and Berggren (1978) for the Cenozoic, and van Hinte (1976), Sigal (1977), and Premoli Silva and Boersma (1977) for the Mesozoic.

Cores 1 through 3 are attributed to the Pleistocene. Few of the studied samples contain a Pleistocene fauna (e.g., 462-2,CC. The planktonic foraminifers in these samples are well preserved and well developed. Among the most important and common forms are Pulleniatina finalis, P. obliquiloculata, Truncorotalia truncatulinoides, Globorotalia tumida, Sphaeroidinella dehiscens dehiscens, and Streptochilus tokelauae. This assemblage is attributed to Zone N22 (early Pleistocene).

The major component of the reworked faunas is a very rich assemblage of Miocene age (N17, N13-N12, N8). Pliocene elements are poorly represented, as are older faunas, which also include some Late Cretaceous forms.

It is worthwhile to mention the abundance of biserial heterohelicids belonging to the genus Streptochilus, represented by all the species described to date by Brönnimann and Resig (1971), some of which are reworked. 


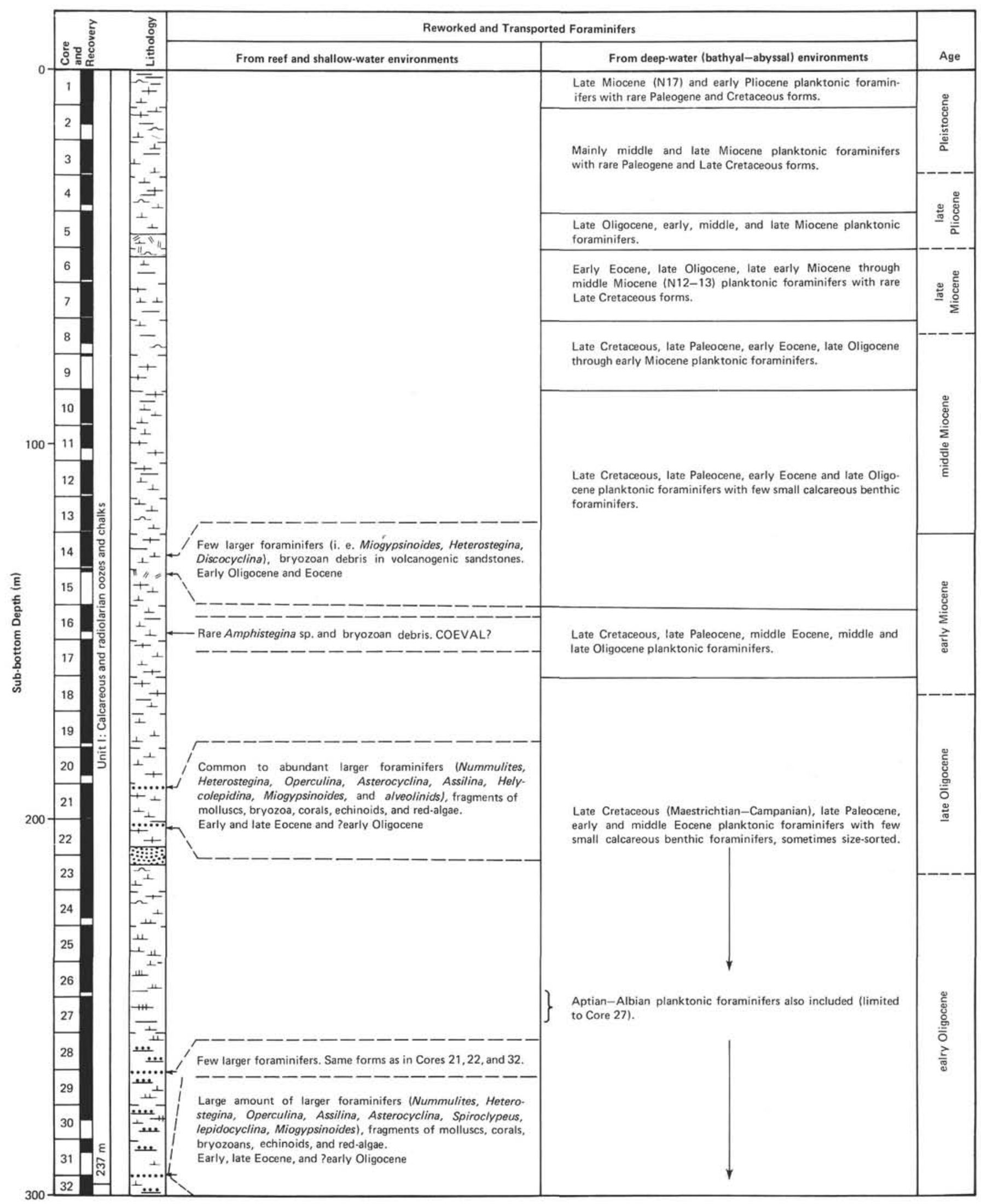

Figure 14. Distribution at Site 462 of foraminifers reworked and transported from reef and shallow-water environments and from deep-water (bathyal and abyssal) environments. 


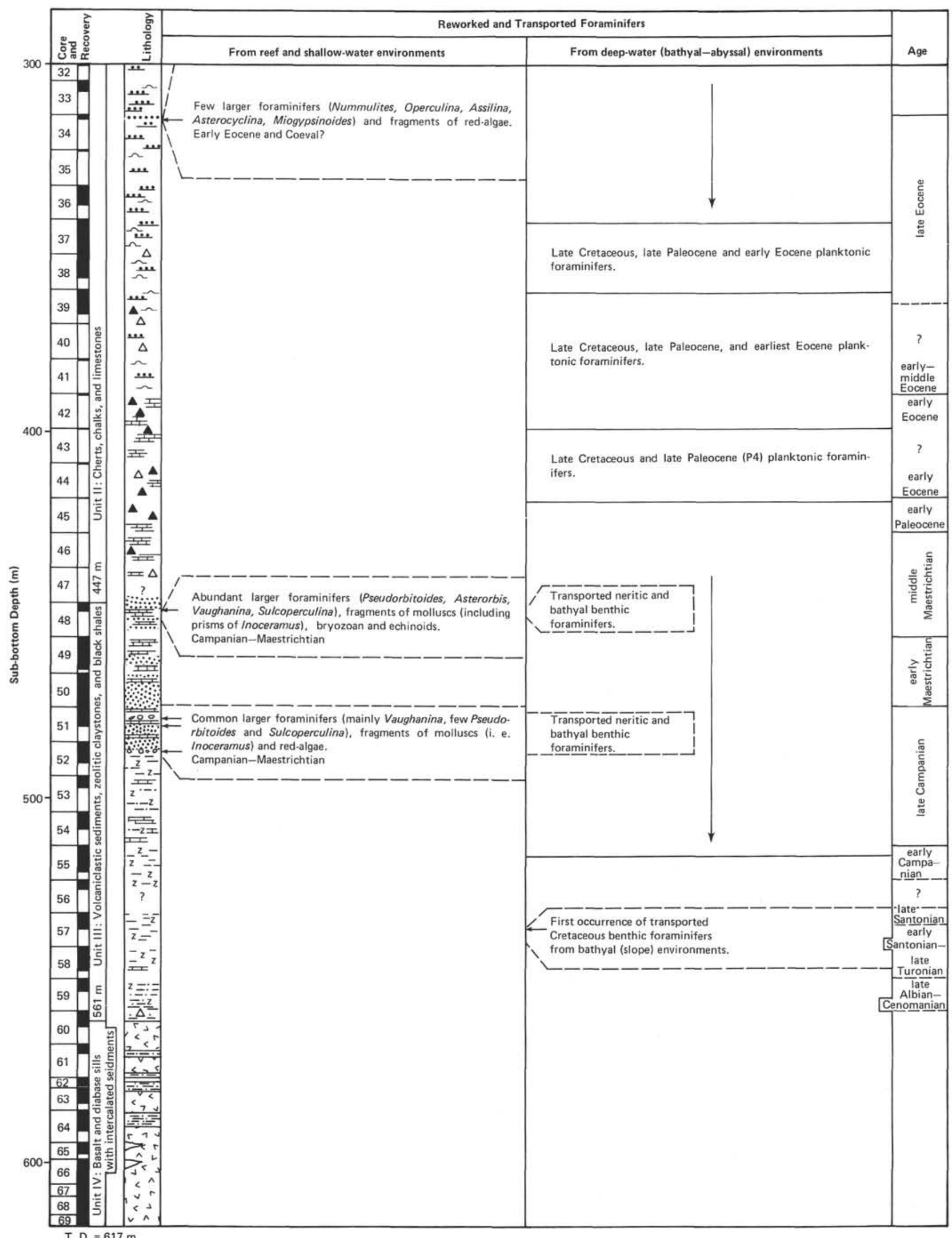

Figure 14. (Continued). 


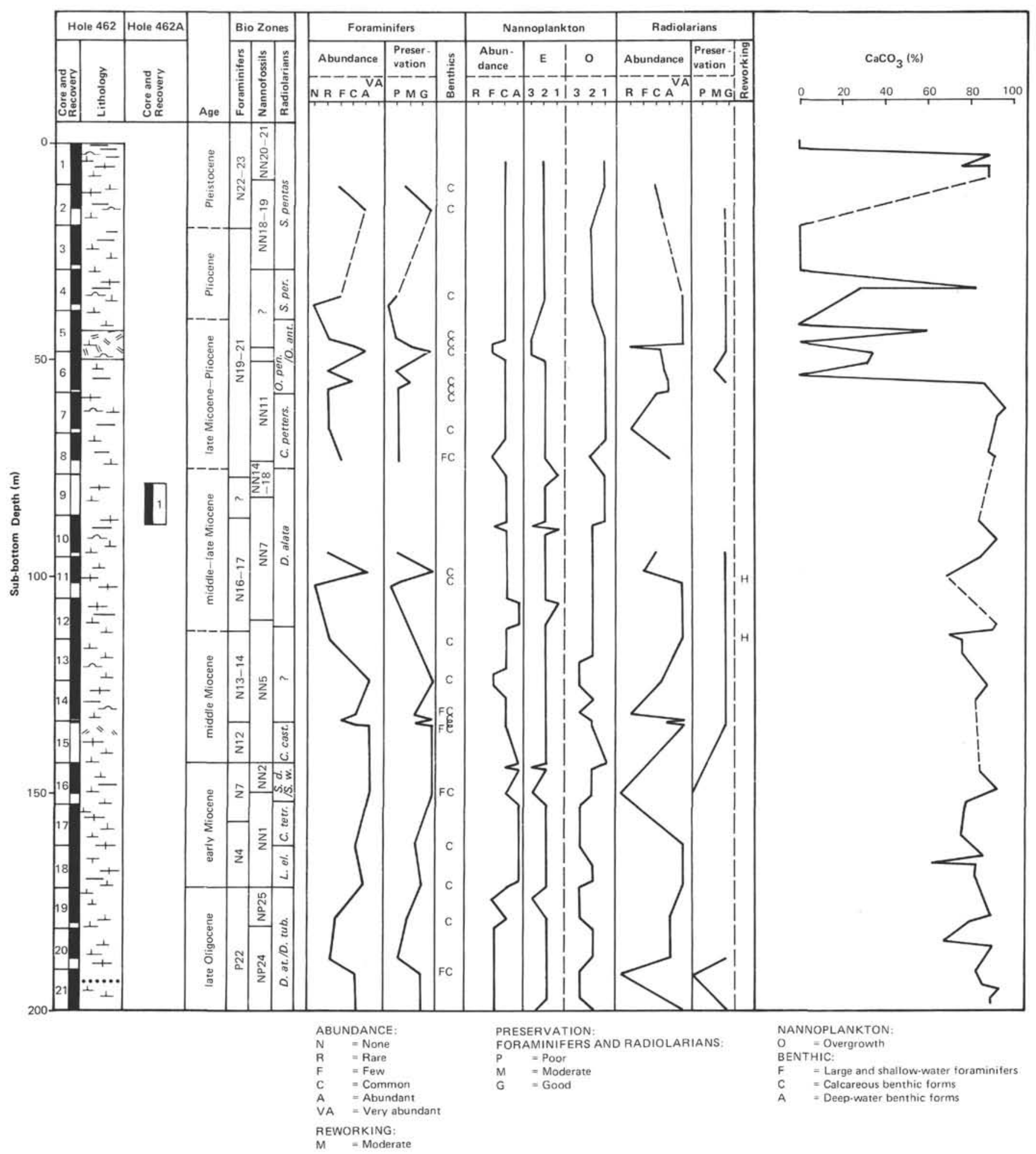

Figure 15. Oligocene to Pleistocene biostratigraphy at Site 462 .

Core 4 is very poor in planktonic foraminifers, while Core 5 yielded a relatively rich assemblage, among which Globorotalia tumida, Pulleniatina obliqueloculata, P. finalis, sphaeroidinellids, globorotalia tosaensis, Streptochilus tokelauae, and Globigerinoides fistulosus are the most common and important species. This assemblage is attributed to Zone PL6 (late Plio- cene). As in the cores above, the major reworked faunal components belong to the Miocene; however, elements of late Oligocene assemblages increase in importance.

Cores 6 through 8 yield rich planktonic-foraminifer faunas attributable primarily to late Miocene Zones N17 and N16; however, few forms of early Pliocene age, such as well-developed specimens of the guide form 


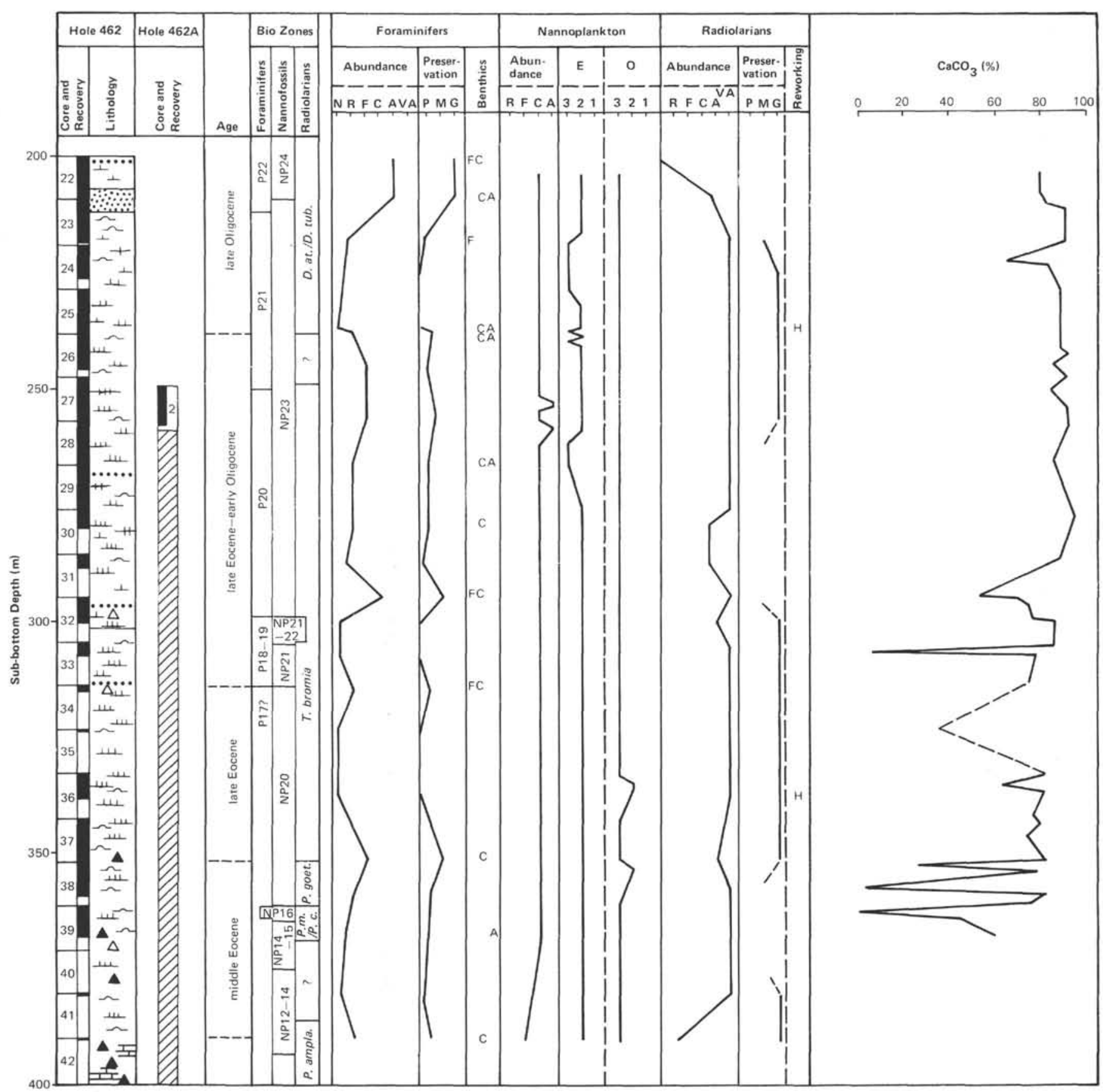

Figure 16. Eocene to Oligocene biostratigraphy at Site 462 .

Globorotalia margaritae, and of late Pliocene to Pleistocene age, such as Streptochilus tokelauae, among others, indicate that those cores are at least Pliocene. In fact, the Pleistocene forms are here interpreted as downhole contaminants. If further studies prove that they are instead in situ, then the base of the Pleistocene should be placed at the base of Core 8 , at about 73 meters subbottom. In this last case, not only the late Miocene faunas, but also the early Pliocene assemblages must be considered reworked.

Core 9 had no recovery. The occurrence of Globorotalia juanai and primitive Pulleniatina at 462-12-5,
$47-48 \mathrm{~cm}$, dates the interval from Core 10 to Core 12 , Section 5, to the late Miocene Zones N17 and N16 (middle part). Globigerinoides ruber and well-developed Globigerina nepenthes are sometimes associated with the above-mentioned species, and their occurrence is consistent with the zonal attribution. In this interval, however, late Miocene faunas are overwhelmed by middle Miocene (Zones N12 and N13) assemblages, which are particularly abundant at the bottom of the coarser graded layers (coarse foraminifer sands). Very large specimens of Globotruncana contusa (late Maestrichtian) and the highest shallow-water skeletal debris are 


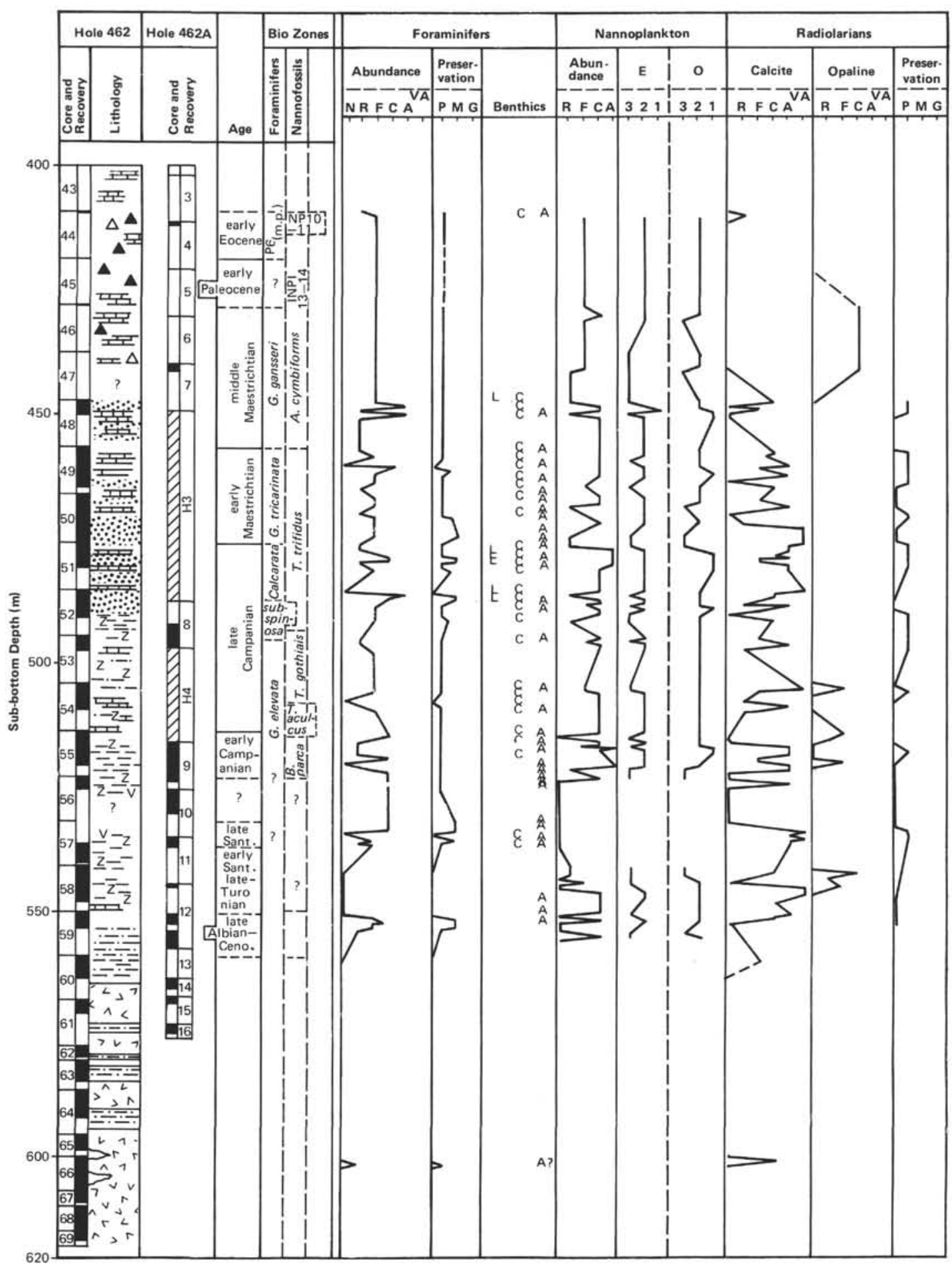

Figure 17. Abundance, preservation, and associated data of Cretaceous to Eocene microfossils.

also reworked in the same layers (Core 11, Section 3; Core 13, Section 5). The lower part of the late Miocene Zone N16 and the middle Miocene Zones N15 and N14 seem to be missing at Site 462 .

Core 12 , Section 6 , to Core $15, \mathrm{CC}$ are attributed to the middle Miocene Zones N13 and N12 on the occurrence of primitive Globigerina nepenthes, common forms transitional to $G$. nepenthes, and Sphaeroidinellopsis subdehiscens. Again, the bulk of the planktonic- foraminifer faunas consists of older assemblages of the early middle Miocene (Zones N11 and N10) and late early Miocene (Zones N8 and N7). Globigerinatella insueta occurs commonly in those layers. In Core 14, Section 5, 79-81 cm and Core 15,CC, relatively large amounts of shallow-water debris are recorded.

Cores 16 and 17, Section 1, are attributed to the early Miocene Zone N7, based on the occurrence of Globigerinita glutinata, Hastigerina siphonifera, and the first 


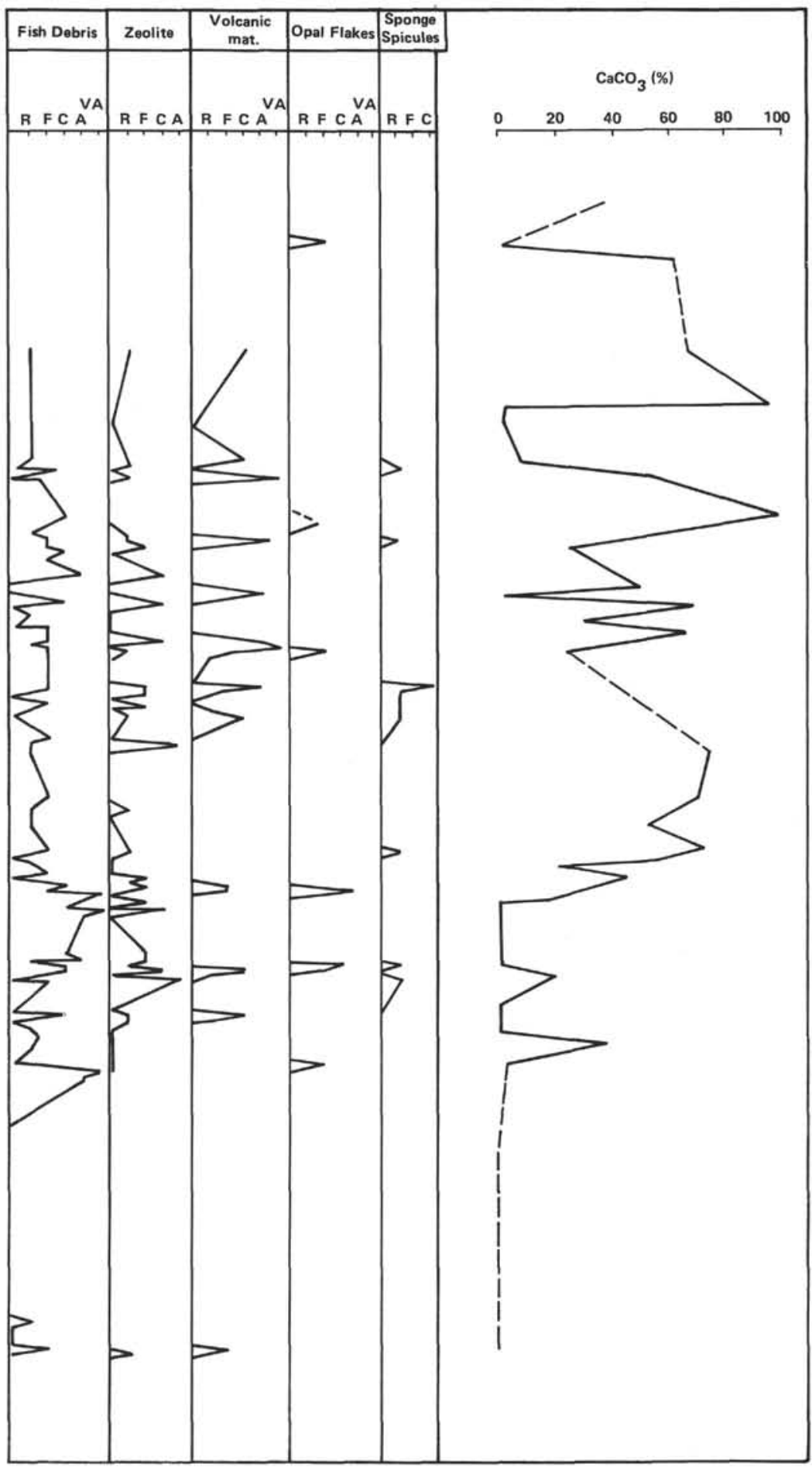

Figure 17. (Continued).

Sphaeroidinellopsis in Core 17, Section 1, 6-8 cm. As above, the dominant planktonic-foraminifer faunas belong to older zones, such as the lower part of Zone N4 (Globorotalia kugleri Zone), then latest Oligocene in age, associated with undifferentiated Oligocene forms.

Although Core 15 had very poor recovery, a new discontinuity in the planktonic-foraminifer record must be hypothesized between Cores 15 and 16 .
The absence of Miocene forms in Core 17, Section 3 through Core 18,CC, which yield rich planktonic-foraminifer faunas attributable to Zone N4, allowed us to locate the Miocene/Oligocene boundary within Core 17 . Faunas attributable to the early Miocene Zones N6 and N5 appear to be missing at Site 462 .

Core 19 through Core 23, Section 2, are attributed to the late Oligocene Zone P22 (Globigerina angulisutu- 
Table 4 . Neogene biostratigraphy.

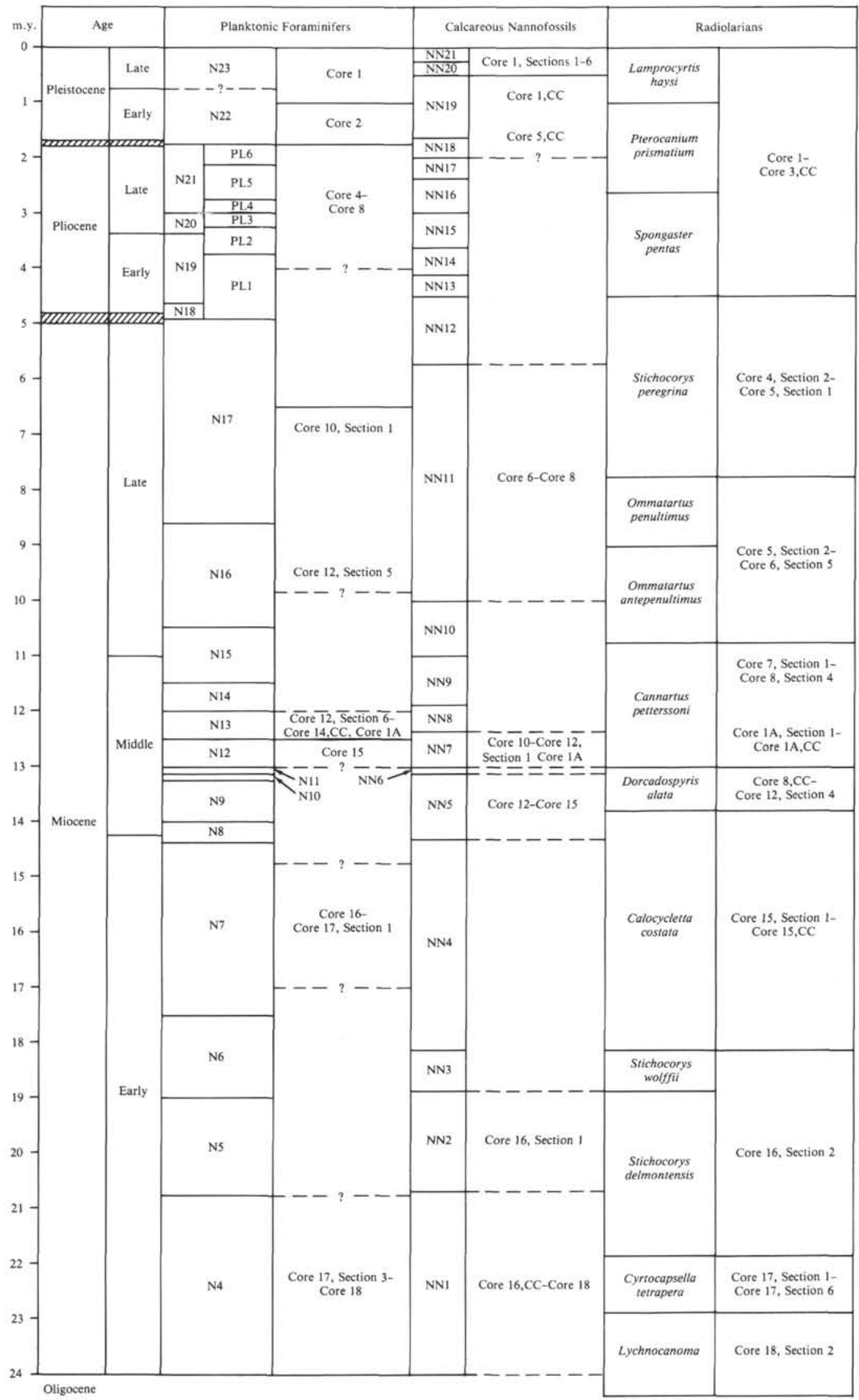

Table 4. Neogene biostratigraphy. 
Table 5. Paleogene biostratigraphy.

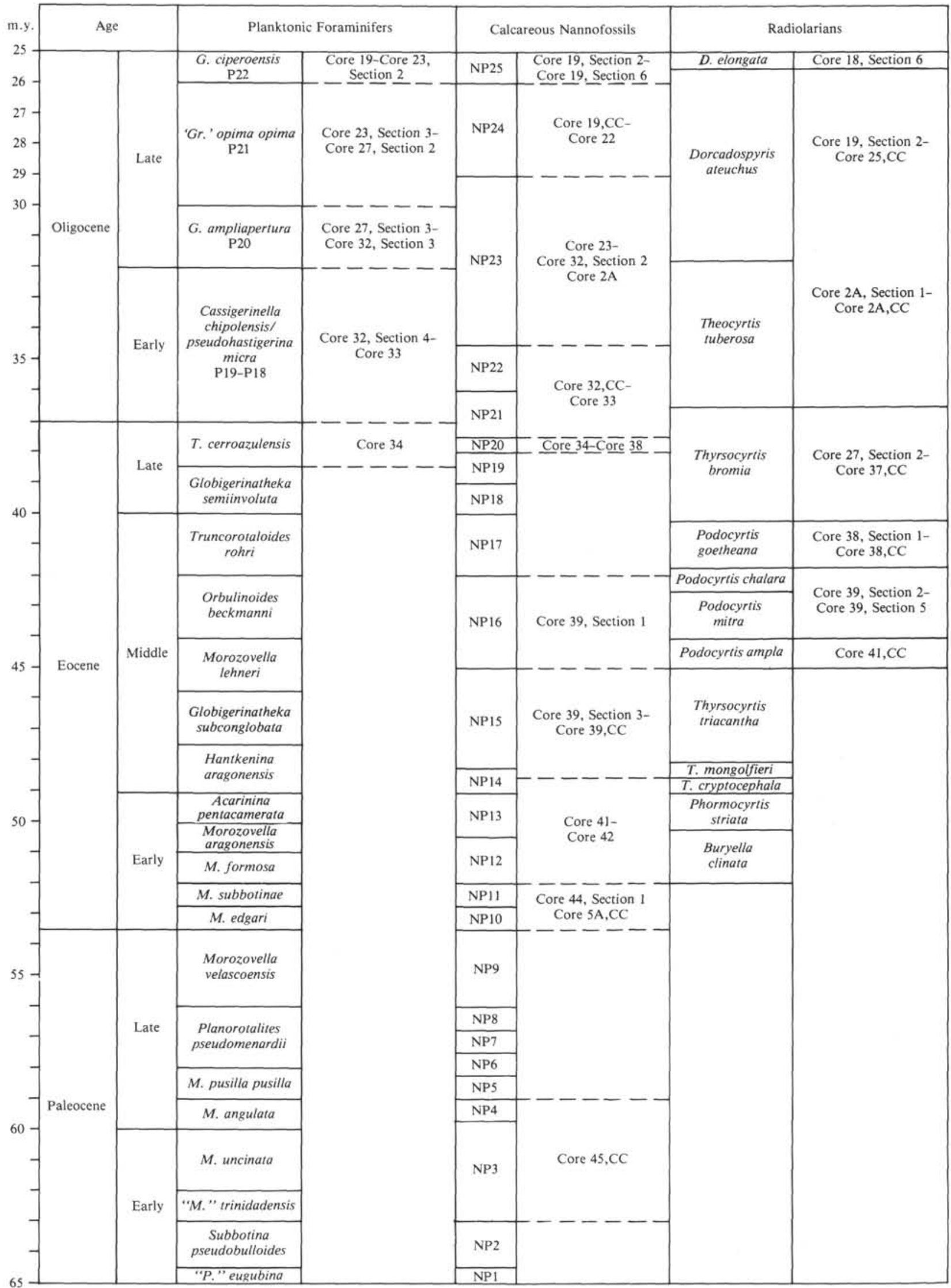


Table 6. Cretaceous biostratigraphy.

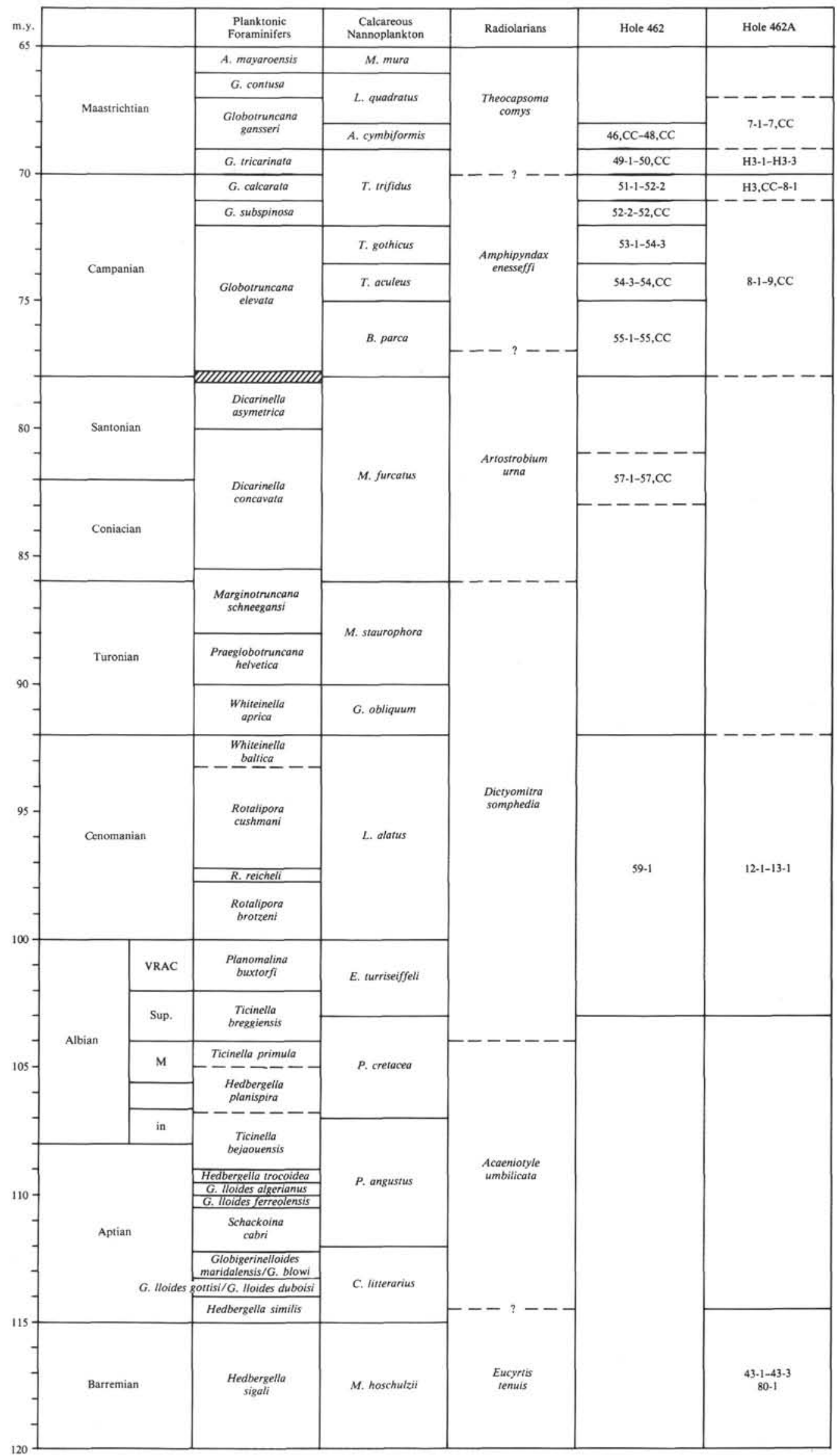


Table 7. Hole 462A samples from Cores 79 and 80 in which Cretaceous calcareous nannoplankton were not found.

\begin{tabular}{llll}
\hline $79-6,0-1$ & $80-1,15,8$ & $80-1,17,7$ & $80-1,18,9$ \\
$79-6,8$ & $80-1,16,1$ & $80-1,17,9$ & $80-1,80$ (pebble) \\
$80-1,1$ & $80-1,16,5$ & $80-1,18$ & $80-1,120-122$ \\
$80-1,15$ & $80-1,17$ & $80-1,18,1$ & $80-2,60$ (pebble) \\
$80-1,15,6$ & $80-1,17,4$ & $80-1,18,3$ & $80-2,110-112$ \\
\hline
\end{tabular}

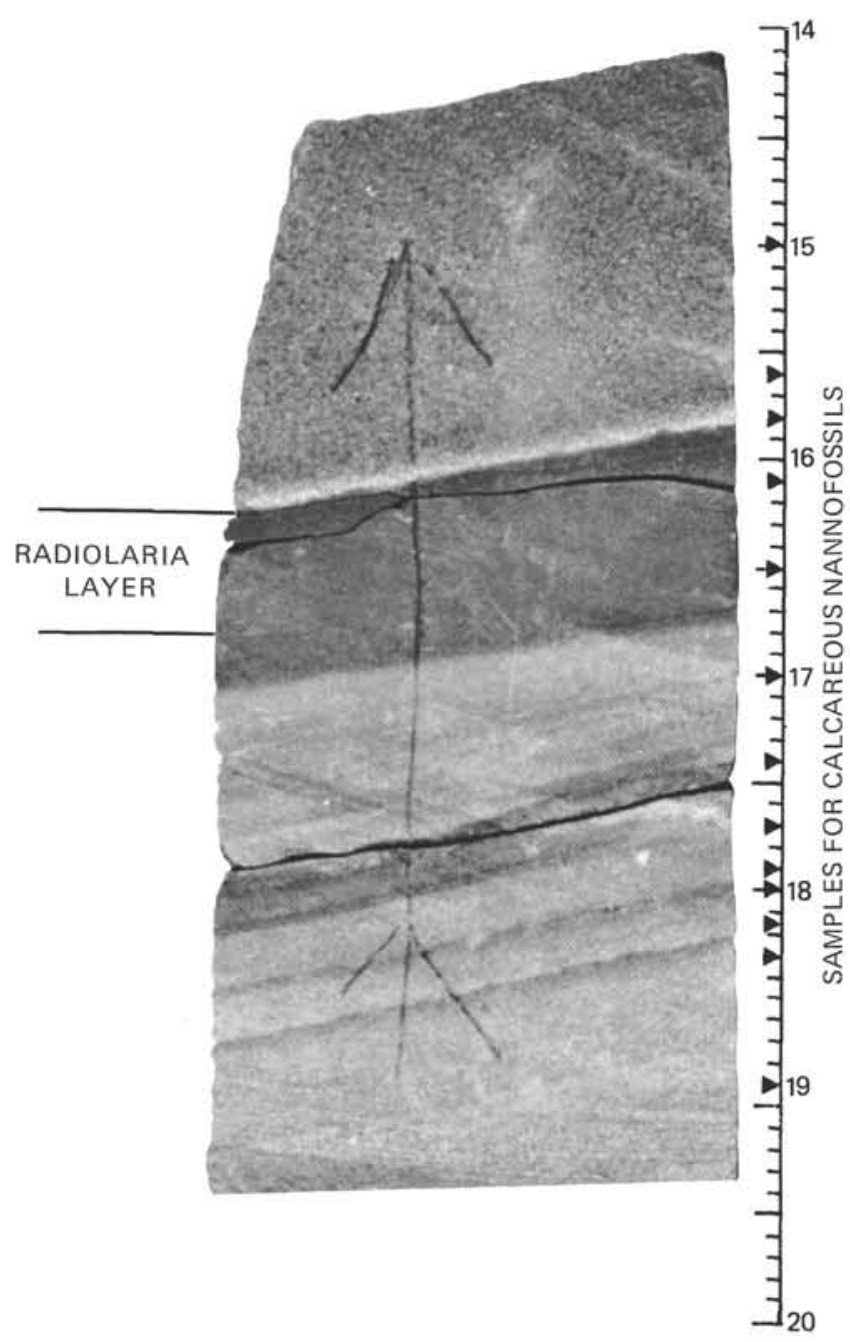

Figure 18. Sample $462 \mathrm{~A}-80-1,14-19.3 \mathrm{~cm}$, with the position of the radiolarian layer and positions of the samples studied for calcareous nannofossils.

ralis Zone) on the occurrence of Globoquadrina praedehiscens and common well-developed Globorotalia siakensis and related forms in Core 23 , Section 3 , 98-100 $\mathrm{cm}$. In agreement with the inferred age, rare Globigerinoides primordius and Globorotalia mendacis are first recorded in Core 22, CC and in Core 22, Section $1,69-72 \mathrm{~cm}$, respectively. The coarser layers are very rich in planktonic foraminifers from early to late Oligocene Zones P19 through P21. Cassigerinella and Chiliguembelina are the dominant forms of the finest fractions $(<150 \mu \mathrm{m})$. Two of the largest shallow-water assemblages are recorded in the coarsest layers in Core 21 , Section $1,1-3 \mathrm{~cm}$ and Core 22 , Section $1,69-71 \mathrm{~cm}$, whereas few skeletal remains occur in Core 23.

The lower part of Core 23 (Section 3 to CC) still yield large planktonic-foraminifer assemblages similar to those of the upper part, except for the absence of Globoquadrina praedehiscens. The occurrence of Globorotalia opima opima, G. siakensis associated with well-developed Globoquadrina baroemoenensis, and less common forms close to Globoquadrina altipsira does indicate that part of Core 23 may belong to the late Oligocene Zone P21 (Globorotalia opima opima Zone). Large numbers of forms belonging to older Oligocene zones (P19 and P20) occur in the same interval.

Below Core 23, layers yielding large planktonic-foraminifer faunas decrease downward, replaced mainly by radiolarian-rich layers, or by minor amounts of pelagicclay layers totally devoid of planktonic foraminifers. Taking into account that heavy reworking from older levels still occurs, the zonal boundaries must be considered only tentative: the boundary between Zones P21 and P20 is arbitrarily located within Core 27.

Well-developed Globoquadrina baroemoenensis are recorded in some samples from Cores 28 and 29, and from the upper part of Core 32. According to Blow (1969), this taxon appears within Zone P20 ("Globigerina" ampliapertura Zone); however, on the basis of personal observation of deep-sea drilling material by one of the authors (IPS), specimens attributable to $G$. baroemoenensis occur at the base of Zone P20. Then Core 32, Section 3, 113-115 cm, which contains the mentioned taxon, is datable approximately to the P19/ P20 zonal boundary, while the overlying cores are attributed to Zone P20. Catapsydrax unicavus, Turborotalia ampliapertura, Tenuitella gemma, Globorotalia opima nana, Globoquadrina galavisi, Cassigerinella chipolensis, and Chiloguembelina spp. are the most important forms identified in this interval. Late Eocene and early Oligocene planktonic-foraminifer assemblages are reworked in the same layers.

From Core 32 to the top of the Mesozoic, between Cores 45 and 46, planktonic foraminifers correlative with nannofossil zones are very rare and limited to a few levels, partly because of the poor recovery in some cores, and mainly because they are absent. Core 34 yielded some planktonic foraminifers, including $S u b$ botina linaperta, $S$. angiporoides, Catapsydrax sp., Chiloguembelina spp., and representatives of the Turborotalia cerroazulensis lineage, along with a rare shallow-water assemblage. An attribution to Zone P17 (latest Eocene) is suggested, which agrees with the age inferred from calcareous nannofossils and radiolarians.

Acarinina nitida, "Globorotalia" guatemalensis, Morozovella acuta, M. gracilis, "Morozovella" edgari, "M." aequa, "M." wilcoxensis and Subbotina sp., characterizing Zone P6 ("M." edgari Subzone), of earliest Eocene age, occur in Core 44 and are not considered reworked. Few other planktonic assemblages were found in this interval (in Cores 37 and 42), but they are clearly reworked (Fig. 14). 
Core 45 , which according to the nannofossils is early Paleocene in age, has only $45 \mathrm{~cm}$ of recovery, most of which is chert. No planktonic foraminifers were found.

The main feature which differentiates the Mesozoic from the Cenozoic is that the reworking from older levels ceased, although the sedimentary patterns remain more or less constant. In the Mesozoic, the presence of carbonates, even still allochthonous in a deep basin well below the $\mathrm{CCD}$, is related more to penecontemporaneous transport.

Planktonic foraminifers are still largely size-sorted, and rather commonly the assemblages are composed only of small-sized individuals. As in the Cenozoic, rich planktonic-foraminifer assemblages are associated with the volcaniclastic layers, which also contain shallowwater debris.

Samples yielding planktonic foraminifers are scarce and spotty, the main lithology being zeolitic clay.

From Core 46 through Core 48 , few to abundant planktonic foraminiferal assemblages were recorded. The preservation is rather poor, and the assemblages are mainly recrystallized. The occurrence of Globotruncana gansseri, Abathomphalus intermedia, and G. aegyptiaca, along with $G$. elevata, Pseudoguembelina costulata, Psg. excolata, and G. arca, characterizes the Globotruncana gansseri Zone, of middle Maestrichtian age. It is within Core 48 that the youngest Mesozoic volcaniclastic layer occurs.

Cores 49 and 50 are assigned to the early Maestrichtian Globotruncana tricarinata Zone. The assemblages are rich and are moderately well preserved. This zone is mainly distinguished on the basis of its negative character: it corresponds to the interval between the extinction of Globotruncana calcarata (lower boundary) and the appearance of $G$. gansseri (upper boundary). Both markers are present below and above Cores 49 and 50 . Globotruncana stuartiformis, G. tricarinata, G. fornicata, G. arca, and Rugotruncana subpenneyi, Schackoina multispinata are among the most characteristic forms.

In Core 51 and Core 52, Section 1, Globotruncana calcarata occurs; consequently, this interval is assigned to the Globotruncana calcarata Zone (total range zone), corresponding to the latest Campanian. Besides the zonal marker, the planktonic-foraminifer assemblage comprises G. plummerae, G. fornicata, G. elevata, Rug. subpenneyi, G. subspinosa, G. bulloides, and Psg. costulata. It is within this interval that a second layer of shallow-water debris occurs.

In the remaining part of Core $52, G$. calcarata is absent; however, on the presence of $G$. subspinosa we attribute this interval to the Globotruncana subspinosa Zone of the late Campanian. Among the most important forms, G. tricarinata, G. arca, G. bulloides, G. fornicata, and G. lapparenti, along with Heterohelix pulchra, H. globulosa, Psg. costulata, Pseudotextularia elegans, and Globigerinelloides alvarezi, are recorded. The samples containing non-size-sorted planktonic-foraminifer assemblages decrease downward, while levels yielding only small forms $(150-63 \mu \mathrm{m})$ increase.
In Cores 53 and 54, only two samples (Core 54, Section 1, 39-45 cm; and Core 54, Section 3, 3-7 cm) still contain large-sized globotruncanids in their residues; all others are dominated primarily by small-sized heterohelicids and hedbergellids. On the occurrence of $G$. arca, G. stuartiformis, G. elevata, G. fornicata, Globigerinelloides volutus, and Psg. costulata, the upper and middle part of the Globotruncana elevata Zone is recognized and assigned to the late Campanian. The occurrences of Globigerinelloides asper and heterohelicids close to Ventilabrella, without Psg. costulata, in Core 55 suggest the lower part of the Globotruncana elevata Zone, attributed to the early Campanian. Planktonic foraminifers in Core 55 are mainly small-sized forms, except for the few specimens of $G$. elevata.

Below Core 55, planktonic foraminifers are recorded only in two samples for Core 57 (Section 3, 53-55 cm and 100-102 cm). The assemblages are poor and of small sizes, and cannot be attributed to a definite zone. Archaeoglobigerina bosquensis, Marginotruncana pseudolinneiana, " $G$." cachensis, Rugoglobigerina pilula, $R$. spp. aff. R. bulbosa, Dicarinella sp., Hedbergella flandrini, and Heterohelix reussi are recorded from Santonian or older levels. Lacking better markers, we attribute this assemblage tentatively to the early Santonian.

There are no planktonic foraminifers recorded below Core 57.

Smaller benthic foraminifers recovered from sediments of Hole 462 constitute two groups: (1) autochthonous agglutinated species indicative of abyssal benthic environments greater than 4000 meters, and (2) allochthonous calcareous and agglutinated species from neritic and bathyal environments. With the exception of the Cretaceous brown zeolitic claystone just above the basalt in Core 60 , resedimentation and vertical sorting exert a strong influence on the recovery and preservation of the biogenic components throughout the cored sequence. This influence is seen in the sporadic distribution and small size of the allochthonous benthic species recovered from sediments in Core 5 to Core 57 .

The autochthonous assemblage is characteristic of the reddish-brown zeolitic claystone typical of Cores 56 to 60 and found between turbidites in the younger cores. Species of Hyperammina, Haplophragmoides, Praecystammina, Paratrochamminoides(?), Glomospira, and Ammodiscus, among others, usually are associated with fish debris and recrystallized radiolarians (Figs. 15-17). Members of this assemblage, along with manganesecoated cyclamminids occur in the reddish-brown clays interbedded in the "pelagic" turbidites of the Miocene through Eocene sediments of Cores 5 to 39. The deepwater foraminifer assemblage is most characteristic of benthic environments between 5000 to 6000 meters, such as those previously reported from Mesozoic sediments in the western Pacific during Leg 20, and in the Indian Ocean during Leg 27.

Allochthonous species first appear in Core 57, as shown in Table 4. They reappear in Core 55 and are found sporadically thereafter throughout the Cretaceous sequence to Core 46 . The assemblages typically 
consist of small, size-sorted, calcareous benthic species of Praebulimina, Gavelinella, Gyroidinoides, Stilostomella, Allomorphina, Ellipsonodosaria, and Pleurostomella, which indicate bathyal source areas above 2500 meters. These assemblages are distinct from those of neritic or reef environments that are restricted to the coarse, graded turbiditic material of the Cretaceous and Cenozoic cores, as shown in Figure 14. The allochthonous bathyal assemblage continues into the Cenozoic until Core 1, with species of Bulimina, Stilostomella, Osangularia, Cibicidoides, Melonis, Laticarinina, and Gyroidina, among others.

Coarse bioclastic debris of shallow-water origin and a number of isolated specimens of larger foraminifers were recovered at Site 462 from Cenozoic and Mesozoic layers. They are among the major components of the larger-size fraction of the volcaniclastic turbiditic sandstones. As the grain-size decreases, pieces of larger foraminifers still are found, but mainly they are replaced by planktonic foraminifers (globotruncanids, etc.).

As shown in Figure 14, the composition of shallowwater material is not constant throughout the cored interval. Instead, the age of the transported material becomes progressively older and roughly approximates the age of the cored material.

The largest amount of shallow-water debris occurs in Core 32, Section 1, 5-8 cm. The major biogenic components of this layer are still the larger foraminifers, among which nummulitids, discocyclinids, and miogypsinids are the dominant forms. Species composition is very similar to that mentioned for the upper layers.

A minor amount of shallow-water debris of limited diversity is recorded in Core 34 , tentatively attributed to the latest Eocene. The faunal assemblages are constituted by several Nummulites, poorly preserved Heterostegina, Miogyspinoides ubaghsi, Polylepidina, and Assilina leymeriei.

A large amount of larger foraminifers is recorded in Core 48, Section 2, 78-81 cm (middle Maestrichtian, Globotruncana gansseri Zone), accompanied by fragments of various mollusks. Foraminifers belong to the Late Cretaceous genera Pseudorbitoides, Asterorbis, Vaughanina, Sulcoperculina, and Lepidorbitoides. Their range is Campanian to Maestrichtian, so that similar ages for the shallow-water forms and the pelagic faunas cannot be ruled out.

The rather rich shallow-water assemblages from Core 51, Section 3, 44-47 cm and Core 52, Section 1, 98-101 $\mathrm{cm}$ (latest Campanian, G. calcarata Zone) are less diverse than those of mid-Maestrichtian age and lack representatives of Asterorbis and Lepidorbitoides. Moreover, they are dominated by relatively large specimens of Vaughanina, whereas specimens of Pseudorbitoides and Sulcoperculina are scarce. The age of these assemblages is not in conflict with that of the associated planktonic foraminifers and calcareous nannofossils.

The Cenozoic sequence of Hole 462A was only spot cored in an attempt to have better recovery than at Hole 462.
The first core, Al, was cored at 80 meters sub-bottom to cover the gap of Core 462-9. It yielded few to common, moderately well preserved planktonic foraminifers belonging to the middle Miocene, possibly to the top of Zone N13. The assemblages are commonly size-sorted, with an enrichment of small forms like Globigerinita glutinata, Globigerina druryi, G. quinque$l o b a$, and Cassigerinella chipolensis. Species are few in comparison with Core 462-10 which in part overlaps it.

Core A2 was recovered at $\mathbf{2 4 9 . 5}$ meters sub-bottom. Core A2, CC contains common planktonic foraminifers, among which the most important species are Turborotalia pseudoampliapertura, T. ampliapertura, Gq. baroemoenensis, G. nana, Chiloguembelina sp., Psh. naguewichiensis, Tenuitella munda, and $T$. gemma. They are assigned to Zones P19 to P18, of early Oligocene age. It is noteworthy that in the same sample abundant reworked Eocene through Cretaceous planktonic assemblages occur with large amounts of volcanic glass and rock fragments, which are recorded at the same depth in Hole 462 (Cores 27 and 28).

Washed Core H1, covering more than 100 meters, yielded very rare planktonic foraminifers in the residues, which are dominated by radiolarians and sponge spicules, except for $\mathrm{H} 1, \mathrm{CC}$, in which Subbotina angiporoides, Catapsydrax unicavus, Gq. tripartita, Cassigerinella chipolensis, Chiloguembelina sp., and Tenuitella gemma were identified. A similar assemblage was recorded in Cores 27 through 32 of Hole 462.

Washed Core H2 (373.0-401.5 m) and Cores A3, A4, and $\mathrm{A} 5$ contain chert and limestone, but few planktonic foraminifers were detected, except for Core A5,CC, in which, from the mixture of different lithologies, three heavily recrystallized planktonics and rare deep-water agglutinated foraminifers were found.

Core $\mathrm{A} 6, \mathrm{CC}$ recovered $7 \mathrm{~cm}$ of chert and limestone, but no foraminifers were found.

Core A7 contains rare planktonic foraminifers that give a middle Maestrichtian age. Preservation in the cross-laminated zeolitic calcarenite is poor, and specimens are recrystallized and fragmented. Species include Globotruncana gansseri, G. arca, and Pseudoguembelina excolata, which characterize the Globotruncana gansseri Zone.

In washed Core H3 (449-487 m), Sections 1 to 3 contain an early Maestrichtian assemblage with species such as Globotruncana aegyptiaca, G. gagnebini, G. caliciformis, G. stuartiformis, and Globotruncanella havanensis, among others. This interval is assigned to the Globotruncana tricarinata Zone and correlated with Cores 49 and 50 of Hole 462.

Sample H3,CC belongs to the Globotruncana calcarata Zone, based on the presence of the zone marker in addition to G. subspinosa, G. bulloides, G. arca, and Globotruncanella havanensis. The base of washed Core $\mathrm{H} 3$ thus correlates with Core 51 and Core 52, Section 1, 98-101 cm, of Hole 462 .

The $G$. calcarata Zone extends into Core 8, Section 1, $35-40 \mathrm{~cm}$, below which the marker species was not recovered. Planktonic foraminifers in Core 8, Sections 2 
and 3 are rare to few and poorly preserved. The meager fauna, which contains Globotruncana arca, G. caliciformis, G. stuartiformis, Pseudoguembelina costulata, and Heterohelix pulchra, with others, is tentatively placed in the late Campanian Globotruncana subspinosa Zone.

Washed Core H4 $(496.5-515.5 \mathrm{~m})$ contains poorly preserved planktonic foraminifers associated with recrystallized radiolarians, zeolite, and pyrite. The assemblage that includes Globotruncana stuartiformis, $G$. arca, G. fornicata, Pseudoguembelina costulata, Heterohelix pulchra, $H$. punctulata, rugoglobigerinids, and Globigerinelloides alvarezi is placed in the late Campanian Globotruncana elevata Zone. Correlation is thus made with Cores 53, 54, and portions of 55 at Hole 462 .

Elements of the Globotruncana elevata Zone continue downward into the grayish-brown claystone of Core 9; however, the fauna is much reduced, and preservation deteriorates. Recovered species include Globotruncana fornicata, Pseudoguembelina costulata, Heterohelix pulchra, and Hedbergella holmdelensis.

Below Core 9, planktonic foraminifers were not recovered, with the exception of displaced greenish claystone at the top of basalt in Core 21 . The moderately well-preserved fauna contains common planktonic foraminifers and the only larger foraminifers from Hole $462 \mathrm{~A}$. The assemblage is assigned to the Globotruncana calcarata Zone on the basis of G. calcarata, G. caliciformis, G. fornicata, G. stuartiformis, and others. The sample correlates in age and biogenic and lithologic components with those of Cores 51 and 52 of Hole 462 and provides evidence of an important paleontological horizon that was missed during the discontinuous coring of the Late Cretaceous section in Hole 462A.

Two distinct assemblages representing autochthonous abyssal foraminifers and allochthonous bathyal and neritic species were recovered from Hole 462A. Abyssal foraminifers made up the assemblages recovered from Cores 10 to 13 , Section 1 , with the exception of an influx of rare allochthonous calcareous species displaced from bathyal environments in Core 12, Section 1.

Below this interval, from Core 13, Section 2, to Core 14 , Section 1, above the first basalt sill, the samples are barren of foraminifers, and biogenic material consists of fish debris, recrystallized radiolarians and rare fibrous organic material in Core 14, Section 1, 29-32 cm.

Allochthonous calcareous benthic species appear in Core 9 , Section 5 , and continue in increasing abundance up to Core 1 , whereas abyssal species become sporadic and were not recovered in Cores 1 or 2 . This is closely similar in age and faunal content to assemblages from Hole 462. For example, the appearance of consistently occurring allochthonous benthic species within Core 9 of Hole $462 \mathrm{~A}$ correlates with a similar pattern in Core 55 of Hole 462. Further, the first influx of calcareous benthics forms in Core 12 of Hole $462 \mathrm{~A}$ is close to a similar occurrence in Core 57 of Hole 462.
Deep-water agglutinated foraminifers again appear in the dark-gray volcaniclastic claystone, siltstone, and sandstone interbedded with basalt in Cores 40, 42, 43, and 46. Assemblages consist of poorly preserved, rare specimens of largely primitive species associated with radiolarians, fish debris, sponge spicules, and carbonized plant material. Abyssal water depths analogous to those earlier alluded to are suggested by these associated biogenic components, as is their similarity to those in younger sediments in Hole $462 \mathrm{~A}$, especially in regard to their co-occurrence in the autochthonous, thin, redbrown claystone units. Poorly preserved radiolarians are more common in the interbedded sediments and were recovered from Cores 40 through 44 and 46; fish debris occurs in Cores 42 and 44 . Material was noticed in carbonized-plant sediments from Cores 40, 42, and 46. A thin $(1 \mathrm{~cm})$ bed of red-brown claystone in Core 80 , Section 1, 15.8-16.5 cm, contains an autochthonous assemblage with rare deep-water agglutinated foraminifers associated with radiolarians and fish debris.

\section{Radiolarians}

Radiolarians are present throughout the cores of Hole 462, although their state of preservation is variable, so that they are sometimes useless for biostratigraphic identification.

From Cores 1 to 22 , the abundance of radiolarians shown in Figure 17 compares only irregularly to that of the other biogenic components. Only three absences of radiolarians were recorded in Cores 16, 20, and 22 .

From Cores 23 to 40 , radiolarians are usually the most abundant biogenic component, and their preservation is almost always good.

From Cores 41 to 60 , the abundance of radiolarians varies considerably, but generally they are less abundant than above (Figs. 15-17). Moreover, their state of preservation is poor at best, in most cases so poor that only general outlines are seen. Commonly they are calcified, the test being filled with and/or replaced by calcite and zeolite.

Only some general remarks on the Cenozoic radiolarian assemblages are made here. The radiolarians from Hole 462 and the ages are given in Figure 14 with the core and biostratigraphic-age determinations.

In Cores 1 to 8, even though radiolarians were abundant (except in Core 1), it has not been possible so far to give a more-precise age than upper Miocene to Quaternary.

The radiolarian assemblages in several samples (e.g., those of the core catchers of Cores 11, 12, 25, and 36) show two states of preservation (recorded as "good" or "moderate"; Figs. 15-17) which correspond to the reworking processes.

No identifiable radiolarians were recorded in the lowermost Cenozoic.

Identification of radiolarians from the Cretaceous interval is nearly impossible, because the tests are replaced 
by zeolite and calcite in large crystals that distort the specimens. Moreover, the general outlines are sometimes hardly recognizable.

However, Core 51 provided somewhat better-preserved specimens (pseudoaulophacids, Dictyomitra torquata, D. duodecimcostata) that give a Late Cretaceous (Campanian) age.

Radiolarians are abundant and well preserved in the Neogene cores of Hole 462A (Cores 1 and 2). They are absent in the Paleogene (Cores 3 to 6), and rare to common but always poorly preserved in the Mesozoic sediments (Cores 7 to 46 ).

In Core 1 , the radiolarians are from the Dorcadospyris alata Zone through the Cannartus petterssoni Zone. In Core 2, the age is difficult to determine with confidence on the basis of information given by Sample 2,CC, in which numerous Eocene radiolarians (Cycladophora turris, Podocyrtis chalara, Theocampe mongolfieri, Lithocyclia aristotelis group, Thyrsocyrtis triacantha) belonging to different zones are mixed with some Oligocene radiolarians (Lychnocanium bipes, Dorcadospyris forcipata). The possibility of contamination cannot be excluded.

In some of the Mesozoic cores, because of the poor preservation of the radiolarians (replaced by calcite and zeolite) and their distortion, only a few vague, high-level taxa can be identified. However, in Cores 43 and 46 some identifications were attempted. In both cores, the radiolarian zone could be the Eucyrtis tenuis Zone, but it seems more likely that in Core 43 it is the top of the zone, and that Core 46 is somewhat older. Radiolarians from the $E$. tenuis Zone again appear in the red-brown claystone of Core 80, Section 1, 15.8-16.5 cm. Rare, poorly preserved (hence undated) radiolarians were also recovered from Core 79.

\section{SEDIMENTATION RATES}

Average sedimentation rates for Hole 462 vary from a high of about $2 \mathrm{~cm} / 10^{3} \mathrm{yr}$ in the Late Cretaceous, late Oligocene, and middle Miocene turbidites to a low of less than $0.2 \mathrm{~cm} / 10^{3} \mathrm{yr}$ in the early Late Cretaceous red clays. The rates are shown in Figure 19. The time scales used are those by Berggren and Van Couvering (1974) for the Neogene, Hardenbol and Berggren (1978) for the Paleogene, and van Hinte (1976) for the Cretaceous. Unconformities are found in the latest Cretaceous, late Paleocene, Eocene, and Miocene. Additional, smaller unconformities may be present, but biostratigraphic resolution does not allow their definite characterization.

\section{IGNEOUS PETROLOGY}

The igneous rocks will be discussed in four parts: Part A, by R. Batiza, which discusses Hole 462 and Hole 462A to Core 74, with his interpretations; Part B, by S. Shcheka, which discusses Hole 462 and Hole 462A down to Core 74, with his interpretation; Part C, by $\mathrm{H}$. Tokuyama, which discusses Hole 462 and Hole $462 \mathrm{~A}$ down to Core 74, with his interpretations; Part D, by K. Seifert, T. Vallier, and K. Windom, which discusses all igneous data on Cores 75 to 92 of Hole 462A.
All parts are based on data which were collected jointly.

Part A (by R. Batiza)

\section{Introduction}

About 33.7 meters of basaltic rock was recovered from Hole 462, and about 450 meters from Hole 462A. Details of the petrology, mineralogy, alteration history, chemical composition, and petrogenesis are discussed elsewhere in this volume. The purpose of this section is to discuss briefly the stratigraphy, mineralogy, and megascopic character of these basaltic rocks.

\section{Rock Fragments Recovered in Core 21}

Several cores of Tertiary sediments contain volcanic detritus. Core 21 (late Oligocene) contains especially abundant and large fragments of igneous rock together with large reef foraminifers.

Thin-section observations of about 20 rock fragments separated from Section 1 of Core 21 revealed the following:

1) Mineral fragments. Fragments of olivine, lavender colored (high-Ti) augite, and colorless augite were identified. Some of these fragments have tiny amounts of volcanic glass and/or crystalline volcanic materials adhering to their surfaces.

2) Rock fragments. A wide variety of rock fragments are contained in this sediment. The most common are fragments of pumice composed of pale-brown glass with abundant stretched or spherical vesicles. Next most abundant are fragments of highly altered hyalopilitic and intersertal-textured basalt. The most interesting fragments observed, however, are holocrystalline rock fragments which contain, among other things, amphibole and potassium feldspar. These are almost certainly some type of alkalic differentiated rock. We can tentatively conclude from these observations that the source of these fragments was petrologically diverse. The pumice fragments are probably calc-alkaline and may have had a source different from that of the other fragments. Both sub-alkaline and alkaline rocks in the source area of the non-pumice fragments may be inferred on the basis of the types of augite found; on the other hand, each kind of rock or mineral fragment may have had a distinct source.

\section{Sill-Complex Igneous Units}

Logging of Hole 462 revealed the presence of five major igneous units separated by sedimentary units of variable thickness. Figure 20 shows that the uppermost igneous unit has been divided into five smaller igneous units, and that the third (counting downward) unit has been divided into three smaller units. Several criteria were employed either singly or in combination as bases for these subdivisions:

1) Megascopically observed grain-size fining or coarsening trends in the cores.

2) Significant mineralogic variations based on thinsection observation. This may be a difference in the 


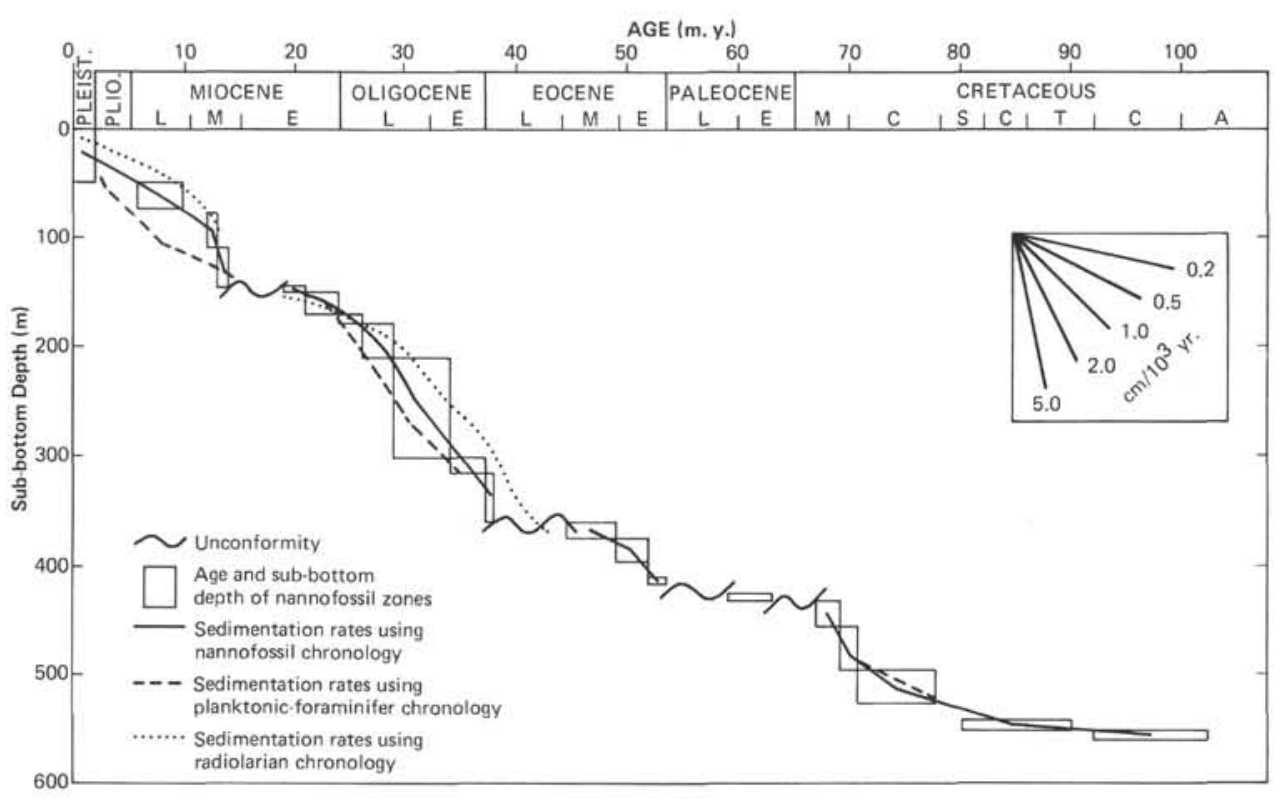

Figure 19. Sedimentation rates for Holes 462 and 462A.

number and kinds of phases present, or a difference in the relative proportions of phases.

3) Chemical differences between rocks with similar textures.

4) The presence of chilled margins.

5) The presence of fine-grained border zones.

6) The presence of in situ sedimentary horizons.

7) Sediment horizons inferred from logs.

Table 8 is a brief summary of the criteria used to distinguish each contact.

\section{Summary of Petrography}

The rocks of Units 1 through 10 are either aphyric or sparsely phyric. They usually have a few phenocrysts of clear to light-brown augite $\left(2 \mathrm{~V} \sim 50-60^{\circ}\right)$, zoned bytownite to labradorite, and occasionally olivine pseudomorphs (usually green smectite after olivine). Augite is also often replaced by smectite, so that positive identification of olivine pseudomorphs is difficult. The textures of the rocks vary from variolitic to diabasic, all intermediate textures being represented. These textural differences are, of course, related to differences of cooling rate and degree of supercooling and are related to position within the cooling units. In the finer-grained rocks, the phenocrysts are set in an altered matrix of glass, quench- or granular-textured augite, skeletal plagioclase laths, microlites and crystallites, and titanomagnetite. Some of the diabases have interstitial patches of brown or green smectite which resemble diktytaxitic cavities. These may be either clay-filled cavities or replaced glassy patches.

The upper portions of Unit 2 are petrographically indistinguishable from Units 1 to 10 . However, beginning at the top of Core 65, patches of distinctive granophyrefacies mineralogy appear. These patches increase in abundance downward, but in a very irregular manner. Some deep horizons, for example, are relatively fine- grained and have no granophyric patches. These patches usually consist of intergrown quartz and feldspar micropegmatite. Many patches include a colorless acicular prismatic phase which is probably apatite. In addition to these patches, many of the rocks of Unit 2 contain subhedral quartz crystals as a separate phase, and also amphibole. The amphibole is brown with green rims, and has the following optical properties: Brown portions: $2 V_{\alpha}=50-60^{\circ}, \delta=0.020 \pm 0.005, Z=0-23^{\circ}$, absorption $>\beta>\alpha$, dispersion $r>\nu$. Crystals are pleochroic, equant euhedral to anhedral; $\alpha=$ straw yellow to colorless, $\beta=$ light brown and $\gamma=$ medium honey brown. The green amphibole differs from the brown amphibole only in color and crystal form. Color is: $\alpha=$ straw yellow to green, $\beta=$ pale yellow-green to apple green, $\gamma=$ deep emerald green, and the crystals are often fibrous. All transitions between fibrous green and more-equant brown amphibole are observed, and green commonly rims brown amphibole. In addition, rims of chlorite needles oriented normal to amphibole crystal faces are commonly observed around green amphibole. These observations suggest that green amphibole is either a reaction product of brown amphibole, or that the color and form difference is the result of continuously varying physical and chemical properties in the rocks during the period of amphibole (and perhaps chlorite) growth. The optical properties of the amphibole suggest that it is a hornblende; it is observed as matted, fibrous patches in the rock, and as replacement and reaction rims of clinopyroxene.

In addition to these granophyric patches, Unit 2 also differs from the other rocks in the abundance of opaque phenocrysts. Tables 9 and 10 show that there are no systematic mineralogic changes through the unit, although the lowest portions of Unit 2 in Hole 462 have veins with euhedral magnetite and chalcopyrite. Rhythmic lavering is not observed on any scale. 
Igneous Rocks: Hole 462

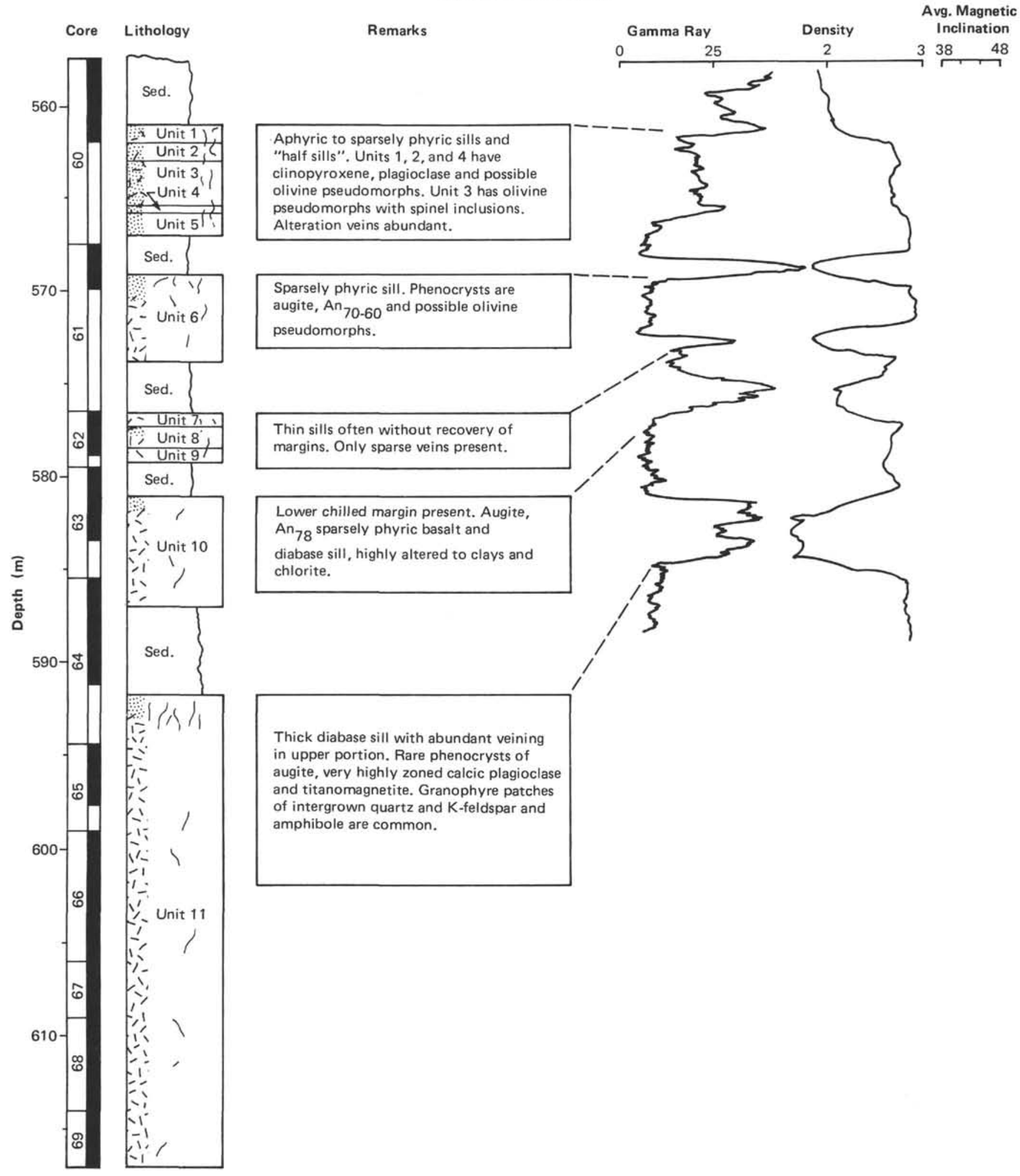

Figure 20. Igneous rocks, Hole 462. 
Table 8. Igneous units.

\begin{tabular}{|c|c|c|c|}
\hline Contact & $\begin{array}{l}\text { Criteria Used } \\
\text { (see text) }\end{array}$ & $\begin{array}{l}\text { Criteria in Which } \\
\text { No Difference } \\
\text { Was Observed } \\
\text { (see text) }\end{array}$ & Remarks \\
\hline Unit 1/Unit 2 & 1,5 & $2,3,4,6,7$ & $\begin{array}{l}\text { Bottom margin of Unit } 1 \\
\text { not observed }\end{array}$ \\
\hline Unit 2/Unit 3 & 1,5 & $2,3,4,6,7$ & $\begin{array}{l}\text { Bottom margin of Unit } 2 \\
\text { not observed }\end{array}$ \\
\hline Unit 3/Unit 4 & $1,2,5$ & $3,4,6,7$ & $\begin{array}{l}\text { Unit } 3 \text { is fine-grained } \\
\text { throughout; contact is } \\
\text { sharp }\end{array}$ \\
\hline Unit 4/Unit 5 & 1 & $2,3,4,5,6,7$ & Contact is sharp \\
\hline $\begin{array}{l}\text { Unit } 5 / \text { Unit } 6 \\
\text { Unit } 6 / \text { Unit } 7\end{array}$ & $\begin{array}{l}1,5,7 \\
1,5,6,7\end{array}$ & $\begin{array}{l}2,3,4,6 \\
2,3,4\end{array}$ & \\
\hline Unit $7 /$ Unit 8 & $1,3,5$ & $2,4,6,7$ & $\begin{array}{l}\text { Bottom marginal zone of } \\
\text { Unit } 7 \text { not observed }\end{array}$ \\
\hline Unit $8 /$ Unit 9 & 1,5 & $2,3,4,6,7$ & $\begin{array}{l}\text { Bottom margin zone of } \\
\text { Unit } 8 \text { not observed }\end{array}$ \\
\hline $\begin{array}{l}\text { Unit } 9 / \text { Unit } 10 \\
\text { Unit } 10 / \text { Unit } 11\end{array}$ & $\begin{array}{l}1,5,6,7 \\
1,2,3,4,5,6,7\end{array}$ & $2,3,4$ & \\
\hline
\end{tabular}

\section{Mode of Intrusion}

There can be little doubt that the igneous units penetrated by Hole 462 are sills. Where chilled margins were recovered, they are sub-horizontal. When recovery permits (as in Unit 10), orderly and symmetrically decreasing grain-size variations are observed approaching the margins. These observations, together with the total lack of characteristic pillow-lava features, gives strong support to this conclusion. However, the presence of volcaniclastic-sediment interlayers between sills may indicate that the sill-producing magmatic episode was associated with contemporaneous extrusive activity nearby. The importance of multiple igneous intrusion versus intrusion into sediments or along sediment/sedi- ment or sediment/sill bedding planes is more difficult to establish. This is primarily because of poor recovery in crucial intervals, mainly in Cores 60,61 , and 62 . The observed grain-size variations in the recovered rocks are consistent with sequential multiple or composite intrusion of Units 2 and 3 into a unit consisting (prior to intrusion) of Units 1 and 4. Similarly, Unit 8 could have been multiply intruded into an igneous unit consisting of Units 7 and 9. Alternatively, Unit 9 could have been intruded into the Unit 7 sediment or Unit 8 sediment bedding plane.

\section{Major-Element Chemistry}

Batiza et al., (this volume) gives the results of shipboard chemical analyses using X-ray-fluorescence (XRF) methods. Loss on ignition was determined gravimetrically. These data permit a few generalizations:

1) Whole-rock chemistry appears to be a function of grain size. Rocks with variolitic or hyalopilitic textures have higher $\mathrm{MgO}, \mathrm{Al}_{2} \mathrm{O}_{3}$, and $\mathrm{K}_{2} \mathrm{O}$; lower $\mathrm{TiO}_{2}, \mathrm{FeO}^{*}$, $\mathrm{MnO}$, and $\mathrm{CaO}$ contents; and lower $\mathrm{FeO}^{*} / \mathrm{MgO}, \mathrm{CaO} /$ $\mathrm{Al}_{2} \mathrm{O}_{3}$, and $\mathrm{TiO}_{2} / \mathrm{FeO}^{*}$ ratios than holocrystalline rocks. This is probably because of a combination of two factors: (a) replacement of glass by smectite and chlorite, and (b) a coincidentally greater degree of fractionation in the holocrystalline rocks (Fig. 20). The composition of the smectite will be important in evaluating the relative importance of each of these or other factors.

2) The holocrystalline rocks are mineralogically and chemically very similar to mid-ocean-ridge tholeiite, but they are moderately to badly altered. Alteration has produced slight changes in the whole-rock major-element chemistry.

Table 9. Petrographic characteristics of igneous rocks, Hole 462.

\begin{tabular}{|c|c|c|c|c|c|c|}
\hline Unit & $\begin{array}{l}\text { Thickness } \\
\text { (m) }\end{array}$ & $\begin{array}{l}\text { No. of Thin } \\
\text { Sections }\end{array}$ & Types of Phenocrysts ${ }^{a}$ & $\begin{array}{l}\text { Total } \% \text { of } \\
\text { Phenocrysts }\end{array}$ & Alteration ${ }^{\mathrm{b}}$ & Textures ${ }^{c}$ \\
\hline 1 & 1 & 3 & 1, 2, An70-65 & $2-10$ & $1,2,3,5,6$ & $\mathrm{~V}, \mathrm{H}, \mathrm{I}$ \\
\hline 2 & 1 & 2 & $1,2, \operatorname{An}_{68}$ & 4 & $1,2,3,5,6$ & $\mathrm{H}, \mathrm{E}$ \\
\hline 3 & 2.5 & 6 & 1, 3, An $80-70$ & $2-10$ & $2,3,4,5,6$ & $\mathrm{~V}, \mathrm{H}$ \\
\hline 4 & 0.14 & 1 & 1,2, An$_{65}$ & 3 & $2,3,4$ & I \\
\hline 5 & 1 & 0 & Aphyric & - & - & E \\
\hline 6 & 4.7 & 2 & 1,3 , An $70-60$ & 1 & $3,4,7$ & D \\
\hline 7 & 1.3 & 1 & 2. An80-50 & 1 & 3,4 & D \\
\hline 8 & 0.62 & 1 & 1,2, An74 $_{74}$ & 1 & $2,3,4$ & v \\
\hline 9 & 1.2 & 0 & - & - & $2,3,7$ & I, E, D \\
\hline 10 & 6 & 6 & 1, An78 & $0-4$ & $2,3,4$ & V, H, I, E, D \\
\hline 11 & 25 (minimum) & 21 & 1,4, An $80-27$ & $0-5$ & $2,3,4,7$ & D \\
\hline
\end{tabular}

a Phenocrysts: 1 = augite; 2 = possible olivine pseudomorphs; 3 = olivine pseudomorphs with spinel inclu-

sions, $4=$ titanomagnetite.

b Alteration: $1=$ calcite; $2=$ chlorite; $3=$ green clay; $4=$ brown clay; $5=$ zeolite; $6=$ iron and manganese

oxides and hydroxides; $7=$ pyrite.

c Textures: $\mathrm{V}=$ variolitic; $\mathrm{H}=$ hyalopilitic; $\mathrm{I}=$ intersertal; $\mathrm{E}=$ equigranular; $\mathrm{D}=$ diabasic.

Table 10. Modal analyses, Hole 462.

\begin{tabular}{|c|c|c|c|c|c|c|c|c|c|}
\hline Sample & Unit & Plagioclase & Augite & $\begin{array}{l}\text { Titano- } \\
\text { magnetite }\end{array}$ & Chlorite & $\begin{array}{l}\text { Green and/or } \\
\text { Brown Clay }\end{array}$ & Amphibole & Quartz & $\begin{array}{l}\text { Total No. } \\
\text { of Points }\end{array}$ \\
\hline $462-61-2,53-56 \mathrm{~cm}$ & 6 & 37 & 34 & 8 & 12 & 7 & - & - & 580 \\
\hline $63-3,119-122 \mathrm{~cm}$ & 10 & 34 & 17 & 9 & 39 & $\operatorname{Tr}$ & - & - & 584 \\
\hline $64-3,79-81 \mathrm{~cm}$ & 11 & 41 & 11 & 7 & 40 & $\mathrm{Tr}$ & - & - & 500 \\
\hline $65-2,27-30 \mathrm{~cm}$ & 11 & 42 & 28 & 6 & 5 & 5 & 12 & 1 & 695 \\
\hline $66-4,12-14 \mathrm{~cm}$ & 11 & 35 & 27 & 9 & 30 & $\mathrm{Tr}$ & - & - & 589 \\
\hline $68-2,37-39 \mathrm{~cm}$ & II & 41 & 29 & 8 & 1 & $\mathrm{Tr}$ & 17 & 3 & 538 \\
\hline $68-2,49-51 \mathrm{~cm}$ & 11 & 34 & 28 & 6 & $\mathrm{Tr}$ & $\mathrm{Tr}$ & 28 & 4 & 465 \\
\hline $69-1,36-38 \mathrm{~cm}$ & 11 & 42 & 16 & 8 & 7 & $\mathrm{Tr}$ & 16 & 11 & 471 \\
\hline
\end{tabular}


Within the set of holocrystalline rocks, the following elemental trends are observed: $\mathrm{P}_{2} \mathrm{O}_{5}, \mathrm{SiO}_{2}, \mathrm{MnO}$, and $\mathrm{CaO}$ remain about constant; $\mathrm{Al}_{2} \mathrm{O}_{3}$ decreases; and $\mathrm{TiO}_{2}$ increases with higher $\mathrm{FeO} * / \mathrm{MgO}$ ratio. $\mathrm{FeO} *$ and $\mathrm{TiO}_{2}$ co-vary, but the variation trend is slightly different than that observed in typical oceanic-crust volcanic suites. It is possible that such a trend results from a combination of fractionation and alteration. Crude stratigraphicchemical variation is observed in Hole 462 , but is probably due simply to the fact that Unit 11 shows the widest compositional variation.

\section{Alteration}

Veining and alteration are moderate to heavy in all the rocks of Hole 462 . Veins are monomineralic and polymineralic and contain:(1) green smectite;(2) brown smectite; (3) mixed smectite and chlorite (celadonite); (4) mixed smectite and $\mathrm{Mn} / \mathrm{Fe}$ oxides and hydroxides; (5) mixed smectite and calcite; (6) mixed smectite, calcite, pyrite, zeolite; and many other assemblages. The relative replacement/emplacement sequences of these minerals based on textural relationships are highly variable, and in some cases at least two generations of a given phase are clearly visible. The following secondary minerals have been identified optically in the rocks of Hole 462:

$\begin{array}{ll}\text { Brown smectite (Al, Mg-rich) } & \text { Calcite } \\ \text { Green smectite (Fe-rich) } & \text { Mn/Fe hydroxides and oxides } \\ \text { Red smectite (very Fe-rich) } & \text { Pyrite } \\ \text { Yellow smectite (Fe-rich) } & \text { Chalcopyrite } \\ \text { Chlorite } & \text { Magnetite } \\ \text { Disordered hydromica (?) } & \text { Amphibole (two kinds) } \\ \text { Chalcedony } & \text { Zeolites (at least two } \\ \text { Quartz } & \text { or three kinds) }\end{array}$

At least two major types of post-solidification alteration probably have affected the rocks: (1) sea-water alteration, which resulted in precipitation of smectites, calcite, zeolite, sulfides, $\mathrm{SiO}_{2}$, and $\mathrm{Mn} / \mathrm{Fe}$ hydroxides, and (2) late-magmatic or deuteric processes which have resulted in the production of micropegmatite, amphibole, and possibly chlorite, quartz, and $\mathrm{Fe}$-oxide mineralization.

\section{Hole 462A}

Figure 21 shows the stratigraphy and mineralogy of the basaltic rocks from Hole $462 \mathrm{~A}$

\section{Physical Characteristics and Mode of Emplacement of the Igneous Units}

The igneous section drilled in Hole 462A has been subdivided into units (Fig. 22). These units were distinguished on the basis of differences in any one or a combination of physical, textural, or lithologic attributes, as were those of Hole 462. The units of Figure 22 contain one or more of five kinds of igneous units: (1) single basalt sills, (2) compound or multiple basalt sills, (3) basalt flows or groups of flows, (4) hyaloclastite/hyaloclastite breccia, and (5) possibly a pillow lava unit. The criteria which have been used to distinguish each of these igneous units are discussed in turn below.

Single sills have been recognized by the same characteristics as were used for the rocks of Hole 462: (1) glassy margins or fine-grained marginal zones with subhorizontal attitude, and (2) orderly coarsening-inward grain-size variations, coarse-grained interiors, and diabasic texture. Units $6,12,13,21$, and 25 (Fig. 22) are some examples of single basalt sills. Their thickness ranges from a few tens of centimeters to over 50 meters. In some cores, baked sediment and glass contacts were recovered, but in most (as with Hole 462) the glassy sill margins were not recovered. In the latter case, however, narrow, fine-grained marginal zones were recognized. The sill units exhibit a narrow range of mineralogical and chemical variations, and the thicker ones (>5-10 $\mathrm{m}$ ) invariably contain patchy granophyric intergrowths.

Multiple sills are more difficult to distinguish with certainty. In some cases (e.g., Units 33 and 34) where fine-grained to glassy apophyses are present, multiple intrusion, at least on a small scale, can be demonstrated. On larger scales, multiple intrusion has been inferred from the alternation of fine-grained and coarser-grained units (as in Units 31 and 33) which lack glassy margins in drill cores where recovery was very high. In such cores, abrupt changes in grain size near horizontal or near-horizontal contacts are observed. These observations support the interpretation that these units represent multiply intruded sills, although we recognize that such features also may be developed within single extrusive bodies.

At least two types of multiple intrusions can be recognized in the rocks of Hole 462A. The first type occurs in the upper portions of the section (e.g., Units 1-5) and is characterized by subtle grain-size variations, but distinct mineralogic differences between the individual units. This type of multiple intrusion may represent the sequential emplacement of one magma batch in a series of several smaller batches, each of which has undergone a different degree of fractionation (perhaps flow differentiation).

The second type of multiple intrusion occurs in the lower portions of the igneous section. This type is characterized by greater differences in grain-size and an absence of mineralogical differences among the various grain-size domains. Units of this type are associated with units of obvious extrusive character and may in fact be portions of thick flows. In this case, the grainsize variations could be due to turbulent flow during cooling, heterogeneous distribution of volatile components, complex isotherm distributions, or other factors.

Flows have the following characteristics: (1) variable but small thickness (0.3-2.0 m) of units; (2) thick (up to $4 \mathrm{~cm}$ ) glassy margins on upper and lower contacts; (3) fine grain size throughout, but a patchy appearance which results from mixed textures; (4) variable attitude of glassy margins (dips of glassy margins range from horizontal to vertical; contorted shapes, often with reentrant surfaces are common); (5) ubiquitous cooling cracks normal to glassy surfaces, and numerous cracks 


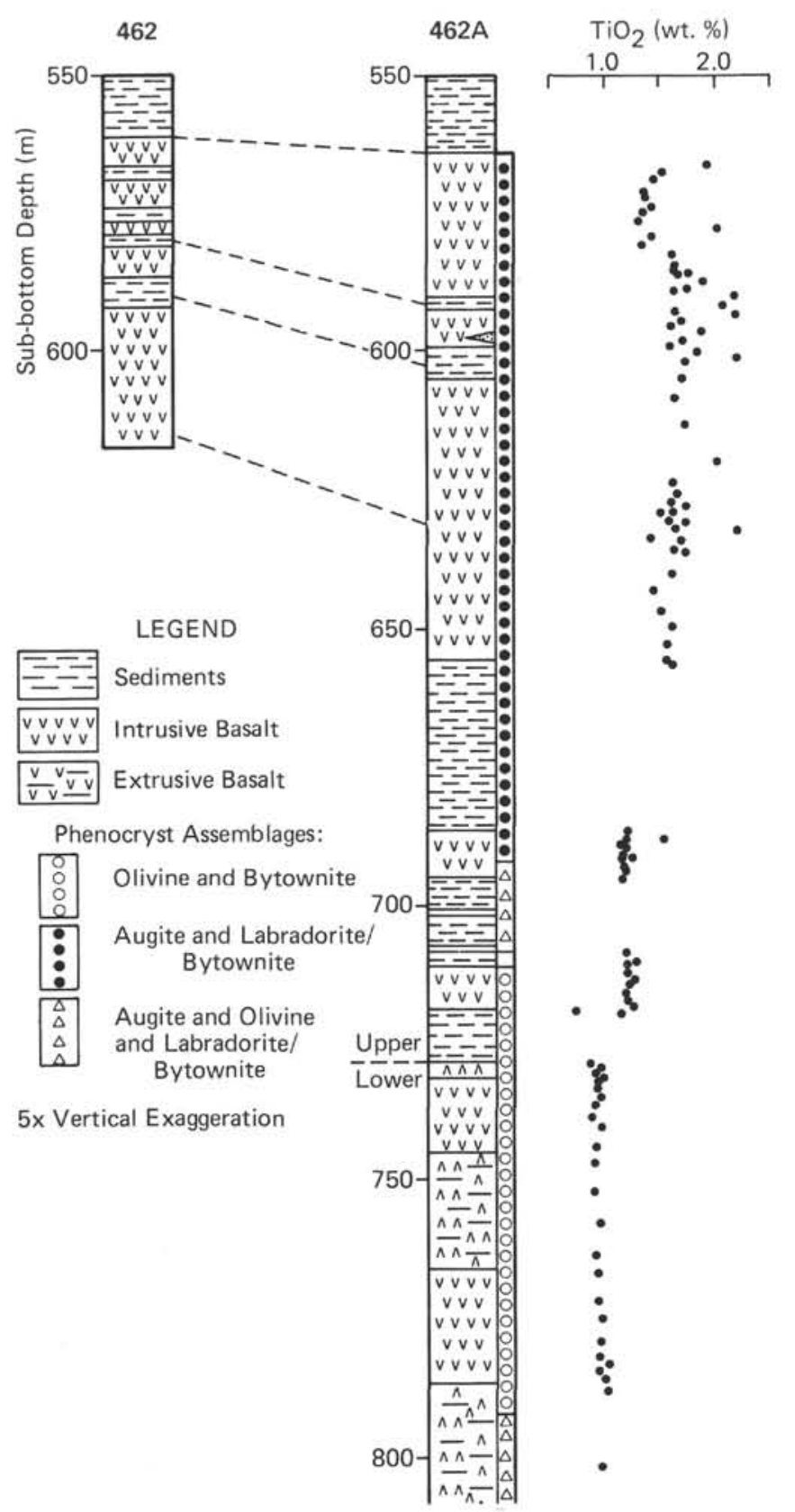

Figure 21. Stratigraphy and mineralogy of basaltic rocks, Holes 462 and $462 \mathrm{~A}$.

in the interior, crystalline portions of units (these interior cracks do not display preferred orientation); (6) inclusions and thin apophyses of fine-grained material in coarser-grained basalt, suggesting turbulent flow and mixing within cooling units.

These characteristics strongly suggest that these units (e.g., Units 23, 26, and 29) are either extrusive or were intruded into very soft, water-rich sediment, but the almost total lack of sediment inclusions or infolded sediment pockets suggests that these units were likely extruded directly onto the sea floor. However, these units have none of the characteristics of pillow lava. They lack (1) radial cooling fractures, (2) concentric struc-

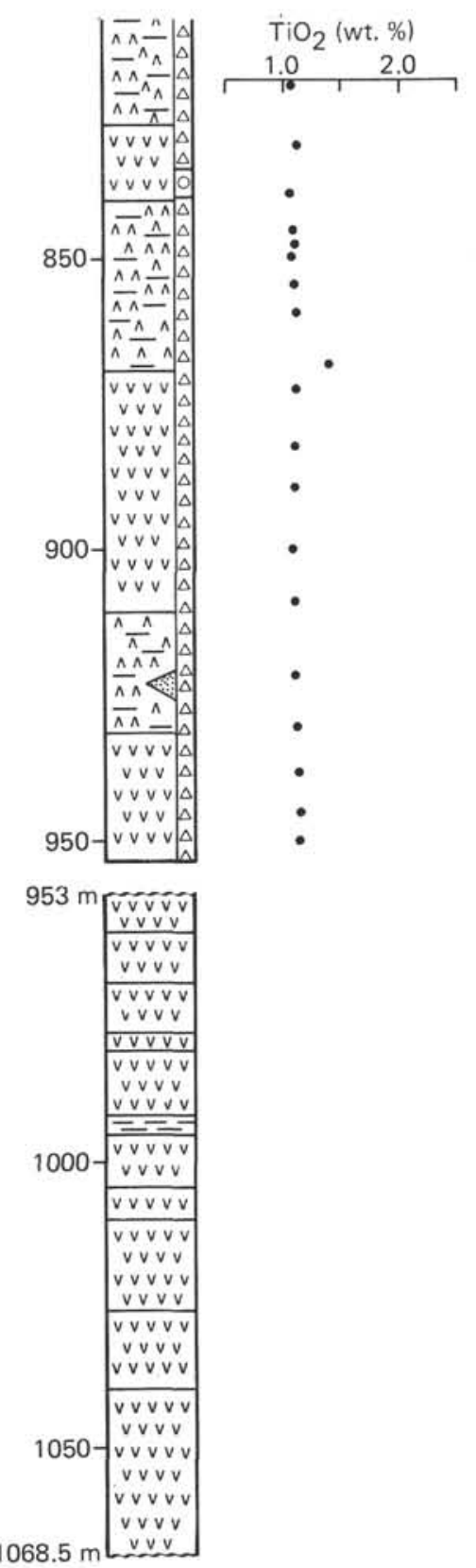

Figure 21. (Continued).

tures, (3) regular, curved surfaces, (4) interior hollows or vugs, and (5) inter-pillow matrix material.

The mode of extrusion of these flows could be either (1) slabby pahoehoe type, or (2) a series of shingled, lobate, and narrow advancing flow fronts similar to pillow lava, but extruded more rapidly. The formation of pillow forms in this case might be inhibited by rapid extrusion rate, as at fast-spreading ridge crests. Hollows apparently have formed between flows or lobes of single flows in the Hole 462A rocks. These vugs are now filled with aggregates of euhedral, inward-pointing phillipsite crystals.

Hyaloclastite and hyaloclastite breccia units are abundant in the upper part of Hole $462 \mathrm{~A}$, but are rare in 


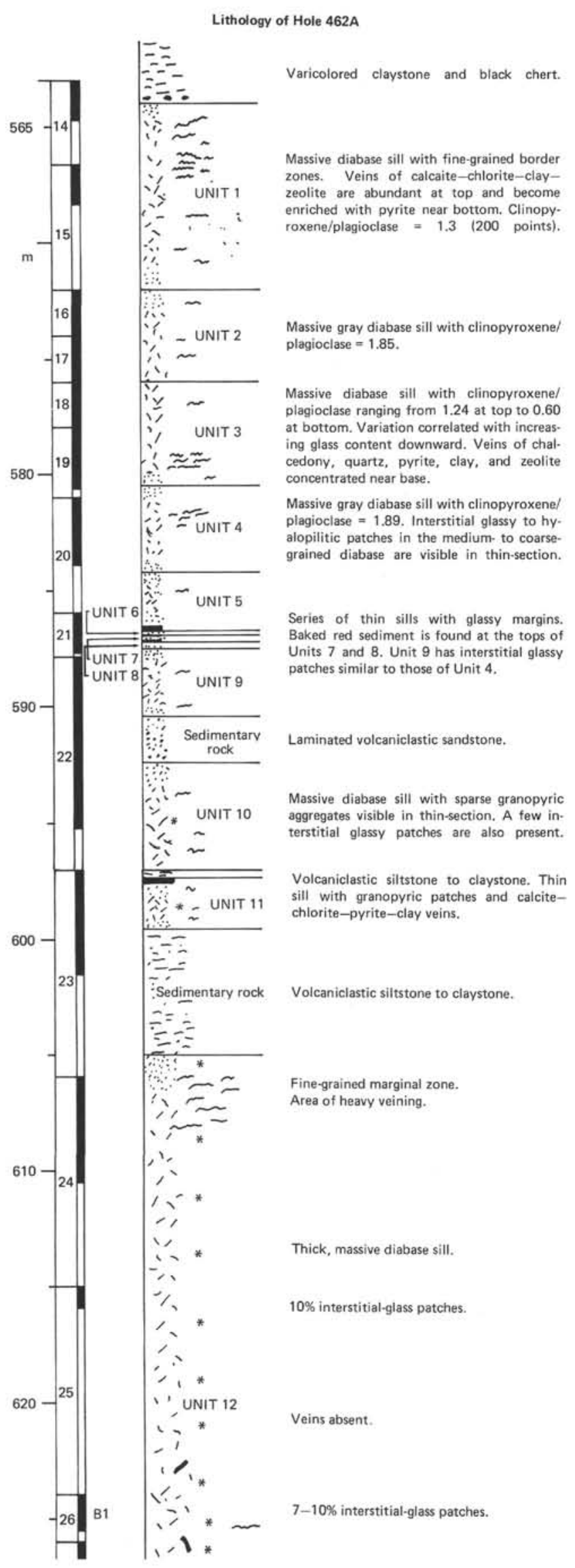

Figure 22. Summary of core data and igneous-rock units.

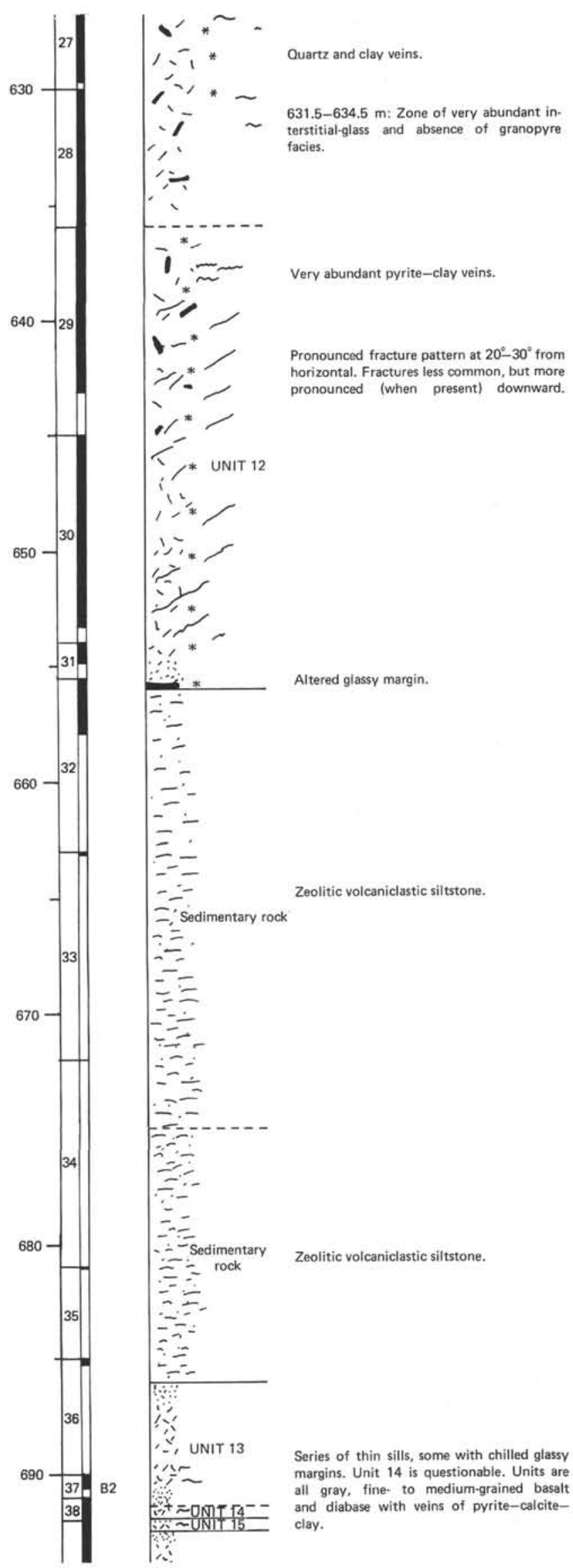

Figure 22. (Continued). 


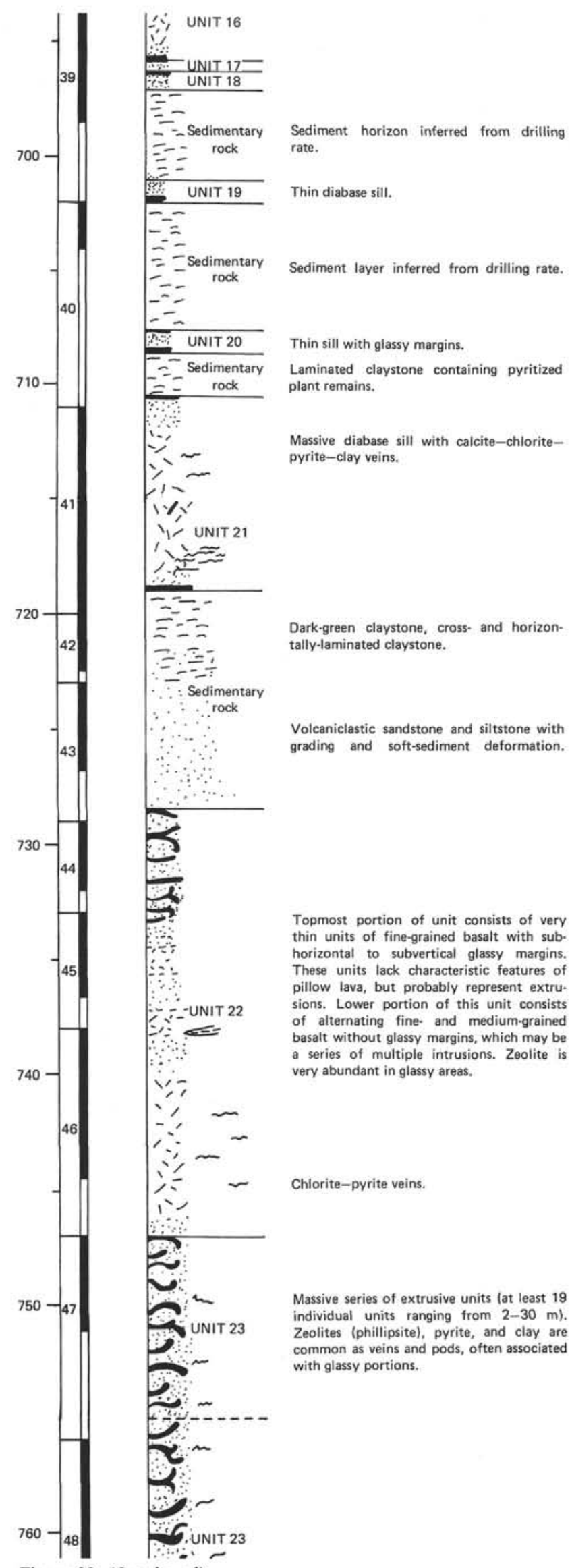

Figure 22. (Continued).

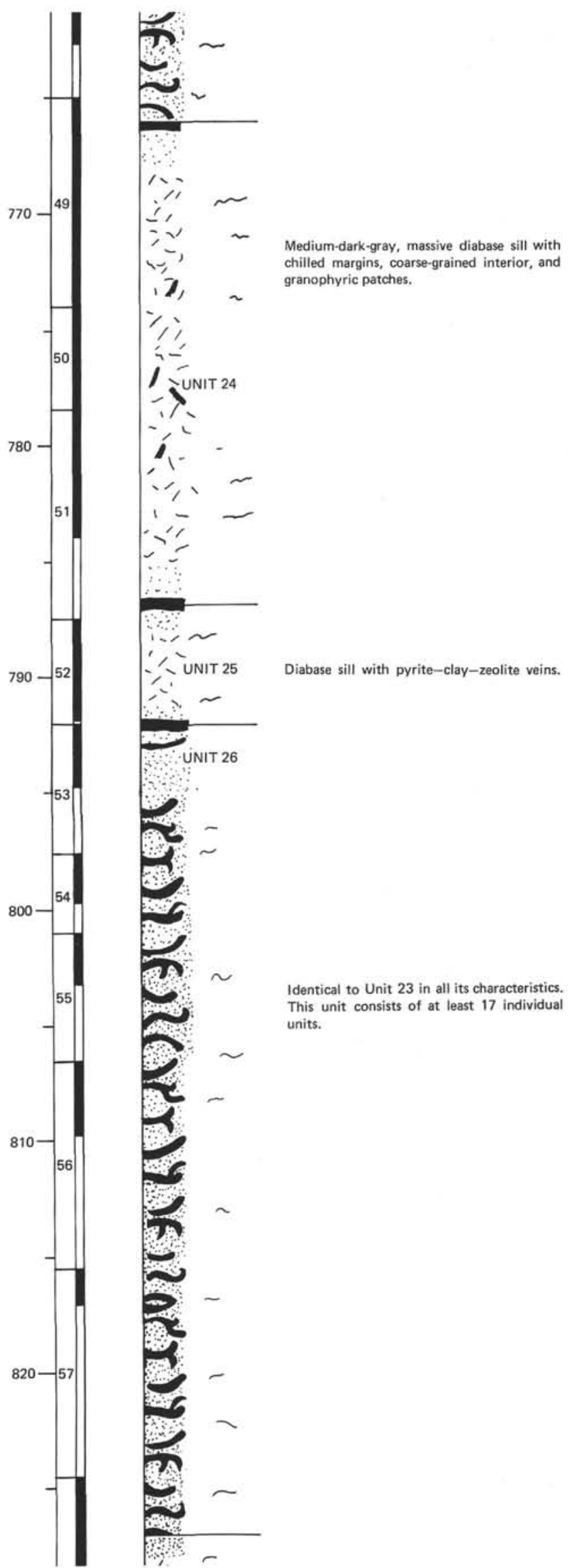

Figure 22. (Continued). 


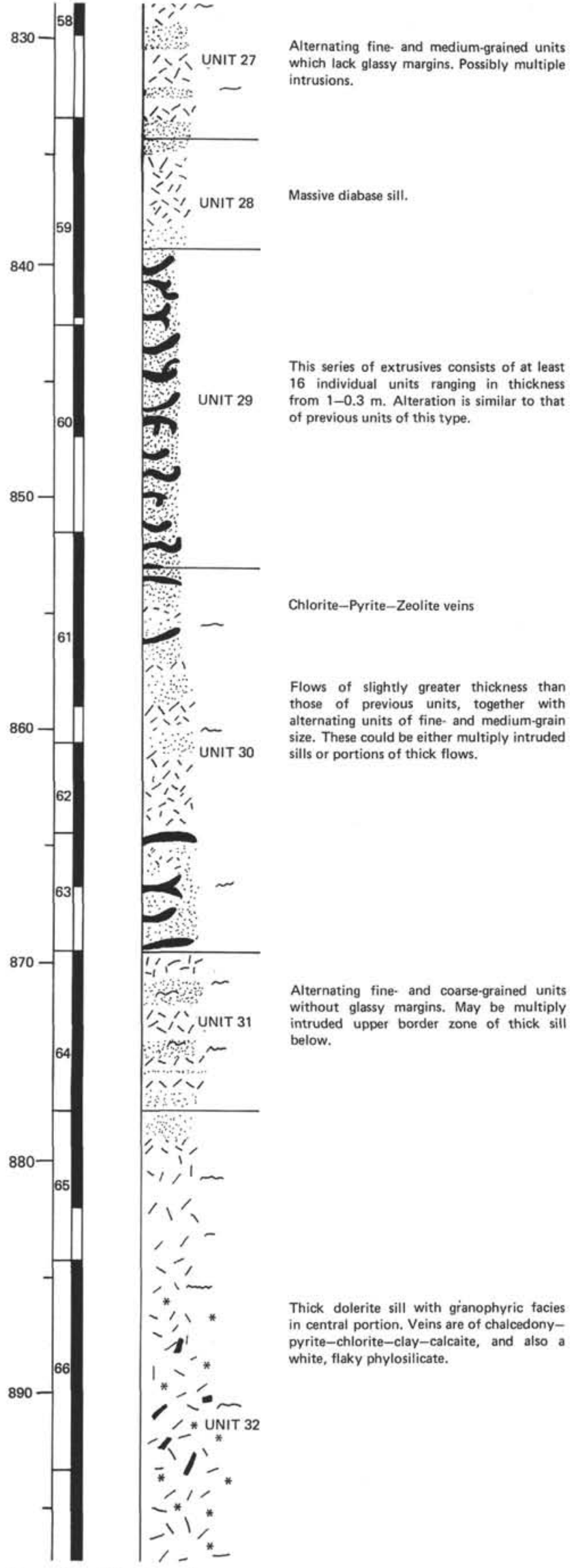

Figure 22. (Continued).

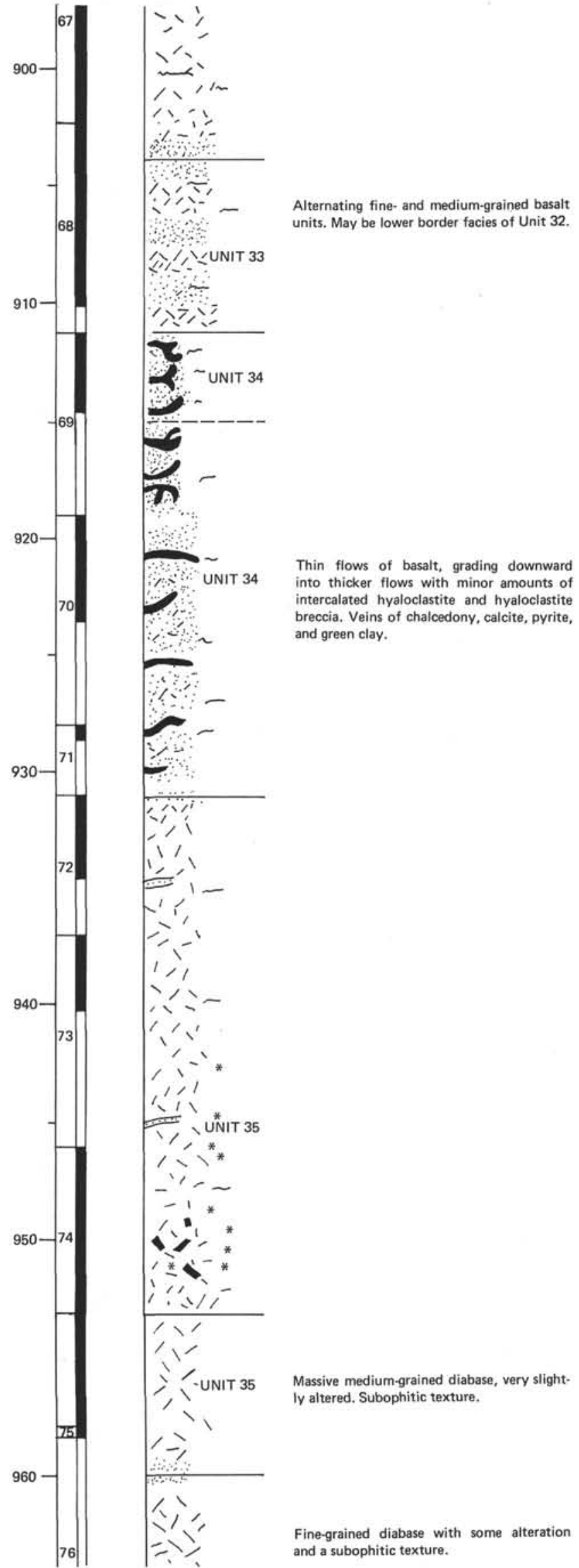

Figure 22. (Continued). 


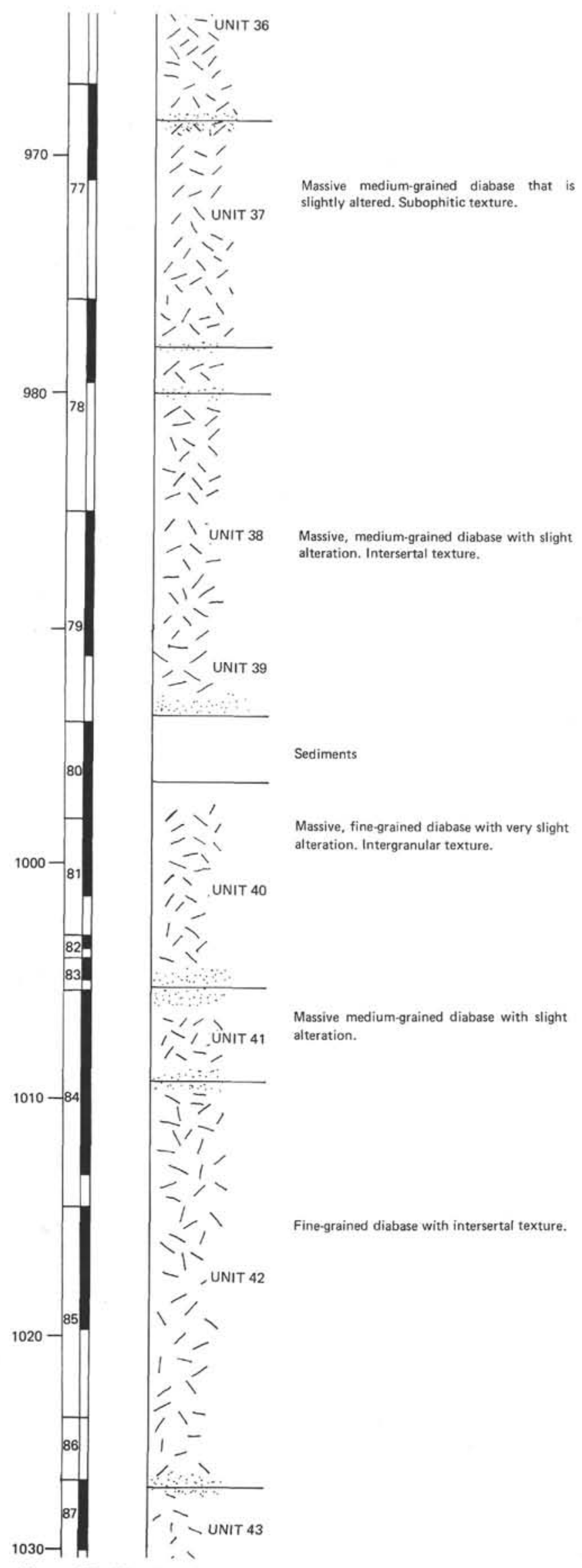

Figure 22. (Continued).

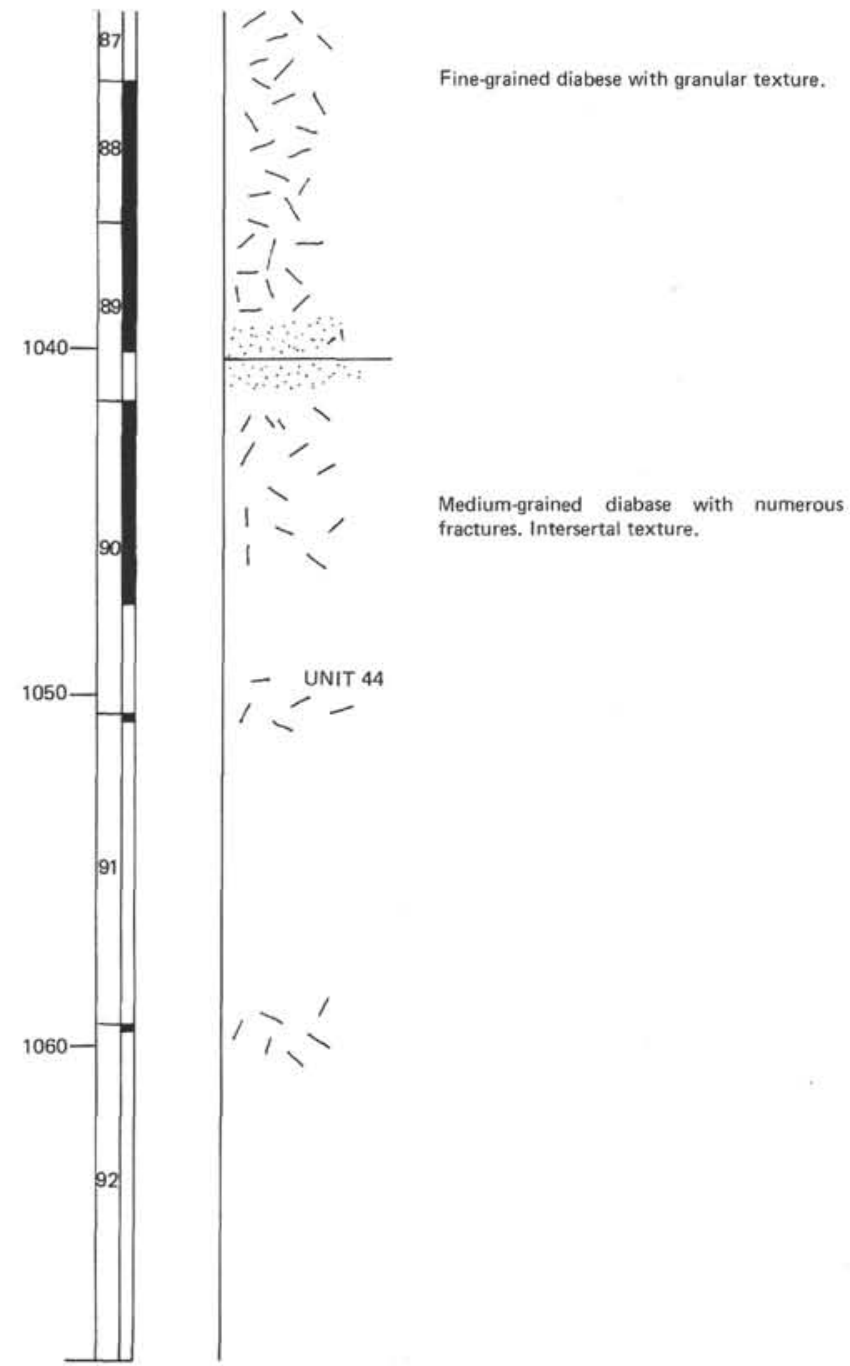

Figure 22. (Continued).

the lower portions. These units will be described elsewhere (Moberly and Jenkyns, this volume). These units are important because they contain deep-water benthicforaminifer tests (Sliter, this volume), among other things. In addition, the presence of hyaloclastites supports the suggestion that at least part of the major Nauru Basin volcanic episode was extrusive.

A single occurrence of possible pillow lava is found at the base of Core 71 (Unit 34). These possible pillows have radial cracks, concentric and curved internal structures, and interior clay-filled vugs, and their grain size increases inward from the margins. They lack glassy margins and have instead altered basalt margins of micro-intrusion breccia. One pillow is about $20 \mathrm{~cm}$ across, and the other about 8 ; they do not have all of the characteristics of typical pillows, but they may nevertheless be genuine pillows, and in this they are unique among the rocks recovered from Hole 462A.

\section{Summary of Petrographic Data}

The igneous rocks of Hole $462 \mathrm{~A}$ are petrographically very similar to those of 462 , and will not be discussed in detail, but a few features which are found only in Hole 
$462 \mathrm{~A}$ will be discussed briefly. The granophyre facies in the thick sills of Hole $462 \mathrm{~A}$ is not confined to the thick sills in which the granophyre fluid was presumably produced, as was the case in Hole 462. Instead, this lowviscosity, $\mathrm{SiO}_{2}$-rich fluid apparently permeated neighboring units. This evidenced by the occurrence of quartz and quartz-feldspar-apatite intergrowths in thin sills adjacent to the thick, granophyre-producing sills (e.g., Unit 12, Figure 22). The mineralogy of the sills of Hole $462 \mathrm{~A}$ is almost identical to that of the Hole 462 sills, but some textural variations are observed. For example, coarser-grained rocks containing interstitial, polygonal patches of glassy to variolitic rock are more common in the Hole $462 \mathrm{~A}$ sills. These patches are probably the result of decompression freezing in the latter stages of the sill's solidification.

Glassy rocks are much more common in Hole 462A than in Hole 462. They display typical vitrophyric to variolitic textures. In some cases, fresh relict olivine phenocrysts are preserved within fresh glass. These glassy rocks are most common and abundant in the extrusive units, which also display a great variety of unusual fine-grained textures. Of particular interest is spinifex-like quench texture developed in groundmass clinopyroxene, which is common in rocks of Units 22 and 23 (Batiza et al., this volume).

A few generalizations about the mineralogy of Hole $462 \mathrm{~A}$ rocks can be made:

1) The basalts are all aphyric or sparsely phyric.

2) Several phenocryst assemblages are observed: (a) olivine (with spinel inclusions) + bytownite; (b) olivine + clinopyroxene + labradorite or bytownite; (c) clinopyroxene + labradorite.

3) These assemblages are distributed more or less systematically through the section and are to some extent reflected in the chemical compositions of the basalts.

Figure 21 shows that, on simple inspection, units of petrographic group (b) appear symmetrically disposed about a group of units of type (a) between about 710 and 790 meters sub-bottom.

\section{Correlation between Holes $\mathbf{4 6 2 A}$ and 462}

Figure 21 shows that some correlations can be made between Holes 462 and $462 \mathrm{~A}$. There is little doubt, for example, that the Unit 11 of Hole 462 (Fig. 20) is the same thick sill encountered in the upper part of Hole $462 \mathrm{~A}$ (Unit 12). In addition, some of the sediment horizons encountered at similar sub-bottom depths in both holes may be continuous between the holes. It is clear, however, that most of the thin sills of Hole 462 do not extend laterally to Hole 462A. Many of the thinner sediment horizons also appear to pinch out.

This pattern suggests significant three-dimensional lithologic heterogeneity on a scale of less than 500 meters (the distance between the holes). However, since the chemical compositions of the uppermost basalts in each hole are very similar, it is probable that they are closely related temporally. They even may have been fed by the same major conduit.

\section{Part B (by S. Shcheka)}

\section{Rock Fragments Recovered in Cores 462-4 to 462-21 and Their Petrologic Significance}

Thin-sections and smear-slide observations of about 50 rock and mineral fragments taken from these cores revealed the following:

1) Scoriaceous, glassy, alkaline basalts with perfectly shaped crystals of olivine and titanaugite. In all fragments, the pale-brown glass is very fresh, and no alteration was observed. Small $(0.1-0.5 \mathrm{~mm})$ inclusions of titanaugite dolerite in the glass probably belong to the early subvolcanic phase of a single volcano.

2) K-feldspar (probably anorthoclase) dolerites with titanaugite, kaersutite, magnetite, and needles of apatite-and a mineral, replaced by calcite, which was probably nepheline.

3) Magnetite-plagioclase-kaersutite-titanaugite dolerites. Coarse Ti-augite phenocrysts are strongly zoned and colored (pinkish-brown) in contact with the groundmass.

4) Plagioclase glassy basalts. The glass is fresh, the clinopyroxene is homogeneous, and the plagioclase laths show flow alignment.

5) Coarse $(>1 \mathrm{~mm})$ fragments of colorless crystals of olivine $\left(2 V_{\gamma} \approx 80^{\circ}\right)$, orthopyroxene $\left(2 V_{\gamma} \approx 80^{\circ}\right)$, and pale-grass-green diopside $\left(2 V_{\gamma} \approx 60^{\circ}\right)$. The diopside looks like chrome diopside. Fine inclusions $(0.1$ $\mathrm{mm}$ ) of translucent spinel octahedrons are commonly observed in the olivine. Being included in glass, these crystals show distinct optical zonation and alteration rims, i.e., they were unstable in the original basalt melt. All five features are characteristic of phases which belong to lherzolite inclusions in alkaline basalt. The large size and high magnesium content (according to optical properties) of these crystals are not features characteristic of basalt phenocrysts.

These results show that the petrologic assemblage of fragments could belong to a stage of edifice-building in which alkaline eruptions alternate with tholeiite eruptions (Hawaiian type). Absence of the slightest signs of metamorphism and weathering in minerals, especially in glass, and the sharp-edged debris are evidence for the formation of such an edifice near Site 462 . The vesicular, trachytic textures of the rocks-in addition to the subvolcanic facies in glassy lavas, combined with the features listed above-are in clear agreement with subaerial explosive eruptions. Consistency of debris composition and texture, along with a considerable age interval (Oligocene-Pleistocene) allow us to suppose that a long-standing volcano of Hawaiian type is near Site 462 (probably on the west side of the Marshall Islands, because of its proximity). Alkali-basalt volcanoes with deep-seated inclusions are commonly located on continental crust-rarely on oceanic islands of the Hawaiian type-but are unknown in oceanic rift zones. These occurrences are correlated with the nature and thickness of the crust in these regions and suggest the possible existence of thick crustal blocks in the Nauru Basin. This correlation is linked to the wider problem of the origin 
of oceanic alkali-basalt magma, which has an important bearing on the reconstruction of oceanic-crust evolution and deserves to be investigated on future DSDP legs.

\section{Chemical Results, Holes 462 and $462 A$}

\section{METHODS}

More than 100 samples of volcanic rock from Holes 462 and $462 \mathrm{~A}$ have been analyzed aboard ship using (XRF) techniques. The Siemens (FRG) XRF spectrometer allowed determination of nine elements: $\mathrm{Si}$, $\mathrm{Ti}, \mathrm{Al}, \mathrm{Fe}, \mathrm{Mn}, \mathrm{Mg}, \mathrm{Ca}, \mathrm{P}$, and $\mathrm{K}$. We will confine this discussion to a brief decription of sample-preparation procedure.

First, all samples are rinsed in distilled water and dried at $110^{\circ} \mathrm{C}$ for about 10 minutes to remove sea-water impurities. Next, the dried sample is crushed in a piston-cylinder "Abish"-type mortar, using a $20,000 \mathrm{lb} /$ in. $^{2}$ hydraulic press, then ground in an agate mortar for 5 to 10 minutes. A quantity of this powder is then heated for at least 6 hours at $110^{\circ} \mathrm{C}$ to remove non-structural water. Unfortunately, this heating step also partly disturbs the crystal structures of low-temperature minerals such as clays, zeolite, and chlorite. About $700 \mathrm{mg}$ of dried powder are then calcinated at $1050^{\circ} \mathrm{C}$ for determination of weight loss on ignition (LOI).

An aliquot of calcinated powder is then fused in a $\mathrm{Rh}-\mathrm{Au}-\mathrm{Pt}$ crucible (OPR-3) with $\mathrm{Li}_{2} \mathrm{~B}_{4} \mathrm{O}_{7}+\mathrm{La}_{2} \mathrm{O}_{3}$ flux (3.4 and $0.6 \mathrm{~g}$, respectively for 2 hours. The glass discs which are thus produced are used for the analyses. Element values are calculated by comparing sample-intensity ratios to a set of standard rocks of known chemical composition. These standards are BR, GA, GH, DRN, MAR, DTS, BCR-1, and PCC-1. Precision and accuracy of the analyses are better than $1 \%$ for the major elements of fresh samples (LOI $\leq 2 \%$ ). Volatile-rich samples may lose some alkali elements during fusion, as determined from experimental petrologic work.

\section{Results and Discussion}

\section{Alteration}

To interpret the chemistry of oceanic basalt magma, one must consider the conditions under which submarine eruptions take place. During oceanic basalt emplacement, the magma consolidates either in direct contact with sea water or in contact with watersaturated rocks. In Holes 462 and $462 \mathrm{~A}$, for example, the water content of sedimentary rocks is more than $20 \%$ at depths of up to 500 meters below the sea floor. Very rapid quenching, even for moderately deep intrusives in such sediments, and sea-water-rock chemical reactions are two important consequences of eruption under these conditions. As a result, the chemical compositions of submarine lavas on freezing may differ greatly from the composition of the original primary magma. In the following discussion, we attempt to describe the specific chemical changes which have resulted from submarine emplacement in the rocks of Holes 462 and 462A. Unfortunately, detailed shipboard mineralogic studies are not possible; thus this discussion will be limited to several short comments. Shore-based laboratory mineralogical studies to be carried out later will add greatly to our understanding of the chemical effects of alteration.

Abundant and diverse products of alteration are represented in the recovered rock samples (Fig. 23). Throughout the drilled interval, olivine has been converted to iddingsite, volcanic glasses are palagonitized, and rocks are cut by numerous veins of chlorite, clay minerals and pyrite. Calcite, opal-quartz, and zeolites are also found. It is important to note that higher-tem- perature secondary minerals such as epidote, albite, actinolite, and adularia, which are invariably encountered in ancient continental basalts, are absent in these rocks. This demonstrates conclusively that the alteration occured at low temperatures $\left(<150^{\circ} \mathrm{C}\right)$.

Following the classification of metasomatic rock facies of Korzhinskiy (1957), the volcanic rocks of Holes 462 and $462 \mathrm{~A}$ can be divided into three groups: (1) facies of near-neutral hydrothermal conditions, resulting in hydration of olivine and glass; (2) facies of acidic hydrothermal conditions, resulting in production of aluminous chlorite, quartz, and pyrite; (3) facies of alkaline conditions, resulting in zeolites and carbonates.

Metasomatic alteration of the first group is a result of sea-water reaction with basalt on a regional scale. The least-stable phases under these conditions, volcanic glass and olivine, are subjected to hydration; the former is palagonitized and the latter is replaced by alkali-poor members of the nontronite-saponite series of smectites. This type of alteration does not result in large-scale removal of highly mobile components such as alkalies; it is essentially isochemical. In addition, plagioclase and clinopyroxene remain unaltered under these conditions. Fresh clinopyroxene and plagioclase are observed in thin sections of the rocks of Hole 462 and $462 \mathrm{~A}$. The plagioclase microphenocrysts of these rocks show primary compositional zonation $\left(\mathrm{An}_{80}-\mathrm{An}_{45}\right)$ related to changes in primary magma chemistry during crystallization.

Metasomatic alteration of the second and third types is local, contrasting with alteration of the first type. This type of alteration occurs after consolidation and cracking of the emplaced rocks, and involves opensystem circulation of high-temperature hydrothermal solutions. In the rocks recovered on Leg 61, such alteration has led to preferential formation of zeolite veins near glassy margins of thin sills and flows. This process was probably promoted by the alkalization of initially acidic volcanic hot-spring waters. Optical examination of the zeolites of Leg 61 rocks reveals the presence of at least three crystomorphologic types: (1) tabular forms, (2) drusy aggregates of euhedral prismatic crystals, and (3) radiating acicular bundles. The second type has the optical properties of phillipsite.

Monomineralic veins of calcite are commonly localized near basalt contacts with sedimentary rocks. Pyrite-chlorite veins are found in the entire section at Holes $462,462 \mathrm{~A}$, and chlorite is being replaced by clay minerals in almost all cores. Pyrite appears to be the latest mineral; it occupies the interior portions of chlorite-clay veins. Thicker veins show the following mineral zonation from margin to core (Figs. 24-29) chlorite + pyrite $(p \mathrm{H}<7) \rightarrow$ calcite $\rightarrow$ zeolite $(p \mathrm{H}>7)$ reflecting the increasing $p \mathrm{H}$ of the circulating solutions, caused by chemical reactions with solid rock. Sometimes opal, rather than zeolite, has replaced calcite grains, which indicates injection of fresh acidic solutions into the system. Colloform textures are characteristic of calcite, opal, and zeolite in veins. In addition, potassium- and aluminum-rich clay minerals are produced under these more-acidic conditions. 


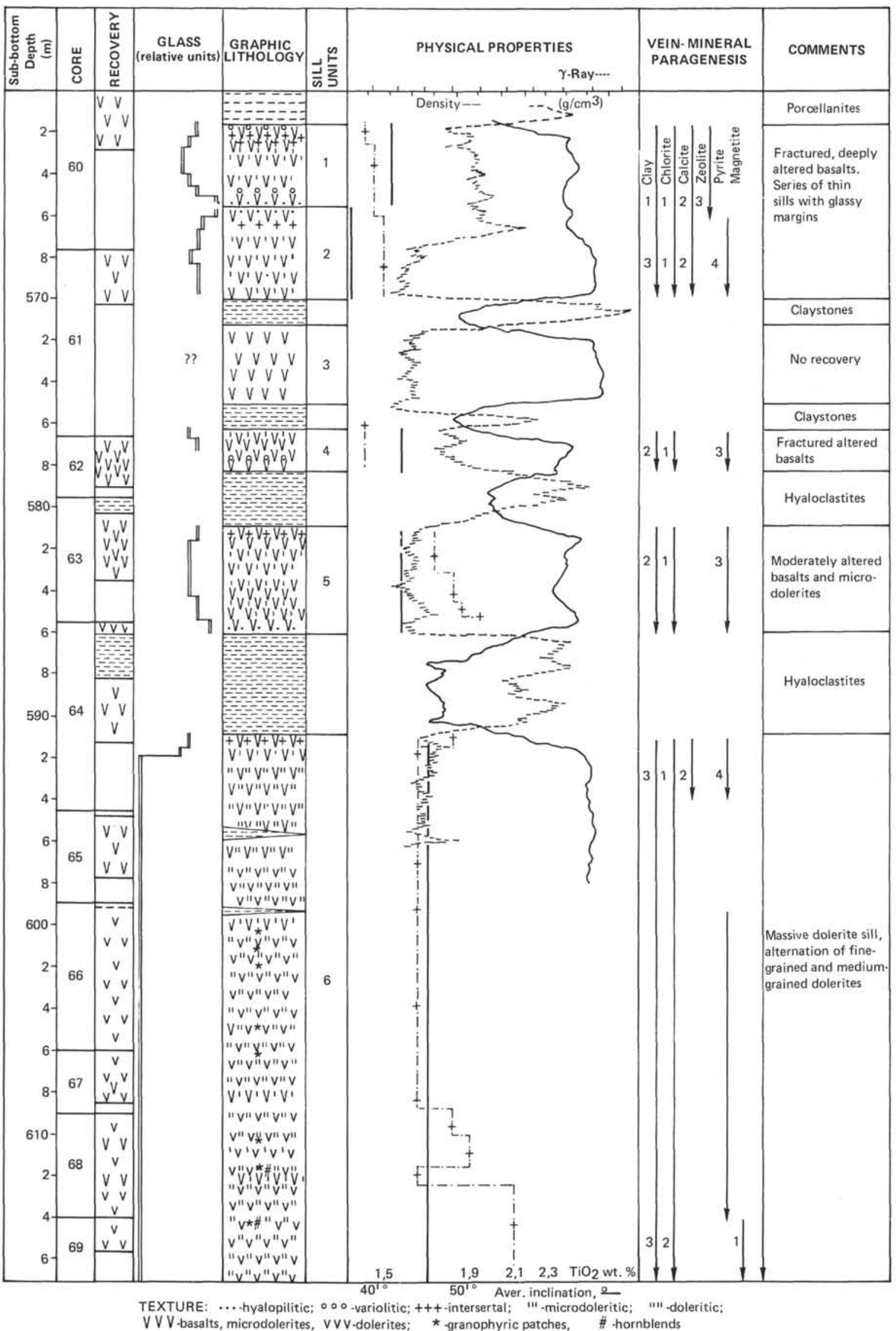

Figure 23. Leg 61 , Hole 462,560 to 617 meters. 


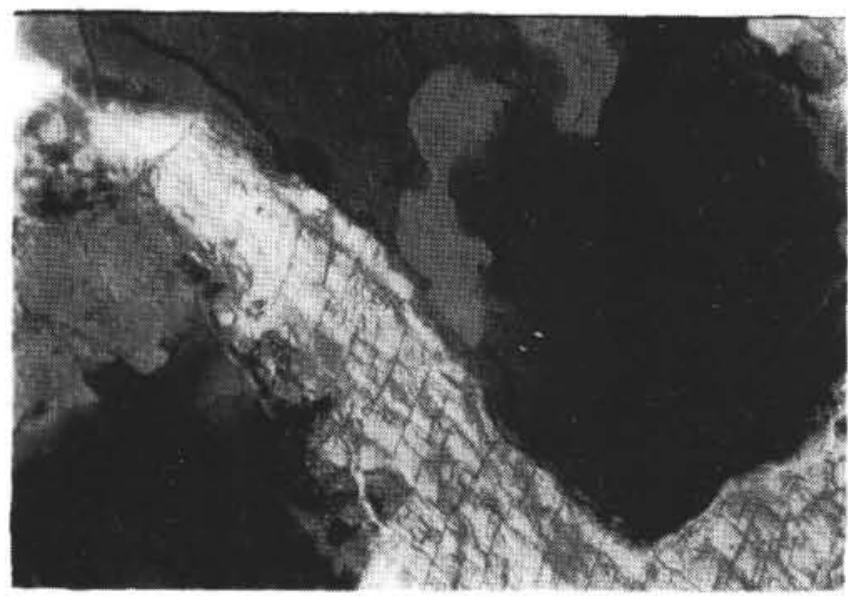

Figure 24. Part of a secondary-mineral vein at $462-60-2,53-57 \mathrm{~cm}$, showing two types of smectite and calcite (field of view is $1.0 \mathrm{~mm}$ ).

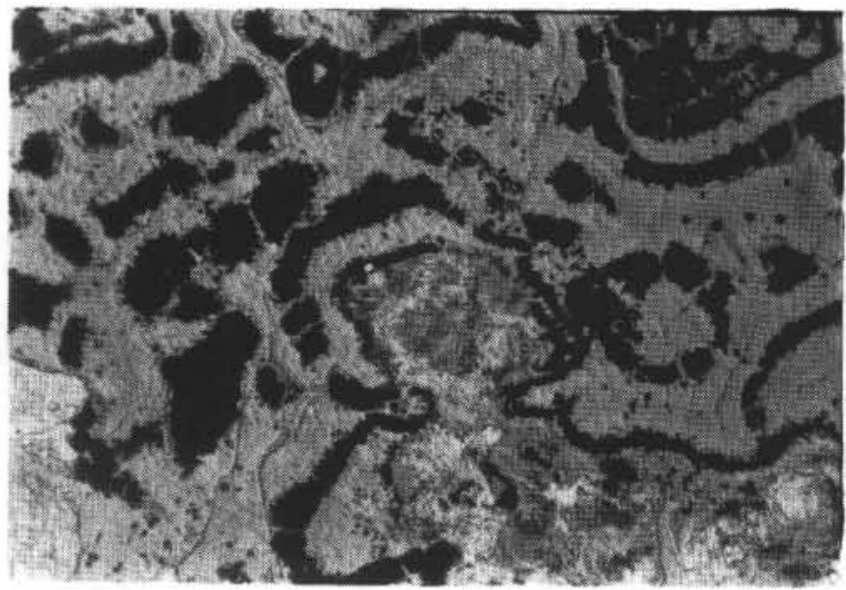

Figure 25. Green smectite and iron-manganese oxides at 462-60-2, $103-107 \mathrm{~cm}$ (field of view is $2.0 \mathrm{~mm}$ ).

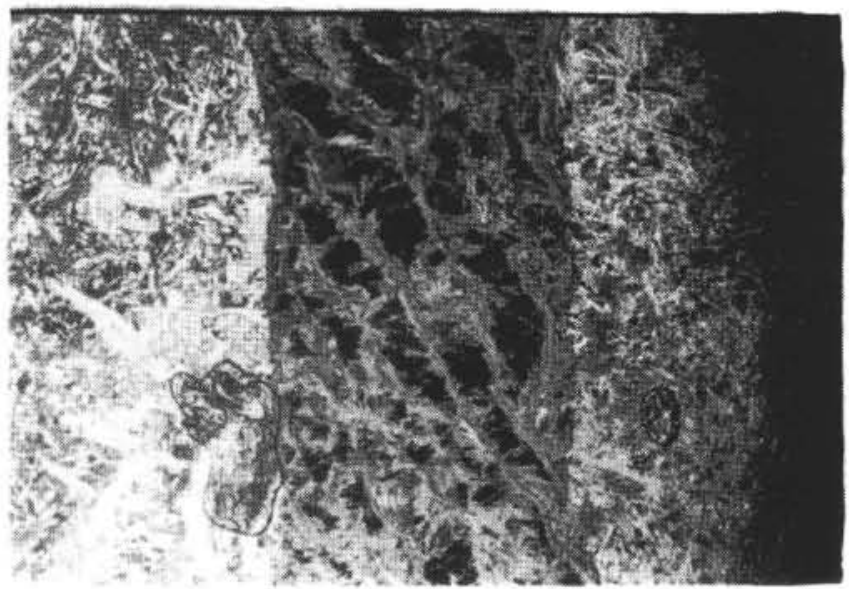

Figure 26. Vein of smectite and opaque material at 462-60-2, 103-107 $\mathrm{cm}$ (field of view is $4.0 \mathrm{~mm}$ ).

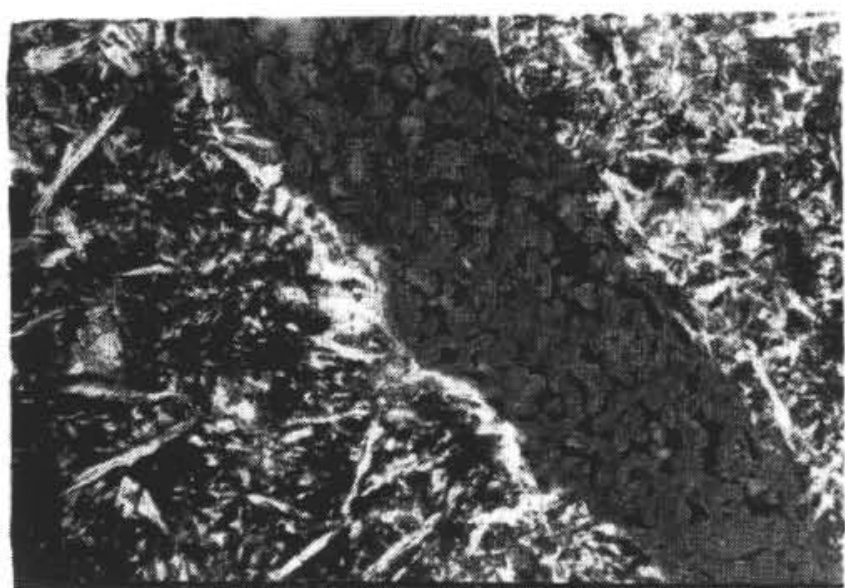

Figure 27. Vein of smectite and opaque material at 462-60-2, 103-107 $\mathrm{cm}$ (field of view is $4.0 \mathrm{~mm}$ ).

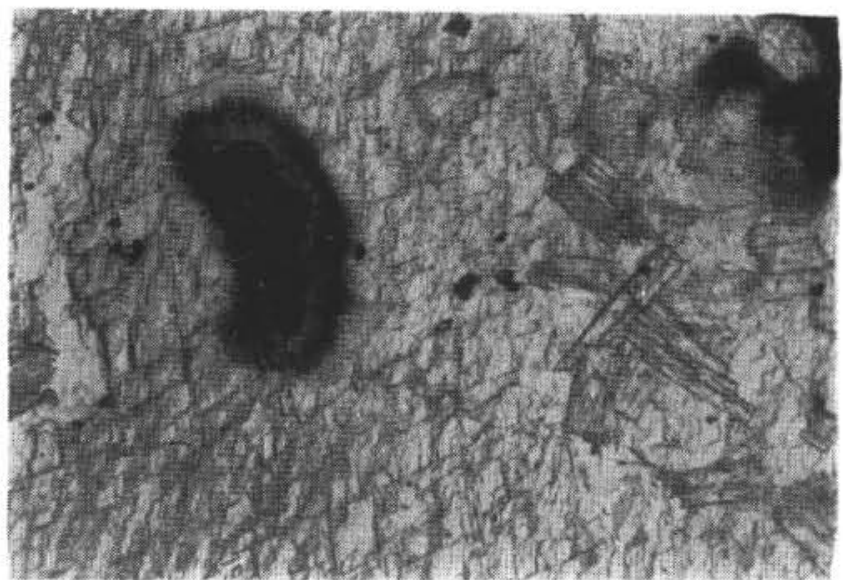

Figure 28. Dark patch consists of Fe-Mn oxide with celadonite rim. Zeolite replaces calcite on the right side of photomicrograph (field of view is $1.0 \mathrm{~mm}$ ). (Same vein as in Fig. 29.)

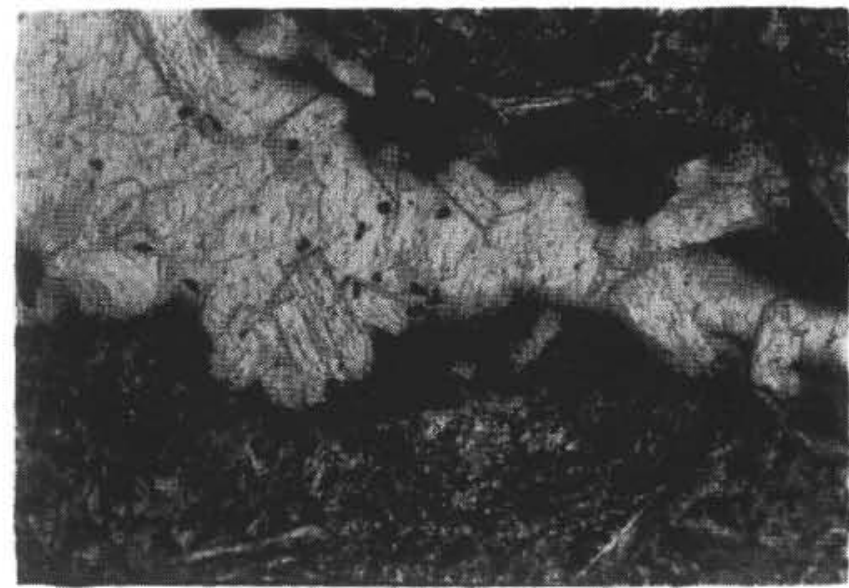

Figure 29. Zoned secondary-mineral vein at 462-60-1, 55-59 cm. Outer part of vein is celadonite (dark), and inner part is calcite. Both minerals are replaced by zeolite (anhedral) (field of view is $3.0 \mathrm{~mm})$. 
According to Korzhinsky's (1957) theory, in agreement with our observations of vein mineral assemblages, acidic alteration is characterized by relative immobile "acidic" elements, such as $\mathrm{Si}, \mathrm{Ti}, \mathrm{Al}$, and $\mathrm{Fe}^{+3}$, and highly mobile $\mathrm{Na}, \mathrm{K}, \mathrm{Ca}, \mathrm{Mg}$, and $\mathrm{Fe}^{+2}$. In processes of alkali alteration, the opposite is true, with the possible exception of $\mathrm{Ti}$ and $\mathrm{Fe}^{+3}$, which are commonly rather refractory in either case. Thus, the chemical composition of the primary magma may be greatly modified by either acidic or alkaline open-system hydrothermal alteration.

Octahedral magnetite is found in contraction cracks of some of the thick sills drilled during Leg 61 (two systems of fractures with dips of about 30 and $60^{\circ}$ ). This mineral appears to be high-temperature infilling, and the cracks within which it is found are cut by all of the other types of veins described previously. These veins are analogous to late-magmatic pneumatolitic ore veins found in many thick sills on continents. Another notable feature of the Leg 61 sills is the presence of euhedral microphenocrysts of magnetite.

The last type of alteration observed in the Leg 61 sills is autometasomatic amphibolitization and biotitization. The phenomenon is well understood and requires no further comment. These are high-temperature phases in the Leg 61 sills; they appear to be Ti-rich, on the basis of their optical properties.

In summary, the following sequence of metasomatic alteration by acid and alkaline solutions can be expected:

1) Late-magmatic phase:

a) Neutral to slightly alkaline stage: Ti-hornblende + Ti-biotite + magnetite veins.

2) Post-magmatic phase:

a) Early alkaline stage: zeolite, calcite.

b) early acidic stage: aluminous chlorite.

c) Late alkaline to neutral stage: $\mathrm{Fe}$ - and $\mathrm{Mg}$-rich clay minerals.

d) Late acidic stage: pyrite, opal, and alkali-alumina-rich clay minerals.

It should be noted that only the acidic and alkalic alteration stages (near veins at Hole 462, 462A) may have resulted in large-scale remobilization of major elements such as $\mathrm{Ca}, \mathrm{Mg}, \mathrm{Fe}, \mathrm{Na}$, and $\mathrm{K}$ with associated modification of initial elemental abundances and ratios.

\section{Basalt Chemistry}

Because as discussed above, alteration has been important in the Leg 61 rocks, it is necessary to assess its importance quantitatively. At present, only LOI provides this capability. We have verified that most of our analyzed samples do not contain large amounts of zeolites, carbonates, and sulfides; thus, measured LOI is probably due almost entirely to water loss. Unfortunately, we do not yet know the oxidation state of iron in the rocks, so that our LOI determinations represent a minimum value. This is because all of the $\mathrm{Fe}^{+2}$ in rock is converted to $\mathrm{Fe}^{+3}$ during the analysis $\left(\mathrm{Fe}_{2} \mathrm{O}_{3} / \mathrm{FeO}=\right.$ 1.11). Nevertheless, we can use the LOI determinations as an index of alteration, because all rocks have been similarly affected, and the original $\mathrm{FeO} / \mathrm{Fe}_{2} \mathrm{O}_{3}$ of even the altered basalts does not vary over a very large range. Thus, the Leg 61 samples with total iron between 11 and 16 wt. $\%$ have corrected actual $\mathrm{H}_{2} \mathrm{O}+$ contents greater than 1.1 to 1.3 wt. \%, as shown in Tables 11 and 12 . Keeping this assumption in mind, we will attempt to determine the main petrochemical characteristics of the Nauru Basin volcanics (Tables 13 and 14).

Because of their high mobility, alkali elements are a very sensitive indicator of rock alteration. In the case of Holes 462 and $462 \mathrm{~A}$, we can use potassium values. Figure 30 shows that the primary $\mathrm{K}$ content of the fresh rocks is extremely low (note that most data plot at the extreme left of the diagram). The $\mathrm{K}$ contents decrease to $10^{-3} \mathrm{wt} . \%$ at the bottom of the section. In the thick sill (Unit 12, 462A; and Unit 6, 462; Fig. 30), potassium abundances are slightly higher in the portions which contain residual granitic material. As with other tholeiitic magmas, this enrichment in potassium is associated with an increase of $\mathrm{SiO}_{2}$ (which does not lead to increased alkalinity) in the residual liquid. Our thin-section observations confirm that enrichment of $\mathrm{K}$ and $\mathrm{H}_{2} \mathrm{O}$ is found most commonly in glassy rocks which have primary water. This observation supports the idea (developed earlier) that the alteration processes which have affected the rocks of Leg 61 are primarily lowtemperature processes, and thus most primary mineral phases are fresh.

Potassium partitioning in the glassy rocks appears to follow three distinct patterns, as follows:

1) Hydration of glass, which does not mobilize potassium. Under such conditions the potassium contents of altered rocks are the same as for fresh rocks of the same type. This stage is characterized by the formation of alkali-deficient nontronite-group smectites, and is equivalent to the near-neutral stage of Korzhinskiy (1957). This type of alteration results only in the dilution of the rock components with water, and does not alter the rock's primary geochemical paragenesis.

2) The second type of alteration is usually multistage, and commonly results in the formation of veins near basalt contacts with sedimentary rocks. The observed assemblage of pyrite, chlorite, calcite, clay mineral, and quartz which is found in such veins is a testament to the acidic regime of this alteration type. In this case, the clay minerals which are stabilized are compositionally distinct from those formed under the conditions of alteration of the first type (as defined earlier).

3) Last, alteration of the third type is characterized by moderate water contents and enrichment of $\mathrm{K}$ in altered rocks. This is confirmed by the optical identification in rocks of this group of chlorite and a mineral which has the optical properties of hydromica. This type of alteration probably occurs at higher temperatures than the first and second types. The chemical composition of chlorite should allow us to estimate the temperature, which may have been as high as $400^{\circ} \mathrm{C}$. Figure 30 shows clearly that $\mathrm{H}_{2} \mathrm{O}$ enrichment is correlated with abundance of alteration products (by visual estimate) in the rocks.

Figure 31 shows that modification of $\mathrm{CaO}$ and $\mathrm{Al}_{2} \mathrm{O}_{3}$ contents (from initial values of $>11$ and $<14.2 \%$, 
Table 11. Chemical analyses of Igneous Rocks, Hole 462.

\begin{tabular}{|c|c|c|c|c|c|c|c|c|c|c|}
\hline $\begin{array}{l}\text { Unit } \\
\text { Sample }\end{array}$ & $\begin{array}{c}1 \\
60-1,90-92 \mathrm{~cm}\end{array}$ & $\begin{array}{c}3 \\
60-2,139-142 \mathrm{~cm}\end{array}$ & $\begin{array}{c}6 \\
61-2,53-56 \mathrm{~cm}\end{array}$ & $\begin{array}{c}7 \\
62-179-81 \mathrm{~cm}\end{array}$ & $\begin{array}{c}8 \\
62-1,127-129 \mathrm{~cm}\end{array}$ & $\begin{array}{c}10 \\
63-1,132-136 \mathrm{~cm}\end{array}$ & $\begin{array}{c}10 \\
63-2,79-83 \mathrm{~cm}\end{array}$ & $\begin{array}{c}10 \\
63-3,119-122 \mathrm{~cm}\end{array}$ & $\begin{array}{c}10 \\
64-1,4-6 \mathrm{~cm}\end{array}$ & $\begin{array}{c}11 \\
64-3,79-81 \mathrm{~cm}\end{array}$ \\
\hline $\mathrm{SiO}_{2}$ & 48.38 & 49.65 & 48.65 & 48.93 & 50.19 & 48.81 & 48.85 & 49.07 & 49.45 & 49.33 \\
\hline $\mathrm{TiO}_{2}$ & 1.40 & 1.42 & 1.46 & 1.39 & 2.18 & 1.76 & 1.84 & 1.85 & 1.91 & 1.84 \\
\hline $\mathrm{Al}_{2} \mathrm{O}_{3}$ & 15.01 & 15.37 & 14.33 & 13.56 & 16.24 & 14.38 & 14.82 & 15.08 & 15.53 & 14.78 \\
\hline $\mathrm{FeO} \cdot$ & 9.47 & 10.36 & 11.94 & 12.33 & 11.66 & 12.09 & 12.14 & 11.73 & 10.78 & 11.75 \\
\hline $\mathrm{MnO}$ & 0.14 & 0.15 & 0.20 & 0.21 & 0.29 & 0.20 & 0.18 & 0.23 & 0.30 & 0.23 \\
\hline $\mathrm{MgO}$ & 7.34 & 7.86 & 7.32 & 6.61 & 6.52 & 7.56 & 7.80 & 7.19 & 7.52 & 7.64 \\
\hline $\begin{array}{l}\mathrm{CaO} \\
\mathrm{Na}_{2} \mathrm{O}\end{array}$ & 11.02 & 11.40 & 11.72 & 11.53 & 7.30 & 11.08 & 10.21 & 10.25 & 10.05 & - 8.97 \\
\hline $\mathrm{K}_{2} \mathrm{O}$ & 0.67 & 0.63 & 0.09 & 0.06 & 1.09 & 0.14 & 0.02 & 0.04 & 0.04 & 0.04 \\
\hline $\mathrm{P}_{2} \mathrm{O}_{5}$ & 0.22 & 0.25 & 0.22 & 0.22 & 0.24 & 0.25 & 0.26 & 0.25 & 0.22 & 0.22 \\
\hline Total & 93.65 & 97.09 & 95.93 & 94.84 & 95.71 & 96.27 & 96.12 & 95.69 & 95.80 & 94.80 \\
\hline $\mathrm{LOI}^{\mathrm{a}}$ & 7.38 & 4.96 & 0.85 & 0.70 & 2.59 & 1.28 & 1.96 & 1.50 & 1.27 & 2.03 \\
\hline $\mathrm{FeO} * / \mathrm{MgO}$ & 1.29 & 1.31 & 1.63 & 1.86 & 1.78 & 1.59 & 1.55 & 1.63 & 1.43 & 1.53 \\
\hline $\mathrm{CaO} / \mathrm{Al}_{2} \mathrm{O}_{3}$ & 0.73 & 0.74 & 0.81 & 0.85 & 0.45 & 0.77 & 0.69 & 0.68 & 0.65 & 0.60 \\
\hline $\mathrm{FeO} / / \mathrm{TiO}_{2}$ & 6.76 & 7.29 & 8.17 & 8.87 & 5.34 & 6.86 & 6.59 & 6.34 & 5.64 & 6.38 \\
\hline
\end{tabular}

${ }^{\text {a }}$ Heated to $110^{\circ}$ for 6 hours prior to determination of LOI; LOI $=$ loss on ignition at $1050^{\circ} \mathrm{C}$.

respectively) is noted in rocks with $\mathrm{H}_{2} \mathrm{O}$ contents greater than 1 to $1.5 \%$. Observed scatter in the data could be due to analytical error. The individual samples which constitute the various alteration groups are the same in this figure as in the others.

It is clear from the plot of LOI against $\mathrm{Fe} / \mathrm{Fe}+$ $\mathrm{Mg}$ (Fig. 32) that iron content shows a slight decrease in abundance with alteration. This tendency is more marked in the rocks of Hole 462 than in those of Hole $462 \mathrm{~A}$. In addition, it can be seen that, for fresh rocks, there is a general tendency for increase of $\mathrm{Fe} / \mathrm{Mg}$ from early to late magmatic phases. This increase is also obvious in the thick differentiated sills, such as Unit 12 of 462A (equivalent to Unit 6 of Hole 462).

It will be noted that two distinct patterns of chemical modification due to alteration are observed (Fig. 31). The first is characterized by depletion of $\mathrm{Ca}$ and enrichment of $\mathrm{K}$ and $\mathrm{Al}$. The second is characterized by enrichment of $\mathrm{K}$ and unmodified abundances of $\mathrm{Ca}$ and $\mathrm{Al}$. This has to do with the preservation or alteration of plagioclase. The first type is the result of deep hydrothermal alteration which affects glass, pyroxene, and plagioclase, whereas in the second type the latter mineral phases are not affected. In both types, aluminum is immobile and is concentrated by removal of more-mobile components from the rocks. This is clearly shown on the plot of $\mathrm{Fe} /(\mathrm{Fe}+\mathrm{Mg})$ against $\mathrm{Ca} / \mathrm{Al}$ (Fig. 33). Increases of $\mathrm{Ca} / \mathrm{Al}$ are characteristic of picritic magmatic tendencies, because pyroxene (high $\mathrm{Ca} / \mathrm{Al}$ ) takes the place of plagioclase (assuming that changes in $\mathrm{Ab} / \mathrm{An}$ of the plagioclase are negligible [20-30 mol \%]). A decrease in this ratio is indicative of more-leucocratic magma compositions, where the albite molecule (low $\mathrm{Ca} / \mathrm{Al}$ ) is enriched relative to pyroxene and anorthite. It can be seen (Fig. 33) that Units 1 and 5 of Hole 462 and Units 8 and 11 of Hole $462 \mathrm{~A}$ have been affected by hydrothermal alteration and are depleted in Ca.

The general tendency in magmatic evolutions, either because of deep-seated fractionation or local differentiation, is for late magmatic phases to be more leucocratic and more iron-rich.

Titanium is the most immobile element in the alteration processes under study; thus, it is of great value in understanding processes of magmatic differentiation of these rocks. The immobility of $\mathrm{TiO}_{2}$ is clearly shown in the plot of $\mathrm{TiO}_{2}$ against $\mathrm{Fe} /(\mathrm{Fe}+\mathrm{Mg}$ ) (Fig. 34). This plot effectively separates altered from fresh rocks: the altered rocks are displaced to apparently more-Mg-rich composition parallel to the $\mathrm{Fe} /(\mathrm{Fe}+\mathrm{Mg})$ axis, which is noted in comparing data for individual samples with average analyses for the same igneous unit.

According to their $\mathrm{TiO}_{2}$ variations (Fig. 34), the rocks of Holes 462 and $462 \mathrm{~A}$ can be divided into five groups arranged in an orderly progression from early to late magmatic phases. This pattern of $\mathrm{TiO}_{2}$ variation is widely observed in thick sills, and is well illustrated in Figure 23. Deviations from this pattern are the result of submarine (instead of continental) emplacement of these basalts. With submarine basalts, it is possible for sea-water penetration to cause quenching at any stage in the solidification of the lavas. Rock textures indicative of this process are observed both in the marginal zones and interiors of sills (e.g., 462A-28-2, 73-75 cm). These textures are characterized by up to 10 to $15 \%$ of interstitial glassy patches within coarser-grained rocks from the interior portions of the thick, 50-meter sills. Fine-grained portions of the same sill do not show these anomalous $\mathrm{TiO}_{2}$ contents. The slight scatter of $\mathrm{Fe} / \mathrm{Mg}$ within the various $\mathrm{TiO}_{2}$-content groups is due to secondary alteration, as well as high analytical error in the $\mathrm{MgO}$ determinations (by XRF method).

Assuming that $\mathrm{TiO}_{2}$ content of altered basalts is an accurate reflection of primary magma chemistry, it is clear that at least two stages of deep-seated evolution have occurred in the Nauru Basin magmas (Fig. 35). The earlier and presumably shallower eruptions are chemically homogeneous and have compositions typical of oceanic tholeiite from other regions of the Pacific, as well as the deep rift valleys of the Atlantic and Indian Oceans (Shcheka et al., 1968). However, the Nauru Basin basalts have extremely low potassium contents. At the Barremian/Cenomanian boundary, we observe an abrupt change of magma composition, as well as mode of emplacement. Above this boundary, the rocks are richer in $\mathrm{Fe}$ and $\mathrm{Ti}$ and are more leucocratic (according to the $\mathrm{Ca} / \mathrm{Al}$ criteria discussed before). In addition, the thick sills above this boundary display extreme local differentiation, leading to the production of residual granitic melt. The rocks above the boundary are also more coarse-grained, suggesting emplacement 
Table 11. (Continued).

\begin{tabular}{|c|c|c|c|c|c|c|c|c|c|}
\hline 11 & 11 & 11 & 11 & 11 & 4 & 4 & 11 & 11 & 11 \\
\hline $64-4,74-76 \mathrm{~cm}$ & $65-1,27-30 \mathrm{~cm}$ & $65-2,23-26 \mathrm{~cm}$ & $66-1,19-21 \mathrm{~cm}$ & $66-4,12-14 \mathrm{~cm}$ & $67-2,90-94 \mathrm{~cm}$ & $68-1,73-75 \mathrm{~cm}$ & $68-2,37-39 \mathrm{~cm}$ & $68-2,49-51 \mathrm{~cm}$ & $69-1,36-38 \mathrm{~cm}$ \\
\hline 49.71 & 49.44 & 49.03 & 49.57 & 49.48 & 50.13 & 49.77 & 50.16 & 49.18 & 48.33 \\
\hline 1.64 & 1.66 & 1.65 & 1.64 & 1.64 & 1.65 & 1.85 & 1.92 & 1.61 & 2.13 \\
\hline 13.59 & 13.60 & 13.22 & 13.36 & 13.64 & 13.32 & 12.96 & 12.70 & 13.22 & 12.01 \\
\hline 12.82 & 12.61 & 12.90 & 12.64 & 12.31 & 12.59 & 13.80 & 14.33 & 12.77 & 16.79 \\
\hline 0.21 & 0.21 & 0.21 & 0.20 & 0.21 & 0.21 & 0.23 & 0.22 & 0.22 & 0.20 \\
\hline 7.61 & 6.95 & 6.90 & 6.72 & 7.24 & 7.41 & 6.55 & 6.30 & 7.01 & 5.47 \\
\hline 11.16 & 11.03 & 10.91 & 11.14 & 11.08 & 11.37 & 10.52 & 10.17 & 11.10 & 9.32 \\
\hline 0.09 & 0.05 & 0.03 & 0.04 & 0.07 & 0.14 & 0.08 & 0.14 & 0.12 & 0.27 \\
\hline 0.25 & 0.24 & 0.23 & 0.22 & 0.21 & 0.25 & 0.25 & 0.25 & 0.26 & 0.25 \\
\hline 97.08 & 95.79 & 95.35 & 95.53 & 95.88 & 97.07 & 96.01 & 96.19 & 95.49 & 94.77 \\
\hline 0.36 & 0.41 & 0.52 & 0.21 & 0.74 & 0.48 & 0.43 & 0.36 & 0.28 & 0.36 \\
\hline 1.68 & 1.81 & 1.86 & 1.88 & 1.70 & 1.69 & 2.10 & 2.27 & 1.82 & 3.06 \\
\hline 0.82 & 0.81 & 0.82 & 0.83 & 0.81 & 0.85 & 0.81 & 0.80 & 0.83 & 0.77 \\
\hline 7.81 & 7.59 & 7.81 & 7.70 & 7.50 & 7.63 & 7.45 & 7.46 & 7.93 & 7.88 \\
\hline
\end{tabular}

below a thicker section of sediments compared to the ones below the boundary.

These changes are characteristic of the waning stages of many volcanic episodes in continental regions, where they are indicative of decreased temperature within deep magma chambers. This leads to volatile enrichment, and enrichment of light elements and $\mathrm{Ti}$ (leucocratic tendencies). This pattern is commonly observed in recently stabilized geological provinces, and we can speculate that vertical movements of the Nauru Basin may have played a part in producing the observed magmatic evolution.

There appear to be two main possible explanations for the sequence of rocks which are found in the Nauru Basin. The first is that the lava found below 730 meters sub-bottom represents typical oceanic tholeiite basement of Barremian or older age. This suggestion is supported by the chemical composition and homogeneity of the magma, and especially by the anomalously low $\mathrm{K}$ contents $\left(0.001-0.01\right.$ wt. $\left.\% \mathrm{~K}_{2} \mathrm{O}\right)$ in both fresh and altered samples. This casts doubt on the presence of a thick layer of $\mathrm{K}$-bearing sediments and limestones below the lower basalts, because the presence of such sediments would lead to high-K alteration in the overlying basalts, as observed in the upper parts of Holes 462 and $462 \mathrm{~A}$. In addition, it is commonly observed on the continents that basic rocks overlying K-rich sedimentary rocks and limestones are enriched in potassium. The reasons for this potassium enrichment are not yet well understood. It could be due to the presence of sialic rocks in the zone of magma generation, to volatile transfer of alkalies, or a number of other processes. Whatever the cause, it is clear that such processes occur. Unfortunately, it is difficult to assess the potential importance of any of these mechanisms to oceanic rocks, because the thickness of the oceanic basement is not well known.

It is also possible that the chemistry of the Nauru Basin igneous complex has been the result of unique conditions of crystallization. For the most part, the Nauru Basin basalts differ from typical pillow basalts.
For example, the Nauru Basin basalts have mostly holocrystalline textures. Even thin sills $(25-35 \mathrm{~cm})$ which have thick $(5-10 \mathrm{~cm})$ glassy margins, grade quickly $(2-5$ $\mathrm{cm}$ ) into holcrystalline, microdoleritic-textured rock. In addition, in compound sills, the marginal zones lack glass and are composed of fine-grained rock with equigranular texture. Micro-injections of magma from the interiors of igneous bodies into the chilled marginal zones is commonly observed. All these observations are consistent with the idea that these basalts crystallized under a crust of water-saturated overlying rocks.

The Nauru Basin sill complex is similar in many respects to the flood basalt or trap complexes of continental platforms (e.g., the Sikerion; Godlevskiy, 1959), where giant eruptions (sometimes up to $1-3 \mathrm{~km}$ thick) culminate in the formation of layered igneous bodies in the more-stable regions. These layered complexes commonly include thin granitic layers. It is possible that despite the great thickness of many of the Nauru Basin sills, the development of rhythmic layering has been impeded by free access of water to the crystallizing sill.

However, the composition of continental trap basalt is different from that of the Nauru Basin basalts. This probably can be attributed to the fact that continental and oceanic crust differ greatly in composition. Therefore, it is possible that eruptions similar in all their fundamental characteristics to continental trap basalts may be present in oceanic regions of high spreading rate, but this fundamental similarity between the oceanic and continental occurrences may be obscured by chemical differences which result from the different crustal type.

An ancient continental anolog of the Nauru complex may be the Precambrian diabase basement complex of the Fenno-Scandian supracrustal massif. This complex is more than $5 \mathrm{~km}$ thick. Rocks from this complex as deep as the Conrad seismic discontinuity have been recovered, and it is composed of homogeneous diabase almost identical chemically to the Nauru Basin diabases.

Finally, despite strong doubt that the Nauru sill complex is underlain by sediments, it is clear that the com- 


\begin{tabular}{|c|c|c|c|c|c|c|c|c|c|c|c|c|c|c|c|c|}
\hline $\begin{array}{l}\text { Unit } \\
\text { Sample }\end{array}$ & $\begin{array}{c}1 \\
14-2,4-7 \mathrm{~cm}\end{array}$ & $\begin{array}{c}\mathrm{t} \\
14-2,29-32 \mathrm{~cm}\end{array}$ & $\frac{1}{15-1,117-120 \mathrm{~cm}}$ & $\frac{2}{16-1,129-131 \mathrm{~cm}}$ & $\stackrel{2}{2}$ & $\begin{array}{c}2 \\
17-2,36-38 \mathrm{~cm}\end{array}$ & $\begin{array}{c}3 \\
18-1,128-130 \mathrm{~cm}\end{array}$ & $\begin{array}{c}3 \\
18-2,48-50 \mathrm{~cm}\end{array}$ & $19-1 .{ }^{3}-12 \mathrm{~cm}$ & $\begin{array}{c}3 \\
19-1,52-54 \mathrm{~cm}\end{array}$ & $\underset{19-2,90-92 \mathrm{~cm}}{4}$ & $\begin{array}{c}4 \\
20-1,72-74 \mathrm{~cm}\end{array}$ & $\begin{array}{c}5 \\
20-1,144-146 \mathrm{~cm}\end{array}$ & $\begin{array}{c}5 \\
20-2,93-95 \mathrm{~cm}\end{array}$ & $\stackrel{5}{21-1,40-42 \mathrm{~cm}}$ & $\stackrel{5}{21-1,93-96 \mathrm{~cm}}$ \\
\hline & 52.23 & 52.97 & & & & & & & & & & & & & & \\
\hline & 1.90 & 1.51 & 1.45 & $\begin{array}{r}49.97 \\
1.40\end{array}$ & $\begin{array}{r}0.09 \\
1.39\end{array}$ & $\begin{array}{r}49.20 \\
1.40\end{array}$ & $\begin{array}{l}0.98 \\
1.37\end{array}$ & 1.34 & 2.01 & 1.40 & $\begin{array}{r}49.68 \\
1.38\end{array}$ & $\begin{array}{r}99.03 \\
1.63\end{array}$ & 1.64 & 1.64 & 1.66 & 1.74 \\
\hline $\mathrm{A}_{2} \mathrm{O}_{3}$ & 18.56 & 15.40 & 13.83 & 14.06 & 13.92 & 13.97 & 14.03 & 13.87 & 16.27 & 13.96 & 13.67 & 13.52 & 13.32 & 13.53 & 13.66 & 14.00 \\
\hline $\mathrm{FeO} \mathrm{O}^{\circ}$ & 9.07 & 9.99 & 12.20 & 12.11 & 11.97 & 11.77 & 12.23 & 12.49 & 11.83 & 12.65 & 12.72 & 13.46 & 13.04 & 13.82 & 13.33 & 13.02 \\
\hline $\begin{array}{l}\mathrm{MnO} \\
\mathrm{MgO}\end{array}$ & $\begin{array}{l}0.07 \\
2.84\end{array}$ & & $\begin{array}{l}0.20 \\
6.63\end{array}$ & $\begin{array}{l}0.20 \\
6.84\end{array}$ & $\begin{array}{l}0.19 \\
6.99\end{array}$ & $\begin{array}{l}0.19 \\
7.30\end{array}$ & $\begin{array}{l}0.19 \\
6.82\end{array}$ & $\begin{array}{l}0.38 \\
7.02\end{array}$ & $\begin{array}{l}0.38 \\
7.16\end{array}$ & $\begin{array}{l}0.23 \\
7.18\end{array}$ & $\begin{array}{l}0.20 \\
6.87\end{array}$ & $\begin{array}{l}0.28 \\
6.90\end{array}$ & $\begin{array}{l}0.11 \\
6.63\end{array}$ & 6.99 & 7.55 & \\
\hline $\mathrm{CoO}$ & 7.65 & $\begin{array}{l}6.34 \\
10.10\end{array}$ & $\begin{array}{l}8.03 \\
11.83\end{array}$ & 12.11 & $\begin{array}{l}6.99 \\
11.85\end{array}$ & $\begin{array}{l}7.30 \\
11.81\end{array}$ & $\begin{array}{l}6.82 \\
11.77\end{array}$ & $\begin{array}{l}71.62 \\
11.08\end{array}$ & 7.88 & $\begin{array}{l}7.18 \\
11.80\end{array}$ & $\begin{array}{l}61.87 \\
11.89\end{array}$ & $\begin{array}{l}0.40 \\
11.42\end{array}$ & $\begin{array}{l}6.03 \\
11.32\end{array}$ & 11.42 & 11.12 & $\begin{array}{l}.0 .32 \\
10.76\end{array}$ \\
\hline $\mathrm{K}_{2} \mathrm{O}$ & 2.85 & 0.83 & 0.06 & 0.06 & 0.02 & 0.06 & 0.08 & 0.05 & 0.41 & 0.04 & 0.03 & 0.02 & 0.11 & 0.14 & 0.13 & 0.12 \\
\hline $\mathrm{P}_{2} \mathrm{O}_{5}$ & 0.21 & 022 & 0.21 & 0.23 & 0.22 & 0.22 & 0.20 & 0.20 & 0.23 & 0.20 & 0.19 & 0.23 & 0.26 & & & \\
\hline Total & 95.10 & 97.34 & 96.96 & 96.55 & 96.17 & 95.57 & 96.68 & 97.04 & 95.06 & 97.03 & 9.51 & 96.58 & 95.30 & & & \\
\hline & 2.46 & 1.5 & 0.63 & 0 . & 0.71 & 0.79 & 0. & 0 . & 0.36 & 0.66 & 0.6 & 0.07 & 0.00 & 0.07 & 0.45 & 1.69 \\
\hline $\mathrm{FeO} * / /$ & 3. & 1. & 1. & 1 & $\begin{array}{l}1.71 \\
0.85\end{array}$ & $\begin{array}{l}1.61 \\
0.84\end{array}$ & $\begin{array}{l}1.79 \\
0.83\end{array}$ & $\begin{array}{l}1.77 \\
0.84\end{array}$ & $\begin{array}{l}1.65 \\
0.48\end{array}$ & $\begin{array}{l}1.76 \\
084\end{array}$ & $\begin{array}{l}1.85 \\
0887\end{array}$ & $\begin{array}{l}1.95 \\
0.94\end{array}$ & $\begin{array}{l}1.96 \\
0.85\end{array}$ & $\begin{array}{l}1.97 \\
084\end{array}$ & $\begin{array}{l}1.76 \\
0.81\end{array}$ & $\begin{array}{l}2.06 \\
0.76\end{array}$ \\
\hline 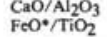 & $\begin{array}{l}0.41 \\
4.77\end{array}$ & $\begin{array}{l}0.065 \\
6.61\end{array}$ & $\begin{array}{l}0.45 \\
8.41\end{array}$ & $\begin{array}{l}0.86 \\
{ }_{8}^{0.65}\end{array}$ & $\begin{array}{l}0.85 \\
8.61\end{array}$ & $\begin{array}{l}0.84 \\
8.40\end{array}$ & $\begin{array}{l}0.833 \\
8.92\end{array}$ & $\begin{array}{l}0.84 \\
9.32\end{array}$ & $\begin{array}{l}0.48 \\
5.88\end{array}$ & $\begin{array}{l}0.84 \\
9.03\end{array}$ & $\begin{array}{l}0.87 \\
9.21\end{array}$ & $\begin{array}{l}0.284 \\
8.25\end{array}$ & $\begin{array}{l}0.885 \\
7.95 \\
7.95\end{array}$ & $\begin{array}{l}0.84 \\
8.42\end{array}$ & $\begin{array}{l}0.081 \\
8.03\end{array}$ & $\begin{array}{l}0.76 \\
7.48\end{array}$ \\
\hline
\end{tabular}

a Heated to $110^{\circ} \mathrm{C}$ for 6 hours prior to determination of LOI; LOI $=$ Loss on ignition at $1050^{\circ} \mathrm{C}$.

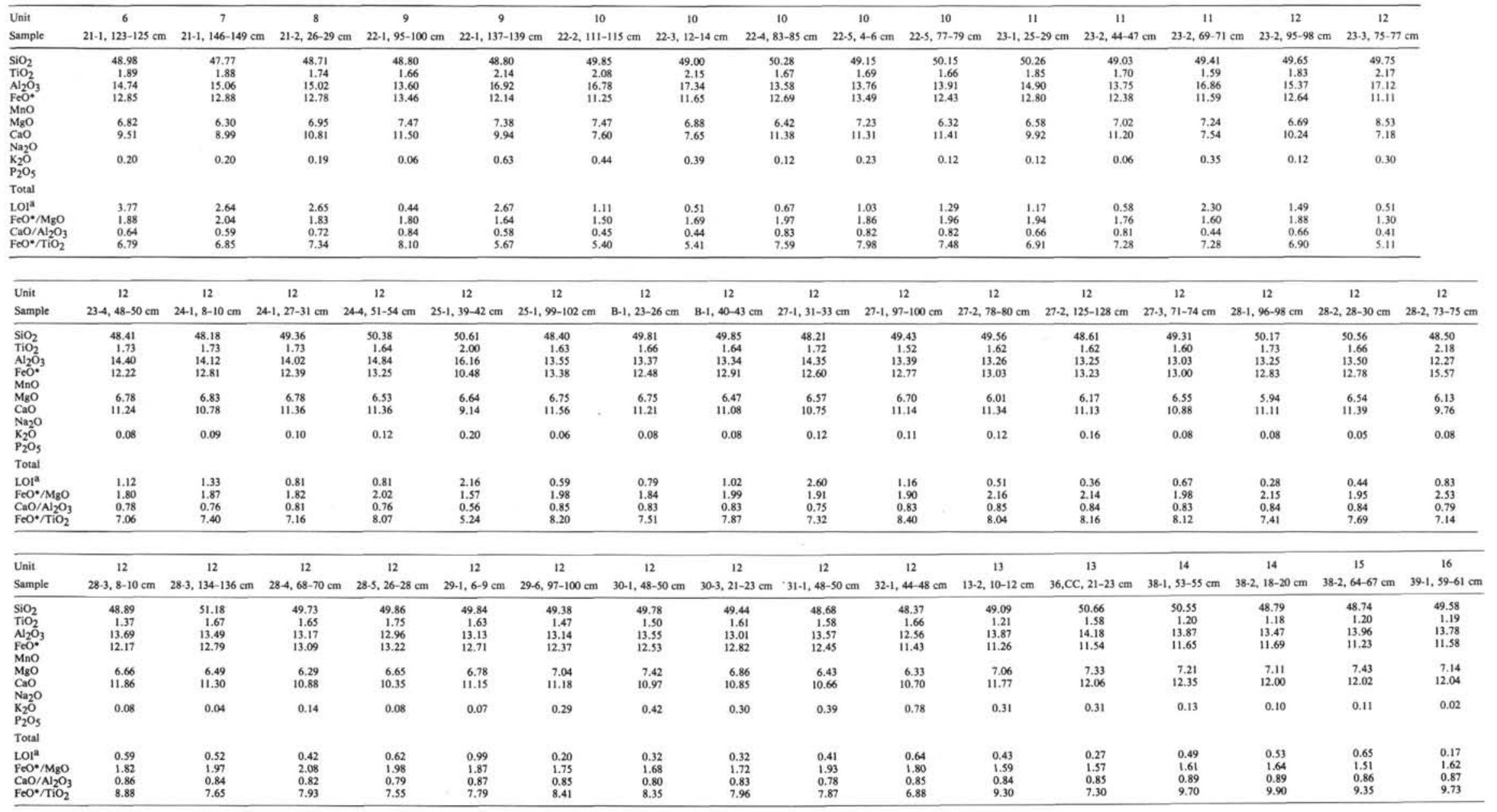




\begin{tabular}{|c|c|c|c|c|c|c|c|c|c|c|c|c|c|c|c|c|}
\hline $\begin{array}{l}\text { Unit } \\
\text { Sample }\end{array}$ & $\begin{array}{c}16 \\
39-2,97-99 \mathrm{~cm}\end{array}$ & $\begin{array}{c}16 \\
39-3,76-78 \mathrm{~cm}\end{array}$ & $\begin{array}{c}16 \\
39-3,142-144 \mathrm{~cm}\end{array}$ & $\begin{array}{c}17 \\
39-4,4-6 \mathrm{~cm}\end{array}$ & $\begin{array}{c}18 \\
39-4,67-70 \mathrm{~cm}\end{array}$ & $\begin{array}{c}18 \\
39-5,98-100 \mathrm{~cm}\end{array}$ & $\begin{array}{c}20 \\
40-1,86-90 \mathrm{~cm}\end{array}$ & $\begin{array}{c}21 \\
40-2,23-25 \mathrm{~cm}\end{array}$ & $\begin{array}{c}21 \\
40-2,41-43 \mathrm{~cm}\end{array}$ & $\begin{array}{c}21 \\
41-1,10-12 \mathrm{~cm}\end{array}$ & $\begin{array}{c}21 \\
41-1,130-133 \mathrm{~cm}\end{array}$ & $\begin{array}{c}21 \\
41-2,110-112 \mathrm{~cm}\end{array}$ & $\begin{array}{c}21 \\
41-4,80-82 \mathrm{~cm}\end{array}$ & $\begin{array}{c}21 \\
41-5,78-80 \mathrm{~cm}\end{array}$ & $\begin{array}{c}21 \\
41-6,100-102 \mathrm{~cm}\end{array}$ & $\begin{array}{c}21 \\
41-7,106-109 \mathrm{~cm}\end{array}$ \\
\hline $\mathrm{SiO}_{2}$ & 48.96 & 48.18 & 48.83 & 48.88 & 48.33 & 48.43 & 49.07 & 49.15 & 49.74 & 50.09 & 49.84 & 50.41 & 50.04 & 50.28 & 50.46 & 49.46 \\
\hline & 1.22 & 1.23 & 1.19 & 1.20 & 1.21 & 1.22 & 1.24 & 1.26 & 1.23 & 1.23 & 1.22 & 1.21 & 1.21 & 1.19 & 1.22 & 0.72 \\
\hline $\begin{array}{l}\mathrm{Al}_{2} \mathrm{O}_{3} \\
\mathrm{FeO} \cdot\end{array}$ & $\begin{array}{l}13.96 \\
11.52\end{array}$ & $\begin{array}{l}13.84 \\
10.92\end{array}$ & $\begin{array}{l}14.16 \\
11.16\end{array}$ & $\begin{array}{l}13.86 \\
11.60\end{array}$ & $\begin{array}{l}14.31 \\
11.26\end{array}$ & $\begin{array}{l}13.98 \\
10.79\end{array}$ & 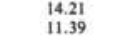 & $\begin{array}{l}14.04 \\
11.25\end{array}$ & $\begin{array}{l}13.76 \\
11.88\end{array}$ & $\begin{array}{l}13.56 \\
12.15\end{array}$ & $\begin{array}{l}13.67 \\
12.16\end{array}$ & $\begin{array}{l}{ }_{13.62}^{13.70} \\
11\end{array}$ & $\begin{array}{l}13.64 \\
11.09\end{array}$ & $\begin{array}{l}13.91 \\
11.04\end{array}$ & 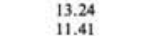 & $\begin{array}{l}11.60 \\
14.20\end{array}$ \\
\hline $\begin{array}{l}\mathrm{MnO} \\
\mathrm{MgO}\end{array}$ & 7,22 & 7.33 & 709 & 7.39 & 7,78 & 710 & 7,48 & 6.59 & 6.73 & 7.17 & 7.24 & 6.79 & 7.36 & 7.35 & 7.03 & \\
\hline $\begin{array}{ll}\mathrm{CaO} \\
\mathrm{CoO}\end{array}$ & 12.09 & 12.41 & 12.21 & 12.23 & 12.36 & 12.10 & 12.30 & 12.15 & 12.41 & 12.04 & 12.36 & 11.97 & 12.04 & 12.08 & 11.83 & 5.05 \\
\hline $\begin{array}{l}\mathrm{Na}_{2} \mathrm{O} \\
\mathrm{K}_{2} \mathrm{O} \\
\mathrm{P}_{2} \mathrm{O}_{5}\end{array}$ & 0.12 & 0.03 & 0.04 & 0.09 & 0.06 & 0.08 & 0.10 & 0.25 & 0.04 & 0.04 & 0.04 & 0.02 & 0.05 & 0.09 & 0.32 & 0.56 \\
\hline Total & & & & & & & & & & & & & & & & \\
\hline $\mathrm{LOI}^{\mathrm{a}}$ & 0.50 & 0.59 & 0.92 & 0.30 & 0.36 & 0.33 & 0.58 & 2.18 & 2.25 & 0.71 & 0.59 & 0.67 & 0.70 & 1.93 & 1.03 & 4.92 \\
\hline $\begin{array}{l}\mathrm{FeO} / \mathrm{MgO}^{2} / \mathrm{AlO}^{2}\end{array}$ & $\begin{array}{l}1.59 \\
086\end{array}$ & $\begin{array}{l}1.48 \\
089\end{array}$ & 0.86 & $\begin{array}{l}1.56 \\
0.88\end{array}$ & $\begin{array}{l}1.44 \\
0.86\end{array}$ & $\begin{array}{l}1.31 \\
0.86\end{array}$ & $\begin{array}{l}1.52 \\
0.86\end{array}$ & $\begin{array}{l}1.52 \\
0.86\end{array}$ & $\begin{array}{l}1.76 \\
0.90\end{array}$ & $\begin{array}{l}1.69 \\
0.88\end{array}$ & $\begin{array}{l}1.69 \\
0.00\end{array}$ & $\begin{array}{l}1.72 \\
0.88\end{array}$ & $\begin{array}{l}1.50 \\
0.88\end{array}$ & $\begin{array}{l}1.50 \\
0.87\end{array}$ & 1.62 & 1.25 \\
\hline $\begin{array}{l}\mathrm{CaOO} \mathrm{A}_{2} \mathrm{O}_{3} \\
\mathrm{FeO} \cdot 1 / \mathrm{O}^{2}\end{array}$ & $\begin{array}{l}0.866 \\
9.44\end{array}$ & $\begin{array}{l}0.89 \\
8.87\end{array}$ & $\begin{array}{l}0.86 \\
9.37\end{array}$ & $\begin{array}{l}0.88 \\
9.66\end{array}$ & $\begin{array}{l}0.86 \\
9.30\end{array}$ & $\begin{array}{l}0.86 \\
8.84\end{array}$ & $\begin{array}{l}0.86 \\
9.18\end{array}$ & $\begin{array}{l}0.869 \\
8.92\end{array}$ & $\begin{array}{l}0.900 \\
9.66\end{array}$ & $\begin{array}{l}0.88 \\
9.87\end{array}$ & $\begin{array}{l}0.90 \\
9.96\end{array}$ & $\begin{array}{l}0.888 \\
9.66\end{array}$ & $\begin{array}{l}0.88 \\
9.16\end{array}$ & $\begin{array}{l}0.87 \\
9.27\end{array}$ & $\begin{array}{l}0.89 \\
9.35\end{array}$ & $\begin{array}{r}0.43 \\
19.72\end{array}$ \\
\hline
\end{tabular}

\begin{tabular}{|c|c|c|c|c|c|c|c|c|c|c|c|c|c|c|c|c|}
\hline $\begin{array}{l}\text { Unit } \\
\text { Sample }\end{array}$ & $\begin{array}{c}21 \\
41-7,96-99 \mathrm{~cm}\end{array}$ & $\begin{array}{c}\text { Sediment } \\
41-7,106-109 \mathrm{~cm}\end{array}$ & $\begin{array}{c}22 \\
44-1,128-130 \mathrm{~cm}\end{array}$ & $\begin{array}{c}22 \\
44-2,7-9 \mathrm{~cm}\end{array}$ & $\begin{array}{c}22 \\
45-1,7-8 \mathrm{~cm}\end{array}$ & $\begin{array}{c}22 \\
45-2,14-17 \mathrm{~cm}\end{array}$ & $\begin{array}{c}22 \\
45-3,30-52 \mathrm{~cm}\end{array}$ & $\begin{array}{c}22 \\
45-5,92-94 \mathrm{~cm}\end{array}$ & $\begin{array}{c}22 \\
46-2,61-63 \mathrm{~cm}\end{array}$ & $\begin{array}{c}22 \\
46-2,72-74 \mathrm{~cm}\end{array}$ & $\begin{array}{c}22 \\
46-2,122-124 \mathrm{~cm}\end{array}$ & $\begin{array}{c}22 \\
46-4,118-120 \mathrm{~cm}\end{array}$ & $\begin{array}{c}23 \\
47-1,88-89 \mathrm{~cm}\end{array}$ & $\begin{array}{c}23 \\
47-2,98-100 \mathrm{~cm}\end{array}$ & $\begin{array}{c}23 \\
48-1,100-102 \mathrm{~cm}\end{array}$ & $\begin{array}{c}23 \\
48-4,52-54 \mathrm{~cm}\end{array}$ \\
\hline $\begin{array}{l}\mathrm{SiO}_{2} \\
\mathrm{TiO}_{2} \\
\mathrm{~A}_{2} \mathrm{O}_{3} \\
\mathrm{FeO}^{2}\end{array}$ & $\begin{array}{l}49.80 \\
1.23 \\
13.83 \\
11.67\end{array}$ & $\begin{array}{r}49.46 \\
0.72 \\
11.60 \\
14.19\end{array}$ & $\begin{array}{r}49.05 \\
0.91 \\
13.83 \\
10.69\end{array}$ & $\begin{array}{l}50.85 \\
0.96 \\
13.47 \\
12.86\end{array}$ & $\begin{array}{l}50.73 \\
0.93 \\
14.30 \\
10.73\end{array}$ & $\begin{array}{r}49.26 \\
0.95 \\
14.46 \\
11.02\end{array}$ & $\begin{array}{c}50.02 \\
0.93 \\
14.20 \\
10.70\end{array}$ & $\begin{array}{l}49.35 \\
0.94 \\
14.53 \\
10.80\end{array}$ & $\begin{array}{r}48.93 \\
0.93 \\
14.50 \\
10.15\end{array}$ & $\begin{array}{r}50.39 \\
0.90 \\
14.31 \\
10.88\end{array}$ & $\begin{array}{r}49.50 \\
0.85 \\
14.37 \\
9.92\end{array}$ & $\begin{array}{l}49.09 \\
0.90 \\
14.10 \\
10.75\end{array}$ & $\begin{array}{r}49.26 \\
0.92 \\
14.15 \\
10.92\end{array}$ & $\begin{array}{r}49.02 \\
0.90 \\
14.04 \\
10.79\end{array}$ & $\begin{array}{r}48.53 \\
0.90 \\
14.04 \\
10.68\end{array}$ & $\begin{array}{l}48.70 \\
0.90 \\
13.83 \\
10.90\end{array}$ \\
\hline $\begin{array}{l}\mathrm{MgO} \\
\mathrm{MaO} \\
\mathrm{CaO}\end{array}$ & $\begin{array}{r}6.59 \\
11.75\end{array}$ & $\begin{array}{r}11.32 \\
5.05\end{array}$ & $\begin{array}{r}7.92 \\
12.62\end{array}$ & $\begin{array}{l}7.93 \\
6.66\end{array}$ & $\begin{array}{r}7.67 \\
12.38\end{array}$ & $\begin{array}{r}7.70 \\
12.83\end{array}$ & $\begin{array}{r}7.56 \\
12.50\end{array}$ & $\begin{array}{r}7.47 \\
12.98\end{array}$ & $\begin{array}{r}7.96 \\
12.57\end{array}$ & $\begin{array}{l}8.07 \\
12.55\end{array}$ & $\begin{array}{r}6.88 \\
11.82\end{array}$ & $\begin{array}{r}7.38 \\
12.65\end{array}$ & $\begin{array}{r}7.79 \\
11.81\end{array}$ & $\begin{array}{l}8.01 \\
12.69\end{array}$ & $\begin{array}{l}7.97 \\
12.77\end{array}$ & $\begin{array}{l}8.15 \\
12.57\end{array}$ \\
\hline $\begin{array}{l}\mathrm{N}_{22} \mathrm{O} \\
\mathrm{P}_{2} \mathrm{O}_{5} \\
\text { Total }\end{array}$ & 0.04 & 0.56 & 0.02 & 0.74 & 0.01 & 0.03 & 0.008 & 0.043 & 0.006 & 0.007 & 0.008 & 0.003 & 0.137 & 0.003 & 0.018 & 0.04 \\
\hline $\begin{array}{l}\mathrm{LO}^{\mathrm{a}} \\
\mathrm{Fec} \\
\mathrm{CaO} / \mathrm{MgOO}^{\circ} / \mathrm{Ag}_{2} \mathrm{O}_{3}\end{array}$ & $\begin{array}{l}0.51 \\
1.77 \\
0.85 \\
0.98\end{array}$ & $\begin{array}{r}4.92 \\
1.25 \\
0.43\end{array}$ & $\begin{array}{l}0.32 \\
1.34 \\
0.91\end{array}$ & $\begin{array}{r}7.46 \\
1.62 \\
0.49\end{array}$ & $\begin{array}{l}0.81 \\
1.39 \\
0.86\end{array}$ & $\begin{array}{l}0.26 \\
1.43 \\
0.88\end{array}$ & $\begin{array}{l}0.66 \\
1.41 \\
0.88\end{array}$ & $\begin{array}{l}0.23 \\
1.44 \\
0.89\end{array}$ & $\begin{array}{l}0.62 \\
1.27 \\
0.86\end{array}$ & $\begin{array}{r}0.96 \\
1.34 \\
0.87\end{array}$ & $\begin{array}{l}0.65 \\
1.44 \\
0.82\end{array}$ & $\begin{array}{l}0.85 \\
1.45 \\
0.89\end{array}$ & $\begin{array}{r}1.97 \\
1.40 \\
0.83\end{array}$ & $\begin{array}{l}0.81 \\
1.34 \\
0.90 \\
0.90\end{array}$ & $\begin{array}{r}0.93 \\
1.34 \\
0.90\end{array}$ & $\begin{array}{r}0.81 \\
1.33 \\
0.90\end{array}$ \\
\hline $\mathrm{FeO} * \pi \mathrm{TO}_{2}$ & 9.48 & $\begin{array}{l}19.73 \\
19.70\end{array}$ & 11.74 & 13.39 & $\begin{array}{l}11.50 \\
11.53\end{array}$ & $\begin{array}{l}0.88 \\
1.60\end{array}$ & $\begin{array}{l}11.58 \\
11.50\end{array}$ & $\begin{array}{l}0.89 \\
11.48\end{array}$ & $\begin{array}{l}0.96 \\
10.91\end{array}$ & $\begin{array}{l}12.08 \\
12.08\end{array}$ & $\begin{array}{l}11.67 \\
11.67\end{array}$ & 11.94 & 11.86 & 11.98 & 11.86 & 12.11 \\
\hline
\end{tabular}

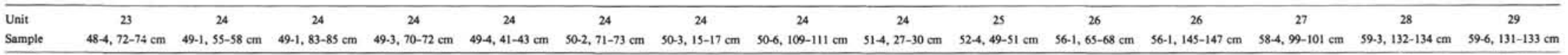

\begin{tabular}{|c|c|c|c|c|c|c|c|c|c|c|c|c|c|c|c|}
\hline $\begin{array}{l}\mathrm{SiO}_{2} \\
\mathrm{TiO}_{2} \\
\mathrm{Al}_{2} \mathrm{O}_{3} \\
\mathrm{FeO}^{*} \\
\mathrm{MnO}\end{array}$ & $\begin{array}{r}48.38 \\
0.92 \\
1.422 \\
10.87\end{array}$ & $\begin{array}{r}48.80 \\
0.93 \\
14.07 \\
10.85\end{array}$ & $\begin{array}{l}49.08 \\
0.92 \\
13.93 \\
10.84\end{array}$ & $\begin{array}{r}49.28 \\
0.95 \\
13.82 \\
11.01\end{array}$ & $\begin{array}{l}48.70 \\
0.95 \\
13.91 \\
10.76\end{array}$ & $\begin{array}{r}48.48 \\
0.93 \\
13.77 \\
10.91\end{array}$ & $\begin{array}{l}49.54 \\
0.99 \\
12.27 \\
11.26\end{array}$ & $\begin{array}{l}49.27 \\
0.91 \\
13.85 \\
10.95\end{array}$ & $\begin{array}{l}48.89 \\
0.99 \\
13.91 \\
11.23\end{array}$ & $\begin{array}{r}48.84 \\
0.98 \\
13.83 \\
11.11\end{array}$ & $\begin{array}{l}49.53 \\
0.95 \\
13.65 \\
10.92\end{array}$ & $\begin{array}{l}49.98 \\
14.99 \\
14.08 \\
10.71\end{array}$ & $\begin{array}{r}48.57 \\
1.02 \\
14.06 \\
10.96\end{array}$ & $\begin{array}{l}49.54 \\
0.98 \\
13.51 \\
11.13\end{array}$ & $\begin{array}{r}50.18 \\
1.01 \\
13.70 \\
11.43\end{array}$ \\
\hline $\begin{array}{l}\mathrm{MgO} \\
\mathrm{MgO} \\
\mathrm{CaO}\end{array}$ & $\begin{array}{r}8.36 \\
13.05\end{array}$ & $\begin{array}{r}7.70 \\
12.59\end{array}$ & $\begin{array}{r}7.96 \\
12.37\end{array}$ & $\begin{array}{c}8.08 \\
12.32\end{array}$ & $\begin{array}{r}8.43 \\
12.44\end{array}$ & $\begin{array}{r}8.51 \\
12.17\end{array}$ & $\begin{array}{r}8.81 \\
11.33\end{array}$ & $\begin{array}{r}8.56 \\
12.15\end{array}$ & $\begin{array}{r}7.81 \\
11.72\end{array}$ & $\begin{array}{r}7.30 \\
12.55\end{array}$ & $\begin{array}{r}7.58 \\
12.41\end{array}$ & $\begin{array}{r}7.98 \\
12.57\end{array}$ & $\begin{array}{r}7.87 \\
12.62\end{array}$ & $\begin{array}{r}7.98 \\
12.22\end{array}$ & $\begin{array}{r}7.78 \\
12.60\end{array}$ \\
\hline $\begin{array}{l}\mathrm{N}_{2} \mathrm{O} \\
\mathrm{P}_{2} \mathrm{O}_{5} \\
\text { Total }\end{array}$ & 0.033 & 0.049 & 0.019 & 0.002 & 0.007 & 0.021 & 0.416 & 0.015 & 0.118 & 0.001 & 0.004 & 0.004 & 0.004 & 0.016 & 0.029 \\
\hline 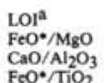 & $\begin{array}{l}0.69 \\
1.30 \\
1.91 \\
0.91 \\
11.81\end{array}$ & $\begin{array}{l}0.14 \\
1.40 \\
0.89 \\
11.66\end{array}$ & $\begin{array}{l}0.85 \\
1.36 \\
0.88 \\
0.178\end{array}$ & $\begin{array}{r}0.98 \\
1.36 \\
0.89 \\
0.158\end{array}$ & $\begin{array}{c}1.20 \\
1.27 \\
0.89 \\
0.132\end{array}$ & $\begin{array}{c}0.93 \\
1.28 \\
0.88 \\
11.73\end{array}$ & $\begin{array}{l}1.08 \\
1.27 \\
0.88 \\
0.137\end{array}$ & $\begin{array}{c}2.32 \\
1.27 \\
0.87 \\
1.03\end{array}$ & $\begin{array}{r}1.16 \\
1.43 \\
0.84 \\
1.34\end{array}$ & $\begin{array}{l}0.26 \\
1.52 \\
0.990 \\
1.133\end{array}$ & $\begin{array}{r}1.25 \\
1.44 \\
0.90 \\
0.149\end{array}$ & $\begin{array}{r}0.31 \\
1.34 \\
0.89 \\
10.81\end{array}$ & $\begin{array}{c}0.51 \\
1.39 \\
0.89 \\
0.974\end{array}$ & $\begin{array}{r}0.82 \\
1.39 \\
0.90 \\
0.1 .39\end{array}$ & $\begin{array}{l}0.29 \\
1.46 \\
0.91 \\
11.31\end{array}$ \\
\hline
\end{tabular}

\begin{tabular}{|c|c|c|c|c|c|c|c|c|c|c|c|c|c|c|c|c|}
\hline $\begin{array}{l}\text { Unit } \\
\text { Sample }\end{array}$ & $\begin{array}{c}29 \\
60-3,99-101 \mathrm{~cm}\end{array}$ & $\begin{array}{c}29 \\
61-1,30-32 \mathrm{~cm}\end{array}$ & $\begin{array}{c}30 \\
61-2,115-118 \mathrm{~cm}\end{array}$ & $\begin{array}{c}30 \\
62-2,10-12 \mathrm{~cm}\end{array}$ & $\begin{array}{c}30 \\
63-1,36-38 \mathrm{~cm}\end{array}$ & $\begin{array}{c}31 \\
44-2,53-59 \mathrm{~cm}\end{array}$ & $\begin{array}{c}31 \\
44-2,106-109 \mathrm{~cm}\end{array}$ & $\begin{array}{c}32 \\
67-6,124-126 \mathrm{~cm}\end{array}$ & $\begin{array}{c}31 \\
64-4,30-32 \mathrm{~cm}\end{array}$ & $\begin{array}{c}32 \\
65-2,60-62 \mathrm{~cm}\end{array}$ & $\begin{array}{c}32 \\
66-7,33-35 \mathrm{~cm}\end{array}$ & $\begin{array}{c}33 \\
68-4,116-118 \mathrm{~cm}\end{array}$ & $\begin{array}{c}34 \text { Sed. } \\
70-1,2-4 \mathrm{~cm}\end{array}$ & $\begin{array}{c}34 \\
72-2,53-55 \mathrm{~cm}\end{array}$ & $\begin{array}{c}35 \\
72-2,124-126 \mathrm{~cm}\end{array}$ & $\begin{array}{c}35 \\
744,72-74 \mathrm{~cm}\end{array}$ \\
\hline $\begin{array}{l}\mathrm{SiO}_{2} \\
\mathrm{TiO}_{2} \\
\mathrm{Al}_{2} \mathrm{O}_{3} \\
\mathrm{FeOO}^{\circ}\end{array}$ & $\begin{array}{l}47.90 \\
1.01 \\
13.70 \\
10.87\end{array}$ & $\begin{array}{l}47.49 \\
1.01 \\
13.64 \\
11.11\end{array}$ & $\begin{array}{l}47.81 \\
1.03 \\
13.87 \\
10.98\end{array}$ & $\begin{array}{r}50.18 \\
1.04 \\
14.07 \\
10.99\end{array}$ & $\begin{array}{r}49.19 \\
1.33 \\
9.02 \\
13.93\end{array}$ & $\begin{array}{l}49.70 \\
0.93 \\
14.53 \\
10.99\end{array}$ & $\begin{array}{c}49.66 \\
0.94 \\
14.47 \\
10.72\end{array}$ & $\begin{array}{r}49.67 \\
0.99 \\
13.81 \\
11.29\end{array}$ & $\begin{array}{l}49.18 \\
1.02 \\
14.23 \\
10.76\end{array}$ & $\begin{array}{l}50.11 \\
1.01 \\
14.02 \\
11.25\end{array}$ & $\begin{array}{l}50.42 \\
1.01 \\
14.04 \\
11.90\end{array}$ & $\begin{array}{l}49.05 \\
1.01 \\
13.94 \\
10.99\end{array}$ & $\begin{array}{l}90.69 \\
0.02 \\
1.25 \\
1.84\end{array}$ & $\begin{array}{c}49.78 \\
1.05 \\
13.74 \\
11.55\end{array}$ & $\begin{array}{r}49.25 \\
1.06 \\
13.79 \\
10.68\end{array}$ & $\begin{array}{l}50.54 \\
1.02 \\
14.02 \\
11.63\end{array}$ \\
\hline $\begin{array}{l}\mathrm{MnO} \\
\mathrm{M} 8 \mathrm{O} \\
\mathrm{CaO} \\
\text { Nano }\end{array}$ & $\begin{array}{r}7.35 \\
12.51\end{array}$ & $\begin{array}{r}7.35 \\
12.36\end{array}$ & $\begin{array}{r}7.55 \\
12.36\end{array}$ & $\begin{array}{r}7.55 \\
12.88\end{array}$ & $\begin{array}{l}10.46 \\
10.90\end{array}$ & $\begin{array}{r}7.69 \\
12.59\end{array}$ & $\begin{array}{r}7.32 \\
12.97\end{array}$ & $\begin{array}{r}8.10 \\
12.34\end{array}$ & $\begin{array}{l}7.47 \\
12.56\end{array}$ & $\begin{array}{r}7.67 \\
12.25\end{array}$ & $\begin{array}{r}8.04 \\
12.38\end{array}$ & $\begin{array}{r}7.46 \\
12.36\end{array}$ & $\begin{array}{l}1.01 \\
2.17\end{array}$ & $\begin{array}{r}7.93 \\
12.15\end{array}$ & $\begin{array}{r}7.58 \\
12.40\end{array}$ & $\begin{array}{c}7.82 \\
12.63\end{array}$ \\
\hline $\begin{array}{l}\mathrm{K}_{2} \mathrm{O} \\
\mathrm{P}_{2} \mathrm{O}_{5} \\
\text { Total }\end{array}$ & 0.021 & 0.096 & 0.042 & 0.018 & 0.074 & 0.05 & 0.03 & 0.045 & 0.11 & 0.074 & 0.093 & 0.034 & 1.73 & 0.09 & 0.09 & 0.04 \\
\hline 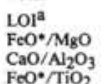 & $\begin{array}{l}0.36 \\
1.47 \\
0.91 \\
10.76\end{array}$ & $\begin{array}{l}0.63 \\
1.51 \\
0.90 \\
1100\end{array}$ & $\begin{array}{r}0.01 \\
1.45 \\
0.89 \\
10.66\end{array}$ & $\begin{array}{l}1.01 \\
1.45 \\
0.91 \\
10.56\end{array}$ & $\begin{array}{r}2.08 \\
1.33 \\
1.20 \\
10.47\end{array}$ & $\begin{array}{r}0.22 \\
1.42 \\
0.86 \\
11.81\end{array}$ & $\begin{array}{l}0.62 \\
1.46 \\
0.89 \\
0.89\end{array}$ & $\begin{array}{r}0.70 \\
1.39 \\
0.89 \\
11.40\end{array}$ & $\begin{array}{r}0.31 \\
1.44 \\
0.88 \\
10.54\end{array}$ & $\begin{array}{l}0.55 \\
1.46 \\
0.87 \\
11.02\end{array}$ & $\begin{array}{r}0.47 \\
1.48 \\
0.88 \\
11.78\end{array}$ & $\begin{array}{r}1.07 \\
1.47 \\
0.88 \\
10.88\end{array}$ & $\begin{array}{l}2.95 \\
1.82 \\
1.73 \\
9.2\end{array}$ & $\begin{array}{r}0.93 \\
1.45 \\
0.88 \\
1100\end{array}$ & $\begin{array}{l}0.76 \\
1.40 \\
0.89 \\
10.07\end{array}$ & $\begin{array}{r}0.90 \\
1.48 \\
0.90 \\
11.40\end{array}$ \\
\hline
\end{tabular}


Table 13. Average chemical compositions of volcanic units, Site 462.

\begin{tabular}{|c|c|c|c|c|c|c|c|c|c|c|c|c|c|c|c|c|c|}
\hline Unit & 1 & 2 & 4 & 5 & 6 & 6 & 1 & 2 & 3 & 4 & 6 & 7 & 8 & 9 & 10 & 11 & 12 \\
\hline \multicolumn{18}{|c|}{ Hole 462 Hole $462 A$} \\
\hline Sample & 2 & 1 & 1 & 7 & 7 & 3 & 1 & 3 & 4 & 3 & 1 & 1 & 2 & 1 & 3 & 4 & 25 \\
\hline $\mathrm{SiO}_{2}$ & 49.01 & 48.65 & 48.93 & 49.04 & 49.51 & 49.42 & 50.96 & 49.75 & 50.21 & 49.73 & 50.30 & 50.33 & 48.84 & 48.80 & 49.86 & 49.34 & 49.38 \\
\hline $\mathrm{TiO}_{2}$ & 1.41 & 1.46 & 1.39 & 1.84 & 1.64 & 1.97 & 1.45 & 1.40 & 1.37 & 1.64 & 1.66 & 1.74 & 1.82 & 1.66 & 1.67 & 1.78 & 1.63 \\
\hline $\mathrm{Al}_{2} \mathrm{O}_{3}$ & 15.19 & 14.33 & 13.56 & 14.95 & 13.42 & 12.56 & 13.83 & 13.98 & 13.88 & 13.45 & 13.66 & 14.00 & 14.88 & 13.60 & 13.75 & 14.60 & 13.52 \\
\hline $\mathrm{Fe}_{2} \mathrm{O}_{3}$ & 11.05 & 13.27 & 13.70 & 12.99 & 14.07 & 16.65 & 13.56 & 13.28 & 13.93 & 14.93 & 14.82 & 14.47 & 14.24 & 14.96 & 14.30 & 13.91 & 14.12 \\
\hline $\mathrm{MnO}$ & 0.14 & 0.21 & 0.21 & 0.23 & 0.21 & 0.22 & 0.20 & 0.20 & 0.21 & 0.20 & & & & & & & \\
\hline $\mathrm{MgO}$ & 7.60 & 7.32 & 6.61 & 7.52 & 7.12 & 6.11 & 6.63 & 7.04 & 6.97 & 6.84 & 7.55 & 6.32 & 6.89 & 7.47 & 6.65 & 6.77 & 6.59 \\
\hline $\mathrm{CaO}$ & 11.21 & 11.72 & 11.53 & 10.40 & 11.11 & 10.00 & 11.83 & 11.92 & 11.79 & 11.39 & 11.11 & 10.76 & 10.16 & 11.50 & 11.37 & 10.89 & 11.06 \\
\hline \multicolumn{18}{|l|}{$\mathrm{Na}_{2} \mathrm{O}$} \\
\hline $\begin{array}{l}\mathrm{K}_{2} \mathrm{O} \\
\mathrm{P}_{2} \mathrm{O}_{5}\end{array}$ & 0.65 & 0.09 & 0.06 & 0.06 & 0.08 & 0.16 & 0.06 & 0.05 & 0.06 & 0.09 & 0.13 & 0.12 & 0.20 & 0.06 & 0.25 & 0.09 & 0.13 \\
\hline $\mathrm{P}_{2} \mathrm{O}_{5}$ & 0.23 & 0.22 & 0.24 & 0.24 & 0.24 & 0.25 & 0.21 & 0.22 & 0.20 & 0.25 & & & & & & & \\
\hline Total & 96.10 & 96.84 & 95.79 & 98.77 & 97.83 & 97.72 & 98.73 & 97.84 & 98.62 & 98.37 & 99.11 & 97.74 & 97.02 & 98.05 & 97.85 & 97.38 & 97.05 \\
\hline LOI & 6.17 & 0.85 & 0.70 & 1.50 & 0.43 & 0.38 & 0.63 & 0.64 & 0.71 & 0.04 & 0.45 & 1.69 & 3.21 & 0.44 & & 1.09 & 0.71 \\
\hline \multirow{2}{*}{$\begin{array}{l}\mathrm{Fe} /(\mathrm{Fe}+\mathrm{Mg})(\text { atomic } \%) \\
\mathrm{CaO} / \mathrm{Al}_{2} \mathrm{O}_{3} \\
\mathrm{FeO} / / \mathrm{TiO}_{2}\end{array}$} & 42.3 & 47.7 & 51.2 & 46.7 & 49.8 & 57.8 & 50.1 & 48.7 & 50.3 & 52.5 & 49.8 & 53.6 & 50.1 & 50.2 & 51.9 & 50.9 & 51.8 \\
\hline & 0.74 & 0.82 & 0.85 & 0.70 & 0.83 & 0.80 & 0.86 & 0.85 & 0.85 & 0.85 & 0.81 & 0.77 & 0.68 & 0.85 & 0.83 & 0.75 & 0.82 \\
\hline
\end{tabular}

All values from tables I-4, I-6.6(7) and 6(3)-primitive and differentiated microdolerites respectively.

plex is unique in the ocean (to our knowledge). Its discovery has important implications for the nature and evolution of oceanic crust.

\section{Part C (by H. Tokuyama)}

Two main rock types have been recovered from Hole 462A: (1) dolerite sills, and (2) basalts with pillow-like structure. Figure 21 shows the lithologic units distinguished in the sequence.

Basalt of type 2 was found only below Core 44 , and further sedimentary layers thicker than 1 meter were not recovered below Core 44. Above Core 44, 21 dolerite sill units have been defined; these are separated by chilled margins from either sediment layers or other sill units. Below Core 44, four dolerite sill units and eight pillowbasalt units have been defined, mainly separated by chilled margins from one another.

The chemical compositions of fresh type 1 basalts from Hole $462 \mathrm{~A}$ are plotted in terms of the ratio $\mathrm{FeO}^{*} / \mathrm{MgO}$ versus $\mathrm{TiO}_{2}$ (Fig. 36). On this figure, two groups may be identified on the basis of differences in $\mathrm{TiO}_{2}$ content: a low $\mathrm{TiO}_{2}$ type (0.9-1.04 wt. \%), and a high $\mathrm{TiO}_{2}$ type (1.18-1.85 wt. \%); the former type was recovered below Core 44 , and the latter type above Core 44.

That the glassy chilled margins of the high- $\mathrm{TiO}_{2}$ type are characterized by microphenocrysts of clinopyroxene (but rare olivine) and that of the low- $\mathrm{TiO}_{2}$ types by microphenocrysts of olivine (but rare clinopyroxene) is reflected by the difference in $\mathrm{Fe} * / \mathrm{MgO}$ ratios of the two types.

There are no large changes in chemical composition within individual low- $\mathrm{TiO}_{2}$ sills, so that fractionation, which might be caused by minor removal of phenocryst phases during cooling, is very low. On the other hand, there are moderate changes in chemical composition of the high- $\mathrm{TiO}_{2}$ sills, particularly in the granophyre schlieren. Thus, it is concluded that the difference between the high- $\mathrm{TiO}_{2}$ type and the low- $\mathrm{TiO}_{2}$ type is due to different magma types. From the bulk chemical composition and petrographic evidence, the type 2 basalt is seen to be the low- $\mathrm{TiO}_{2}$ type. However, the pillow structure which these basalts exhibit is not normal; therefore they might not have been intrusive, but eruptive. Above this type 2 rock, thick sediment layers (mainly hyaloclastic) were recovered; the high- $\mathrm{TiO}_{2}$, type 1 rock commonly is intruded into sediment. From this evidence, it is inferred that there was a significant time gap between low- $\mathrm{TiO}_{2}$ type and high- $\mathrm{TiO}_{2}$ volcanism. The earlier volcanism was characterized by alternating eruptions of the atypical pillow lava, and intrusions of sills with low $\mathrm{TiO}_{2}$ content; the later volcanic episode was characterized by intrusion of high- $\mathrm{TiO}_{2}$ sills within sediment. From the paleontological data, it might be inferred that the age of the earlier volcanism is late Barremian, and that of the later volcanism Cenomanian.

In comparison with the FAMOUS glass data (Bryan and Moore, 1977) and possible off-ridge intrusive or extrusive samples from this area (Bryan et al., 1976), both types 1 and 2 are depleted in $\mathrm{TiO}_{2}$. From a petrologic viewpoint, both types 1 and 2 may have been produced by olivine fractionation of abyssal tholeiite in the upper mantle; however, the lithologic sequence of igneous rocks at Site 462 is very different from sequences formed at oceanic ridges. Therefore, the volcanic sequence at Site 462 might have formed by a process unlike that operating at oceanic ridges. Normal oceanic basement which would have formed, according to this model, at a typical ocean ridge could therefore directly underlie the sill-pillow complex.

An interesting aspect of Nauru Basin volcanism is that the above-described off-ridge volcanism produced intrusives rather than central volcanoes. One hypothesis that could account for this is that ridge-crest-related volcanism ceased from late Barremian to Cenomanian time in this region. If this cessation occurred, the lack of a normal tensional regime, like that prevailing at typical ridge crests, might have impeded access of magma to the surface. Instead of rising to the surface, the magma would have cooled and partly crystallized in the upper mantle. Small leaks from this chamber then might have ascended to the surface and produced the pillow-and-sill 
Table 13. (Continued).

\begin{tabular}{|c|c|c|c|c|c|c|c|c|c|c|c|c|c|c|c|c|c|c|c|c|}
\hline 13 & 14 & 15 & 16 & 17 & 18 & 19 & 20 & 21 & 22 & 23 & 24 & 25 & 26 & 27 & 28 & 29 & 30 & 31 & 32 & 33 \\
\hline 1 & 2 & 1 & 1 & 1 & 4 & 2 & 1 & 7 & 9 & 7 & 4 & 1 & 2 & 1 & 2 & 2 & 3 & 1 & 3 & 1 \\
\hline 50.66 & 49.67 & 48.74 & 49.58 & 48.18 & 48.62 & 49.11 & 49.32 & 50.13 & 49.59 & 48.82 & 48.93 & 48.84 & 49.75 & 48.57 & 49.86 & 47.70 & 49.69 & 49.18 & 50.07 & 49.05 \\
\hline 1.58 & 1.19 & 1.20 & 1.19 & 1.23 & 1.20 & 1.25 & 1.24 & 1.21 & 0.92 & 0.91 & 0.95 & 0.98 & 0.97 & 1.02 & 1.0 & 1.01 & 1.03 & 1.02 & 1.00 & 1.01 \\
\hline 14.18 & 13.67 & 13.96 & 13.78 & 13.84 & 14.08 & 14.12 & 14.00 & 13.64 & 14.29 & 14.04 & 13.83 & 13.83 & 13.87 & 14.06 & 13.60 & 13.67 & 13.97 & 14.23 & 13.97 & 13.94 \\
\hline 12.83 & 12.97 & 12.48 & 12.87 & 12.14 & 12.45 & 12.58 & 12.79 & 12.89 & 11.81 & 12.04 & 12.13 & 12.35 & 12.02 & 12.81 & 12.51 & 12.20 & 12.21 & 11.96 & 12.76 & 12.22 \\
\hline 7.33 & 7.16 & 7.43 & 7.14 & 7.33 & 7.40 & 7.14 & 6.73 & 7.07 & 7.62 & 7.99 & 8.40 & 7.30 & 7.78 & 7.87 & 7.88 & 7.35 & 7.55 & 7.47 & 7.94 & 7.46 \\
\hline 12.06 & 12.18 & 12.02 & 12.04 & 12.41 & 12.23 & 12.23 & 12.32 & 12.01 & 12.54 & 12.67 & 12.27 & 12.55 & 12.48 & 12.62 & 12.41 & 12.43 & 12.62 & 12.56 & 12.32 & 12.36 \\
\hline 0.31 & 0.12 & 0.11 & 0.02 & 0.03 & 0.07 & 0.17 & 0.13 & 0.04 & 0.02 & 0.03 & 0.01 & 0.00 & 0.00 & 0.00 & 0.02 & 0.06 & 0.03 & 0.11 & 0.07 & 0.03 \\
\hline 98.95 & 96.99 & 95.88 & 96.62 & 95.16 & 96.10 & 96.50 & 96.73 & 96.99 & 96.79 & 96.50 & 96.52 & 95.85 & 96.87 & 96.32 & 97.28 & 94.42 & 97.10 & 96.53 & 98.13 & 96.07 \\
\hline 0.27 & 0.41 & 0.65 & 0.17 & & 0.36 & 1.37 & 1.67 & 0.91 & 0.60 & 0.71 & 1.35 & 0.26 & 0.78 & 0.51 & 0.52 & 0.50 & 0.50 & 0.31 & 0.57 & \\
\hline 47.0 & 47.7 & 45.8 & 47.7 & 45.5 & 46.2 & 47.5 & 48.2 & 48.4 & 43.9 & 43.0 & 42.2 & 45.8 & 43.8 & 43.7 & 44.7 & 45.4 & 44.9 & $\begin{array}{c}44.6 \\
0.88\end{array}$ & $\begin{array}{c}44.8 \\
0.88\end{array}$ & $\begin{array}{r}96.07 \\
0.88\end{array}$ \\
\hline 0.85 & 0.89 & 0.86 & 0.87 & 0.90 & 0.87 & 0.87 & 0.88 & 0.88 & 0.88 & 0.90 & 0.89 & 0.91 & 0.90 & 0.90 & 0.91 & 0.91 & 0.90 & 0.88 & 0.88 & \\
\hline
\end{tabular}

Table 14. Average chemical compositions of two types of altered basalts.

\begin{tabular}{lccc}
\hline & \multicolumn{1}{c}{ Unit } & $\mathrm{I}(8)$ & $\mathrm{II}(10)$ \\
\hline & Sample & $(462+462 \mathrm{~A})$ & $(462+462 \mathrm{~A})$ \\
\hline $\mathrm{SiO}_{2}$ & 49.79 & 50.26 \\
$\mathrm{TiO}_{2}$ & 1.21 & 1.60 \\
$\mathrm{Al}_{2} \mathrm{O}_{3}$ & 14.23 & 15.15 \\
$\mathrm{Fe}_{2} \mathrm{O}_{3}$ & 11.94 & 13.22 \\
$\mathrm{Mn}$ & 0.14 & 0.30 \\
$\mathrm{MgO}$ & 7.47 & 7.23 \\
$\mathrm{CaO}$ & 11.42 & 7.25 \\
$\mathrm{Na}_{2} \mathrm{O}$ & & \\
$\mathrm{K}_{2} \mathrm{O}$ & 0.42 & 0.95 \\
$\mathrm{P}_{2} \mathrm{O}_{5}$ & 0.23 & 0.23 \\
$\mathrm{Total}$ & 96.85 & 96.19 \\
$\mathrm{LOI}$ & 2.72 & 3.30 \\
$\mathrm{Fe} /(\mathrm{Fe}+\mathrm{Mg})$ (atomic \%) & 44.5 & 49.4 \\
$\mathrm{CaO} / \mathrm{Al}_{2} \mathrm{O}_{3}$ & 0.80 & 0.48 \\
$\mathrm{FeO} / \mathrm{TiO}$ & & \\
\hline
\end{tabular}

complex. Later, during Cenomanian time, the ridge might have become a typical active spreading center again, thus allowing magma to rise at the locus of renewed tension. By this time, however, the magma would have been fractionated, and the ridge crest would have been covered by some thickness of sediments. Therefore, this renewed volcanism would have been emplaced into the sediment as fractionated basalt sills.

\section{Part D (by K. Seifert, T. Vallier, and K. Windom)}

\section{Introduction}

Coring was resumed at Site $462 \mathrm{~A}$ at a sub-bottom depth of 953 meters on July 19, 1978. Between July 19 and $25,115.5$ meters of rock was penetrated to give a total hole depth of 1068.5 meters at Site 462A. Total core recovered from the 115.5 meters drilled was 60.20 meters, giving a recovery of $52 \%$, including both sediments and basalt. Less than 3 meters of sediment core was recovered, and approximately 112.5 meters of igneous rocks were drilled.

\section{Physical Characteristics of Igneous Units}

The recovered igneous rocks were divided into 11 units on the basis of grain-size variations. Available chemical and mineralogical data are insufficient to determine if these textural units represent genetically distinct units and to definitively distinguish between an intrusive or extrusive origin. The almost total absence of glass or indications of pillow structures suggests that the entire igneous section consists of intrusive sills, and the fine-grained texture of even the thicker units seems to indicate that intrusion occurred at very shallow depth. The 11 igneous units delineated in the post-July-19 drilling at Hole $462 \mathrm{~A}$ start with the continuation of Unit 35 (Figs. 21 and 22) and go into Unit 44. Some decrease in plagioclase relative to augite occurs near the bases of Units 35 and 37 . The fine-grained boundary layers between Units 41 and 42 and Units 42 and 43 contain several times more clay-mineral alteration than is found within the units.

\section{Petrography}

Preliminary studies of 27 thin-sections show variations in textures and compositions that are correlatable with cooling histories and alteration, rather than original magma compositions. The textures range from subophitic to intergranular, intersertal, and variolitic, and the mineralogical compositions show a wide range (Table 15).

Textures of coarser-grained rocks, generally from cooling-unit interiors, are subophitic and intergranular. As cooling unit boundaries are approached, the rocks become finer-grained and textures are intersertal and variolitic; these textures were observed together in thin sections of several rocks. Glass, now altered to smectite, occurs mostly in the interstices between grains. In those rocks having variolitic textures, the glass occurs both interstitially and as intergrowths with plagioclase and/or clinopyroxene in radiating varioles.

Microphenocrysts are common in the finer-grained rocks that have intersertal and variolitic textures. Most are clinopyroxene, olivine (pseudomorphed by smec- 


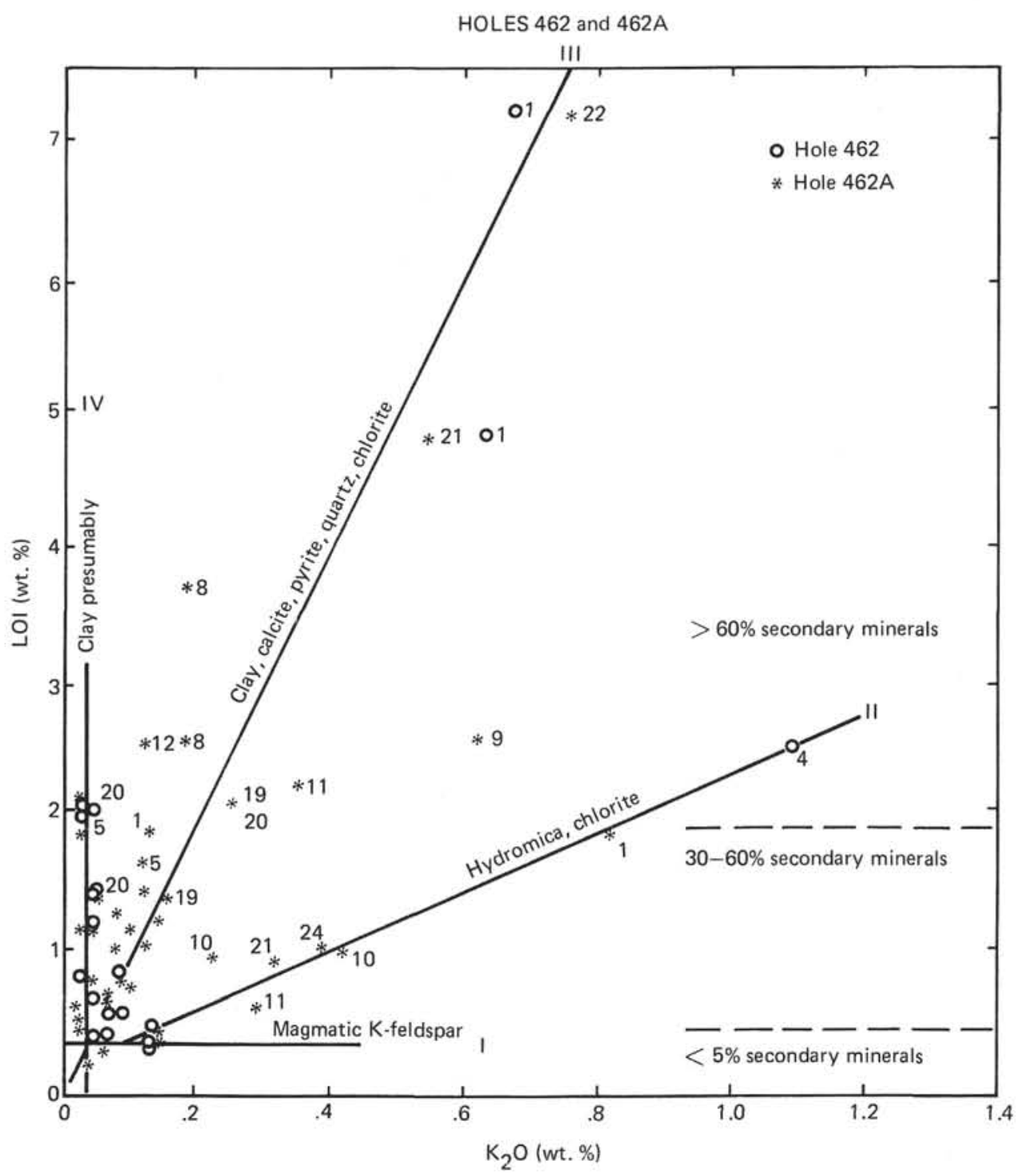

Figure 30. Correlation of $\mathrm{K}_{2} \mathrm{O}$ and LOI for various types of altered volcanic rocks. Figures near points are numbers of units.

tites), and plagioclase that range in longest diameter from about 0.2 to $0.5 \mathrm{~mm}$. Olivine microphenocrysts are particularly well developed, indicating their early crystallization. Some plagioclase microphenocrysts are zoned. Clinopyroxene (augite) microphenocrysts apparently crystallized at about the same time as the plagioclase microphenocrysts.

Primary phases of the basaltic rocks are plagioclase, clinopyroxene, olivine, titanomagnetite, and sideromelane. Both olivine and sideromelane are altered to smectite in nearly all studied thin-sections. Plagioclase contents range from 21 to $58 \%$ and average $44 \%$. Clinopyroxene (augite) contents range from 18 to $47 \%$. Titanomagnetite ranges from 2 to $14 \%$. Glass content originally ranged from 1 to $49 \%$ and averaged about $12 \%$, the amount varying with relative proximity to a coolingunit margin and thickness of the cooling unit.

The variations in composition are caused by cooling histories and resultant differentiation, mostly by crystal settling. Overall, the rocks probably are olivine tholei- ites, similar to those described from the upper part of Hole $462 \mathrm{~A}$ and in the adjacent pilot hole (Hole 462).

\section{Vein Minerals}

Fracturing is common in the basalts. Many of these fractures are filled with veins containing one or more of the minerals pyrite (and marcasite), zeolite, calcite, and a green clay-like mineral. Fracturing seems to be most intense in the finer-grained parts of the basalt, although it is by no means restricted to such areas.

Pyrite occurs both as cubes and as more-massive vein coatings. It is found in association with zeolite, calcite, and dark-green clay. Its occurrence appears to be confined to the veins. Some of the sulfide has the appearance of chalcopyrite, although slightly oxidized pyrite may give the same appearance. Shore-based chemical studies will resolve this question.

Calcite occurs as individual crystals and groups of crystals, and as very fine-grained veins. It is usually clear to white, but also occurs as light-pink veins. 


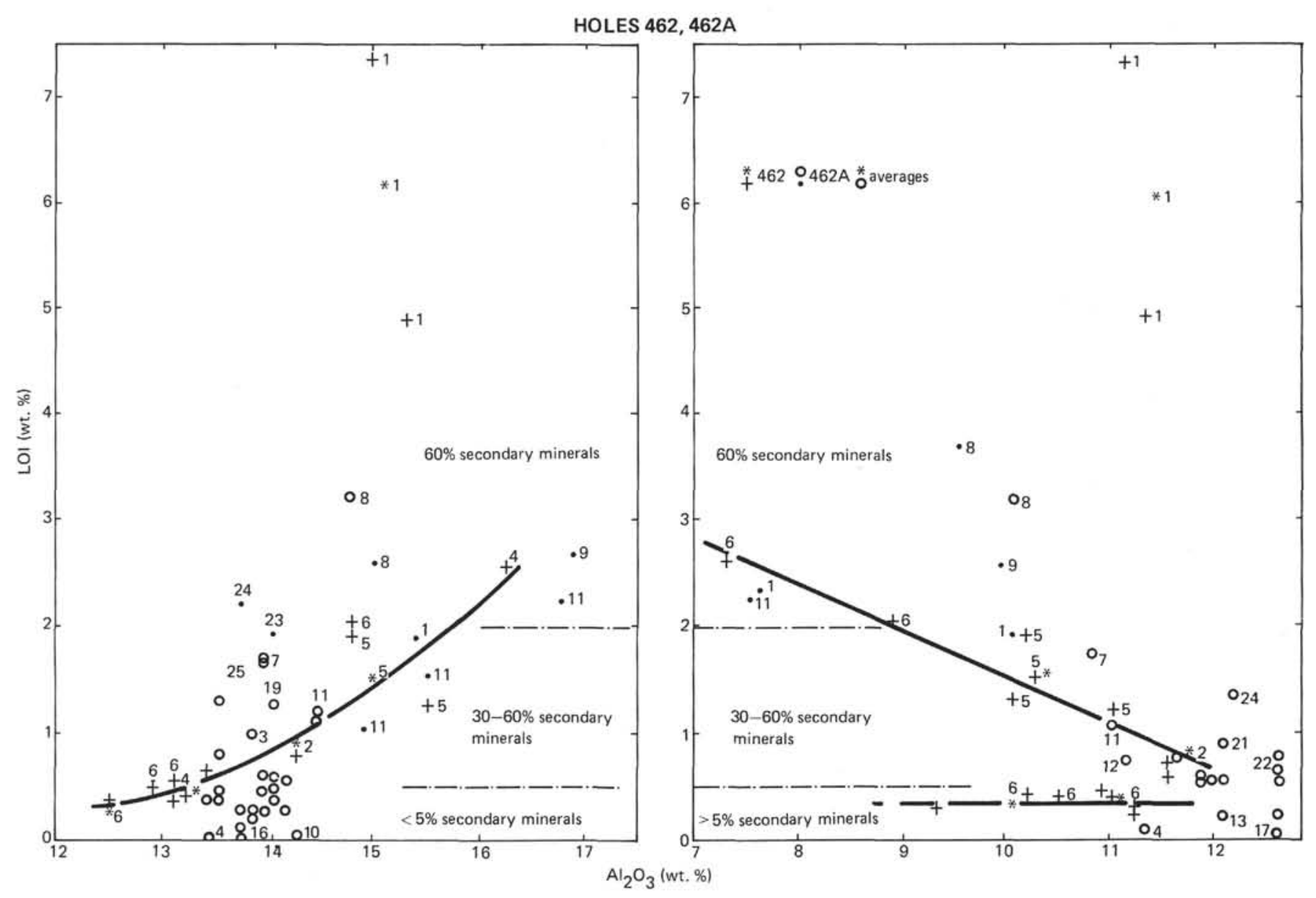

Figure 31. Correlation of $\mathrm{Al}, \mathrm{Ca}$, and $\mathrm{LOI}$ in volcanics. Figures near points are unit numbers.

Calcite is found in association with pyrite, zeolite, and the dark-green clay.

Zeolite has been identified in some of the veins. Optical examination indicates the presence of thomsonite in at least some of the zeolite-bearing veins; the presence of phillipsite has been inferred from a partial optical examination of other veins. The zeolite varies from large fibrous grains to smaller radiating clusters. It is found in association with pyrite and calcite; its association with the dark-green clay mineral has not been unambiguously determined.

The dark-green clay mineral is the most abundant of the vein minerals. It is very fine-grained and often exhibits slickensides. Virtually all of the original fractures (those not obviously induced by drilling) contain a coating of this material. No unequivocal determination of this material has been made, largely because of its very fine grained size; it is tentatively called smectite, but it may be chlorite. Shore-based X-ray-diffraction and/or DTA tests should resolve this question. The clay mineral associated with both pyrite and calcite.

Other vein minerals are also present. A light-green material forming a vein greater than $1 \mathrm{~cm}$ wide was recovered in Core 89 . The material is extremely finegrained, and it has not been identified.

\section{PALEOMAGNETISM}

\section{Introduction}

The paleomagnetic studies utilized the shipboard Digico spinner magnetometer and Schonstedt alternating field (AF) demagnetizer. During this leg, both of these instruments were limited in their capabilities. The Digico will not reliably give repeatable measurements below intensities of $1 \times 10^{-5} \mathrm{emu} / \mathrm{cm}^{3}$, normally a very high intensity for sedimentary rocks. The Schonstedt demagnetization unit had some anhysteretic remanent magnetization (ARM) potential, particularly above 500 Oe; a result of the dented and nonconcentric shielding cans. Susceptibility of basalt samples was measured using the Bison susceptibility meter.

Measurements were made on 2.5-cm-diameter, 2.4$\mathrm{cm}$-long mini-cores, oriented by a scribe line parallel to the edge of the large core. Recovery in the holes was generally high, providing very large pieces of the main core to sample. Paleomagnetic samples were generally taken from these large core pieces, which provided long edges from which the mini-core orientation was obtained. Thus, orientation errors could be minimized. Both sediments and basalts were studied, and each will be described separately. 


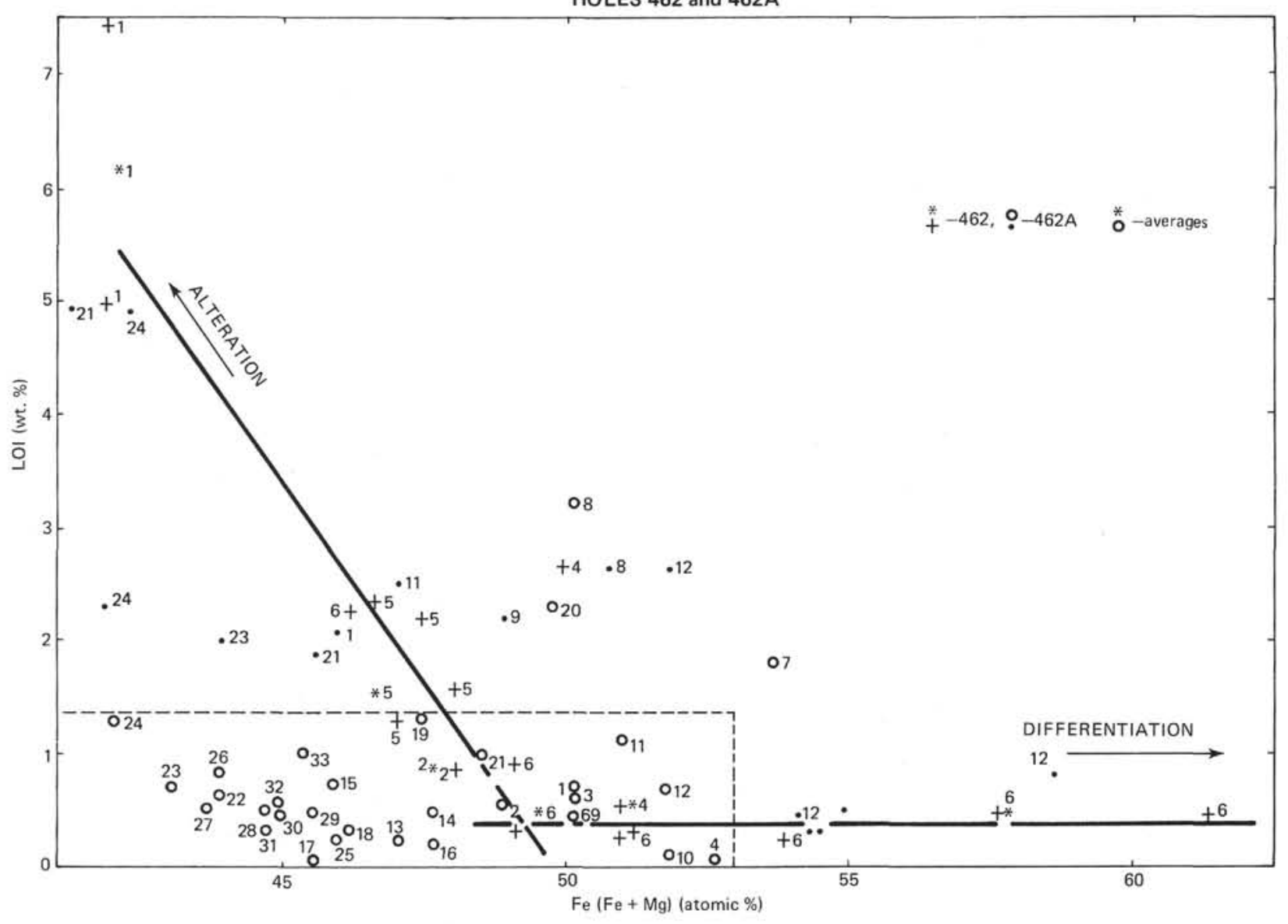

Figure 32. Correlation of $\mathrm{Fe} /(\mathrm{Fe}+\mathrm{Mg})$ and $\mathrm{LOI}$ for volcanic rocks. Figures near points are unit numbers.

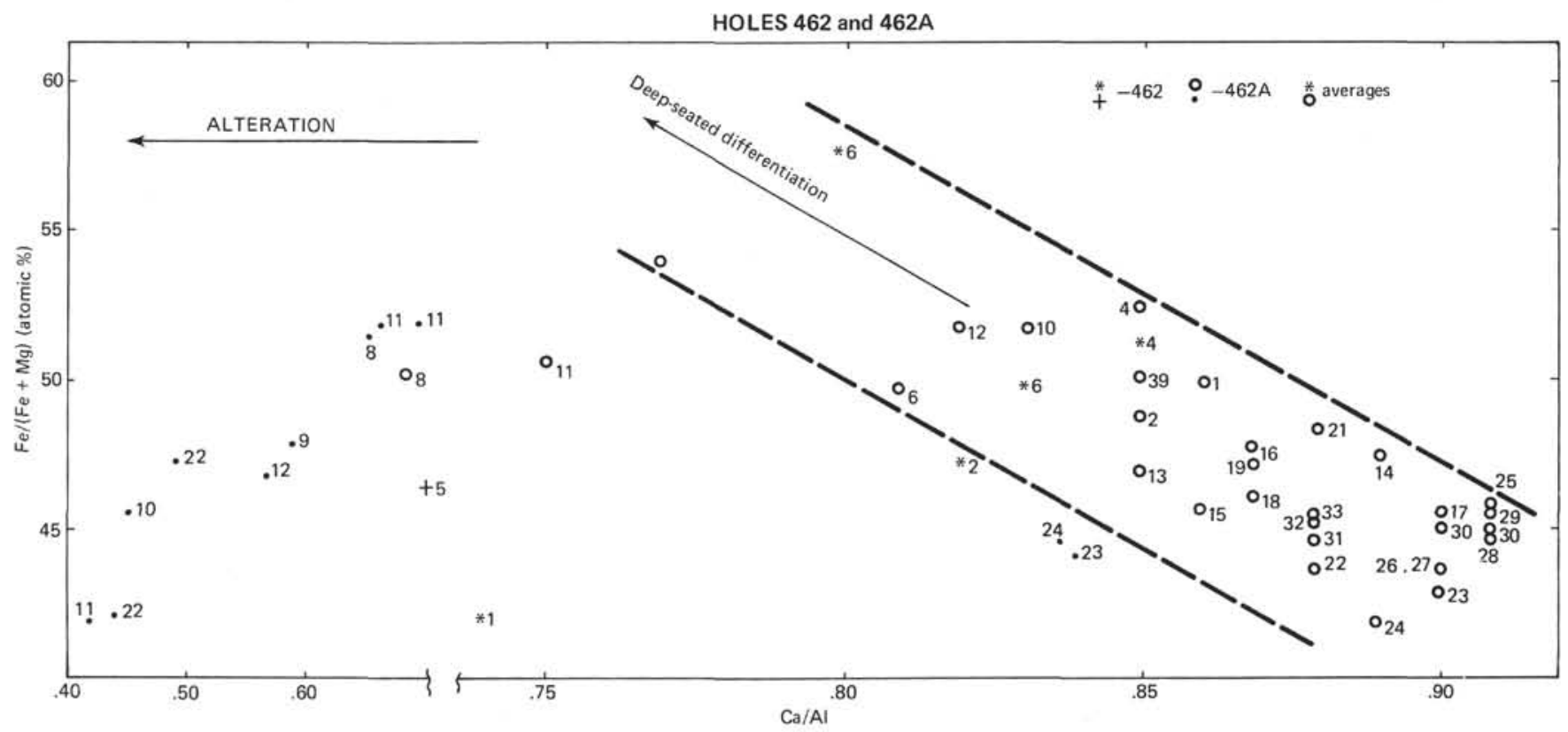

Figure 33. Correlation of $\mathrm{Fe} /(\mathrm{Fe}+\mathrm{Mg})$ and $\mathrm{Ca} / \mathrm{Al}$ ratios in volcanic rocks. Figures near points are unit numbers. 


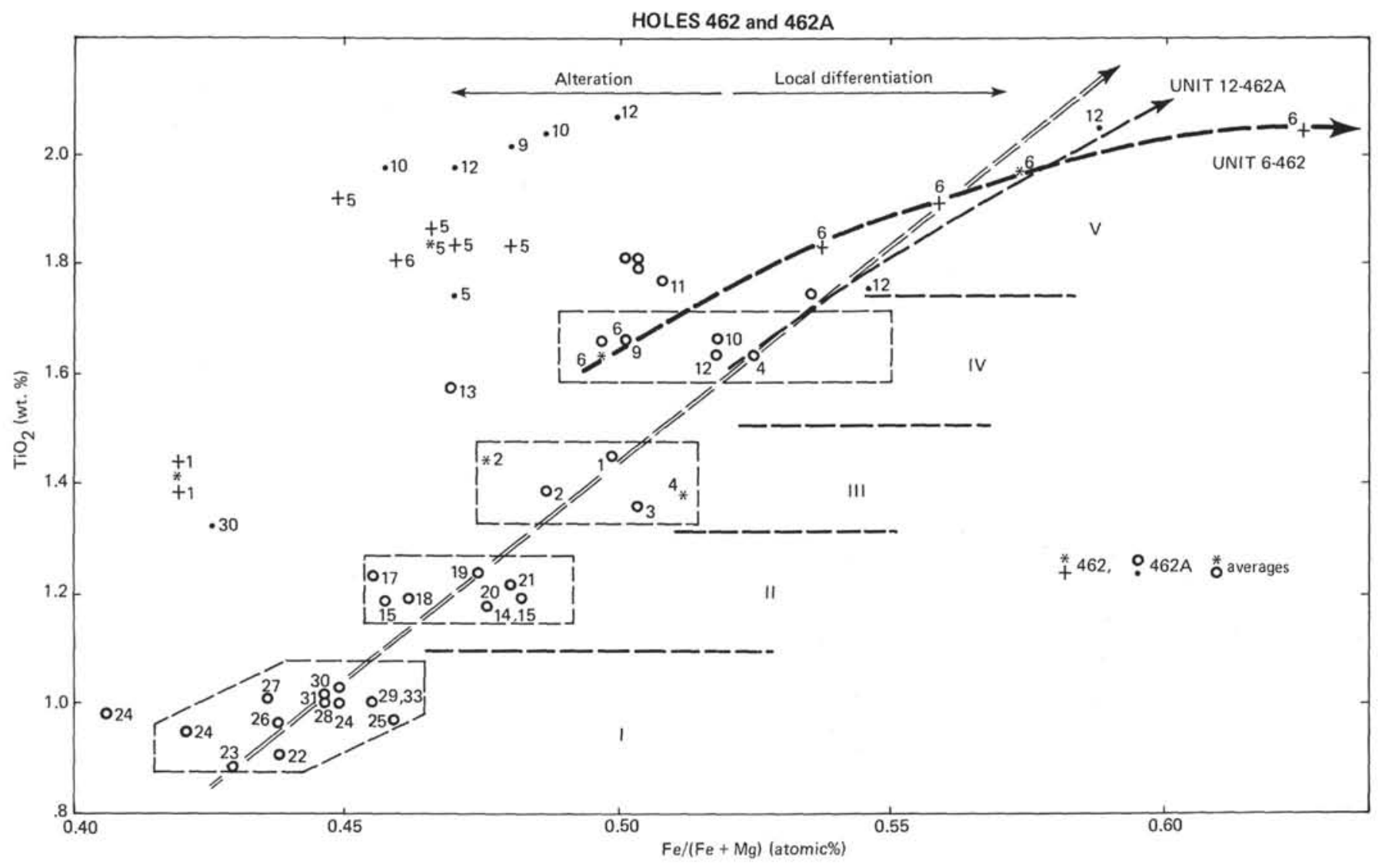

Figure 34. Correlation of $\mathrm{Ti}$ and $\mathrm{Fe} /(\mathrm{Fe}+\mathrm{Mg})$ ratio in volcanics. Figures near points-unit numbers. Dashed line encloses points of fresh rocks.

\section{Early Campanian to Cenomanian Sediments}

Paleomagnetic samples of early Campanian to Cenomanian sediments from both Holes 462 and 462A have been measured. The samples were taken to bracket the reversed interval corresponding to Anomalies 33 and 34 of the sea-floor-spreading pattern, the reversed interval which serves as the younger boundary of the Cretaceous long normal-polarity interval. The study was undertaken in an attempt to better correlate the biostratigraphic age correlations (particularly using nannofossils) with the geomagnetic-reversal pattern in early Campanian-Santonian time.

Sampling was begun where the foraminifer age suggested the upper boundary of the reversed interval. The reversal of polarity was indeed detected at that very point.

Cores from both Holes 462 and $462 \mathrm{~A}$ were sampled at roughly $75-\mathrm{cm}$ intervals through about five core barrels, and periodically at closer spacings. Surprisingly, these sediments are very strongly magnetized $(0.5-2.5 \times$ $10^{-4} \mathrm{emu} / \mathrm{cm}^{3}$ ) and easily could be measured on the Digico magnetometer. Furthermore, their intensity and stability permitted AF demagnetization, often in excess of $400 \mathrm{Oe}$, while remaining within the reliable portion of the Digico measurement range. Many samples were demagnetized stepwise at $12.5,25,50,75,100,125,150$, $200,250,300,350$, and 400 Oe. Almost all samples were demagnetized to at least $100 \mathrm{Oe}$.
Cores from both holes show natural remanent magnetization (NRM) directions changing from southernhemisphere normal (negative) inclinations to reversed (positive) inclinations, beginning at about 516.5 meters sub-bottom depth in Hole 462 (Core 55), and about 517.5 meters in Hole 462A (Core 9). Reversed polarity persists to 524 meters in Hole 462 , and to 525 meters in $462 \mathrm{~A}$, changing back to normal in Cores $462-56$ and $462 \mathrm{~A}-10$, respectively. Both polarity boundaries occur within core-barrel segments, not at breaks between segments. The remainder of each core remains normal into the Cenomanian, at which point basalt was encountered in both holes.

Although the inclinations are shallow and widely scattered, the reversal of polarity is clearly defined. AF demagnetization did little to reduce the scatter. Very little or no change in directions was effected by demagnetization. The NRM and demagnetized data are illustrated in Steiner (this volume). The magnetization is rather hard, exhibiting median destructive fields (MDF) greater than $150 \mathrm{Oe}$ (generally greater than $200 \mathrm{Oe}$ ).

From the results obtained so far, it appears either that the recorded inclinations were very dispersed for some reason, or that it is not possible to clean these magnetizations effectively by AF demagnetization. These sediments may be similar to those encountered at DSDP Site 105. Those sediments, although Jurassic, were of similar red-brown colors and had high intensities and MDFs similar to those of the Site 462 


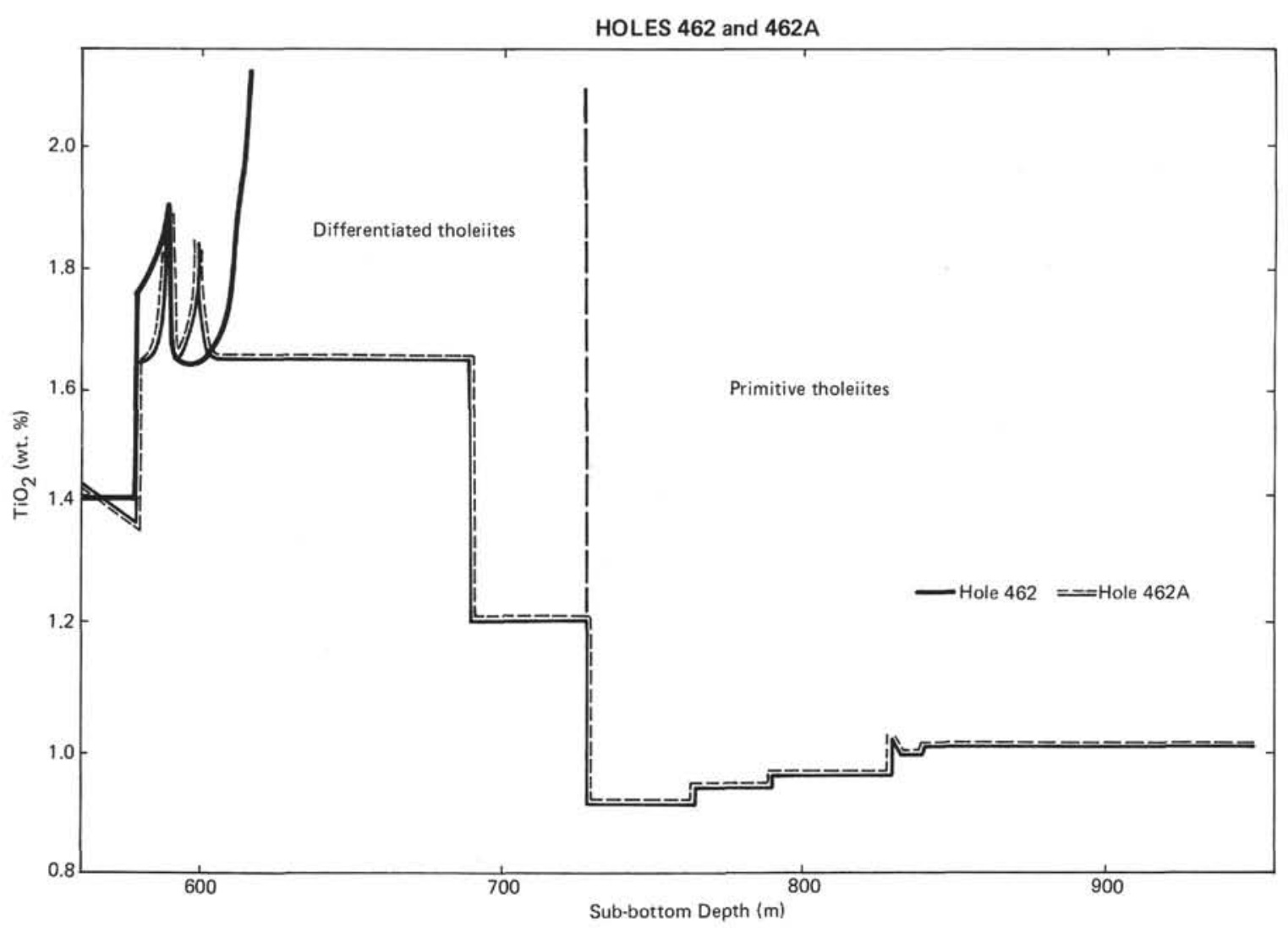

Figure 35. Variations of $\mathrm{TiO}_{2}$ content in volcanic rocks.

sediments. They could effectively be cleaned only by thermal demagnetization. Thus, thermal demagnetization will be attempted on Site 462 samples on shore.

Within the reversed interval, in cores from both Holes 462 and $462 \mathrm{~A}$, an excursion of inclinations occurs at exactly the same point within the sediments relative to the reversal boundaries. The feature spans only $20 \mathrm{~cm}$, but is so persistent as to occur in sediments of different color in each core. Occurring within the reversedpolarity interval, it consists of a shallowing of positive reversed inclinations, steepening into negative (apparently "normal") inclination values, and back again. Because this occurs at exactly the same level in both holes, cores from both holes were resampled to study this feature in more detail. The directions are illustrated and the details are described in Steiner (this volume).

\section{Igneous Rock}

In both Holes 462 and $462 \mathrm{~A}$, both the igneous rocks and the intercalated sediments were sampled to include as many of the petrographic units and sedimentary intervals as possible. This was based on the availability of material that was clearly oriented with respect to the updirection of the hole. Nearly all of the petrographic units and the intercalated sedimentary units within these holes were sampled. Natural remanent magnetization and bulk susceptibility were measured. AF demagnetization has been carried out on most samples to obtain a stable inclination. AF demagnetization was performed at (12.5), 25, 50, (75), 100, 150, 200, 250, 300,
400 , and 500 Oe. (The steps shown in parentheses were not done routinely on all samples.) The low coercivity of the magnetization precluded application of the 400 - and $500-O e$ steps to most igneous samples.

The shipboard Digico magnetometer has a detrimental effect on many samples after AF demagnetization was begun. The magnetometer incorporates as its shield from the earth's field a set of mu-metal cans. These cans have very narrow diameters, so that upon insertion a sample has to pass less than $1 \mathrm{~cm}$ from the can edges, an area of high magnetic field strength. It has been demonstrated repeatedly on Leg 61 basalts that the position and location of the sample as it enters the magnetometer can influence or determine the obtained direction. Samples generally are susceptible to the influence of this ring field around the magnetometer mouth only after demagnetization has begun. NRM measurements do not show much of the effect. Some samples are more susceptible than others-coarser-grained and high-susceptibility samples generally being the most susceptible. However, the influence begins to appear at different times during demagnetization of a sample, and often the influence on the directional change is too subtle to be detected immediately, if at all. Sometimes it can appear as a very smooth change away from the progressive demagnetization path of the natural remanence to a progressive path of increasing magnetization imparted by the can. Even in less-severe cases, it appeared that a combination of both processes produced the obtained directions. Even some visually fine-grained, low-suscep- 


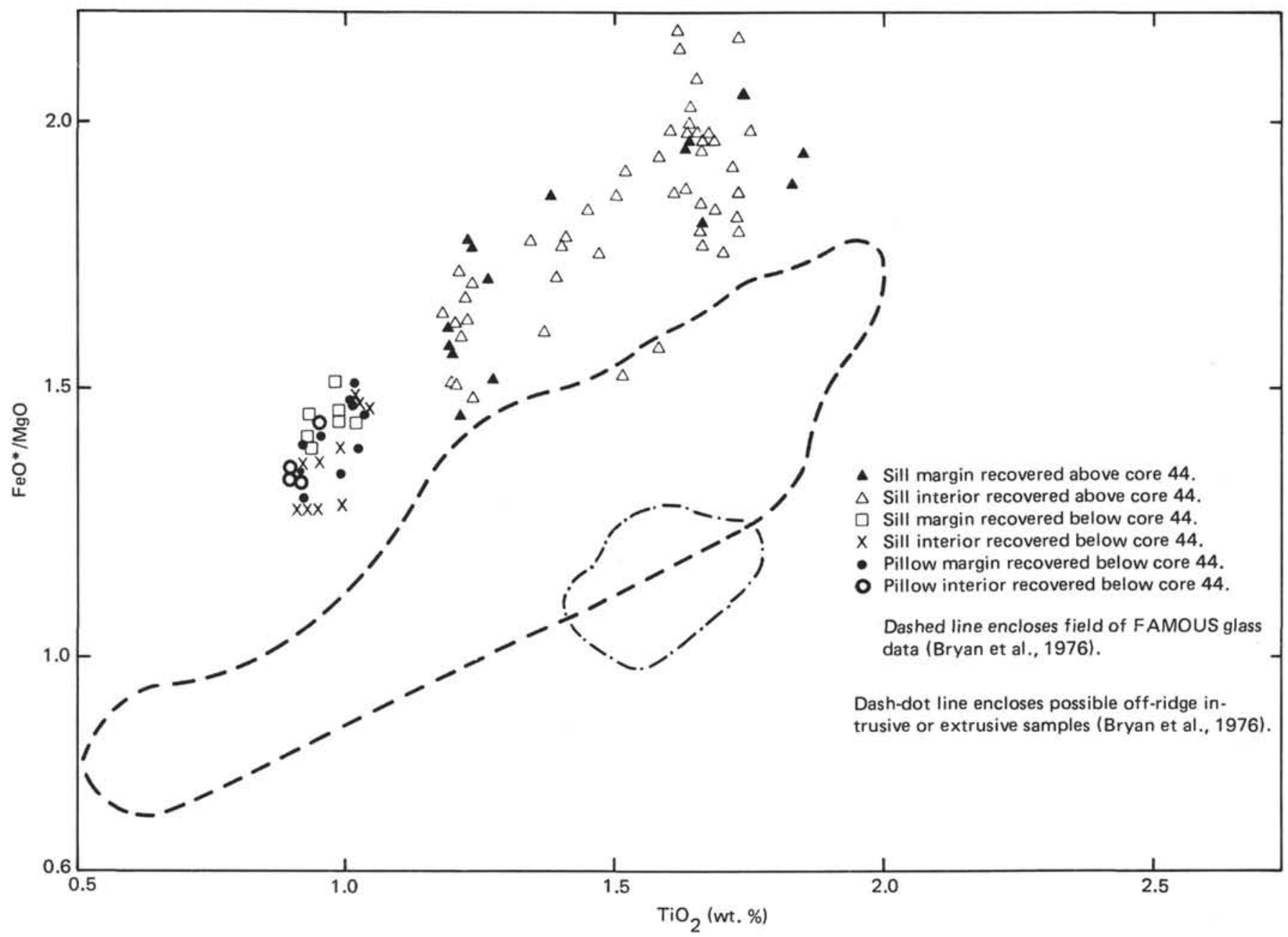

Figure 36. Covariation of $\mathrm{FeO}^{*} / \mathrm{MgO}$ and $\mathrm{TiO}_{2}$ for $\mathrm{Hole} 462 \mathrm{~A}$.

Table 15. Petrographic characteristics of igneous rocks in Hole $462 \mathrm{~A}$ below 953 meters.

\begin{tabular}{|c|c|c|c|c|c|c|c|c|c|}
\hline Sample & Plagioclase & Clinopyroxene & Titanomagnetite & $\begin{array}{l}\text { Altered } \\
\text { Olivine }\end{array}$ & Clay & $\begin{array}{c}\text { Other } \\
\text { Minerals }\end{array}$ & Textures $^{5}$ & Phenocrysts ${ }^{b}$ & $\begin{array}{l}\text { No. of } \\
\text { Points }\end{array}$ \\
\hline $462 \mathrm{~A}-75-04,78-80$ & 54 & 37 & 7 & - & 3 & - & $\mathrm{s}$ & & 1000 \\
\hline $75-05,31-32$ & 54 & 36 & 5 & $\operatorname{Tr}$ & 5 & - & s & & 700 \\
\hline $75-05,122-124$ & 58 & 31 & 6 & $\mathrm{Tr}$ & 5 & - & s & & 1000 \\
\hline $76-01,59-61$ & 38 & 39 & 7 & $\mathrm{Tr}$ & 16 & - & s & & 1000 \\
\hline $77-01,75-77$ & 42 & 41 & 14 & 2 & 1 & - & I-v & $\mathrm{O}, \mathrm{C}, \mathrm{P}$ & 1000 \\
\hline $77-01,121-123$ & 40 & 47 & 5 & - & 8 & - & $\mathrm{s}$ & & 1000 \\
\hline $77-02,70-73$ & 40 & 40 & 8 & $\operatorname{Tr}$ & 12 & - & S-V & $\mathrm{o}$ & 1000 \\
\hline $78-01,5-9$ & 35 & 43 & 6 & $\mathrm{Tr}$ & 16 & $\overline{-}$ & S-IS & o & 1000 \\
\hline $78-01,96-98$ & 38 & 44 & 8 & $\mathrm{Tr}$ & $\begin{array}{l}10 \\
10\end{array}$ & $\bar{z}+$ & V-S & o & 1000 \\
\hline $78-02,87-89$ & 41 & 38 & 9 & - & 12 & - & Is & & 1000 \\
\hline $79-01,138-140$ & 43 & 39 & 5 & $\overline{2}$ & 11 & $=$ & Is & $\mathrm{O}, \mathrm{C}$ & 1000 \\
\hline $79-02,135-137$ & 42 & 39 & 7 & 2 & 10 & Calcite (tr.) & Is-I & O, C, P & 1000 \\
\hline $79-05,42-44$ & 46 & 38 & 6 & 1 & 8 & - & I & 0 & 1000 \\
\hline $79-05,135-137$ & 41 & 43 & 9 & 2 & 5 & - & $1-\mathrm{v}$ & $\mathrm{O}, \mathrm{C}, \mathrm{P}$ & 1000 \\
\hline $81-01,72-74$ & 48 & 43 & 6 & - & 3 & - & I & & 1000 \\
\hline $81-03,58-60$ & 43 & 36 & 13 & 1 & 7 & - & I & $\mathrm{O}, \mathrm{C}, \mathrm{P}$ & 1000 \\
\hline $84-03,138-140$ & 51 & 35 & 7 & i & 6 & - & i & $\mathrm{O}, \mathrm{C}, \mathrm{P}$ & 1000 \\
\hline $84-04,49-51$ & $\begin{array}{l}11 \\
39\end{array}$ & 22 & 4 & 1 & 36 & $=$ & Is & $6, \mathrm{C}, \mathrm{F}$ & 1000 \\
\hline $84-05,75-77$ & 43 & 43 & 6 & $\mathrm{Tr}$ & 8 & & s & 0 & 1000 \\
\hline $88-02,83-85$ & 50 & 37 & 4 & 2 & ${ }_{7}^{\circ}$ & & I & o & 500 \\
\hline $88-02,119-121$ & 46 & 36 & 5 & - & 12 & $\begin{array}{l}\text { Alkalic } \\
\text { Feldspar (tr.) } \\
\text { Glass (2) }\end{array}$ & s & & 1000 \\
\hline $88-02,125-127$ & 54 & 33 & 3 & - & 11 & & I & & 500 \\
\hline$-02,38-40$ & 30 & 31 & 2 & $\mathrm{Tr}$ & 35 & Calcite (2) & Is & 0 & 500 \\
\hline $89-02,72-74$ & 21 & $\begin{array}{l}1 \\
18\end{array}$ & 12 & - & 49 & - & $\mathrm{v}-1$ & $C, P$ & 500 \\
\hline $90-01,24-26$ & $\begin{array}{l}21 \\
49\end{array}$ & $\begin{array}{l}10 \\
34\end{array}$ & 6 & $\bar{z}$ & 11 & $\overline{-}$ & Is & & 500 \\
\hline $90-03,60-63$ & 52 & 34 & 7 & - & 6 & - & Is & $\mathbf{P}$ & 500 \\
\hline $90-05,40-42$ & 53 & 35 & 5 & - & 7 & - & Is & & 500 \\
\hline
\end{tabular}

a $\mathrm{S}=$ subophitic; $\mathrm{I}=$ intergranular; $\mathrm{V}=$ variolitic; Is = intersertal.

$\mathrm{b} \mathrm{O}=$ olivine; $\mathrm{C}=$ clinopyroxene; $\mathrm{P}=$ plagioclase. 
tibility rocks began to be biased once they were below $50 \%$ of their NRM intensities. The evidence for magnetometer bias is discussed in detail in Steiner (this volume). To a large extent, the bias has been removed by careful re-examination of the data, although some scatter remains which may testify to a remaining influence. The information and conclusions presented here are reasonably free of this influence.

\section{Natural Remanent Magnetization}

All samples, basalt and interbedded sediment, display negative NRM inclinations. Because the site was in the southern hemisphere during the Mesozoic (Larson, 1976; Lancelot and Larson, 1975), these samples possess a normal magnetization. Upon demagnetization, the initial -50 to $-70^{\circ}$ (and occasionally $-80^{\circ}$ ) inclinations decrease to values between -30 and $-55^{\circ}$. The site is now at $7^{\circ} \mathrm{N}$ (present inclination, $14^{\circ}$ ), and we believe that it moved north from only as far south as 20 to $30^{\circ} \mathrm{S}$ since the emplacement of these rocks (Larson, pers. comm.). Thus, it is puzzling to obtain a steep negative overprint on these inclinations. In general, all coarsergrained rocks (Hole 462A) displayed higher inclinations than the finer-grained rocks. Evidence from the lower part of Hole 462A (discussed in Steiner, this volume) suggests that the overprint is a drilling remanence.

\section{Demagnetization}

Most of the fine-grained basalts have NRM inclinations nearer the stable inclination, and they move to their stable inclination value with about 70 to $30 \%$ of their NRM intensity remaining. MDFs are usually between 80 and 120 Oe. The coarser-grained basalts and some of the fine-grained ones require the destruction of 80 to $90 \%$ of their NRM intensity before yielding a stable direction. Here, stable means that two or more consecutive demagnetization steps, usually 50 Oe apart, yield the same direction. The MDFs of coarse-grained samples range from 20 to $70 \mathrm{Oe}$.

\section{Stable Inclinations, Hole 462 and the Upper Part of Hole 462A}

Hole 462 generally exhibits very stable inclinations. Very little change occurs during demagnetization, except in the uppermost samples. The basalts of this hole have three distinct groups of stable inclinations. The upper six samples plotted in Figure 37 group around a mean of $-38^{\circ}$, (standard deviation $\left.=4.3^{\circ}\right)$. The next four samples, below an 8-meter recovery gap, have a mean of $-42.6^{\circ}$ (standard deviation $\left.=1.9^{\circ}\right)$. Finally, the lower 13 samples are grouped around $-48.2^{\circ}$ (standard deviation $=2.6^{\circ}$ ). These three groups of inclinations correspond to separate petrologic units and suggest that petrologic Units 1 through 6 are contemporaneous, and that Units 7 through 10 are contemporaneous.

The only other magnetic feature which changes noticeably within Hole 462 is susceptibility, a distinct increase corresponding to the boundary between the second and third magnetic units. Susceptibility is appreciably higher in the lower unit, which may be related to the larger grain size. In the bottom of the hole, there is an enrichment in magnetite, both within the basalt and in a magnetite vein within the basalt. The host rock does not show any higher intensity or susceptibility, but a sample from a magnetite vein exhibiting octahedrons of magnetite does. Nevertheless, the direction remains the same as in the rest of the unit.

The upper basalts of Hole $462 \mathrm{~A}$ resemble those of Hole 462 in some ways, although for the most part they are quite different. As in Hole 462, the upper basalts of Hole 462A have lower inclinations than underlying units. Values for Core 15 through part of Core 18 group around $-25^{\circ}$. Cores 18 and 19 display a gradual increase to higher inclinations, -30 to $-40^{\circ}$. Subsequent cores down through Core 24 have scattered inclinations giouped around $-50^{\circ}$. The MDFs are much lower than those of Hole 462, averaging around 30 to $50 \mathrm{Oe}$. A considerable amount of soft component is removed during $\mathrm{AF}$ demagnetization, whereas there was little to none in Hole 462 . Correlation between Holes 462 and $462 A$ is not entirely obvious. In both holes, the upper inclinations are shallow relative to the underlying units, but the stable inclinations of higher units of Hole 462A do not correlate well with those of Hole 462 . Recovery was very poor in the upper part of Hole 462, which contributes to the poor correlation. The stable inclinations of the upper two-thirds of petrographic Unit 12 are fairly similar to those of Unit 11 in Hole 462. Inclinations in Hole $462 \mathrm{~A}$ are slightly higher and much more scattered, probably artifacts of the overprinting at Hole 462A. The marked susceptibility increase in Hole 462 between magnetic Units 2 and 3, is not clearly apparent in Hole $462 \mathrm{~A}$, although there is an increase at the same level (591 m), and it continues to be generally higher downhole from that point. Thus, in both susceptibility and stable inclination, there seems to be a correlation of petrographic Units 11 (Hole 462) and 12 (Hole 462A) in the two holes.

\section{Stable Inclination in the Remainder of Hole $462 \mathrm{~A}$}

Unit 12 is considered to be a very large sill (Fig. 22). In its lower third, remanence becomes harder, MDFs doubling in value from around 35 Oe to about 70 Oe. NRM intensities increase abruptly at this point. Thus, magnetic data suggest that the lower third of Unit 12 is really a different petrologic unit.

Immediately underlying Unit 12 is a volcaniclastic sedimentary section. Samples from this section show the same directions as the overlying basalt, and very stable remanence. The same was true of another volcaniclastic sedimentary unit between petrologic Units 9 and 10 . The sediments were probably re-heated by the basalt intrusions.

The basalts of the upper petrographic units in both holes have experienced reduction alteration. Such alteration could have remagnetized these rocks, but measurements from samples centered on large chlorite-clay veins (as much as $6 \mathrm{~mm}$ across), or from samples riddled with veins, show the same directions and similar MDFs as large non-veined areas. Similarly, the magnetite vein in Hole 462 showed this same inclination, about $-50^{\circ}$. 


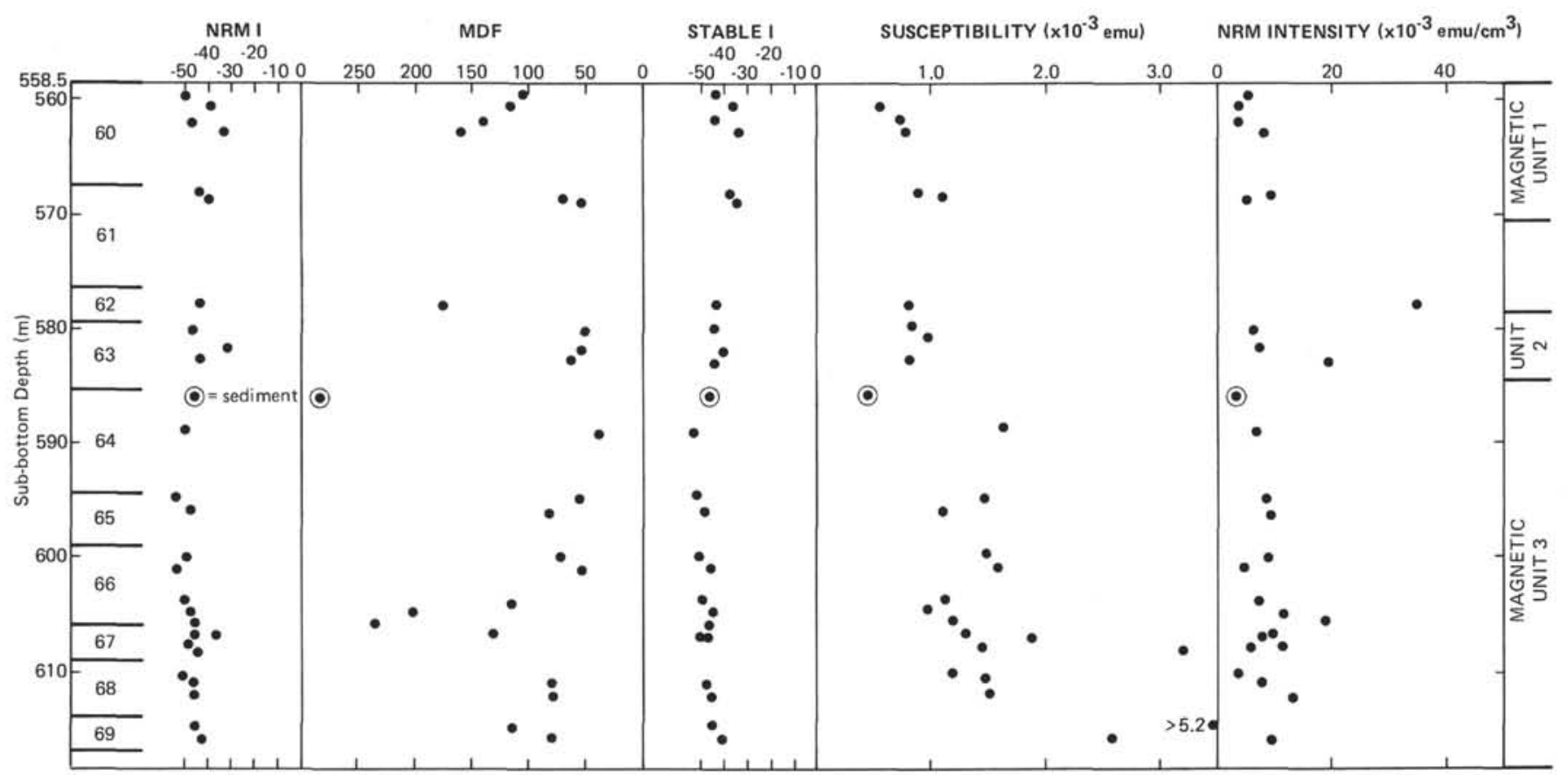

Figure 37. Some magnetics versus depth in hole.

The alteration is of interest because of the reducing nature and because magnetite is observed to be associated with it, suggesting that some remagnetization occurred. Both petrologic data (this summary) and the similarity of directions from heavily veined sediment and lessaffected samples suggest that the alteration was deuteric, occurring shortly after emplacement.

Recovery was poor below petrologic Unit 12 and the underlying sediments. Petrologic Units 13 to 15 consist of only one or two samples each, and directions are scattered. Intensities are higher than in Units 1 to 11 , and are comparable to the lower third of Unit 12. By Unit 16 (Core 39), the inclination seems to be shallower. At this point, titanium content decreases abruptly and remains low throughout the rest of the recovered basalt sequence, decreasing again at 730 meters (Fig. 21). From the point of the first Ti decrease (691 m sub-bottom), NRM intensity increases noticeably and remains higher than before throughout the remainder of the section. This suggests that the titanomagnetites below this point also have a lower titanium content than those above it.

Units 17 to 20 are again very narrow, and only a few samples with scattered directions were obtained. The next thick unit down-hole, Unit 21, has only two reliable values, both also shallow. Other values are questionable, for several reasons. Intervening between Units 18 and 21 are several poorly recovered sediment sequences (Fig. 22). One of these was dated as late Aptian (Core 40) and had sufficient material for a single paleomagnetic sample. It gave an inclination of $-31^{\circ}$; however, the beds are inclined, and the inclination may be unreliable.

Below Unit 21, sediments again are encountered. Recovery at the base of these sediments (Core 43), dated as Barremian to Hauterivian, allowed the taking of nine samples. These have NRM inclinations of $-45^{\circ}$; on demagnetization, they steepen to around $-50^{\circ}$. Their stable inclinations are identical to those of the higher sediments and intrusives, even though the surrounding basalts are shallower.

Below the Barremian sediments, very fine-grained basalts occur, which are interpreted petrologically to be extrusive rocks. They display shallower NRM and demagnetized inclination than those higher in the core. The demagnetized inclination is $35.7^{\circ}$ (standard deviation $=8^{\circ}$ ). These samples have relatively high MDFs, and the directions are less scattered than higher in the hole.

A thick, coarse-grained sill underlies the fine-grained rocks. The susceptibility values are relatively high. MDFs are low, and no stable inclination could be isolated. As discussed in Steiner (this volume), the magnetometer has a marked influence on these samples, causing their directions to appear to reverse in inclination during AF demagnetization. None of the inclinations for this unit are valid. Another small sill very similar to Unit 24 underlies it. Of two samples taken within it, the lower one shows the same susceptibility to the magnetometer, while the top one does not.

Below these high-susceptibility sills, inclinations in the finer-grained rocks (Cores 53-63) are similar to those of the fine-grained rocks above the sills, which have $-36^{\circ}$ inclinations, but there is more scatter in the data. The scatter is probably a reflection of the interspersed samples of fine-grained margins and coarser-grained flow interiors. The fine-grained samples throughout the rest of the section to Core 65 show the same stable inclinations, but because of the magnetometer's influence on coarse-grained, high-susceptibility rocks, the coarsergrained samples below about 825 meters sub-bottom 
generally were not demagnetized. A few trials showed that the magnetometer influence is too large to determine stable inclinations. These samples will be demagnetized on shore.

At about Core 64 to 65 (670-677 m sub-bottom, below petrologic Unit 30 ), susceptibility increased notably, from values around 1.0 to $1.2 \times 10^{-3}$ Gauss $/ \mathrm{cm}^{3}$ to values of 1.3 to $1.5 \times 10^{-3}$ Gauss $\mathrm{cm}^{3}$. NRM intensity increases markedly about $7 \times 10^{-3}$ Gauss to around $18 \times 10^{-3}$ Gauss, larger than anything observed higher in the core. Almost all material is interpreted as sills. However, even a fine-grained unit intercalculated at 910 meters sub-bottom (Cores 69 to 70 , petrologic Unit 34) shows these high intensities. The intensities remain high to the bottom of this hole, being generally higher in the coarser-grained samples. It is also at this point $(677 \mathrm{~m})$ that apparently total remagnetization occurs in the core, which continues to the bottom of the hole. All NRM inclinations are very steep upward values of -70 to $-85^{\circ}$. Only two fine-grained intervals (petrographic Units 34 and 43) preserve the shallower NRM inclinations characteristic of the rest of the core.

Demagnetization of the coarse-grained samples proved useless. Attempted samples showed MDFs below $50 \mathrm{Oe}$, and no stable direction could be established. It appears that a drilling remanence has completely remagnetized the samples and caused the large increase in intensity. It is most interesting that NRM intensity seems to increase when the drilling rate is slower. With a lower rate, the time during which the rocks are under the influence of the magnetic field of the bottom assembly and the vibrations associated with drilling will be longer, increasing the intensity of a viscous magnetization. However, even the fine-grained units which still retain a stable magnetization show this large increase of intensity.

The two fine-grained units within the highly remagnetized sequence show NRM directions comparable to those of stable units higher in the hole. They also demagnetize to stable directions. Unit 34 displays a stable inclination of approximately $-38^{\circ}$. Unit 43 , however, displays a stable inclination of $-51^{\circ}$, suggesting a genetic affinity with the sill sequence very near the top of the basaltic pile. On-shore demagnetization of the coarse units may provide information on this possibility.

At 993 meters sub-bottom, 4 meters of sediment shows one reversed and two normal directions. The fine-grained sediment carries a stable remanence, while the coarse-grained material like the surrounding basalt, is remagnetized. The three fine-grained samples exhibit stable inclinations of $+42,-49$, and $-37^{\circ}$. One would assume that this is a record of a field reversal, which would be consistent with the sediment's Barremian age, the Barremian being a time of frequent reversals. However, the reversed sample has magnetic properties unlike those of the rest of the stable sediment in that interval, and somewhat distinct from those of sediment samples higher in the hole. First, the sample is from red sediment, which suggests baking. Second, the NRM in- tensity is abnormally high $\left(1.25 \times 10^{-2}\right.$ Gauss $)$ in comparison either to that of immediately underlying samples, or to that of other sedimentary samples in either hole. It also shows a very stable remanence and high MDF compared to those of the next two lower samples. All this makes one wonder about the origin of its remanence. Enclosing lavas are all heavily remagnetized, showing the monotonous, steep, upward magnetization, but do not hint at reversed igneous magnetization. All this leaves the meaning of the reversed sample ambiguous.

\section{Summary}

1. Campanian to Cenomanian sediments have recorded the reversal corresponding to Anomalies 33 and 34 , bounding the Cretaceous long normal interval. The inclinations are low in contrast to the high inclinations of the basaltic sequence.

2. The igneous rock magnetization is relatively soft.

3. A steep up-hole remanence (probably drilling remanence) is overprinted on the igneous magnetizations.

4. All basalts and intercalated sediments (except one sample) are normally magnetized.

5. Two main groups of inclination are identified in the igneous rocks: approximately $-50^{\circ}$ for the upper intrusives down to Core 32 , and approximately $-37^{\circ}$ for the intercalated extrusives and intrusives down to Core 65 . The inclination changes slightly above the appearance of presumably extrusive units, suggesting that the upper intrusives (564-656 m) were emplaced at a different time than the units below 691 meters. The difference in age cannot be determined from these data. The vast difference between the overlying-sediment inclinations and the igneous-rock inclinations suggests that the igneous rocks probably record secular variations in the dipole field.

6. A completely overprinting remanence was acquired (apparently by drilling) in the lower half of the igneous section.

\section{PHYSICAL PROPERTIES, WELL LOGS, AND UYEDA DOWN-HOLE TEMPERATURE PROBE}

\section{Physical Properties: Laboratory}

\section{METHODS}

Sound velocity (compressional $)^{4}, 2$-minute GRAPE ${ }^{5}$ wet-bulk den$\operatorname{sity}^{4}$ (ratio of sediment weight to its volume), and continuous GRAPE wet-bulk density measurements were performed on laboratory samples, using methods described in Appendix I (this volume).

Cohesion or shear strength $\left(\mathrm{g} / \mathrm{cm}^{2}\right)$ of clayey sediment was measured by the techniques described in Boyce (1976c), using a $1.6 \mathrm{~cm}$ (diameter) $\times 1.6 \mathrm{~cm}$ (height) vane. The vane was rotated with its axis parallel to bedding of a split core.

Gravimetric determination of wet-bulk density, wet-water content (ratio of the "weight of pore water" to "weight of the wet-saturated sediment or rock," expressed as a per cent), and porosity (ratio of "pore volume"' to the "volume of the wet-saturated rock," expressed

\footnotetext{
${ }^{4}$ Velocity, 2-minute GRAPE wet-bulk density, and thermal-conductivity measurements were done by R. Boyce, N. Fujii, and K. Thompson.

Gamma-Ray Attenuation Porosity Evaluator.
} 
as per cent) used traditional gravimetric water-immersion techniques ${ }^{6}$ on 20-gram samples, as described in Appendix I.

Heat conductivity was measured with a quick thermal conductivity meter (QTM); this device uses a rectangular pad with a heater and thermocouple, which is placed on a flat rock sample, and the thermal conductivity is "automatically" measured and displayed on a panel. The technique and calibration are discussed in Appendix I.

\section{Results}

All data on sound velocity, wet-bulk density, water content, porosity, impedance, and heat conductivity are listed in Tables 16 and 17, and all except heat conductivity and vane shear strength are charted against depth. These data will not be further discussed, except intervalvelocity discussions in the well-logging section, and best can be studied in Figures 38 through 48 . When plotting the laboratory density and velocity on logging data, be advised that the vertical depths may be off as much as \pm 20 meters.

\section{Logging Program in Sedimentary Rock and Basalt, Based on Gearhart-Owen Equipment}

\section{METHODS}

The logging program can provide interpretive data for solutions of geophysical and geological problems: First, in situ geophysical parameters can be provided-sound velocity, density, porosity, electrical conductivity, and temperature. These data allow a more-integrated geophysical section to be determined. This integrated geophysical section will be at in situ conditions, which are difficult if not impossible to duplicate in laboratory measurements, and which will allow interpretation of remote-sensing data, such as seismic-reflection and -refraction data, gravity surveys, electrical resistivity surveys, and geothermal data. Second, the density (gamma-ray back-scatter) and porosity (neutron) logging data provide indexes to other physical parameters and allow the bulk mineral density (grain or matrix density) of the formation to be estimated statistically, which is the key (with the aid of sound velocity) to identification of certain sedimentary strata, some "potential ore deposits," and some igneous and metamorphic rocks. Third, natural gamma radiation (1) generally will distinguish argillaceous (high-count) formation from non-argillaceous sedimentary formation, and (2) in basalt is related to the $\mathrm{K}_{2} \mathrm{O}$ content or some "alteration minerals." Fourth, if the porosity derived from the density $\log$ (assuming a $2.7-\mathrm{g} / \mathrm{cm}^{3}$ grain density in sediments, and $3.0 \mathrm{~g} / \mathrm{cm}^{3}$ in basalt) does not match the porosity derived from the electric logs, then the following types of anomalies may be indicated: (1) minerals of extremely high or low grain density (different from 2.7 $\mathrm{g} / \mathrm{cm}^{3}$ ), (2) interstitial-water-salinity anomalies, (3) metallic minerals that are conductors of electricity, or (4) temperature anomalies. The continuous temperature log will assist in interpreting the electric logs and potentially locating zones of hydrothermal circulation and zones of fractured formations, and two or more temperature runs perhaps will allow a more accurate estimation of in situ temperature. Fifth, even when continuously coring, it is impossible to have complete core recovery, and the logging program provides data in the missing gaps, thus providing a more-representative, integrated geologic section, so that investigators are not misled by biased core recovery.

The logging tools and interpretation precautions are discussed in Appendix I. Where the hole is washed out, the data are not accurate.

The following suite of Gearhart-Owen logging tools were attempted at Hole 462:

1) Temperature $\log$ (thermocouple), $3.65 \mathrm{~cm}$ in diameter (absolute and differential temperature, $\pm 0.05^{\circ} \mathrm{C}$ ) (successful).

2) Sonic log (bore-hole compensated system, $9.21 \mathrm{~cm}$ diameter), caliper, and gamma-ray log (GR) (unsuccessful).

3) Density log (bore-hole compensated) (CDL), $6.99 \mathrm{~cm}$ in diameter, caliper, and GR (successful).

\footnotetext{
${ }^{6}$ Gravimetric measurements were done by J. Rutherford and J. Pine aboard ship.
}

4) Induction $\log$ and 16 -inch $(40-\mathrm{cm})$ normal resistivity (successful).

The following suite of Gearhart-Owen logging tools were attempted at Hole 462A:

1) Neutron-log (thermal neutron), single detector and centered (free, therefore qualitative), $4.29 \mathrm{~cm}$ in diameter, and GR were run through the pipe, drill collars ( $>6737 \mathrm{~m}$ ), and bumper ends (6074$6084 \mathrm{~m}$ ) to bottom (semi-successful).

2) Sonic log (bore-hole compensated system), caliper, and GR (semi-successful).

The GR tool is run with each logging run for stratigraphic control. The GR also allows the density and velocity on two different logging runs to be correlated, because the depths are not accurate enough.

In general, when interpreting any of these logs, one should consult Lynch (1962) and a Gearhart-Owen manual to determine what precautions and data corrections are necessary, and to find the proper charts in various manuals and perform any needed corrections.

In regard to the sonic tool, Lynch (1962) discusses problems of (1) large hole diameters and low formation velocities $(<2.1 \mathrm{~km} / \mathrm{s}),(2)$ noise (high-velocity spikes), and (3) cycle skipping (low-velocity spikes).

\section{Results}

At Hole 462, of the attempted logging suite, only (1) the two temperature logs and GR; (2) the density, caliper, and GR; and (3) the induction log 16-inch normal and GR were successful. However, the data are only good below 349 meters below the sea floor, because the hole was washed out above this.

At Hole 462, the guard-neutron-GR and the sonicGR logs were capable of logging only the washed-out portion of the hole (above $349 \mathrm{~m}$ ), but only the neutron $\log$ was technically successful; because of the washed out hole, it appears to be of little use or value.

At Hole 462A, a gamma-ray-neutron combination was run through pipe, drill collars $(>6737 \mathrm{~m})$, and bumper subs $(6074-6084 \mathrm{~m})$ to a total depth of 947 meters below the sea floor.

Also at Hole 462A, the sonic, caliper, and GR logs were run in the open hole from 211 to 1050 meters; however, the upper (211-390 m) part of the hole was $95 \%$ washed out, and in general the formation velocities were too low $(<2.1 \mathrm{~km} / \mathrm{s})$ to be measured accurately with corresponding large diameter of the hole, as the tool is centered in the hole. Below 390 meters, all of the lowvelocity layers are subject to the same problems. This problem is discussed in Lynch (1962). In the basaltic parts of the hole, noise (as "high-velocity spikes") (Lynch, 1962) is a serious problem; many obvious examples with velocities about $7 \mathrm{~km} / \mathrm{s}$ or greater are obvious artifacts.

The sonic-log data in soft formations may be affected by disturbance of the drill bit and in situ temperature disequilibrium. If these softer formations are drill-disturbed, the in situ overburden pressure could be partly released (e.g., horizontal expansion).

\section{In Situ Interval-Velocity Estimates}

The following in situ velocities were estimated using the Gearhart-Owen well logs and DSDP laboratorymeasured velocities. Laboratory-velocity values are corrected to in situ conditions, using techniques in Boyce (1976a). The following intervals may or may not correspond to other lithologic or time units discussed elsewhere in this volume: 


\begin{tabular}{|c|c|c|c|c|c|c|c|c|c|c|c|c|c|c|c|c|}
\hline \multirow[b]{3}{*}{ Core } & \multirow[b]{3}{*}{ Section } & \multirow[b]{3}{*}{$\begin{array}{c}\text { Interval } \\
(\mathrm{cm})\end{array}$} & \multirow[b]{3}{*}{$\begin{array}{c}\text { Depth in } \\
\text { Hole } \\
(\mathrm{m})\end{array}$} & & & & & & \multirow{3}{*}{$\begin{array}{c}\text { Heat } \\
\text { Conductivity } \\
\text { at } 21^{\circ} \mathrm{C} \text { C } \\
\left(\text { cal. } \times 10^{-3}\right) \\
\left(\mathrm{cm} \cdot \mathrm{s}^{\circ} \mathrm{C}\right)\end{array}$} & \multicolumn{2}{|c|}{$\begin{array}{l}\text { GRAPE } \\
\text { "Special" wet- } \\
\text { Bulk Density } \\
\text { 2-Minute Count } \\
\left(\mathrm{g} / \mathrm{cm}^{3}\right)\end{array}$} & \multicolumn{3}{|c|}{ Gravimetric } & \multirow[b]{3}{*}{$\begin{array}{c}\text { Acoustic } \\
\text { Impedance } \\
\left(\mathrm{g} \cdot 10^{5} / \mathrm{cm}^{2} \cdot \mathrm{s}\right)\end{array}$} & \multirow[b]{3}{*}{ Lithology } \\
\hline & & & & & Com & pressional- & Sound Velocity & & & & & & Wet-Water & & & \\
\hline & & & & $\begin{array}{c}\text { Beds } \\
(\mathrm{km} / \mathrm{s})\end{array}$ & $\begin{array}{c}\begin{array}{c}1 \\
\text { Beds } \\
(\mathrm{km} / \mathrm{s})\end{array} \\
\end{array}$ & $\begin{array}{l}\text { Ani } \\
1-\frac{1}{1}-\frac{1}{(k m / s)}\end{array}$ & $\begin{array}{l}\text { sotropy } \\
\left(1-\frac{1}{(\%)} / \perp\right.\end{array}$ & $\begin{array}{c}\text { Temperature } \\
\left({ }^{\circ} \mathrm{C}\right)\end{array}$ & & $\begin{array}{c}1 \\
\text { Beds }\end{array}$ & $\stackrel{\perp}{\text { Beds }}$ & $\begin{array}{l}\text { Wet-Bulk } \\
\text { Density } \\
\left(\mathrm{g} / \mathrm{cm}^{3}\right)\end{array}$ & $\begin{array}{l}\text { Content } \\
\text { (salt } \\
\text { corrected) } \\
(\%)\end{array}$ & $\begin{array}{l}\text { Porosity } \\
\text { (salt } \\
\text { corrected) } \\
(\%)\end{array}$ & & \\
\hline 1 & 6 & $147-149$ & 9.47 & - & - & - & - & - & - & - & - & - & 73.7 & - & - & Interstitial-water sample (1.W.) \\
\hline 5 & 4 & $145-147$ & 44.45 & - & - & - & - & - & - & - & - & - & 63.3 & - & - & 1.w. \\
\hline 10 & 4 & $145-147$ & 91.95 & - & - & - & - & - & - & - & - & - & 35.1 & - & - & I.W. \\
\hline 12 & 6 & $40-42^{\mathrm{d}}$ & 112.90 & - & - & - & - & - & - & $1.197^{\mathrm{d}}$ & - & - & - & - & - & Disturbed radiolarian ooze (10YR $5 / 4)$ \\
\hline 14 & 6 & $16-26$ & 131.76 & - & - & - & - & - & 3.00 & - & 1.625 & - & - & - & - & Nannofossil ooze (10YR $8 / 2$ ) \\
\hline 16 & 5 & $0-2$ & 149.00 & $-\overline{-}$ & - & - & - & $\bar{m}$ & - & - & - & 1.26 & 69.1 & 84.7 & - & Clay (10YR 3/2) \\
\hline 16 & 5 & $0-10^{e}$ & 149.00 & 1.565 & 1.539 & 0.026 & 1.69 & 22 & 1.81 & & $1.416^{\mathrm{e}}$ & 1.43 & 53.9 & 75.1 & 2.20 & Clay (10YR 3/2) \\
\hline 16 & 5 & $140-142$ & 150.40 & $-\overline{-}$ & $\overline{s \in 0}$ & - & - & $\overline{20}$ & - & $-\overline{c o s}$ & - & 1.65 & 39.4 & 63.3 & - & Clay (10YR $3 / 2)$ \\
\hline 19 & 5 & $0-2^{f}$ & 177.50 & 1.548 & 1.552 & 0.004 & 0.26 & 22 & - & $1.284^{f}$ & - & - & - & - & 1.99 & Clay $(10 Y R 2 / 2)$ \\
\hline 19 & 5 & $0-10$ & 177.51 & - & - & - & - & 22 & 1.17 & 1.258 & - & - & - & - & - & Clay (10YR $2 / 2)$ \\
\hline 19 & 5 & $122-124$ & 178.73 & $-\overline{0}$ & - & - & - & $\overline{0}$ & 2.68 & 1.700 & - & - & - & - & - & Nannofossil ooze (N9) \\
\hline 19 & 5 & $142-146$ & 178.92 & 1.550 & - & - & - & 22 & 2.82 & 1.615 & - & - & - & - & 2.528 & Radiolarian nannofossil ooze (10YR $7 / 4)$ \\
\hline 20 & 4 & $145-147$ & 180.45 & $-\bar{c}$ & - & - & - & - & - & - & - & - & 35.4 & - & - & I.W. \\
\hline 21 & 2 & $142-144$ & 193.42 & 1.596 & $\overline{-17}$ & - & - & 22 & - & 1.665 & - & 1.63 & 40.1 & 63.9 & 2.60 & Radiolarian nannofossil chalk-00ze (10YR $8 / 2$ ) \\
\hline 24 & 5 & $0-38$ & 225.00 & 1.536 & 1.517 & 0.019 & 1.25 & 22 & 2.78 & $1.492^{8}$ & - & 1.51 & 47.9 & 70.6 & 2.29 & Nannofossil radiolarian ooze (10YR $4 / 2)$ \\
\hline 25 & 4 & $95-97$ & 233.95 & 1.594 & 1.605 & -0.011 & -0.69 & 23 & - & - & 1.597 & 1.56 & 44.0 & 66.9 & 2.50 & Nannofossil ooze (10YR 8/2) \\
\hline 26 & 4 & $145-147$ & 234,45 & - & - & - & - & - & - & - & - & - & 27.2 & - & - & 1.W. \\
\hline 28 & 6 & $44-54$ & 259.94 & - & - & - & - & - & $3.02^{\mathrm{h}}$ & - & - & - & - & - & - & Nannofossil ooze (N9) \\
\hline 28 & 6 & $139-142$ & 260.89 & - & - & - & - & - & $2.86^{i}$ & - & - & - & - & - & - & Radiolarian nannofossil ooze (10YR $7 / 4)$ \\
\hline 30 & 2 & $149-150$ & 278.99 & $\overline{-}$ & - & - & - & $\bar{n}$ & - & - & - & - & 30.8 & - & - & \\
\hline 32 & 2 & $65-67$ & 297.15 & 3.371 & $\overline{-\infty}$ & - & - & 23 & - & 2.106 & - & 2.08 & 8.7 & 17.7 & 7.01 & Nannofossil chalk (N9) \\
\hline 32 & 4 & $54-56$ & 300.04 & 1.648 & 1.609 & 0.039 & 2.42 & $23 ?$ & - & - & 1.789 & 1.60 & 39.9 & 62.2 & 2.57 ? & Nannofossil chalk-ooze (N9) \\
\hline 34 & $\mathrm{CC}$ & $14-16$ & 315,13 & 3.378 & - & - & - & $20 ?$ & - & - & - & 2.12 & 7.2 & 14.8 & 7.16 & Chert (laminated, black and tan) \\
\hline 35 & 1 & $30-33$ & 323.80 & 1.644 & $1.656 \mathrm{i}$ & -0.012 & -0.72 & 18 & - & 1.734 & - & 1.70 & 35.9 & 59.7 & 2.82 & Nannofossil ooze-chalk (N9) \\
\hline $36^{j}$ & 1 & $105-107$ & 334.05 & $1.656^{\mathrm{j}}$ & $1.646^{\mathrm{j}}$ & 0.010 & 0.61 & 19 (meas.) & - & - & 1.710 & 1.56 & 43.99 & 66.8 & 2.57 ? & Nannofossil chalk (mottled, tan and orange) \\
\hline 36 & 3 & $0-2$ & 336.00 & - & - & - & - & & - & - & - & - & 35.3 & - & - & I.w. \\
\hline 37 & 1 & $20-30$ & 342.70 & - & - & - & - & - & 2.78 & - & - & - & - & - & - & Nannofossil chalk (N9) \\
\hline 37 & 1 & $60-63$ & 343.10 & 1.618 & 1.609 & 0.009 & 0.56 & 23 & - & 1.643 & 1.648 & 1.64 & 38.8 & 62.2 & 2.64 & Nannofossil chalk (N9) \\
\hline 38 & i & $27-30$ & 352.27 & 1.672 & 1.639 & 0.033 & 2.01 & 23 & - & 1.277 & 1.287 & 1.32 & 59.2 & 76.4 & 2.16 & Nannofossil radiolarian chalk (10YR $6 / 2$ ) \\
\hline 39 & 1 & $4-6$ & 361.54 & 1.770 & 1.688 & 0.082 & 4.86 & 24 & 3.12 & 1.730 & 1.738 & 1.70 & 35.3 & 58.6 & 2.87 & Nannofossil chalk (laminated) (N9) \\
\hline 39 & $i$ & $50-53$ & 362.03 & 1.666 & 1.660 & 0.006 & 0.36 & 24 & 2.31 & 1.506 & 1.404 & 1.44 & 49.5 & 69.3 & 2.39 & Nannofossil radiolarian chalk (10YR $6 / 2$ ) \\
\hline 42 & 1 & $11-12$ & 390.11 & 4.112 & 4.049 & 0.63 & 1.56 & $23 ?$ & - & - & 2.314 & 2.30 & 5.5 & 12.2 & 9.31 & Siliceous limestone (N8) \\
\hline 42 & 1 & $44-46$ & 390.44 & 4.819 & - & - & - & $23 ?$ & - & - & - & 2.56 & 2.1 & 5.2 & 12.34 & Chert $(5 Y 2 / 1)$ \\
\hline 43 & i & $5-7$ & 399.55 & 5.186 & - & - & - & $22 ?$ & - & - & - & 2.44 & 5.2 & 12.4 & 12.65 & Chert (brown with white specks) (5YR 3/4) \\
\hline 43 & 1 & $15-17$ & 399.65 & 2.118 & - & - & - & $22 ?$ & - & - & 2.077 & 1.99 & 20.4 & 39.7 & 4.21 & Limestone (10YR 8/2) \\
\hline 44 & 1 & $16-18$ & 409.16 & 2.624 & 2.581 & 0.043 & 1.67 & $22 ?$ & - & - & 2.408 & 2.29 & 12.4 & 27.8 & 5.91 & Limestone $(5 Y 7 / 2)$ \\
\hline 44 & 1 & $27-29$ & 409.27 & 4.666 & - & - & - & $22 ?$ & - & - & - & 2.23 & 9.7 & 21.0 & 10.41 & Chert (laminated and spotted) (5YR 3/2) \\
\hline 44 & 1 & $36-38$ & 409.36 & 3.279 & 2.882 & 0.397 & 13.78 & $22 ?$ & - & 2.131 & - & . & - & - & 6.14 & Limestone (laminated) (5G 6/1) \\
\hline 47 & $\mathrm{CC}$ & $2-5$ & 437.60 & - & 2.185 & - & - & 15 & - & - & - & 2.13 & 16.2 & 33.6 & 4.65 & Limestone (10YR $6 / 2)$ \\
\hline 47 & $\mathrm{CC}$ & $21-23$ & 437.80 & - & 4.290 & - & - & 15 & - & - & - & - & - & - & - & Chert (porcellanite) (10YR 5/4) \\
\hline 48 & 1 & $0-2$ & 447.06 & - & - & - & - & - & - & - & - & - & 25.9 & - & - & I.W. \\
\hline 48 & 1 & $29-31$ & 447.29 & 2.004 & - & - & - & 23 & 3.97 & - & 1.992 & 2.11 & 19.2 & 39.5 & 4.23 & Sandstone (laminated) $(5 \mathrm{G} 4 / 1)$ \\
\hline 48 & i & $116-118$ & 448.16 & 2.524 & 2.406 & 0.118 & 4.90 & 23 & - & 1.991 & - & 1.97 & 19.8 & 37.9 & 4.74 ? & Limestone (5GY 6/1) \\
\hline 48 & 2 & $48-50$ & 448.98 & 1.780 & 1.753 & 0.027 & 1.54 & 23 & - & $1.938 ?$ & - & 1.74 ? & 33.3 & $56.6 ?$ & 3.05? & Claystone $(5 \mathrm{GY} 4 / 1)$ \\
\hline 49 & 2 & $25-27$ & 458.25 & 2.011 & 1.955 & 0.056 & 2.86 & 23 & - & 2.037 & 1.962 & 2.00 & 20.4 & 39.8 & 3.91 & Volcanic siltstone ( $5 \mathrm{GY} 6 / 1$ ) \\
\hline 49 & 2 & $125-127$ & 459.25 & 1.919 & 1.877 & 0.042 & 2.23 & 23 & $3.12 ?$ & 1.798 & 1.791 & 1.79 & 32.7 & 56.9 & 3.36 & Limestone (5GY 6/1) \\
\hline 49 & 3 & $53-55$ & 460.03 & 1.969 & 1.840 & 0.129 & 7.01 & 23 & $3.94 ?$ & 2.042 & 2.046 & 2.02 & 21.8 & 42.9 & 3.72 & Nannofossil chalk $(5 Y 7 / 1)$ \\
\hline 50 & 2 & $131-132$ & 468.81 & 2.190 & 2.168 & 0.022 & 1.01 & 23 & 2.80 & 1.982 & 1.950 & 1.96 & 26.4 & 50.3 & 4.25 & Volcanic sandstone (SG $6 / 1$ ) \\
\hline so & 4 & $3-6$ & 470.53 & 2.351 & 2.298 & 0.053 & 2.31 & 23 & 2.79 & 1.978 & 1.947 & 1.96 & 26.0 & 49.6 & 4.50 & Volcanic sandstone $(5 \mathrm{G} 6 / 1)$ \\
\hline 50 & 5 & $144-146$ & 473.44 & 1.825 & 1.736 & 0.089 & 5.13 & 23 & 3.05 & 1.831 & 1.797 & 1.77 & 34.1 & 58.7 & 3.07 & Volcanic mudstone (5G $6 / 1)$ \\
\hline 51 & 1 & $98-100$ & 476.48 & 2.128 & 2.036 & 0.092 & 4.52 & 23 & $4.24,4.40$ & - & 2.252 & 2.18 & 15.6 & 33.1 & 4.44 & Limestone $(5 \mathrm{GY} 6 / 1)$ \\
\hline 51 & 2 & $63-67$ & 477.63 & 1.834 & 1.755 & 0.079 & 4.50 & 23 & 2.96 & - & - & 1.80 & 32.7 & 57.4 & 3.16 & Volcanic siltstone $(5 \mathrm{G} 6 / 1)$ \\
\hline 52 & 1 & $6-8$ & 485.06 & 2.011 & 1.894 & 0.117 & 6.18 & 23 & 3.30 & 1.880 & - & 1.80 & 30.0 & 52.6 & 3.41 & Volcanic breccia coarse sandstone $(5 \mathrm{G} 6 / 1)$ \\
\hline 52 & 1 & $52-54$ & 485.52 & 1.852 & 1.780 & $0.072 ?$ & 4.04 & 23 & - & 1.994 & 1.994 & 1.96 & 24.7 & 47.4 & 3.49 & Laminated sandstone-claystone $(5 \mathrm{G} 6 / 1)$ \\
\hline 52 & 2 & $78-81$ & 487.28 & 2.078 & 1.981 & 0.097 & 4.89 & 23 & - & 2.168 & - & 2.11 & 17.9 & 37.0 & 4.18 & Calcareous volcanic claystone $(5 \mathrm{G} 6 / 1)$ \\
\hline 53 & 1 & $2-3$ & 494.52 & 2.127 & 1.922 & 0.205 & 10.67 & $22 ?$ & - & - & 2.236 & $2.02 ?$ & $21.8 ?$ & 42.9? & $3.88 ?$ & Claystone (5Y 4/1) \\
\hline 53 & 1 & $52-54$ & 495.02 & 1.852 & 1.780 & 0.072 & 4.04 & $22 ?$ & - & - & - & 1.89 & 27.4 & 50.4 & 3.36 & Laminated siltstone-claystone $(5 Y 4 / 1)$ \\
\hline 53 & $\mathrm{CC}$ & $1-3$ & 497.10 & 2.262 & 1.980 & 0.282 & 14.24 & $22 ?$ & - & - & 1.992 & 1.97 & 20.5 & 39.6 & 3.52 & Calcareous claystone $(5 \mathrm{Y} 6 / 1)$ \\
\hline 54 & 1 & $7-9$ & 504.07 & 1.974 & 1.900 & 0.074 & 3.89 & 23 & 5.12 & - & 2.242 & 2.22 & 13.6 & 29.5 & 4.22 & Limestone (5Y 6/1) \\
\hline 54 & 1 & $145-147$ & 505.44 & $2.409 ?$ & 2.302 & 0.107 & 4.65 & 23 & - & - & 2.071 & 2.06 & 18.3 & 36.7 & 5.11 & Limestone (SBG 7/2) \\
\hline
\end{tabular}




\begin{tabular}{|c|c|c|c|c|c|c|c|c|c|c|c|c|c|c|c|c|}
\hline 54 & 1 & $148-149$ & 505.48 & - & - & - & - & - & - & - & - & - & 30.1 & - & - & I.W. \\
\hline 54 & 3 & $82-84$ & 507.82 & $1.990 ?$ & $2.190 ?$ & -0.200 & -9.13 & 23 & 4.11 & - & 2.302 & 2.20 & 14.5 & 31.0 & $4.82 ?$ & Limestone (5Y $6 / 1$ ) \\
\hline 55 & 1 & $84-86$ & 514.34 & 2.261 & 2.122 & 0.139 & 6.55 & 21 & 4.42 & - & 2.080 & 2.16 & 16.2 & 34.2 & 4.58 & Limestone (5Y $6 / 1)$ \\
\hline 55 & 2 & $67-69$ & 515,67 & 2.395 & 2.257 & 0.138 & 6.11 & 21 & - & - & 2.056 & 2.00 & 21.0 & 40.9 & 4.51 & Limestone (SB $7 / 4$ ) \\
\hline 55 & 3 & $54-56$ & 517.04 & 2.526 & 2.641 & -0.115 & -4.35 & 21 & 4.25 & - & 1.950 & 1.95 & 22.2 & 42.2 & 5.15 & Limestone (5Y $6 / 8$ ) \\
\hline 55 & 5 & $14-16$ & 519.64 & 2.083 & 1.825 & 0.258 & 14.14 & 21 & - & - & 1.696 & 1.78 & 33.2 & 57.5 & 3.25 & Claystone (5Y $4 / 1$ ) \\
\hline 56 & i & $100-102$ & 523.50 & 1.861 & 1.676 & 0.185 & 11.04 & 21 ? & $2.47 ?$ & - & 1.800 & 1.80 & 32.0 & 56.3 & 3.02 & Claystone (10R $2 / 2)$ \\
\hline 57 & i & $135-137$ & 532.85 & 1.971 & 1.625 & 0.346 & 21.29 & 21 ? & - & - & - & 1.88 & 28.6 & 52.6 & 3.06 & Claystone (IOR $3 / 7)$ \\
\hline 57 & 2 & $102-104$ & 534.02 & 1.867 & 1.818 & 0.049 & 2.70 & 21 ? & - & - & 1.874 & 1.82 & 30.0 & 53.4 & 3.31 & Siltstone (laminated) (10R 4/2) \\
\hline 57 & 3 & $45-47$ & 534.95 & 1.750 & 1.728 & 0.022 & 1.24 & 21 ? & 2.99 & - & 1.765 & 1.73 & 36.2 & 61.1 & 2.99 & Sandstone $(5 \mathrm{G} 6 / 1)$ \\
\hline 58 & i & $69-71$ & 541.19 & 1.860 & 1.793 & 0.067 & 3.74 & 23 & 2.70 & - & 1.624 & 1.62 & 37.5 & 59.5 & 2.90 & Zeolitic claystone (5YR $4 / 1$ ) \\
\hline 58 & 3 & $145-147$ & 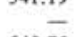 & 1000 & - & - & - & - & - & - & - & - & 37.6 & - & - & \\
\hline 58 & 4 & $75-77$ & 545.75 & 2.001 & 1.913 & 0.088 & 4.60 & 23 & 3.24 & - & 2.022 & 1.99 & 21.9 & 42.7 & 3.81 & Zeolitic mudstone (5YR $5 / 2$ ) \\
\hline 58 & 4 & $\mid 29-131$ & 546.29 & 2.388 & 2.282 & 0.106 & 4.65 & 23 & 3.88 & - & 1.926 & 1.92 & 22.8 & 42.7 & 4.38 & Nannofossil-rich marlstone $(2.5 \mathrm{YR} \mathrm{8/2)}$ \\
\hline 59 & i & $45-47$ & 549.95 & 1.970 & 1.753 & 0.217 & 12.38 & 23 & 3.01 & - & 1.839 & 1.84 & 28.1 & 50.6 & 3.23 & Zeolitic mudstone (5YR 5/4) \\
\hline 59 & i & $63-65$ & 550.13 & 1.950 & 1.839 & 0.111 & 6.04 & 23 & 2.92 & - & 1.890 & 1.89 & 26.5 & 48.8 & 3.48 & Zeolitic marlstone (SYR 5/2) \\
\hline 60 & i & $0-5$ & 558.50 & 5.292 & - & - & - & 23 & - & 2.687 & - & - & - & - & 14.22 & Cherl (SYR 4/1) \\
\hline 60 & i & $12-14$ & 558.62 & 1.713 & - & - & - & 23 & - & 2.015 & - & - & - & - & 3.45 & Claystone (10R 3/2) \\
\hline 60 & 1 & $43-45$ & 558.93 & 1.765 & 1.917 & -0.152 & -7.93 & 23 & - & 2.046 & - & - & - & - & 3.92 & Claystone (10R $2 / 2)$ \\
\hline 60 & 2 & $63-65$ & 560.63 & 5.154 & - & - & - & 23 & 3.79 & $2.882^{\mathrm{k}}$ & - & 2.80 & 3.0 & 8.1 & 14.43 & Basalt (cracks) (half core) \\
\hline 60 & 2 & $63-65$ & 560.63 & $5.0461, \mathrm{~m}$ & $5.042^{\mathrm{m}}$ & 0.004 & 0.08 & 23 & - & 2.810 & - & - & - & - & - & Basalt (cracks) (mini-core) \\
\hline 60 & 2 & $78-80$ & 560.78 & - & $4.290^{\mathrm{m}}$ & - & - & 23 & - & 2.843 & - & - & - & - & $11.37 ?$ & Basalt (vein parallel to velocity path) \\
\hline 60 & 2 & $78-80$ & 560.78 & $4.049^{\mathrm{m}}$ & - & - & - & 23 & - & $\overline{0}$ & - & - & - & - & - & Basalt (vein across velocity path) \\
\hline 61 & 1 & $48-51$ & 567.98 & $5.526^{\mathrm{m}}$ & $5.465^{\mathrm{m}}$ & 0.061 & 1.12 & 19 & 4.77 & 2.893 & - & 2.86 & 1.8 & 4.9 & 15.63 & Basalt (cracks) \\
\hline 61 & 1 & $126-128$ & 568.76 & $5.346^{\mathrm{m}}$ & $5.332^{\mathrm{m}}$ & 0.014 & 0.26 & 19 & - & 2.883 & - & 2.89 & 1.7 & 4.9 & 15.41 & Basalt \\
\hline 62 & 1 & $85-87$ & 577.35 & $5.863^{\mathrm{m}}$ & $5.864^{\mathrm{m}}$ & 0.001 & 0.02 & 19 & 7.00 & 3.073 & - & 2.88 & 1.9 & 5.2 & 16.9 & Basalt (coarse-grained) \\
\hline 62 & 2 & $32-34$ & 578.32 & $4.832^{\mathrm{m}}$ & $4.796^{\mathrm{m}}$ & 0.036 & 0.75 & 24 & - & - & - & - & - & - & - & Basalt \\
\hline 62 & 2 & $109-111$ & 579.09 & $5.310^{\mathrm{m}}$ & $5.275^{\mathrm{m}}$ & 0.035 & 0.66 & 19 & 4.32 & 2.872 & - & 2.98 & 0.7 & 2.0 & 15.7 & Basalt (fine-grained) \\
\hline 63 & 1 & $58-60$ & 580.08 & - & $3.113^{\mathrm{m}}$ & - & - & 19 & - & $\overline{0}$ & - & 2.32 & 15.9 & 36.1 & 7.22 & Volcanic glass \\
\hline 63 & 2 & $32-34$ & 581.32 & $4.794^{\mathrm{m}}$ & $4.521^{\mathrm{m}}$ & 0.273 & 6.04 & 19 & 4.15 & 2.816 & - & $2.56 ?$ & $5.0 ?$ & $12.4 ?$ & 11.57 & Basalt (near cracks) \\
\hline 63 & 3 & $117-120$ & 583.67 & $4.716^{\mathrm{m}}$ & $4.826^{\mathrm{m}}$ & -0.110 & -2.28 & 19 & 3.49 & 2.798 & - & $2.74 ?$ & $5.5 ?$ & $14.6 ?$ & 13.22 & Basalt (cracked) \\
\hline 64 & 1 & $105-107$ & 586.55 & $2.897^{\mathrm{m}}$ & $2.941^{\mathrm{m}}$ & -0.044 & -1.50 & 23 & - & 2.176 & - & 2.15 & 19.0 & 39.8 & 6.32 & Claystone $(5 \mathrm{G}, 2 / 1)$ \\
\hline 64 & 2 & $113-115$ & 588.13 & $2.415^{\mathrm{m}}$ & $2.682^{\mathrm{m}}$ & -0.267 & -9.96 & 23 & - & 1.926 & - & 1.94 & 26.6 & 50.2 & 5.20 & Claystone ( $5 \mathrm{G} 4 / 1$ ) \\
\hline 64 & 3 & $48-50$ & 588.98 & $4.878^{\mathrm{m}}$ & $4.82 \mathrm{1}^{\mathrm{m}}$ & 0.057 & 1.18 & 23 & 4.18 & 2.809 & - & 2.79 & 4.4 & 11.8 & 13.45 & Basalt \\
\hline 65 & 1 & $38-40$ & 594.88 & $5.435^{\mathrm{m}}$ & $5.325^{\mathrm{m}}$ & 0.110 & 2.07 & 23 & 7.27 & 2.989 & - & 2.97 & 2.2 & 6.5 & 15.82 & Basalt \\
\hline 65 & 2 & $7-9$ & 596.07 & $5.429^{\mathrm{m}}$ & $5.408^{\mathrm{m}}$ & 0.021 & 0.39 & 23 & 4.67 & 2.940 & - & 2.96 & 2.2 & 6.2 & 16.01 & Basalt \\
\hline 66 & 1 & $25-27$ & 599.25 & $5.415^{\mathrm{m}}$ & $5.269^{\mathrm{m}}$ & -0.146 & -2.77 & 19 & 4.79 & 2.996 & - & 2.97 & 2.2 & 6.3 & 15.65 & Basalt \\
\hline 66 & 1 & $25-27$ & 599.25 & $5.854^{\mathrm{n}}$ & - & - & - & 15 & - & - & - & - & - & - & - & Basalt \\
\hline 66 & 1 & $25-27$ & 599.25 & $5.816^{\mathrm{n}}$ & - & - & - & 15 & - & - & - & - & - & - & - & Basalt \\
\hline 66 & 2 & 61.5-63.5 & 601.12 & $5.177^{\mathrm{m}}$ & $5.171^{\mathrm{m}}$ & 0.006 & 0.12 & 20 & 5.10 & 2.934 & - & 2.96 & 2.8 & 8.0 & 15.31 & Basalt \\
\hline 66 & 2 & $61.5-63.5$ & 601.12 & $5.622^{\mathrm{n}}$ & - & - & - & 15 & - & - & - & - & - & - & - & Basalt \\
\hline 66 & 2 & $61.5-63.5$ & 601.12 & $5.766^{\mathrm{n}}$ & - & - & - & 15 & - & - & - & - & $\overline{0}$ & - & -7 & Basalt \\
\hline 66 & 4 & $81-83$ & 604.31 & $5.365^{\mathrm{m}}$ & $5.337^{\mathrm{m}}$ & 0.028 & 0.52 & 20 & 4.70 & 2.885 & - & 2.95 & 2.7 & 7.9 & 15.74 & Basalt \\
\hline 66 & 4 & $81-83$ & 604.31 & $5.699^{\mathrm{n}}$ & - & - & - & 15 & - & - & - & - & - & - & - & Basalt \\
\hline 66 & 4 & $81-83$ & 604.31 & $5.582^{\mathrm{n}}$ & - & - & - & 15 & - & - & - & $\overline{0}$ & $\bar{n}$ & $\overline{7}$ & -7 & Basalt \\
\hline 66 & 5 & $54-56$ & 605.54 & $5.318^{\mathrm{m}}$ & $5.218^{\mathrm{m}}$ & 0.086 & 1.65 & 21 & 4.63 & 2.953 & - & 2.95 & 2.6 & 7.6 & 15.39 & Basalt \\
\hline 66 & 5 & $54-56$ & 605.54 & 5.590 & - & - & - & 15 & $=$ & - & - & - & - & - & $=$ & Basalt \\
\hline 66 & 6 & $8-10$ & 606.58 & $5.304^{\mathrm{m}}$ & $5.504^{\mathrm{mm}}$ & 0.200 & 3.63 & 21 & 5.22 & 2.990 & - & 2.98 & 2.2 & 6.3 & 16.40 & Basalt \\
\hline 66 & 6 & $8-10$ & 606.58 & $5.947^{\mathrm{n}}$ & - & - & - & 15 & - & - & - & - & - & - & - & Basalt \\
\hline $\begin{array}{l}66 \\
677^{\circ}\end{array}$ & 6 & $\begin{array}{r}8-10 \\
3-15\end{array}$ & 606.58 & $\begin{array}{l}5.877^{\mathrm{n}} \\
584^{\mathrm{n}}\end{array}$ & $\bar{z}$ & $\bar{z}$ & $\bar{z}$ & 15 & $\overline{4.52} 4.12$ & $2 \overline{951}$ & $=$ & $\overline{296}$ & $\overline{2.2}$ & $\overline{6.2}$ & $17 \overline{20}$ & $\begin{array}{l}\text { Basalt } \\
\text { Basalt }\end{array}$ \\
\hline $\begin{array}{l}67^{\circ} \\
67^{2}\end{array}$ & $\begin{array}{l}1 \\
2\end{array}$ & $\begin{array}{c}13-15 \\
123-126\end{array}$ & $\begin{array}{l}606.13 \\
608.73\end{array}$ & $\begin{array}{l}5.811^{n} \\
5.795^{n}\end{array}$ & $\bar{z}$ & $\overline{-}$ & $=$ & $\begin{array}{l}15 \\
15\end{array}$ & $\begin{array}{l}4.52,4.12 \\
5.105 .39\end{array}$ & $\begin{array}{l}2.951 \\
2.924\end{array}$ & $\bar{z}$ & $\begin{array}{l}2.96 \\
2.96\end{array}$ & $\begin{array}{l}2.2 \\
2.3\end{array}$ & $\begin{array}{l}6.2 \\
6.7\end{array}$ & 17.15 & $\begin{array}{l}\text { Basait } \\
\text { Basalt }\end{array}$ \\
\hline $\begin{array}{l}67 \\
68\end{array}$ & 1 & $24-26$ & $\begin{array}{l}608.73 \\
609.24\end{array}$ & $\begin{array}{l}5.7 .755^{n-1} \\
5.13^{n}\end{array}$ & $\bar{z}$ & $\overline{-}$ & $\overline{-}$ & 15 & -10 & 2.893 & - & $\begin{array}{l}2.90 \\
2.95\end{array}$ & 1.0 & 2.9 & 17.15 & Basalt \\
\hline $\begin{array}{l}88 \\
68\end{array}$ & 2 & $66-68$ & 611.16 & $5.948^{n}$ & $=$ & $\bar{z}$ & $=$ & 15 & 4.29 & 2.991 & - & 2.99 & 0.8 & 2.2 & 17.78 & Basalt \\
\hline 68 & 3 & $\begin{array}{l}+0-68 \\
15-17\end{array}$ & & $5.935^{\mathrm{n}}$ & $\bar{z}$ & $\bar{z}$ & $\bar{z}$ & 15 & 3.97 & 3.047 & $=$ & 3.00 & 0.6 & 1.8 & 17.81 & Basalt \\
\hline 68 & 3 & $102-104$ & 613.02 & $5.870^{n}$ & $=$ & $\overline{-}$ & $\bar{z}$ & 15 & 5.06 & 3.009 & $=$ & 2.98 & 0.7 & 1.9 & 17.49 & Basalt \\
\hline 69 & $i$ & $24-26$ & 614.24 & $5.221^{\mathrm{n}}$ & $=$ & $=$ & - & 15 & 6.86 & - & - & 2.90 & 2.4 & 6.8 & 15.14 & Basalt (cracked) \\
\hline 69 & 2 & $36-38$ & 615.86 & $5.640^{n}$ & - & - & - & 15 & 5.31 & $2 . \overline{973}$ & $=$ & 2.93 & 1.5 & 4.2 & 16.53 & Basalt \\
\hline
\end{tabular}

a Temperature estimated from time after core was on deck until measurement. The time after core was on deck was estimated in heat-conductivity measurements. Temperature was estimated from the "time-temperature curve" and assumes that cores were at $14.2^{\circ} \mathrm{C}$ when they arrived on deck.

eg and $\mathrm{ege}=2.7 \mathrm{~g} / \mathrm{cm}^{2}$ for sedimentary rock, and $3.00 \mathrm{~g} / \mathrm{cm}^{3}$ for basaltic rock.

Impedance is generally the product of the gravimetric wet-bulk density and vertical velocity.

Vane shear strength $=370.0 \mathrm{~g} / \mathrm{cm}^{2}$, remolded $=57.9 \mathrm{~g} / \mathrm{cm}^{2}$, sensitivity $=7.1$.

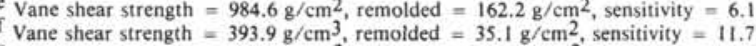

$\mathrm{B}$ Vane shear strength $=289.5 \mathrm{~g} / \mathrm{cm}^{3}$, remolded $=59.9 \mathrm{~g}^{\prime} \mathrm{cm}^{2}$, sensitivity $=4.8$.

Analog GRAPE $=1.65 \mathrm{~g} / \mathrm{cm}^{3}, 62.7 \%$.
Analog GRAPE $=1.55 \mathrm{~g}^{2} \mathrm{~cm}^{2}, 6.7 \%$.

Below Core 36, cores were firm; therefore, we waited - 2hours be fore velocity measurements. Above Core 36, temperature measurements show that cores were within $1102^{\circ} \mathrm{C}$ of room temperature. All 2-Minute GRAPE on basalt mini-cores are through the axis of the mini-core.

Velocities are on mini-cores and are through diameter of mini-core.

n Full diameter $(6.6 \mathrm{~cm})$ core, run immediately when core arrived on deck (cores).

All cores below (and including 67 have velocities measured on the "full diameter cores," 


\begin{tabular}{|c|c|c|c|c|c|c|c|c|c|c|c|c|c|c|c|c|}
\hline \multirow[b]{3}{*}{ Core } & \multirow[b]{3}{*}{ Section } & \multirow[b]{3}{*}{$\begin{array}{l}\text { Interval } \\
(\mathrm{cm})\end{array}$} & \multirow[b]{3}{*}{$\begin{array}{l}\text { Depth in } \\
\text { Hole } \\
\text { (m) }\end{array}$} & \multirow{2}{*}{\multicolumn{5}{|c|}{ Compressional-Sound Velocity }} & \multirow{3}{*}{$\begin{array}{c}\text { Heat } \\
\text { Conductivity } \\
\text { at } 21^{\circ} \mathrm{C} \\
\left(\text { cal. } \times 10^{-3}\right) \\
\frac{\left(\mathrm{cm} \cdot \mathrm{s} \cdot{ }^{\circ} \mathrm{C}\right)}{}\end{array}$} & \multicolumn{2}{|c|}{$\begin{array}{c}\text { GRAPE } \\
\text { "Special" Wet- } \\
\text { Bulk Densityb } \\
\text { 2-Minute Count } \\
\left(\mathrm{g} / \mathrm{cm}^{3}\right)\end{array}$} & \multicolumn{3}{|c|}{ Gravimetric } & \multirow[b]{3}{*}{$\begin{array}{c}\text { Acoustic } \\
\text { Impedance } \\
\left(\mathrm{g} \cdot 10^{5} / \mathrm{cm}^{2} \cdot \mathrm{s}\right)\end{array}$} & \multirow[b]{3}{*}{ Lithology } \\
\hline & & & & & & & & & & \multirow[b]{2}{*}{$\begin{array}{c}1 \\
\text { Beds }\end{array}$} & & & Wet-Water & & & \\
\hline & & & & $\begin{array}{c}\begin{array}{c}1 \\
\text { Beds } \\
(\mathrm{km} / \mathrm{s})\end{array} \\
.\end{array}$ & $\begin{array}{c}\stackrel{\perp}{\text { Beds }} \\
(\mathrm{km} / \mathrm{s})\end{array}$ & 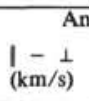 & $\begin{array}{l}\text { isotropy } \\
\left(1-\frac{1}{(\%) / \perp}\right. \\
(\%)\end{array}$ & $\begin{array}{l}\text { Temp. }{ }^{\mathrm{a}} \\
\left({ }^{\circ} \mathrm{C}\right)\end{array}$ & & & $\stackrel{1}{\text { Beds }}$ & $\begin{array}{l}\text { Wet-Bulk } \\
\text { Density } \\
\left(\mathrm{g} / \mathrm{cm}^{3}\right)\end{array}$ & 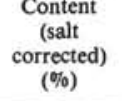 & 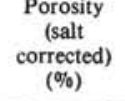 & & \\
\hline 1 & 1 & $2-3$ & 78.52 & $1.509 \mathrm{~g}$ & - & - & - & $18^{\mathrm{d}}$ & - & - & - & - & - & - & - & Nannofossil ooze (10YR $8 / 2$ ) \\
\hline$i$ & $\mathrm{i}$ & $9-12$ & 78.59 & 1.5298 & - & - & - & $18^{\mathrm{d}}$ & - & - & - & - & - & - & - & Radiolarian ooze (5YR 5/2) \\
\hline 1 & 1 & $14-16$ & 78.64 & 1.5688 & - & - & $=$ & $18^{\mathrm{d}}$ & - & - & - & - & $=$ & - & - & Foraminifer nannofossil ooze (SYR 9/2) \\
\hline$i$ & 1 & 44-46 & 78.94 & 1.5338 & $=$ & $=$ & $=$ & $18^{d}$ & $=$ & - & - & 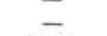 & $=$ & $\bar{z}$ & $=$ & Nannofossil radiolarian ooze (10YR $5 / 4$ ) \\
\hline 2 & 2 & $72-74$ & 250.22 & $1.592 \mathrm{~g}$ & - & - & - & $19^{d}$ & - & - & - & 1.63 & 39.4 & 62.8 & 2.59 & Nannofossil ooze (lump) (10YR $8 / 2$ ) \\
\hline 2 & 5 & $41-42$ & 255.91 & - & - & - & - & - & - & - & - & 1.57 & 42.0 & 64.1 & - & Interstitial-water sample (I.W.) \\
\hline 3 & 1 & $1-3$ & 401.51 & $4.854 \mathrm{~g}$ & - & - & - & $20 ?$ & - & 2.477 & - & 2.55 & 1.7 & 4.1 & 12.37 & Chert (laminated) (N7) \\
\hline 4 & i & $0-2$ & 411.02 & 3.8698 & - & - & - & 24 & - & - & - & 2.07 & 6.6 & 13.3 & 8.01 & Porcellanite (irregular edge) $(5 \mathrm{G} 4 / 1)$ \\
\hline 4 & 1 & $14-16$ & 411.14 & 3.5808 & - & - & - & 24 & - & - & - & 2.34 & 7.1 & 16.2 & 8.38 & Siliceous limestone (N9) \\
\hline 4 & i & $54-55$ & 411.54 & $5.016^{8}$ & - & - & - & 24 & - & - & - & 2.52 & 0.8 & 1.9 & 12.64 & Chert (5Y $6 / 1)$ \\
\hline 4 & i & $66-68$ & 411.66 & 2.6678 & - & - & - & 24 & - & - & - & 1.97 & 11.0 & 21.1 & 5.25 & Limestone (laminated) (10YR $8 / 2$ to $6 / 2$ ) \\
\hline 5 & $\mathrm{i}$ & $3-5$ & 420.53 & (orientation?) & $4.464^{\mathrm{g}}$ & - & - & 20 ? & - & - & - & 2.58 & 0.4 & 0.9 & 11.52 & Chert (quartzose) (10YR 2/2) \\
\hline 5 & i & $18-20$ & 420.68 & (orientation?) & $4.852^{8}$ & - & - & 20 ? & - & - & - & 2.55 & 0.7 & 1.7 & 12.37 & Chert (quartzose) (10R 4/2) \\
\hline 6 & $\mathrm{CC}$ & - & 430.00 & $2.916^{8}$ & - & - & - & 15 & - & - & $\underline{-}$ & - & - & - & - & $\begin{array}{l}\text { Limestone }(10 Y R \quad 7 / 2) \\
\text { (1) }\end{array}$ \\
\hline 6 & CC & - & 430.05 & 4.4878 & - & - & - & 15 & $=$ & - & $=$ & $\overline{-}$ & $\overline{-}$ & $\overline{-}$ & $=$ & Chert (10YR 2/2) \\
\hline 7 & 1 & $39-41$ & 439.89 & $2.818 \mathrm{~g}$ & $2 . \overline{9558}$ & $-\overline{0.137}$ & $-\overline{4} .64$ & 22 & 3.01 & $\bar{z}$ & $=$ & $\bar{z}+1+r+1+1$ & $=$ & 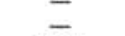 & $\overline{5.26}$ & Sandstone (calcarenite) (10YR 6/2) \\
\hline 7 & 2 & $123-125$ & 442.23 & 2.8598 & $2.653^{8}$ & 0.206 & 7.76 & 22 & - & $\bar{z}$ & $\bar{z}$ & $1 . \overline{91}$ & $\overline{14.8}$ & 27.7 & $\begin{array}{l}.20 \\
5.07\end{array}$ & Siliceous limestone (10YR $7 / 2$ ) \\
\hline $\mathrm{H}-3$ & 1 & $20-22$ & 449.20 & $2.096 \mathrm{~g}$ & 1.9788 & 0.118 & 5.97 & 21 & $=$ & $\overline{-}$ & $\bar{z}$ & 2.08 & $\begin{array}{l}14.0 \\
18.8\end{array}$ & 38.1 & 4.11 & Claystone (5YR 4/1) \\
\hline $\mathrm{H}-3$ & 2 & $8-10$ & 450.58 & 2.7118 & $2.051^{8}$ & 0.660 & 32.18 & 21 & 5.21 & - & - & 2.21 & 14.2 & 30.7 & $\begin{array}{l}4.11 \\
4.53\end{array}$ & Sandstone $(5 \mathrm{G} 6 / 1)$ \\
\hline $\mathrm{H}-3$ & 2 & $121-122$ & 451.71 & 2.0378 & $2.089 \mathrm{~g}$ & -0.052 & -2.49 & 21 & - & $=$ & $\overline{-}$ & 2.06 & 18.1 & 36.5 & 4.30 & Limestone (SB $7 / 1$ ) \\
\hline 8 & 1 & $121-123$ & 488.21 & $2.252^{\mathrm{g}}$ & $2.126^{8}$ & 0.126 & 6.03 & $20 ?$ & - & - & - & 2.14 & 15.9 & 33.1 & 4.55 & Calcareous claystone ( 5 Y $6 / 1)$ \\
\hline 8 & 2 & $38-40$ & 488.88 & 1.7678 & 1.7538 & 0.014 & 0.80 & $20 ?$ & - & - & - & 1.77 & 33.5 & 59.9 & 3.10 & Volcanic-ash sandstone $(5 Y 4 / 1)$ \\
\hline 8 & 3 & $19-21$ & 490.19 & 2.1898 & 1.9808 & 0.209 & 10.56 & $20 ?$ & - & - & 2.040 & 1.99 & 22.1 & 42.8 & 3.94 & $\begin{array}{l}\text { Claystone (5YR } 4 / 1 \text { ) } \\
\text { (1) }\end{array}$ \\
\hline 8 & 3 & $134-136$ & 491.34 & $2.610 \mathrm{~g}$ & 2.2798 & 0.331 & 14.52 & $20 ?$ & 3.92 & - & 2.193 & 2.14 & 16.0 & 33.4 & 4.88 & Limestone (5Y $6 / 1$ ) \\
\hline H-4 & 2 & $28-30$ & 498.29 & $2.838 \mathrm{~g}$ & 2.5438 & 0.295 & 11.60 & 21 ? & 5.08 & - & 2.216 & 2.20 & 13.5 & 28.9 & $\begin{array}{l}4.00 \\
5.59\end{array}$ & Limestone (10YR $7 / 1$ ) \\
\hline $\mathrm{H}-4$ & 2 & $110-112$ & 499.10 & 2.6508 & $2.356 \mathrm{~g}$ & 0.294 & 12.48 & 21 & 5.42 & $\overline{-}$ & 2.134 & 2.04 & 17.4 & $\begin{array}{l}28.9 \\
34.5\end{array}$ & 4.81 & Limestone (10YR 7/1) \\
\hline $\mathrm{H}-4$ & 3 & $40-42$ & 499.90 & $2.181 \mathrm{~g}$ & 2.1448 & 0.037 & $\begin{array}{l}1.46 \\
1.73\end{array}$ & ${ }_{21}^{21}$ & $\begin{array}{l}3.42 \\
4.54\end{array}$ & $\bar{z}$ & 2.239 & 2.22 & $\begin{array}{l}17.4 \\
13.9\end{array}$ & $\begin{array}{l}34.3 \\
30.1\end{array}$ & $\begin{array}{l}4.81 \\
4.76\end{array}$ & Limestone (10YR 7/1) \\
\hline $\mathrm{H}-4$ & 3 & 67-69 & 500.17 & 2.2198 & 2.1248 & 0.095 & 4.47 & 21 & 4.63 & - & 2.244 & 2.21 & 14.0 & 30.3 & $\begin{array}{l}4.70 \\
4.69\end{array}$ & Limestone (10YR 7/1) \\
\hline 9 & 1 & 90-94 & 516.40 & 2.3638 & $2.088 \mathrm{~g}$ & 0.275 & $\begin{array}{l}4.41 \\
13.17\end{array}$ & 21 & - & $=$ & -2.24 & 1.87 & 24.3 & 44.3 & $\begin{array}{l}4.09 \\
3.90\end{array}$ & Claystone (10YR 2/2) \\
\hline 9 & i & $129-131$ & 516.79 & $2.546^{8}$ & 2.4208 & 0.126 & 5.21 & 21 & 4.09 & - & - & 1.97 & 19.5 & 38.9 & 4.77 & $\begin{array}{l}\text { Limstone }(10 \mathrm{Y} \text { R } 6 / 2) \\
\text { Lime }\end{array}$ \\
\hline 9 & 4 & $17-19$ & 520.17 & $2.262 \mathrm{~g}$ & 2.1148 & 0.148 & 7.00 & 21 & 3.81 & $\overline{-}$ & $\overline{-}$ & 2.08 & 18.7 & 37.8 & 4.40 & Limestone (SB 7/1) \\
\hline 9 & 6 & $42-44$ & 523.42 & $1.832 \mathrm{~g}$ & $1.736 \mathrm{~g}$ & 0.096 & 5.53 & 21 & - & - & - & 1.81 & 31.0 & 54.8 & 3.14 & Claystone (SYR 4/4) \\
\hline 10 & 1 & $25-27$ & 525.25 & $1.833^{\mathrm{g}}$ & $1.671^{8}$ & 0.162 & 9.69 & $20 ?$ & - & - & - & 1.76 & 33.7 & 57.8 & 2.94 & Claystone (SYR 4/4) \\
\hline 10 & 2 & $47-49$ & 526.97 & 1.8448 & 1.6448 & 0.200 & 12.17 & 20 ? & - & - & - & 1.68 & 38.5 & 63.2 & 2.76 & $\begin{array}{l}\text { Claystone (5YR 4/4) } \\
\text { (5YR }\end{array}$ \\
\hline 10 & 3 & $133-135$ & 529.33 & $1.946^{\mathrm{B}}$ & 1.8228 & 0.124 & 6.81 & $20 ?$ & - & - & - & 1.85 & 30.2 & 54.4 & 3.37 & Claystone (10YR 2/2) \\
\hline 11 & 1 & $93-95$ & 535.43 & 1.9258 & 1.8338 & 0.092 & 5.02 & 20 ? & $=$ & - & $=$ & 1.83 & 30.7 & 54.9 & 3.35 & Claystone (5Y 4/1) \\
\hline 11 & $i$ & $140-142$ & 535.90 & 2.0928 & 2.0558 & 0.037 & 1.80 & 20 ? & $=$ & $\overline{-}$ & $=$ & 1.88 & 29.1 & 53.4 & 3.86 & Siltstone (laminated) (5GY $6 / 1)$ \\
\hline 11 & CC & $1-3$ & 536.33 & 1.9258 & $\begin{array}{l}1.8658 \\
1.858\end{array}$ & 0.060 & 3.22 & $20 ?$ & 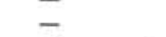 & - & $=$ & 1.89 & 28.1 & 51.7 & $\begin{array}{l}3.00 \\
3.52\end{array}$ & Sandstone $(5 \mathrm{G} 4 / 1)$ \\
\hline 12 & 1 & $81-83$ & 544.81 & $1.826^{8}$ & 1.7568 & 0.070 & 3.99 & $20 ?$ & $\bar{z}$ & - & $=$ & 1.66 & 36.9 & 60.0 & 2.91 & Claystone (SYR 4/4) \\
\hline 13 & $i$ & $19-21$ & 533.19 & 1.9088 & $1.831^{8}$ & 0.077 & 4.21 & 20 ? & - & - & - & $\begin{array}{l}1.00 \\
1.88\end{array}$ & 27.7 & 50.9 & $\begin{array}{l}2.91 \\
3.44\end{array}$ & Claystone (5YR 4/4) \\
\hline 13 & 2 & 65-67 & 555.15 & 2.2958 & 2.0898 & 0.206 & 9.86 & 20 ? & $=$ & - & $\overline{-}$ & 2.07 & 17.6 & 35.6 & 4.32 & Claystone (laminated) (10YR 2/2) \\
\hline 13 & 2 & 93-94 & 555.93 & - & - & - & - & $20 ?$ & - & - & - & 1.80 & 31.2 & 54.8 & - & Claystone (mottled) $(10 \mathrm{YR} 6 / 2)$ \\
\hline 14 & $i$ & $27-29$ & 563.27 & 2.2898 & - & - & - & 15 & - & - & - & 1.91 & 25.9 & 48.2 & 4.37 & Claystone (10YR 2/2) \\
\hline 14 & 2 & $31-33$ & 564.81 & $5.289^{\mathrm{f}}$ & - & - & - & 15 & - & 2.798 & - & - & - & - & - & Basalt clasts in breccia \\
\hline 15 & 1 & $0-5$ & 566.50 & 2.0858 & - & - & - & 15 & - & 1.796 & - & $=$ & - & - & 3.74 & Siltstone, laminated \\
\hline 15 & 1 & $78-81$ & 567.28 & $6.300^{\mathrm{f}}$ & $\overline{-}$ & $\bar{z}$ & $z$ & 15 & $\overline{-}$ & 2.984 & ב & 2.99 & $\overline{0.4}$ & 1.2 & $\begin{array}{l}3.84 \\
18.84\end{array}$ & Basalt (dense) \\
\hline 15 & 1 & $78-81$ & 567.28 & $6.186^{\mathrm{f}}$ & $=$ & $\bar{z}$ & $\bar{z}$ & 15 & $=$ & -2.904 & $=$ & - & -0.4 & -2 & 18.04 & Basalt (dense) \\
\hline 15 & 1 & $78-81$ & 567.28 & $\begin{array}{l}5.894^{\mathrm{e}} \\
5\end{array}$ & $=$ & $=$ & $\bar{z}$ & 19 & $=$ & $\overline{-}$ & $=$ & $\overline{-}$ & $=$ & $z$ & $\overline{-}$ & $\begin{array}{l}\text { Basalt (dense) } \\
\text { Basal (dense }\end{array}$ \\
\hline 16 & 1 & 34-36 & 572.34 & $5.915^{\mathrm{f}}$ & - & - & - & 15 & - & 3.000 & - & 2.98 & $\overline{0.6}$ & $\overline{1.7}$ & $\overline{17.63}$ & Basalt (aense) \\
\hline 16 & 1 & $62-64$ & 572.62 & $6.091^{\mathrm{f}}$ & $=$ & $\bar{z}$ & $\bar{z}$ & 15 & $=$ & 2.979 & $=$ & 2.99 & 0.5 & 1.4 & 18.21 & $\begin{array}{l}\text { Basait } \\
\text { Basalt }\end{array}$ \\
\hline 17 & 1 & $88-91$ & 574.88 & $5.812^{\mathrm{f}}$ & - & $=$ & $\overline{-}$ & 15 & $\overline{4.69}$ & 2.919 & $\overline{-}$ & 2.98 & 0.6 & 1.7 & $\begin{array}{l}18.21 \\
17.32\end{array}$ & $\begin{array}{l}\text { Basat } \\
\text { Basalt }\end{array}$ \\
\hline 17 & 2 & $52-54$ & 576.92 & $6.090^{\mathrm{f}}$ & - & - & - & 15 & 5.16 & 2.903 & - & 2.97 & 0.8 & 2.3 & $\begin{array}{l}17.09 \\
18.09\end{array}$ & Basalt (vein) \\
\hline 18 & 2 & $15-17$ & 577.65 & $5.349^{\mathrm{f}}$ & - & - & - & 15 & $4.49 ?$ & 2.931 & - & 2.82 & 2.7 & 7.5 & 15.08 & Basalt (vein) \\
\hline 18 & 2 & $60-62$ & 578.10 & $5.971_{f}^{\mathrm{f}}$ & - & - & - & is & - & 3.048 & - & 2.97 & 0.7 & 2.1 & 17.73 & Basalt (2-mm vein) \\
\hline 19 & 1 & $34-36$ & 578.34 & $5.842^{f}$ & - & - & - & 15 & - & - & - & 2.97 & 0.6 & 1.7 & 17.35 & Basalt (cracked) \\
\hline 19 & 2 & $119-121$ & 580.69 & $4.657^{f}$ & - & - & - & 15 & - & - & - & 2.69 & 4.2 & 11.0 & 12.52 & Basalt (vein) \\
\hline 20 & 1 & $27-29$ & 581.27 & $5.4211^{f}$ & $=$ & $=$ & $z$ & 24 & 4.29 & - & $\overline{-}$ & 2.87 & 1.5 & 4.3 & 15.56 & Basalt (cracked) \\
\hline
\end{tabular}




\begin{tabular}{|c|c|c|c|c|c|c|c|c|c|c|c|c|c|c|c|c|}
\hline 20 & 2 & $6-8$ & 582.56 & $6.028^{f}$ & - & - & - & 24 & 4.53 & 3.162 & - & 2.99 & 0.2 & 0.6 & 18.02 & Basalt \\
\hline 21 & 1 & $86-88$ & 586.86 & $5.273^{f}$ & - & - & - & 15 & - & - & - & 2.89 & 0.9 & 2.5 & 15.24 & Basalt (cracked) \\
\hline 22 & 2 & $1-3$ & 589.51 & $2.706^{8}$ & $2.303^{8}$ & 0.403 & 17.50 & $22 ?$ & - & 2.208 & - & 2.12 & 17.0 & 35.1 & 4.88 & Claystone (N3) \\
\hline 22 & 3 & $53-55$ & 591.53 & $5.605^{f}$ & - & - & - & 15 & - & 2.933 & - & 2.94 & 0.5 & 1.5 & 16.48 & Basalt \\
\hline 22 & 5 & $59-61$ & 594.59 & $5.883^{f}$ & - & - & - & 15 & - & 2.996 & - & 2.97 & 0.4 & 1.2 & 17.47 & Basalt \\
\hline 23 & 1 & $143-146$ & 598.43 & $5.211 \mathrm{I}^{\mathrm{f}}$ & - & - & - & 15 & - & 2.956 & - & 2.94 & 0.6 & 1.8 & 15.32 & Basalt (cracks across velocity path) \\
\hline 23 & 3 & $8-10$ & 600.08 & $5.167^{\mathrm{f}}$ & - & - & - & 15 & - & 2.965 & - & 2.91 & 0.9 & 2.5 & 15.04 & Basalt (cracks parallel to velocity path) \\
\hline 23 & 4 & $70-72$ & 602.20 & $5.080^{\mathrm{f}}$ & - & - & - & 15 & - & 2.868 & - & 2.83 & 1.6 & 4.3 & 14.38 & Basalt \\
\hline 24 & $i$ & $16-18$ & 606.16 & $5.186^{\mathrm{f}}$ & $\overline{-}$ & - & - & 15 & 4.17 & 2.876 & - & 2.85 & 1.4 & 4.0 & 14.78 & Basalt \\
\hline 24 & 2 & $8-11$ & 607.58 & $5.501^{\mathrm{f}}$ & $\overline{-}$ & $=$ & $\overline{-}$ & is & 3.86 & 3.023 & - & 2.89 & 0.6 & 1.8 & 15.90 & Basalt \\
\hline 24 & 3 & $19-21$ & 609.19 & $5.372^{\mathrm{f}}$ & $\bar{z}$ & $\bar{z}$ & $=$ & 15 & - & - & - & 2.89 & 1.0 & 2.8 & 15.53 & Basalt \\
\hline 25 & 1 & 83-86 & 615.83 & $5.517^{\mathrm{f}}$ & - & - & - & 15 & - & 2.971 & - & 2.91 & 1.1 & 3.2 & 16.05 & Basalt \\
\hline 27 & 2 & $10-12$ & 627.60 & $5.918^{f}$ & - & - & - & 15 & - & 3.055 & - & 3.00 & 0.4 & 1.1 & 17.75 & Basalt \\
\hline 27 & 2 & $72-74$ & 628.22 & $5.797 \mathrm{f}$ & - & - & - & 15 & - & 3.033 & - & 2.99 & 0.5 & 1.4 & 17.33 & Basalt \\
\hline 28 & 1 & $119-121$ & 631.19 & $5.974^{f}$ & - & - & - & 15 & 4.35 & 3.079 & - & 2.98 & 0.5 & 1.3 & 17.80 & Basalt \\
\hline 28 & 2 & $89-92$ & 632.39 & $6.031^{\mathrm{f}}$ & - & - & - & 15 & 4.75 & 3.054 & - & 2.99 & 0.4 & 1.3 & 18.03 & Basalt \\
\hline 28 & 3 & $75-77$ & 633.75 & $5.953^{\mathrm{f}}$ & - & - & - & 15 & 4.51 & 3.114 & - & 2.99 & 0.7 & 2.0 & 17.80 & Basalt \\
\hline 28 & 4 & $139-142$ & 635.89 & $5.817^{f}$ & - & - & - & 15 & 4.60 & 2.971 & - & 2.99 & 0.5 & 1.5 & 17.39 & Basalt \\
\hline 29 & 1 & $9-11$ & 636.09 & $5.873^{\mathrm{f}}$ & - & - & - & 15 & - & 2.969 & - & 2.96 & 1.0 & 2.9 & 17.38 & Basalt (velocity path across vein) \\
\hline 29 & 2 & $117-119$ & 638.67 & $5.679 \mathrm{f}$ & - & - & - & 15 & 4.84 & - & - & - & - & - & - & Basalt (cracked) \\
\hline 29 & 3 & $44-46$ & 639.44 & $6.062^{\mathrm{f}}$ & - & - & - & 15 & - & 2.991 & - & 2.95 & 1.3 & 3.6 & 17.88 & Basalt \\
\hline 29 & 4 & $70-73$ & 641.20 & $6.145^{\mathrm{f}}$ & $=$ & - & $\overline{-}$ & 15 & 5.10 & 3.070 & - & 2.98 & 1.0 & 2.9 & 18.31 & Basalt \\
\hline 29 & 5 & $6-8$ & 642.06 & $5.257^{\mathrm{f}}$ & - & - & - & 15 & - & - & - & 2.99 & 0.9 & 2.7 & 15.71 & Basalt (velocity path, across 4-mm vein) \\
\hline 30 & 1 & $42-44$ & 645.42 & $6.198^{\mathrm{f}}$ & $=$ & $=$ & $=$ & 15 & 4.84 & 3.025 & $=$ & 2.75 & 4.9 & 13.1 & 17.04 & Basalt \\
\hline 30 & 2 & $34-36$ & 646.84 & $6.107^{f}$ & - & - & - & 15 & 5.38 & 3.082 & - & 2.95 & 1.1 & 3.0 & 18.02 & Basalt \\
\hline 30 & 3 & $19-21$ & 648.19 & $6.154^{f}$ & - & - & - & 15 & 3.97 & 3.050 & $=$ & 2.99 & 0.8 & 2.2 & 18.40 & Basalt \\
\hline 30 & 4 & $14-16$ & 649.64 & $6.169^{f}$ & - & - & - & 15 & 5.18 & 3.050 & - & 3.00 & 0.8 & 2.4 & 18.51 & Basalt \\
\hline 31 & 1 & $56-58$ & 654.51 & $5.880^{\mathrm{f}}$ & - & - & - & 15 & - & 2.991 & - & 3.01 & 0.8 & 2.2 & 17.70 & Basalt \\
\hline 32 & i & $31-33$ & 655.81 & $5.672_{f}^{f}$ & - & - & - & 15 & - & 2.952 & - & 2.92 & 1.1 & 3.2 & 16.56 & Basalt veins \\
\hline 32 & 2 & $42-45$ & 657.42 & $3.117^{\mathrm{f}}$ & - & - & - & $\sim 15$ & 3.33 & - & 2.068 & 2.03 & 21.3 & 42.2 & 6.33 & Sandstone (5GY 4/1) \\
\hline 32 & 2 & $42-45$ & 657.42 & $3.125^{8}$ & $2.881^{8}$ & 0.244 & 8.47 & -21 & - & - & - & - & - & - & - & Sandstone $(5 \mathrm{GY} 4 / 1)$ \\
\hline 33 & $\mathrm{CC}$ & $1-3$ & 663.10 & $2.981^{8}$ & - & - & - & 15 & - & - & - & - & - & - & - & Sandstone (5GY $4 / 1)$ \\
\hline 35 & $\mathrm{CC}$ & $0-2$ & 681.10 & - & $2.898^{8}$ & - & - & 15 & & & & & & & $\pi$ & Sandstone (SGY $4 / 1$ ) \\
\hline B-2 & 1 & $69-71$ & 690.69 & $5.677^{\mathrm{f}}$ & - & - & $\overline{-}$ & 24 & - & - & - & 2.95 & 1.2 & 3.5 & 16.75 & Basalt \\
\hline 38 & 1 & $89-91$ & 691.89 & $5.988^{f}$ & - & - & - & 15 & 4.36 & 3.019 & - & 2.96 & 1.0 & 3.0 & 17.72 & Basalt \\
\hline 38 & 2 & $6-8$ & 692.56 & $6.054^{\mathrm{f}}$ & - & - & - & 15 & 4.76 & 3.055 & - & 2.97 & 1.1 & 3.2 & . $\quad 17.98$ & Basalt \\
\hline 39 & 1 & $139-141$ & 693.39 & $5.937^{f}$ & - & - & - & 15 & 3.61 & 3.040 & - & 2.96 & 1.1 & 3.1 & 17.57 & Basalt \\
\hline 39 & 2 & $107-109$ & 694.57 & $5.977^{\mathrm{f}}$ & - & - & - & is & $5.77 ?$ & 2.959 & - & 2.95 & i.i & 3.1 & 17.63 & Basalt \\
\hline 39 & 3 & $105-107$ & 696.05 & $5.889^{f}$ & - & - & - & 15 & 4.54 & 2.967 & - & & 0.9 & 2.6 & 17.55 & Basalt \\
\hline 40 & 1 & $25-27$ & 702.25 & $5.700^{f}$ & - & - & - & 15 & - & - & $=$ & 2.95 & 1.3 & 3.6 & 16.82 & Basalt \\
\hline 40 & i & $99-101$ & 702.99 & $2.965^{\mathrm{f}}$ & - & - & - & 15 & 3.43 & - & - & - & - & - & - & Volcanic laminated claystone (N3) \\
\hline 40 & $\mathrm{i}$ & 99-101 & 702.99 & 2.9528 & 3.1638 & -0.211 & -6.67 & 21 & - & - & 2.124 & 2.12 & 20.1 & 41.6 & 6.71 & Volcanic laminated claystone (N3) \\
\hline 40 & 2 & $42-44$ & 703.92 & $5.617^{f}$ & - & - & - & 15 & 4.36 & 2.951 & - & 2.94 & 1.3 & 3.6 & 16.52 & Basalt \\
\hline 41 & 1 & $51-53$ & 711.51 & $5.889^{\mathrm{f}}$ & - & - & - & is & - & 3.046 & - & 3.00 & 1.1 & 3.3 & 17.67 & Basalt \\
\hline 41 & 3 & $124-126$ & 715.24 & $5.980^{\mathrm{f}}$ & - & - & - & 15 & - & 3.045 & - & 2.99 & 1.1 & 3.1 & 17.88 & Basalt \\
\hline 41 & 5 & $80-82$ & 717.80 & $5.992^{\mathrm{f}}$ & - & $\overline{-}$ & - & 15 & - & 2.938 & - & 2.98 & 1.0 & 2.9 & 17.86 & Basalt \\
\hline 41 & 7 & $108-110$ & 721.08 & $2.964^{\mathrm{f}}$ & $\bar{z}+$ & $\bar{z}$ & - & 15 & - & - & - & - & - & - & - & Claystone (spotted) (N4) \\
\hline 41 & 7 & $108-110$ & 721.08 & 2.8298 & $2 . \overline{95} 8 \mathrm{8}$ & $-\overline{0.129}$ & -4.36 & 21 ? & - & - & - & 2.19 & 18.2 & 38.7 & 6.48 & Claystone (spotted) N4) \\
\hline 41 & 8 & $14-16$ & 721.64 & $3.438^{\mathrm{f}}$ & $2.9380^{\circ}$ & -0.12 & -4.30 & 15 & - & - & - & - & - & - & - & Sandstone (5G 4/1) \\
\hline 41 & 8 & $14-16$ & 721.64 & $\begin{array}{l}3.3988 \\
3.3988\end{array}$ & 3.3938 & 0.005 & 0.15 & $21 ?$ & - & 2.168 & - & 2.12 & 18.2 & 37.7 & 7.19 & Sandstone (5G 4/1) \\
\hline 42 & 1 & $24-26$ & 720.24 & $2.453^{\mathrm{f}}$ & - & - & - & 15 & - & - & - & - & - & - & - & Claystone (5G 4/1) \\
\hline 42 & 1 & $24-26$ & 720.24 & $2.346^{8}$ & 1.9558 & 0.391 & 20.00 & $21 ?$ & - & - & - & 1.88 & 24.6 & 45.1 & 3.68 & Claystone (5G 4/1) \\
\hline 42 & 2 & $46-48$ & 721.96 & $3.002^{\mathrm{f}}$ & - & - & - & 15 & - & - & - & - & - & - & - & \\
\hline 42 & 2 & $46-48$ & 721.96 & $2.944^{8}$ & $2.813^{8}$ & 0.131 & 4.66 & 21 ? & - & - & - & 2.15 & 18.3 & 38.5 & 6.05 & Sandstone (5GY 4/1) \\
\hline 43 & 1 & $145-147$ & 724.45 & $2.632^{\mathrm{g}}$ & 2.4978 & 0.135 & 5.41 & 20 & - & - & - & 2.04 & 21.7 & 43.3 & 5.09 & Sandstone (5Y $4 / 1)$ \\
\hline 43 & 2 & $145-147$ & 725.95 & $2.630^{\mathrm{g}}$ & $2.456^{\mathrm{g}}$ & 0.174 & 7.08 & 20 & - & - & - & 2.04 & 21.2 & 42.2 & 5.01 & Laminated claystone and siltstone ( 5 Y $3 / 1$ ) \\
\hline 44 & $i$ & $0-2$ & 729.00 & $2.072^{\mathrm{f}}$ & - & - & - & 15 & - & - & - & - & - & - & - & Claystone (5YR 3/2) \\
\hline 44 & $i$ & $15-17$ & 729.15 & $4.976 \mathrm{f}$ & - & - & - & 15 & - & - & - & 2.98 & 0.7 & 2.0 & 14.83 & Basalt (chilled margin) \\
\hline 44 & 3 & $139-141$ & 733.39 & $5.502^{\mathrm{f}}$ & - & - & $=$ & 15 & - & - & - & 2.95 & 1.3 & 3.5 & 16.23 & Basalt \\
\hline 45 & 1 & $\begin{array}{l}135-141 \\
105-107\end{array}$ & 734.05 & $5.771^{\mathrm{f}}$ & $=$ & $=$ & - & 15 & 4.45 & 2.994 & - & 2.93 & 1.0 & 3.0 & 16.91 & Basalt \\
\hline 45 & $\begin{array}{l}1 \\
3\end{array}$ & $\begin{array}{c}10-101 \\
4-6\end{array}$ & 736.04 & $5.903^{\mathrm{f}}$ & $=$ & $\bar{z}$ & $\bar{z}$ & 15 & 4.52 & 3.001 & - & 2.96 & 0.7 & 2.1 & 17.47 & Basalt \\
\hline 46 & 1 & $119-121$ & 739.19 & $5.976^{f}$ & - & $=$ & $=$ & 15 & 3.71 & 2.961 & - & 2.93 & 0.8 & 2.3 & 17.51 & Basalt \\
\hline 46 & 2 & $112-114$ & 740.62 & $6.089^{\mathrm{f}}$ & - & - & - & 15 & 4.84 & - & - & 2.94 & 0.7 & 2.0 & 17.90 & Basalt (cracks and veins) \\
\hline 46 & 4 & $13-15$ & 742.63 & $6.068^{\mathrm{f}}$ & - & - & - & 15 & 4.35 & 2.958 & - & 2.95 & 0.6 & 1.8 & 17.90 & Basalt \\
\hline 46 & 5 & $80-83$ & 744.80 & $5.332^{\mathrm{f}}$ & - & - & - & 15 & 4.07 & - & - & 2.89 & 1.7 & 4.8 & 15.41 & Basalt (cracks) \\
\hline 47 & 1 & $59-61$ & 747.59 & $5.513^{\mathrm{f}}$ & - & - & - & 15 & - & - & - & 2.89 & 2.2 & 6.3 & 15.93 & Basalt (cracks) \\
\hline 47 & 2 & $11-13$ & 748.61 & $5.968^{\mathrm{f}}$ & - & - & - & 15 & - & 2.982 & - & 2.96 & 1.0 & 2.8 & 17.67 & Basalt \\
\hline 47 & 3 & $36-38$ & 750.36 & $5.660^{f}$ & - & - & - & 15 & - & 2.926 & - & 2.91 & 1.2 & 3.4 & 16.47 & Basalt (cracks) \\
\hline 48 & 1 & $110-112$ & 757.10 & $5.737^{\mathrm{f}}$ & - & - & - & 15 & 5.45 & 2.900 & - & 2.96 & 1.0 & 2.9 & 16.98 & Basalt \\
\hline 48 & 4 & $61-63$ & 761.11 & $6.026^{\mathrm{f}}$ & - & - & - & 15 & 4.32 & 2.945 & - & 2.97 & 0.7 & 2.1 & 17.90 & Basalt \\
\hline 49 & $i$ & $81-83$ & 765.81 & $5.811^{\mathrm{f}}$ & $=$ & $=$ & $=$ & 15 & 4.20 & 2.979 & - & 2.95 & 0.9 & 2.5 & 17.14 & Basalt \\
\hline 49 & 3 & 6-8 & 768.06 & $5.683^{\mathrm{f}}$ & $\overline{-}$ & 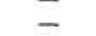 & $=$ & 15 & 3.76 & 2.922 & - & 2.93 & 1.0 & 2.9 & 16.65 & Basalt \\
\hline
\end{tabular}


GRAPE

Bulk Density

2-Minute Çoun
$\left(\mathrm{g} / \mathrm{cm}^{3}\right)$

Gravimetric

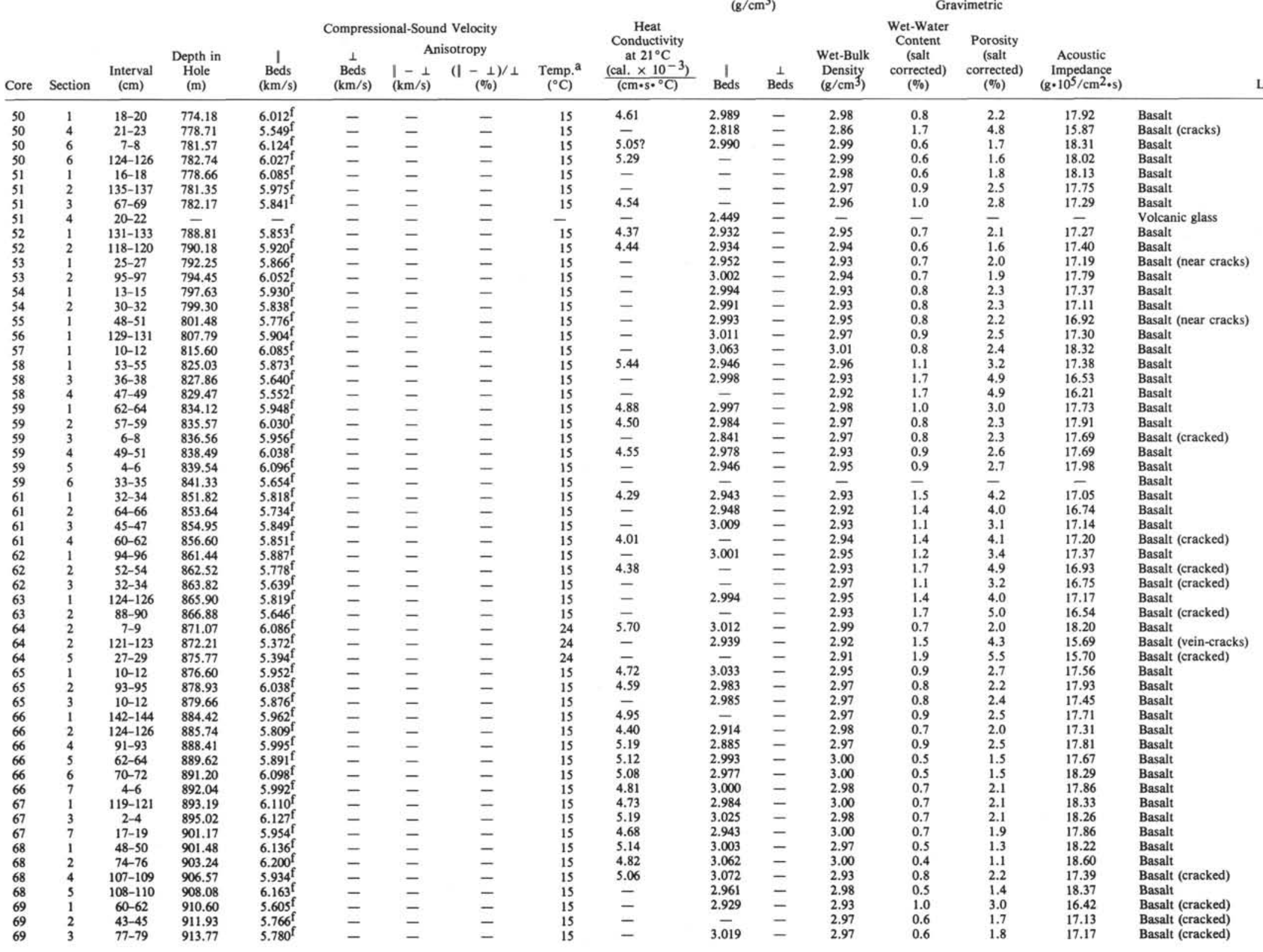




\begin{tabular}{|c|c|c|c|c|c|c|c|c|c|c|c|c|c|c|c|c|}
\hline 70 & 1 & $121-123$ & 920.22 & 4.159 & - & - & - & 15 & 4.44 & 2.984 & - & - & - & - & 12.41 & Slickenside (green) \\
\hline 70 & 2 & $77-79$ & $\begin{array}{l}920.22 \\
921.27\end{array}$ & $5.759 \mathrm{f}^{4}$ & $\bar{z}$ & $=$ & $\bar{z}$ & 15 & - & - & $\overline{-}$ & 2.95 & 0.9 & 2.6 & 16.99 & $\begin{array}{l}\text { Basalt }\end{array}$ \\
\hline 71 & i & $44-46$ & 928.44 & $5.374^{f}$ & - & - & - & is & 4.2 & 2.925 & - & 2.92 & 1.6 & 4.6 & 15.69 & Basalt (vein) \\
\hline 72 & 1 & 43-45 & 931.43 & $5.757^{f}$ & - & - & - & 15 & - & 3.036 & - & 2.96 & 1.1 & 3.0 & 17.04 & Basalt \\
\hline 72 & 2 & $44-46$ & 932.94 & $6.017 \mathrm{f}$ & - & - & - & 15 & - & 3.153 & - & 2.97 & 0.6 & 1.7 & 17.87 & Basalt \\
\hline 73 & 1 & $37-39$ & 937.37 & $5.452^{f}$ & - & - & - & 15 & - & 2.957 & - & 2.93 & 1.4 & 3.9 & 15.97 & Basalt \\
\hline 73 & 2 & $19-21$ & 938.69 & $5.511 \mathrm{f}$ & - & - & - & 15 & - & 2.896 & - & 2.94 & 1.1 & 3.1 & 16.20 & Basalt \\
\hline 73 & 3 & $52-54$ & 940.52 & $5.896 \mathrm{f}$ & - & - & - & 15 & - & 2.985 & - & 2.96 & 1.0 & 2.9 & 17.45 & Basalt \\
\hline 74 & 1 & $5-7$ & 946.05 & $5.850 \mathrm{f}$ & - & - & - & 24 & 4.30 & 3.178 & - & 2.94 & 1.3 & 3.7 & 17.20 & Basalt \\
\hline 74 & 2 & $79-81$ & 948.29 & $5.999 \mathrm{f}$ & - & - & - & 24 & 4.84 & 3.028 & $\overline{-}$ & 2.95 & 1.1 & 3.3 & 17.70 & Basalt \\
\hline 74 & 3 & $118-120$ & 950.18 & $6.071^{\mathrm{f}}$ & - & - & - & 24 & 5.13 & 2.957 & $\overline{-}$ & 2.97 & 1.1 & 3.1 & 18.03 & Basalt \\
\hline 74 & 4 & $123-125$ & 951.73 & $5.90 \mathrm{f}^{\mathrm{f}}$ & - & - & - & 24 & - & 2.969 & $=$ & 2.94 & 1.3 & 3.7 & 17.35 & Basalt \\
\hline 74 & 5 & $94-96$ & 952.94 & $5.978^{f}$ & $=$ & $\bar{z}$ & $\overline{-}$ & $\begin{array}{l}24 \\
24\end{array}$ & $\overline{4.16}$ & $\begin{array}{l}3.909 \\
3.046\end{array}$ & $=$ & 2.96 & 1.6 & 4.6 & 17.69 & Basalt \\
\hline 75 & 2 & $31-33$ & 954.81 & $6.231^{\mathrm{e}}$ & $6.256^{\mathrm{e}}$ & -0.025 & -0.40 & 21.5 & 4.87 & 2.948 & $=$ & 2.96 & 1.7 & 3.4 & 18.52 & Basalt \\
\hline 75 & 4 & $10-13$ & 957.60 & - & $6.293^{\mathrm{e}}$ & -0.020 & -0.40 & 21.5 & $\begin{array}{l}5.01 \\
5.35\end{array}$ & 2.932 & $=$ & 2.98 & 0.9 & 2.7 & 18.75 & Basalt \\
\hline 76 & 1 & $43-45$ & 958.43 & $5.960^{\mathrm{C}}$ & $6.097^{\mathrm{e}}$ & -0.137 & -2.25 & 20 & 4.84 & 3.002 & $\overline{-}$ & 2.99 & 1.1 & 3.3 & 18.23 & Basalt \\
\hline 77 & 1 & $20-23$ & 967.21 & $5.874^{e}$ & $5.885^{\mathrm{e}}$ & -0.011 & -0.19 & $17 ?$ & 4.58 & 3.048 & - & 2.97 & 1.1 & 3.1 & 17.48 & Basalt \\
\hline 77 & 2 & $70-73$ & 969.20 & $5.774^{\mathrm{e}}$ & $5.761^{\mathrm{e}}$ & 0.013 & 0.23 & $17 ?$ & - & - & - & 2.97 & 1.6 & 4.7 & 17.11 & Basalt \\
\hline 77 & 2 & $75-78$ & 969.25 & - & - & - & - & - & 4.75 & 2.961 & - & - & - & - & - & Basalt \\
\hline 78 & 1 & 91-93 & 976.93 & $5.948^{e}$ & $6.048^{e}$ & -0.100 & -1.65 & 21 & 4.64 & 2.995 & - & 2.95 & 1.5 & 4.4 & 17.84 & Basalt \\
\hline 78 & 2 & $82-84$ & 978.32 & $5.756^{\mathrm{e}}$ & $5.814^{\mathrm{e}}$ & -0.058 & 1.00 & 21 & 4.54 & 2.943 & - & 2.95 & 1.2 & 3.4 & 17.15 & Basalt (fractured) \\
\hline 79 & 1 & $138-140$ & 986.38 & $5.667^{\mathrm{e}}$ & $5.670^{e}$ & -0.003 & -0.05 & 21 & 4.44 & 2.963 & - & 2.92 & 2.2 & 6.3 & 16.56 & Basalt \\
\hline 79 & 1 & $138-140$ & 986.38 & $5.800^{\mathrm{h}}$ & $5.695^{\mathrm{h}}$ & 0.105 & 1.84 & 21 & & & & & & & & Basalt \\
\hline 79 & 2 & $135-137$ & 987.85 & $5.582^{\mathrm{e}}$ & $5.612^{\mathrm{e}}$ & -0.030 & -5.35 & 21 & 4.47 & 2.970 & - & 2.92 & 1.9 & 5.4 & 16.39 & Basalt \\
\hline 79 & 2 & $135-137$ & $\begin{array}{l}981.83 \\
987.85\end{array}$ & $5.590^{\mathrm{h}}$ & $5.499^{\mathrm{h}}$ & $\begin{array}{r}-0.030 \\
0.091\end{array}$ & $\begin{array}{r}-3.30 \\
1.65\end{array}$ & ${ }_{21}^{21}$ & 4.47 & 2.970 & - & 2.92 & 1.9 & 5.4 & 10.39 & Basalt \\
\hline 79 & 5 & $42-44$ & $\begin{array}{l}991.42 \\
991.43\end{array}$ & $6.029^{\mathrm{e}}$ & $5.937^{\mathrm{e}}$ & 0.092 & 1.55 & ${ }_{21}^{21}$ & 4.88 & 3.025 & - & 2.98 & 1.0 & 2.8 & 17.69 & Basalt \\
\hline 79 & 5 & $42-44$ & 991.42 & $6.109^{\mathrm{h}}$ & $6.073^{\mathrm{h}}$ & 0.036 & 0.59 & 21 & - & - & - & - & - & - & - & Basalt \\
\hline 80 & 1 & $30-32$ & 994.30 & $2.909^{e}$ & $2.934^{\mathrm{e}}$ & 0.025 & -0.85 & 21 & 3.43 & 2.269 & - & 2.22 & 15.4 & 33.4 & 6.51 & Siltstone (N4) \\
\hline 80 & i & $103-106$ & 995.03 & $2.947^{\mathrm{e}}$ & $2.858^{\mathrm{e}}$ & 0.089 & 3.11 & 21 & 2.88 & 2.220 & - & 2.16 & 16.9 & 35.6 & 6.17 & Sandy mudstone (N3) \\
\hline 80 & 2 & $68-70$ & 996.08 & $2.945^{\mathrm{e}}$ & $2.940^{\mathrm{e}}$ & 0.005 & 0.17 & 21 & 3.17 & 2.205 & - & 2.17 & 16.8 & 35.7 & 6.38 & Sandy siltstone (SYR $2 / 1$ ) \\
\hline 80 & 3 & $42-44$ & 997.42 & $5.375^{\mathrm{e}}$ & $5.435^{\mathrm{e}}$ & -0.059 & -1.09 & 21 & 4.22 & 2.961 & - & 2.91 & 2.0 & 5.7 & 15.82 & Basalt \\
\hline 81 & 1 & $94-96$ & 998.94 & - & - & - & - & - & 4.87 & - & - & - & - & - & - & Basalt \\
\hline 81 & 1 & $\begin{array}{l}90-92 \\
902\end{array}$ & 998.90 & $6 . \overline{111} 1^{\mathrm{e}}$ & $5 . \overline{950} \mathrm{e}$ & $\overline{0.161}$ & $\overline{2.71}$ & $\overline{19}$ & - & $=$ & $\bar{z}$ & 2.98 & 0.9 & 2.6 & 17.73 & Basalt \\
\hline 81 & 3 & $41-42$ & 1001.41 & ${ }^{0.11}$ & - & - & - & - & $\overline{4.44}$ & $=$ & $\overline{-}$ & - & - & - & - & Basalt \\
\hline $\begin{array}{l}81 \\
81\end{array}$ & 3 & $58-60$ & 1001.58 & $5.817^{\mathrm{e}}$ & $5 . \overline{913^{\mathrm{e}}}$ & -0.096 & -1.62 & 19 & - & 3.066 & $\underline{-}$ & 2.98 & 1.1 & 3.2 & 17.62 & Basalt \\
\hline 84 & i & $107-109$ & 1006.57 & $6.095^{\mathrm{e}}$ & $6.144^{e}$ & -0.049 & -0.80 & 19 & 4.87 & 3.007 & - & 3.00 & 0.4 & 1.2 & 18.43 & Basalt \\
\hline 84 & 3 & $108-110$ & 1009.58 & $6.145^{\mathrm{e}}$ & $5.920^{\circ}$ & 0.225 & 3.80 & 19 & 4.62 & - & - & 2.97 & 1.0 & 3.0 & 17.58 & Basalt \\
\hline 84 & 5 & $75-75$ & 1012.25 & 6.165 & $6.174^{\mathrm{e}}$ & -0.009 & -0.15 & 19 & 4.87 & 2.982 & - & 3.00 & 1.0 & 2.5 & 18.52 & Basalt \\
\hline 85 & 1 & $118-120$ & 1015.68 & $6.066^{\mathrm{e}}$ & $6.059^{e}$ & 0.007 & 0.12 & 19 & 4.74 & 3.010 & - & 2.99 & 1.3 & 3.8 & 18.12 & Basalt \\
\hline 85 & 3 & $34-36$ & 1017.84 & $6.227^{\mathrm{e}}$ & $6.246^{\mathrm{e}}$ & -0.019 & -0.30 & 19 & 5.00 & 2.998 & - & 3.00 & 1.6 & 4.6 & 18.74 & Basalt \\
\hline 87 & 1 & $31-33$ & 1026.31 & $6.039^{e}$ & $5.994^{e}$ & 0.045 & 0.75 & 22 & 4.75 & 2.973 & - & 2.97 & 1.7 & 4.8 & 17.80 & Basalt \\
\hline 87 & 2 & $37-39$ & 1027.87 & $5.999^{e}$ & $6.074^{\mathrm{e}}$ & -0.075 & -1.23 & 22 & 4.90 & 3.024 & - & 2.99 & 1.6 & 4.5 & 18.16 & Basalt \\
\hline 88 & 2 & $45-48$ & 1034.45 & $6.104^{\mathrm{e}}$ & $6.047^{\mathrm{e}}$ & 0.057 & 0.94 & 21 & $5.66,5.55$ & 2.989 & - & 3.01 & 1.2 & 3.6 & 18.20 & Basalt \\
\hline 88 & 3 & $17-20$ & 1035.67 & $5.961^{\mathrm{e}}$ & $5.891^{\mathrm{e}}$ & 0.007 & 0.12 & 21 & 4.51 & 2.982 & - & 2.96 & 1.6 & 4.7 & 17.44 & Basalt \\
\hline 89 & 1 & $62-65$ & 1037.12 & $6.080^{\mathrm{e}}$ & $6.069^{\mathrm{e}}$ & 0.011 & 0.18 & 20 & 4.49 & 2.962 & - & 2.95 & 1.7 & 4.8 & 17.90 & Basalt \\
\hline $\begin{array}{l}89 \\
89\end{array}$ & 3 & $121-123$ & 1040.71 & $5.569^{e}$ & $5.781^{\mathrm{e}}$ & -0.212 & $\begin{array}{l}-3.67 \\
-3.67\end{array}$ & 20 & 4.13 & 2.960 & - & 2.96 & 2.4 & 6.8 & 17.11 & Basalt \\
\hline 90 & 1 & $86-88$ & 1042.36 & $5.544^{\mathrm{e}}$ & $5.644^{\mathrm{e}}$ & -0.100 & -1.77 & 21 & 431,432 & 2.956 & - & 2.96 & 2.3 & 6.7 & 16.71 & Basalt \\
\hline 90 & 3 & $78-80$ & 1045.28 & $5.748^{e}$ & $5.664^{\mathrm{e}}$ & 0.084 & 1.48 & 21 & 4.38 & 2.966 & - & 2.96 & 2.3 & 6.7 & 16.77 & Basalt \\
\hline 90 & 4 & 99-101 & 1046.99 & $5.548^{\mathrm{e}}$ & $5.554^{\mathrm{e}}$ & -0.006 & 0.11 & 21 & 4.38 & 2.916 & - & 2.92 & 2.6 & 7.5 & 16.22 & Basalt \\
\hline
\end{tabular}

a Temperature estimated from time after core on deck until measurement. The time after the core was on deck was estimated in the heat-conductivity measurements. Temperature was estimated using "time-temperature curve," assuming that cores were at $\sim 14^{\circ} \mathrm{C}$ when they arrived on deck.

$\mathrm{e}_{\mathrm{g}}$ and $\mathrm{egc}=2.7$ for sedimentary rocks, and 3.0 for basaltic rocks.

d Measured.

e Velocity measured on a mini-core (across diameter).

Velocity measured on a whole core. Basalt velocity on whole core; for Core 16-74, immediately after it arrived on deck.

8 This velocity was measured on D-shaped sample after 2 hours $\left(-21^{\circ} \mathrm{C}\right)$ at room temperature $\left(24^{\circ} \mathrm{C}\right)$.

Half of whole core, wrapped $(2.8 \mathrm{~cm})$. 


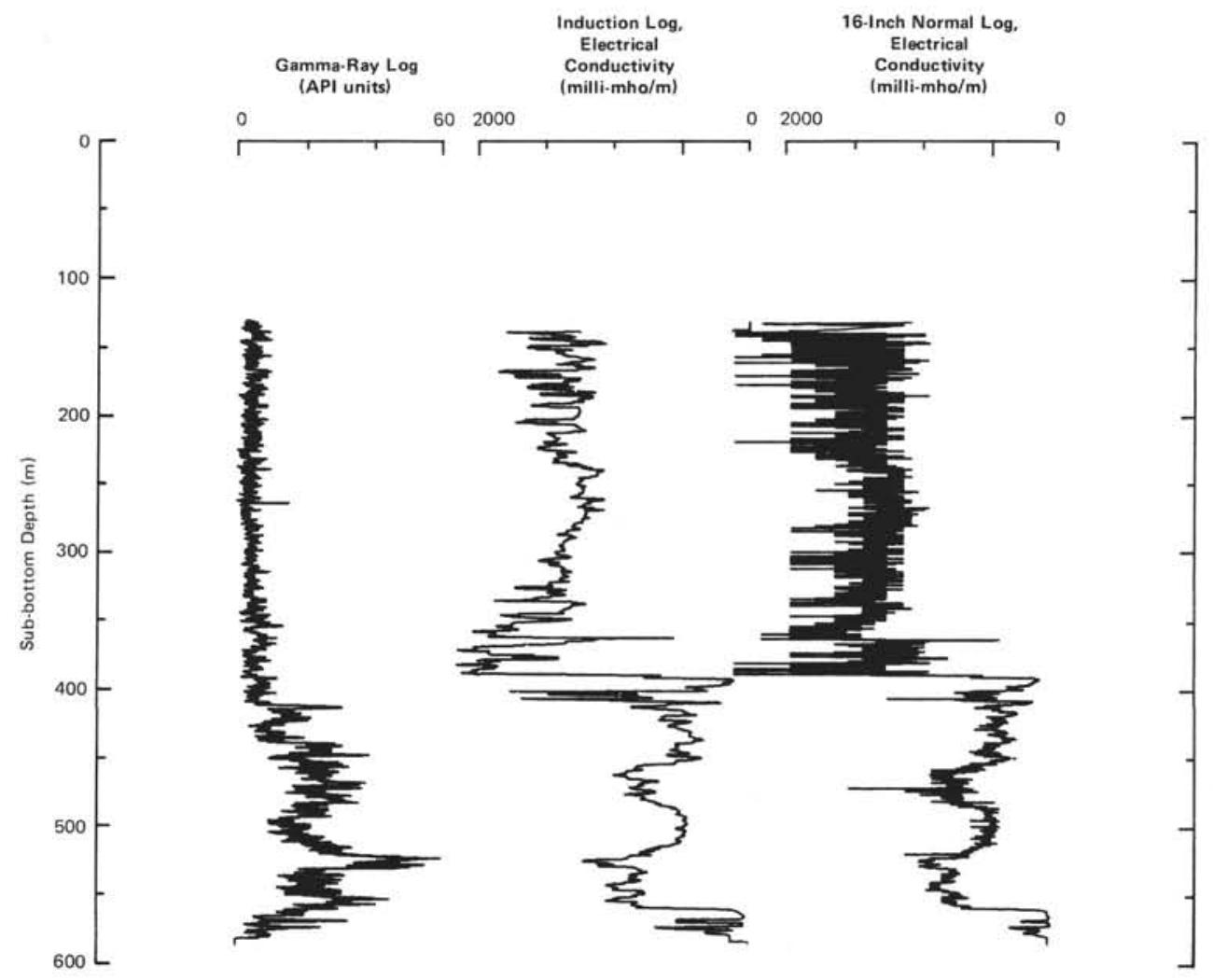

Figure 38. Gamma-ray log, induction $\log$, and 16-inch normal electrical-resistivity log from a single wireline lowering in Hole 462.

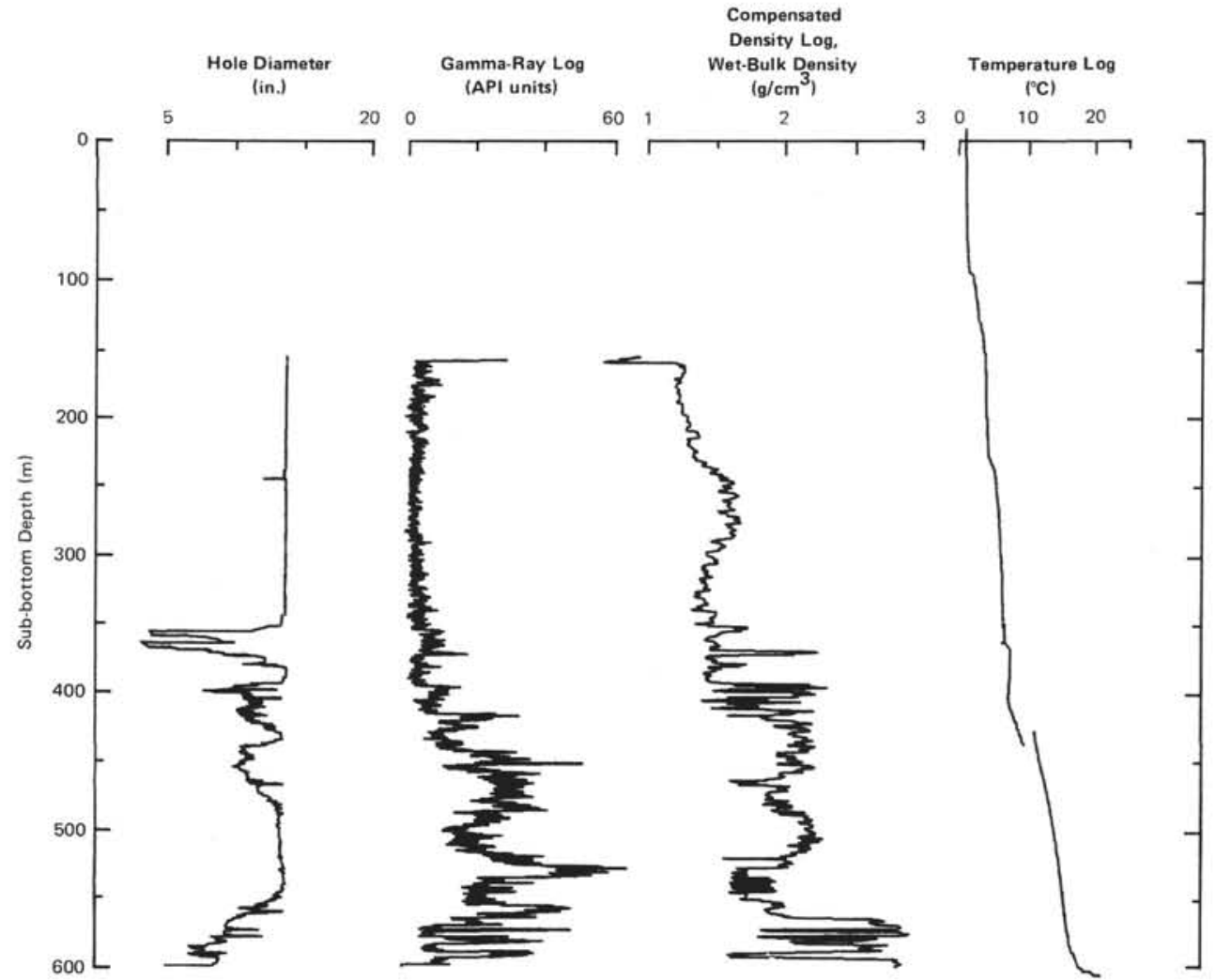

Figure 39. Caliper (hole-diameter) log, gamma-ray log, compensated density log, and the second temperature log, Hole 462. 


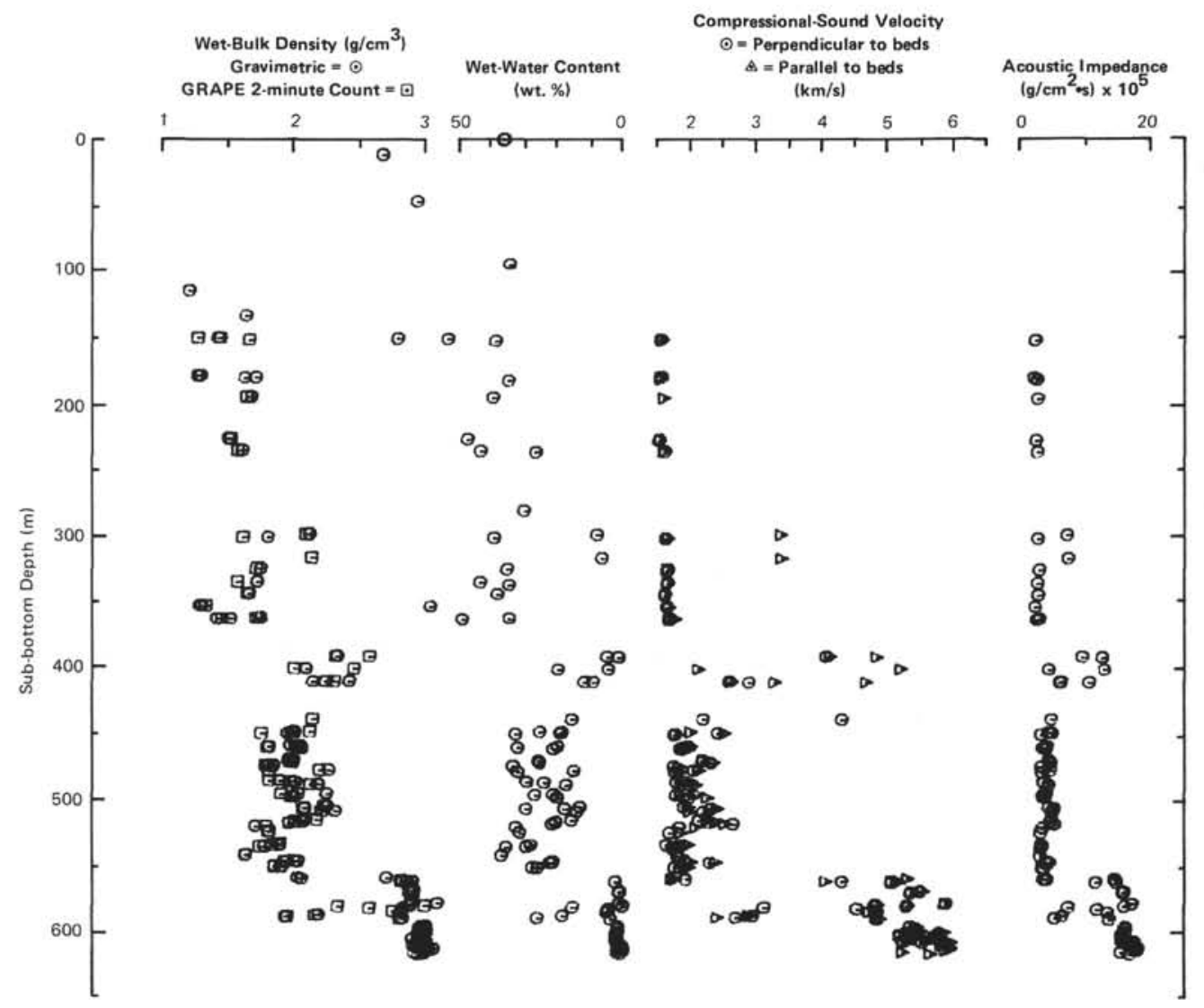

Figure 40. Laboratory-measured density, wet-water content, compressional-sound velocity, and acoustic impedance, Hole 462 .

1) From 0 to 150 meters: Pleistocene to early Miocene radiolarian ooze, foraminifer nannofossil ooze, siliceous mud, and nannofossil ooze have an estimated in situ velocity of $1.57 \mathrm{~km} / \mathrm{s}$. This is based on laboratory velocities, as there are no sonic-log data with this interval.

2) From 150 to 390 meters: middle Eocene to early Miocene nannofossil ooze and chalk, radiolarian nannofossil ooze and chalk, and radiolarian ooze and chalk have an estimated in situ interval velocity of $1.75 \mathrm{~km} / \mathrm{s}$ $(1.70 \mathrm{~km} / \mathrm{s}$ is the average if the high velocities of chert are not included). These velocities are primarily on laboratory velocities, as the sonic-log data in this interval for the most part appear to be artifacts. However, the sonic log does suggest the presence of $3 \%$ highvelocity limestone or chert in this interval.

3) From 390 to 447 meters: middle Maestrichtian to early middle Eocene chert and limestone have an estimated in situ interval velocity of $2.2(?) \mathrm{km} / \mathrm{s}$. This velocity is based on the sonic log. Laboratory samples in this interval are only from the high-velocity limestone and chert (as great as $5.2 \mathrm{~km} / \mathrm{s}$ ) probably representing biased recovery of hard and more-resistant layers.

4) From 447 to 522 meters: late Albian-Cenomanian to early Campanian volcaniclastics and limestone have an estimated interval velocity of $2.3 \mathrm{~km} / \mathrm{s}$. This estimate is from laboratory-measured velocities, as the sonic-log data $(1.8 \mathrm{~km} / \mathrm{s})$ may be in part an artifact of the hole's diameter being too large to measure accurately the formation's low velocities (Lynch,1962).

5) From 522 to $\sim 560$ meters: ?late Santonian to late Albian-Cenomanian claystone, siltstone, zeolitic marl, and minor chert have an estimated in situ interval velocity of $1.94 \mathrm{~km} / \mathrm{s}$. This estimate is based on laboratorymeasured velocities, as the sonic-log data may be an artifact of the formation's log velocities and corresponding large hole diameters.

6) From $\sim 560$ to $\sim 729$ meters: basalt and intercalated claystone and sandstone have an estimated in situ interval velocity of $4.76 \mathrm{~km} / \mathrm{s}$. This is a subjective interpretation of the Gearhart-Owen sonic log: it assumes that the 54.5 meters of sediment has an average velocity of $2.7(?) \mathrm{km} / \mathrm{s}$, and that the remaining basalt has an average velocity of $5.78 \mathrm{~km} / \mathrm{s}$. Extremely low velocities $(<2.1 \mathrm{~km} / \mathrm{s})$ may be artifacts of the large hole diameters in the washed-out parts of the hole.

7) From $\sim 729$ to 1068 meters (total depth): basalt and minor intercalated claystone and sandstone has an estimated in situ velocity of $5.63 \mathrm{~km} / \mathrm{s}$. This is a subjective estimate from the Gearhart-Owen sonic log. 


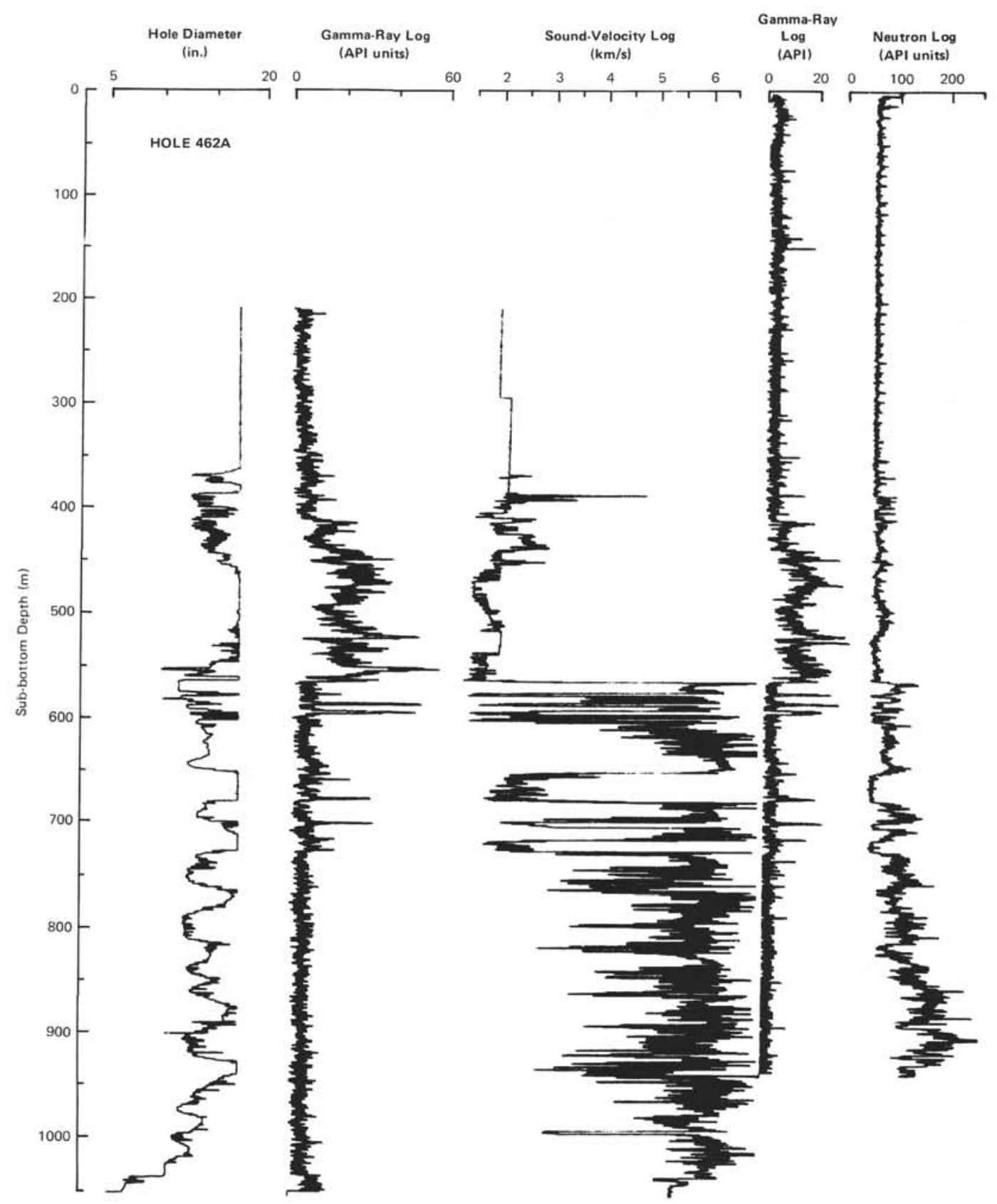

Figure 41. Caliper (hole-diameter) log, gamma-ray log, and compensated compressional-sound-velocity Log (run on a single lowering), and gamma-ray and neutron log (both run through drill string, and both on a single wire-line lowering), Hole 462A.

\section{Comparison of Electric Log to Density Log}

As a check on the quality of the density log and electrical-conductivity $\log$, the porosity derived from the density log was compared to the induction log at 5640 meters from the rig floor on the log.

1) The formation electrical resistivity $\left(R_{\mathrm{o}}\right)$ after borehole correction is $3.096 \mathrm{ohm}-\mathrm{m}$.

2) The interstitial water (36\% salinity) has an electrical resistivity $\left(R_{\mathrm{w}}\right)$ (after Thomas et al., 1934; pressure corrections of Horne and Frysinger, 1963) of 0.2248 ohm-m at $13.5^{\circ} \mathrm{C}$ (from second Gearhart-Owen temperature $\log )$.

3) Archie's (1942) equation

$$
F=R_{\mathrm{o}} / R_{\mathrm{w}}=\phi^{-2}
$$

gives a porosity $(\phi)$ of $25 \%$.

4) The compensated density log gives a density of $2.24 \mathrm{~g} / \mathrm{cm}^{3}$, which, assuming a grain density of 2.7 $\mathrm{g} / \mathrm{cm}^{3}$, represents a porosity of $27 \%$.

5) Therefore, the electrical log appears to be giving quantitative data relative to the density log. 


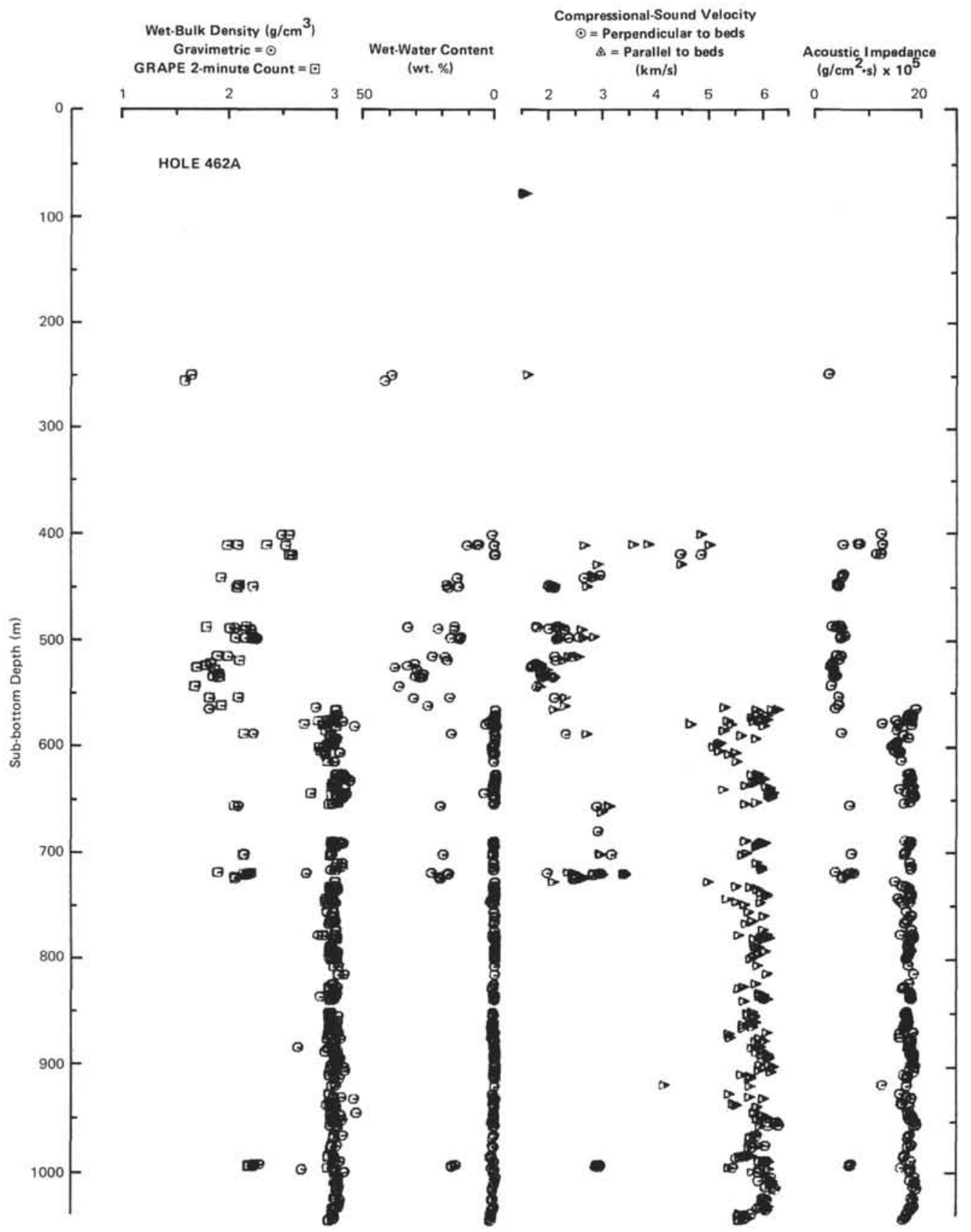

Figure 42. Laboratory-measured density, wet-water content, compressional-sound velocity, and acoustic impedance, Hole 462A.

The density log compares very well with density data measured in the laboratory (GRAPE 2-minute data) when the latter are plotted over the log, considering the sampling differences.

The good comparison of the electric log and density $\log$ also suggests that the second-temperature-log data can be used to quantitatively interpret the electric log. A cursory inspection of conductivity and density curves does not indicate any unusual anomalies in the logged section.
Lithologic Characterization by the Density, Sonic, and Gamma-Ray Logs

The stratigraphic section is divided into nine units (which do not coincide necessarily with units discussed elsewhere in this volume).

1) From 0 to 160 meters, the GR is of low intensity and is attenuated by the pipe and bottom-hole assembly. In general, the low GR intensity suggests biogenic oozes of low "clay" content (early Miocene-Pleistocene bio- 


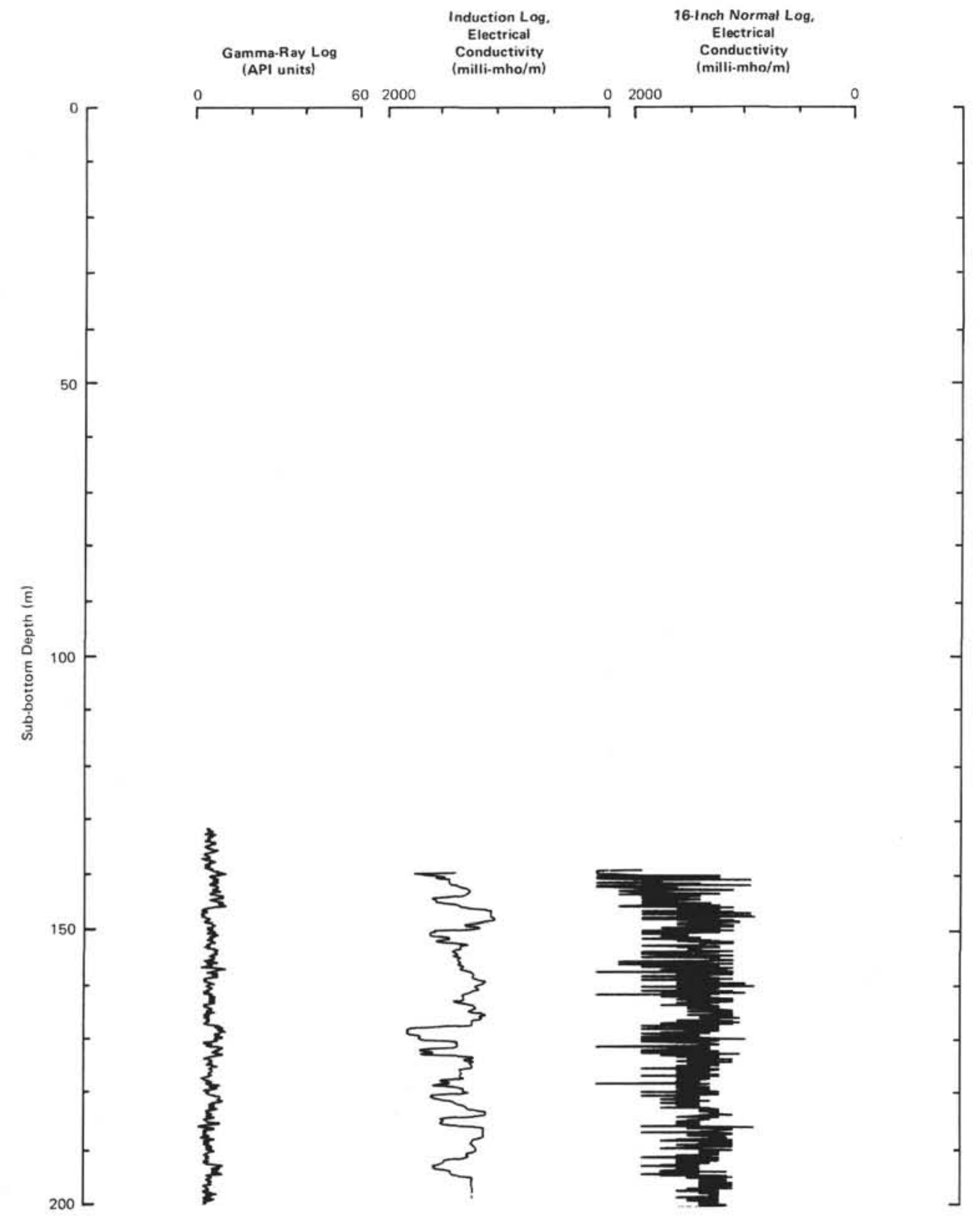

Figure 43. Gamma-ray log, induction $\log$, and 16-inch normal electrical-resistivity log from a single wireline lowering in Hole 462.

genic oozes). A high GR response at 48 to 53 meters may represent an ashy or more-clayey layer.

2) From 160 to 350 meters, the GR is in general low intensity, indicating a formation with a relatively uniform, low clay content (primarily late Eocene to early Miocene biogenic oozes). Minor variations of the GR intensity could represent "clayey" or ashy layers.

3) From 350 to 411 meters, the GR intensity is greater and more variable than in the overlying formation, indicating a greater and variable "clay" content (or greater number of thin "clay" layers). The low density values $\left(1.5-1.9 \mathrm{~g} / \mathrm{cm}^{3}\right)$ represent chalk layers, and the higher density values represent layers of limestone and chert, the latter being up to $<5$ meters thick. (This interval is early? to middle Eocene.)
4) From 411 to 522 meters, the GR varies greatly and is greater than in the overlying formation, indicating that this formation has a greater clay content than the overlying formation and a very irregular clay content, or that numbers of thin clay layers vary in proportion to the GR intensity. In general, the density is 2.0 to 2.2 $\mathrm{g} / \mathrm{cm}^{3}$; however, high GR counts from 461 to 463 meters indicate "claystone" whose density is $1.7 \mathrm{~g} / \mathrm{cm}^{3}$. (This interval is early Campanian to early(?) Eocene limestone, chert, and volcaniclastics, with wide variation in density and "clay" content, or number of thin "clayey" layers.)

5) From 522 to 532 meters, low-density $\left(1.7 \mathrm{~g} / \mathrm{cm}^{3}\right)$ claystone is indicated by high gamma-ray count. High gamma-ray count may also be related to organic-car- 


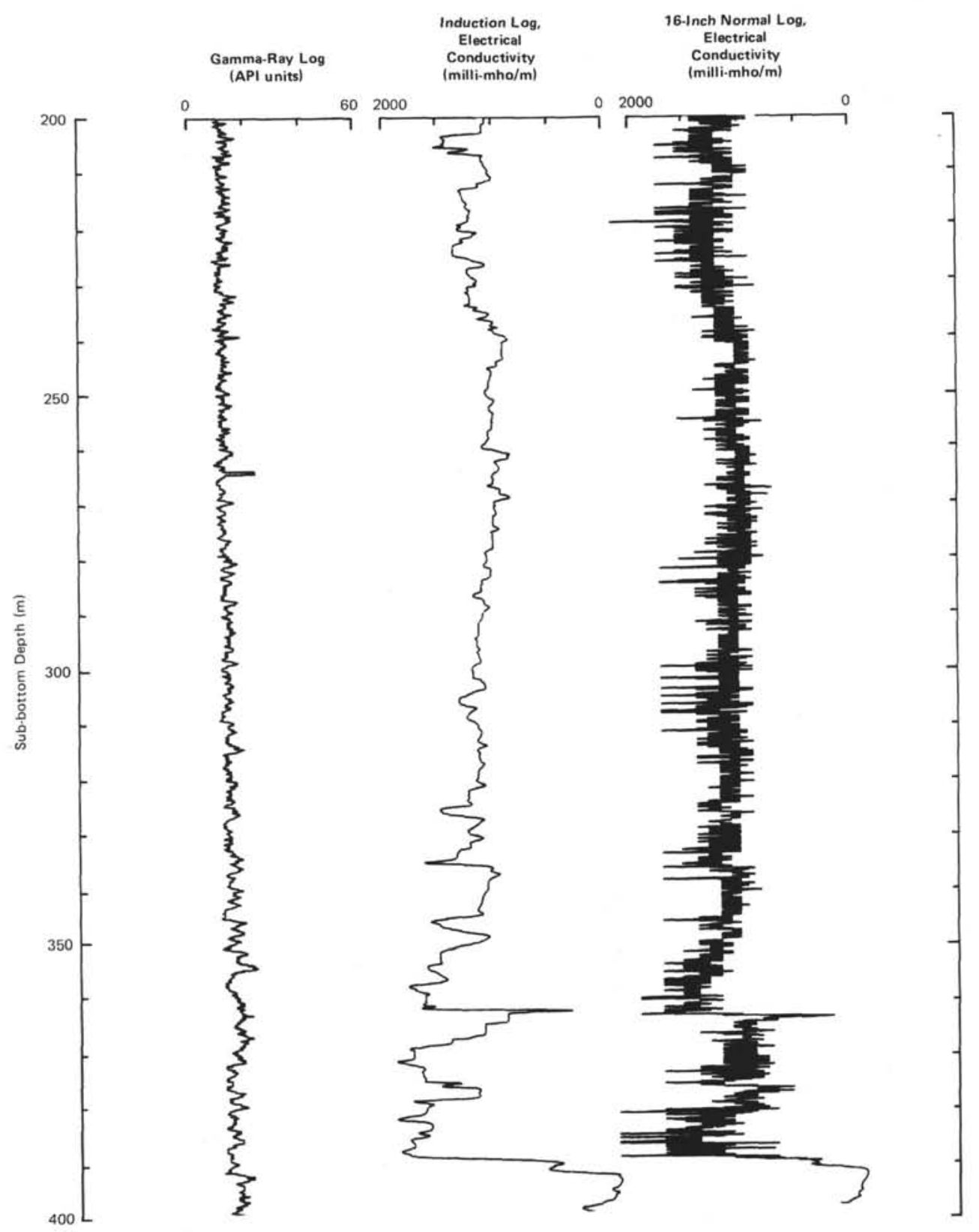

Figure 43. (Continued).

bon-rich or zeolitic lithologies. The 522-meter horizon is near the Santonian/Campanian boundary, and the interval is Santonian(?).

6) From 537 to 549 meters, a low-density (1.7-1.9 $\mathrm{g} / \mathrm{cm}^{3}$ ) layer has a moderate GR intensity, indicating a formation with medium clay content (or a medium number of thin clay layers). This interval is Santonian claystone, zeolitic claystone, siltstone, and mudstone. The Santonian/Coniacian boundary is near 549 meters and appears to be marked by a GR change.

7) From 549 to 561 meters, the high GR intensity indicates a "clayey" formation (or greater number of thin clayey layers). This interval is Cenomanian to late $\mathrm{Al}$ - bian(?) zeolitic claystone, nannofossil radiolarian marl, chert, and claystone.

8) From 561 to 565 meters, the $2.7 \mathrm{~g} / \mathrm{cm}^{3}$ density suggests a sedimentary formation such as limestone or marlstone. However, the cores recovered basalts; therefore, the layer is probably fractured $2.9-\mathrm{g} / \mathrm{cm}^{3}$ basalt. The GR is higher than lower basalt (below $565 \mathrm{~m}$ ), suggesting either greater $\mathrm{K}_{2} \mathrm{O}$ content, greater clay content, fractures, or some other form of alteration.

9) From $\sim 565$ to $\sim 1068$ meters, the low-GR, highdensity $\left(2.9 \mathrm{~g} / \mathrm{cm}^{3}\right)$ layer and the high-velocity layer ( $>4 \mathrm{~km} / \mathrm{s}$ ) are basalt, sedimentary interbeds being indicated by high GR counts, low density $\left(1.7-1.9 \mathrm{~g} / \mathrm{cm}^{3}\right)$, 


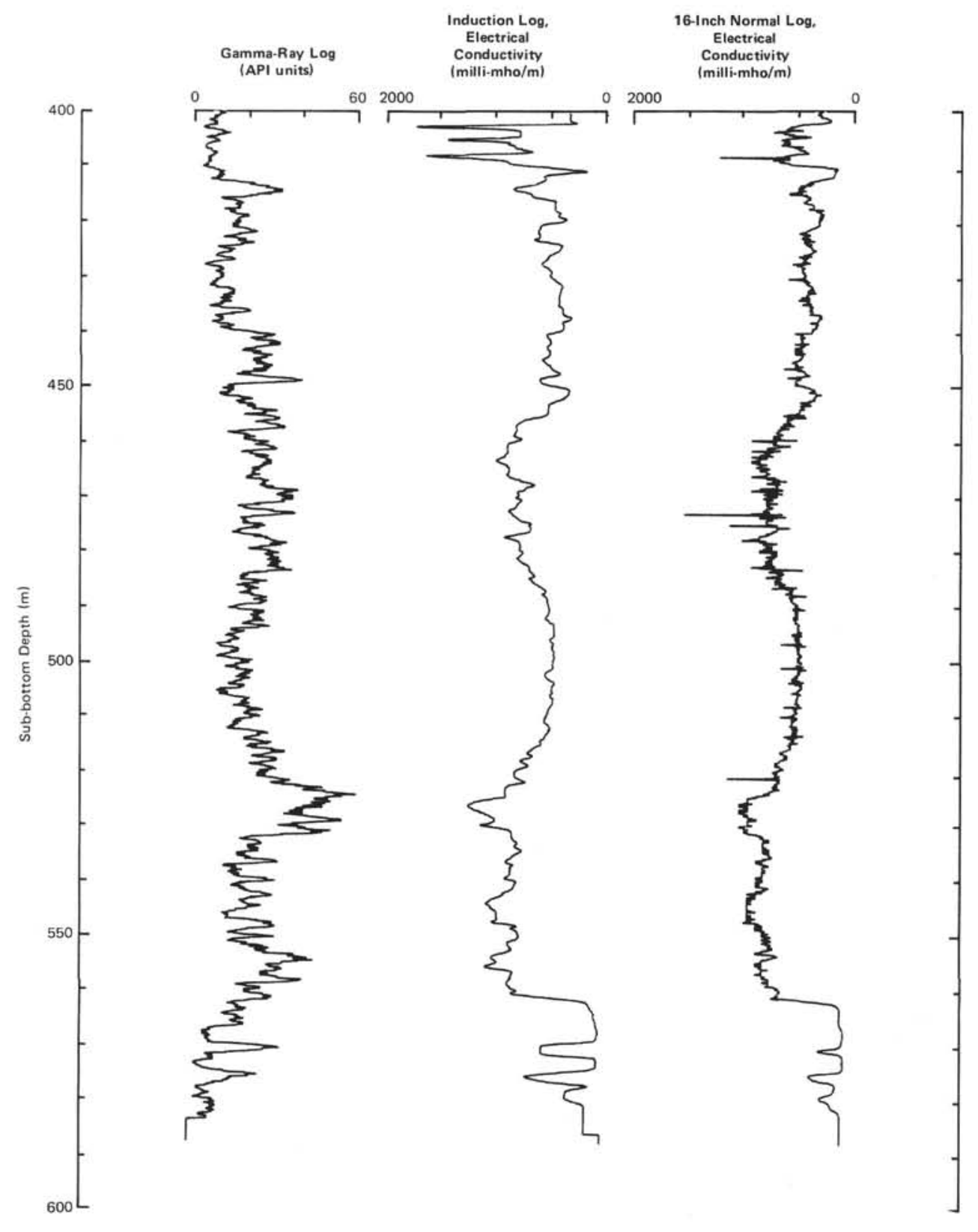

Figure 43. (Continued).

and low(?) velocities $(<4.0 \mathrm{~km} / \mathrm{s})$. Thirty-two per cent of the section appears to be sedimentary in the upper 565 to 729 meters of the basalt sills, whereas below 729 meters the basalt-sill section appears to have about $5 \%$ (?) sedimentary material.

The high porosity, neutron log, low density log, and low sonic log in some parts of the basalt section may indicate fractured zones. Sill units are indicated at some depths by increasing and then decreasing velocities (with increasing depth), by the lab data, and by the sonic log; and in some cores, by increasing and decreasing density on the analog GRAPE (462A, Core 22 is a good example), which appears to directly correspond to grain size.

In a given lithologic unit where the mineralogy is simple (such as clay and carbonate) and where porosity is similar throughout, the GR can be calibrated to estimate percentages of clay (or other GR contributions):

$$
\begin{aligned}
G R_{\mathrm{L}}= & \mathrm{GR} \text { intensity in the non-clayey material } \\
& \text { (e.g., pure chalk, ooze, or limestone). } \\
G R_{\mathrm{H}}= & \begin{array}{l}
\text { GR intensity is the "clayey" material } \\
\text { (e.g., claystone, shale, etc.). }
\end{array}
\end{aligned}
$$




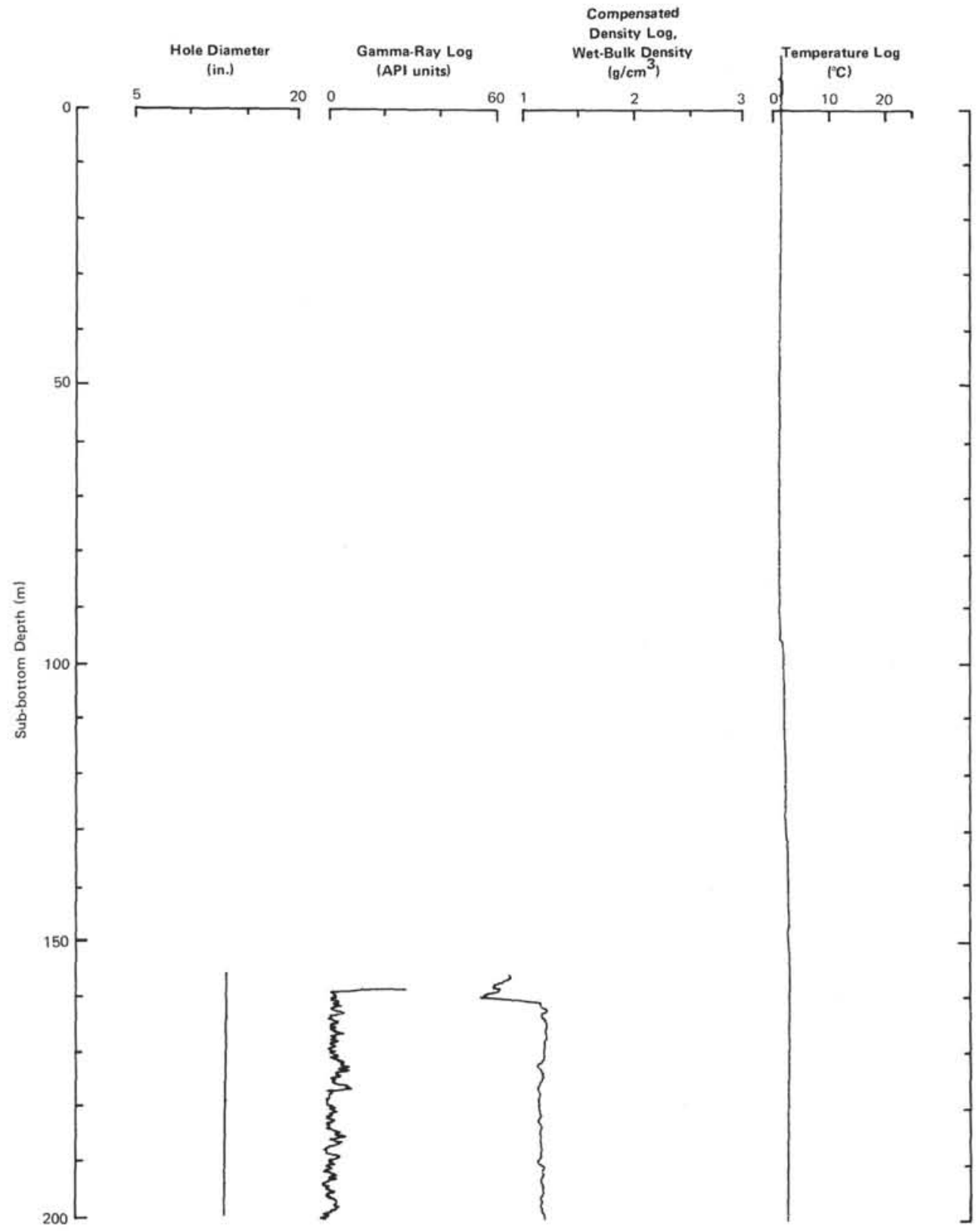

Figure 44. Caliper (hole-diameter) log, gamma-ray $\log$, compensated density log, and the second temperature log, Hole 462.

$G R_{\mathrm{c}}=$ any GR on the log.

$E=$ empirical calibration curve for each lithologic unit.

The estimated per cent of clayey minerals is given by

$$
E\left[\frac{G R_{\mathrm{H}}-G R_{\mathrm{c}} \text { (formation) }}{G R_{\mathrm{H}}-G R_{\mathrm{L}}}\right] \times 100 .
$$

The unit from 161 to 351 meters is too low in GR to do this, but the unit from 351 to 561 meters might be calibrated as follows (assuming that the high GR is not related to other radioactive sources, such as authigenic minerals at unconformities, or hydrothermal deposits):

$$
\begin{aligned}
G R_{\mathrm{L}} & =1 \text { API unit } \\
G R_{\mathrm{H}} & =70 \text { API units }
\end{aligned}
$$

Therefore, percentage of "clay" in that section may be estimated by the expression:

$$
E\left(\frac{70 A P I-G R_{\mathrm{c}} \text { (formation) }}{70 A P I-1 A P I}\right) \times 100 .
$$




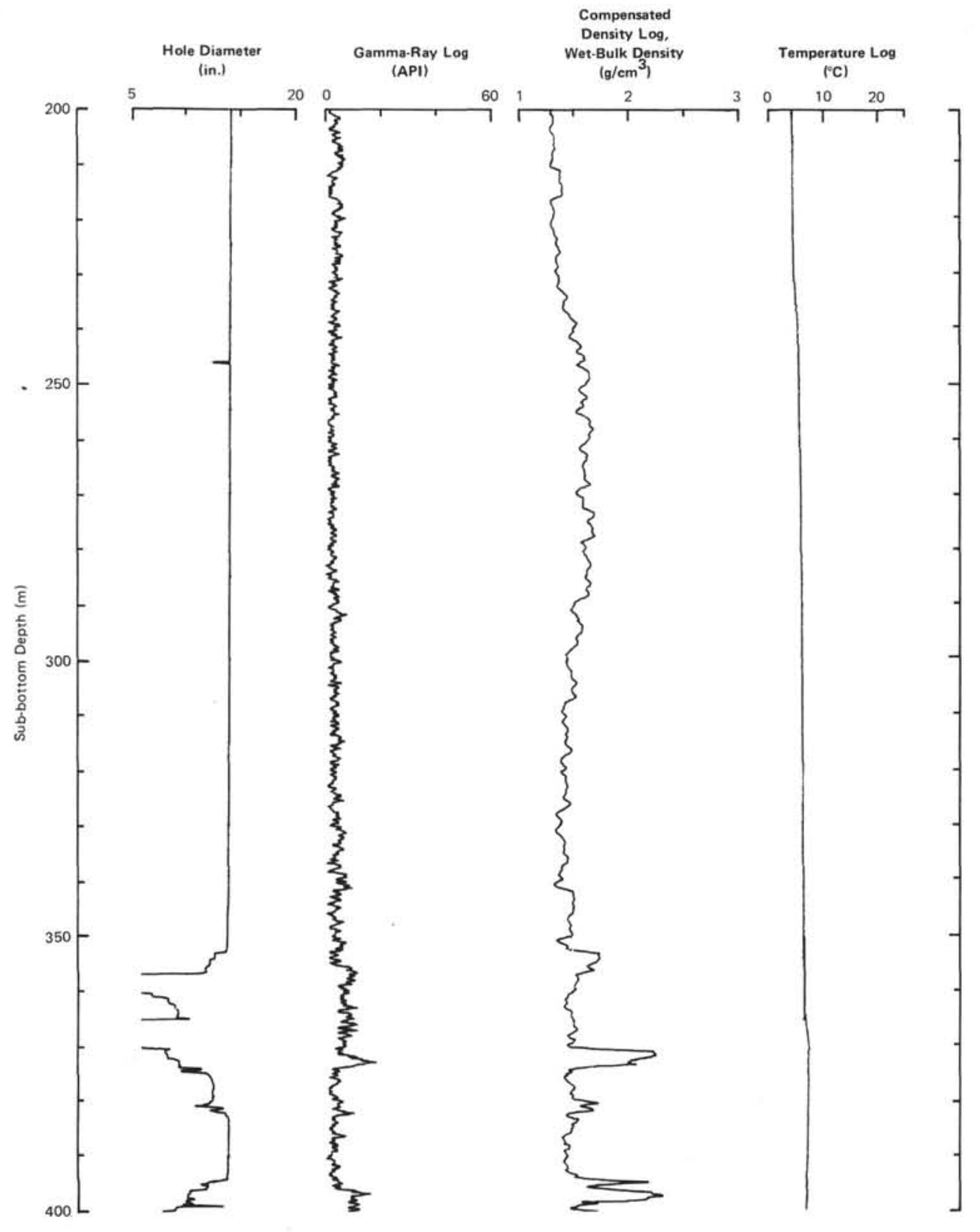

Figure 44. (Continued).

This relationship could be calibrated for basalt, for example, if the $\mathrm{K}_{2} \mathrm{O}$ content or alteration material is significant:

$$
\begin{aligned}
G R_{\mathrm{H}} & =\begin{array}{l}
\mathrm{GR} \text { intensity in high } \mathrm{K}_{2} \mathrm{O} \text { content }\left(\mathrm{K}_{2} \mathrm{O}\right. \\
\text { measured }) .
\end{array} \\
G R_{\mathrm{L}} & =\begin{array}{l}
\mathrm{GR} \text { intensity in low } \mathrm{K}_{2} \mathrm{O} \text { content }\left(\mathrm{K}_{2} \mathrm{O}\right. \\
\text { measured }) .
\end{array} \\
G R_{\mathrm{c}}= & \text { any } \mathrm{GR} \text { count in the basalt section. } \\
E & =\text { calibration curve for each basalt unit. }
\end{aligned}
$$

$$
\% \mathrm{~K}_{2} \mathrm{O}=E\left[\frac{G R_{\mathrm{H}}-G R_{\mathrm{c}}}{G R_{\mathrm{H}}-G R_{\mathrm{L}}}\right] \times 100 .
$$

In summary, the GR could be calibrated empirically to measure variations of a variety of mineral constituents.

Unconformities sometimes are marked by higher gamma-ray counts. This could be related to (1) a lower sedimentation rate, so that more authigenic radioactive 


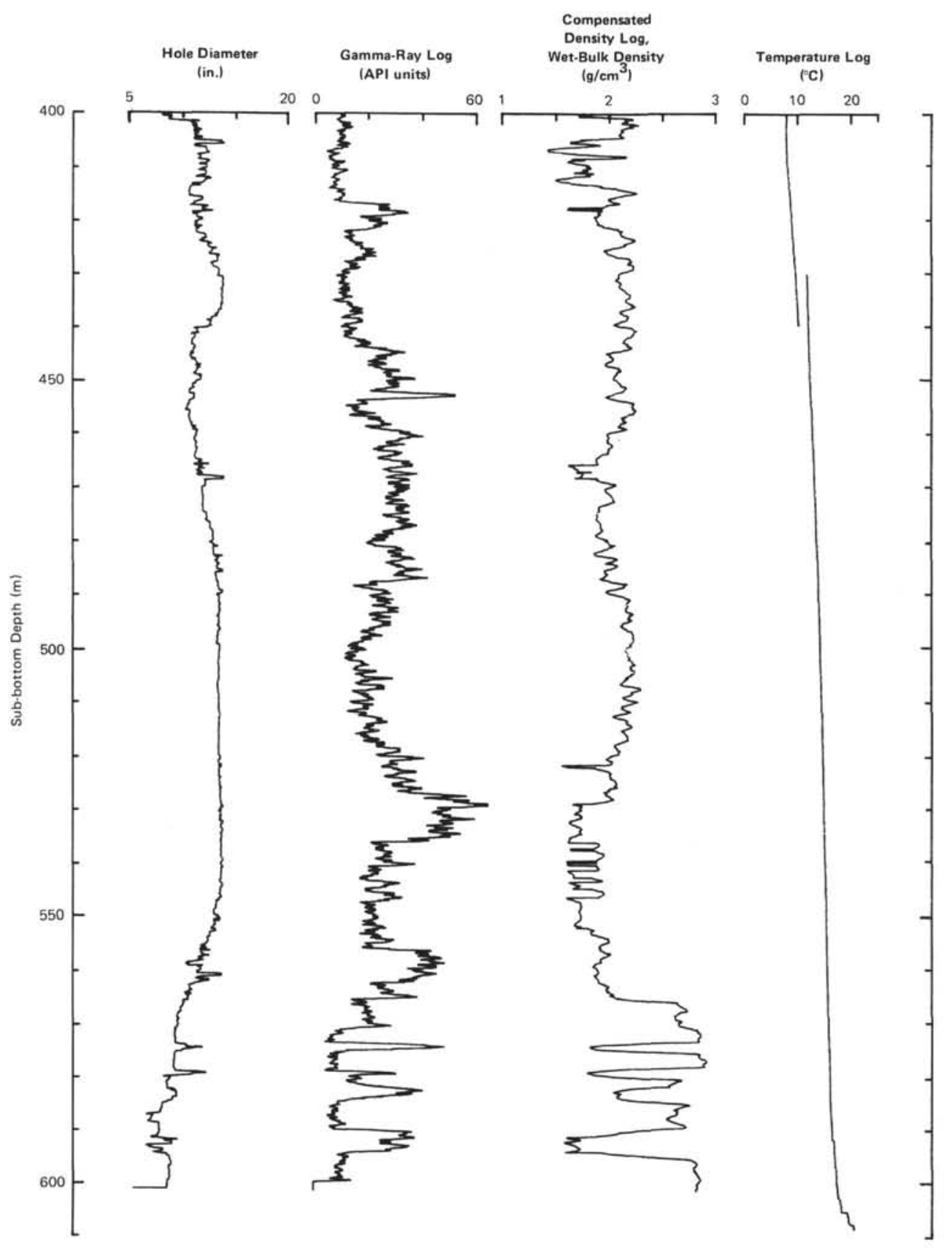

Figure 44. (Continued).

ions can be concentrated, or (2) dissolving of carbonate, giving more "clayey" material along an unconformity than in the overlying formation (where the sedimentation rate may be higher). These are generalities and there are many exceptions.

\section{Gearhart-Owen Temperature Log}

Two Gearhart-Owen temperature logs were run. The first soon (11-13 hours) ceased after circulation, and the second after 42 to 44 hours. These runs were (1) to detect any permeable fractures and hydrothermal circulation in the basalt section (to know if heat is transported by convection of hydrothermal water or by simple "heat conductivity" of the rock), (2) to help calcu- late a "true" in situ temperature with the results of both temperature logs. Another primary reason for the second logging run is to approximately measure the hole temperature, so that the electric logs can be interpreted properly.

The following data permit calculation of "true" in situ temperatures:

1) At 2305 hours on 5 June 1978, we stopped drilling.

2) At 0100 hours on 6 June, we stopped circulation (485 barrels of mud were pumped at 0415 hours).

3) The first temperature log started at 1203 hours on 6 June and ended at 1403 hours in the bottom of the hole. (The probe was left about 8 minutes to be certain it had reached equilibrium.) 


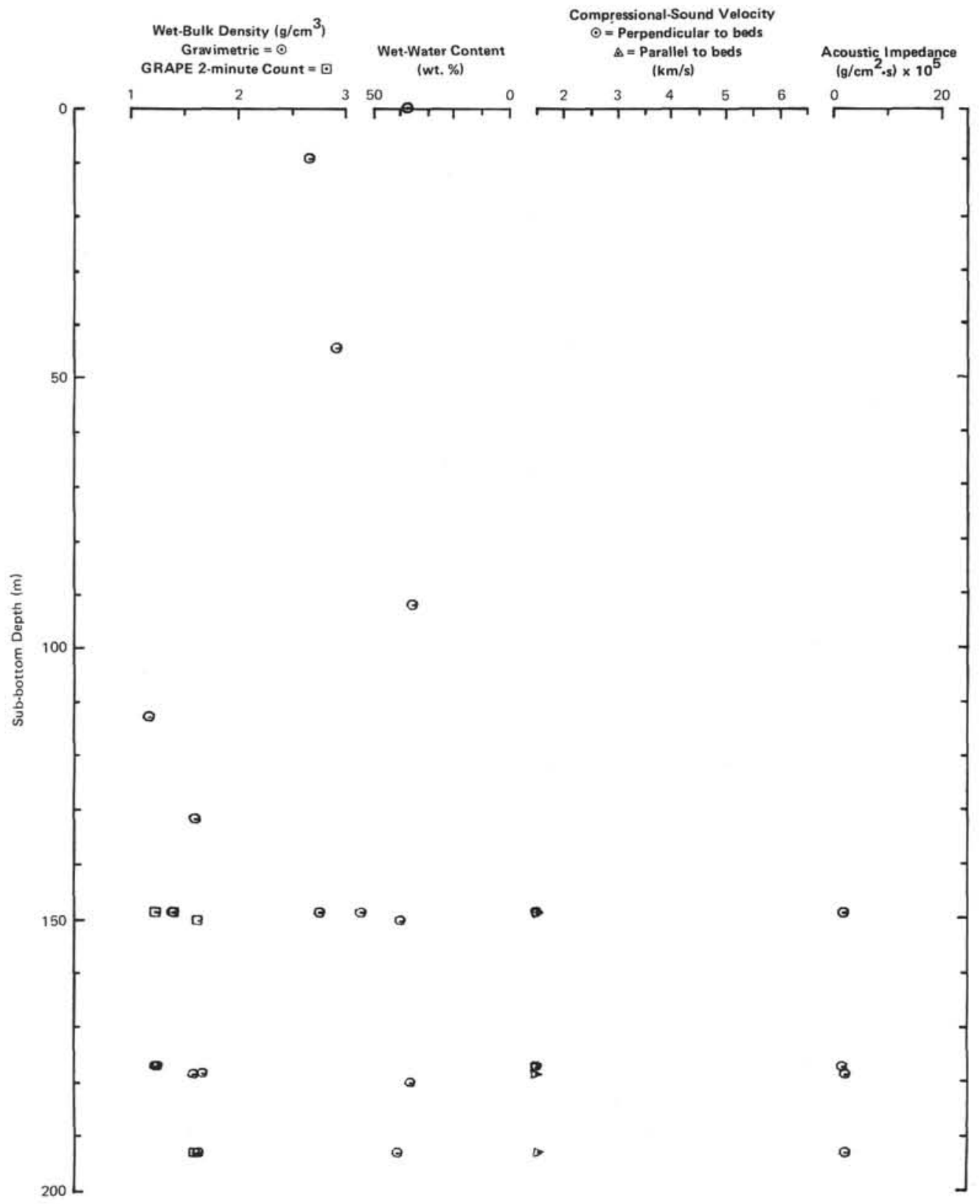

Figure 45. Laboratory-measured density, wet-water content, compressional-sound velocity, and acoustic impedance, Hole 462 .

4) Above 349 meters, the hole is washed out; therefore, data above this point are questionable.

5) The second temperature log started at 1900 hours and ended at 2100 hours on 7 June 1978 (it remained on bottom about 10 minutes).

The first temperature log found a high-over-low temperature anomaly (while going down the hole) in the basalt section suggesting some combination of the following: (1) convection of the mud in the hole, (2) flow of warmer formation water from the basalt into the hole, causing a high temperature anomaly, (3) flow of hole fluids into permeable fractured basalt, causing a negative temperature anomaly, or (4) fracturing of the basalt, the drilling fluids cooling the fractured portions of the basalt more than the massive portions.

The bottom water is $\sim 1.4^{\circ} \mathrm{C}$, and the temperature at 608 meters (second temperature $\log$ ) in the hole was $22.4^{\circ} \mathrm{C}$.

\section{Uyeda Temperature Probe}

\section{METHODS}

Temperatures "ahead" of the drill bit (temperature could be affected by the cooling effects of circulation during drilling) were measured with the Uyeda temperature probe (theoretical precision and accuracy $\pm 0.05(?)^{\circ} \mathrm{C}$ ). This probe measures and electronically stores temperatures at 2 -minute intervals while being lowered and inserted into the formation at the bottom of the hole. 


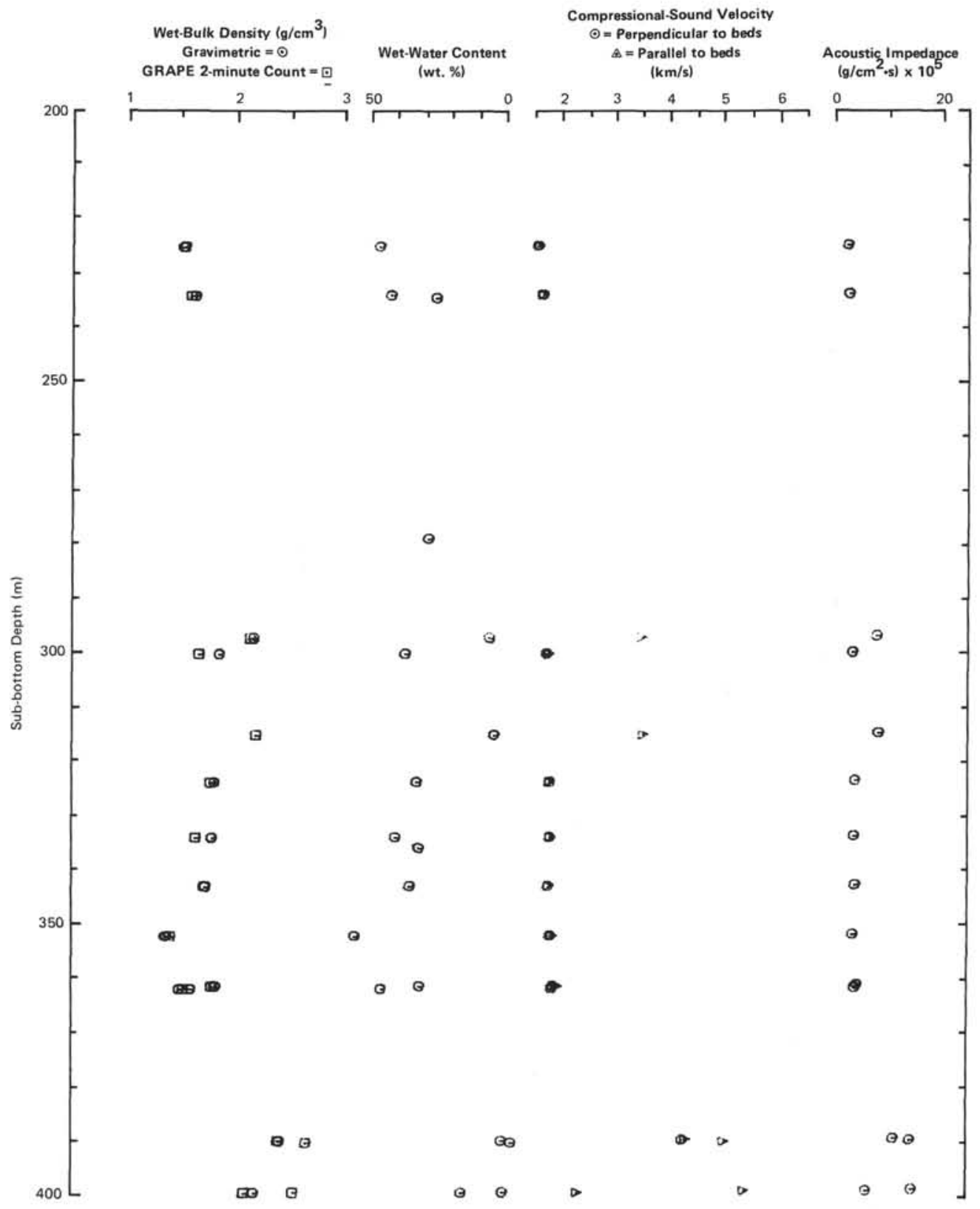

Figure 45. (Continued).

\section{Results}

Only three measurements are valid: (1) $8.4^{\circ} \mathrm{C}$ at 133.5 meters; (2) $10.7^{\circ} \mathrm{C}$ at 181 meters; and (3) $12.3^{\circ} \mathrm{C}$ at 219 meters. In this interval, an average temperature gradient of $45^{\circ} \mathrm{C} / \mathrm{km}$ was obtained.

Another set of three measurements (using a different thermistor) gave anomalous results and 2.0 to $4.3^{\circ} \mathrm{C}$ for $1.9^{\circ} \mathrm{C}$ bottom-water temperatures (as measured in the first set of data). This will be subject to further study.
The temperature gradient is related to heat flow as follows:

$$
\frac{g}{K}=\frac{T_{1}-T_{2}}{D_{1}-D_{2}}
$$

where

$$
\begin{aligned}
g & =\text { heat flow }\left(\mu \mathrm{cal} / \mathrm{cm}^{2}\right) . \\
T_{1} & =\text { temperature at } 200 \mathrm{~m}\left({ }^{\circ} \mathrm{C}\right) .
\end{aligned}
$$




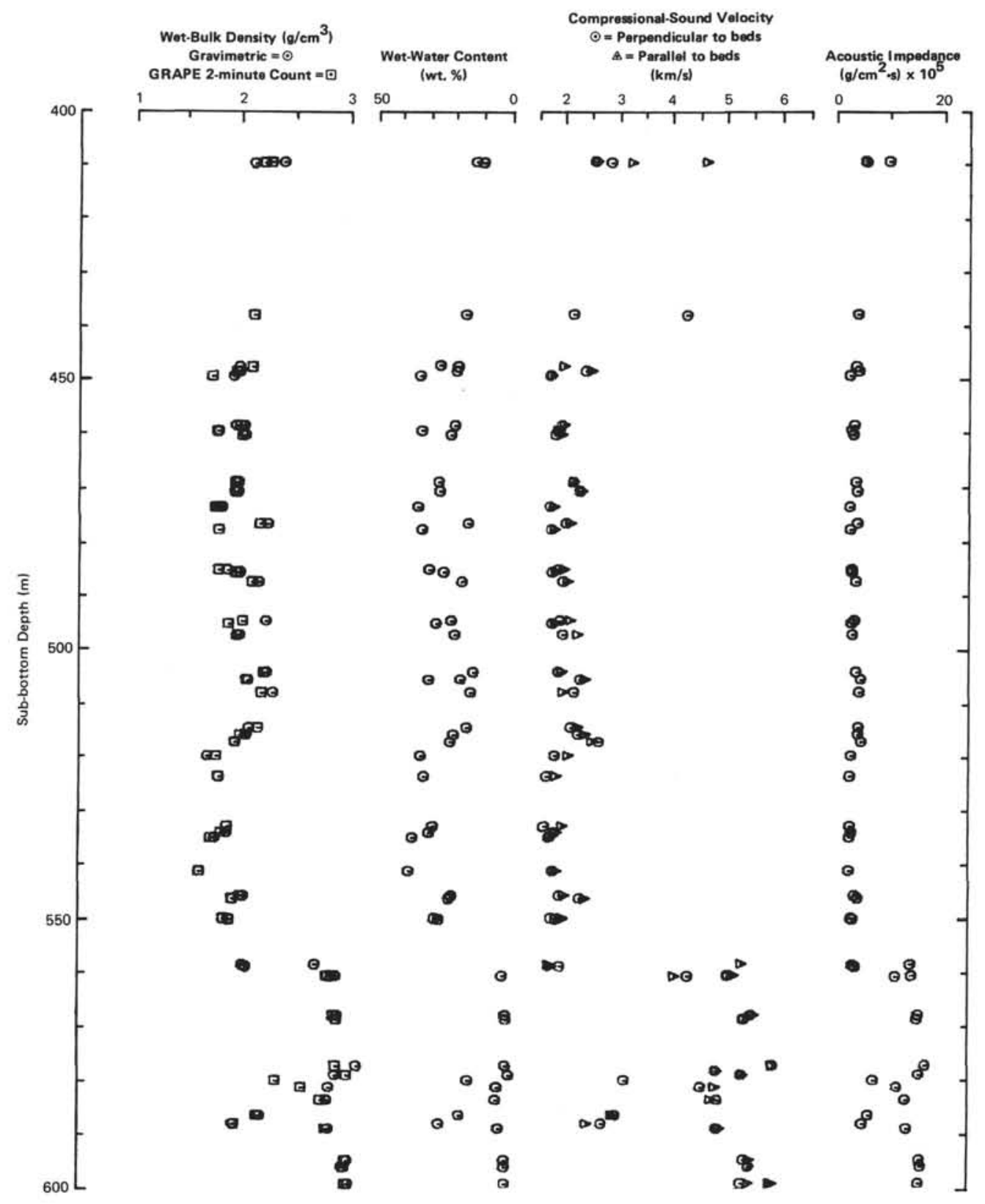

Figure 45. (Continued).

$T_{2}=$ temperature at $100 \mathrm{~m}\left({ }^{\circ} \mathrm{C}\right)$.

$D_{1}=$ depth of $200 \mathrm{M}(\mathrm{cm})$.

$D_{2}=$ depth of $100 \mathrm{M}(\mathrm{cm})$.

$K=$ heat conductivity of the formation $\left[10^{-3} \mathrm{cal} /\left(\mathrm{sec} \cdot \mathrm{cm} \cdot \mathrm{C}^{\circ}\right)\right]$

then

Site 462 heat flow $=1.15 \mu \mathrm{cal} / \mathrm{cm}^{2}$

$$
\begin{aligned}
= & {\left[2.56 \times 10^{-3} \mathrm{cal} /\left(\mathrm{cm} \cdot \mathrm{sec} \cdot{ }^{\circ} \mathrm{C}\right)\right] } \\
& {\left[45^{\circ} \mathrm{C} / \mathrm{km}\right] }
\end{aligned}
$$

The gradient of $45^{\circ} \mathrm{C} / \mathrm{km}$ corresponds to a heat flow of $1.15 \mu \mathrm{cal} / \mathrm{cm}^{2}$, which compares well to a predicted typical heat flow value of $1.1 \mu \mathrm{cal} / \mathrm{cm}^{2}$ (Lee and Uyeda, 1965).

Because

$$
g=\left(\frac{T_{1}-T_{2}}{D_{1}{ }^{1} D_{2}}\right)(K)
$$

However, the formation conductivity is determined using porosity values of disturbed sediment, which may or may not represent accurately the in situ formation. Calculation and assumptions of the conductivity are discussed below.

The formation conductivity value between 100 to 200 meters was determined as follows: the average analog GRAPE density was $1.6 \mathrm{~g} / \mathrm{cm}^{3}$, and by assuming a $2.7-\mathrm{g} / \mathrm{cm}^{3}$ grain density a porosity of $65 \%$ can be de- 


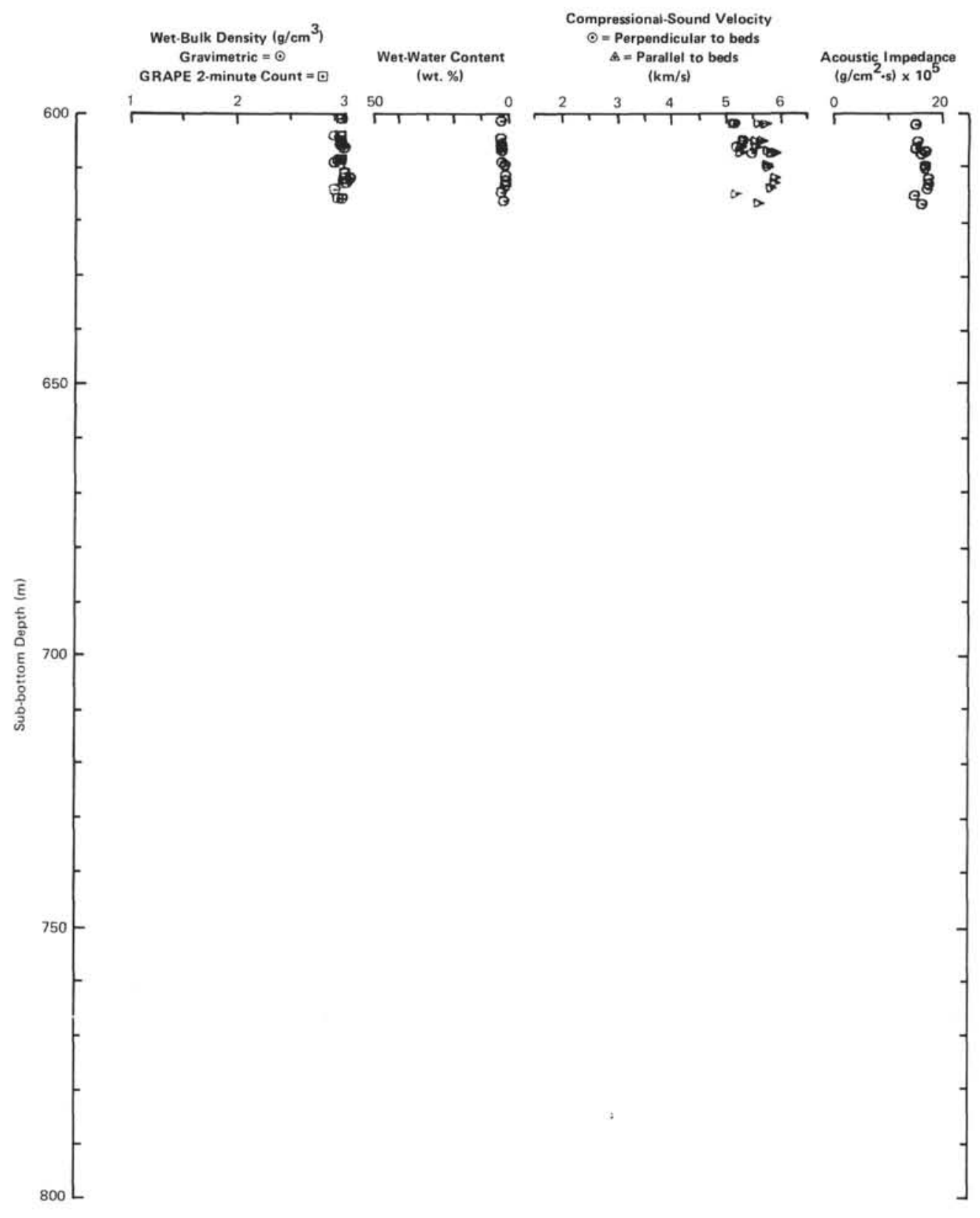

Figure 45. (Continued).

rived. However, when overburden pressure is released, the porosity here will increase by about three porosity units (Hamilton, 1976); therefore, we subtract 3\% from $65 \%$, obtaining a $62 \%$ porosity under in situ conditions. Our conductivity-porosity measurements at Hole 462 are compatible with the "porosity-conductivity" diagram in Nafe and Drake (1963); thus, for a carbonate section, using the Nafe and Drake (1963) diagram and $62 \%$ porosity, we obtain an average conductivity value of $2.60 \mathrm{cal} /\left(\mathrm{cm} \cdot \mathrm{sec} \cdot{ }^{\circ} \mathrm{C}\right)$ under laboratory conditions. This was corrected $(-1.5 \%)$ to $2.56 \mathrm{cal} /\left(\mathrm{cm} \cdot \mathrm{sec} \cdot{ }^{\circ} \mathrm{C}\right)$ under in situ conditions (Bullard, $1963 ; 25^{\circ} \mathrm{C}$ to $10^{\circ} \mathrm{C}$ $=-4 \%$; and from one atmosphere to $500 \mathrm{~kg} / \mathrm{cm}^{2}=$ $+2.5 \%$; therefore, a total $-1.5 \%$ correction must be applied to the laboratory-determined conductivity).
Comparison of the Uyeda temperature data cannot precisely be made to the Gearhart-Owen continuous temperature log, because the hole was washed out seriously in the interval of interest; however, the change in slope seen on the Uyeda probe (depth/temperature plot) can also be seen in the Gearhart-Owen temperature log, but this could also be an artifact of the hole conditions. The Uyeda probe read $1.9^{\circ} \mathrm{C}$ for bottom water, whereas the Gearhart-Owen log read about $1.4^{\circ} \mathrm{C}$.

\section{CORRELATION OF DRILLING RESULTS AND SEISMIC DATA}

Seismic profiling on Glomar Challenger during Leg 61 was carried out with Bolt 20- and 120 -in. ${ }^{3}$ air guns, firing at 10 -second intervals. The EDO \#2 recorder was 


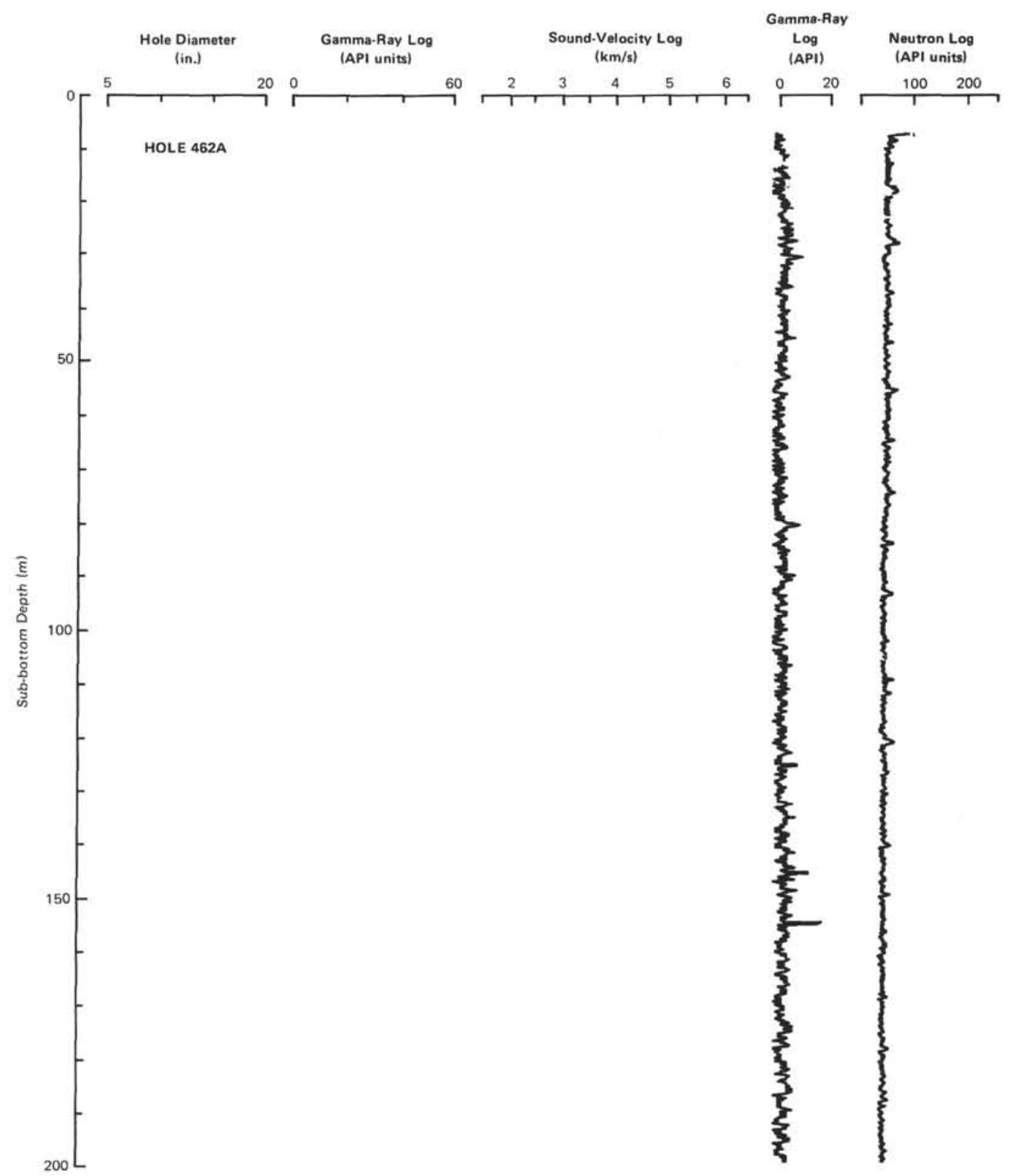

Figure 46. Caliper (hole-diameter) log, gamma-ray log, and compensated compressional-sound-velocity $\log$ (run on a single wire-line lowering), and the neutron log and gamma-ray log (both run through drill string, and both on a single wire-line lowering), Hole $462 \mathrm{~A}$.

run with various delays, using the $40-$ to $160-\mathrm{Hz}$ filter setting, and the EDO \#1 recorder was run on a 10second sweep, using the $10-$ to $80-\mathrm{Hz}$ filter setting. Figure 49 is an enlarged version of the EDO \#1 record, made as Glomar Challenger approached Site 462 at 6.7 knots from the north-northwest. The correlations shown to the right of the seismic profile are based on shipboard Hamilton-frame velocity measurements, from which interval compressional velocity $\left(V_{\mathrm{c}}\right)$ values were derived; on lithologies encountered in the continuous coring program, and on natural gamma/compensated density/caliper logs; drilling rates were also taken into account.

From 0 to 0.19 seconds sub-bottom, the record shows numerous parallel, closely spaced reflectors, probably (acoustic artifacts aside) the result of numerous, thin, distal turbidite layers consisting of foraminifer-rich basal portions that grade up through nannofossil oozes into light-brown radiolarian oozes. These turbidites range up to 8 meters in thickness. At 0.19 seconds, which corresponds to a sub-bottom depth of 150 meters, there is a change in interval $V_{\mathrm{c}}$ from 1.57 to $1.75 \mathrm{~km} / \mathrm{s}$, and an unconformity of middle Miocene age. However, neither the interval $V_{\mathrm{c}}$ increase nor the unconformity appears to be identifiable in the seismic record. In the interval 0.31 to 0.35 seconds, a relatively transparent layer exists, roughly corresponding to the transition from calcareous ooze to chalk in the cores of Oligocene age between 216 and 243 meters, and to a slight density increase on the compensated density log (which may be 


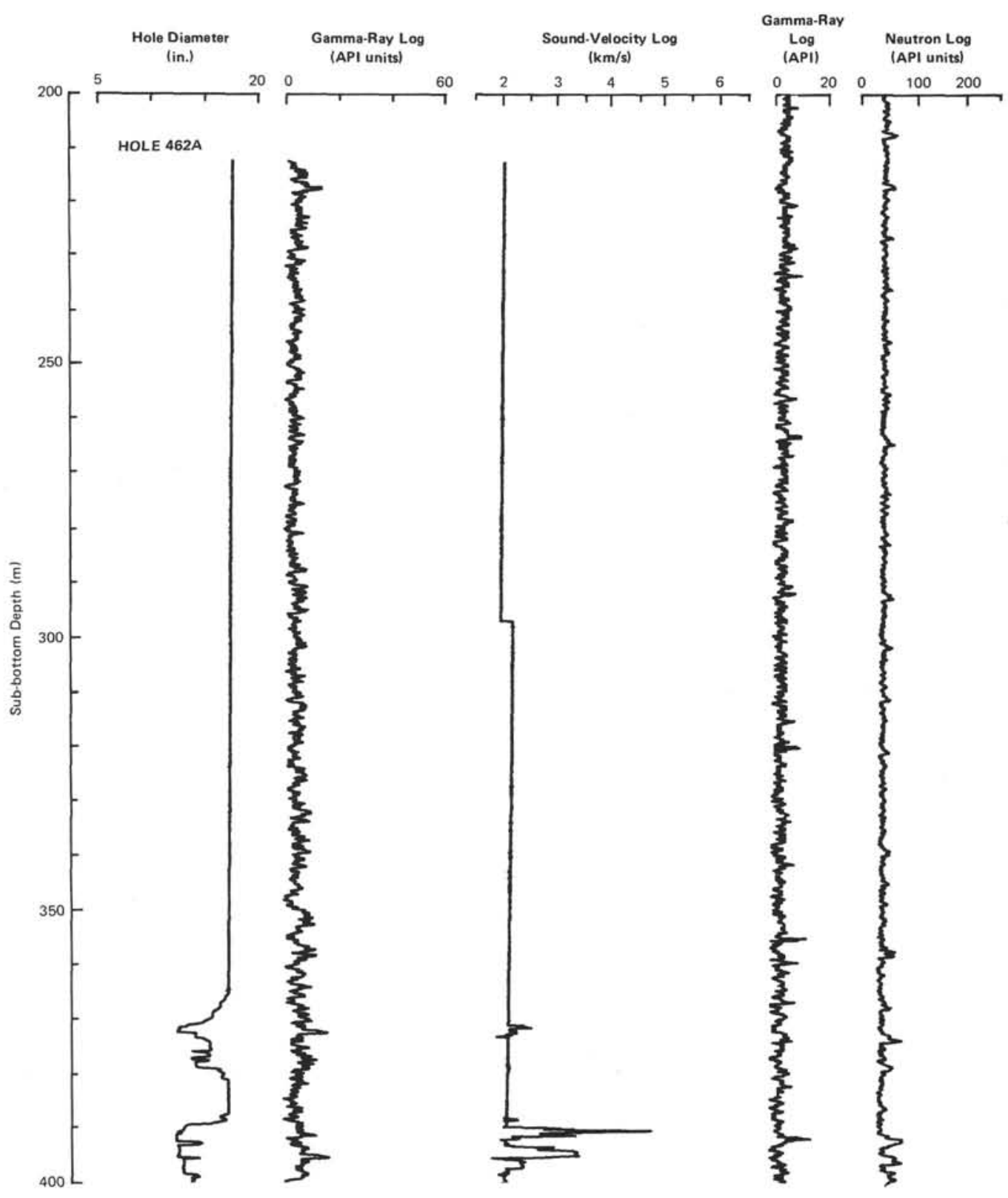

Figure 46. (Continued).

an artifact, because the hole was washed out). Whereas minor porcellanite and chert occurrences were noted between 300 and 380 meters sub-bottom, the major chert build-ups in limestone were first drilled at 390 meters in strata of early Eocene age. This major chert section is obvious in the compensated density log. The 390 -meter level was picked on the seismic profile where a subtle change in reflector character is seen at 0.46 seconds. This is at the top of a high interval $V_{\mathrm{c}}$ of 2.20 $\mathrm{km} / \mathrm{s}$. The bottom of this $2.20-\mathrm{km} / \mathrm{s}$ interval corresponds to the 0.52 -second pick on the seismic profile, but surprisingly there is no obvious change in reflector spacing or character. Between 0.52 and 0.58 seconds sub-bottom is a slightly higher-velocity interval of 2.30 $\mathrm{km} / \mathrm{s}$, the top of which is near the Mesozoic/Cenozoic boundary and the first appearance of a sequence of vol- caniclastic sandstone, siltstone, and zeolitic claystone of Campanian to early to middle Maestrichtian age at 447 meters sub-bottom. The bottom of the $2.23-\mathrm{km} / \mathrm{s}$ interval at $\mathbf{5 2 2}$ meters sub-bottom in strata of early Campanian age corresponds to the 0.58 -second pick on the seismic profile, where a slight change in the thickness and spacing of the reflectors is seen. Between 0.58 and 0.62 seconds sub-bottom, there is a low-velocity interval of $1.94 \mathrm{~km} / \mathrm{s}$ that extends from 522 to 560 meters subbottom; it is occupied by zeolitic mudstones and welllaminated orange and black shales and mudstones of Cenomanian to early Campanian(?) age. At a sub-bottom depth of 560 meters, basalt sills intercalated with shales and mudstones were drilled to total depth at 617 meters. The sill top was picked at 0.62 seconds subbottom, where a major change in reflector intensity and 


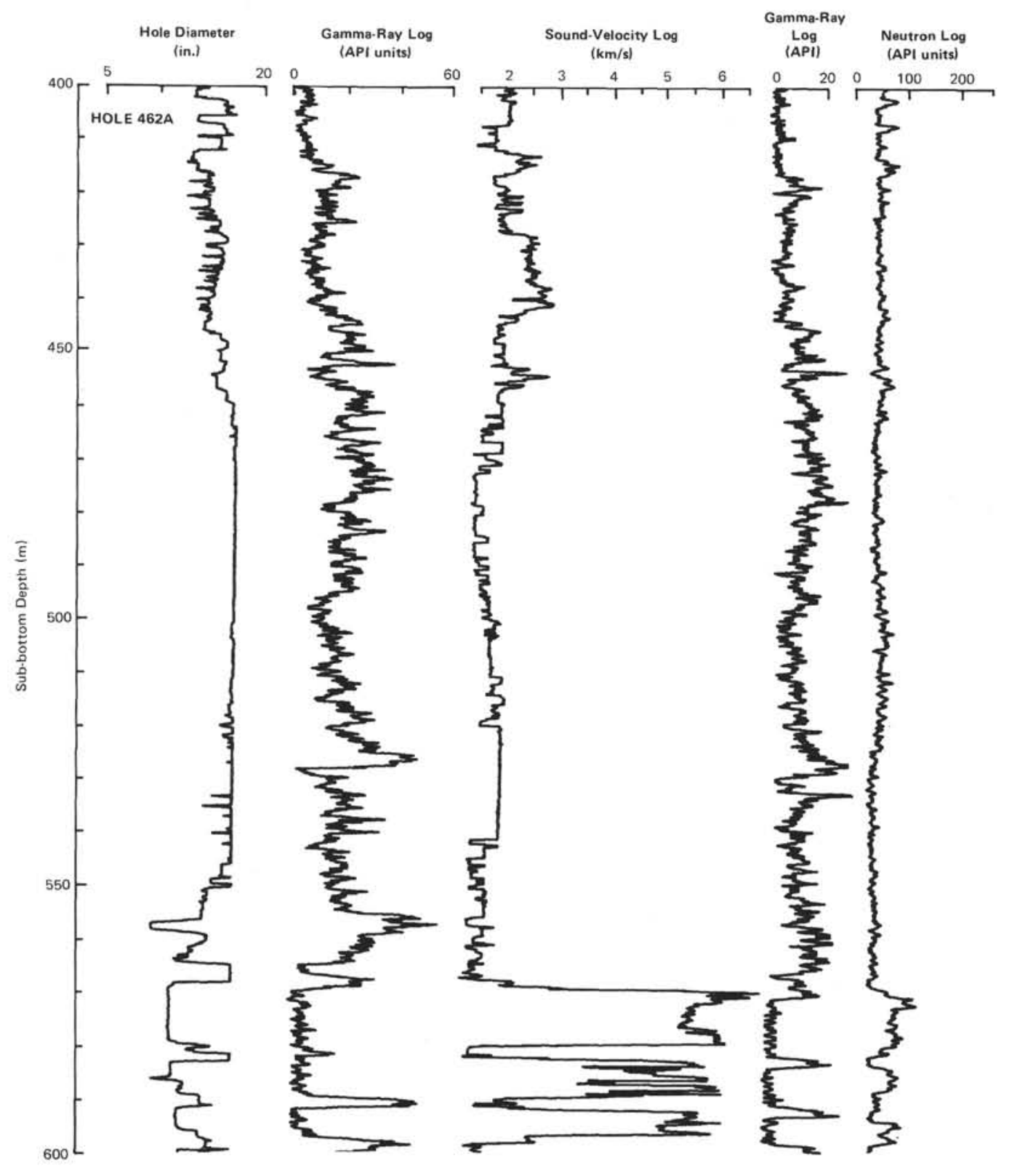

Figure 46. (Continued).

spacing can be seen. At this level, the reflectors lose their high degree of parallelism, and when traced across the seismic profile they show considerable relief.

The sub-bottom time picks for the Glomar Challenger seismic profile were transferred to the Kana Keoki seismic profile run during the site survey for Site 462 (Fig. 50). This air-gun profile was run at a filter setting of 30 to $100 \mathrm{~Hz}$, but a larger gun was used. The 0.46 - and 0.52 -second picks correspond to the same picks on the Glomar Challenger record, and could possibly correspond to the $2.20-\mathrm{km} / \mathrm{s}$ interval on the Glomar Challenger record, which is interpreted to be the 390 to 447 -meter interval which extends from the top of the major chert horizon to the top of the volcaniclastic sandstone and siltstone section. The 0.58 -second pick fits the lowest relatively flat horizontal reflector, at the top of the $1.94-\mathrm{km} / \mathrm{s}$ zeolitic shale section that lies above the sills at 560 meters. At 0.62 -seconds, the reflectors are broken and irregular, indicating the top of the sill and intercalated shale-mudstone section at Site 462, which extends to the total depth 617 meters.

We believe that the true basement, the surface of the presumed 148-m.y.-old plate, is not to be seen on either the Glomar Challenger line or the Kana Keoki line.

The Kana Keoki line passed 0.5 nautical miles north of Site 462 and was run on a course of $067^{\circ}$; the Challenger line was run on a course of $145^{\circ}$ over the site. The two lines therefore are nearly perpendicular to each other.

Refer to Wipperman et al. (this volume) for a discussion of depth-velocity relations derived from ASPER work and refraction shooting, using ocean- 


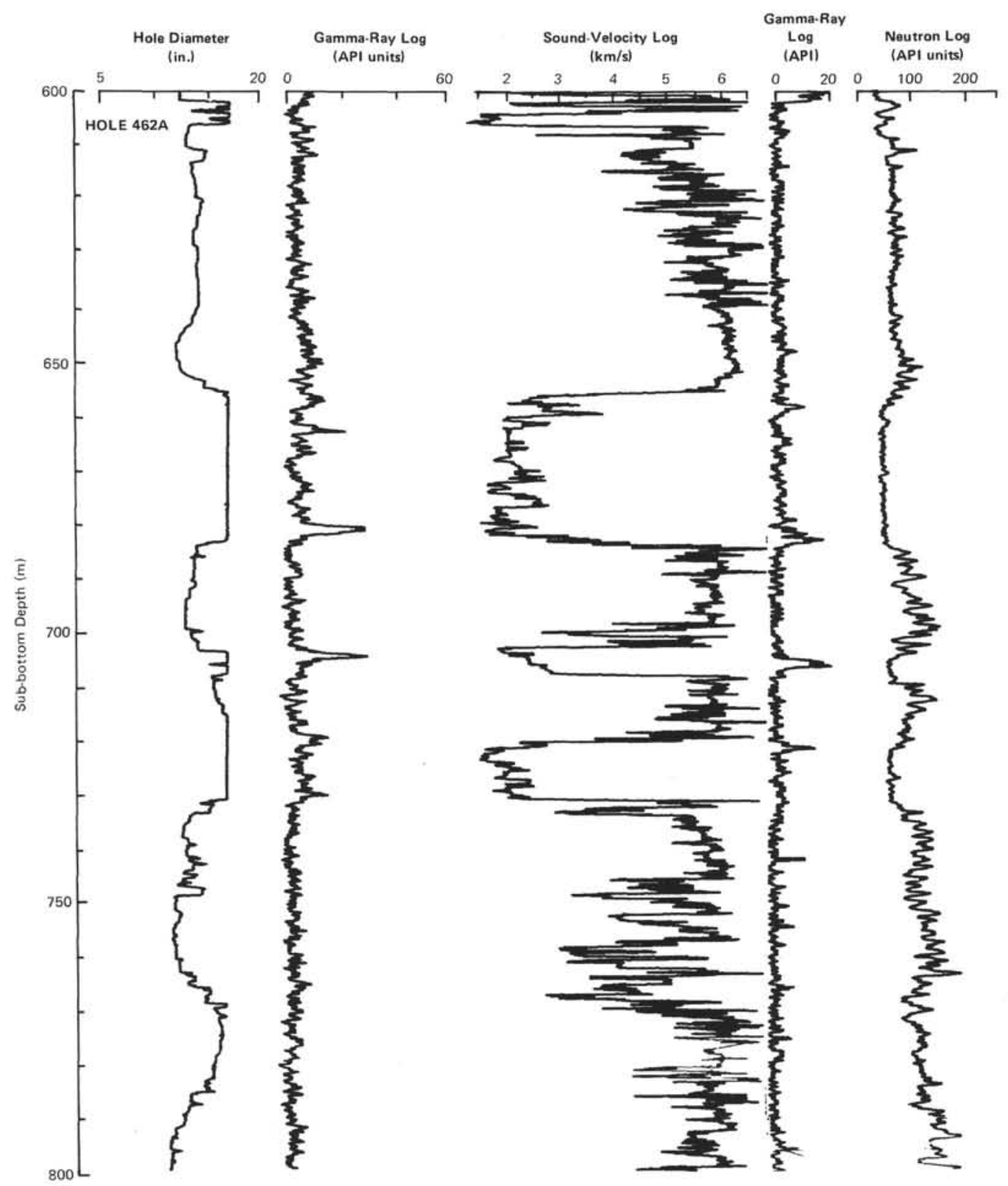

Figure 46. (Continued).

bottom seismometers and sonobuoys during the sitesurvey operations on Kana Keoki.

\section{SUMMARY AND CONCLUSIONS}

\section{Introduction}

The following text synthesizes the major scientific results of drilling at Site 462 in the Nauru Basin. Certain other topics are discussed in the previous sections of this site report. For conclusions and summaries of results concerning detailed biostratigraphy, organic geochemistry, physical properties, and seismic correlation, the reader is referred to these sections. The last part of the following text contains speculations concerning the areal extent and thickness of the mid-Cretaceous volcanic complex in the western central Pacific Ocean basin, and its relation to the Late Jurassic magneticanomaly pattern of the Nauru Basin. Caveat emptor.

\section{Sedimentation and Stratigraphy}

Sedimentation in the Nauru Basin since at least Cenomanian time has been dominated by deposition of turbidites from surrounding highs (Fig. 1). As shown in Figure 14, faunas from shallow-bank and reef environments, as well as faunas from deep-water environments, have been redeposited in the Nauru Basin. Turbidite 


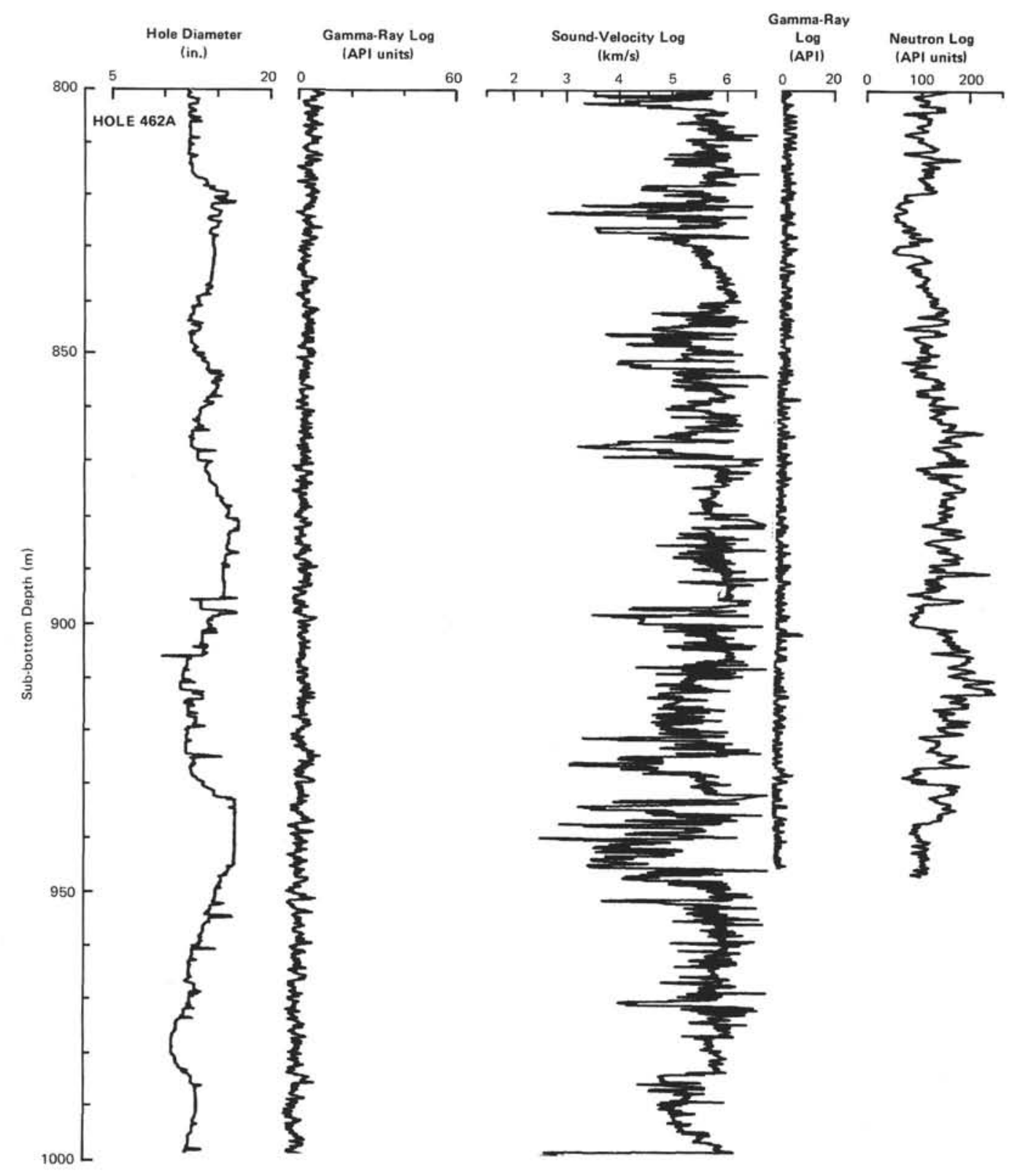

Figure 46. (Continued).

sources must have included the Marshall Islands, the Ontong-Java Plateau, and the eastern Caroline Islands.

Three major sedimentary units were delineated at Site 462 (Fig. 51):

1) 0 to 297 meters; calcareous and radiolarian oozes and chalks, mainly of turbidite origin and of Oligocene or younger age.

2) 297 to 447 meters; cherts, chalks, and limestones of Eocene to Maestrichtian age.

3) 447 to 599 meters; volcanogenic and zeolitic sandstones, mudstones, and limestones, extending down into the sill complex.

Sediments found deep within the sill complex are discussed in the section on igneous petrology.

The present water depth of the Site is 5180 meters, and it therefore lies well below the CCD. The normal "background" sediments are brown-red clays. However, Unit 1 is made up of turbidites 0.1 to 8 meters thick. A typical turbidite is made up of a basal layer of white foraminifer-nannofossil ooze that grades up into light-brown radiolarian ooze, which in turn is capped by brown pelagic clay. Within Unit 1, the ooze/chalk transition lies between 230 and 250 meters. Much of the fine-fraction $\mathrm{CaCO}_{3}$ in the form of small planktonic and benthic foraminifers and nannofossils probably has its origin in the highly eroded northeast face of the Ontong-Java Plateau. The bathymetry of Site 462 (Fig. 4) shows turbidite and levee features, indicating flow into the area from the southwest.

Against this general background of turbidite oozes and chalks, two less common but significant lithologic contributions are found in Unit 1, ash and shallow- 


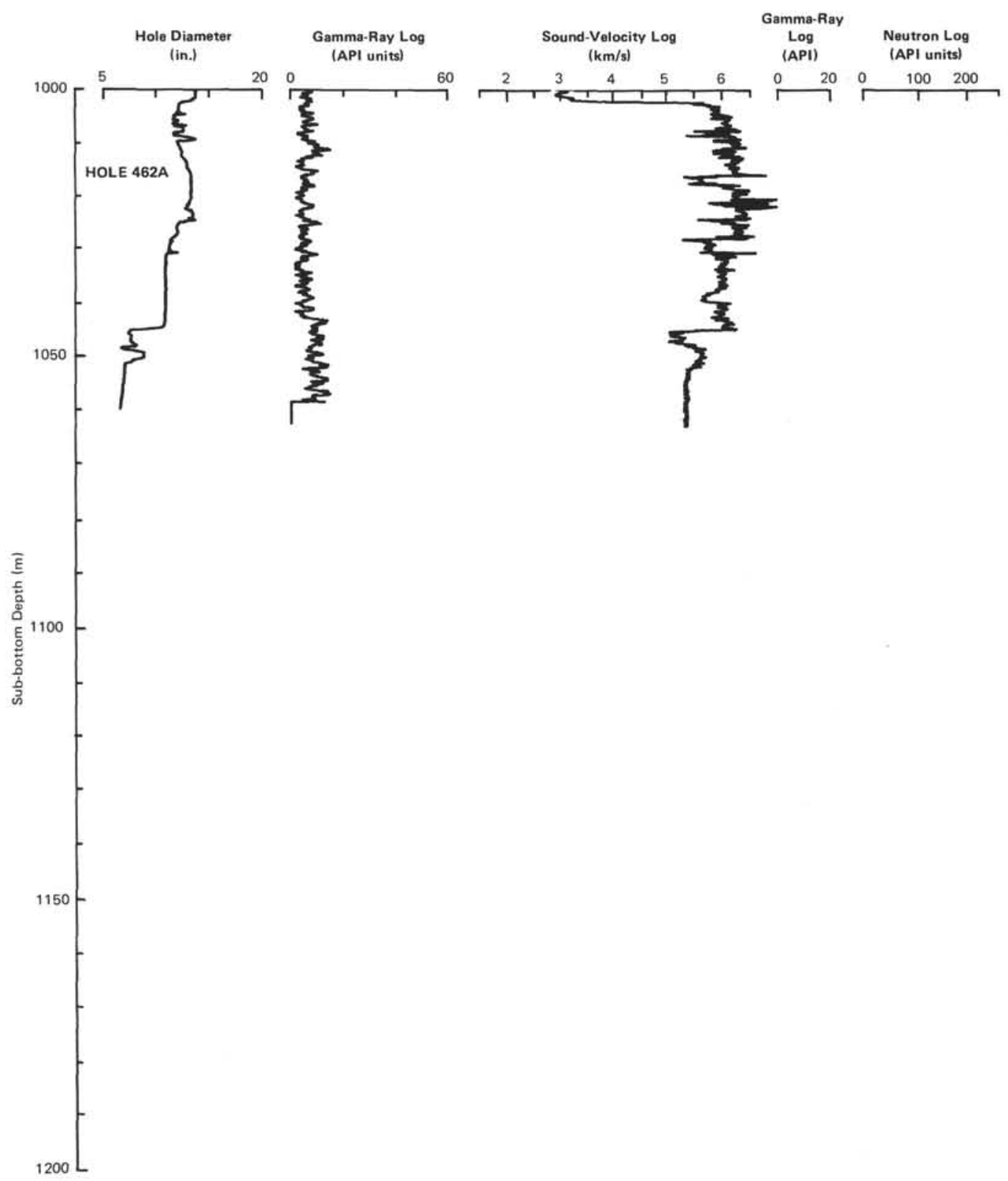

Figure 46. (Continued).

water sand. The ash is found in Cores 4,5 , and 6 , and also was indicated by a modest increase in the drilling rate at the bottom of Core 5. Judging from inspection of the first-run gamma-ray log, we believe that the principal ashy interval is between 44 and 50 meters.

The ashy component is brown within radiolarian ooze, and greenish-gray within carbonate ooze. Yellowbrown glass, glass partly altered and crowded with opaque dust, feldspar, pyroxene, and some amphibole are the components from volcanic activity nearby. Perhaps they record the growth of Kusaie Island, the easternmost and apparently youngest of the Caroline Islands chain. Kusaie is the island closest to Site 462 , lying about $260 \mathrm{~km}$ to the southwest.

Sands of shallow-water origin characterize parts of Cores 21, 22, 29, 32, and 34 and are thickest at about 210 meters sub-bottom. According to the gamma-ray and density logs, the principal interval is at 207 to 212 meters. The carbonate component of the coarse fraction is a mixture of chalky-lustered, recrystallized, highly abraded fragments of large foraminifers, mollusks, echinoid spines, calcareous red algae, corals, and, rarely, bryozoans. Rare fragments of white to pale-yellow calcite spar are also present. Identified large foraminifers include Heterostegina spp., Spherogypsina sp., Chapmanina(?), discocyclinids, and nummulitids. Core 22 was especially rich, containing, among other large foraminifers, alveolinids, Cyclocypeus, lepidocyclinids, etc.

This assemblage is Eocene in age, but also contains Paleocene and Cretaceous redeposited elements. The assemblage indicates an origin in a reef to shallow-bank environment. In thin-section, intensely recrystallized and strongly calcite-cemented rock fragments contain- 


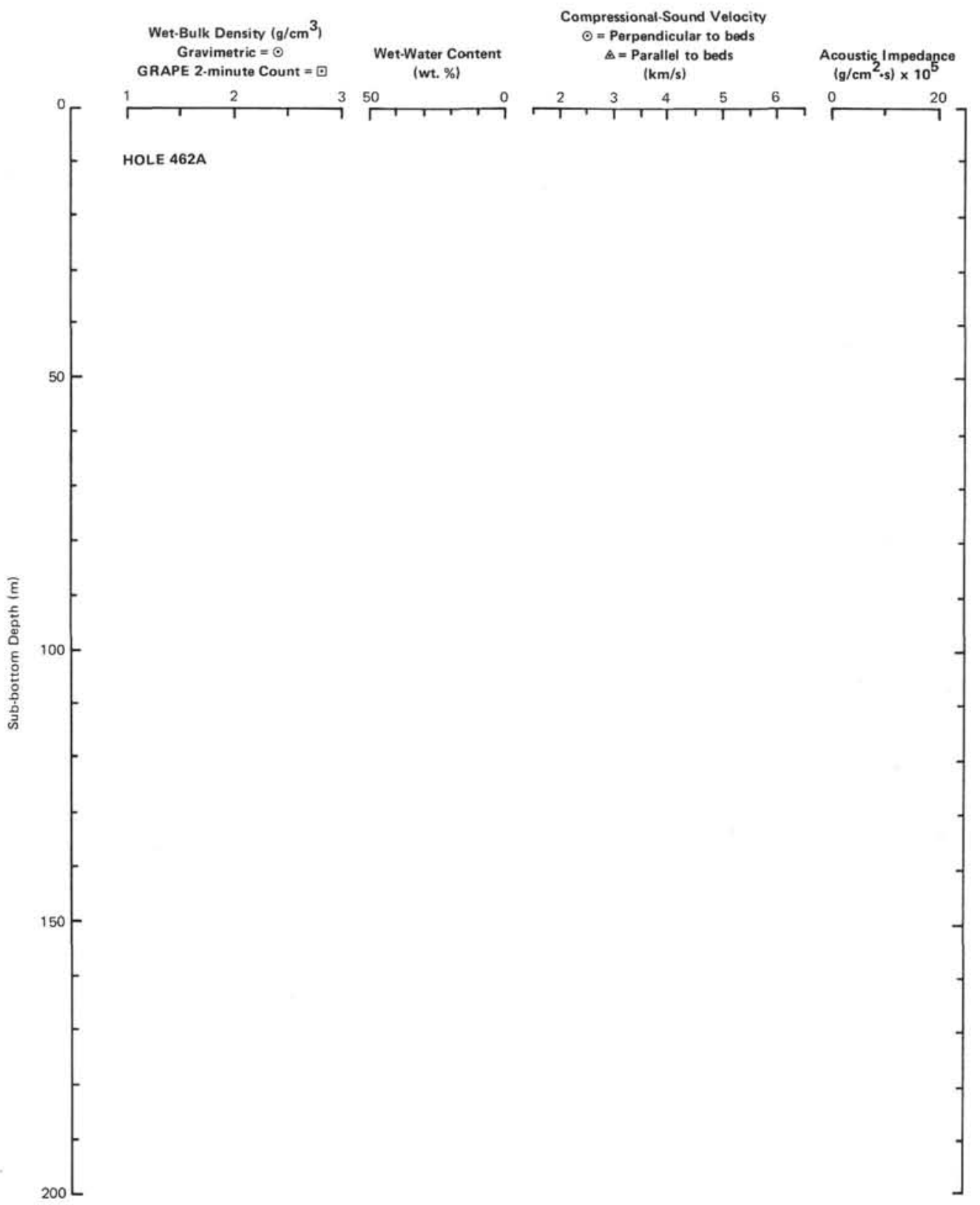

Figure 47. Laboratory-measured density, wet-water content, compressional-sound velocity, and acoustic impedance, Hole 462A.

ing the above-listed fossil elements are seen. This indicates that lithified reef rock, as well as individual skeletal fragments of Eocene age, was transported into the deeper-water Oligocene facies. A similar event took place during Oligocene time in the Line Islands (Winterer, Ewing, et al., 1973).

Volcanic grains are another component of the sand. They are mainly lithic grains (commonly vesicular and opaque to transmitted light at their greatest thickness), but vitric and crystal (pyroxene) grains are also present. Like the lime sand, they are detrital. Probably they represent times in the Oligocene when the Marshall Islands atolls were above sea level, and foraminifers of probable Eocene age and volcanic rock were eroded from the tops and submarine slopes of the islands. The Ralak
Chain of the Marshalls lies about 230 to $400 \mathrm{~km}$ northeast and east of the site (Fig. 1), and the unnamed group of the Marshalls (containing Enewetak Atoll and numerous closer atolls, seamounts, and guyots) is the same distance to the northwest. Enewetak Atoll was emergent during the Oligocene.

Unit 2 is essentially a diagenetically advanced and older version of Unit 1 . Turbidites dominate this limestone-and-chert unit. The cherts are the normal types encountered at many DSDP sites. At 447 meters, there is a fairly sharp break in the type of sedimentation, from the dominantly calcareous Unit 2 to a volcaniclastic-rich Unit 3.

Unit 3 embraces the time interval between late Campanian/early Maestrichtian and Cenomanian. The top 


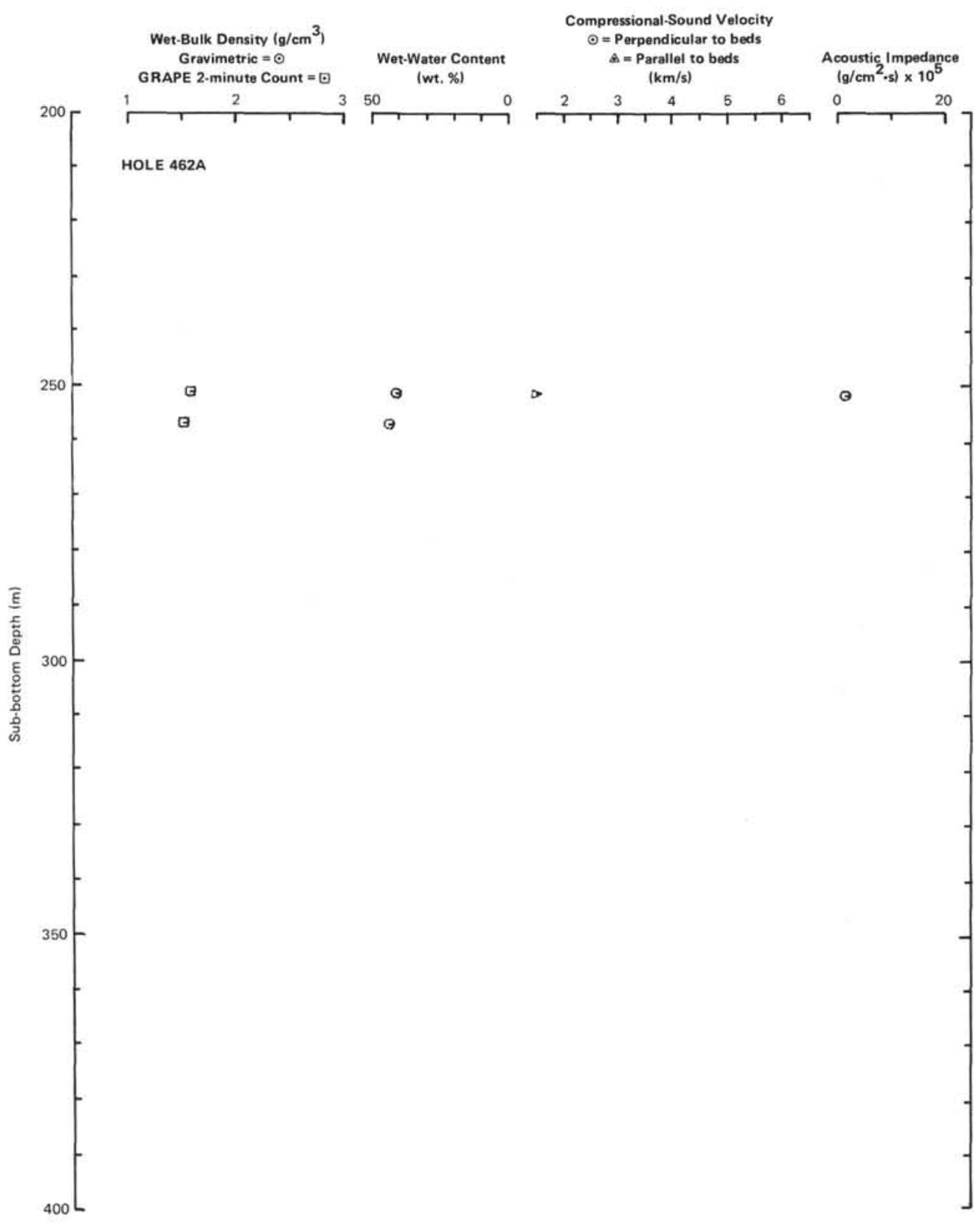

Figure 47. (Continued).

of the unit comprises light-olive-gray to pale-yellow nannofossil chalks and limestones. These sediments, which contain considerable percentages of unspecified carbonate, traces of volcanogenic grains, and very sparse radiolarians and sponge spicules, are interpreted as a pelagic product in which the amount of redeposition has been modest.

Interbedded and intermixed with these "host" lithologies are a series of greenish-gray to greenish-black volcaniclastic sediments. These deposits are perhaps the most striking feature of this unit; they display a range of sedimentary structures: tabular and trough cross-lamination, horizontal and parallel lamination, angular and scoop-shaped scours, and pebbly mudstone conglomerates whose clasts range up to $2 \mathrm{~cm}$ in length. Grading is obvious in many of the volcaniclastic sediments, and one bed, attaining a thickness of 2.55 meters, fines upward from a dark-greenish-gray, granular base to a greenish-gray, burrow-mottled, clay-rich nannofossil limestone. Slump structures, both within the scale of the core itself and apparently extending over several tens of centimeters, characterize particularly the basal levels of the volcaniclastic sediments; inclined bedding, up to $30^{\circ}$ from the horizontal, is present locally. The basal part of the volcaniclastic section comprises a matrix-rich volcanic breccia ("wackestone"), where sparse altered mafic clasts are enveloped in bluish-gray clay. Volcanic glass, heavy minerals, radiolarians, sponge spicules, fish remains, and clay constitute the fine fraction.

Associated with these volcaniclastic sediments are a variety of shallow-water skeletal grains. In Core 48-2, of Maestrichtian age, abraded tests of large benthic fora- 


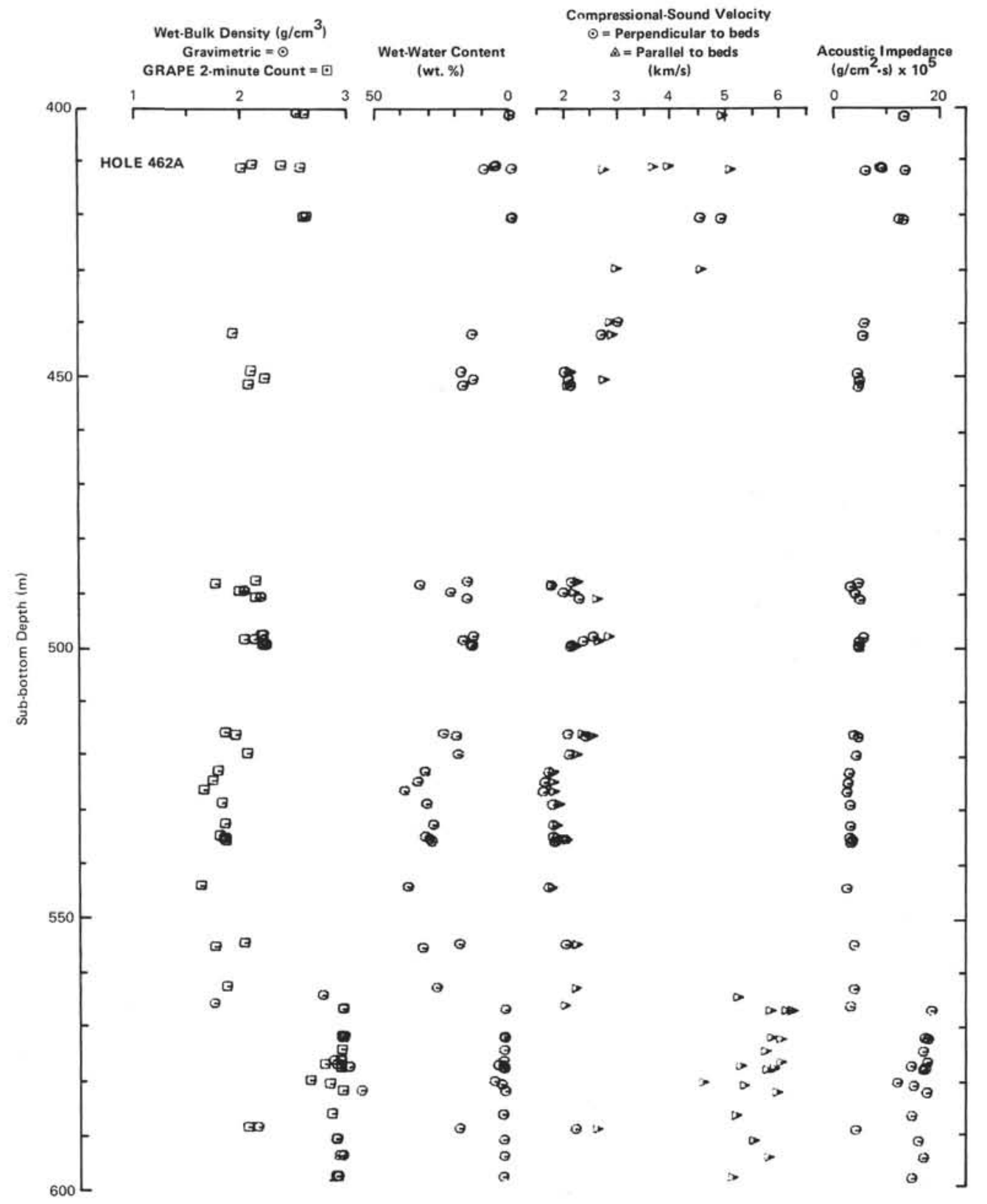

Figure 47. (Continued).

minifers (including Pseudorbitoides, Vaughanina, and Asterorbus), are found.

In Core 51-3, of late Campanian age, the coarsegrained carbonate components are a poorly sorted mixture of small $(<1 \mathrm{~mm})$, unidentifiable calcite fragments, large foraminifers, echinoid spines (rare), fragments of white to yellow calcite spar and mollusk shells. Many of the large foraminifers are relatively well preserved, but most, like the echinoid spines, are thickly coated with clear to white and yellow, subhedral calcite crystals. There is a striking contrast between well-preserved (slightly chalky), large foraminifers and calcitecoated forms that appear to have been broken out of calcite rock. Identified large benthic foraminifers in- clude Vaughanina sp., Pseudorbitoides sp., and amphisteginids. In Core 52, rudist fragments were found.

These shallow-water fossils of Maestrichtian to late Campanian age indicate that shallow banks within the photic zone existed, probably in the Marshall Islands area, as noted above. The presence of calcite-cemented material mixed with the free individual foraminifer tests suggests that these banks may have emerged, and that subsequently fragments of these emergent limestones mixed with co-existing reef and fore-reef material in the turbidites.

The coincidence of redeposited fossils of Campanian-Maestrichtian age in deeper-water facies of the same age at Site 462 and at Sites 165 (Leg 17), 315, and 


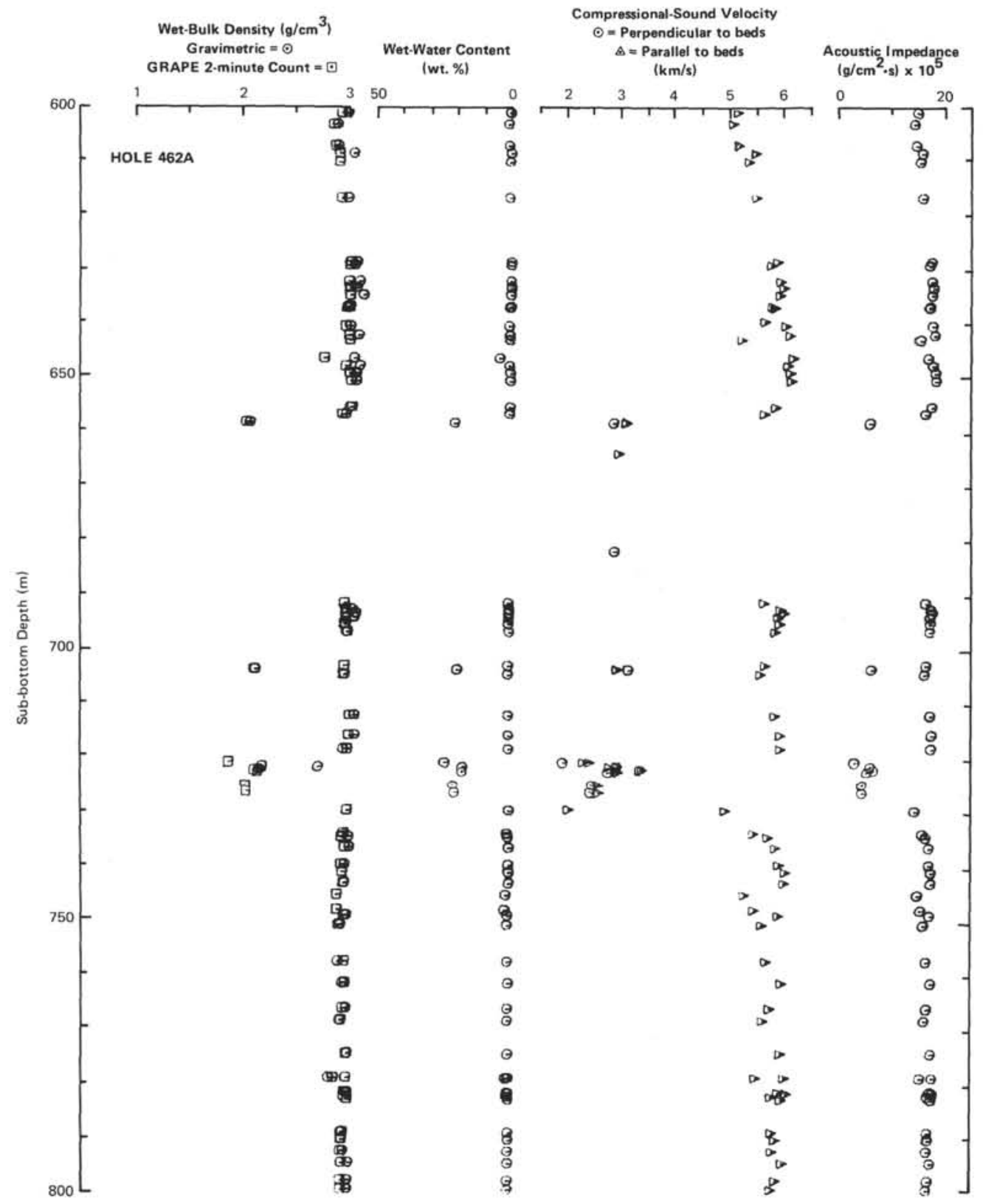

Figure 47. (Continued).

316 (Leg 33) in the Line Islands indicates that during Campanian-Maestrichtian time shallow-water carbonate banks and reefs existed over a wide area of the central Pacific Basin.

The volcaniclastic sediments, with their associated fauna, are clearly redeposited, and because many of them display features typical of Bouma sequences they readily may be interpreted as turbidites. The matrix-rich volcanic breccias probably were formed by deposition from a plastic, mobile mass-possibly a debris flow. It is possible that the original texture was more granular, and that considerable in situ devitrification of glass to clay minerals has taken place. All these volcaniclastic sediments presumably reflect synchronous nearby volcanism.
Below the volcaniclastic sediments are light-olivegray claystones to limestones, typically in sequences that are calcareous and laminated at the base and pass upwards into more-clay-rich, burrowed tops. Above this burrowed level, zeolitic claystones, usually consisting of pale-bluish-green and pale-brown layers $(2-3 \mathrm{~cm}$ thick) are typically developed. The olive-gray limestones to claystones here are interpreted as redeposited material, and the zeolitic claystones as the product of background pelagic sedimentation. Farther down the section, the thickness of the zeolitic claystones gradually increases, and colors of grayish-red and reddish-brown dominate over the pale-bluish-green hues. Olive-green claystones die away downward until the pale-reddish-brown, zeolitic claystones to siltstones, locally evincing faint hori- 


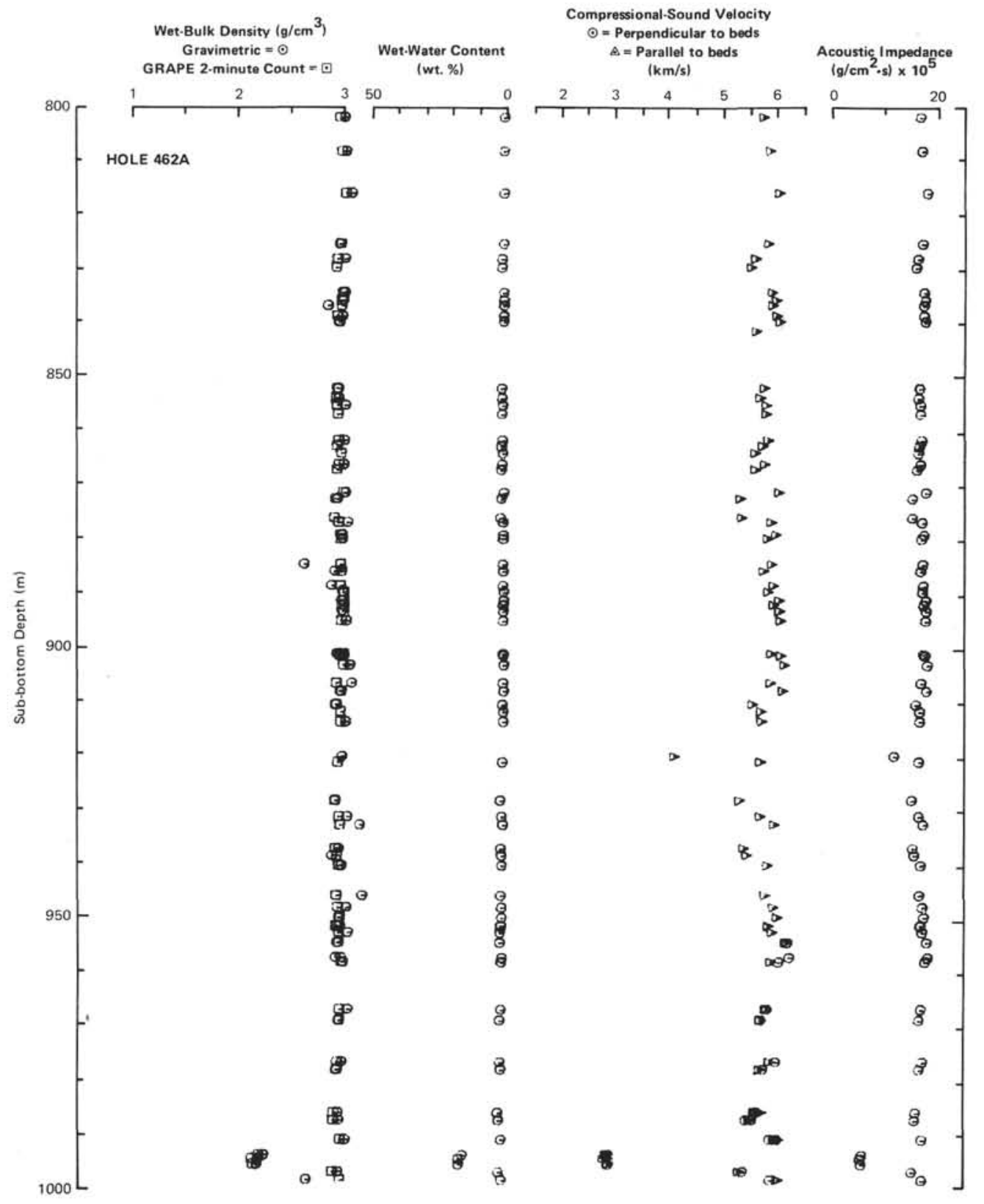

Figure 47. (Continued).

zontal lamination, become the dominant lithology. Traces of radiolarians, sponge spicules, fish teeth, and nannofossils constitute the fauna and flora. Occasionally, beds of greenish-gray, horizontally laminated volcaniclastics are interbedded (Core 57, Section 3 , and core catcher). Near the base of the section, green mottles and calcite veins occur, and horizontal lamination is common; a nannofossil marlstone is recorded from Core 58, Section 4. Core 59, also zeolitic mudstone (with nannofossils in Section 1) is dominantly reddishto light-brown, but contains horizontal, millimeter-scale laminae colored dark yellowish-orange, moderate brown, and grayish-green. Most significant perhaps are interbedded reddish-brown and greenish-brown horizontal laminae and a distinct black horizon. Zeolitic mud- stone, containing a piece of moderate-brown porcellanite is in contact with basalt.

The zeolitic mudstones presumably represent alteration products of fine-grained volcanic material which has undergone modest redeposition; the former presence of siliceous organisms, tentatively identified in smear slides, is supported by the presence of chert.

The grayish-brown to black sediments, dated at about the Cenomanian/Turonian boundary, are intriguing in that similarly colored, coeval, organic-rich sediments are recorded from a variety of locations within the major ocean basins and in pelagic sections on land.

The discovery at Site 462 of redeposited bank and reef skeletal debris of Campanian-Maestrichtian age is 

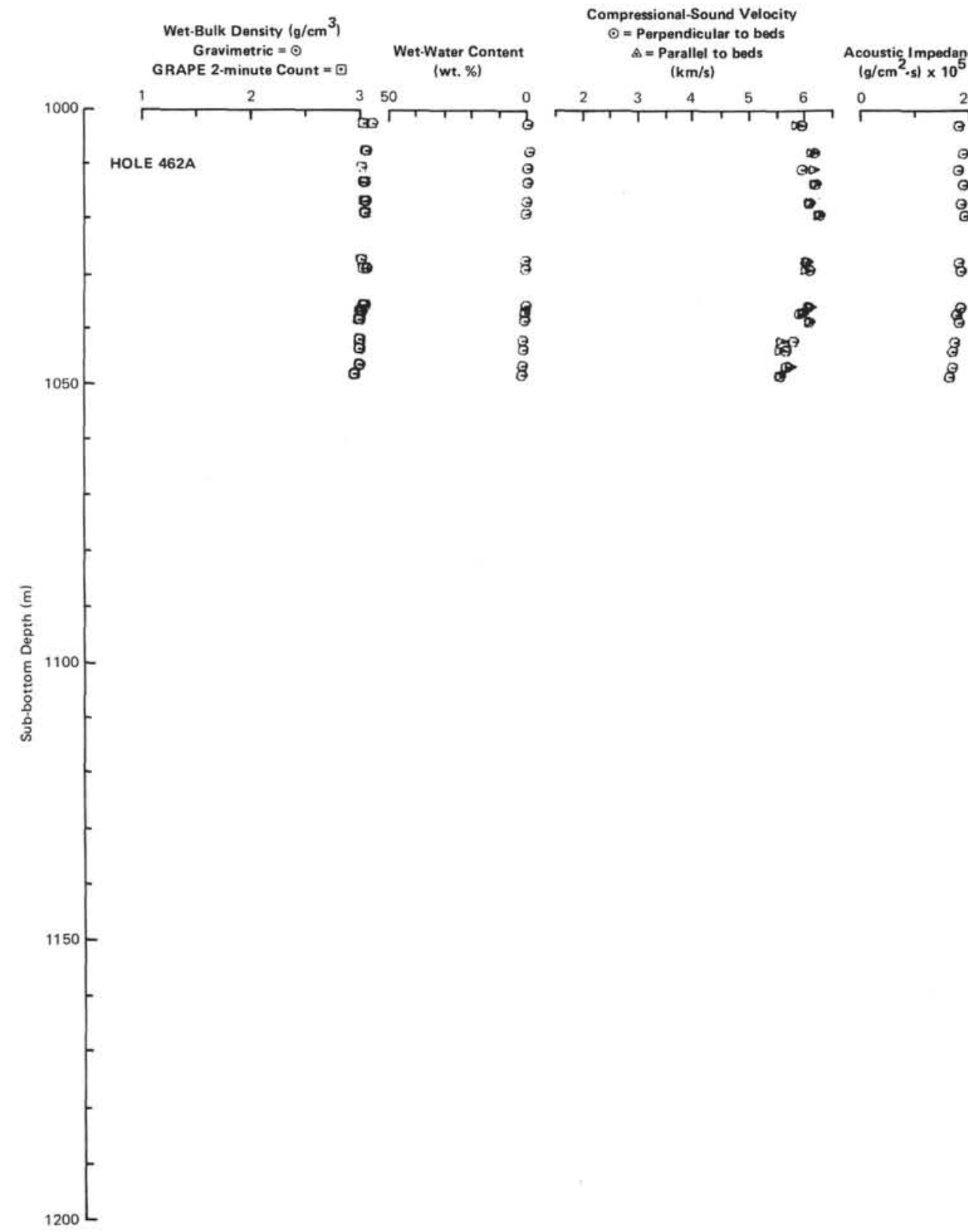

Figure 47. (Continued).

of considerable interest. It shows that the Marshall Islands, the logical source of this material, have a Cretaceous shallow-water-reef history comparable to the Line Islands. Prior to Leg 61, our knowledge of the age of the Marshall Islands was confined entirely to the results of the Enewetak drilling; there, basalt was reached below middle Eocene reefs. We must now assume that perhaps drilling at Enewetak stopped in post-Cretaceous basalt flows and that the Cretaceous reef was not reached.

\section{Igneous Petrology}

Site 462 is the location of a mid-Cretaceous volcanic complex at least 500 meters thick that presumably overlies sediments and volcanic basement of Late Jurassic age. The mid-Cretaceous volcanic section drilled at Site
462 represents a voluminous outpouring of basalt magma. The total volume of lava is uncertain, because the thickness and lateral extent of the complex is not well known, although it may well fill the Nauru Basin. The volcanic complex is a huge, non-edifice-building, off-ridge outpouring of basalt magma. As such, it is both unique and enigmatic.

The volcanic complex is made up of single sills, multiple sills, extrusive or semi-extrusive flows, and hyaloclastic sediments. The upper 170 meters of the complex, from 560 to 730 meters sub-bottom, is made up of interbedded single sills, multiple sills, and hyaloclastic sediments. The single sills are characterized by (1) glassy margins or fine-grained marginal zones with sub-horizontal attitude, and (2) orderly, coarsening-inward grain-size variations, coarse-grained interiors, and dia- 


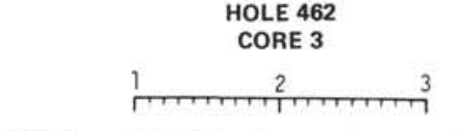

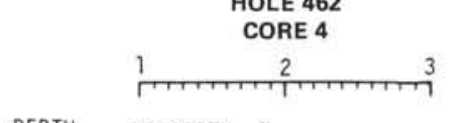
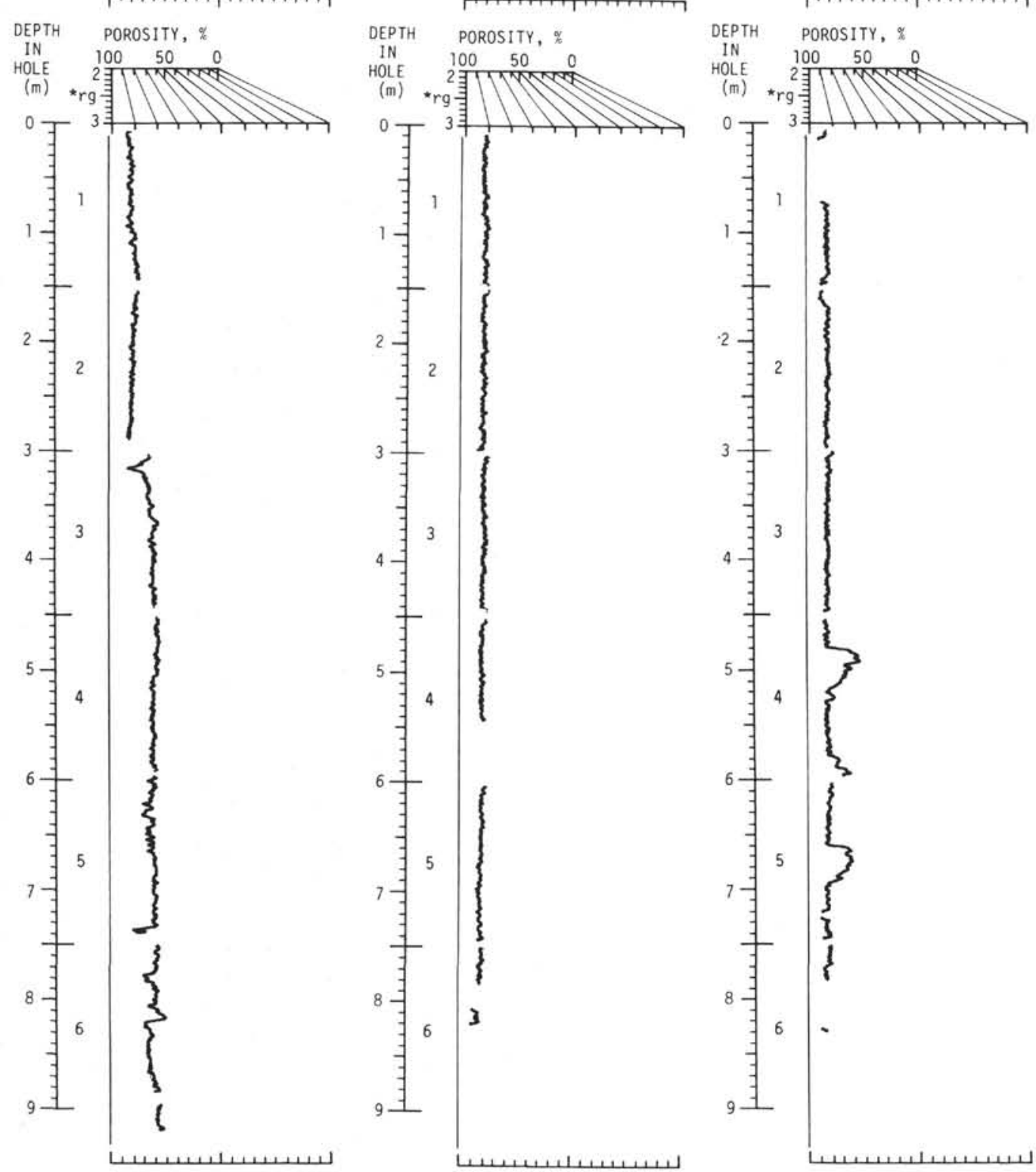

All Leg 61 GRAPE analog computer data have been edited for publication. For Leg 61 Analog GRAPE data, all rock diameters were measured by hand, usually one measurement per $5-\mathrm{cm}$ core segment. Some of these core segments are very rough and irregular; therefore, when these diameters (and assumption of offset from the gamma-ray beam, as described by Equation 36 in Boyce, 1976b) are applied to the raw GRAPE data, then the resulting adjusted data (dotted lines) are subject to huge errors, particularly when small irregulardiameter core segments are scanned and the calculated (Equation 38) offset is incorrect. The unadjusted GRAPE data are plotted as a solid line, with "diameter-adjusted" data presented as a dotted line. This allowed the obvious errors to be corrected by hand. More importantly, this presentation allows investigators to manipulate the data. Investigators interested in the density of a specific layer or rock piece should check the sample diameter from the core photographs and make the appropriate diameter corrections as discussed in Boyce (1976b)

Figure 48. Continuous GRAPE wet-bulk density versus depth in each core.

Note: The upper scale is GRAPE Wet-Bulk Density (1.0 to 3.0 $\mathrm{g} / \mathrm{cm}^{3}$ ): solid lines (—) are GRAPE analog data, assuming a $6.61-\mathrm{cm}$ core diameter; dotted lines $(\cdots \cdots)$ are GRAPE analog data adjusted for actual core diameter; circled $(\odot)$ dots are the wet-bulk density calculated from 2-minute counts on a stationary sample: scale to be determined by selecting the proper grain density $\left(r_{g}\right)$ and extrapolating horizontally. 

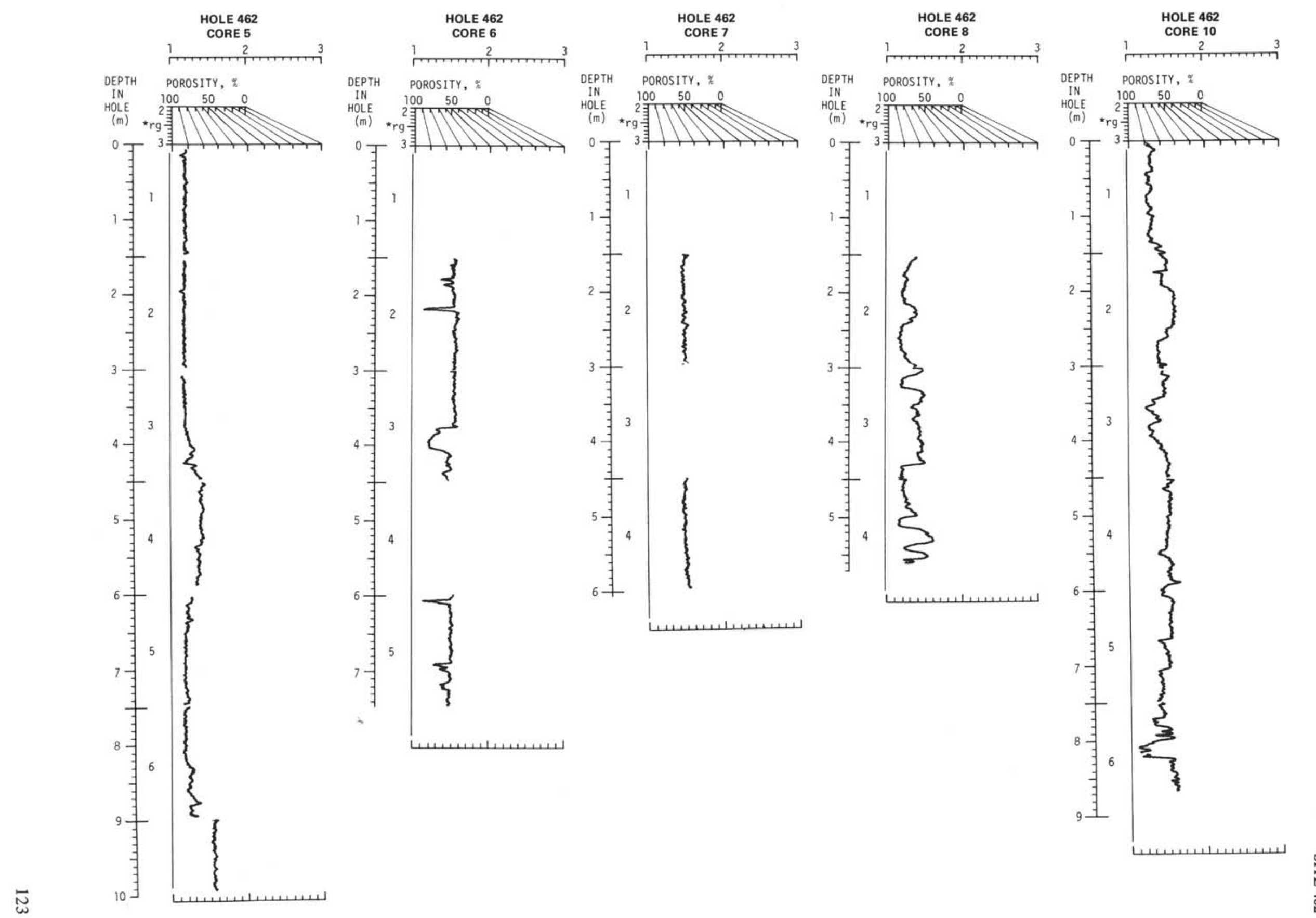

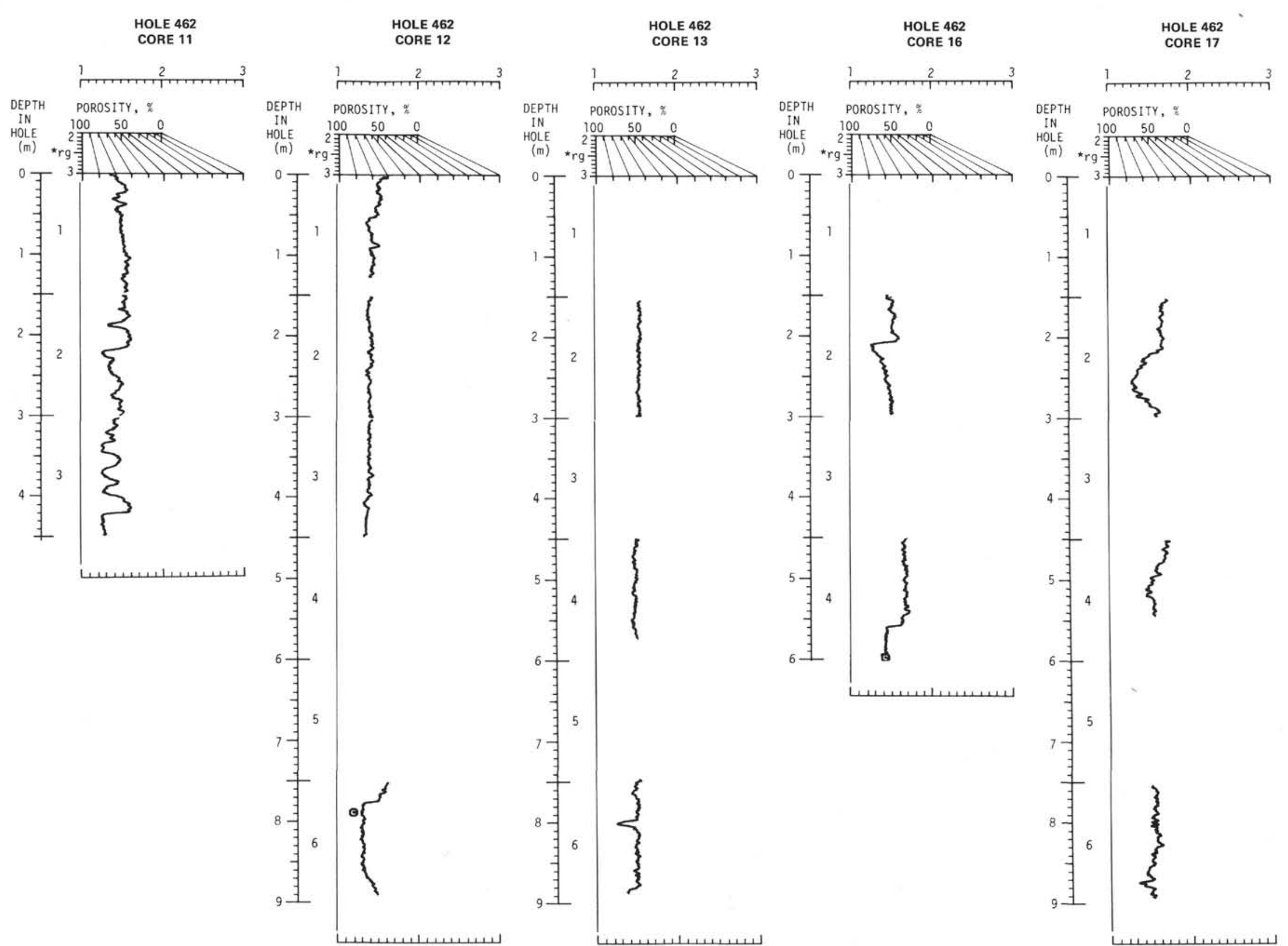

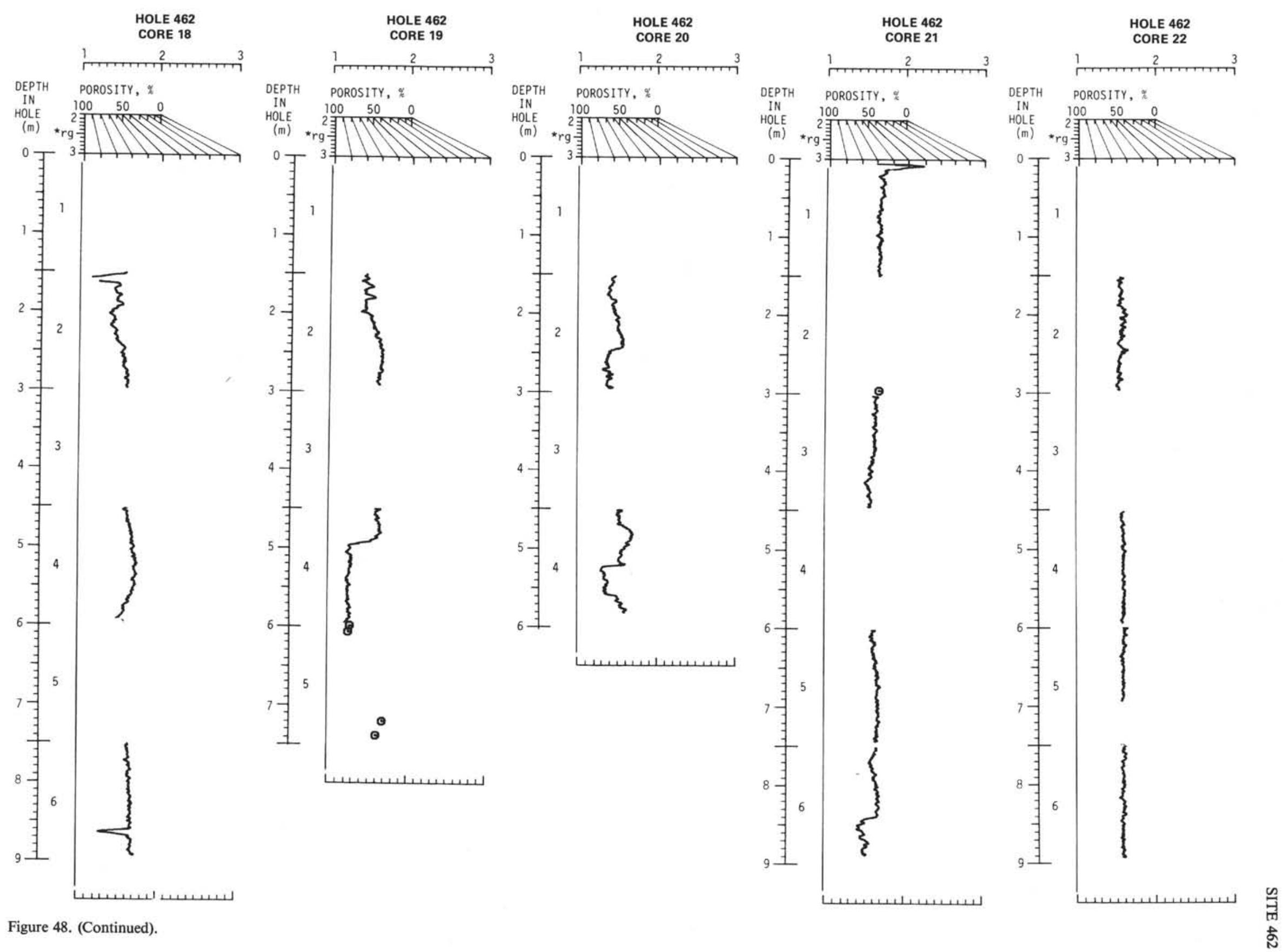


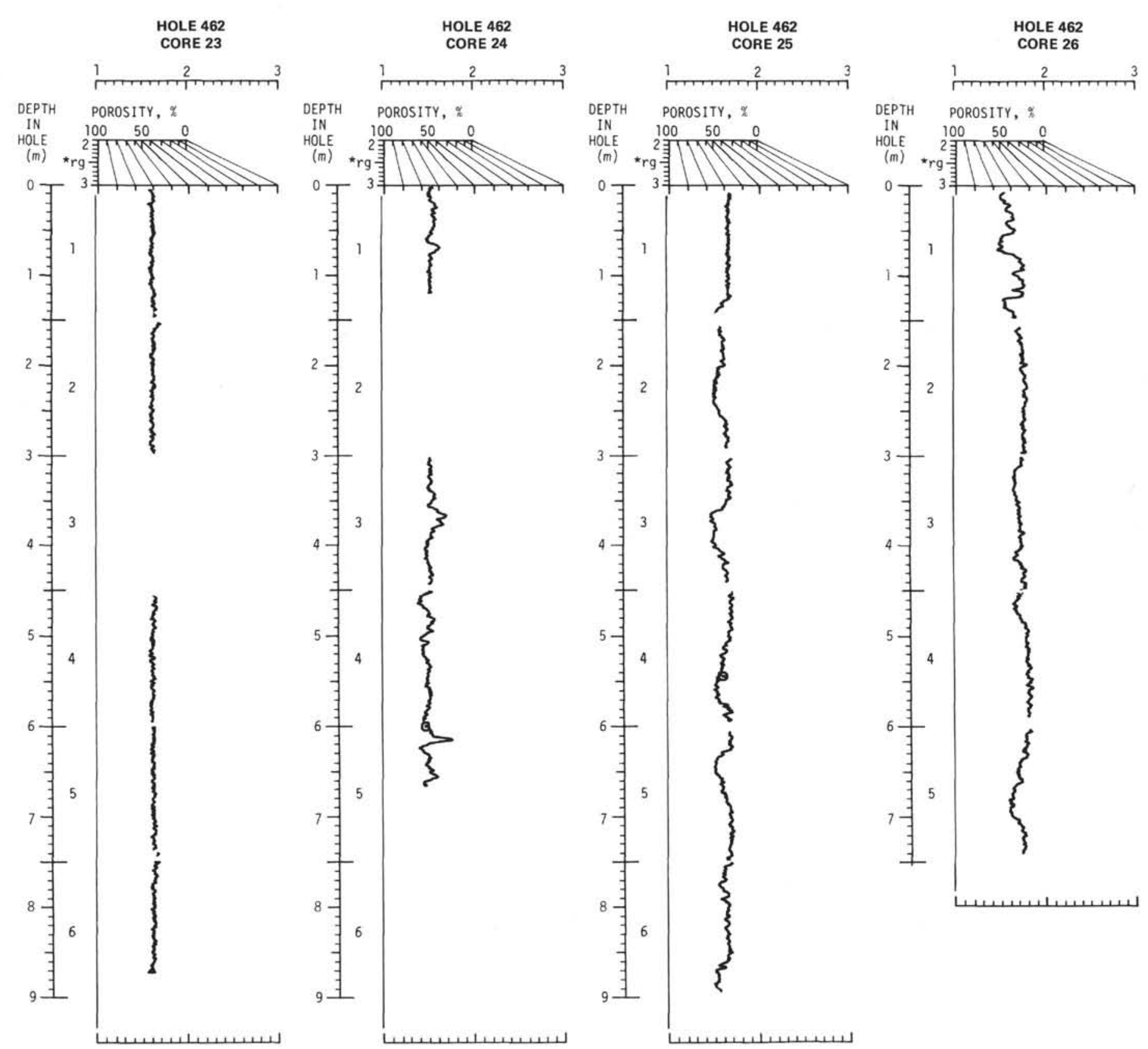

HOLE 462
CORE 27

DEPTH POROSITY, * HOLE $100 \quad 50 \quad 0$ (m) ${ }^{2}$ rg 青 110 呵 青 1 多 寺

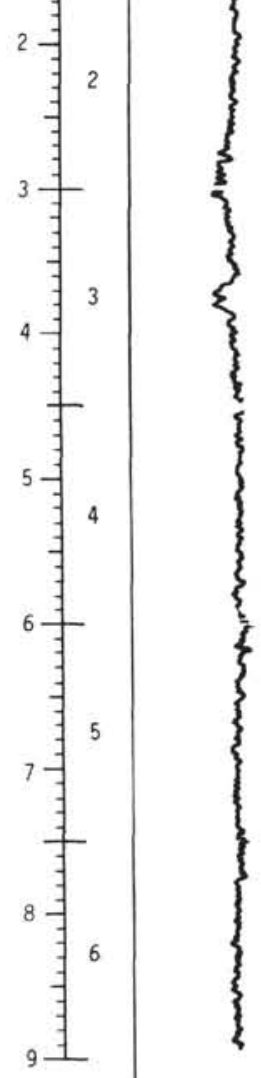




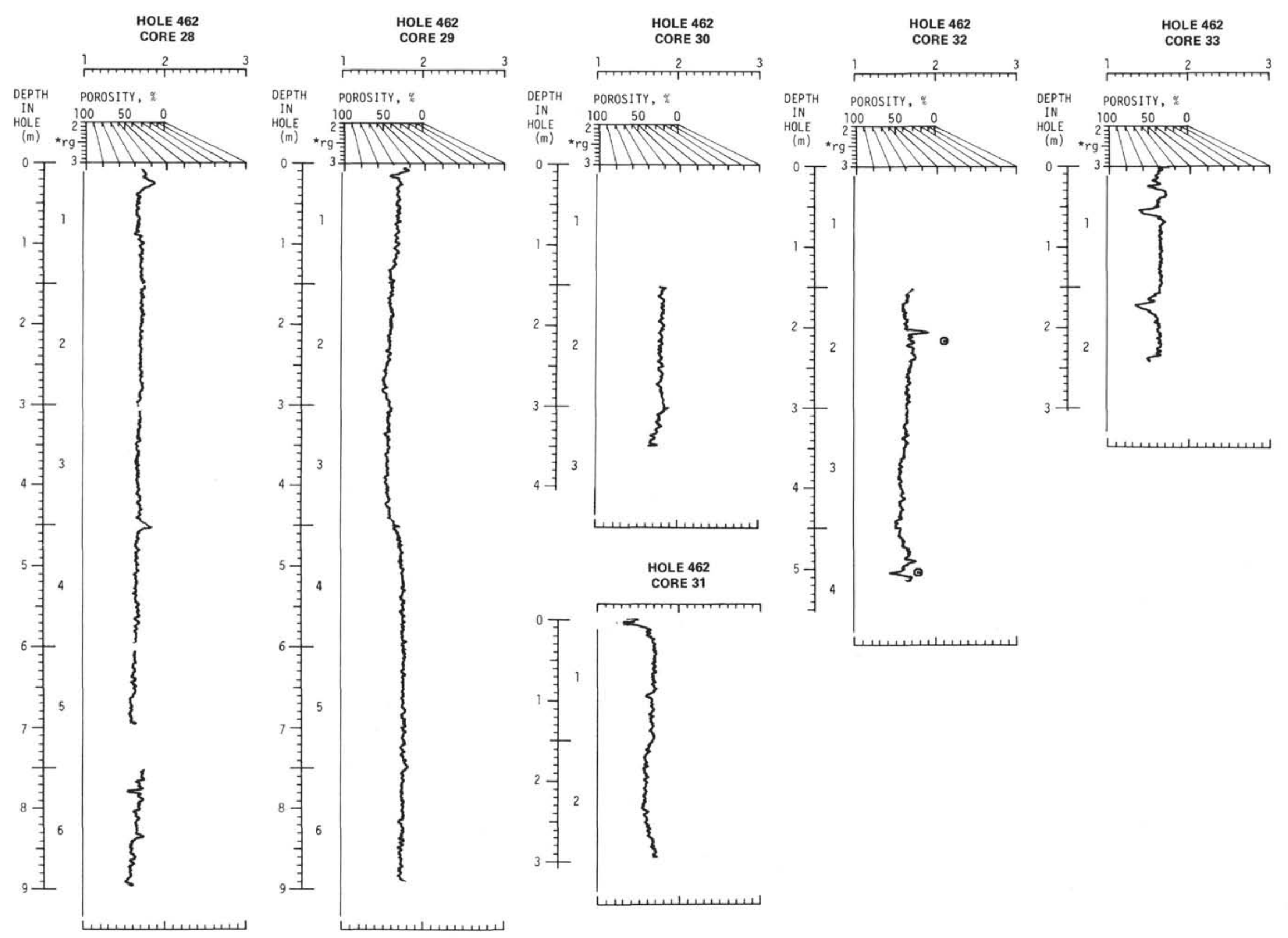




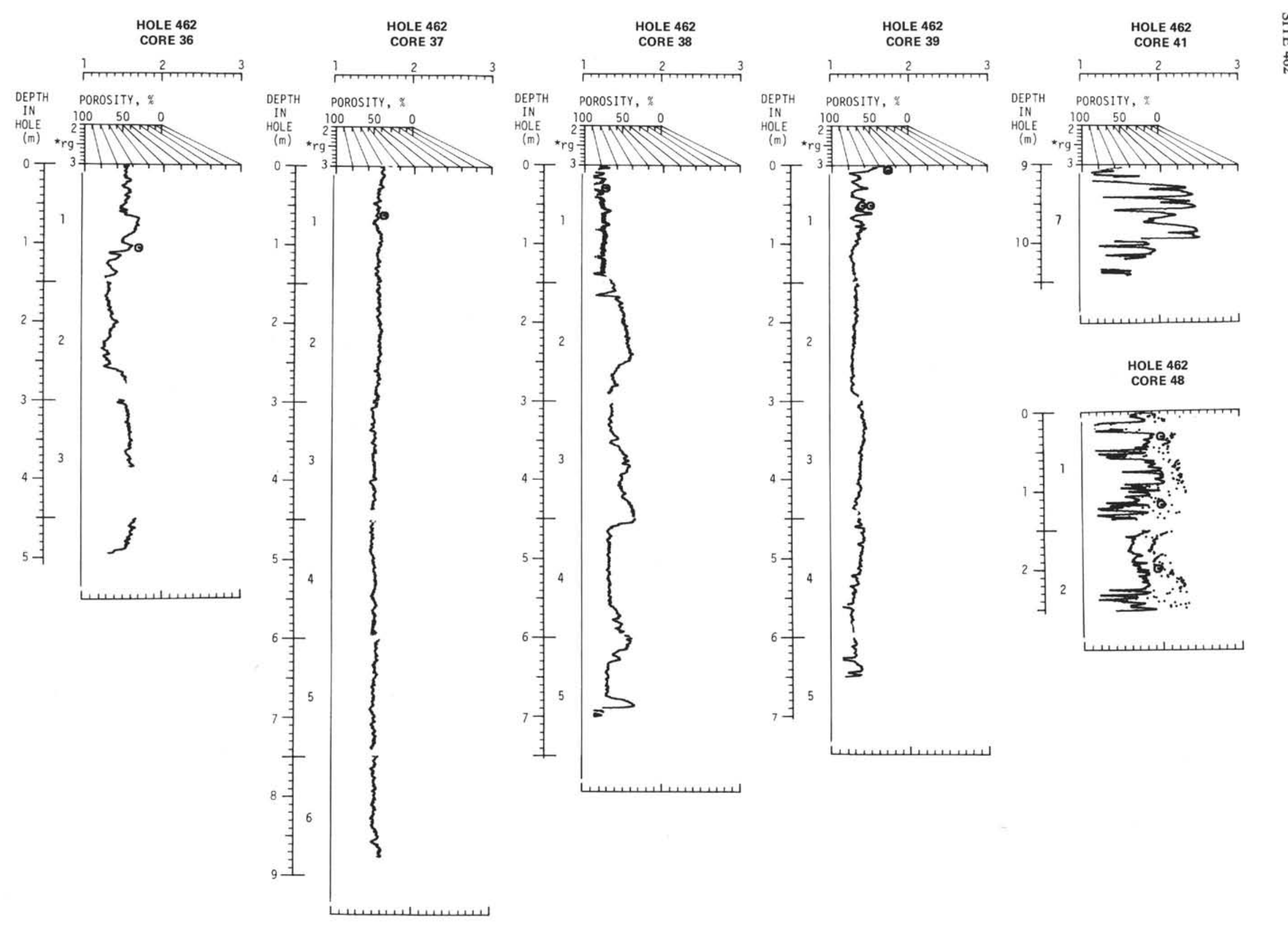




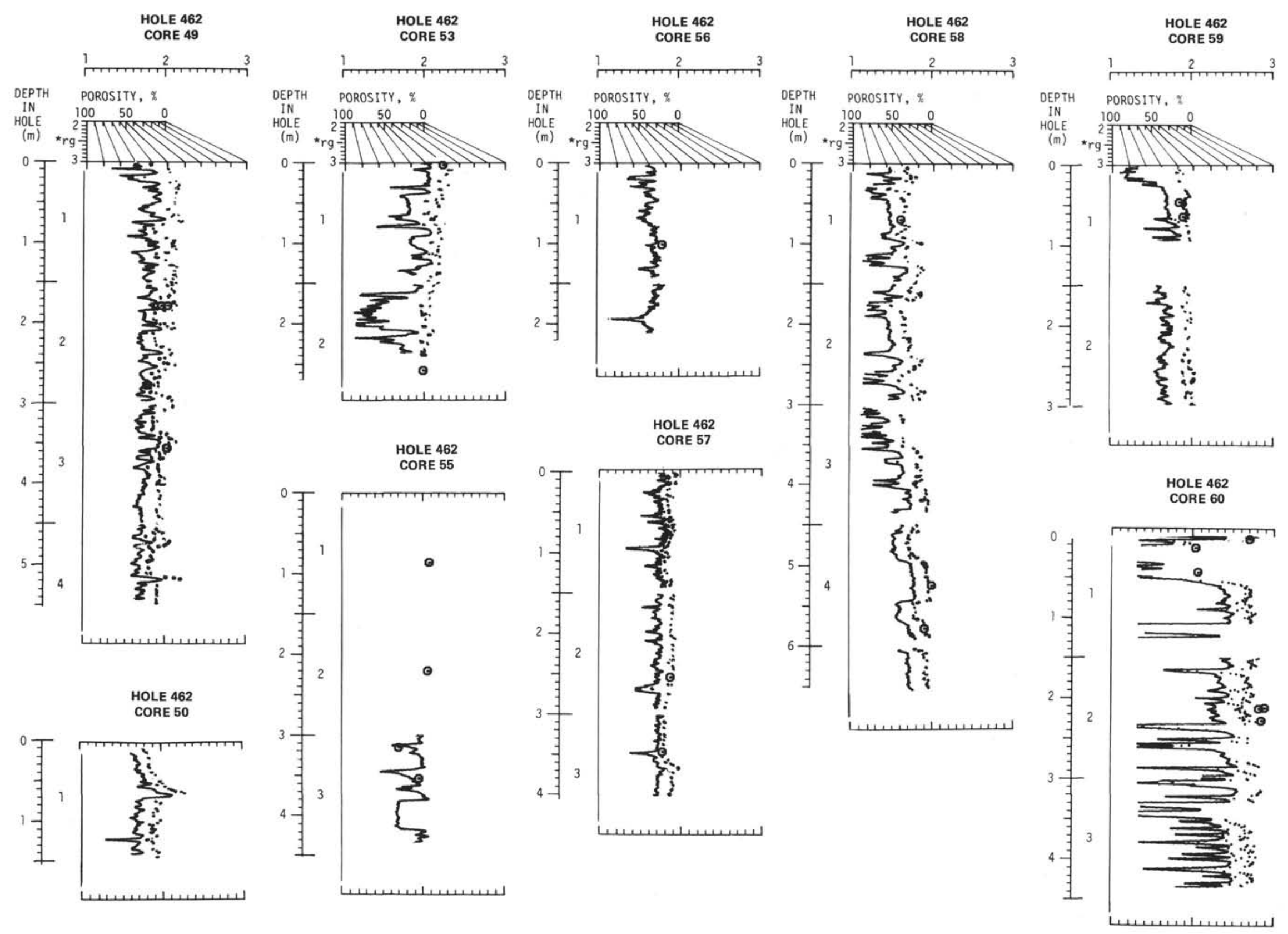



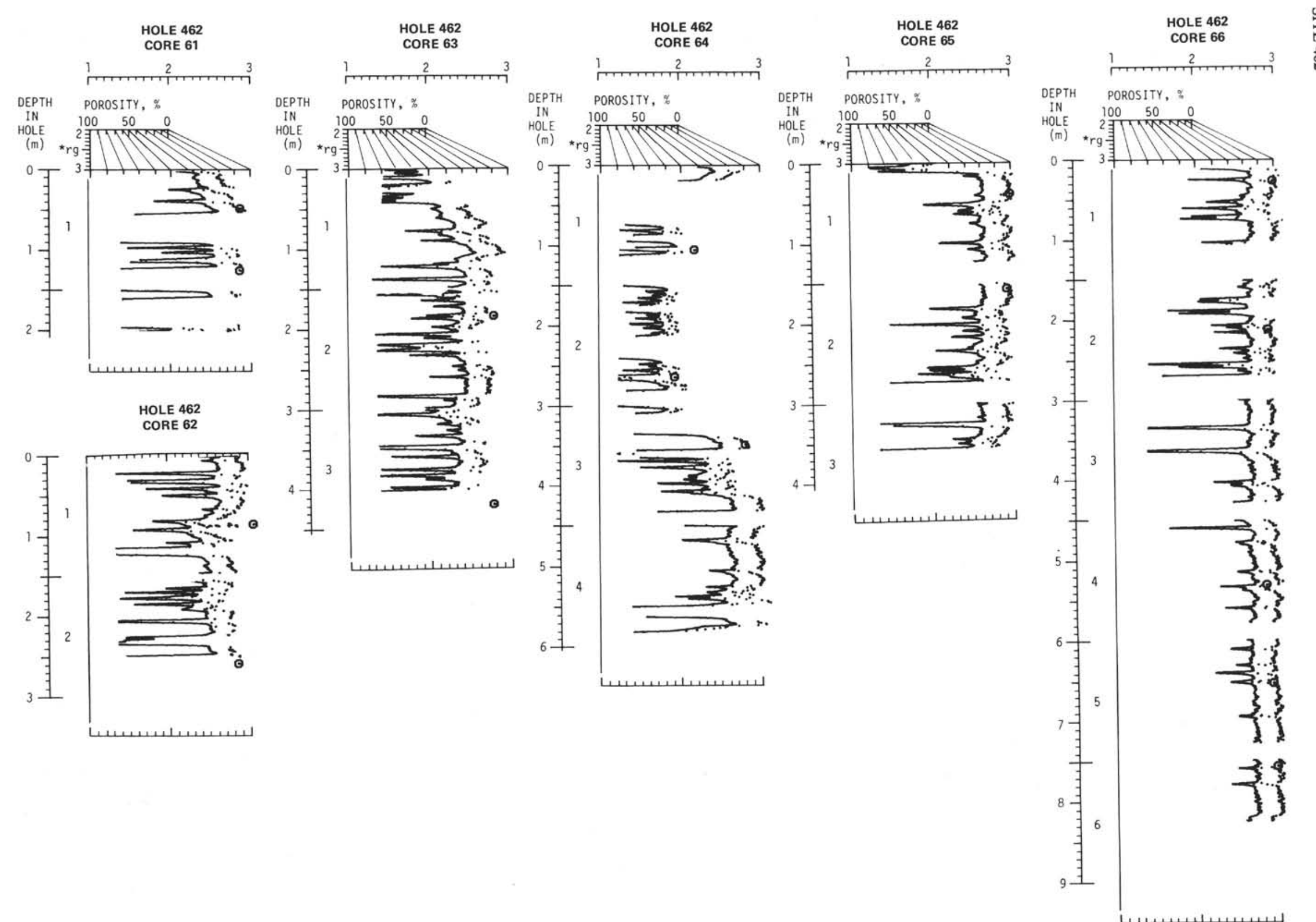


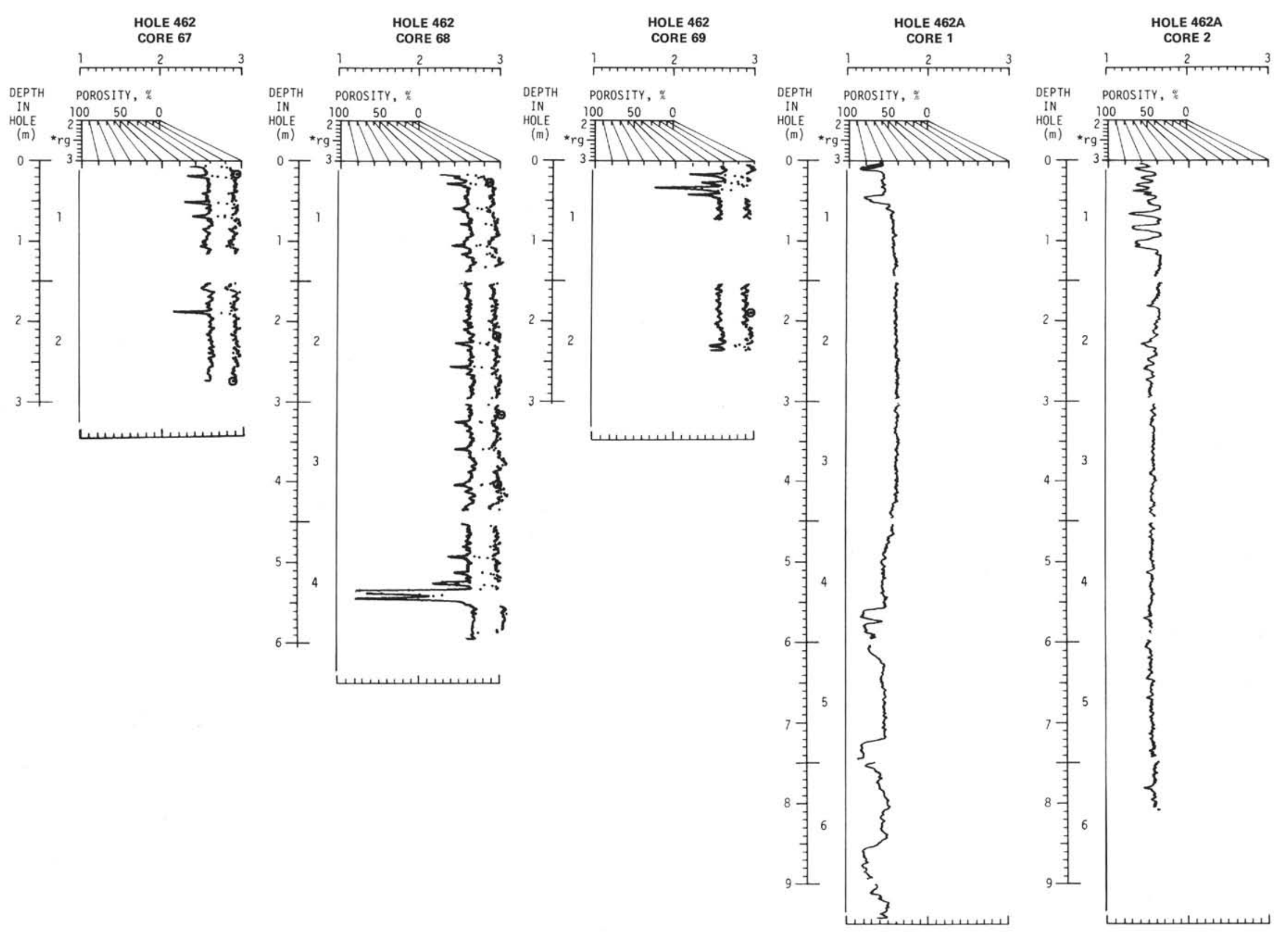




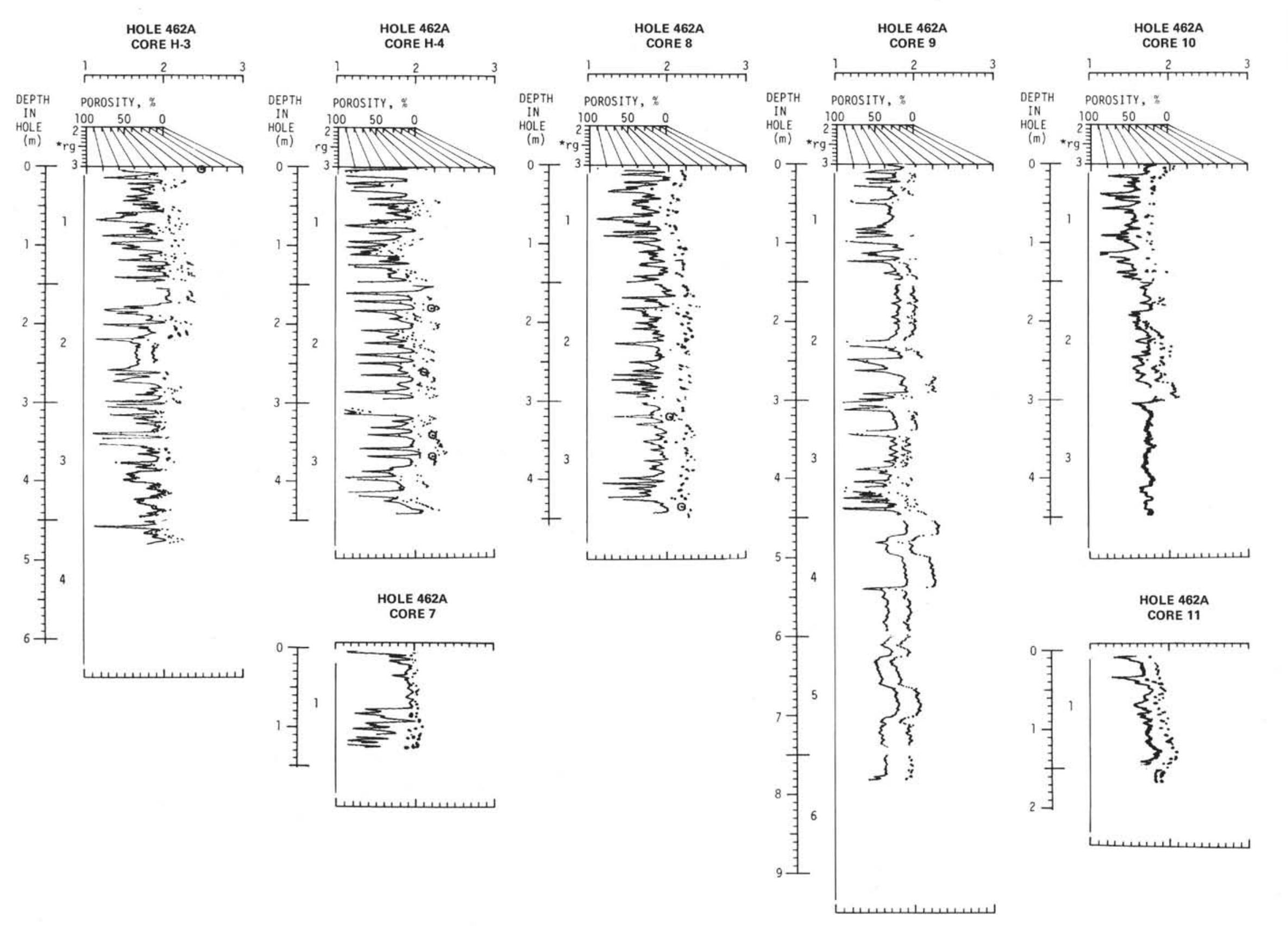




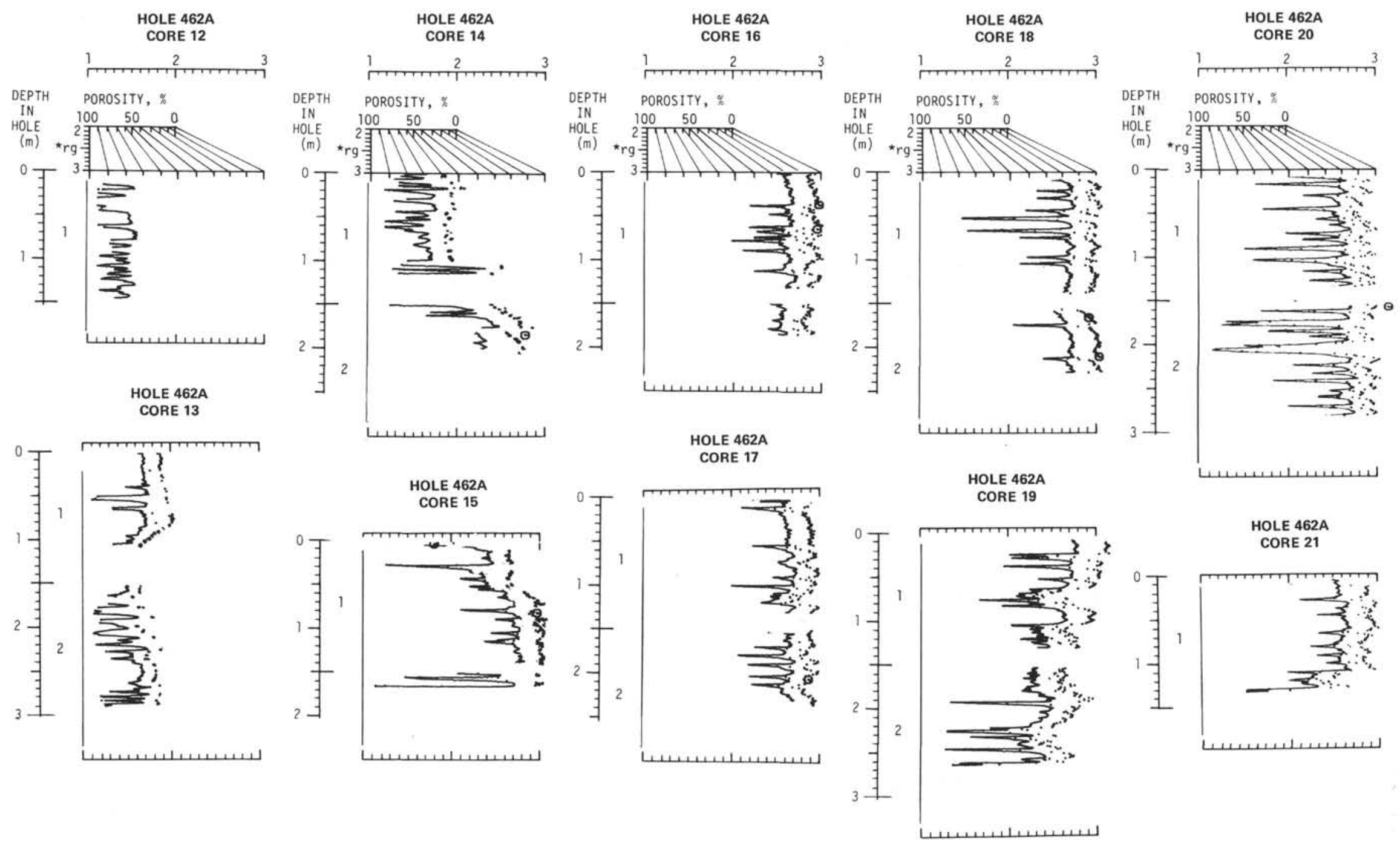

Figure 48. (Continued). 


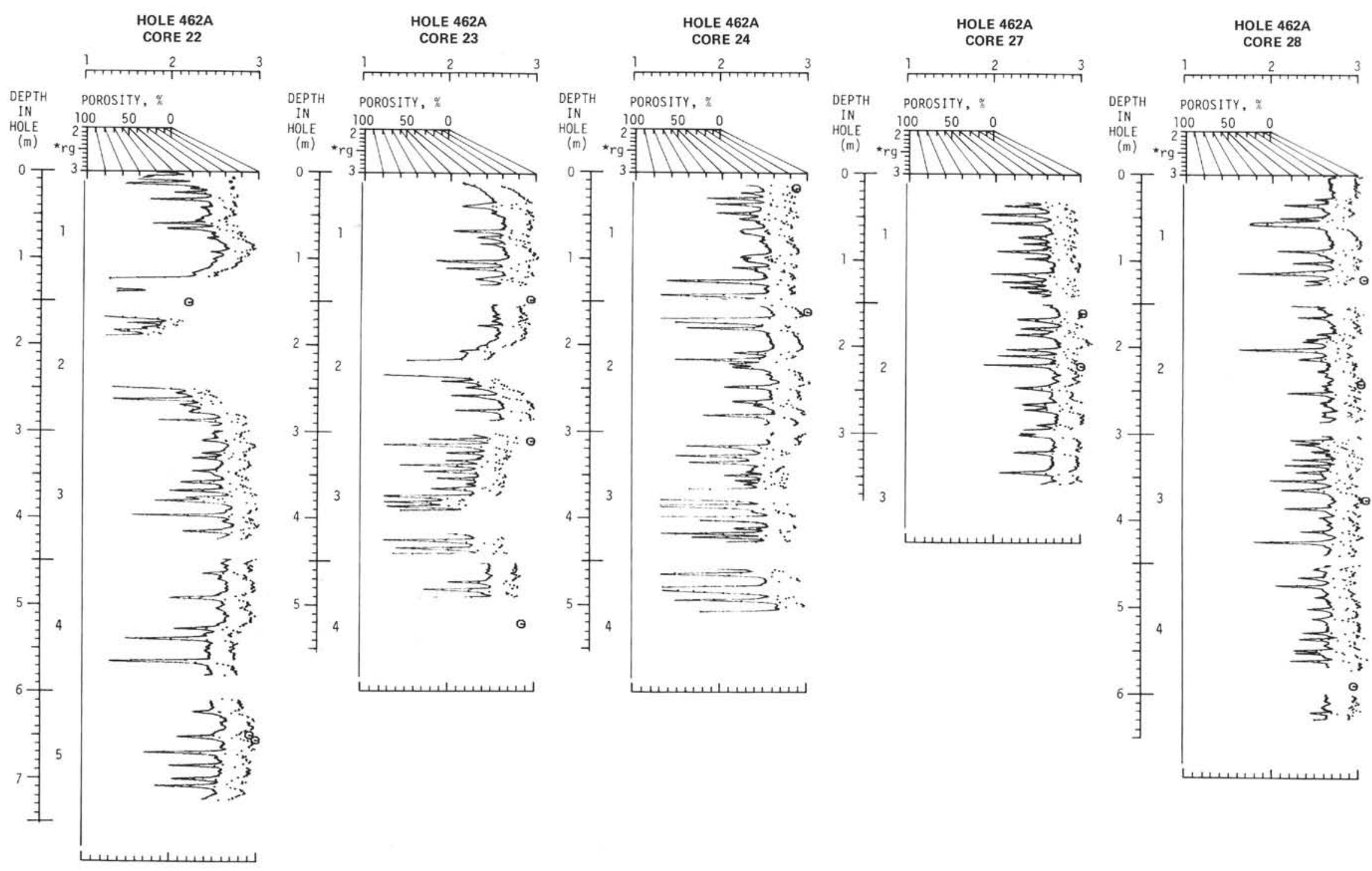




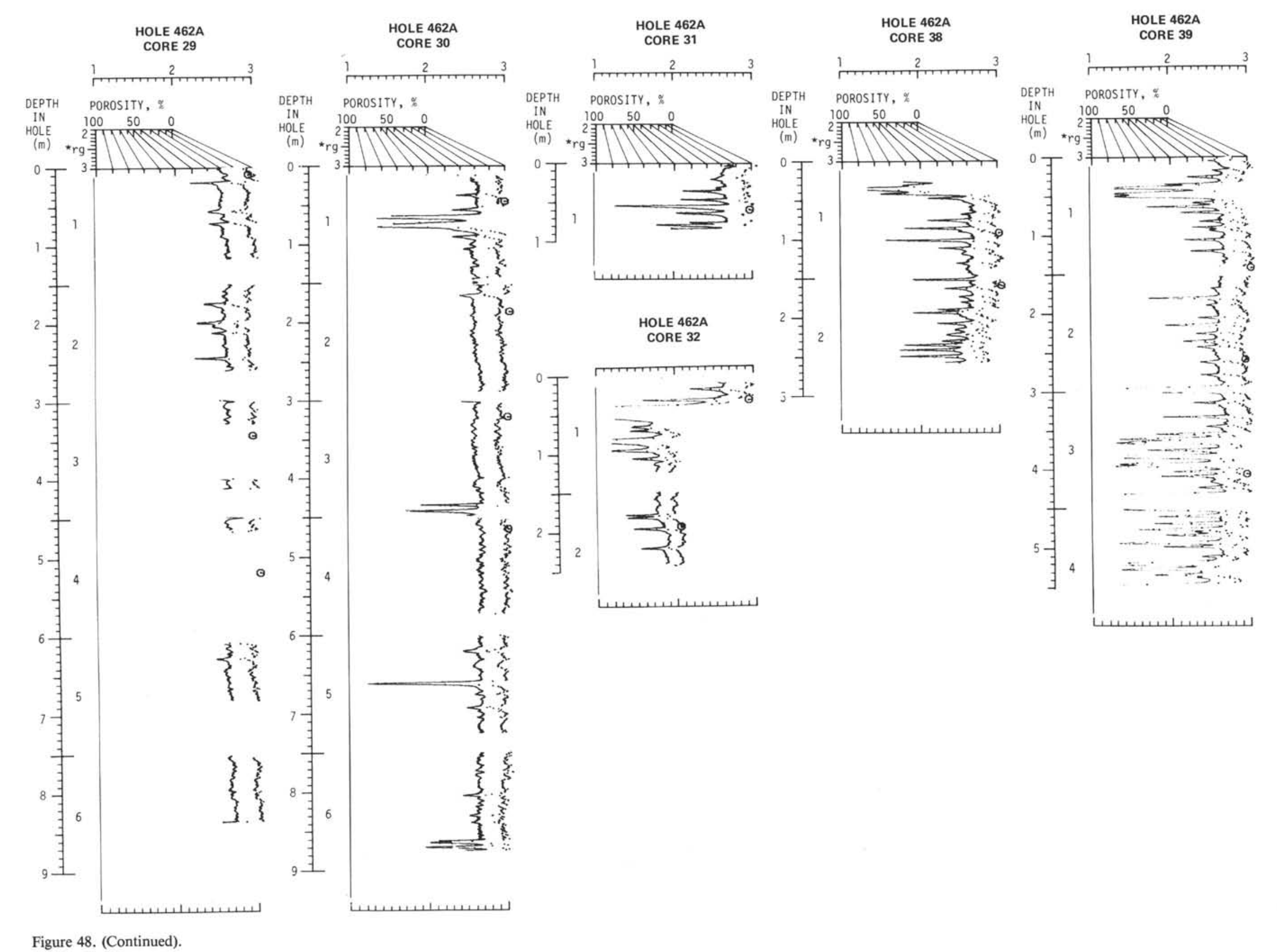




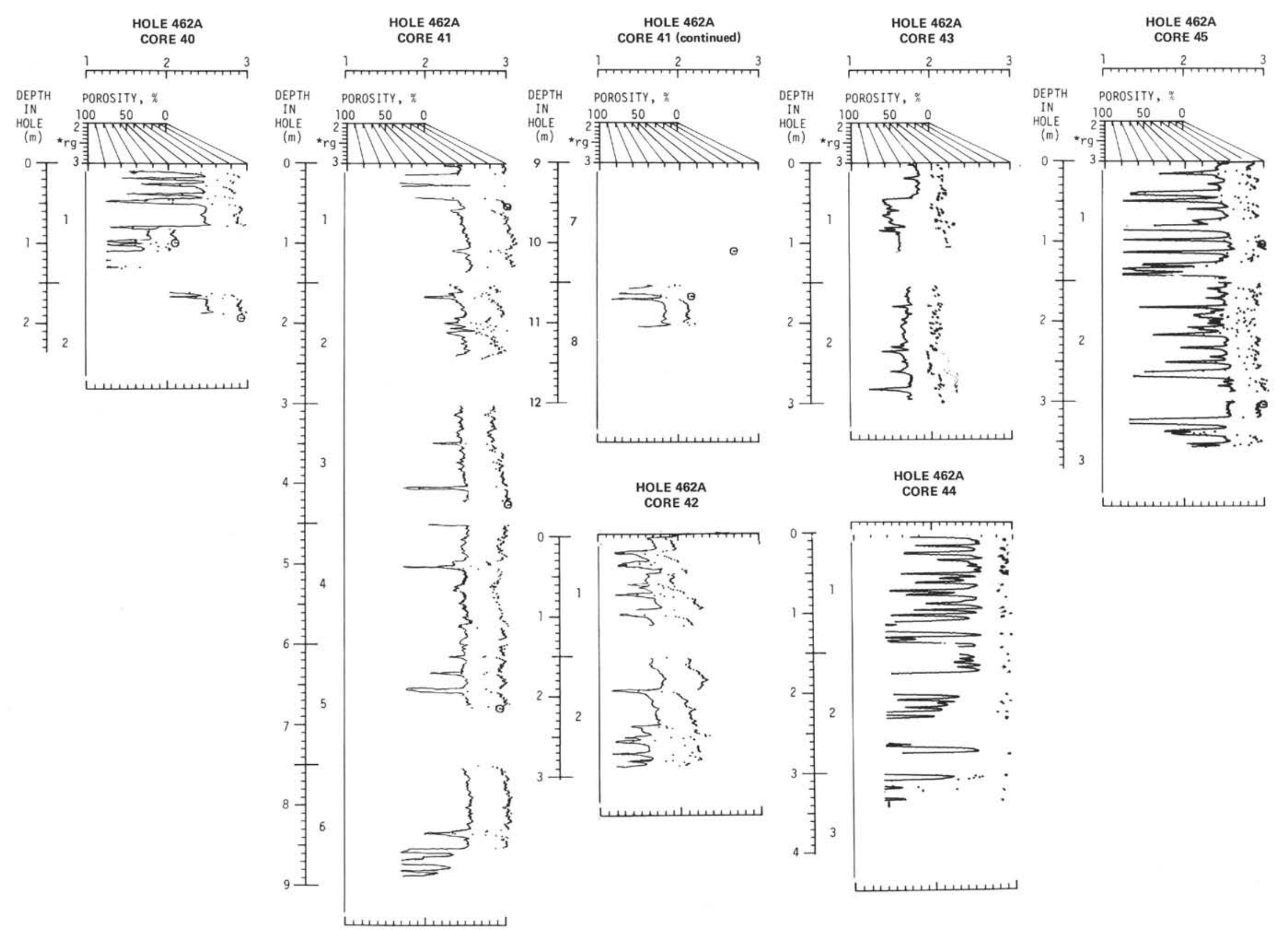




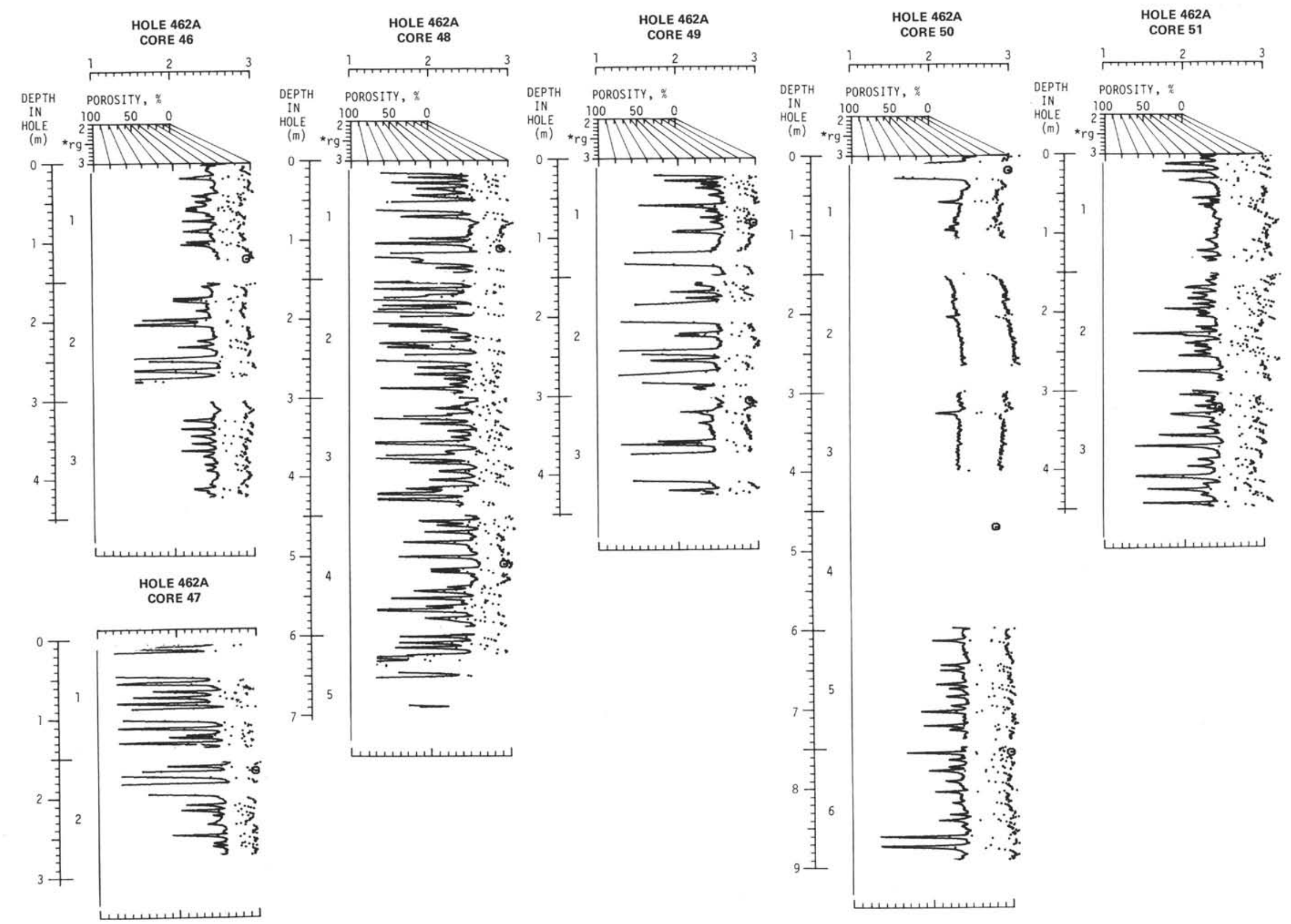




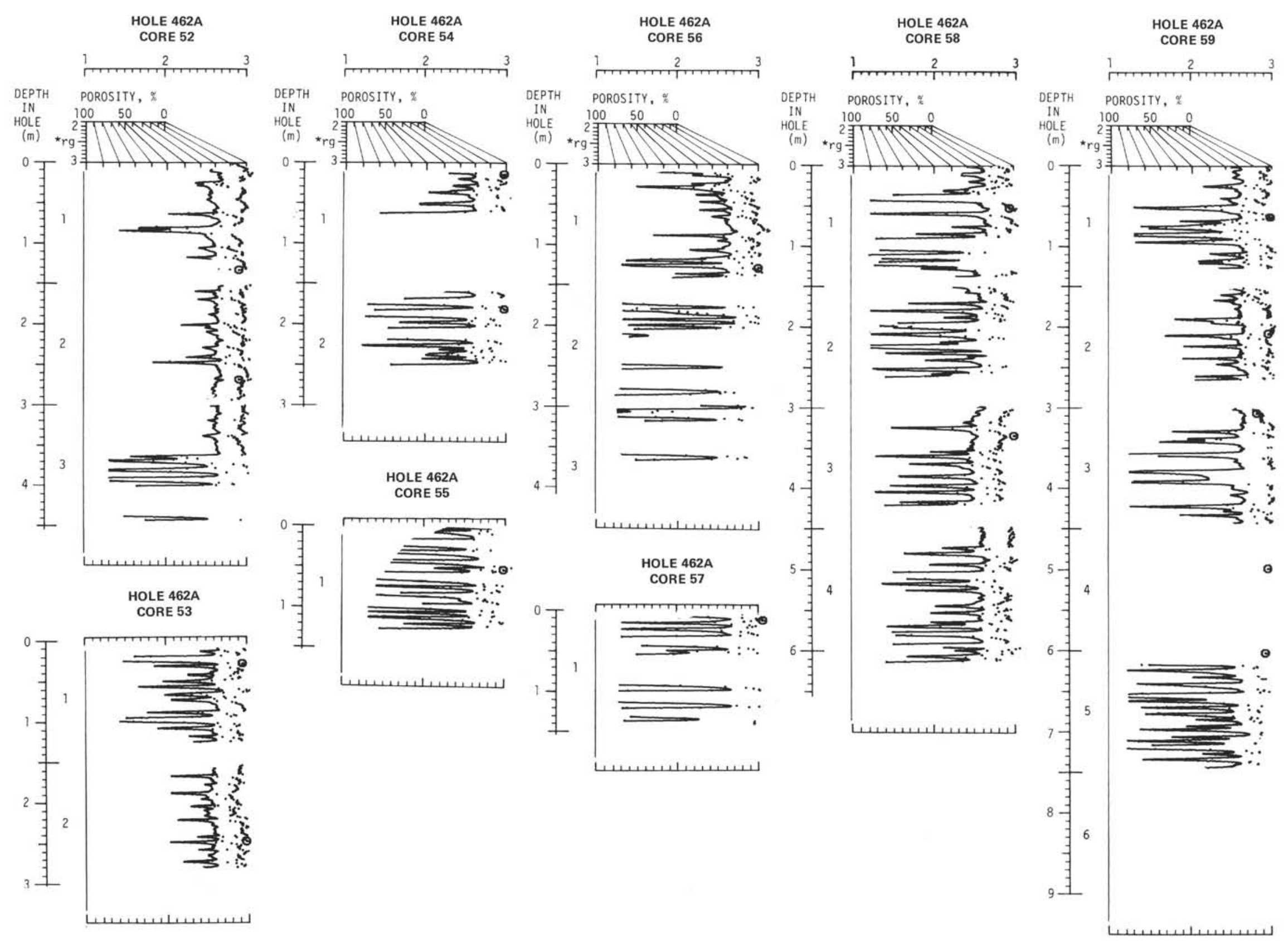




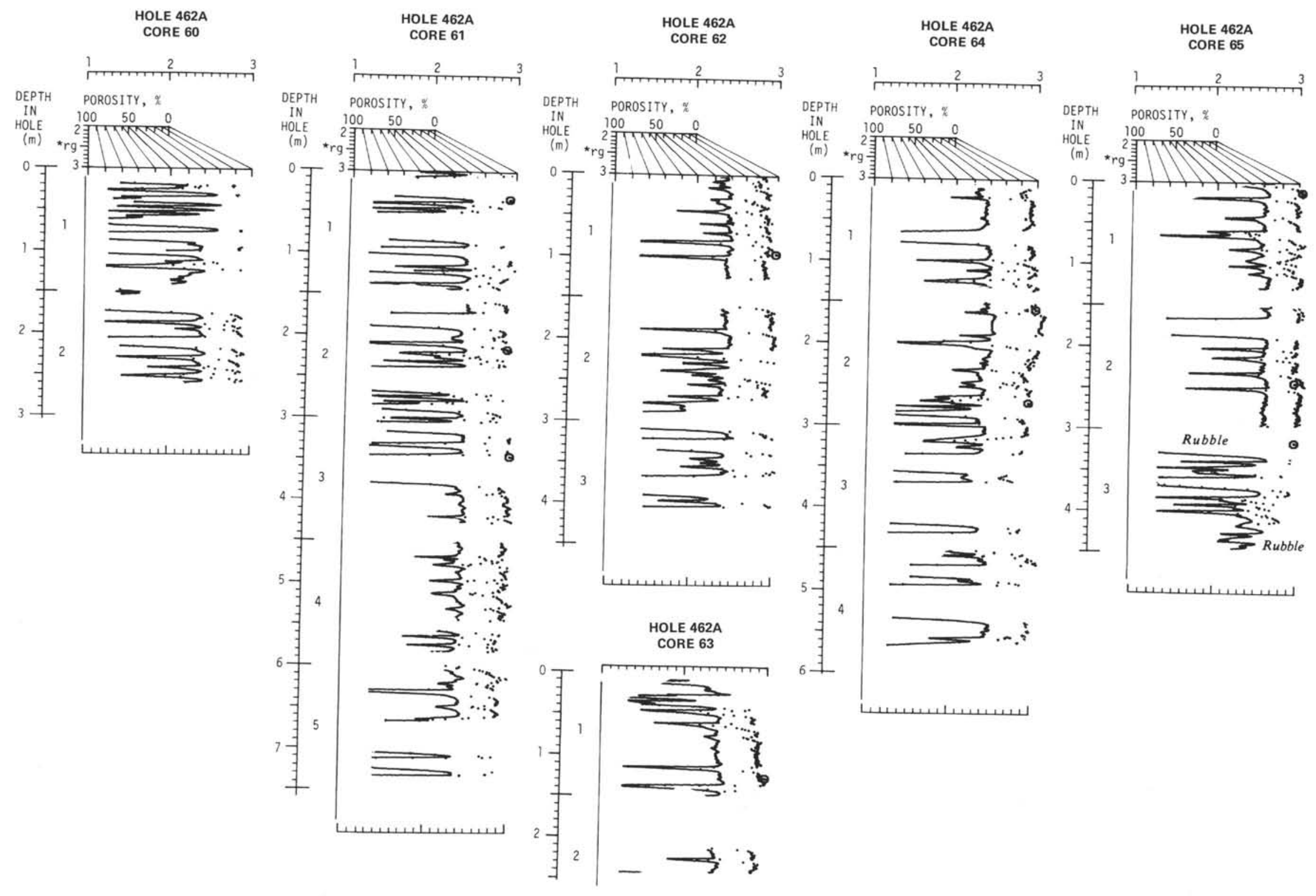




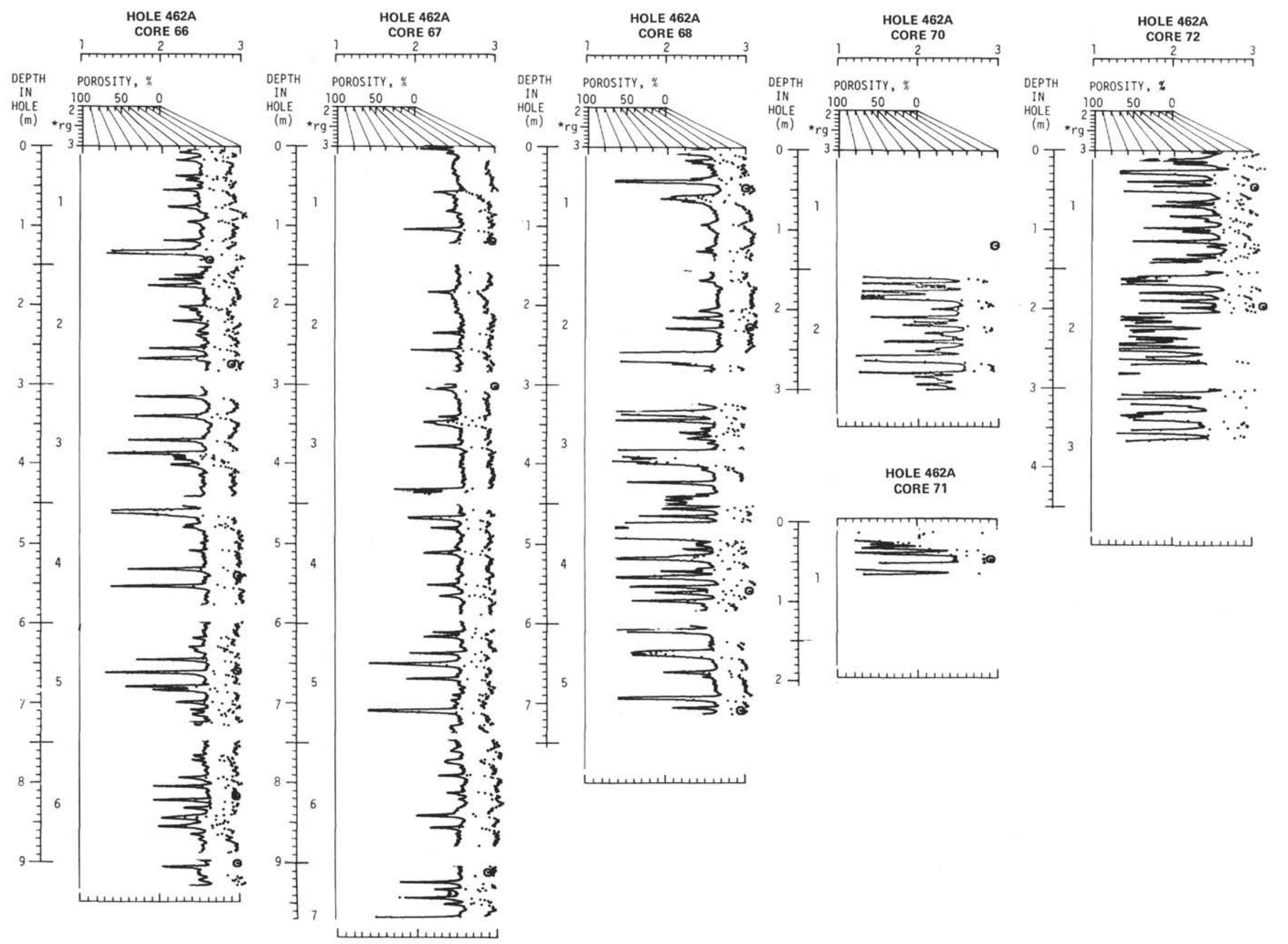




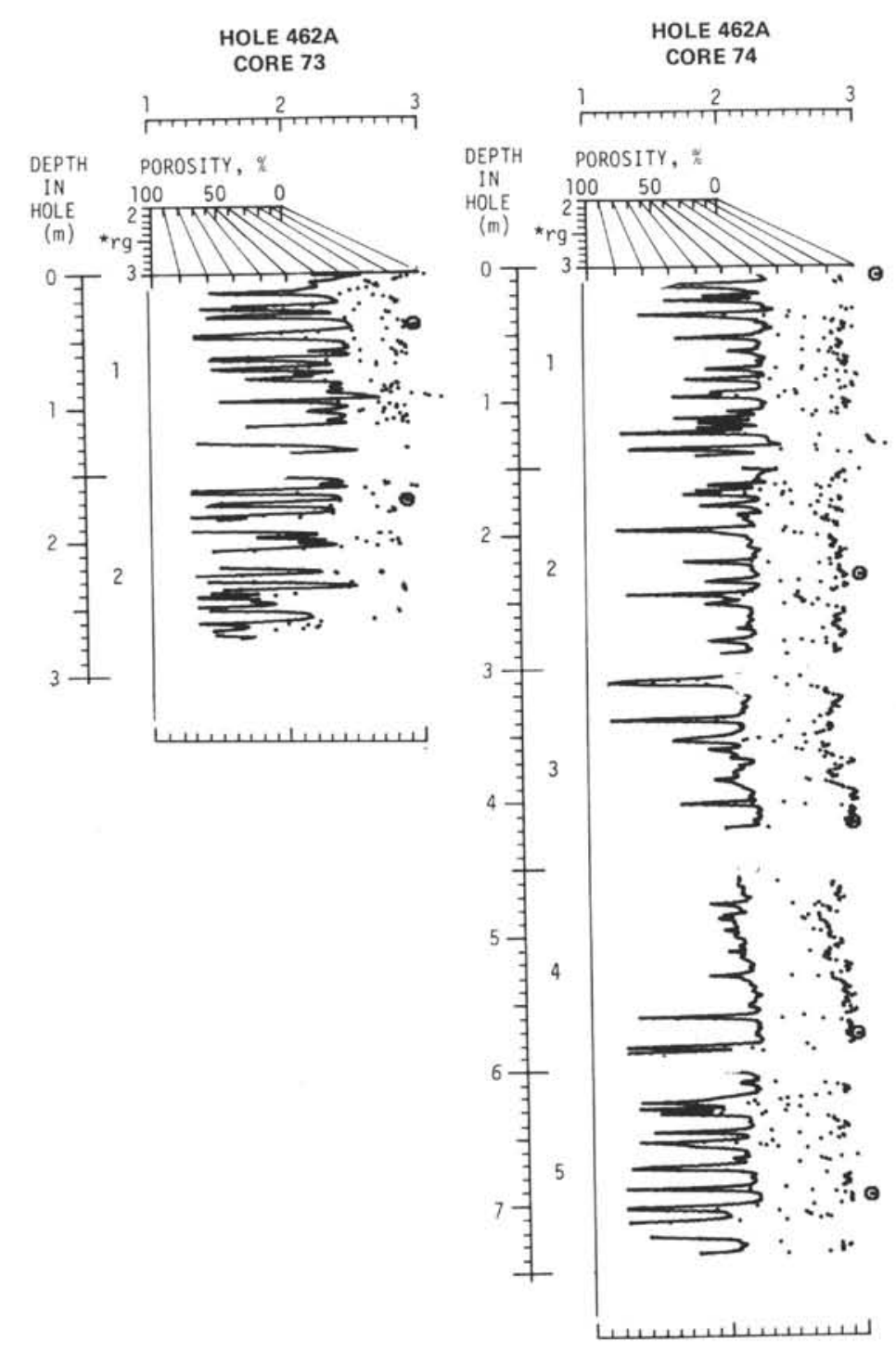

Figure 48. (Continued). 


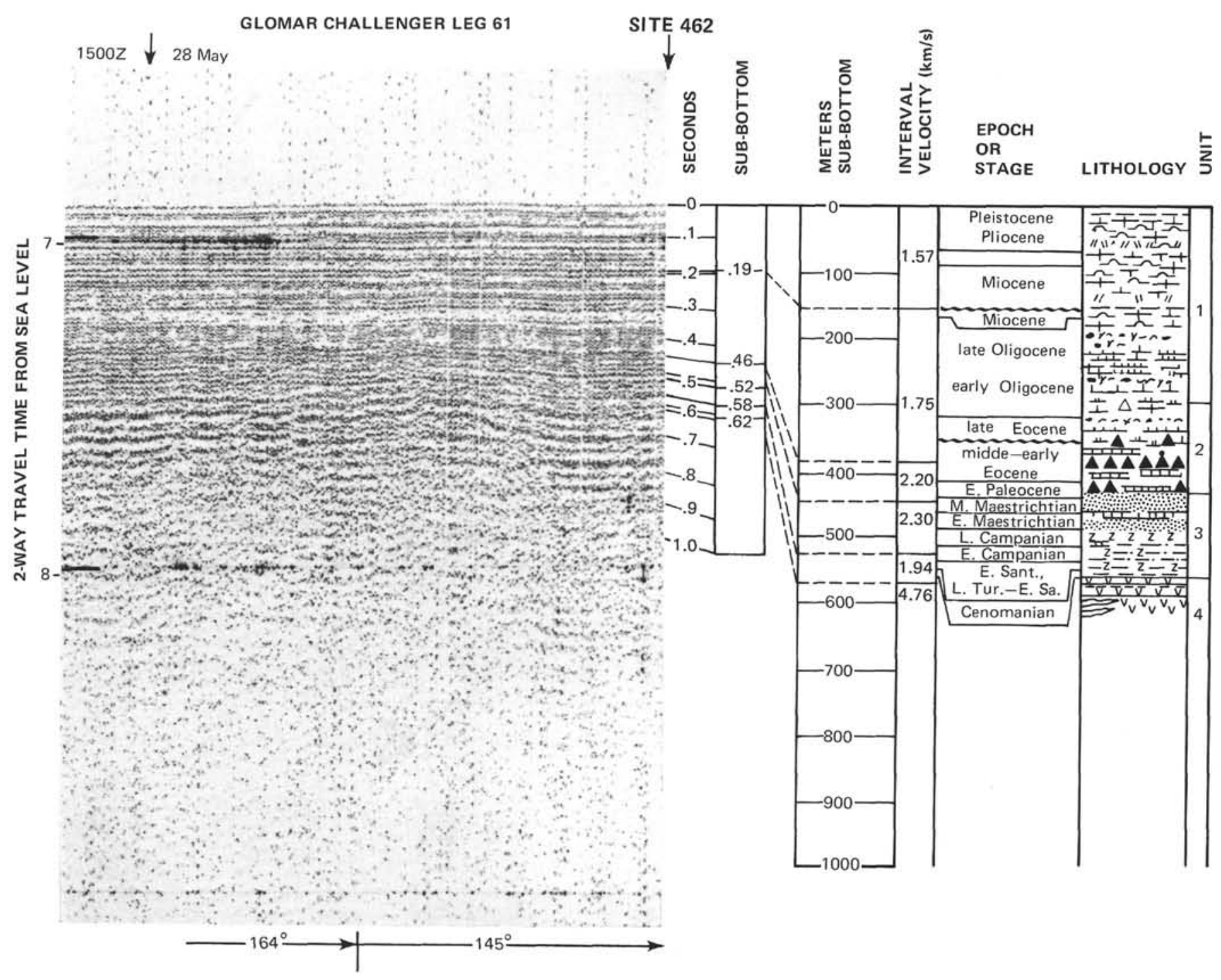

Figure 49. Correlation of drilling results and seismic data.

basic textures. Their thicknesses range from a few tens of centimeters to over 50 meters. Multiple sills are more difficult to distinguish, but where fine-grained to glassy apophyses are present, multiple intrusion can be demonstrated on a small scale; on larger scales, it has been inferred from the presence of alternating fine-grained and coarser-grained units which lack glassy margins.

The upper part of the sill complex in Hole 462 consists of intercalated igneous and sedimentary units, the latter largely hyaloclastitic. Four of these were found in Cores $63,64,65$, and 66 , between 580 and 606 meters sub-bottom (Fig. 9). The first, stratigraphically highest of these horizons is a grayish-black to black, waxy claystone with relict hyaloclastite texture, containing abundant zeolites and fragments of dark material which may be either organic or Fe-rich material. Chemical analysis of the material (XRF) reveals a composition very similar to that of the enclosing sill, except for an elevated $\mathrm{Mg}$ content. The second and thickest of these sedimentary intervals comprises greenish-black siltstones to claystones which are horizontally and cross-laminated. The component particles are chiefly altered volcanic glass set in a matrix of clay that probably resulted from terminal devitrification of an igneous precursor. The material at $65-1,0-20 \mathrm{~cm}$ is essentially identical to this; that at $66-1$, $0-16 \mathrm{~cm}$, however, is grayish-red and grayish-blue-green volcaniclastic claystones containing some fish debris.

The above-described sediments presumably are rafts or relict layers of considerable lateral extent, enveloped during emplacement of the basic sill; therefore, they are likely to have undergone considerable thermal metamorphism. The stratigraphically highest intercalation, with its black, waxy character, is similar to dark Cenomanian sediments that lie directly above the sill; these are inferred to have been deposited under reducing conditions. The grayish-red and grayish-blue-green volcaniclastic claystones, perhaps the product of an oxidizing environment, may be pre-Cenomanian. These remarks are, however, entirely unsubstantiated: much would depend on whether the intrusion had merely pried apart the sediments, or whether any material had been assimilated. Redeposition has clearly operated during forma- 
SITE 462

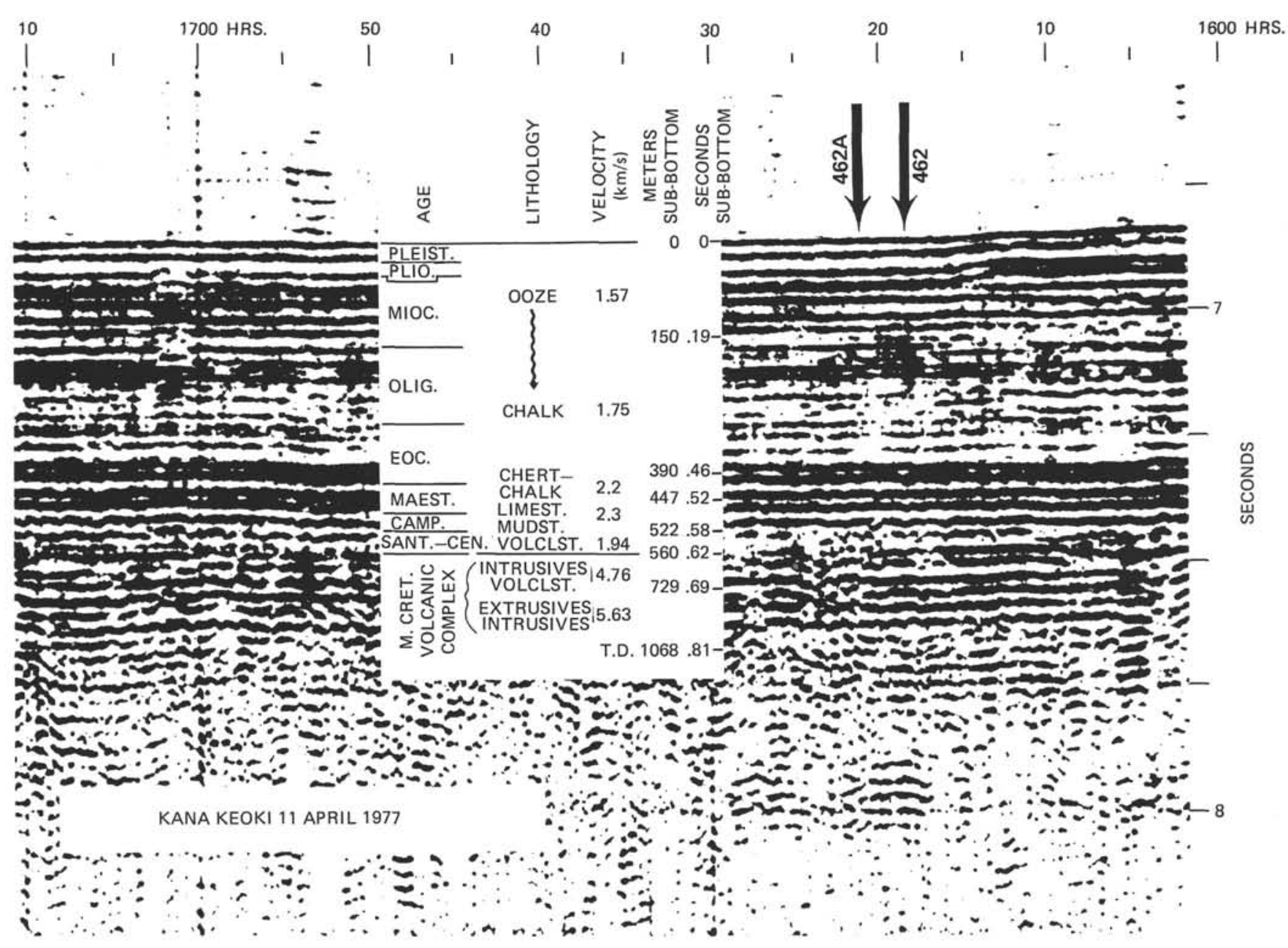

Figure 50. Kana Keoki seismic run, 0.5 miles north of Site 462 .

tion of the cross- and horizontally laminated, greenishblack siltstones that constitute the two central intercalations. For example, in Hole 462A, Core 20, which is roughly equivalent to Cores 62 and 63 in Hole 462, volcaniclastic sandstones and siltstones show abundant grading, cross- and parallel laminations and softsediment deformation.

The middle 200 meters of the volcanic complex, from 730 to 930 meters, consists of sills similar to those described above, interbedded with extrusive or semiextrusive flows. No sediments were recovered in this interval. The flows have the following characteristics: (1) variable but small thickness $(0.3-2.0 \mathrm{~m})$ of units; (2) thick (up to $4 \mathrm{~cm}$ ) glassy margins on upper and lower contacts; (3) fine grain size throughout, but a patchy appearance which results from mixed textures; (4) variable attitudes of glassy margins; dips of glassy margins range from horizontal to vertical; contorted shapes, often with re-entrant surfaces are common; (5) cooling cracks normal to glassy surfaces are ubiquitous, and numerous cracks are present in the interior, crystalline portions of units; these interior cracks do not display preferred orientation; (6) inclusions and thin apophyses of finegrained material in more-coarse-grained basalt, which suggest turbulent flow and mixing within cooling units.
These characteristics and the total lack of sediment inclusions leave little doubt that these units were extruded directly onto the sea floor; however, they have none of the characteristics of pillow lava. They lack (1) radial cooling fractures, (2) concentric structures, (3) regular curved surfaces, (4) interior hollows or vugs, and (5) inter-pillow matrix material. The mode of extrusion of these flows could be either: (1) slabby pahoehoe type, or (2) a series of shingled, lobate, narrow advancing flow fronts similar to pillow lava, but extruded more rapidly.

From 930 to 1068 meters (total depth), generally silltype basalts were recovered, except for about 3 meters of volcaniclastic sediments at 994 to 998 meters, described below. The sills in this interval are generally thicker than those above and consist of fine- to mediumgrained diabase. Below 1000 meters, the basalts are finer grained, having textures ranging from variolitic to subophitic to intergranular or intersertal. They may represent an intercalation of sills and flows, although no contacts were recovered.

At 994 meters below the sea floor, below 428 meters of almost continuous diabase, $239 \mathrm{~cm}$ of volcaniclastic sediment was recovered at 79-6, 80-1, and 80-2. The uppermost portion of this unit, at 79-6, is grayish red, 


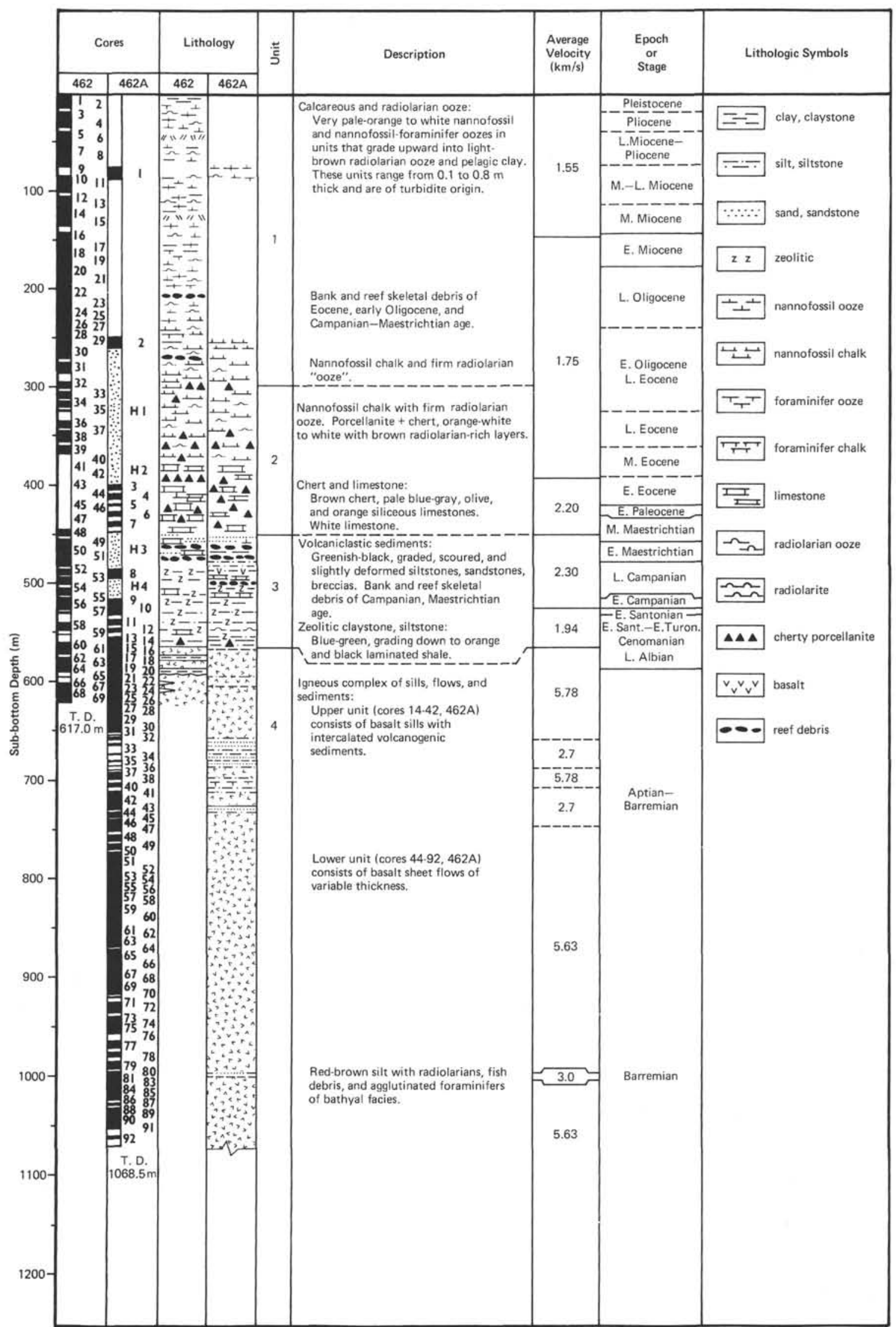

Figure 51. Columnar sections at Site 462, showing cored intervals, lithologic units, interval seismic velocities, and ages. 
and the lower portion, in Core 80 , is various shades of dark gray and brownish-black. Sandy and rarely pebbly siltstone occurs. This unit exhibits evidence of scour, parallel and cross-laminations, and three obvious instances of graded bedding, becoming finer upward from fairly sharp contacts. Between 42.5 and $62.5 \mathrm{~cm}$ in Section $80-1$ is a conglomerate layer. The matrix of this unit is the same kind of sandy siltstone described above. The clasts are angular, oriented parallel to bedding, made up of "intraformational" material, and average 5 to $8 \mathrm{~mm}$ in size. The largest clast, at $55 \mathrm{~cm}$, measures about $20 \times$ $5 \mathrm{~mm}$. Rarely, basalt pebbles occur as clasts, but no carbonate material was observed. The coarsest material in this layer occurs near the middle, from 51 to $56 \mathrm{~cm}$, the grain size grading both up and down to coarse-sand size. Underlying the conglomerate is $117 \mathrm{~cm}$ of generally homogeneous sandy siltstone containing rare coarser and finer laminae. A second conglomerate, also containing angular clasts, occurs between 59 and $65 \mathrm{~cm}$ in Section 80-2. The clasts are "intraformational" material, average about $5 \mathrm{~mm}$ in size, and ranging up to 15 $\mathrm{mm}$. Boundaries of this unit are rather abrupt. The lowest unit in this sequence is $46 \mathrm{~cm}$ of sandy siltstone containing faint parallel layering at $1-$ to $2-\mathrm{cm}$ intervals. At the base of this unit is a 1- to 2-cm interval of lightergray material, and on one corner of the lowest piece $(80-2,101 \mathrm{~cm})$ is a small amount of black, vitreous material.

Several smear slides taken along this unit reveal the sediment composition: almost entirely $(95 \%+)$ very angular, shard-like, clear to olive-colored grains of smectite (nontronite?). Trace amounts (1-2\% each) of glass, feldspar, and opaque minerals also occur. No carbonate grains were observed. One thin layer $(80-1,18$ $\mathrm{cm})$ contained Barremian radiolarians, fish debris, and an agglutinated-foraminifer assemblage. This assemblage indicates bathyal to abyssal depths of deposition. Thus, these oldest fossils, of Barremian age, recovered at Site 462 show that the Nauru Basin was perhaps $5 \mathrm{~km}$ deep at that time, approximately 30 m.y. after formation of the underlying basement at the site. Such a depth is not inconsistent with the depth predicted by an exponential subsidence curve.

Petrographically, the basalts are aphyric to sparsely phyric and have a few phenocrysts of clear to lightbrown augite, zoned bytownite to labradorite, and occasionally olivine pseudomorphs, usually altered to green smectite. Sideromelane and augite are also often replaced by smectite. Opaque minerals are generally represented by titanomagnetite. Textures range from glassy to variolitic to diabasic, all intermediate textures being represented. In the thicker sills, patches of distinctive granophyre-facies mineralogy appear. These patches usually consist of intergrown quartz and potassium feldspar micro-pegmatite, many patches also including a colorless, acicular, prismatic phase which could be apatite.

Fracturing is common in the basalts. Most of these fractures are filled with veins containing one or more of the minerals pyrite (and marcasite), zeolite, calcite, magnetite, chlorite, various smectites, and a green claylike mineral.
At least two major types of post-solidification alteration have probably affected the rocks: (1) sea-water alteration, which has resulted in the precipitation of smectites, calcite, zeolite, sulfides, $\mathrm{SiO}_{2}, \mathrm{Mn}-\mathrm{Fe}$ hydroxides; and (2) late-magmatic or deuteric processes which have resulted in the production of micro-pegmatite, amphibole, and possibly chlorite, quartz, and $\mathrm{Fe}-$ oxide mineralization.

About 150 samples from Holes 462 and 462A down to 953 meters were analyzed for $\mathrm{Si}, \mathrm{Al}, \mathrm{Ti}, \mathrm{Mg}, \mathrm{Fe}, \mathrm{Ca}$, and $\mathrm{K}$, and about 15 for $\mathrm{Mn}$ and $\mathrm{P}$, using shipboard XRF techniques. All analyzed samples have chemical compositions very similar to those of altered mid-oceanridge tholeiite, like those reported widely in the Initial Reports of previous DSDP legs, and elsewhere. The rocks display a narrow range of $\mathrm{TiO}_{2}, \mathrm{~K}_{2} \mathrm{O}, \mathrm{MgO}, \mathrm{CaO}$, and $\mathrm{SiO}_{2}$, but unusually large variation in the abundance of $\mathrm{Al}_{2} \mathrm{O}_{3}$ and $\mathrm{FeO}$ in the light of the narrow variation of the other major oxides. Few of the inter-element correlations which are the hallmark of abyssal tholeiite $(\mathrm{K}-\mathrm{Ti}, \mathrm{Mg}-\mathrm{Fe}, \mathrm{Mg}-\mathrm{Ca}, \mathrm{K}-\mathrm{Ca}$, etc.) are observed in the rocks of Hole $462 \mathrm{~A}$. Those which are observed, such as $\mathrm{TiO}_{2}$ versus $\mathrm{FeO} / \mathrm{MgO}$, display a scatter much greater than normal for oceanic tholeiite, and the abundances of $\mathrm{TiO}_{2}$ for a given $\mathrm{Fe} / \mathrm{Mg}$ are different than those usually observed. Another significant difference between the rocks of Hole $462 \mathrm{~A}$ and mid-ocean-ridge tholeiite is the extremely low $\mathrm{K}_{2} \mathrm{O}$ abundance of the former. Many of the analyzed samples have $\mathrm{K}_{2} \mathrm{O}$ abundances which are comparable to those of dunite.

Holes 462 and $462 \mathrm{~A}$ are separated by about 500 meters, and some igneous correlations can be made between the two holes. There is little doubt that the thick sill at the bottom of Hole 462 is the same sill at Hole $462 \mathrm{~A}$ between 605 and 656 meters. In addition, some of the sediment horizons encountered at similar sub-bottom depths in both holes may be continuous between the holes. It is clear, however, that most of the thin sills of Hole 462 do not extend laterally to Hole 462A. Many of the thinner sediment horizons also appear to "lens out."

This pattern suggest significant three-dimensional lithologic heterogeneity on a scale of less than 500 meters. However, since the chemical compositions of the uppermost basalts in each hole are very similar, it is probable that they are closely related temporally. They even may have been fed by the same major conduit.

\section{Paleomagnetism}

Late Cretaceous sediments were measured on the shipboard Digico spinner magnetometer and demagnetized with the Schonstedt AF demagnetizer in an attempt to isolate the top of the Cretaceous long normalpolarity interval in Nauru Basin sediments.

Sampling of time-equivalent sections of early Campanian through Cenomanian age in Holes 462 and 462A shows the presence of the reversed interval corresponding to Anomalies 33 and 34, the end of the Cretaceous long normal-polarity interval. In addition to the reversal, there is a peculiar deviation of inclinations just preceding the termination of this reversed period. Its occurrence in both cores in precisely the same stratigraphic 
position suggests that it may be a real feature of the magnetic field. Scattered inclinations from Site 462 cores suggest a paleolatitude of $7^{\circ} \mathrm{S}$ in early Campanian to Santonian time. Sparse sampling through the Cenomanian suggests a steepening to $10^{\circ}$ or more.

The mid-Cretaceous volcanic complex was sampled continuously to determine its magnetic properties. A plot of NRM intensity, susceptibility, stable inclination, and petrology versus depth is shown in Figure 52 that summarizes these results. The basalts show a generally strong NRM intensity that increases with depth and becomes scattered toward the bottom of the hole. The NRM inclination also steepens in this fashion, pointing to an increase in drilling remanence associated with the

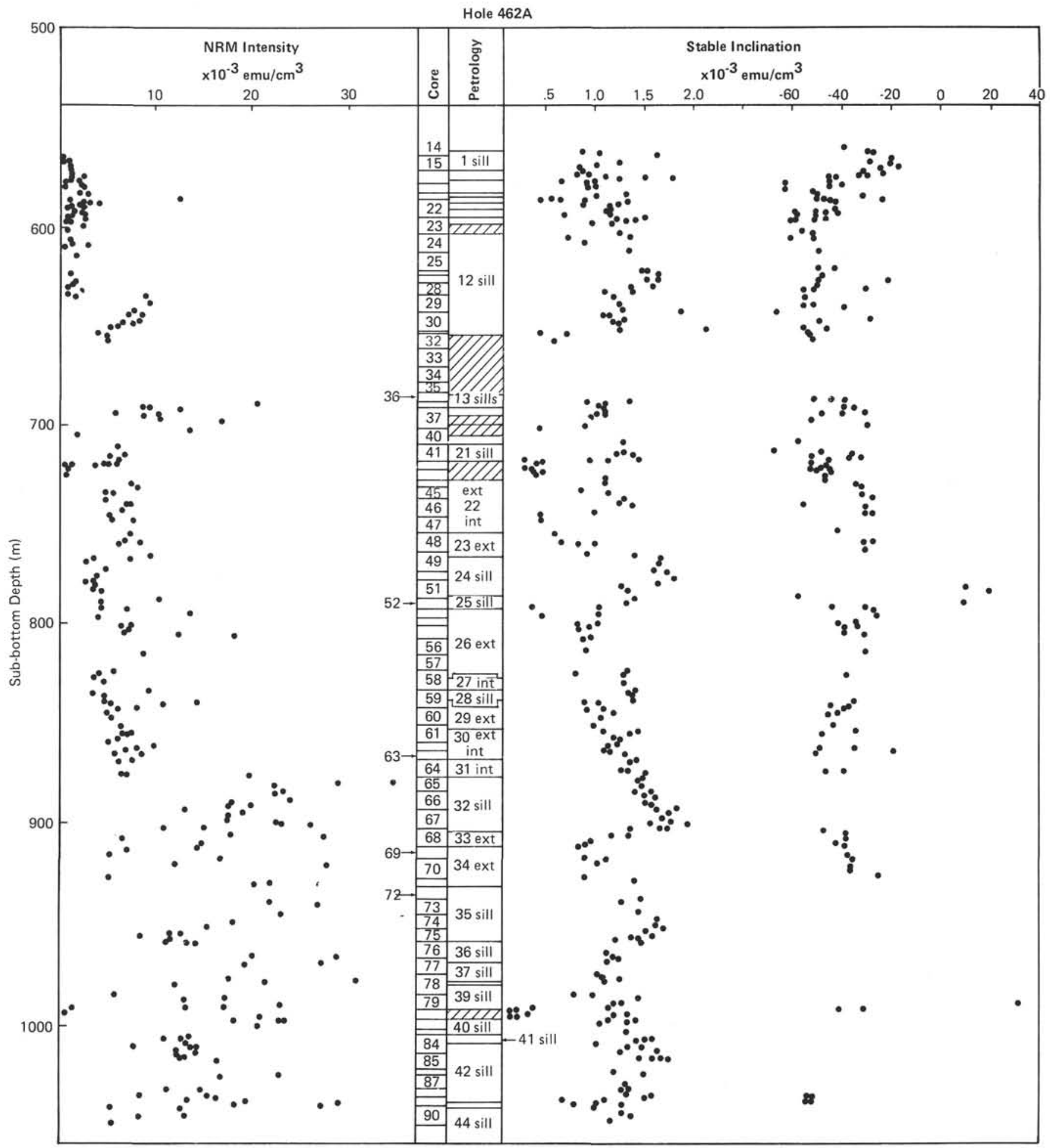

Figure 52. Paleomagnetism at Hole 462A. 
lower part of the sill complex. The sills in the upper part of the section do not show this pronounced drilling remanence, for no apparent reason. The most accurate estimate of NRM intensity probably comes from the interval between 564 and 875 meters: 0.005 to 0.010 $\mathrm{emu} / \mathrm{cm}^{3}$.

Although the basalts are relatively strongly magnetized, this magnetization is rather soft, median destructive fields of the finer-grained rocks ranging from 80 to $120 \mathrm{Oe}$, and those of the coarser-grained samples from 20 to $70 \mathrm{Oe}$. This demagnetization lowers the NRM inclination from very steep up-hole values to "stable" inclinations that average 30 to $50^{\circ}$ up. Many of the samples have directions that will not stabilize, but continue to decrease in inclination as stronger demagnetizing fields are applied. An inclination range of 30 to $50^{\circ}$ corresponds to a paleolatitude of formation of 16 to $31^{\circ} \mathrm{S}$, in general agreement with reconstructions by Lancelot and Larson (1975) for this region during the mid-Cretaceous. Also in agreement with the mid-Cretaceous age of the complex is its ubiquitous normal magnetization, except for one sediment sample in Core 80, at 994 meters. This volcaniclastic material is unambiguously oriented and reversely magnetized. Although it is volcaniclastic, adjacent pelagic material is Barremian, so the possibility exists that it is included material that is considerably older than most of the volcanic complex. Except for this sample, the sediments have stable inclinations well within the range of the igneous rocks. They are also characterized by relatively strong NRM intensities and MDFs considerably larger than those of the basalts.

Susceptibility is relatively larger and generally ranges from 1.0 to $1.5 \times 10^{-3}$. There is often a distinct tendency for susceptibility to correlate with petrology, extrusive sequences showing considerably lower susceptibility than sill-type basalts.

In summary, the magnetic properties of the volcanic complex suggest that it was emplaced in a relatively short time on the Pacific Plate, at about $25^{\circ} \mathrm{S}$, sometime during the mid-Cretaceous normal magnetic interval.

\section{Regional Geology and Geophysics}

Site 462 in the northern Nauru Basin is the location of a mid-Cretaceous volcanic complex at least 500 meters thick composed of sills, flows, and volcaniclastic sediments. It presumably overlies Jurassic-aged sediments and oceanic crust, as evidenced by the well-substantiated magnetic-anomaly correlations in this area. It is likely that this volcanic complex is present throughout the Nauru Basin, and it may extend to adjacent regions. Within the Nauru Basin, we correlate the presence of the volcanic complex with seismic-profiler records that show many flat-lying, low-amplitude reflections beneath the middle Eocene chert horizon. These flat-lying reflectors obscure the original basement surface, which presumably has the form of smoothed, buried, abyssal hills typical of other areas of sea floor generated at fast spreading rates. The Nauru Basin is also characterized by a lack of refracted arrivals observed on sonobuoys, and a thick unit of $3.5-$ to $4.5-\mathrm{km} / \mathrm{s}$ material measured with wide-angle reflections. Explosives shot to oceanbottom seismometers recorded an abnormally thick layer $(\sim 2.5-3.0 \mathrm{~km})$ characterized by upper crustal "Layer 2" velocities $(\sim 5.0-6.0 \mathrm{~km} / \mathrm{s})$. These characteristics are probably due to propagation of acoustic energy through the volcanic complex, the underlying Jurassic sediments, and Jurassic basement at Site 462 .

The Cretaceous volcanic complex at Site 462 probably is between 500 and 1000 meters thick. It is likely that it thickens to the south, as evidenced by a smooth, uphill, southerly gradient that cannot be explained by age progression along a cooling curve, nor by lithospheric flexure near a subduction zone. The sea floor shoals by about 700 meters from anomaly M26 at Site 462 to anomaly M16 near Nauru Atoll, $500 \mathrm{~km}$ to the south. We interpret this shoaling as a thickening of the mid-Cretaceous volcanic complex that is substantially greater than the change in depth if the complex is in isostatic equilibrium.

Late Jurassic magnetic anomalies M29 to M20 are well-lineated, high-amplitude anomalies that exhibit the fine-scale features and characteristic amplitude envelope that make them recognizable lineations on a worldwide scale (see Larson and Schlanger, this volume). Although the sea floor trends uphill across these lineations, both the sea floor and the middle Eocene chert horizon remain as relatively smooth surfaces. South of M20 are anomalies M19 to M16, which are lineated but anomalously low-amplitude features; they also lack characteristic small-scale features and uniform crosssectional shapes. The sea-floor and middle Eocene chert surfaces in this region are rough, apparently covering faults or small seamounts formed during the culmination of the mid-Cretaceous volcanic event. This thickening of the sill complex presumably has disrupted the underlying oceanic crust enough to deform the Late Jurassic magnetic signature.

Besides the Nauru Basin, the mid-Cretaceous volcanic event likely is present in other areas. The OntongJava Plateau to the west has Aptian basalts sampled at Site 289 that are similar in chemistry to the Site 462 igneous units. No obvious fracture zone, ridge, island chain, or other tectonic feature offsets the Nauru Basin from the Ontong-Java Plateau, so it is at least consistent with the available evidence that they represent the same volcanic event. To the east, across the Marshall Islands, drilling at Site 169 bottomed in a midCretaceous sill likely related to the same event. The island chains themselves, such as the Marshalls, Gilberts, and Line Islands, may represent slightly later culminations of the mid-Cretaceous outpouring. The Mid-Pacific Mountains and the "basement" of the present-day Caribbean also appear to be related to this mid-Cretaceous volcanic event. Thus, this event appears to have regional, if not worldwide, significance (see Schlanger and Premoli Silva, this volume; Larson and Schlanger, this volume).

Returning to the mid-Cretaceous volcanic complex at Site 462 and the well-defined Jurassic magnetic anomaly pattern of that region, it may well be asked how these two features can co-exist in the same area. Although the 
volcanic complex is strongly magnetized with mid-Cretaceous remanent magnetization, we do not believe this is difficult to explain if viewed simply as a magnetic problem. Since the volcanic complex was emplaced during the mid-Cretaceous, it is uniformly and normally magnetized. It presumably extends over a broad area, and thus can be approximated as a uniformly magnetized slab that is horizontally infinite. Such a body will produce no magnetic anomaly, regardless of its remanent magnetic intensity, because no magnetization variation exists in any horizontal direction.

The crucial, unanswered question raised by Site 462 is the manner in which this large volume of volcanic material was subsequently injected into this area without disturbing the existing, well-defined magnetic-anomaly pattern. The igneous units at Site $\mathbf{4 6 2}$ are generally thin and fine grained to glassy, indicating emplacement at shallow depths, in close proximity to source conduits. Thus, the volcanic complex could not have its sources tens or hundreds of kilometers away and cannot be explained as having flowed in from a large horizontal distance to simply cover the underlying oceanic crust. It must have source conduits within the site survey area $(100 \times 100 \mathrm{~km})$, which is the location of magnetic anomalies M26, M27, and M28. These anomalies are well lineated, and no fracture zones, offsets, or seamounts disturb the anomaly pattern.

The simplest and least-disruptive manner to fracture the Jurassic basement to provide local magma conduits is probably doming and tension cracking associated with thermal uplift that accompanied the Cretaceous event. If this occurred as simple pull-apart rifts, with little or no dip-slip displacement, it would at least appear possible that the fracturing could have occurred without significant disruption of the magnetic structure of the country rock.

The manner in which these Cretaceous dikes cooled is crucial, because oceanic basalt can be demagnetized at low temperatures $\left(100-150^{\circ} \mathrm{C}\right)$ if heat is applied for long enough periods of time (10-100 yr) (see Larson and Schlanger, this volume). Thus, conductive cooling of these Cretaceous dikes alone will thermally demagnetize much of the adjacent Jurassic basement. It is possible but unlikely that the Cretaceous volcanic complex had only a few source vents, because that would require the unlikely coincidence that Site $\mathbf{4 6 2}$ is fortuitously located next to one of them. We suspect instead that the Nauru Basin was pervaded by stress cracks and dikes, and that convective cooling by sea water admitted through these tension fractures was also required to maintain the Jurassic basement below its magnetic blocking temperature for extended periods of time. The questions raised by the coexistence of the Cretaceous volcanic complex with the Jurassic magnetic-lineation patterns are considered in more detail by Larson and Schlanger (this volume).

\section{REFERENCES}

Archie, G. E., 1942. The electrical resistivity log as an aid in determining some reservoir characteristics. Am. Inst. Mining Metall. Pet. Engineers Trans., 146:54.
Berggren, W. A., and Van Couvering, J. A. 1974. The late Neogene. Paleogeogr., Paleoclimatol., Paleoecol., 16, nos. 1, 2.

Blow, W. H., 1969. Late middle Eocene to Recent planktonic foraminiferal biostratigraphy. In Brönnimann, P., and Renz, H. H. (Eds.), Proceedings of the First International Conference on Planktonic Microfossils: Leiden (E. J. Brill), pp. 199-421.

Boyce, R. E., 1976a. Sound velocity-density parameters of sediment and rock from DSDP drill Sites $315-318$ on the Line Islands Chain, Manihiki Plateau, and Tuamoto Ridge in the Pacific Ocean. In Schlanger, S. O., Jackson, E. D., et al., Init. Repts. DSDP, 33: Washington (U.S. Govt. Printing Office), 695-728. 1976b. Definition and laboratory techniques and wet-water content, wet-bulk density, and porosity parameters by gravimetric and gamma ray attenuation techniques. In Schlanger, S. O., Jackson, E. D., et al., Init. Repts. DSDP, 33: Washington (U.S. Govt. Printing Office), 931-963.

1976c. Deep Sea Drilling procedures for shear strength measurements of clayey sediment using Modified Wykeham Farrance Laboratory Vane Apparatus. In Barker, P., Dalziel, I. W. D., et al., Init. Repts. DSDP, 36: Washington (U.S. Govt. Printing Office), 1059-1068.

Brönnimann, P., and Resig, J., 1971. A Neogene globigerinacean biochronologic time-scale of the southwestern Pacific. In Winterer, E. L., Riedel, W. R., et al., Init. Repts. DSDP, 7, Pt 1: Washington (U.S. Govt. Printing Office), 1235-1469.

Bryan, W. B., and Moore, J. G., 1977. Compositional variations of young basalts in the Mid-Atlantic-Ridge rift valley near lat. $36^{\circ}$ $49^{\prime}$ N. Geol. Soc. Am. Bull., 88:556-570.

Bryan, W. B., Thompson, G., Frey, F. A., et al., 1976. Inferred settings and differentiation in basalts from the Deep Sea Drilling Project. J. Geophys. Res., 81:4285-4304.

Bukry, D., 1973. Low-latitude coccolith biostratigraphic zonation. In Edgar, N. T., Saunders, J. B., et al., Init. Repts. DSDP, 15: Washington (U.S. Govt. Printing Office), 685-703. , 1975. Coccolith and silicoflagellate stratigraphy, northwestern Pacific Ocean, Deep Sea Drilling Project, Leg 32. In Larson, R. L., Moberly, R., et al., Init. Repts. DSDP, 32: Washington (U.S. Govt. Printing Office), 677-701.

Bullard, E. C., 1963. The flow of heat through the floor of the ocean. In Hill, M. N. (Ed.), The Sea (Vol. 3): New York (Interscience), 218-232.

Cande, S. C., Larson, R. L., and La Breque, J. L., 1978. Magnetic lineations in the Jurassic Quiet Zone. Earth Planet. Sci. Lett., 41:434-440.

Godlevskiy, M. N., 1959. Traps and Ore-Bearing Intrusions of the Noril'sk Region: Moscow (Gosgeoltechizdat). [in Russian]

Hamilton, E. L., 1976. Variations of density and porosity with depth in deep-sea sediments. J. Sediment. Petrol., 46:280-300.

Hardenbol, J., and Berggren, W. A., 1978. A new Paleogene numerical time scale. Am. Assoc. Petrol. Geol. Studies Geol., 6:213-234.

Horne, R. A., and Frysinger, G. R., 1963. The effect of pressure on the electrical conductivity of sea water. J. Geophys. Res., 68:19671973.

Houtz, R. E., 1976. Seismic properties of layer 2A in the Pacific. $J$. Geophys. Res., 81:6321-6331.

Korzhinskiy, D. S., 1957. Analysis of Mineral Paragenesis: Moscow (Gosgeoltechizdat). [in Russian]

Lancelot, Y., and Larson, R. L., 1975. Sedimentary and tectonic evolution of northwestern Pacific. In Larson, R. L., Moberly, R., et al., Init. Repts. DSDP, 32: Washington (U.S. Govt. Printing Office), 925-939.

Larson, R. L., 1976. Late Jurassic and Early Cretaceous evolution of the western central Pacific Ocean. J. Geomagnet. Geoelec., $28: 219-236$.

Lee, W. H. K., and Uyeda, S., 1965. Review of heat flow data. Am. Geophys. Union Monogr., 8:87-190.

Lynch, E., 1962. Formation Evaluation: New York (Harper and Row).

Martini, E., 1971. Standard Tertiary and Quaternary calcareous nannoplankton zonation. In Farinacci, A. (Ed.), Proceedings of the Second Planktonic Conference, Roma 1970 (Vol. 2): Rome (Ediz. Technoscienza), 739-785.

Nafe, J. E., and Drake, C. L., 1963. Physical properties of marine sediments. In Hill, M. H. (Ed.), The Sea (Vol. 3): New York (Interscience), 749. 
Premoli Silva, I., and Boersma, A., 1977. Cretaceous planktonic foraminifera of DSDP Leg 39, South Atlantic. In Supko, P. R., Perch-Nielsen, K., et al., Init. Repts. DSDP, 39: Washington (U.S. Govt. Printing Office), 615-641.

Schlanger, S. O., Jackson, E. D., et al., 1976. Init. Repts. DSDP, 33: Washington (U.S. Govt. Printing Office).

Schlanger, S. O., and Jenkyns, H. C., 1976. Cretaceous oceanic anoxic events: causes and consequences. Geol. en Mijnbouw, 55: 179-184.

Shcheka, S. A., Kurentsova, N. A., and Volynets, O. N., 1978. Ultrabasic paragenesis of basalt phenocrysts. Typomorphism of RockForming Minerals: Vladivostok (Far East Science Center). [in Russian]
Sigal, J., 1977. Essai de zonation du Cretace mediterraneen a l'aide des foraminiferes planctoniques. Geol. Mediterraneene, 4:99-108.

Thierstein, H. R., 1976. Mesozoic calcareous nannoplankton biostratigraphy of marine sediments. Mar. Micropaleont., 1:325-362.

Thomas, B. D., Thompson, T. G., and Utterback, C. L., 1934. The electrical conductivity of sea water. J. Conseil, Internat. Explor. Mer, 9:28-35.

van Hinte, J. E., 1976. A Cretaceous time scale. Bull. Am. Assoc. Petrol. Geol., 60:498-516.

Winterer, E. L., Ewing, J. I., et al., 1973. Init. Repts. DSDP, 17: Washington (U.S. Govt. Printing Office). 


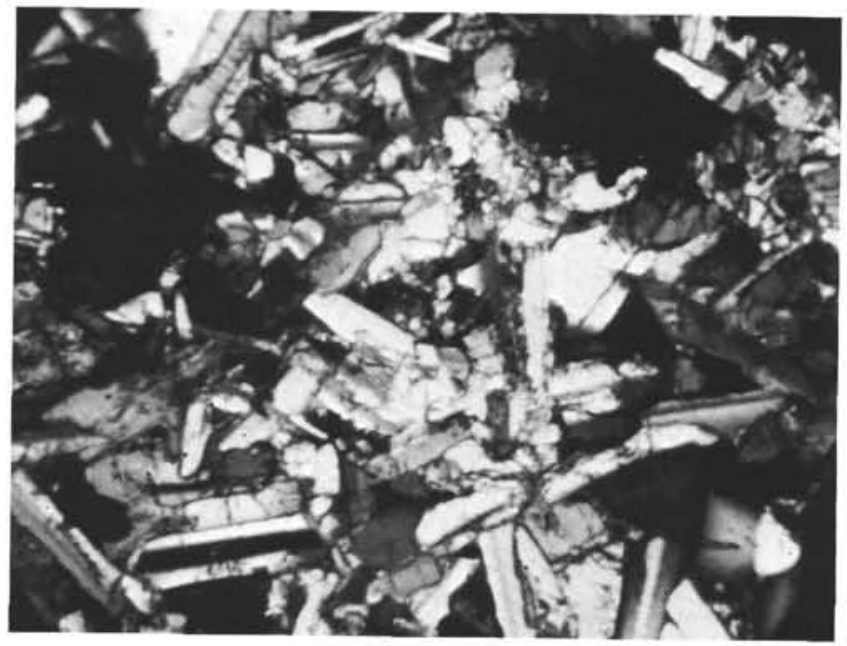

Plate 1. Typical subophitic texture, Section 462A-74-4 (width of photomicrograph $=3 \mathrm{~mm}$ )

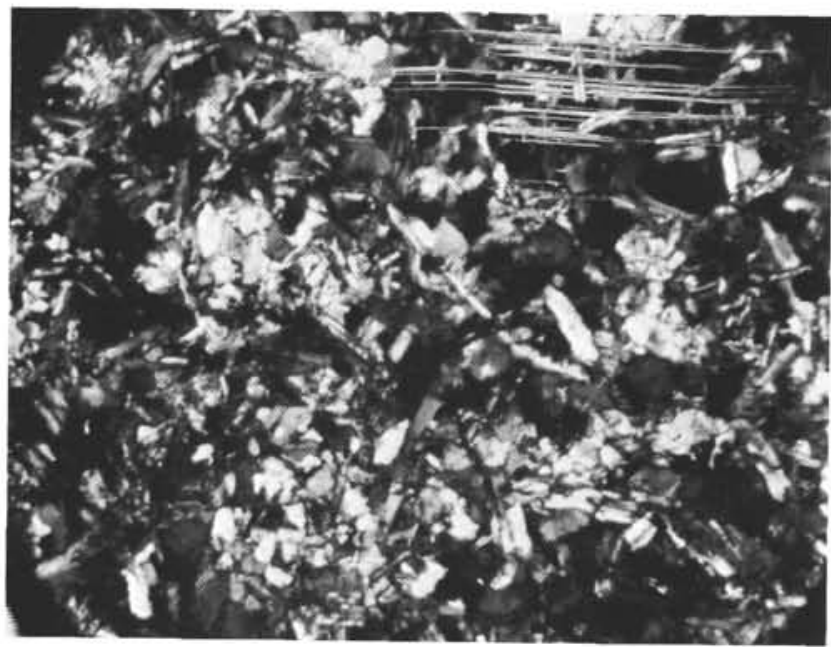

Plate 2. Typical intergranular texture, Section 462A-90-5 (width of photomicrograph $=3 \mathrm{~mm}$ ).

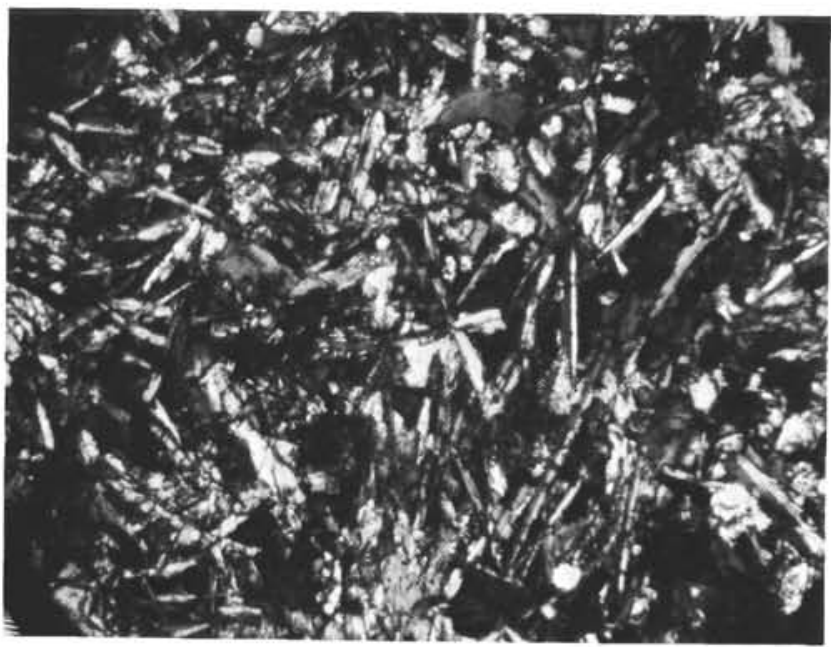

Plate 3. Typical intersertal texture, Section 462A-79-2, (width of photomicrograph $=3 \mathrm{~mm}$ ).

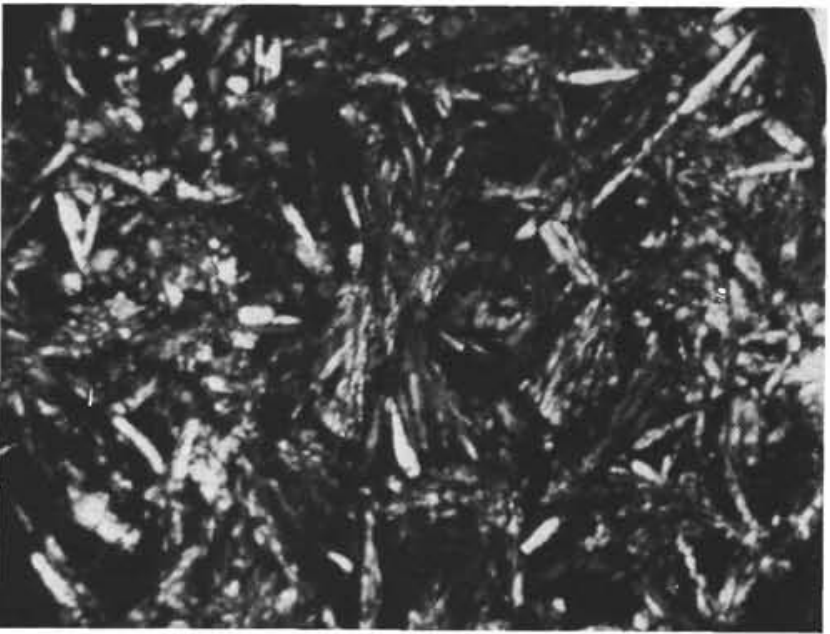

Plate 4. Typical variolitic texture, Section 462A-77-2 (width of photomicrograph $=3 \mathrm{~mm}$ ).

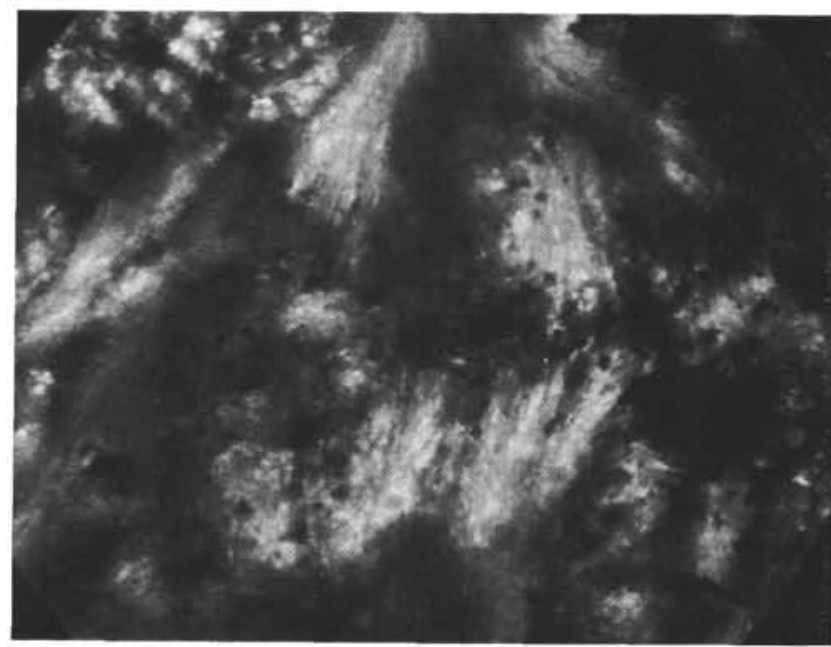

Plate 5. Close up of variolite, Section 462A-89-2 (width of photomicrograph $=0.5 \mathrm{~mm}$ ).

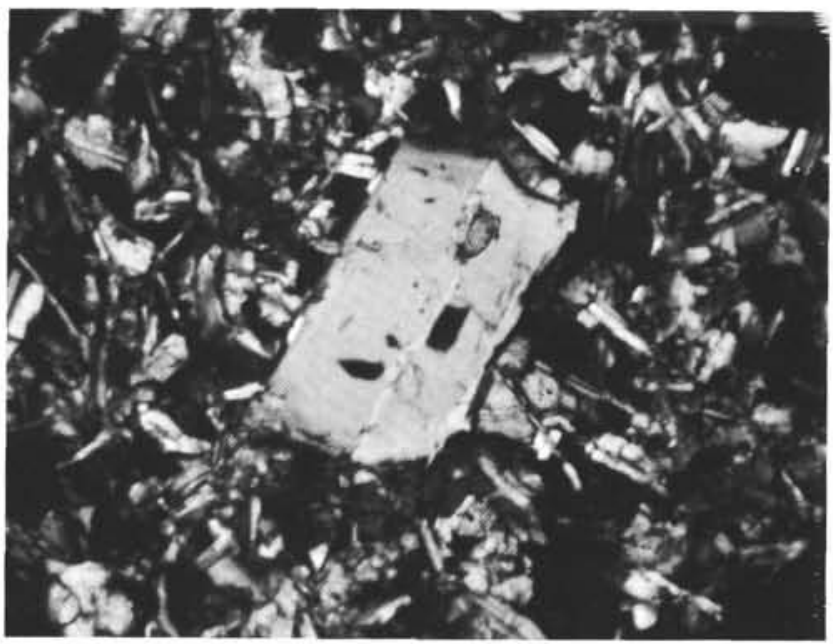

Plate 6. Plagioclase phenocryst in intergranular matrix, Section 462A$81-1$ (width of photomicrograph $=3 \mathrm{~mm}$ ). 


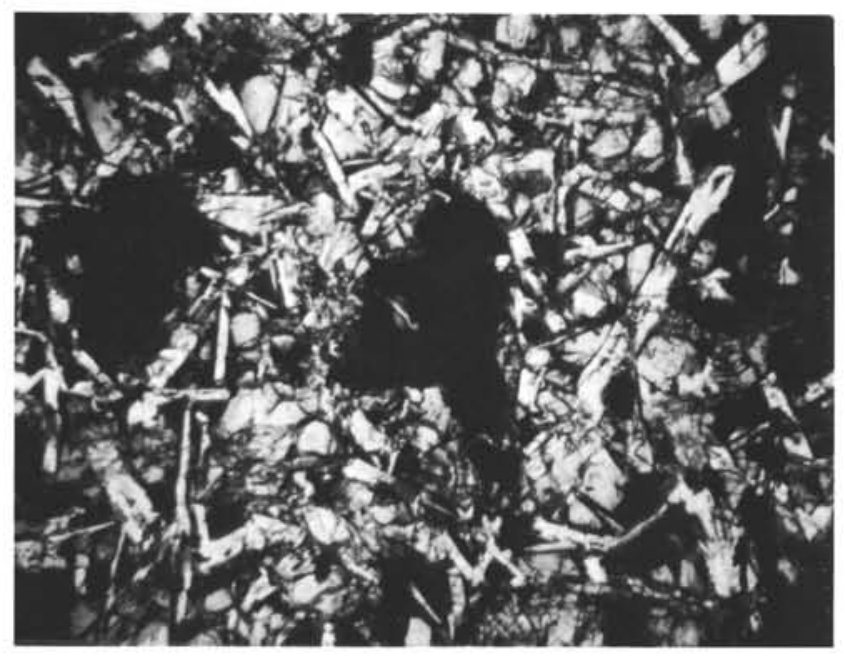

Plate 7. Olivine pseudomorph in intersertal matrix, Section 462A$77-1$ (width of photomicrograph $=3 \mathrm{~mm}$ ).

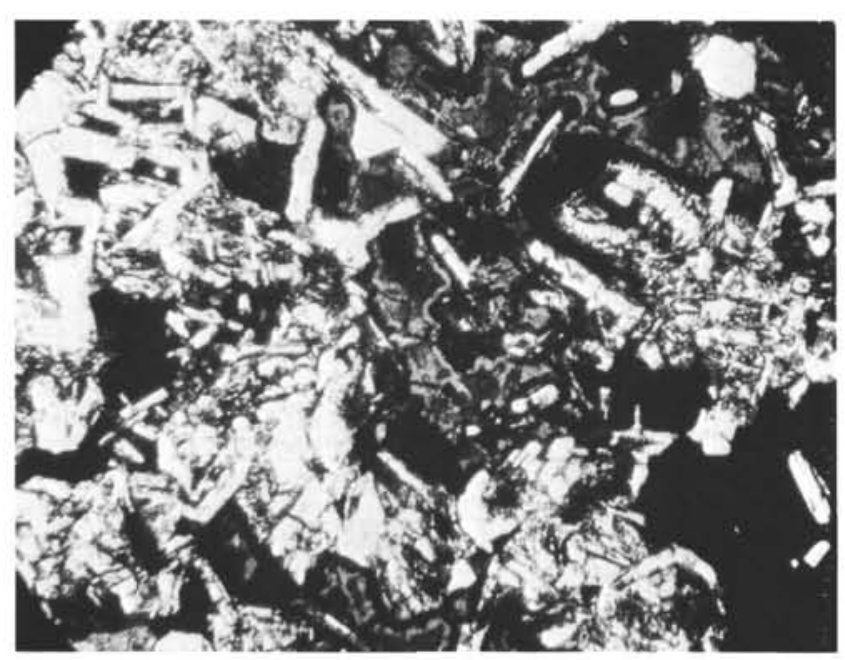

Plate 8. Interstitial glass, Section $462 \mathrm{~A}-88-2$ (width of photomicrograph $=3 \mathrm{~mm}$ ).

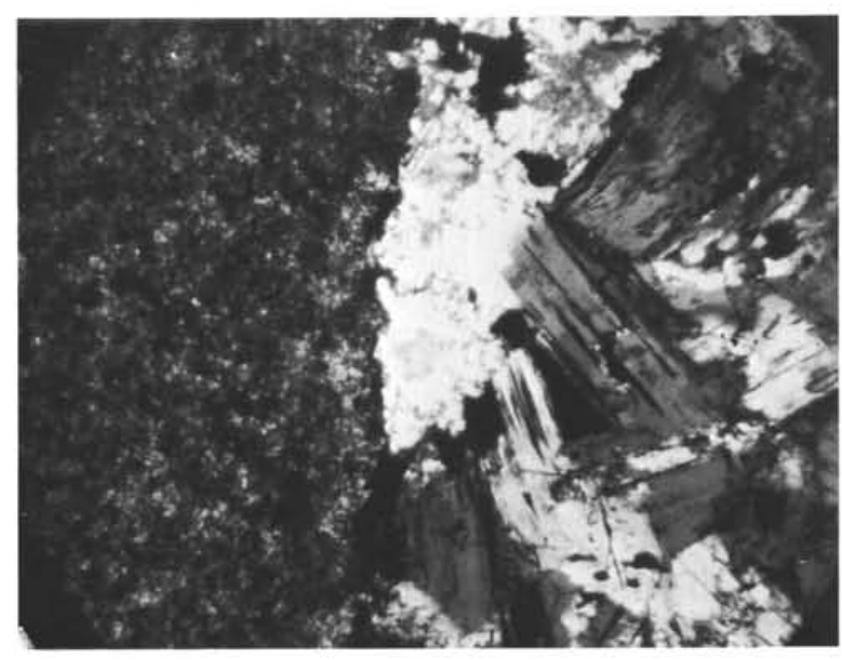

Plate 9. Contact of zeolite-bearing vein with basalt, Section 462A-901 (width of photomicrograph $=3 \mathrm{~mm}$ ). 

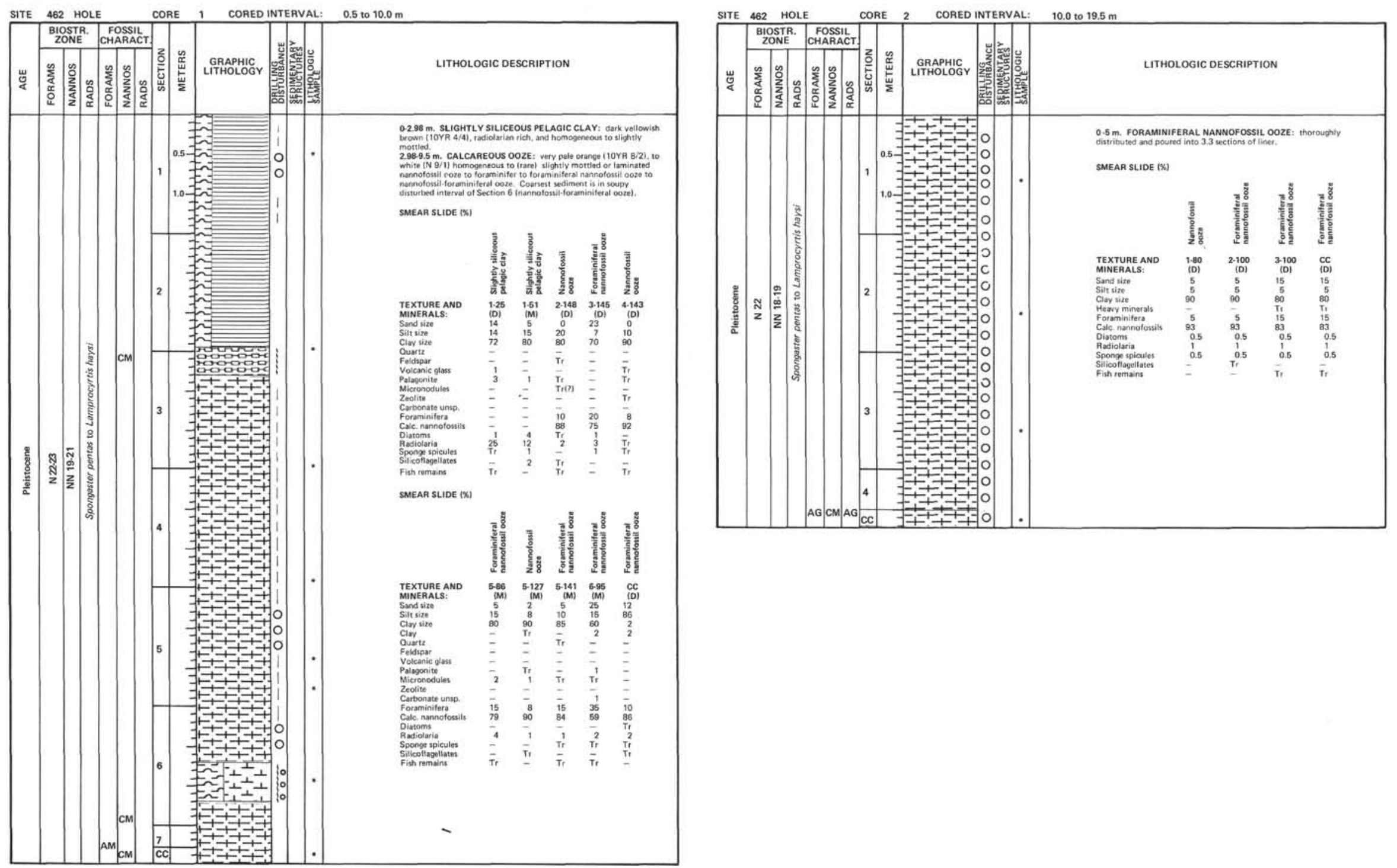

Information on core description sheets, for ALL sites, represents field notes taken aboard ship under time pressure. Some of this information has been refined in accord with postcruise findings, but production schedules prohibit definitive correlation of these sheets with subsequent findings. Thus the reader should be alerted to the occasional ambiguity or discrepancy. 


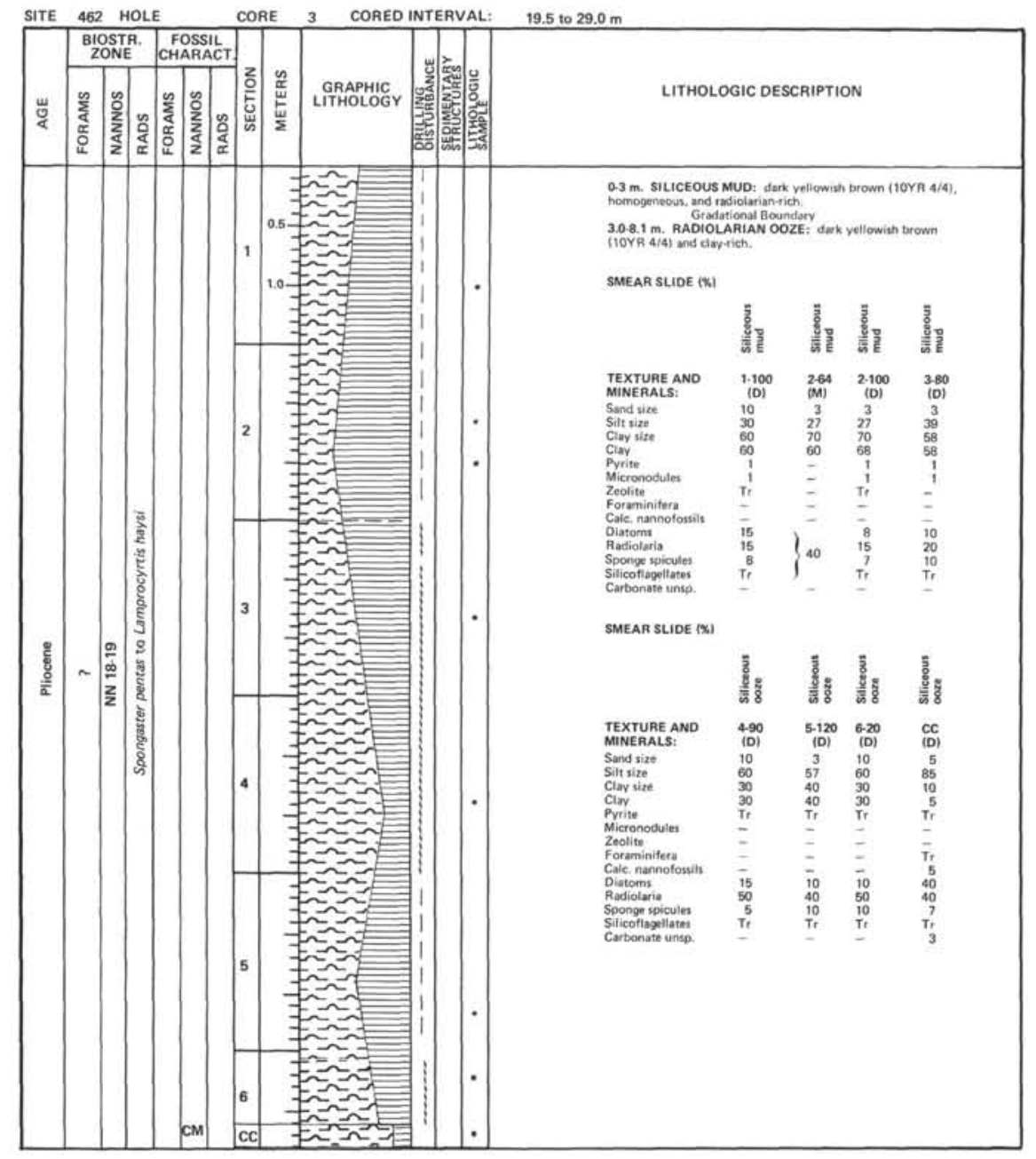

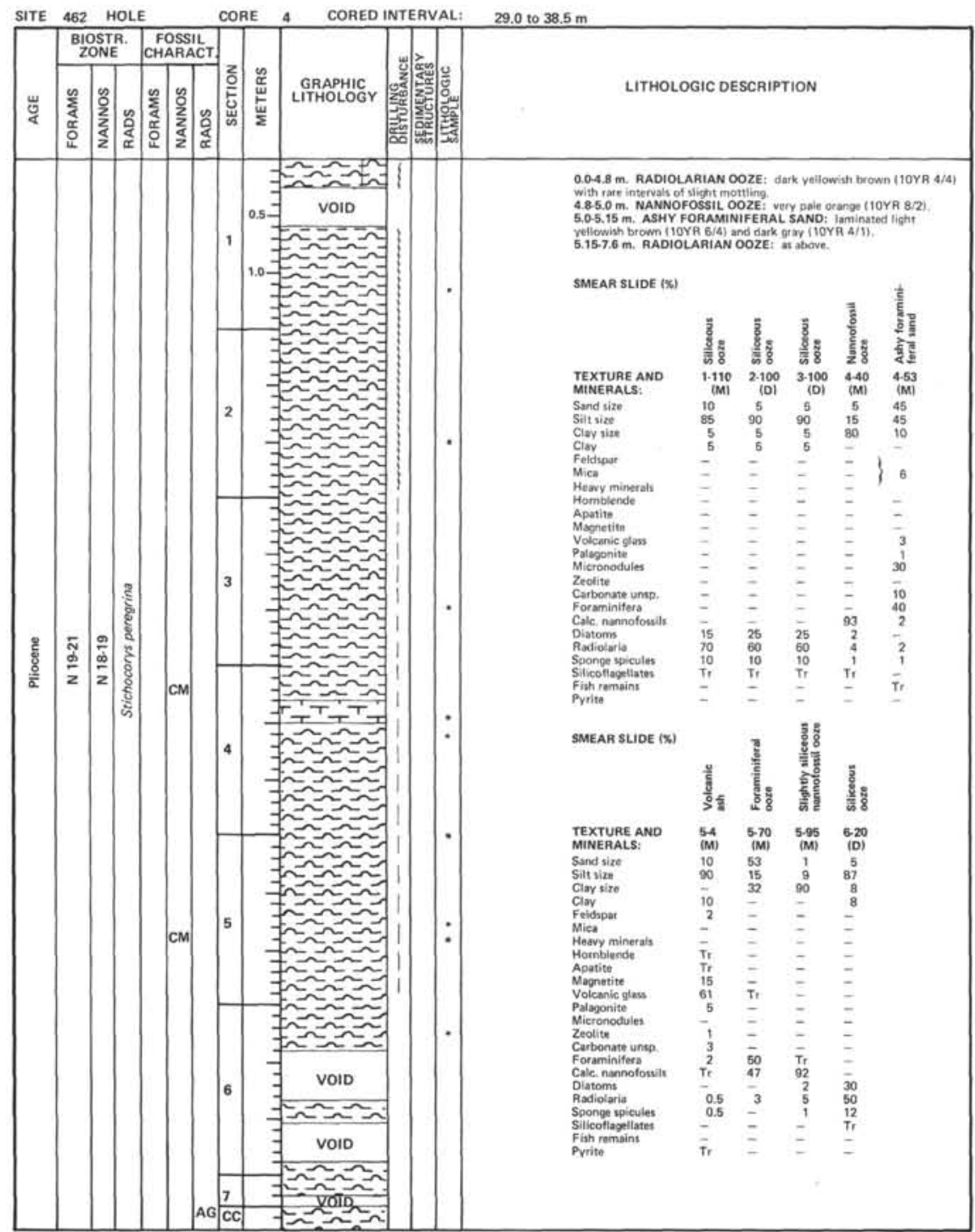




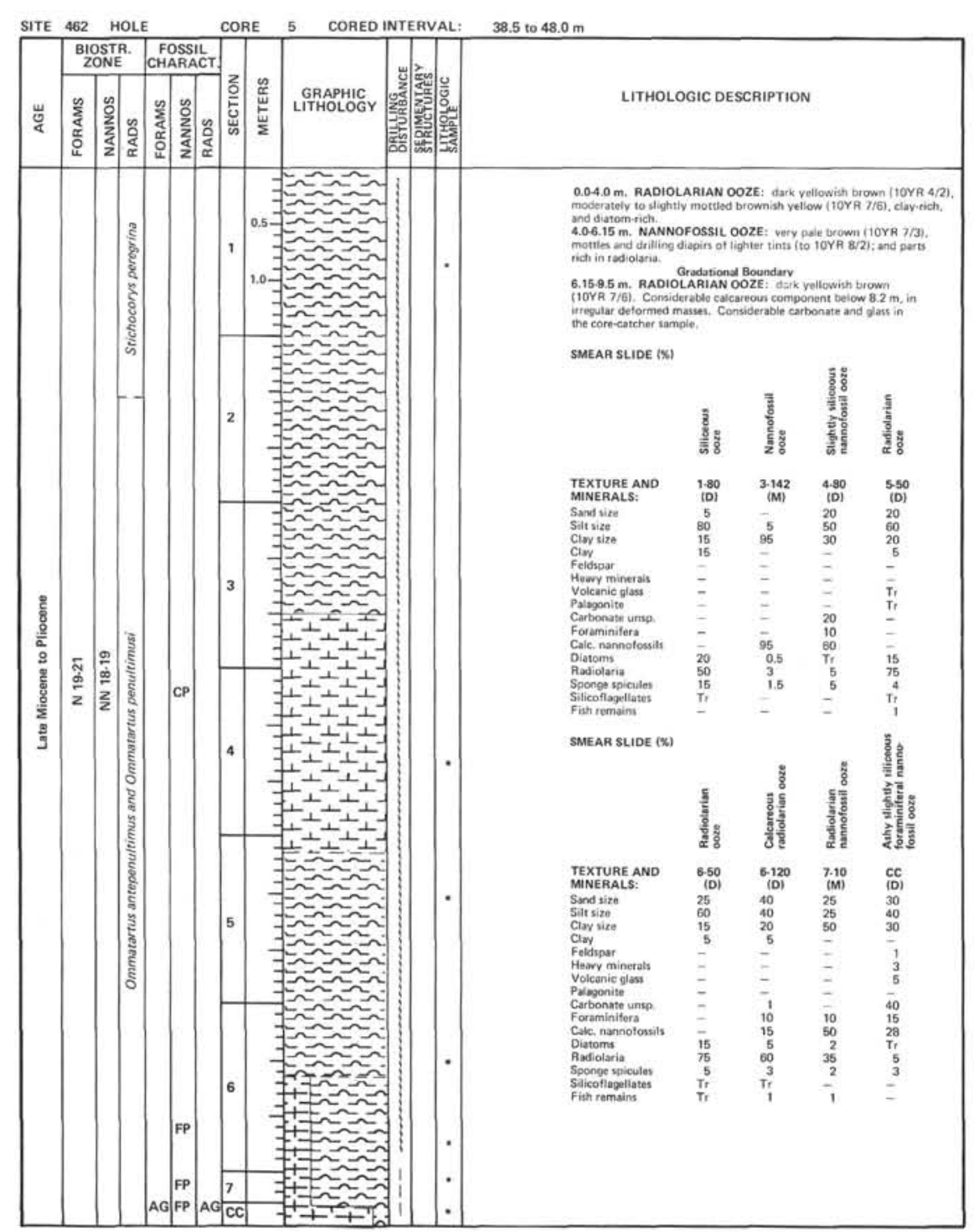

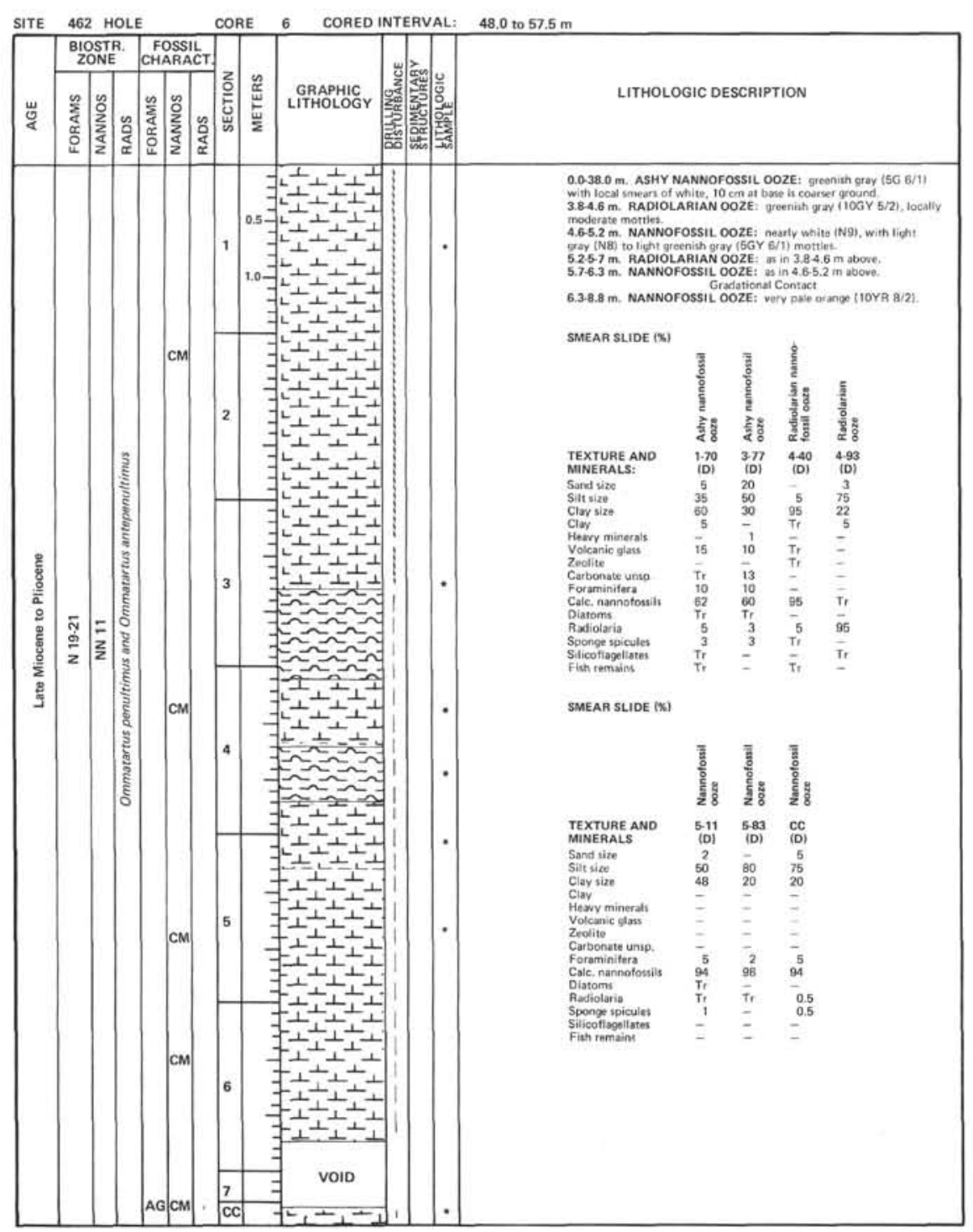



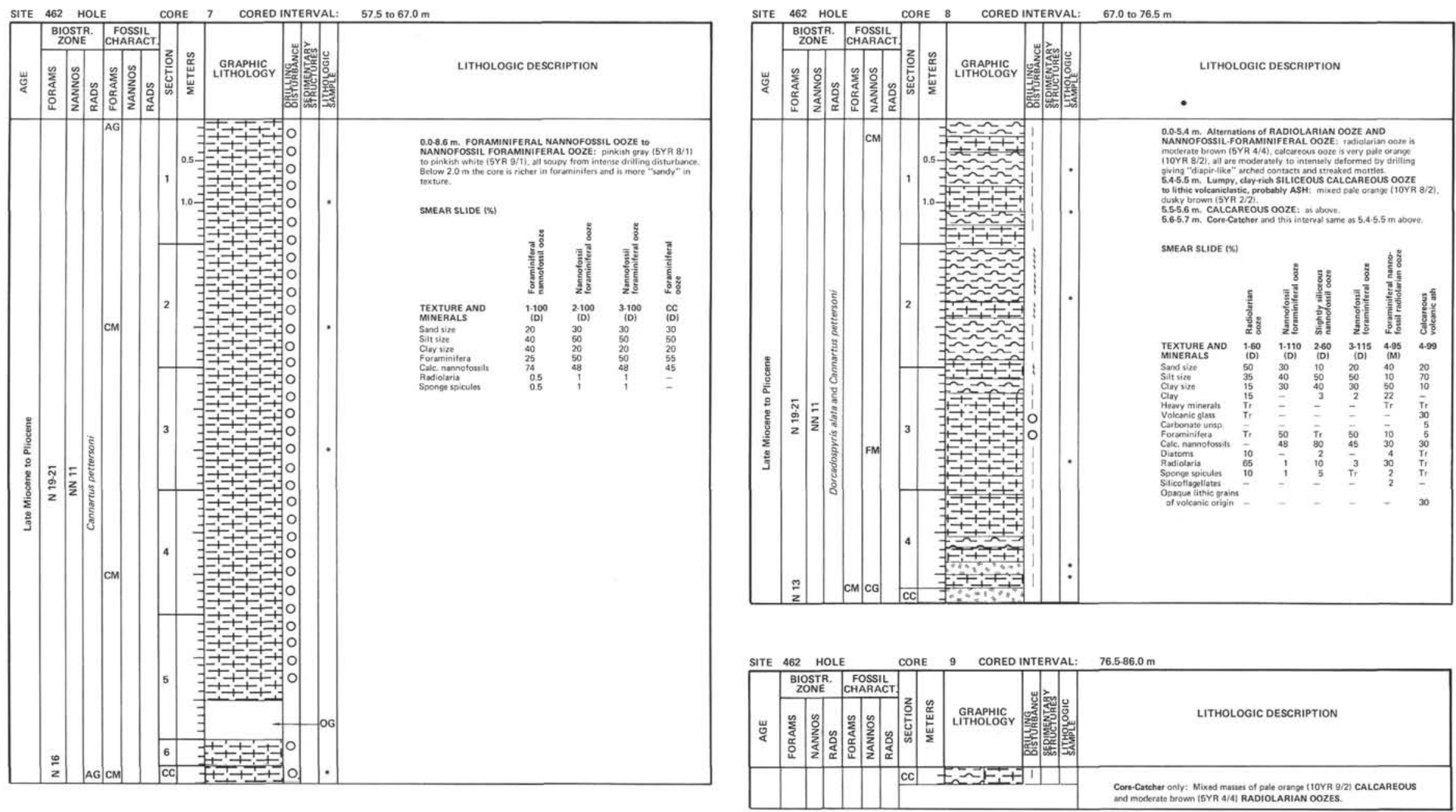

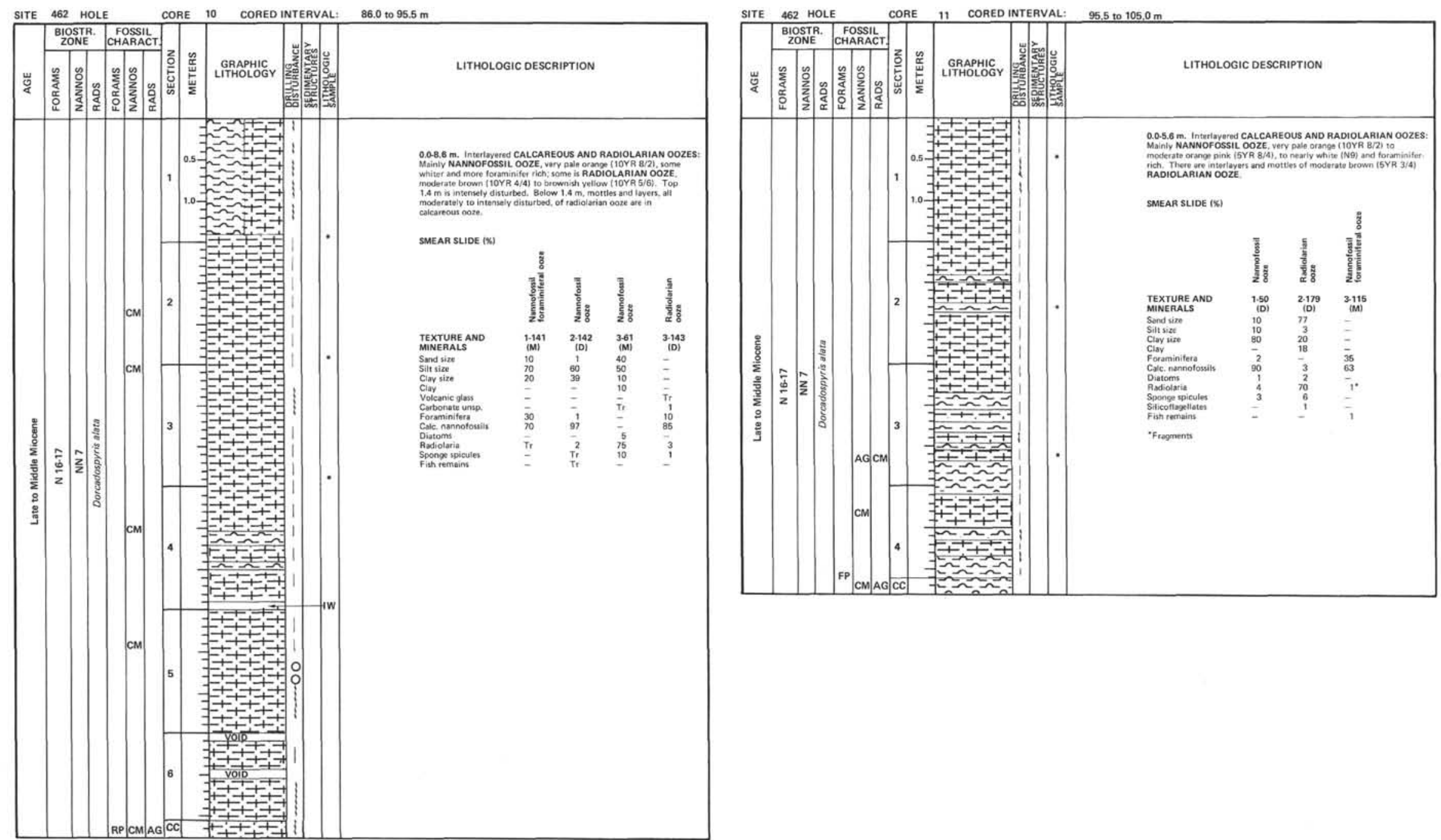

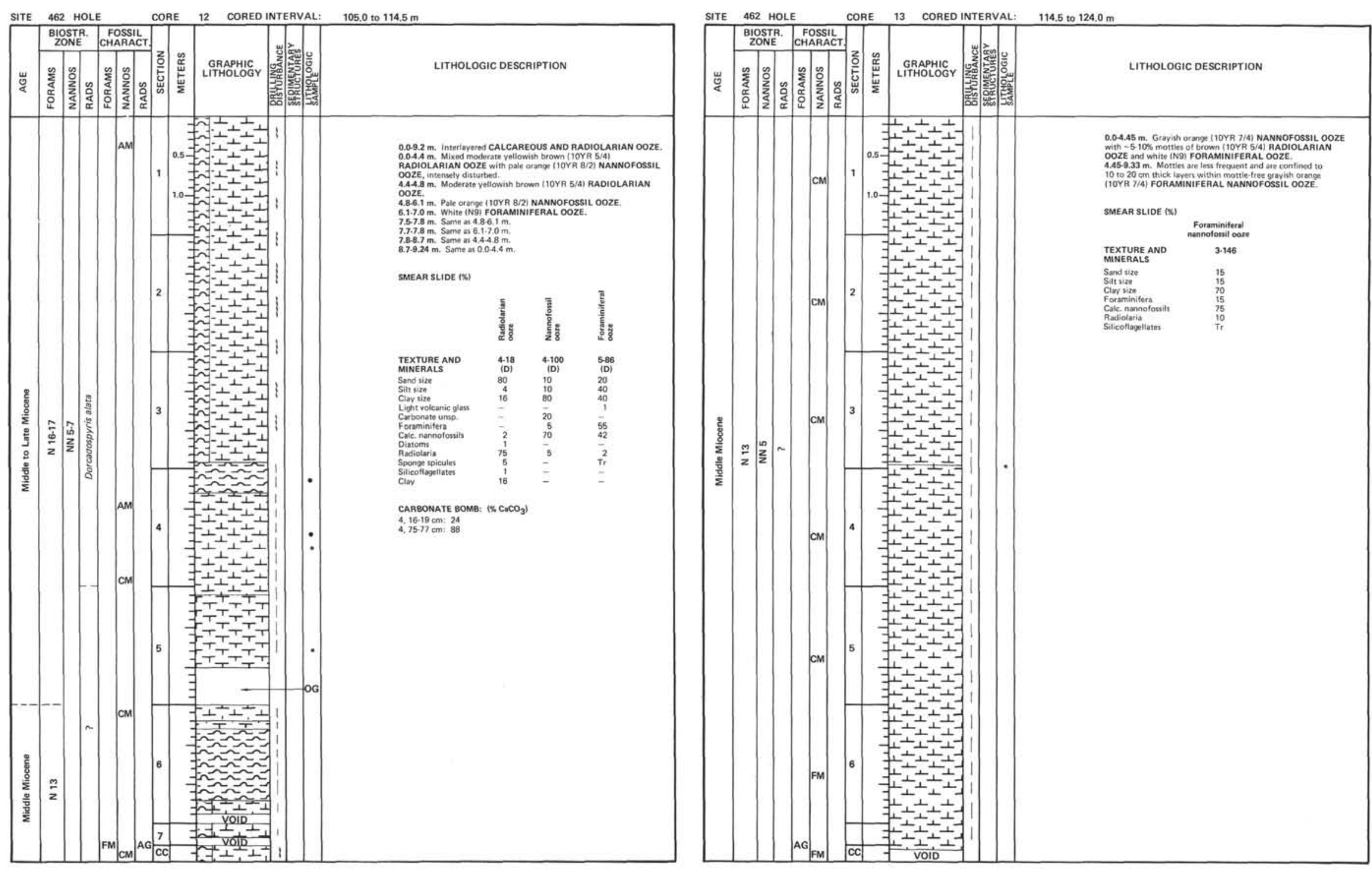


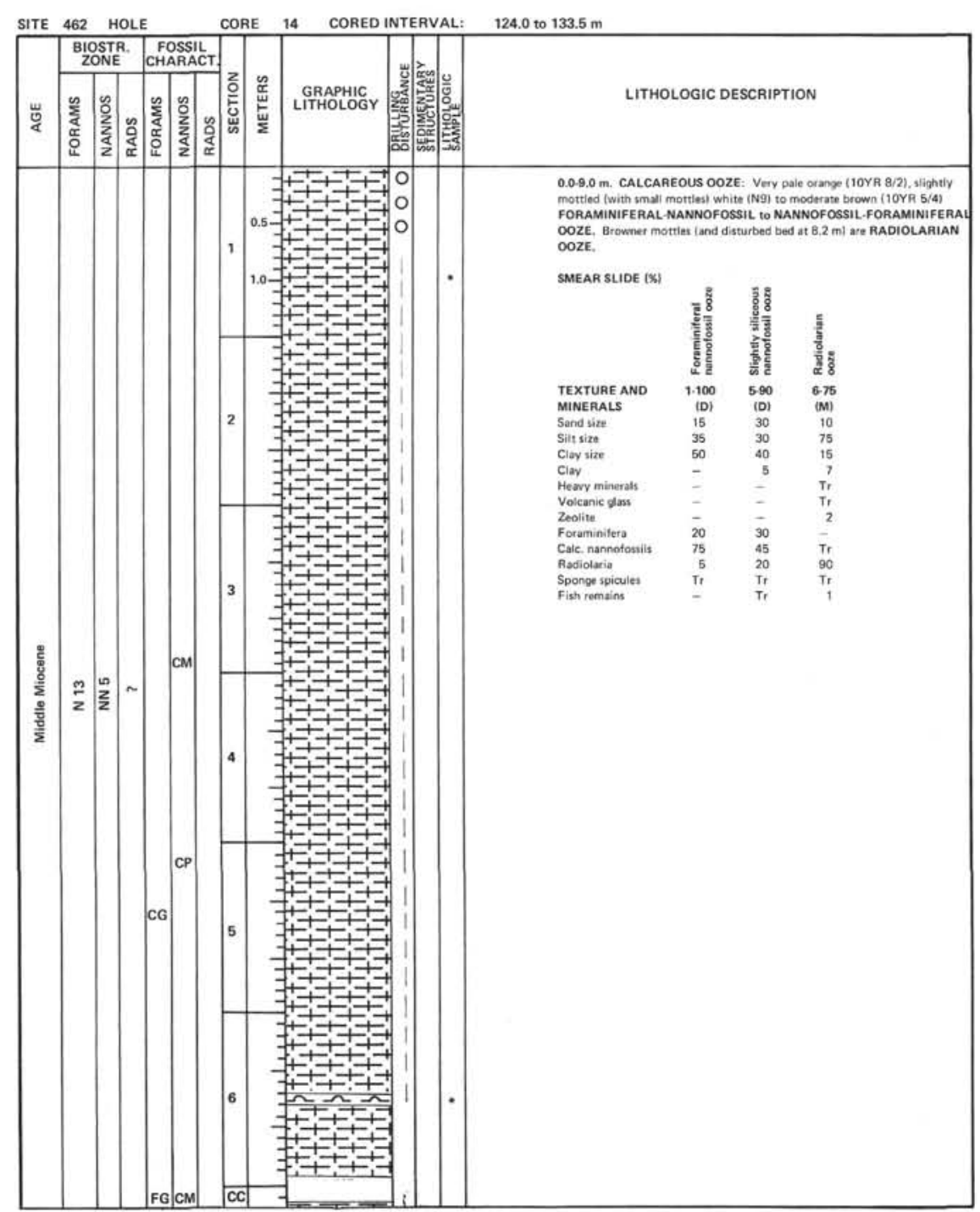

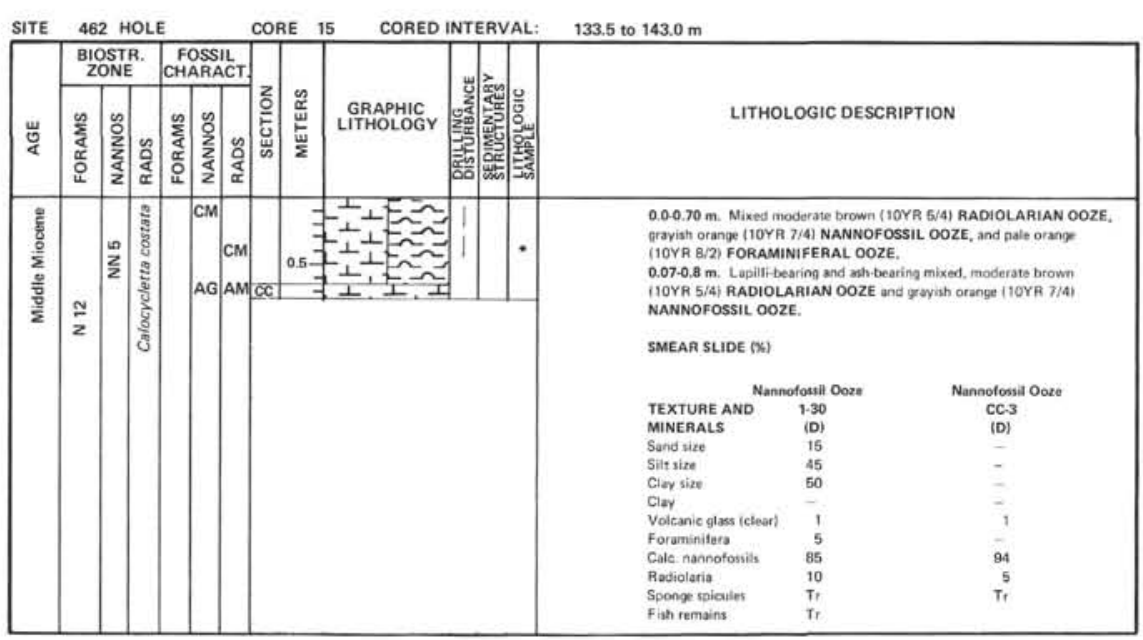



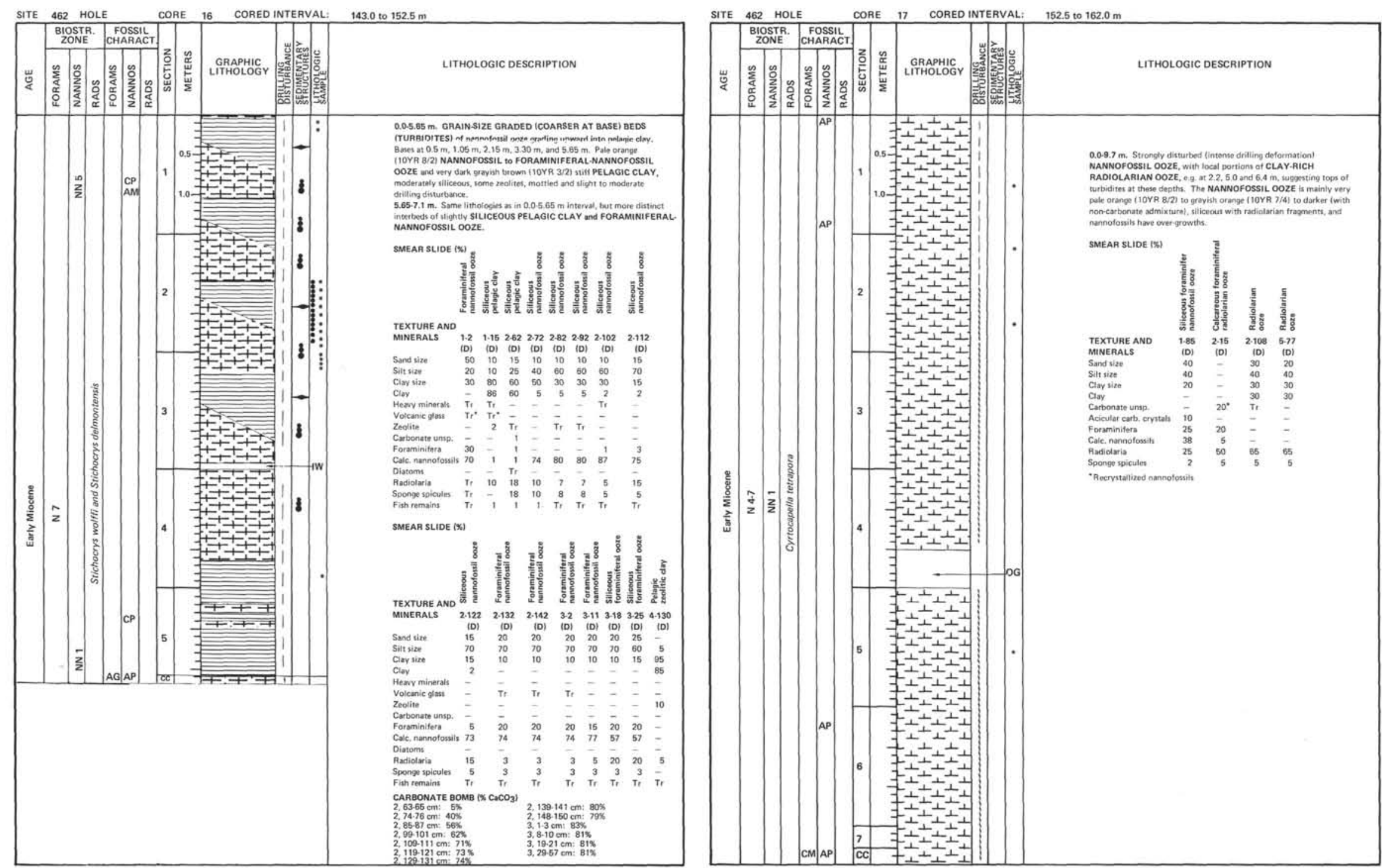

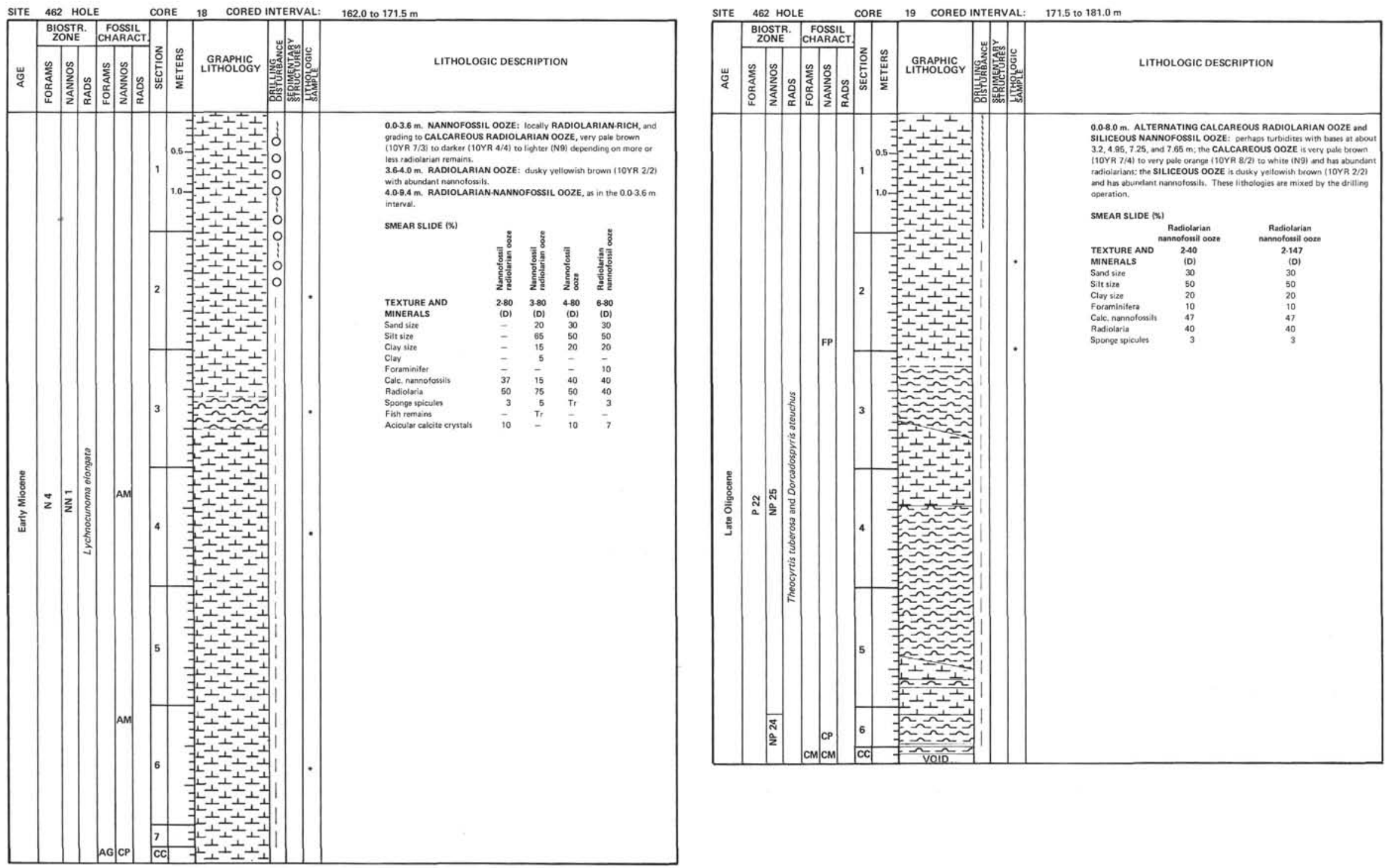

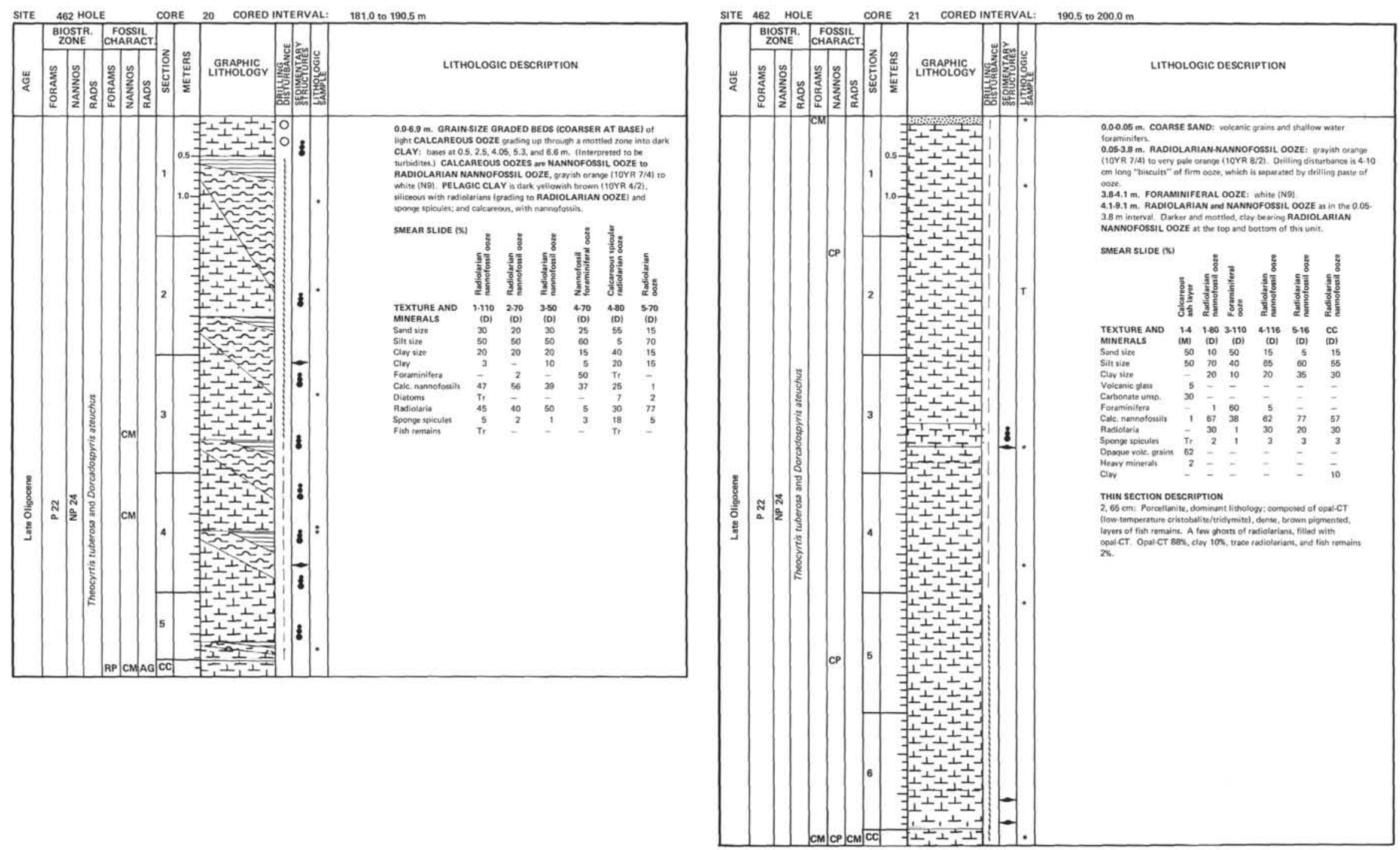

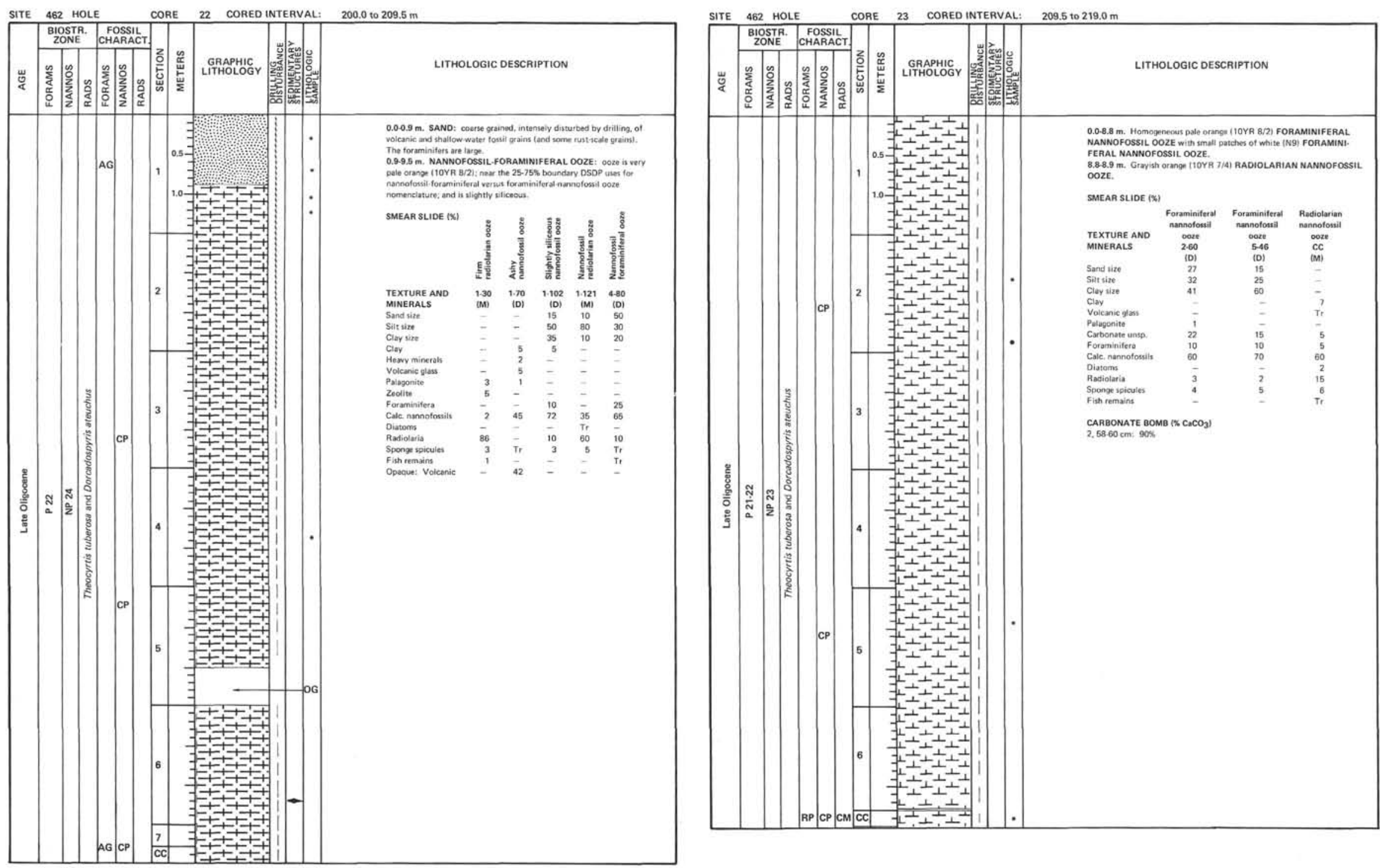

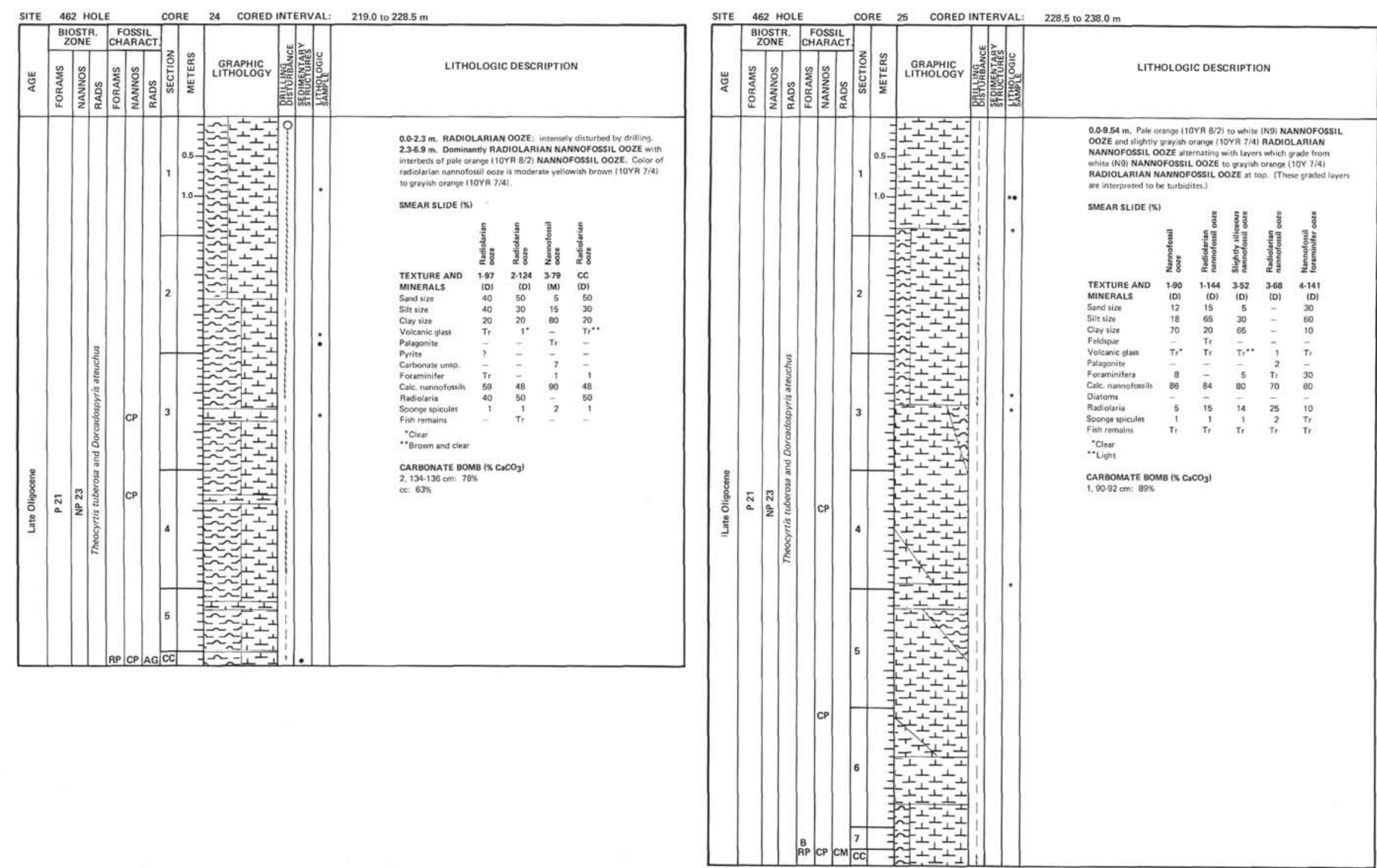

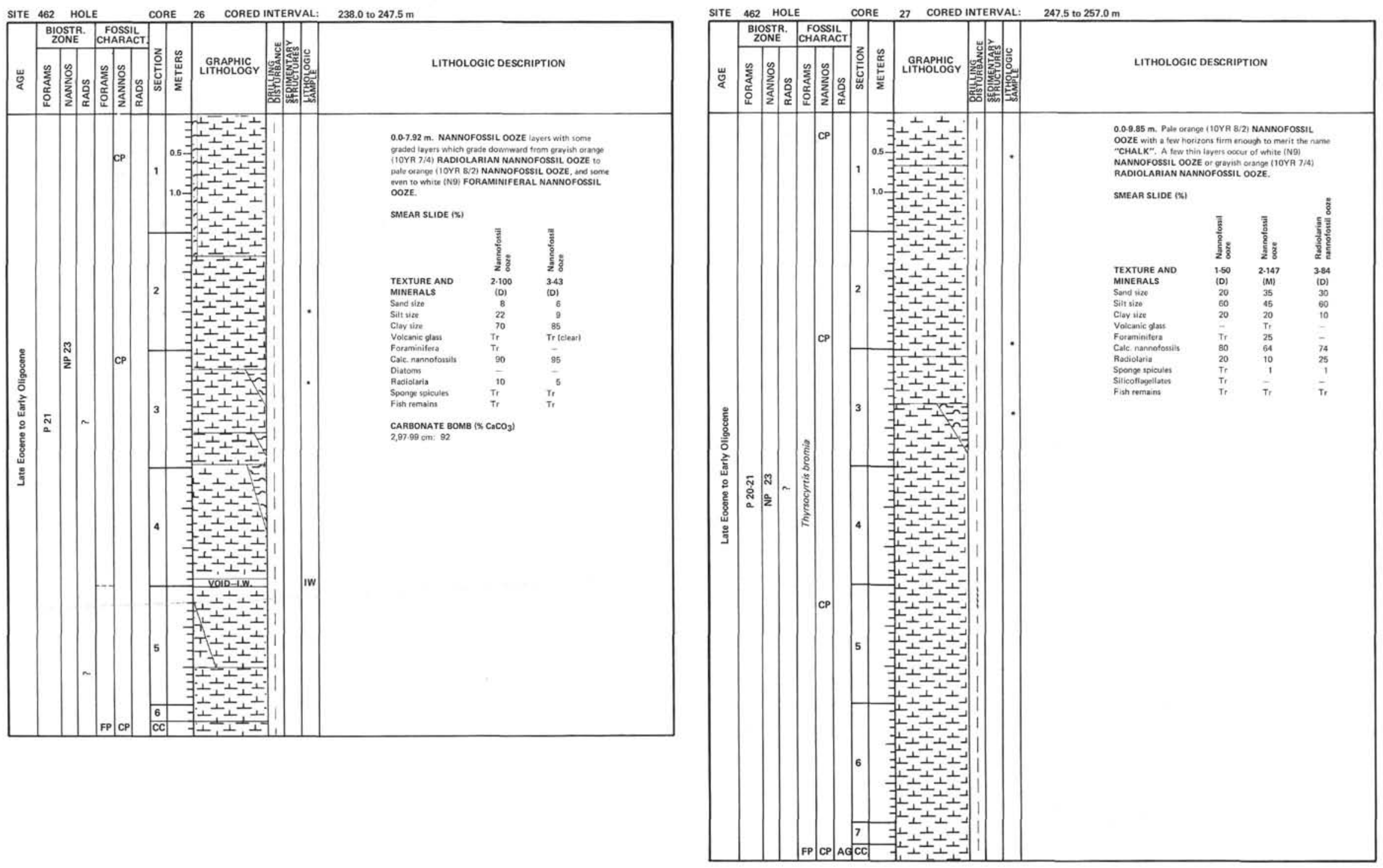

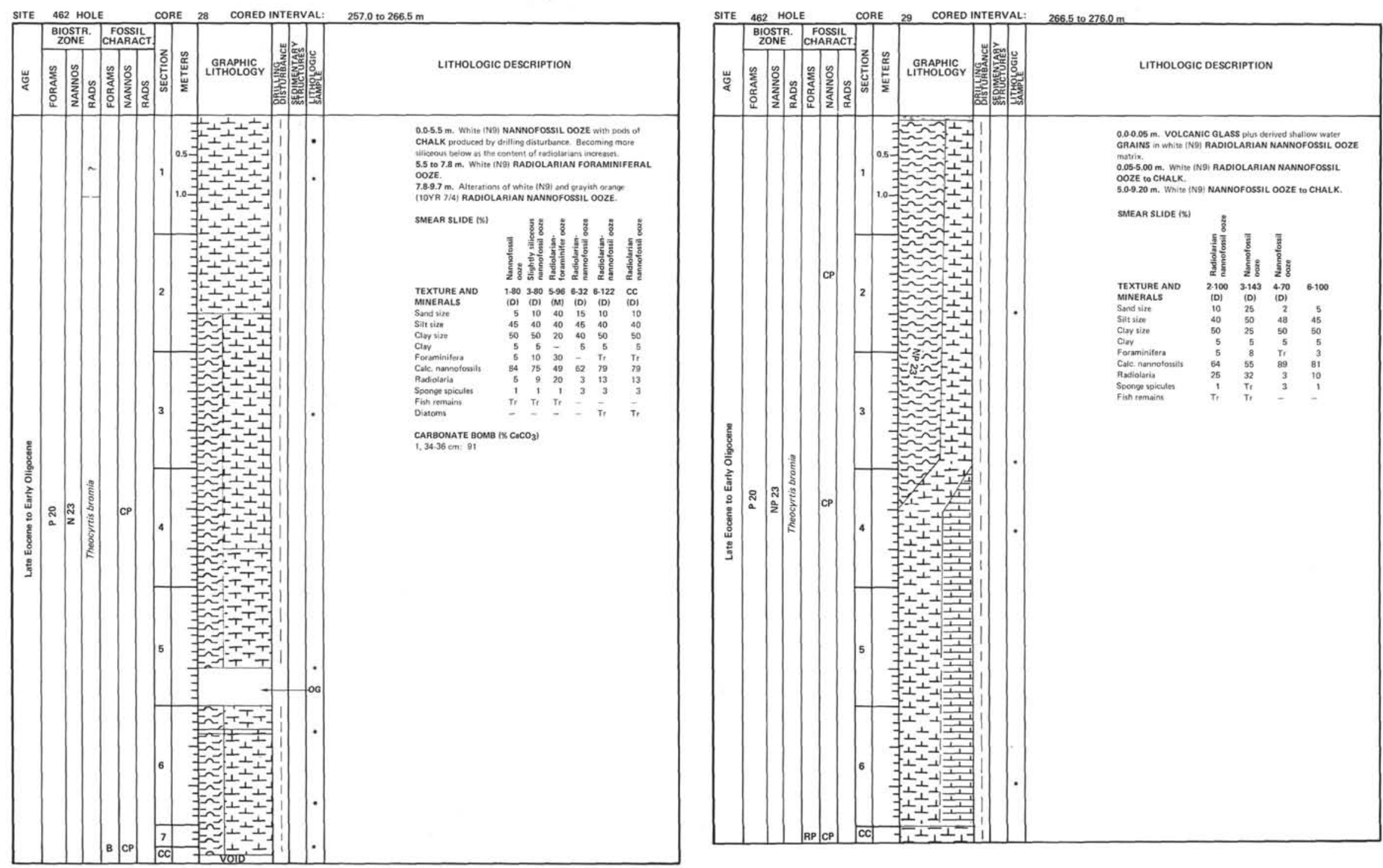


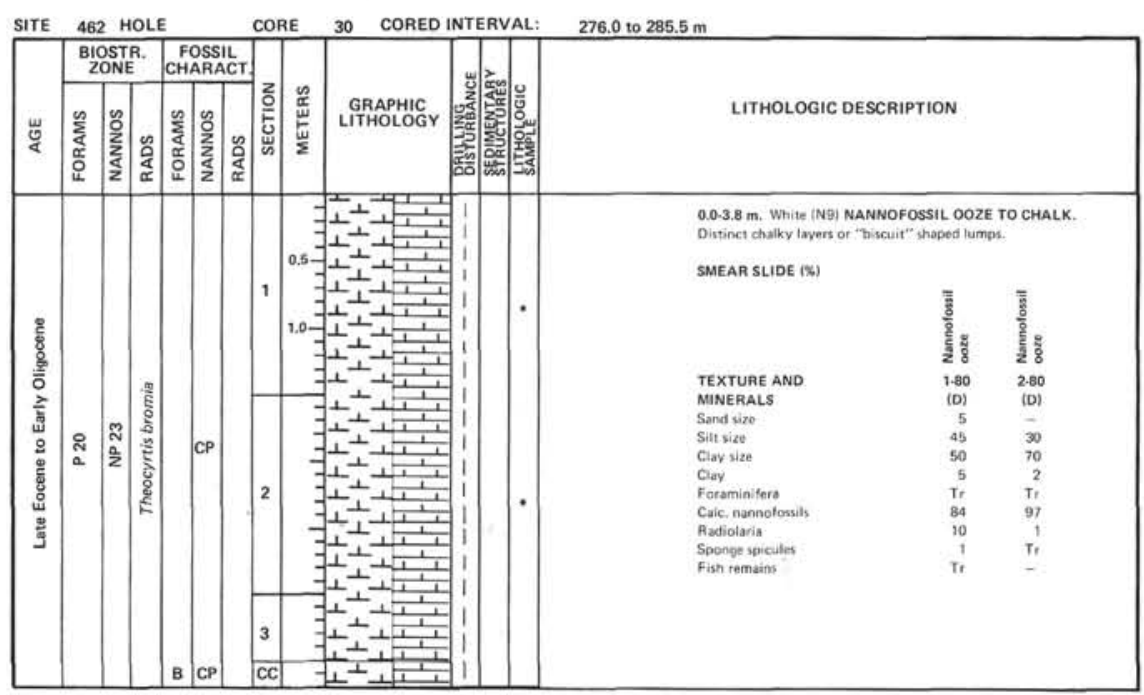

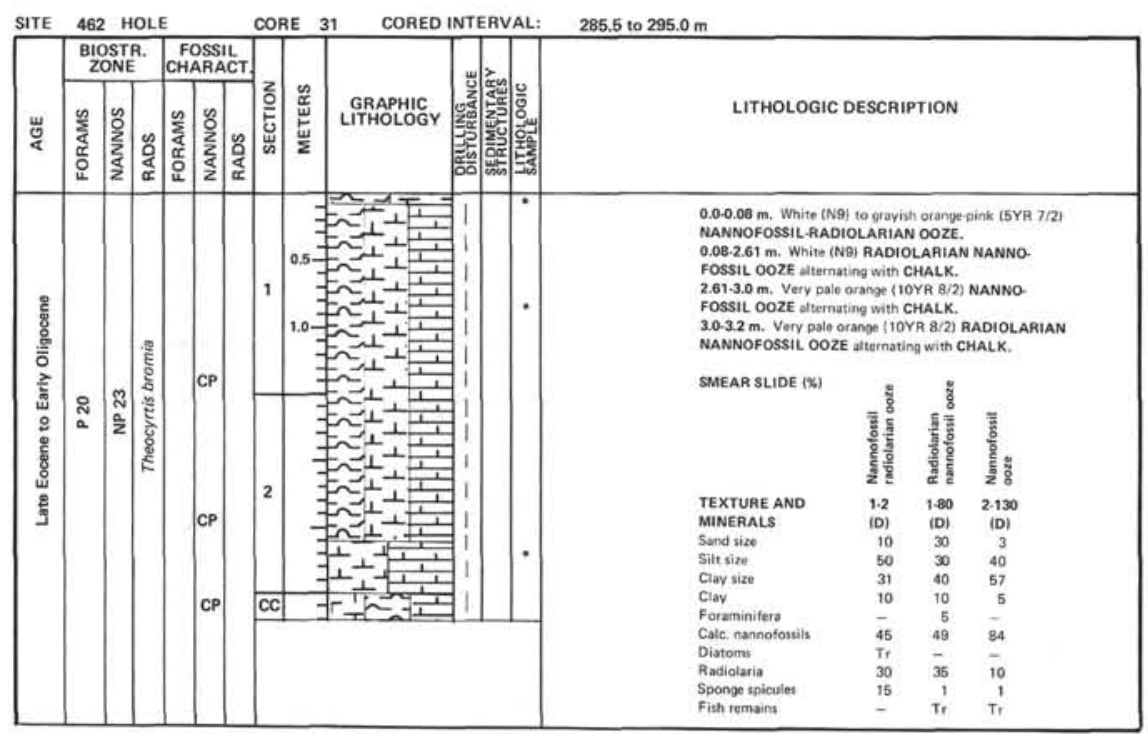

SITE 462 HOLE CORE 32 CORED INTERVAL: 295.0 to $304.5 \mathrm{~m}$

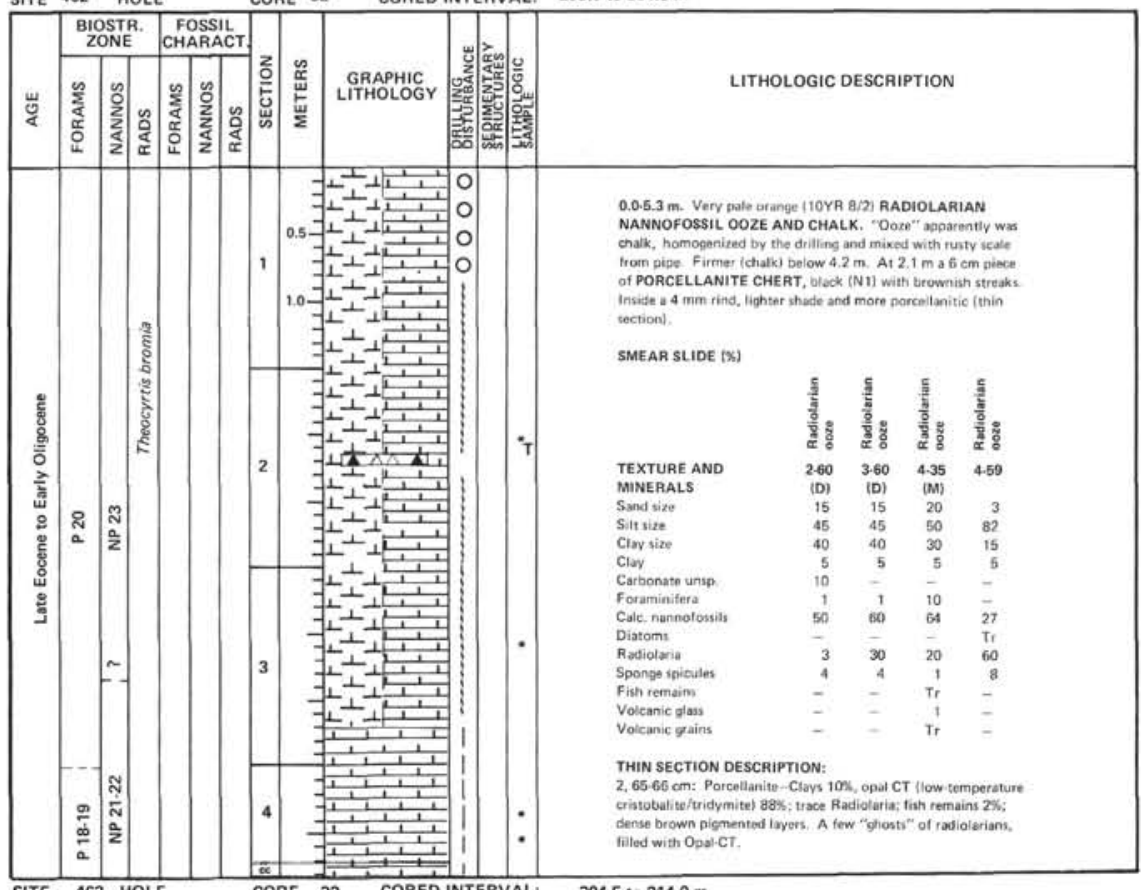

\section{SITE 462 HOLE CORE 33 CORED INTERVAL: 304.5 to $314.0 \mathrm{~m}$}

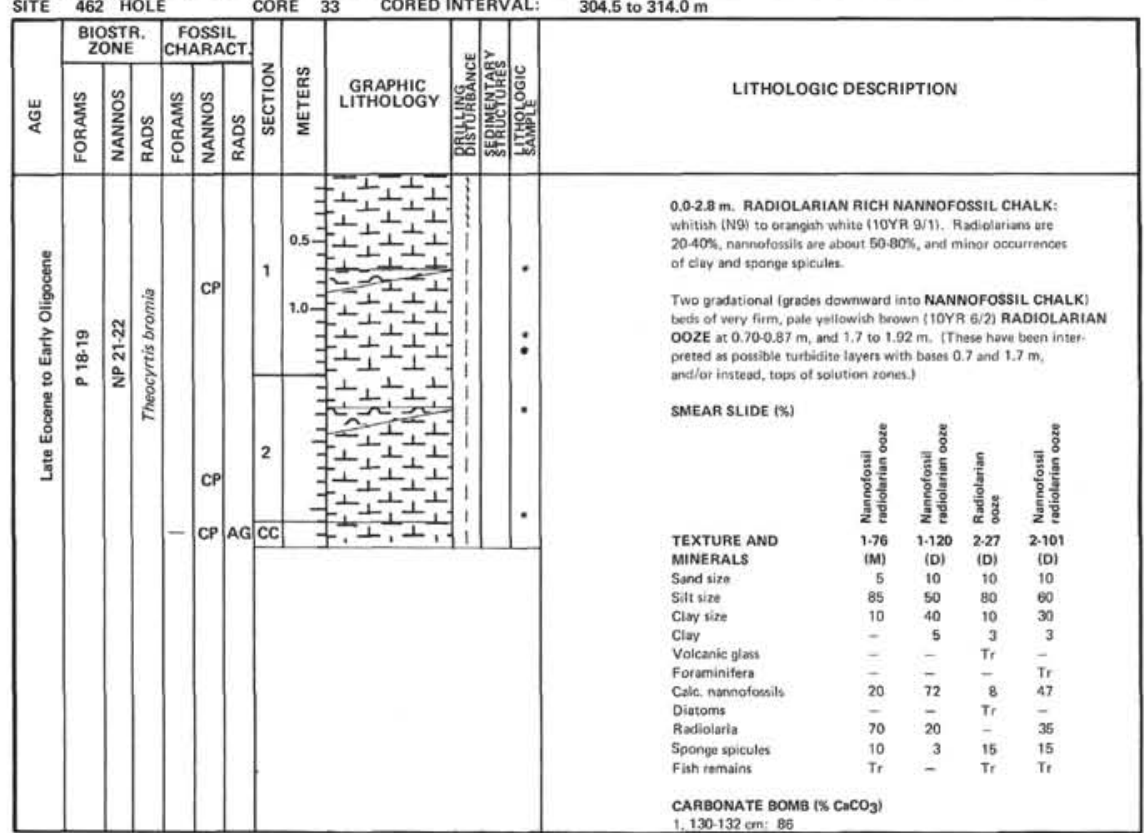



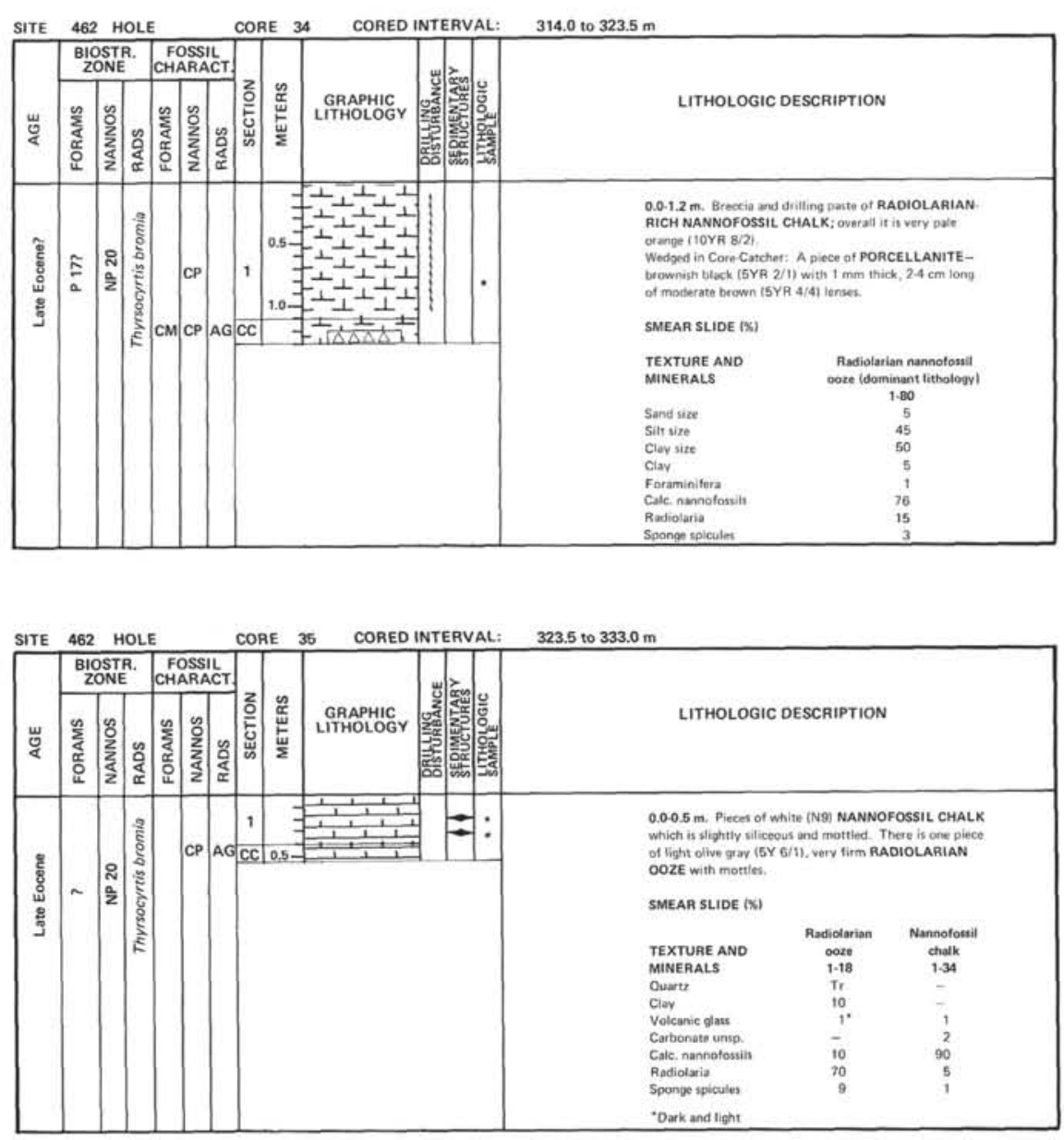

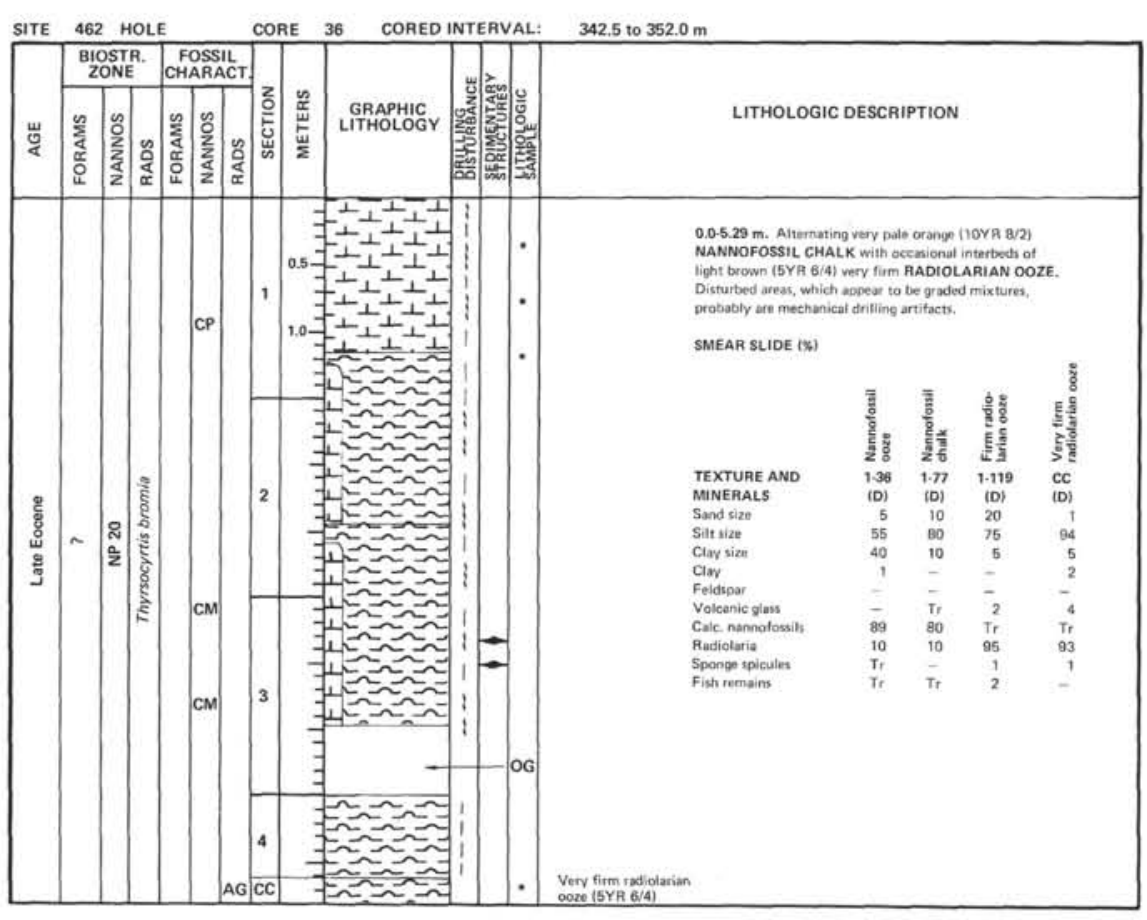



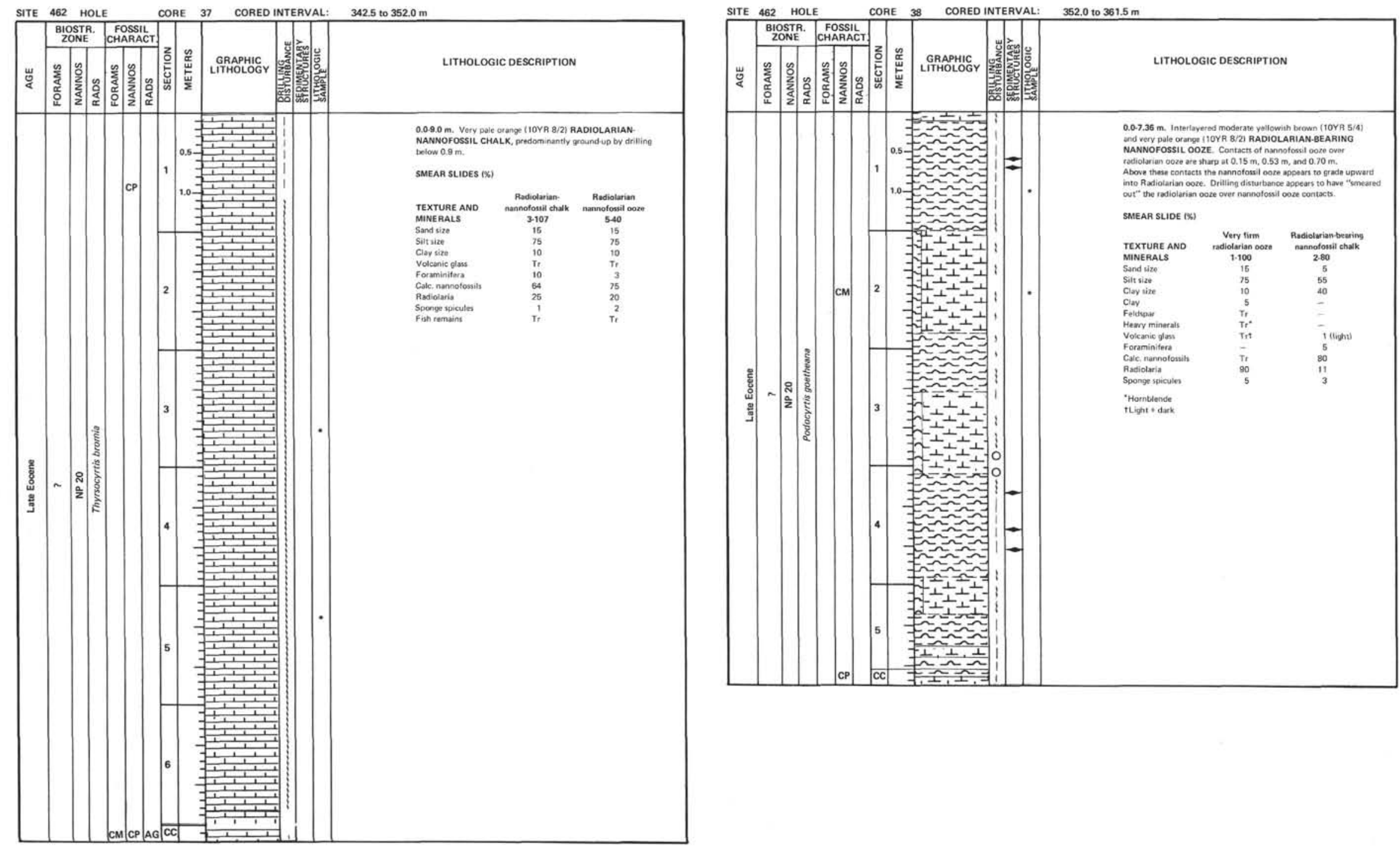


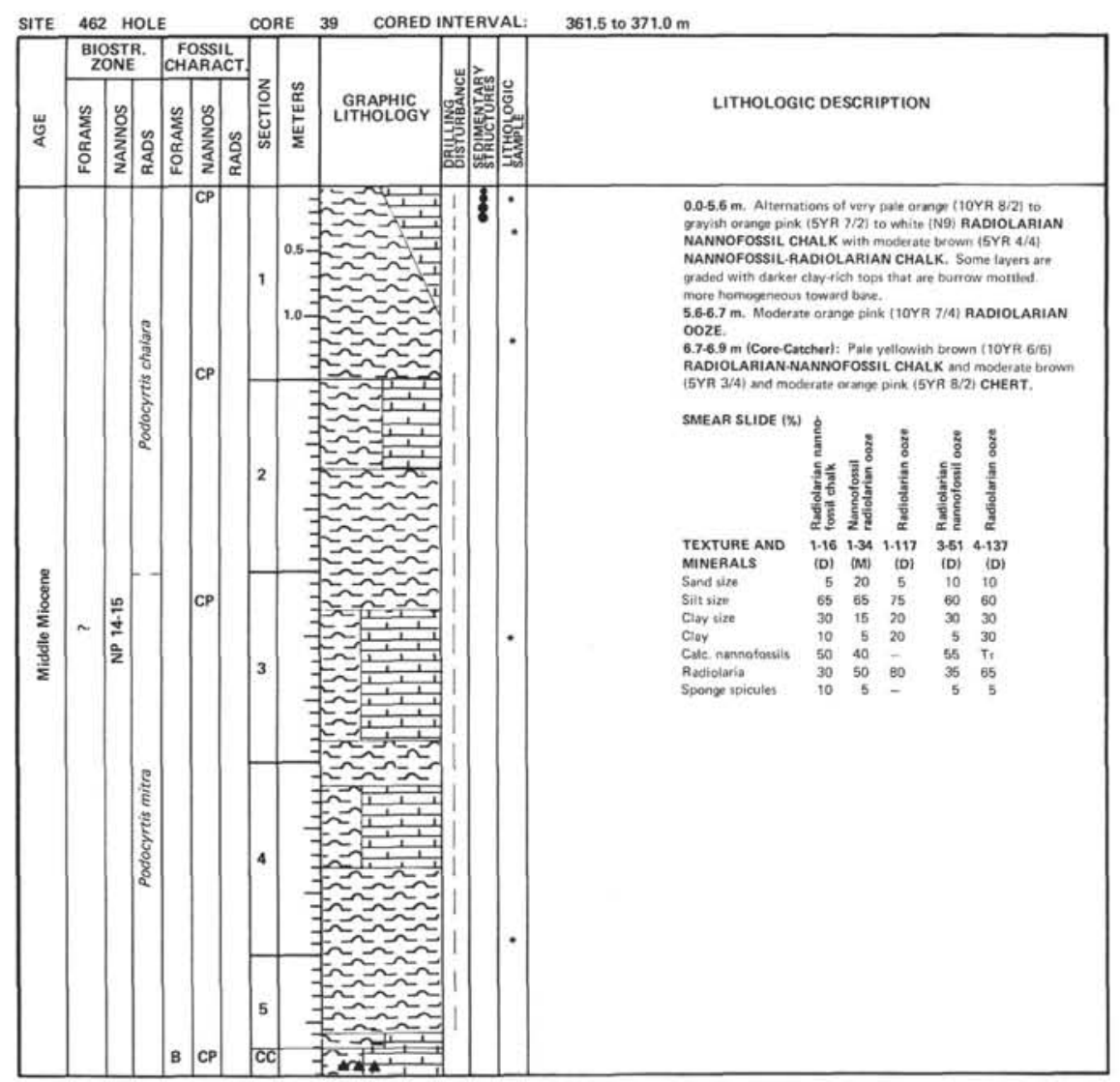

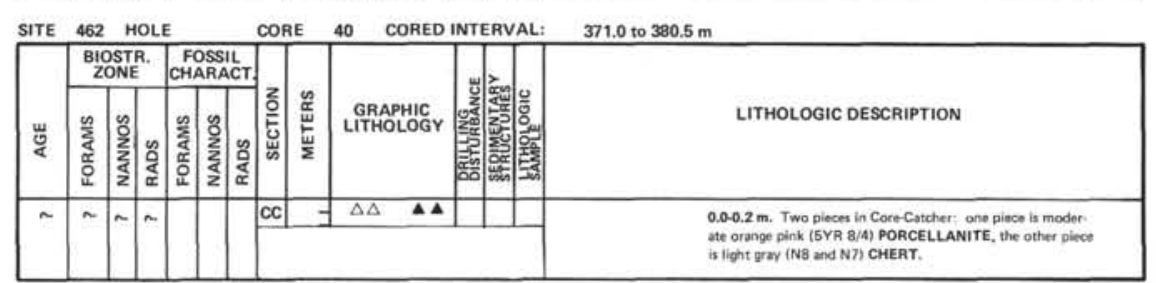
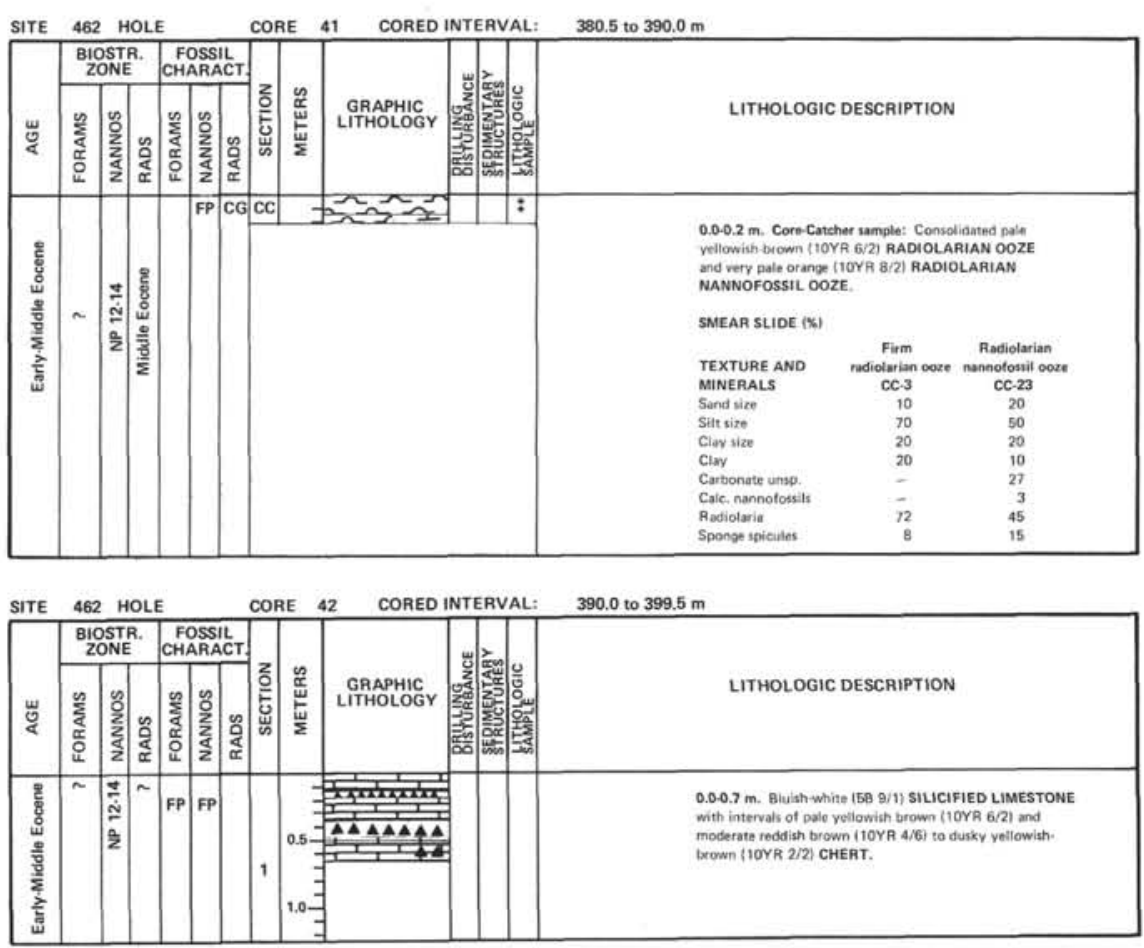

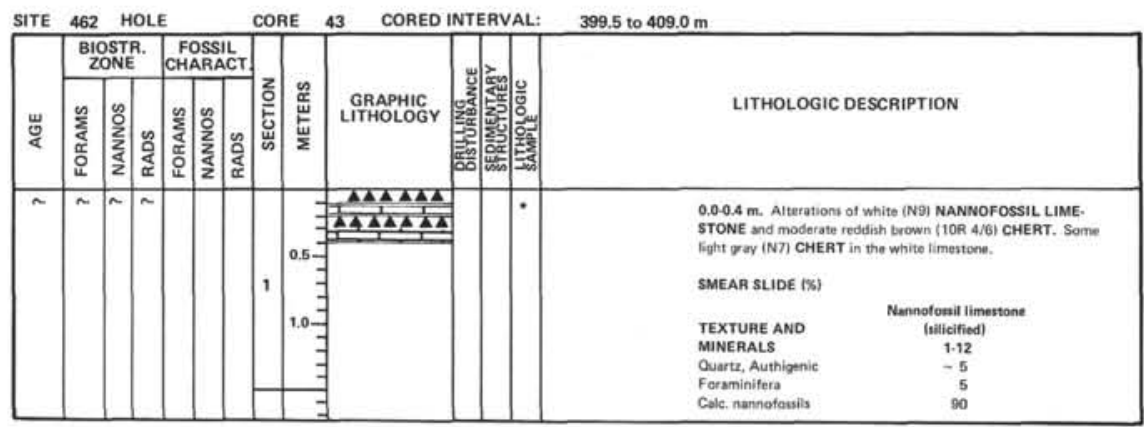



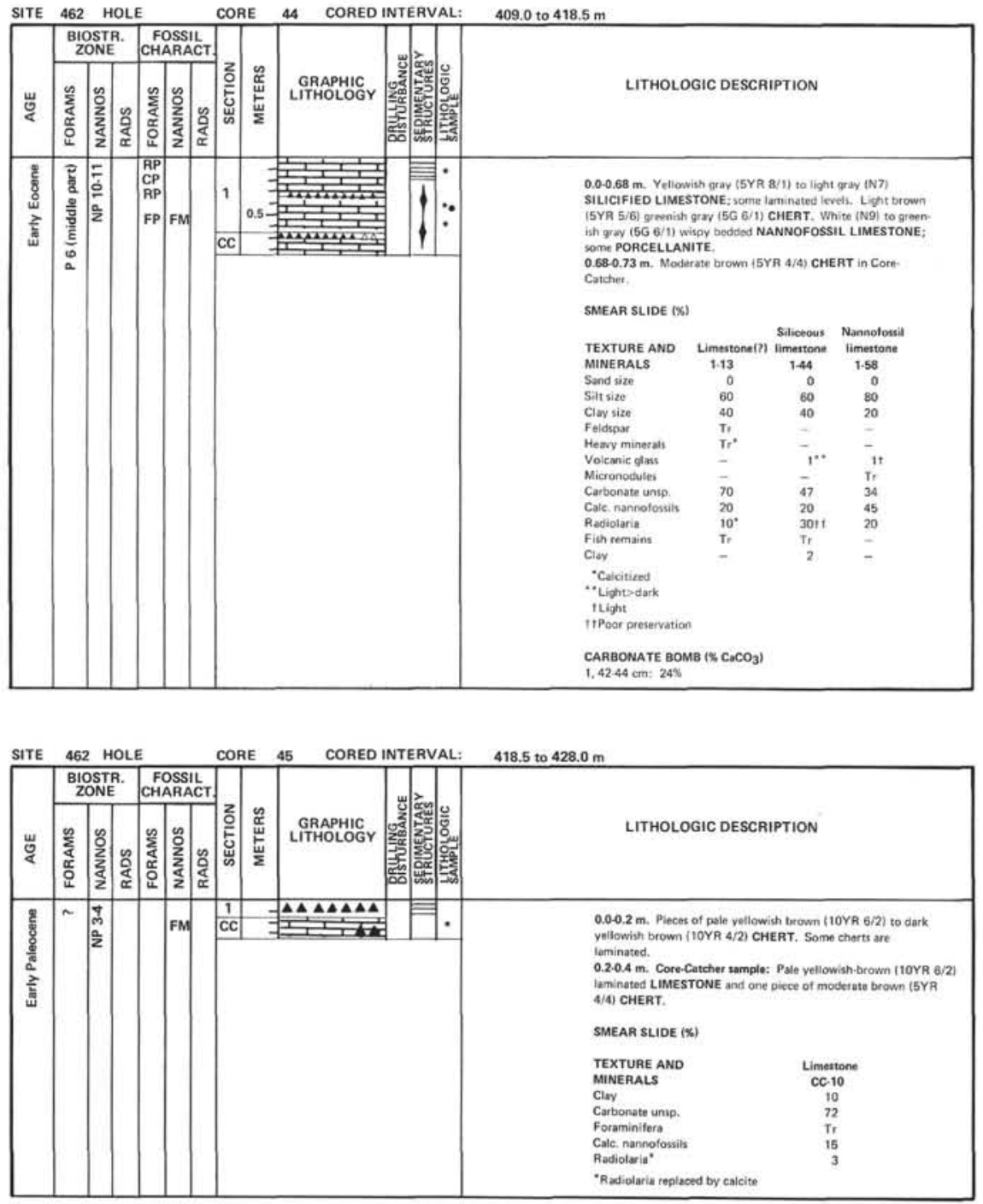

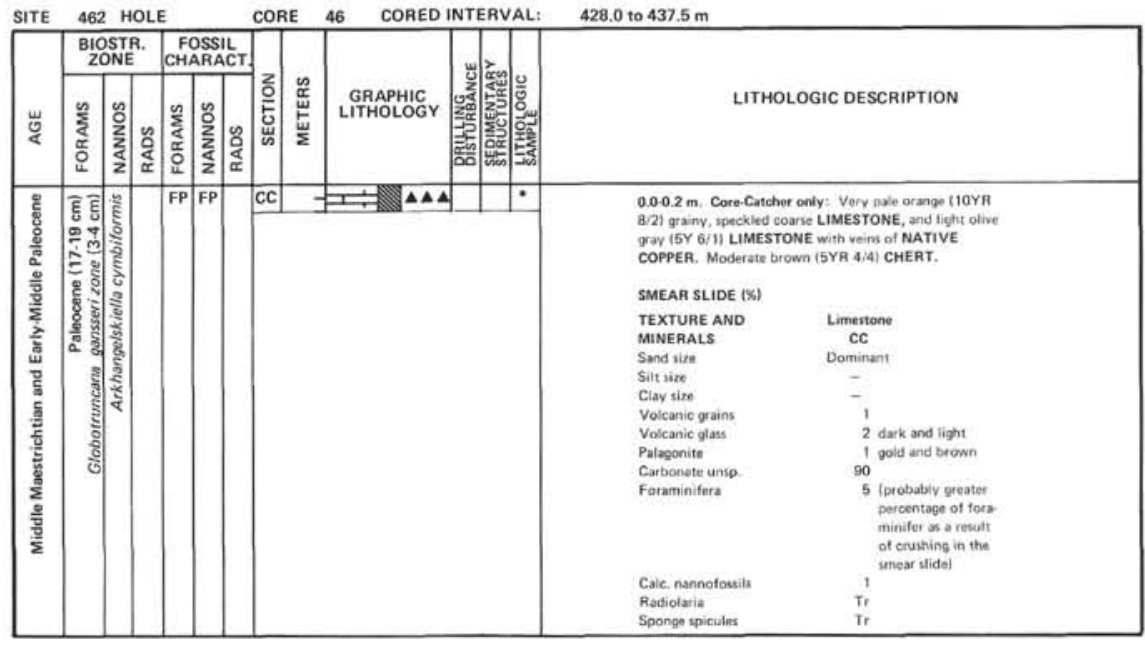

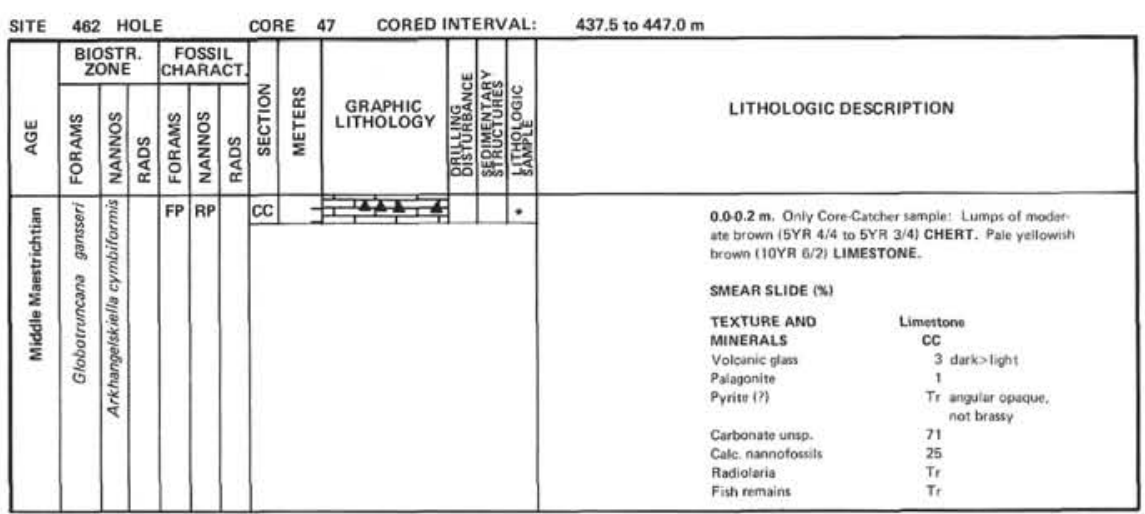




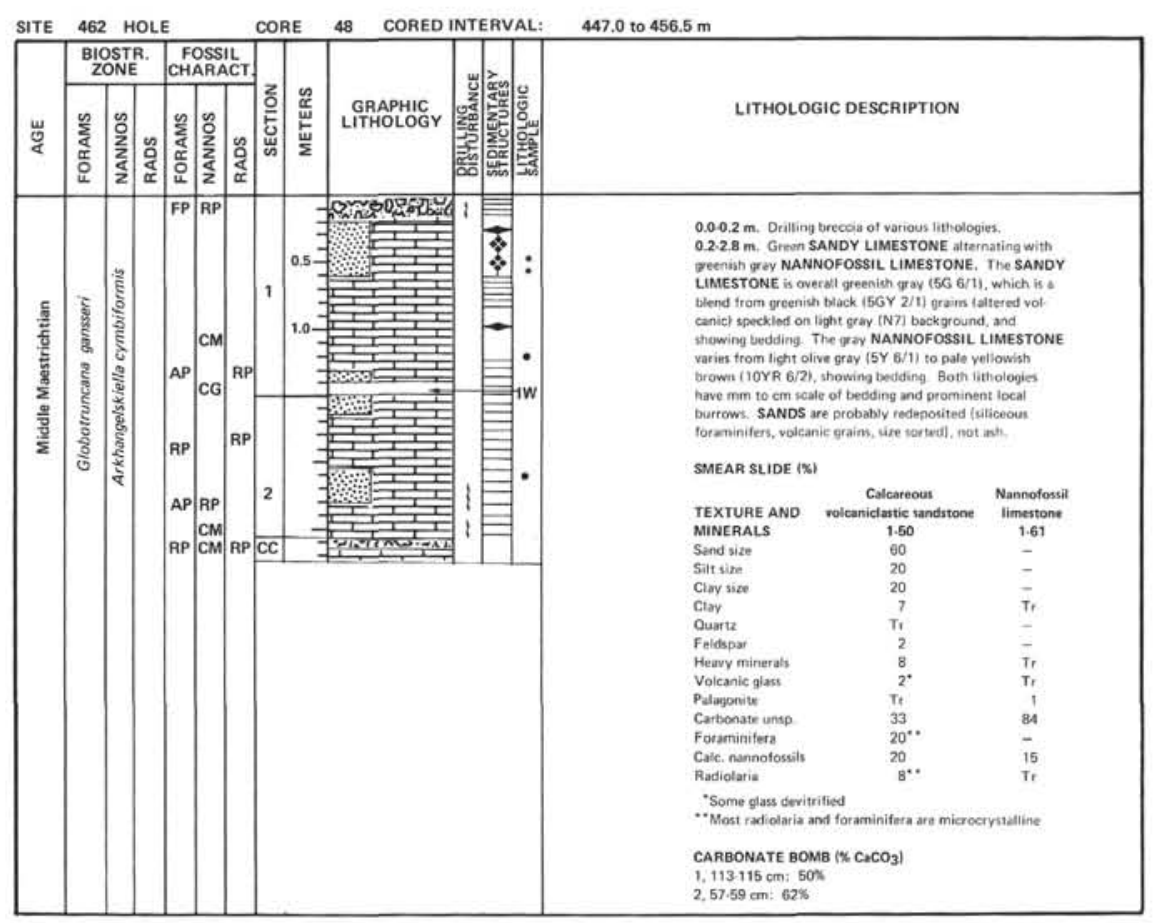

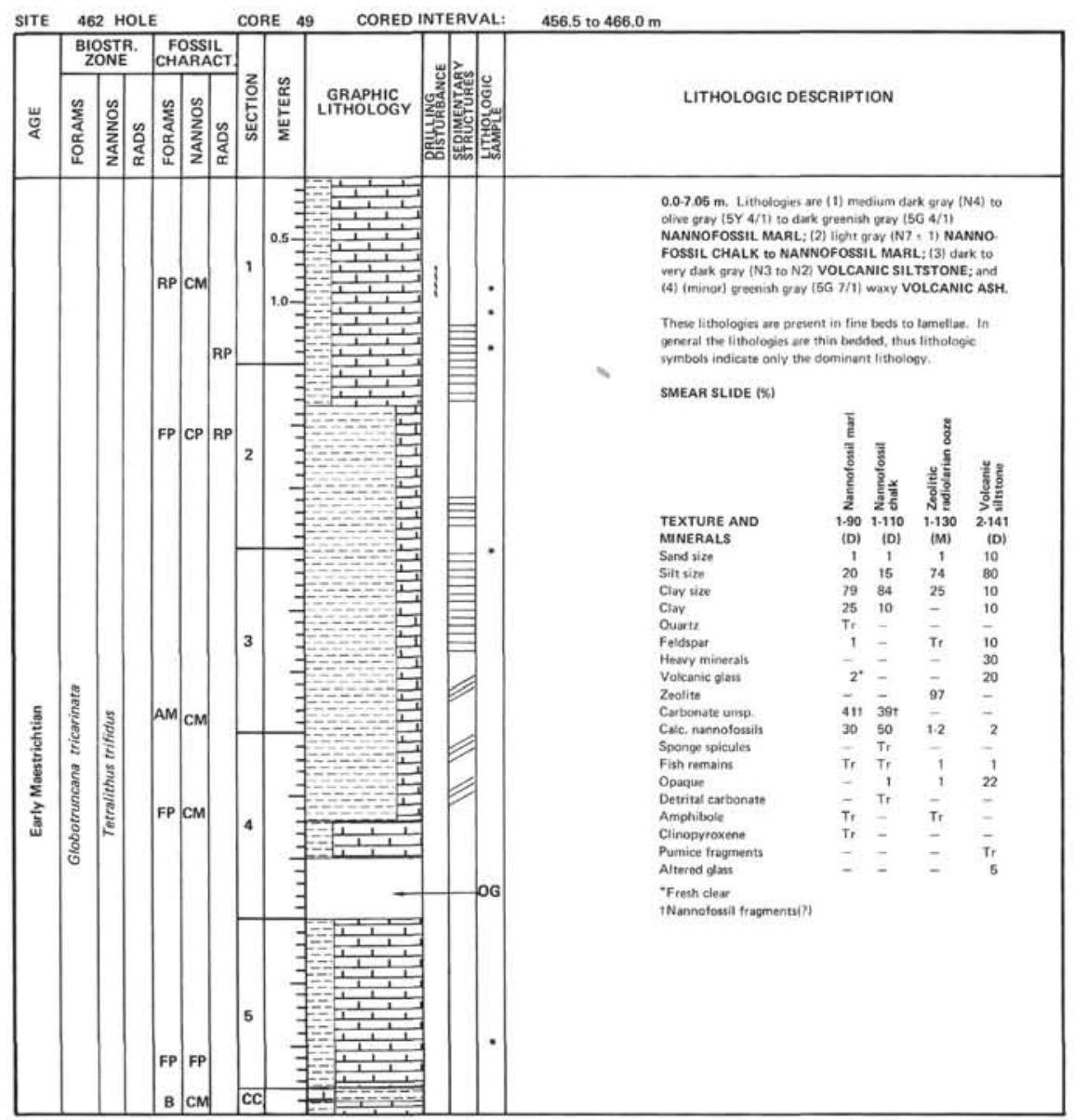



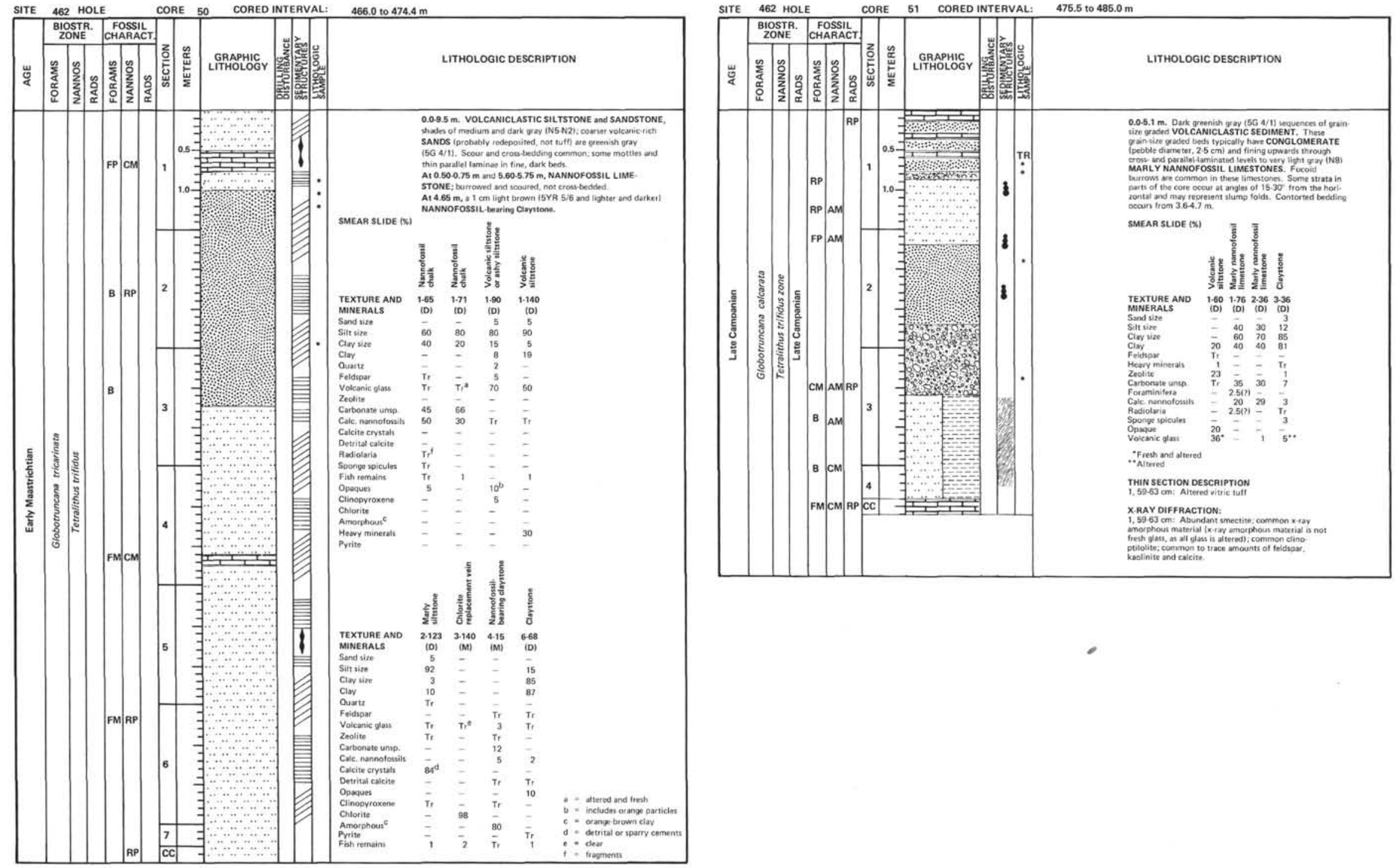

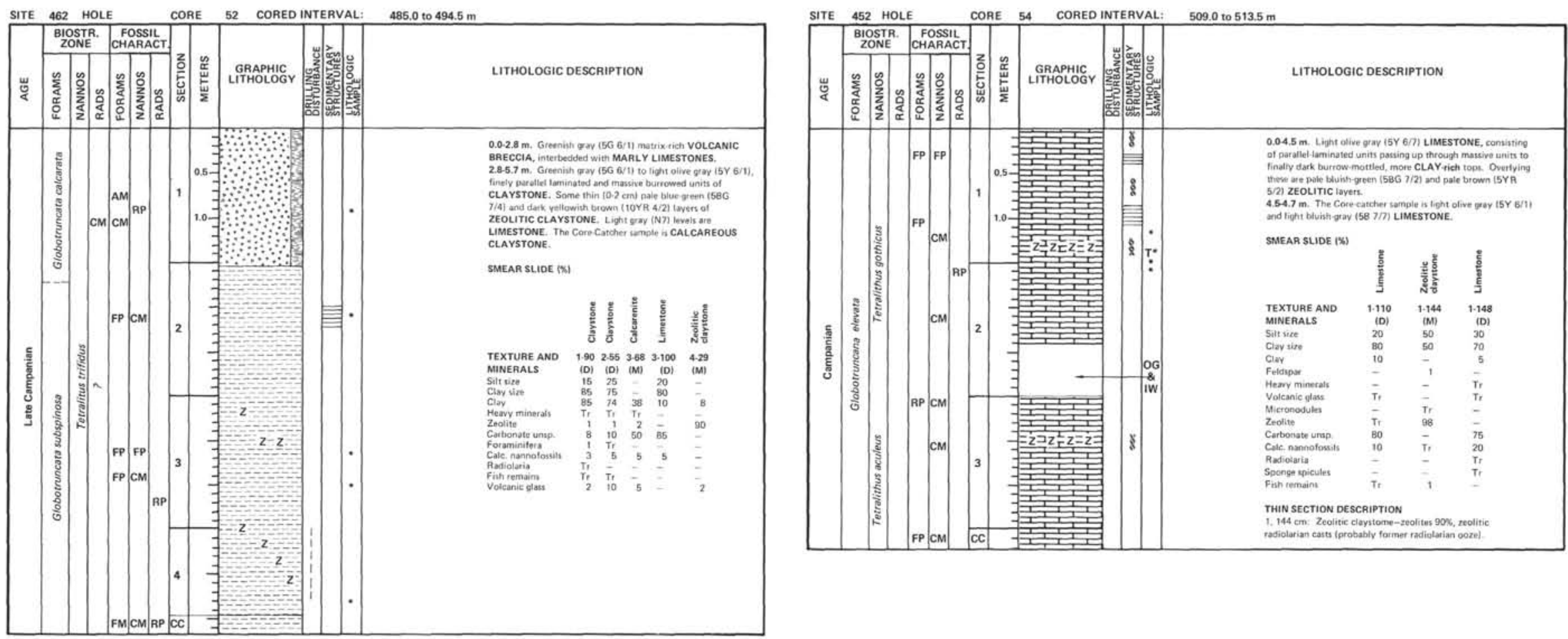

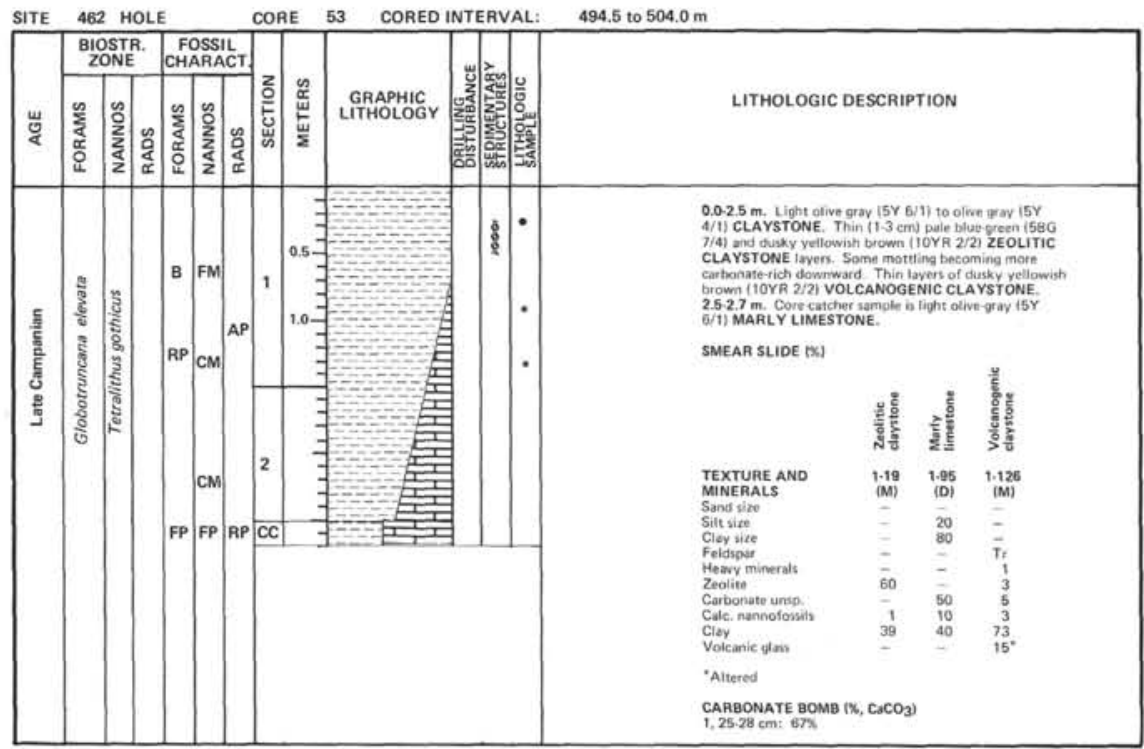




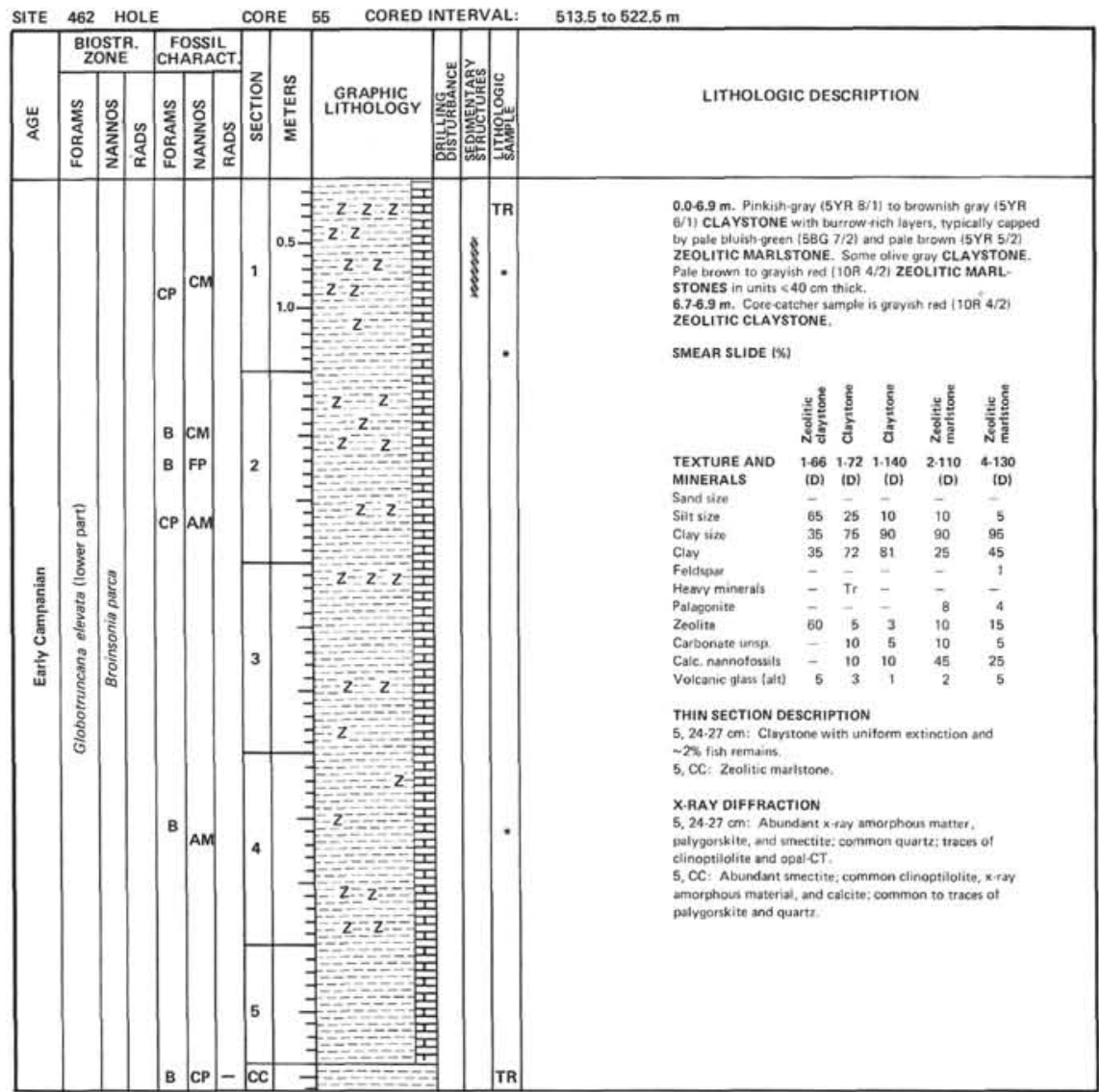

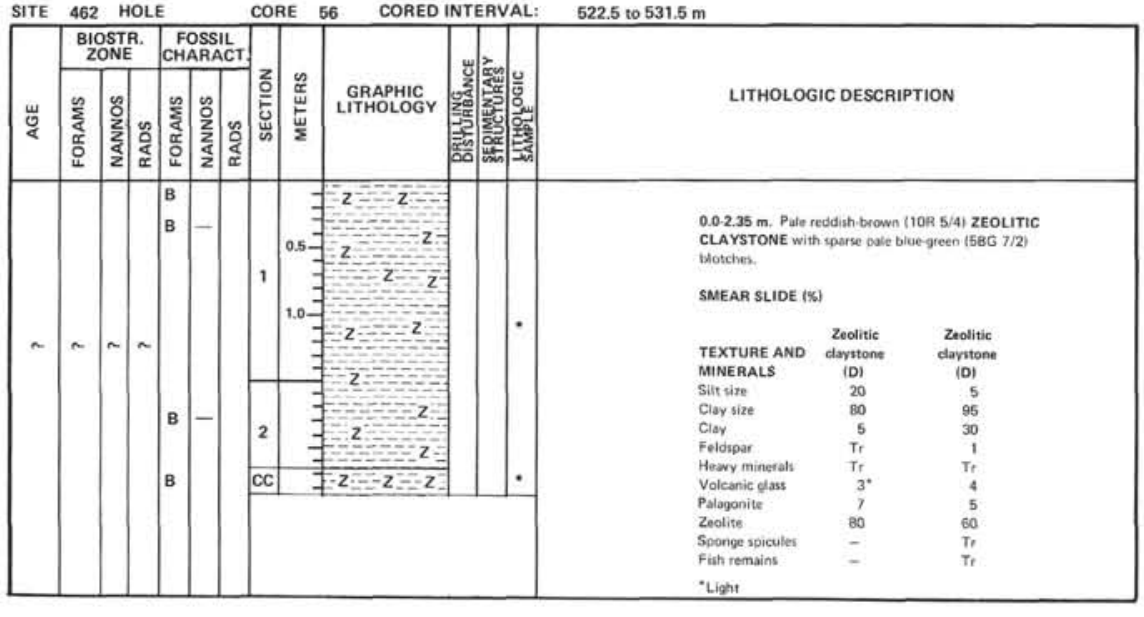

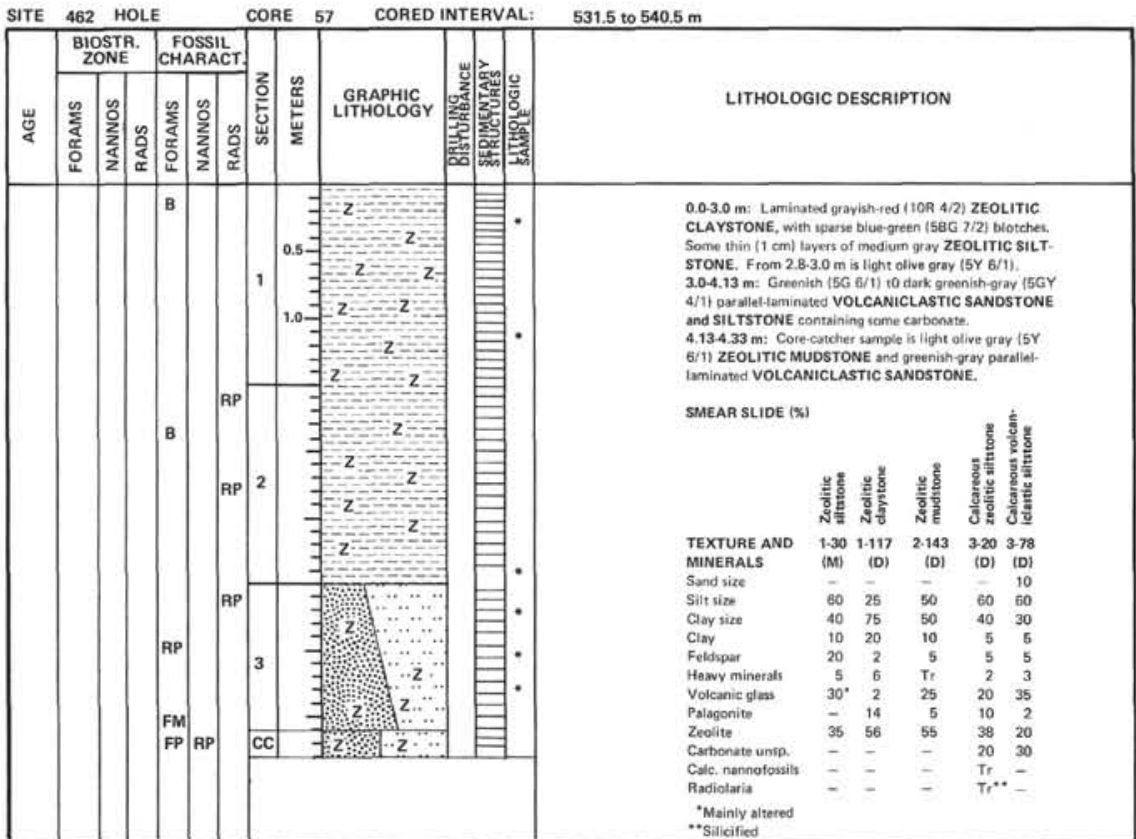




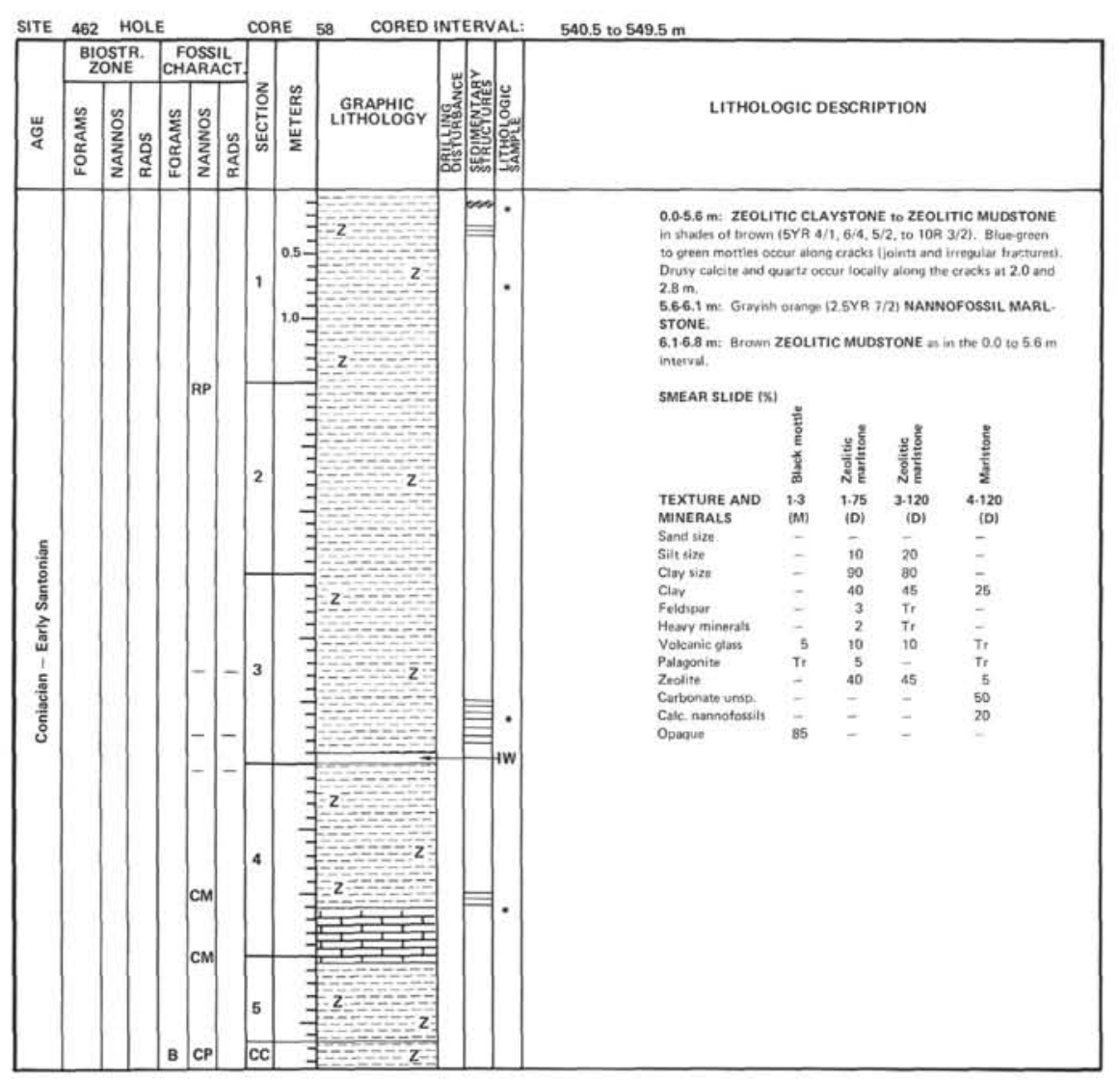

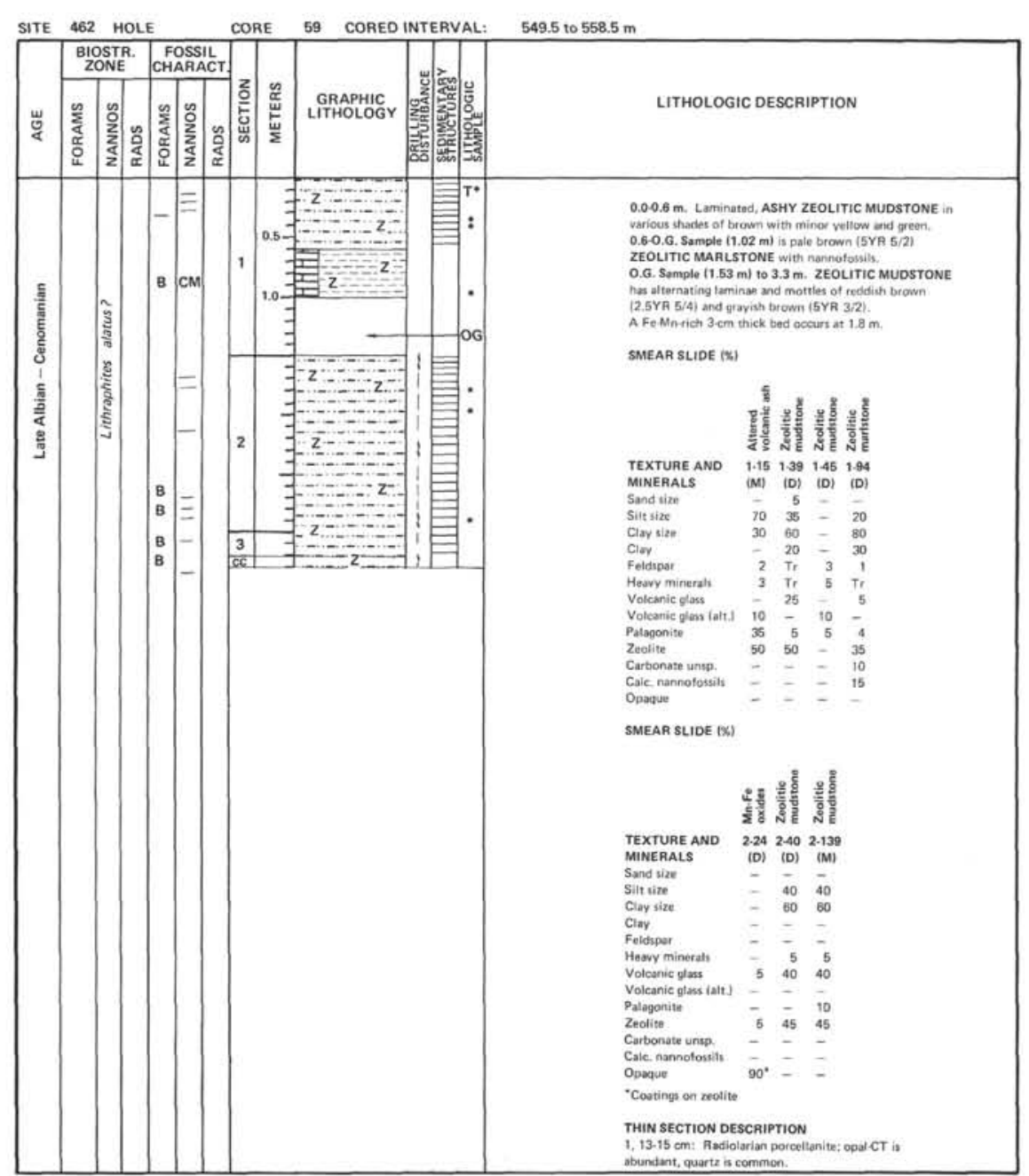




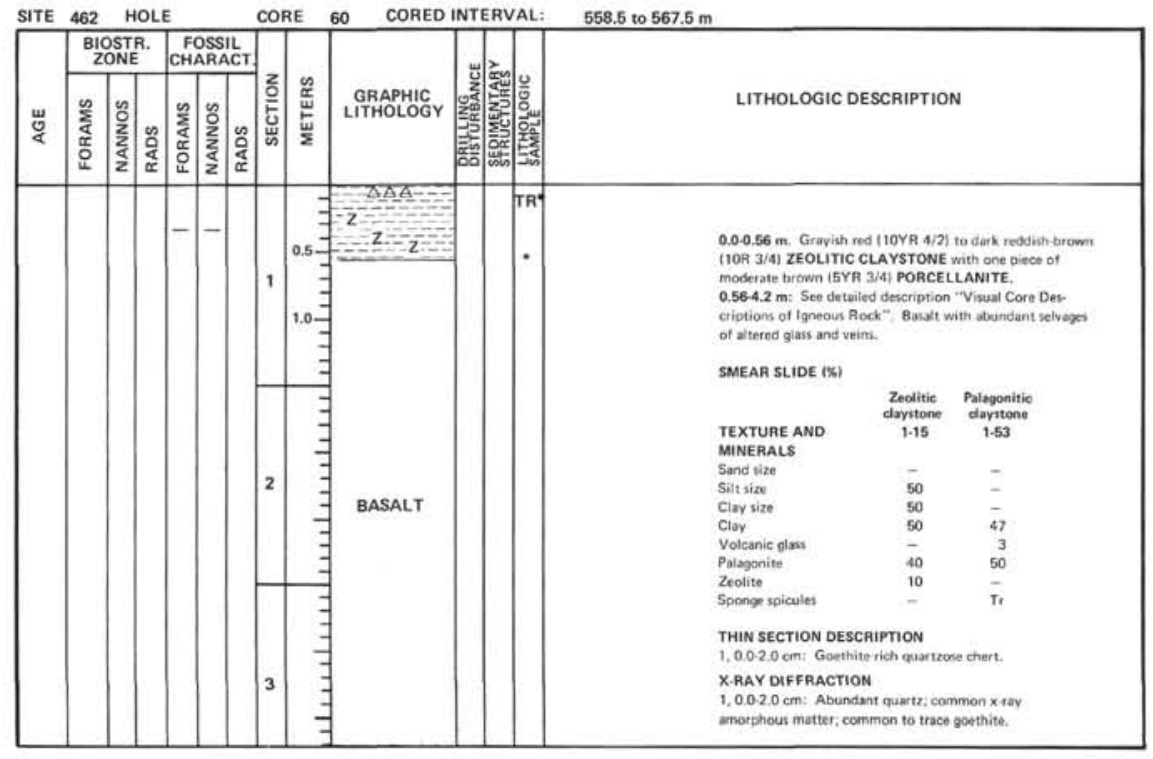



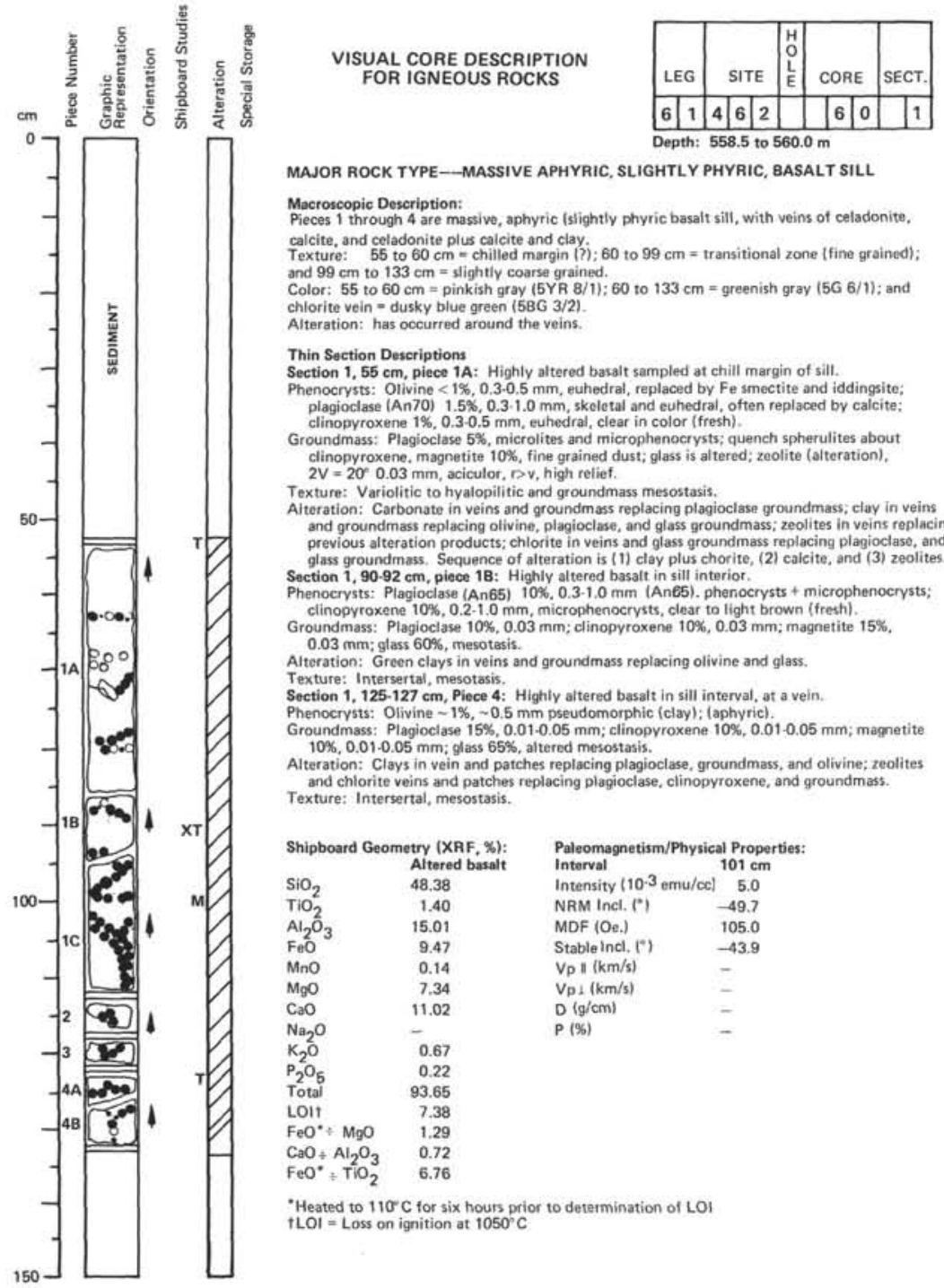

MAOR ROCK TYPE - MASSIVE APHYRIC SUIGHTLY PHYPIC, BASALT SILL

Macroscopic Deseription:
Pieces 1 through 4 are

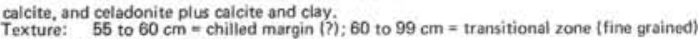

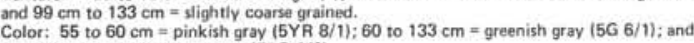
chlorite vein - dusky blue green $(586) 3 / 2)$.

Shin Section Descriptions

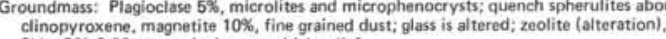
teration: Carbonsto in veins and groundnastass macing plagioclase groundmass; clay in veins ass replacing olivine, plagioclase, and glass ground

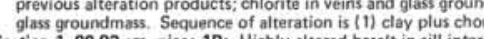
Phenocrysts $92 \mathrm{~cm}$, piece 18 : Highly altered bass clinopyroxene $10 \%, 0.2 \cdot 1.0 \mathrm{~mm}$, microphenocrysts, clear to light brown (rieth. $0.03 \mathrm{~mm}$; glass $60 \%$, mesotesis.
Alteration: Green clays in veins and groundmass replacing olivine and glass. Alteration: Green clays in veins Section 1, 125.127 cm, Piece 4: Highily aitered basalt th

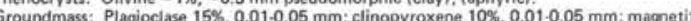
$10 \%, 0.01 .0 .05 \mathrm{~mm}$; glass 655 , altered mesostasis. This Texture: Intersertal, mesostasis.

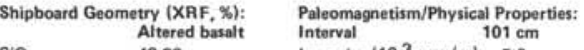

$\mathrm{SiO}_{2} \quad 48.38 \quad$ Intensity (10.-3 emu/ccl 5.0

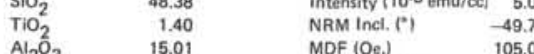

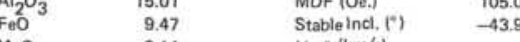

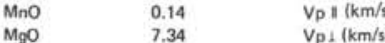

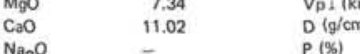

$\mathrm{Na}_{2} \mathrm{O} \quad-.67$

$\begin{array}{lr} & 0.22 \\ \mathrm{P}_{2} \mathrm{O}_{5} & \\ \text { Total } & 93.65\end{array}$

\begin{tabular}{ll} 
& \\
$\mathrm{FeO}^{\circ} \div \mathrm{MgO}$ & 7.38 \\
\hline
\end{tabular}

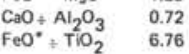

Heated to $110 \mathrm{C}$ for six hours prior to determination of LO

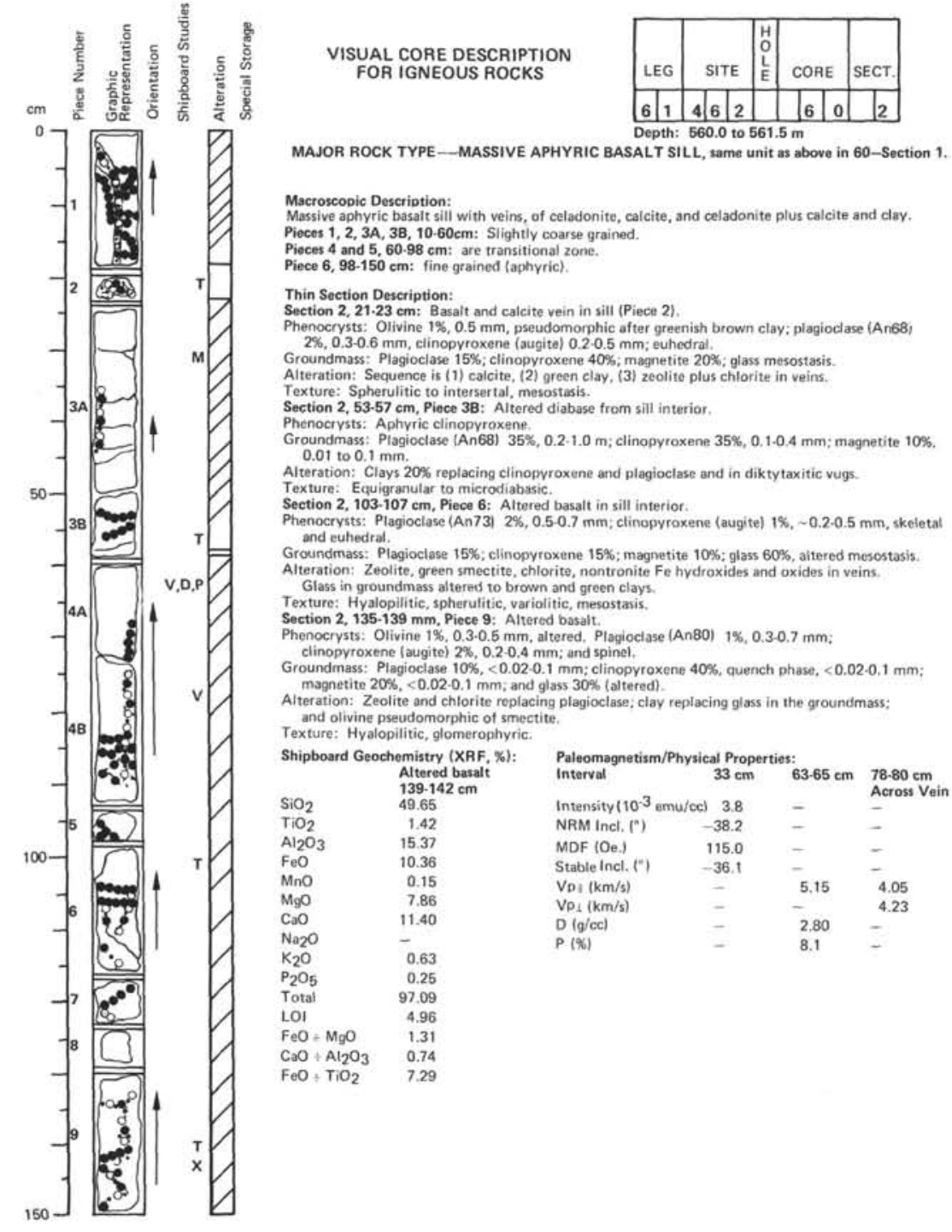




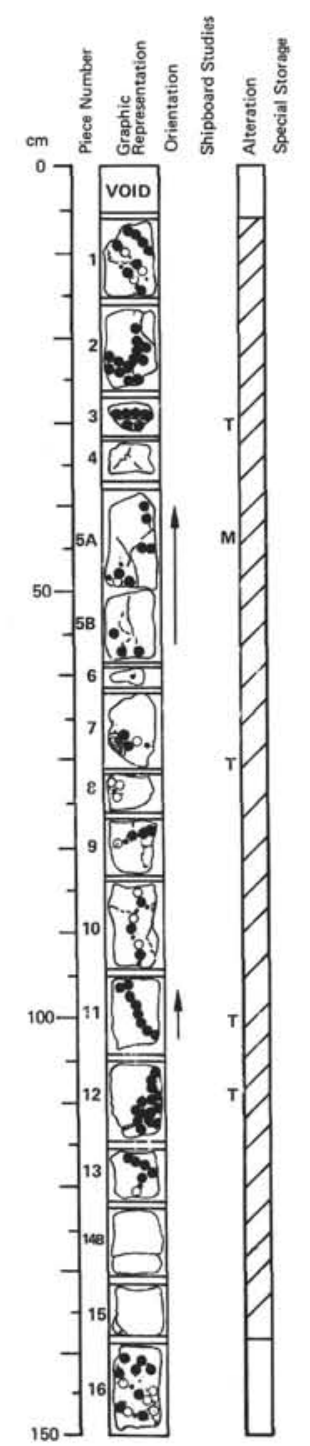

\section{VISUAL CORE DESCRIPTION
FOR IGNEOUS ROCKS

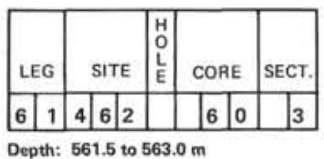
MAJOR ROCK TYPE--MASSIVE APHYRIC BASALT SILL

Macroscopic Description:

Massive aphyric basalit sill with veins, of celadonite, calcite, and celadonite plus calcite and clay. Same unit as above in Core 60, Section 1. Pieces $1.15(140 \mathrm{~cm})$ are fine grained. Thin Section Descriptions:

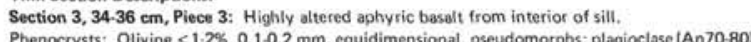
$1.15 \%, 02.0 .6 \mathrm{~mm}$ elongated tabuter clinopyroxono (avitel $1.22 \%, 0.20 .4 \mathrm{~mm}$, euhedral to

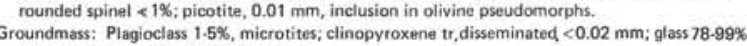

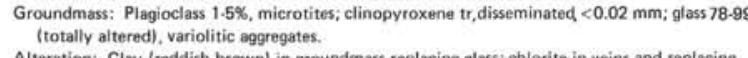

Selacing glass; chlorite in veins and replacin phenocrysts. Chlorite in veins replacing all minerats. Texture: Variolitic.

Section 3, 66-69 cm, Piece 7: Altered aphyric basalt sill.

(An80-72) 8\%, 0.2.2.0 mm

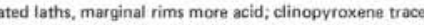

disseminate Plagioclase (An75) 10\%, <0.2 mm, microlites; clinopyroxene 30\%(3), <0.05 mm, glass $59 \%$, intersertal, partily altered.

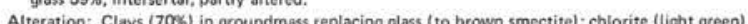
in veins replacing all minerals; olivine in phenocerysts altered to smectite.

Section 3,97.102 cm, Piece 11: Altered aphyric basalt sill, $0.04-1.0 \mathrm{~mm}$; elongated laths, glomeroporphyric agrag egates; clinopyroxene $5 \%, 0.2-0.4 \mathrm{~mm}$, (a) Groundmass: Plagioclase $10 \%,<0.2 .06 \mathrm{~mm}$, small microtites, zonation distinct; clinopyroxene $2 \%$, $<0.04 \mathrm{~mm}$, rounded grains; disseminated grains and stelleo aggregate: magnetite $20 \%,<0.004 \mathrm{~mm}$, dust-like; ;ilmenite(?): glass $68 \%$ altered.
Atteration: Reddish-brown Fe-rich saponite(?) and smectite (interstitiall) replacing olivine, Alteration: Reddish-brown Fe-rich sapo

Texture: Hyatopilitic movariolitic.

Section 3, 108-113 cm, Piece 12: Altered aphyric basalt sil.

(An42-65) 2\%, $0.5-0.2 \mathrm{~mm}$, elongated aths, often glom

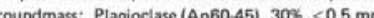

more acid margins; clinopyroxene ilimenite(?): glass 35\%, interstitial, altered. (a) Texture: Intersertal.

Paloomagnetism/Physical Properties :

Intensity $\left(10^{-3} \mathrm{emu} / \mathrm{cc}\right) \quad 41.2$

DF (Oe.)

140.0
-42.9

(1) $(\mathrm{km} / \mathrm{s})$

$\mathrm{D}(\mathrm{g} / \mathrm{cc})$
$\mathrm{P}(\%)$

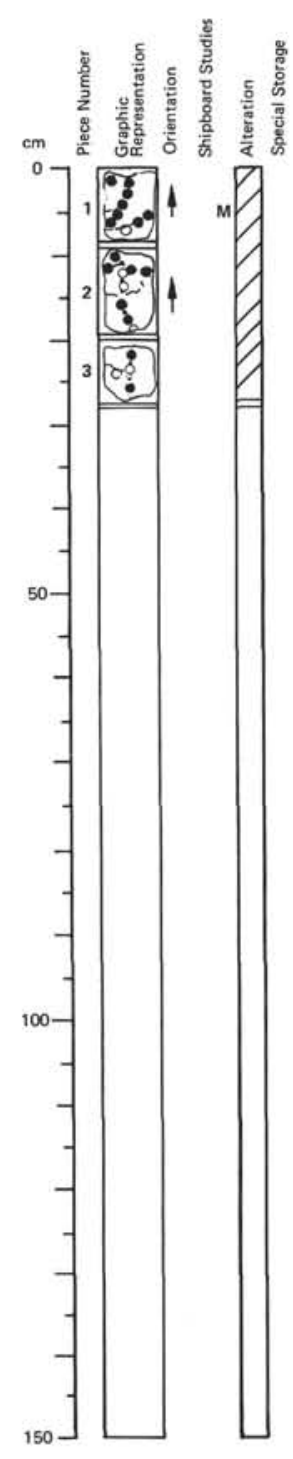

\section{VISUAL CORE DESCRIPTION OUS ROCKS}

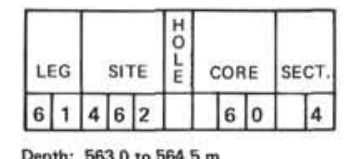

MAJOR ROCK TYPE--MASSIVE APHYRIC BASALT SILL

Macroscopic Description

Same unit as above in Core 60 , Section 1 . Pieces 1.3 are aphyric basalt

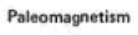

Interval $5 \mathrm{~cm}$

Intensity $\left(10^{-3}\right.$ emu/cel 7.9

$\begin{array}{ll}\text { MDF (Oe.) } & -34.4 \\ \text { Stable Incl. (") } & -34.0\end{array}$ 

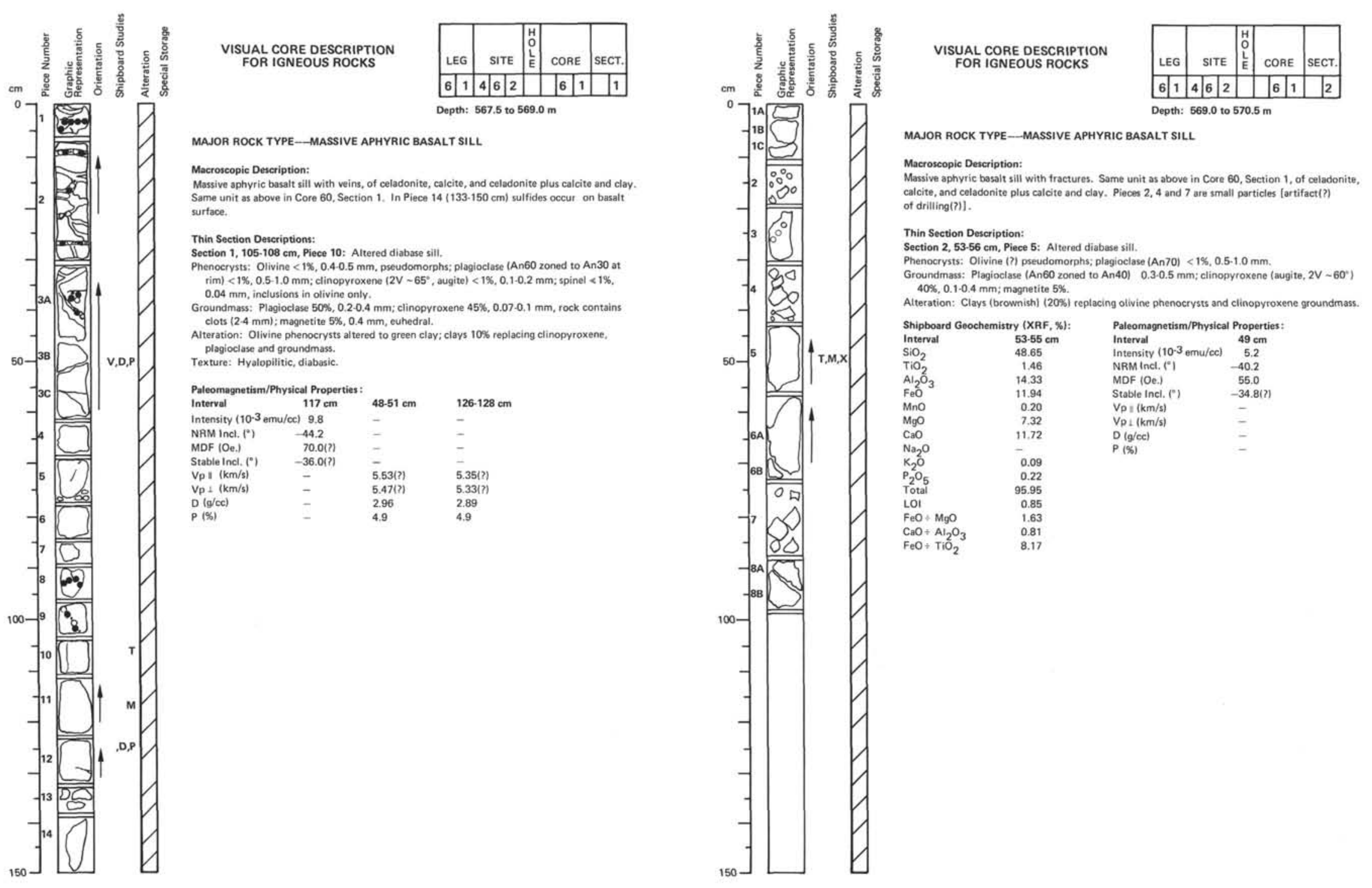

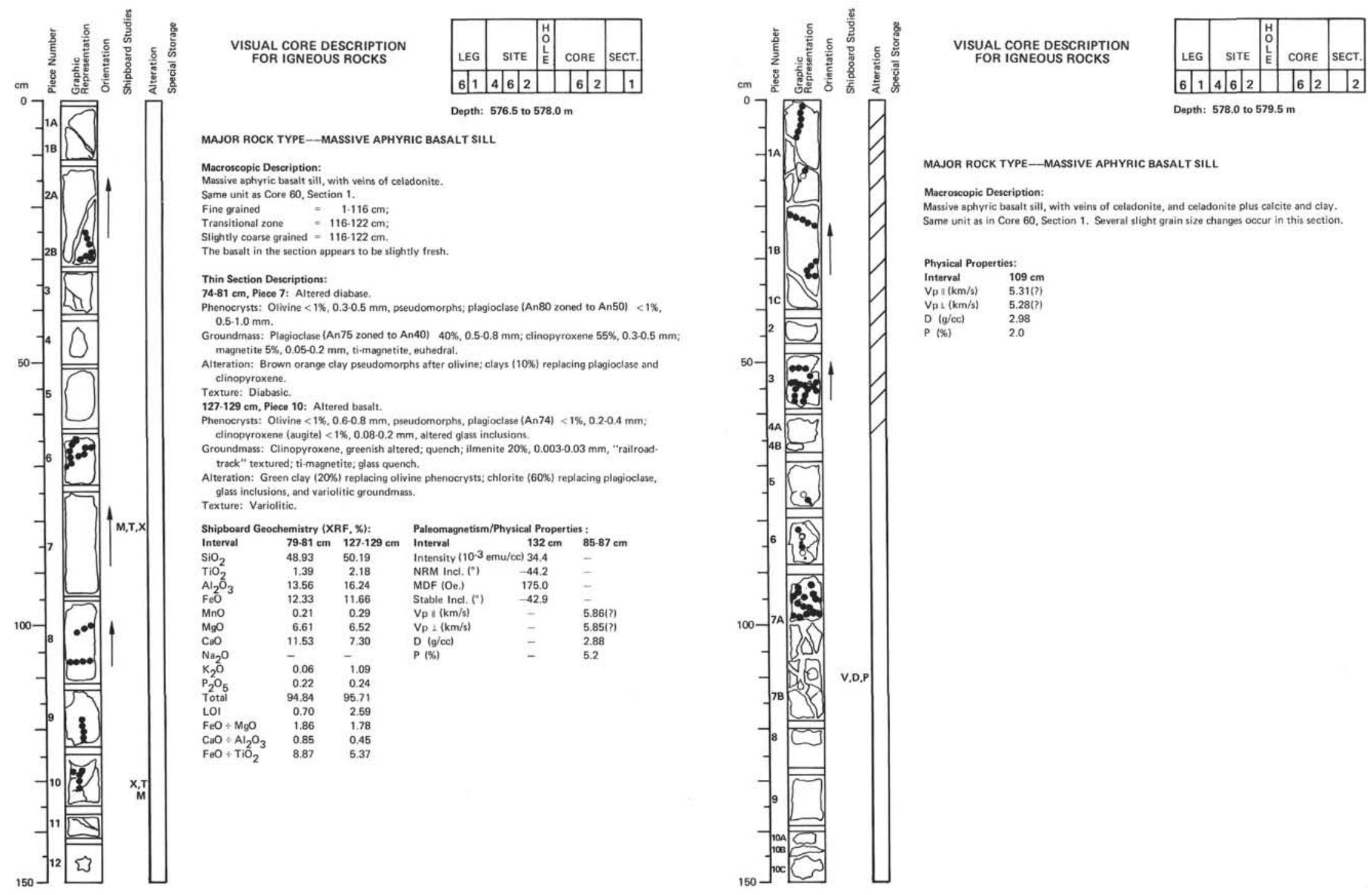


\begin{tabular}{|c|c|c|c|c|c|c|c|c|c|}
\hline \multirow[b]{2}{*}{ 岁 } & \multicolumn{4}{|c|}{\begin{tabular}{c|c|} 
BIOSTR, & FOSSIL \\
ZONE & CHARACT.
\end{tabular}} & \multirow{2}{*}{\multicolumn{2}{|c|}{ 空 }} & \multirow[b]{2}{*}{$\begin{array}{l}\text { GRAPHIC } \\
\text { LITHOLOGY }\end{array}$} & \multirow{2}{*}{ 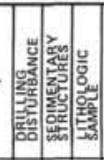 } & \multirow[b]{2}{*}{ LITHOLOGIC DESCRIPTION } \\
\hline & 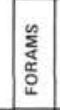 & 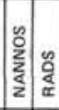 & 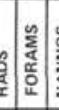 & 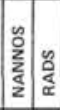 & & & & & \\
\hline & & & & & 1 & 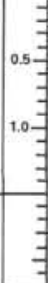 & $\begin{array}{l}\text { BASALT } \\
\text { VoID }\end{array}$ & $T$ & 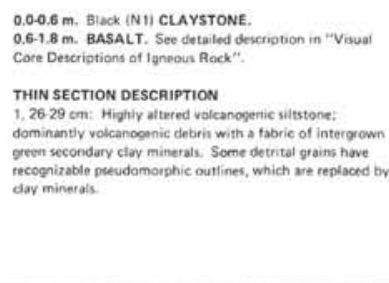 \\
\hline
\end{tabular}



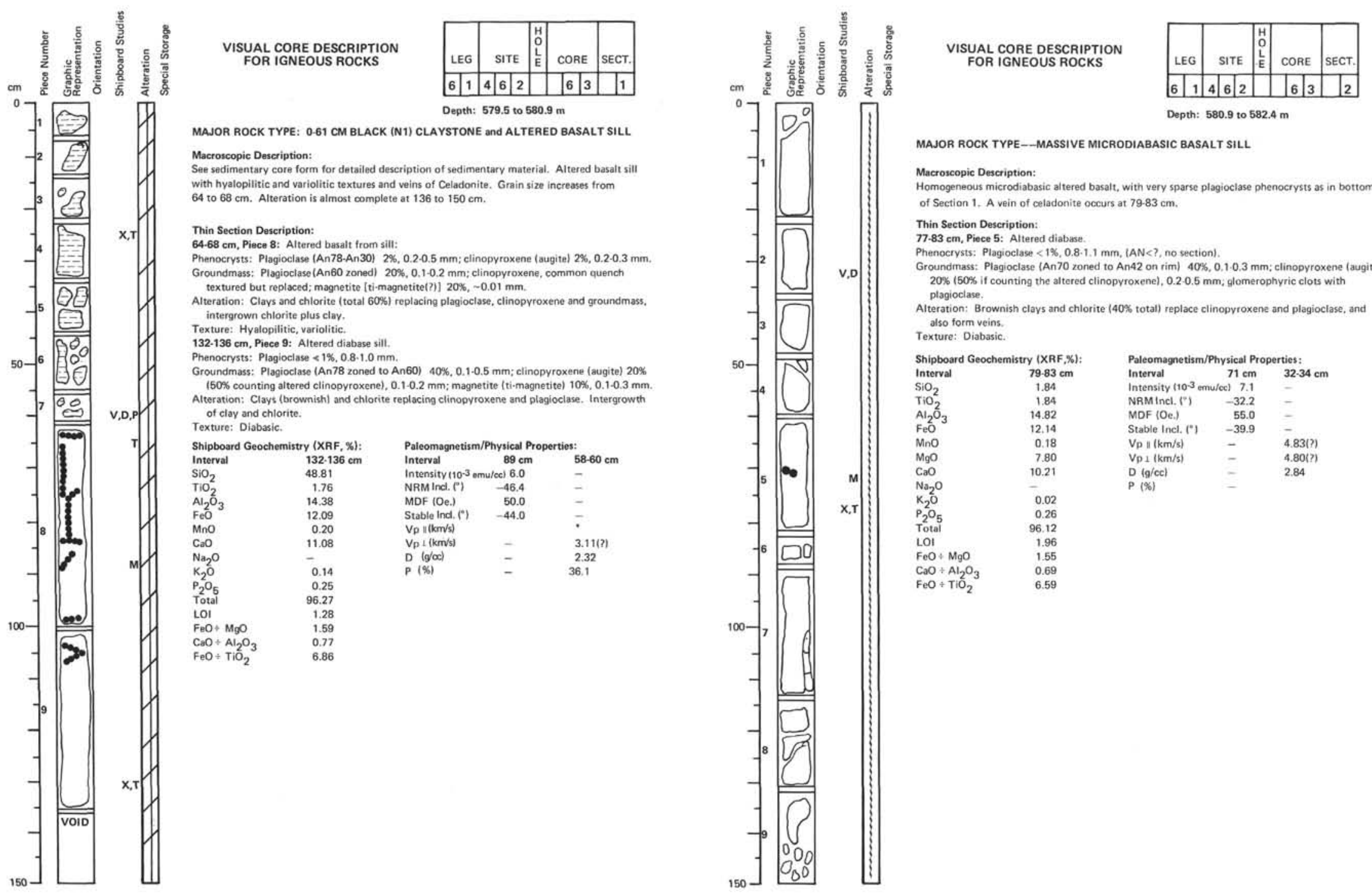

MAJOR ROCK TYPE--MASSIVE MICRODIABASIC BASALT SILL

Macroscopic Description:

mogene Us microdiabasic altered basalt, with very sparse plagioclase phenocrysts as in bottom of Section 1. A vein of celadonite occurs at $79-83 \mathrm{~cm}$.

Thin Section Description:

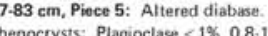

Groundrmass: Plagioclase (An70 zoned to An42 on $20 \%$ (50\% if counting the altered clinopyroxene), $0.20 .5 \mathrm{~mm}$; glomerophyric clots with

Alteration: Brownish clays and chlorite $140 \%$ total) replace clinopyroxene and plagioclase, and olso form veins.
Texture: Diabasic.

Shipboard Geochemistry (XRF, Y): Interval $79.83 \mathrm{~cm}$

$\mathrm{SiO}_{2}$

$\mathrm{TiO}_{2}$

$\mathrm{FeO}_{2} \mathrm{O}_{3}$

$\mathrm{MgO}$

$\mathrm{CaO}_{\mathrm{Na}_{2} \mathrm{O}}$

$\mathrm{Na}_{2} \mathrm{O}$
$\mathrm{K}_{2} \mathrm{O}$
$\mathrm{P}_{2} \mathrm{O}_{5}$
Total

Total
LOI

$\mathrm{FeO}+\mathrm{MgO}_{\mathrm{O}}$

$\mathrm{CaO}$
$\mathrm{FeO} \div \mathrm{Al}_{2} \mathrm{O}_{3}$

\begin{tabular}{|c|c|c|}
\hline & & \\
\hline Interval & $71 \mathrm{~cm}$ & $32 \cdot 34 \mathrm{~cm}$ \\
\hline Intensity $110^{-3} \mathrm{er}$ & (ce) 7.1 & \\
\hline NRM Incl. (") & -32.2 & - \\
\hline MDF (Oe.) & 55.0 & - \\
\hline Stable Incl. $\left({ }^{\circ}\right)$ & -39.9 & \\
\hline$V_{p} \|(\mathrm{km} / \mathrm{s})$ & - & $4.83(?)$ \\
\hline$v_{p} \perp(\mathrm{km} / \mathrm{s})$ & - & $4.80(?)$ \\
\hline D $(g / c c)$ & - & 2.84 \\
\hline$P(\%)$ & - & \\
\hline
\end{tabular}



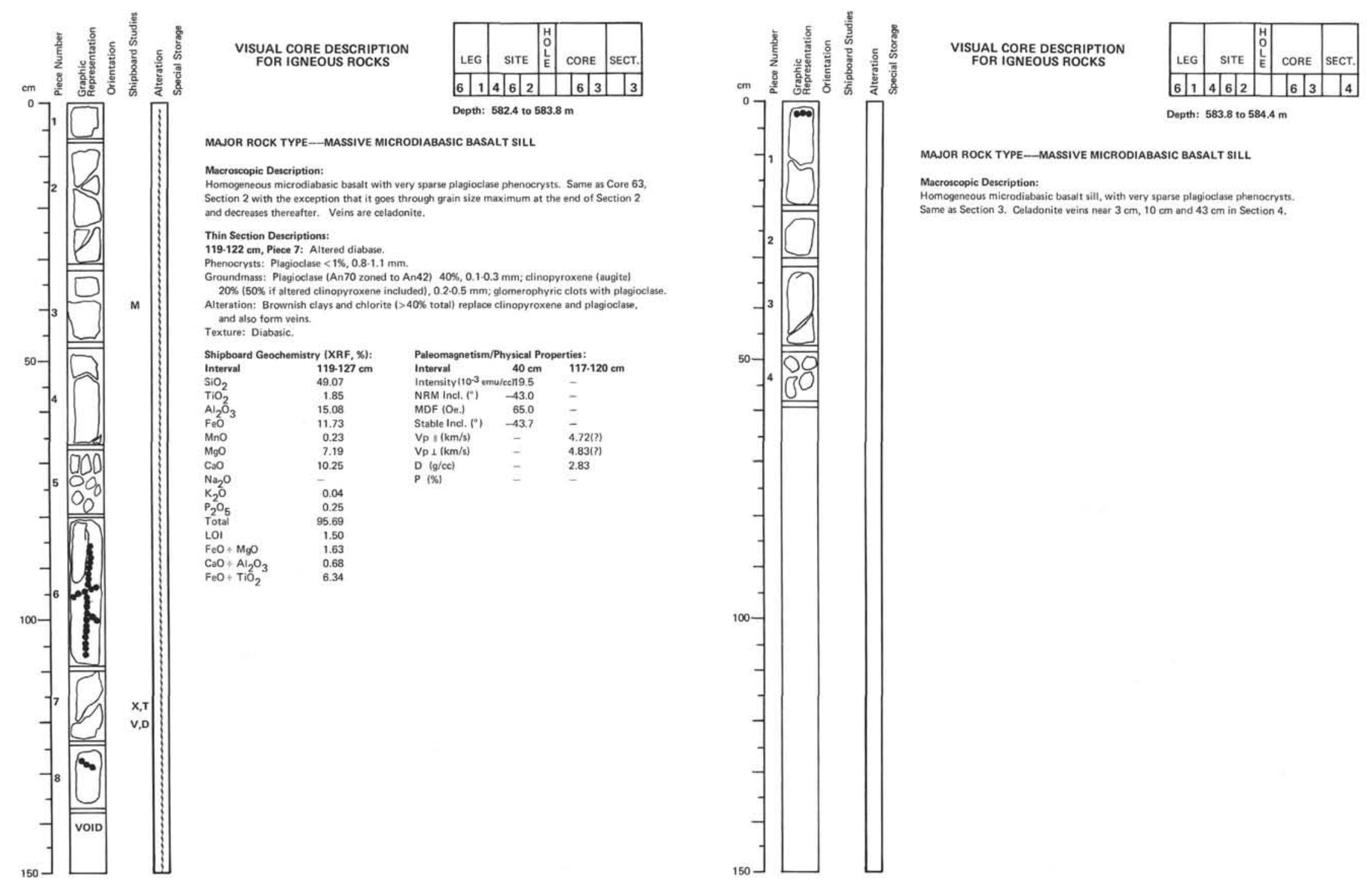


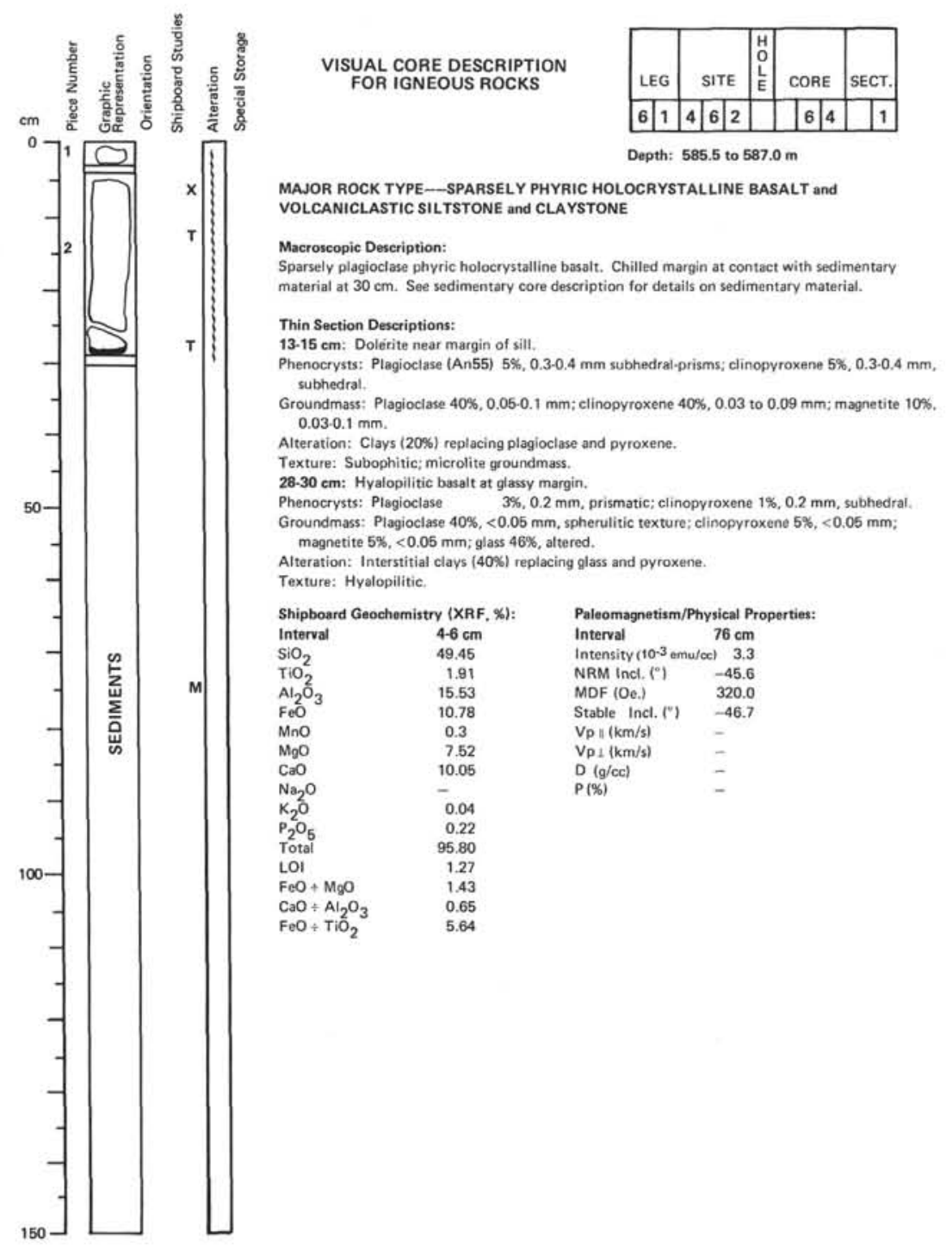




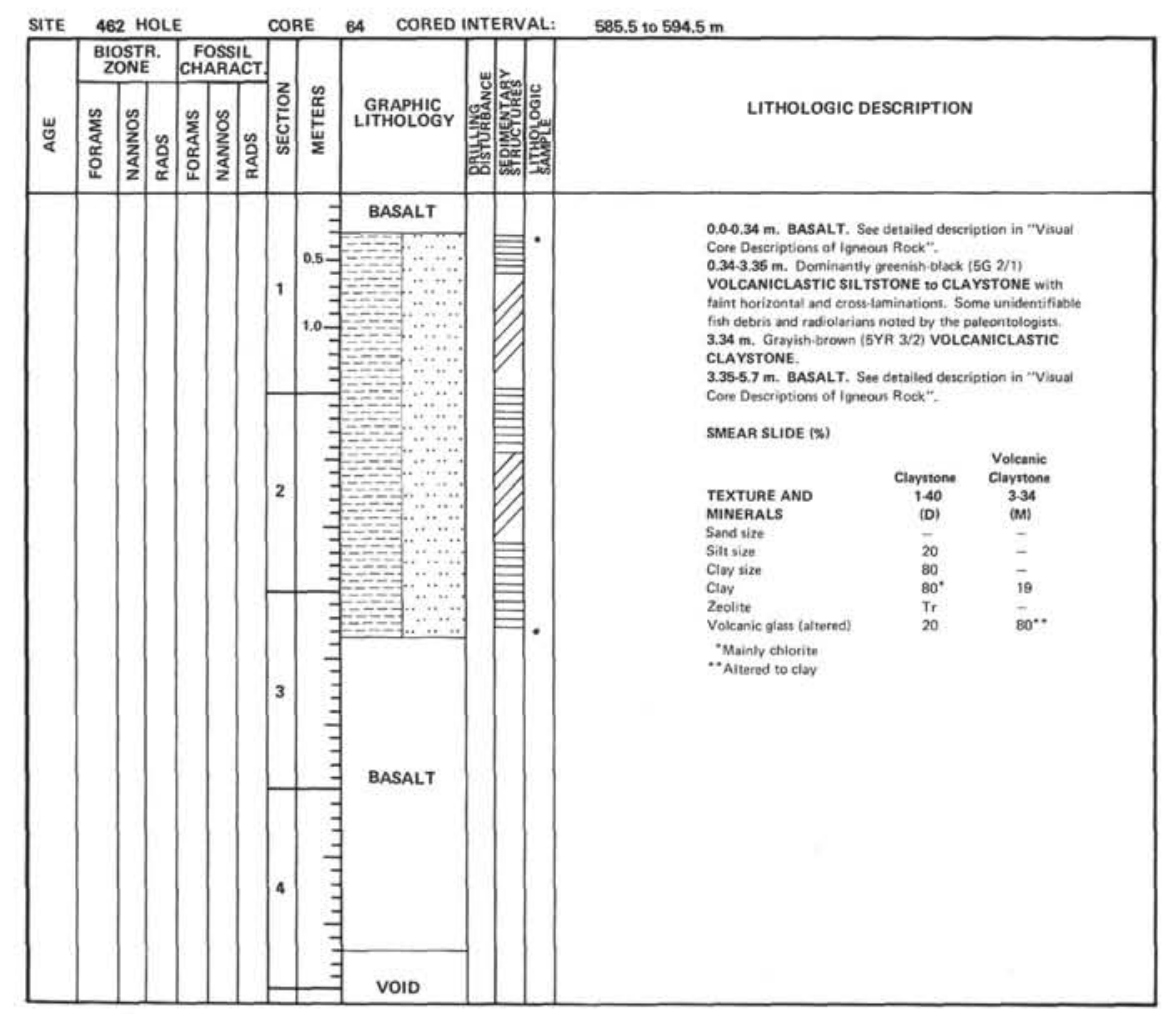



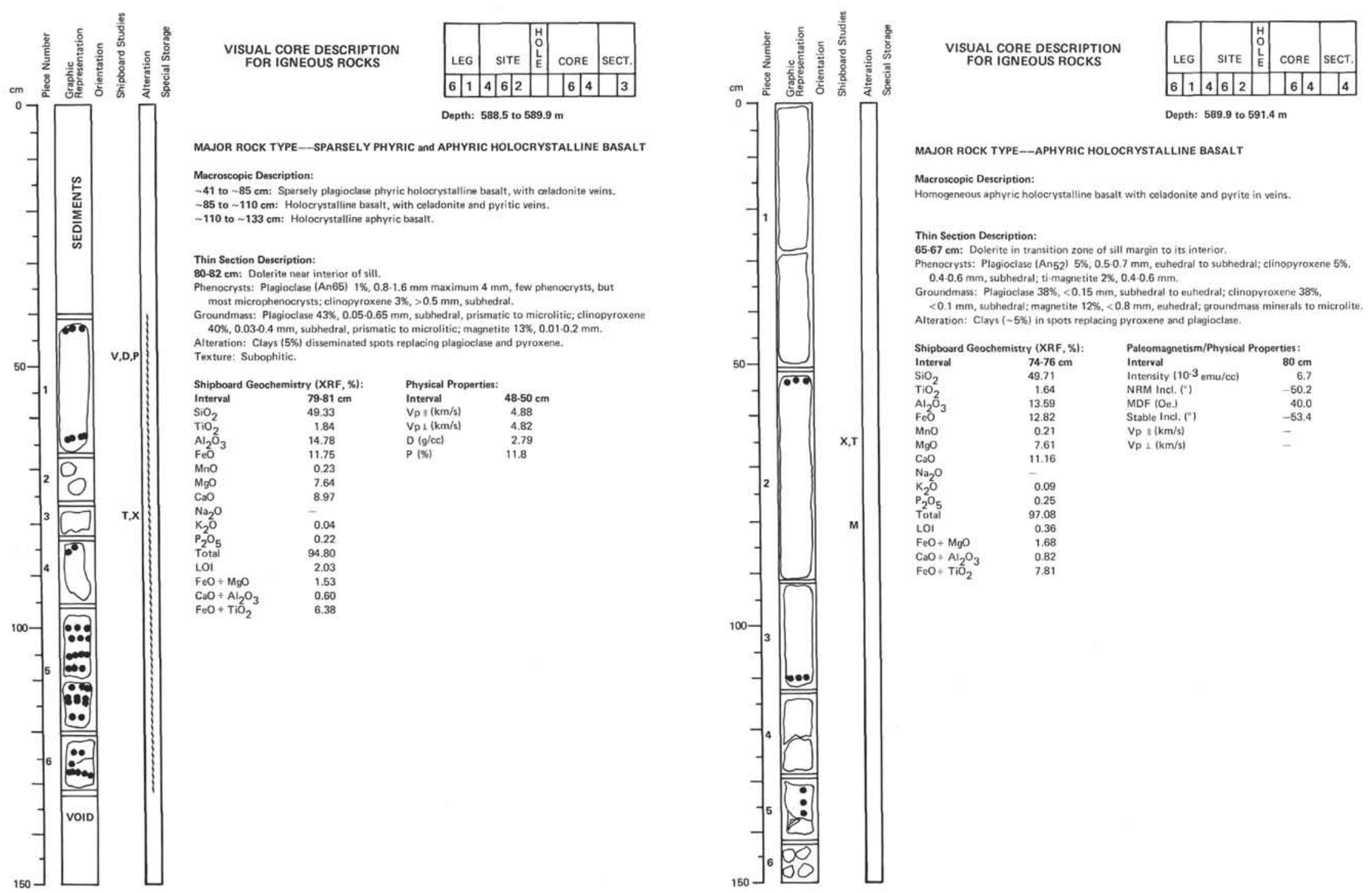


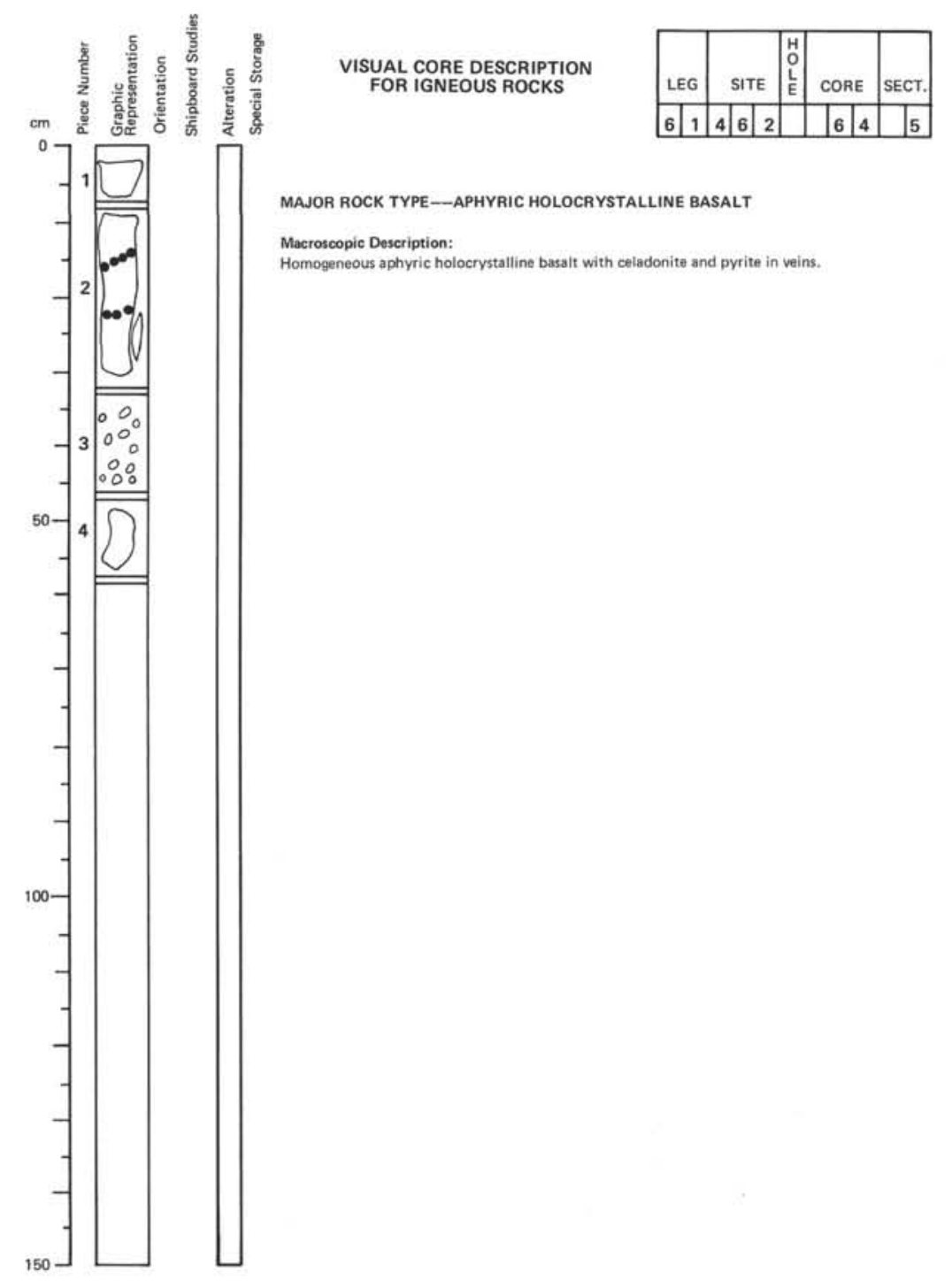




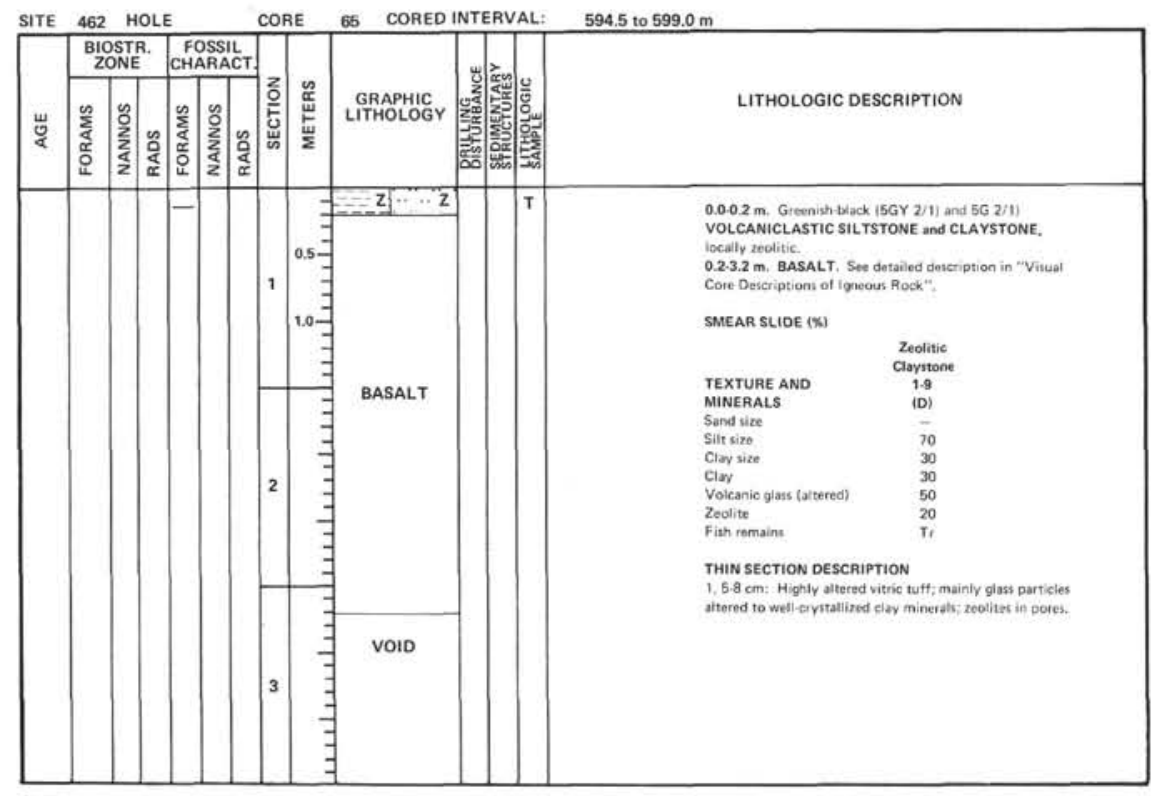



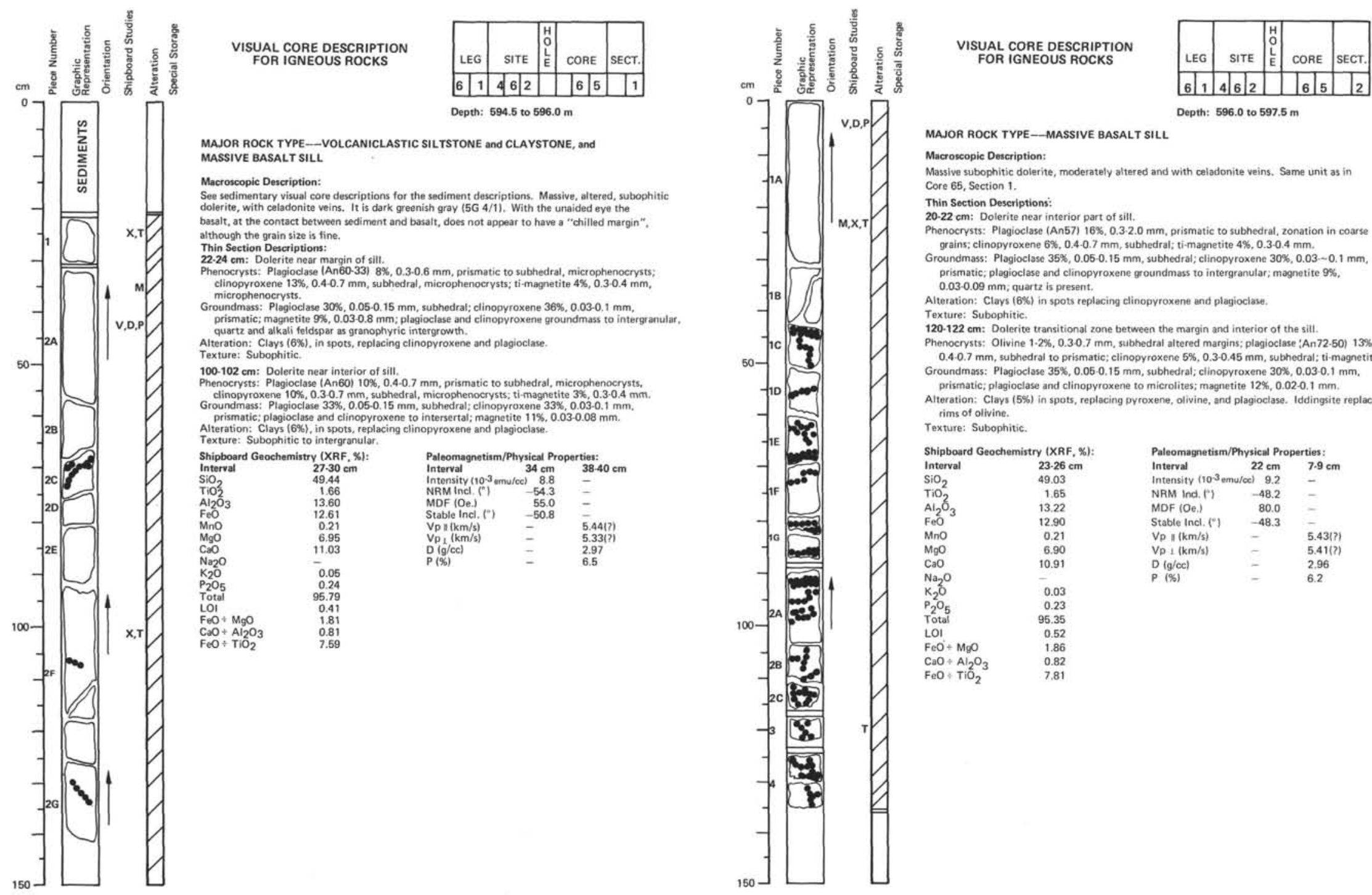

MAJOR ROCK TYPE--MASSIVE BASALT SILL

Macroscopic Description:

Massive subophitic dolerite, moderately altered and with celadonite veins. Same unit as in The section 1 .

The Section Descriptions:

Phenocrysts: Plagioclase (An57) 16\%, 0.3.2.0 mm, prismatic to subhedral, zonation in coarse grains; clinopyroxene $6 \%, 0.4-0.7 \mathrm{~mm}$, subhedral; ti-magnetite $4 \%, 0.3 .0 .4 \mathrm{~mm}$. Groundmass: Plagioclase $35 \%, 0.05-0.15 \mathrm{~mm}$, subhedral; clinopyroxene $30 \%, 0.03 \cdots 0.1 \mathrm{~mm}$ 0.03-0.09 $\mathrm{mm}$; quartz is present.

Alteration: Clays (6\%) in spots replacing clinopyroxene and plagiociase

Texture: Subophitic.
120.122 cm: Dolerite transitional zone between the margin and interior of the silt. 0407 me Groundmass: Plagioclase 35\%, $0.05-0.15 \mathrm{~mm}$, subhedral; clinopyroxene $30 \%, 0.03 .0 .1 \mathrm{~mm}$. prismatic; plagioclase and clinopyroxene to microlites; magnetite $12 \%, 0.02-0.1 \mathrm{~mm}$. Alteration: Clays (5\%) in spots, replacing pyroxene, olivine, and plagioclase. Iddingsite replacing Texture: Subophitc.

Shipboard Geochemistry (XRF, \%:

Interval $\quad 23.26 \mathrm{~cm}$

$\begin{array}{ll}\mathrm{SiO}_{2} & 49.03 \\ \mathrm{TiO}_{2} & 1.65 \\ \mathrm{AH}_{2} & 13.22\end{array}$

$\begin{array}{ll}\mathrm{Al}_{2} \mathrm{O}_{3} & 13.22 \\ \mathrm{FeO} & 12.90\end{array}$

$\begin{array}{lr}\mathrm{MnO} & 0.21 \\ \mathrm{MgO} & 6.90\end{array}$

$\begin{array}{rr}\mathrm{M}_{9} \mathrm{O} & 6.90 \\ \mathrm{CaO} & 10.91\end{array}$

$\mathrm{Na}_{\mathrm{K}_{2} \mathrm{O}} \mathrm{O} \quad-0.03$

$\mathrm{P}_{2} \mathrm{O}_{5}$
$\mathrm{P}_{2}$

LOI

$\mathrm{FeO}+\mathrm{MgO}$
$\mathrm{CaO}+\mathrm{Al}_{2} \mathrm{O}_{3}$
$\mathrm{FeO}+\mathrm{TiO}_{2}$

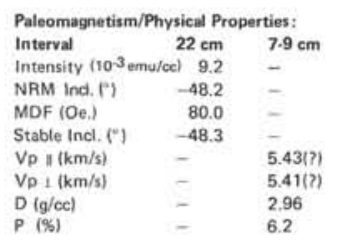

$150 \_\square$ 


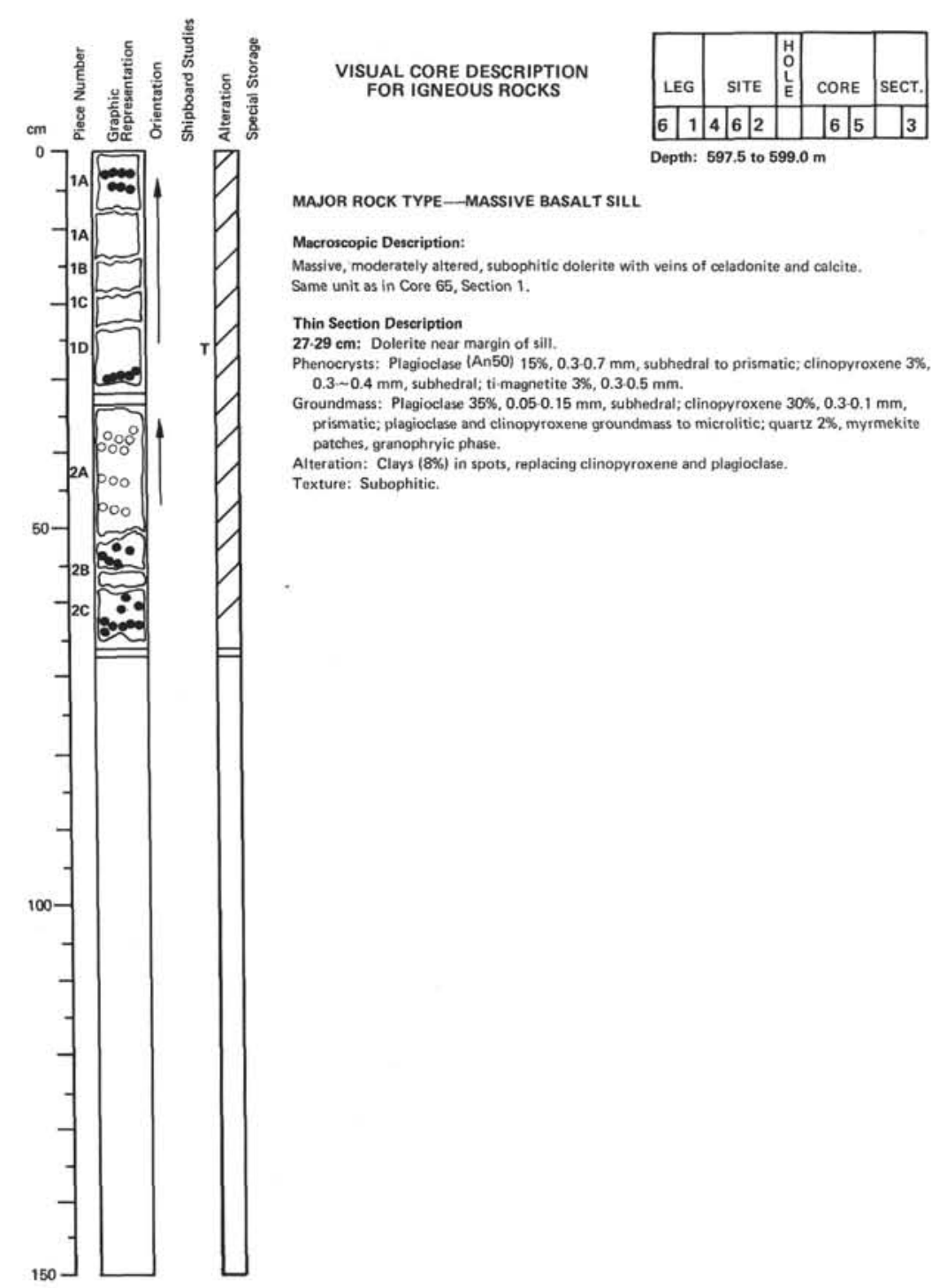




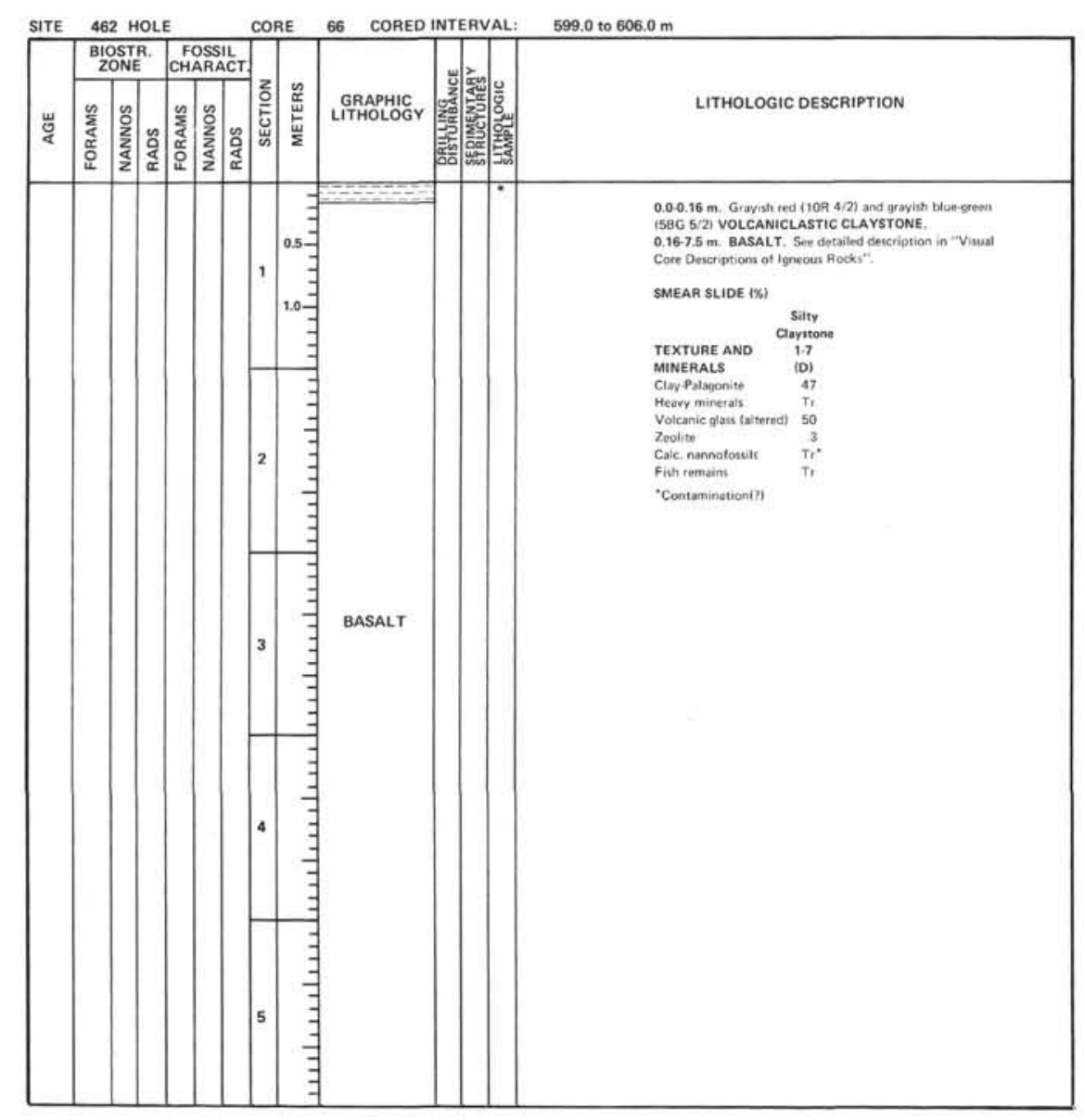



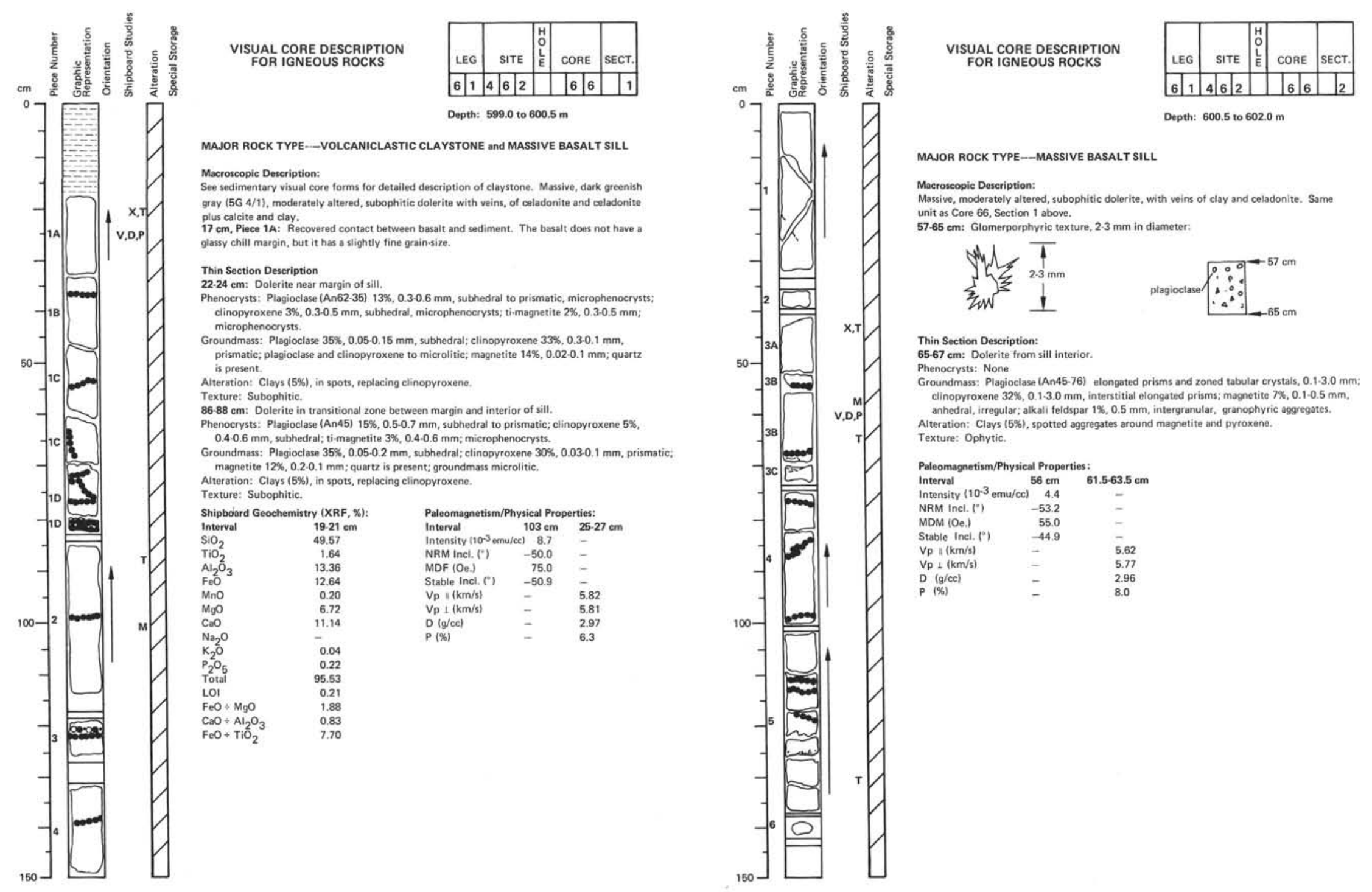

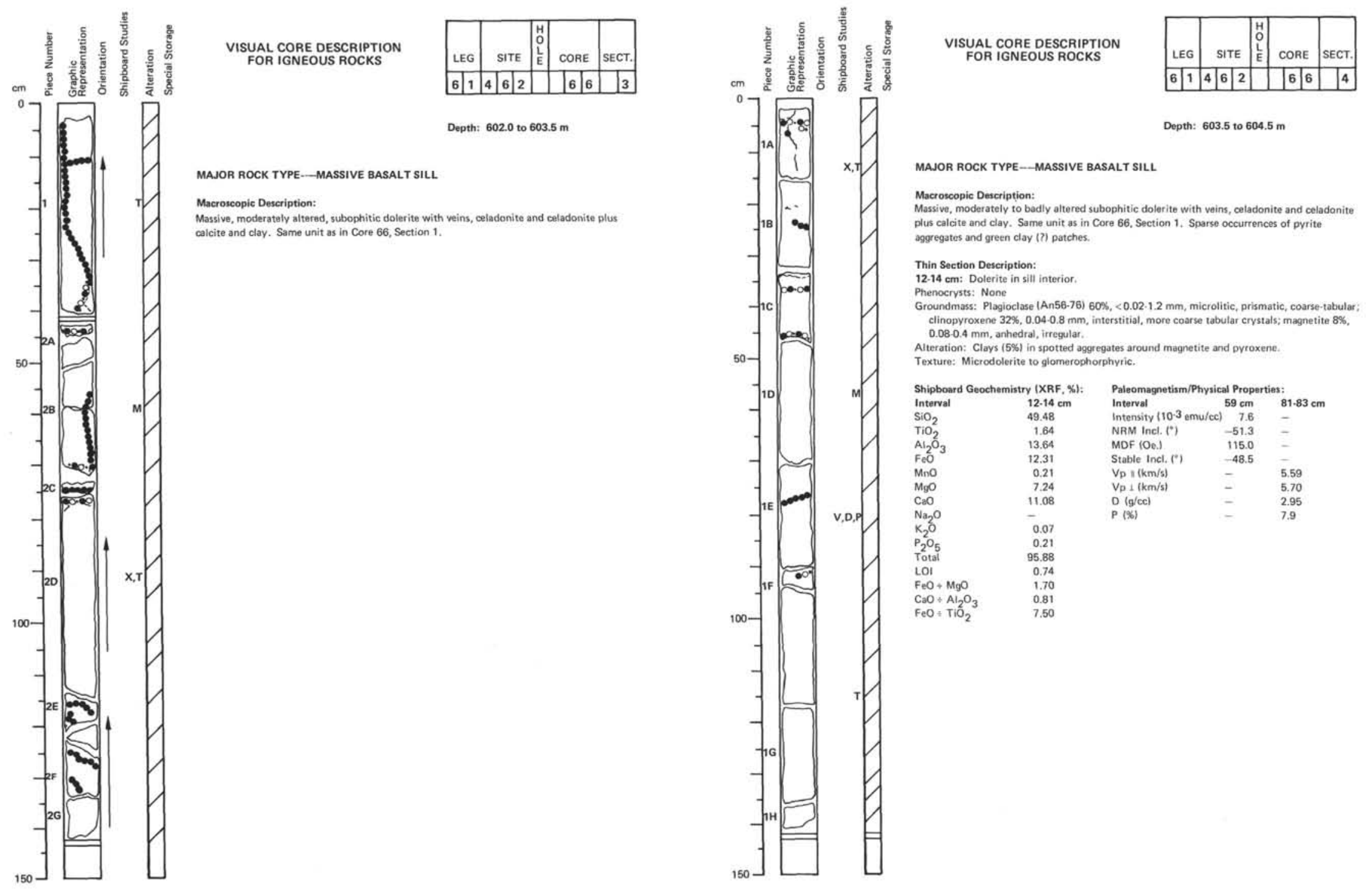

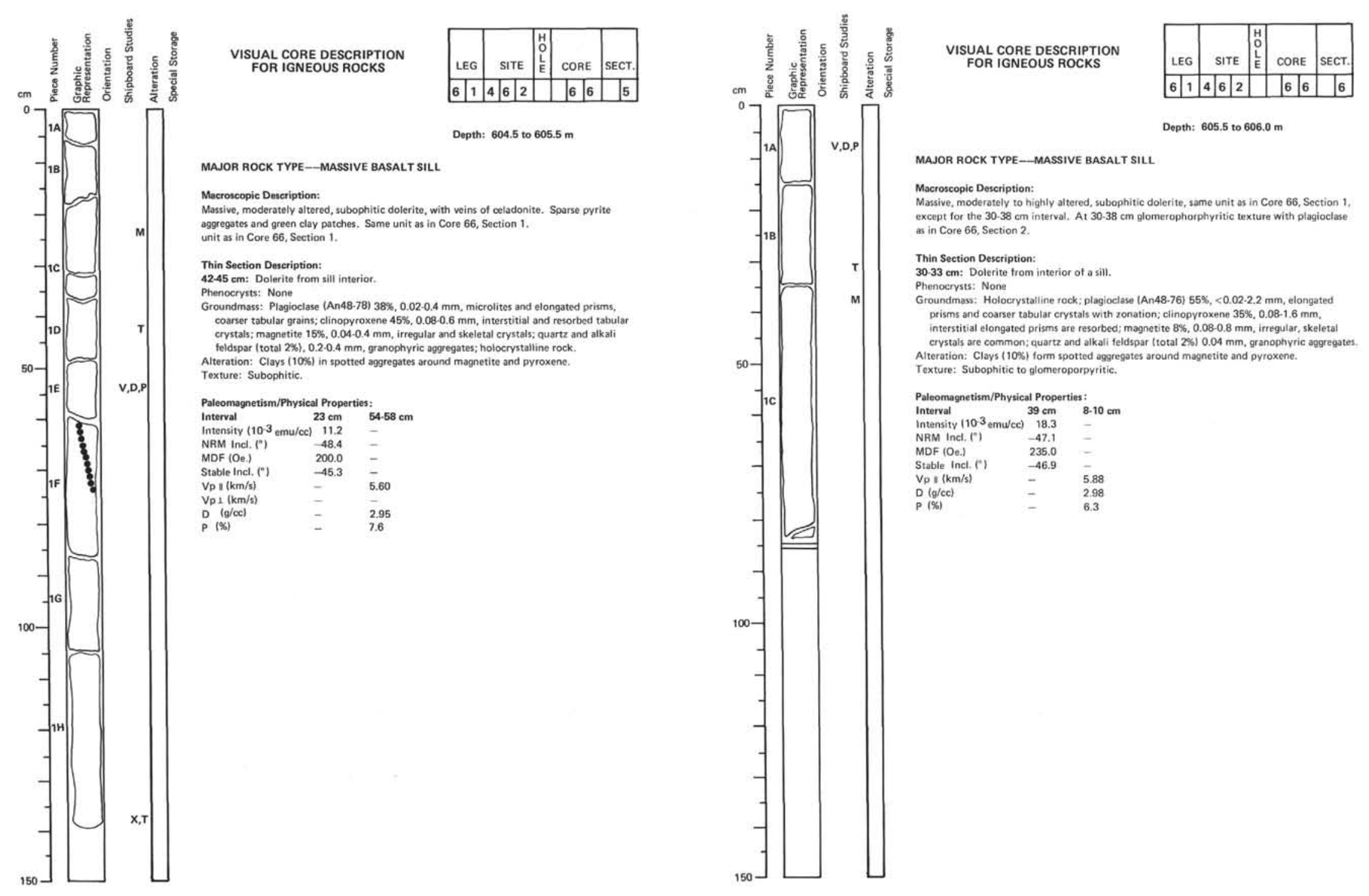

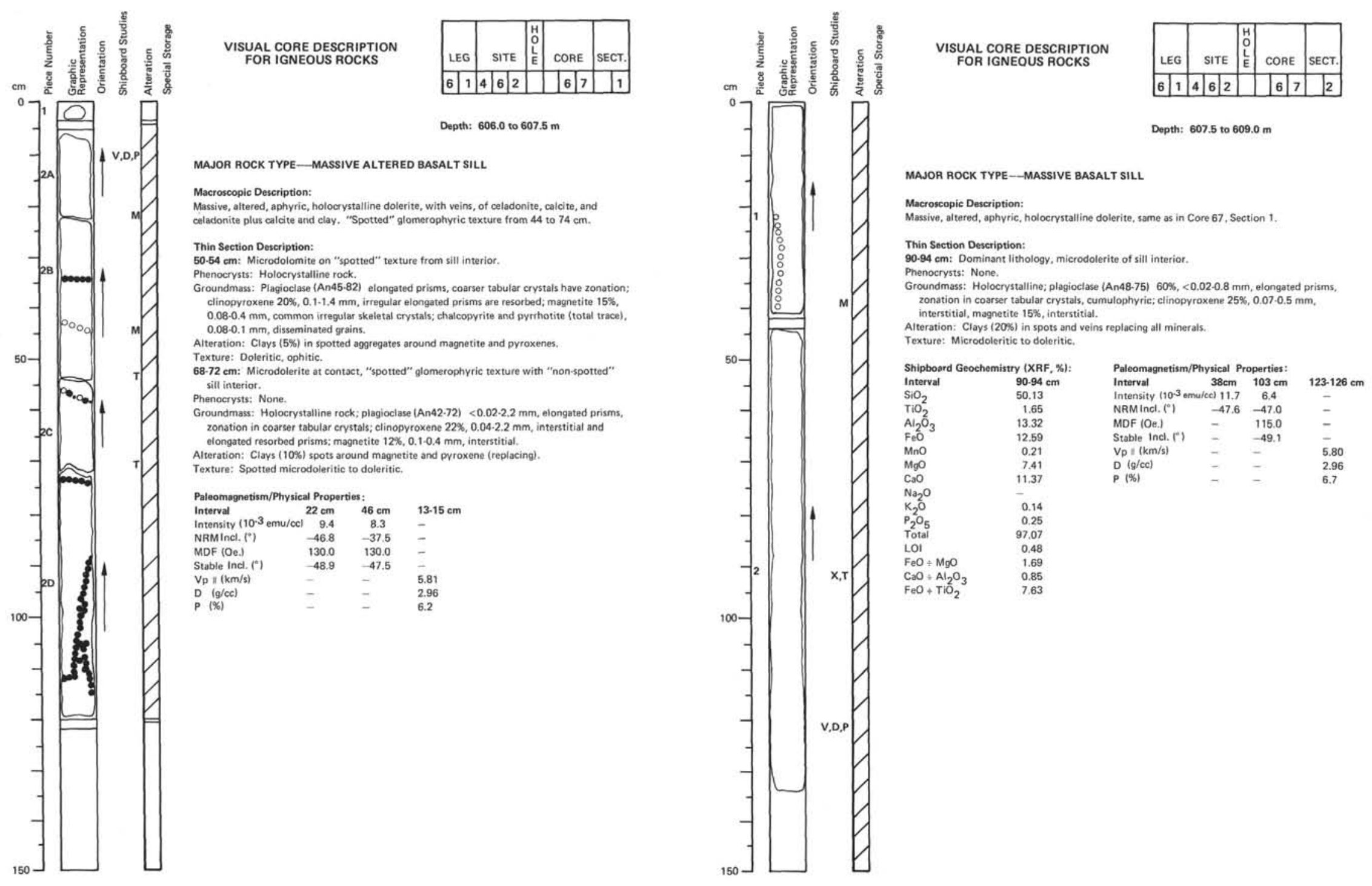


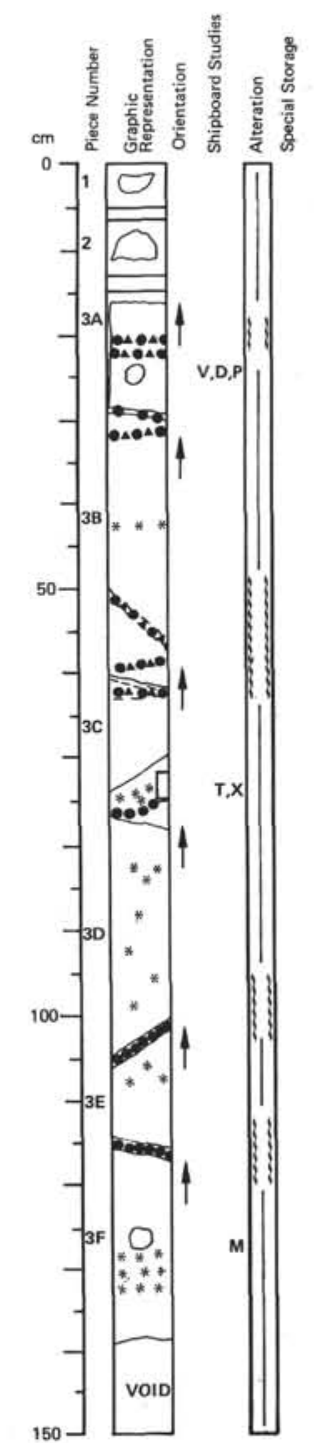

\section{VISUAL CORE DESCRIPTION
FOR IGNEOUS ROCKS

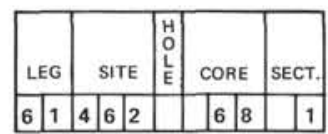

Depth: 609.0 to $610.4 \mathrm{~m}$

\section{MAJOR ROCK TYPE-MASSIVE BASALT SILL}

Macroscopic Description:
Massive, altered aphyric dolerite, with veins, It is identical to the previous section (Core 67, Section 2). Alteration is greater near celadonite veins. Within the celadonite veins the stellated peels of pyrite frequently occurs.

$$
\begin{aligned}
& * * * \quad \text { - intervals enriched in clinopyroxene and plagioclase glomerporphyritic } \\
& \text { aggrogates. }
\end{aligned}
$$

\section{Thin section}

Mictostion:

Phenocrysts: None

roundmass: Holocrystalline rock: ollvine $18,02.0 .4 \mathrm{~mm}$, altered (to brown smectite), equidimensional; plagioclase (An $40-100) 40 \%, 0.04 \times 0.1 \mathrm{~mm}$ to $0.1 \times 1.2 \mathrm{~mm}$, elongated
prisms, zonation of the coarser tabular laths and near quartz; clinopyroxene $45 \%, 0.2-2.0 \mathrm{~mm}$ intersstitial and elongated resorbed prisms; magnetite $12 \%, 0.06-0.6 \mathrm{~mm}$, interstitial; pyrrhotic ergrowths with magnetite; quartz $1 \%, 0.08-1.2 \mathrm{~mm}$, interstitial

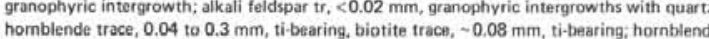
and biotite reaction rims with magnetite.

Shipboard Geochemistry (XRF, Y):
Interval
$73.75 \mathrm{~cm}$

Interval $\quad 73.75 \mathrm{~cm}$

$\mathrm{SiO}_{2}$

${ }_{\mathrm{Al}}^{\mathrm{TiO}_{2} \mathrm{O}_{3}}$

$\mathrm{MnO}$

$\mathrm{MgO}$

$\mathrm{CaO}$
$\mathrm{Na}_{2} \mathrm{O}$
$\mathrm{K}_{2} \mathrm{O}$

$\mathrm{K}_{2} \mathrm{O}$
$\mathrm{P}_{2} \mathrm{O}_{5}$
Total

$\mathrm{FeO} \div \mathrm{MgO}$

$\mathrm{FeO} \div \mathrm{MgO}^{-2}+\mathrm{Al}_{2} \mathrm{O}_{3}$
$\mathrm{FeO}+\mathrm{TiO}_{2}$

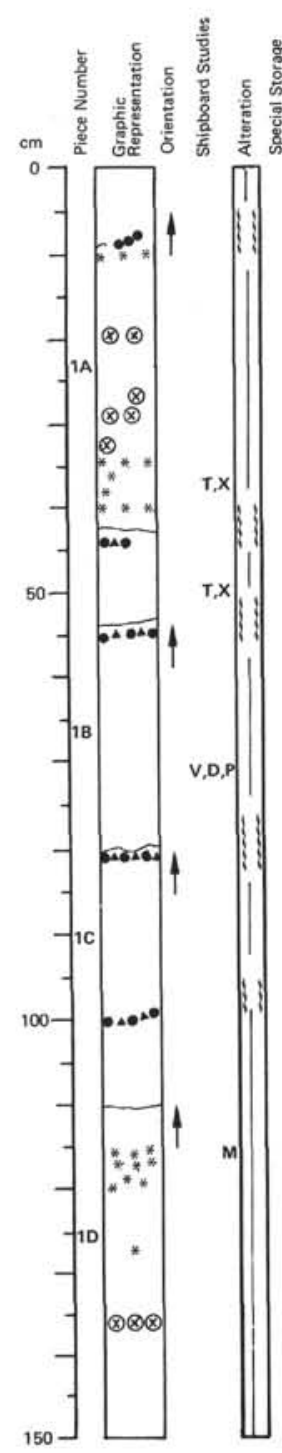

VISUAL CORE DESCRIPTION FOR IGNEOUS ROCKS

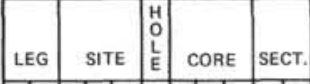

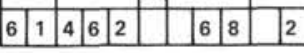
Depth: 610.4 to $511.9 \mathrm{~m}$

\section{MAJOR ROCK TYPE-MASSIVE BASALT SILL}

\section{Macroscopic Description:}

hyritic clinopyroxene-plagicclase dolerites with celadonit 68. Section 1. See Core 68. Section 1 for codes to Thin Section Description $49.51 \mathrm{~cm}$ : Microdolerite from sill interio Phenocrysts: None

reck; olivine $2 x, 0.2-0.5$ nun, attered, equidimensional; plagioclase

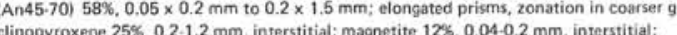
pyrrohotite 2\%, $0.04 \cdot 0.1$ intergrowths with magnetite: brown homblende $1 \%, 0.05-0.4 \mathrm{~mm}$, ti.bearing, rims around magne tite; partly changed to green hormblende; biotite trace, 0.02 Aleration: $c$ . Clays (3\%) replacing olivine and partly pyroxene. Texture: Doleritic lophitic Pr.39 cm: Microdolerite from sill interior.

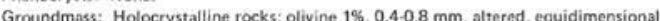

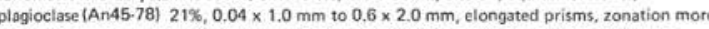
distinct in coarse grains: clinopyroxene $60 \%, 0.42 .2 \mathrm{~mm}$, interstitial, poikilophitic laths:

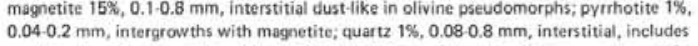
needles of apatite; brown hornblende $1 \%, 0.06-0.4 \mathrm{~mm}$, ti. bearing, rims around magnetite partly oxidized, biotite trace, $0.02 .0 .08 \mathrm{~mm}$, ti. bearing, rare plates near magnetite. Texture: Doleritic lophition

Shipboard Geochemistry (XRF, \%):

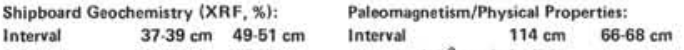

$\begin{array}{llll}\text { Interval } & 37.39 \mathrm{~cm} & 49.51 \mathrm{~cm} & \\ \mathrm{SiO}_{2} & 50.15 & 49.18\end{array}$

$\begin{array}{lrr}\mathrm{TiO}_{2} & 1.92 & 1.61 \\ \mathrm{Al}_{2} \mathrm{O}_{3} & 12.70 & 13.22\end{array}$

$\begin{array}{lll}\mathrm{Al}_{2} \mathrm{O}_{3} & 12.70 & 13.22 \\ \mathrm{FeO} & 14.33 & 12.77\end{array}$

$\begin{array}{lll}\mathrm{MnO} & 0.22 & 0.22 \\ \mathrm{M} 0 \mathrm{O} & 630 & 7.01\end{array}$

$\begin{array}{lrr}\mathrm{MgO} & 6.30 & 7.01 \\ \mathrm{CrO} & 10.17 & 11.10\end{array}$

$\mathrm{Na}_{2} \mathrm{O} \quad-\quad-$

$\begin{array}{lrr}\mathrm{N}_{2} \mathrm{O} & 0.14 & 0.12 \\ \mathrm{P}_{2} \mathrm{O}_{5} & 0.25 & 0.26 \\ \text { Total } & 96.19 & 95.49\end{array}$

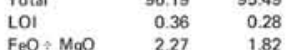

$\mathrm{C} . \mathrm{O}+\mathrm{Al}_{2} \mathrm{O}_{3} \quad 0.80 \quad 0.85$

Intensity $\left(10^{-3}\right.$ emu/cec) 7.9 NRM Incl. P') $\quad-47.8$ $\begin{array}{lrr}\text { Stable incl. (") } & 80.0 \\ -48.1 & -\end{array}$

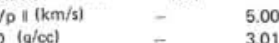
$D(g / c \infty)$
$P(x)$ 

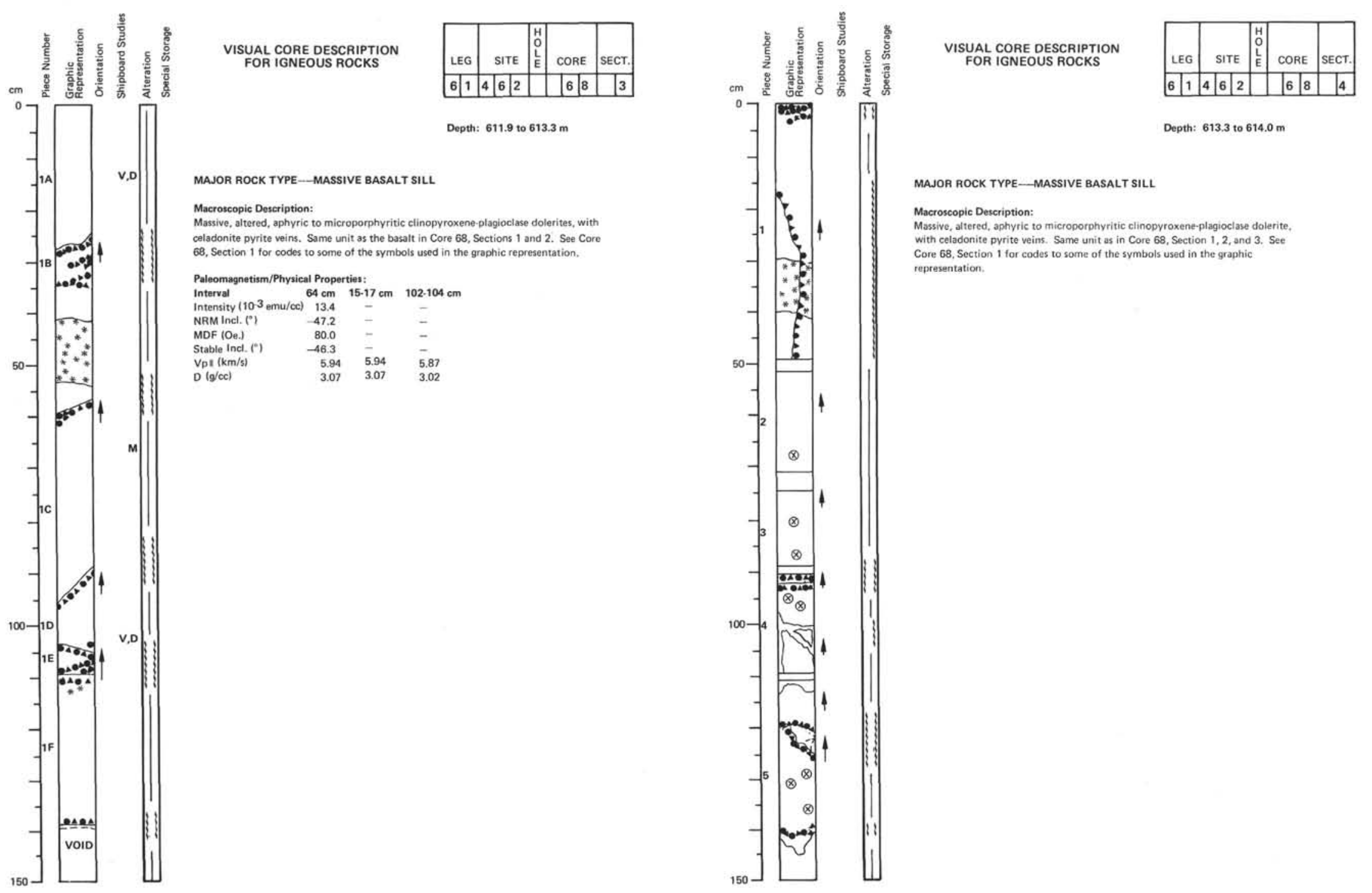

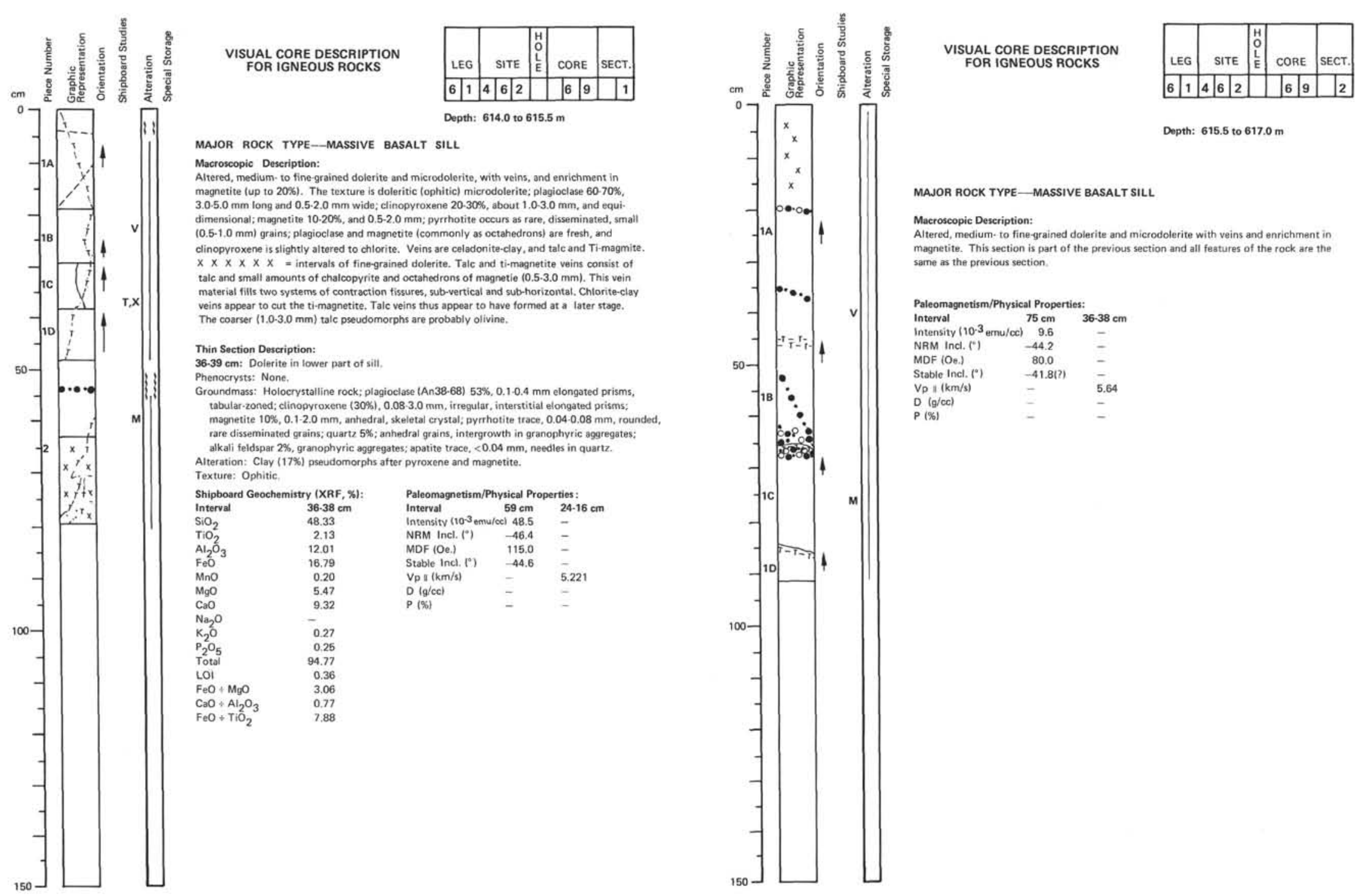

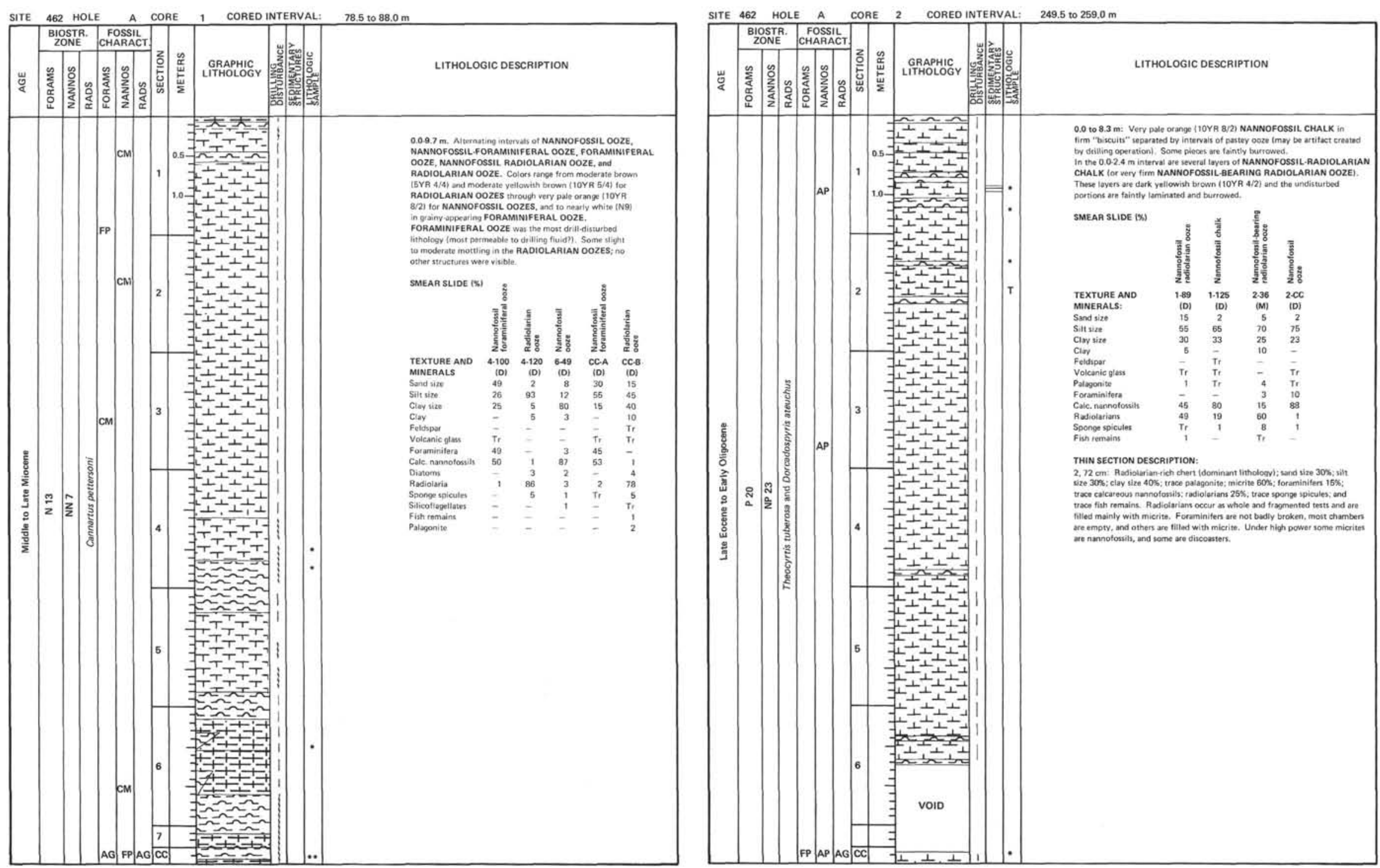


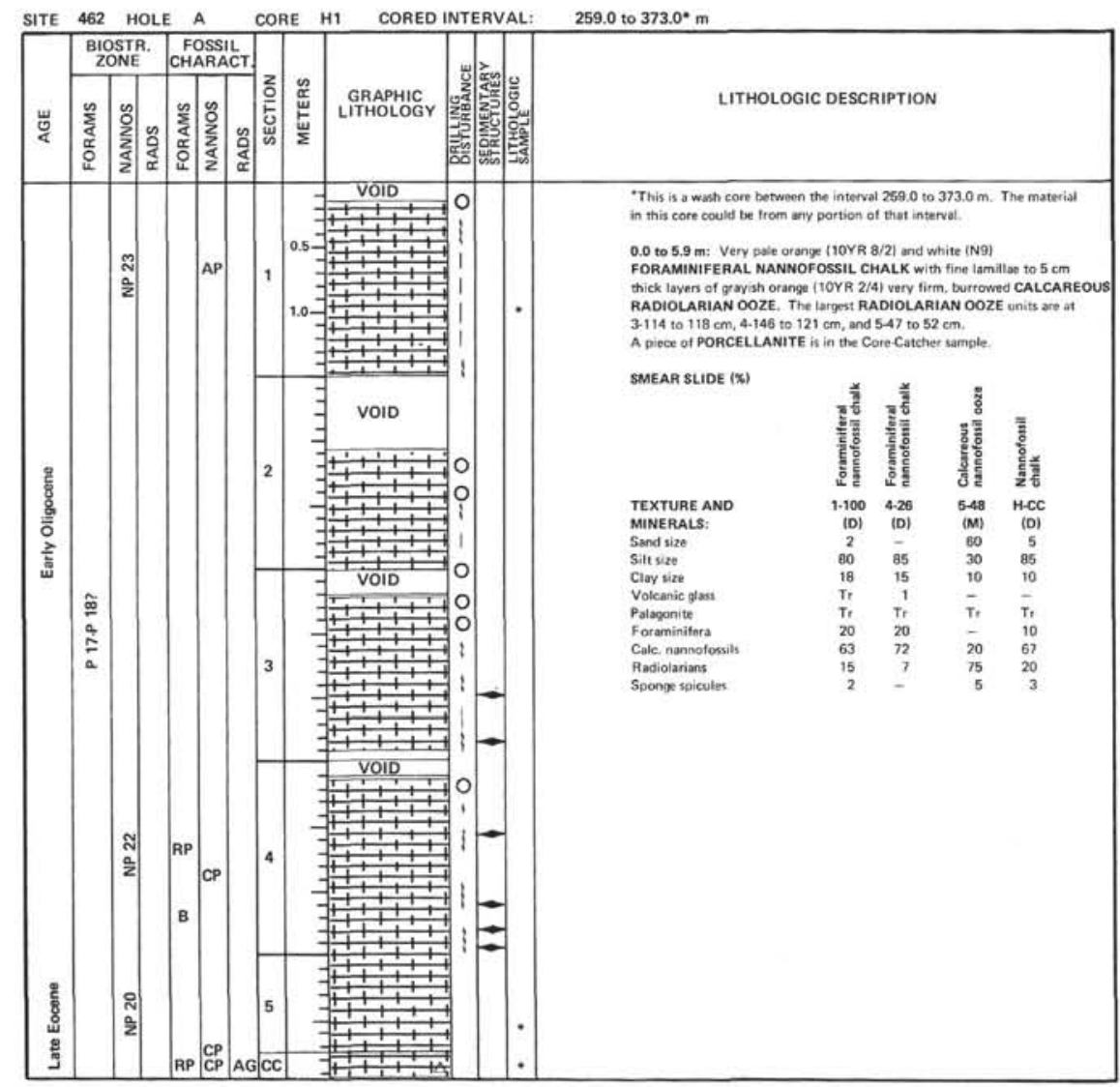

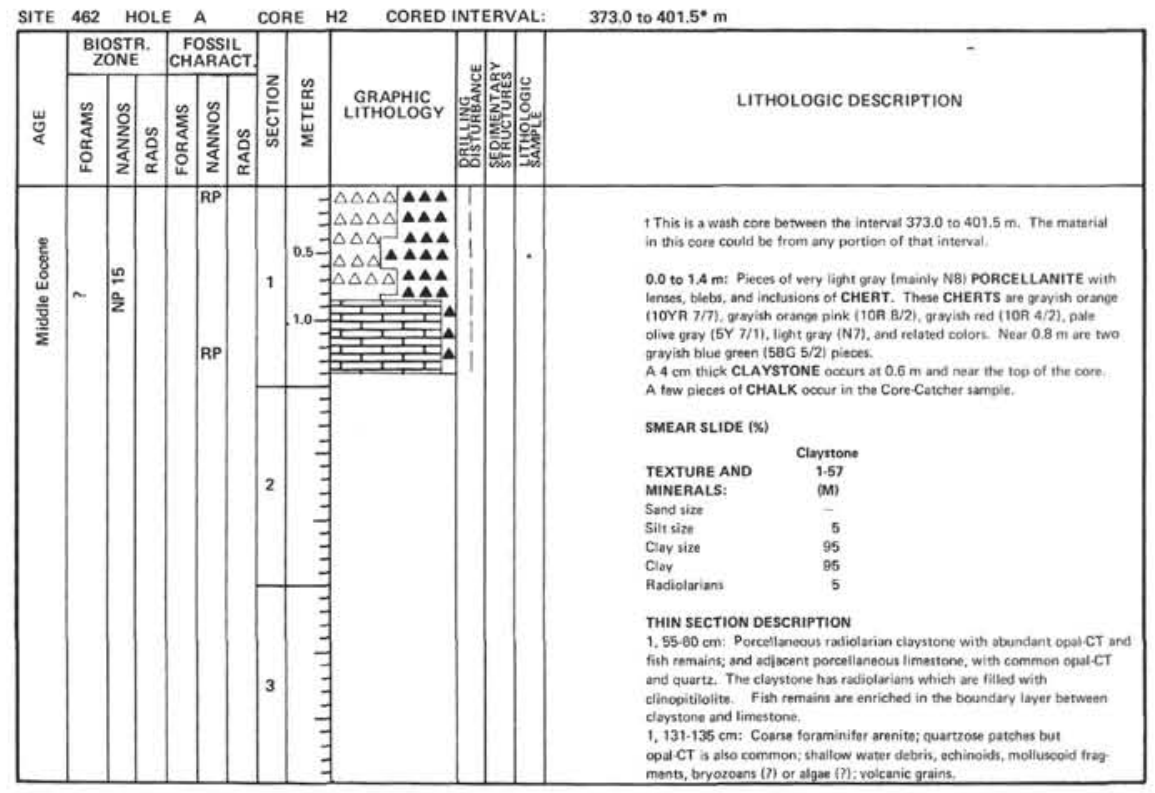

SITE 462 HOLE A CORE 3 CORED INTERVAL: $401.504041 .0 \mathrm{~m}$

\begin{tabular}{|c|c|c|c|c|c|c|}
\hline \multicolumn{3}{|c|}{\begin{tabular}{|c|c|} 
BBIOSRF. & FOSSIIL \\
ZONE & CHABACT \\
\end{tabular}} & \multirow[b]{2}{*}{ 惢 } & \multirow{2}{*}{ LRAPHIC } & \multirow{2}{*}{ 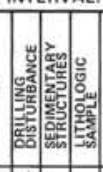 } & \multirow[b]{2}{*}{ LITHOLOGIC DESCRIPTION } \\
\hline 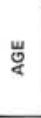 & 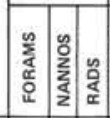 & 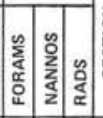 & & & & \\
\hline n & & & & $\Delta \Delta \Delta^{A}$ & \begin{tabular}{|l|l}
$\Delta$ & $\mathrm{RT}$ \\
\end{tabular} & 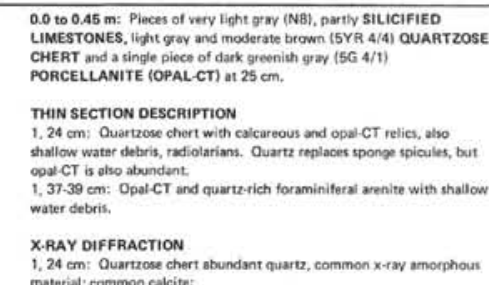 \\
\hline
\end{tabular}




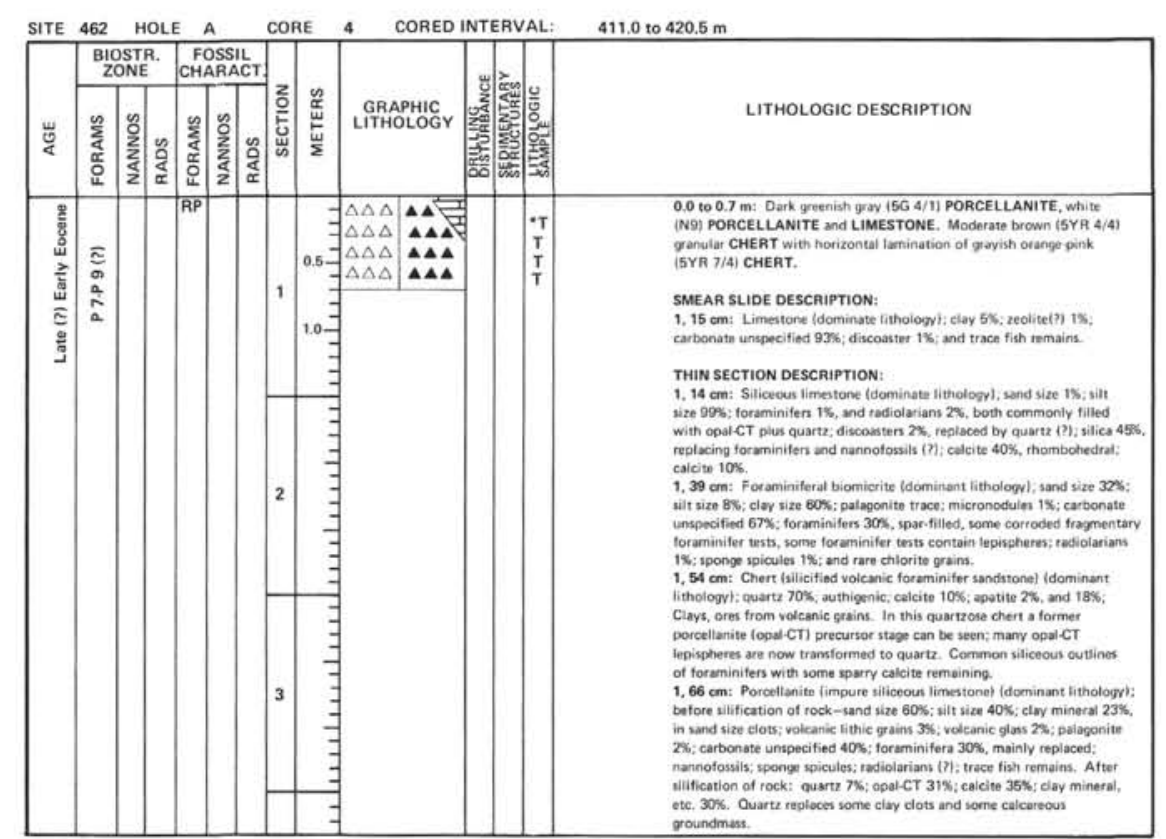

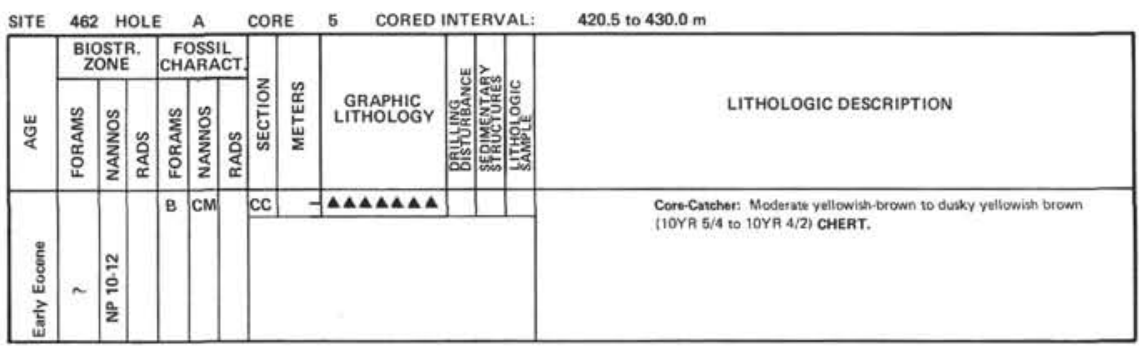

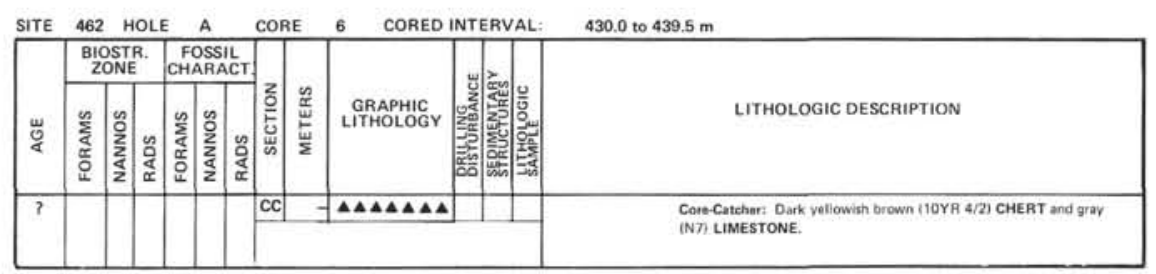

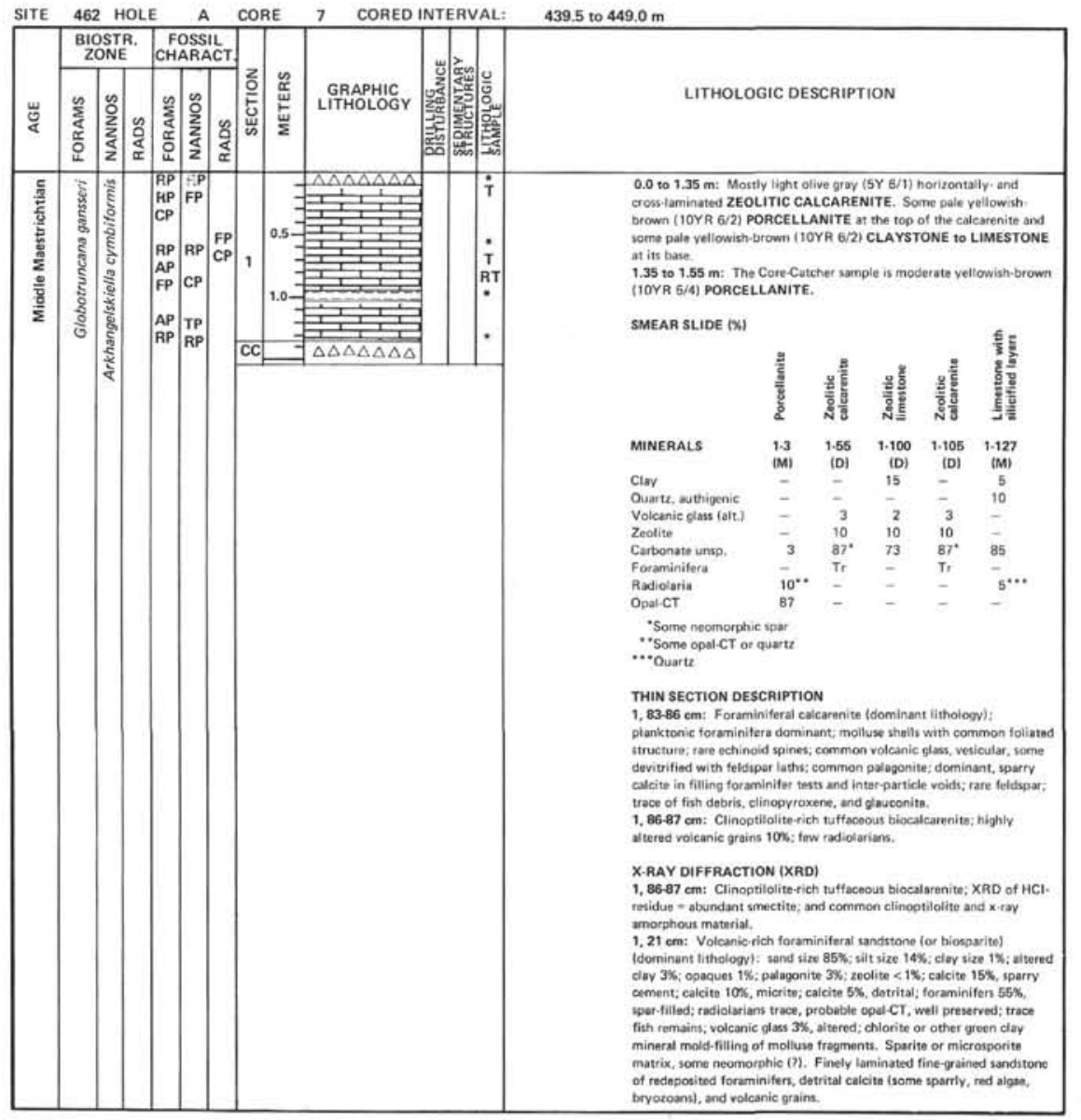



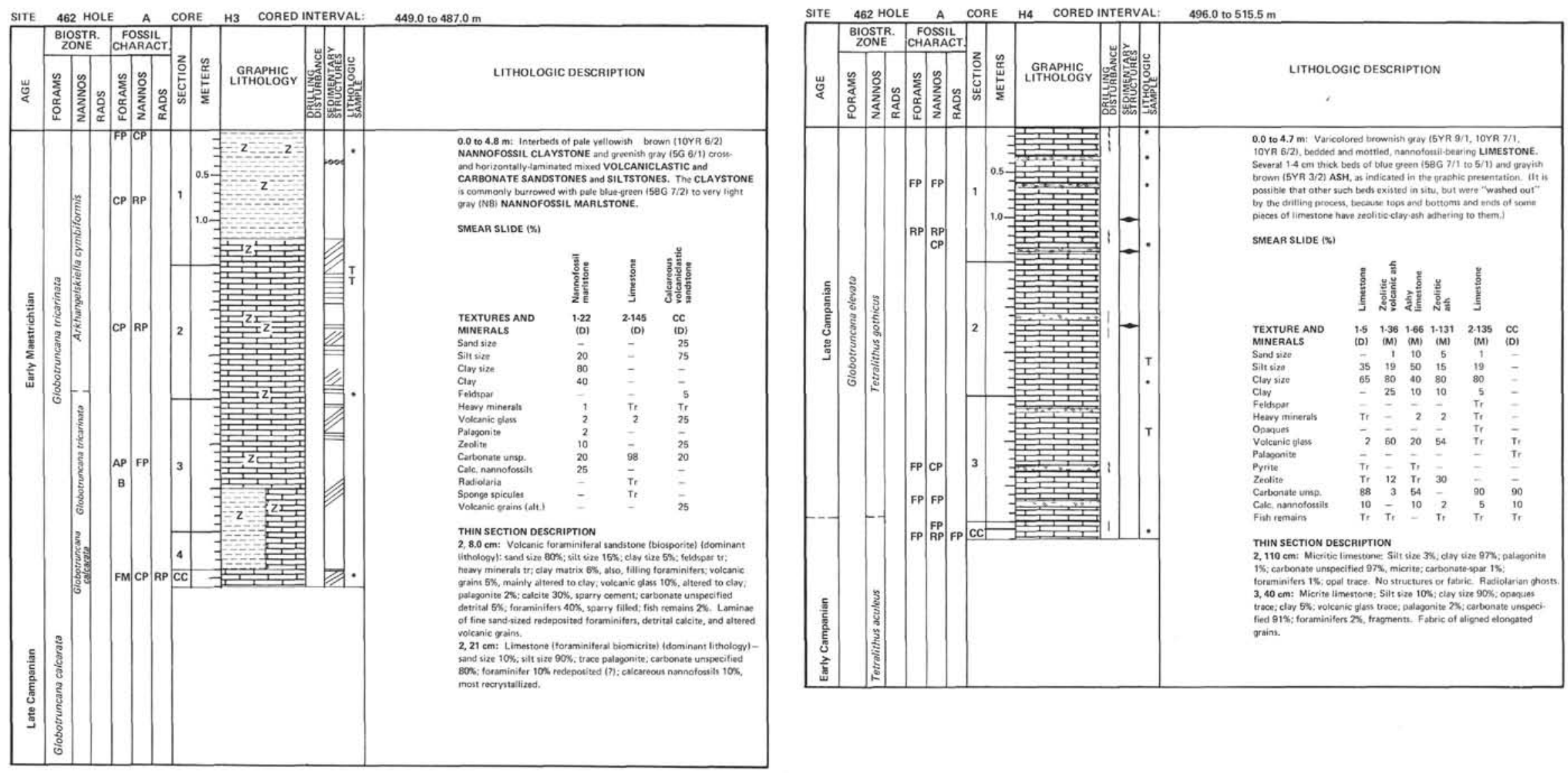


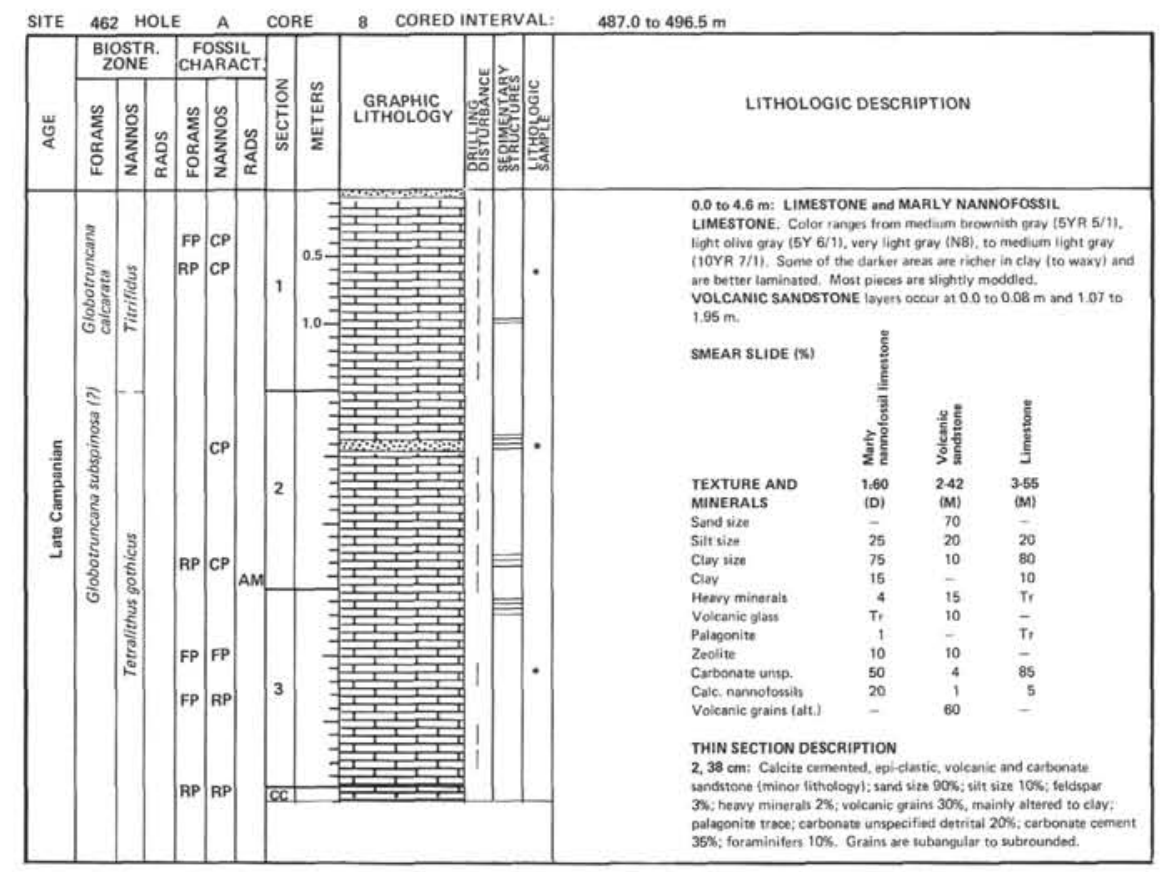

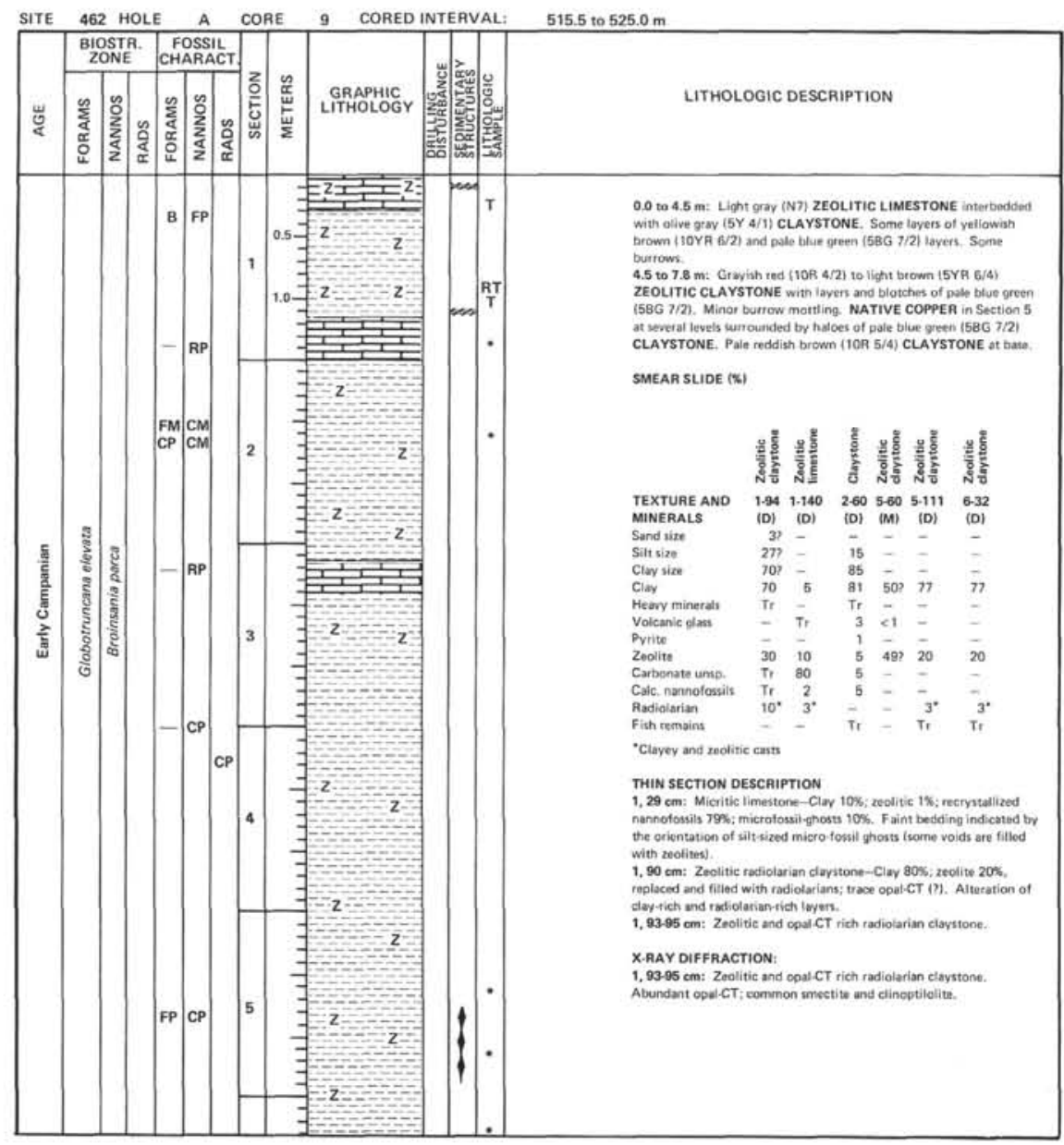




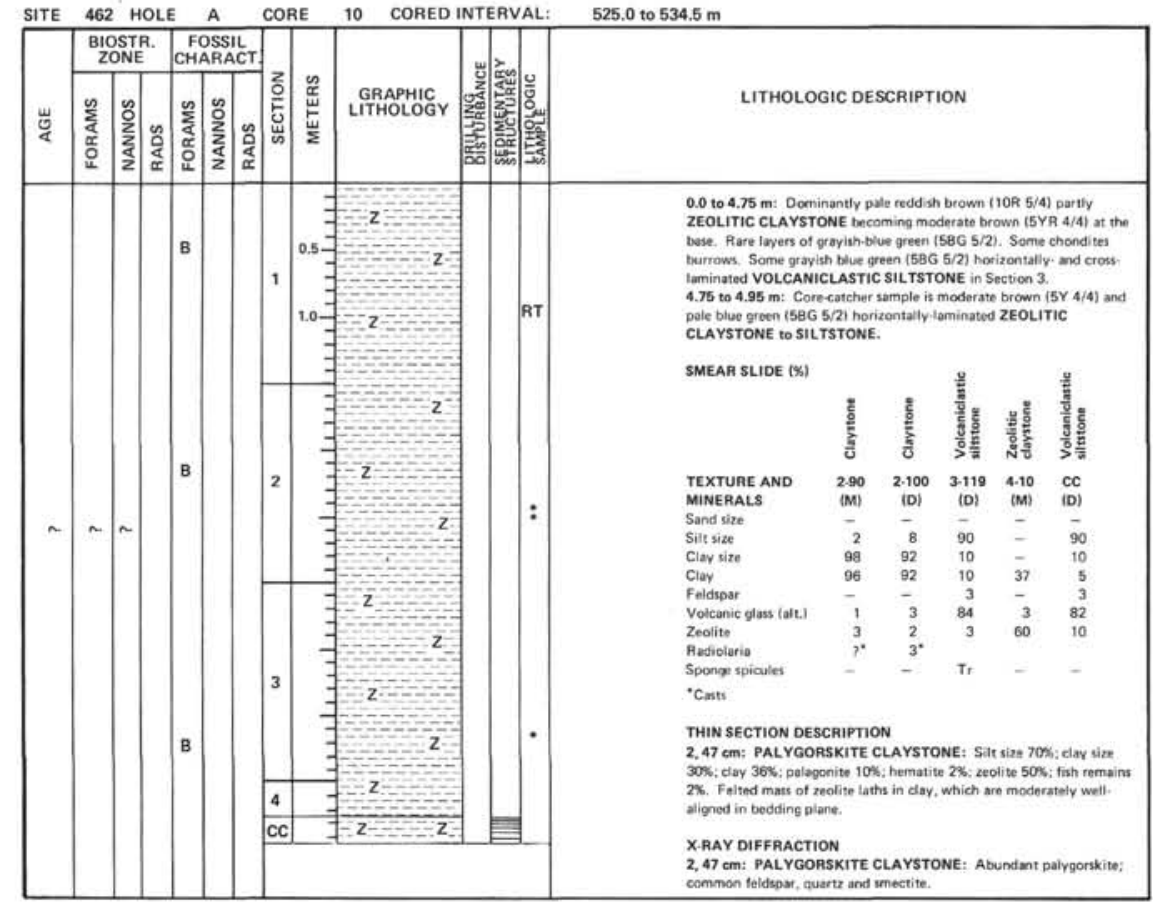

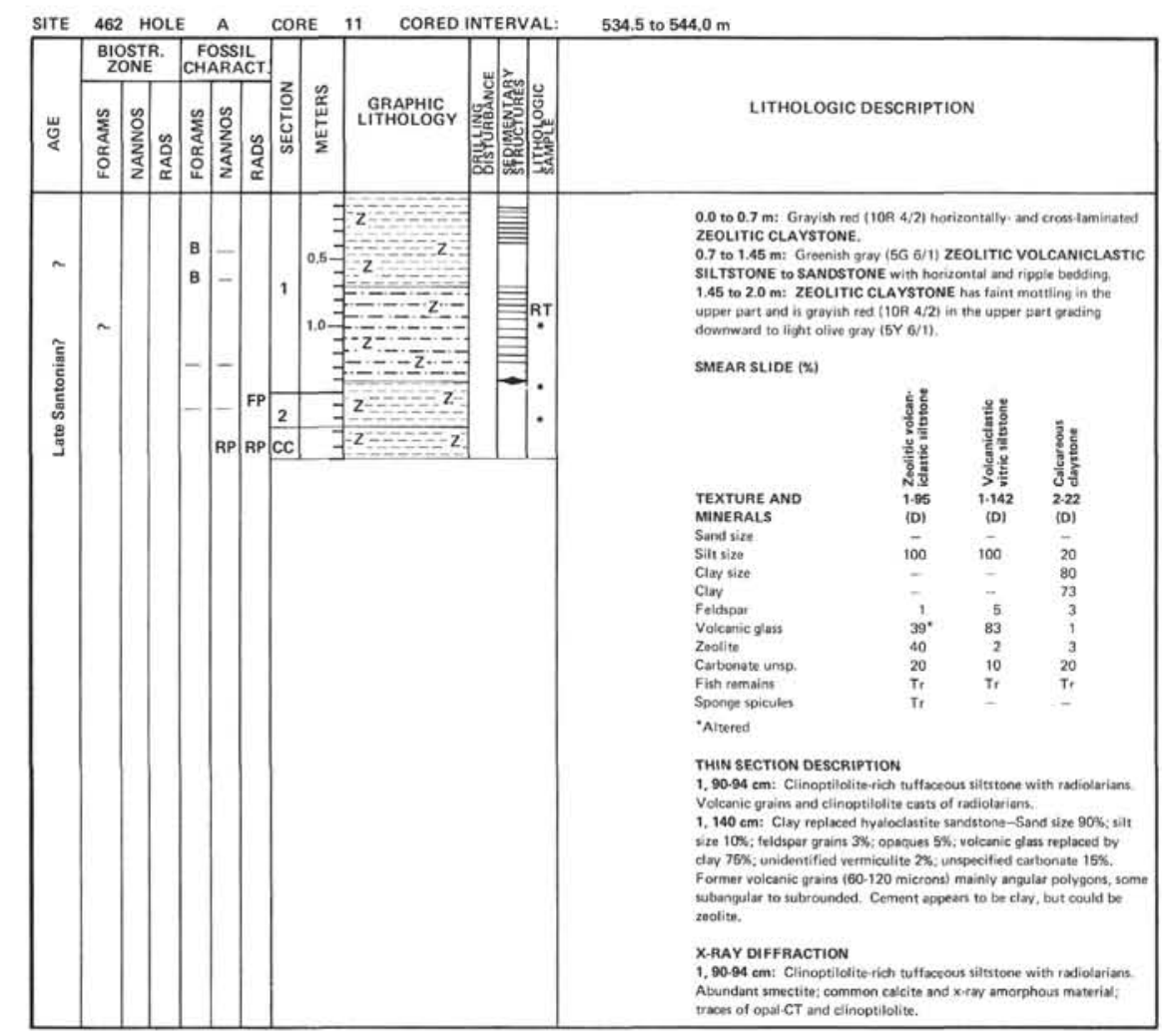



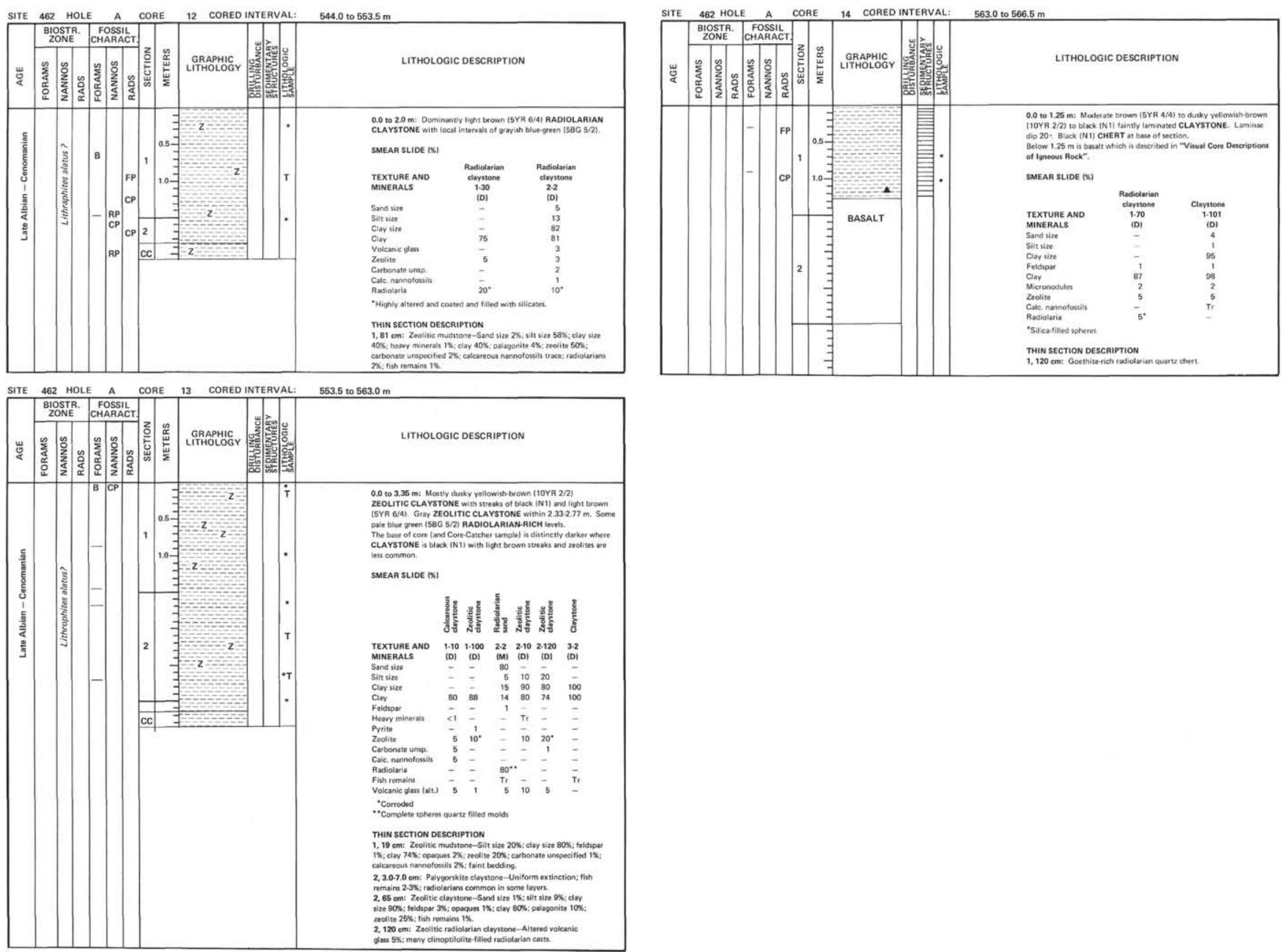


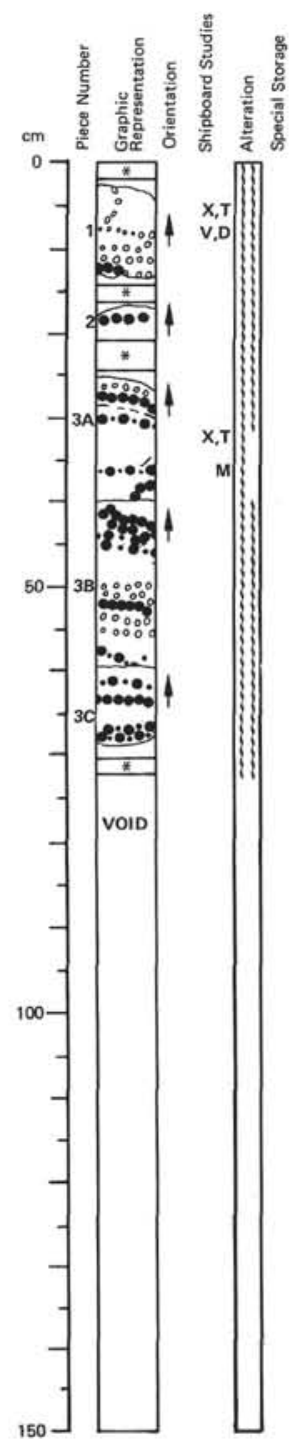

\section{VISUAL CORE DESCRIPTION
FOR IGNEOUS ROCKS

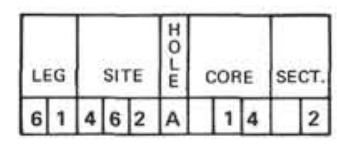

Depth: 565.0 to $566.5 \mathrm{~m}$

\section{MAJOR ROCK TYPE--BASALT SILL}

Macroscopic Doscription:

numerous veins of calcite (thickestl), celadonite, and clay-celadonite-calcite veins. Key to

symbols in graphic presentation is: in Explanatory Notes chapter (this volume).

or tho

phenocrysts and interstitial), and about 8.10\% magnetite (small irregular grains). Pyroxene

partly altered to light green smectite.

of the microdolerite is more fine grained.

Thin Section Description:

Mis. Shopconstor phyric to aphyric basalt from chilled margin (topl.

elongated prisms with the marrinal envelopes $0.6 \mathrm{~mm}$, (aphyric $=52 \%$, phyric $=$ tracee), aphyric = trace) $0.5 \mathrm{~mm}$, equidimensional; magnetite (phyric $=8 \%$, aphyric = trace).

$0.6 \mathrm{~mm}$, deeply altered to dark brown oxides.
Groundmass: Plagioclase

Groundmasss. Plagioclase (An35.65). microlites, altered; elinopyroxene, altered, equidimensiona

magnetite $10 \%$; $<0.04 \mathrm{~mm}$; glass $>70 \%$, altered.

colloform aggregates; clays in margins of veins and groundmass, replacing glass. The clays in the veins are bright green, and in the glass are pale green. Pyrite in margin of vein replacing vein in filling. The pyrite is altered to hydroxide

$29.32 \mathrm{~cm}$ : Altered basalt from interior of sill.

Phenocrysts: Plagioclase < $1 \%, 0.8-1.0 \mathrm{~mm}$, laths, highly al tered

Groundmass: Plagioclase (An80 zoned to An 38 ) 27., $0.10 .5 \mathrm{~mm}$, highily altered; clinopyroxene (augite) $25 \%, 0.1 \cdot 0.4 \mathrm{~mm}$, subhedrat to euhedral, $2 \mathrm{~V}$ angle $\sim 40^{\circ}$; $T$ T-magnetite $10 \%, 0.004$

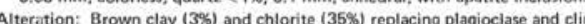

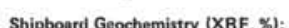

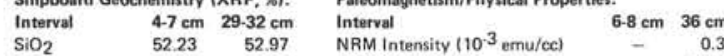

$\begin{array}{lll}\mathrm{TiO}_{2} & 1.90 & 1.51\end{array}$

$\begin{array}{llll}\mathrm{Al}_{2} \mathrm{O}_{3} & 18.56 & 15.40 & \text { NRM Incl. } \\ \text { MDF }(\mathrm{Oe}) & \end{array}$

$\mathrm{MnO} \quad 9.07 \quad 9.99 \quad$ Stable Incl. $\quad$ (C)

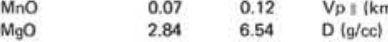

$\begin{array}{lll}\mathrm{C} . \mathrm{O} & \mathbf{7 . 6 5} \quad 1.10\end{array}$

$\begin{array}{lll}\mathrm{Na}_{2} \mathrm{O}_{5} & - & - \\ \mathrm{K}_{2} \mathrm{O} & 2.85 & 0.83\end{array}$

$\begin{array}{lll}\mathrm{K}_{2} \mathrm{O} & 2.85 & 0.83 \\ \mathrm{P}_{2} \mathrm{O}_{5} & 0.21 & 0.22 \\ & & \end{array}$

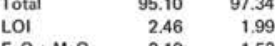

$\begin{array}{lll}\mathrm{FeO}+\mathrm{Mg}_{9} \mathrm{O} & 3.19 & 1.52 \\ \mathrm{CaO}+\mathrm{Al}_{2} \mathrm{O}_{3} & 0.41 & 0.65\end{array}$

$\begin{array}{lll}\mathrm{C}_{3} \mathrm{O}+\mathrm{Al}_{2} \mathrm{O}_{3} & 0.41 & 0.65 \\ \mathrm{FeO}+\mathrm{TiO}_{2} & 4.77 & 6.61\end{array}$ 


\begin{tabular}{|l|l|l|l|l|l|l|l|l|}
\hline SITE & 462 HOLE A & & \\
\hline
\end{tabular}



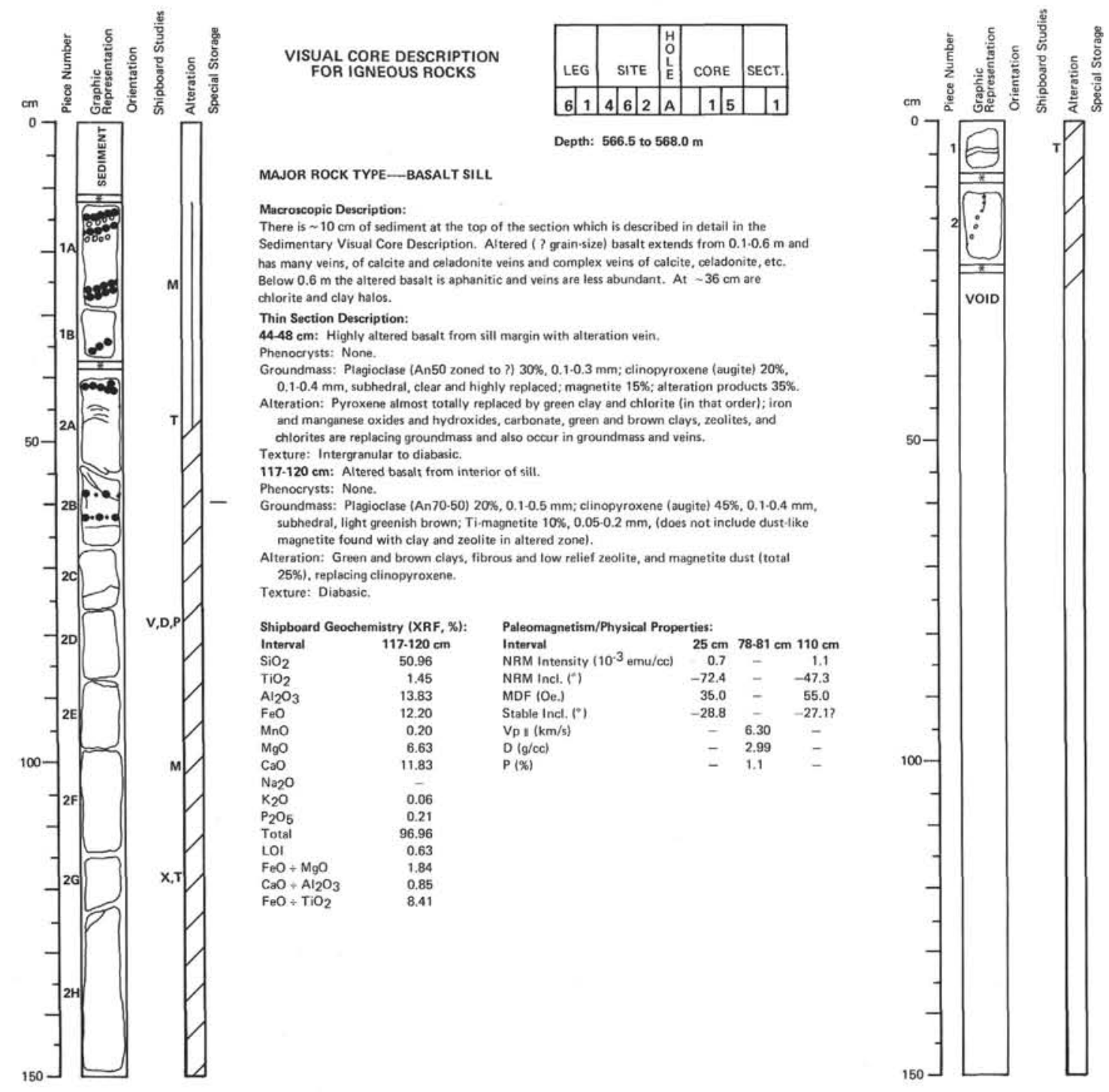

\section{VISUAL CORE DESCRIPTION

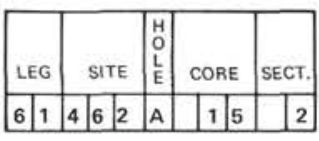 \\ Depth: 568.0 to $568.2 \mathrm{~m}$}

\section{MAJOR ROCK TYPE--BASALT SILL}

Basalt with veins of calcite and pyrite. Slight coarsening of grain-size in a zone from $3.0-5.0 \mathrm{~cm}$

Thin Section Description:

from sill interior.

(A) $35 \%, 0.1-0.5 \mathrm{~mm}, 2 \mathrm{~V}$ angle $\sim 55^{\circ} ;$ Ti-magnetite $10 \%, 0.005-0.2 \mathrm{~mm}$ (also fine grained,

Alteration: Clays $\left.355^{\circ}\right)$ clayl. clays $35 \%$, green alteration.

plus pyrite (colloform), (2) calcite (colloform), (3) clay (boum), (4) deas I) calcite (5) quartz (granular), and (6) second generation calcite.

Texture: Diabasic. 

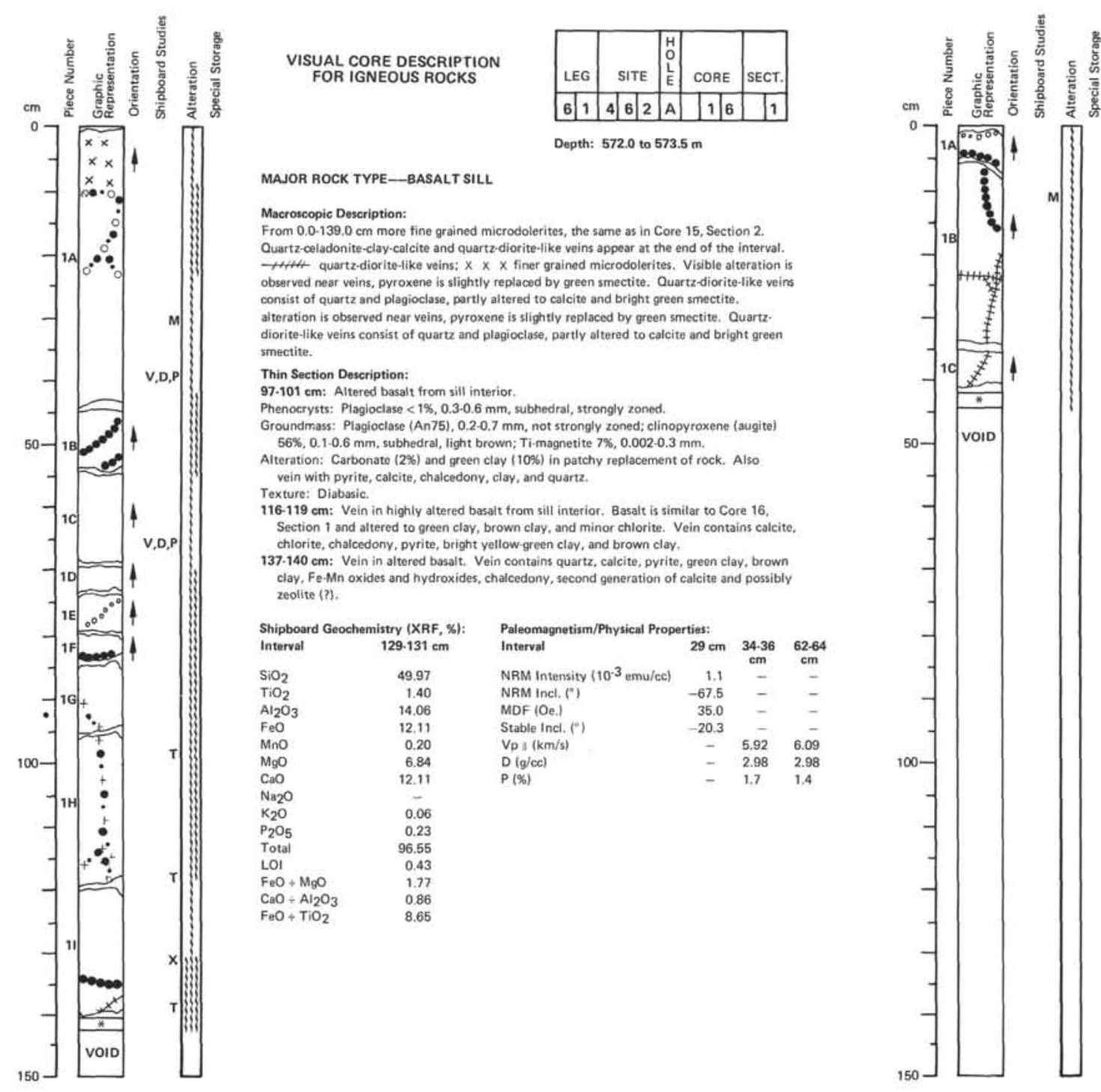

VISUAL CORE DESCRIPTION
FOR IGNEOUS ROCKS

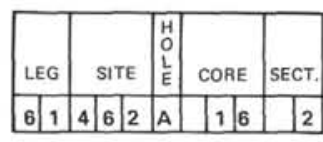

MANOR ROCK TYPE - BASALT SILL

Macroscopic Description

Microdolerites the same as in Core 16, Section 1.

\section{Paleomagnetis
Interval}

$12 \mathrm{~cm}$

NhM ind.

Stable Incl. (1\%

$12 \mathrm{~cm}$
1.3
-62.6
40.0
-27.2

\section{Depth: 573.5 to 574.0}




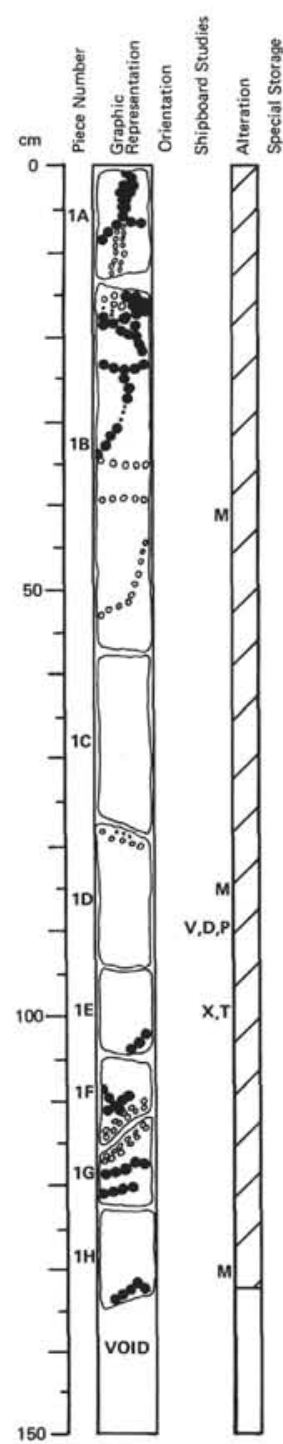

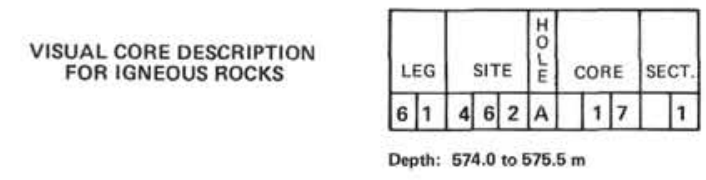

\section{MAJOR ROCK TYPE--BASALT SILL}

Macroscopic Description:

Massive subophitic dolerite with veins of coldsonite, calcite, clay, and calcite plus celadonite an

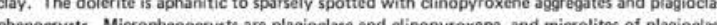
clinopyrovene and Timacrestite (plagioclase > clinopyroxene > T Tivagnetite) The dogerite. chlorite veins and day veins are, respectively, medium bluigh gray $15 \mathrm{~B} 5 / 1)$, dark green, and ligh olive brown (5Y 5/6). Sulfide (pyrite) occurs in some veins. Alteration is moderate to slightly moderate.

Sulfide (pyrite) occurs in some vein

so slightly moderate.

Thin Section Description

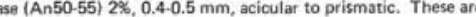

considered to be microphenocrysts.

$0.2 \mathrm{~mm}$, subhedral; microlitic to groundmas

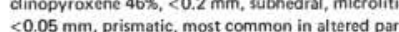

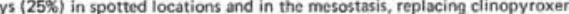
Texture: Subophitic

\begin{tabular}{|c|c|c|c|c|c|}
\hline & ry $(X R F, X):$ & Paloomagnetism/Physical Pror & operties: & & \\
\hline Interval & $98.100 \mathrm{~cm}$ & $\begin{array}{l}\text { Interval } \\
\text { Int }\end{array}$ & $41 \mathrm{~cm}$ & $88.91 \mathrm{~cm}$ & $129 \mathrm{~cm}$ \\
\hline & 50.03 & NRM Intensity $\left(10^{3} \mathrm{emu} / \mathrm{cc}\right)$ & 1.2 & - & 2.4 \\
\hline & $\begin{array}{r}1.39 \\
1390\end{array}$ & NRM Indt. (19) & -35.1 & $\overline{-}$ & $\begin{array}{r}-24.0 \\
550\end{array}$ \\
\hline $\begin{array}{l}\mathrm{Al}_{2} \mathrm{O}_{3} \\
\mathrm{FeO}\end{array}$ & $\begin{array}{l}13.92 \\
11.97\end{array}$ & $\begin{array}{l}\text { MDF (Oe.I } \\
\text { Stable Inct. (") }\end{array}$ & $\begin{array}{r}50.3 \\
-20.3\end{array}$ & $\overline{-}$ & $\begin{array}{r}56.0 \\
-18.4\end{array}$ \\
\hline $\mathrm{MnO}$ & 0.19 & $V_{p},(\mathrm{~km} / \mathrm{s})$ & -20.3 & 5.81 & -10.4 \\
\hline MoO & 6.99 & $\mathrm{D}(\mathrm{g} / \mathrm{cc}) \mathrm{s} / \mathrm{s})$ & 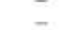 & 2.98 & \\
\hline CaO & $\begin{array}{r}6.99 \\
11.85\end{array}$ & $\begin{array}{l}\text { P } \\
P\left(\phi_{0}\right)(c)\end{array}$ & $\overline{-}$ & 1.7 & $\overline{-}$ \\
\hline $\mathrm{Na}_{2} \mathrm{O}$ & & & & & \\
\hline $\mathrm{K}_{2} \mathrm{O}$ & 0.02 & & & & \\
\hline $\begin{array}{lll}\mathrm{N}_{2} \mathrm{O}_{2} & \mathrm{P}_{5}\end{array}$ & 0.22 & & & & \\
\hline Total & 96.17 & & & & \\
\hline LOI & 0.71 & & & & \\
\hline $\mathrm{FeO}+\mathrm{MgO}$ & 1.71 & & & & \\
\hline $\mathrm{C} 3 \mathrm{O}+\mathrm{Al}_{2} \mathrm{O}_{3}$ & 0.85 & & & & \\
\hline $\mathrm{FeO} \div \mathrm{TiO}_{2}$ & 8.61 & & & & \\
\hline
\end{tabular}

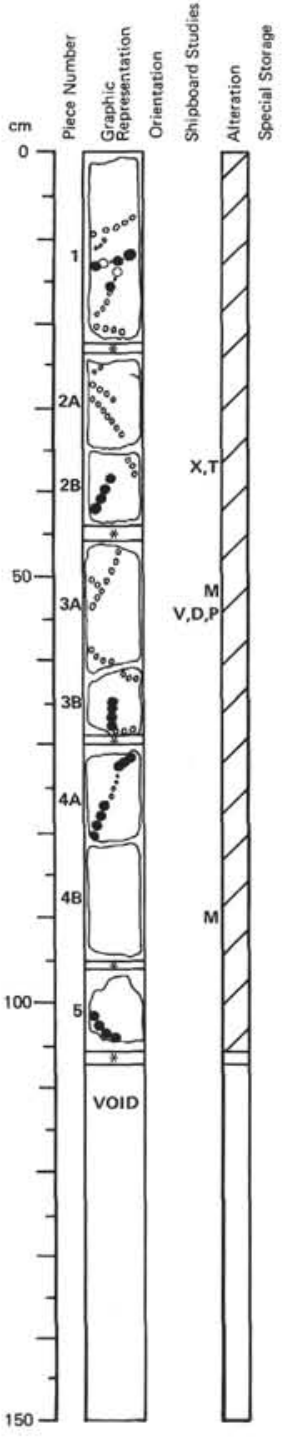

VISUAL CORE DESCRIPTION

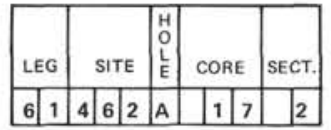

Depth: 575.5 to $577.0 \mathrm{~m}$

MAJOR ROCK TYPE-BASALT SILL

Macroscopic Descriptio

Thin Section Description:

$36-38 \mathrm{~cm}$ : Subophitic dolerite from sill interior.

Phenocrysts: Plagioclase (An55-60) $3 \%, 0.5<1.0 \mathrm{~mm}$, prismatic; clinopyroxene $1 \%, 0.5 \mathrm{~mm}$ with plagiociase laths; phenocrysts to microphenocrys

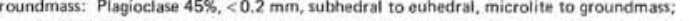
clinopyroxene $46 \%,<0.2 \mathrm{~mm}$, euhedral, microlite to groundmass; magnetite $5 \%,<0.05 \mathrm{~mm}$

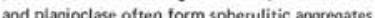
Alteration: Clays (30\%) in spotted locations and mesostasis, replacing pyroxene.

\begin{tabular}{|c|c|c|c|c|}
\hline \multicolumn{2}{|c|}{ Shipboard Geochemistry (XRF, \%): } & \multicolumn{3}{|c|}{ Paleomagnetism/Physical Properties: } \\
\hline Interval & $36-38 \mathrm{~cm}$ & Interval & $52.54 \mathrm{~cm}$ & \\
\hline & 49.26 & NRM Intensity $\left(10^{-3}\right.$ emu/cc) & & \\
\hline $\mathrm{TiO}_{2}$ & 1.40 & NRM Incl, ()$\left.^{\prime}\right)$ & - & -34.0 \\
\hline $\begin{array}{l}\mathrm{Al}_{2} \mathrm{O}_{3} \\
\mathrm{FeO}^{2}-\mathrm{l}\end{array}$ & 13.97 & MDF (Oe.) & - & 45.0 \\
\hline $\begin{array}{l}\mathrm{FeO}_{\mathrm{MnO}}-2-25 \\
\mathrm{MnO}\end{array}$ & $\begin{array}{cc}11.77 \\
0.19\end{array}$ & $\begin{array}{l}\text { Stable Incl. }(") \\
V_{0}, k m / s\end{array}$ & $\overline{09}$ & -24.4 \\
\hline $\mathrm{MgO}$ & $\begin{array}{l}0.19 \\
7.30\end{array}$ & 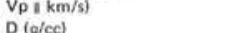 & 6.09 & \\
\hline $\mathrm{C} 2 \mathrm{O}$ & $\begin{array}{r}11.30 \\
11.81\end{array}$ & $\begin{array}{l}D(g / c) \\
P(\$)\end{array}$ & 2.97 & $\overline{-}$ \\
\hline
\end{tabular}

$\mathrm{N}_{\mathrm{N}_{2} \mathrm{O}} \mathrm{O}$

$\begin{array}{lr}\mathrm{N}_{2} \mathrm{O}_{5} & 0.06 \\ \mathrm{P}_{2} & 0.22 \\ \text { Total } & 95.57\end{array}$

LOI

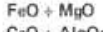

$\mathrm{C}=0.8 \mathrm{O}+\mathrm{Al}_{2} \mathrm{O}_{3}$ 

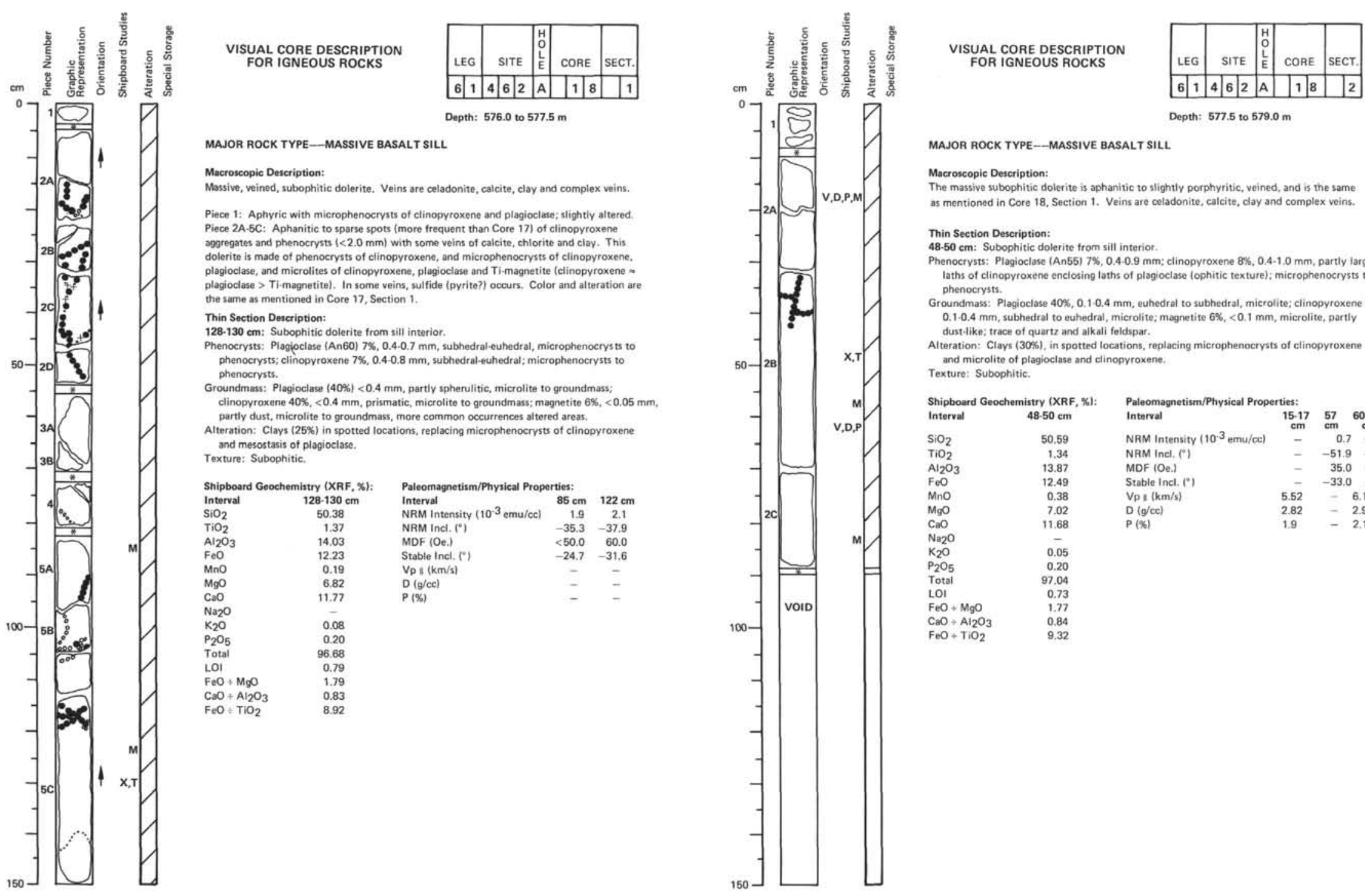

MAJOR ROCK TYPE--MASSIVE BASALT SILL

The massive subophitic dolerite is aphanitic to slightily porphyritic, veined, and is the same as mentioned in Core 18, Section 1. Veins are celadonite, calcite, day and complex veins.

\section{Thin Section Description:}

48.50 cm: Subophitic dolerite from sill interio

henocrysts: Plagioclase (An55) 7\%, $0.40 .9 \mathrm{~mm}$; clinopyroxene 8\%, 0.4.1.0 mm, partly iarge phenocrysts. Groundmass: Plagioclase 40\%, $0.10 .4 \mathrm{~mm}$, euhedral to subhedral, microlite; clinopyroxene 395, $0.1-0.4 \mathrm{~mm}$, subhedral to euhedral, microlite; magnetite $6 \%,<0.1 \mathrm{~mm}$, microlite, partliv
dust-like: trace of guartz and alkali feldspar, Alteration: Clays (30\%), in spotted locations, crophenocrysts of elinopyroxent and microlite of plagioclase and clinopyroxene.
Texture- Subophitic.

\begin{tabular}{|c|c|c|c|c|}
\hline \multicolumn{2}{|r|}{ mistry (XRF, צ): } & \multicolumn{2}{|c|}{ Paleomagnetism/Physical Properties: } & \multirow{3}{*}{$\begin{array}{cc}57 & 60.62 \\
\mathrm{~cm}\end{array}$} \\
\hline Interval & $48.50 \mathrm{~cm}$ & Interval & $\begin{array}{c}15.17 \\
\mathrm{~cm}\end{array}$ & \\
\hline $\mathrm{SiO}_{2}$ & 50.59 & NRM Intensity $\left(10^{-3} \mathrm{emu} / \mathrm{cc}\right)$ & - & \\
\hline $\mathrm{TiO}_{2}$ & 1.34 & NRM Incl. $\left({ }^{\circ}\right)$ & - & -51.9 \\
\hline $\mathrm{Al}_{2} \mathrm{O}_{3}$ & 13.87 & MDF $(0)$. & - & 35.0 \\
\hline $\mathrm{FeO}_{\mathrm{O}}-(-2)$ & 12.49 & Stable Incl. (1") & - & -33.0 \\
\hline $\mathrm{MnO}$ & 0.38 & $V_{p} i(\mathrm{~km} / \mathrm{s})$ & 5.52 & \\
\hline MgO & 7.02 & $\mathrm{D}(\mathrm{g} / \mathrm{cc})$ & 2.82 & - \\
\hline CaO & 11.68 & $P(\boldsymbol{w})$ & 1.9 & \\
\hline
\end{tabular}



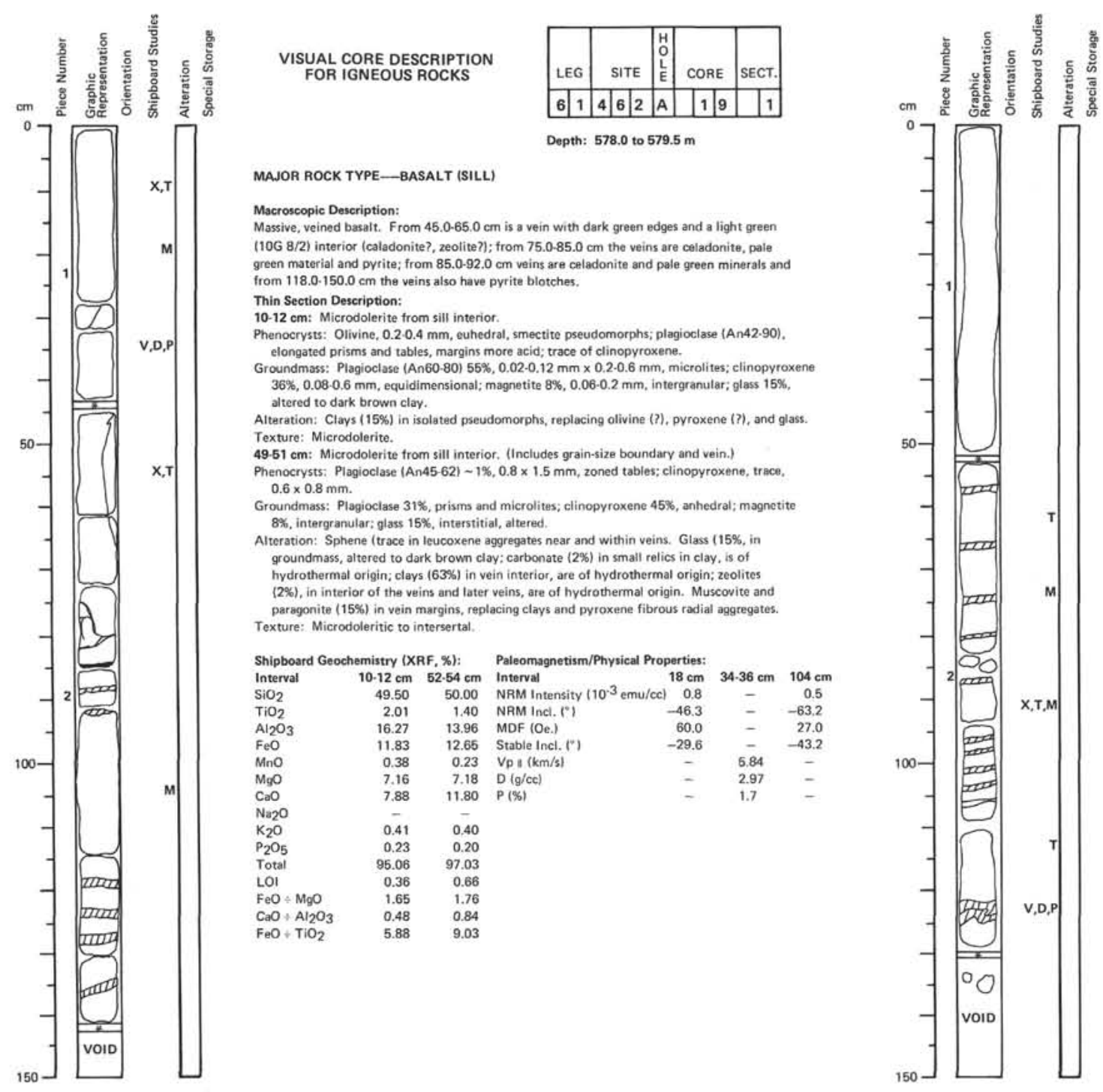

\section{VISUAL CORE DESCRIPTION
FOR IGNEOUS ROCKS

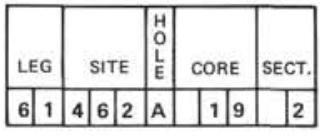

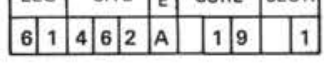

\section{MAJOR ROCK TYPE-BASALT (SILL)}

Macroscopic Deseription:
Massive, veined basatt. From $45.0-65.0 \mathrm{~cm}$ is a vein with dark green edges and a light green (1) from $118.0 .150 .0 \mathrm{~cm}$ the veins also have pyrite blotches.

Thin Section Description:

10-12 cm: Microdolerite from sill interior.
Phenocrysts: Olivine, 0.2-0.4 mm, euhedral, smectite pseudomorphs; plagioclase (An42-90),

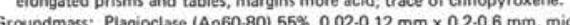
$36 \%, 0.08 .0 .6 \mathrm{~mm}$, equidimensional; magnetite $8 \%, 0.06-0.2 \mathrm{~mm}$, intergranular; glass $15 \%$, oltered to dark brown clay.
Altaration: Clays (15\%) in isolated pseudomorphs, replacing olivine (?), pyroxene (?), and glass. Texture: Microdolerite.

(rom sill interior. (Includes grain-size boundary and vein.) $0.6 \times 0.8 \mathrm{~mm}$. Groundmass: Plagioclase $31 \%$, prisms and microlites;
8\%, intergranular; glass $15 \%$, interstitial, altered.

8\%, intergranular; glass $15 \%$, interstitial, altered.

Arteration. Sphene (roce in hydrothermal origin; clays (63\%) in vein interior, are of hydrothermal origin: zeolites (2\%), in interior of the veins and later veins, are of hydrothermal origin. Muscovite and parragonite

\begin{tabular}{|c|c|c|c|c|c|c|}
\hline Shipboard Geo & hemistry (XF & AF, \%): & Paleomagnetism/Physical Prope & perties: & & \\
\hline & & $52.54 \mathrm{~cm}$ & Interval & $18 \mathrm{~cm}$ & $34.36 \mathrm{~cm}$ & $104 \mathrm{~cm}$ \\
\hline $\mathrm{SiO}_{2}$ & 49.50 & 50.00 & NRM Intensity $\left(10^{-3} \mathrm{emu} / \mathrm{cc}\right)$ & & & $\begin{array}{r}0.5 \\
-632\end{array}$ \\
\hline $\mathrm{TiO}_{2}$ & 2.01 & 1.40 & NAM Incl. $(" 1)$ & -46.3 & $\overline{-}$ & -63.2 \\
\hline $\mathrm{Al}_{2} \mathrm{O}_{3}$ & 16.27 & 13.96 & MDF (Oe.) & & - & \\
\hline $\mathrm{FeO}$ & 11.83 & 12.65 & Stable Incl. (") & -29.6 & 5 & -43.2 \\
\hline MnO & 0.38 & 0.23 & 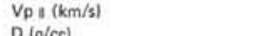 & - & 6.84 & \\
\hline $\mathrm{MgO}$ & 7.16 & $\begin{array}{r}7.18 \\
1180\end{array}$ & $D(g / c)$ & $=$ & 2.97 & $=$ \\
\hline $\begin{array}{l}\mathrm{CaO} \\
\mathrm{N}_{2} \mathrm{O}\end{array}$ & $\begin{array}{c}7.88 \\
-\end{array}$ & 11.80 & & & & \\
\hline $\mathrm{K}_{2} \mathrm{O}$ & 0.41 & 0.40 & & & & \\
\hline $\mathrm{P}_{2} \mathrm{O}_{5}$ & 0.23 & 0.20 & & & & \\
\hline Total & 95.06 & 97.03 & & & & \\
\hline LOI & 0.36 & 0.66 & & & & \\
\hline $\mathrm{FeO} \div \mathrm{MgO}$ & 1.65 & 1.76 & & & & \\
\hline $\mathrm{CaO}+\mathrm{Al}_{2} \mathrm{O}_{3}$ & 0.48 & 0.84 & & & & \\
\hline $\mathrm{FeO}+\mathrm{TiO}_{2}$ & 5.88 & 9.03 & & & & \\
\hline
\end{tabular}

\section{MAJOR ROCK TYPE-BASALT ISILL)}

Macroscopic Description:

(50) as shown in graphic presentation. From $77.0 .105 .0 \mathrm{~cm}$ is a zone of fine grain:size. Thin Section Description:

$58.60 \mathrm{~cm}$ : Altered aphyric basalt trom sill bottom

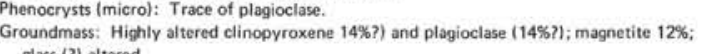

Alteration: Pale grayish green clays (6005) are replacing all minerals and glass. $89.93 \mathrm{~cm}$ : Altered phyric basalt of sill top.

Microphenocrysts. Trace plagioclase: clinopyroxene $\sim 28,0.2 \cdot 1.0 \mathrm{~mm}$, euhedral.

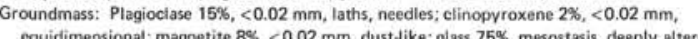
all minerals and glass $113.116 \mathrm{~cm}$ : Slightly phyric basalt from next to glassy margin of a sill.
Phenocrysts: Plagioclase (trace), $0.1 \times 1.2 \mathrm{~mm}$, elongated prisms; clinopyroxene $-2 \%, 0.2-1.0$ Groundmass: Plagioclase 20\%, <0.04 mm, latts; clinopyroxene 2\%, $0.04 \mathrm{~mm}$, irregular:

magnetite $8 \%,<0.02 \mathrm{~mm}$, dust-like; glass $70 \%$, opaque mesostasis. Alteration: Clays (70\%) replacing glass in the mesostasis.

Texture: Intersertal.

\begin{tabular}{|c|c|c|c|c|c|}
\hline & $\operatorname{try}(X R F, x):$ & Paleomagnetism/Physical Prop & perties: & & \\
\hline & $90.92 \mathrm{~cm}$ & $\log ^{2} \quad 3$ & $73 \mathrm{~cm}$ & & $119.121 \mathrm{~cm}$ \\
\hline $\mathrm{SiO}_{2}$ & 49.88 & NRM Intensity $\left(10^{-3} \mathrm{emu} / \mathrm{cc}\right)$ & & 0.7 & \\
\hline & 1.38 & NRM Incl. (") & -48.9 & -41.4 & - \\
\hline $\mathrm{Al}_{2} \mathrm{O}_{3}$ & 13.67 & MDF (Oe.) & & 50.0 & - \\
\hline Feo & 12.72 & Stable Incl. $\left({ }^{\circ}\right)$ & -34.2 & -43.8 & $\cdot$ \\
\hline $\mathrm{MnO}$ & 0.20 & $V_{p},(\mathrm{~km} / \mathrm{s})$ & - & - & 4.61 \\
\hline $\mathrm{MgO}$ & 6.87 & $D(g / c c)$ & - & - & 2.6 \\
\hline $\begin{array}{l}\mathrm{CaO} \\
\mathrm{Na}_{2} \mathrm{O}\end{array}$ & 11.89 & $P\left(\xi_{0}\right)$ & & & \\
\hline $\mathrm{K}_{2} \mathrm{O}$ & 0.05 & - Vein & & & \\
\hline & 0.19 & & & & \\
\hline Total & 96.51 & & & & \\
\hline LOI & 0.66 & & & & \\
\hline $\mathrm{FeO} \div \mathrm{MgO}$ & 1.85 & & & & \\
\hline $\mathrm{CaO}+\mathrm{Al}_{2} \mathrm{C}$ & 0.87 & & & & \\
\hline $\mathrm{FeO}+\mathrm{T}_{1} \mathrm{O}_{2}$ & 9.21 & & & & \\
\hline
\end{tabular}




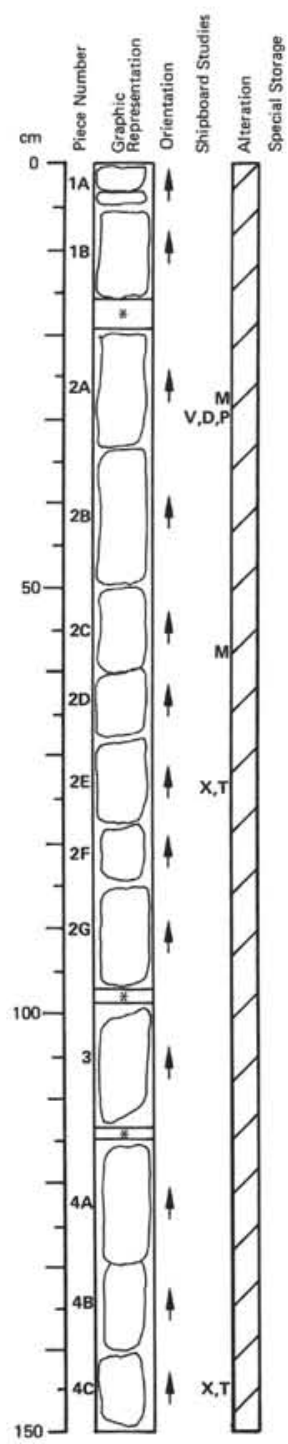

VISUAL CORE DESCRIPTION
FOR IGNEOUS ROCKS

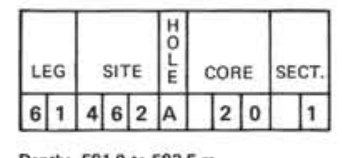

MAJOR ROCK TYPE-BASALT (SILL)

Macroscopic Deserription:
Massive fine grain-sized basalt with veins. From $35.0-60.0 \mathrm{~cm}$, veins of celadonite pyrite occur which are $0.5 .20 \mathrm{~mm}$ thick. From $-550 \mathrm{~cm}$ and downward, the rock appears to subtly become finer in grain size and more leucocratic.

Thin Section Description:

$72.74 \mathrm{~cm}$ : Slightily phyric basalt trom area next to glassy margin of a sitt.

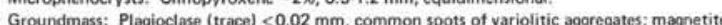
7\%, dust like, intergranular and spots in mesostasisis glass $300 \%$, attered, spots and interstitide Vugs: Vugs $2 \%, 0.08 \mathrm{~mm}$, in groundmass, zeolite fillings, elongated to irregular shapes, surrounded by variolitic aggregates,

144.146 cm:

Phenocrysts: Olivine (25) pseudomorphs of green clay; plagioclase (An60) 1\%, 0.2.0.4 mm; clinopy roxene (augite) $2 \%, 0.30 .6 \mathrm{~mm}$, euhedral, twinned and with inclusions.

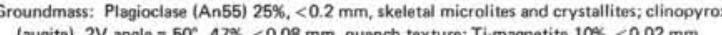
anhedral to whedral. Alteration: Green and brol Texture: Intersertal

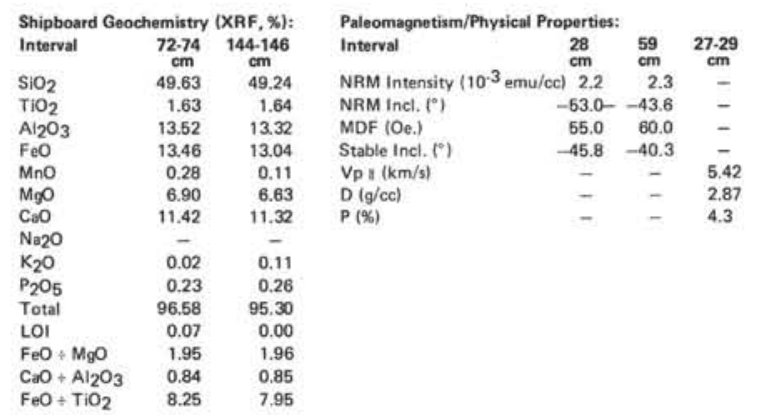
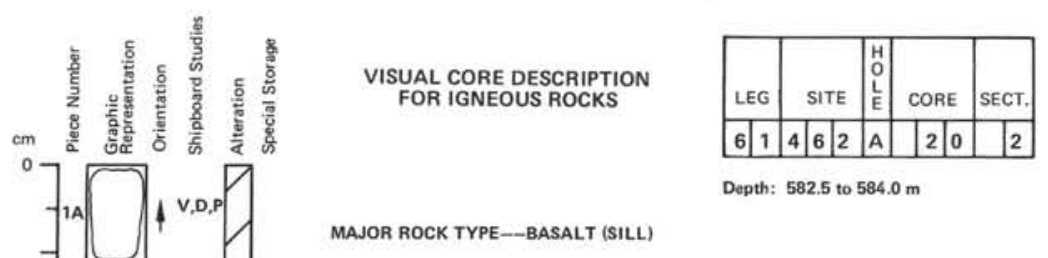

Macroscopic Description:

Massive fine grain-sized basalt. From $100.0-120.0 \mathrm{~cm}$ are $1-2 \mathrm{~mm}$ thick veins of celadonite plus pyrite.

Thin Section Description:

$93.95 \mathrm{~cm}$ : Altered basalt from sill interio

Groundmass: Plagioclase (An60-An50) 25\%, 0.2.0.5 mm, euhedral-anhedral; Ti-magnetite 10\%, $0.005 \cdot 0.2 \mathrm{~mm}$; glass $3 \%$, alteren 10 Alteration: Green clays replacing glass (3\%) and clinopyroxene (10\%); zeolitas (5\%) replacing Texture: Interger

\begin{tabular}{|c|c|c|c|c|c|}
\hline \multirow{2}{*}{\multicolumn{2}{|c|}{ Shipboard Geochemistry (XRF, Y): }} & \multicolumn{4}{|c|}{ Paleomagnetism/Physical Properties: } \\
\hline & & Interval & $6.8 \mathrm{~cm}$ & $71 \mathrm{~cm}$ & \\
\hline $\mathrm{SiO}_{2}$ & 50.32 & NRM Intensity $\left(10^{-3} \mathrm{emu} / \mathrm{cc}\right)$ & - & 1.9 & 2.8 \\
\hline & 1.64 & NRM Ind. (") & - & -76.3 & -54.1 \\
\hline $\mathrm{Al}_{2} \mathrm{O}_{3}$ & 13.53 & MDF (Oe.) & - & 40.0 & 45.0 \\
\hline & 13.82 & Stable Ind. $\left(^{\circ}\right)$ & - & -64.9 & -49.7 \\
\hline $\mathrm{MnO}$ & - & $V_{p} \|(\mathrm{km} / \mathrm{s})$ & 6.03 & - & - \\
\hline $\mathrm{MgO}$ & 6.99 & $\mathrm{D}(g / \mathrm{ccl})$ & 2.99 & - & \\
\hline $\mathrm{CaO}$ & 11.42 & $P(\%)$ & 0.5 & - & - \\
\hline $\begin{array}{l}\mathrm{Na}_{2} \mathrm{O} \\
\mathrm{K}_{2}\end{array}$ & & & & & \\
\hline $\begin{array}{l}{ }^{2}{ }_{2} \mathrm{O} \\
P_{2} \mathrm{O}_{5}\end{array}$ & 0.14 & & & & \\
\hline $\begin{array}{l}22^{2} 5 \\
\text { Total }\end{array}$ & - & & & & \\
\hline LOI & 0.07 & & & & \\
\hline $\mathrm{FeO}+\mathrm{MgO}$ & 1.97 & & & & \\
\hline $\mathrm{C} 2 \mathrm{O}+\mathrm{Al}_{2} \mathrm{O}_{3}$ & 0.84 & & & & \\
\hline $\mathrm{FeO} \neq \mathrm{TiO}_{2}$ & 8.42 & & & & \\
\hline
\end{tabular}




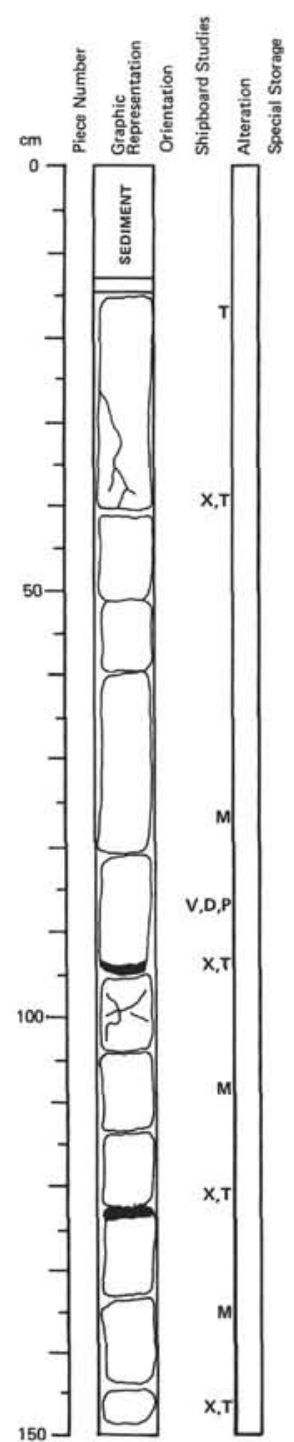

\section{VISUAL CORE DESCRIPTION
FOR IGNEOUS ROCKS}

\section{\begin{tabular}{|l|l|l|l|l|}
\hline LEG & SITE & $\begin{array}{l}\text { H } \\
\text { L } \\
\text { E }\end{array}$ & CORE & SECT. \\
\hline
\end{tabular}

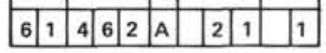
Depth: 586.0 to $587.5 \mathrm{~m}$

\section{MAJOR ROCK TYPE-BASALT ISILL)}

Sediment from $0.0-14.0 \mathrm{~cm}$. (See Sedimentary Visual Description.) Three basalt sills (units)? Unit 1 occurs from $15.0 \sim 96.0 \mathrm{~cm}$, grainsize increses 1 rom $15.0 \mathrm{~cm}$ to a maximum at 40.0 .

Unit 2 oceurs from $\sim 96.0 \sim 123.0 \mathrm{~cm}$. Veined basalt without any Unit 3 occurs from $~ 123.0-150.0 \mathrm{~cm} / 7$. The upper boundary is marked by a glassy margin Thin section Deeciption:

$16-20 \mathrm{~cm}$ (Piece 1A): Highly altered diabase from sill interior.

Phenocrysts: Plagioclase « $1 \%, 0.9 \cdot 1.0 \mathrm{~mm}$; clinopyroxene (augite) $2 \%, 0.4-0.8 \mathrm{~mm}$, with ophitic plagioclase.

(A) in, subhedral, light brown; magnetite (Ti) $5 \%,<0.1 \mathrm{~mm}$, subhedral to euhedral; glass $2 \%$, small Alteration: Brown clays $(25 \%)$ in large patches $(2 \mathrm{~mm})$, replacing all minerals.

Texture: Diabasic.

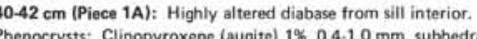

Groundmass: Plagioclase (An75-45) 20\%, 0.2.0.5 mm, subhedral to euhedral; clinopyroxene laugite$36 \%, 0.1 \cdot 0.3 \mathrm{~mm}$, subhedral, light brown; Ti-magnetite $5 \%,<0.05 \mathrm{~mm}$; glass $8 \%$, interstitial altered glass patches.

Ir as (1) large patches of clay with minor (late) chlorite. Texture: Diabsic

$95.96 \mathrm{~cm}$ (Piece 1C): Altered glassy basalt from bottom chill margin of sill. Phenocrysts: Plagioclase (An78-65) 2x, <0.15 mm, zoned, euhedral, and microphenocrysts, clinopyroxene (augite) $3 \%, 0.05-0.2 \mathrm{~mm}$; euhedral, and microphenocrysts.

Alteration: Clays and chlorite replacing groundmass, glass, and clinopyroxene.

Texture: Variolic.

Phenocrysts: Plagioclase (An55.65) 1\%, 0.3.-.5 mm; oscillatory zoning; clinopyroxene (augite) 2\%, $0.5-1.0 \mathrm{~mm}$, subophitic texture.

Groundmass: Plagioclase (An60) 40\%, $0.1 .0 .3 \mathrm{~mm}$; clinopyroxene (augite) $37 \%$, <0.02 mm,
subhedral to anhedral, light brown, magnetite (Ti) $5 \%,<0.05 \mathrm{~mm}$, subhedral ; glass $15 \%$, altered subhedral to anhedral, ightr brown, magnetite 1 in
interstitial glass patches. Alteration: Green clays (100) 1)

glass patches.

Texture: Interstitial, subophitic clinopyroxene.

Tere

(augite) $3 \%, 0.1-0.2 \mathrm{~mm}$,

min, skeletal and microlites; clinopyroxene $38 \%,<0.0$ glass plucked from section ?).

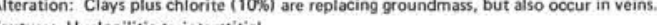

Leg 61, Site 462, Hole A, Core 21, Section 1-Continued

\begin{tabular}{|c|c|c|c|c|}
\hline \multirow{2}{*}{\multicolumn{5}{|c|}{ Shipboard Geochemistry (XRF, X): }} \\
\hline & & & & \\
\hline $\mathrm{SiO}_{2}$ & 50.53 & 50.33 & 48.98 & 47.77 \\
\hline $\mathrm{THO}_{2}$ & 1.66 & 1.74 & 1.89 & 1.88 \\
\hline $\mathrm{Al}_{2} \mathrm{O}_{3}$ & 13.66 & 14.00 & 14.74 & 15.06 \\
\hline $\mathrm{FeO}$ & 13.33 & 13.02 & 12.85 & 12.88 \\
\hline & & & & \\
\hline & 7.55 & 6.32 & 6.82 & 6.30 \\
\hline $\begin{array}{l}\mathrm{CaO} \\
\mathrm{N} 22 \mathrm{O}\end{array}$ & 11.12 & 10.76 & $\stackrel{9.51}{-}$ & 8.99 \\
\hline $\begin{array}{l}\mathrm{Na}_{2} \mathrm{O} \\
\mathrm{K}_{2} \mathrm{O}\end{array}$ & 0.13 & 0.12 & 0.20 & 0.20 \\
\hline $\mathrm{P}_{2} \mathrm{O}_{5}$ & - & - & 2.20 & - \\
\hline Total & - & - & $=$ & \\
\hline & 0.45 & 1.69 & 3.77 & \\
\hline $\mathrm{FeO}=\mathrm{MgO}$ & 1.76 & 2.06 & 1.88 & 2.04 \\
\hline $\mathrm{CaO}+\mathrm{Al}_{2} \mathrm{O}_{3}$ & 0.81 & 0.76 & 0.64 & 0.59 \\
\hline $\mathrm{FeO}=\mathrm{TiO}_{2}$ & 8.03 & 7.48 & 6.79 & 6.85 \\
\hline Paleomagnetism & Physical Pr. & perties: & & \\
\hline Interval & $76 \mathrm{~cm}$ & $86-88 \mathrm{~cm}$ & $108 \mathrm{~cm}$ & $135 \mathrm{~cm}$ \\
\hline $\begin{array}{l}\text { NRMM Intensity } \\
\left(10^{-3} \text { emu/cel }\right.\end{array}$ & 10 & - & 125 & 25 \\
\hline NRM Incl. & -73.1 & 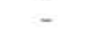 & -56.2 & -52.6 \\
\hline MDF (Oe.) & 20.0 & - & 50.0 & 25.0 \\
\hline Stable Incl. (") & -64.2 & - & -52.6 & -49.3 \\
\hline$v_{p} \|(k$ & & 5.27 & & \\
\hline big & - & 2.89 & - & - \\
\hline$P(\%)$ & - & 2.5 & - & - \\
\hline
\end{tabular}



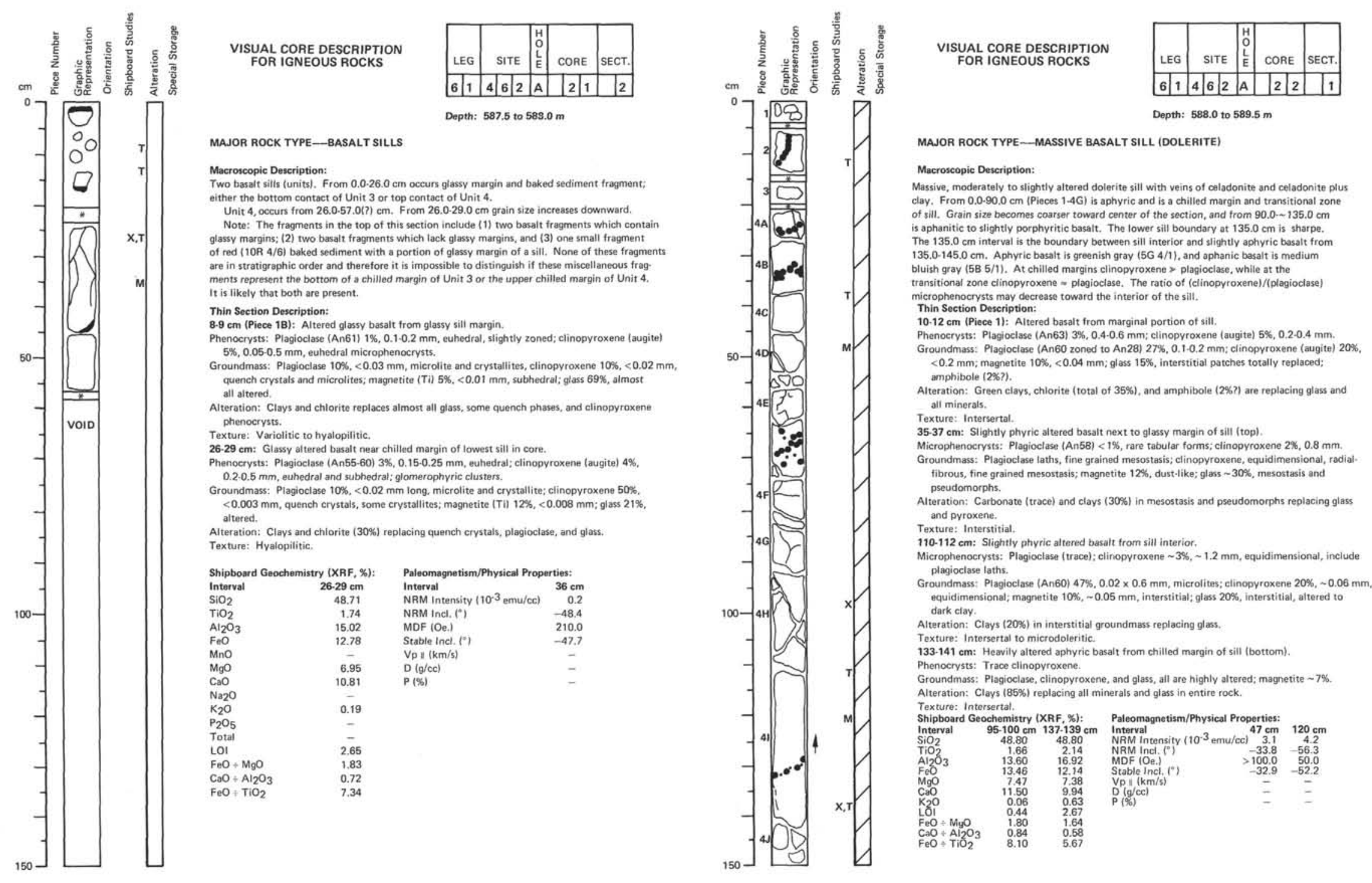


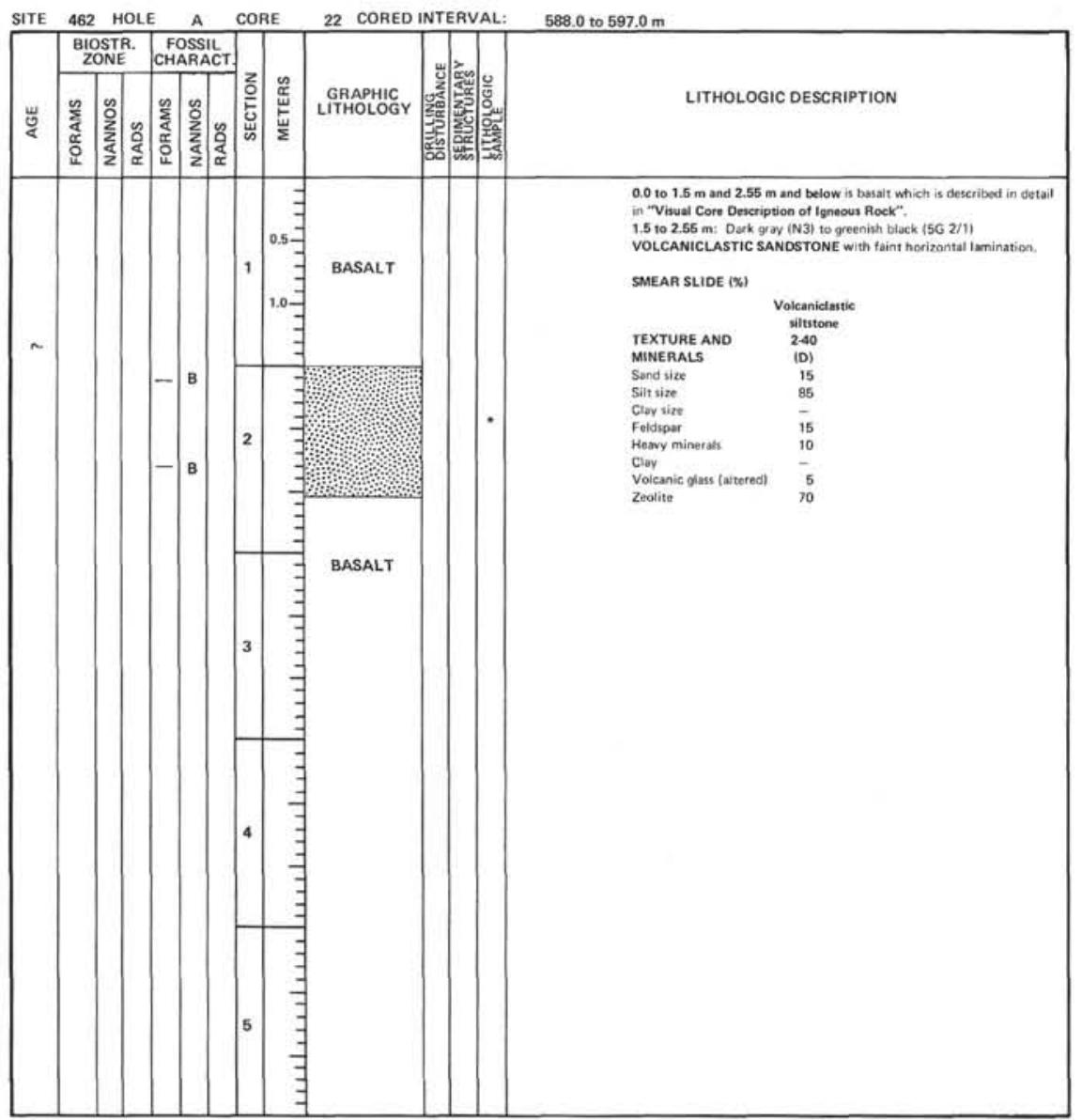



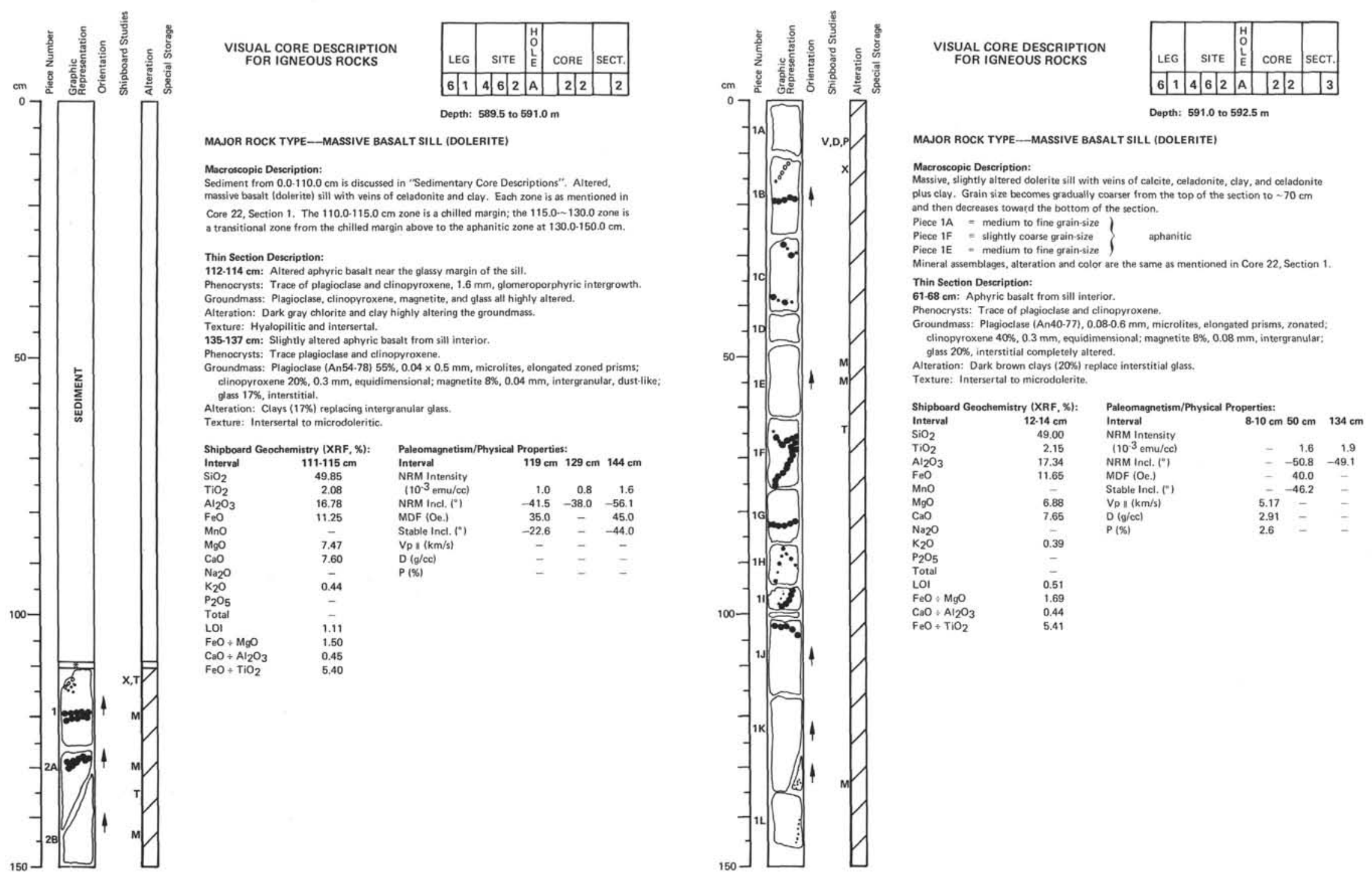


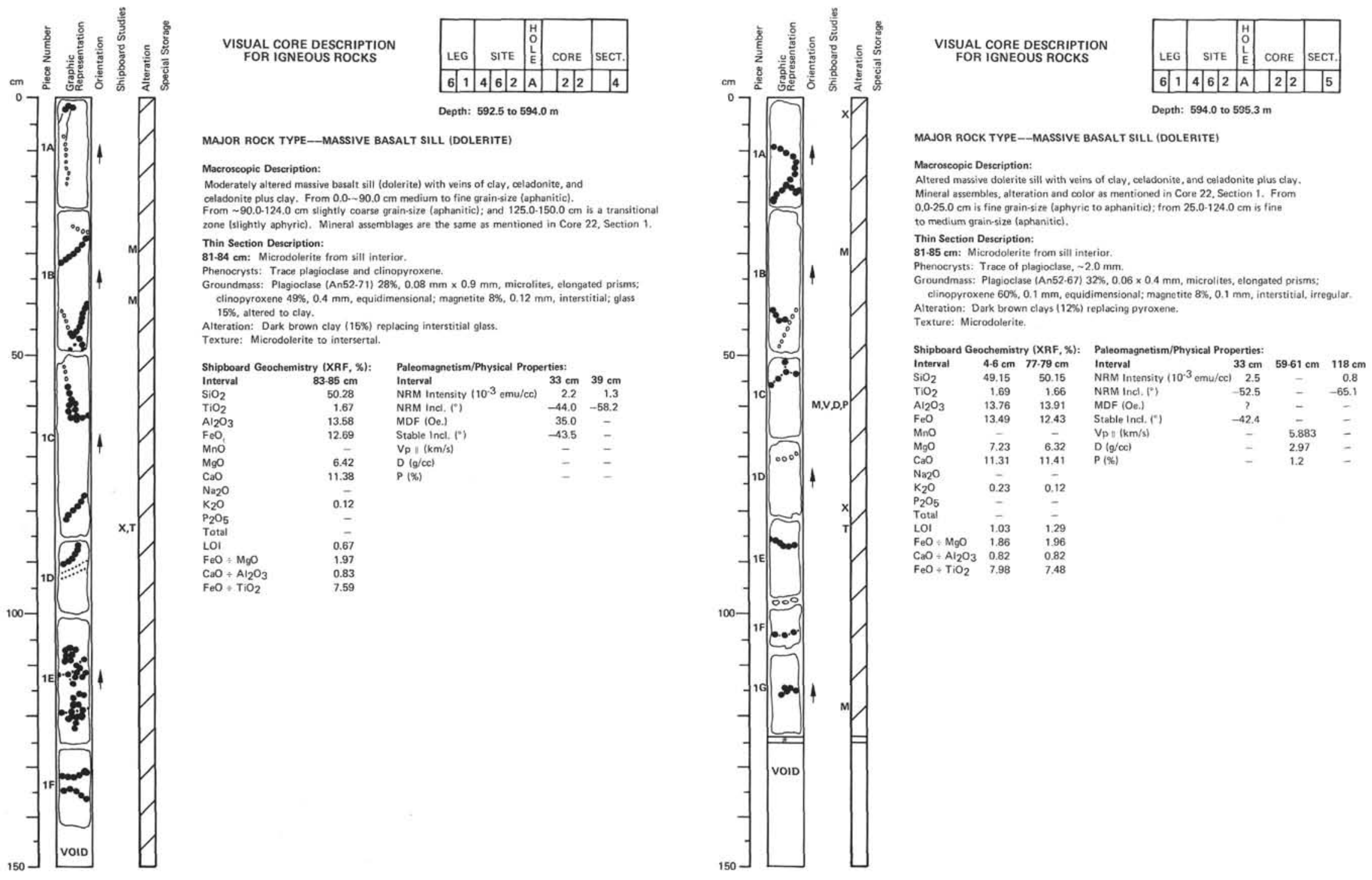




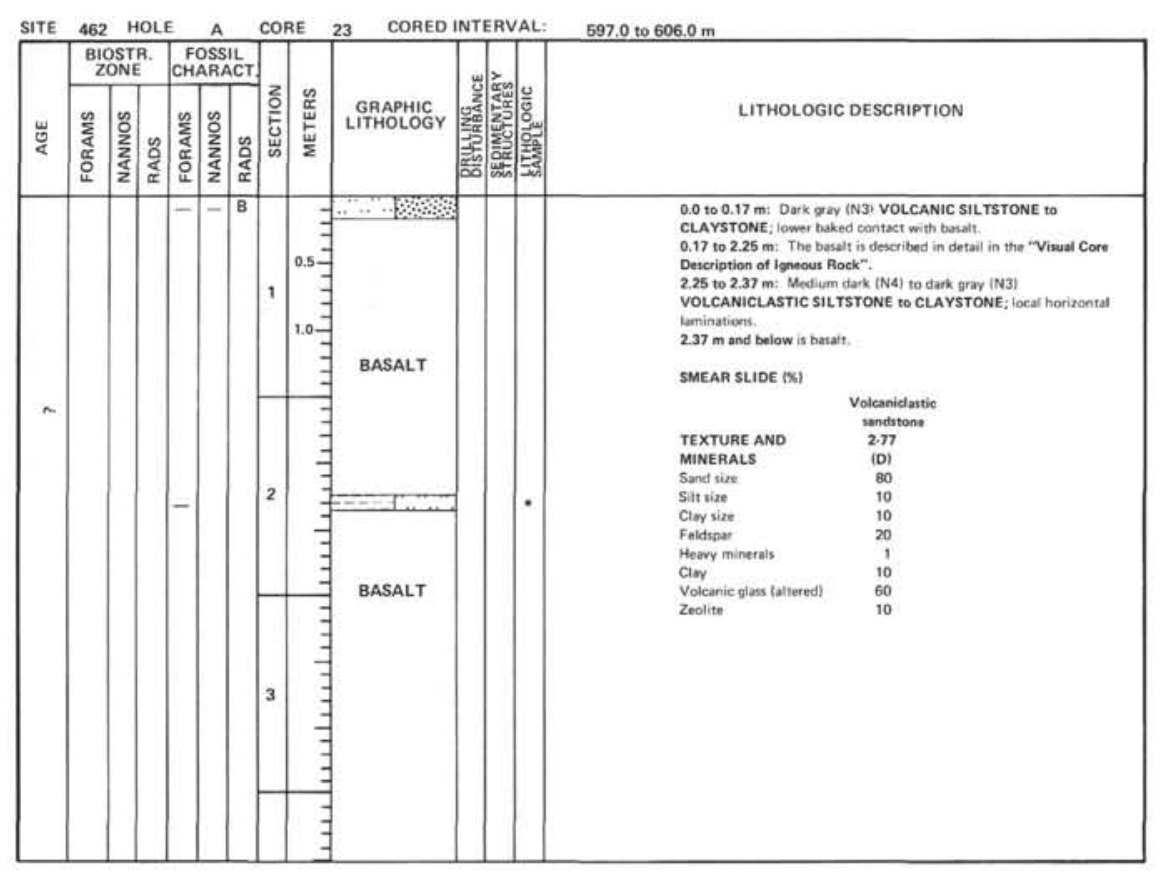




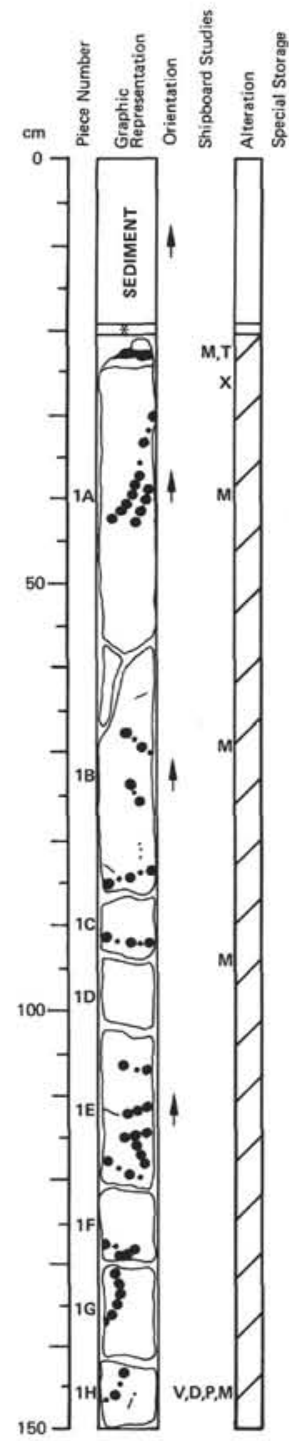

VISUAL CORE DESCRIPTION
FOR IGNEOUS ROCKS

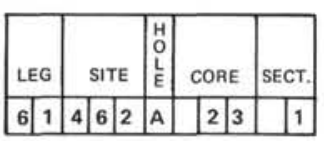

\section{Depht: 597.0 to $599.5 \mathrm{~m}$}

\section{MAJOR ROCK TYPE - MASSIVE BASALT SILL (DOLERITE)} plus clay. From $0.0-20.0 \mathrm{~cm}$ is sediment which is discussed in the "Sedimantary Core Baret Description

ent (sharp) contact, very dark red (5R 2/6). From 21,0-23.0 cm (Piece 1A): Basalt is aphyric, hyalopilitic.

From 23.0.30.0 cm (Piece iA): Bassolt is slightly phyricic transitional

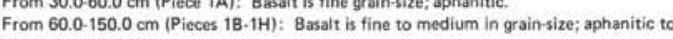
slightly porphyritic

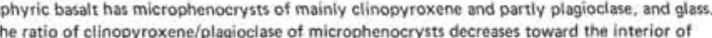
the sill.

Aphanitic to sightly porphyritic basalt is made of microphenocrysts of clinopyroxene and Aphyric to hyalopilitic basalt is medium dark gray (N4) and aphanitic to stightly porpyritic basalt is medium bluish gray (58 5/1).

. Thin Section Description:

$19.21 \mathrm{~cm}:$ Moderately al

(5) 5 miclinopyroxene 5\%, pseudomorphs Groundmass: Plagioclase 5.6\%, and clinop

5.6\%, <0.1 mm, altered to clay and magnetite $8 \%, 0.01 \mathrm{~mm} ;$ glass $75 \%$, altered.

Alteration: Carbonate (15:) in veins and replacing clinopyroxene phenocrysts. Clays and

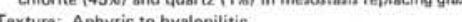

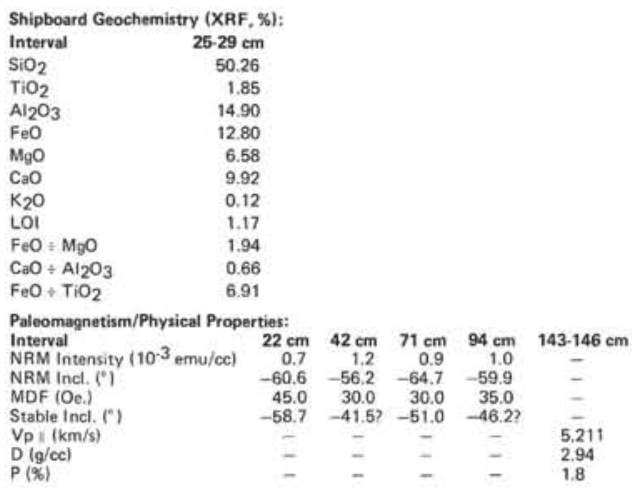

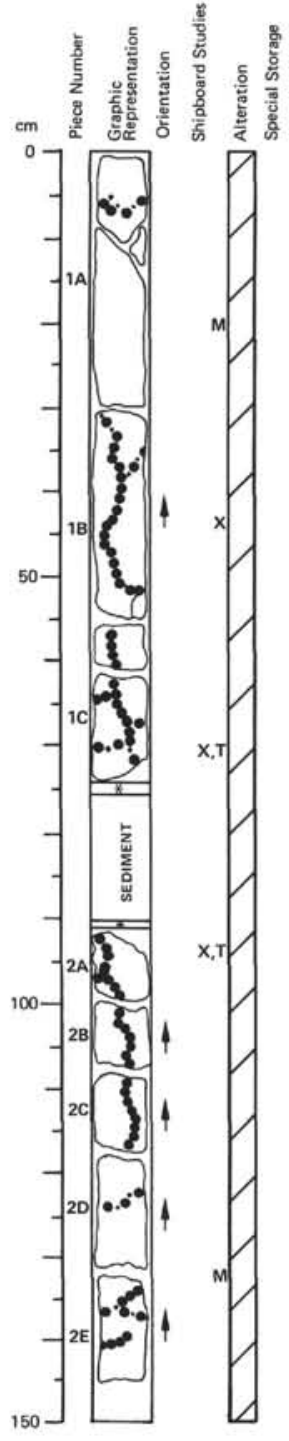

VISUAL CORE DESCRIPTION

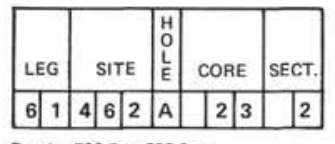

MAJOR ROCK TYPE-MASSIVE BASALT SILL (DOLERITE)

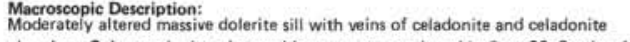

From $0.0 .50 .0 \mathrm{~cm}$ (Pieces 1A. 18): Basalt has a fine to medium grtins size and is porphyritie

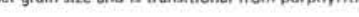
From 70.0.74.0 cm (Piece 1C): Basalt is stightly aphyric to aphyric.

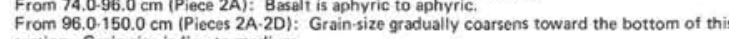
Grainsize is tine to medium

\section{Thin Section Description:}

attered basalt next to glassy sill. ( Groundmass: Plagioclase $40 \%,<0.4 \mathrm{~mm}$, subhedral to euhedral, microlite; clinopyroxene $38 \%$ $<0.1 \mathrm{~mm}$, subhedral, microlite; magnetite $5 \%,<0.05 \mathrm{~mm}$, angular; giass $15 \%$, mesostas Texture: Intersertal to replaced

$95.98 \mathrm{~cm}$ : Basalt next to glassy margin of sill.

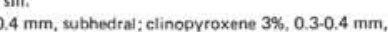
ubophitic in some areas.

fral, partly microlite; clinopyroxene $35 \%$.

<.1 mm, subhedral, partly microlite; glass $15 \%$, mostly altered. Therution. Clays 35 -40\%) replacing groundmass of clinopyroxene and glass.

\begin{tabular}{|c|c|c|c|c|c|c|}
\hline Shipboard Geo & ochemist & Y (XRF, & & Paleomagnetism/Physical Prope & erties: & \\
\hline Interval & $\begin{array}{c}44.47 \\
\mathrm{~cm}\end{array}$ & 69.71 & cm & Interval & cm & 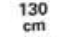 \\
\hline $\mathrm{SiO}_{2}$ & 49.03 & 49.41 & 49.65 & NRM Intensity $\left(10^{-3} \mathrm{emu} / \mathrm{cc}\right)$ & 2.2 & 0.6 \\
\hline $\mathrm{TiO}_{2}$ & 1.70 & 1.59 & 1.83 & NRM Incl, $\left(0^{\circ}\right)$ & -66.1 & -57.0 \\
\hline $\mathrm{Al}_{2} \mathrm{O}_{3}$ & 13.75 & 16.86 & 15.37 & MDF (Oe.) & 35.0 & 50.0 \\
\hline $\mathrm{FeO}$ & 12.38 & 11.59 & 12.64 & Stable Incl. (") & -51.9 & $?$ \\
\hline MnO & & & & $V_{p},(\mathrm{~km} / \mathrm{s})$ & & - \\
\hline $\mathrm{MgO}$ & 7.02 & 7.24 & 6.69 & $D(g / c)$ & - & - \\
\hline $\mathrm{caO}$ & 11.20 & 7.54 & 10.24 & $P(\%)$ & - & - \\
\hline $\mathrm{Na}_{2} \mathrm{O}$ & & $\overline{0.35}$ & $\overline{0.12}$ & & & \\
\hline $\mathrm{K}_{2} \mathrm{O}$ & 0.06 & 0.35 & 0.12 & & & \\
\hline $\begin{array}{lll}\mathrm{P}_{2} \mathrm{O}_{5} & -1 \\
T & \end{array}$ & $\overline{-}$ & $\overline{-}$ & $\overline{-}$ & & & \\
\hline $\begin{array}{l}\text { lotal } \\
\text { LoI }\end{array}$ & 0.58 & 2.30 & 1.49 & & & \\
\hline $\mathrm{FeO}+\mathrm{MgO}$ & 1.76 & 1.60 & 1.88 & & & \\
\hline $\mathrm{CaO}+\mathrm{Al}_{2} \mathrm{O}_{3}$ & 0.81 & 0.44 & 0.66 & & & \\
\hline $\mathrm{FeO}+\mathrm{TiO}_{2}$ & 7.28 & 7.28 & 6.90 & & & \\
\hline
\end{tabular}



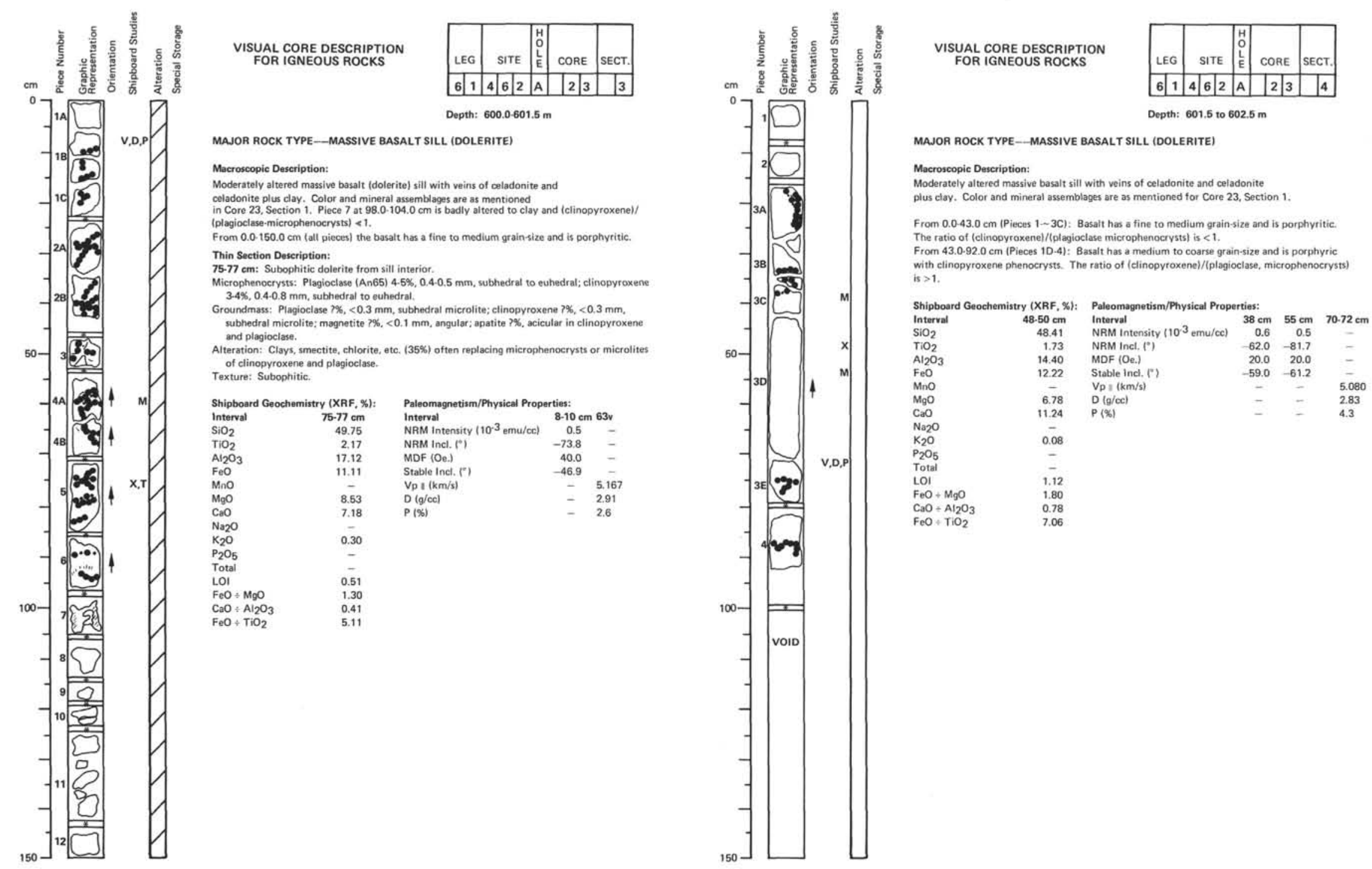


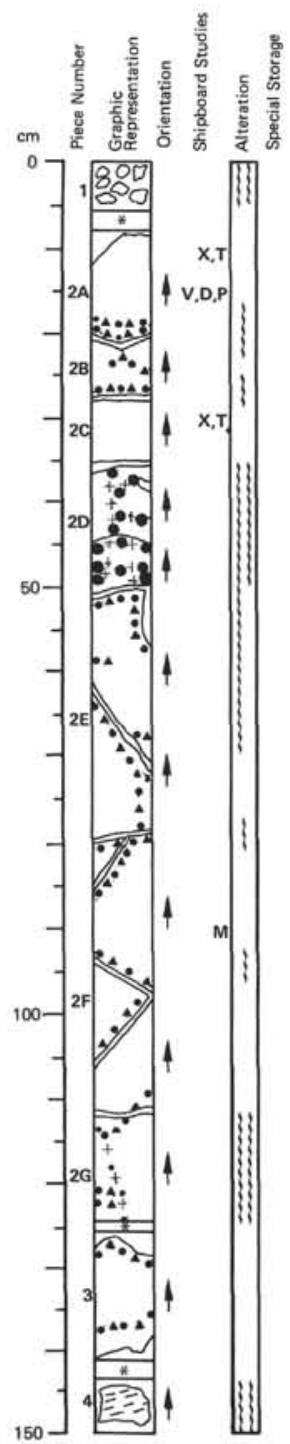

\section{VISUAL CORE RESCRIITTION
FOR IGNEOUS ROCKS

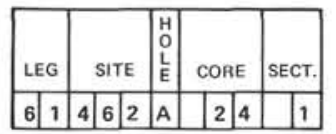

MAJOR ROCK TYPE-MASSIVE BASALT SILL (DOLERITE)

\section{Macroscopic Description:}

Massive aphyric microdolerites with veins of celadonite plus pyrite and celadonite plus quartz. Thin veins $10.5-2.0 \mathrm{~mm}$ ) consist of celadonite and pyrite, but quartz

From $0.0 .150 .0 \mathrm{~cm}$ the mi

represent the same unit as in Core 23 , Section 4 . Pyroxene is partly altered to chlorite Intervals from $25.0 .32 .0 \mathrm{~cm}$ and from $80.0 \cdot 107.0 \mathrm{~cm}$ hove a finer grain-size.

Thin Section Description:

8.10 cm: Subophitic dolerite from sill interior.

$0.409 \mathrm{~mm}$, subhedral: clinopyroxene $3.4 \%$

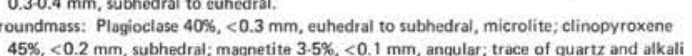
feldspar.
Alteration: Clays (35\%) often replace microphenocrysts and microlites of plagioclase and Texture: Subophitic

$27.31 \mathrm{~cm}$ : Subophitic dolerite from interior of sill. icrophenocrysts: Plagioclase (An65) 6.8\%, 0.41.5 mm, subhedral to euhedral; clinopyroxene $6.8 \%, 0.3-0.4 \mathrm{~mm}$, subhedral to zuhedral, of ten glomeroporphyritic.

$<03 \mathrm{~mm}$, haghectrat quartz and alkali feldspar.

\begin{tabular}{|c|c|c|c|c|c|}
\hline \multirow{2}{*}{\multicolumn{3}{|c|}{$\begin{array}{l}\text { Shipboard Geochemistry (XRF, X): } \\
\text { It. }\end{array}$}} & \multicolumn{3}{|c|}{ netism/Physical Properties: } \\
\hline & & & 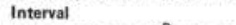 & $16-18 \mathrm{~cm}$ & $\mathrm{~cm}$ \\
\hline $\mathrm{SiO}_{2}$ & 48.18 & 49.36 & NRM Intensity $\left(10^{-3} \mathrm{emu} / \mathrm{ccl}\right.$ & $1-$ & 0.9 \\
\hline $\mathrm{TiO}_{2}$ & 1.73 & 1.73 & NRM Incl. (") & - & -65.2 \\
\hline $\mathrm{A}_{2} \mathrm{O}_{3}$ & 14.12 & 14.02 & MDF (Oe.) & - & 25.0 \\
\hline $\mathrm{FeO}$ & 12.81 & 12.39 & Stable Incl. (") & ${ }^{-}$ & $-53.9 ?$ \\
\hline $\mathrm{MnO}$ & & & $V_{p} t(k m / s)$ & 5.186 & - \\
\hline $\mathrm{MgO}_{\mathrm{g}}>2>-2$ & 6.83 & 6.78 & $\mathrm{D}(\mathrm{g} / \mathrm{ccc})$ & 2.85 & - \\
\hline $\mathrm{CaO}$ & 10.78 & 11.36 & $P($ () & 4.0 & - \\
\hline
\end{tabular}

$\begin{array}{llll}\mathrm{CaO} & 10.78 & 11.36 & \mathrm{P}(\%) \\ \mathrm{Naz} & & \end{array}$

$\begin{array}{lll}\mathrm{K}_{2} \mathrm{O} & 0.09 & 0.10 \\ \mathrm{~K}_{2} & - & -\end{array}$

$\mathrm{P}_{2} \mathrm{O}_{5}$
Total

$\begin{array}{lll}\text { LOI } & 1.33 & 0.81\end{array}$

$\mathrm{Fe}_{\mathrm{F}} \mathrm{O}+\mathrm{MgO}_{\mathrm{g}} \quad 1.87 \quad 1.82$

$\begin{array}{lll}\mathrm{CaO}+\mathrm{Al}_{2} \mathrm{O}_{3} & 0.76 & 0.81 \\ \mathrm{FeO}+\mathrm{TiO}_{2} & 7.40 & 7.16\end{array}$

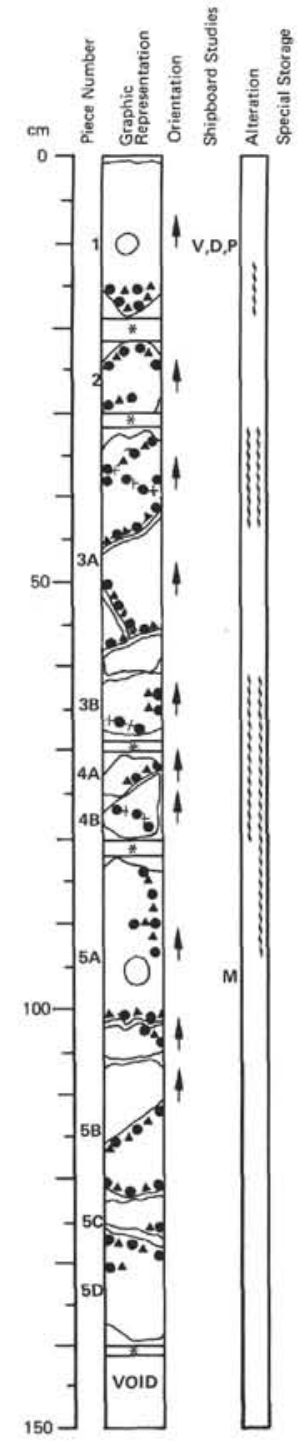

\section{VISUAL CORE DESCRIPTION
FOR IGNEOUS ROCKS

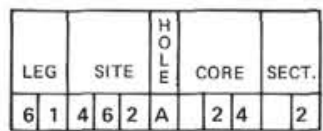

Depth: 607.5 to $609.0 \mathrm{~m}$

MAJOR ROCK TYPE--MASSIVE BASALT SILL (DOLERITE)

Macroscopic Description:

Casconite plas quartz. This dolerite is of the 4 as in Section 1 of

\begin{tabular}{|c|c|c|}
\hline \multirow{2}{*}{\multicolumn{3}{|c|}{ Paleomagnetism/Physical Properties: }} \\
\hline & $8.11 \mathrm{~cm}$ & \\
\hline NRM Intensity $\left(10^{-3} \mathrm{emu} / \mathrm{cc}\right]$ & & \\
\hline NRM Ind. [I) & & -62.6 \\
\hline DF iC & - & 35.0 \\
\hline$(")$ & $=$ & -52.7 \\
\hline$V_{p},(k t$ & 5.501 & \\
\hline$D(g / c)$ & 2.89 & \\
\hline & & \\
\hline
\end{tabular}



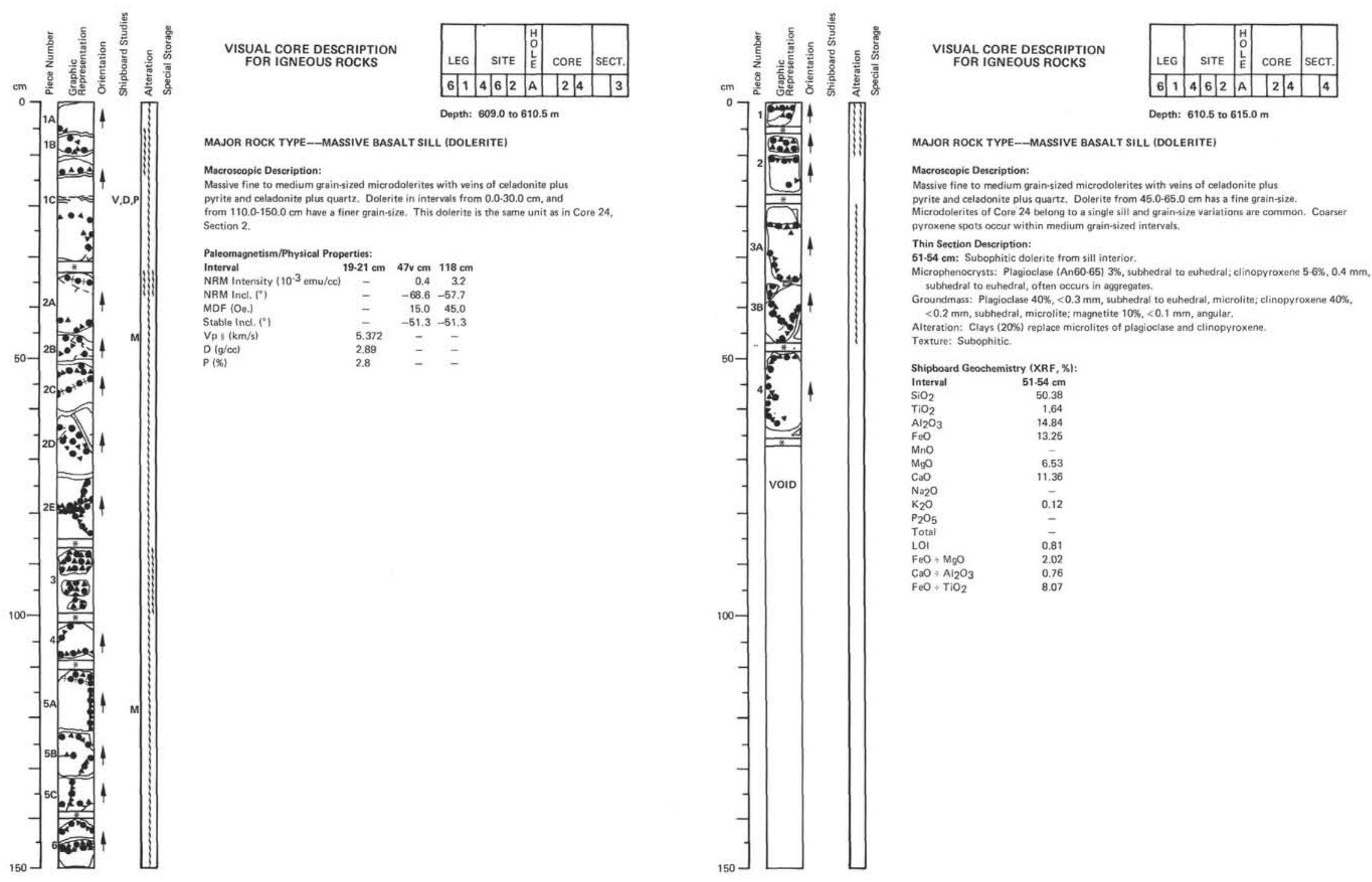

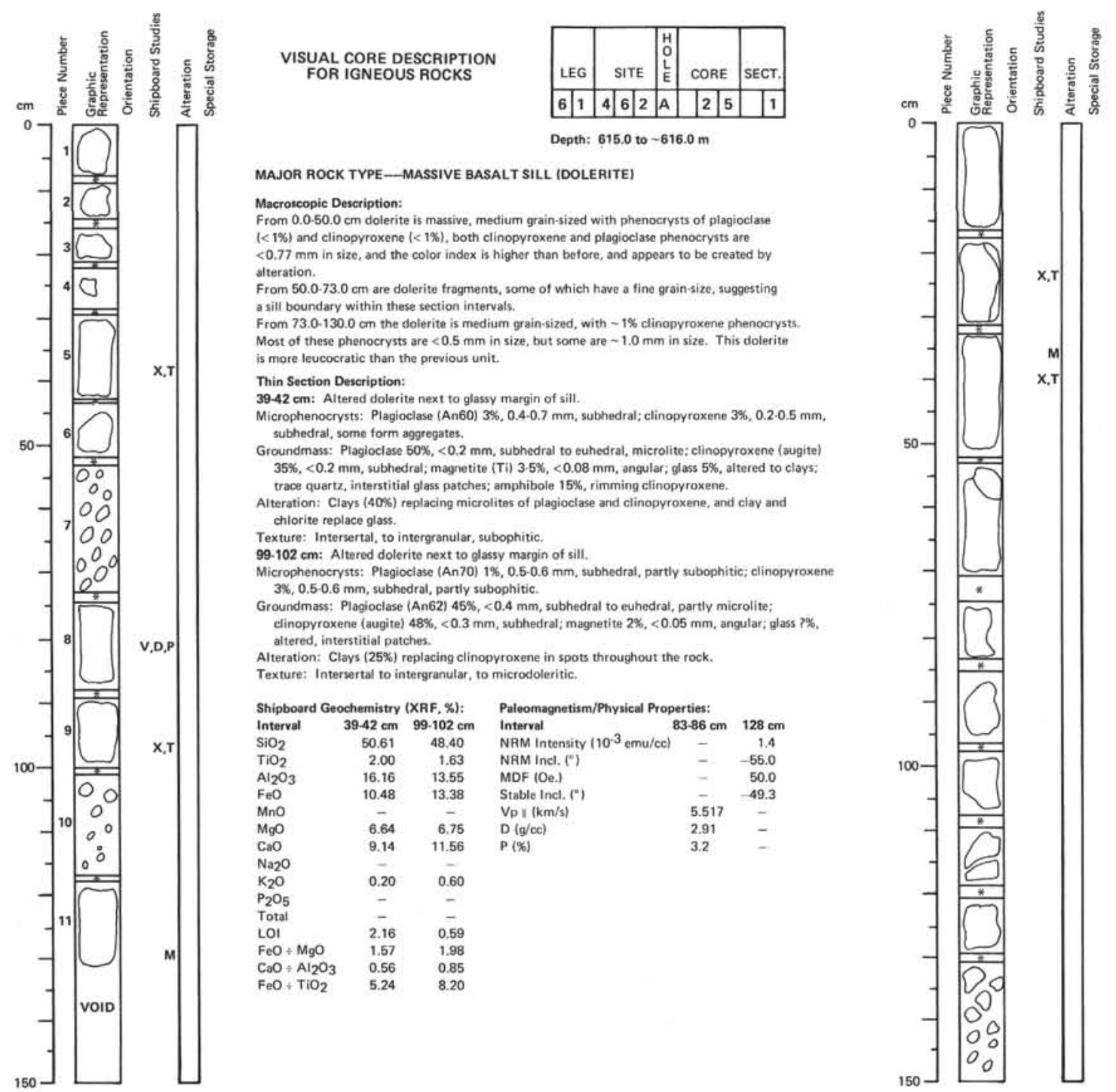
Depth: 615.0 to $\sim 616.0 \mathrm{~m}$

MAJOR ROCK TYPE--MASSIVE BASALT SILL (DOLERITE)

Macroscopic Description:

作 $<0.77 \mathrm{~mm}$ in size, and the color index is higher than betore, and appears to be created by From $50.0 .73 .0 \mathrm{~cm}$ are dolerite fragments, some of which have a fine grain-size, suggesting From $73.0 .130 .0 \mathrm{~cm}$ the dolerite is medium Most of these phenocrysts are $<0.5 \mathrm{~mm}$ in size, but some are $\sim 1.0 \mathrm{~mm}$ in size. This dolerite is more leucocratic than the previous unit.

Thin Section Description:

$39-42 \mathrm{~cm}$ : Aitered dolerite next to glassy margin of sill.

.

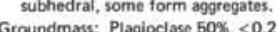

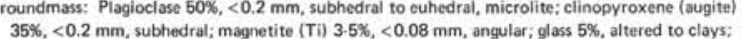
trace quartz, interstitial glass patches; amphibole $15 \%$, rimming clinopyroxene. chlorite replace glass.

Texture: Intersertal, to intergranular, subophitic,

. Altered dolerite next to glassy margin of sill. 3\%, 0.5-0.6 mm plaghoclase (An70) 1\%, 0.5-0.0

Th, $0.50 .6 \mathrm{~mm}$, subhedrat, partiy subophitic.

attered, interstitial patches

in spots throughout the rock.

Shipboard Geochemistry (XRF, X):

$\begin{array}{lrr}\text { Interval } & 39.42 \mathrm{~cm} & 99.102 \mathrm{~cm} \\ \mathrm{SiO}_{2} & 50.61 & 48.40\end{array}$

$\begin{array}{lrr}\mathrm{TiO}_{2} & 2.00 & 1.63 \\ \mathrm{Al}_{2} \mathrm{O}_{3} & 16.16 & 13.55 \\ \mathrm{~F}_{2} \mathrm{O} & 10.8 & 13.38\end{array}$

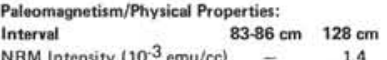

$\mathrm{FeO}$

NAM Intens
NAM Incl.
MDF $(0$.

$\begin{array}{lll}- & \text { Stable Incl. } \\ \mathrm{V}_{\mathrm{D}} \mathrm{l}(\mathrm{km} / \mathrm{s})\end{array}$

$\begin{array}{llll}9.14 & 11.56 & P(\%)\end{array}$

$\begin{array}{lll}\mathrm{K}_{2} \mathrm{O} & 0.20 & 0.60\end{array}$

${ }_{\text {Total }} \mathrm{P}_{2} \mathrm{O}_{5}$

$\begin{array}{lll}\text { LOI } & \overline{2.16} & \overline{0.59}\end{array}$

$\begin{array}{lll}\mathrm{FeO} \div \mathrm{MgO} & 1.57 & 1.98\end{array}$

$\mathrm{C} 20 \div \mathrm{Al}_{2} \mathrm{O}_{3} \quad 0.56 \quad 0.85$

\begin{tabular}{rr}
$-\quad 14$ \\
$-\quad-55.0$ \\
\hline
\end{tabular}

$\begin{array}{rr}- & 50.0 \\ -\quad & -49.3 \\ 5517 & -\end{array}$

2.91
3.2

8.20
VISUAL CORE DESCRIPTION
FOR IGNEOUS ROCKS

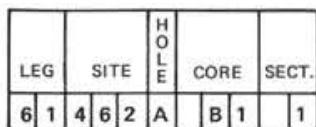
Depth: 816.0 to $626.0 \mathrm{~m}$
MAJOR ROCK TYPE.-MASSIVE BASALT SILL (DOLERITE)

Macroscopic Description:

Moth

Thin Section Description:

$23-26 \mathrm{~cm}$ : Altered dolerite from interior of sill.

Phenocrysts: Trace of plagioclase: clinopyroxene laugitel $<1 \%,<0.5 \mathrm{~mm}$.

$33 \%,<025 \mathrm{~m}$.

Texture: Microdolerite.

$40.43 \mathrm{~cm}$ : Altered diabase from sill interior.

Groundmass: Plagioclase (An60 zoned in An30, rare An70) 20\%, $0.1-0.3$ mm; clinopyroxenes (augite) $35 \%,<0.2 \mathrm{~mm}$ : magne ite (Ti) $10 \%, 0020 \mathrm{~mm}$ : glass $10 \%$, totally replaced glass patchos; trace quartz, alkoli feldspart, amphiboleen?; and apatic

Alteration: Brown clays (25\%) replacing glass, plagioclase, and clinopyroxene.

$\begin{array}{lll}\text { Interval } & 23.26 \mathrm{~cm} & 40-43 \mathrm{~cm}\end{array}$

$\begin{array}{lrrr}\text { Interval } & 23.26 \mathrm{~cm} & 40.43 \mathrm{~cm} \\ \mathrm{SiO}_{2} & 49.81 & 49.85 \\ \mathrm{~T}_{2} & .60 & \end{array}$

$\begin{array}{lrr}\mathrm{TiO}_{2} & 1.66 & 1.64 \\ \mathrm{Al}_{2} \mathrm{O}_{3} & 13.37 & 13.34 \\ \mathrm{Fe} & 12.48 & 12.91\end{array}$

Interval

$\mathrm{MnO}$

$\begin{array}{lll}\mathrm{MgO} & -7.75 & 6.47 \\ & 1127 & \end{array}$

$\mathrm{Na}_{2} \mathrm{O}-1.21-$

$\begin{array}{lll}\mathrm{K}_{2} \mathrm{O} & 0.08 & 0.08 \\ \mathrm{P}_{2} \mathrm{O} & - & -\end{array}$

$\begin{array}{lll}\text { Total } & - & - \\ \text { LOI } & 0.79 & 1.02\end{array}$

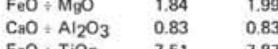




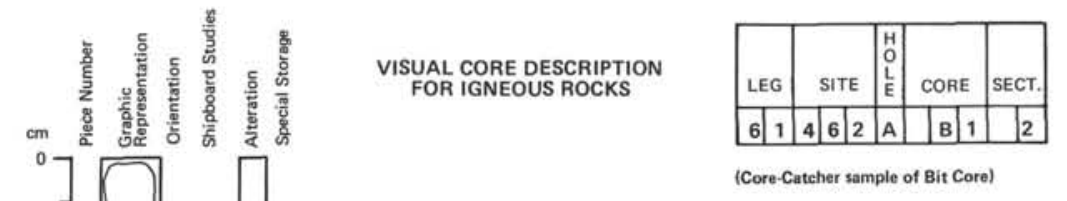

MAJOR ROCK TYPEMASSIVE BASALT SILL (DOLERITE)

Macroscopic Description:
Massive dolerite sill with $1 \%$ clinopyroxene phenocrysts $(-1.0 \mathrm{~mm})$, and veins of ofladonite.

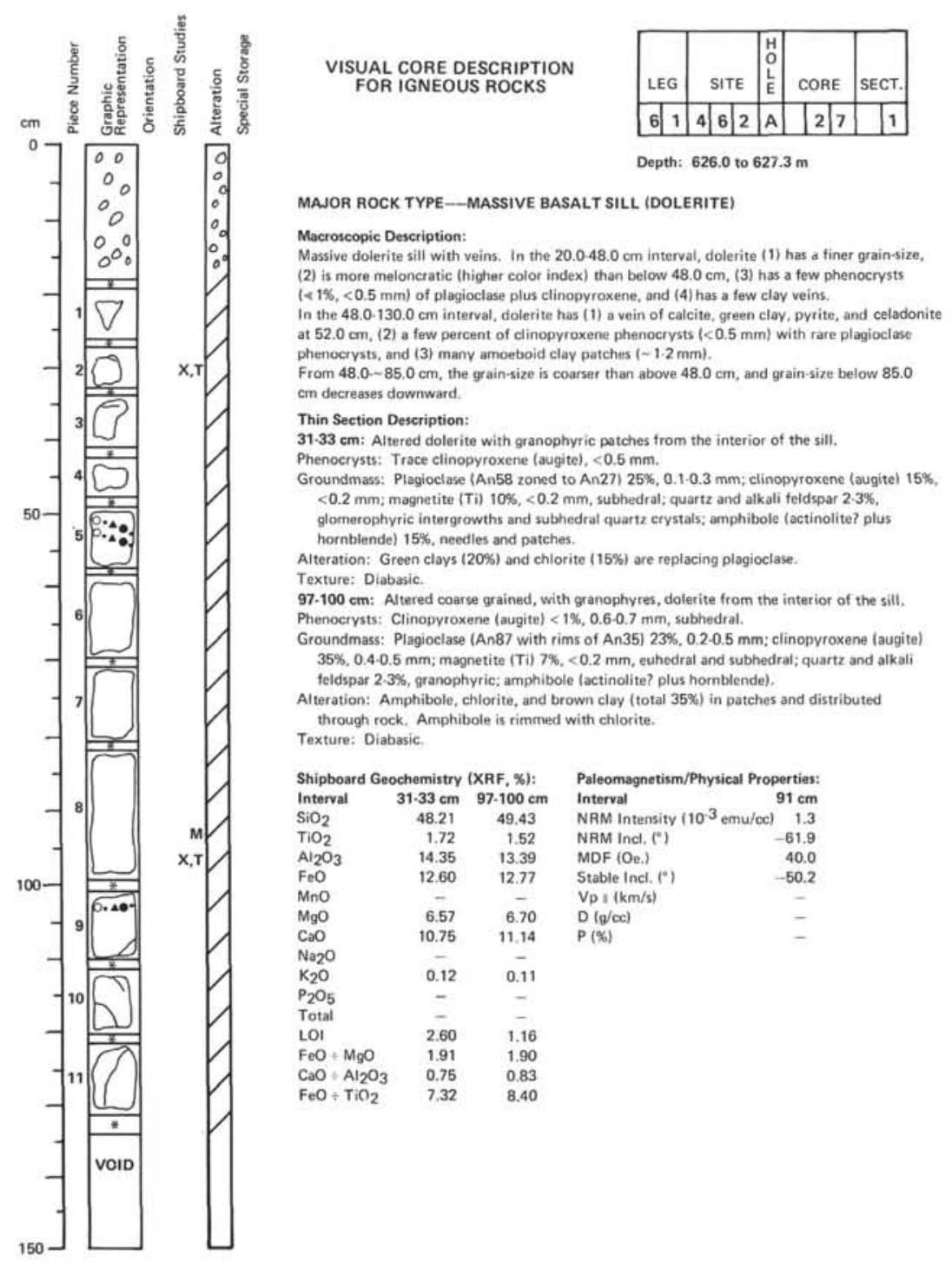



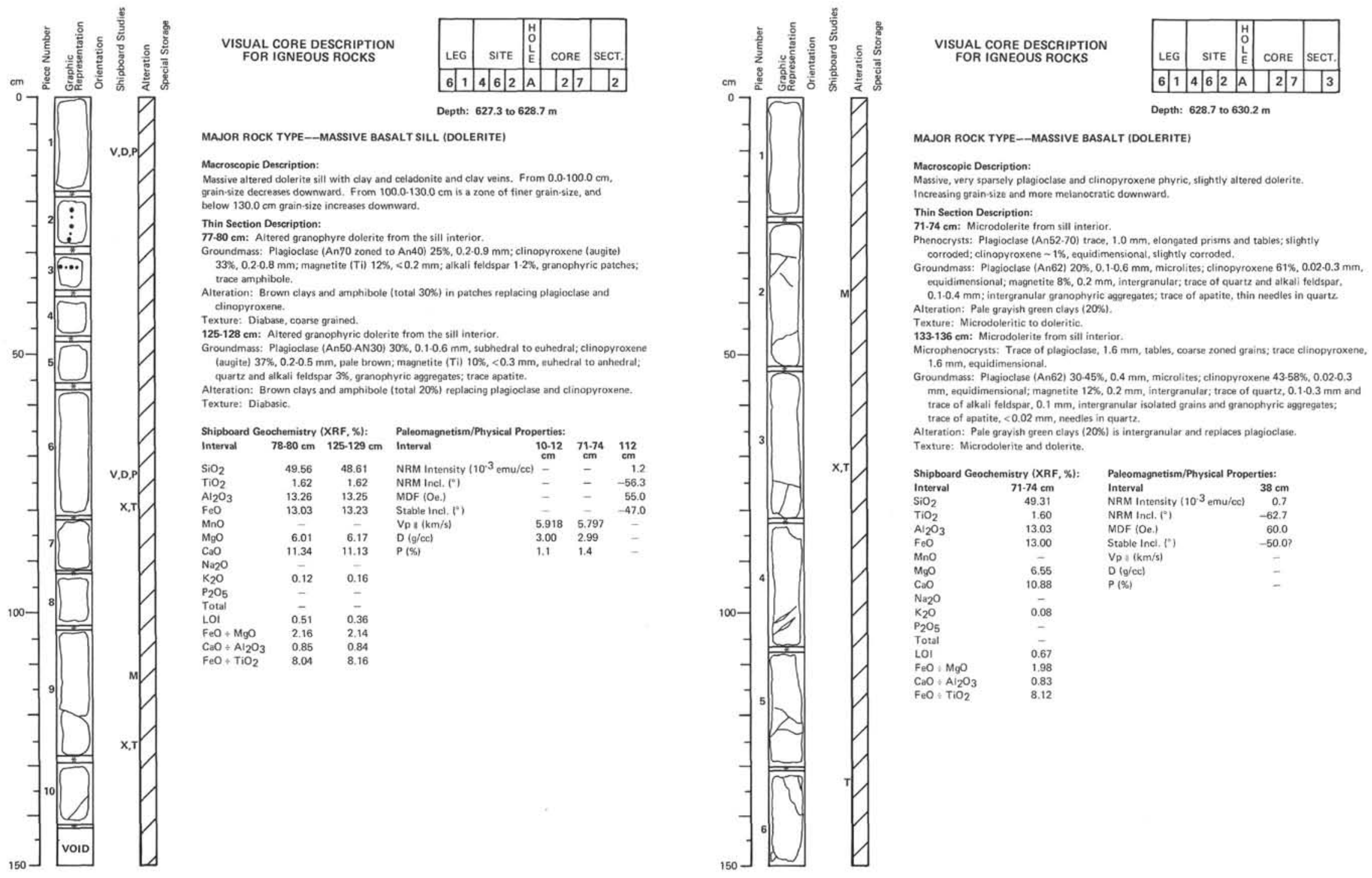

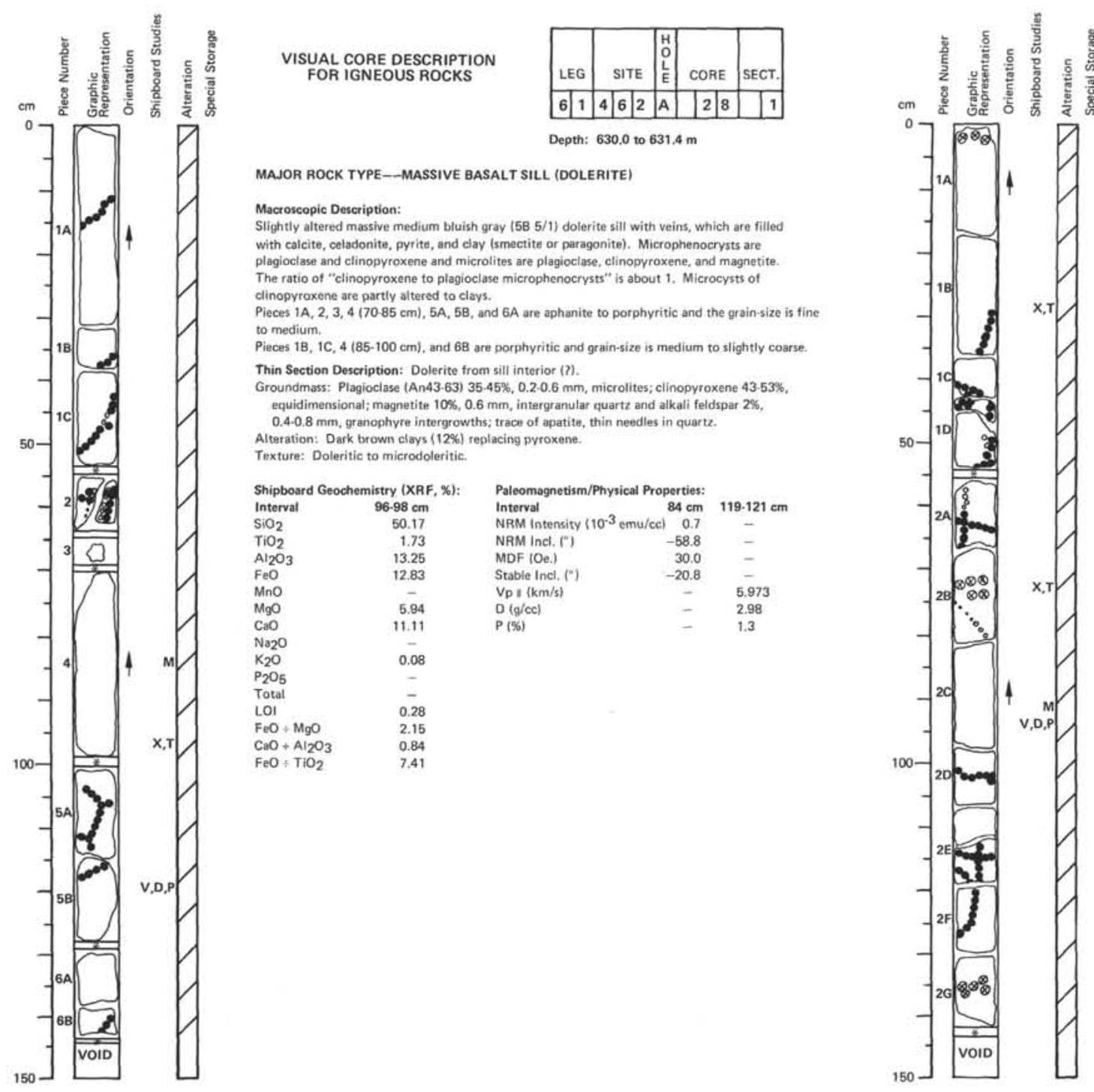

\section{\begin{tabular}{|c|c|c|c|c|c|}
$\begin{array}{c}\text { VISUAL CORE DESCRIPTION } \\
\text { FOR IGNEOUS ROCKS }\end{array}$ & LEG & SITE & 足 & & \\
L & CORE & SECT. \\
\hline
\end{tabular} \begin{tabular}{|l|l|l|l|l|l|l|l|}
\hline 6 & 1 & 4 & 6 & 2 & A & 2 & 8 \\
\hline
\end{tabular} Depth: 631.4 to $632.8 \mathrm{~m}$}

\section{SALT SILL (DOLERITE)}

\section{Macroscopic Desceription}

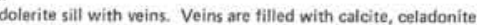
coarse grain-size and is porphyyritic las mentioned in Core 28, Section 11.

From $0.03 .0 \mathrm{~cm}, 72.070 .0 \mathrm{~cm}$, and $13.0133 .0 \mathrm{~cm}$, dolerite has a coarse grain size and

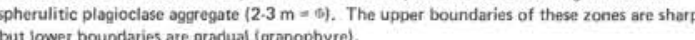

\section{Thin Section Description:}

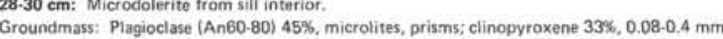
equidimensional; magnetice $7 \mathrm{~N}, 0.04 .0 .4 \mathrm{~mm}$, intergranular; glass $15 \%, 0.7 \mathrm{~mm}$, interstit Alteration: Clays (20\%) reolacing interstitial glass.

Texture: Spoted microdolecitio to dontial

$73.75 \mathrm{~cm}$ : Variolitic dolerite from sill interior.
Groundmass: Plagioclase (An52-62) $38 \%, 0.06-4.0 \mathrm{~mm}$, elongared prisms and tables, microit to: . hyalopiliticita

Alteration: Clays (106) replacing glass.
Texture: Spotted dolerite to variolite.

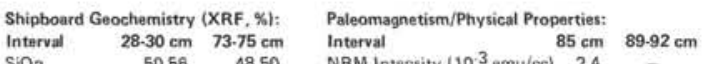

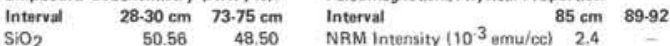

$\begin{array}{lllll}\mathrm{TiO}_{2} & 1.66 & 2.18 & \text { NRM Incl. (1) } & -60.5 \\ & 13.50 & 12.27 & \text { MDF }(0 .) & -51.7\end{array}$

$\begin{array}{llllr}\mathrm{Al}_{2} \mathrm{O}_{3} & 13.50 & 12.27 & \text { MDF }(\mathrm{Oe} \text {.) } & 30.0 \\ \mathrm{FeO} & 12.78 & 15.57 & \left.\text { Stable (ncl. }()^{2}\right) & -51.7\end{array}$

$\begin{array}{lll}\mathrm{MnO} & - & -\end{array}$

$\begin{array}{lrr}\mathrm{MgO} & 6.54 & 6.13 \\ \mathrm{CaO} & 11.39 & 9.76\end{array}$

$D(g / c c)$
$P(\%)$

$\begin{aligned} 30.0 & - \\ -51.7 & -\end{aligned}$

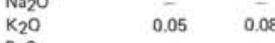

$\mathrm{P}_{2} \mathrm{O}_{5}-$

LOI $\quad 0.44 \quad 0.83$

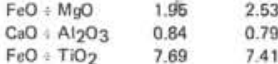




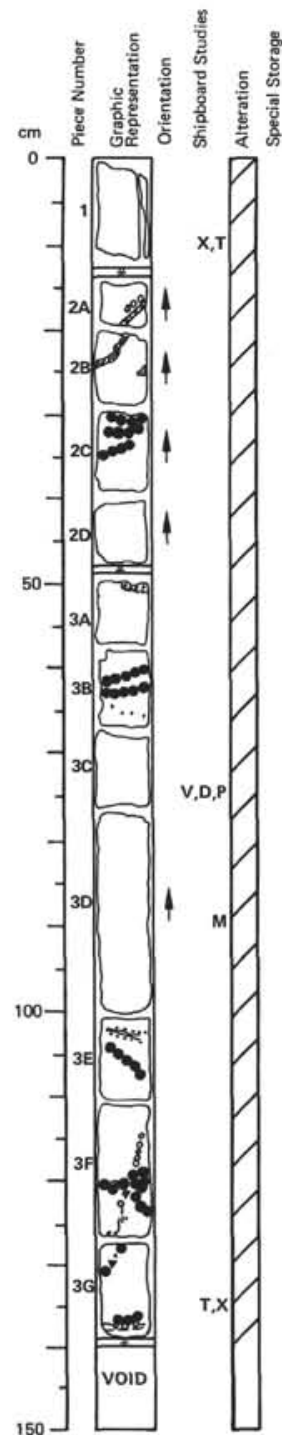

VISUAL CORE DESCRIPTION
FOR IGNEOUS ROCKS

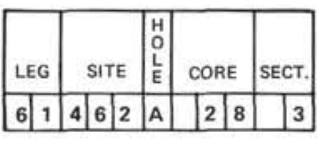
Depth: 632.8 to $634.2 \mathrm{~m}$

\section{MAOR ROCK TYPE MASSIVE BASALT SILL (DOLERITE)}

\section{Macroscopic Description}

the ins of quartz, calcite plus celadonite and pyrite, $3 C, 3 F$, and $3 G$ proceeds along veins (with pyrite). From $0.0665 .0 \mathrm{~cm}$, dolerite is porphyric dighty porohyritic and has fine to medium grainsize.

Thin Section Description:

icrodolerite from sill interior.

Croundmass: Plogioclase (An60-72) 405., $0.1-1.8 \mathrm{~mm}$, microlites, prisms; clinopyroxene 38

Brown clays (20\%) replacing interstitial glass.

Texture: Microdolerite to variolite.

Microphenocrysts: Trace of plagioclase, $1.2 \mathrm{~mm}$, elongated prisms; clinopyroxene $\sim 1 \%, 0.5 \mathrm{~mm}$

Groundmass: Plagicclase (An6865) 35.40\%, nierolites; clinopyroxene 58.53\%, $0.03 \mathrm{~mm}$ onal; magnetite $7 \%, 0.2 \mathrm{~mm}$, intergranular. Alteration: Clay (15\%) forming brown pseudomorphs of all minerals and pale green groundmas. Texture: Microdolerites

\begin{tabular}{|c|c|c|c|c|c|}
\hline \multicolumn{3}{|c|}{ ipboard Geochemistry (XRF, X): } & \multicolumn{3}{|c|}{ Paleomagnetism/Physical Properties: } \\
\hline Interval & $8-10 \mathrm{~cm} 1$ & $34.136 \mathrm{~cm}$ & Interval & $15-77 \mathrm{~cm}$ & \\
\hline $\mathrm{SiO}_{2}$ & 48.89 & 51.18 & NRM Intensity $\left(10^{-3} \mathrm{emu} / \mathrm{ccc}\right)$ & & 0.8 \\
\hline & 1.37 & 1.67 & NRM Incl. (\%) & - & \\
\hline $\mathrm{Al}_{2} \mathrm{O}_{3}$ & 13.69 & 13.49 & MDF $\left(O_{e}.\right)$ & - & 30.0 \\
\hline $\mathrm{FeO}_{\mathrm{eO}}-(-1-3$ & 12.17 & 12.79 & Stable Incl. $\left(1^{\circ}\right)$ & & $-31.7 ?$ \\
\hline $\mathrm{MnO}$ & & & $V_{p} \|(\mathrm{km} / \mathrm{s})$ & 5.953 & - \\
\hline $\mathrm{MgO}_{9} \mathrm{O}-2-2-1$ & 6.66 & 6.49 & $D(g / c c)$ & 2.99 & - \\
\hline $\mathrm{CaO}$ & 11.86 & 11.30 & $P\left(x_{0}\right)$ & 7.0 & - \\
\hline $\mathrm{Na}_{2} \mathrm{O}$ & & & & & \\
\hline $\begin{array}{l}\mathrm{K}_{2} \mathrm{O} \\
\mathrm{P}_{2} \mathrm{O}_{5}\end{array}$ & 0.08 & 0.04 & & & \\
\hline $\begin{array}{l}\mathrm{P}_{2} \mathrm{O}_{5} \\
\text { (otal }\end{array}$ & - & - & & & \\
\hline LOI & 0.59 & 0.52 & & & \\
\hline $\mathrm{FeO}+\mathrm{MgO}$ & 1.82 & 1.97 & & & \\
\hline $\mathrm{C}_{2} \mathrm{O} \div \mathrm{Al}_{2} \mathrm{O}_{3}$ & 0.86 & 0.84 & & & \\
\hline $\mathrm{FeO}+\mathrm{TiO}_{2}$ & 8.88 & 7.65 & & & \\
\hline
\end{tabular}

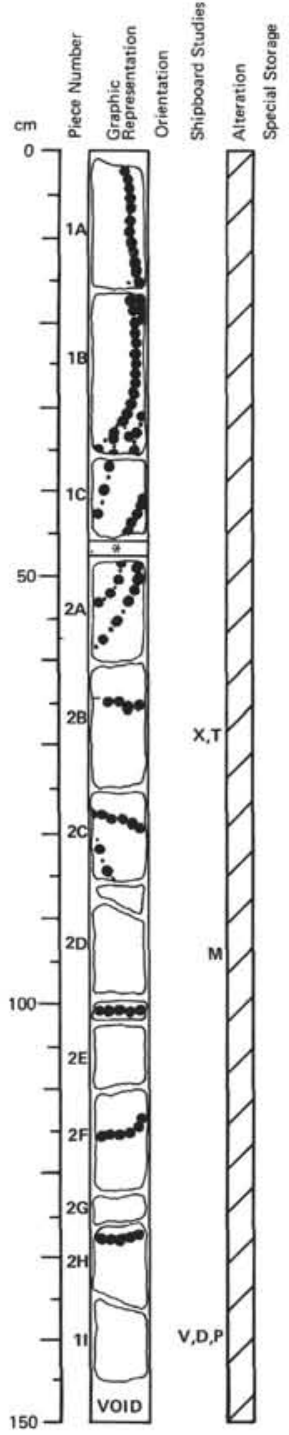

VISUAL CORE DESCRIPTION

OR IGNEOUS ROCKS

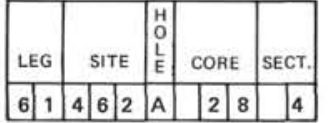

Depth: 634.2 tc 635.6

MPOP ROCK TYPE MASSIVE BASALT IDOLERITE and clay. The sili is the same as in Core 28 , Section 1. From $0.0-150.0 \mathrm{~cm}$, dolerite has A A

Thin Section Description:

Microphenocrysts: Plagioclase (An 72) 2\%, $0.81 .2 \mathrm{~mm}$, elongated prisms; clinopyroxene 1\%, 1.2

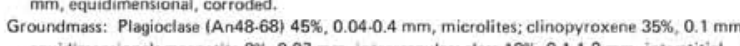
$0.07 \mathrm{~mm}$, intergranutar; glass $12 \%, 0.1 \cdot 1.3 \mathrm{~mm}$, interstitial Alteration: Clays (20\%5)

gray groundmass.
Texture: Spotted microdoleritic to hyalopilitic

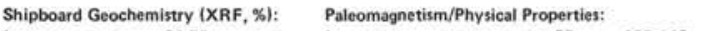

$\begin{array}{lrl}\text { Interval } & 68.70 \mathrm{~cm} \\ \mathrm{SiO}_{2} & 49.73 \\ \mathrm{~T}_{2} & 1.35\end{array}$

$\begin{array}{lr}\mathrm{TiO}_{2} & 1.65 \\ \mathrm{Al}_{2} \mathrm{O}_{3} & 13.17\end{array}$

$\begin{array}{ll}\mathrm{Al}_{2} \mathrm{O}_{3} & 13.17 \\ \mathrm{FeO} & 13.09\end{array}$

$\mathrm{MnO}$
$\mathrm{MgO}$

$\begin{array}{lr}\mathrm{NaO} & 10.88 \\ \mathrm{Na} 2 \mathrm{O} & -\end{array}$

$\mathrm{K}_{2} \mathrm{O} \quad 0.14$

$\mathrm{P}_{2} \mathrm{O}_{5}$
Total

0.42

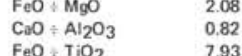

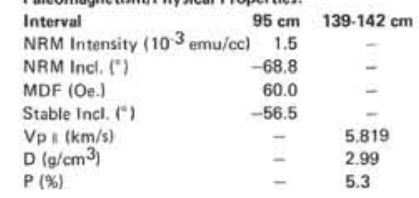

0.14
-
- 

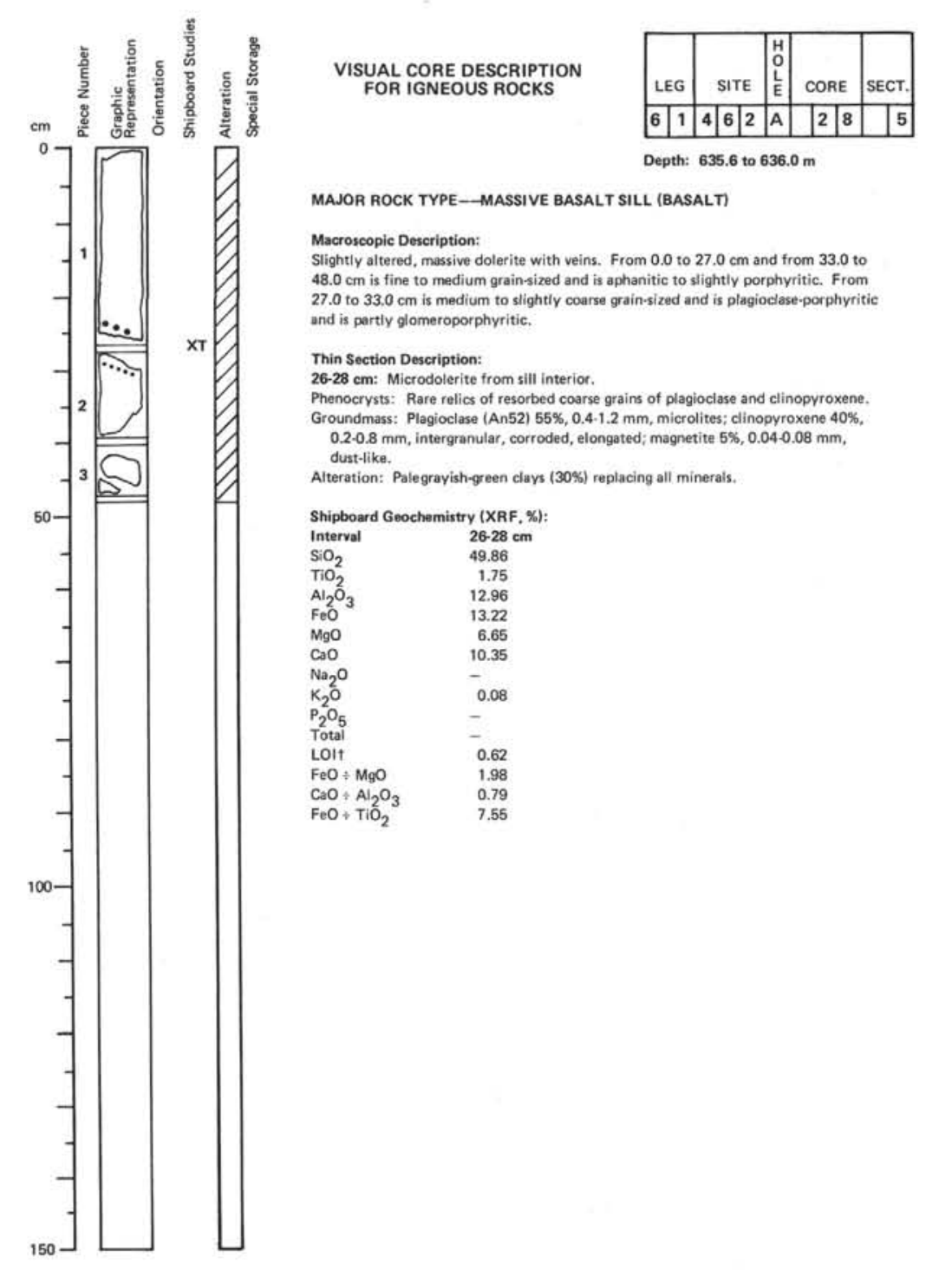

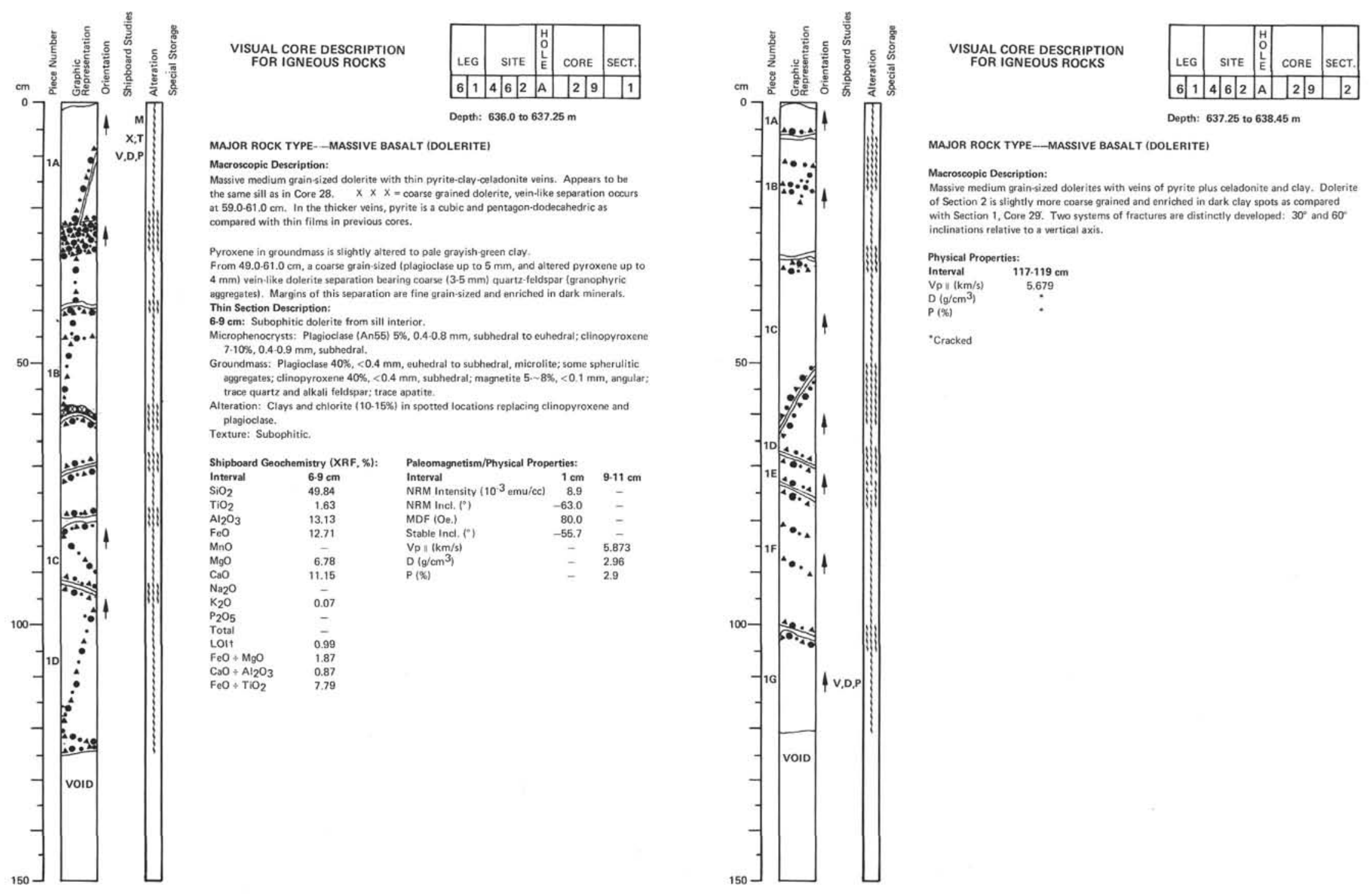

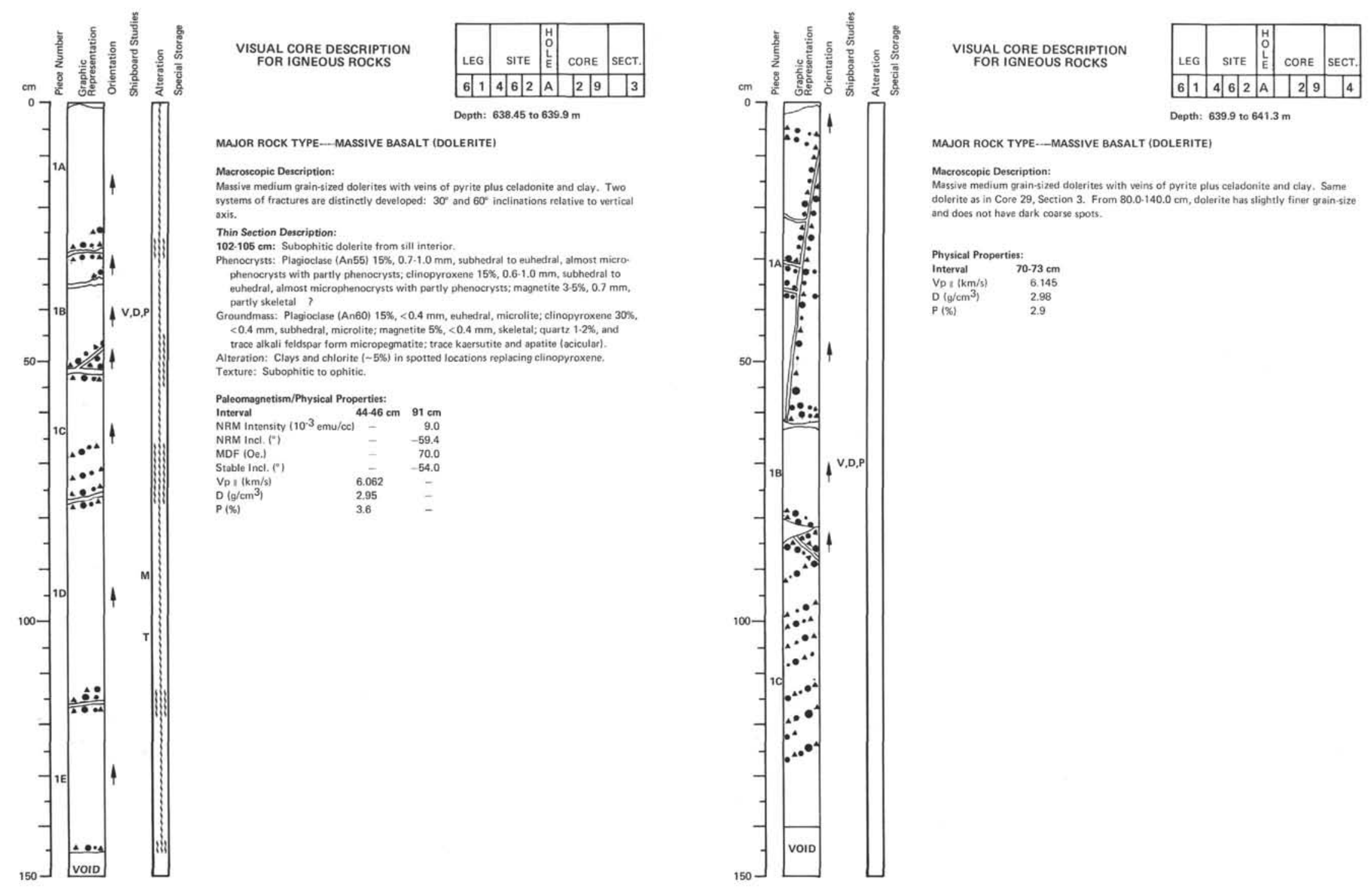

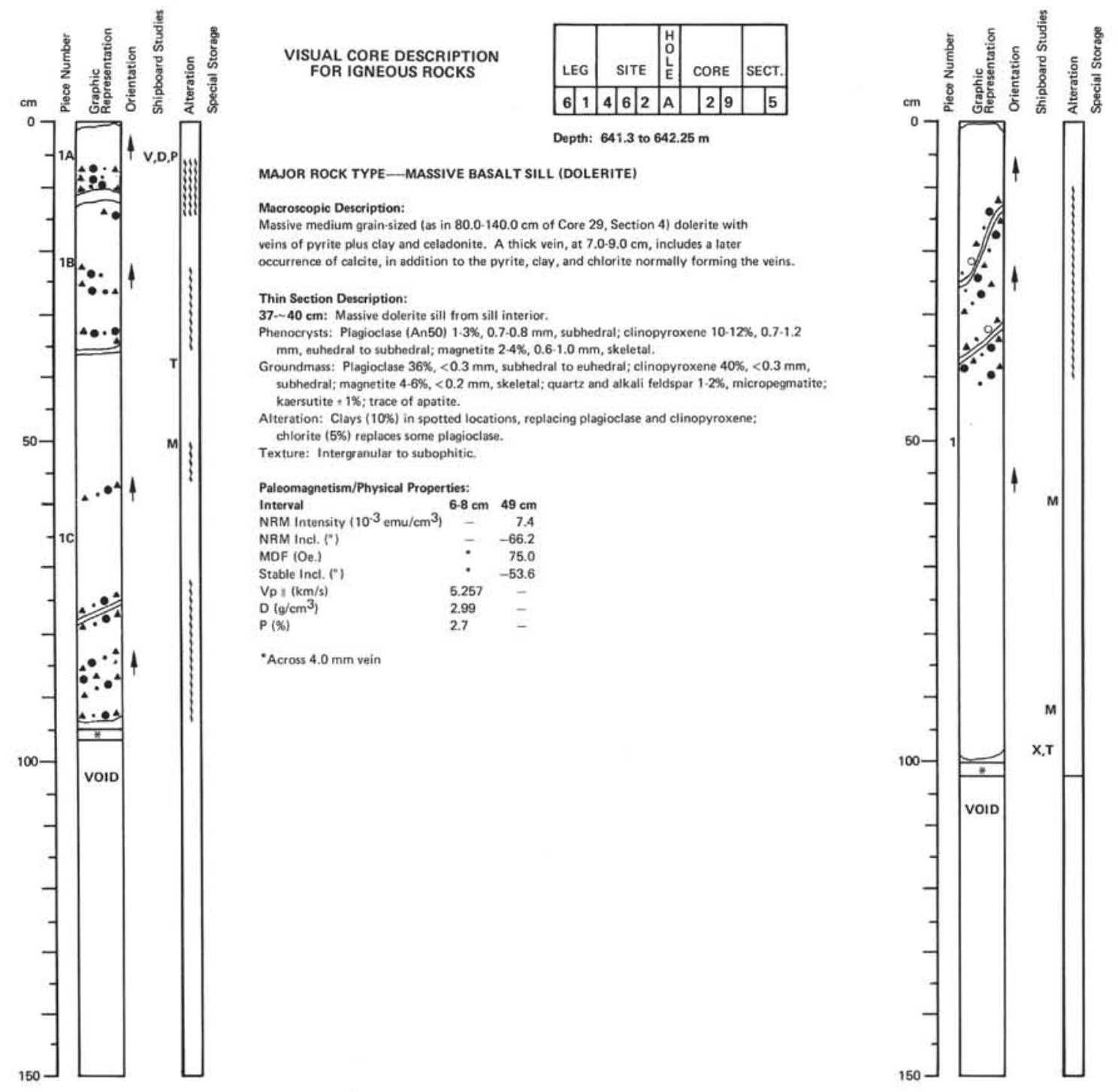

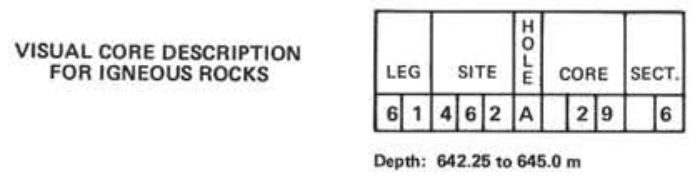

MAJOR ROCK TYPE--MASSIVE BASALT SILL (DOLERITE)

Macroscopic Description: Veins are typically composed of a combination of pyrite, clav, and celadonite, and thicker veins also include calcite.

Phenocrysts: Plagioclase (An60-63) $2 \cdot 3 \%, 0.5-0.9 \mathrm{~mm}$, subhedral to euhedral, partly phenocrysts clinopyroxene $5.7 \%, 0.5-0.9 \mathrm{~mm}$, subhedral, partly phenocrysts; magnetite $1 \cdot 2 \%, 0.7 \mathrm{~mm}$, skeletal, partly phenocrysts.

Groundmass: Plagioclase $41 \%,<0.3 \mathrm{~mm}$, euhedral to subhedral, microlite; clinopyroxene $40 \%$,

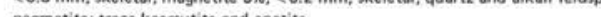
Aiteration: Clays (15\%) replacing clino clinopyroxene: chlorite (5\%) replacing plagioclase. Shipbog

\begin{tabular}{|c|c|c|}
\hline & ry (XRF, X): & Paleomagnetism/Physical Properties \\
\hline Interval & $97.100 \mathrm{~cm}$ & $\begin{array}{l}\text { Interval } \\
6 \mathrm{~cm}\end{array}$ \\
\hline $\mathrm{SiO}_{2}$ & 49.38 & NRM Intensity $\left(10^{-3} \mathrm{emu} / \mathrm{cc}\right) \quad 8.2$ \\
\hline & 1.47 & NRM Ind. $\left({ }^{\circ 1}\right) \quad-68.6$ \\
\hline $\mathrm{Al}_{2} \mathrm{O}_{3}$ & 13.14 & MDF $(0 e)$. \\
\hline $\mathrm{FeO}$ & 12.37 & Stable Incl. $\left.1^{\circ}\right)$ \\
\hline MnO & - & $V_{\rho}:(\mathrm{km} / \mathrm{s})$ \\
\hline $\mathrm{MgO}$ & 7.04 & $\mathrm{D}\left(\mathrm{g} / \mathrm{cm}^{3}\right)$ \\
\hline CaO & 11.18 & $P(\$)$ \\
\hline $\begin{array}{l}\mathrm{Na}_{2} \mathrm{O} \\
\mathrm{K}_{2} \mathrm{O}\end{array}$ & & \\
\hline $\begin{array}{ll}\mathrm{K}_{2} \mathrm{O} \\
\mathrm{P}_{2} \mathrm{O}_{5}\end{array}$ & 0.29 & \\
\hline $\begin{array}{l}\mathrm{P}_{2} \mathrm{~T}^{2} \mathrm{~T} \\
\text { Total }\end{array}$ & - & \\
\hline LOI & 0.20 & \\
\hline $\mathrm{FeO}+\mathrm{MgO}$ & 1.75 & \\
\hline $\mathrm{CaO}+\mathrm{Al}_{2} \mathrm{O}_{3}$ & 0.85 & \\
\hline $\mathrm{FeO}=\mathrm{TiO}_{2}$ & 8.41 & \\
\hline
\end{tabular}



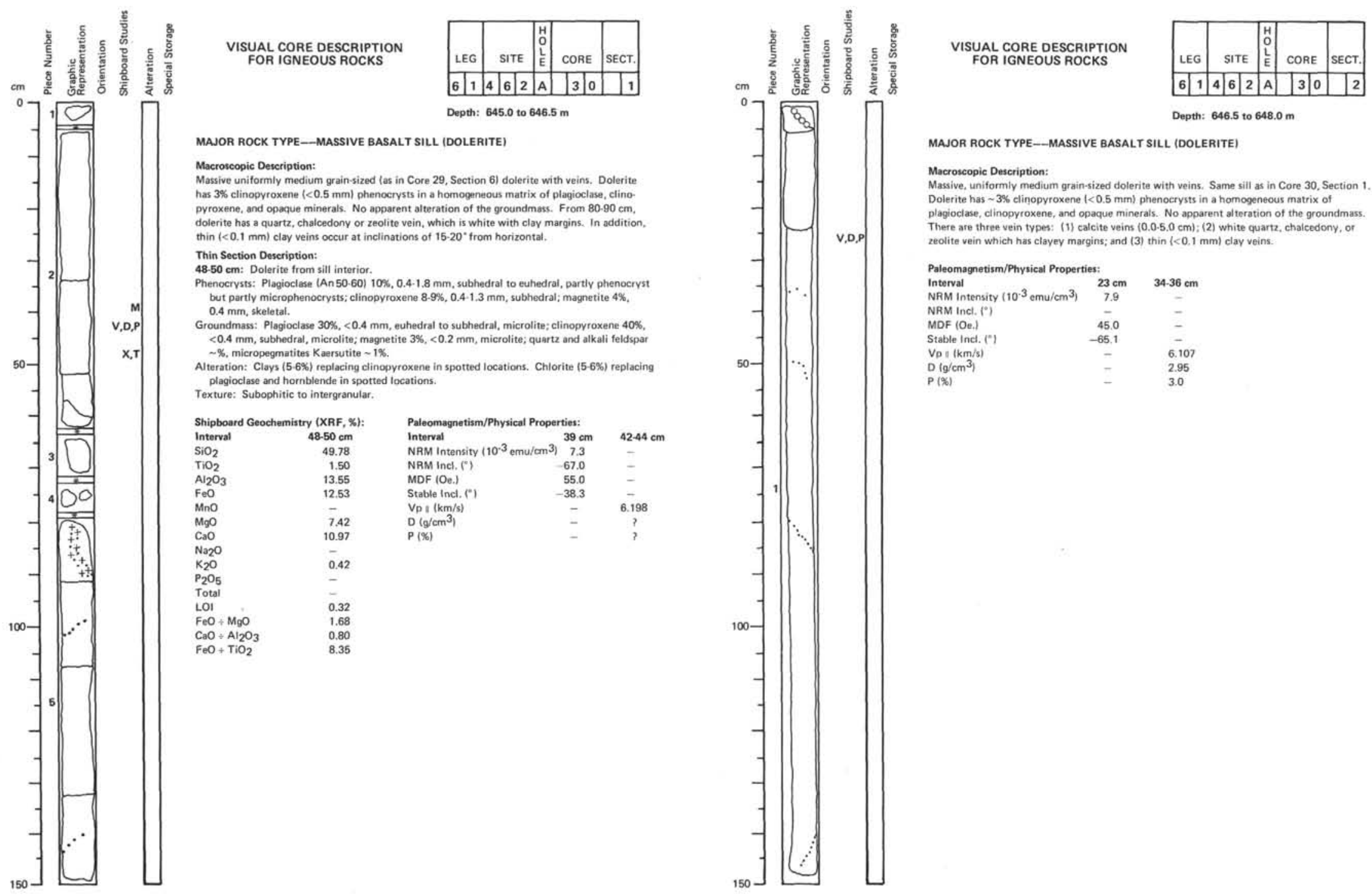

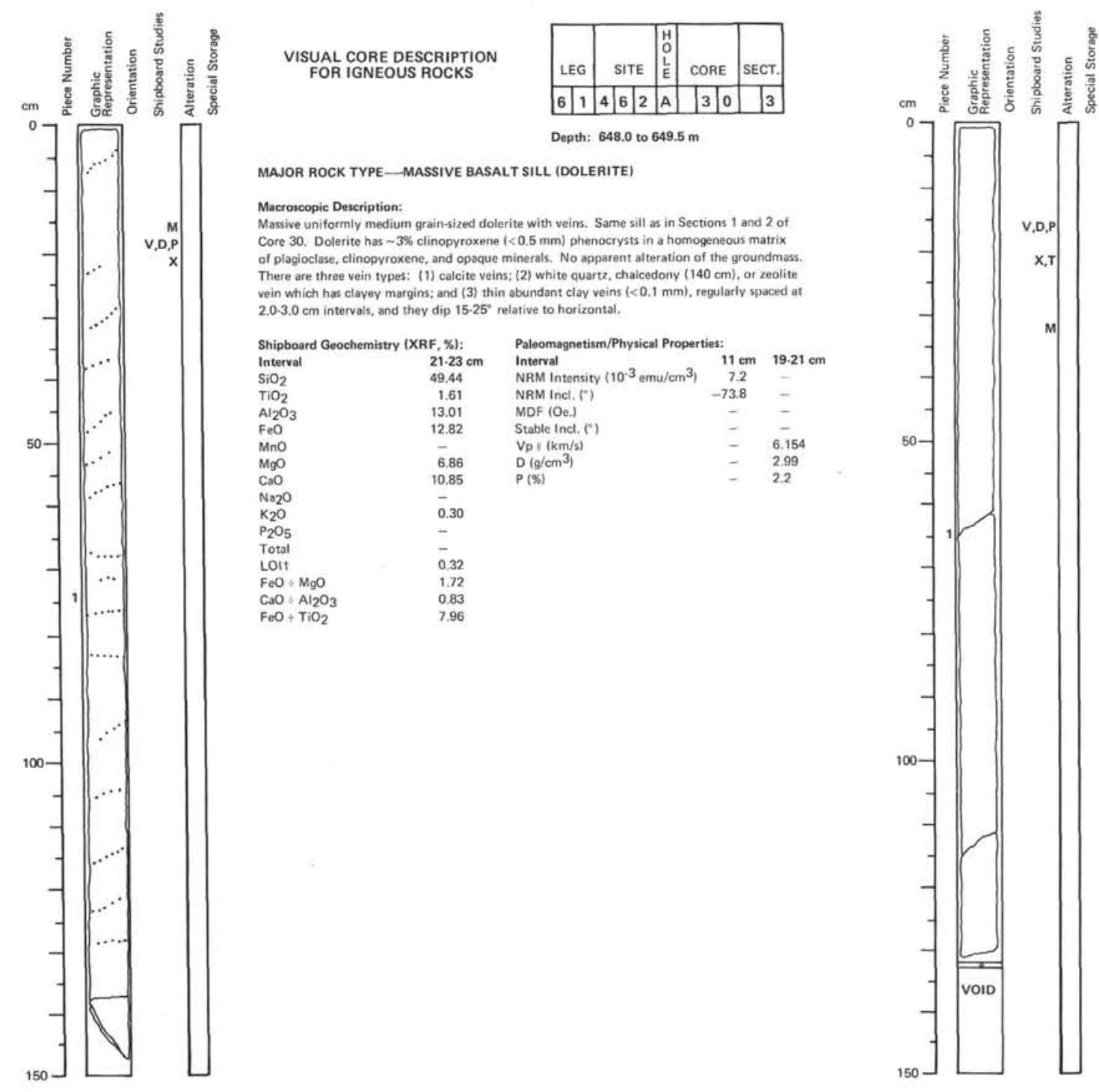
VISUAL CORE DESCRIPTION
FOR IGNEOUS ROCKS

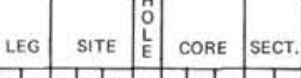

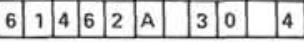
Depth: 649.5 to $650.8 \mathrm{~m}$

MAJOR ROCK TYPE-_MASSIVE BASALT SILL (DOLERITE)

Macroscopic Description:

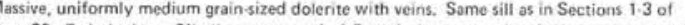
Cort 30. Dolerite has $-3 \%$ clinopyroxene $(<0.5 \mathrm{~mm} /$ phenocrysts in a homogeneous matrix There are three vein types: (1) calcite vein: (2) white quartz, chalcedony, or uelit we whe which has clayey margins; ond (3) thin $(<0.1 \mathrm{~mm}$ ) abundant clay veins, regularly spaced at 2.0-3.0 cm intervals, and they dip $15-25^{\circ}$ relative to horizontal:

Phenocrysts: Plagioclase (An $40-6016.8 \%, 0.40 .7 \mathrm{~mm}$, subhedral, zoned; clinopyroxene $4 \%$ 0408 : P.

Groundmass: Plagioclase $42 \%,<0.4 \mathrm{~mm}$, subhedral to euthedal: clinopyroxene $40 \%,<0.4 \mathrm{~mm}$ Whedral; magnetite $3.4 \%,<0.2 \mathrm{~mm}$, skeletal to acicular; ouartz and alkali feldspar $-1 \%$,

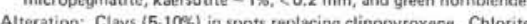
Ters.

\begin{tabular}{|c|c|c|}
\hline \multicolumn{3}{|l|}{ Phys } \\
\hline Interval & $14.16 \mathrm{~cm}$ & \\
\hline NRM Intensity $\left(10^{-3} \mathrm{emu}^{\mathrm{em}} \mathrm{cm}^{3}\right.$ & & 6.4 \\
\hline NRM Incl. $\left(0^{\circ}\right)$ & 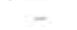 & -72.2 \\
\hline MDF (Oe.) & - & 50.0 \\
\hline Stable Incl. (") & - & -28.07 \\
\hline$V p \|(\mathrm{km} / \mathrm{ss})$ & 6.107 & \\
\hline $\mathrm{D}\left(\mathrm{g} / \mathrm{cm}^{3}\right)$ & 3.00 & - \\
\hline$P(\%)$ & 2.3 & - \\
\hline
\end{tabular}

P(g) $(\mathrm{gm})$ 

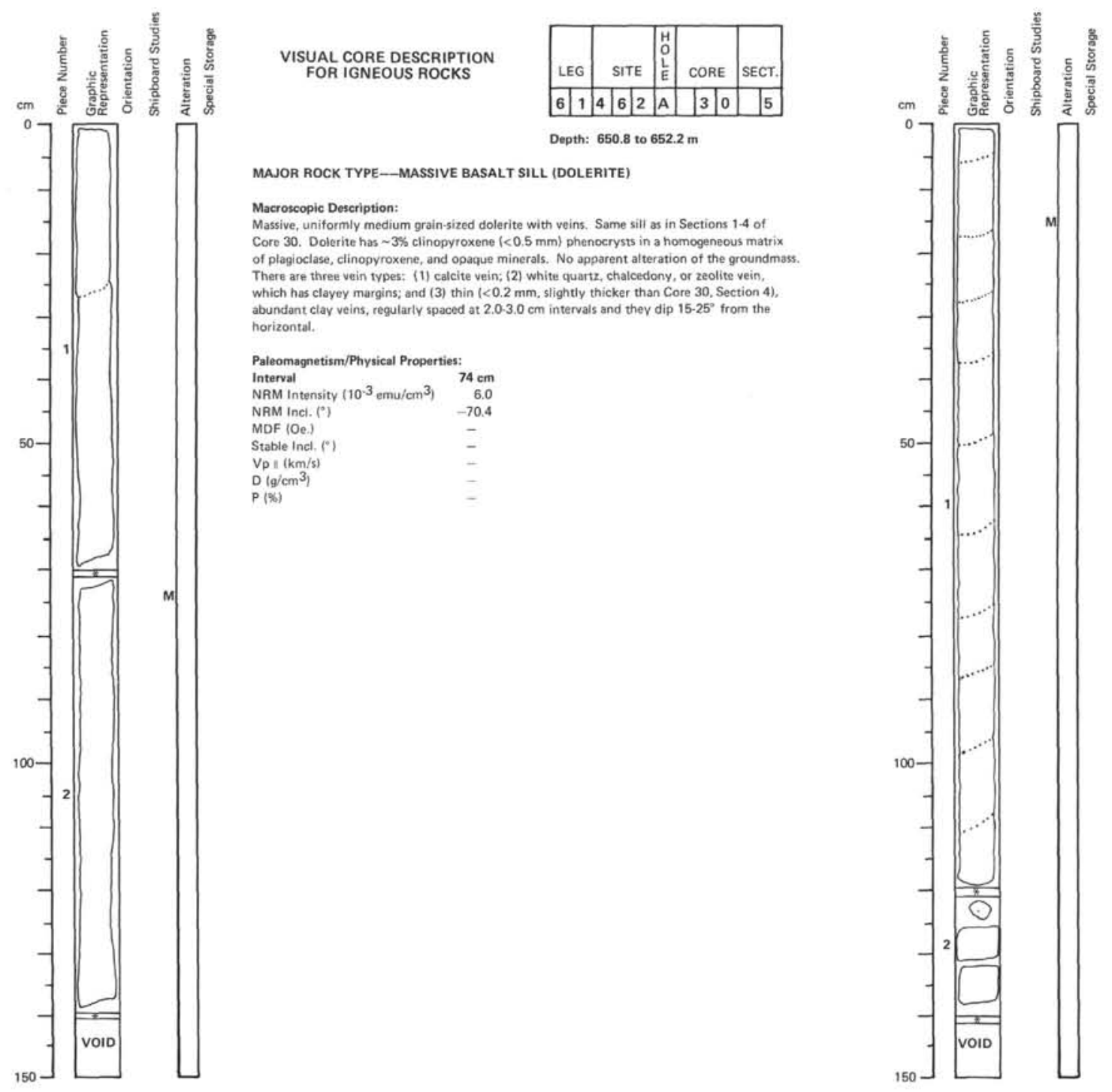

\section{VISUAL CORE DESCRIPTION

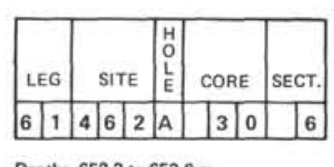

MAJOR ROCK TYPE--BASALT SILL (DOLERITE)

Macroscopic Description:

The plagioclase clinopyroxene There are three vein types: (1) calcite vein: (2) white quartz, chalcedony, or zeolitt vein, which has clayey margins; and (3) thin $(<0.2 \mathrm{~mm}$, slightly thicker than Core 30 . Section 5) abundant $\begin{array}{lr}\text { Paleomagnetism: } & \\ \text { Interval } & 17 \mathrm{~cm} \\ \text { NRM Intensity }\left(10^{-3} \mathrm{emu} / \mathrm{cm} 3\right) & 5.0 \\ \text { NRM Incl. }\left(C^{\prime}\right) & -78.6\end{array}$

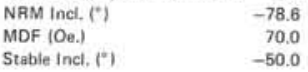



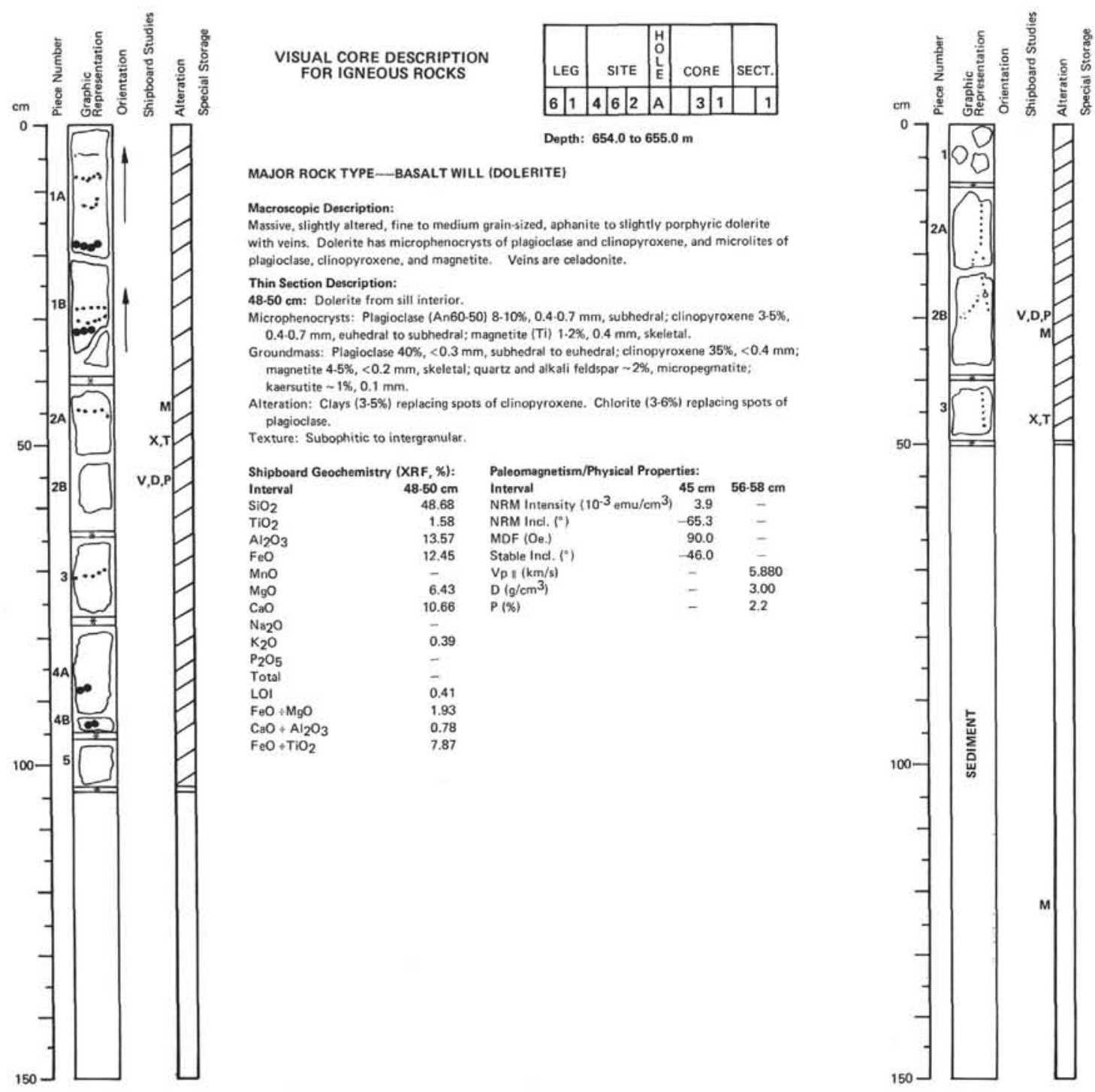

\section{VISUAL CORE DESCRIPTION

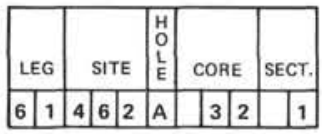

BASALT WILL IDOLERITE

Massive, signty altered, inne to medium grain-sized, aphanite to slightly porphyric dolerite

Thin Section Description:

Microphenocrysts: Plagioclase (An60-50) 8-10\%, 0.4-0.7 mm, subhedrat; clinopyroxene 3.5\%, 0.4.0.7 mm, euhedral to subhedral; magnetite (Ti) $1.2 \%, 0.4 \mathrm{~mm}$, skeletal. (a) ropegnatite: Aiteration: Clays (3.5\%) plagioclase.
Texture: Subophitic to intergranular.

\begin{tabular}{|c|c|c|c|c|}
\hline & (XRF, \%): & Paleomagnetism/Physical Properti & & \\
\hline $\begin{array}{l}\text { Interval } \\
\text { Sion }\end{array}$ & $\begin{aligned} 48.50 \mathrm{~cm} \\
4868\end{aligned}$ & $\begin{array}{l}\text { Interval } \\
\text { NRM Intensity }\left(10^{-3} \mathrm{emu}^{-\mathrm{cm}^{3}}{ }^{4}\right.\end{array}$ & $\begin{aligned} 45 \mathrm{~cm} \\
3.9\end{aligned}$ & $56-58 \mathrm{~cm}$ \\
\hline & $\begin{array}{r}48.68 \\
1.58\end{array}$ & 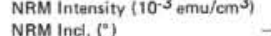 & $\begin{array}{r}3.9 \\
-6.3\end{array}$ & \\
\hline $\begin{array}{l}\mathrm{TiO}_{2} \\
\mathrm{Al}_{2} \mathrm{O}_{3}\end{array}$ & $\begin{array}{r}1.58 \\
13.57\end{array}$ & $\begin{array}{l}\text { NRMM Intel }\left(l^{2}\right) \\
\operatorname{MDF}(0) \text { ) }\end{array}$ & & - \\
\hline $\begin{array}{l}\mathrm{A}_{2} \mathrm{O}_{2} \mathrm{O}_{3} \\
\mathrm{~F}^{2} \mathrm{O}\end{array}$ & $\begin{array}{l}13.57 \\
12.45\end{array}$ & $\begin{array}{l}\text { MDF (oe.). } \\
\text { Stable Incl. (") }\end{array}$ & $\begin{array}{l}90.0 \\
-46.0\end{array}$ & \\
\hline $\begin{array}{l}\mathrm{FeO} \\
\mathrm{MnO}\end{array}$ & 12.45 & 列 $1(\mathrm{~km} / \mathrm{s})$. & -46.0 & 5.880 \\
\hline $\mathrm{MgO}$ & 6.43 & $\mathrm{D}\left(\mathrm{g} / \mathrm{cm}^{3}\right)$ & - & 3.00 \\
\hline $\mathrm{CaO}$ & 10.66 & $P(x)$ & - & 2.2 \\
\hline $\mathrm{Na}_{2} \mathrm{O}$ & & & & \\
\hline $\mathrm{K}_{2} \mathrm{O}$ & 0.39 & & & \\
\hline $\mathrm{P}_{2} \mathrm{O}_{5}$ & - & & & \\
\hline Total & - & & & \\
\hline ㄴoI & 0.41 & & & \\
\hline $\mathrm{F}_{e} \mathrm{O}+\mathrm{MgO}_{9} \mathrm{O}$ & 1.93 & & & \\
\hline $\mathrm{CaO}+\mathrm{Al}_{2} \mathrm{O}_{3}$ & 0.78 & & & \\
\hline $\mathrm{FeO}_{\mathrm{e}}+\mathrm{TiO}_{2}$ & 7.87 & & & \\
\hline
\end{tabular}

\section{MAJOR ROCK TYPE--BASALT SILL (DOLERITE) AND LOWER SEDIMENT CONTACT}

\section{Macroscopic Description:}

Massive, moderately altered dolerite with veins of clay. From $0.0-30.0 \mathrm{~cm}$, the dolerite has a fine grain-size and is slightly aphyvric. From $30.0 .50 .0 \mathrm{~cm}$, the dolerite is aphyric with pyroxene microphenocrysts" $=1$. Dolerite at $50.0 \mathrm{~cm}$, the lower contact of the sill with sediments, may be chilled (7). See Sedimentary Core Barrel Descriptions for a detailed description of sedimentary rock.

Thin Section Description

4.46 cm: Dolerite next to glassy margin of a sil.

$0.40 .8 \mathrm{~mm}$, prismatic; clinopyroxene 2.39 $8 \mathrm{~mm}$, subhedral, some aggregate.

roundmass: Plagioclase $42 \%,<0.2 \mathrm{~mm}$, subhedral; clinopyroxene $42 \%,<0.05 \mathrm{~mm}$, subhedral;

magnetite $2.3 \%,<0.01 \mathrm{~mm}$, dust-like; glass $5.10 \%$, altered to clay.
Alteration: Clays (10-203), replacing interstitial glass and clinopyroxene. Chlorite in veins

$\begin{array}{lllll}\text { Shipboard Geochemistry (XRF, \%): } & \text { Paleomagnetism/Physical Properties: } \\ \text { Interval } & 44.48 \mathrm{~cm} & \text { Interval } & 123 & 31 \cdot 33\end{array}$

$\mathrm{SiO}_{2} \quad 48.37 \quad$ NAM Intensity $\left(10^{-3} \mathrm{emu}_{\mathrm{em}} \mathrm{cm}^{3}\right) \quad 107 \quad \mathrm{~cm} \quad \mathrm{~cm}$

$\mathrm{TiO}_{2}-1.66$ NPM Ind (")

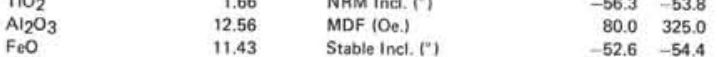

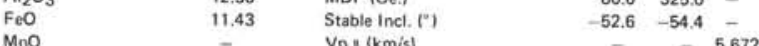

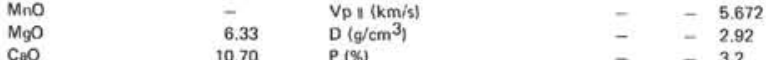

$\mathrm{Na}_{2} \mathrm{O}$

$\mathrm{K}_{2} \mathrm{O}$

$\mathrm{P}_{2} \mathrm{O}_{5}$
Total

$\mathrm{FeO}+\mathrm{MgO}_{\mathrm{O}}$

$\mathrm{CaO}^{2}+\mathrm{Al}_{2} \mathrm{O}$

$\overline{0.78}$

0.64
1.80
0.85
6.88 

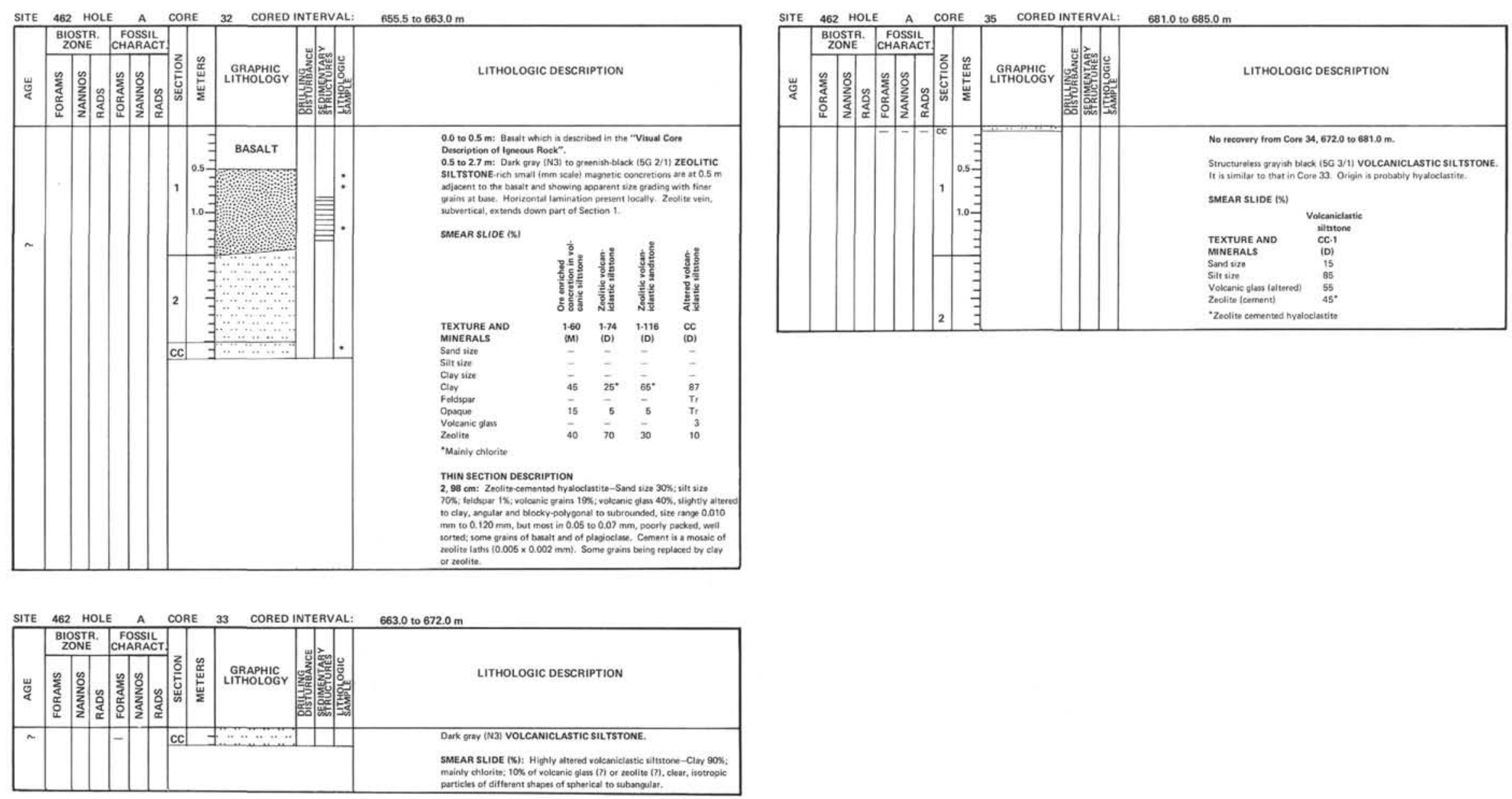


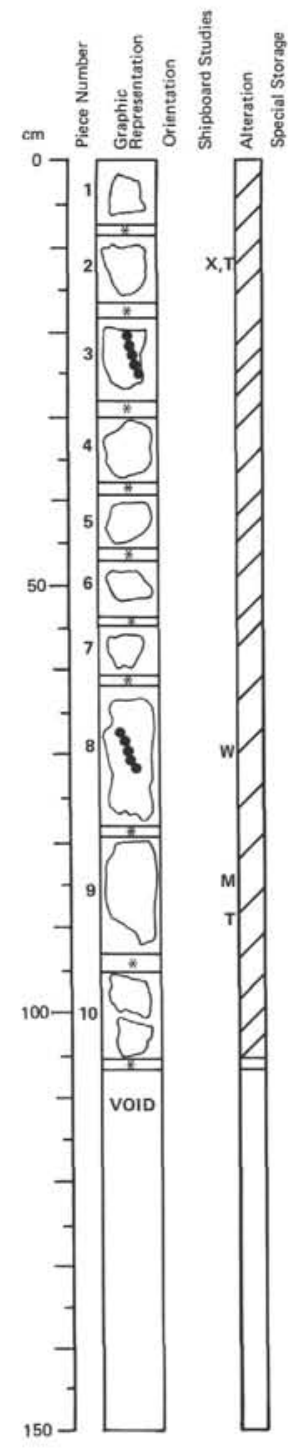

\section{VISUAL CORE DESCRIPTION

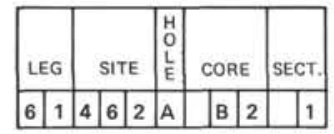

\section{MAJOR ROCK TYPE-BASALT SILL (DOLERITE)}

\section{Macrosscopic Description:}

cieintation and stratigraphic order are not known for the piecess recowered, Textures of pieces (a) as follows:
Pieces 1 to 2 :

Pieces 3 to 7: Medium grain-sized and are interserta.

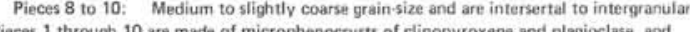

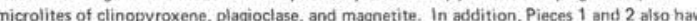
microlites of glass.

(a)

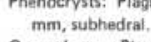

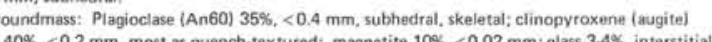
Alteration: Greenish brown clay (10\%) replacing clinopyroxenen and gass.

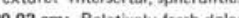

sill interio

clinopyroxene (sugite) $46 \%, 0.20 .8 \mathrm{~mm}$ 1.25, altered, variolitici; trace quartz and alkal'

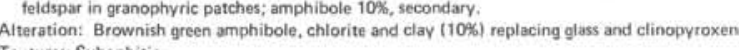
Subophitic.

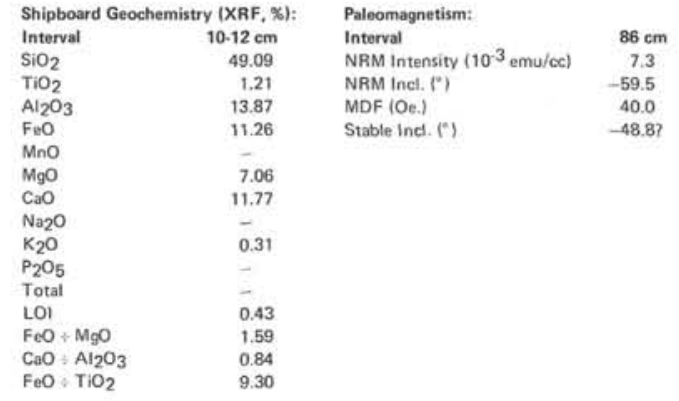

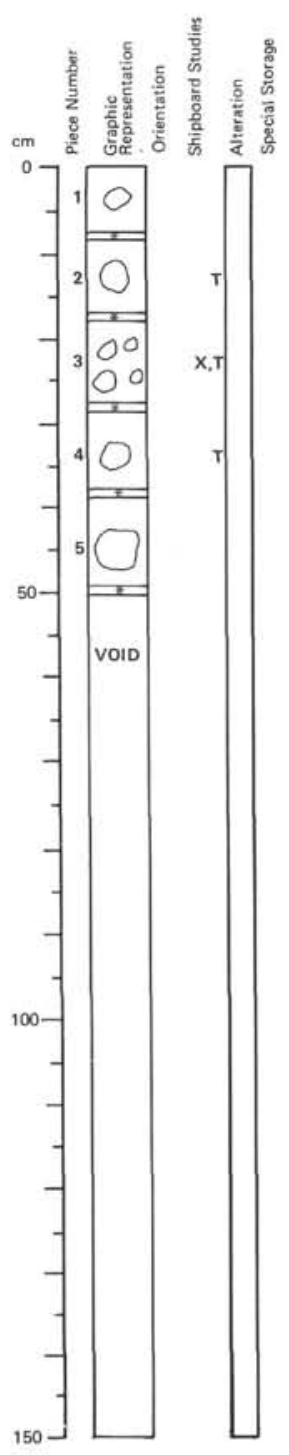

VISUAL CORE DESCRIPTION

\begin{tabular}{|l|l|l|l|l|}
\hline & & H. & & \\
0 & & \\
LEG & SITE & CORE & SECT. \\
\hline
\end{tabular}

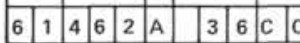
Depth: 689.8 to $690.0 \mathrm{~m}$

MAJOR ROCK TYPE - BASALT SILL (DOLERITE)

Macroscopic Description

eces and all piecess except №. 5 are out of

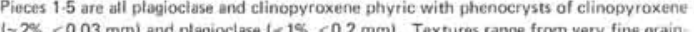

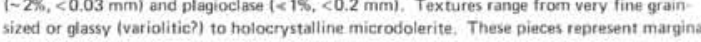
and inner crystallitine facies of a basatitic sill, respectively.

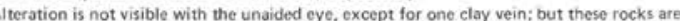
green stones", suggesting significicant groundmass alteration,

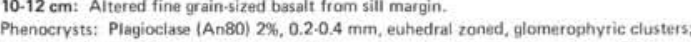
clinopyroxene (augite) $3 \%, 0.1-0.3 \mathrm{~mm}$, subhedral, golmerophyric dusters.

37\%, <0. 2 mo Texture: Hyalopilitic, spherulitic

$21.23 \mathrm{~cm}$ : Variolitic bassalt trom glassy sill margh

Doporphyric aggregates; clinopyroxene $0.4 \mathrm{~mm}$, glomeroporphyric aggregates

Groundmass: Plagioclase $-2 \%,<0.04 \mathrm{~mm}$, laths in variolitic mesostasis; clinopyroxene $>1 \%$,
0.08 mm, equidimensionali, magnetite $7 \%,<0.01 \mathrm{~mm}$, dust-like: 1 lass $>95 \%$, variolitic mesostasis.

Carbonate (19) replacing clinopyroxene and plagioclsse in tomeroporphyritic Brown clays (906) replacing glass mesostasis.

Phenocrysss: Plagioclase $1 \%$, 03.05 sill inter. <1\%. $0.4 \mathrm{~mm}$, subophitic Groundmass: Plagioclase (An65) 7\%, 0.1.0.3 mm, laths; clinopyroxene (augite) ?\%, 0.1.0.2 mm; magnetite (Ti) $7 \%$, <0.04 mm; amphibole $2 \%$, secondary, replacing clinopyroxene. Afteration: Brown clays (15\%) replacing all minerals,

\begin{tabular}{|c|c|}
\hline \multicolumn{2}{|c|}{ Shipboard Geochemistry (XRF, \%): } \\
\hline Interval & $21.23 \mathrm{~cm}$ \\
\hline $\mathrm{SiO}_{2}$ & 50.66 \\
\hline & 1.58 \\
\hline $\mathrm{Al}_{20} \mathrm{O}_{3}$ & \\
\hline $\mathrm{FeO}$ & 11.54 \\
\hline $\begin{array}{l}\mathrm{MnO} \\
\mathrm{MgO}\end{array}$ & \\
\hline $\begin{array}{l}\mathrm{MgO}_{90} \\
\mathrm{C}_{3} \mathrm{O}\end{array}$ & 7.33 \\
\hline $\begin{array}{l}\mathrm{CaO}_{\mathrm{Na}} \\
\mathrm{Na}^{2}\end{array}$ & 12.06 \\
\hline & 0.31 \\
\hline $\mathrm{P}_{2} \mathrm{O}_{5}$ & - \\
\hline Total & - \\
\hline $\mathrm{FeO}+\mathrm{MgO}_{\mathrm{gO}}$ & 1.57 \\
\hline $\mathrm{CaO} \div \mathrm{Al}_{2} \mathrm{O}_{3}$ & 0.85 \\
\hline $\mathrm{F} 0 \mathrm{O}+\mathrm{TiO}_{2}$ & 7.30 \\
\hline
\end{tabular}



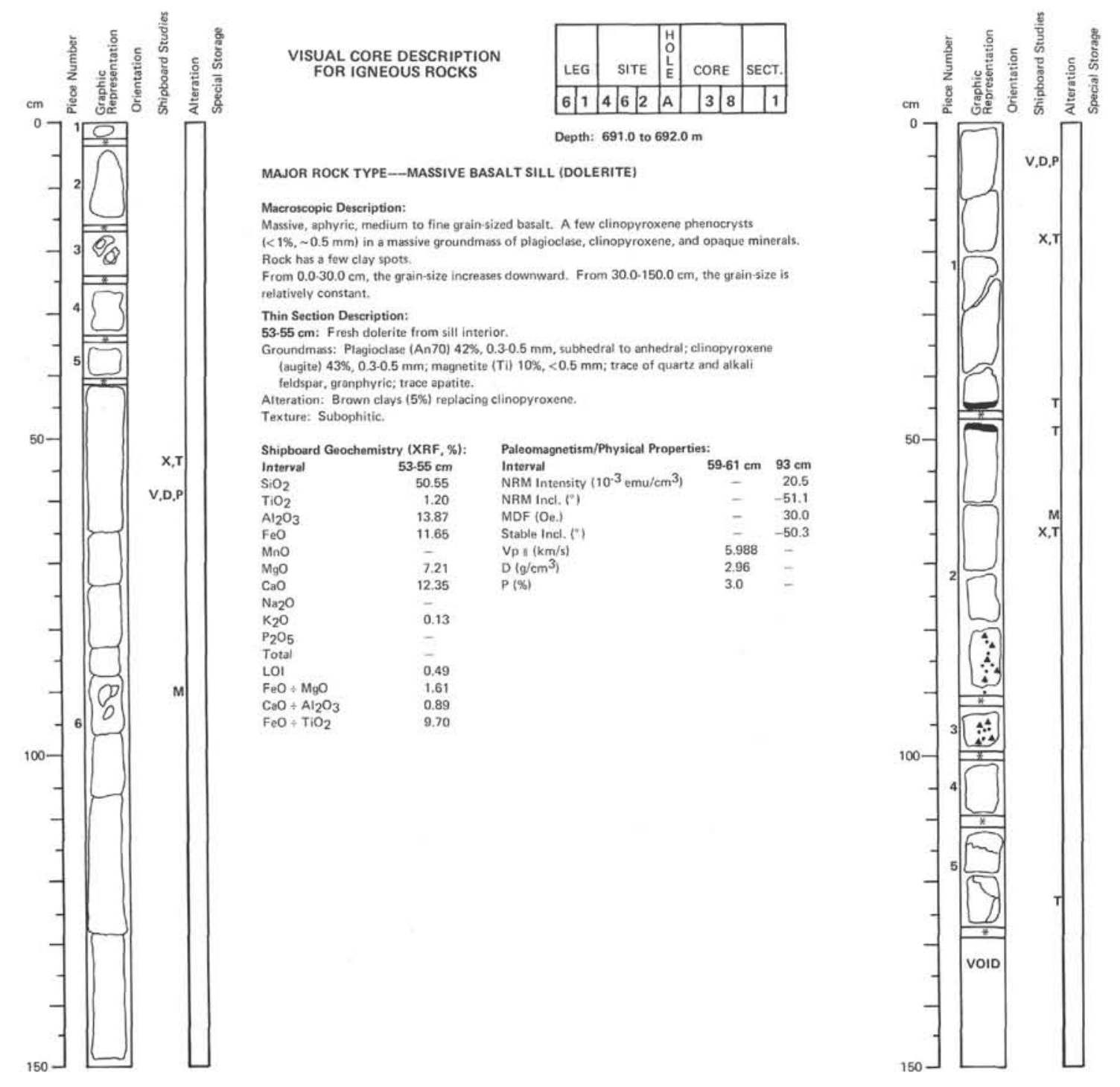

\section{VISUAL CORE DESCRIPTION FOR IGNEOUS ROCKS

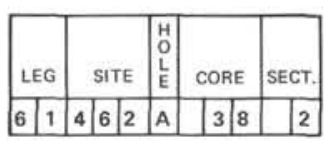 \\ Depth: 691.0 to $692.0 \mathrm{~m}$}

MAJOR ROCK TYPE- -MASSIVE BASALT

(a) $44.45 \mathrm{~cm}$. The basalt within 0.0 and $44.0 \mathrm{~cm}$ has a few plagioclase and clinopyroxene phenocrysts
$(<1 \%, 0.2-0.3 \mathrm{~mm})$ in a homogenoous fine grain-sized matrix. Clay spots of alteration are present from the glassy margin $(44.0 \mathrm{~mm})$ upward. From the glassy margin (44.0 mm) upward.
From $48.0 .130 .0 \mathrm{~cm}$, basalt has a glassy margin $47.48 \mathrm{~cm}$ and then downward from $48.0 \mathrm{~cm}$ grain
size gradually

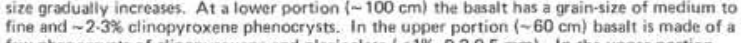
few phenocrysts of clinopyroxene and plagioclase $(<1 \%, 0.2-0.5 \mathrm{~mm})$. In the upper portion.

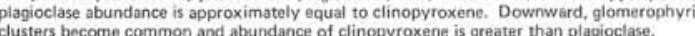
At $80.0 \cdot 90.0 \mathrm{~cm}$, veins are of pyrite plus calcite. At $110.0 \cdot 125.0 \mathrm{~cm}$, veins are pyrite plus clay. Thin Soction Description:
$18.20 \mathrm{~cm}:$ Relatively fresh dolerite from sill interior.

Groundmass: Pisgioclase (An60) $41 \%, 0.10 .2 \mathrm{~mm}$; clinopyroxene (augite) $41 \%, 0.1-0.2 \mathrm{~mm}$; -magnetite (Ti) $5 \%,<0.04 \mathrm{~mm}$; glass $\sim 3 \%$, alterec interstitial patches; trace quartz and alkal foldspar granophyric patches.
Alteration: Brown clayy (10\%) replacing clinopyroxene and glass.

Toxturo: Dolertite.
$42-46 \mathrm{~cm}:$ Frest basalt from glassy sill margin.
Phe . Alteration: Clays (5-20\%) in spotty replacement of glass and clinopyroxene.

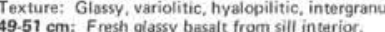

Phenocrysts: Plagioclase (An70) 4\%, 0.1.0.3 mm, euhedral, glomerophyric aggregates; clino.

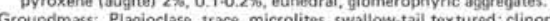
and skeletal; glass 94\%, appears sither devitrified of altered, broin. Texture: Glassy to varioliticic.

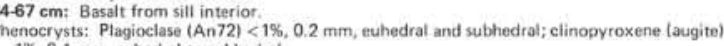

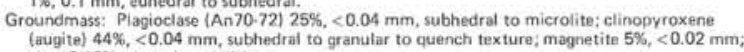
Alteration: Brown clay (25\%) replacing microlites and glass.

Textres

Phenocrysts: Plagioclase (An 70$)<1 \%, 0.1 .0 .3 \mathrm{~mm}$, euhedrat, glomerophyric clots: clinopyroxene Groundmass: Plagioclase (An 70$) 25 \%,<0.04 \mathrm{~mm}$, subhedral, lath, microlites; clinopyroxene (T) $<0.02 \mathrm{~mm}$; glass (alteredi).
Alteration: Brown clays $(25 \%)$ replacing glass and minerals.

\begin{tabular}{|c|c|c|c|c|c|}
\hline & nistry (XRF & & Paleomagnetism/Physical Proper & rties & \\
\hline & $18-20 \mathrm{~cm}$ & $64.67 \mathrm{~cm}$ & Interval & & \\
\hline & $\begin{array}{l}48.79 \\
1.18\end{array}-19$ & $\begin{array}{r}48.74 \\
1.20\end{array}$ & NRM Intensitv $\left(10^{-3} \mathrm{emu} / \mathrm{cm}^{3}\right)$ & & 8.6 \\
\hline $\mathrm{Al}_{2} \mathrm{O}_{3}$ & 13.47 & 13.96 & MDF (Oe.) & - & $\begin{array}{l}-0.0 \\
85.0\end{array}$ \\
\hline $\mathrm{FeO}_{\mathrm{N}} \mathrm{O}-\mathrm{O}$ & 11.69 & 11.23 & Stable Incl. $\left({ }^{\circ}\right)$ & 6054 & -42.0 \\
\hline $\begin{array}{l}\mathrm{MgO} \\
\mathrm{CaO}\end{array}$ & 12.00 & $\begin{array}{r}1.43 \\
12.02\end{array}$ & $\begin{array}{l}\mathrm{Vpp}(\mathrm{ikm} / \mathrm{st}) \\
\mathrm{D}\left(\mathrm{g} / \mathrm{cm}^{3}\right)^{2}\end{array}$ & $\begin{array}{l}0.057 \\
2.97\end{array}$ & $=$ \\
\hline $\begin{array}{l}\mathrm{K}_{2} \mathrm{O} \\
\mathrm{L} 01\end{array}$ & 0.10 & 0 & & & \\
\hline$=\mathrm{N}$ & 0.53 & & & & \\
\hline A & 0.89 & & & & \\
\hline & & & & & \\
\hline
\end{tabular}




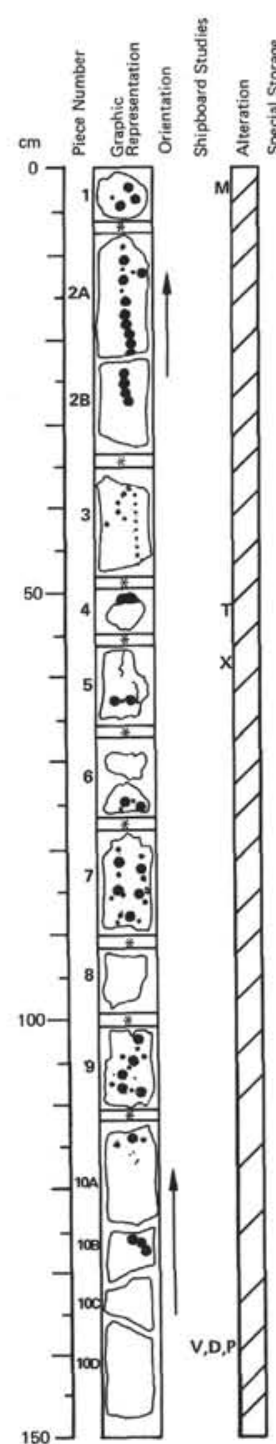

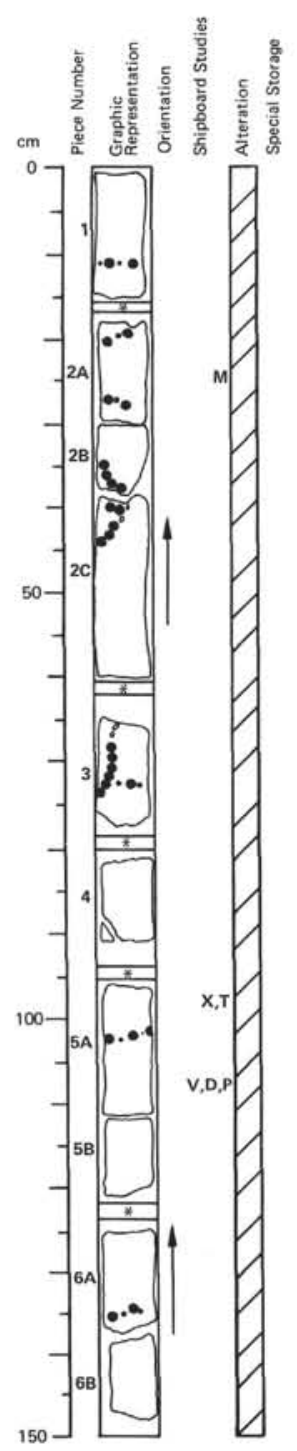

\section{VISUAL CORE DESCRIPTION
FOR IGNEOUS ROCKS

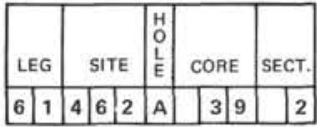
\begin{tabular}{|l|l|l|l|l|l|l|l|}
\hline 6 & 1 & 4 & 6 & 6 & A & 3 & 9 \\
\hline
\end{tabular} MAJOR ROCK TYPE---MASSIVE BASALT Macroscopic Description:
Slightly altered to tresh bo Paragonitel. From $50.0 .520 \mathrm{~cm}$ heps 1.31 , besalt has a tine to slightly coarse grain-size. From $55.0 .150 .0 \mathrm{~cm}$, basalt has a tine to stightly medium grain-size, and grainsize increases downward.

1.3 are hyalopilitic to interstitial; have an abundance of clinopyroxene phenocrysts greater than plagioclase phenocrysts; and has microlites of plagicclase, clinopyroxene, magnetite roxene greater than plagioclase micro phenocrysts, and glass and microlite groundmass ertions are medium light gray (N4)

Thin Section Description:

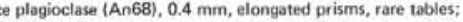

Cinopyroxene $-18,0.3 \mathrm{~mm}$, euhedra.

\begin{tabular}{|c|c|c|c|c|}
\hline \multicolumn{2}{|c|}{ Shipboard Geochemistry (XRF, \%): } & \multicolumn{3}{|l|}{ Paleomagnetism/Physical Properties: } \\
\hline & $59.61 \mathrm{~cm}$ & & $4 \mathrm{~cm}$ & $39-141 \mathrm{~cm}$ \\
\hline $\mathrm{SiO}_{2}$ & 49.58 & NRM Intensity $\left(10^{-3} \mathrm{emu} / \mathrm{cm}^{3}\right)$ & 9.0 & \\
\hline $\mathrm{TiO}_{2}$ & $\begin{array}{r}1.19 \\
1.79\end{array}$ & NAM Incl. $\left({ }^{\circ}\right)$ & -52.4 & - \\
\hline $\begin{array}{l}\mathrm{Al}_{2} \mathrm{O}_{3} \\
\mathrm{Fen}\end{array}$ & $\begin{array}{l}13.78 \\
1158\end{array}$ & MDF (Oe.) & 50.0 & \\
\hline $\begin{array}{l}\mathrm{FeO} \\
\mathrm{MnO}\end{array}$ & $\begin{array}{c}11.58 \\
-\end{array}$ & $\begin{array}{l}\text { Stable Incl. (") } \\
V_{p}(\mathrm{~km} / \mathrm{s})\end{array}$ & -38.8 & 5.937 \\
\hline $\mathrm{MgO}$ & 7.14 & $\left.\mathrm{D}\left(\mathrm{g} / \mathrm{cm}^{3}\right)^{\prime}\right)$ & - & 2.96 \\
\hline $\mathrm{CaO}_{2}$ & 12.04 & $P\left(x_{1}\right)$ & - & 3.1 \\
\hline $\mathrm{Na}_{2} \mathrm{O}$ & & & & \\
\hline $\mathrm{K}_{2} \mathrm{O}$ & 0.02 & & & \\
\hline $\mathrm{P}_{2} \mathrm{O}_{5}$ & - & & & \\
\hline Total & - & & & \\
\hline LOI & 0.17 & & & \\
\hline $\mathrm{FeO}+\mathrm{MgO}_{\mathrm{g}}$ & 1.62 & & & \\
\hline $\mathrm{CaO} \div \mathrm{Al}_{2} \mathrm{O}_{3}$ & & & & \\
\hline $\mathrm{FeO}+\mathrm{TiO}_{2}$ & 9.73 & & & \\
\hline
\end{tabular}

\section{MAJOR ROCK TYPE--MASSIVE BASALT}

Macroscopic Domelodon:

Slightly fresh partagonite). This is the same unit as in Core 39, Section 1. From $0.0 .50 .0 \mathrm{~cm}$ (7) (Pieces $1.2 \mathrm{C}$ ), basalt has stightly medium to medium grain-size, and From 50.0 (?) $150.0 \mathrm{~cm}$ (Pieces 2.6B), basalt has a medium grain-size. Thin Section Description:

te from sill interior. (A) henoctysts: Olivine trace, euhedral thombic clay pseudomorphs; plagioclase (An58-68) Groundrmass: Olivina $5 \%, 02 \mathrm{~mm}$, clay 0 , $0.4 \mathrm{~mm}$, equidimensional. elongated prisms; clinopyroxene $7 \%, 0.008 \mathrm{~mm}$, equidimensional; magnetite $7 \%, 0.040 .2$,

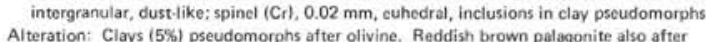
Texture: Microdoleritic.

\begin{tabular}{|c|c|c|c|c|}
\hline \multicolumn{2}{|c|}{ Shipboard Geochemistry (XRF, X): } & \multicolumn{3}{|c|}{ Paleomagnetism/Physical Properties: } \\
\hline Interval & $97.99 \mathrm{~cm}$ & Interval & $26 \mathrm{~cm}$ & $107.108 \mathrm{~cm}$ \\
\hline $\mathrm{SiO}_{2}$ & 48.96 & NRM intensity $\left(10^{-3} \mathrm{emu} / \mathrm{cm}^{3}\right)$ & & - \\
\hline $\mathrm{TiO}_{2}$ & 1.22 & NRM ind. $\left(0^{\circ}\right)$ & -72.0 & - \\
\hline $\mathrm{Al}_{2} \mathrm{O}_{3}$ & 13.96 & MDF (Oe.) & - & - \\
\hline $\mathrm{FeO}_{\mathrm{H}}-\mathrm{O}-\mathrm{l}-\mathrm{S}$ & 11.52 & Stable Incl. (1) & - & - \\
\hline $\begin{array}{l}\mathrm{MnO} \\
\mathrm{MnO}\end{array}$ & $\overline{722}$ & $\begin{array}{l}V_{p} \|(\mathrm{km} / \mathrm{s}) \\
0\left(0 / \mathrm{pm}^{3}\right)\end{array}$ & $=$ & 5.977 \\
\hline $\mathrm{CaO}_{\mathrm{O}}$ & 12.09 & P(\%) & 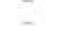 & $\begin{array}{l}2.96 \\
3.1\end{array}$ \\
\hline
\end{tabular}



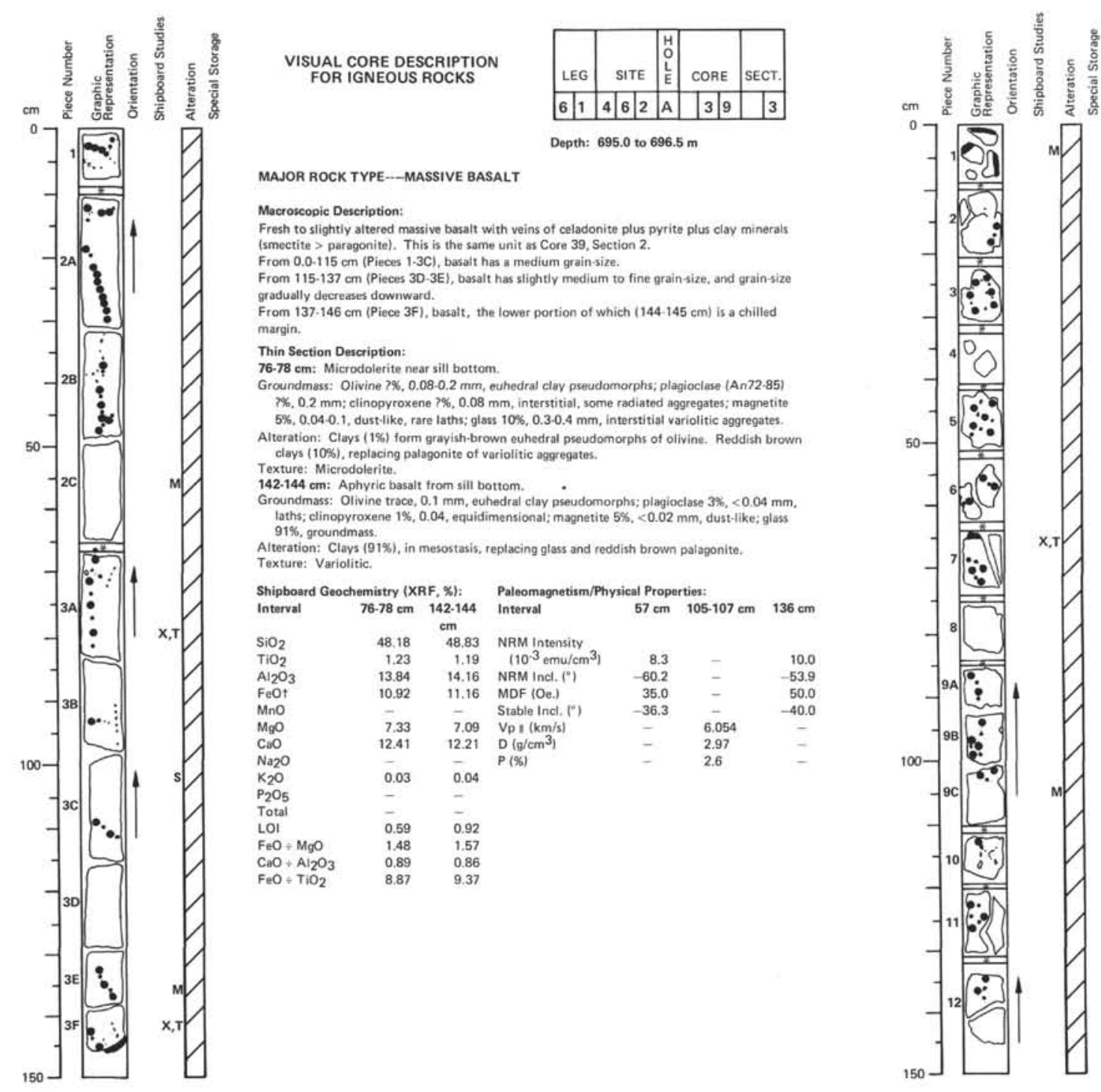

\section{VISUAL CORE DESCRIPTION FOR IGNEOUS ROCKS

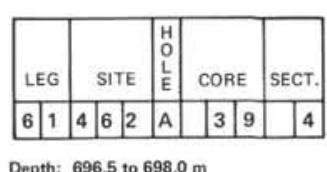

MAJOR ROCK TYPE--MASSIVE BASALT

(s) paragonite). Three units are observed:

Unit A cocurs trom 0.0-64.0 cm (Pieces 1-6). From 0.0.9.0 cm (Piecte 1) is a glessy chilled Unit B occurs from $64.120 \mathrm{~cm}$ (Pieces 7.10). From $64.66 \mathrm{~cm}$ (upper part of Piece 7) is a gasss chilled basalt margin. From 66-93(?) $\mathrm{cm}$ (Pieces 7. lower part, to upper part of Piece 9A, bassatt increases in grain-size from hine to stighty medium. From 03 (P) $120 \mathrm{~cm}$ is without a chilled margin, and grain-size increases downward from fine to slightly medium grain-size.

Thin Section Description:

67.70 cm: Aphyric basalt from sill top.

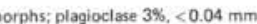
lath, ch: Alteration: Clays (91\%) in Texture: Variolitic.

\begin{tabular}{|c|c|c|c|c|}
\hline \multicolumn{3}{|c|}{ Shipboard Geochemistry (XRF, X): } & Paleomagnetism: & \\
\hline Interval & $4.6 \mathrm{~cm}$ & $67.70 \mathrm{~cm}$ & & \\
\hline $\mathrm{SiO}_{2}$ & 48.88 & 48.33 & NRM Intensity $\left(10^{-3} \mathrm{emu} \mathrm{cm}^{3}\right)$ & \\
\hline $\mathrm{TiO}_{2}$ & 1.20 & 1.21 & NAM incl. $P^{* 1}$ ) & -38.2 \\
\hline $\mathrm{Al}_{2} \mathrm{O}_{3}$ & 13.86 & 14.36 & MDF (Oe.) & 65.0 \\
\hline $\mathrm{FeO}$ & 11.60 & 11.26 & Stable Incl. (") & -26.5 \\
\hline $\mathrm{MnO}$ & & & & \\
\hline MgO & 7.39 & 7.78 & & \\
\hline $\mathrm{CaO}$ & 12.23 & 12.36 & & \\
\hline $\mathrm{Na}_{2} \mathrm{O}$ & & - & & \\
\hline $\mathrm{K}_{2} \mathrm{O}$ & 0.09 & 0.06 & & \\
\hline$P_{2} O_{5}$ & - & - & & \\
\hline Total & & - & & \\
\hline Lolt & 0.30 & 0.36 & & \\
\hline 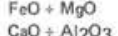 & 1.56 & 1.44 & & \\
\hline $\begin{array}{l}\mathrm{CaO}+\mathrm{A}_{2} \mathrm{O}_{3} \\
\mathrm{FeO}+\mathrm{TOO}_{2}\end{array}$ & $\begin{array}{l}0.88 \\
9.66\end{array}$ & $\begin{array}{l}0.86 \\
9.30\end{array}$ & & \\
\hline
\end{tabular}



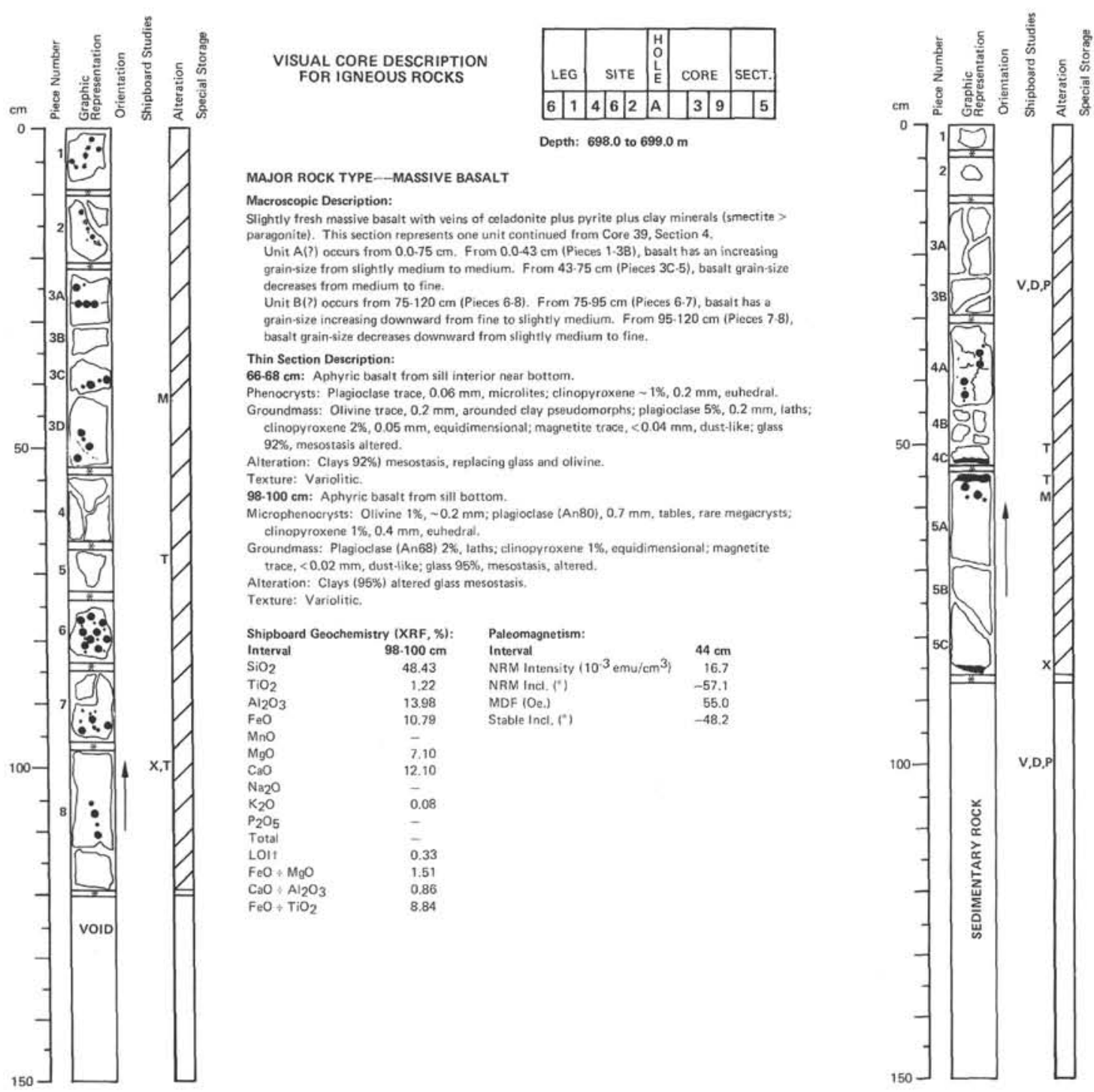

VISUAL CORE DESCRIPTION
FOR IGNEOUS ROCKS

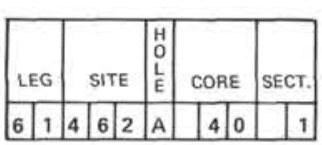

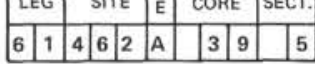

\section{MAJOR ROCK TYPE - MASSIVE BASALT}

Thes paragonite). This section represents one unit continued Itrom Core 39. Section 4. grain-size from slightly medium to medium. From $43.75 \mathrm{~cm}$ (Pieces $3 C .5$ ), basalt grain-size decreases from medium to fine.

Unit B(7) occurs from $75-120 \mathrm{~cm}$ (Pieces 6.8). From $75.95 \mathrm{~cm}$ (Pieces 6.77). besolt has 0 grain-size increasing downward from fine to slightly medium. From $95.120 \mathrm{~cm}$ (Pieces 7.8), The size decreases downward from slightly medium to fine.

Phenocrysts: Plagioclase trace, $0.06 \mathrm{~mm}$, microlites; clinopyroxene $\sim 1 \%, 0.2 \mathrm{~mm}$, tuhedral Groundmass: Olivine trace, $0.2 \mathrm{~mm}$, arounded clay pseudomorphs clinopyroxenc $2 \%, 0.05$ Aiteration: Clays 928 ) mesostasis, replacing glass and olivine. Texture: Variolitic.

Microphen Apric basalt from sill bottom. cinopyroxene $1 \%, 0.4 \mathrm{~mm}$, euted di Groundasass: Plagioclase (An68) 2\%, laths; clinopyroxene 1\%, equidimensional: magnetite A

Texture: Variolitic

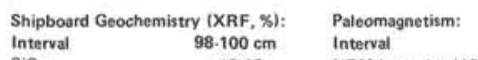

\begin{tabular}{|c|c|c|c|}
\hline & & & \\
\hline nterval & $\begin{array}{l}98.100 \mathrm{~cm} \\
4483\end{array}$ & $\begin{array}{l}\text { Interval } \\
\text { SBM }\end{array}$ & $44 \mathrm{~cm}$ \\
\hline & 1,22 & NRM Incl. $(")$ & -57.1 \\
\hline & 13.98 & MDF $(0)$. & 55.0 \\
\hline & 10.79 & Stable Incl. $\left({ }^{\circ}\right)$ & -48.2 \\
\hline
\end{tabular}

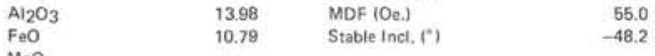

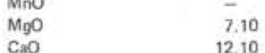

$\mathrm{Ka}_{2} \mathrm{O}$

${ }_{\mathrm{P} 2 \mathrm{O}_{5}}^{\mathrm{P}_{2}}$

$\mathrm{FeO}+\mathrm{MaO}$

$\mathrm{CaO}+\mathrm{Al}_{2} \mathrm{O}_{3}$

1.51

$\mathrm{FeO}+\mathrm{TiO}_{2} \quad \begin{aligned} & 0.86 \\ & \mathrm{~B}\end{aligned}$

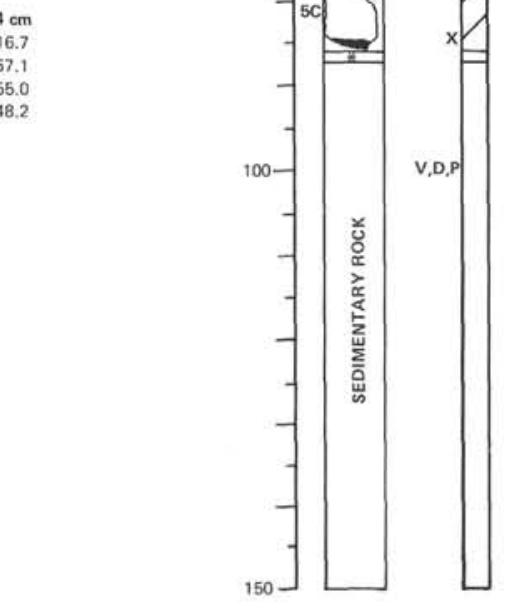

MAJOR ROCK TYPE-

Depth: 702.0 to $702.9 \mathrm{~m}$

Macroscopic Description:

Unit A occurs from $0.0 .54 .0 \mathrm{~cm}$ (Pieces $1.4 \mathrm{C}$ ). From $0.0 \sim 19.0 \mathrm{~cm}$, basalt has a grain-size $30.0 \mathrm{~cm}$ (Pieces $3 \mathrm{~A} \cdot 3 \mathrm{~B}$ ), bassalt has a medium grain, size. From $30.0 .54 .0 \mathrm{~cm}$ (Piecos $4 \mathrm{~A} \cdot 4 \mathrm{CC}$ ). (U) $(55-57 \mathrm{~cm}$ ?) and increasing grain-size downward to slightly medium grain-size. From 64.0. $71.0 \mathrm{~cm}$, basalt has a slightly medium grain site. From $71.0 .86 .0 \mathrm{~cm}$, basalt has a decreasing Sediment trom $860.150 .0 \mathrm{~cm}$ is described in the Sedimenary

Thin Section Description:

Microphenocrysts: Olivine 2\%, 0.4 mm, pseudomorohs; plagioclase (An65-70) 1.2\%, $0.4 .0 .6 \mathrm{~mm}$ subhedrat, torms aggregates Groundmass: Plagioclase $20 \%$, <0.15 mm, subhedral, clinopyroxene $30.355 \%$, < $0.06 \mathrm{~mm}$, stightly Alteration: Clays (30s) in mesostasis, replacing glass, plagioclase, und clinopyroxere. Texture: Hyalopilitic

$57-60 \mathrm{~cm}$ : Massive basalt from glassy margin.

Microphenocrysts: Olivine 1\%, $0.2 \mathrm{~mm}$, pseudomorphs; plagioclase (An65) 1\%, $0.30 .4 \mathrm{~mm}$,

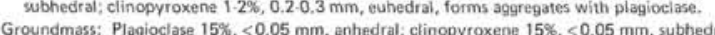

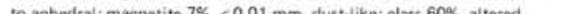
Alteration: Clays and zeolite (20-30\%3) replaced glass mesostasis and olivine. Texture: Hyalopilitic to aphyric.

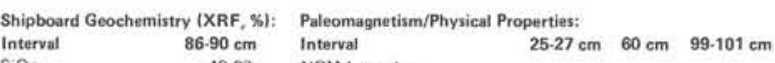

$\begin{array}{lllll}\text { Interval } & 86.90 \mathrm{~cm} & \text { Interval } & 25.27 \mathrm{~cm} \quad 60 \mathrm{~cm} & 99.101 \mathrm{~cm}\end{array}$

$\begin{array}{lcc}\mathrm{SiO}_{2} & 49.07 & \mathrm{NRM} \text { intensity } \\ \mathrm{TiO}_{2} & 1.24 & \left(10^{-3} \text { emu/cm }{ }^{3}\right)\end{array}$

$\begin{array}{lll}\mathrm{Al}_{2} \mathrm{O}_{3} & 14.21 & \text { NRM Inci. } \\ \mathrm{F} \mathrm{FO} & 11.39 & \text { MDF }\end{array}$

$\mathrm{MnO}$ MDF (Oe)

$\begin{array}{rr}\mathrm{MgO}_{\mathrm{O}} & 7.48 \\ \mathrm{C}_{3} \mathrm{O} & 12.30\end{array}$

$\mathrm{Na}_{2} \mathrm{O}$

$\mathrm{K}_{2} \mathrm{O}$
$\mathrm{P}_{2} \mathrm{O}_{5}$
$\mathrm{~N}^{2}$

LoIt

0.58
$\mathrm{CO}+\mathrm{MgO}$

$\mathrm{V}_{\mathrm{p}, 1}(\mathrm{~km} / \mathrm{si})$

D $\left[\mathrm{g} / \mathrm{cm}^{3}\right)$

$-\quad 13.7$
$-\quad-62.8$
$-\quad 70.0$

$0.10 \quad P(x)$

5.700

5.900
2.95

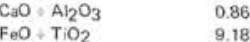

tVolcanic elaystone 


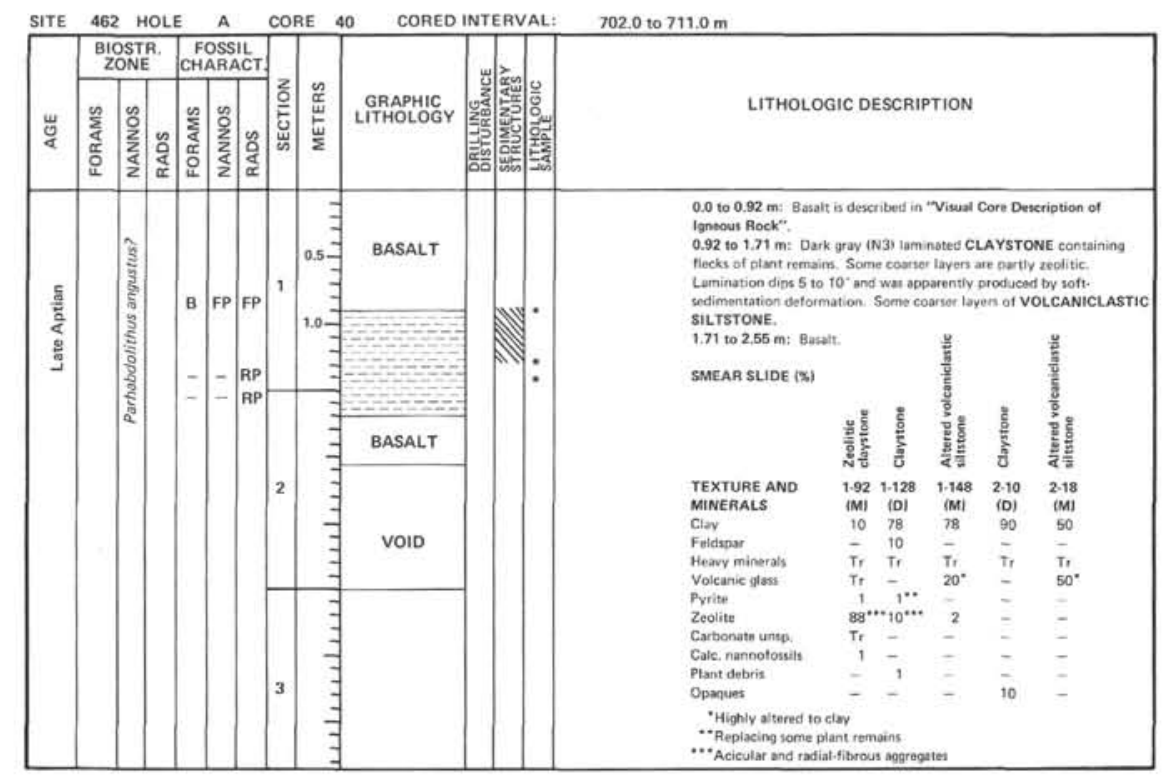



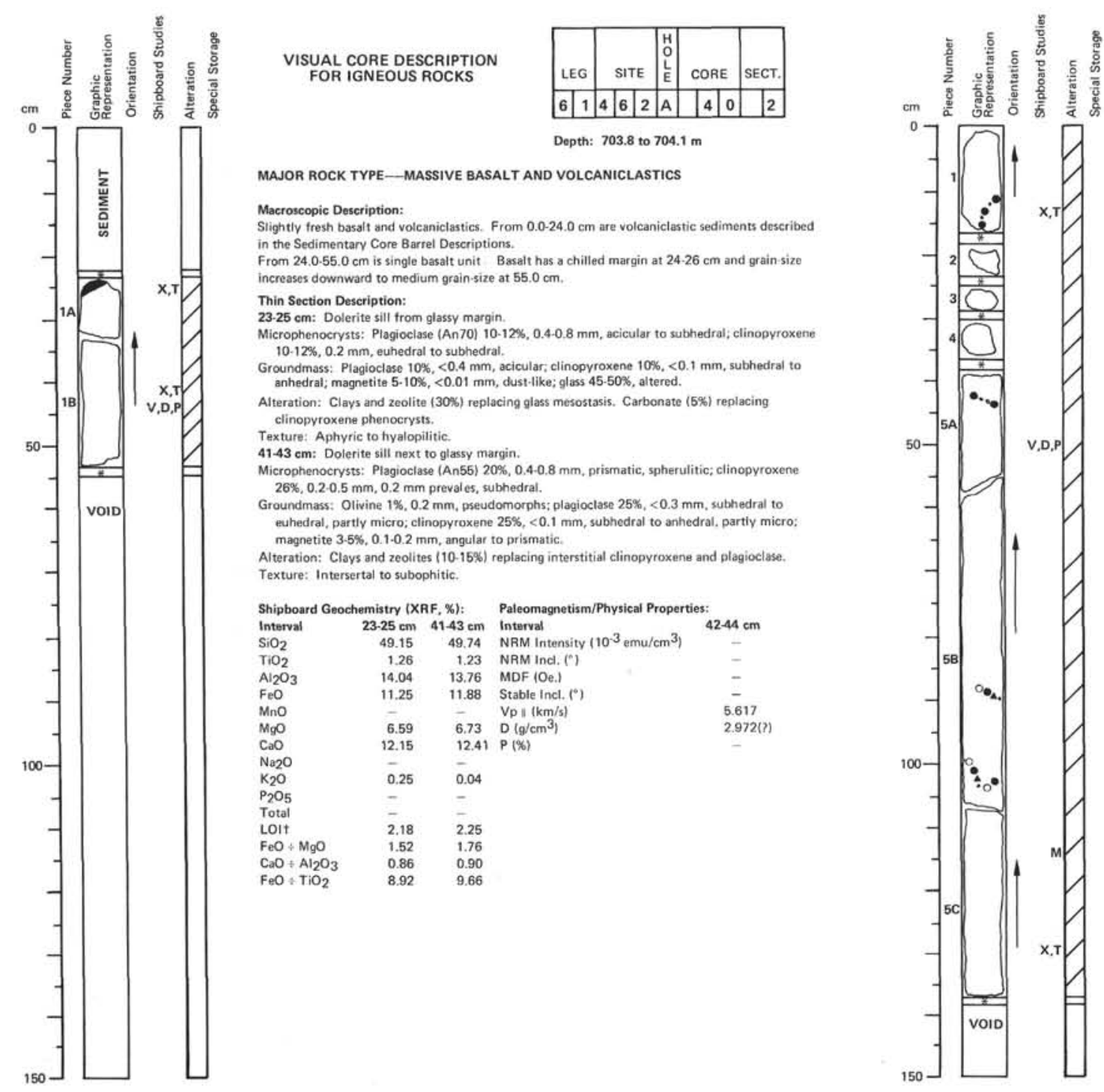

\section{VISUAL CORE DESCRIPTION
FOR IGNEOUS ROCKS

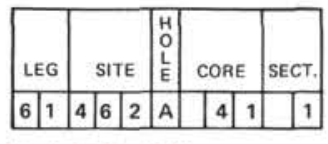

Depth: 711.0 to $712.4 \mathrm{~m}$

\section{MAJOR ROCK TYPE--MASSIVE BASALT SILL (DOLERITE)}

Macroscopic Description:

Slightly fresh medium gray (N5) massive dolerito with veins of calcite plus celadonite, plus pyrite, plus smectite. Grain size groduallv increases downward, from medium to slightly of plagioclase and clinopyroxene, whose ratio (plagioclase/clinopyroxene) is approximately one it has a groundmass of plagioclase, clinopyroxene, and Ti-magnetite microlites.

Thin Section Description:

10.12 cm: Dolerite from sill interior

Microphenocrysts: Plagioclase (An65) $40 \%, 0.30 .8 \mathrm{~mm}, 0.8 \mathrm{~mm}$ is acicular type. $0.3 \mathrm{~mm}$ $0.2 \mathrm{~mm}$, angular.

Groundmass: Plagioclase, $5 \%,<0.1 \mathrm{~mm}$, subhedral, partly microlitic; clinopyroxene $5 \%$, $<0.1 \mathrm{~mm}$, subhedrat, partly microlitic; magnetite $2 \%$, <0.1 mm, dust. like,
Alterations: Clays (3-8\%) and chlorite (3\%) replacing interstitial plagioclase. Alterations: Clays (3-8\%) and chlorite (3\%) replacing interstitial plagiocise.

$130.133 \mathrm{~cm}$ : Dolerite from sill interion.

Microphenocrysts: Plagioclase (An65) 10\%, 0.3.0.8 mm, acicular and also subhedral, megacrystals (An75 80) of 2.0.2.5 mm; clinopyroxene 10\%, 0.3.0.4 mm, subhedral;

Groundimass: Plagioclase $35 \%,<0.2 \mathrm{~mm}$, subhedral, microitic; clinopyroxene $40 \%,<0.2 \mathrm{~mm}$,

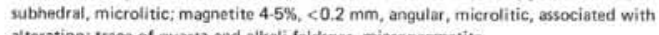

Alteration: Carbonate (5-10\%) replacing spots in plagioclase. Chlorite (3\%) occurs within Texture: Intersertal to intergranular.

Shipboard Geochemistry (XRF, \%): Paleomagnetism/Physical Properties:

$51.53 \mathrm{~cm} 115 \mathrm{~cm}$

$\mathrm{SiO}_{2} \quad 50.09 \quad \begin{array}{cc}\mathrm{cm} \\ \mathrm{T}_{2}\end{array}$

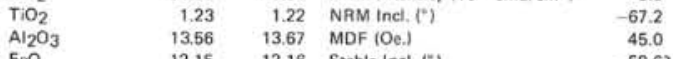

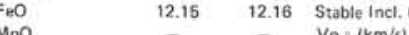

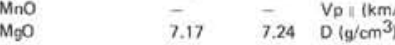

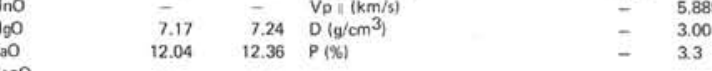

$\mathrm{K}_{2} \mathrm{O}$

$\mathrm{P}_{2} \mathrm{O}_{5}-\mathrm{N}_{2}-$

Total

$\begin{array}{lll} & 0.71 & 0.59 \\ \mathrm{FeO}+\mathrm{O}+\mathrm{MOO} & 1.69 & 1.69\end{array}$

$\begin{array}{lll}\mathrm{FeO}+\mathrm{MgO}_{9} \mathrm{O} & 1.69 & 1.69 \\ \mathrm{CaO}+\mathrm{Al}_{2} \mathrm{O}_{3} & 0.88 & 0.90 \\ \mathrm{FeO}+\mathrm{T}_{2} \mathrm{O}_{2} & 9.87 & 9.96\end{array}$ 

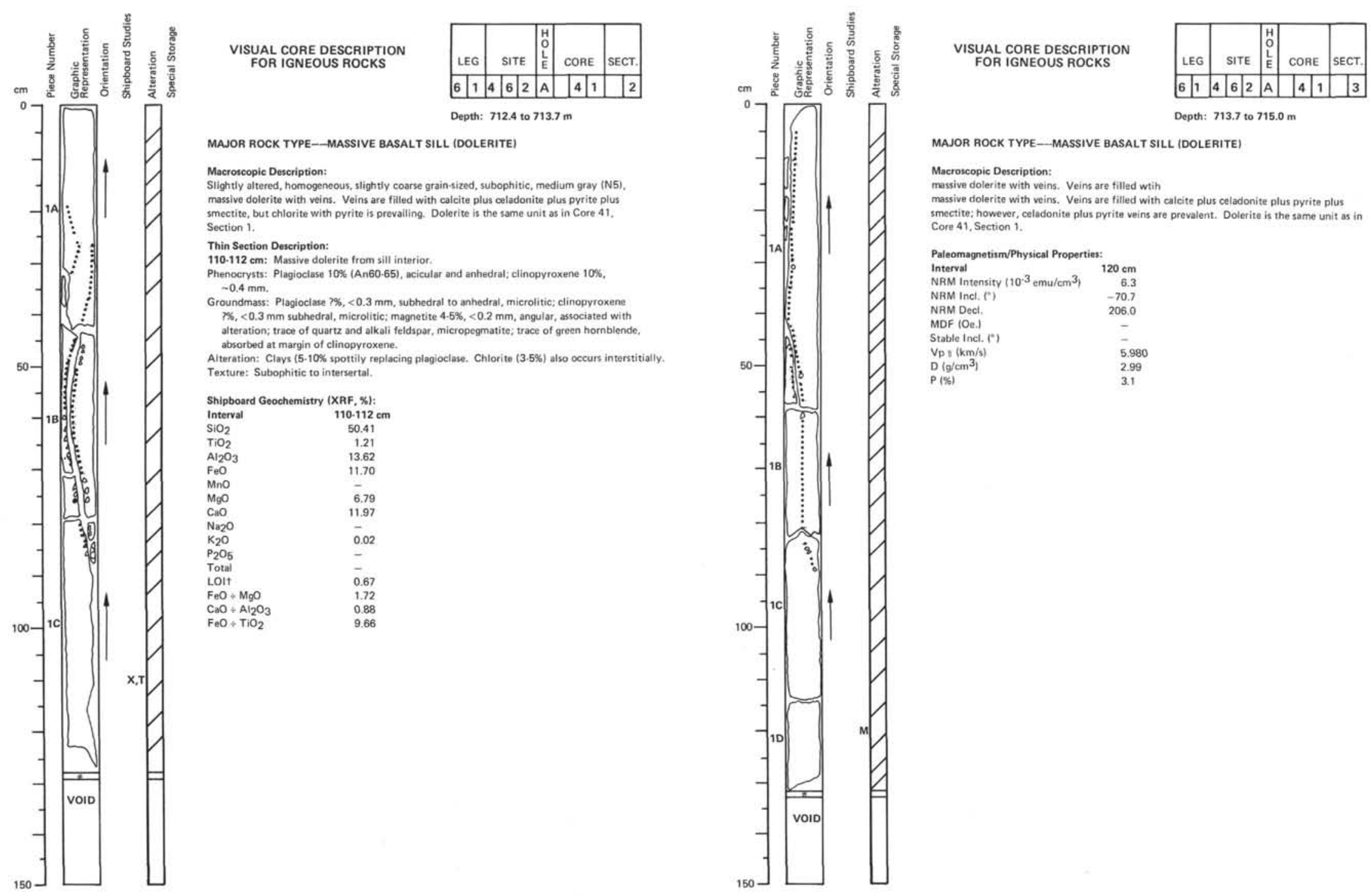

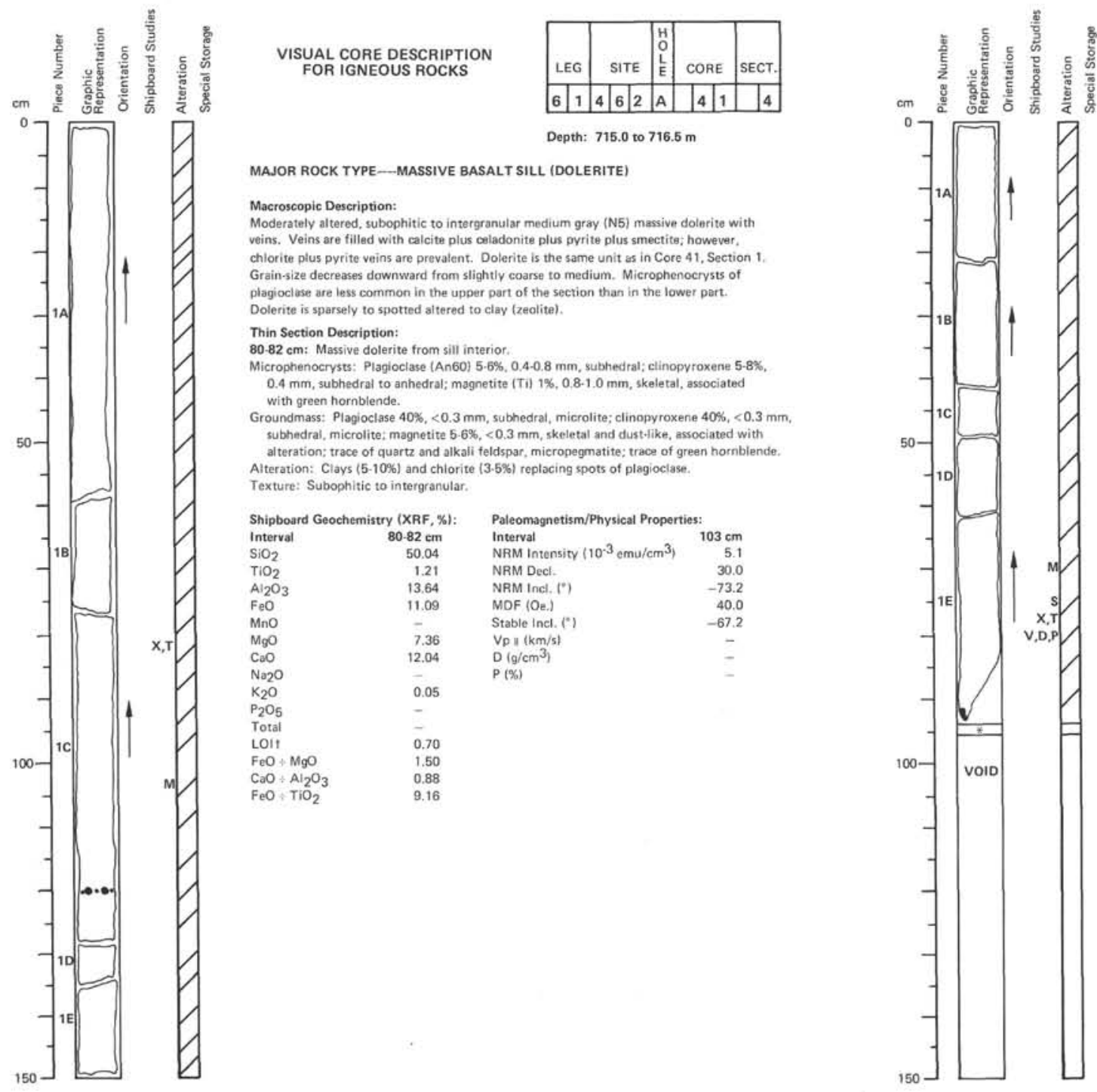

\section{VISUAL CORE DESCRIPTION
FOR IGNEOUS ROCKS

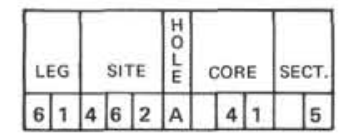 Depth: 716.5 to $717.4 \mathrm{~m}$}

MAJOR ROCK TYPE--MASSIVE BASALT SILL (DOLERITE)

Macroscopic Description: Slightly altered, homogeneous medium grainsize, intergranular to intersertal, medium gray (N5) massive dolerite. Dolerite is the same unit as in Core 41 , Section 1. Thin Section Description: Me $\mathrm{cm}$ : Mosswe dolerite from sill interic

$10-13 \%, 0.5-1.0 \mathrm{~mm}$, subhedral, partiy phenocrysts Groundmass: Plagiocisse $35 \%,<0.4 \mathrm{~mm}$, subhedral, miter (Tilitie: clinopyroxene $35 \%,<0.3 \mathrm{~mm}$ subhedral to anhedral, microlite; magnetite $5.8 \%,<0.2 \mathrm{~mm}$; trace of quartz and alkali Texter of plagioclase.

\section{Shipboard Geochemistry (XRF, ж):}

$\begin{array}{lr}\text { Interval } & 78.80 \mathrm{~cm} \\ \mathrm{SiO}_{2} & 50.28 \\ \mathrm{TiO}_{2} & 1.19 \\ \mathrm{Ai}_{2} & 1391\end{array}$

$\mathrm{TiO}_{2} \mathrm{O}_{3}$

$\mathrm{FeO}$

$\mathrm{MnO}$
$\mathrm{MgO}$
$\mathrm{CaO}$

$\mathrm{Na}_{2} \mathrm{O}$

$\mathrm{K}_{2} \mathrm{O}$
$\mathrm{P}_{2} \mathrm{O}_{5}$

Total
Loit

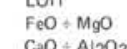

$\mathrm{C} a \mathrm{O}+\mathrm{Al}_{2} \mathrm{O}_{3}$
$\mathrm{FeO}=\mathrm{TiO}_{2}$

Paleomagnetism/Physical Properties
Interval

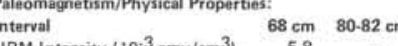

MOF (Oe.)

Stable Incl. 4 (")

$V_{p} \|(\mathrm{km} / \mathrm{s})$
$\mathrm{D}\left(\mathrm{g} / \mathrm{cm}^{3}\right)$

7.35

0.09

$\mathrm{P}(\mathrm{g} / \mathrm{cm})$
$\mathrm{P}(\mathrm{s})$

-77.4
30.0
-4347

1.93

1.93
1.50
0.87 

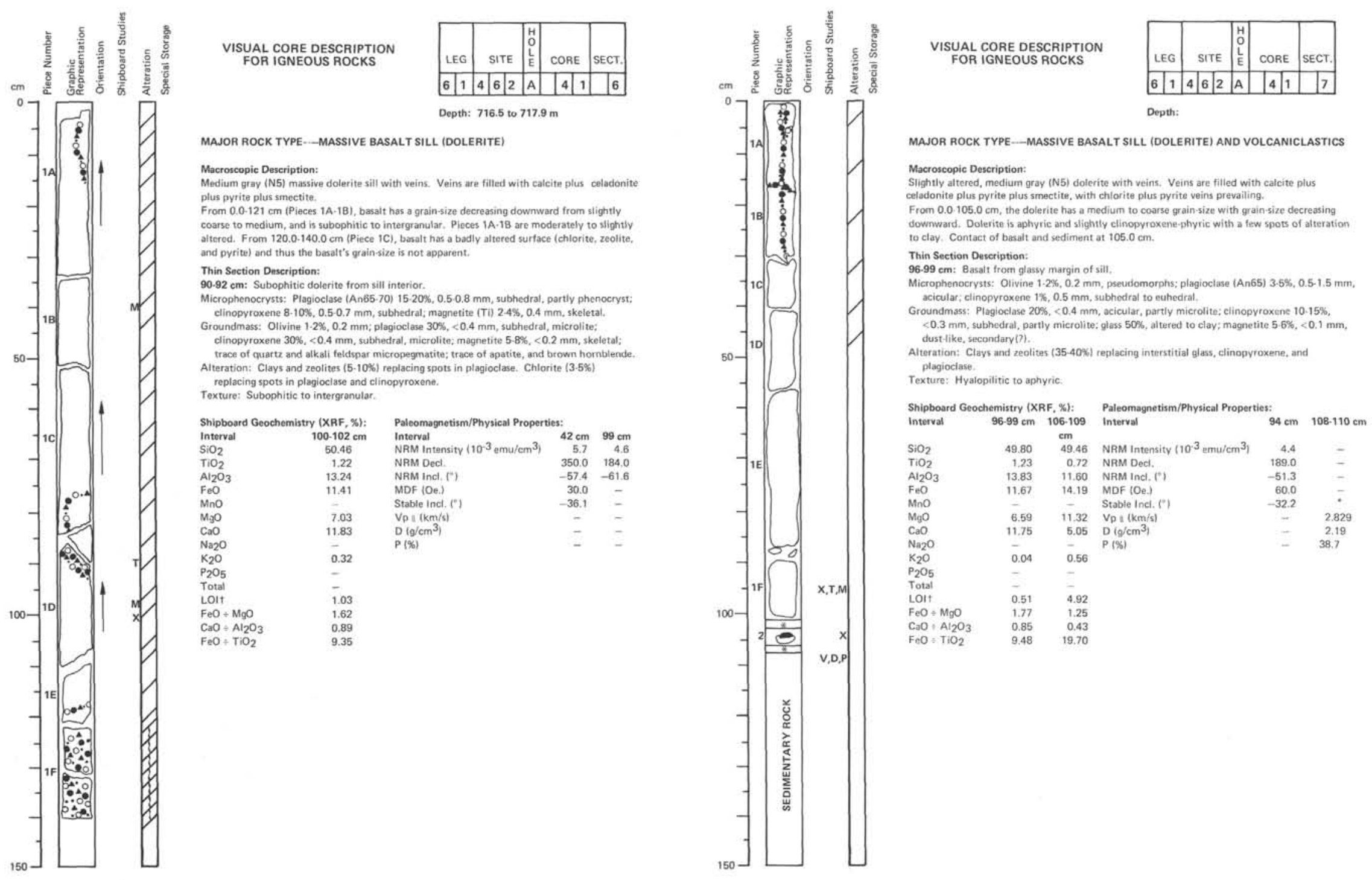


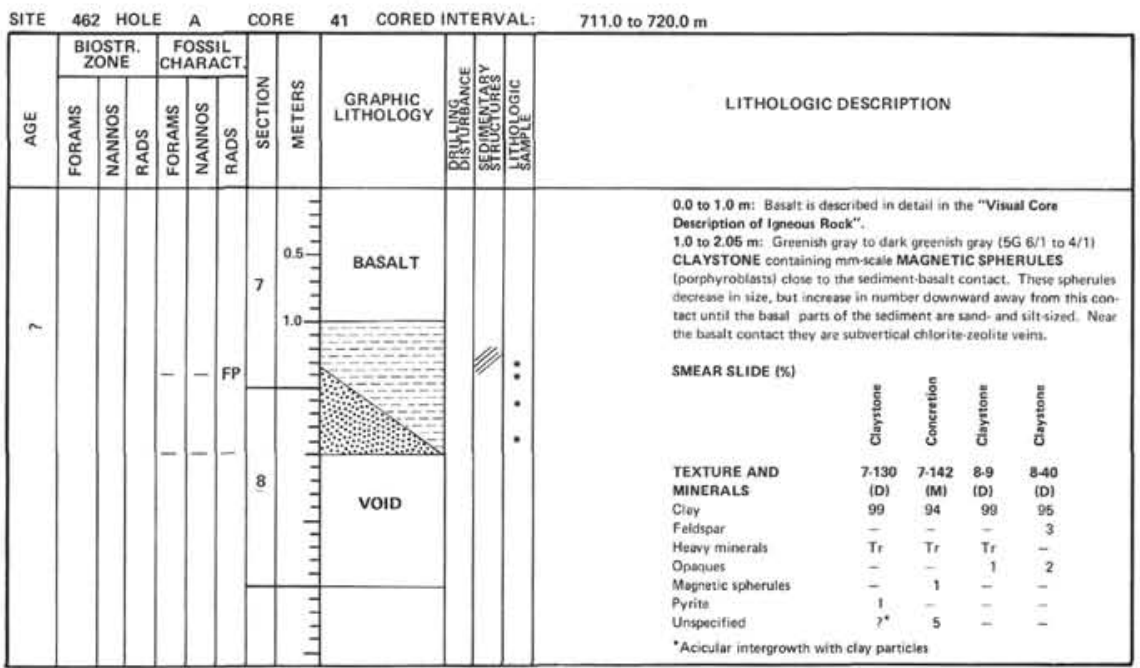

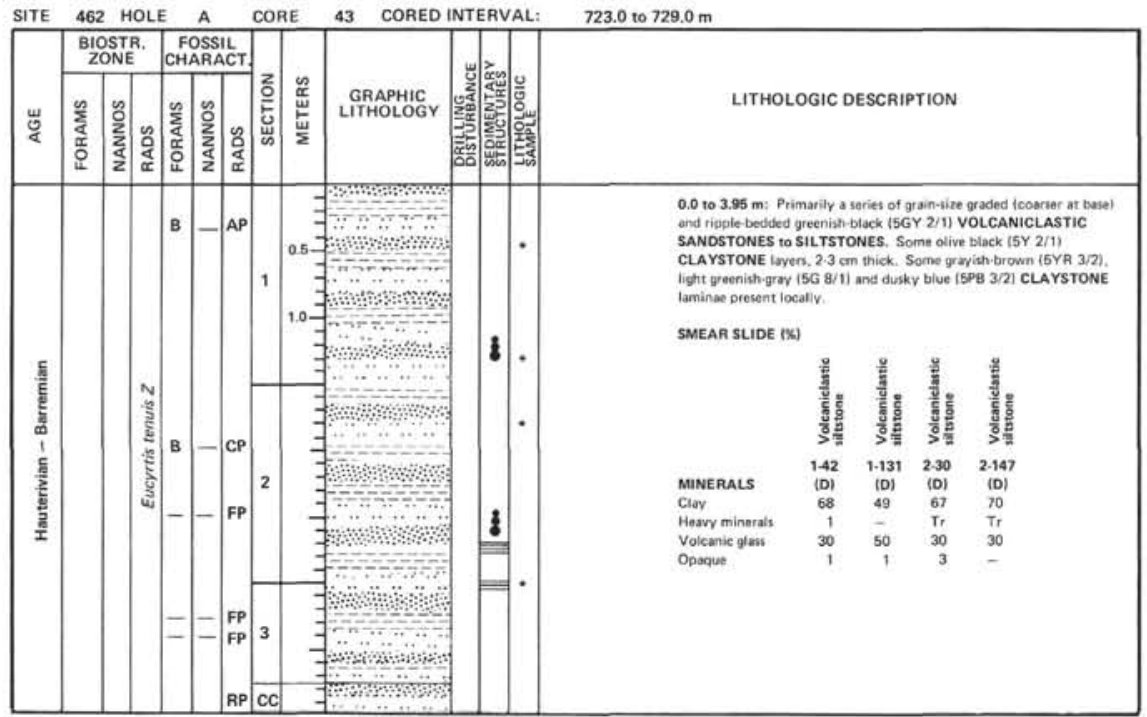

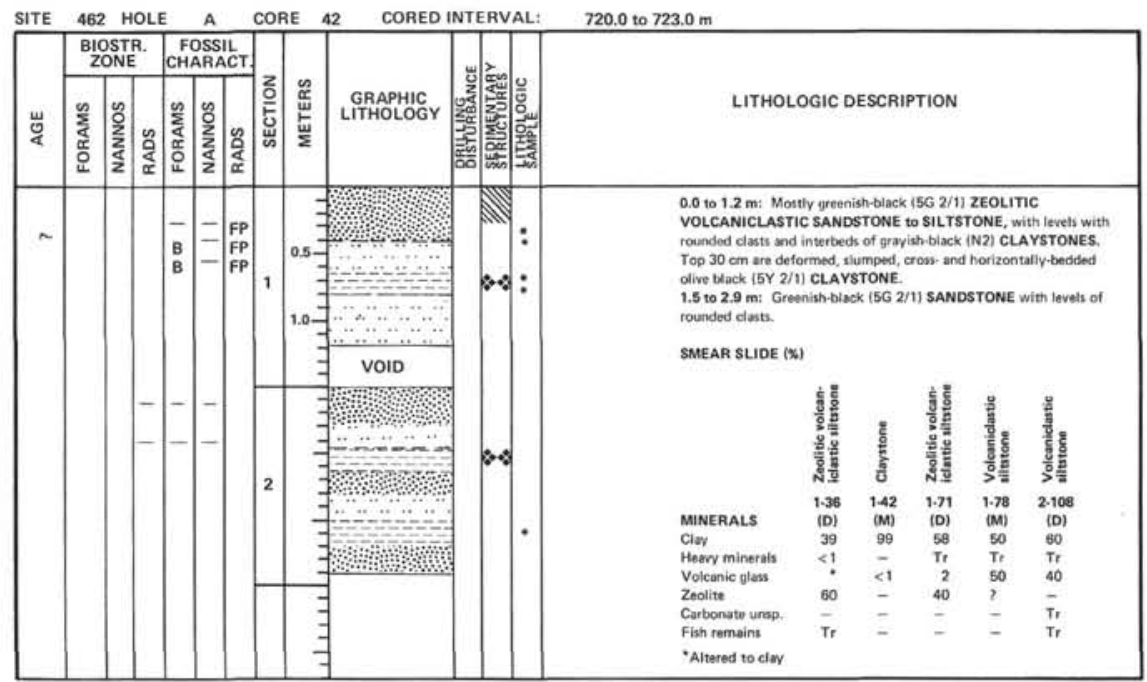




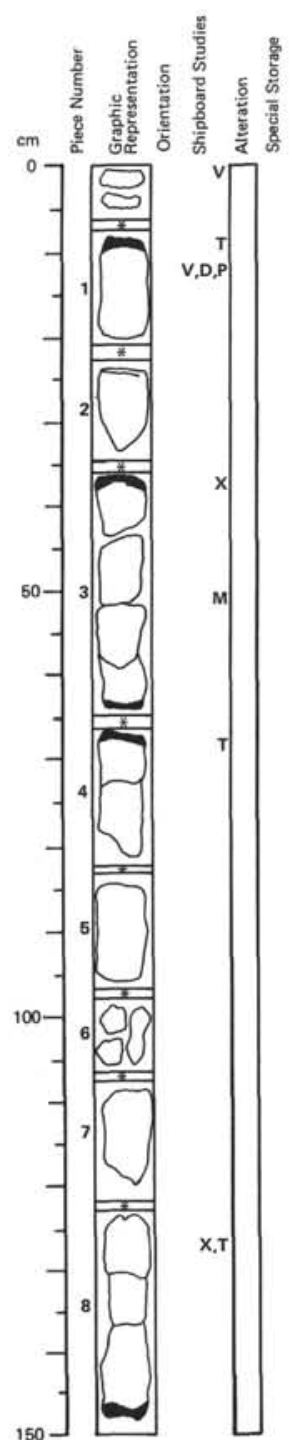

VISUAL CORE DESCRIPTION FOR IGNEOUS ROCKS

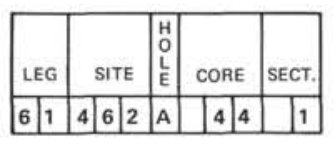

MAJOR ROCK TYPE--BASALT

Macroscopic Description

政

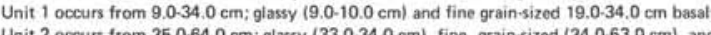
glassy $(63.0 .64 .0 \mathrm{~cm})$ basalt. Unit 3 occurs from $66.0 \cdot 148.0 \mathrm{c}$

The above units have clayey altered spots and glass is partly altered to chlorite.

a t tow clinopyroxene phenocrysts (3.4\%) with a variably glassy and holocrystalline units of plagioclase, clinopyroxene, and opaque minerals.

Thin Section Description:

Phenocrysts: Olivine 2\%, 0.1-0.6 mm, pseudomorphs; plagioclase (An65) 2\%, 0.2.0.5 mm Undmass: Plagioclase $3 \%, 0.05 \mathrm{~mm}$, skeletal, microlite,

nd crystallite; magnetite (Ti

olivine.
Alteration: Clays (var. \%) replacing glass, olivine, and plagioclase. Zeolite (var. \$) replacing

Phenocrysts: Olivine 3\%, 0.2-0.5 mm, pseudomororhss; plagiocilase IAn58 zoned to An30) clinopyroxene (augite) $18,<0.05 \mathrm{~mm}$; spinel (picotiter, indusions in olivine pseudomorntas

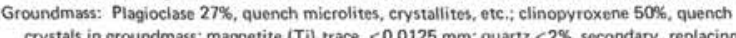
groundmass; amphibole trace, fibrous, brown, replacing olivine. replacing olivine, plagioclase and groundmass.

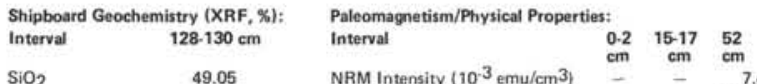

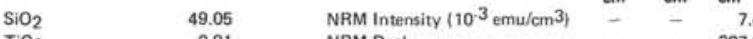

$\begin{array}{lrl}\mathrm{TiO}_{2} & 0.91 & \text { NRM Decl. } \\ \mathrm{Al}_{2} \mathrm{O}_{3} & 13.83 & \text { NRM Incl. (") }\end{array}$

$\mathrm{FeO} \quad 1000$

NRM Incl. $(")$
MDF $(D e$.

Stable inct. (1)

$V P \| 1(\mathrm{~km} / \mathrm{s})$

$D\left(g / \mathrm{cm}^{3}\right)$
$P(\%)$

TClaystone

$+\quad-43.0$

$\mathrm{MaO} \quad 12.62$

$\begin{array}{ll}\mathrm{Na}_{2} \mathrm{O} & - \\ \mathrm{K}_{2} \mathrm{O} & -02\end{array}$

$\mathrm{P}_{2} \mathrm{O}_{5}$

Felt

$\mathrm{FeO}+\mathrm{MgO}_{9} \mathrm{O}$
$\mathrm{CaO}+\mathrm{Al}_{2} \mathrm{O}_{3}$

$\mathrm{FeO} \div \mathrm{TiO}_{2}$

0.32
1.34

1.34
0.91
11.74

11.74

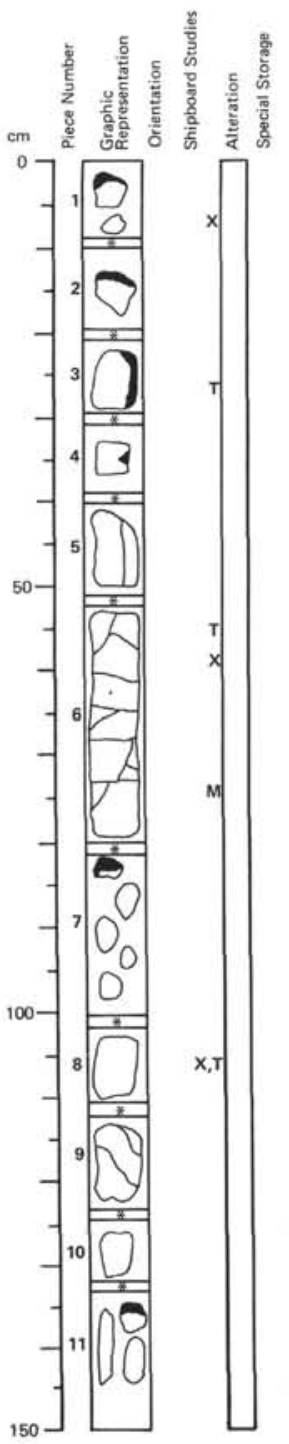

VISUAL CORE DESCRIPTION

FOR IGNEOUS ROCKS

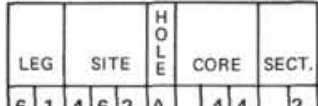

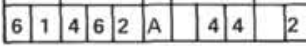

Depth: 730.5 to $732.0 \mathrm{~m}$

MAJOR ROCK TYPE--BASALT

Macroscopic Description Th: glassy basalt portions are from $0.0-37.0 \mathrm{~cm}$ and a fine (1) $37.0-80.0 \mathrm{~cm}$. grain-size basalt from 83.0 to about 135.01 ? $7 \mathrm{~cm}$ (ffragments to $1507 \mathrm{~cm}$ ) where gluss $(2 \mathrm{~cm}$ occurs on one of the pieces near the bottom of the section.

Thin Section Description:

$30 \mathrm{~cm}$ : Altered glassy busalt from glassy maroin.

Cerysts: Olivine $3 \%, 0.2-0.4 \mathrm{~mm}$, pseudornorphs, euhedral; plagioclase (An80) $2 \%, 0.2-0.5 \mathrm{~mm}$, .edhedrat; spinel $<1 \%,<0.03 \mathrm{~mm}$, inclusions in olivine pseudomorphs.

C. teration: Brown clays (51\%) replacing glass and olivi and also occurs as veins.
Texture: Glassy to variolitic

Texture: Glass to variolitic.

. distribution; clinopyroxene (augitel $3 \%,<0.1$
$<1 \%,<0.03 \mathrm{~mm}$, inclusions in pseudomoths

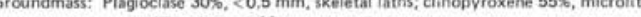

,

lassy basalt from pillow interior.

Phenocrysts: Olivine 1\%, 0.1-0.2 mm, pseudomorphs; plagioclase (An75) 5\%, up to $0.5 \mathrm{~mm}$,

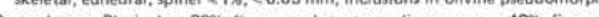

Alteration. Clows $115 \%$ ) and

also occur in veins. Chlorite (18) replacing plagioclase phenocrysts.

\begin{tabular}{|c|c|c|c|}
\hline & & \multicolumn{2}{|l|}{ Palcomanentism/Physical Properties: } \\
\hline Interval & $7.9 \mathrm{~cm} \quad 7.9 \mathrm{~cm}$ & 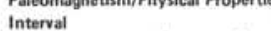 & \\
\hline $\mathrm{SiO}_{2}$ & 50.85 & NRM Intensity $\left(10^{-3} \mathrm{emu}^{-\mathrm{cm}^{3}}\right)$ & \\
\hline $\mathrm{THO}_{2}$ & 0.96 & NRM Decl. & \\
\hline $\mathrm{Al}_{2} \mathrm{O}_{3}$ & 13.47 & NRM Inct. ( (") & \\
\hline $\mathrm{FeO}$ & 12.86 & MDF (Oe.) & \\
\hline Mno & - & Stable Ind. (") & \\
\hline $\mathrm{MgO}$ & 7.93 & $\begin{array}{l}V_{p} \|(\mathrm{km} / \mathrm{s}) \\
D_{\left(\mathrm{g} / \mathrm{g} \mathrm{m}^{3}\right)}\end{array}$ & \\
\hline $\mathrm{CaO}$ & 6.66 & $D\left(g / \mathrm{cm}^{3}\right)$ & \\
\hline $\begin{array}{l}\mathrm{Na}_{2} \mathrm{O} \\
\mathrm{K}_{2} \mathrm{O}\end{array}$ & - & $P(\%)$ & \\
\hline $\begin{array}{l}\mathrm{K}_{2} \mathrm{O} \\
\mathrm{P}_{2} \mathrm{O}\end{array}$ & $\begin{array}{l}0.74 \\
-\end{array}$ & & \\
\hline LOI & 7.46 & & \\
\hline $\mathrm{FeO} \div \mathrm{Mg}_{9} \mathrm{O}$ & 1.62 & & \\
\hline $\mathrm{CaO} \div \mathrm{Al}_{2} \mathrm{O}_{3}$ & 0.49 & & \\
\hline $\mathrm{FeO}+\mathrm{TiO}_{2}$ & 13.39 & & \\
\hline
\end{tabular}



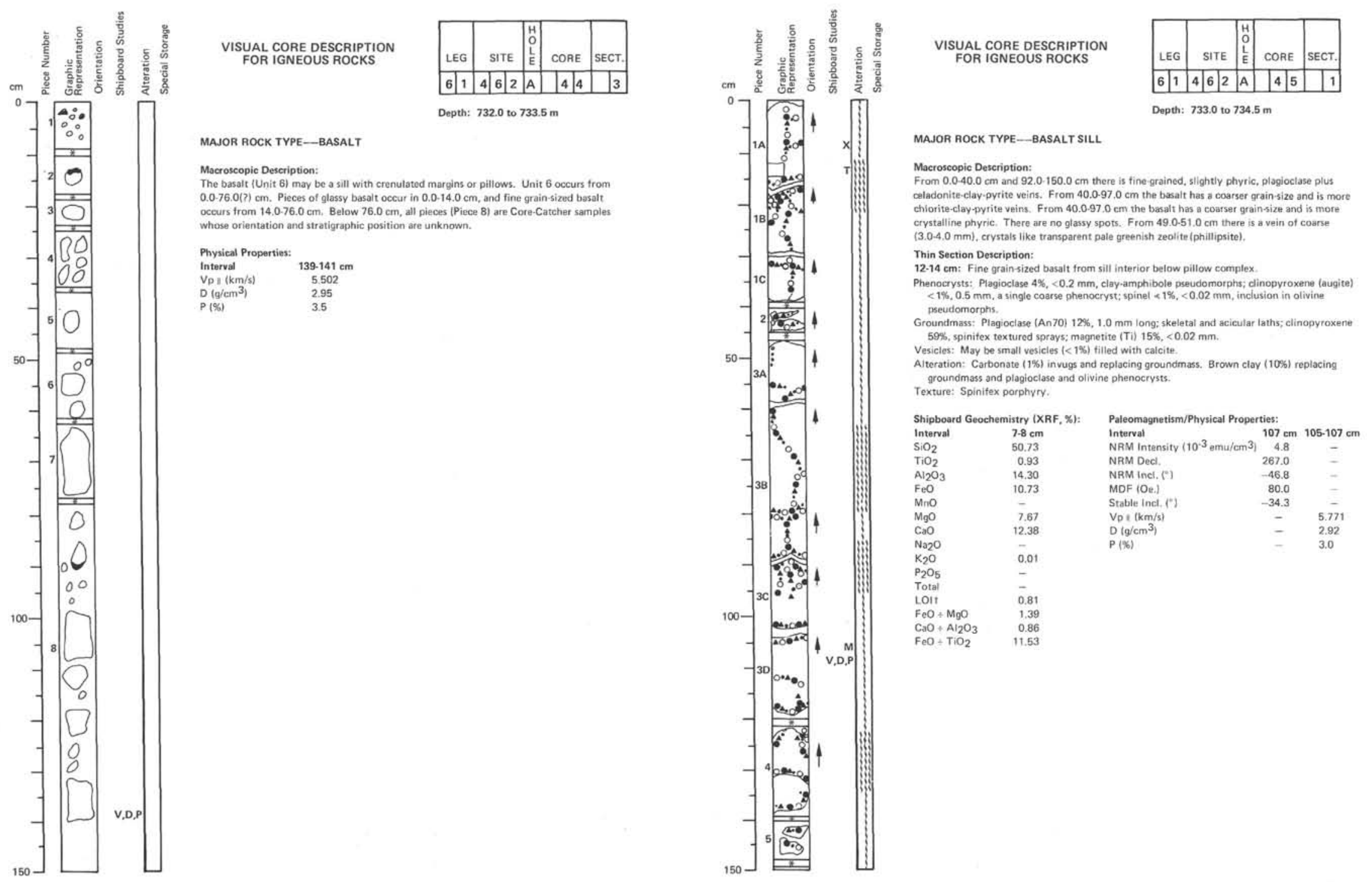

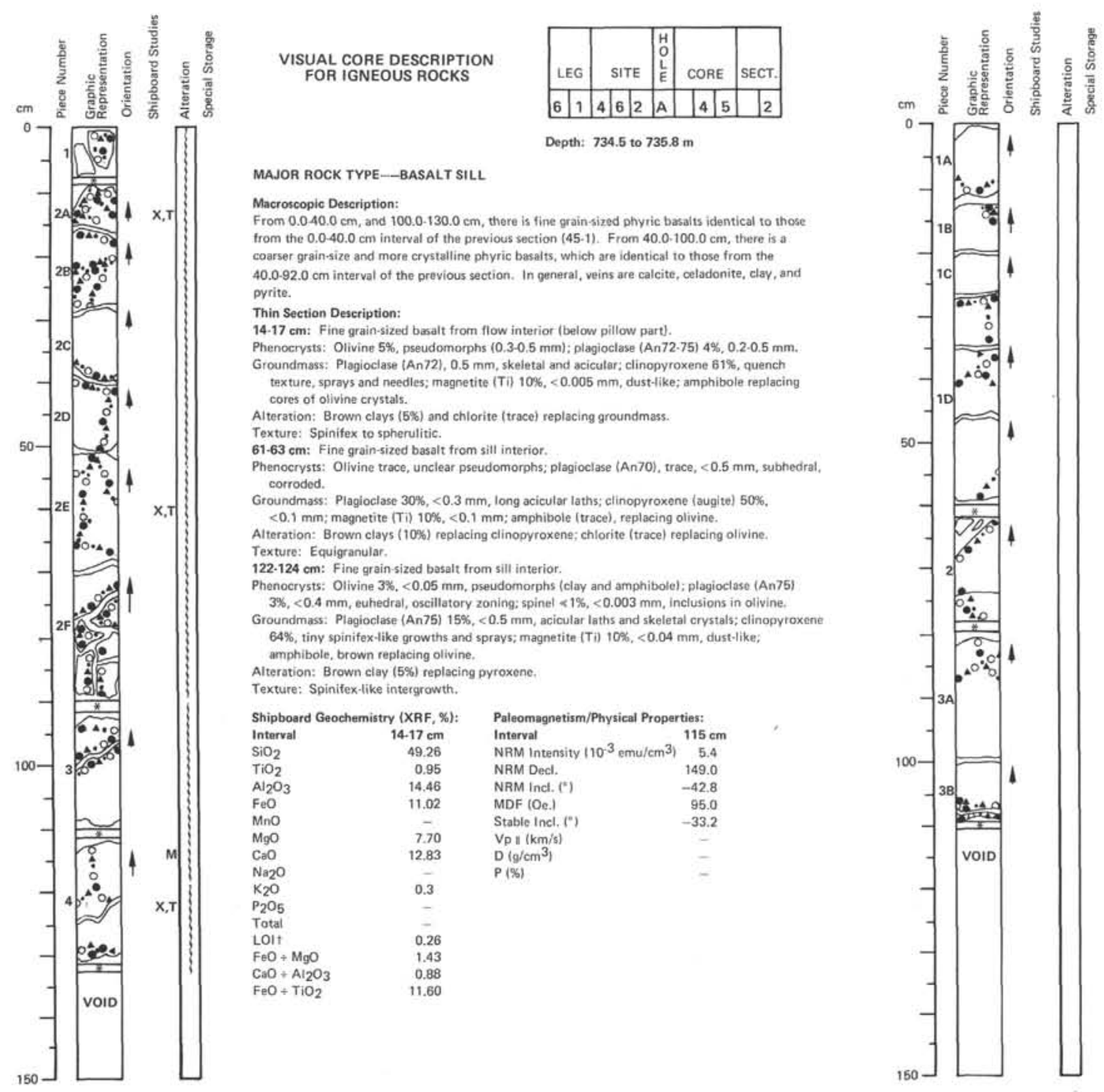

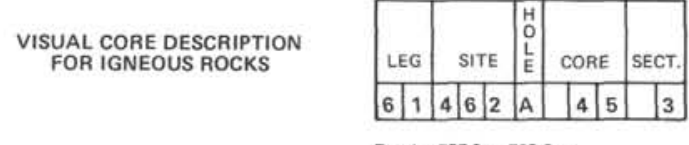

MAJOR ROCK TYPE - -BASALT SILL

Macroscopic Description

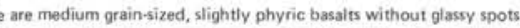
They are more ardilline than the middle of the previous section. Veins are calcite oudedenite. clay-pyrite.

Thin Section Description:

50.52 cm: Altered fine grainsized basalt from sill interior.
Phenocrysts: Olivine 2\%, $0.3 .0 .5 \mathrm{~mm}$, pseudomorphs; plagioclase (An65) $2 \%, 0.2 \cdot 0.4 \mathrm{~mm}$.

$51 \%, 0.1 \mathrm{~mm}$, wench and Vesicles: Vesicles are <1\%; one vesicle is egg-shaped, $0.4 \mathrm{~mm}$ in diameter, and is emp Alteration: Brown clays (15\%) in patches, replacing all minerals.

Shiphoard Geochemistry (XRF, צu:

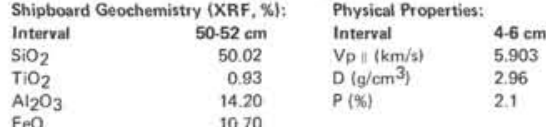

$\begin{array}{ll}\mathrm{Al}_{2} \mathrm{O}_{3} & 14.20 \\ \mathrm{FeO} & 10.70\end{array}$

$\mathrm{MnO}$
$\mathrm{MgO}$

$\mathrm{CaO}_{\mathrm{Na}_{2} \mathrm{O}} \quad 12.50$

$\mathrm{K}_{2} \mathrm{O}-0.008$

$\mathrm{P}_{2} \mathrm{O}_{5}$
Total

0.66

$\begin{array}{ll}\mathrm{FeO}+\mathrm{MgO}_{9} \mathrm{O} & 1.41 \\ \mathrm{C} & 0.88\end{array}$ 


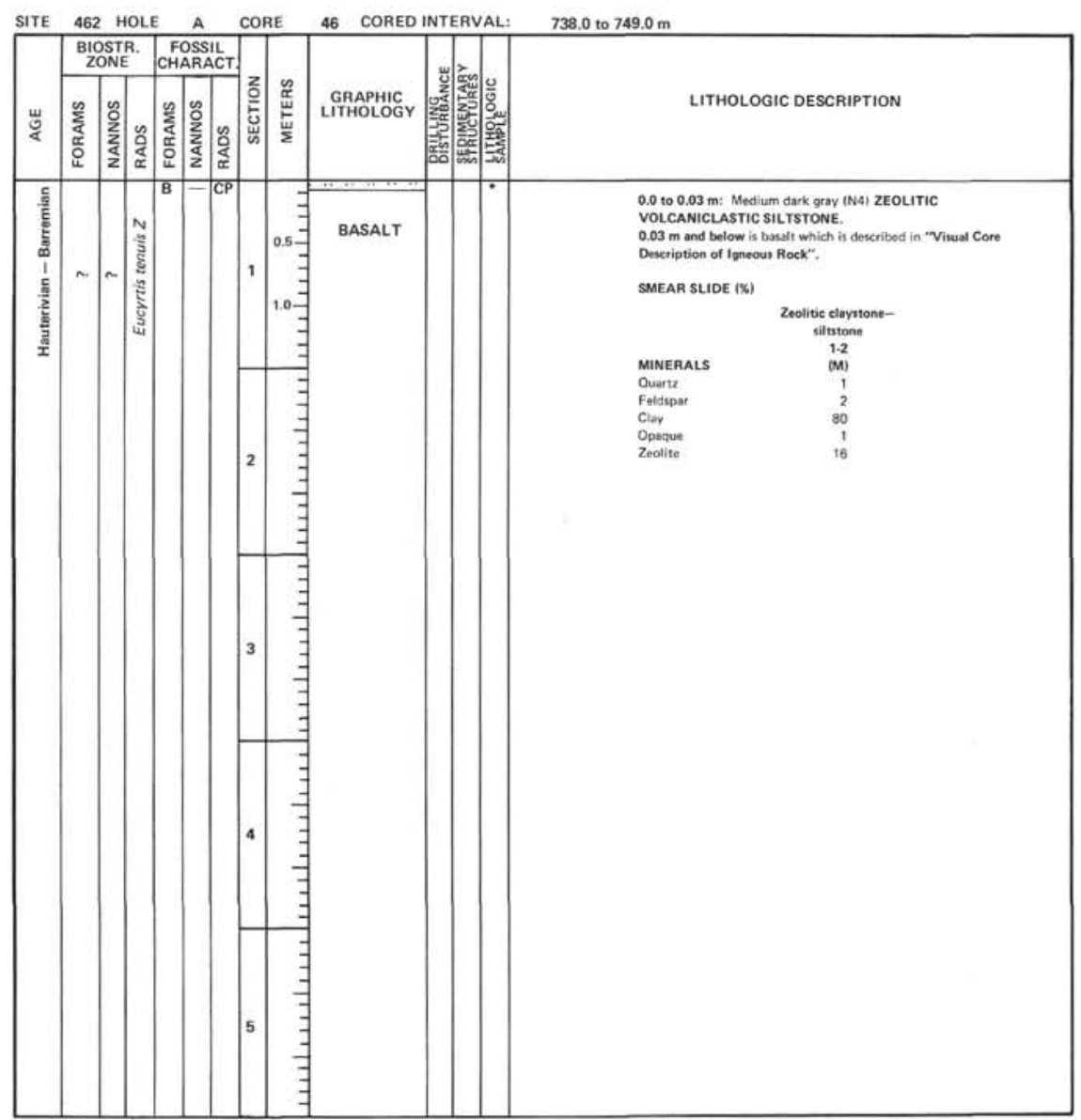




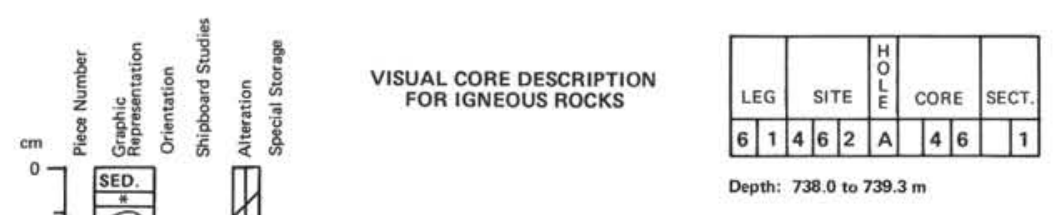

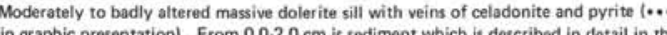

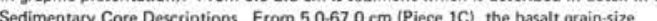
increases from fine to slightly medium and the basalt is hyalopilitic to intersertal. A distinc upper chilled margin was not found. Microphenocrysts of clinopyroxene are often altered to clay minerals and groundmass also appears to be badily attered. in the groundmass, acicular a small amount of plagioclase, and groundmass of plagioclase, clinopyroxene, magnerite, and From 67.0-131.0 cm, the medium gray (N5) basalt is medium grain-sized and is intersertal to intergranular. Consituent minerals are the same as $7.0 \mathrm{~m} 5.0-67.0 \mathrm{~cm}$ interval, excep/4 The

Thin Section Description:

It from sill interior

(An68) $2 \%, 0.2 .0 .8 \mathrm{~mm}$ Groundmass: Plagioclase (An 70 ) 25\%, $20.10 .5 \mathrm{~mm}$, bladed ons in olivine. (augite) $45 \%,<0.2 \mathrm{~mm}$, granular and quench; magnetite (Ti) 10\%, $<0.04 \mathrm{~mm}$. Texture: Equigranular.

\begin{tabular}{|c|c|c|}
\hline \multicolumn{3}{|c|}{ Paloomagnetism/Physical Properties: } \\
\hline Interval & $33 \mathrm{~cm}$ & $119-121 \mathrm{~cm}$ \\
\hline NRM Intensity $\left(10^{-3} \mathrm{emu} / \mathrm{cm}^{3}\right)$ & & \\
\hline NRM Decl. & 142.0 & \\
\hline NRM Incl. (") & -68.8 & - \\
\hline MDF (Oe.) & 35.0 & - \\
\hline Stable Inct. $\left({ }^{\circ}\right)$ & -33.27 & \\
\hline $\begin{array}{l}V_{p, ~}\left(\mathrm{kmm}^{3} / \mathrm{s}\right) \\
\mathrm{D}\left(\mathrm{g} / \mathrm{cm}^{3}\right)\end{array}$ & z & 2.93 \\
\hline$P(\%)$ & - & 2.3 \\
\hline
\end{tabular}

100

$P(\%)$

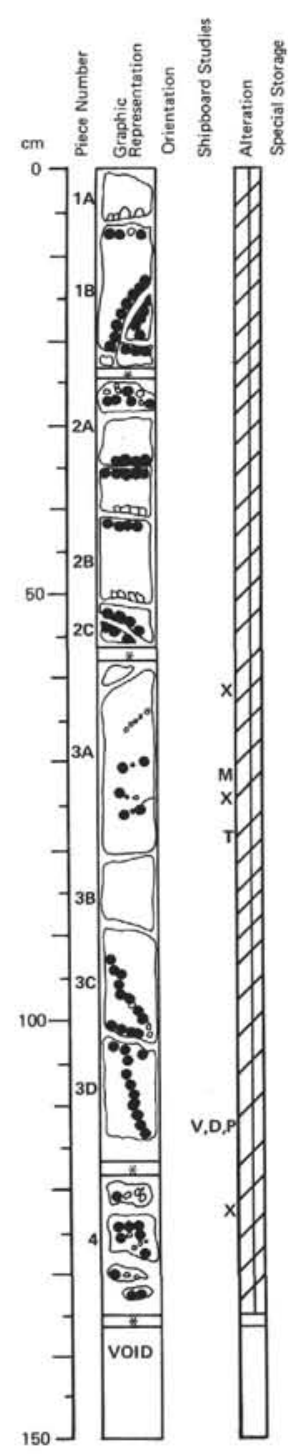

VISUAL CORE DESCRIPTION

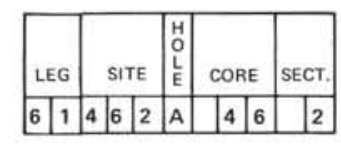

Dupth: 739.3 to $740.6 \mathrm{~m}$

\section{MAJOR ROCK TYPE--BASALT SILL}

Macroscopic Description:

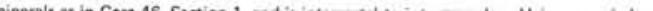

(O)

opyroxene (augite) $40 \%$

Texture: Equigranula.

Shipboard Geochemistry (XRF, \%): Paleomagnetism/Physical Properties:

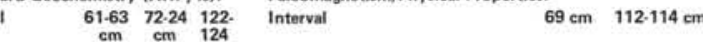

$\mathrm{SiO}_{2} \quad 48.93 \quad 50.39 \begin{array}{cc}\mathrm{cm} \\ 49.50\end{array}$

$\begin{array}{llllll}\mathrm{TiO}_{2} & 0.93 & 0.90 & 0.85 & \text { NRM Ded. } & 173.0\end{array}$

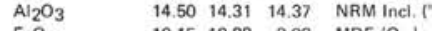

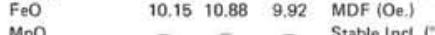

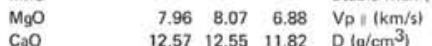

$\mathrm{Na}_{2} \mathrm{O}-\mathrm{O}-\mathrm{P}(\%)$

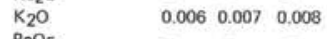

Total

$\mathrm{FeO}+\mathrm{MgO} \quad$\begin{tabular}{llll}
0.62 & 0.96 & 0.65 \\
\hline & 127 & 1.34 & 1.44
\end{tabular}

$\begin{array}{llll}\mathrm{CaO}_{2}+\mathrm{Al}_{2} \mathrm{O}_{3} & 0.86 & 0.87 & 0.82\end{array}$

$\mathrm{FO}^{\mathrm{O}}+\mathrm{TiO}_{2} \quad 10.91 \quad 12.08 \quad 11.67$ 


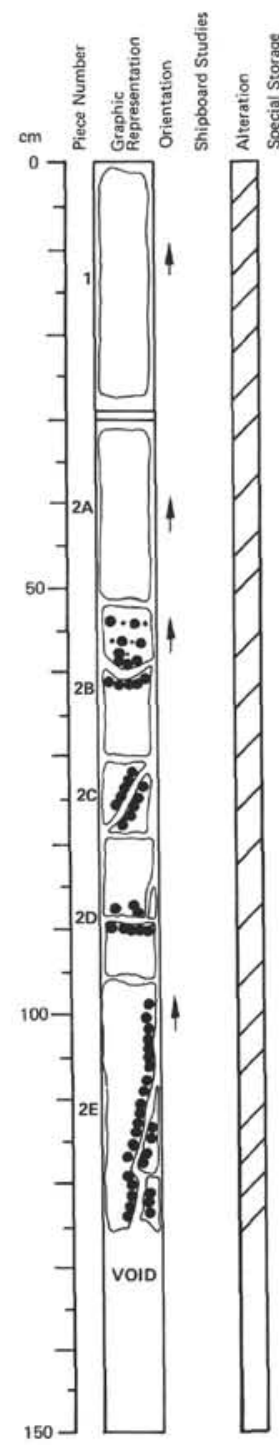

VISUAL CORE DESCRIPTION
FOR IGNEOUS ROCKS

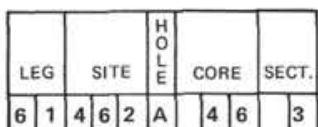

Depth: 740.6 to $7419 \mathrm{~m}$

MAJOR ROCK TYPE--BASALT SILL

Moderately altered, silightiy medium to medium grain-sized, massive dolerite sith. te is the same unit as in Core 46, Section 2 . (a)

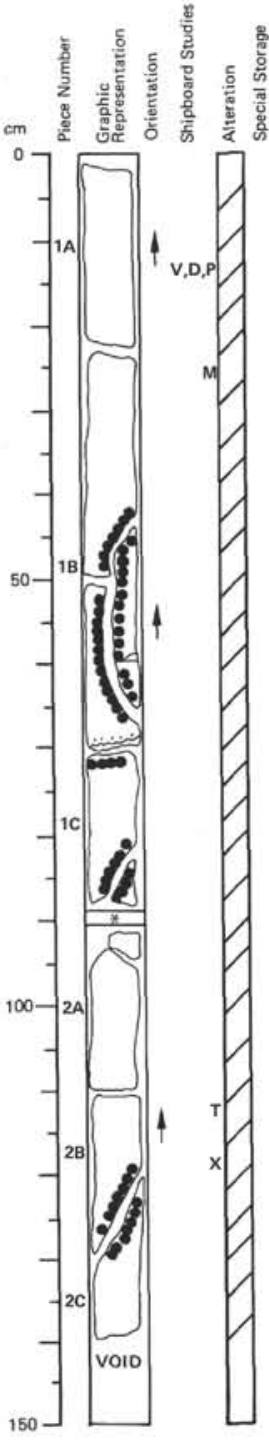

VISUAL CORE DESCRIPTION

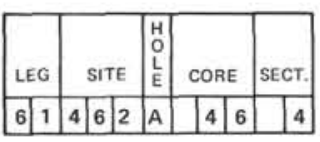

Depth: 741.9 to $743.3 \mathrm{~m}$

\section{MAJOR ROCK TYPE--BASALT SILL}

Macroscopic Description:

Moderatly disces

Fom $0.710 \mathrm{~cm}$ it has a shint

thas the same constituent minerusdium to medium grain-size and is intersertal to intergranulat medium to slightly coarse grain-size and is intergranular to subophitic. This bassalt is made of microphenocrysts to phenocrysts of clinopyroxene, plagioclase, and magnetite (2), and microlites

Phenocrysts: Olivine 10\%, 0.3.0.5 mm, pseudomorphs; plagiociase (An 75 ) $2 \%, 0.2 .0 .4 \mathrm{~mm}$ clinopyroxene (augite) 5\%, 0.1-0.2 mm, microphenocrysts; spinel <1\%, <0.003 mm,

Groundmass: Plagioclase ( $\sim$ An70) $25 \%, 0.2-0.4 \mathrm{~mm}$, subhedral laths; clinopyroxene (augite) $35 \%, 0.1 \cdot 0.2 \mathrm{~mm}$, granular and subhedral; magnet it Alteration: 8 rown clays (15\%) in patches replacing rock and also occurs in veins. Shiphord Gocter

\begin{tabular}{|c|c|c|c|c|}
\hline \multicolumn{2}{|c|}{ Shipboard Geochemistry (XRF, \%): } & \multicolumn{3}{|c|}{ Paleomagnetism/Physical Properties: } \\
\hline Interval & $118.120 \mathrm{~cm}$ & & $29 \mathrm{~cm}$ & $13.15 \mathrm{~cm}$ \\
\hline $\mathrm{SiO}_{2}$ & 49.09 & NRM Intensity $\left(10^{-3} \mathrm{emu}^{-\mathrm{cm}^{3}}\right)$ & & \\
\hline & 0.90 & NRM Decl. & & - \\
\hline $\mathrm{Al}_{2} \mathrm{O}_{3}$ & & NRM Incl. $\left({ }^{\circ}\right)$ & & \\
\hline Feo & 10.75 & MDF (Oe.) & 50.0 & - \\
\hline Mno & - & Stable Inci, $\left(1^{\circ}\right)$ & -55.0 & \\
\hline 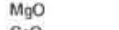 & 7.38 & $V_{p}:(\mathrm{km} / \mathrm{ss})$ & - & 6.068 \\
\hline $\mathrm{C}_{0} \mathrm{O}$ & 12.65 & $\mathrm{D}\left(\mathrm{g} / \mathrm{cm}^{3}\right)$ & - & 2.95 \\
\hline $\begin{array}{l}\mathrm{N}_{2} \mathrm{O} \\
\mathrm{K}_{2} \mathrm{O}\end{array}$ & 0.003 & $P(\$)$ & & \\
\hline $\mathrm{P}_{2} \mathrm{O}_{5}$ & - & & & \\
\hline Total & & & & \\
\hline Loit & 0.85 & & & \\
\hline $\mathrm{FeO} \div \mathrm{MgO}_{\mathrm{O}}$ & 1.45 & & & \\
\hline $\mathrm{CaO} \div \mathrm{Al}_{2} \mathrm{O}_{3}$ & 0.89 & & & \\
\hline $\mathrm{FeO}+\mathrm{TiO}_{2}$ & 11.94 & & & \\
\hline
\end{tabular}



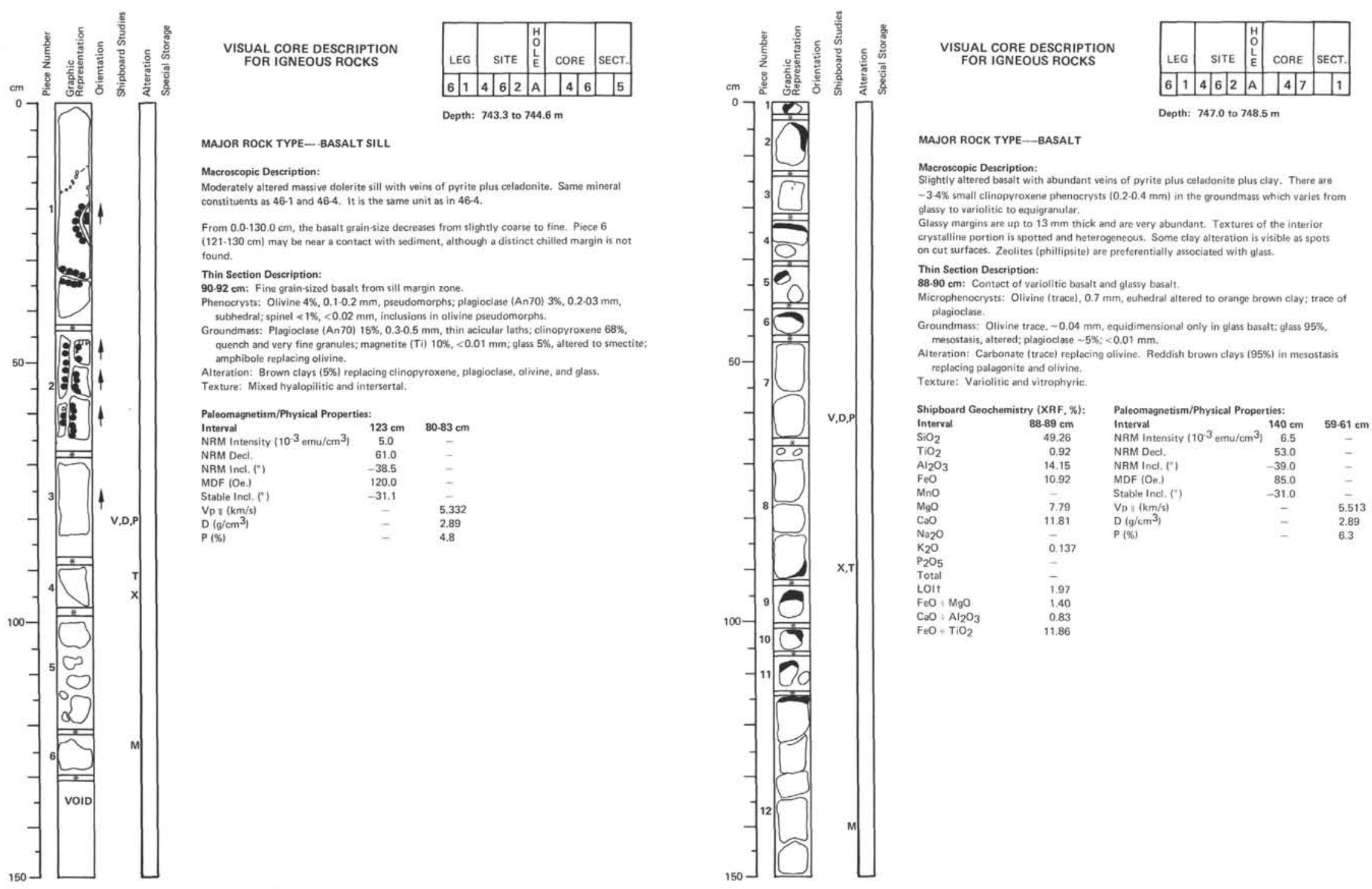

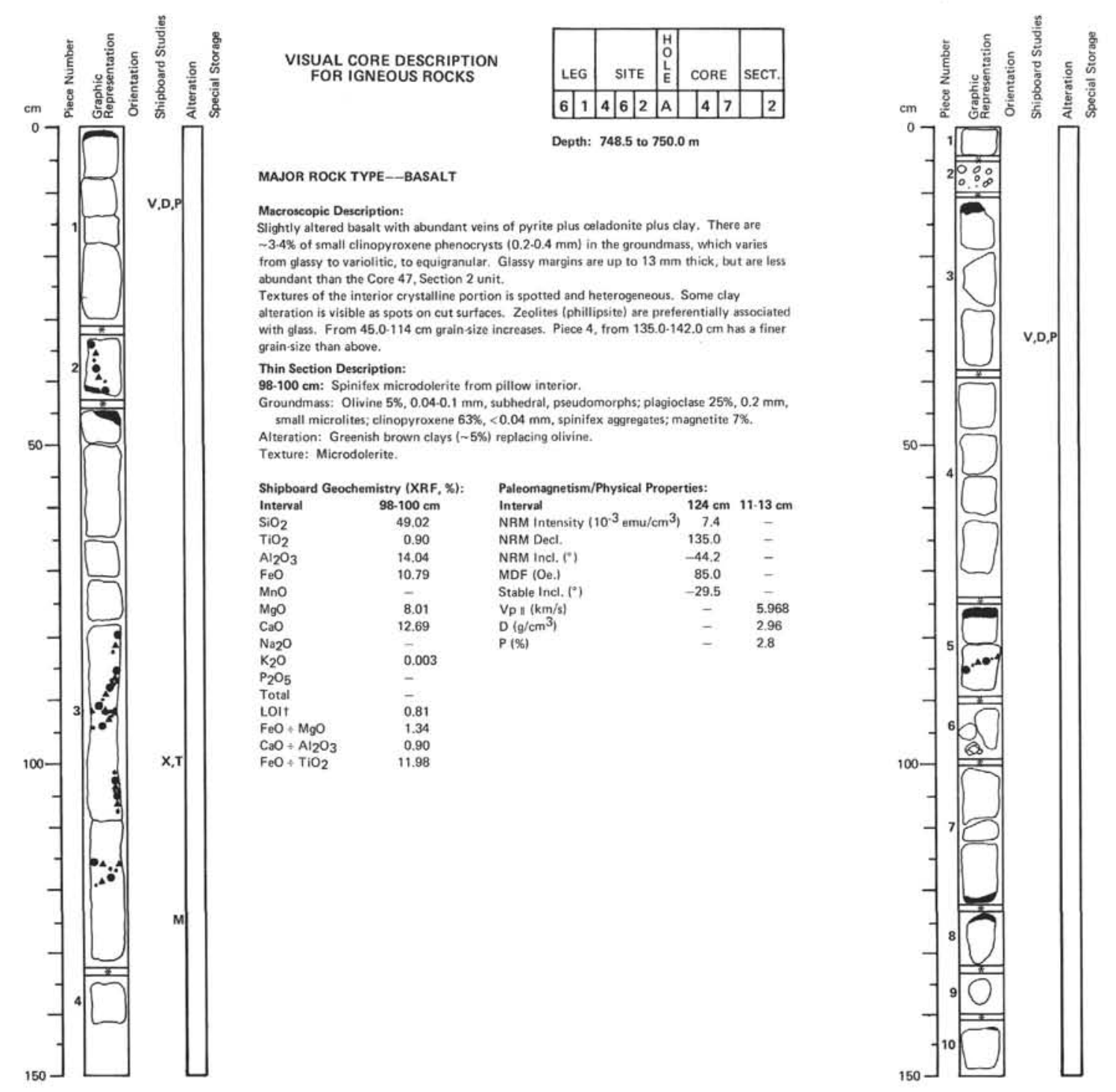

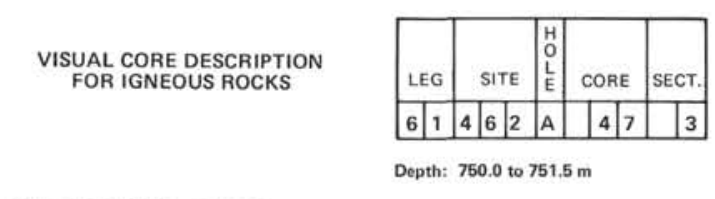

MAJOR ROCK TYPE--BASALT

Macroscopic Description:

Slightiy altered basalt with veins of pyrite plus celadonite plus clay. There are $-3-4 \%$ small variolitici, to equigranular, Glassy margins are up to $13 \mathrm{~mm}$ thick. Textures of the interior crystalline portion is spotted and heterogeneous. Some clay alteration is visible as spots on cut surfaces. Zeolites (phillipsite) are preferential associated with glass. Zeolite fragments occur at $5.0-10.0 \mathrm{~cm}$ from the top of the section,
From $77.0 \sim 100.0 \mathrm{~cm}$, basalt grain:size increases, and from $\sim 100.0 \sim 120.0 \mathrm{~cm}$, grain-size From $77.0 \sim 17$

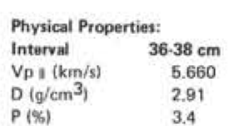



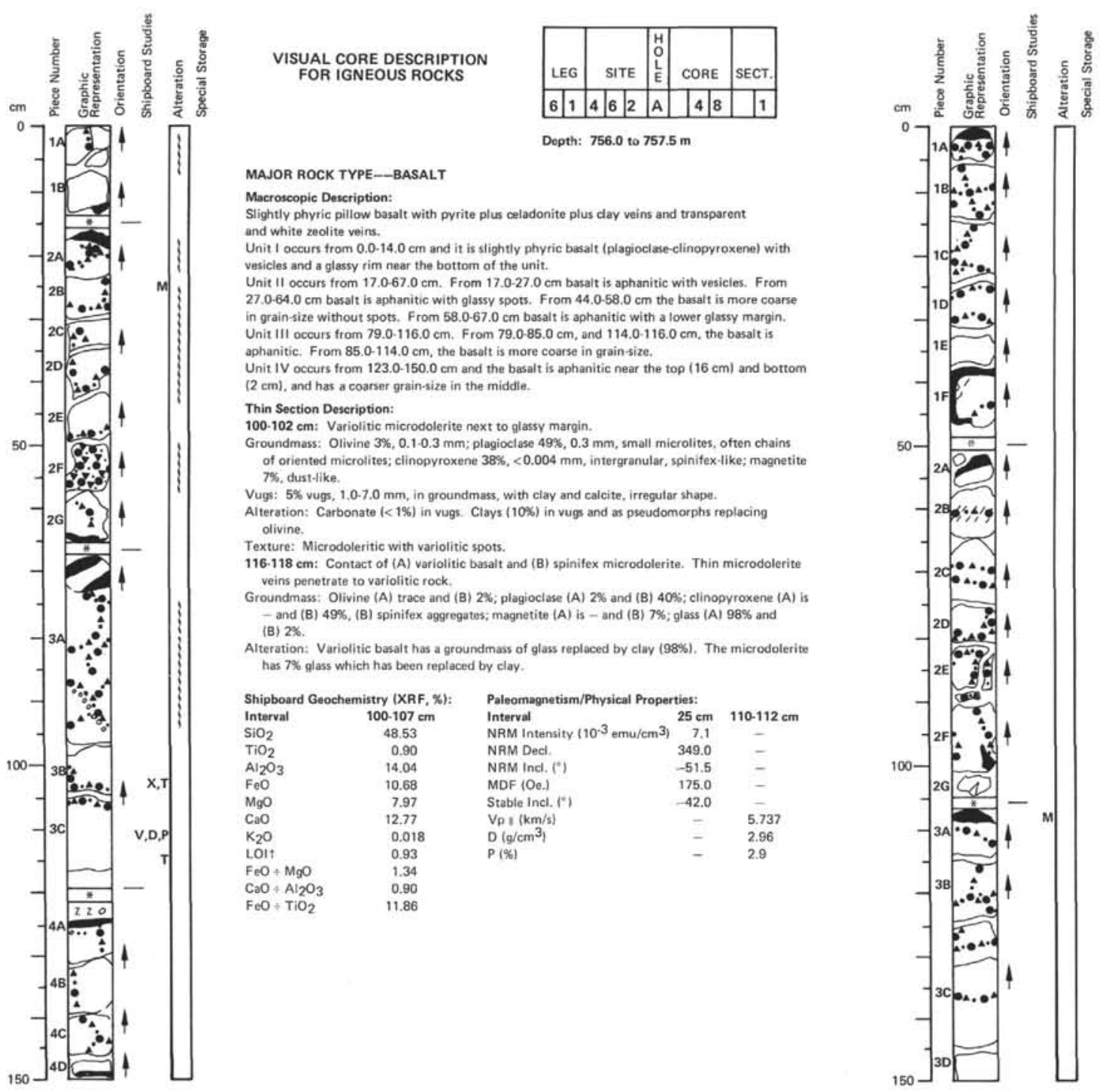

\section{VISUAL CORE DESCRIPTION \\ FOR IGNEOUS ROCKS \\ \begin{tabular}{|l|l|l|l|l|}
\hline & & $\begin{array}{l}\text { Ho } \\
\text { L }\end{array}$ & & \\
LEG & SITE & CORE & SECT. \\
\hline
\end{tabular}

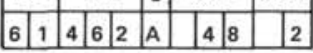

MAJOR ROCK TYPE---BASALT

Macroscopic Description

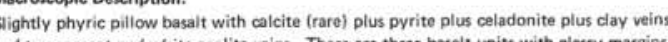
Whe veins. There are three bosalt units with glassy margins

Unit l occours from $0.049 .0 \mathrm{~cm}$.

Unit litocurs trom $50.0 .104 .0 \mathrm{~cm}$

These are the same as Piece 4 E basalts in Core 48

From $125.0-150.0 \mathrm{~cm}$, basalts have a medium grain-size.

$\begin{array}{lc}\text { Paleomagnetism: } & \\ \text { Interval } & 108 \mathrm{~cm} \\ \text { NRM I Itensity }\left(10^{-3} \mathrm{emu} / \mathrm{cm}^{3}\right) & 6.1 \\ \text { NRM Decl. } & 115.0 \\ \text { NRM Inci. (") } & -40.8 \\ \text { MDF (Oe.) } & 100.0 \\ \text { Stable Incl. (") } & -28.3\end{array}$



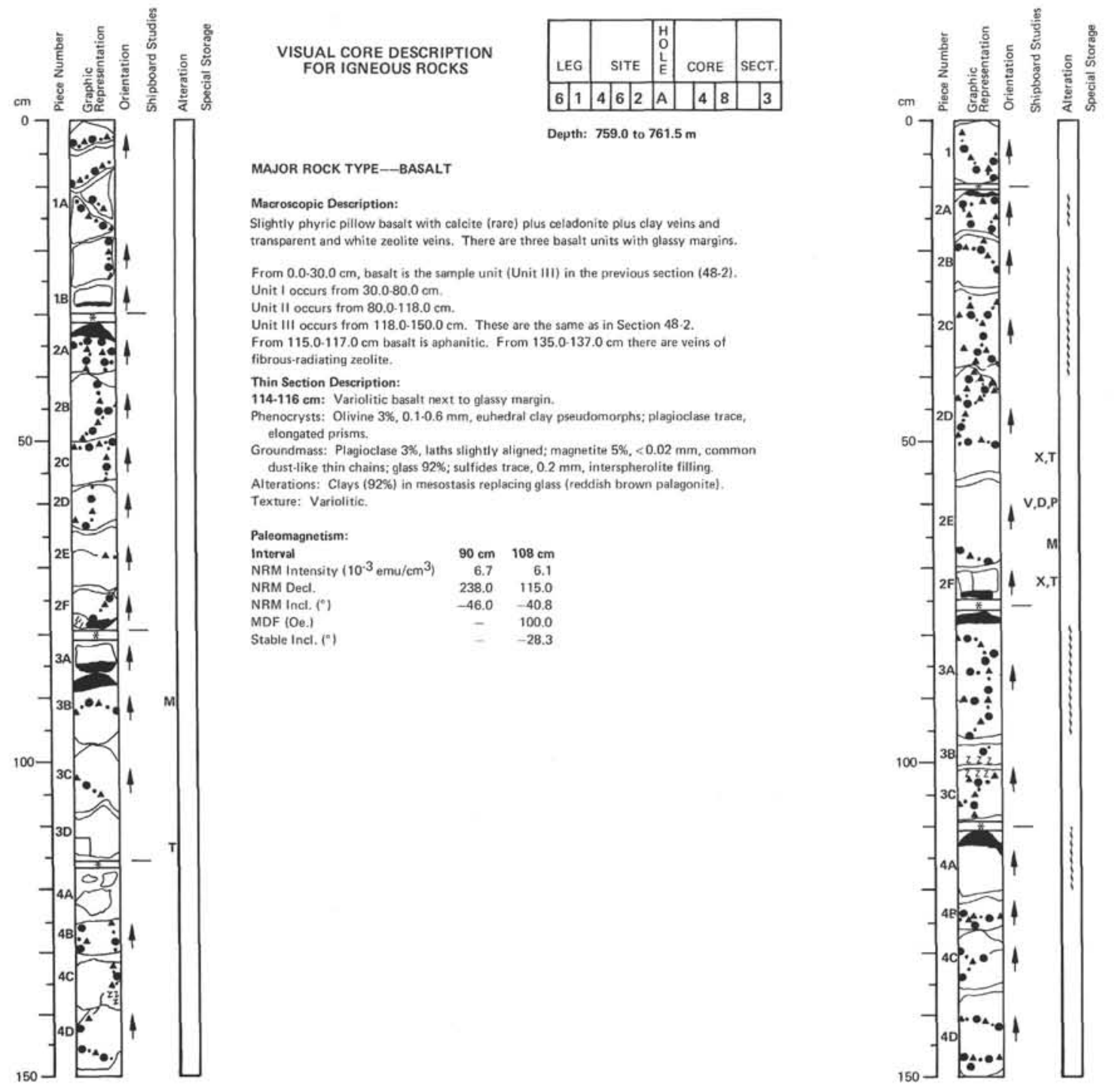

\section{VISUAL CORE DESCRIPTION FOR IGNEOUS ROCKS

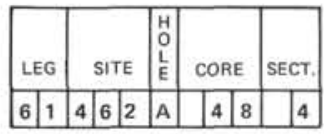 \\ Depth: 761.5 to $763.0 \mathrm{~m}$}

MAJOR ROCK TYPE--BASALT

Mighty phyric pillow basalt with colcite (rare) plus celadonite plus clay veins and tansprenter .

Nit ll occurs from $76.0 .109 .0 \mathrm{~cm}$

Unit III occurs from $111.0 .150 .0 \mathrm{~cm}$

Thin Section Description

作 Groundmass: Plagioclase (An62) 32\%, $0.4 \mathrm{~mm}$, microlites; clinopyroxene $61 \%, 0.02-0.04 \mathrm{~mm}$, Aiteration: Clays (20) tors magnetite 5x, 0.02-0.05 $\mathrm{mm}$, dust-like.

Texture: Variolitic.

Microphenocrysts: Olvait from glassy margin. $0.8 \mathrm{~mm}$, elongated prisms

列 Vesicles: Vugs $1 \%, 0.4 \cdot 1.0 \mathrm{~mm}$, along contact, clay and calcite filing, irregular elongated shape. Alteration: Carbonate (traoee) in vugs. Clays (96\%) replacing glass mesostasis (palagonitt) w Texture: Variolitic.

\begin{tabular}{|c|c|c|}
\hline & & \\
\hline Interval & $52.54 \mathrm{~cm}$ & 72.74 \\
\hline $\mathrm{SiO}_{2}$ & 48.70 & 48.38 \\
\hline $\mathrm{TiO}_{2}$ & 0.90 & 0.92 \\
\hline $\mathrm{Al}_{2} \mathrm{O}_{3}$ & 13.83 & \\
\hline $\mathrm{FeO}^{2}$ & 10.90 & 10.87 \\
\hline $\begin{array}{l}\mathrm{MnO} \\
\text { Mno }\end{array}$ & & \\
\hline $\mathrm{MgO}$ & 8.15 & 8.36 \\
\hline $\begin{array}{l}\mathrm{C}_{\mathrm{CaO}} \\
\mathrm{Na}_{2} \mathrm{O}\end{array}$ & 12.57 & $\begin{array}{l}13.05 \\
-\end{array}$ \\
\hline & 0.04 & 0.033 \\
\hline $\mathrm{P}_{2} \mathrm{O}_{5}$ & 1 & 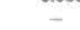 \\
\hline Total & & \\
\hline LOI & 0.81 & 0.69 \\
\hline $\mathrm{FeO}+\mathrm{MgO}_{\mathrm{g}}$ & 1.33 & 1.30 \\
\hline $\mathrm{CaO}+\mathrm{Al}_{2} \mathrm{O}_{3}$ & 0.90 & 0.91 \\
\hline $\mathrm{FeO}=\mathrm{TiO}_{2}$ & 12.11 & 11.81 \\
\hline
\end{tabular}

\section{Paleomagnetism/Physical Properties:} $65 \mathrm{~cm} \quad 61.63 \mathrm{~cm}$ NRM In NRM Dect. NRM ind.

Stable Incli, "

$\mathrm{V}_{\mathrm{p} \|(\mathrm{km} / \mathrm{s})}$ $\mathrm{D}\left(\mathrm{g} / \mathrm{cm}^{3}\right)$ $P(\%)$ 8.5
242.0
-44.7
85.0
-32.7 44.7
85.0
-32.7

$\begin{array}{ll}\mathrm{C} \\ \mathrm{FeO}+\mathrm{Al}_{2} \mathrm{O}_{3} & 0.90 \\ & 12.11\end{array}$ 


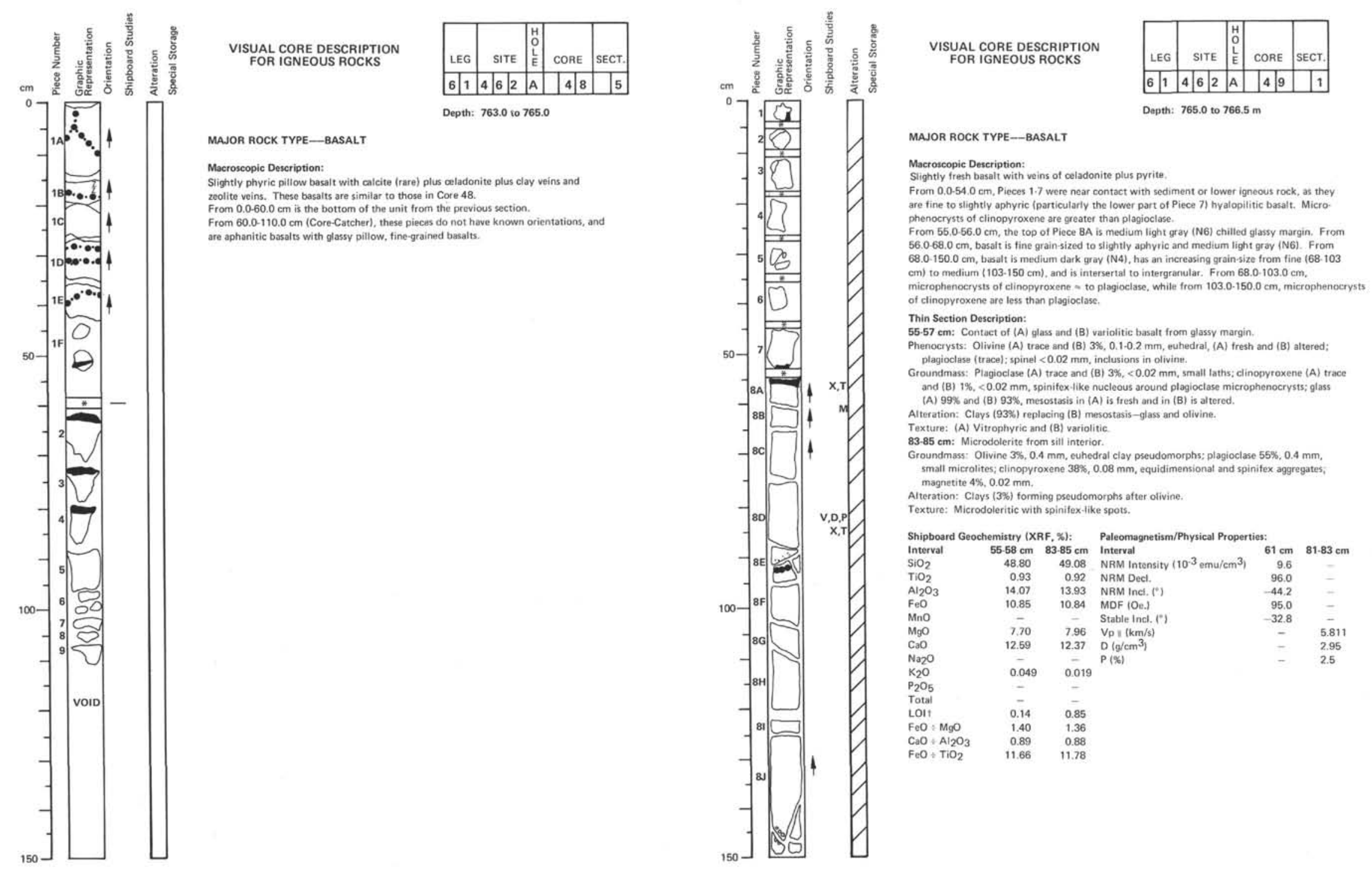



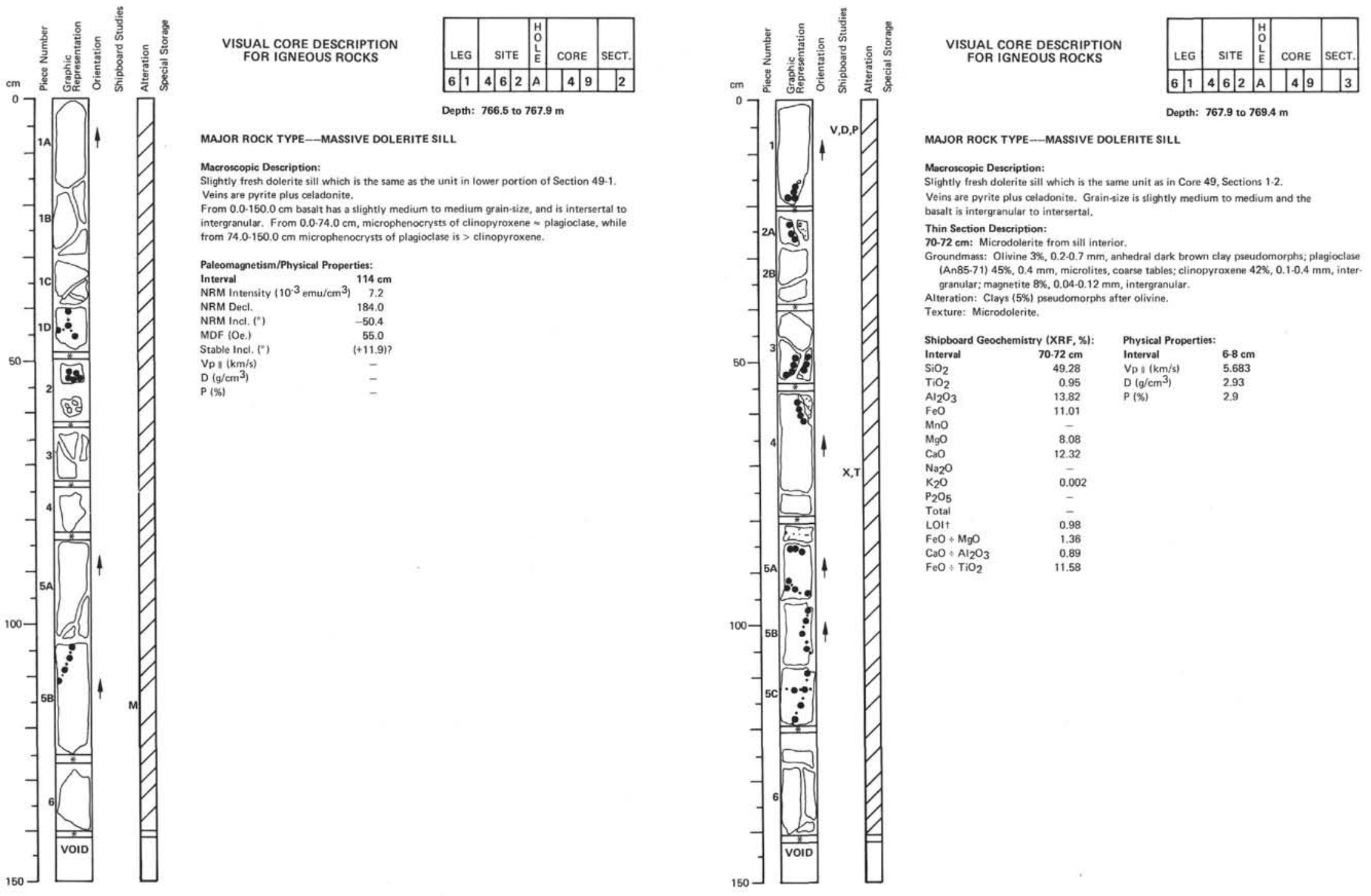

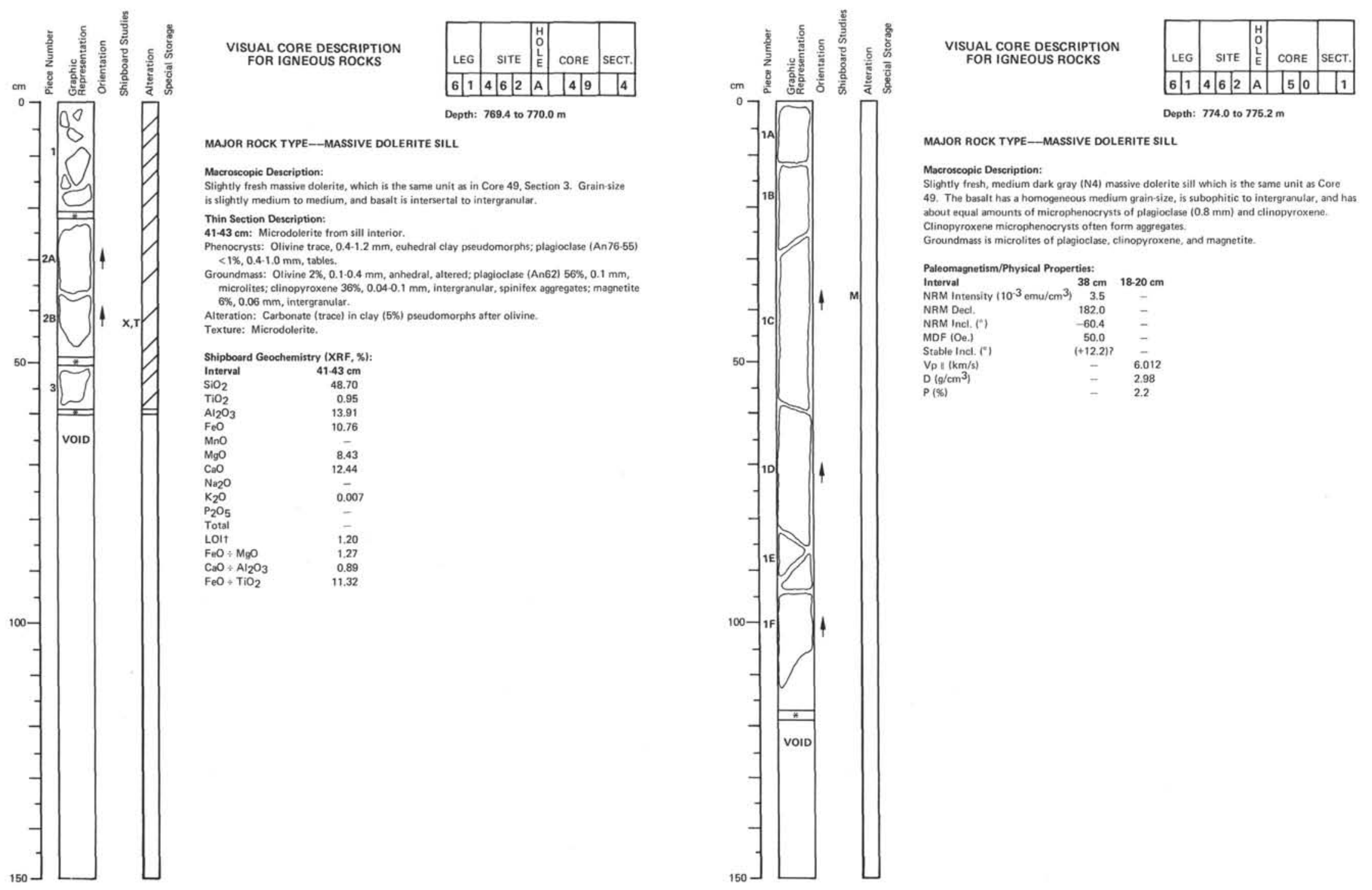

MAJOR ROCK TYPE-MASSIVE DOLERITE SILL

Macroscopic Description:

Slightly tresh, medium dark gray (N4) massive dolerite sill which is the same unit as Core as a homogeneous medium grain-size, is subophitic to intergranular, and has about equal amounts of microphenocrysts of plagioclase $(0.8 \mathrm{~mm})$ and clinopyroxene. Groundmass is microlites of plagioclase, clinopyroxene, and magnetite.

\begin{tabular}{|c|c|c|}
\hline \\
\hline Interval & $38 \mathrm{~cm}$ & $18.20 \mathrm{~cm}$ \\
\hline NRM Intensity $\left(10^{-3} \mathrm{emu} / \mathrm{cm}^{3}\right)$ & 3.5 & \\
\hline NRM Decl. & 182.0 & \\
\hline NRM Incl. (") & -60.4 & - \\
\hline MDF (Oe.) & 50.0 & - \\
\hline Stable Incl. $\left({ }^{\circ}\right)$ & $(+12.2) ?$ & \\
\hline $\begin{array}{l}V_{V} p\left(\mathrm{~km}^{3} / \mathrm{s}\right) \\
\mathrm{D}\left(\mathrm{q} / \mathrm{cm}^{3}\right)\end{array}$ & - & $\begin{array}{l}6.012 \\
298\end{array}$ \\
\hline$P(\$)$ & - & 2.2 \\
\hline
\end{tabular}

$$
\text { . }
$$



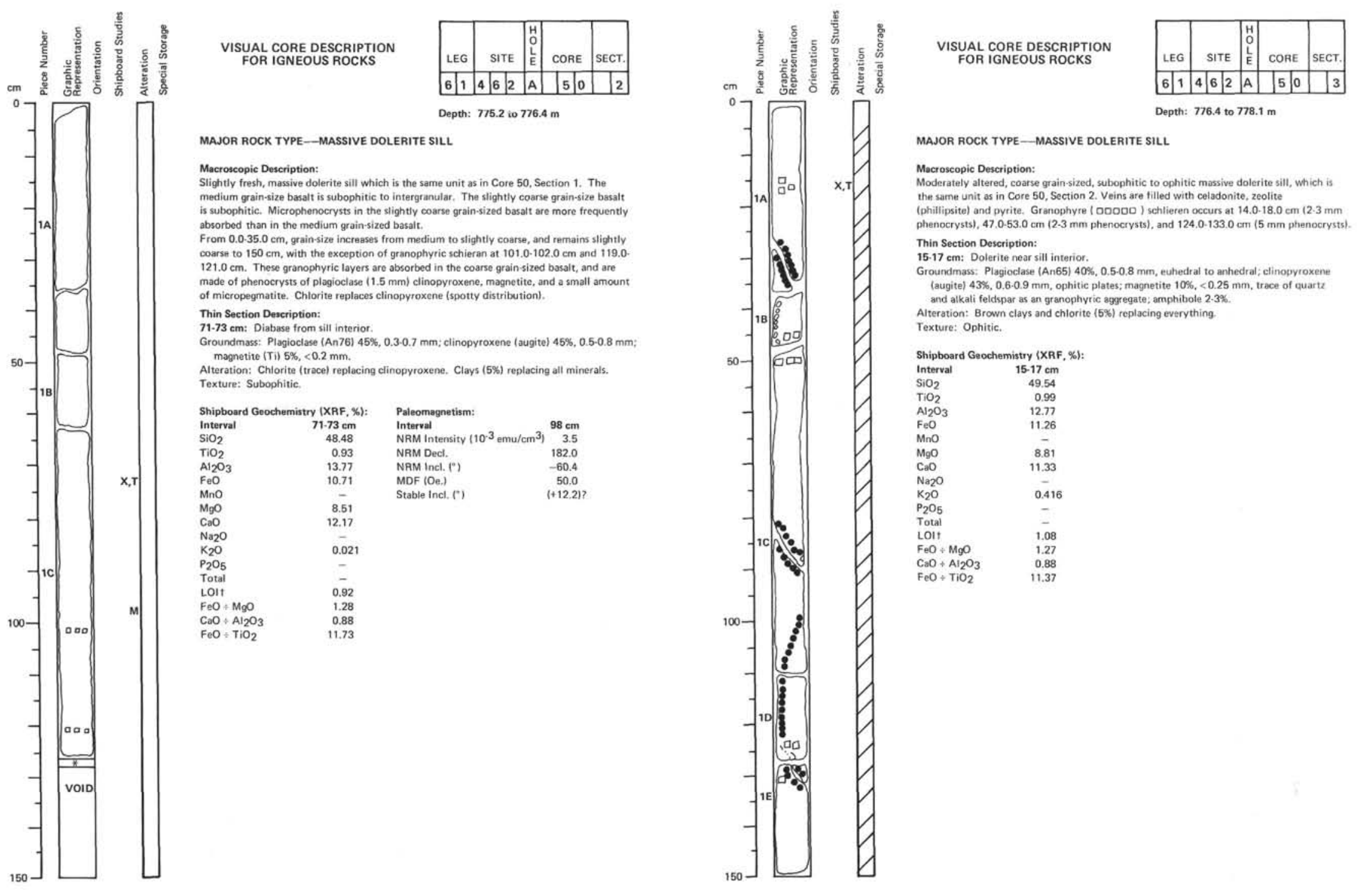

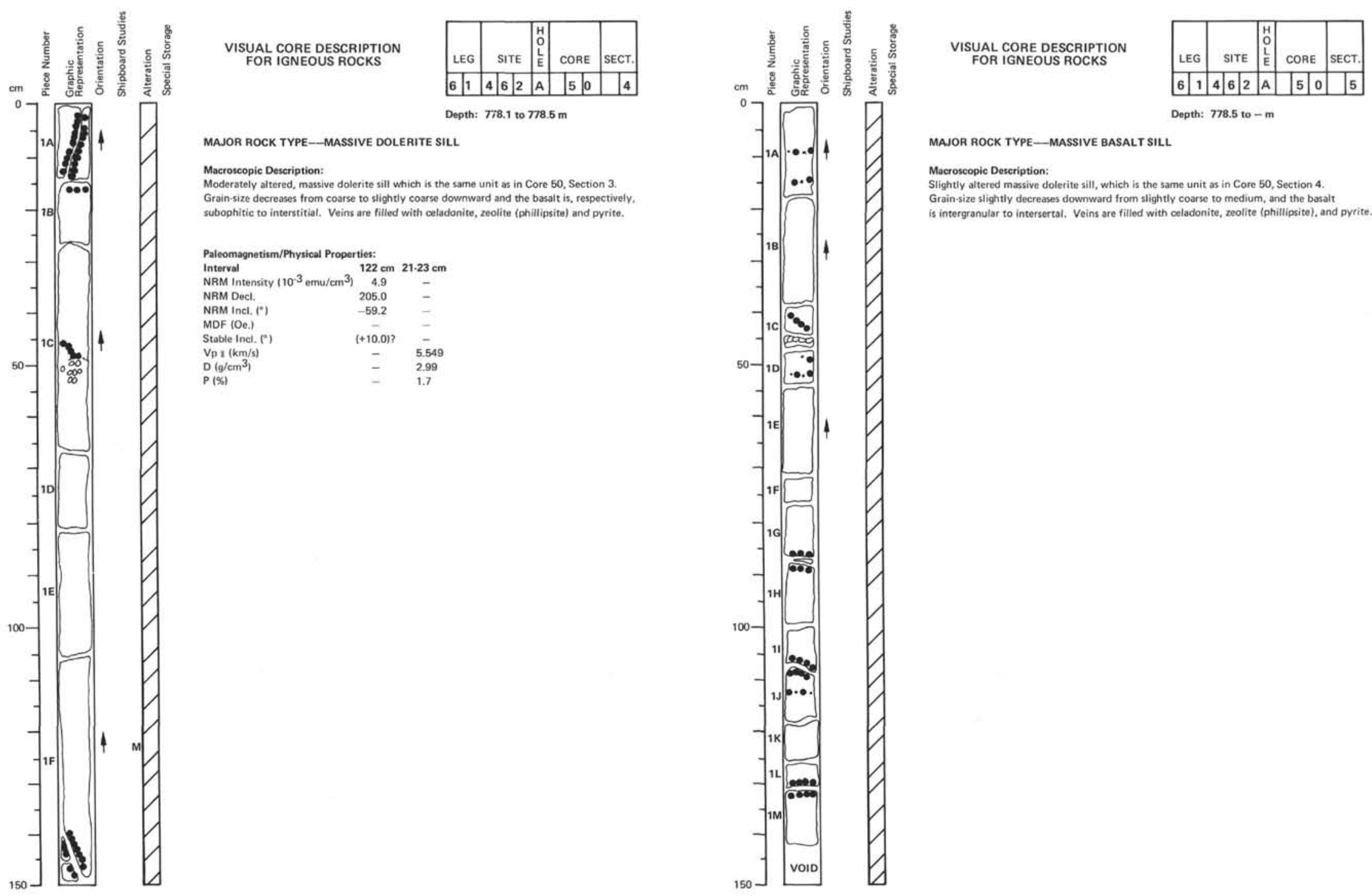

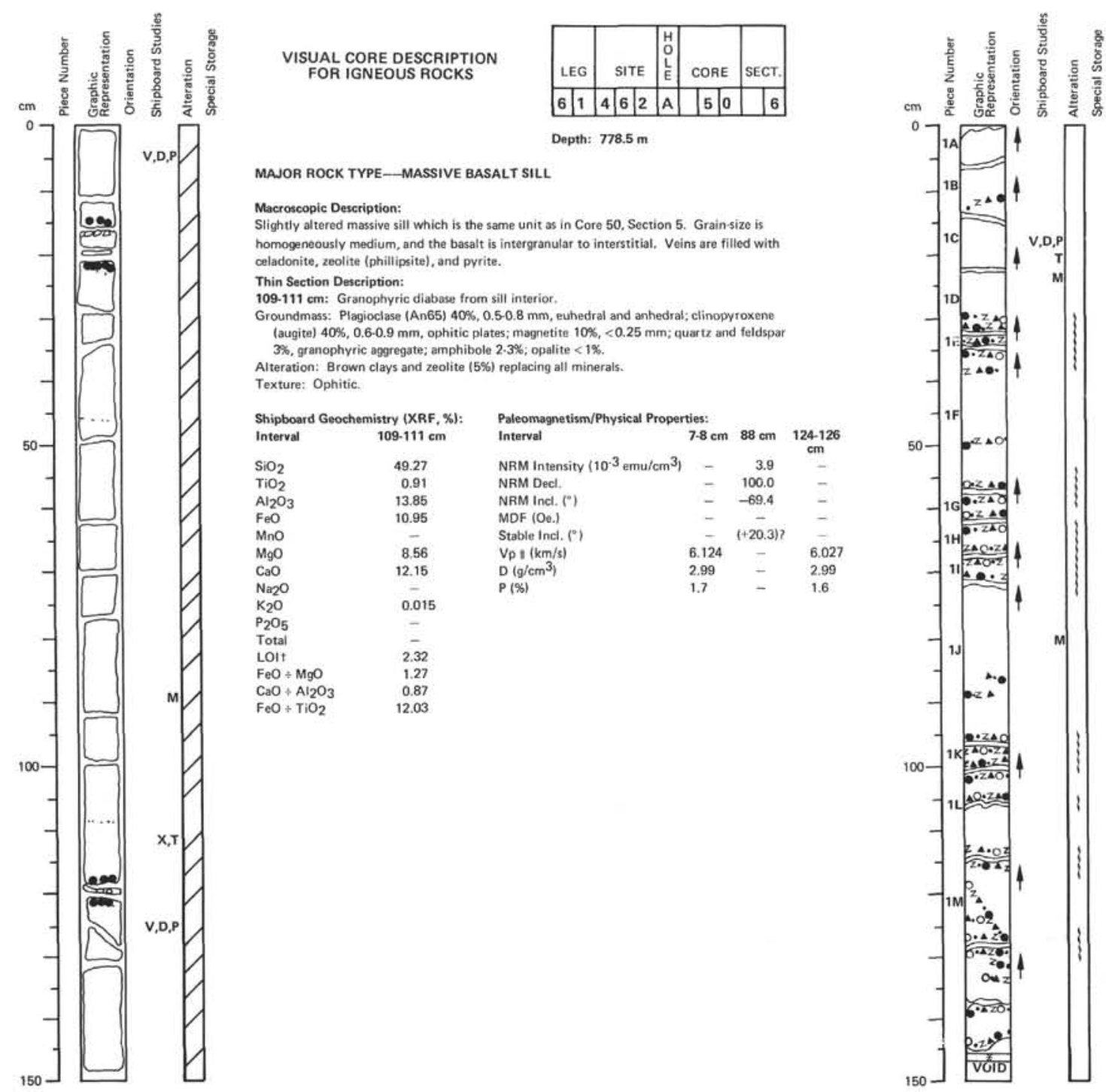
VISUAL CORE DESCRIPTION

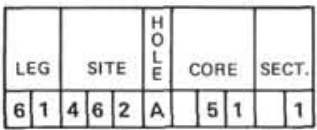 Depth: 778.5 to $780.0 \mathrm{~m}$

MAJOR ROCK TYPE--MASSIVE BASALT SILL

Macroscopic Description:

highty ahered, homogeneneously medium grain-sized, microdolerite with veins of pyrite

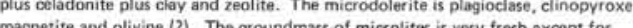
mall diveren ined Thin Section Description:

$20.22 \mathrm{~cm}$ : Microdolerite trom sill interior.

roundmass: Olivine 2\%, $0.2 \mathrm{~mm}$, euhedral and anhedral, attered; plagioclase (An 60-68)

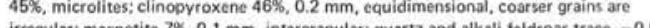
$\sim 0.15 \mathrm{~mm}$, elongated plates. Alteration: Gravish green days (5\%) pseudomorphs of olivine and plagiociase

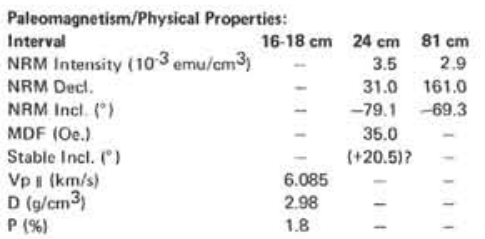



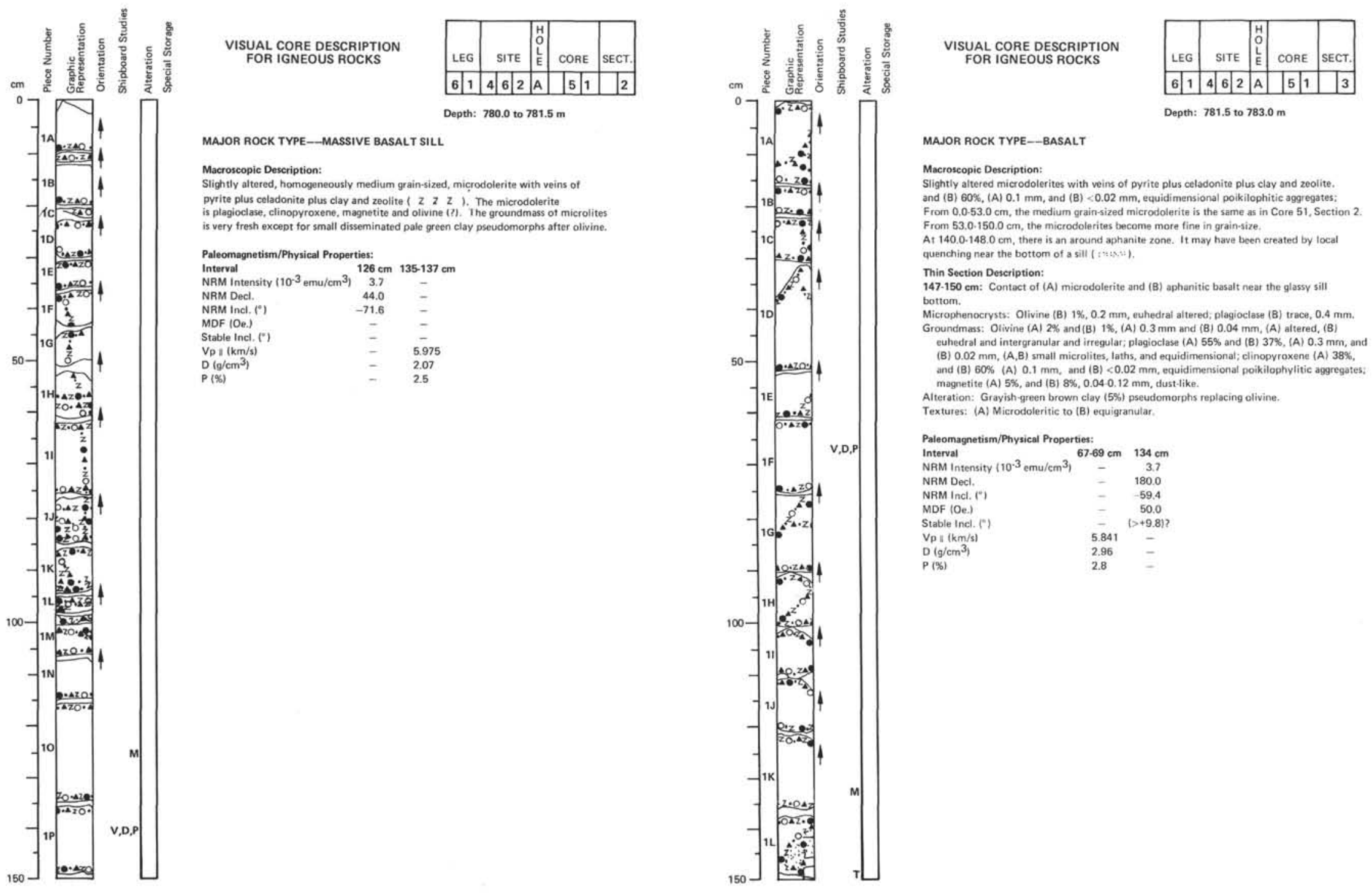

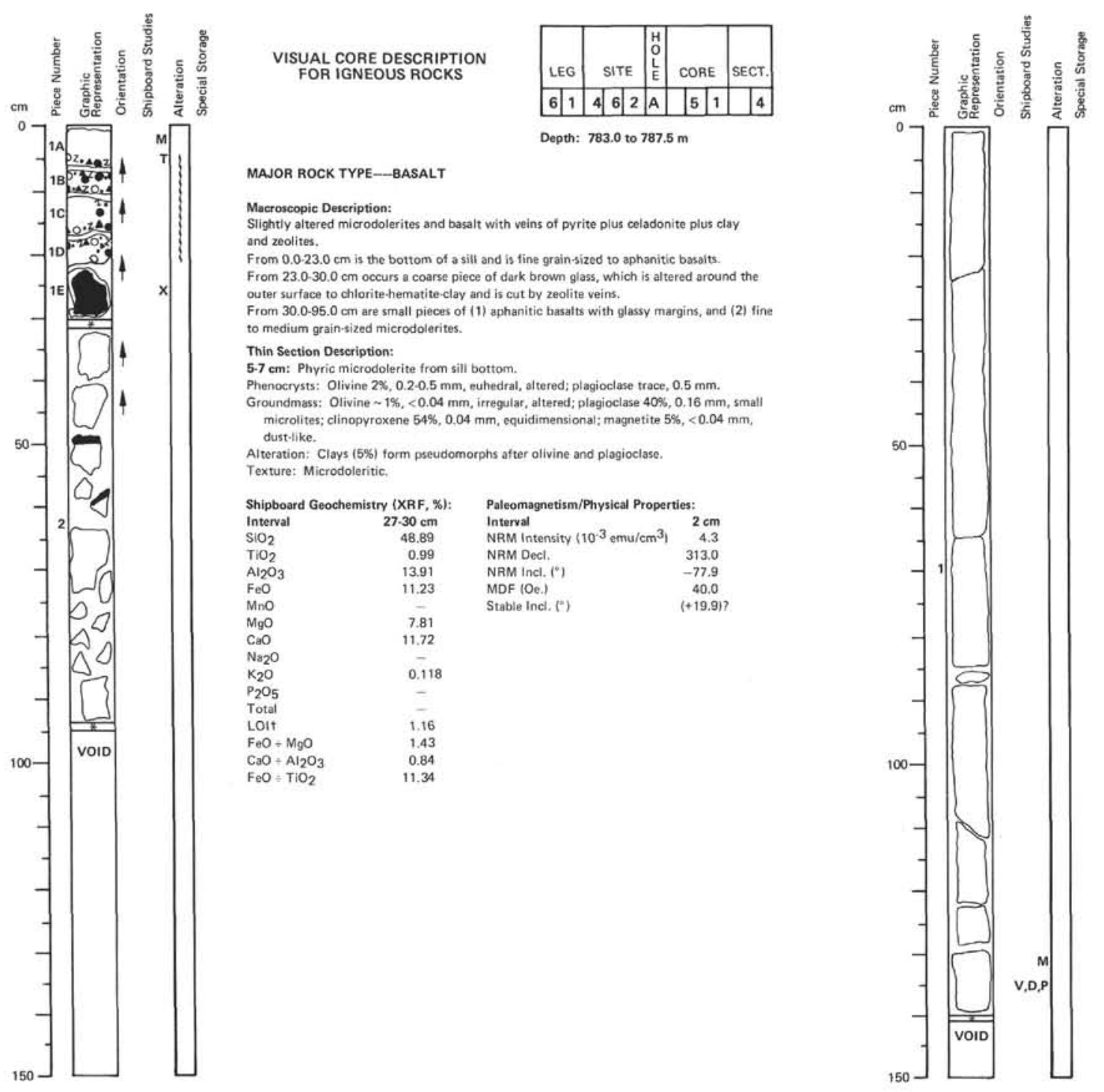

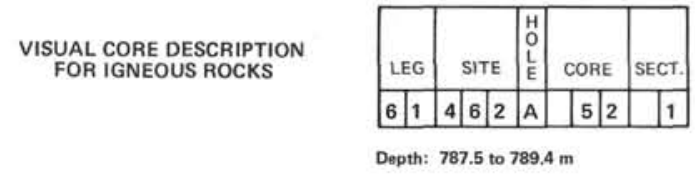

MAJOR ROCK TYPE--BASALT

Macroscopic Description:

Slightly altered, homogeneously coarse grain-sized dolerite with veins of green clay variations, but the section appears to be one unit. There are a few patches of brow day.

\begin{tabular}{|c|c|c|}
\hline \multicolumn{3}{|c|}{ Paleomagnetism/Physical Properties: } \\
\hline Interval & $128 \mathrm{~cm}$ & $131.133 \mathrm{~cm}$ \\
\hline NRM Intensity $\left(10^{-3} \mathrm{emu} / \mathrm{cm}^{3}\right)$ & 10.3 & \\
\hline NRM Decl. & 29.0 & - \\
\hline NRM Inct. (") & -85.1 & - \\
\hline MDF $(O e)$. & 35.0 & - \\
\hline Stable Incl. $\left.11^{\circ}\right)$ & -58.4 & \\
\hline$V_{p} \|(\mathrm{km} / \mathrm{s})$ & - & 5.853 \\
\hline 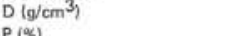 & - & 2.95 \\
\hline
\end{tabular}



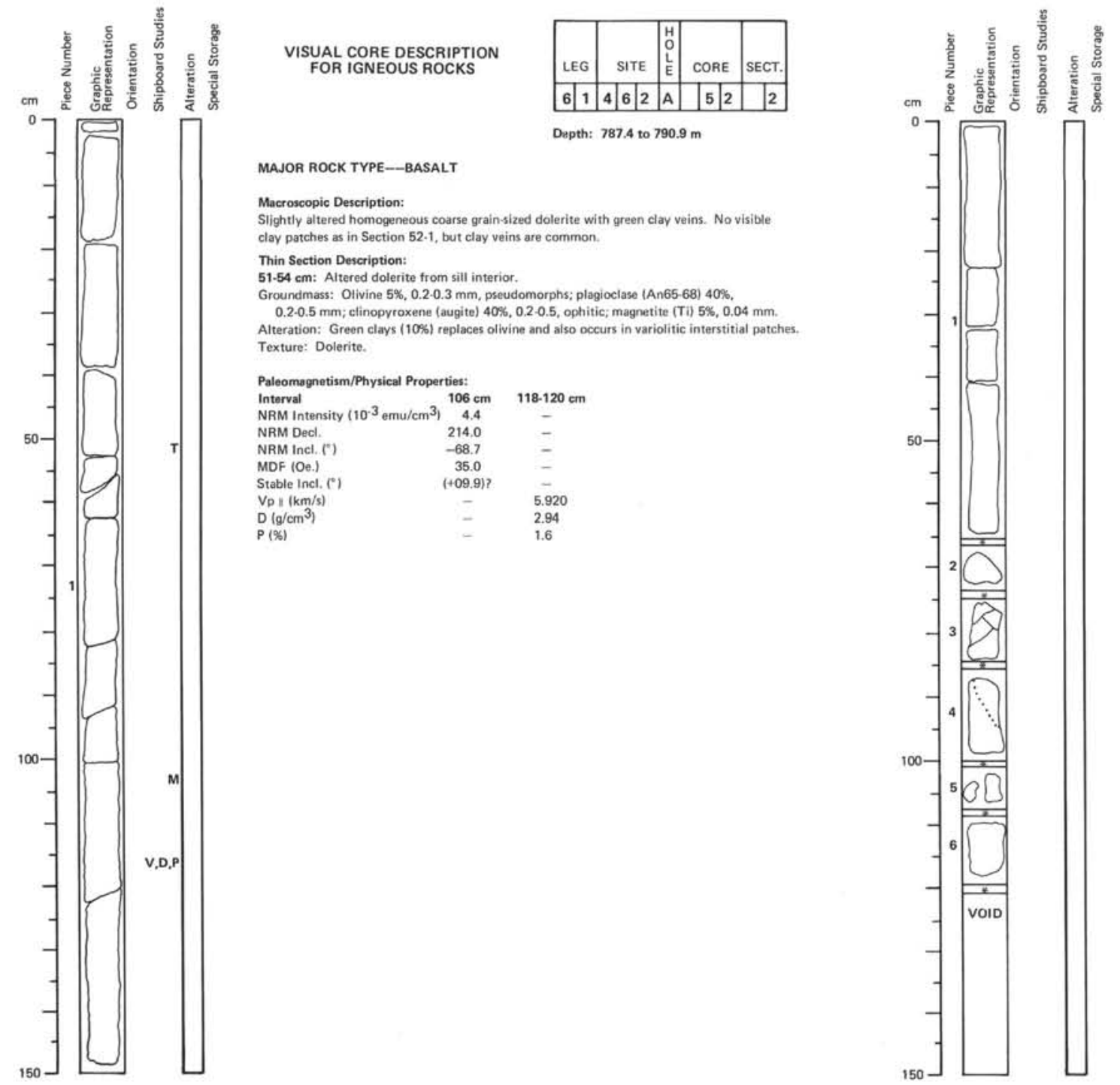
VISUAL CORE DESCRIPTION FOR IGNEOUS ROCKS

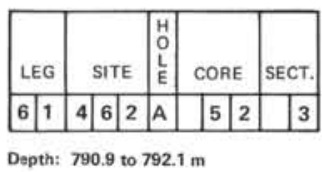

MAJOR ROCK TYPE-BASALT

\section{Macroscopic Description:}

Whity a hered doterite with green clay veins. Grain-size decreases downwward and the fine grains sized rock has $1.2 \%$ mafic phenocrysts $(\sim 0.2 \sim 0.5 \mathrm{~mm})$ in a fine
grained gray matrix. 

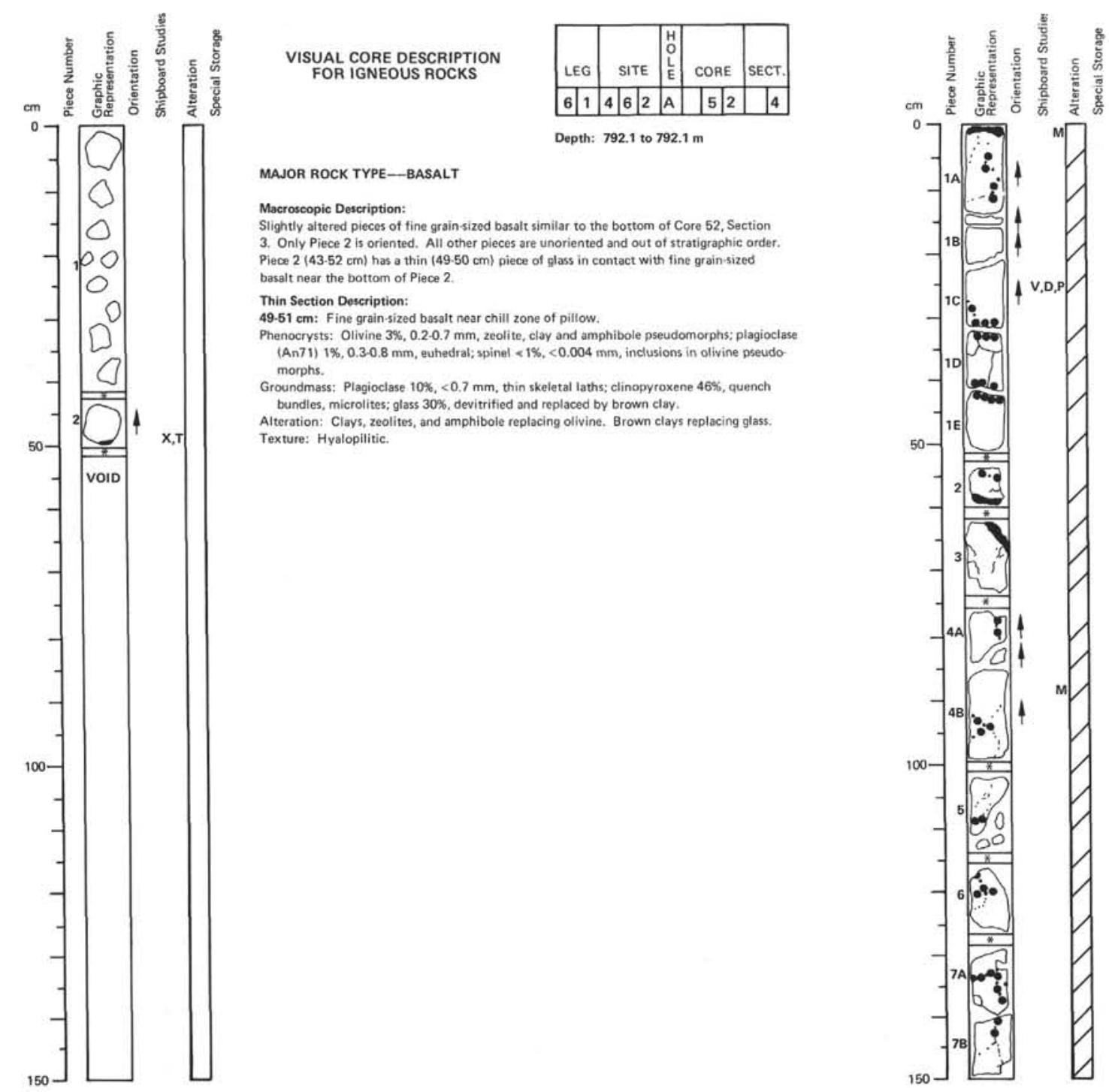

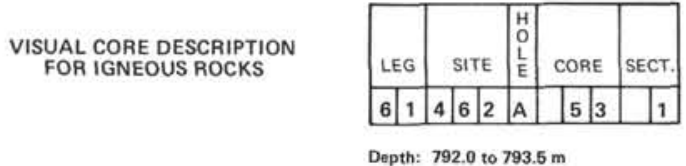

MAJOR ROCK TYPE--MASSIVE BASALT

Macroscopic Description:

Slightly altered units of basalt with veins filled with celadonite plus pyrite.

of the occurs from 0.0-60.0 cm. It has thin $(1 \mathrm{~cm})$ glassy margins at the top and bottom

$25.0 .59 .0 \mathrm{~cm}$. The be increases from $1.0 .25 .0 \mathrm{~cm}$ to a fine grainsize and decreases from

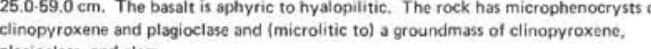

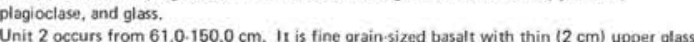
margins. Grain-size increases downward from $62.0 \mathrm{~cm}$.

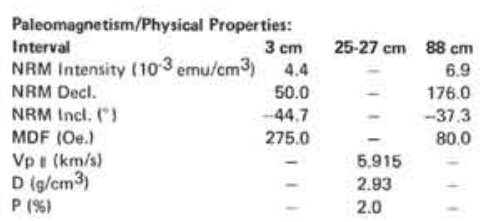



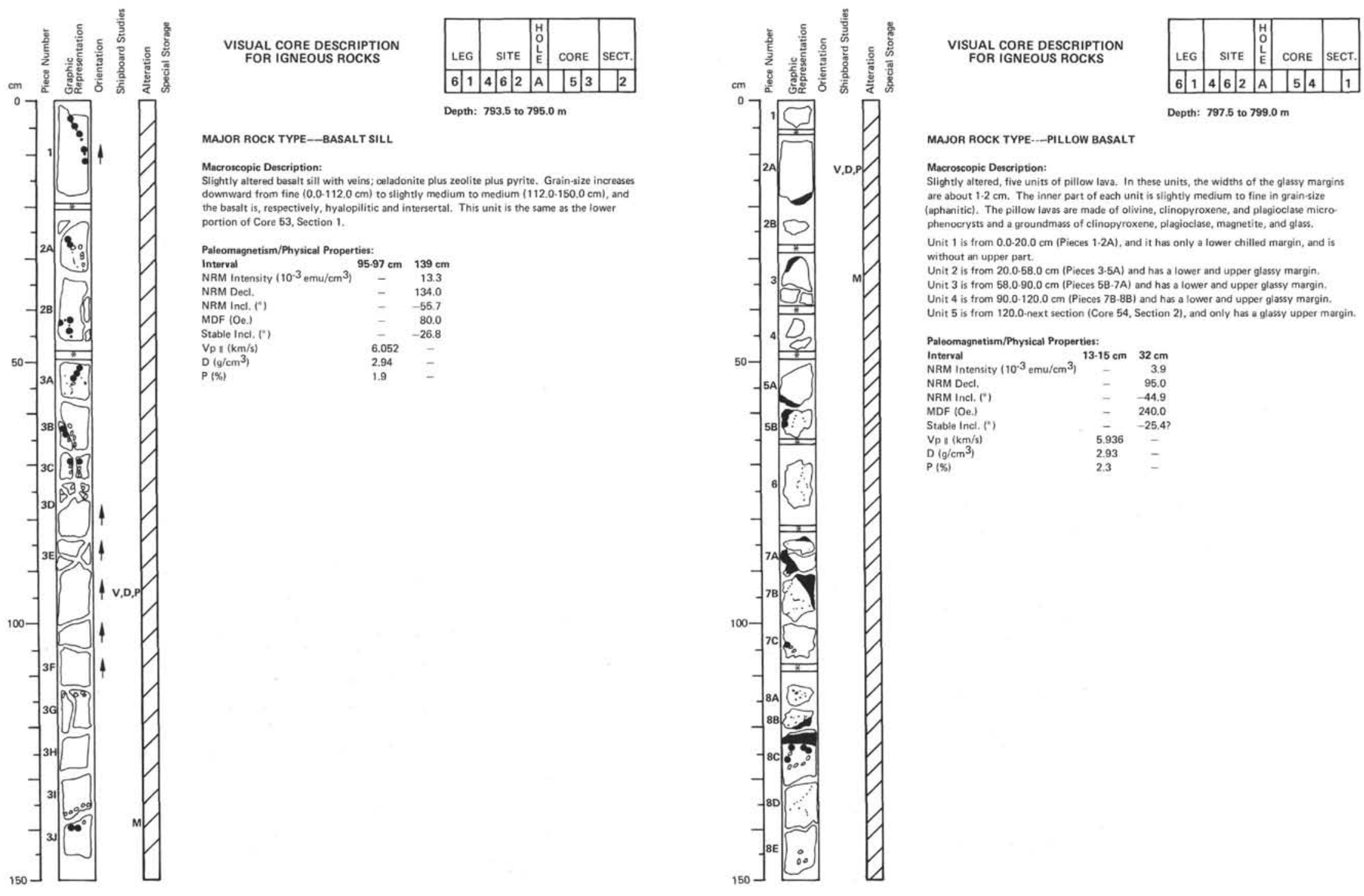


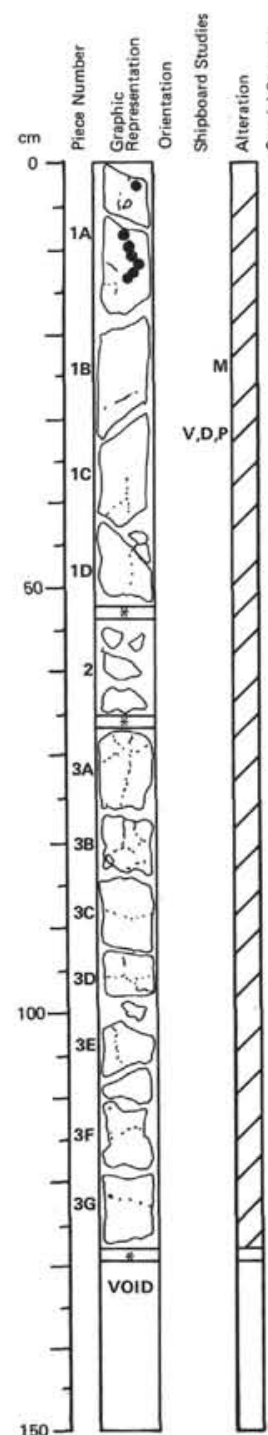

\section{VISUAL CORE DESCRIPTION
FORIGNEOUS ROCKS

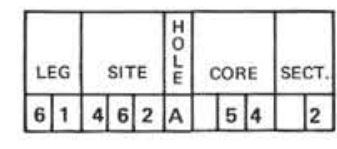

MAJOR ROCK TYPE —-PILLOW BASALT

Macroscopic Description:

Iwa, with veins of (phillipsite?) zeolite size (aphanitic). The pillow levas each unit is slightly medium to fine in grain. microphenocrysts and a groundmass of clinopyroxene, plagioclasse, magnetite, and glass Unit 5 occurs from $0.0-66.0 \mathrm{~cm}$ and is a continuation of the basalt unit of Core 54 , Section 1 , and it does not have a distinct lower glassy margin.

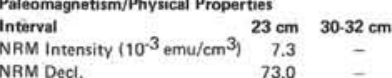

NRM Decl.

MDF (Oe.)

Stable Incl. $\left(l^{\circ}\right.$

Dor $1 \mathrm{~km} / \mathrm{s}$

73.0
-48.9
80.0

-48.9
80.0
$-35.5 ?$

$P(\%)$

2.93

2.3
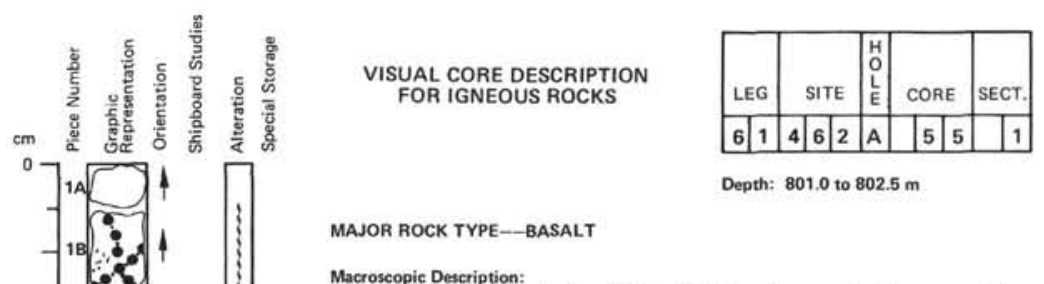

Depth: 801.0 to $802.5 \mathrm{~m}$

Macroscopic Description:

microdolerites divided by glassy margins. Texture near the anlar with vesicles, which grades to microdolerites in the Unit 1 is from $0.0 \cdot 30.0$

Unit 2 is from $30.0 \cdot 93.0 \mathrm{~cm}$.

Unit 4 is from $130.0 .150 .0 \mathrm{~cm}$ glass. Clay pseudomorphs of olivine. Veins are zeolite druses $(x \times x \times)$, pyrite pli celadonite plus clay (........), and autonomous calcite plus clay ( ..........

Thin Section Description:

Per

phs: plagioclase (An70.75) Groundmass: Plagiodare (variable \&), skeletal microlites; clinine pseudomorphs. quench textured bundies; glass (variable \%), variably devitrified or replaced by clay. Alteration: Clays, zeolitess, chionte (variable so., replacing plagioclase, olvinine, and glass.

Interval

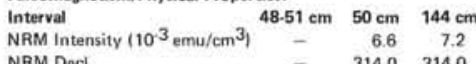

NRMM Decl.

MDF $(0 \mathrm{C}$.

$\mathrm{Vp}_{\mathrm{p}} \|(\mathrm{km} / \mathrm{s})$

D $\left(g / \mathrm{cm}^{3}\right)$

$\begin{array}{lll}-1 & -1 \\ -1 & -33.2\end{array}$

5.776

2.95

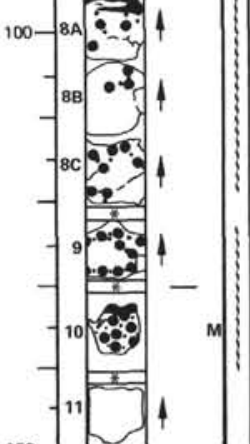




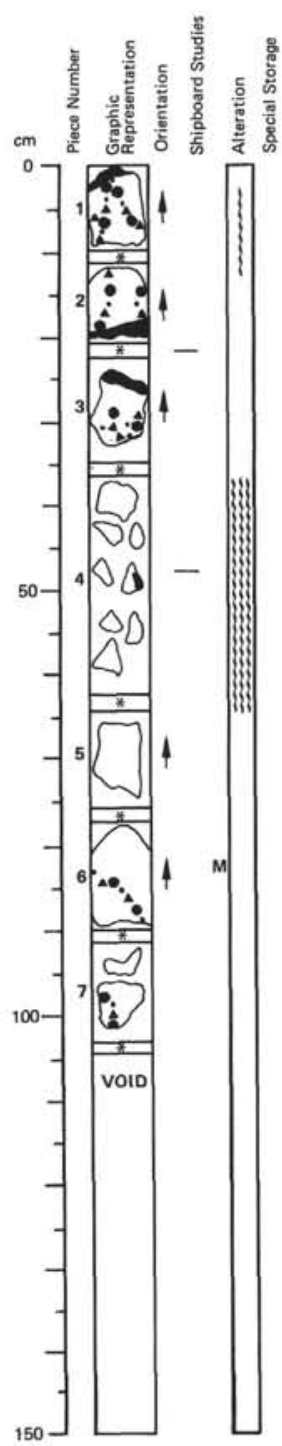

\section{VIIUAL CORE DESCRIPTION
FOR IGNEOUS ROCKS}

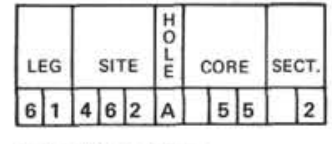

\section{MAJOR ROCK TYPE-BASAL}

Macroscopic Description:

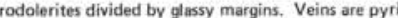
Unit 2 occurs from $35.0-62.0 \mathrm{~cm}$ and it is of small pieces, some of which have glassy magh

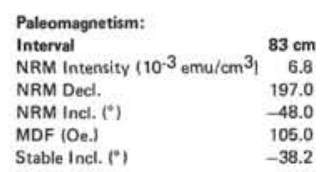

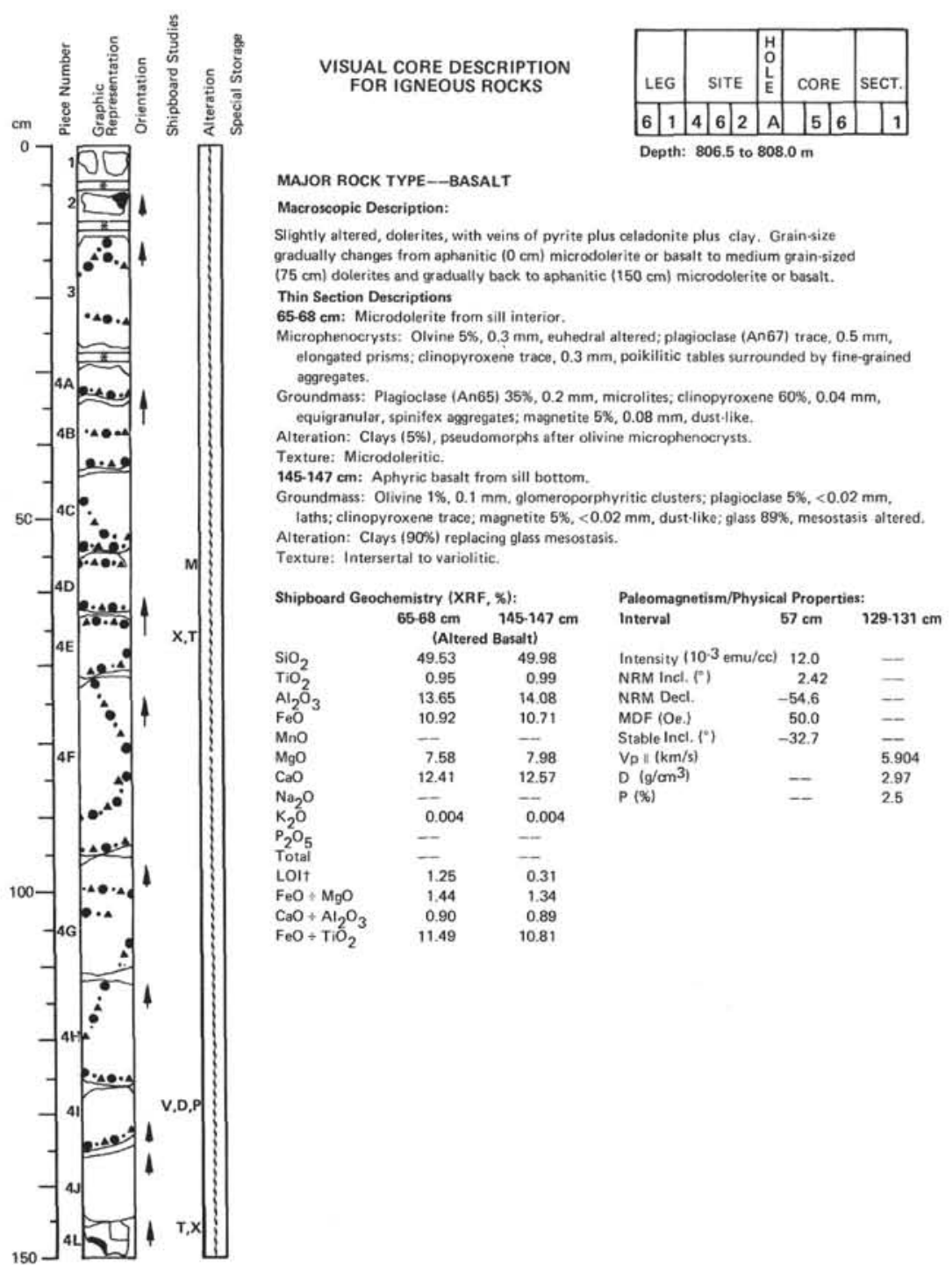



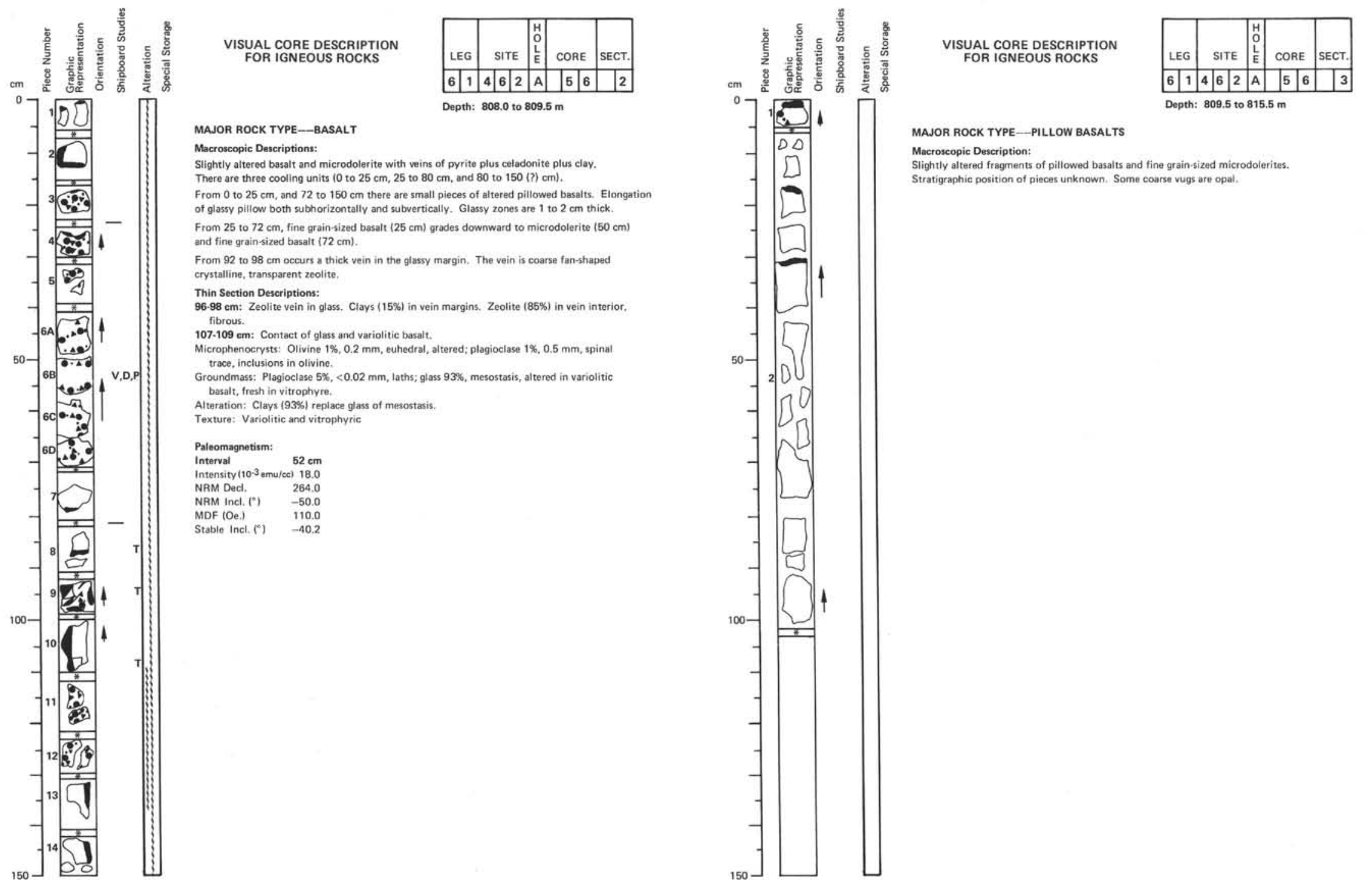

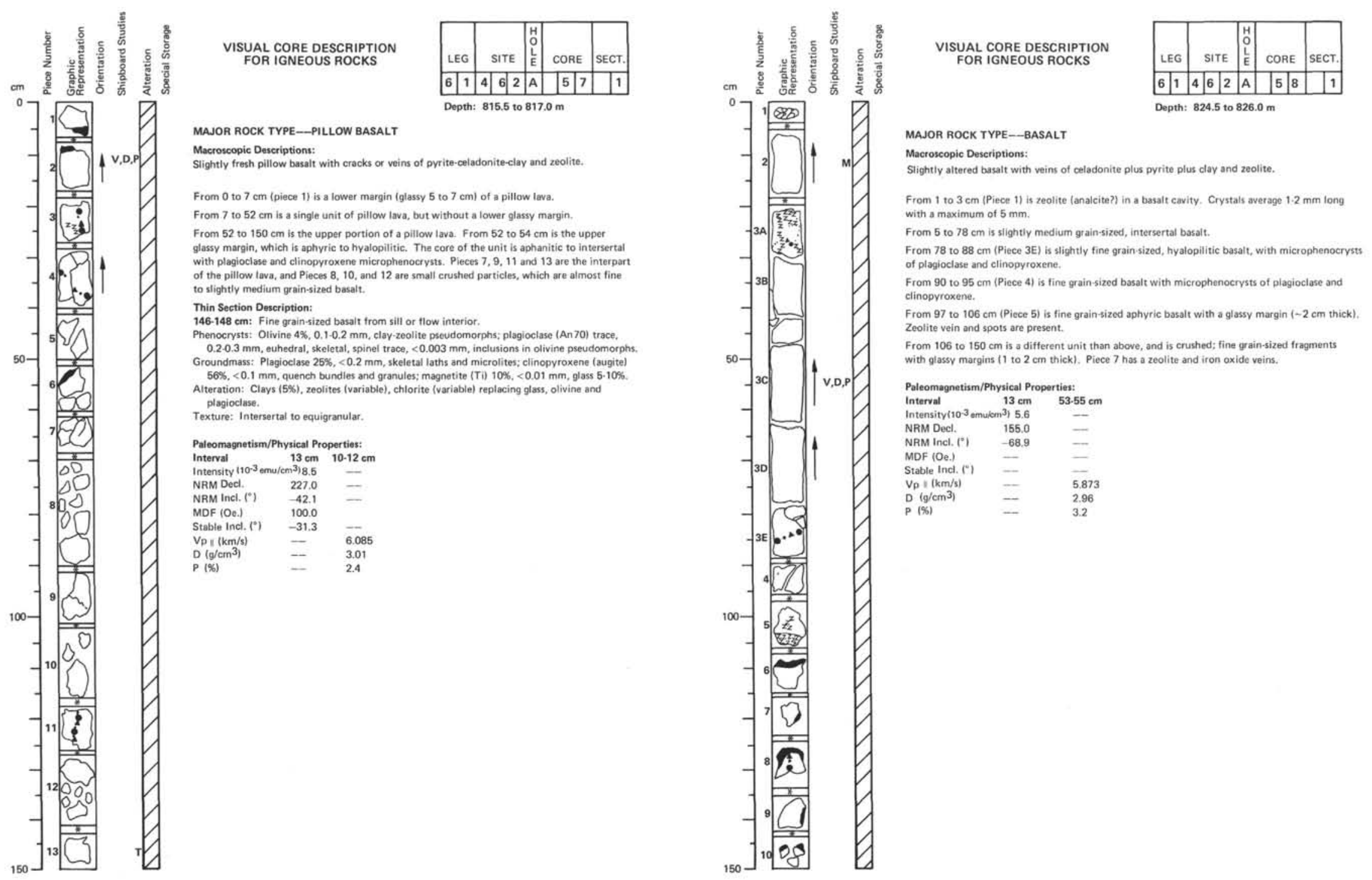


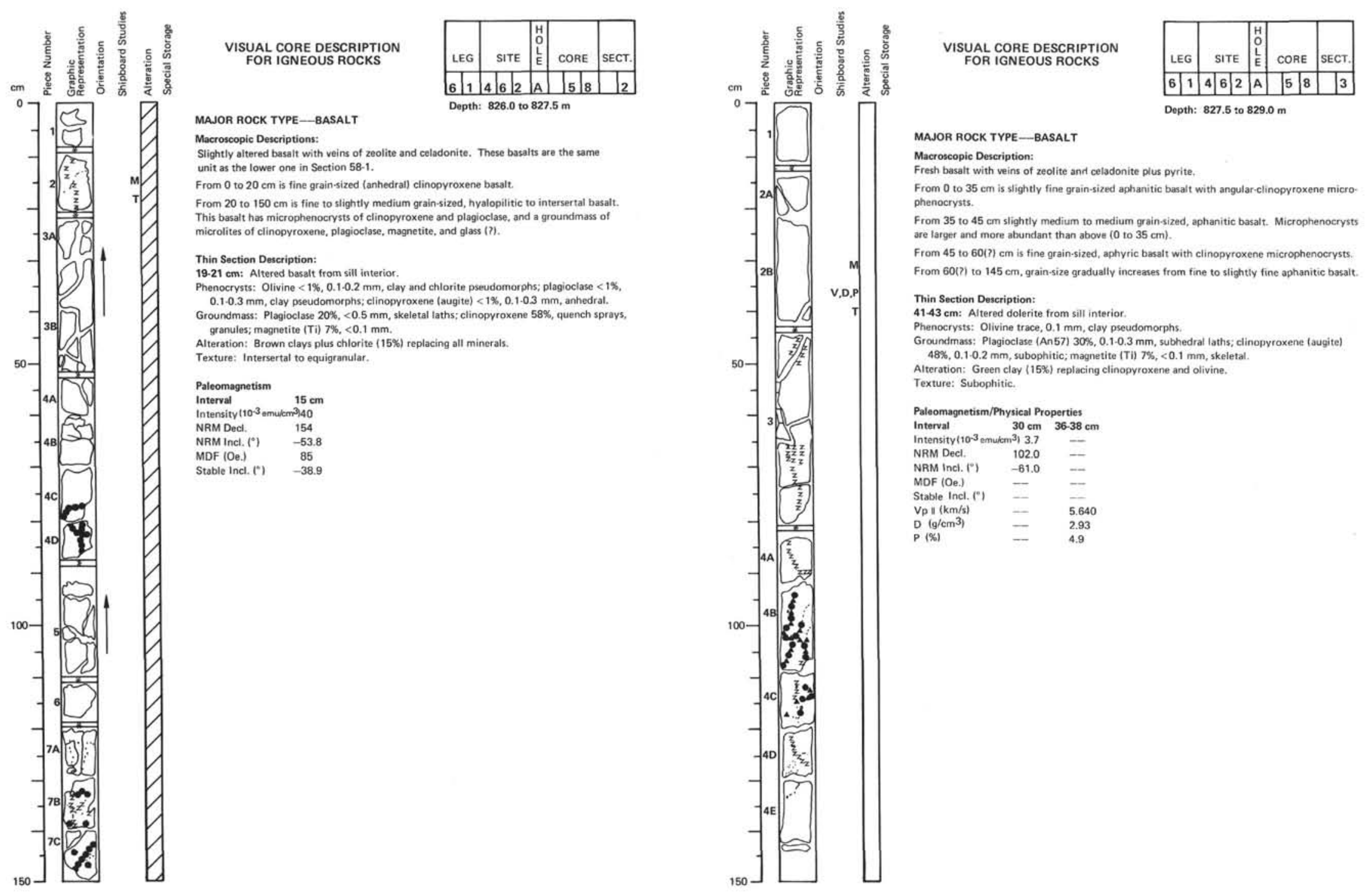



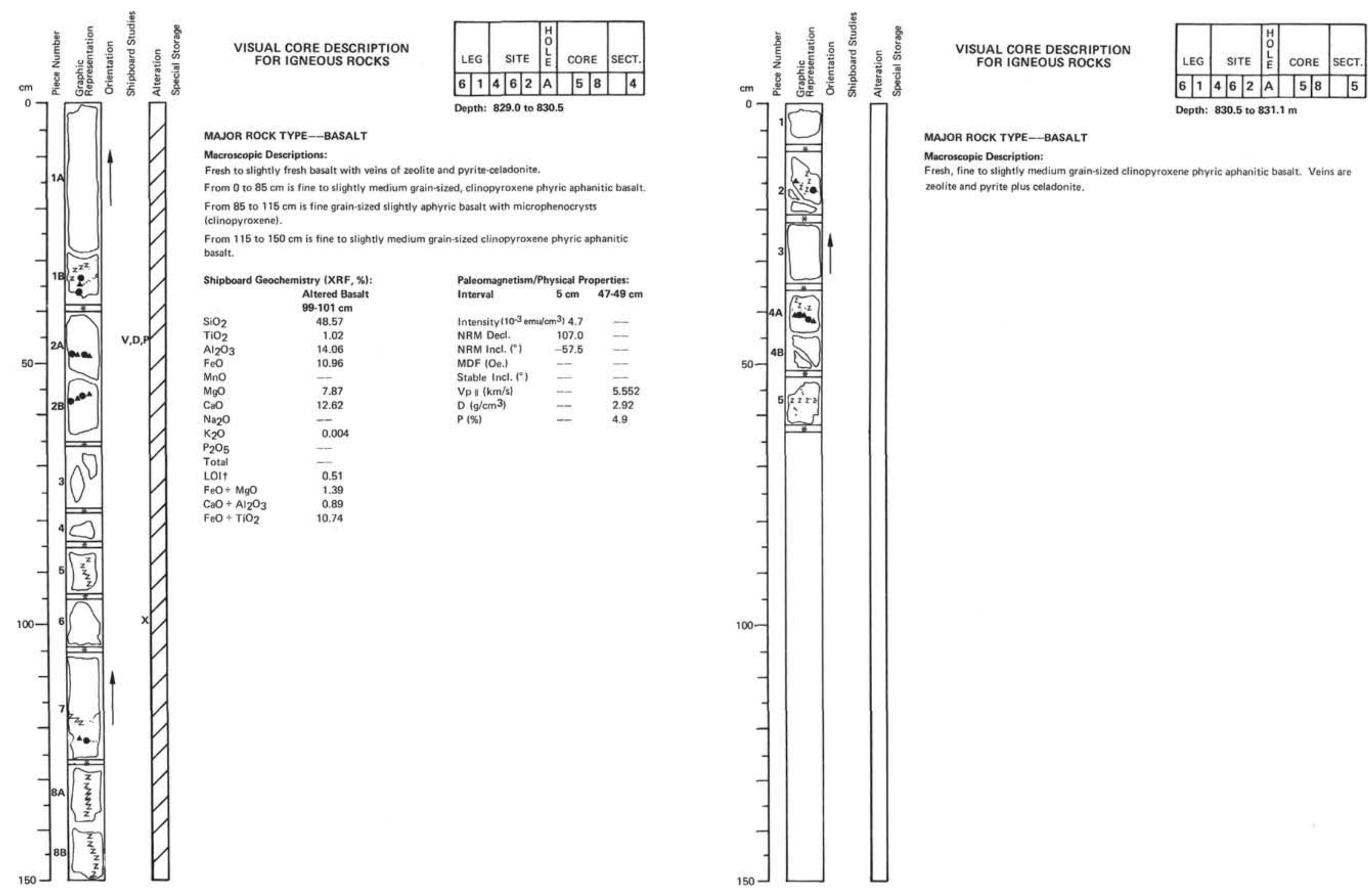

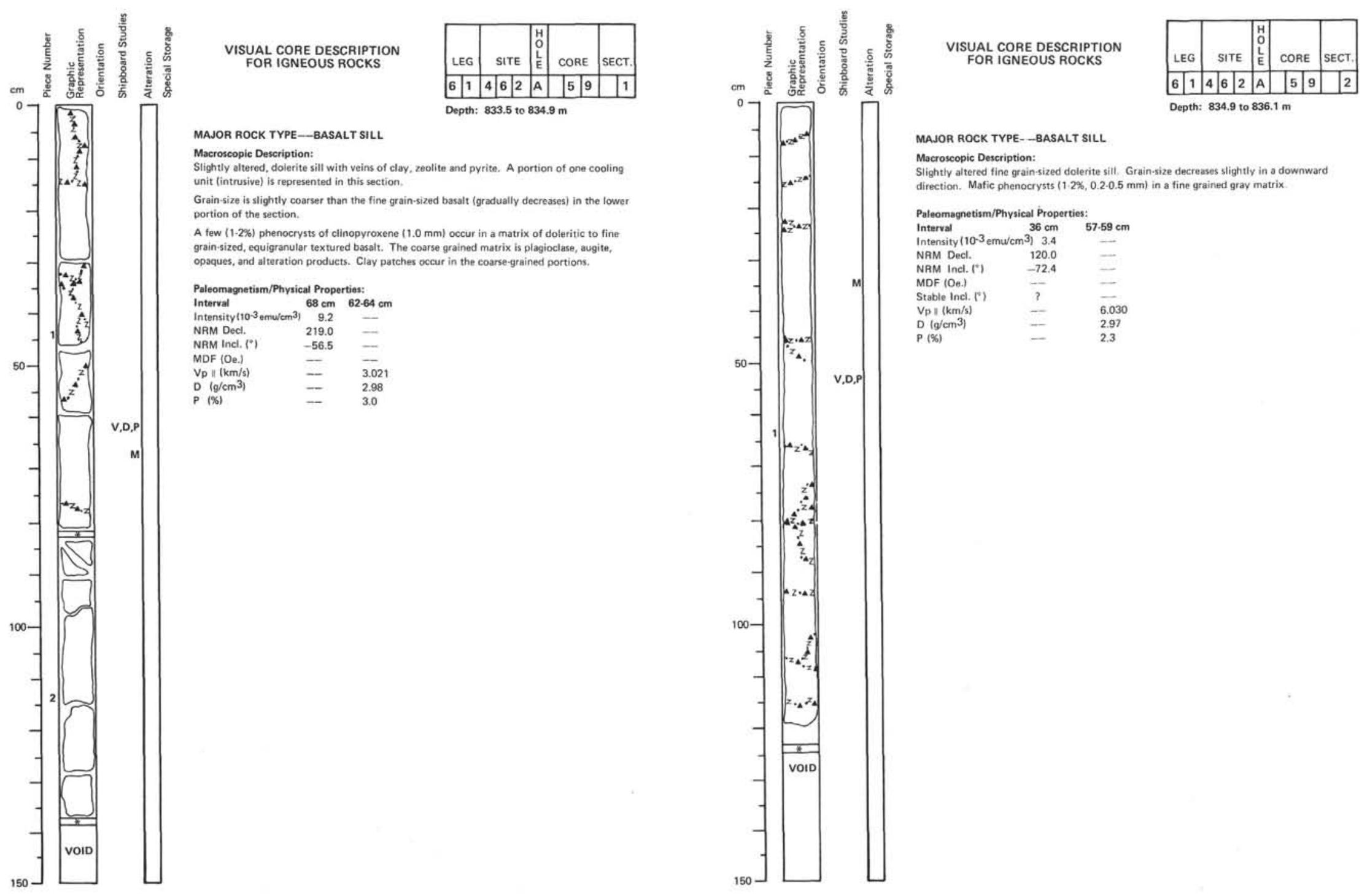

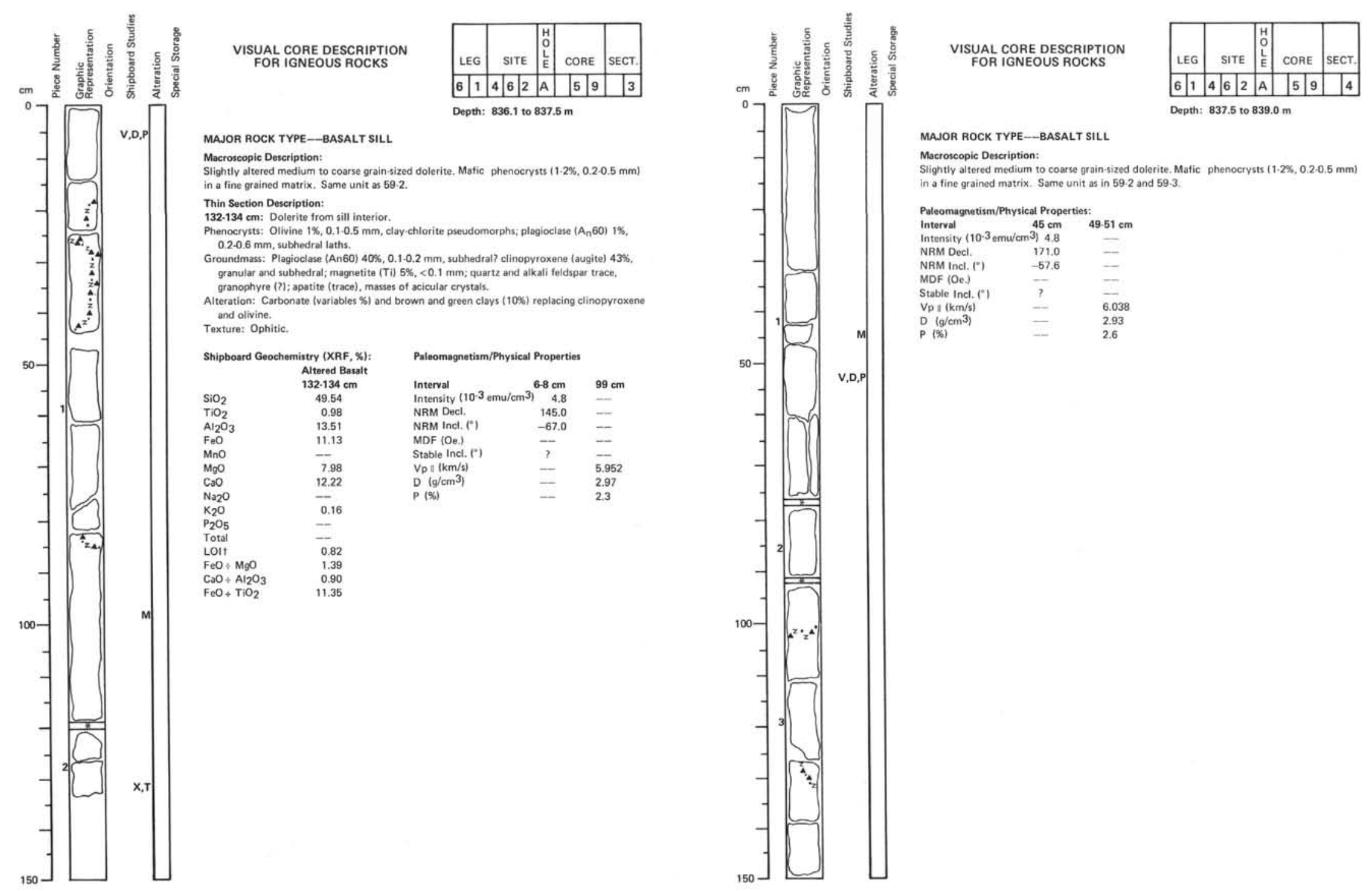

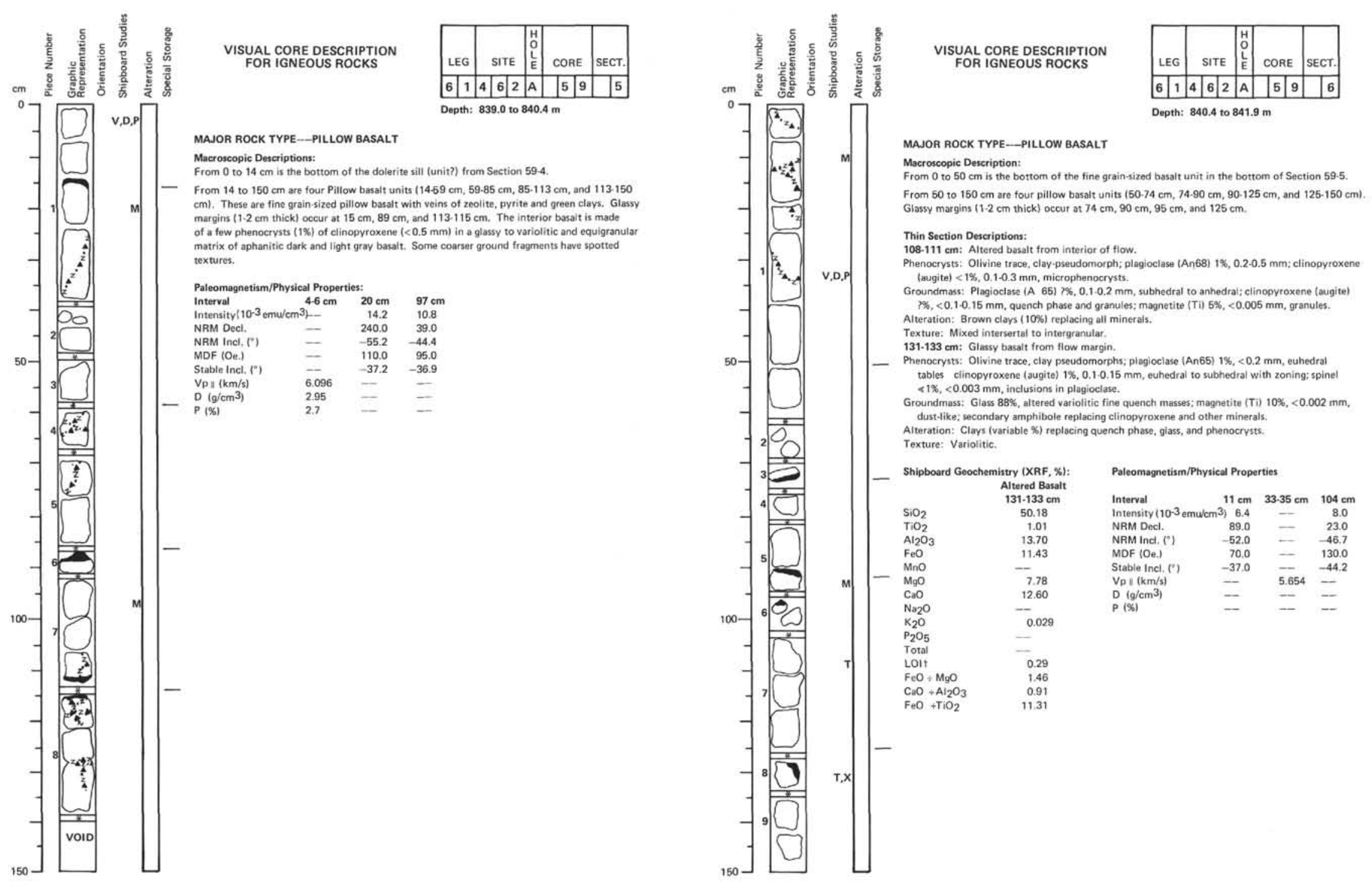

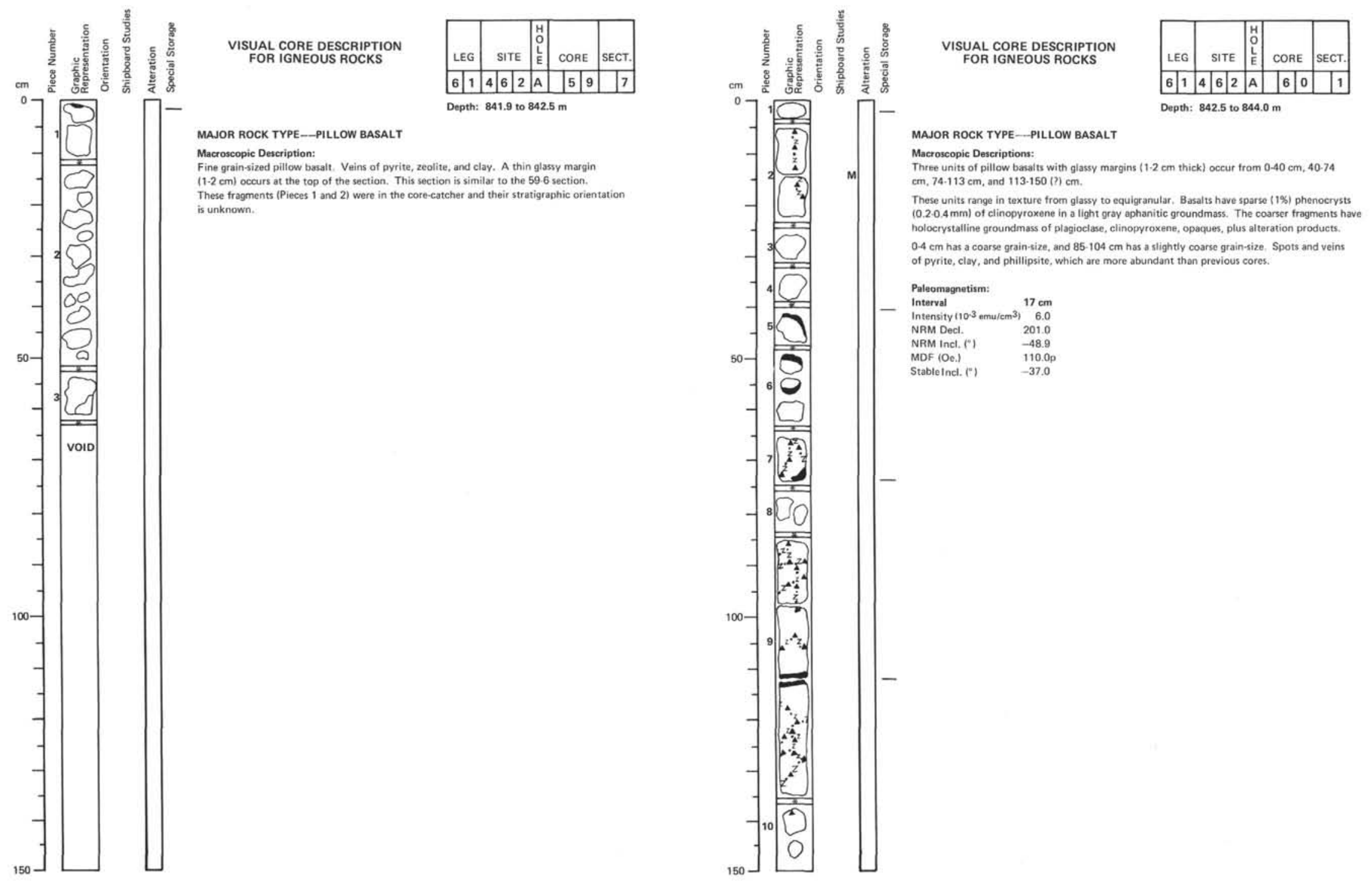

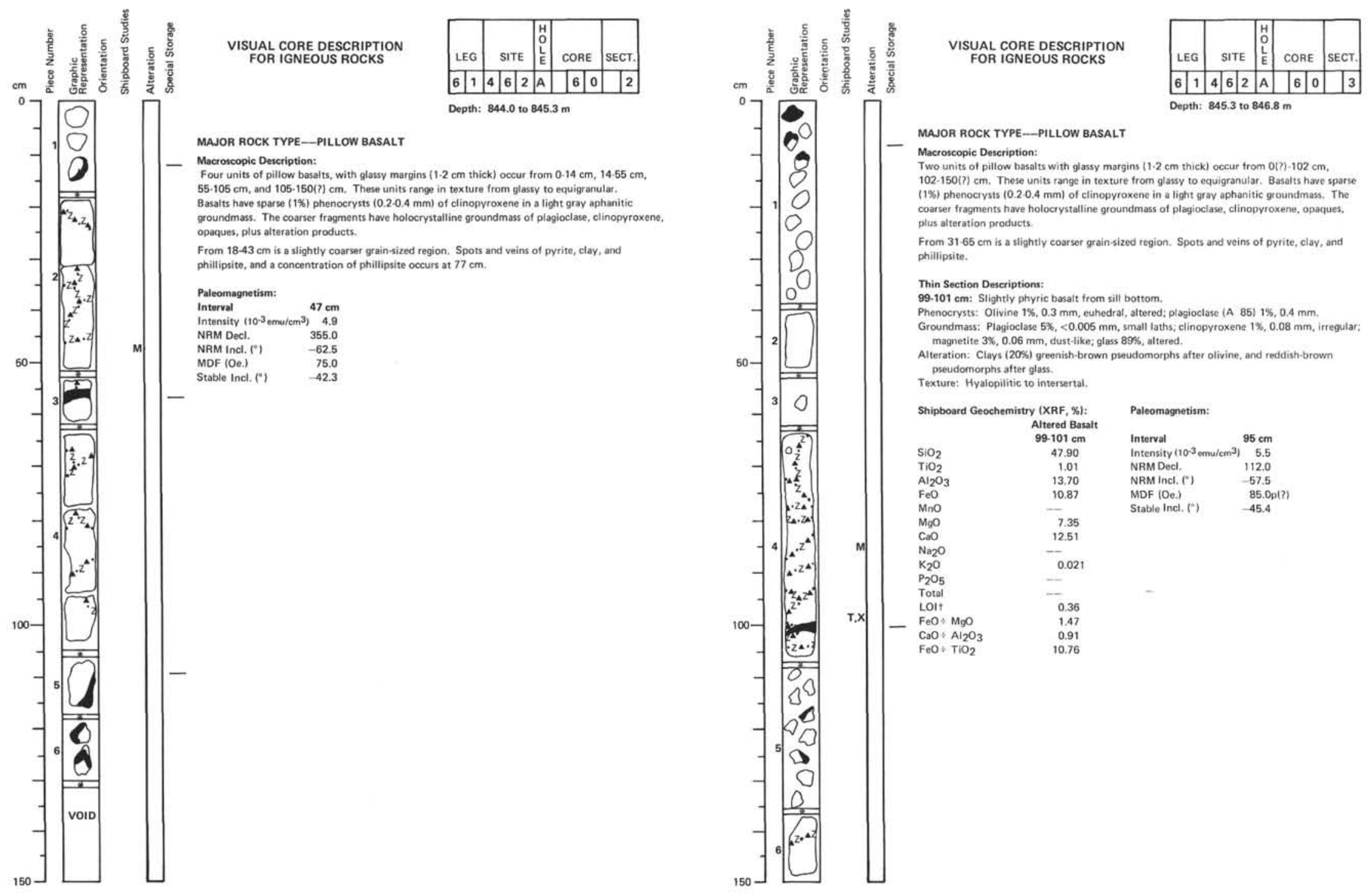

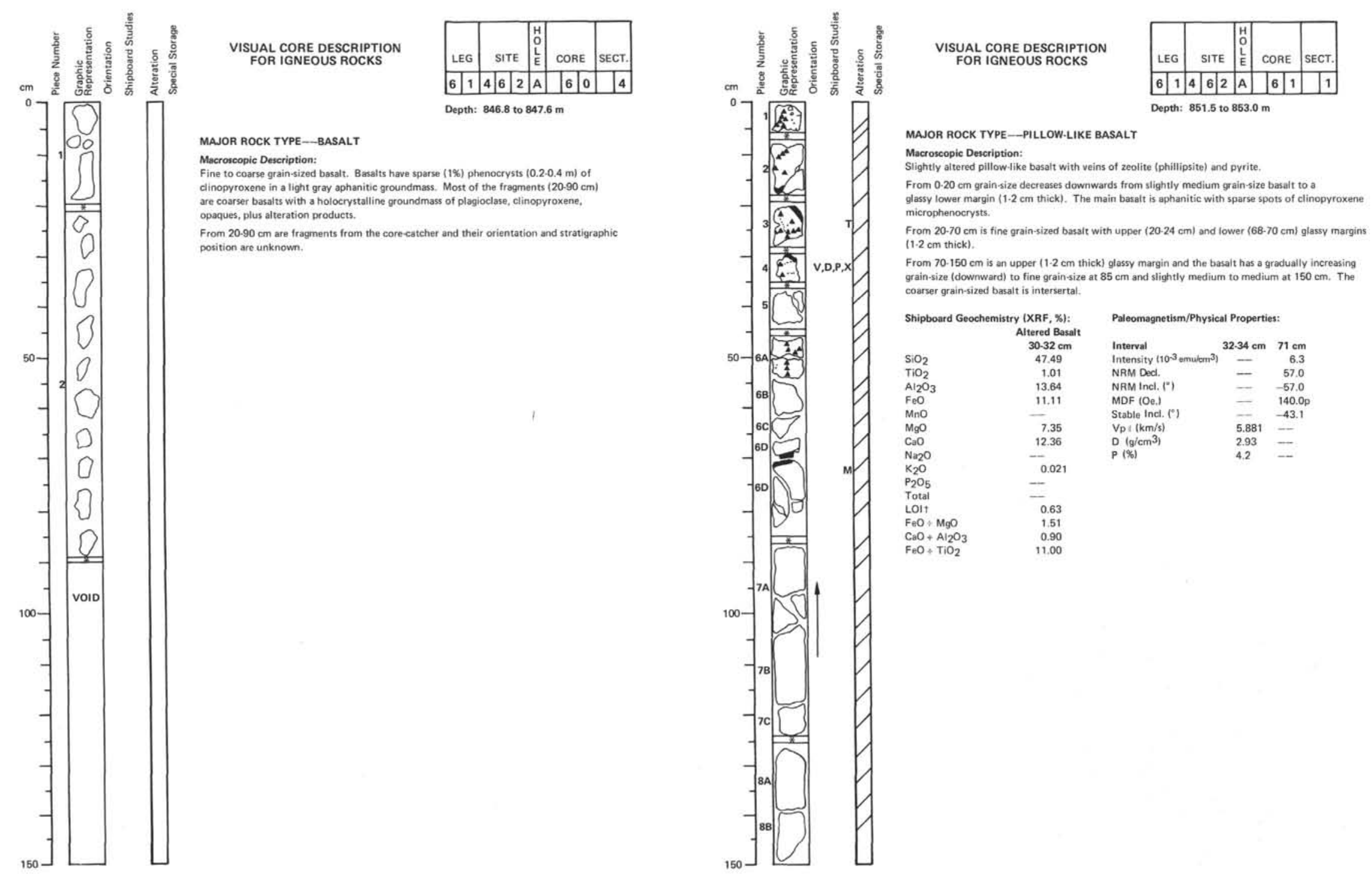

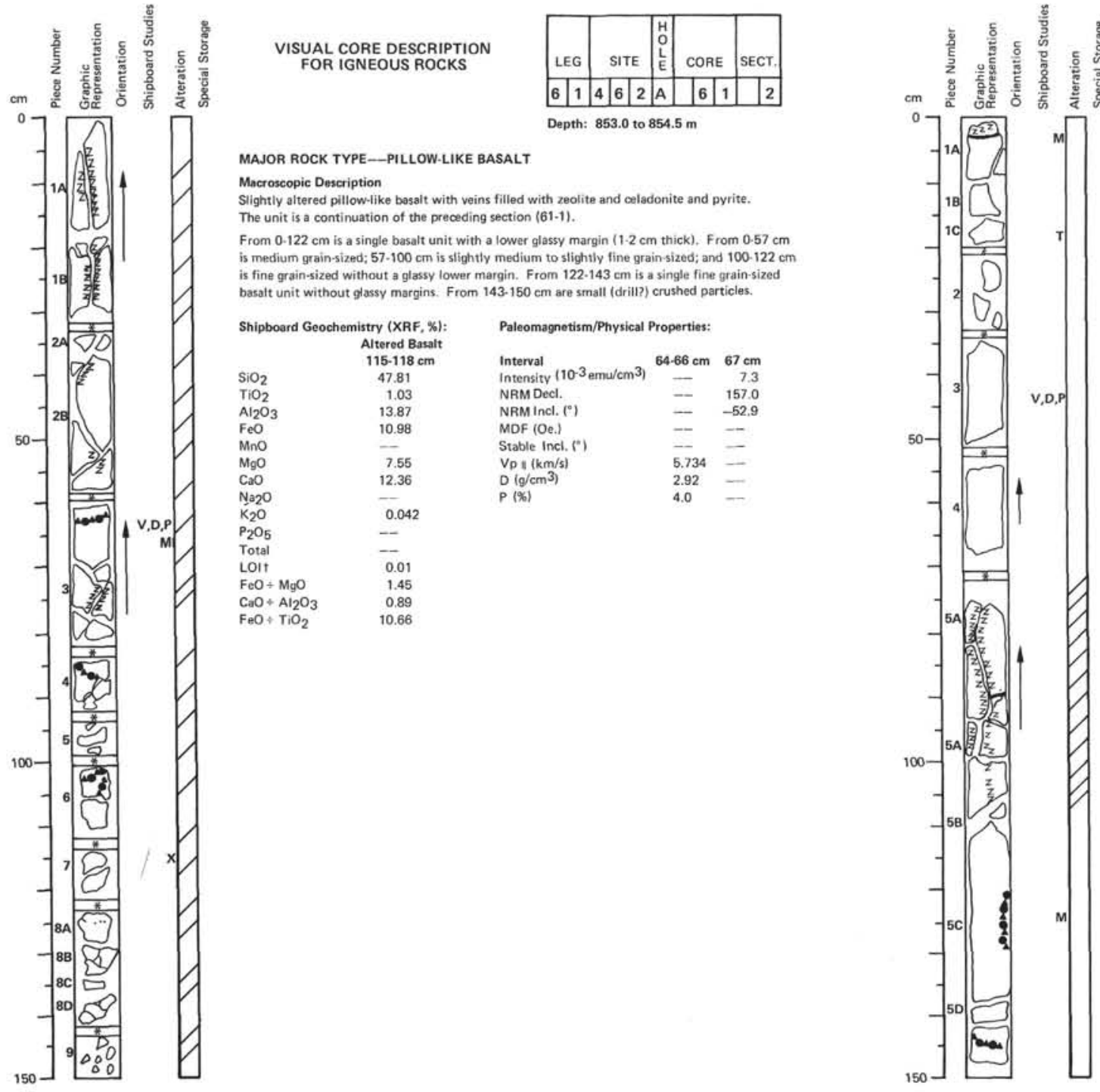

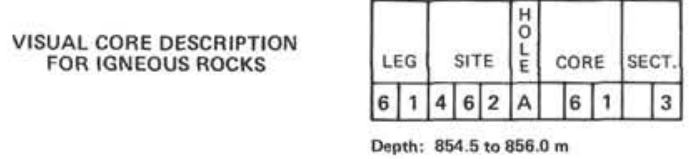

MAJOR ROCK TYPE-BASALT

Macroscopic Description:

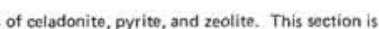
tame unit as in Section 61.2

Frm $0.70 \mathrm{~cm}$ is an upper glassy margin $(2.3 \mathrm{~cm})$ and the lower portion is basalt with micro. slightly fine lincreasingl, and from $21.68 \mathrm{~cm}$ is slightly medium to medium, From 75.150 (?) $\mathrm{cm}$ is medium grain-sized equigranular, plagioclase and clinopyroxene basalt. From $0.70 \mathrm{~cm}$ and Piece $56(-110 \mathrm{~cm})$ are fresh, and $15.110 \mathrm{~cm}$ (Piece 5A) is slightly altered with abundant

Thin Section Descriptions: Groundmass: Plagioclase $(5228), 0.3 \mathrm{~mm}$, microlites; clinopyroxene $39 \%, 0.12 \mathrm{~mm}$, intersertal .

\begin{tabular}{|c|c|c|c|}
\hline \multicolumn{4}{|c|}{ Paleomagnetism/Physical Properties: } \\
\hline Interval & $3 \mathrm{~cm}$ & $45-47 \mathrm{~cm}$ & \\
\hline Intensity $\mid 10^{-3} \mathrm{emu}_{\mathrm{em}} / \mathrm{cm}^{3}$ ] & 7.2 & & \\
\hline NRM Decl. & 320.0 & - & \\
\hline $\begin{array}{l}\text { NRM Inct. (") } \\
\text { MDE (Oe) }\end{array}$ & 44.3 & - & -57.3 \\
\hline $\begin{array}{l}\text { MDF (Oe) } \\
\text { Stable Incl. }\left(0^{\circ}\right)\end{array}$ & 140.0p & - & \\
\hline 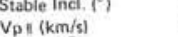 & -35.6 & $\overline{5.849}$ & \\
\hline$D\left(g / \mathrm{cm}^{3}\right)$ & - & 2.93 & \\
\hline$P(\$)$ & -- & 3.1 & -- \\
\hline
\end{tabular}



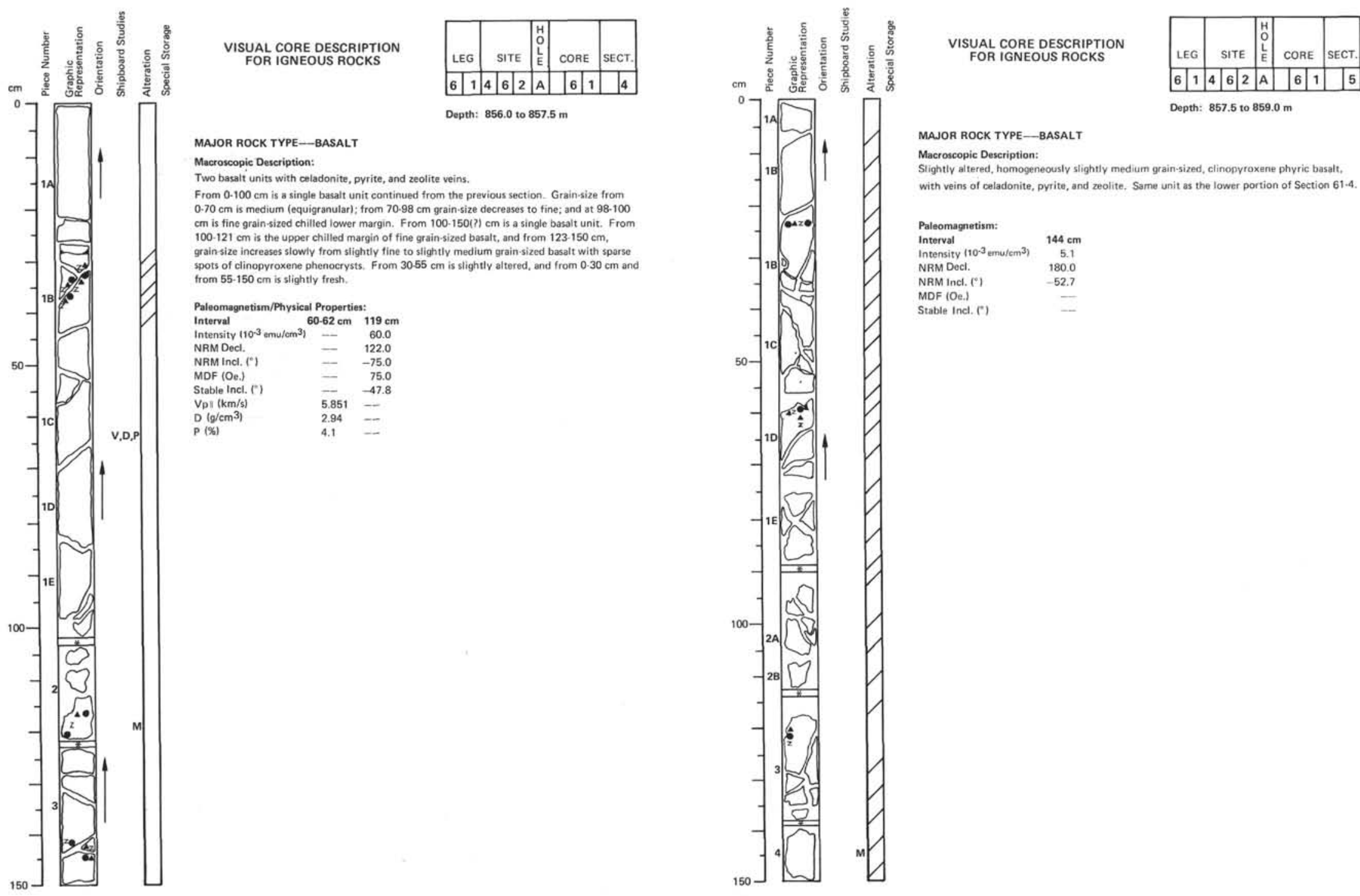


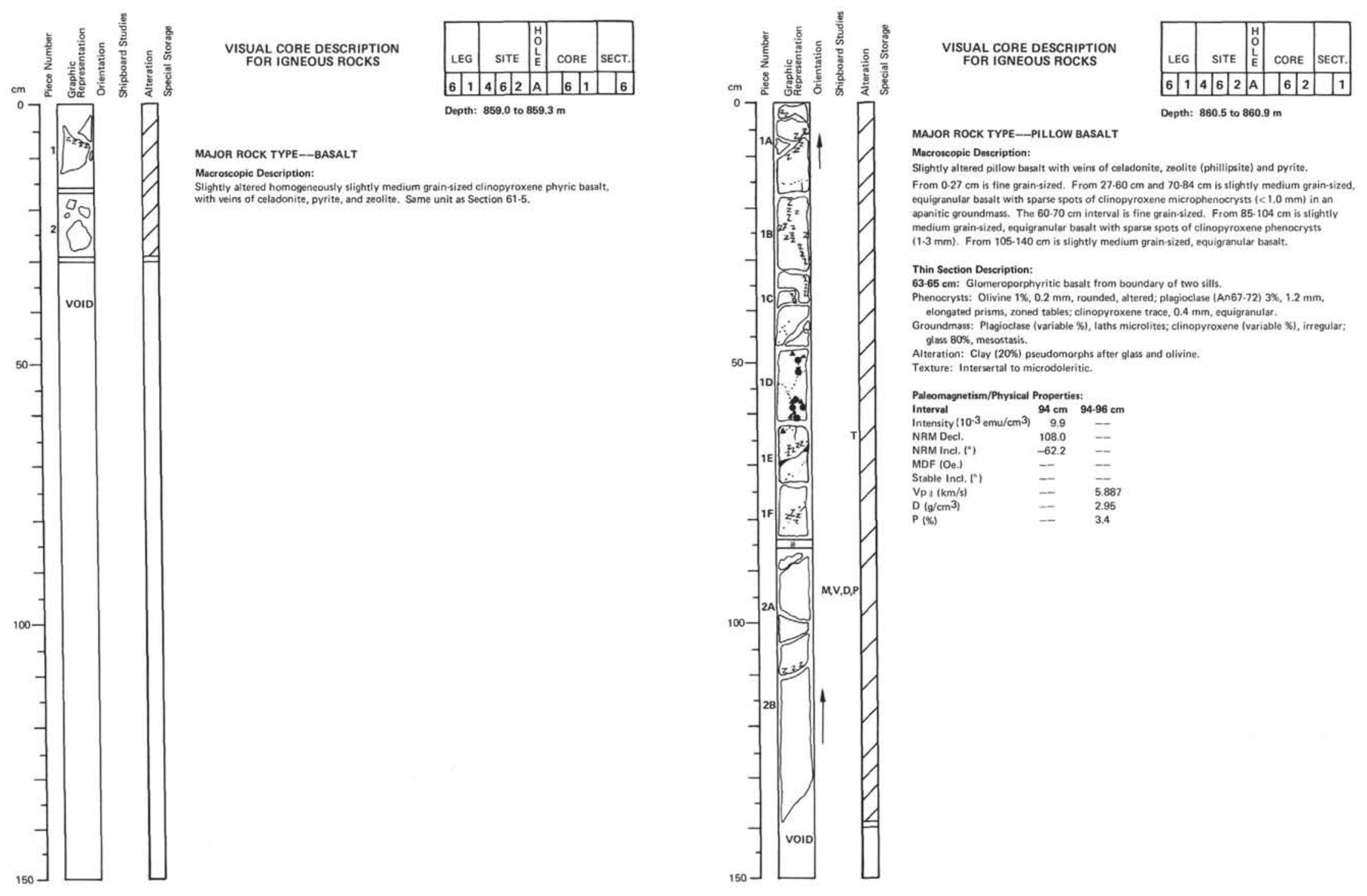



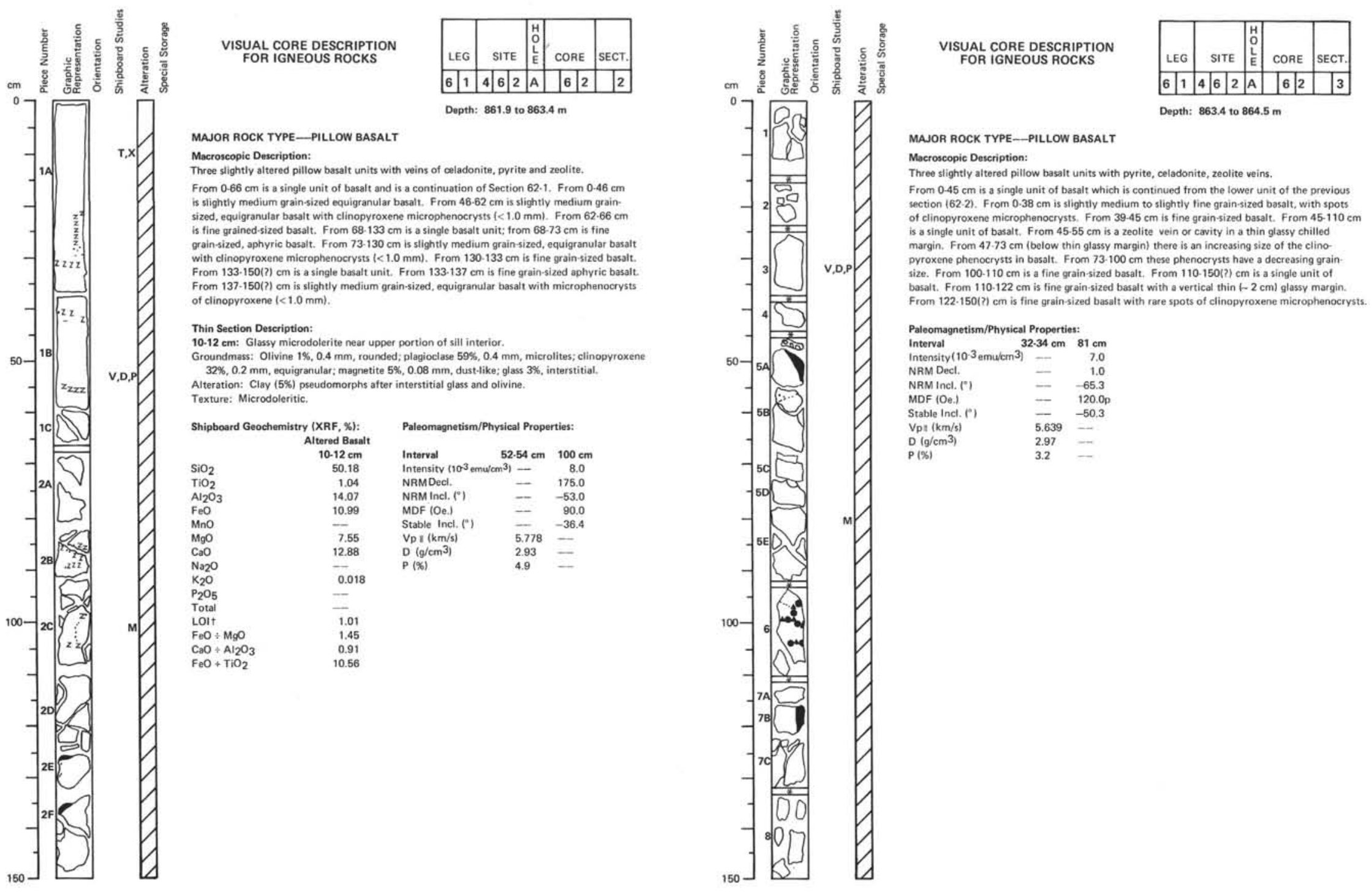

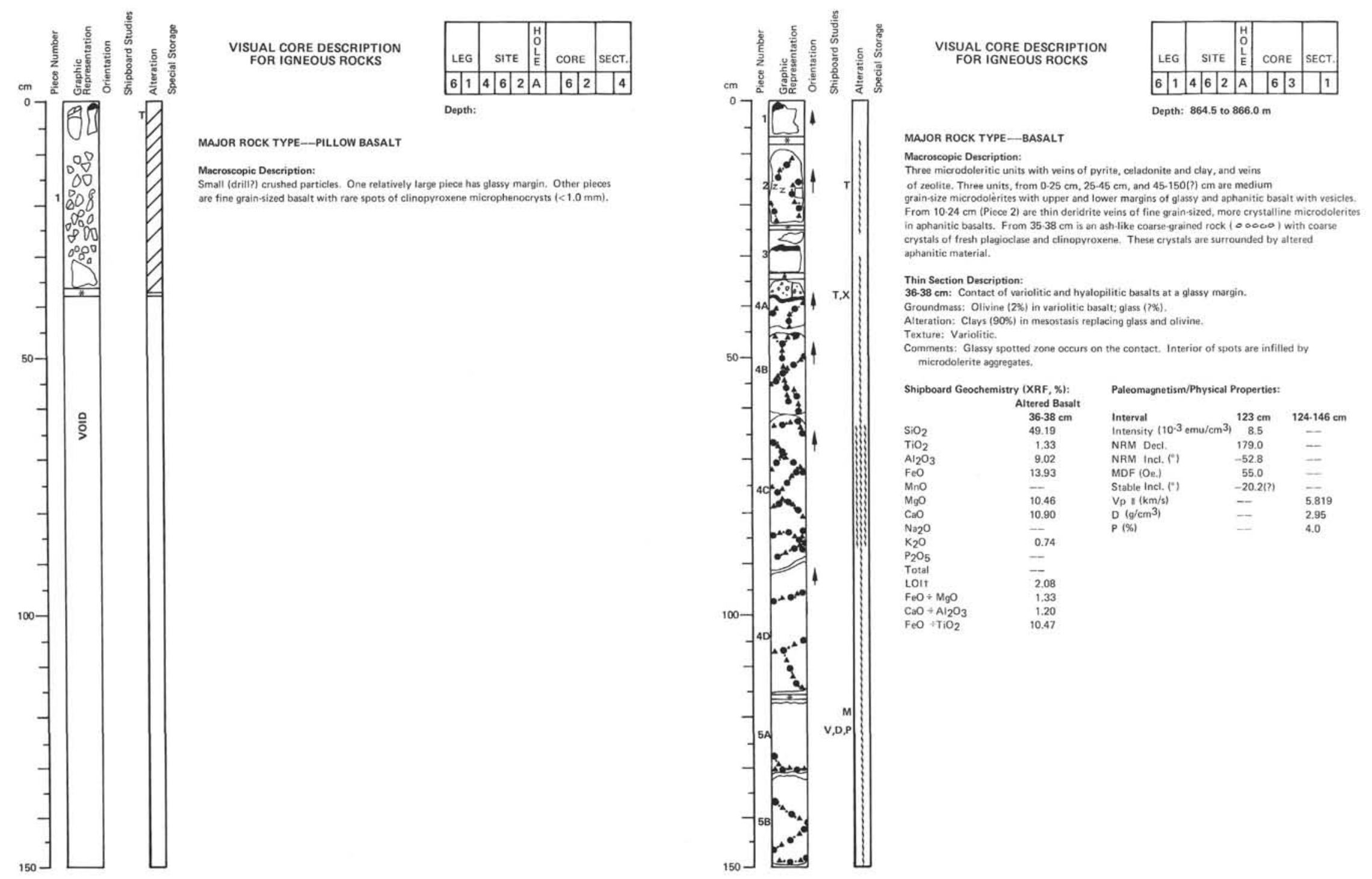

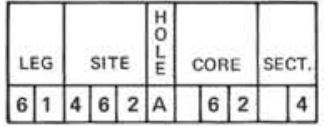

\section{MAJOR ROCK TYPE-_-PILLOW BASALT}

Macroscopic Description:

Small (drilit? crushed particles, One relatively large piece has glassy margin, Other piecee VISUAL CORE DESCRIPTION

\section{\begin{tabular}{l|l|l|l|l|l|l|l|l|l|l|}
6 & 1 & 4 & 6 & 2 & $A$ & 6 & 2 & & 4
\end{tabular}}

Depth: 

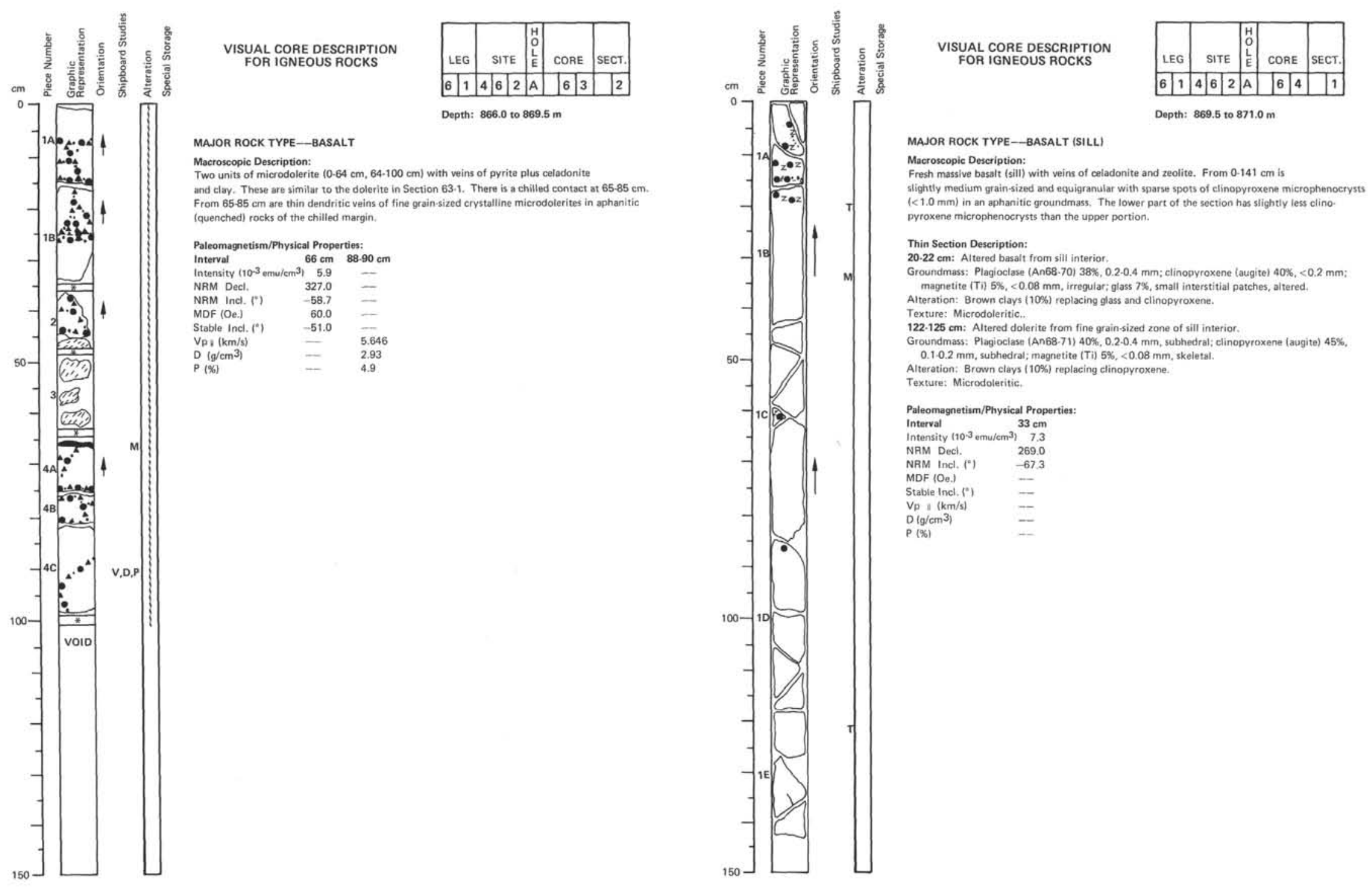

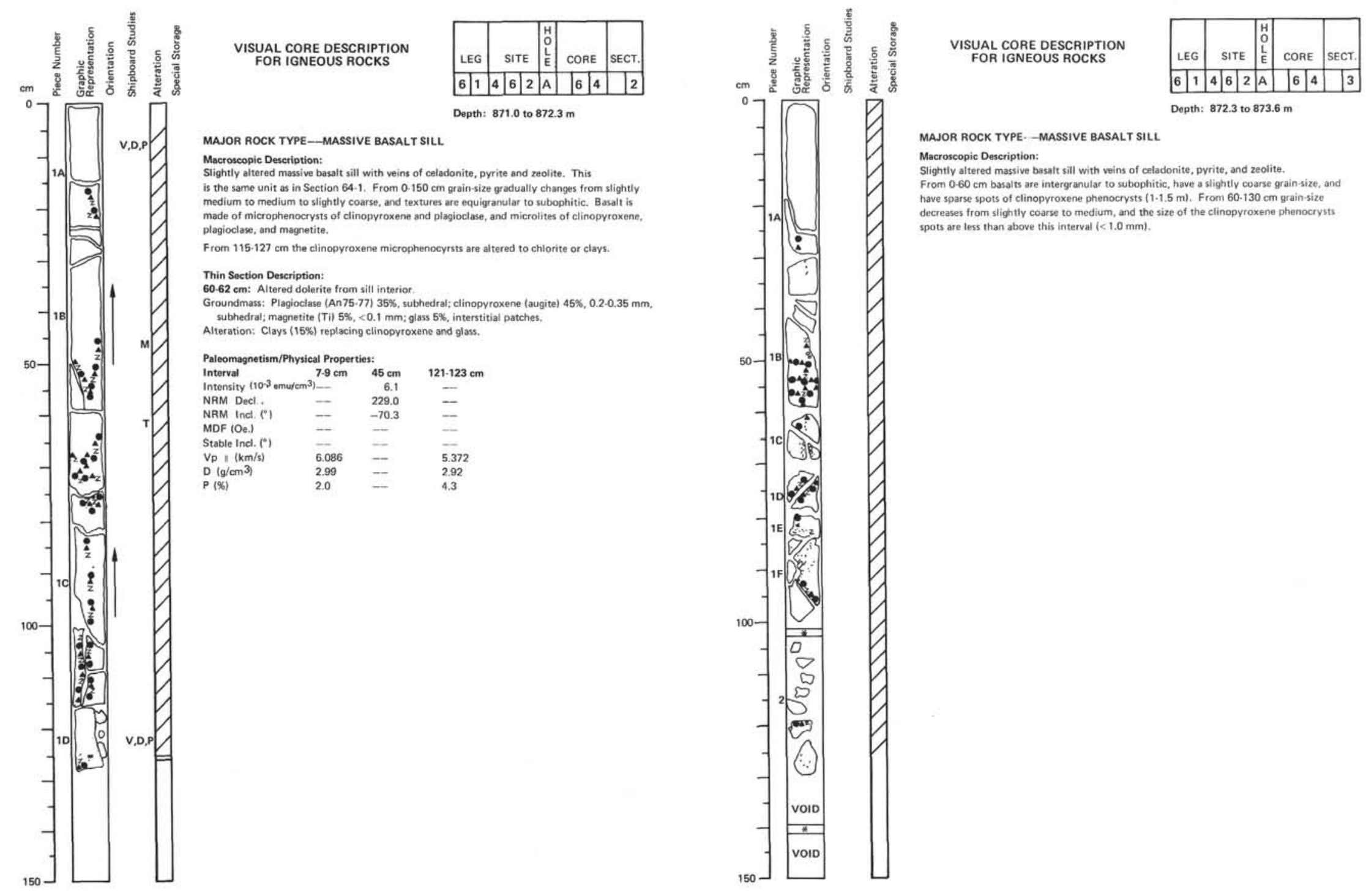

MAJOR ROCK TYPE- - MASSIVE BASALT SILL

Macroscopic Description: From $0.60 \mathrm{~cm}$ bassalts are intergranular to subophitic, have a slightly coarse grain-size, and have sparse spots of clinopyroxene phenocysts $(1 \cdot 1.5 \mathrm{~m})$. From $60.130 \mathrm{~cm}$ grain-size decreases from slightly coarse to medium, and the size of the clinopyroxene phenocryst spots are less than above this interval $(<1.0 \mathrm{~mm})$. 

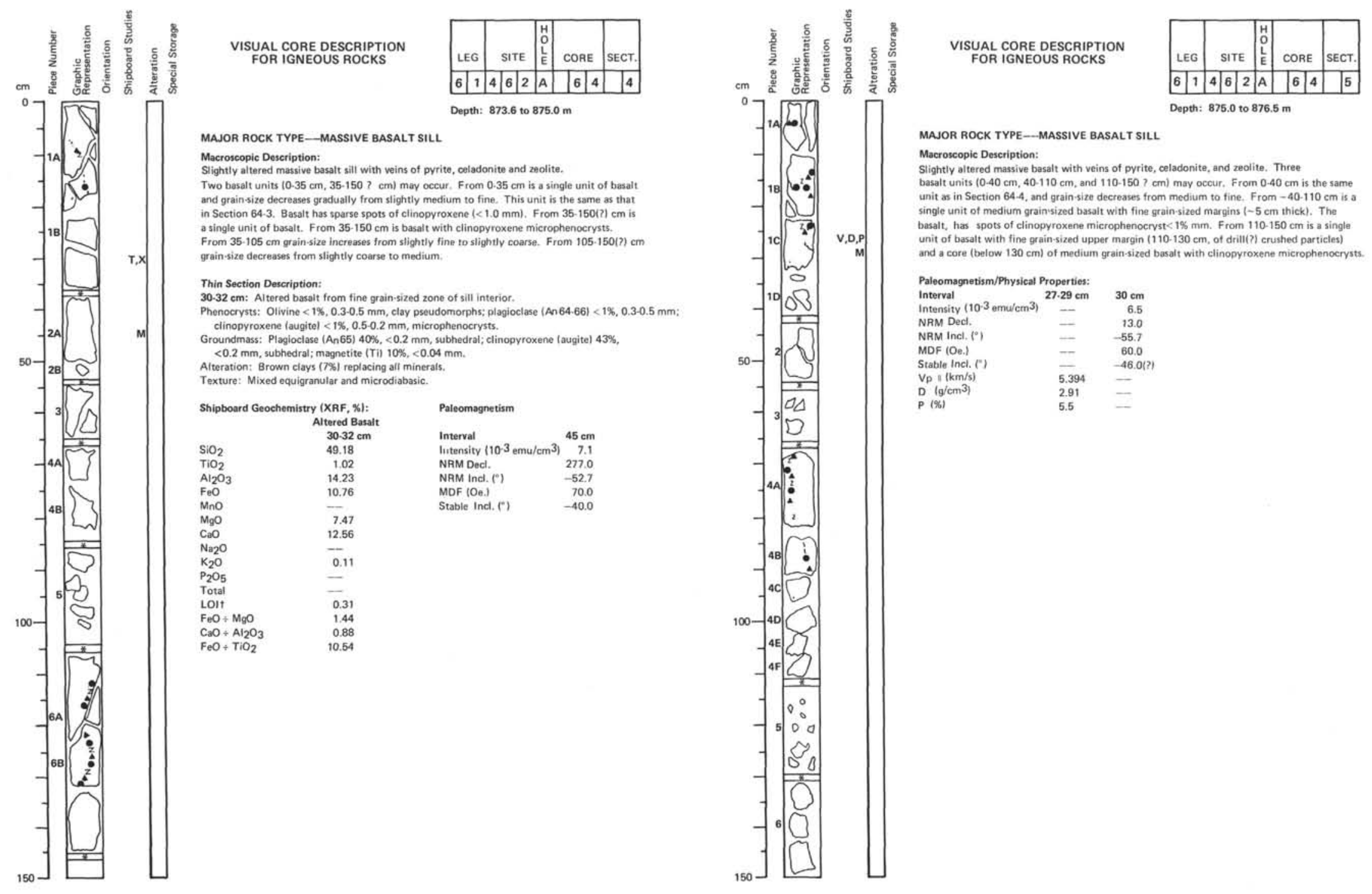

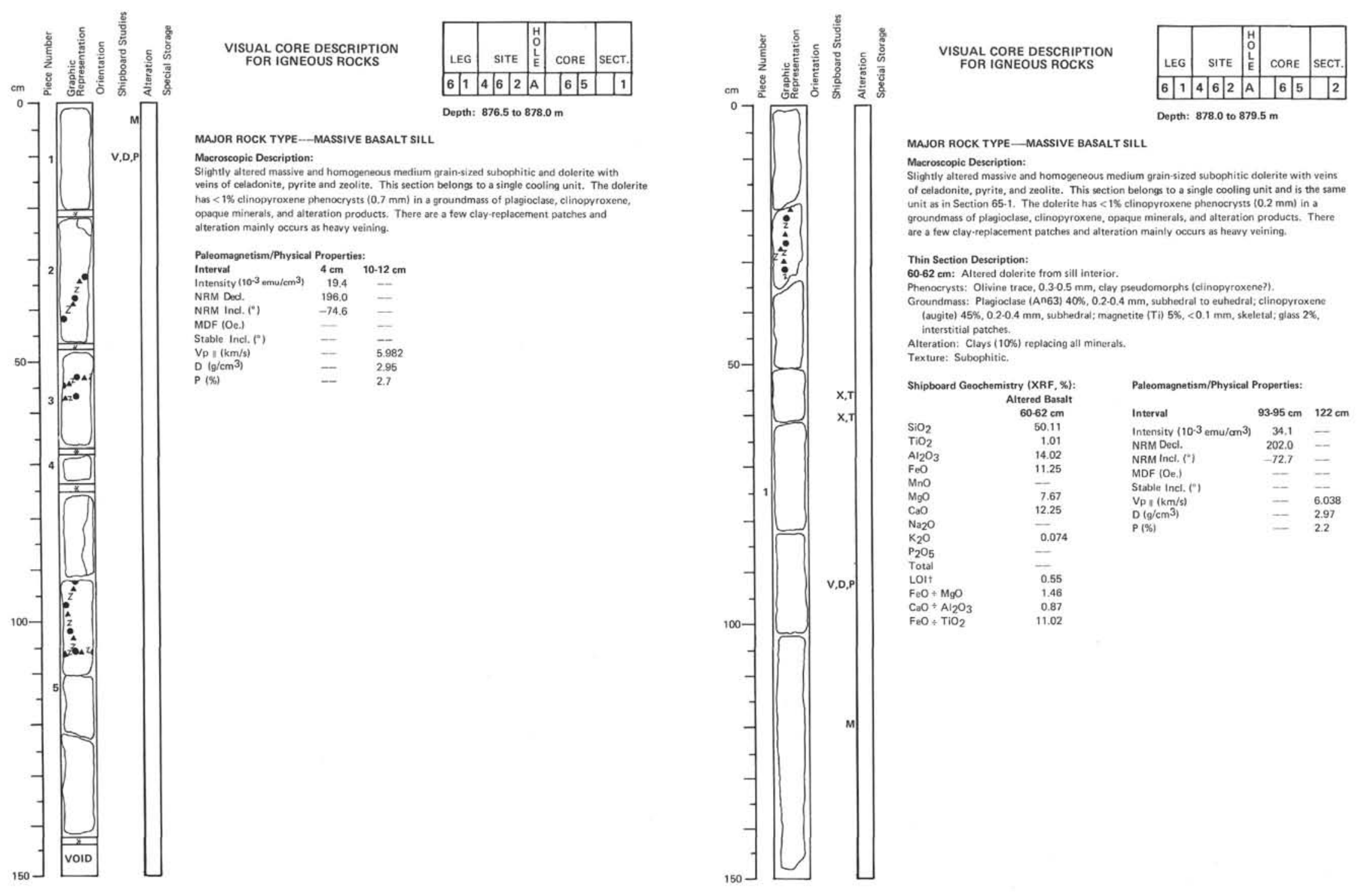


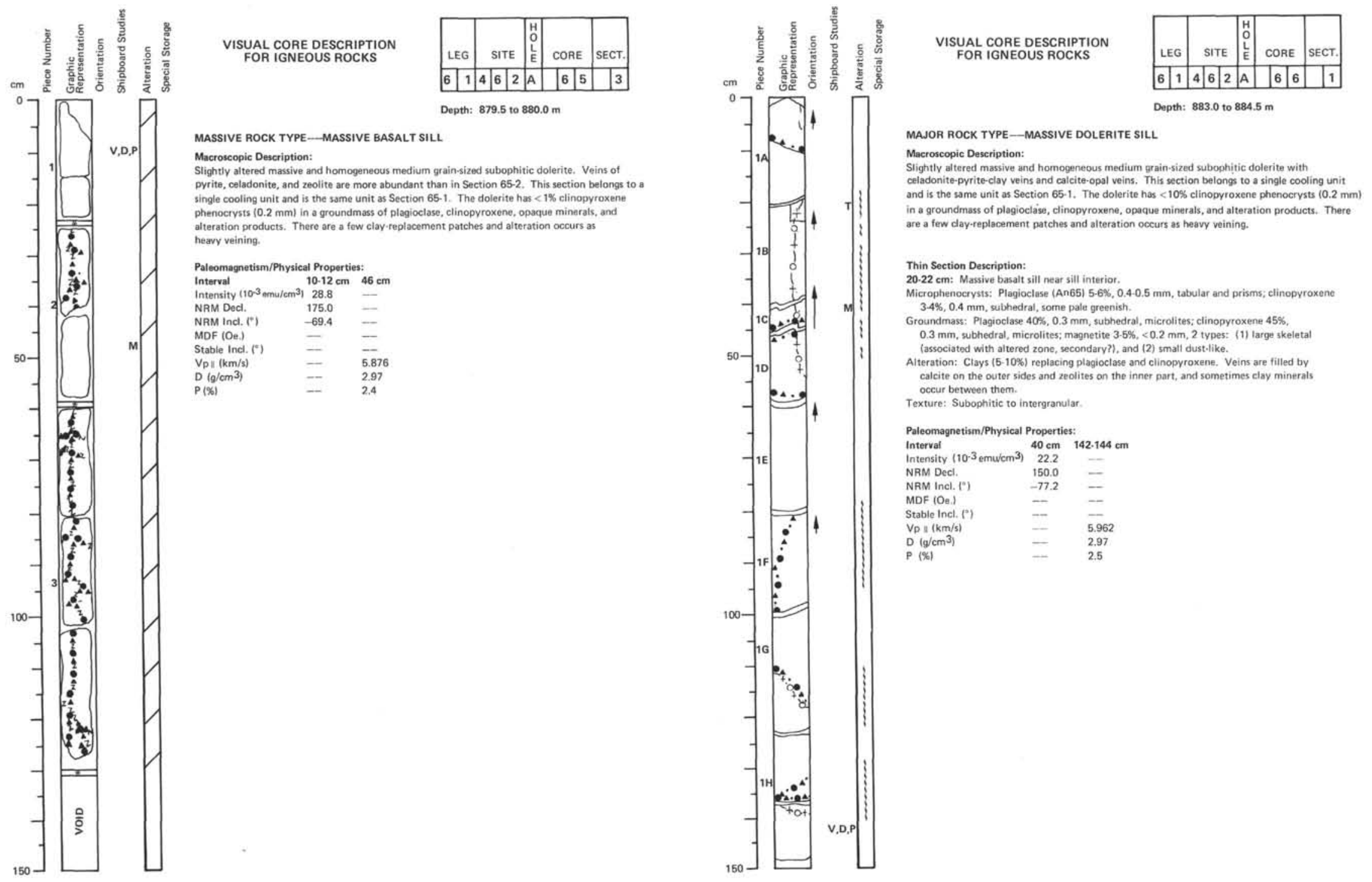



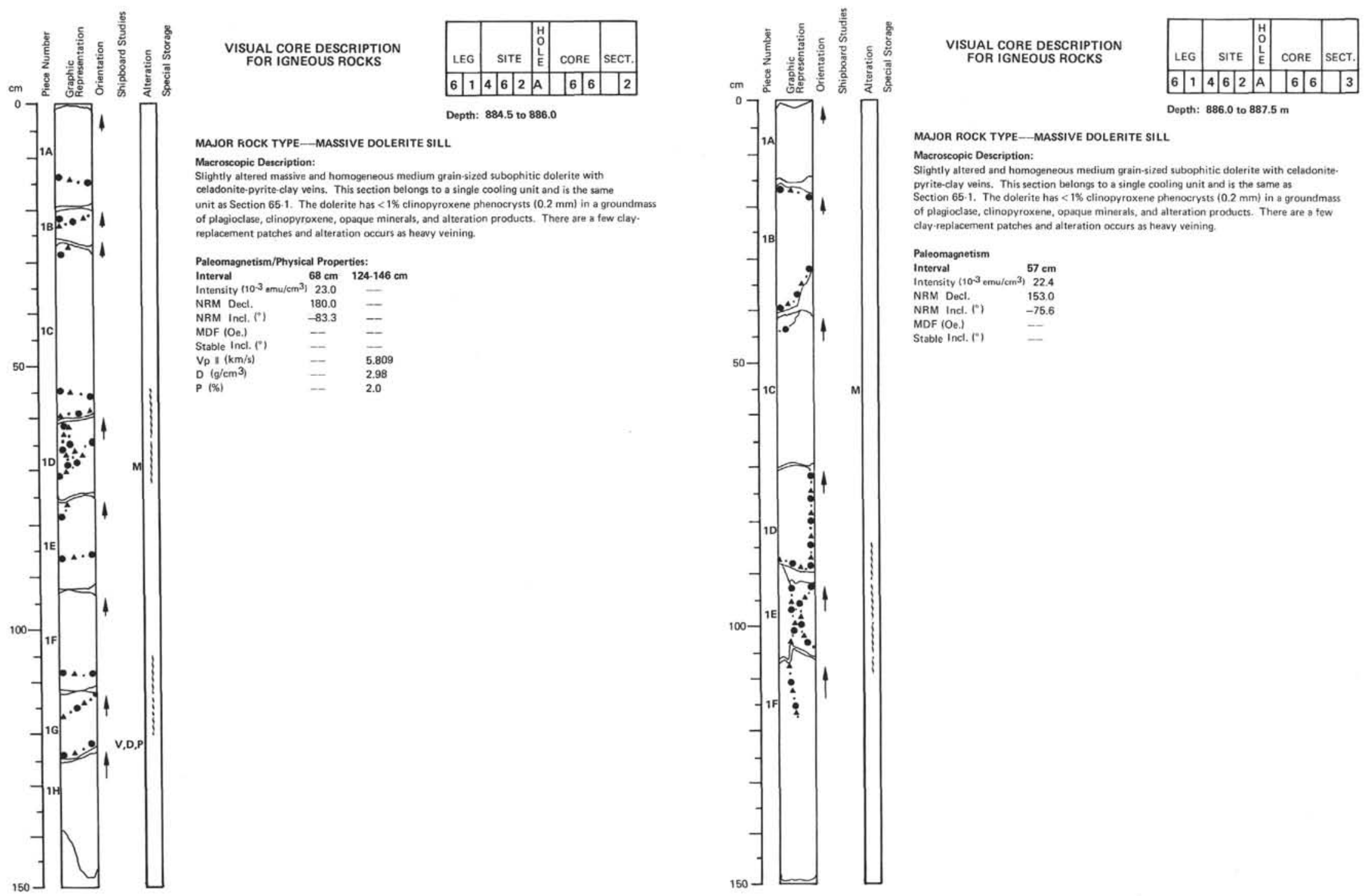

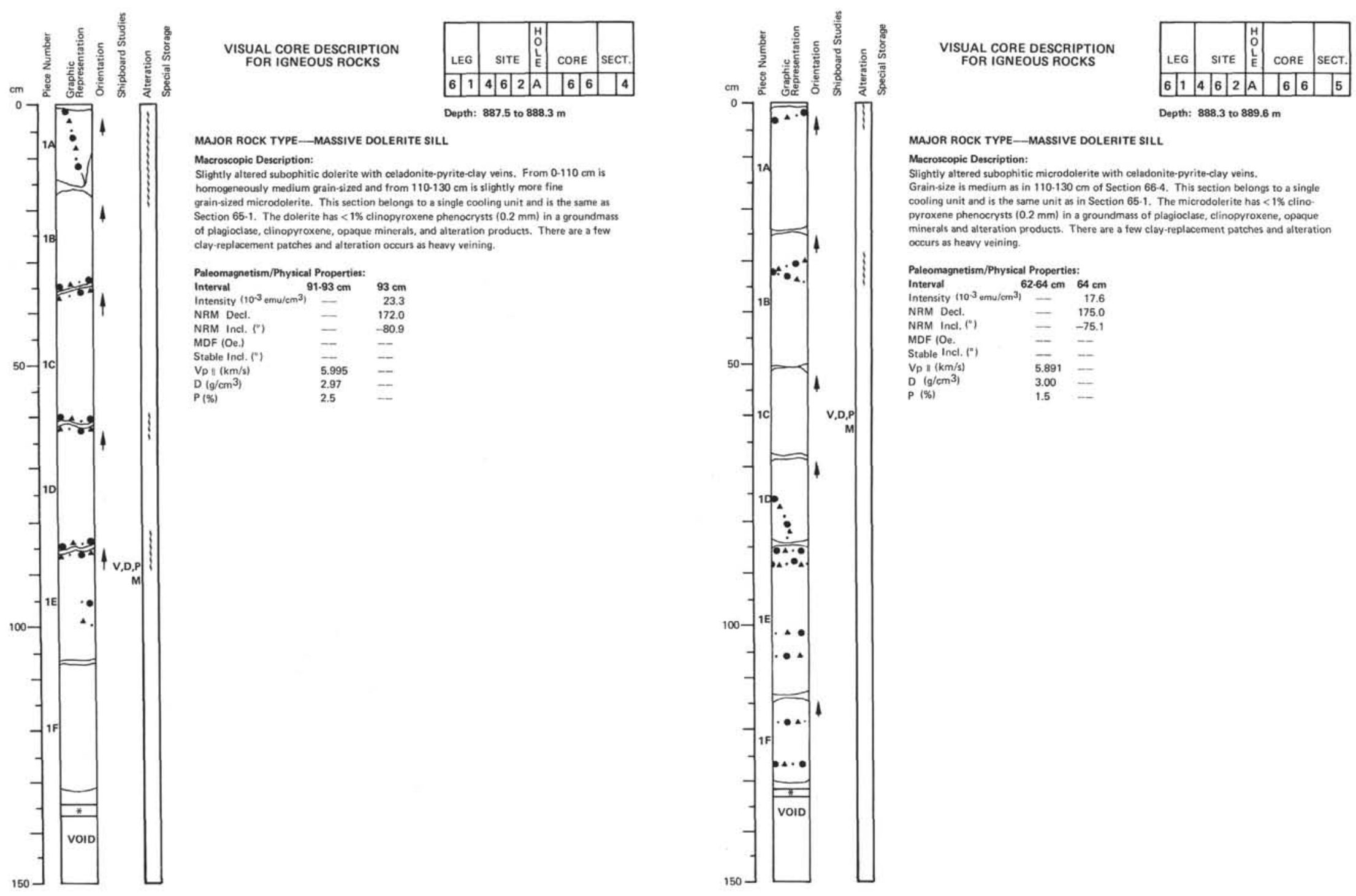


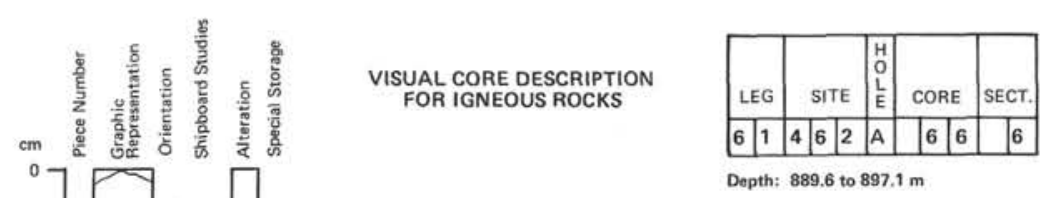

MAJOR ROCK TYPE--MASSIVE DOLERITE SILL

Macroscopic Description:

Slightly altered subophitic microdolerite with celadonitt-pyrite-clay veins. Grain-

cm of Section 66-4. This section belongs to a single cooling

phenocrysts $(0.2 \mathrm{~mm})$ in a groundmass of plajoct

alteration products. There are a few clay-replacement patches and alteration occurs as heavy

veining.

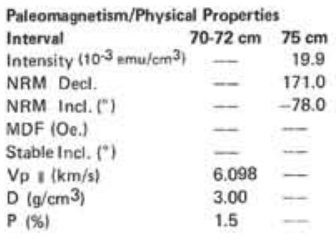

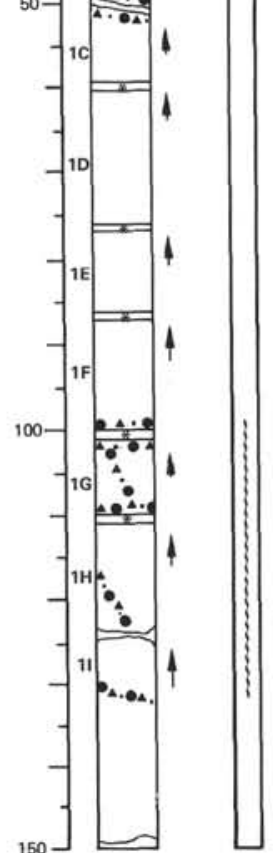

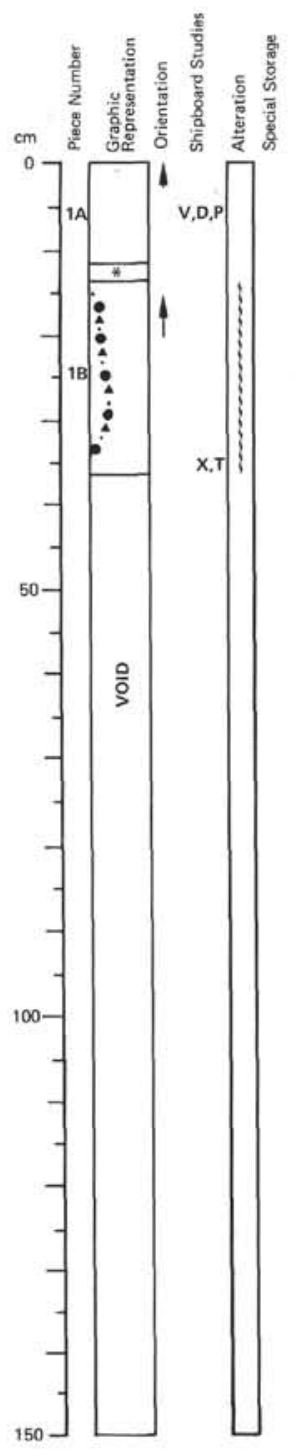

VISUAL CORE DESCRIPTION FOR IGNEOUS ROCKS

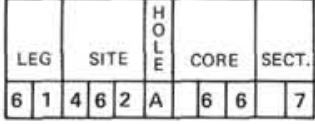

\section{1 to 8920 m}

MAJOR ROCK TYPE---MASSIVE DOLERITE SILL

\section{Macroscopic Desceription:} 政 $(0.2 \mathrm{~mm})$ in a groundmass of plagion $65-1$. The microdolerite has $<1 \%$ clinopyroxene phenocry Where are a few clay -eplacement patches and alteration occurs as heavy veinir

Thin Section Description:

政 $15 \%, 0.5 \cdot 1.0 \mathrm{~mm}$, partly subhedral; magnetite $3 \%$, skelet:

(n) mass: Plagioclase $25 \%,<0.3 \mathrm{~mm}$, microlites; clinopyroxone $25 \%, 0.4 \mathrm{~mm}$, microlites: pegmatite (34\%), skeletal magnetite associated; trace of green hornblende and opatite Afteration: Clays (5-6\%) replacing plagioclase; chlorite (1-3\%) in spots replacing clinopyroxene. Texture: Subophitic to intergranular:

$\begin{array}{lcll} & \begin{array}{c}\text { Altered Basalt } \\ 33.35 \mathrm{~cm}\end{array} & \begin{array}{l}\text { Interval } \\ \mathrm{Vp}(\mathrm{km} / \mathrm{s})\end{array} & 4.6 \mathrm{~cm} \\ \mathrm{SiO}_{2} & 49.67 & 592 \\ \mathrm{TiO}_{2} & 0.99 & \mathrm{D}\left(\mathrm{g} / \mathrm{cm}^{3}\right) & 2.98 \\ \mathrm{Al}_{2} \mathrm{O}_{3} & 13.81 & \mathrm{P}(5) & 2.1 \\ \mathrm{Fe} \mathrm{O} & 11.29 & & \end{array}$

11.29

8.10

$-7$

$-$

olt

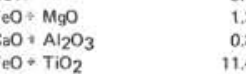



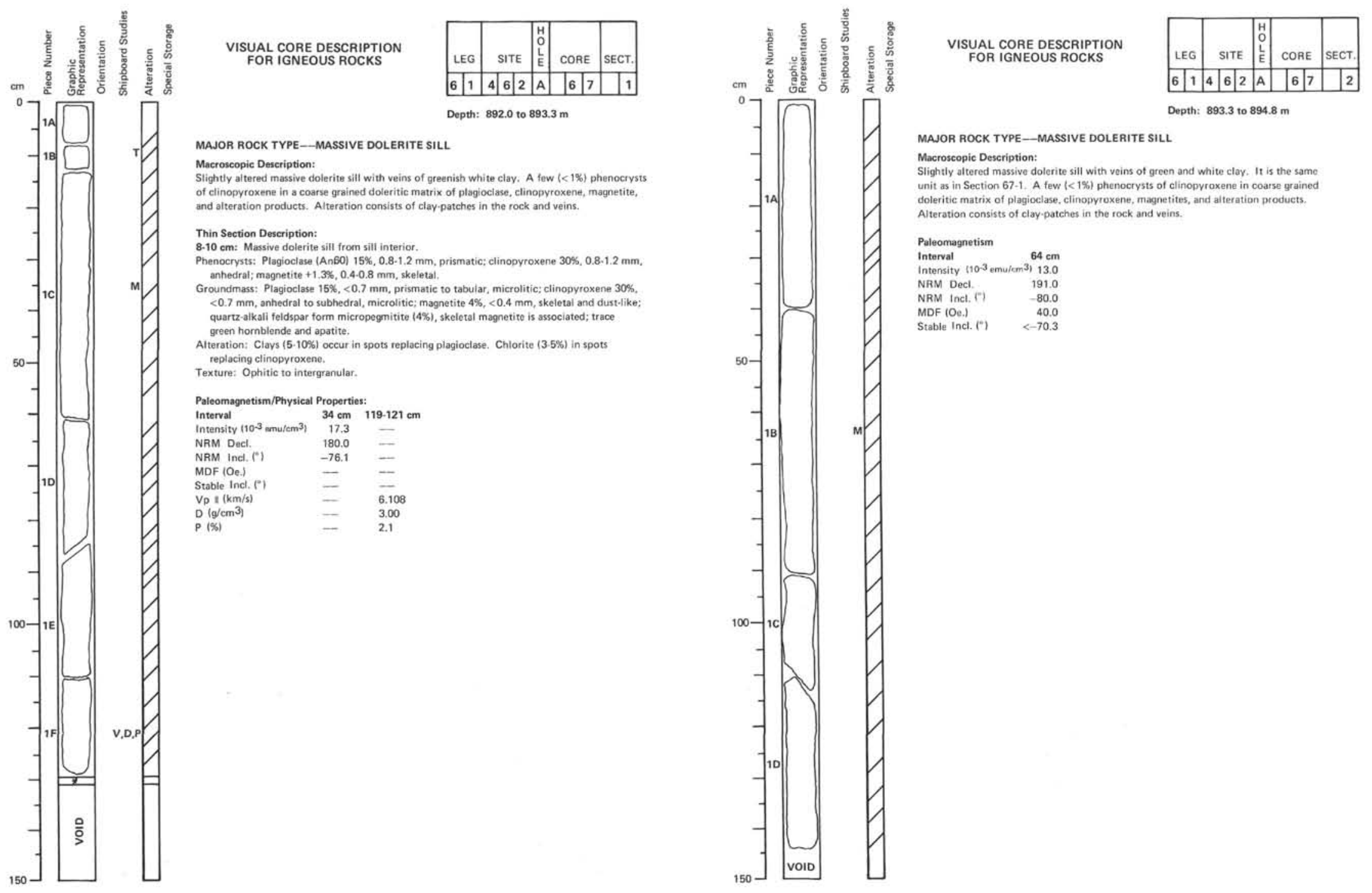

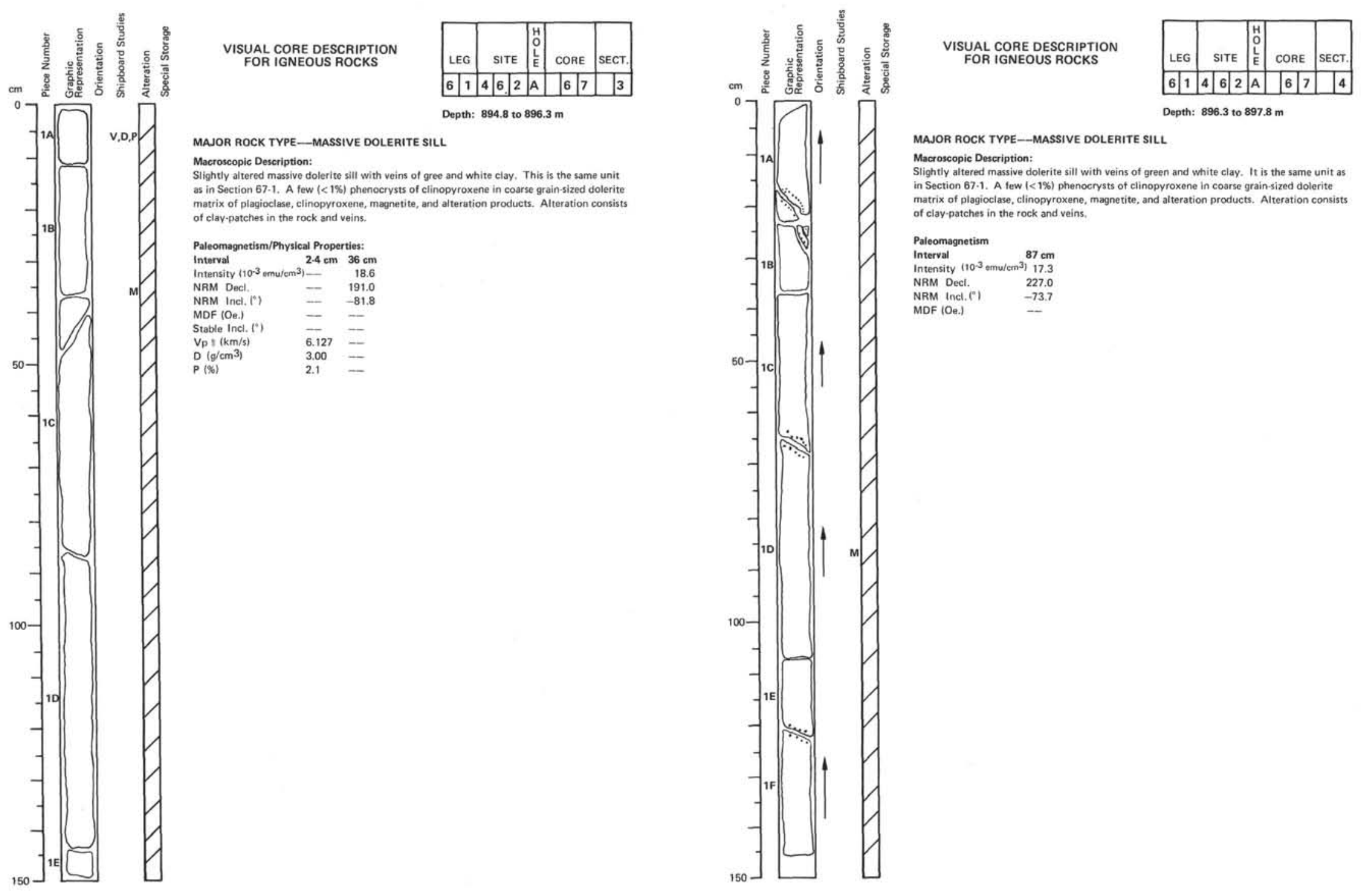


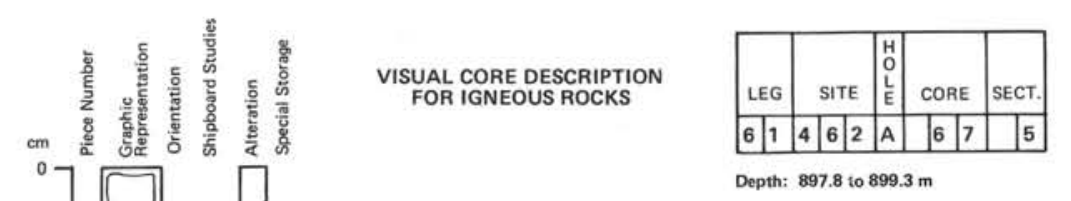

MAJOR ROCK TYPE--MASSIVE DOLERITE SILL as in Section 67.1. A fou i< 1 . a of clay-patches in the rock and veins.

\section{Paleomagnetism}

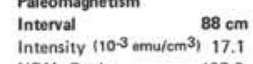

NRM Decl. 187.0

Stable Incl, (7) =

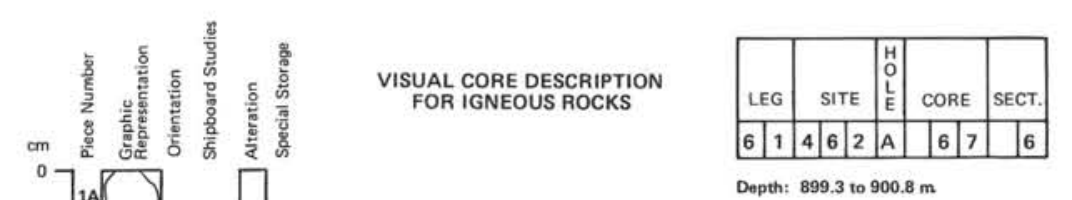

MAJOR ROCK TYPE-MASSIVE DOLERITE SILL

Macroscopic Description

Slightly altered massive dolerite sill with veins of green and white clay. It is the same unit as in

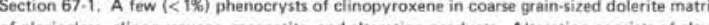

Thin Section Description

$124.126 \mathrm{~cm}$ : Massive dolerite sill near sill interior.

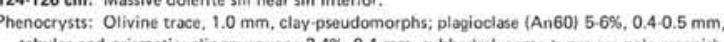
Groundmass: Olivine 1.3\%, $0.4 \mathrm{~mm}$, chlorite-pseudomorphs coe existing with magnetite: plagioclase $40 \%, 0.3 \mathrm{~mm}$, suthedral, microlite; clinooviroxene $45 \%, 0.3 \mathrm{~mm}$, subhedral, micro lite; magnetite $3.5 \%<0.2 \mathrm{~mm}$; Type 1 is skeletal and Type 2 is dust-like, skeletal type is Alteration: Clays (1\%) replacing plagioclase. Chlorite (2-4\%) replaces olivine and clinopyroxene. e: Subophitic to intergranular.

\begin{tabular}{|c|c|c|c|}
\hline Shipboe & $\begin{array}{l}\text { listry (XRF, } 8 \text { ): } \\
\text { Altered basalt }\end{array}$ & Paleomagnetism: & \\
\hline & $124.126 \mathrm{~cm}$ & Interval & \\
\hline $\mathrm{SiO}_{2}$ & 49.67 & Intensity $\left(10^{-3} \mathrm{emu} / \mathrm{cm}^{3}\right)$ & \\
\hline $\begin{array}{l}\mathrm{TiO}_{2} \\
\mathrm{Al}_{2} \mathrm{O}_{3}\end{array}$ & $\begin{array}{c}0.99 \\
1381\end{array}$ & $\begin{array}{l}\text { NRM Decl. } \\
\text { NRM Ind () }\end{array}$ & $\begin{array}{l}223.0 \\
-71.9\end{array}$ \\
\hline $\mathrm{FeO}$ & 11.29 & MDF (Oe.) & \\
\hline $\mathrm{MnO}$ & & Stable Incl. $\left({ }^{*}\right)$ & \\
\hline
\end{tabular}

$\begin{array}{lll}\mathrm{MnO} & - & \text { Stable Inct. } \\ \mathrm{MgO} & -10 & \end{array}$

$\mathrm{Na}_{2} \mathrm{O}$

$\mathrm{K}_{2} \mathrm{O} \quad 0.045$

Total

$\begin{array}{ll}\mathrm{FeO}+\mathrm{MgO}_{2} \mathrm{O} & 1.39 \\ \mathrm{CaO}+\mathrm{Al}_{2} \mathrm{O}_{3} & 0.89 \\ \mathrm{Fe}+ & 1.40\end{array}$

100

0.89
$\mathrm{FeO}+\mathrm{TiO}_{2}$ 


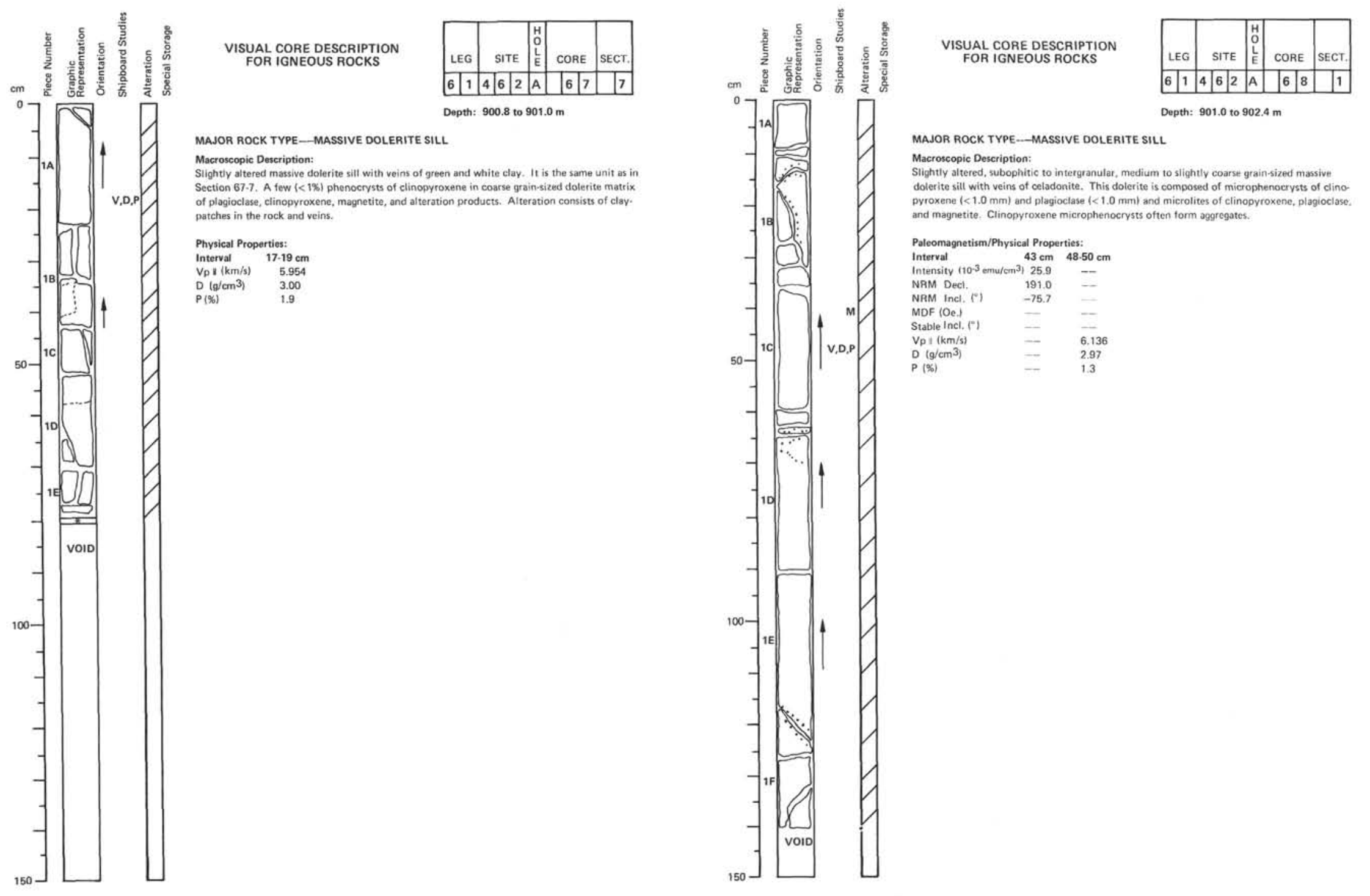



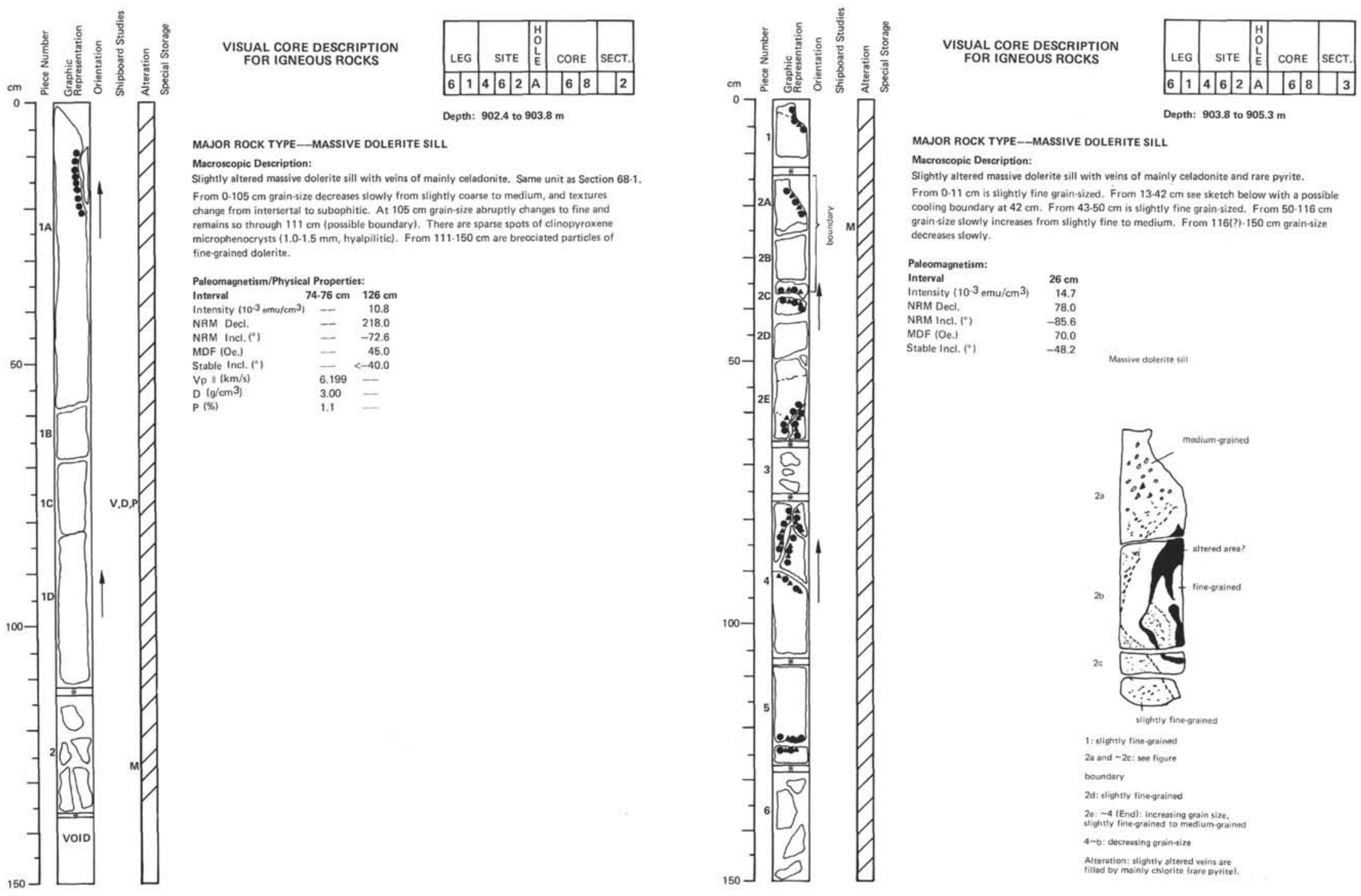

MAJOR ROCK TYPE--MASSIVE DOLERITE SILL

Macroscopic Description

Slightly altered massive dolerite sill with veins of mainly celadonite and rare pyrite.

From $0.11 \mathrm{~cm}$ is slightly fine grain-sized. From $13.42 \mathrm{~cm}$ see sketch below with a possible cooling boundary at $42 \mathrm{~cm}$. From $43.50 \mathrm{~cm}$ is slightly fine grain-sized, From $50-116 \mathrm{~cm}$ decreases slowily.

Paleomagnetism:

Intorval

Intensity $\left(10^{-3} \mathrm{emu}^{\mathrm{m}} \mathrm{cm}^{3}\right)$
NRM Decl.

NRM Inct, ( (") $\quad-85.6$

$\begin{array}{rr}\text { MDF (Oe.) } & 70.0 \\ \text { Stable Incl. (P) } & -48.2\end{array}$

Massive doterite sal

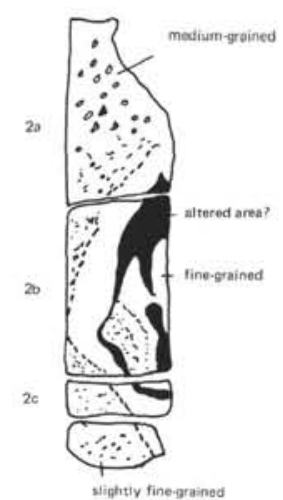

1: tulightly fine-grained

2a and 2 2c: see fioure

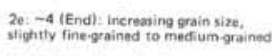

a-b deccusing grain-size

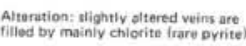



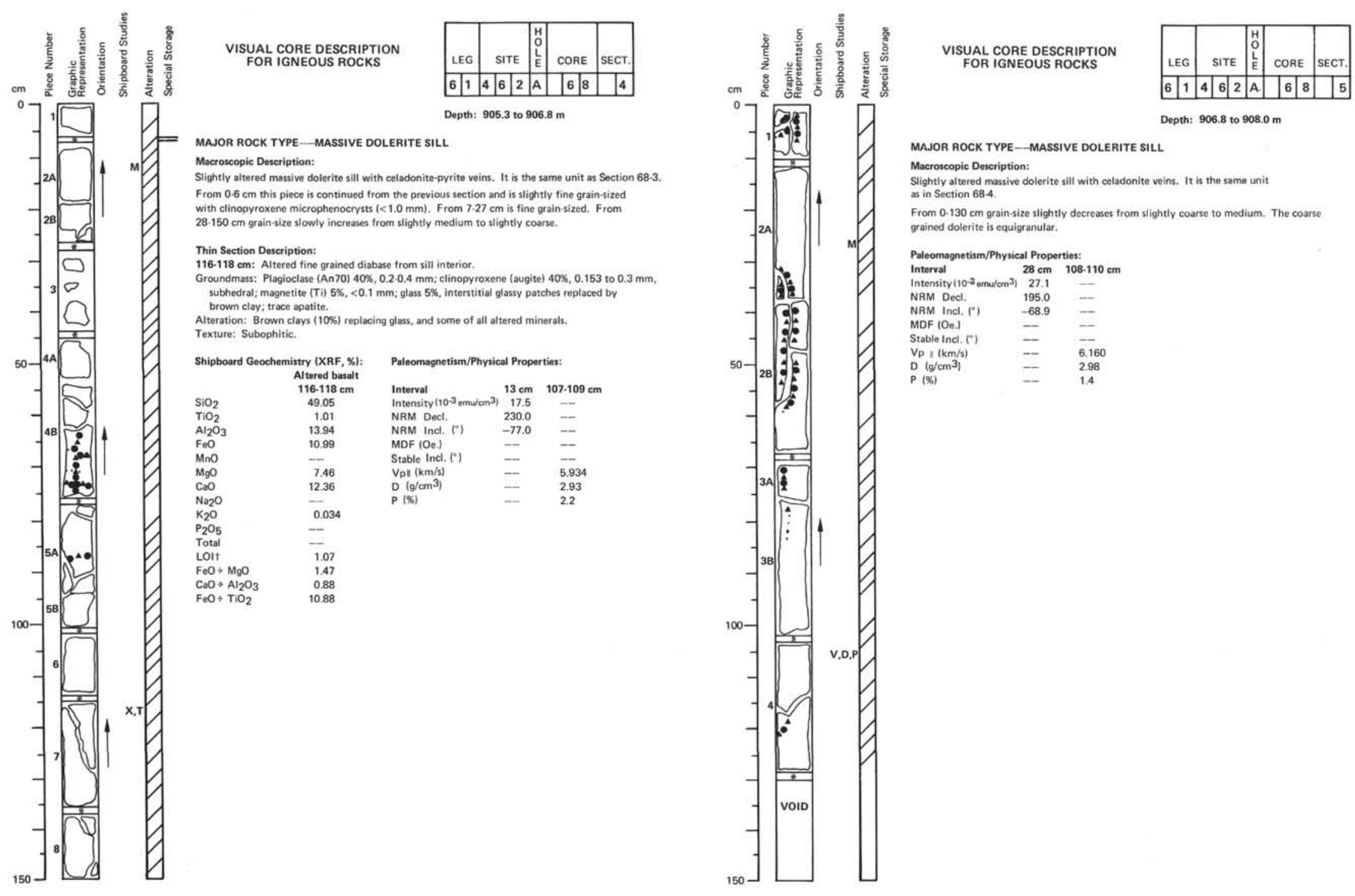

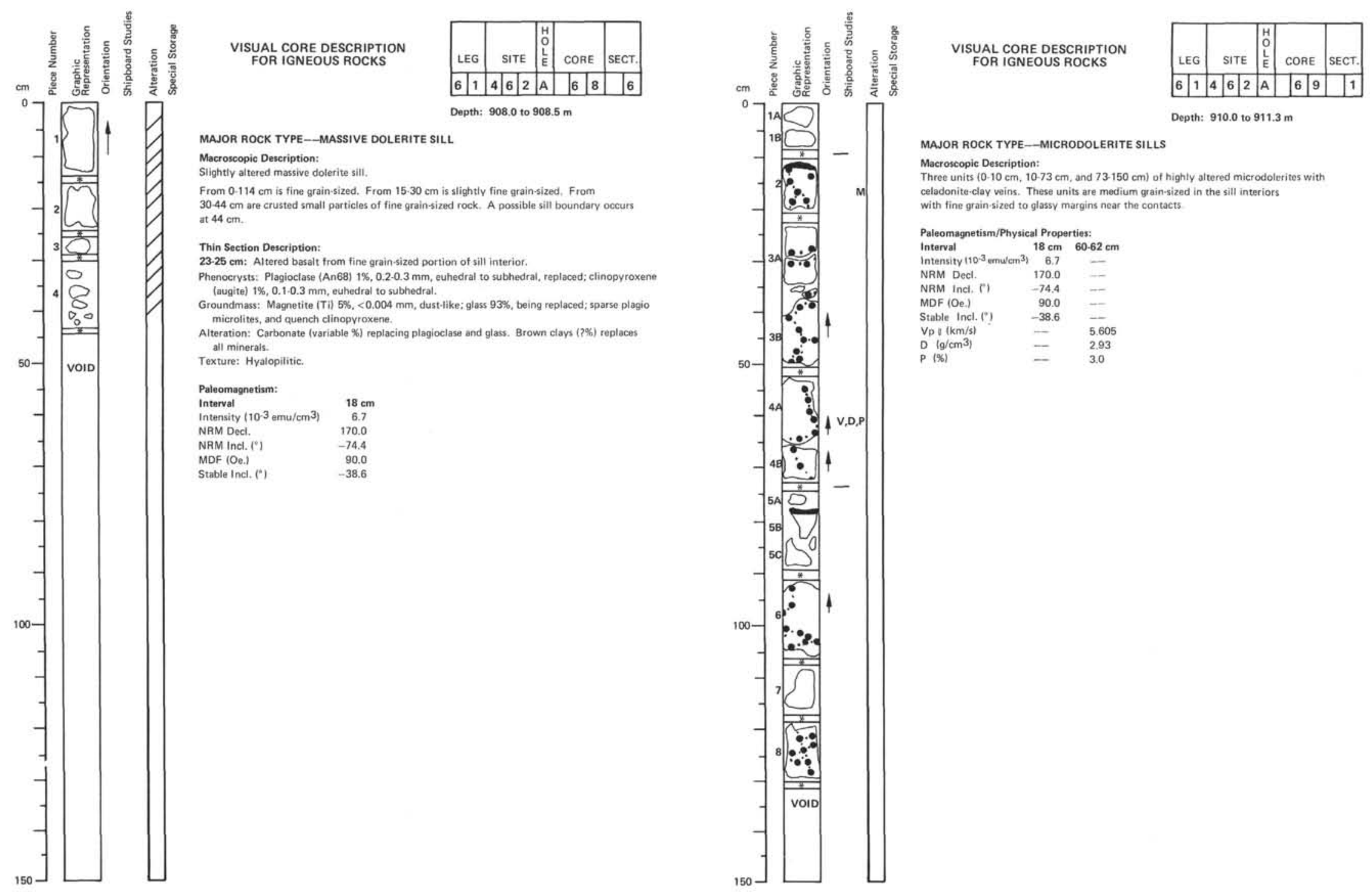

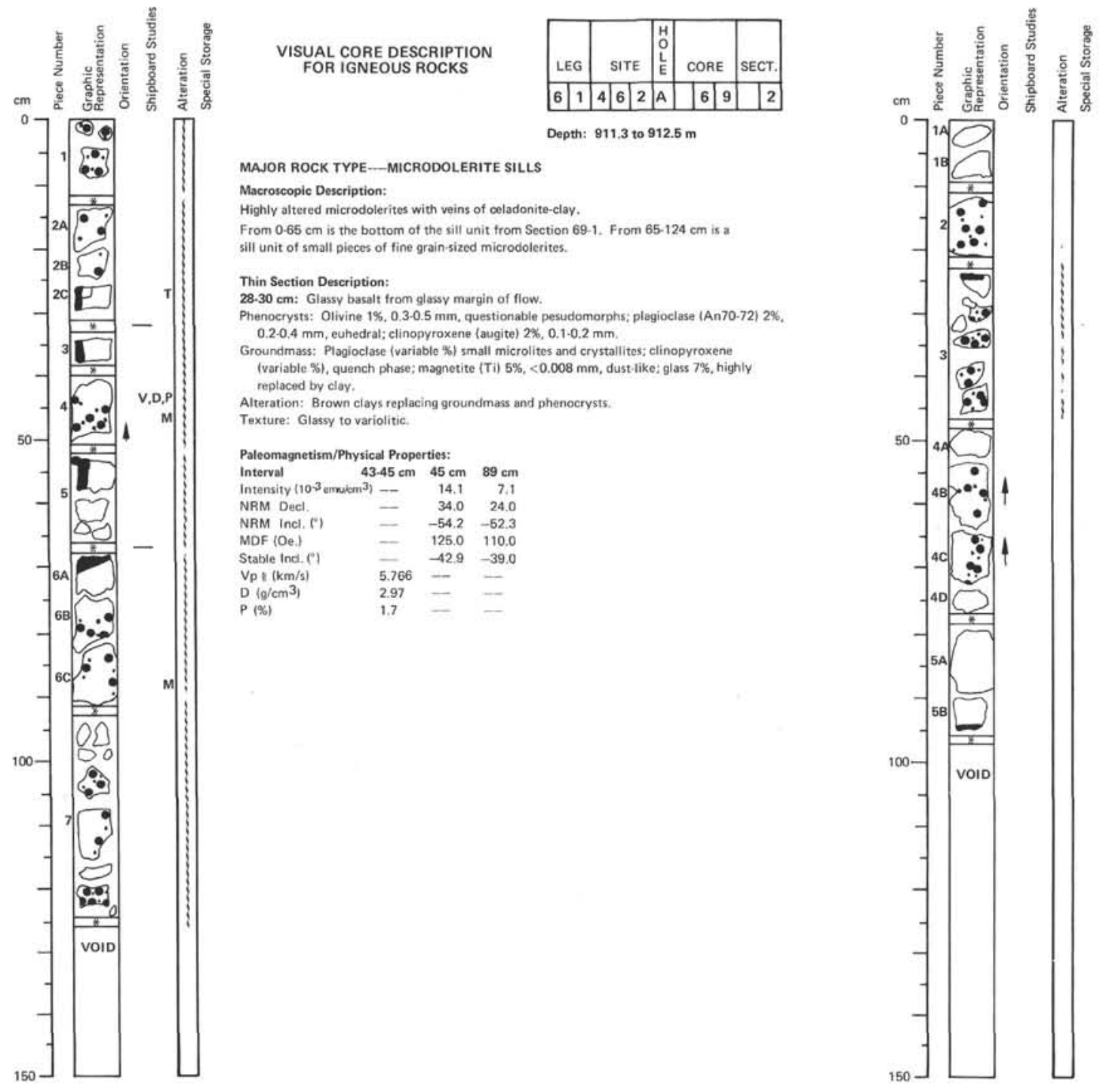

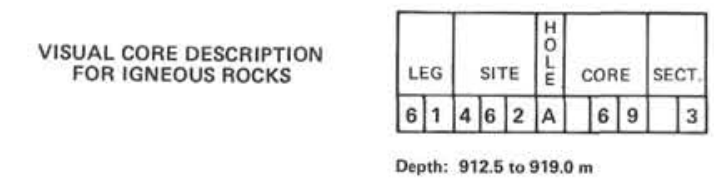

MAJOR ROCK TYPE-MICRODOLERITES

Macroscopic Description:

Two units $(0.21 \mathrm{~cm}$ and $21.95 \mathrm{~cm})$ of highly altered microdolerites with veirs of celadonite-clay.

Highly altered microdolerites with veins of oeladonite-clay

From $0.65 \mathrm{~cm}$ is the bottom of the sill unit from Section $69-1$. From $65-124 \mathrm{~cm}$ is

-

Thin Section Description

Phenocrysts: Olivine $1 \%, 0.3-0.5 \mathrm{~mm}$, questionable pesudomorph

Groundmass: Plagioclase (variable \%) small microlites and crystallites: clinopyroxene

replaced by clay.

Alteration: Brown clays replacing groundmass and phenocrysts.

Glassy to variolitic.

Paleomagnetism/Physical Properties:
Interval
$43.45 \mathrm{~cm} \quad 45 \mathrm{~cm} \quad 89 \mathrm{~cm}$

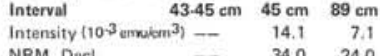

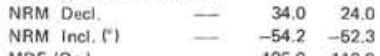

Stoplocil - 125.0110 .0

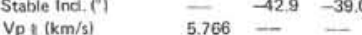

D $\left\{g / \mathrm{cm}^{3}\right\}$

$2.97=$

$P(\%)$

$$
\begin{aligned}
& \begin{array}{l}
\text { Physical Properties: } \\
\text { Interval } 77.79 \text { o }
\end{array} \\
& \begin{array}{lr}
\text { Interval } & 77.79 \mathrm{~cm} \\
V_{p} \|(\mathrm{km} / \mathrm{s}) & 5.780
\end{array} \\
& \begin{array}{ll}
\mathrm{D}\left(\mathrm{g} / \mathrm{cm}{ }^{3}\right) & 2.97 \\
\mathrm{P}\left(\xi_{0}\right) & 1.8
\end{array}
\end{aligned}
$$



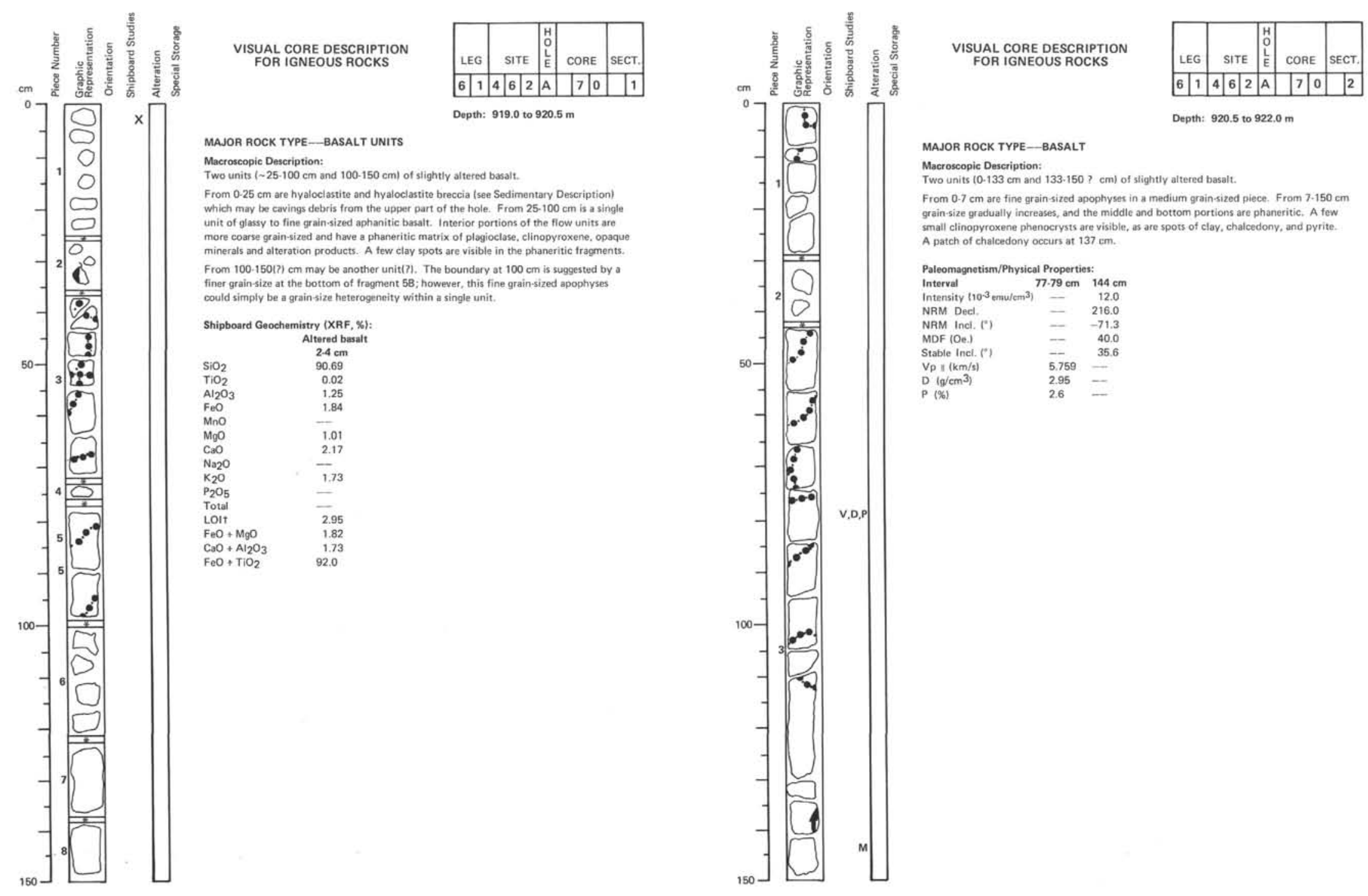

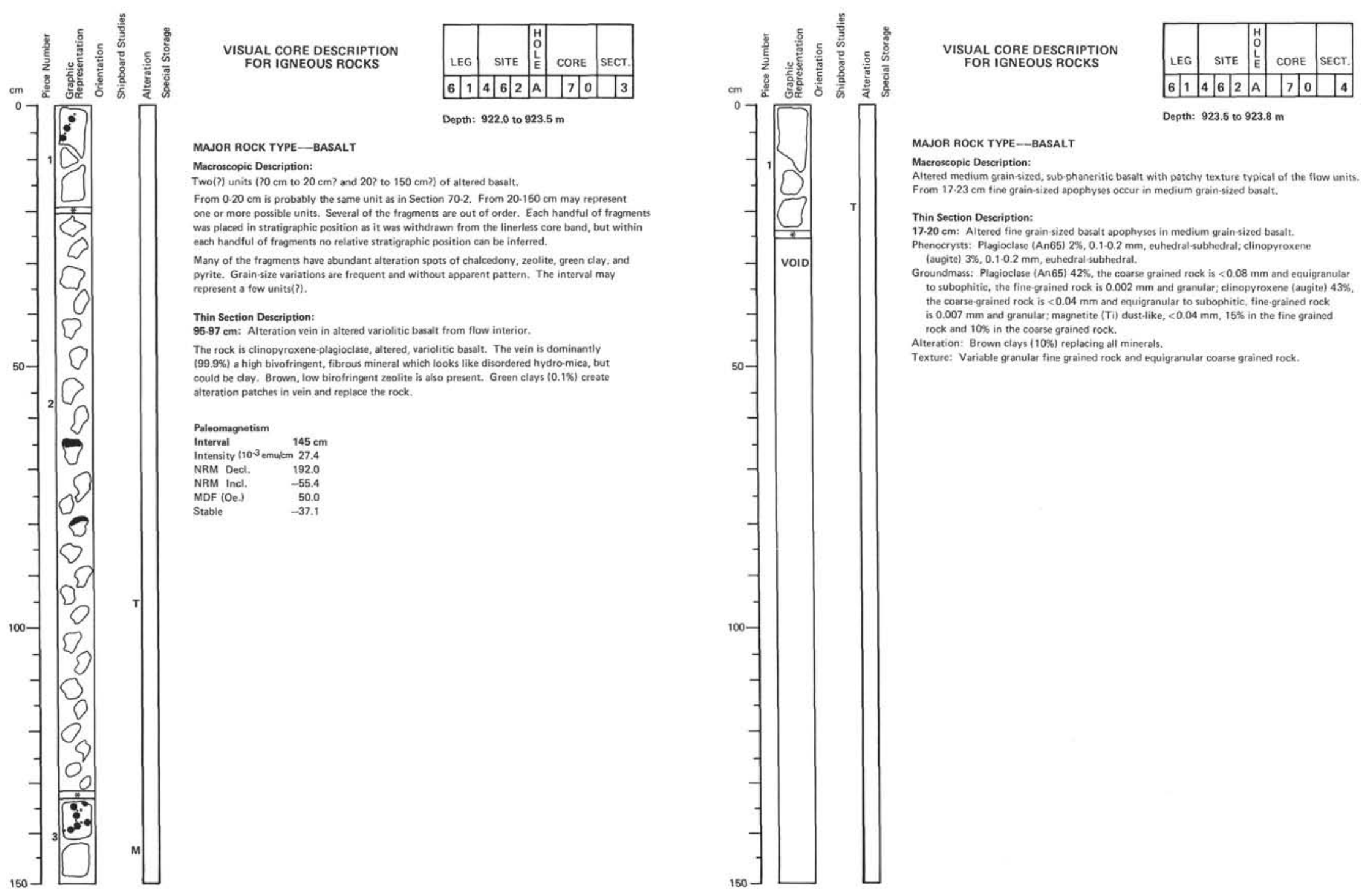

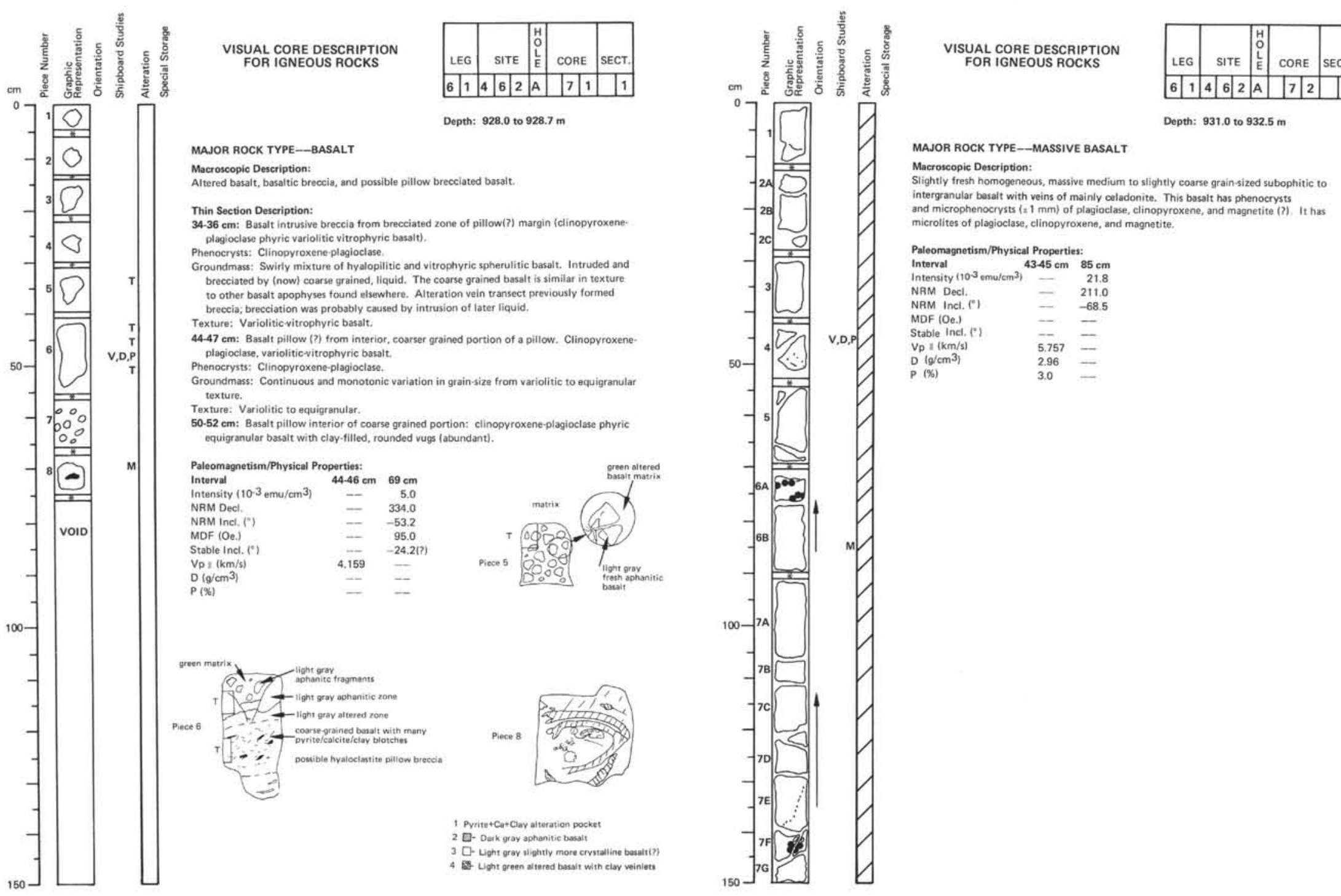

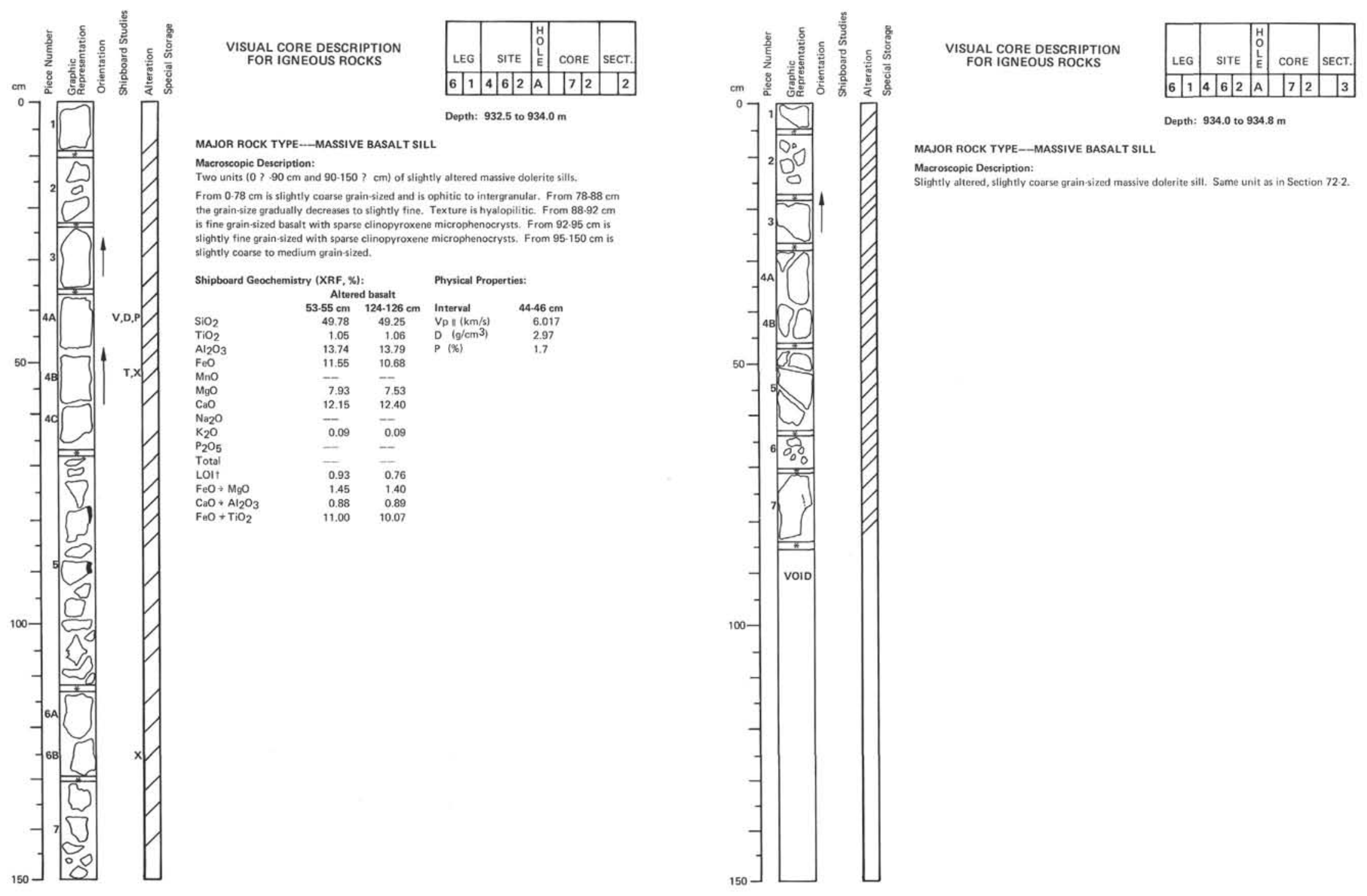

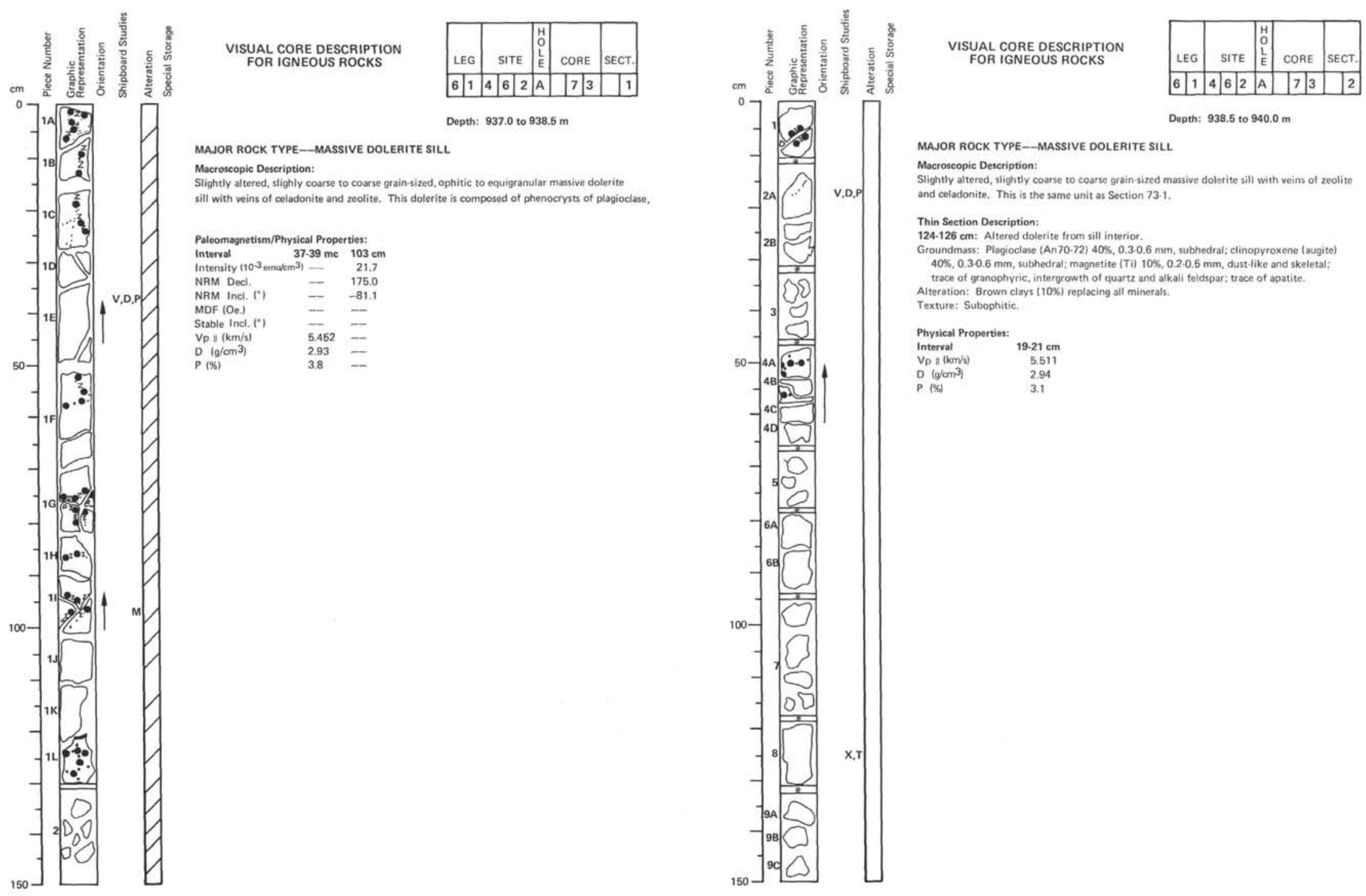

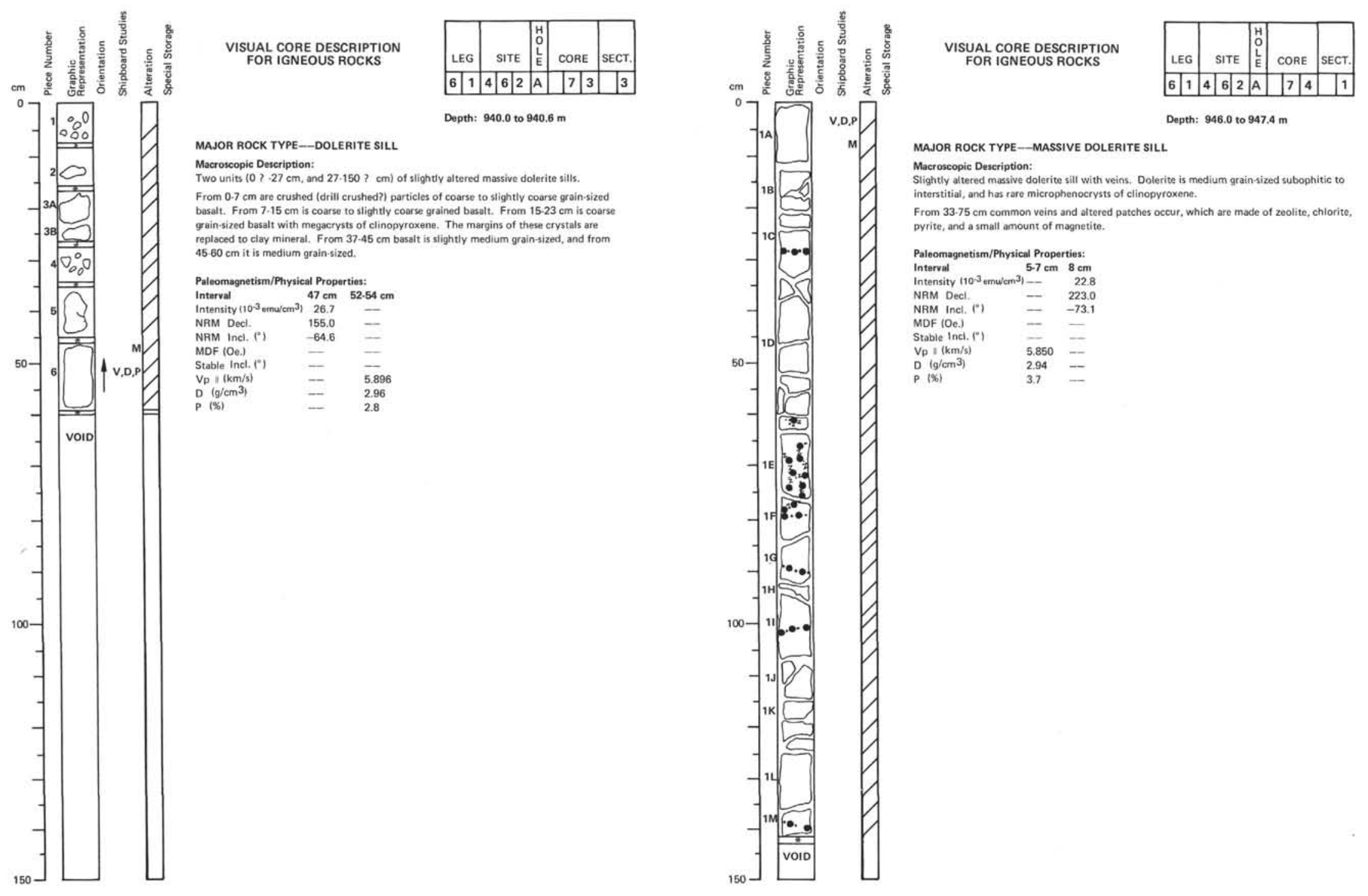

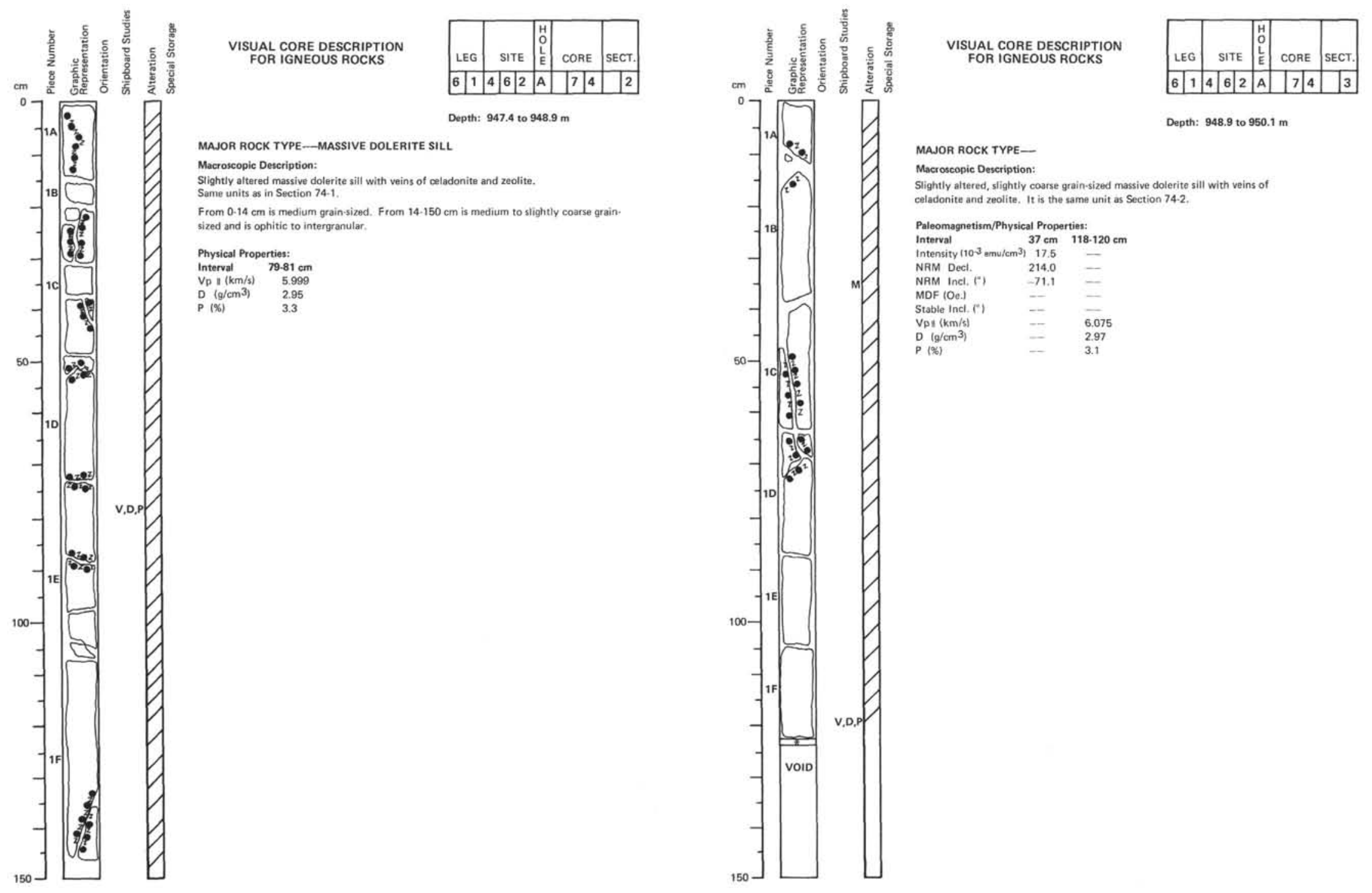

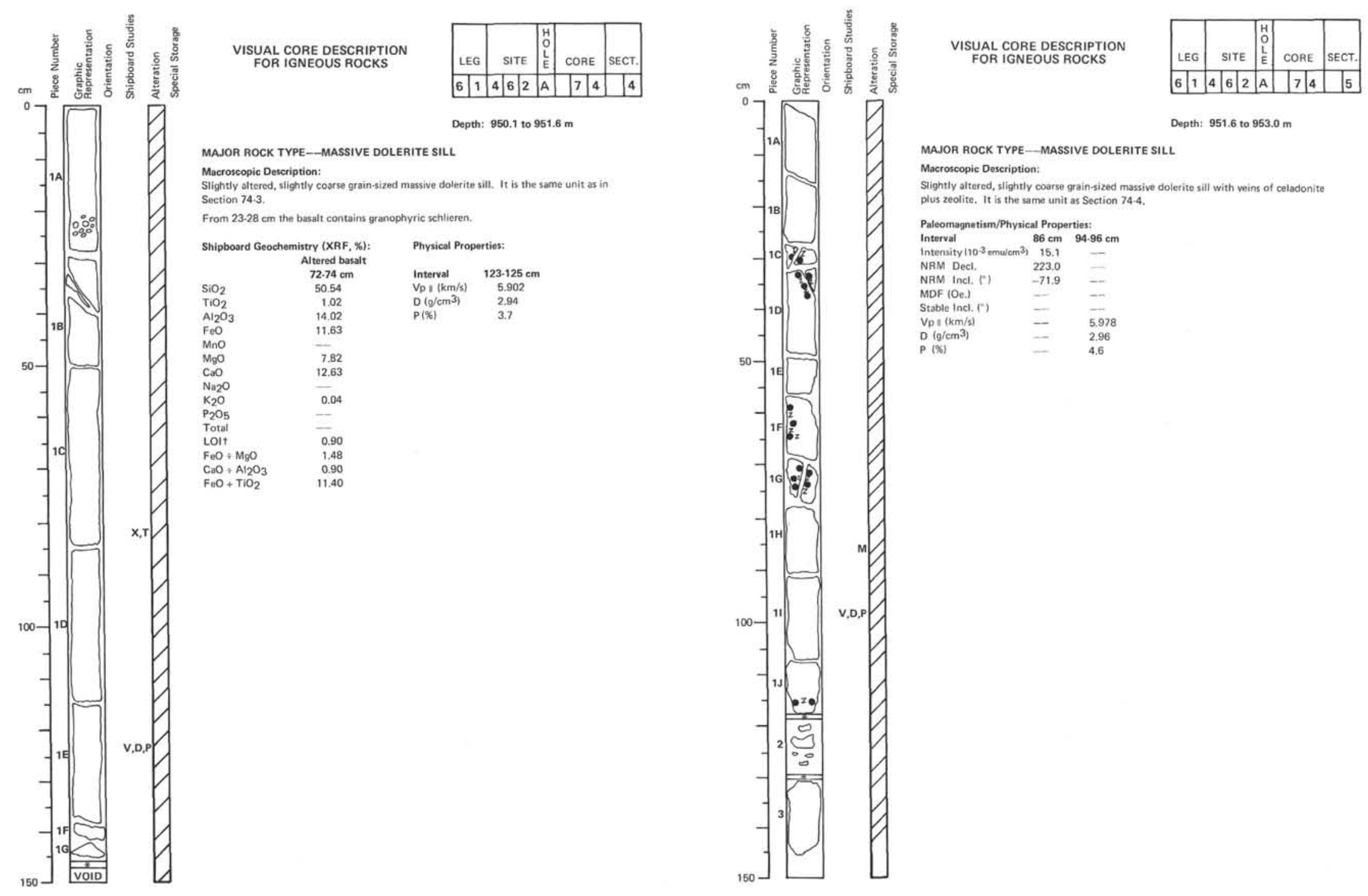

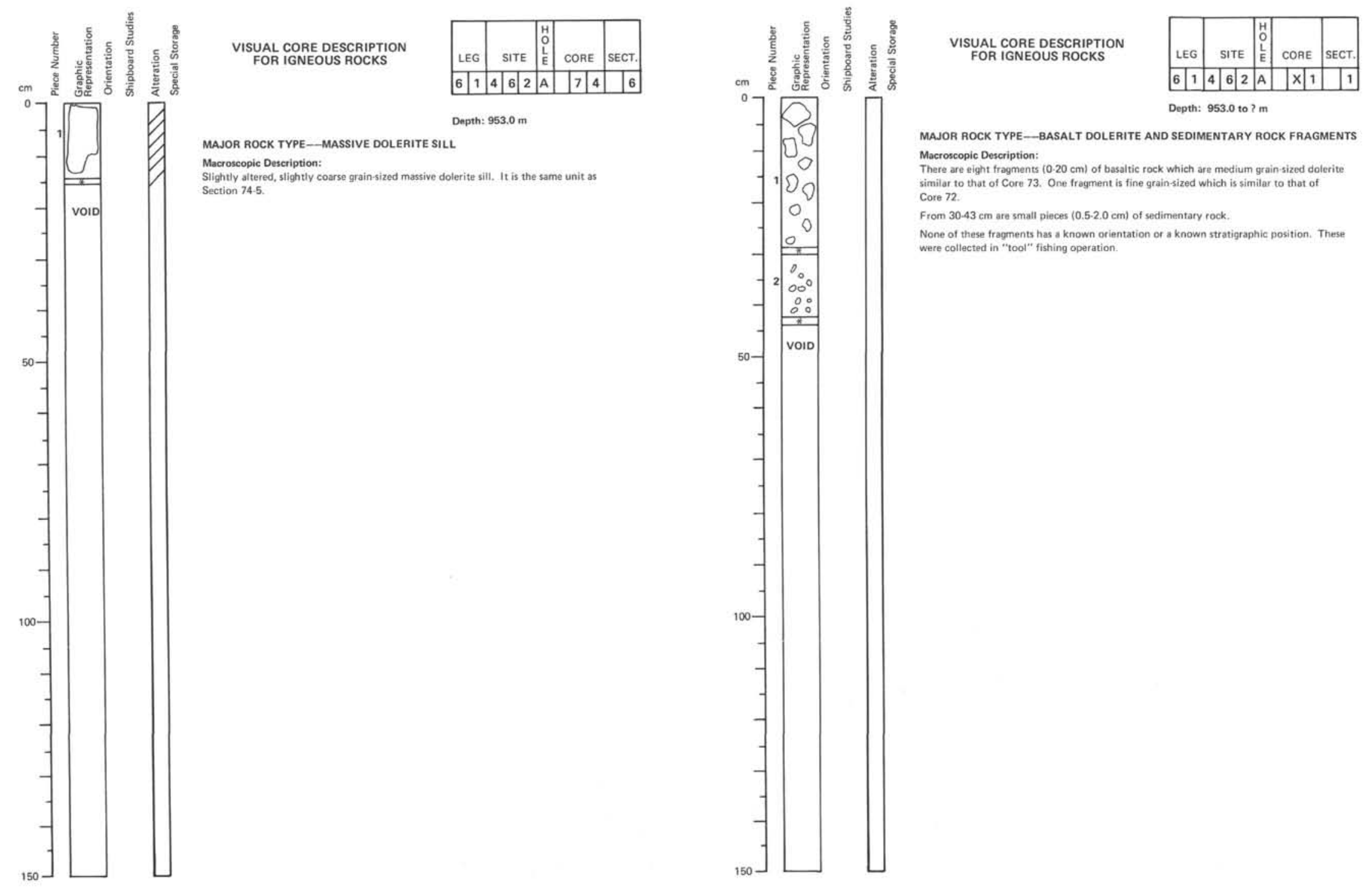

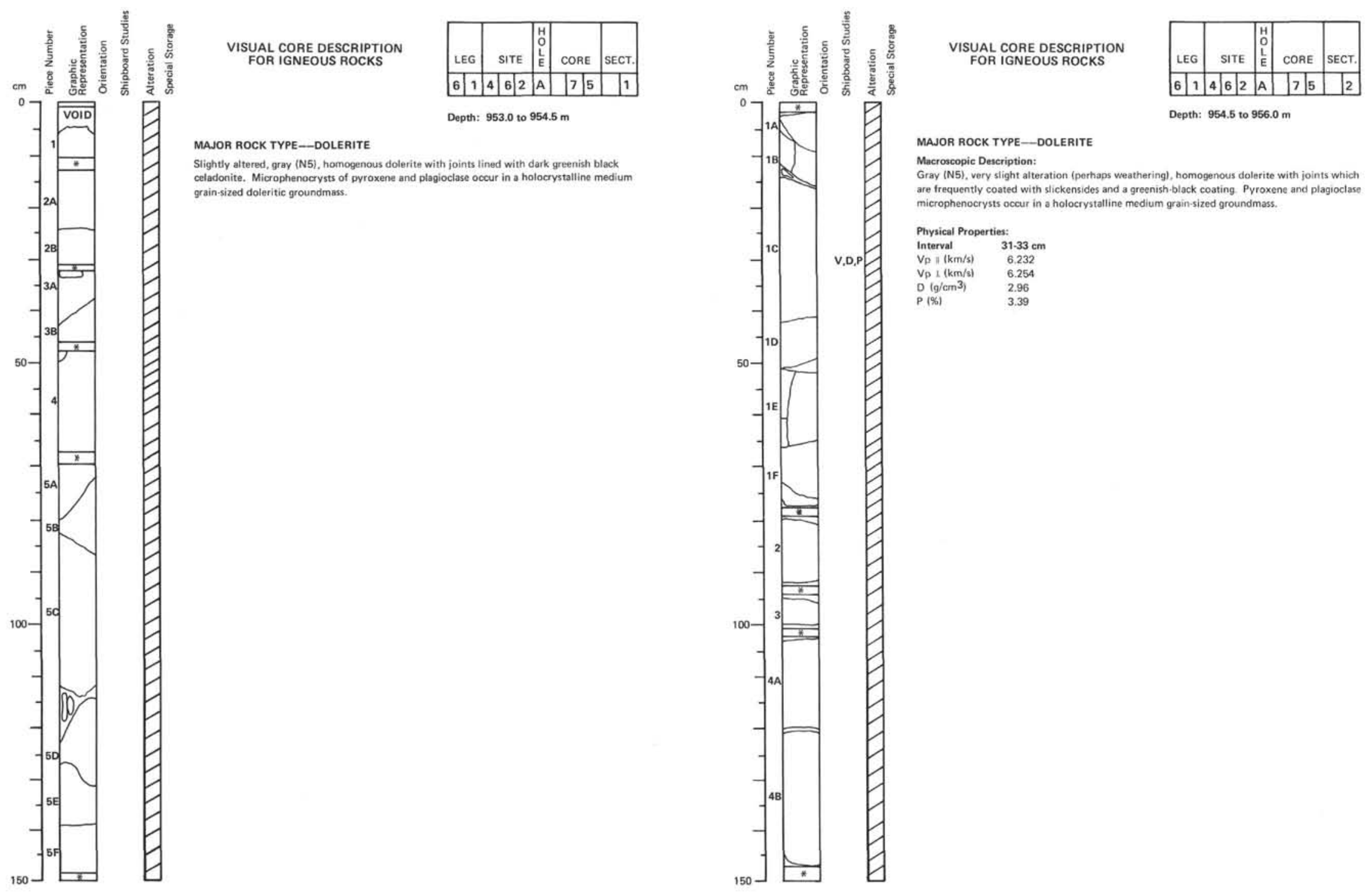

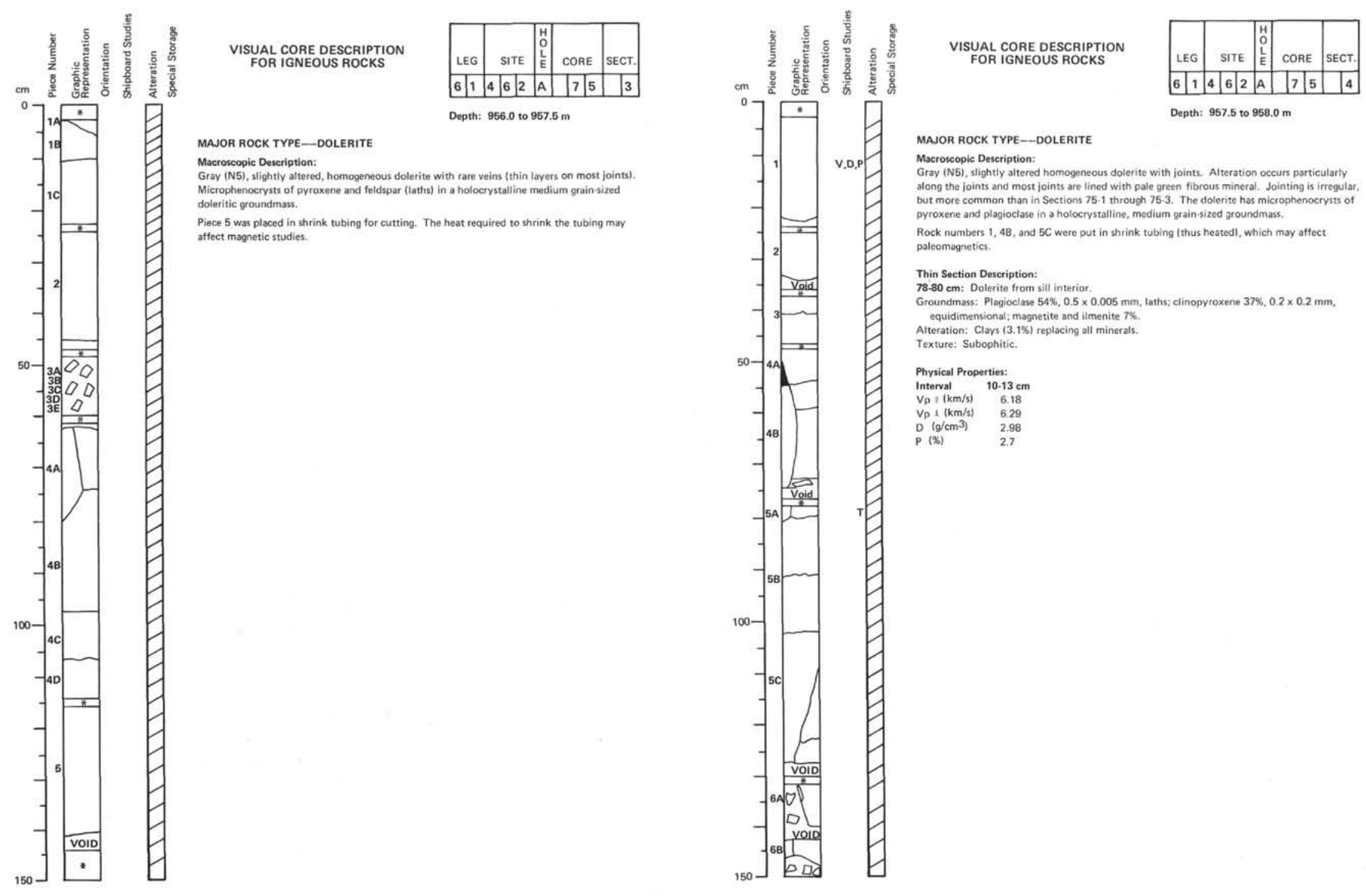

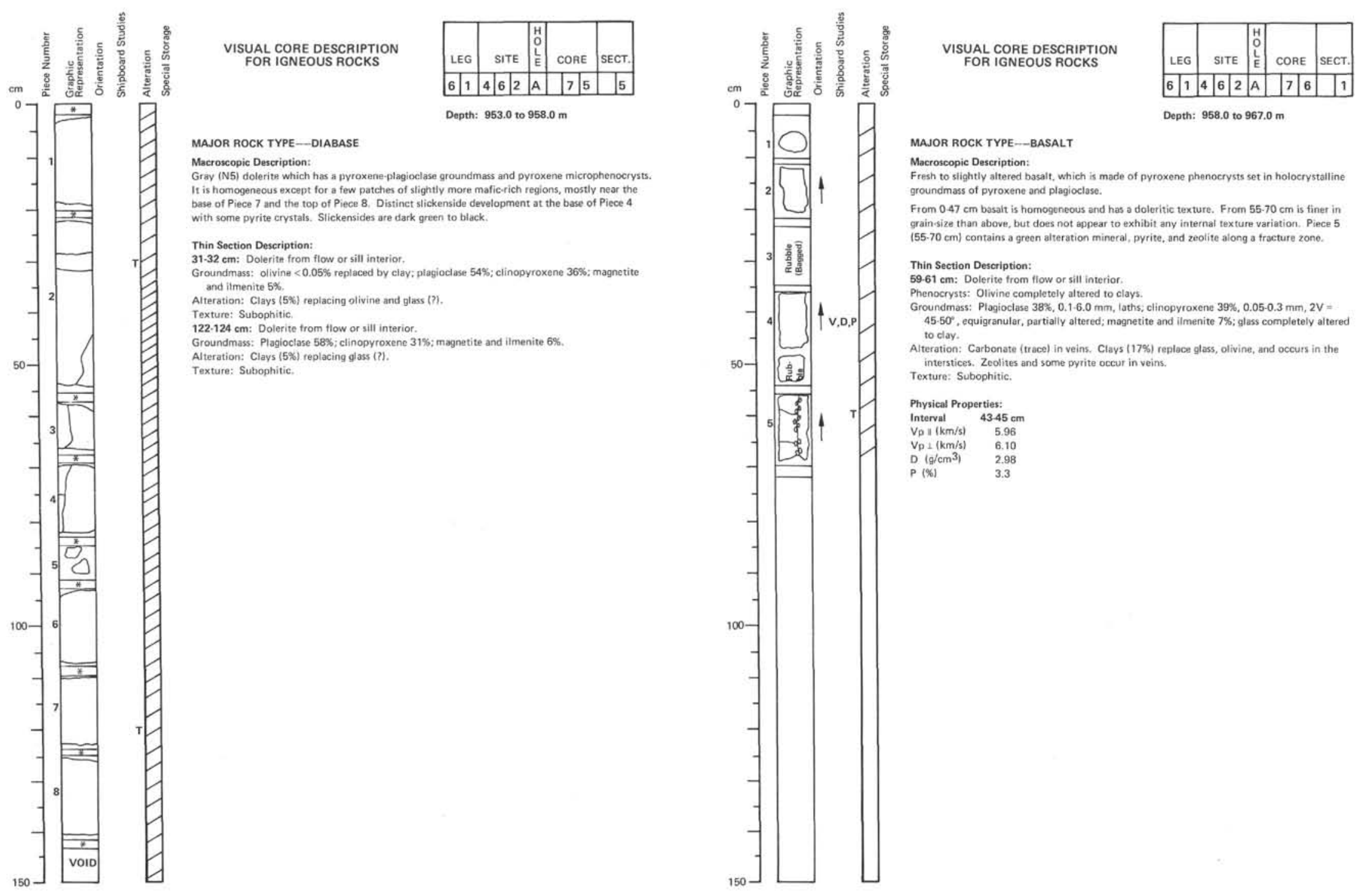

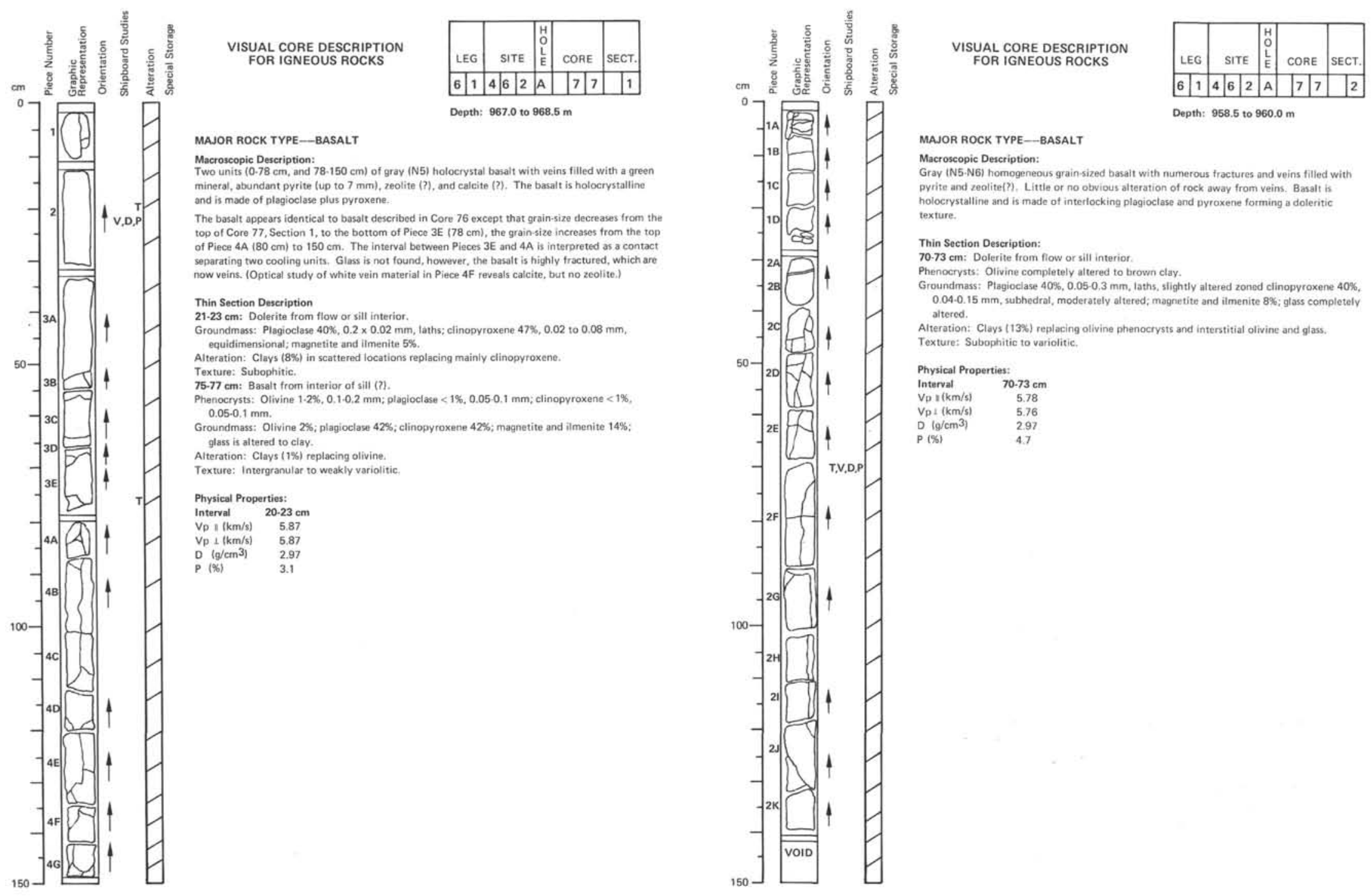


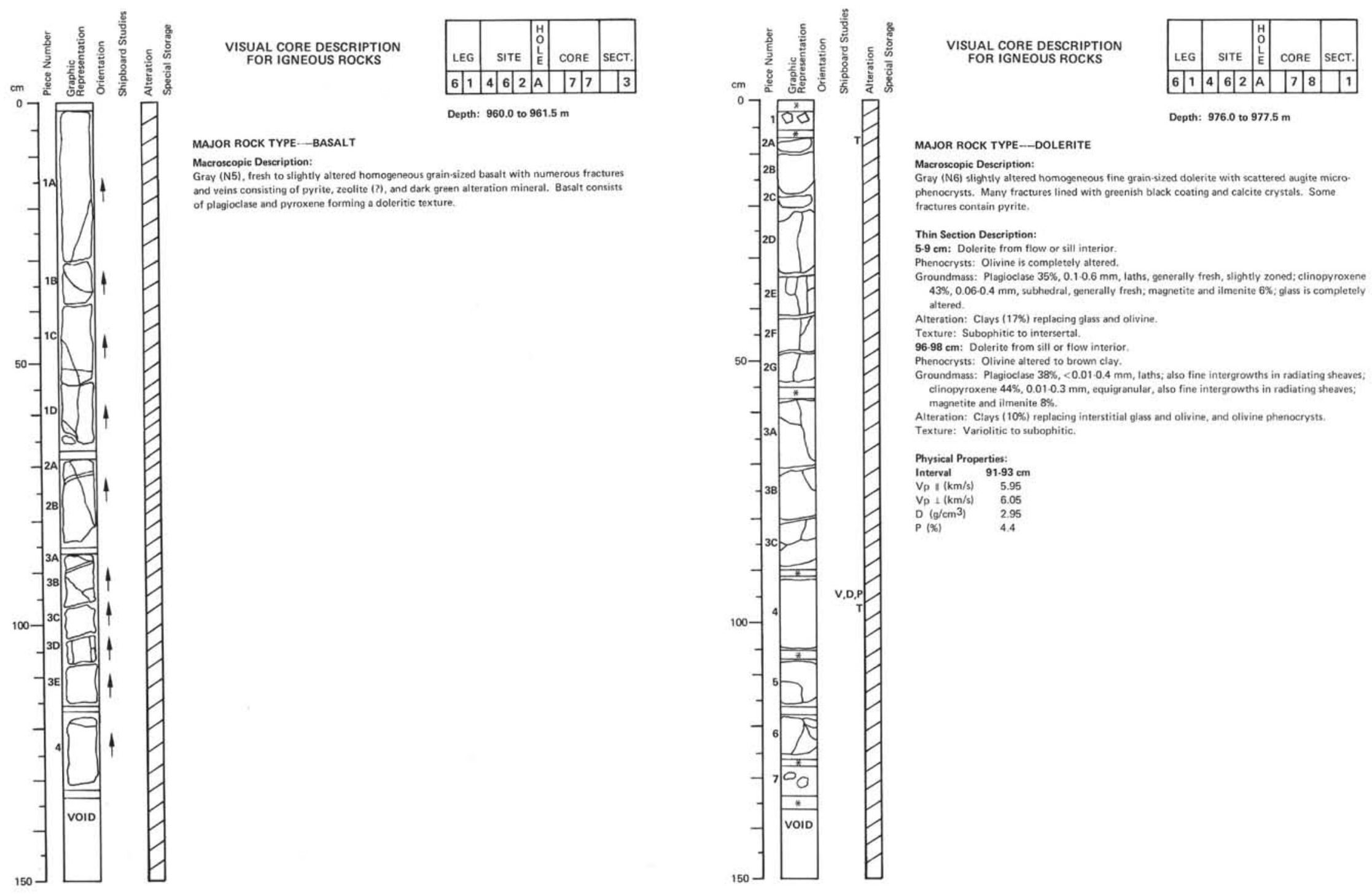



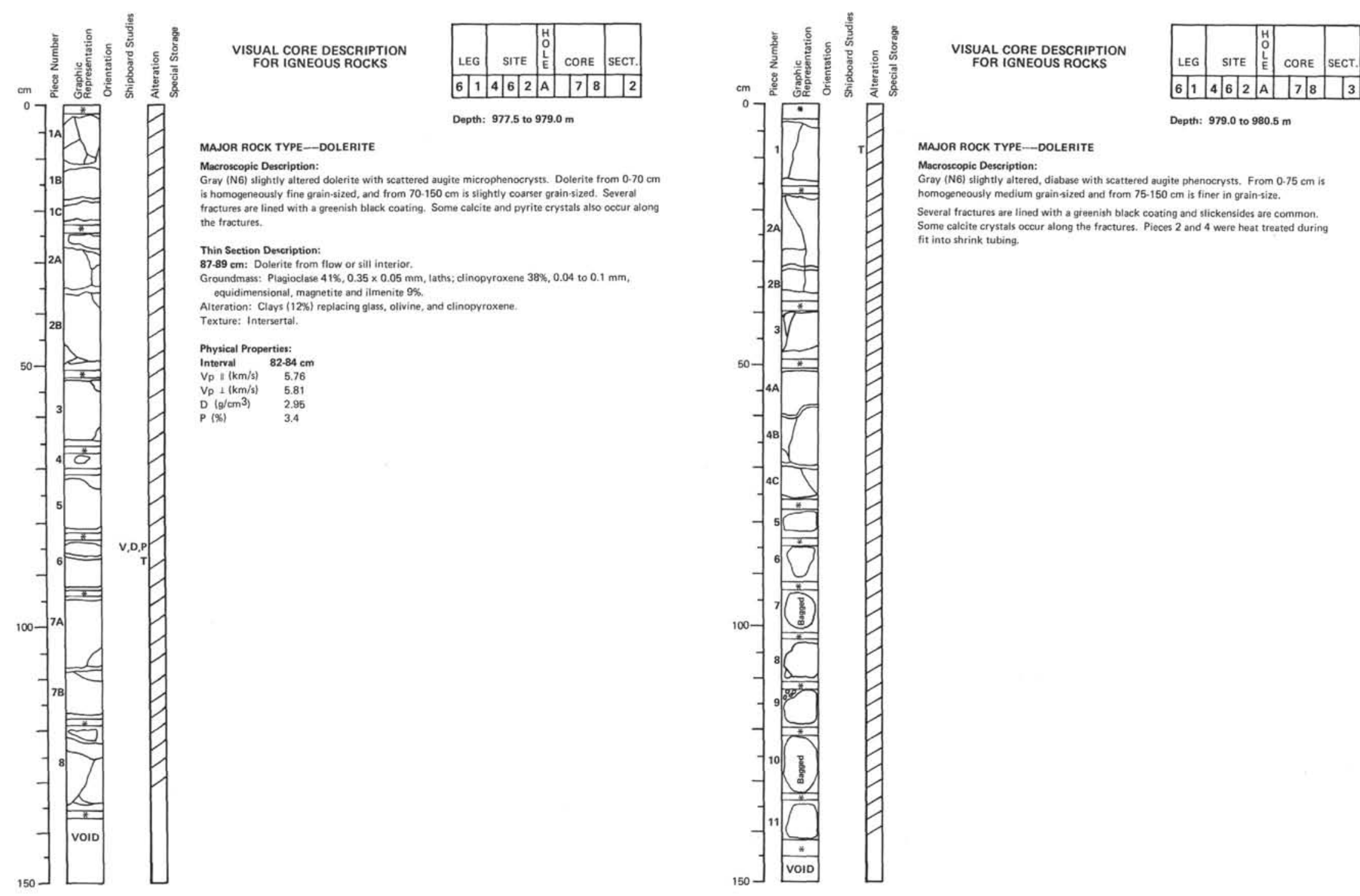

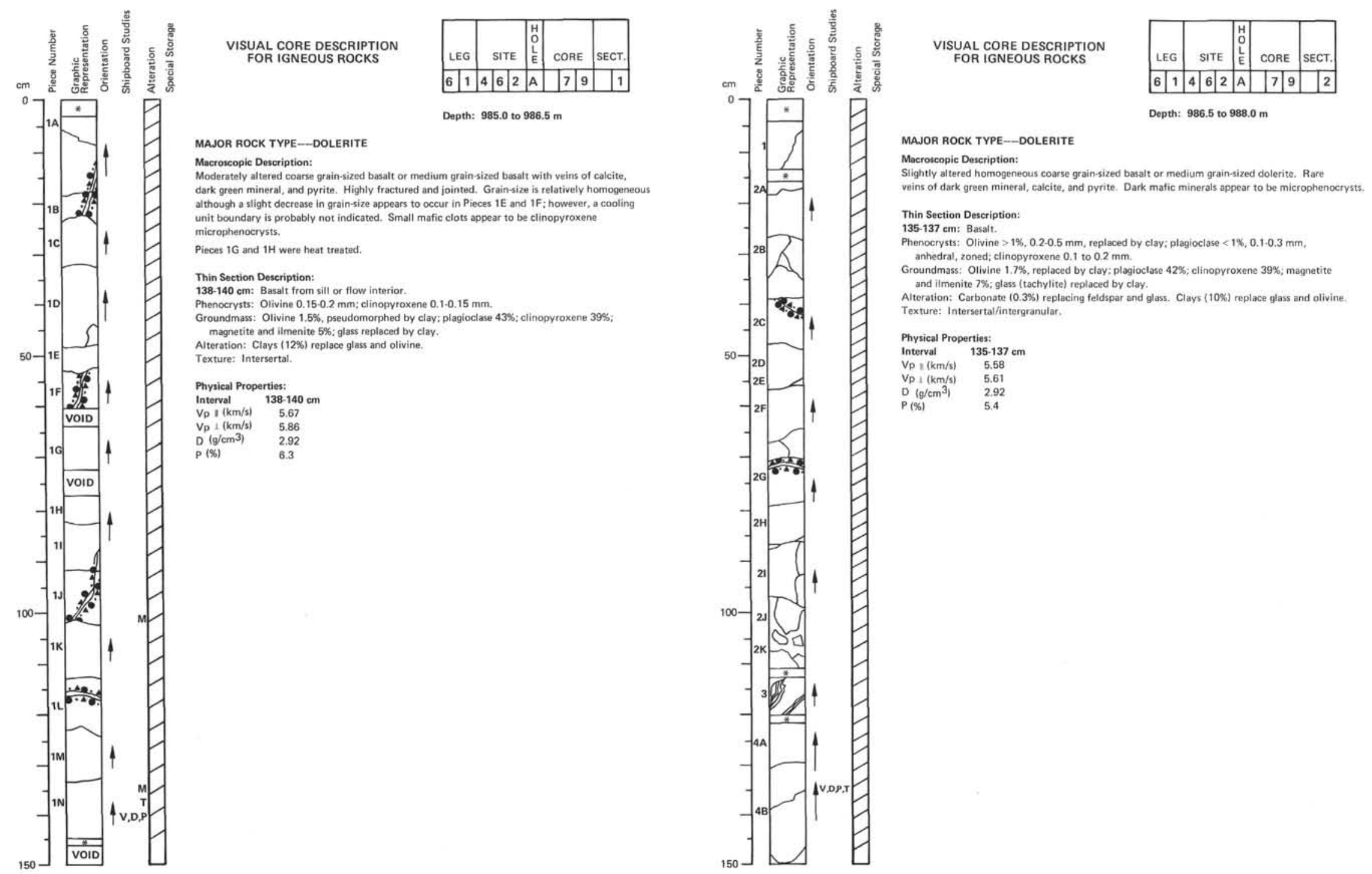

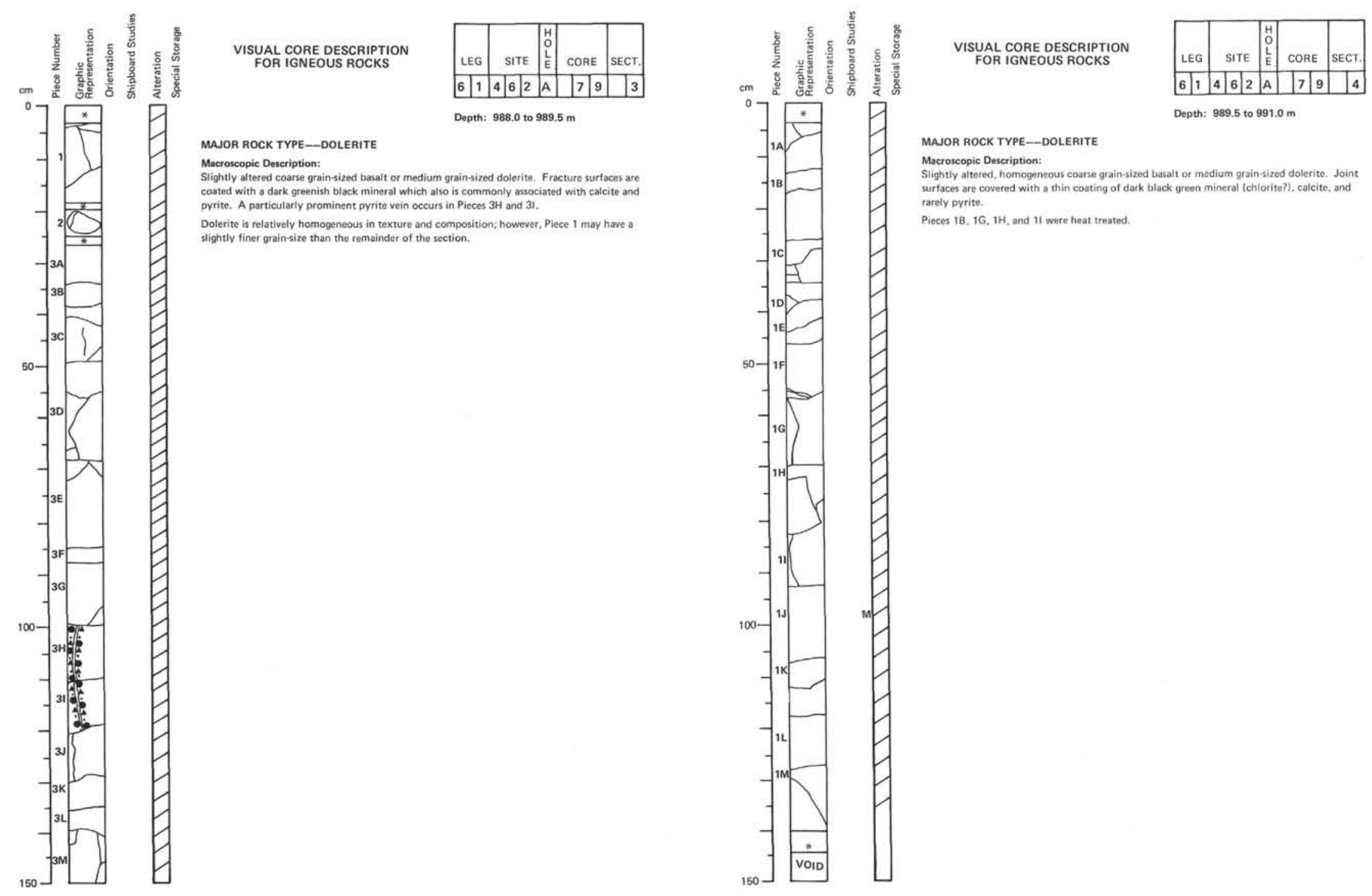


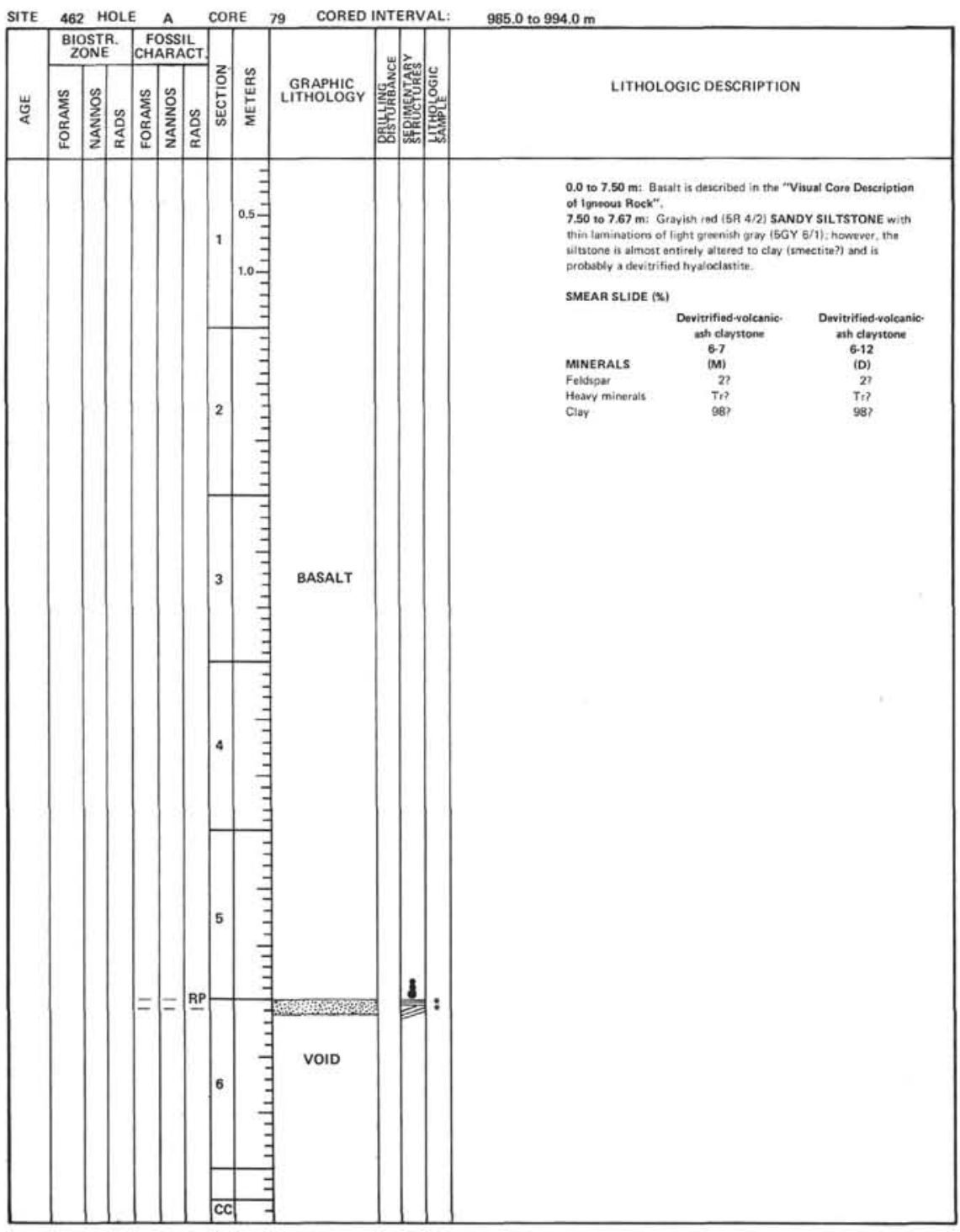



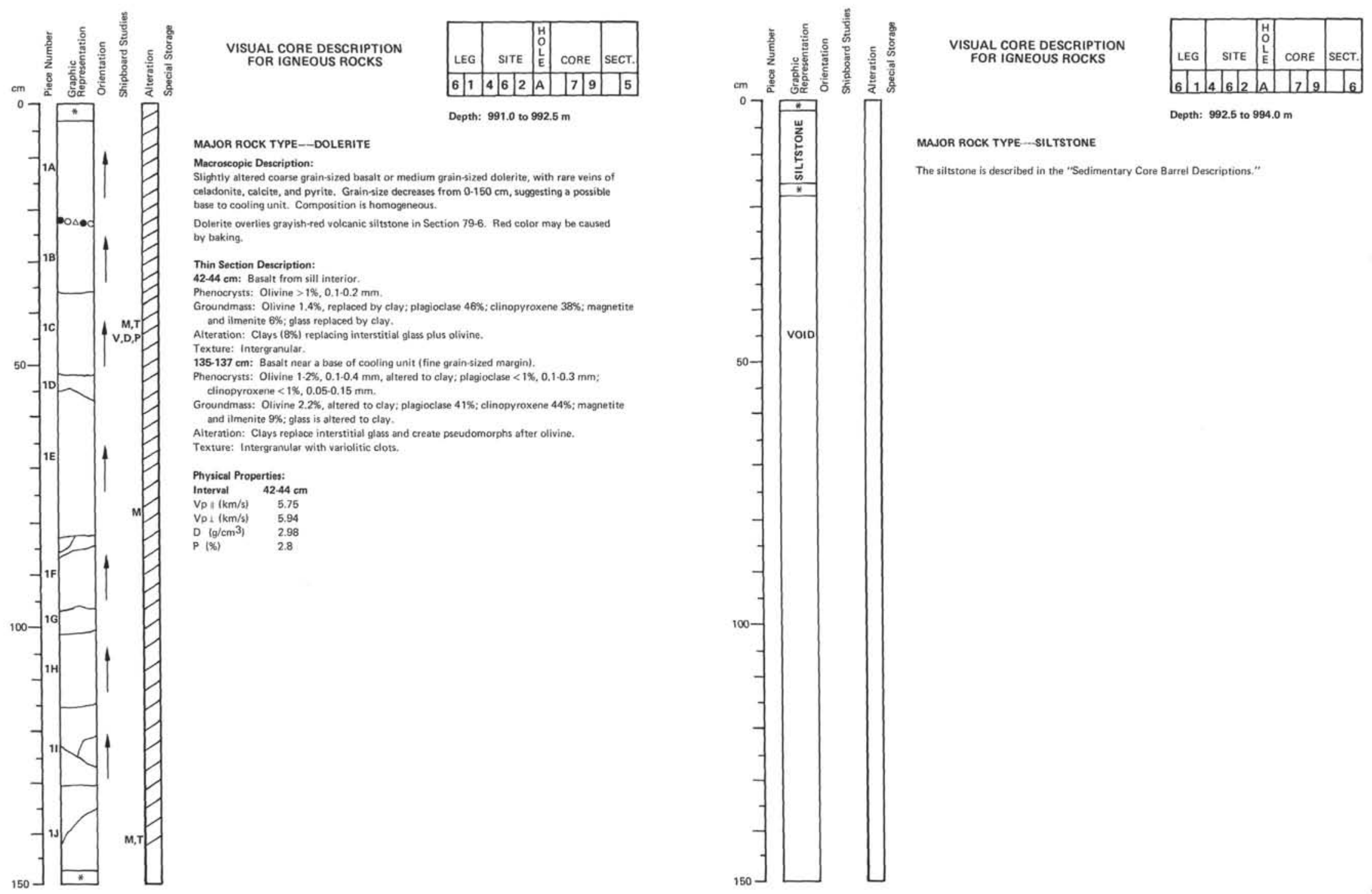

MAJOR ROCK TYPE - SILTSTONE

Depth: 992.5 to $994.0 \mathrm{~m}$

The siltstone is described in the "Sedimentary Core Barrel Descriptions." 


\begin{tabular}{|c|c|c|c|c|c|c|c|c|}
\hline & & & E A & $\mathrm{cor}$ & & COAED II & INTERVAL & 34.0 to $998.0 \mathrm{~m}$ \\
\hline 岁 & 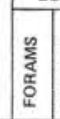 & $\frac{\sum_{2}^{2}}{2}$ & 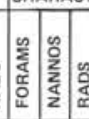 & 总 & 总 & $\begin{array}{l}\text { GRAPHIC } \\
\text { LITHOLOGY }\end{array}$ & 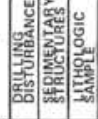 & LITHOLOGIC DESCRIPTION \\
\hline 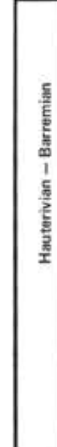 & & 施 & $\begin{array}{c}B \\
- \\
-\end{array}$ & 1 & & $\begin{array}{c}- \\
\\
\\
\text { BASALT }\end{array}$ & 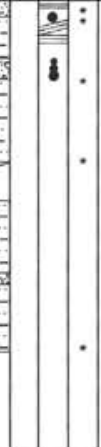 & 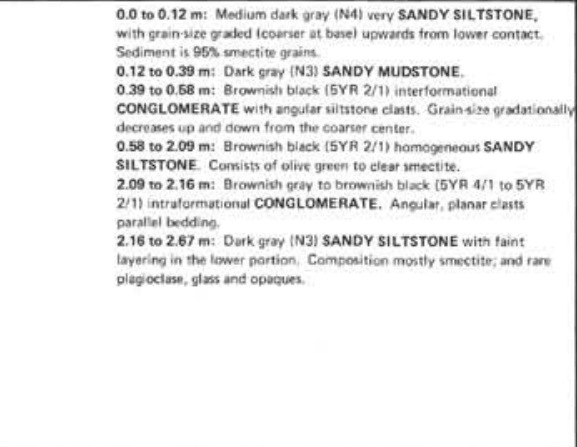 \\
\hline
\end{tabular}




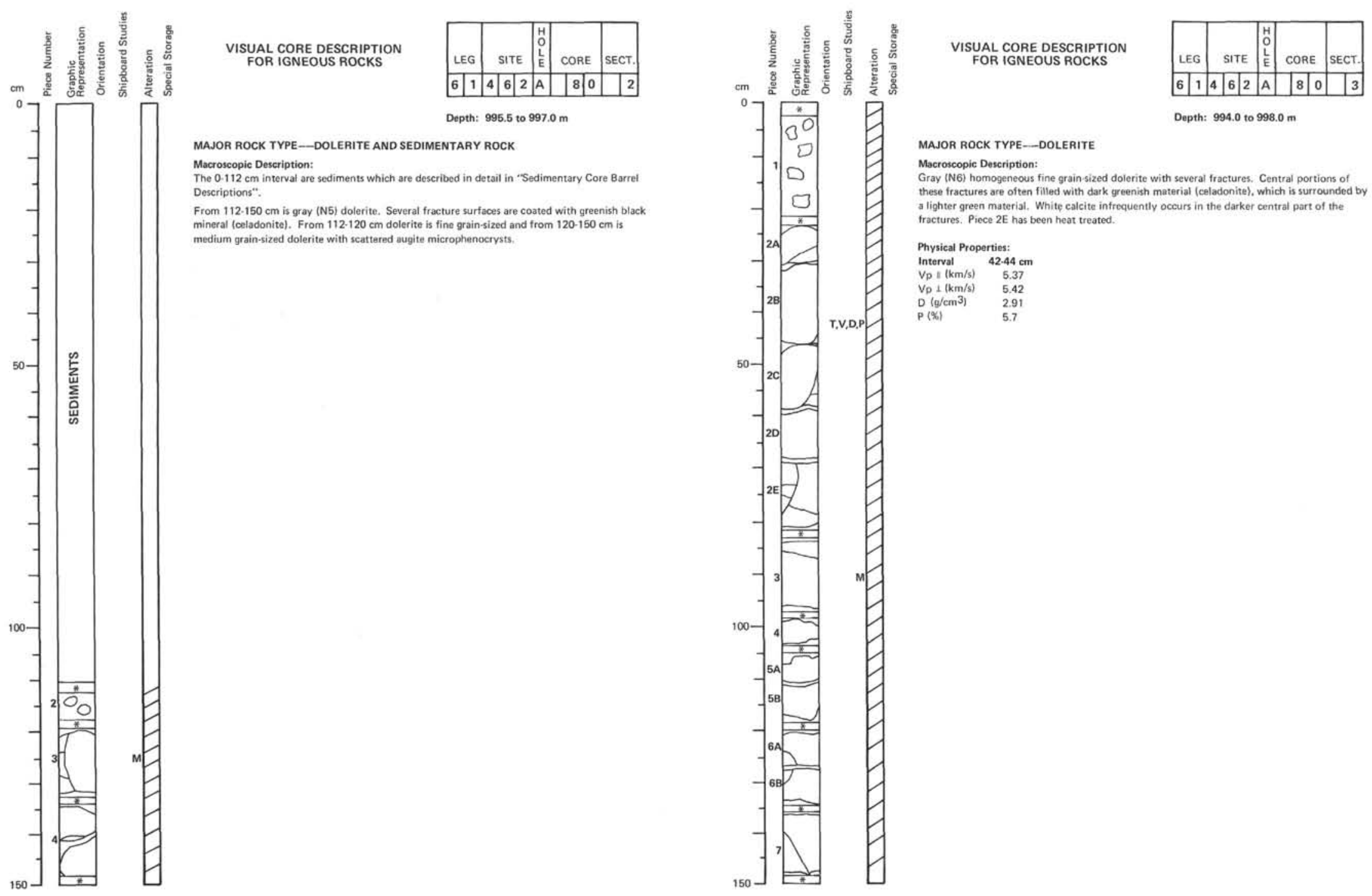




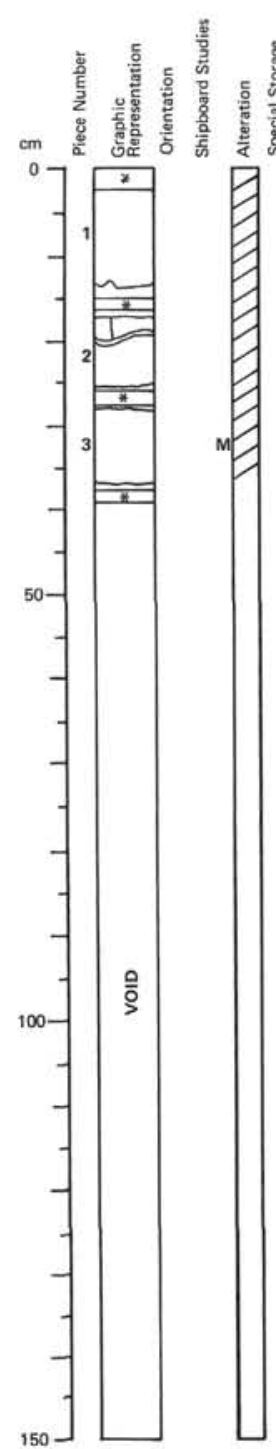

\section{VISUAL CORE DESCRIPTION FOR IGNEOUS ROCKS

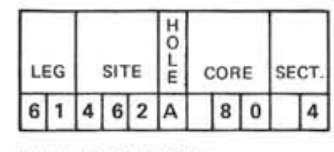

MAJOR ROCK TYPE--DOLERITE

Macroscopic Description:
Gray (NG) fine grain-sized homogeneous dolerite which has scattered augite mierophenocrysts.

Piece 2 has been heat treated.

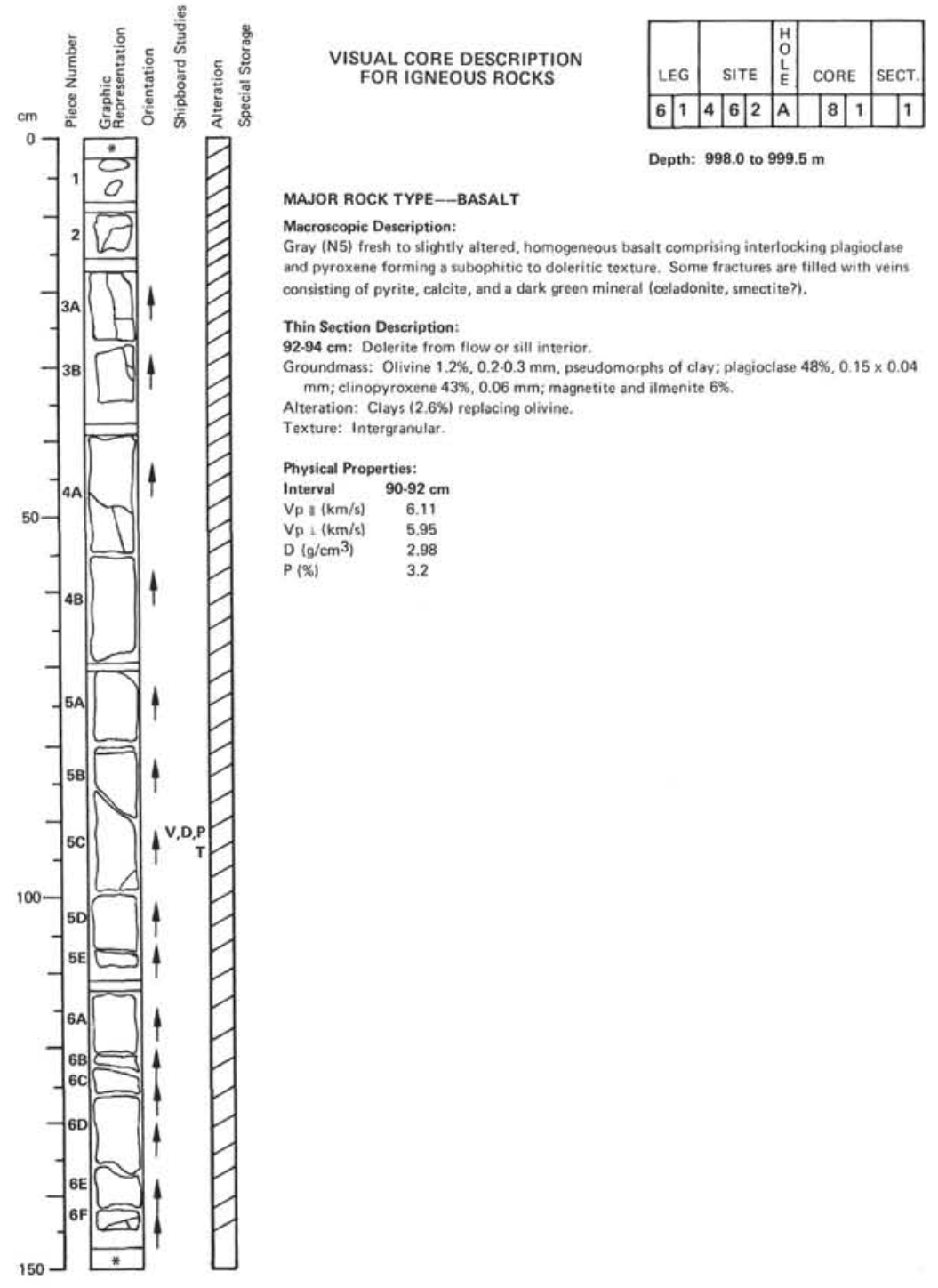



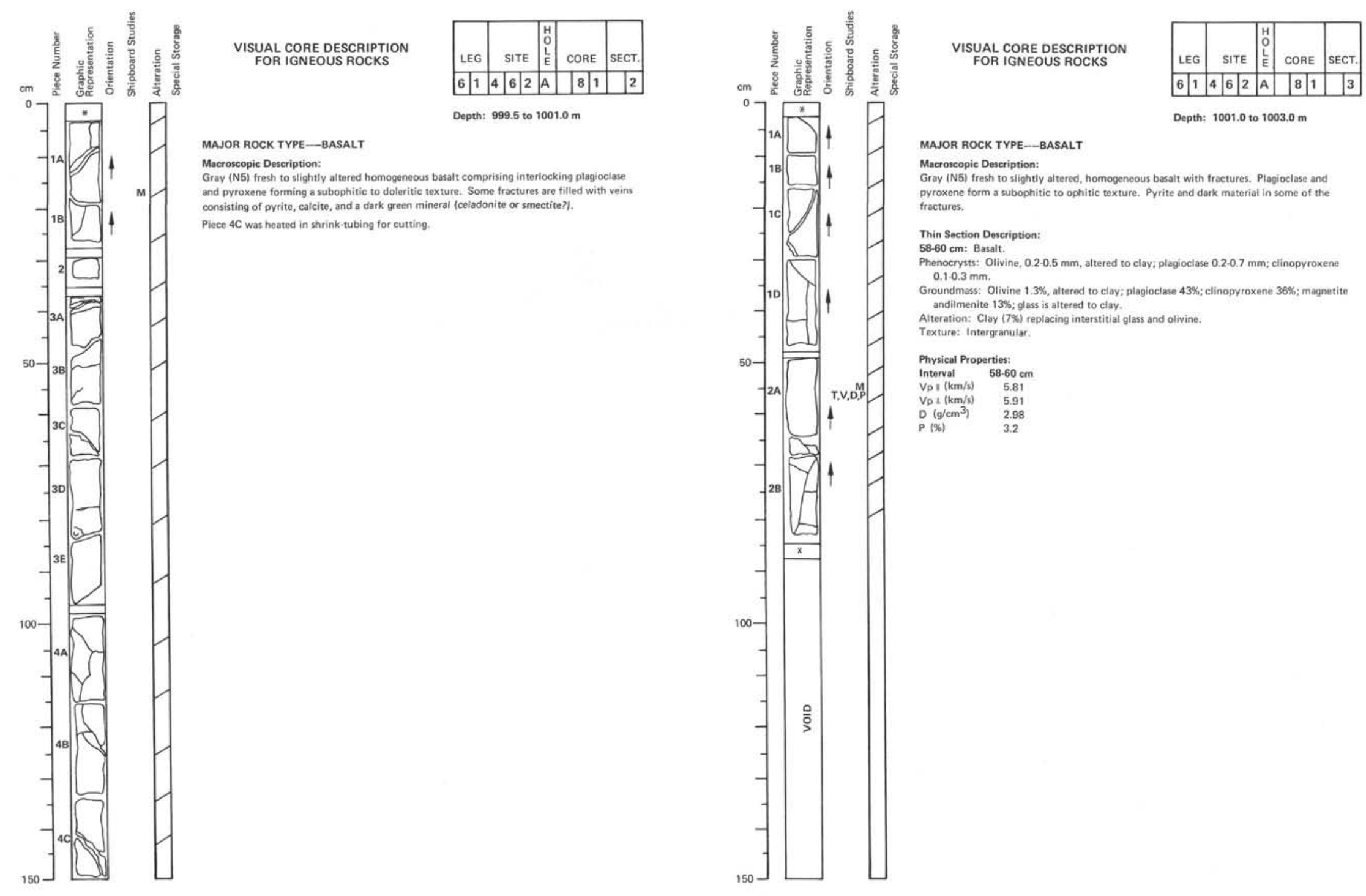

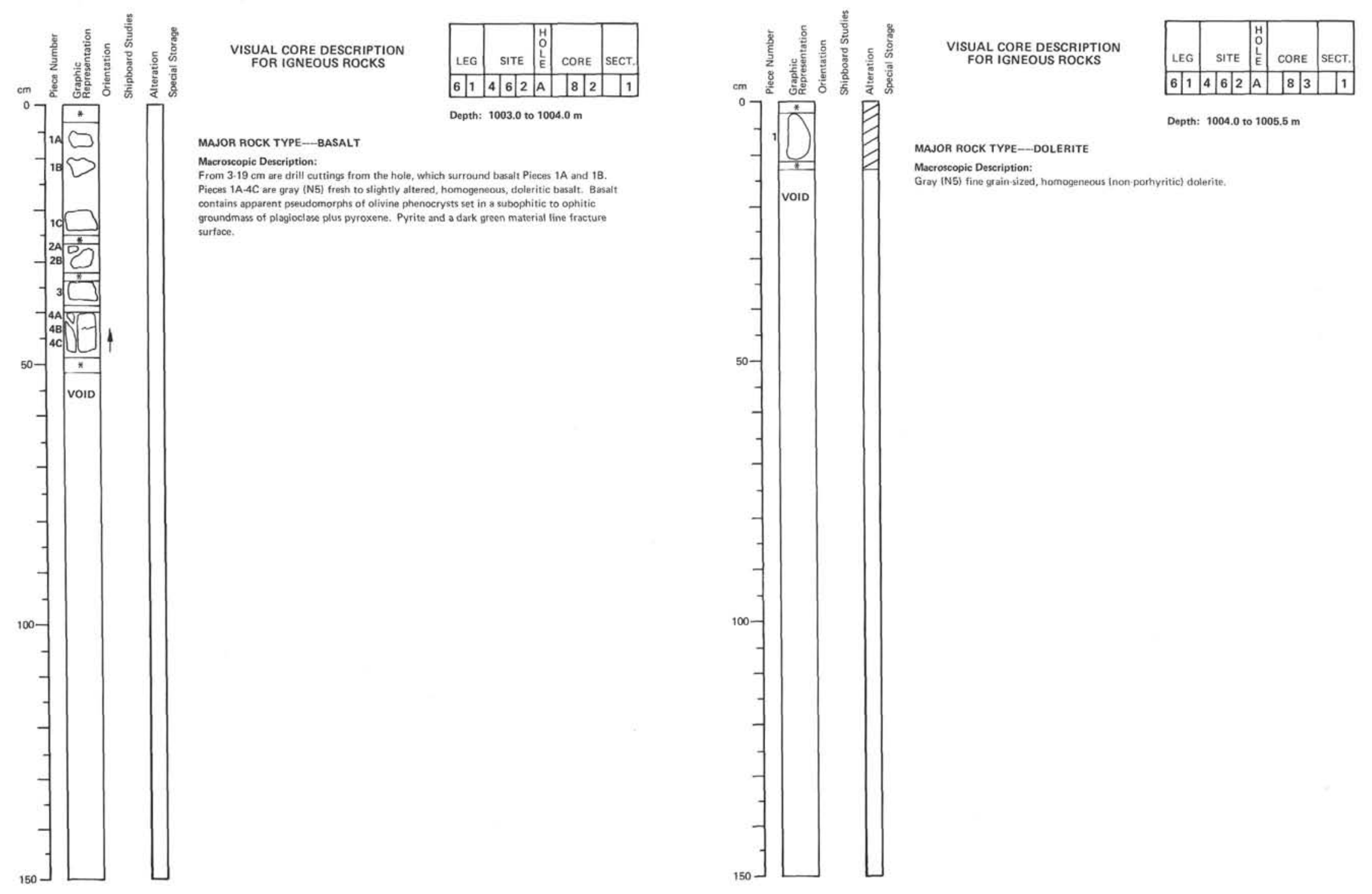

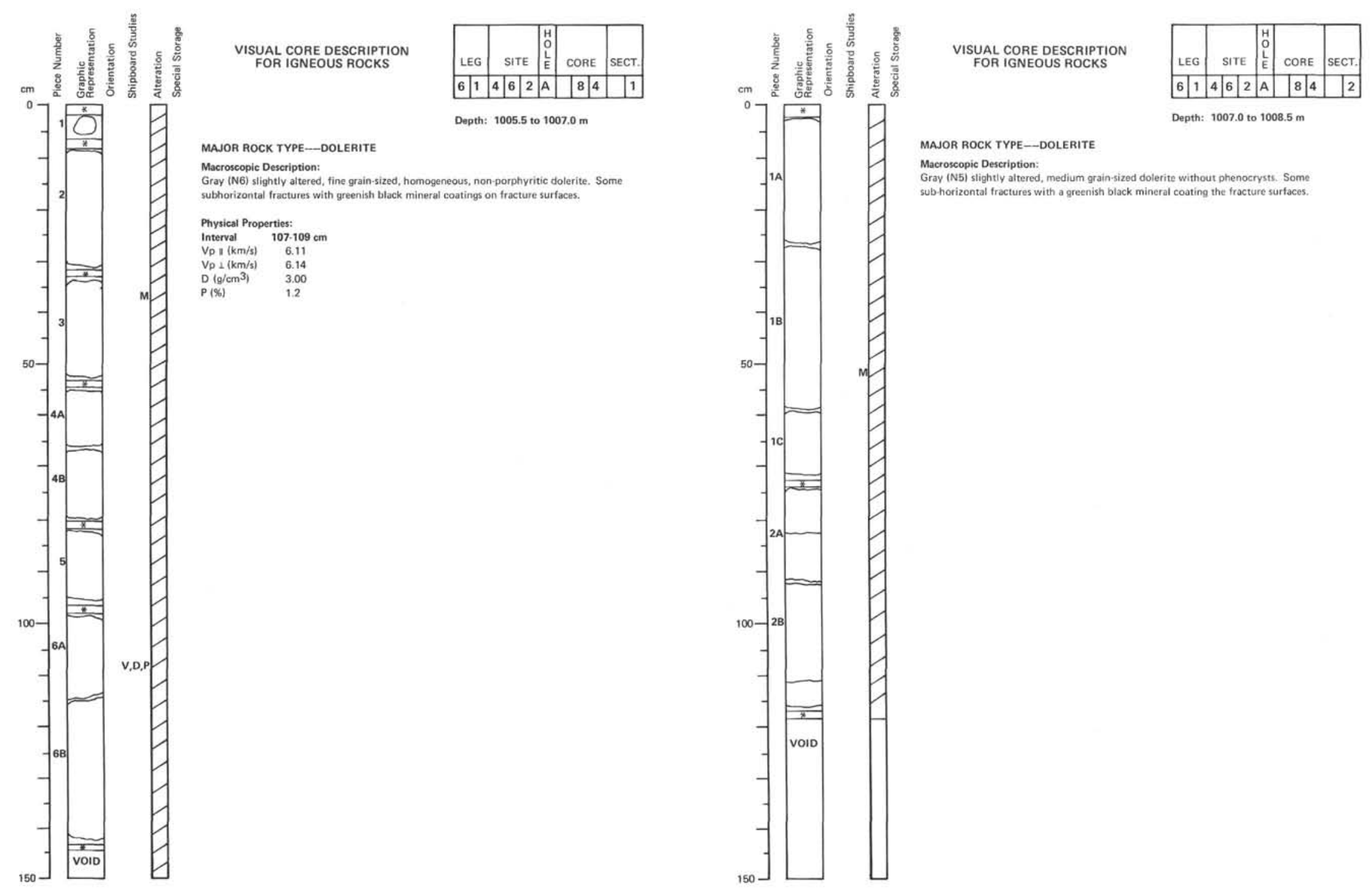

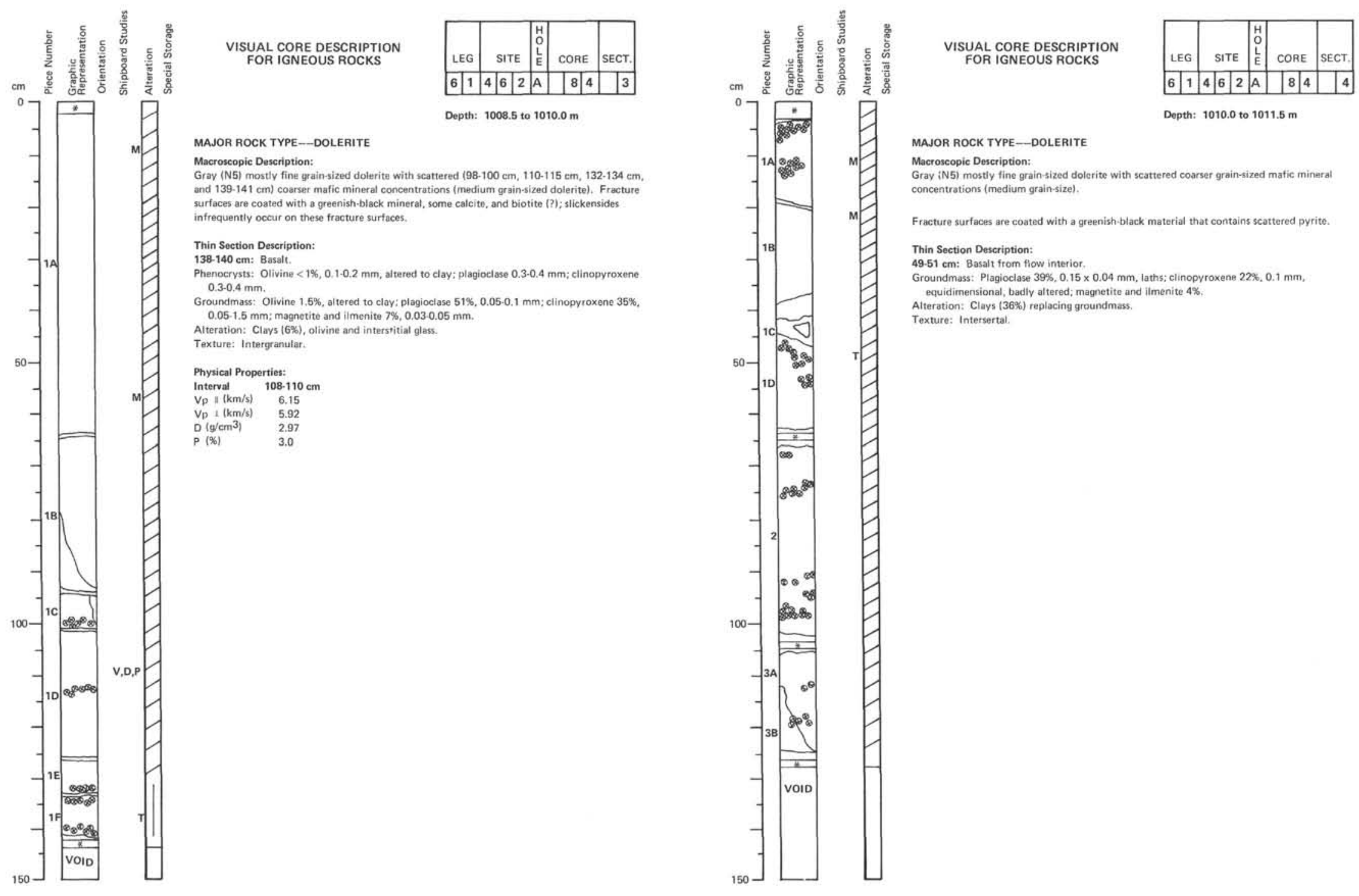

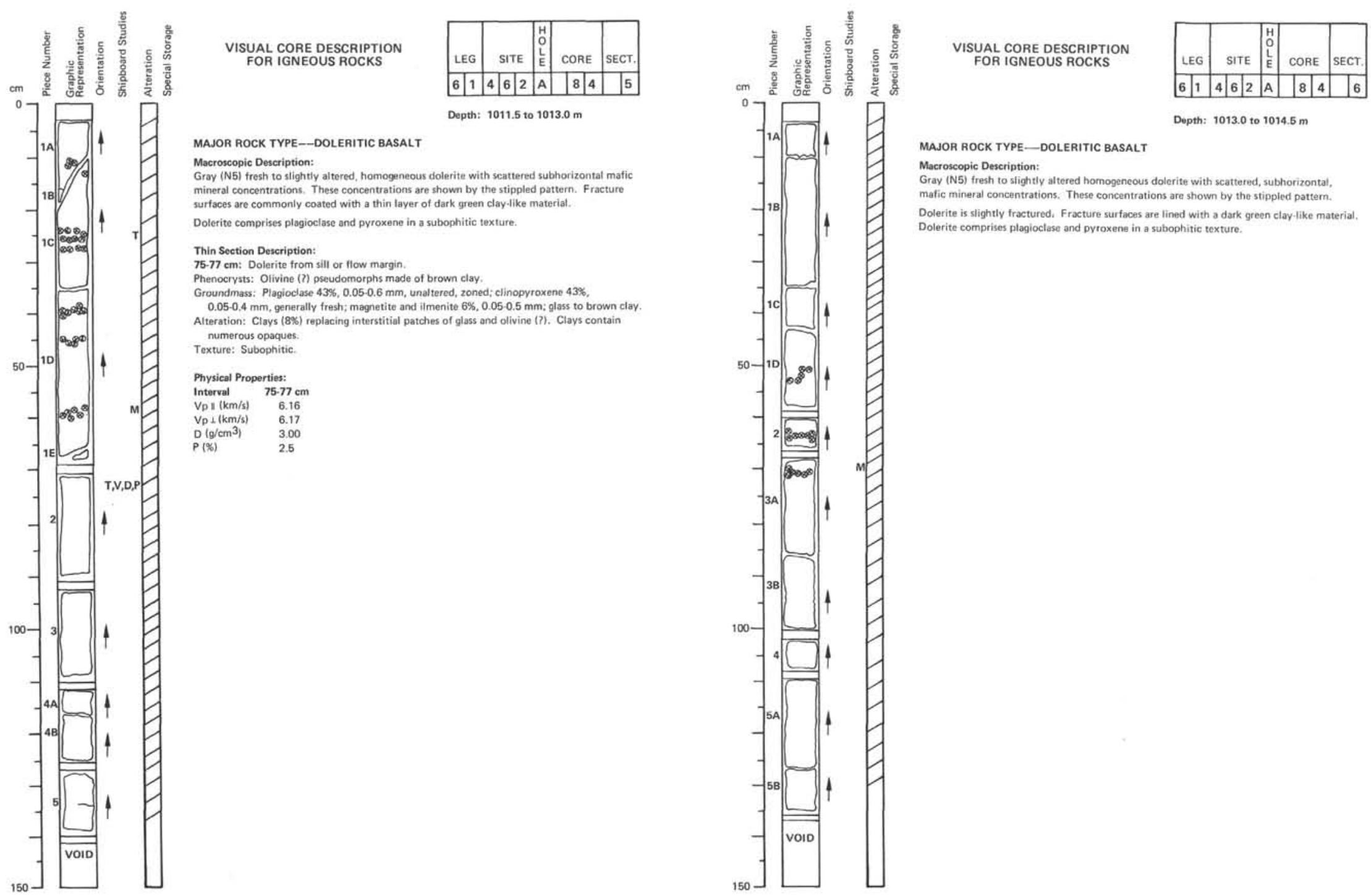

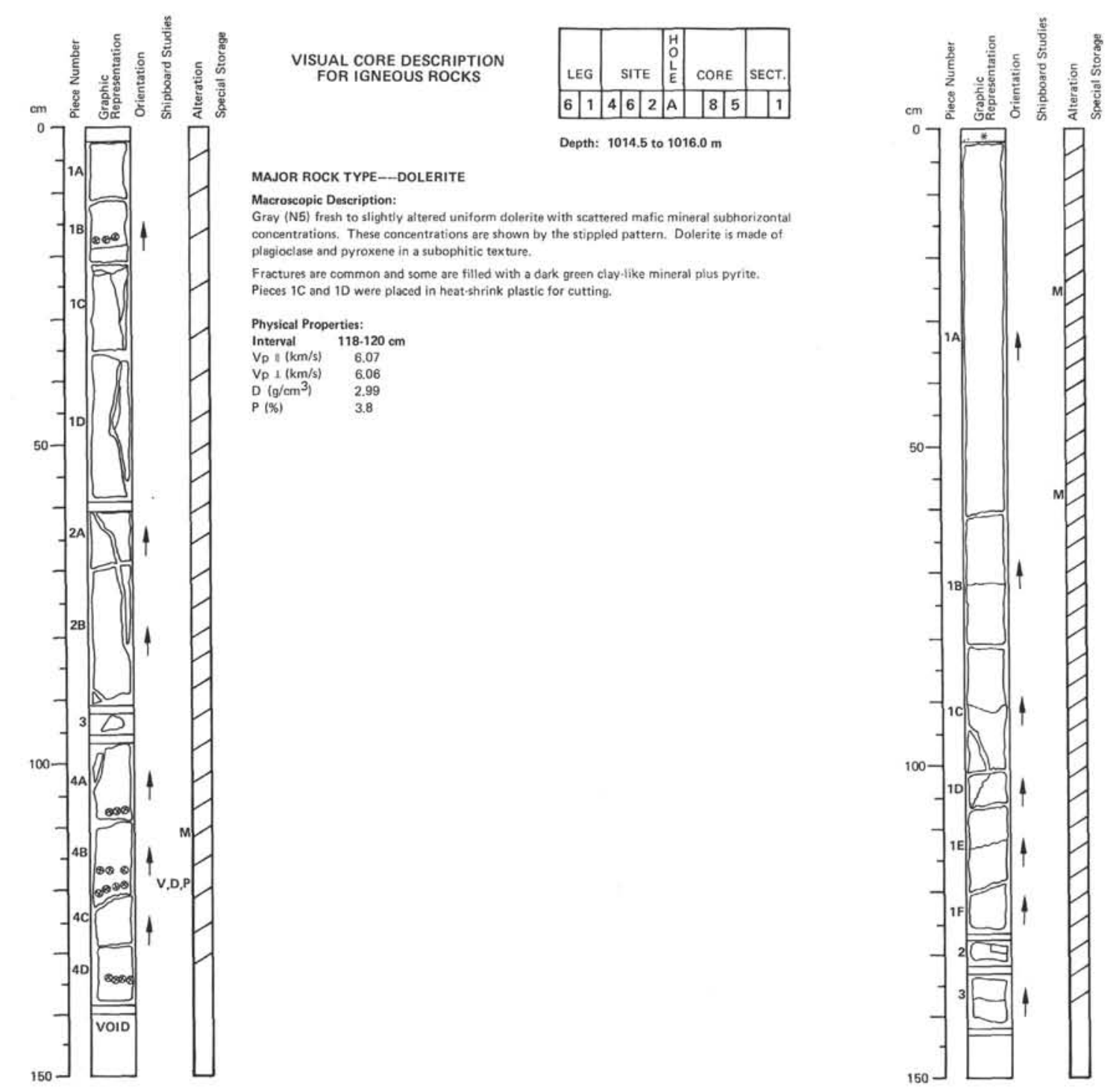
VISUAL CORE DESCRIPTION

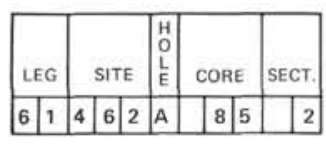 \begin{tabular}{|l|l|l|l|l|l|l|l|l|}
\hline 6 & 1 & 4 & 6 & 2 & $A$ & 8 & 5 & 2 \\
\hline
\end{tabular}
Depth: 1016.0 to $1017.5 \mathrm{~m}$

MAJOR ROCK TYPE--DOLERITE

Macroscopic Destription:

pyroxene in a subophitic texture. Fractures are common and some are filled with light green clay-like material.

Macroscopic Description: blagioclase and pyroxene in a subophitic texture.

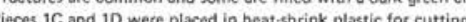

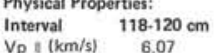

$V_{p} 1(\mathrm{~km} / \mathrm{s}) \quad 6.07$

$\begin{array}{ll}\mathrm{D}\left(\mathrm{g} / \mathrm{cm}^{3}\right) & 2.99 \\ \mathrm{P}(\%) & 3.8\end{array}$$$
150
$$

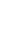



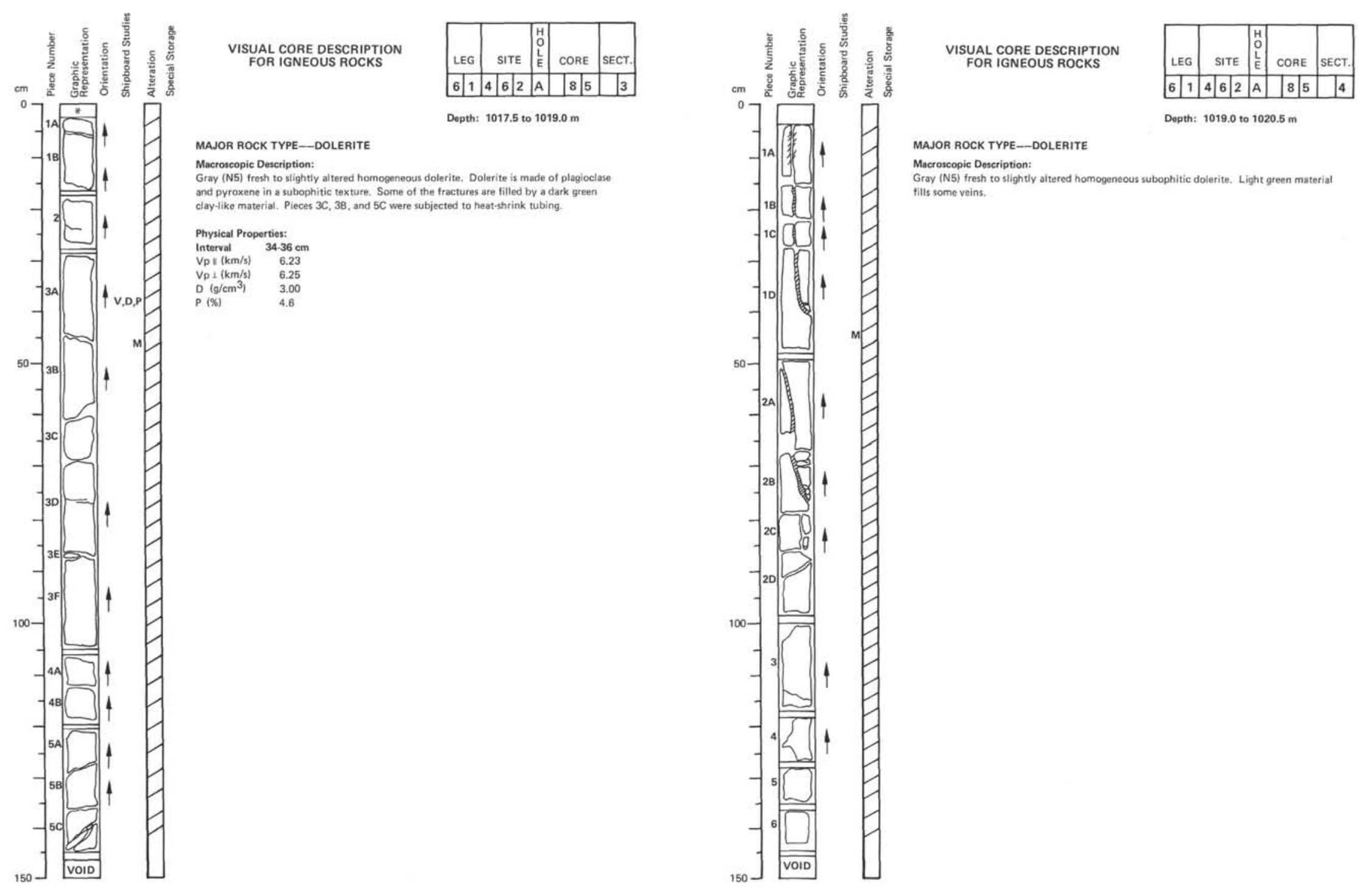


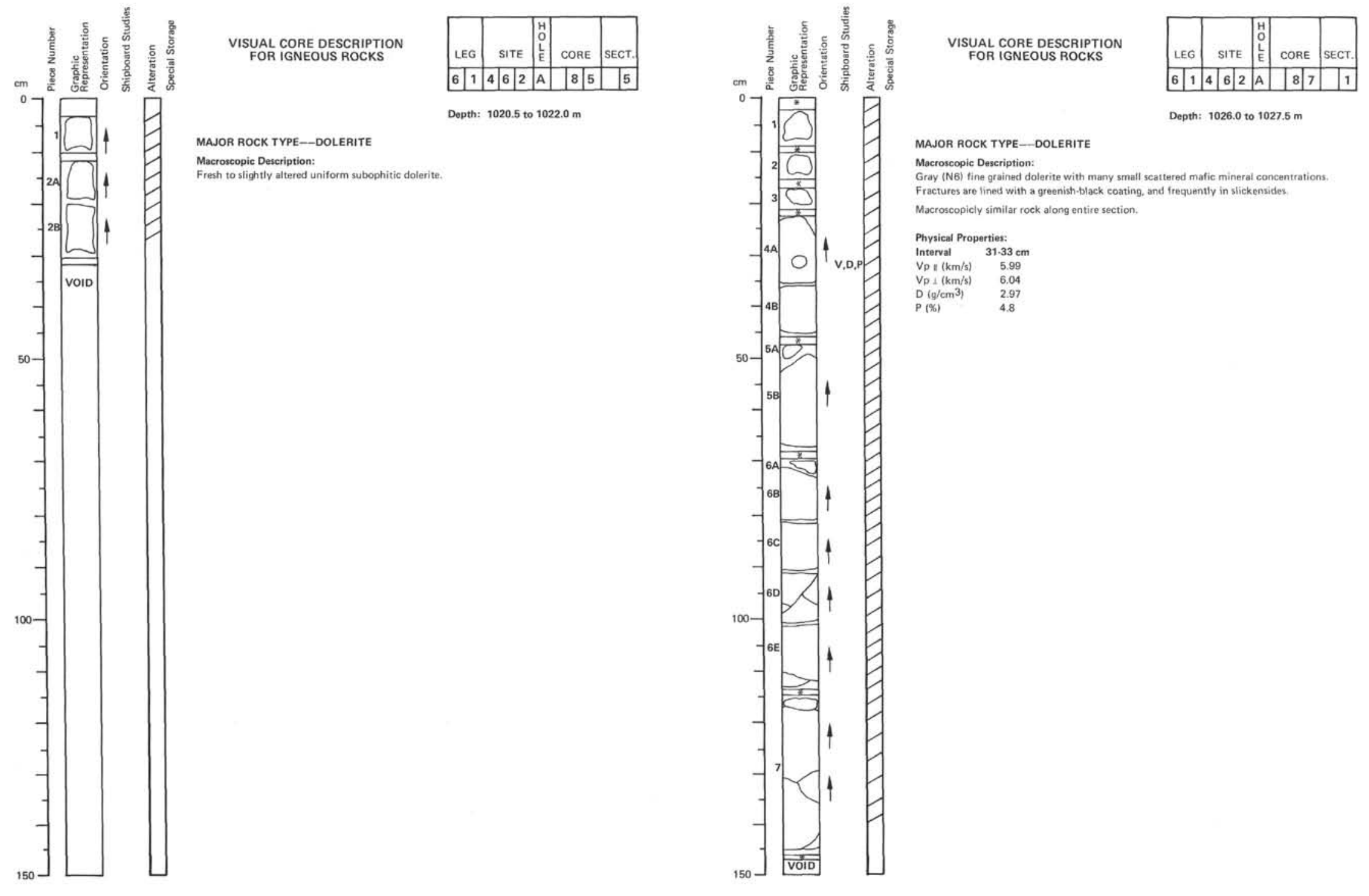



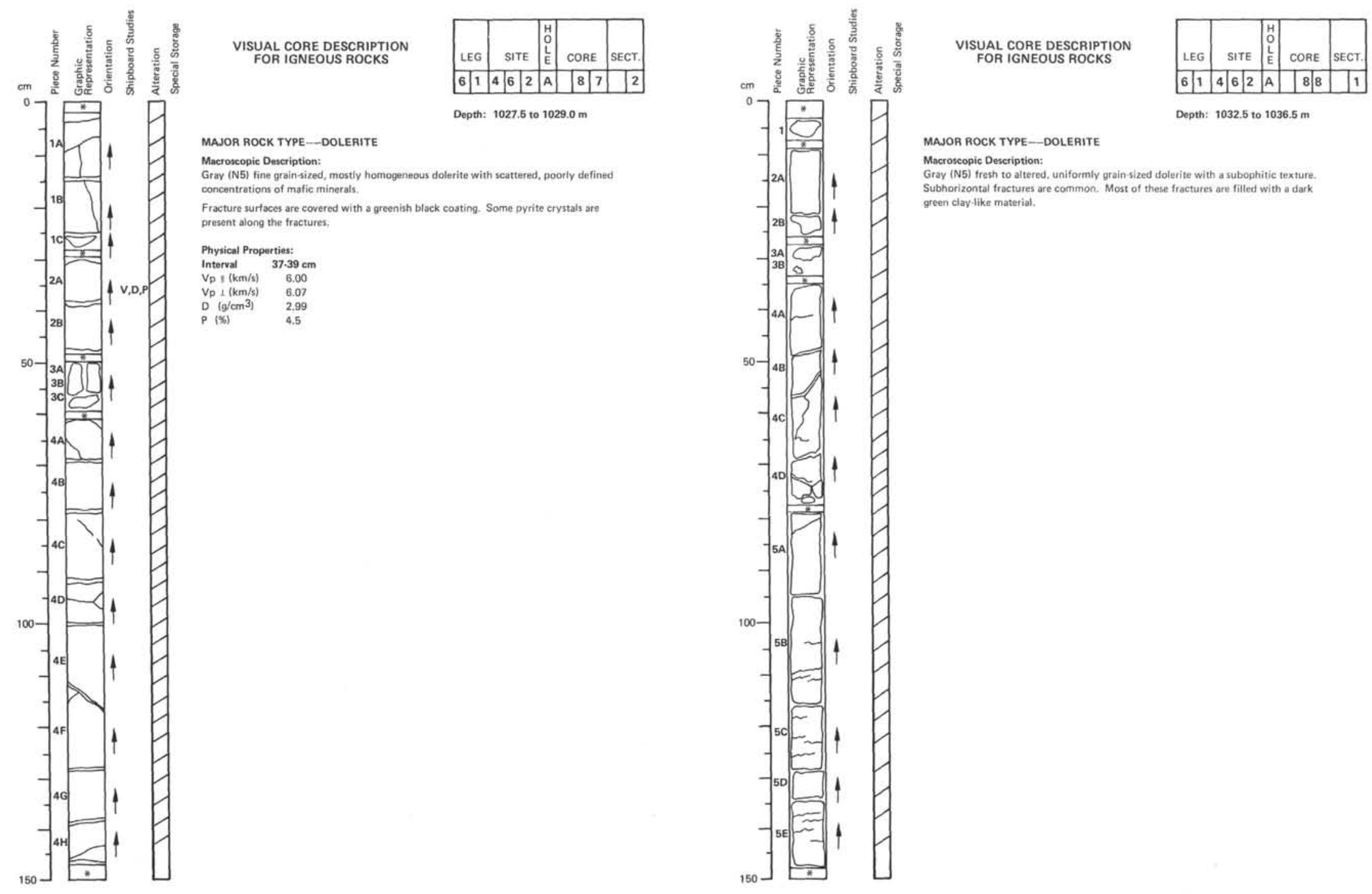

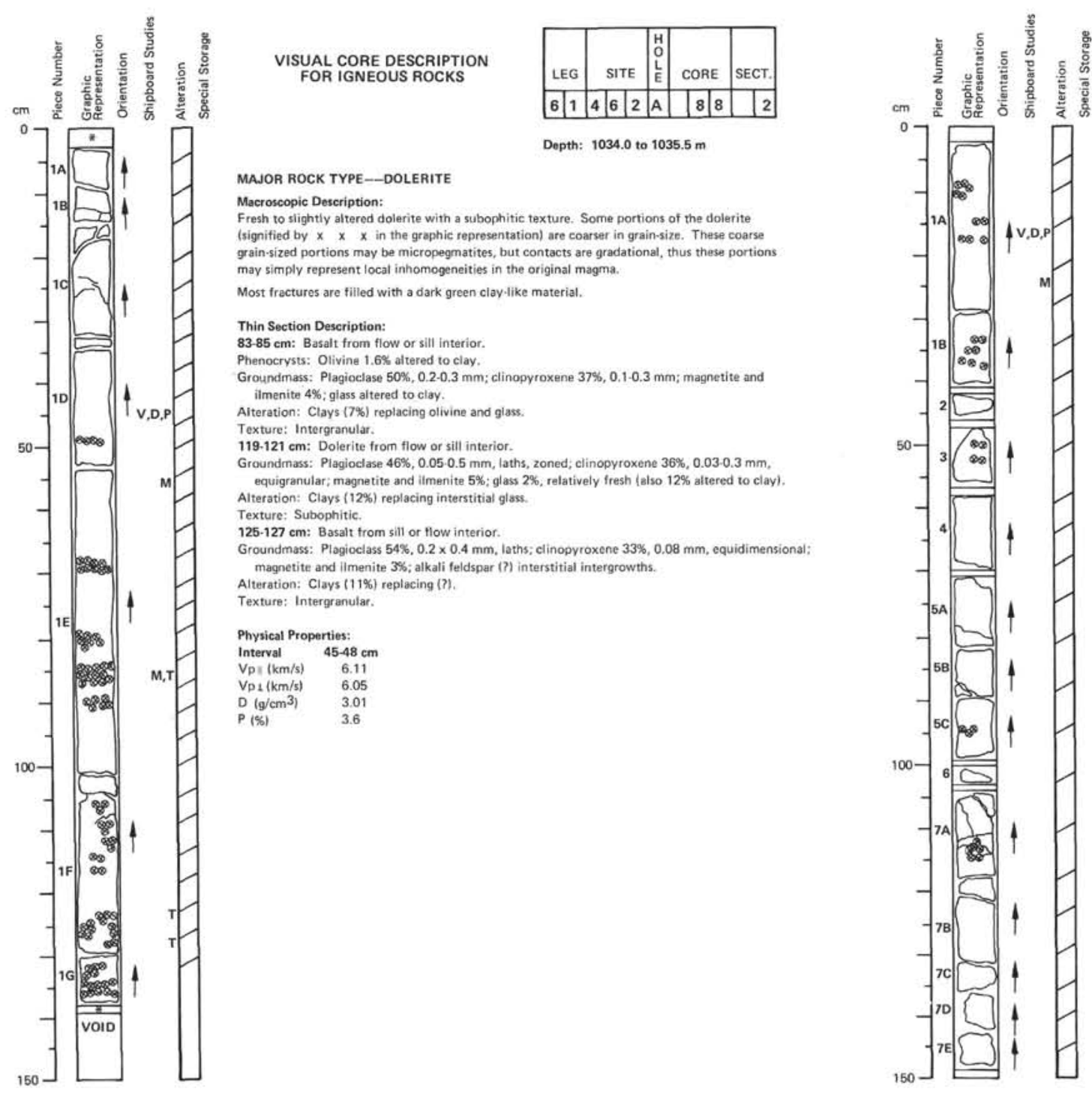

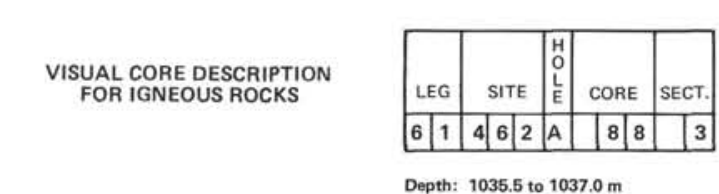

MAJOR ROCK TYPE--DOLERITE

Macroscopic Description:
Gray (N5) fresh to slightly altered subophitic dolerite. Some areas are coarser grain-sized ix $x$ th and have gradstional contacts. These aress may represent inhomogeneities in clay-like materist.

Interval Properties: $17.20 \mathrm{~cm}$ $\begin{array}{ll}V_{D}(\mathrm{~km} / \mathrm{s}) & 5.96 \\ V_{0}(\mathrm{kgm} / \mathrm{ss}) & 5.89\end{array}$ $\begin{array}{ll}\mathrm{D}\left(\mathrm{g} / \mathrm{cm}^{3}\right) & 2.96 \\ \mathrm{P}(\%) & 4.7\end{array}$ 

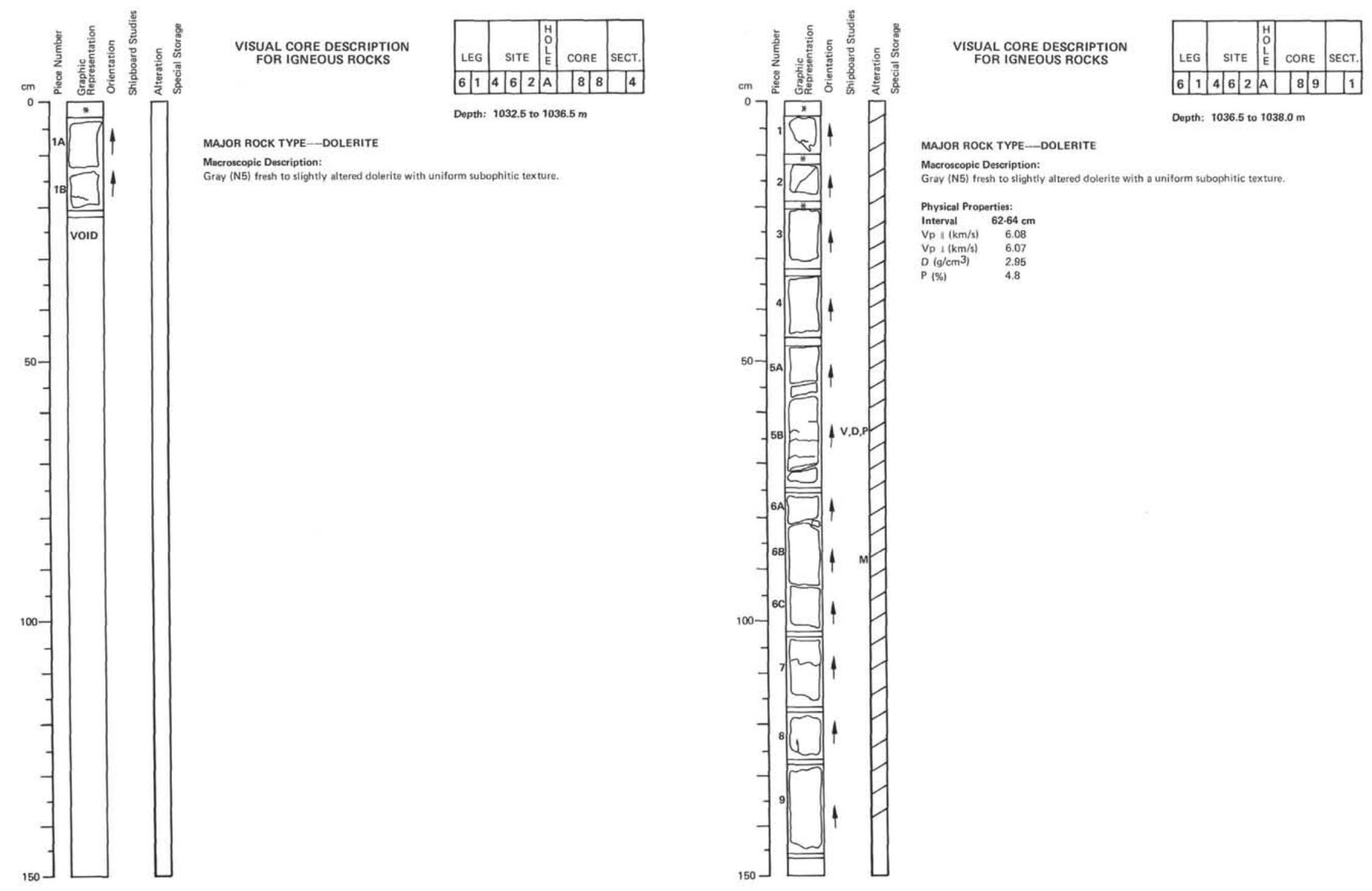

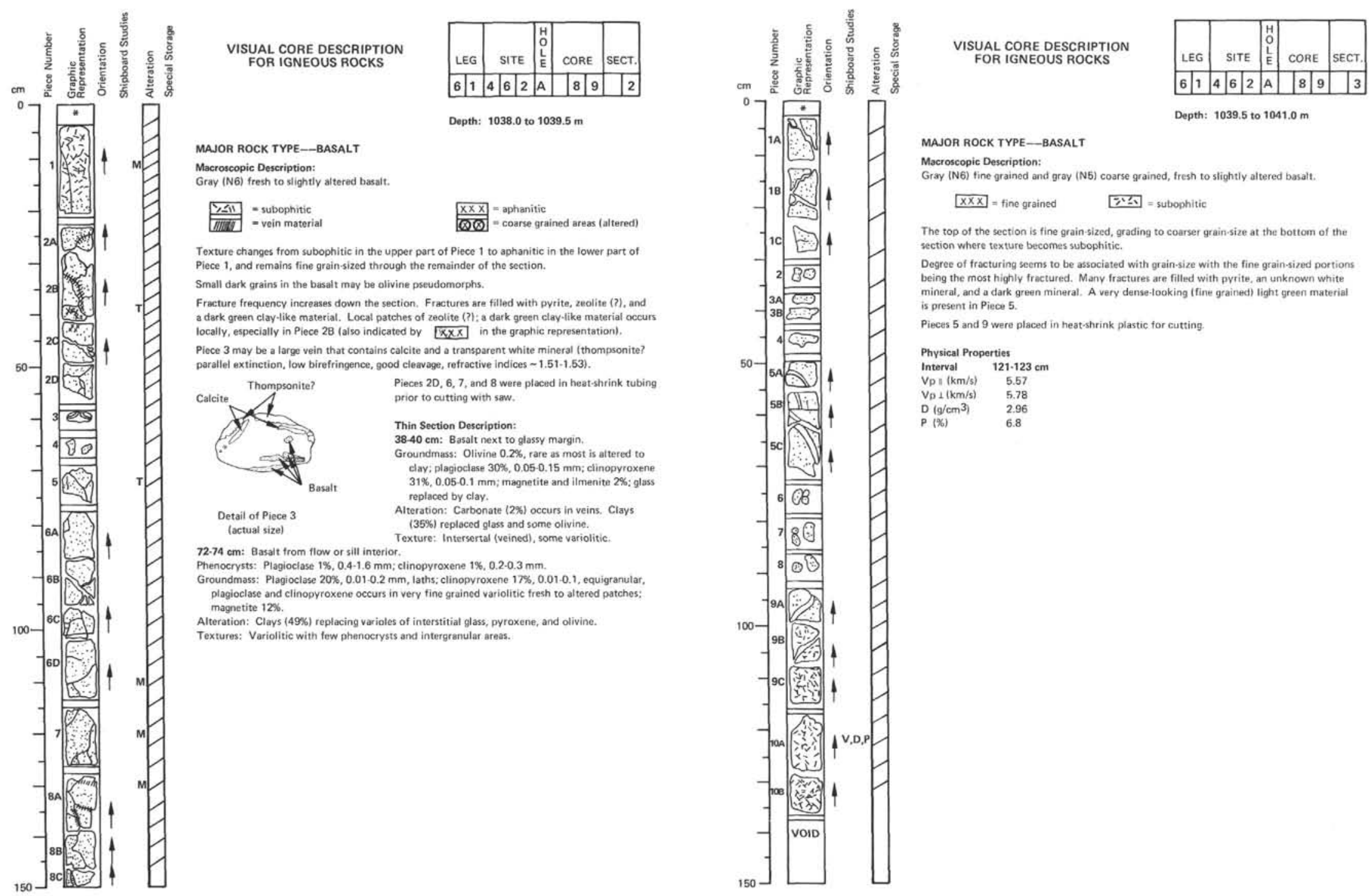

\section{MAJOR ROCK TYPE--BASALT}

Macroscopic Description:

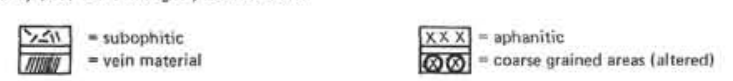

Texture changes from subophitic in the upper part of Piece 1 to aphanitic in the lower part of Piece 1, and remains fine grainsized through the remainder of the section.

Small dark grains in the basalt may be olivine pseudomorphs.

Fracture frequency increases down the section. Fractures are filled with pyrite, zeolite (?). and \begin{tabular}{l} 
a dark green clay-like material. Local patches of zeolite (?): a dark green clay-like material oc \\
locally, especially in Piece 28 (also indicated by \\
\hline$x \times x$ in the graphic representation).
\end{tabular} 政 parallet extinction, low bireffringence, good cleavage, reftractive indices $~-1.51-1.53$ ). $\begin{array}{ll}\text { Thompsonite? } & \text { Pieces } 2 \mathrm{D}, 6,7 \text {, and } 8 \text { were placed in heat-shrink tubing } \\ \text { calcite } & \text { prior to cutting with saw. }\end{array}$ Calcite

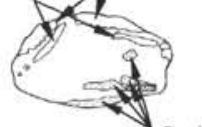

Thin Section Description:

Groundmass: Oivine $0.2 \%$, rare as most is attered to are replaced by clay.

Detail of Piece 3 Alteration: Carbonate (2\%) occurs in veins. Clays (sctual size) (35\%) replaced glass and some olivine.
Texture: Intersertal (veined), some variolitic.

$72.74 \mathrm{~cm}:$ : Basalt trom flow or sill interior

clinopyroxene $1 \%, 0.2 \cdot 0.3 \mathrm{~mm}$

Groundmass: Plagioclase 20\%, $0.01 .0 .2 \mathrm{~mm}$, laths; clinopyroxene 17\%, 0.01-0.1, equigranular, pagioclase and clinopyroxene occurs in very tine grainco varioilite treesh to altered patches: magnetite $12 \%$.

(a)

Textures: Variolitic with tew phenocrysts and intergrancular areas.

\section{MAJOR ROCK TYPE-BASALT}

Gray (NE) fine grained and gray (N5) coarse grained, fresh to slightily altered basalt.

$$
x x x=\text { fine grained } \quad[7: 2 \text { s }=\text { subophitic }
$$

The top of the section is fine grainstized, gr:
section where texture becomes subophitic.

Degree of fracturing seems to be associated with grain-size with the fine grain-sized portions being the most highly frictured. Many fractures are filled with pyrite, an unknown white

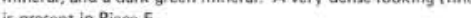

Physical Properties
Interval $121.123 \mathrm{~cm}$

$V_{p} \cap(\mathrm{km} / \mathrm{s}) \quad 5.57$

$\begin{array}{ll}\mathrm{D}\left(\mathrm{g} / \mathrm{cm}^{3}\right) & 2.96 \\ \mathrm{P}(\%) & 6.8\end{array}$ 

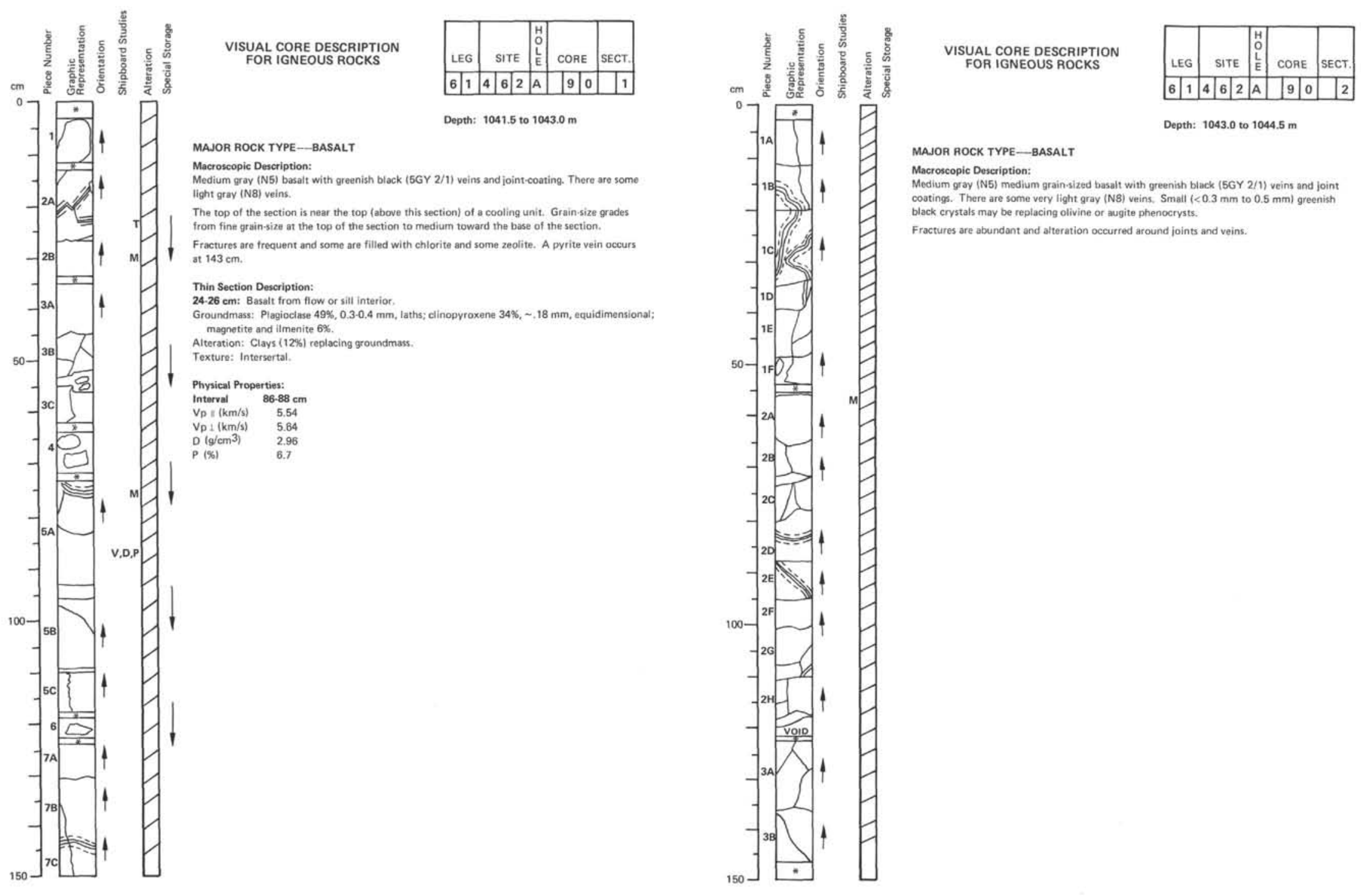

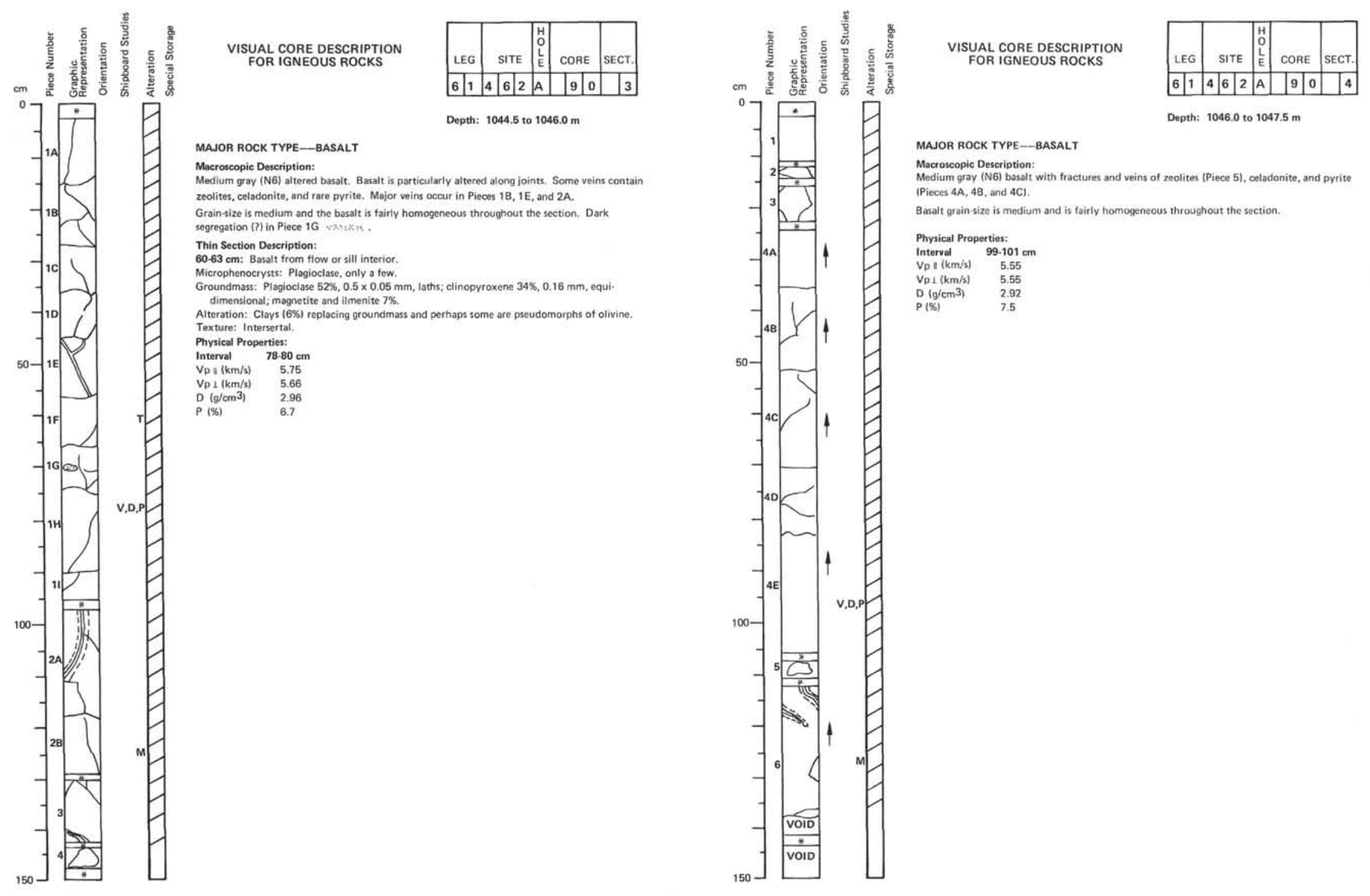

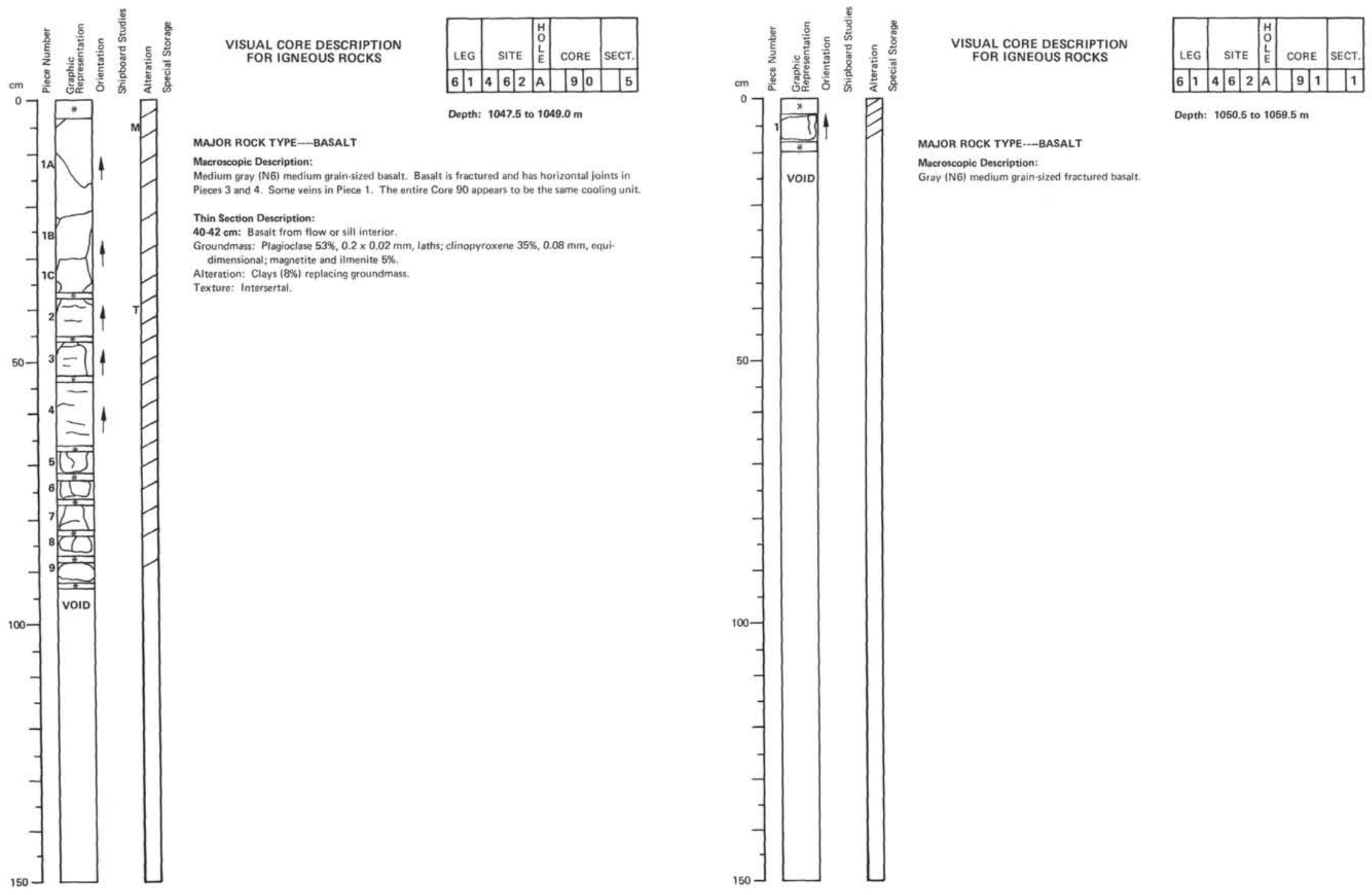

Depth: 1050.5 to $1059.5 \mathrm{~m}$ 


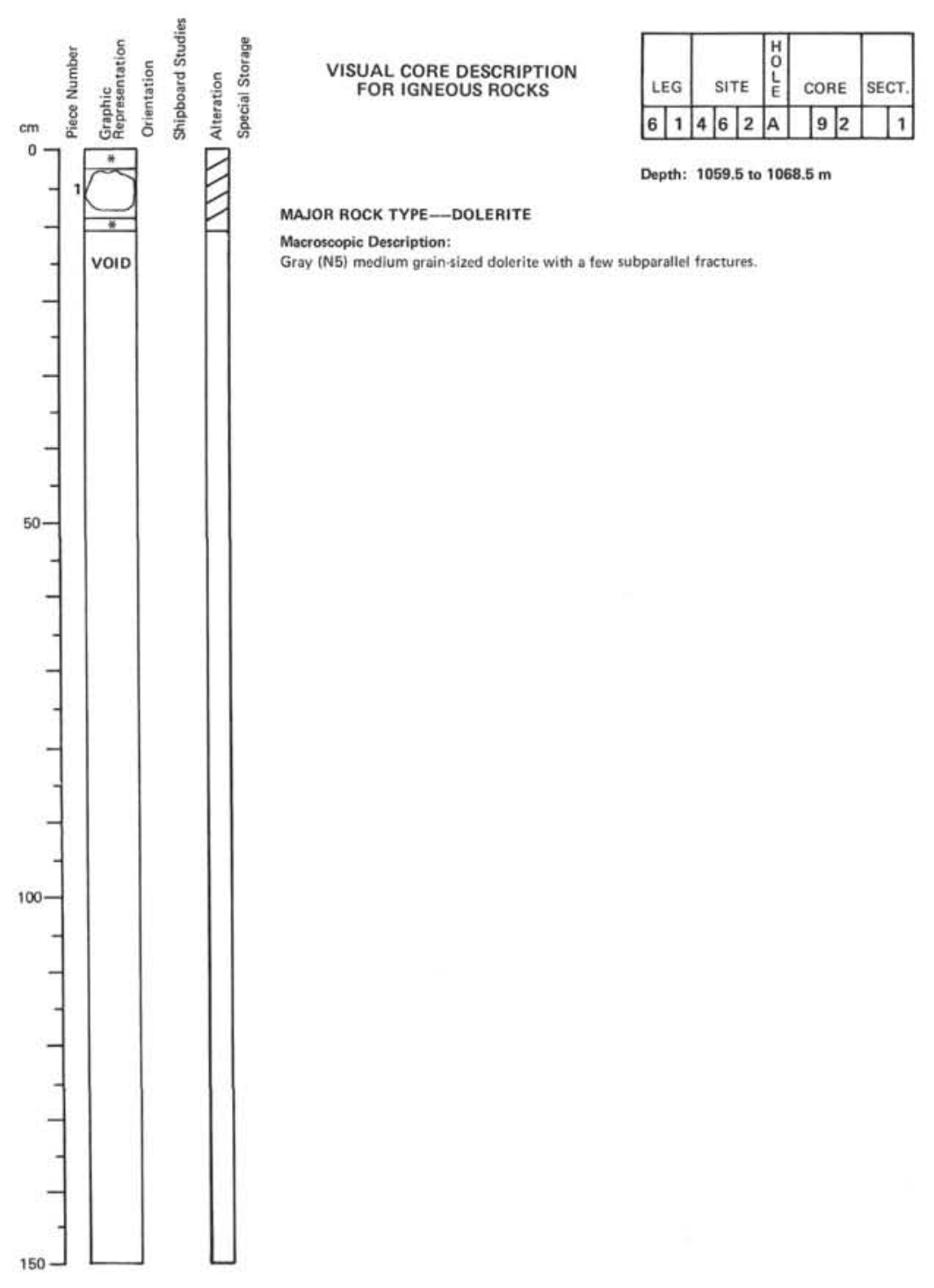



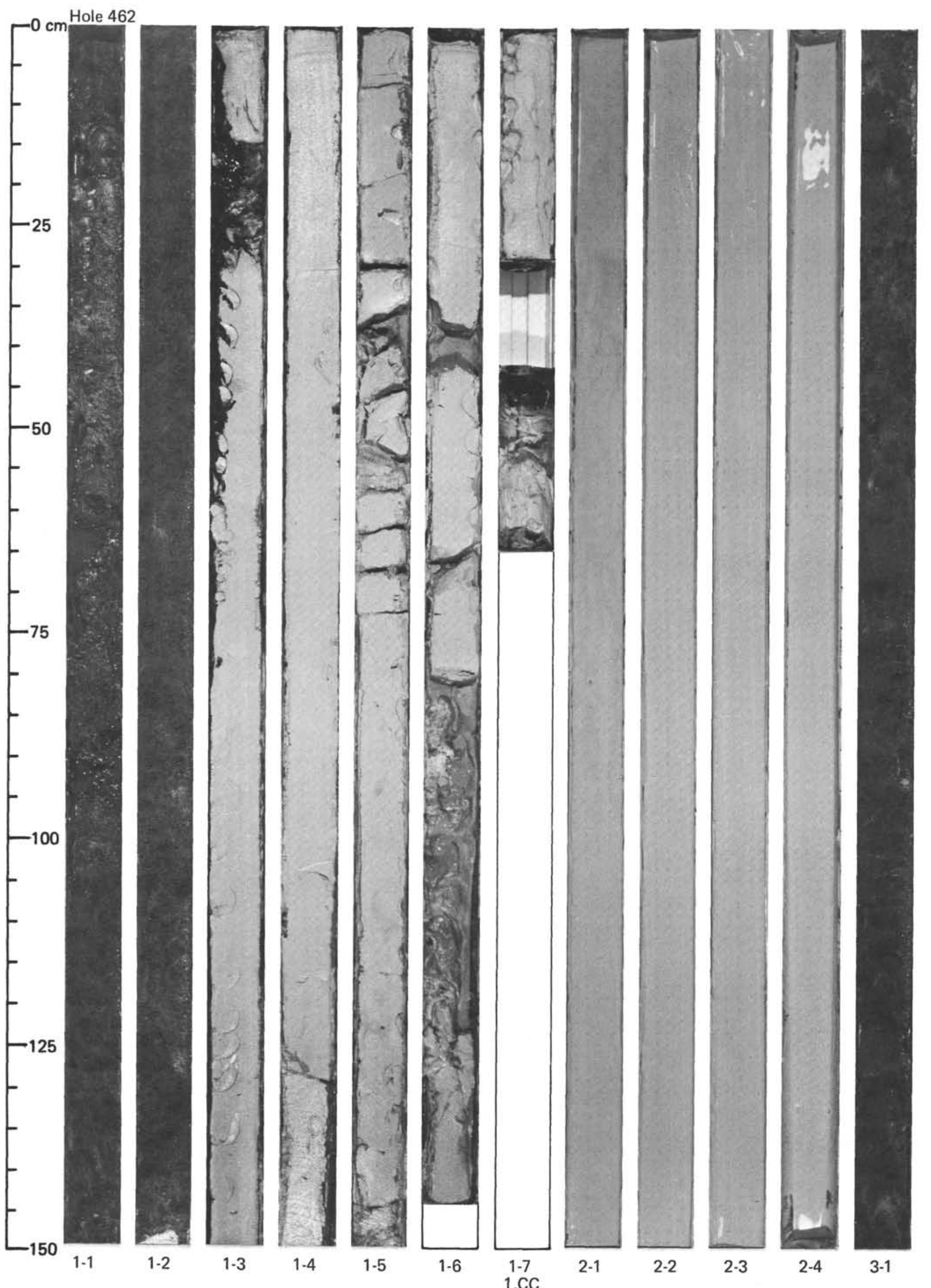
SITE 462

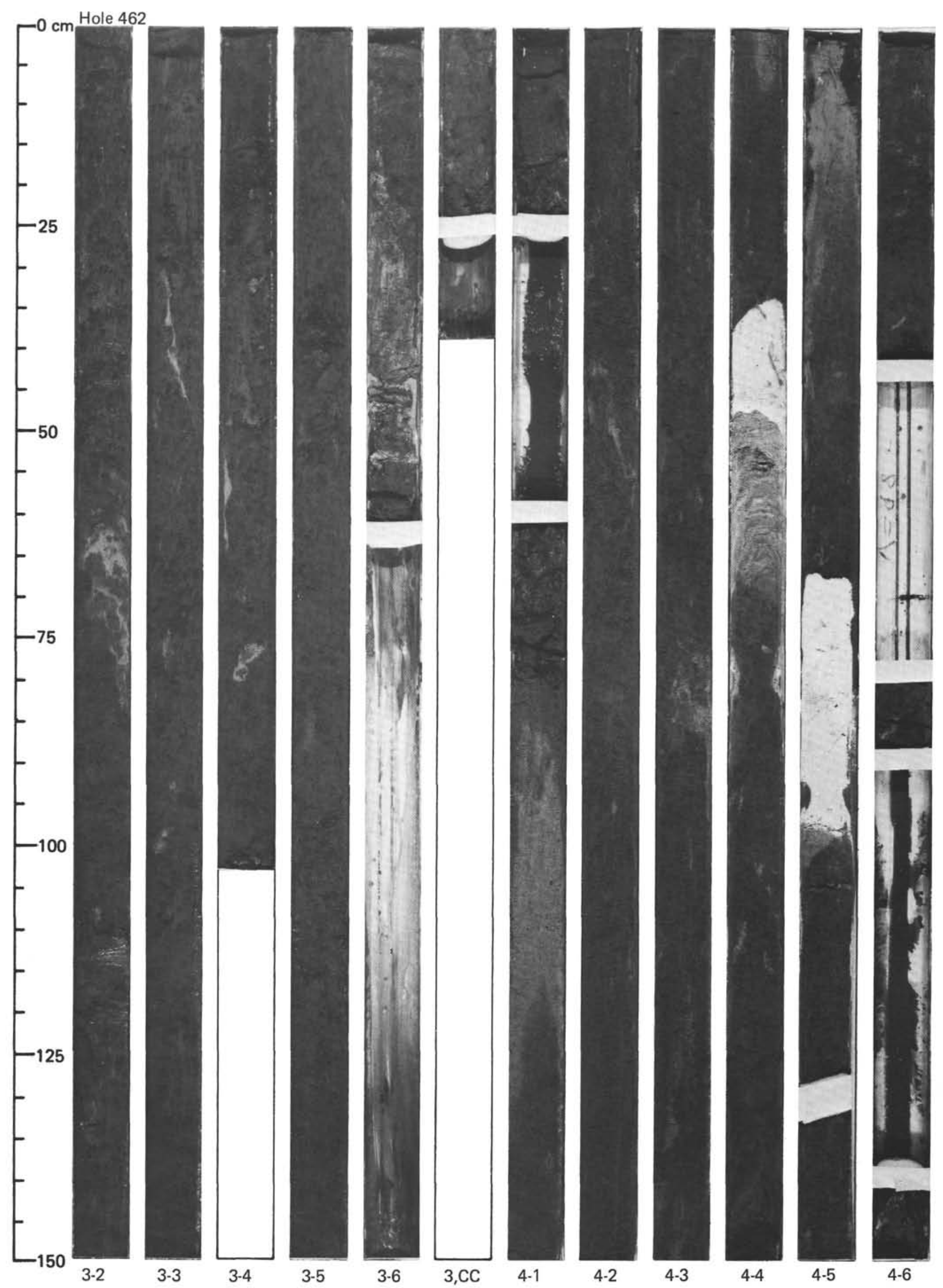




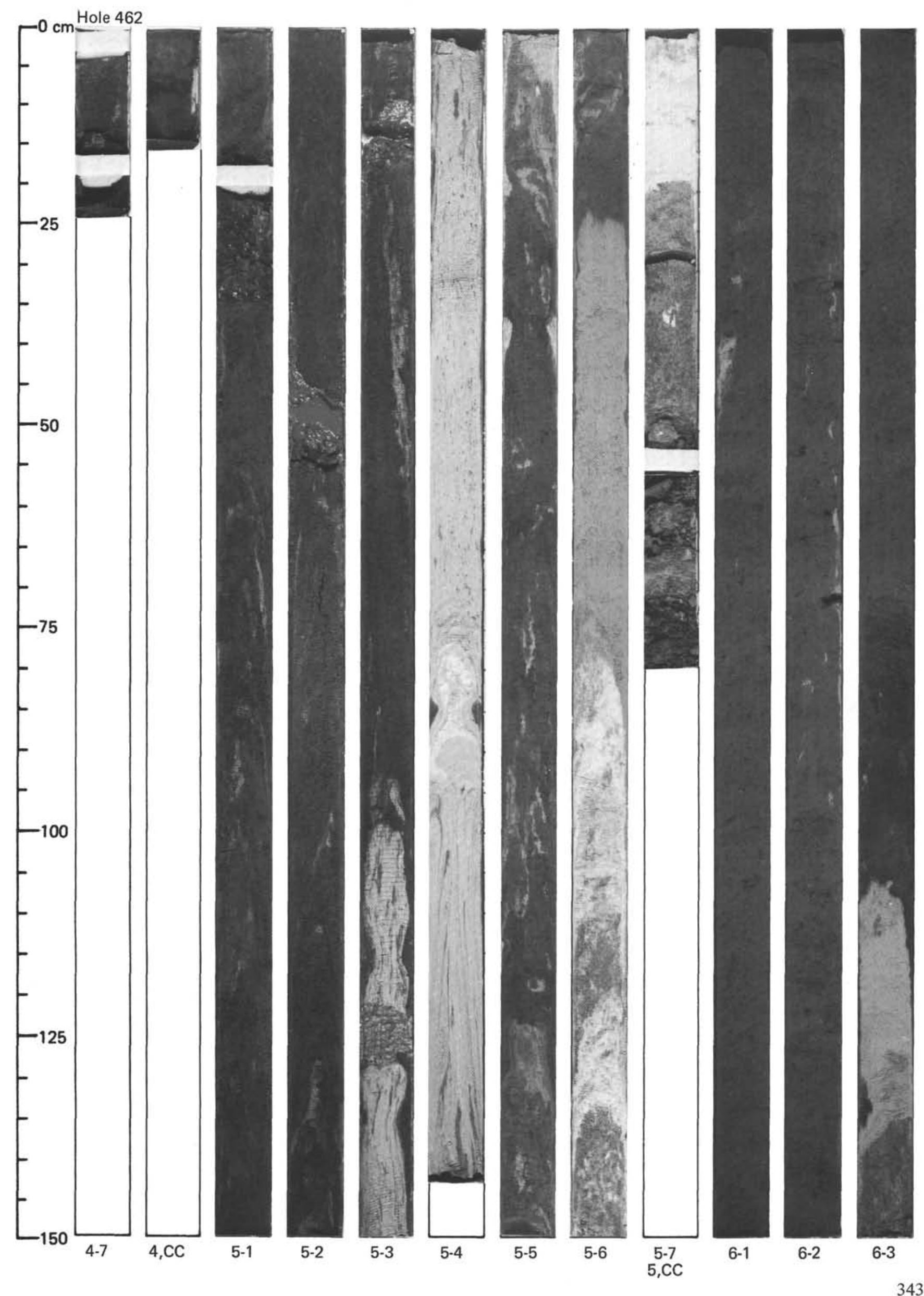


SITE 462

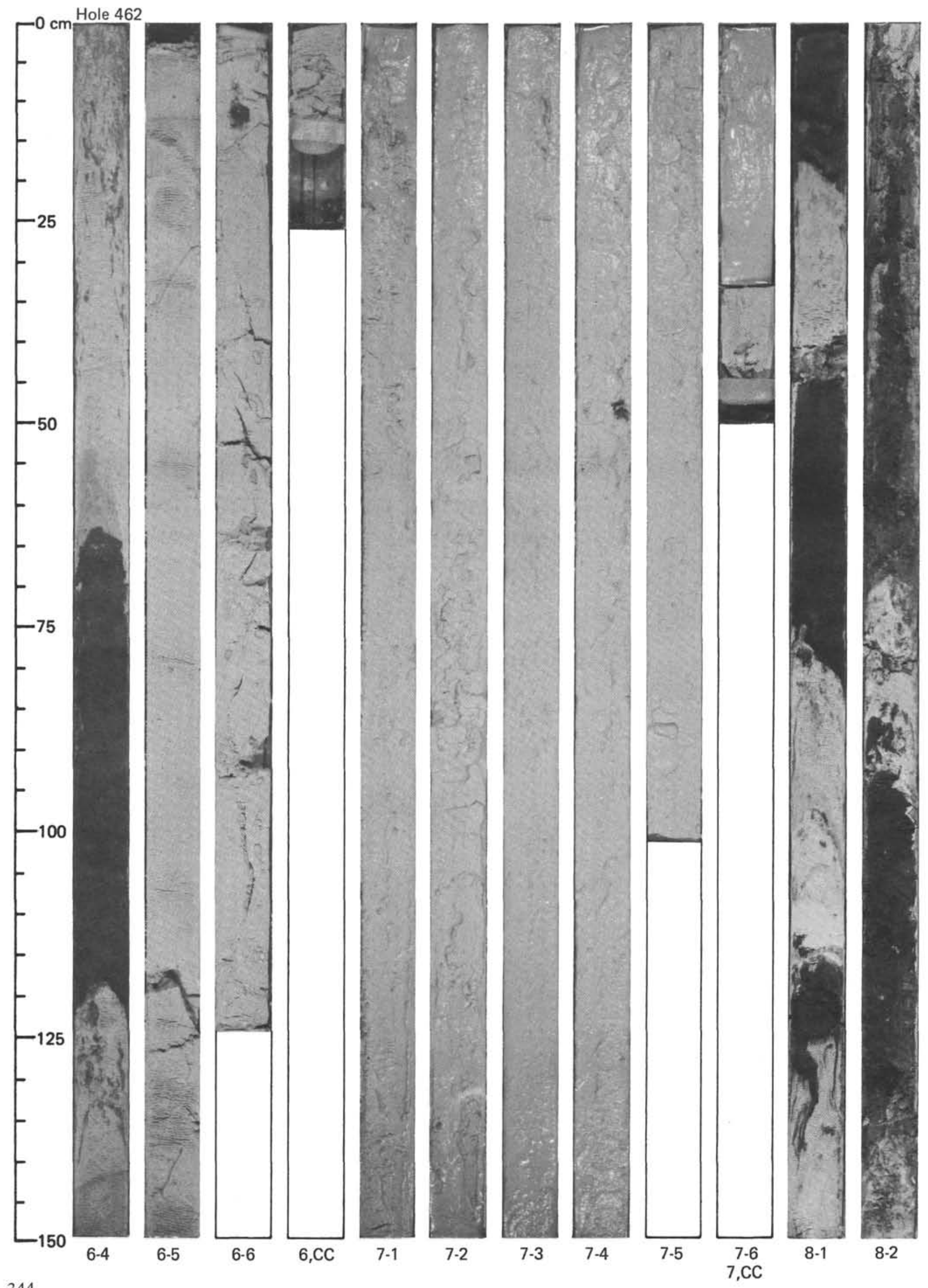



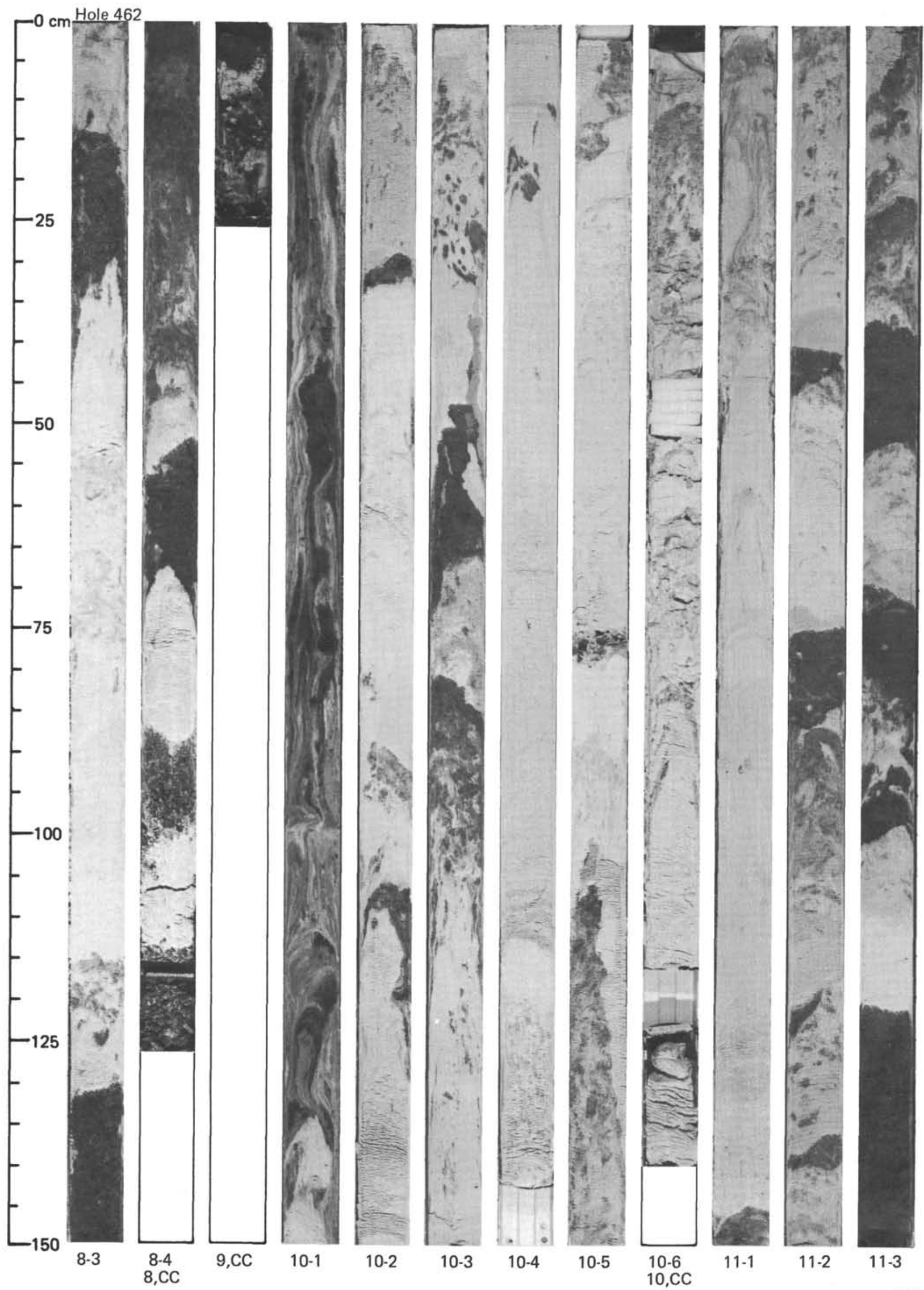


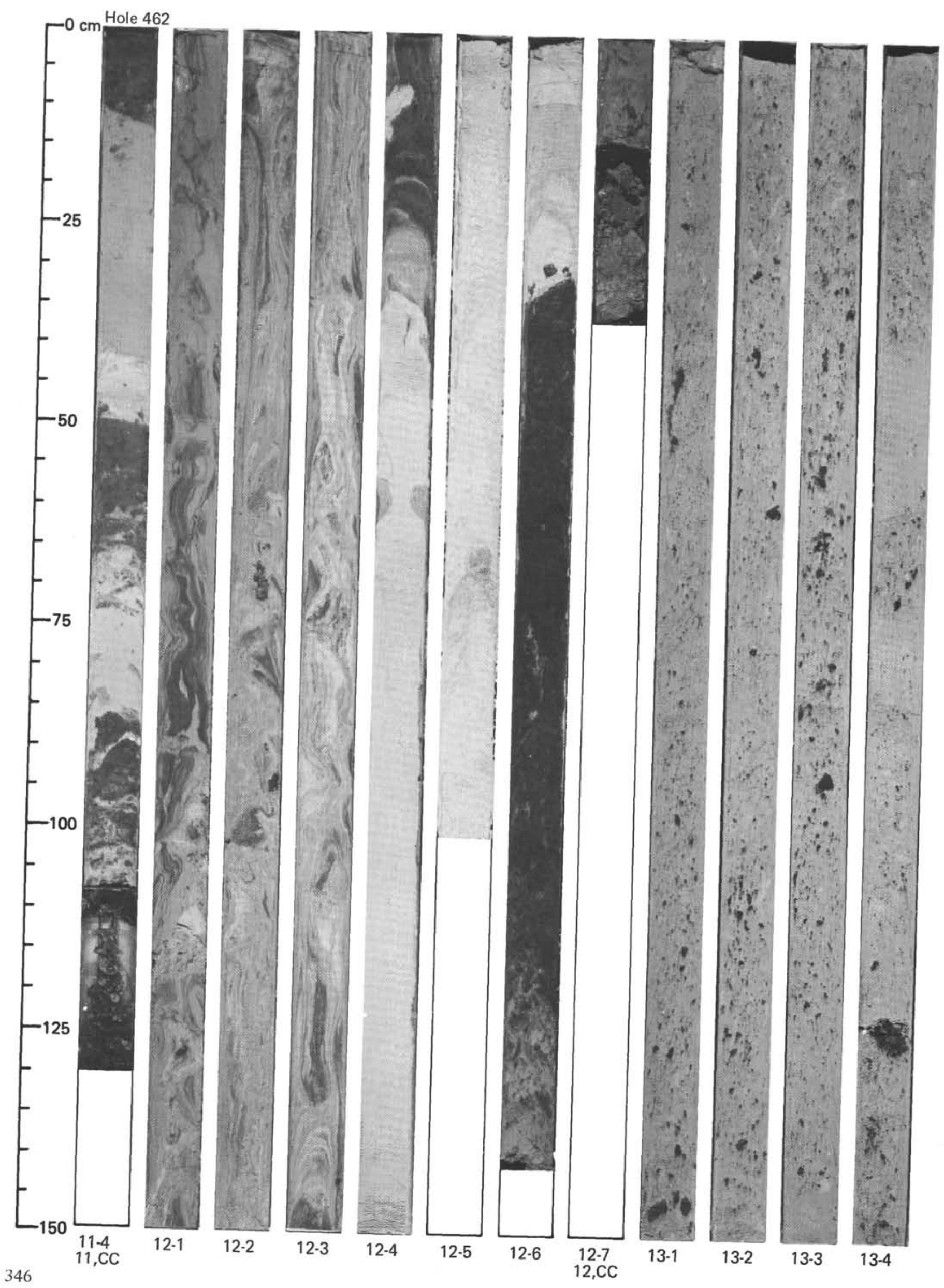




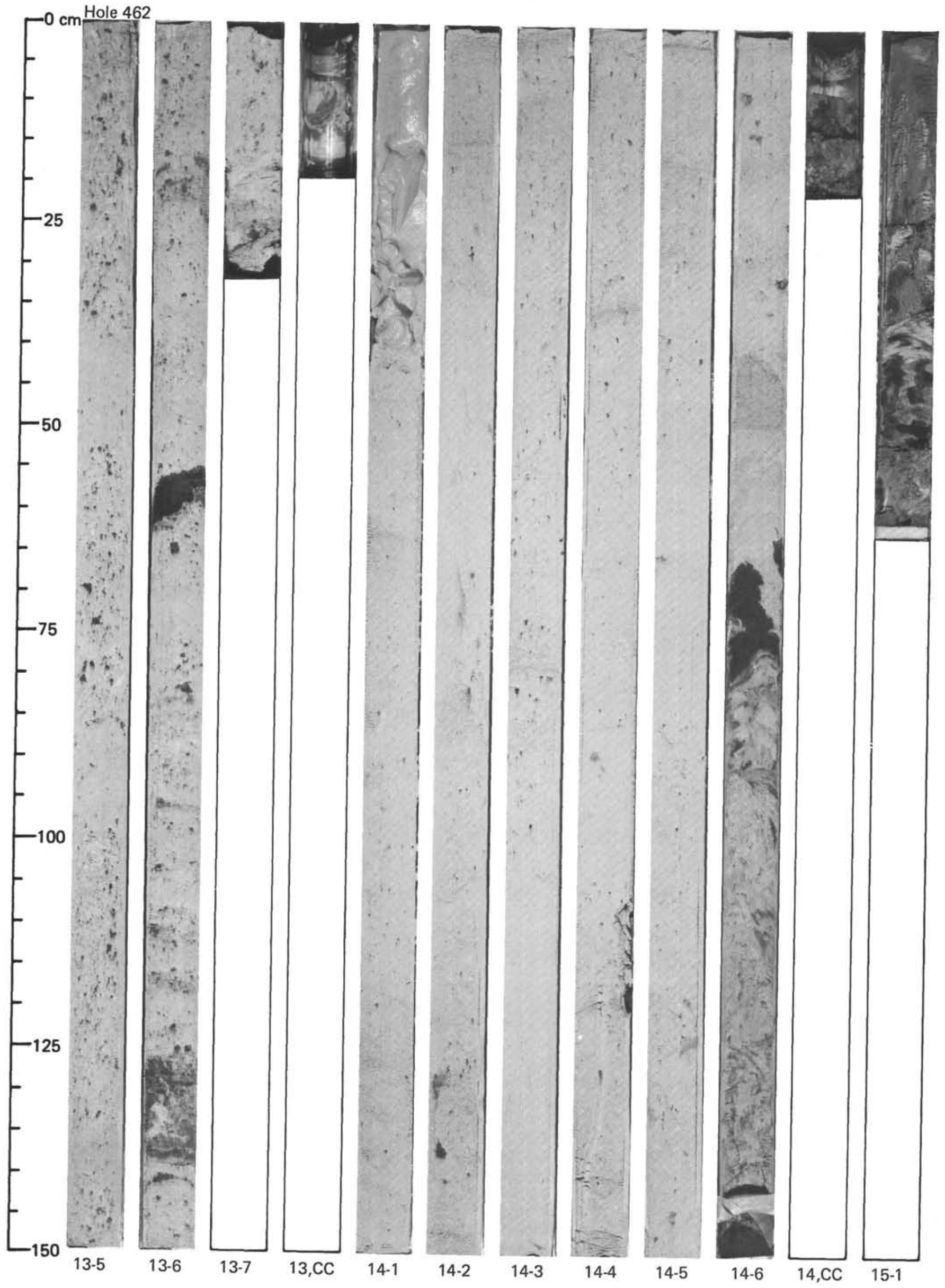




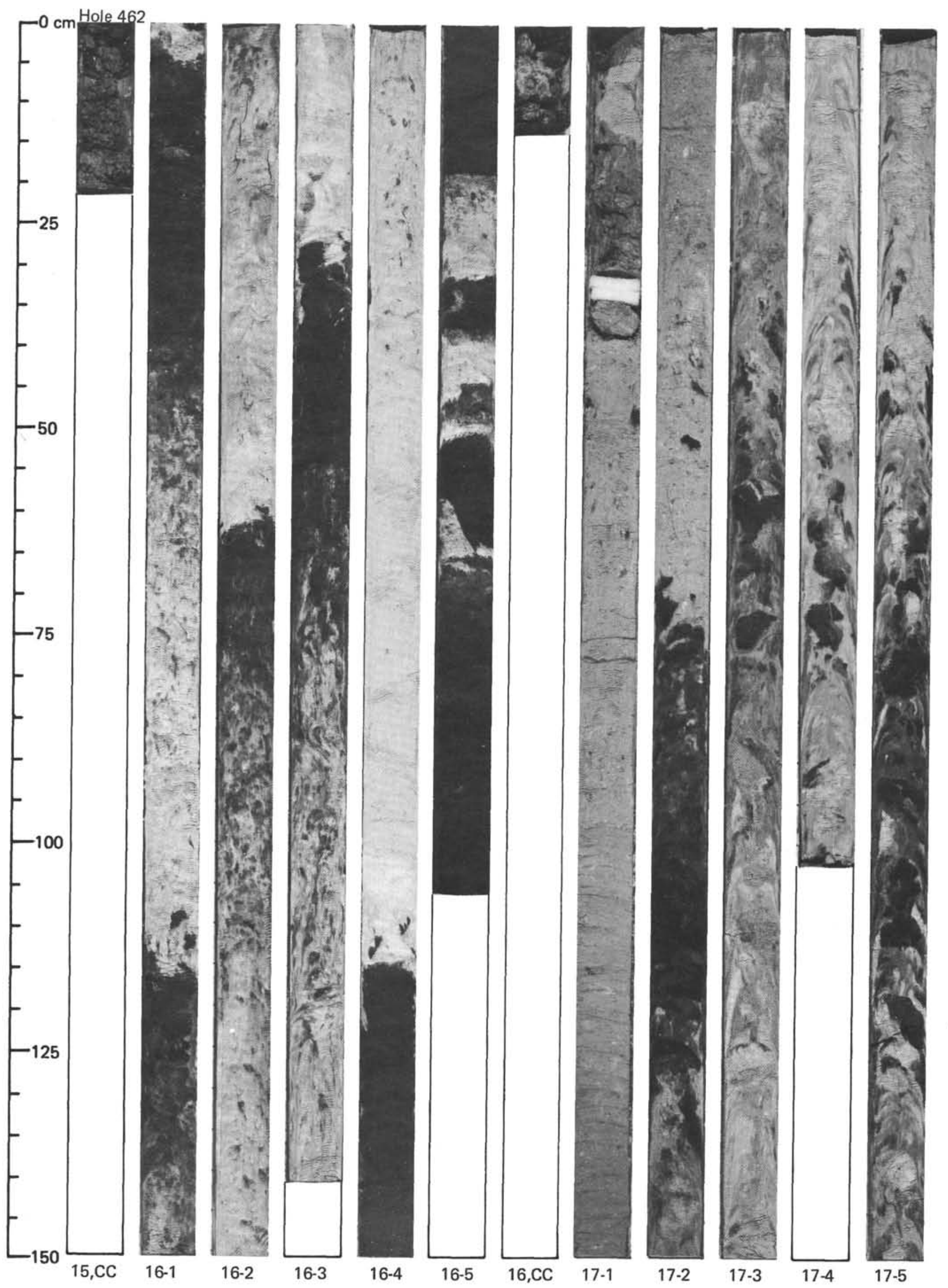



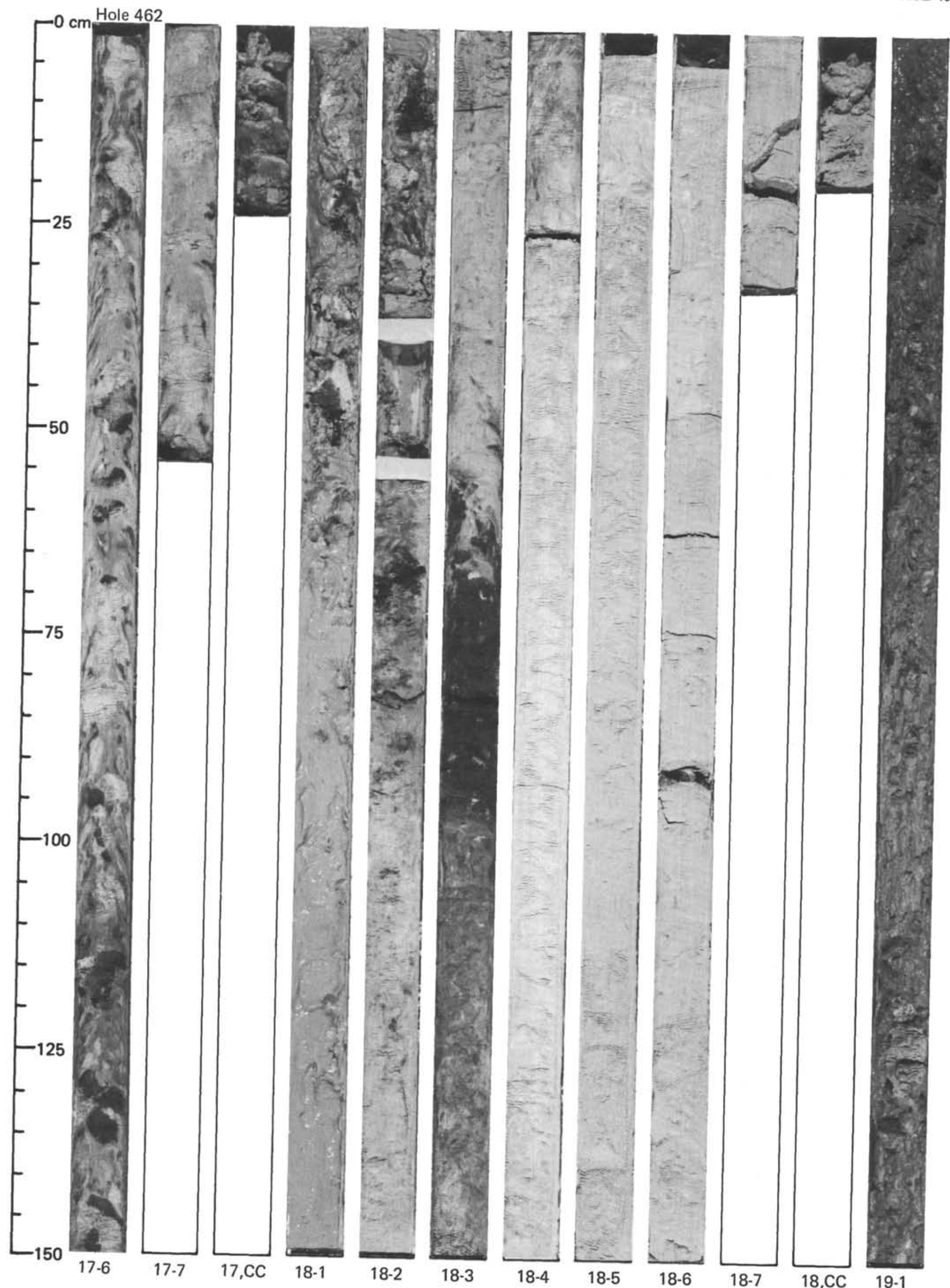


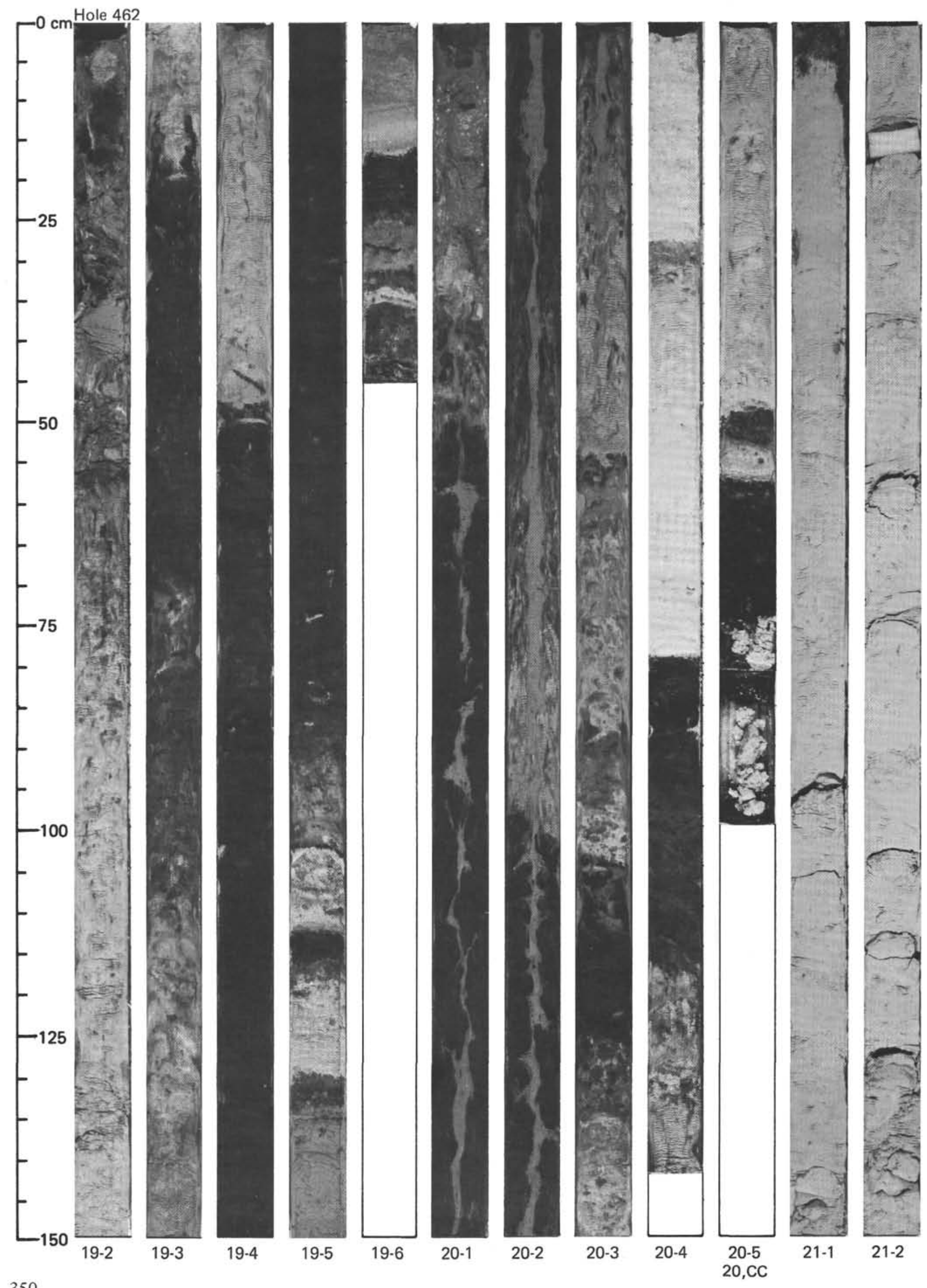




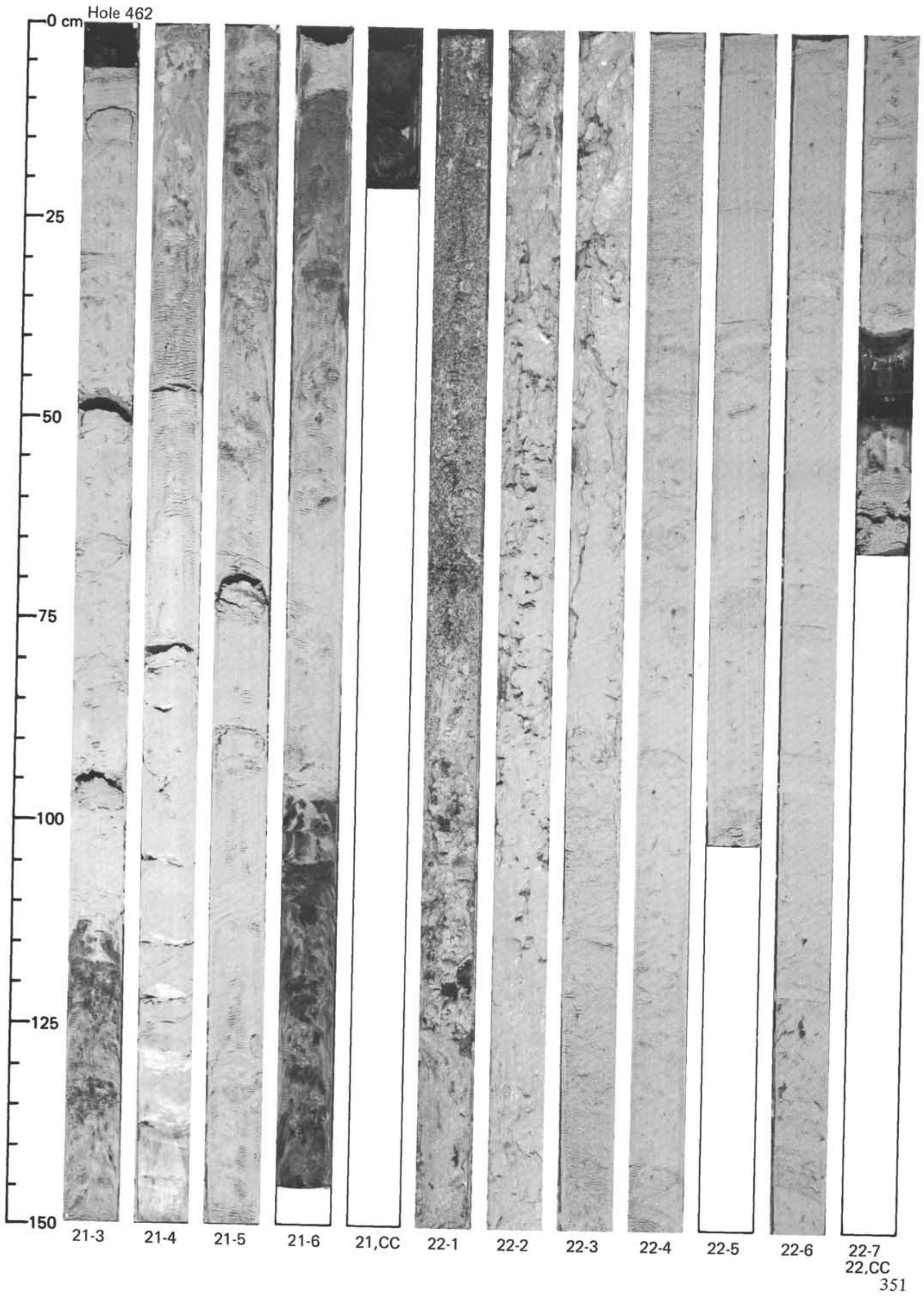




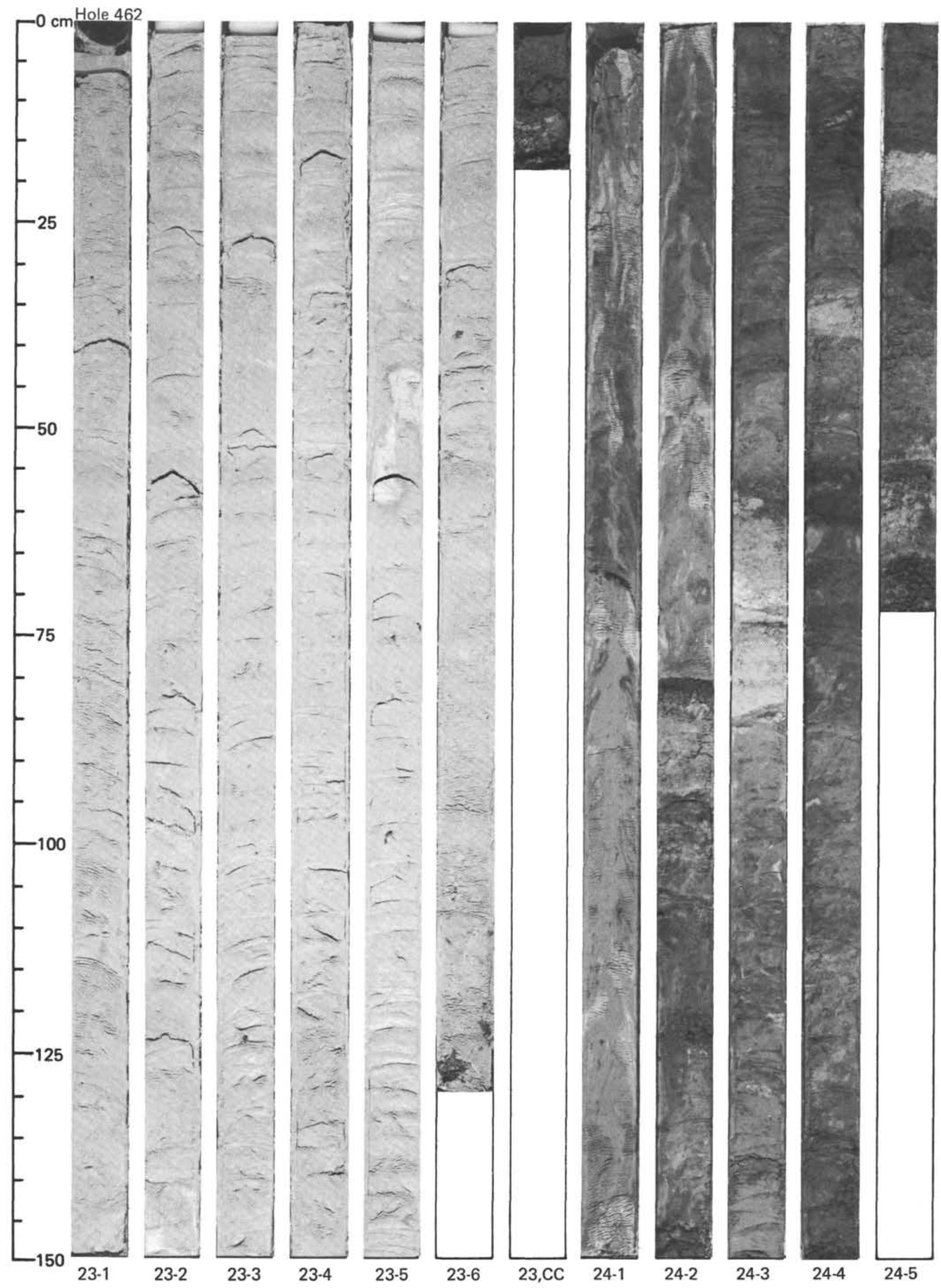




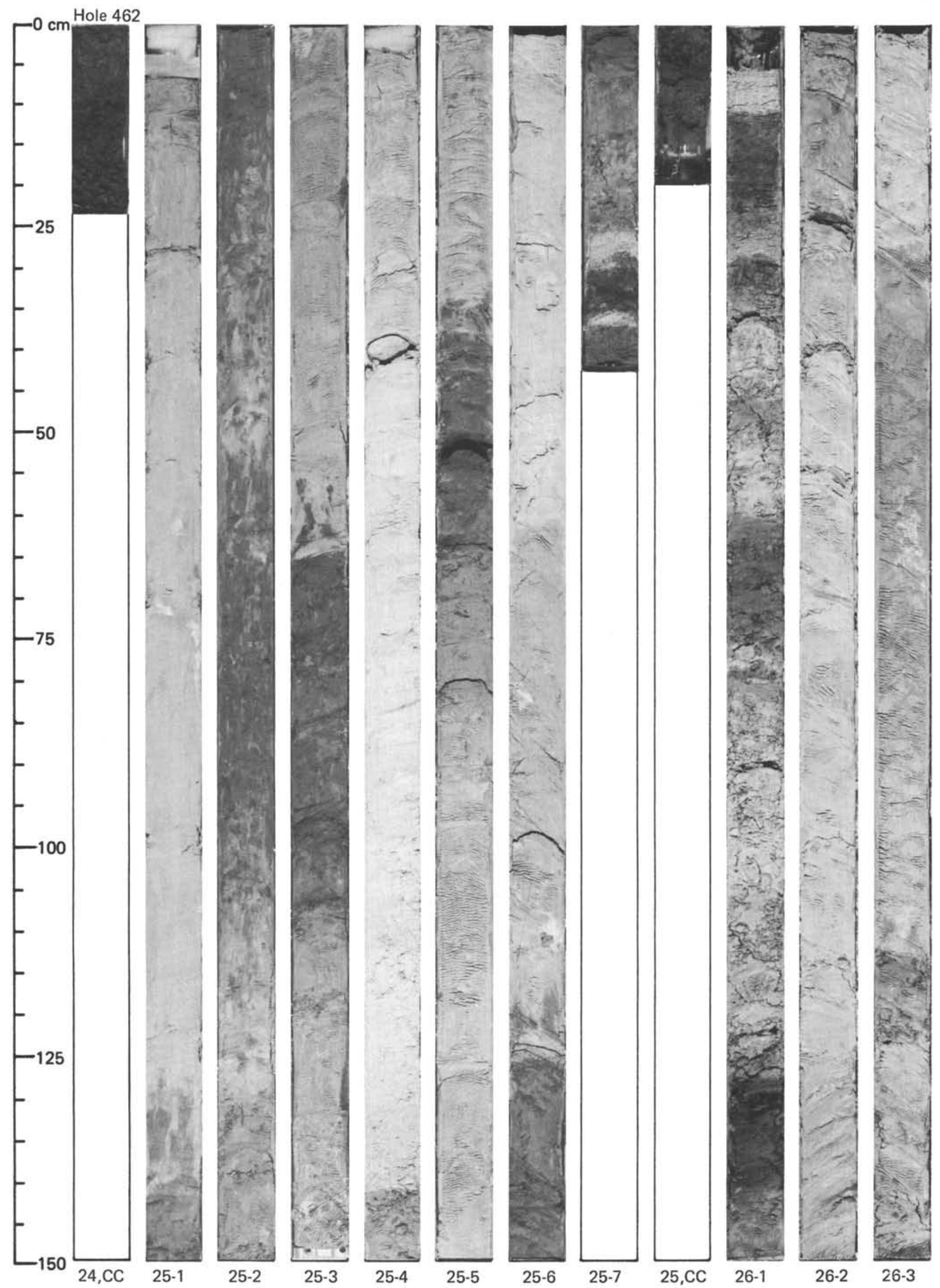




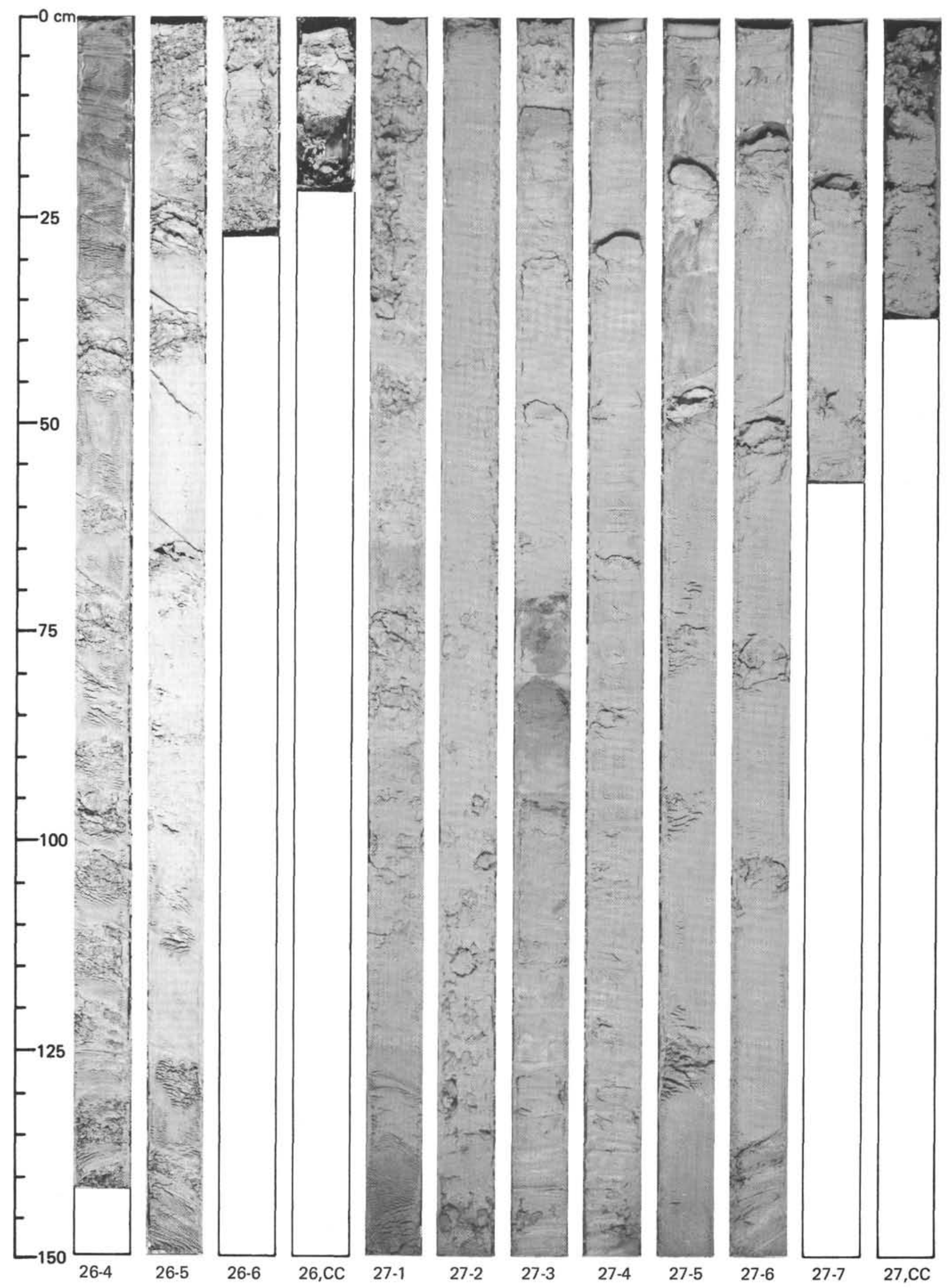




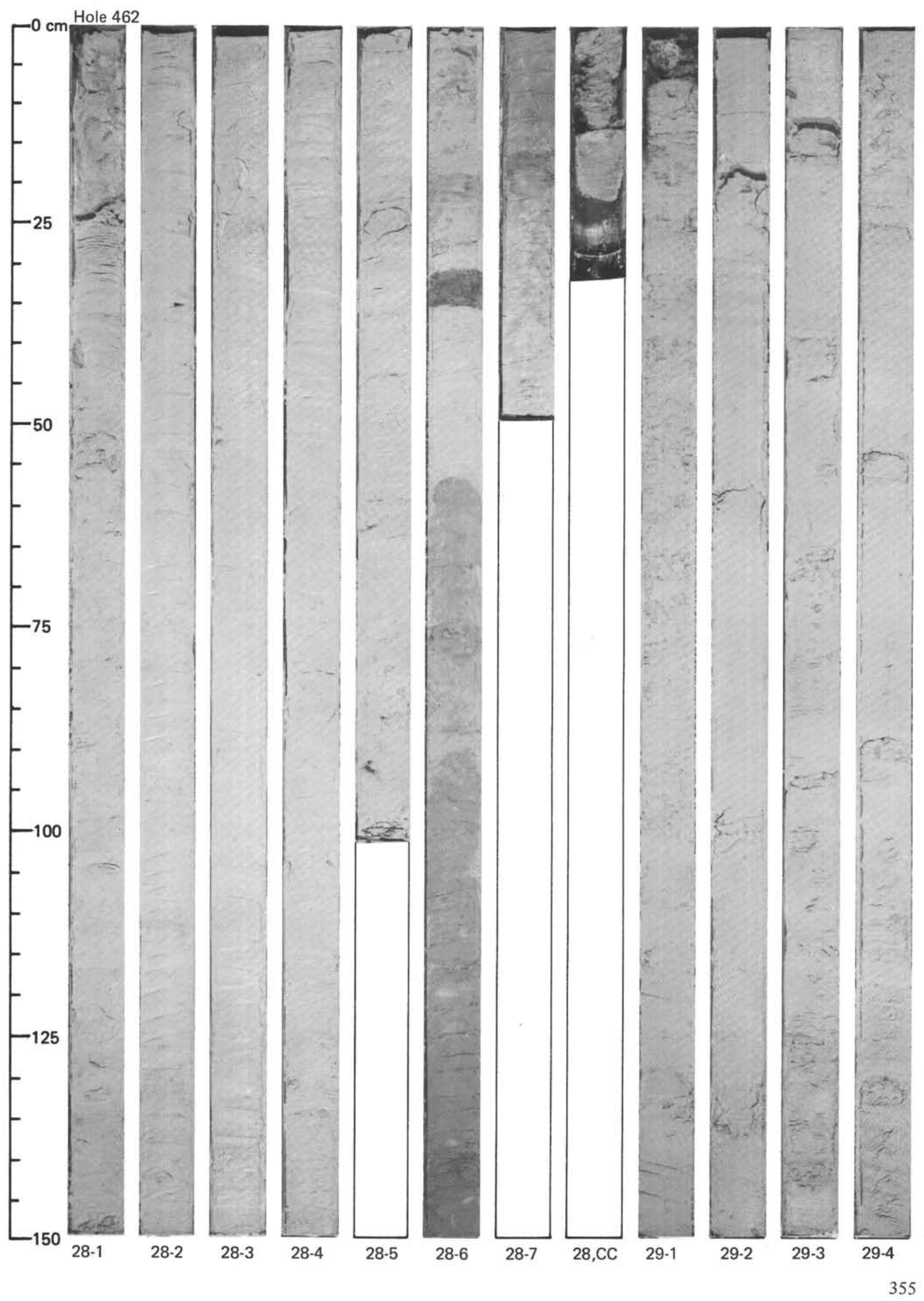




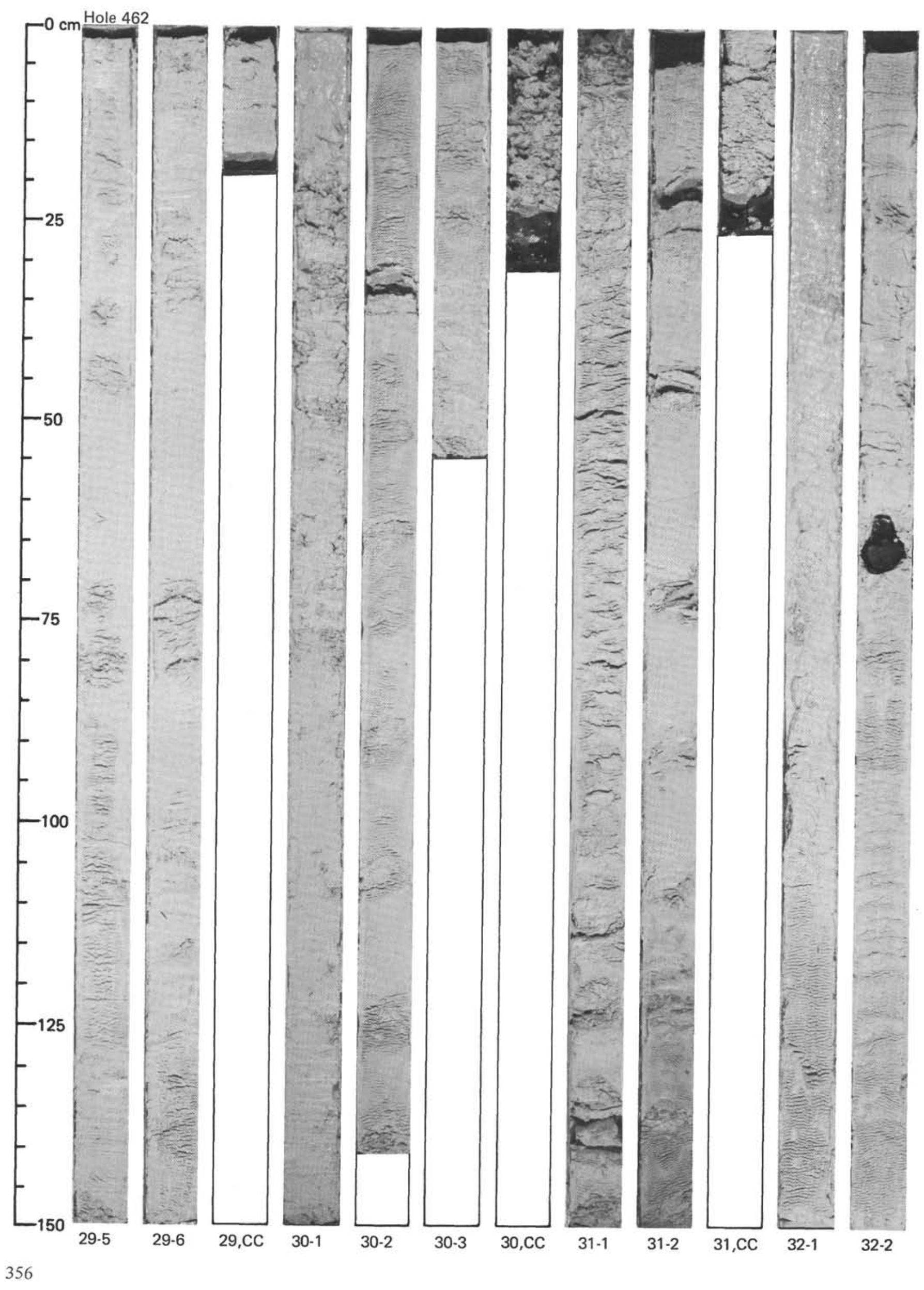




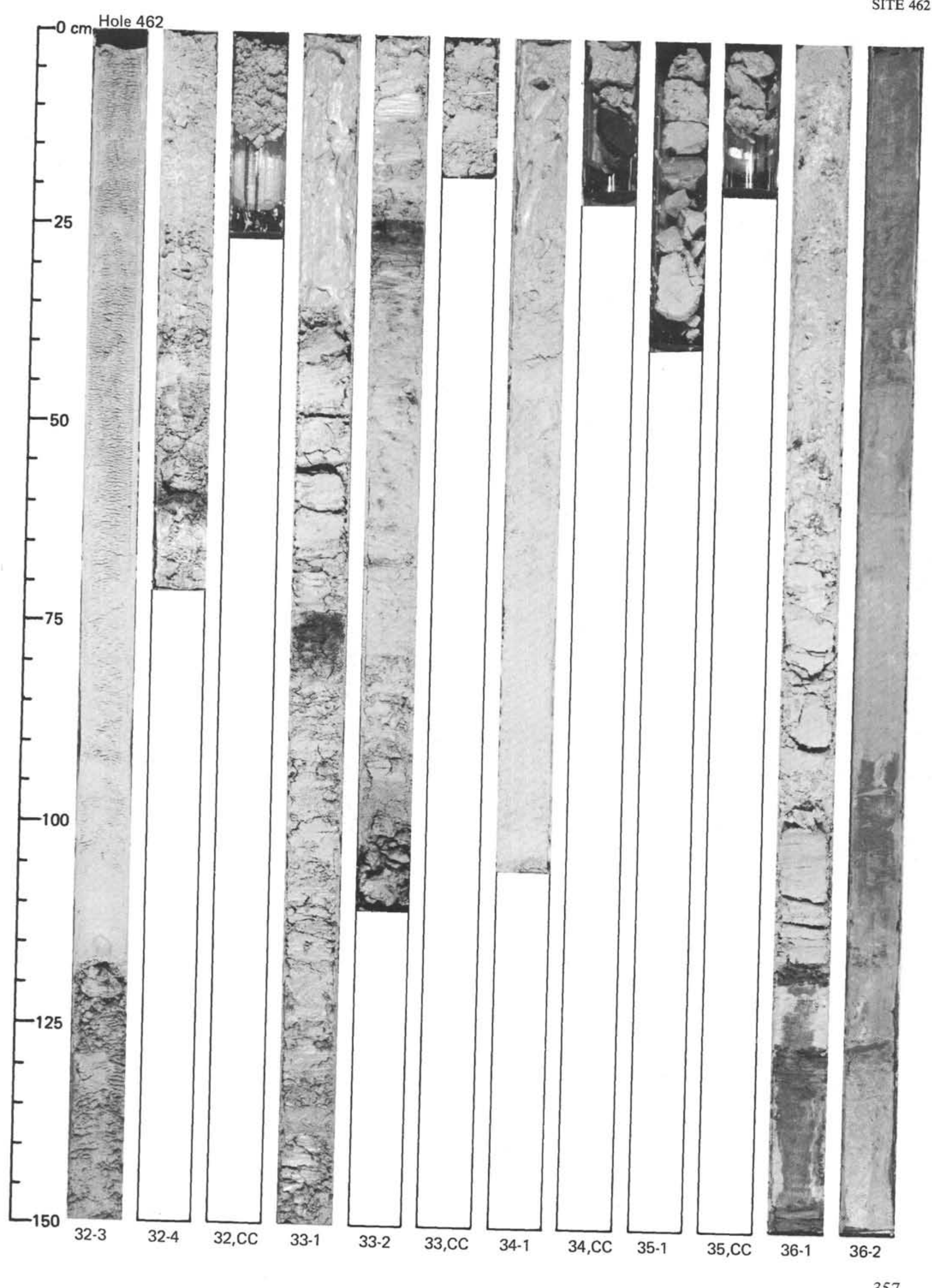




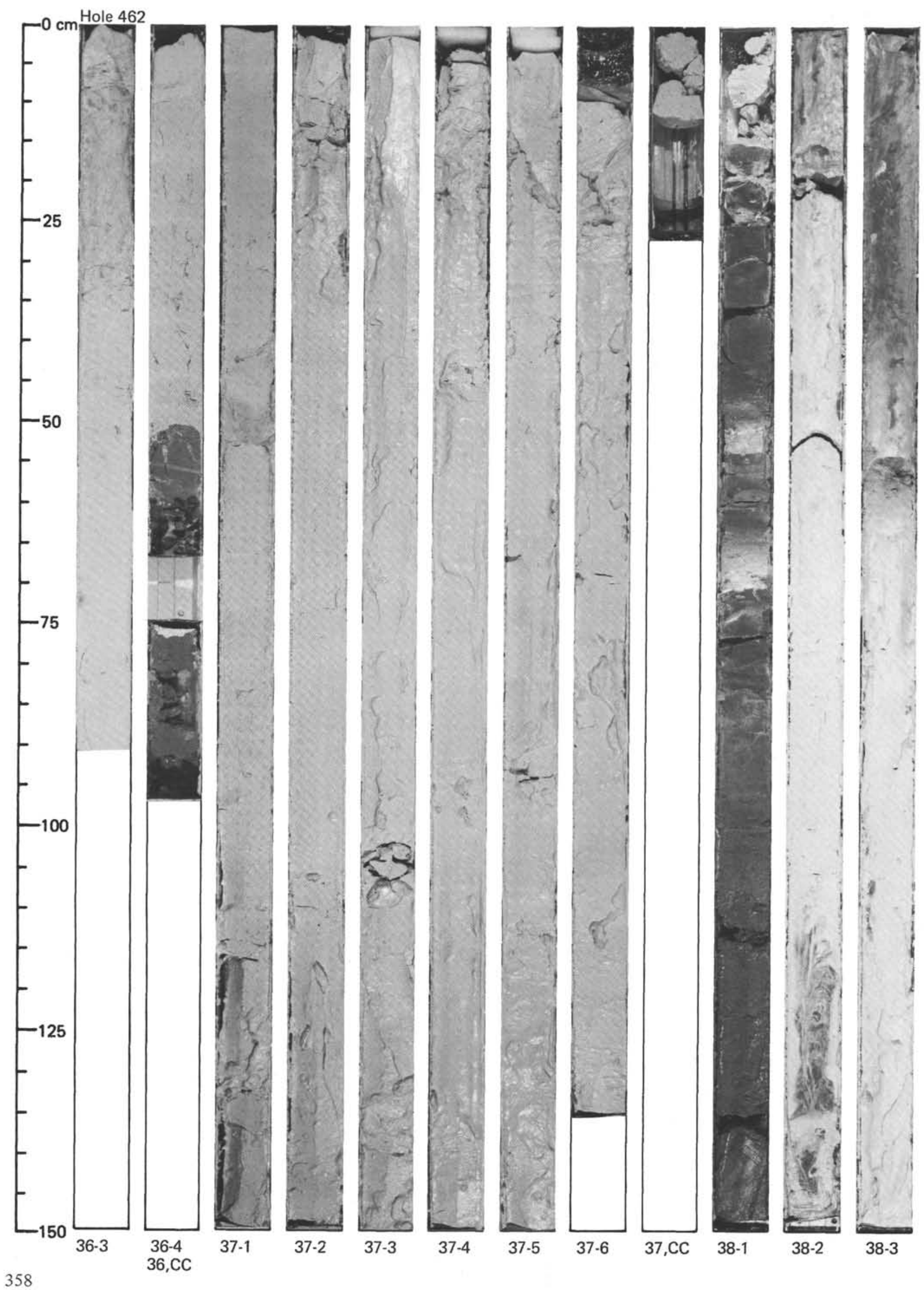



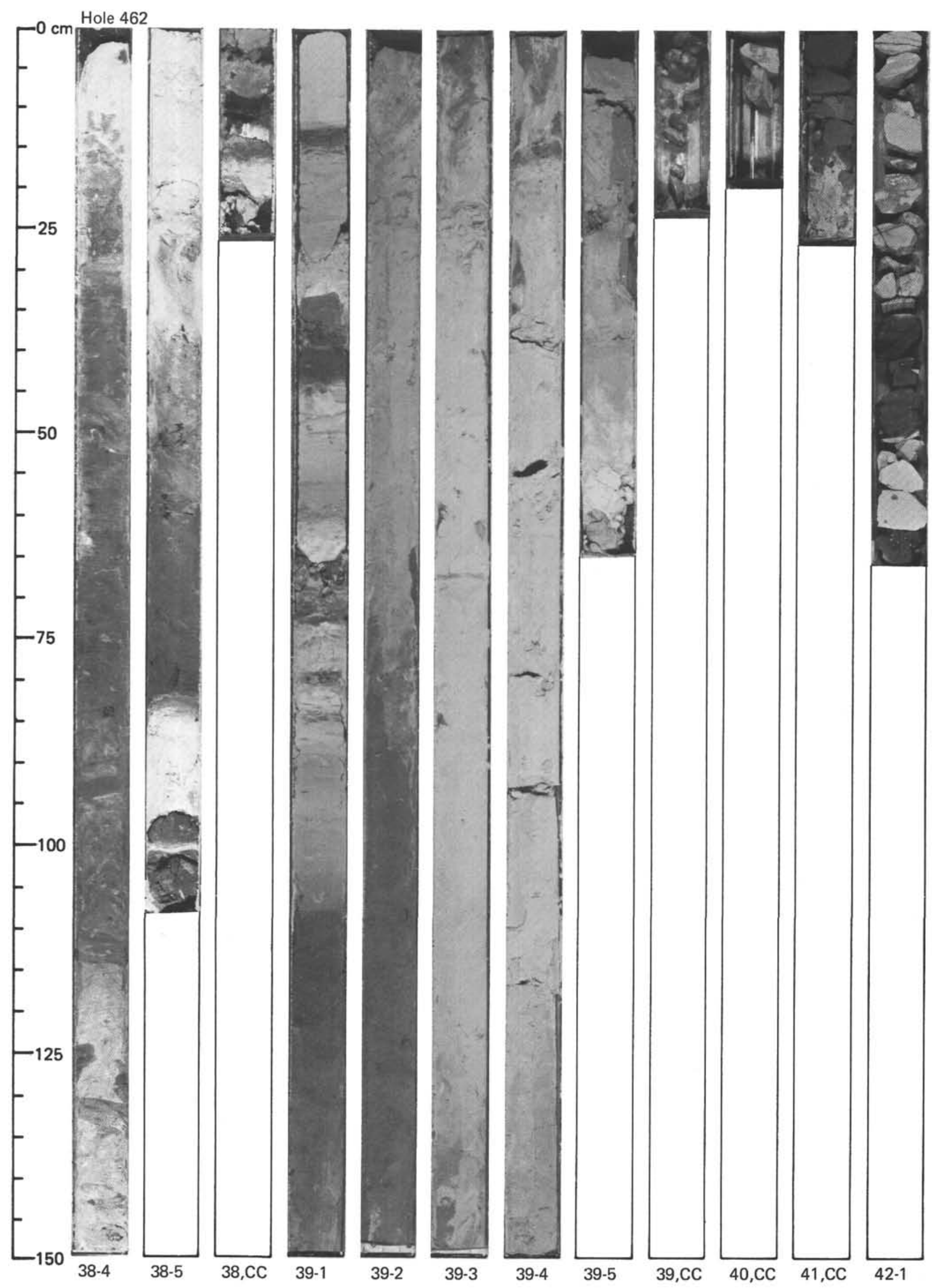


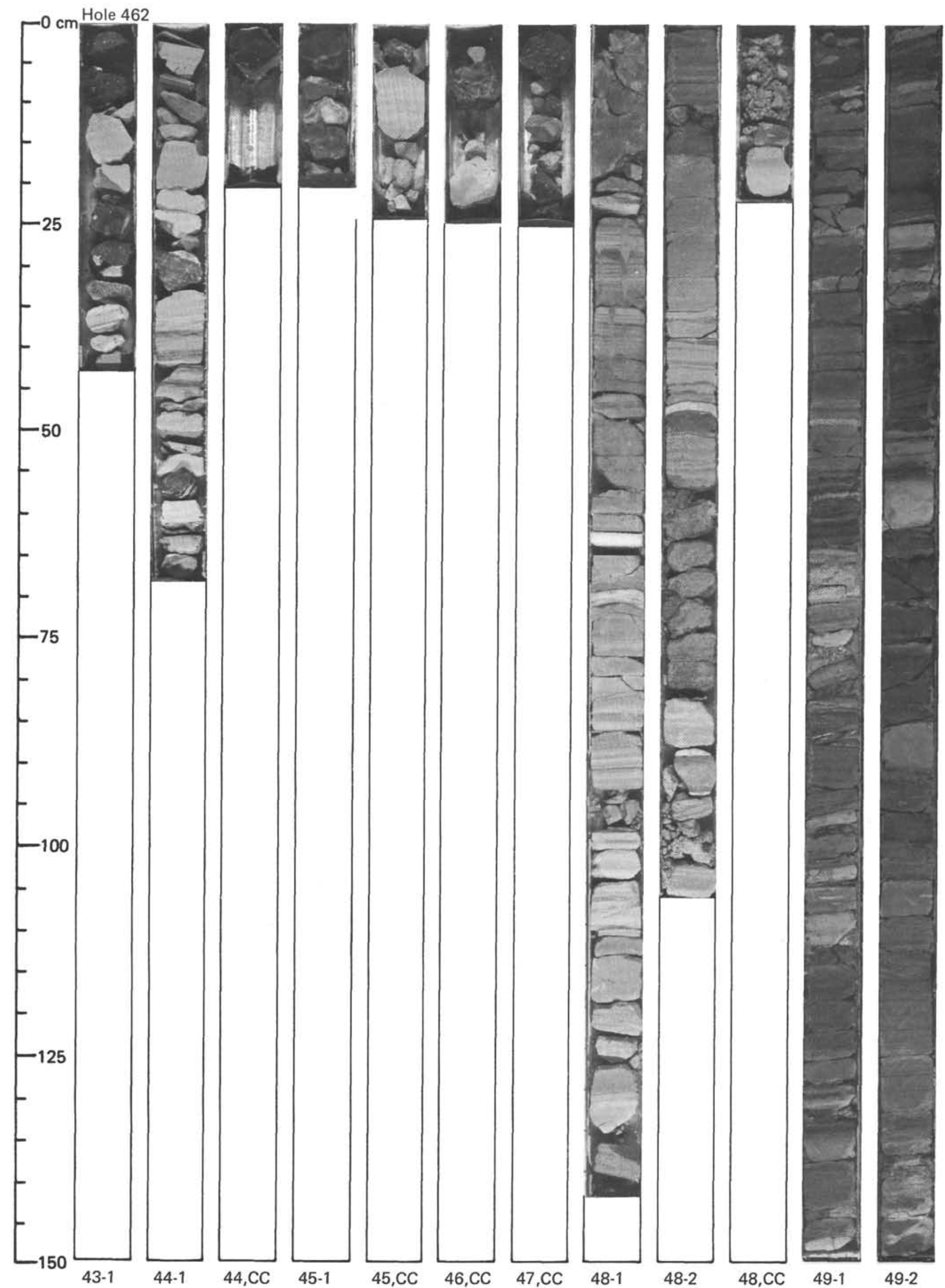




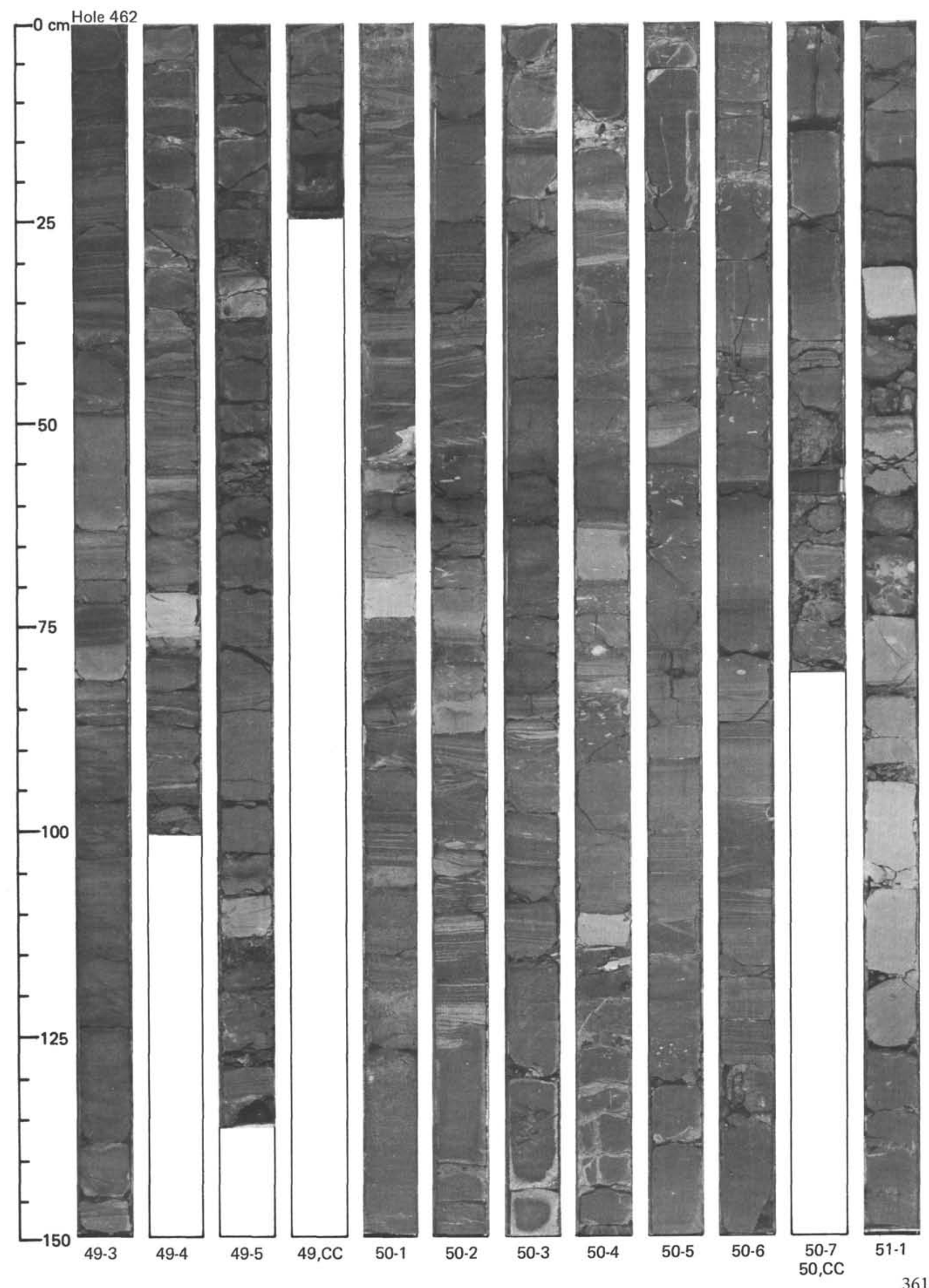



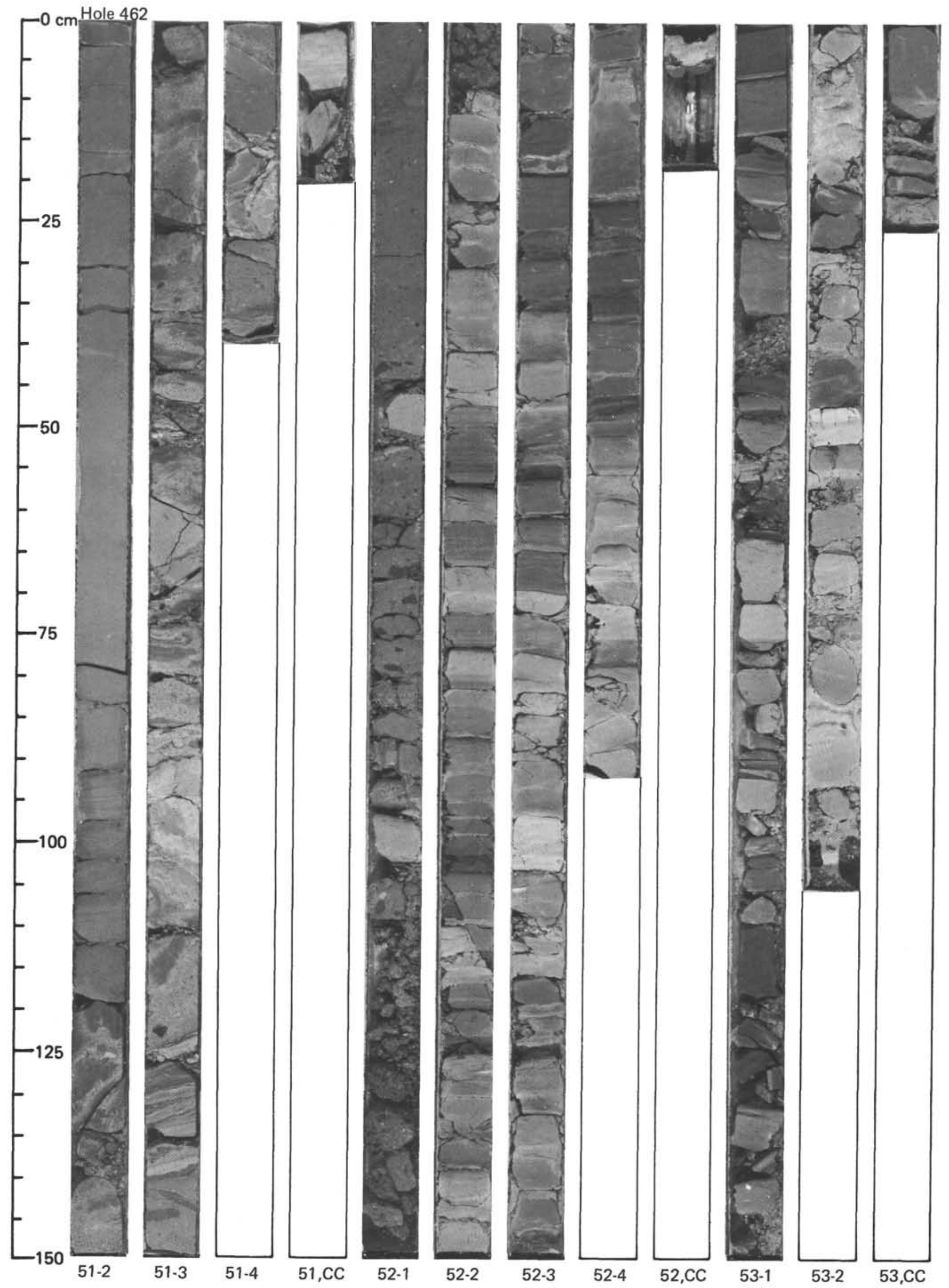

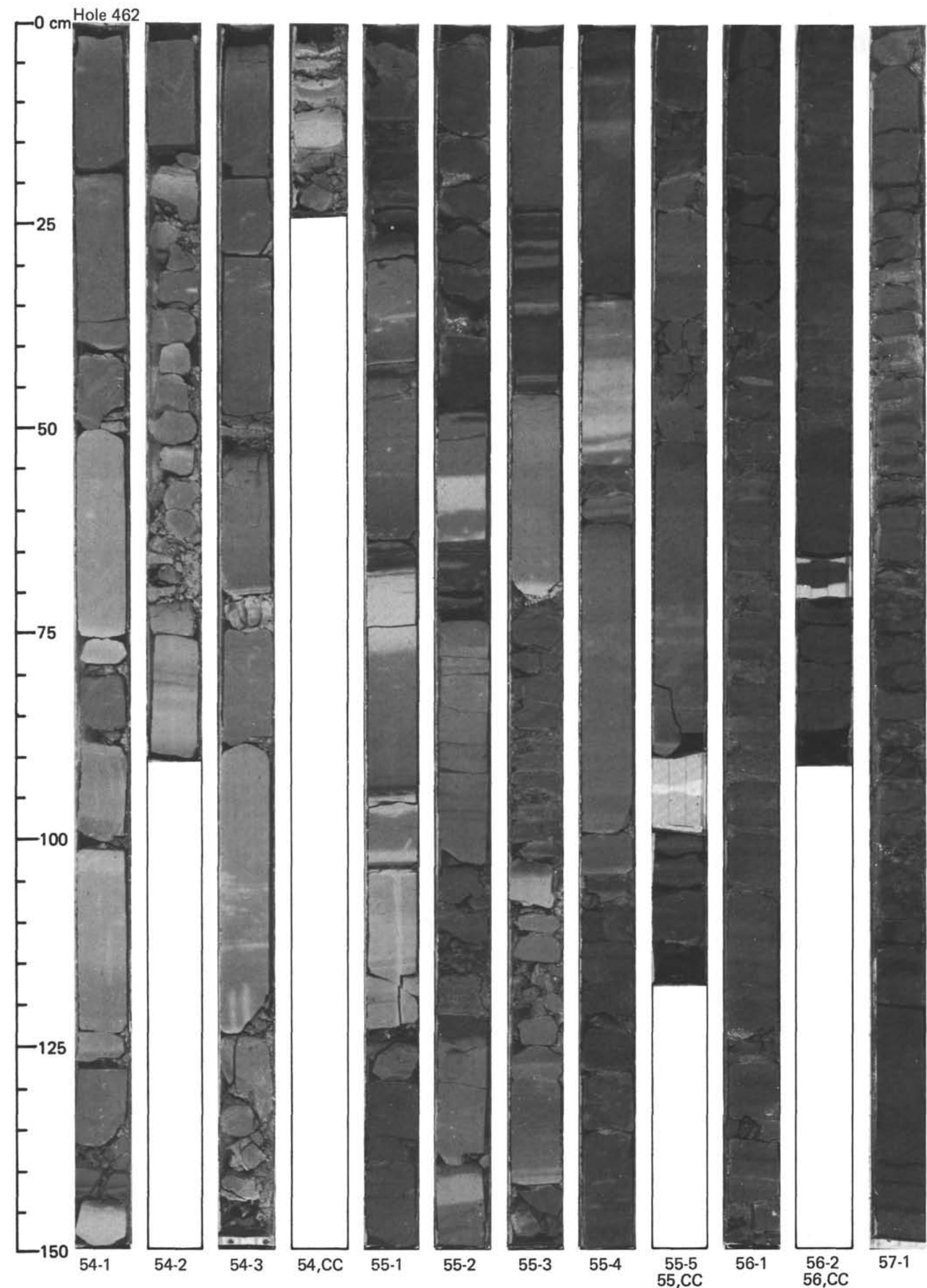


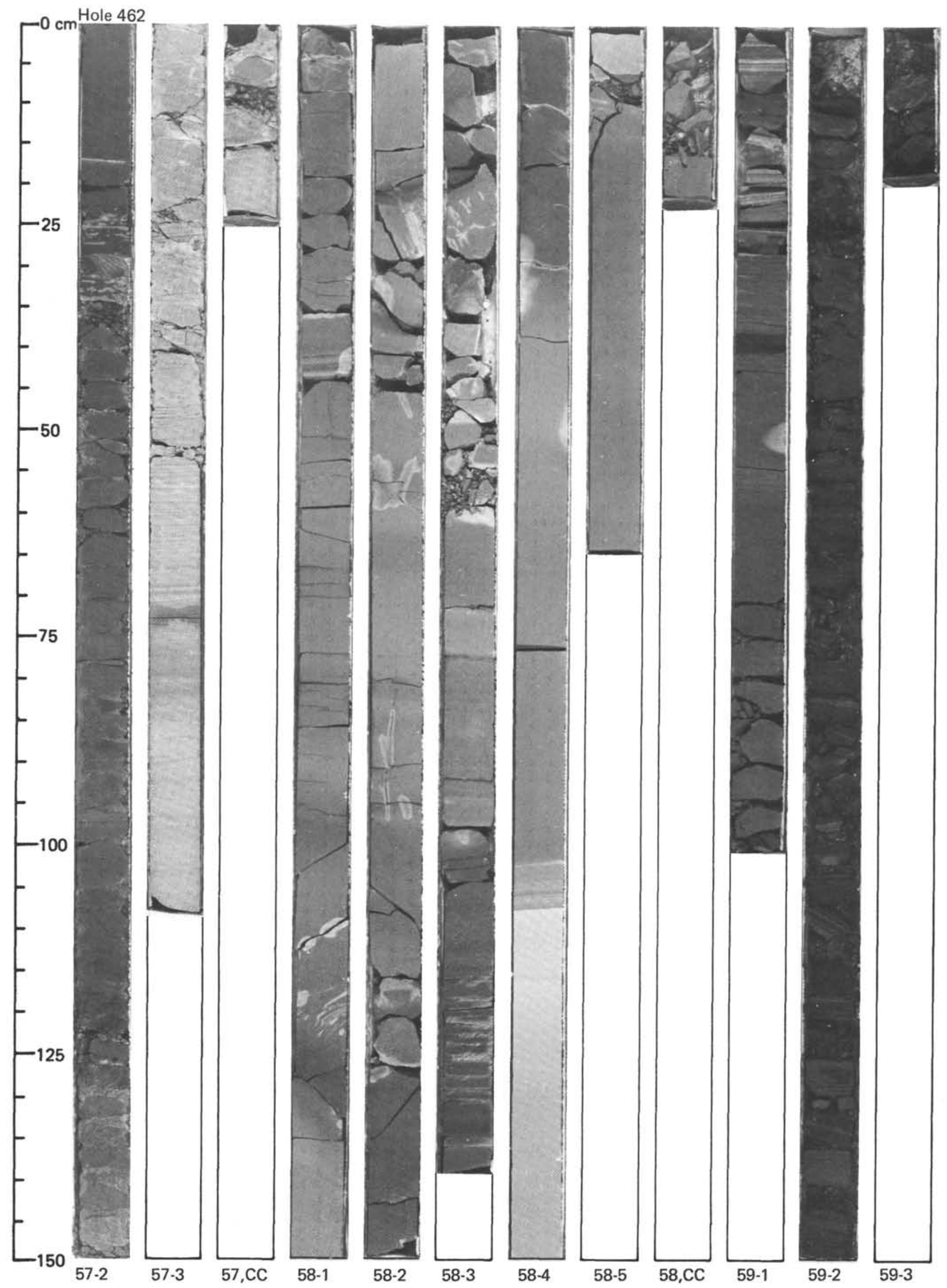




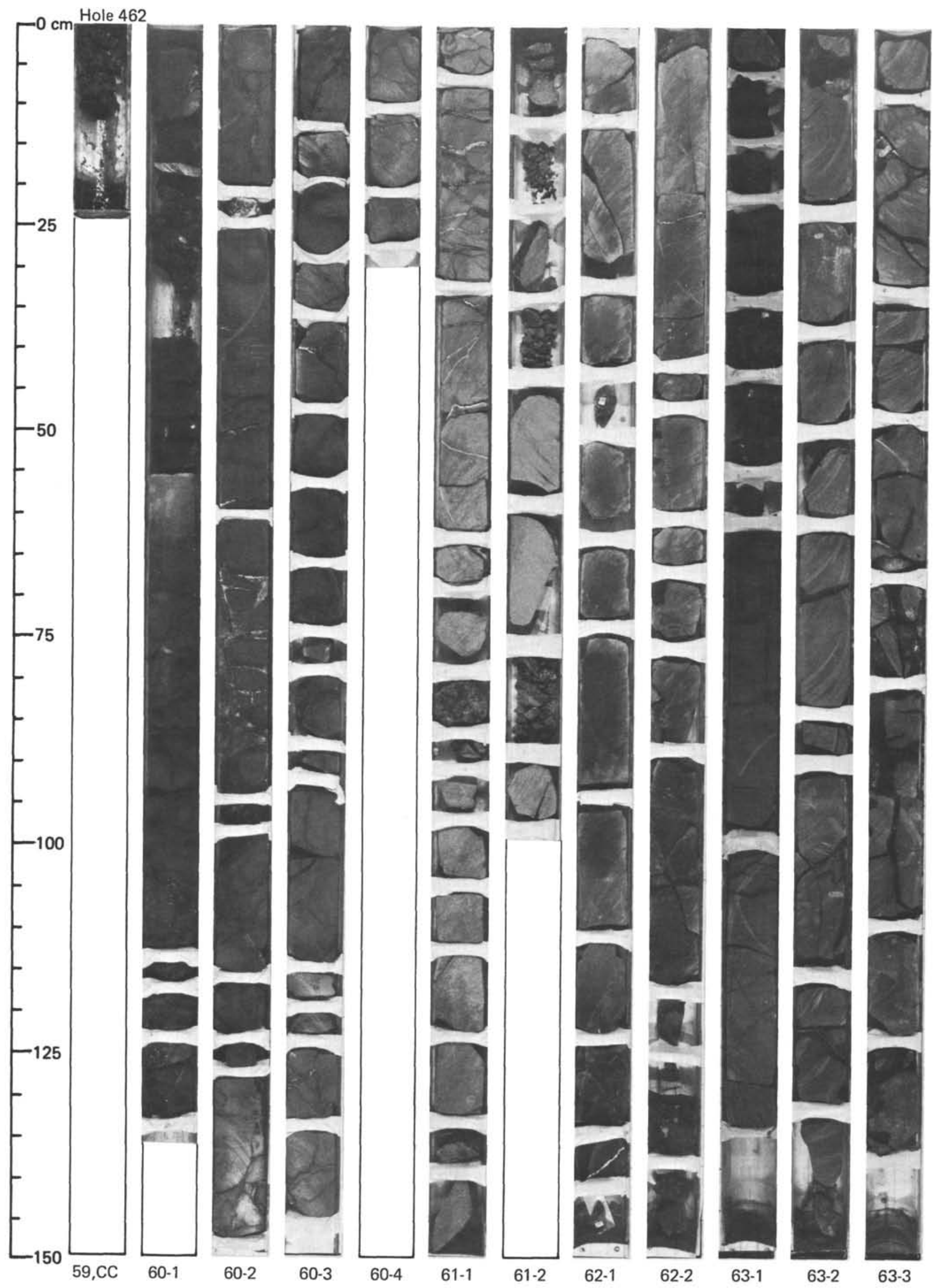




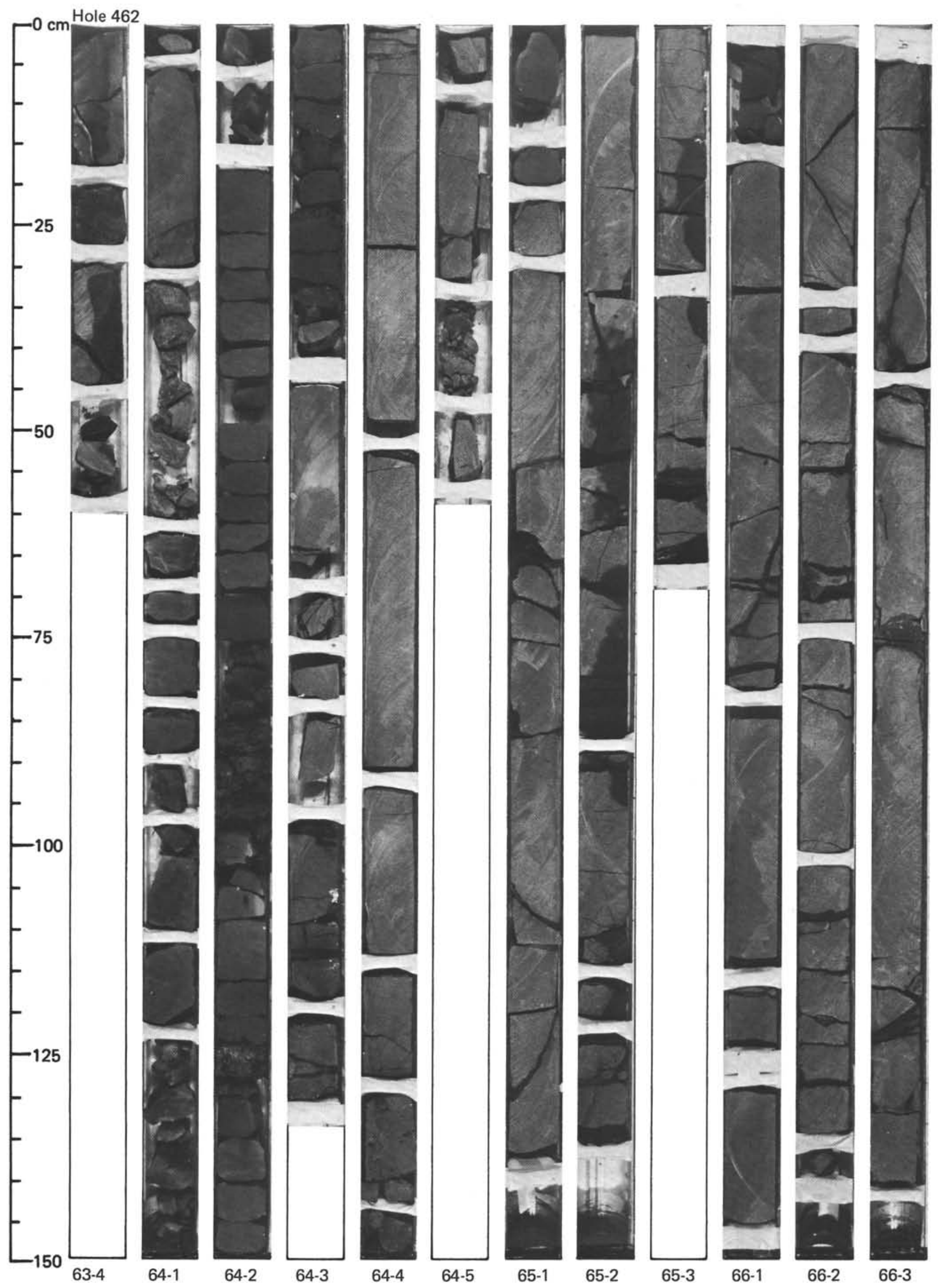




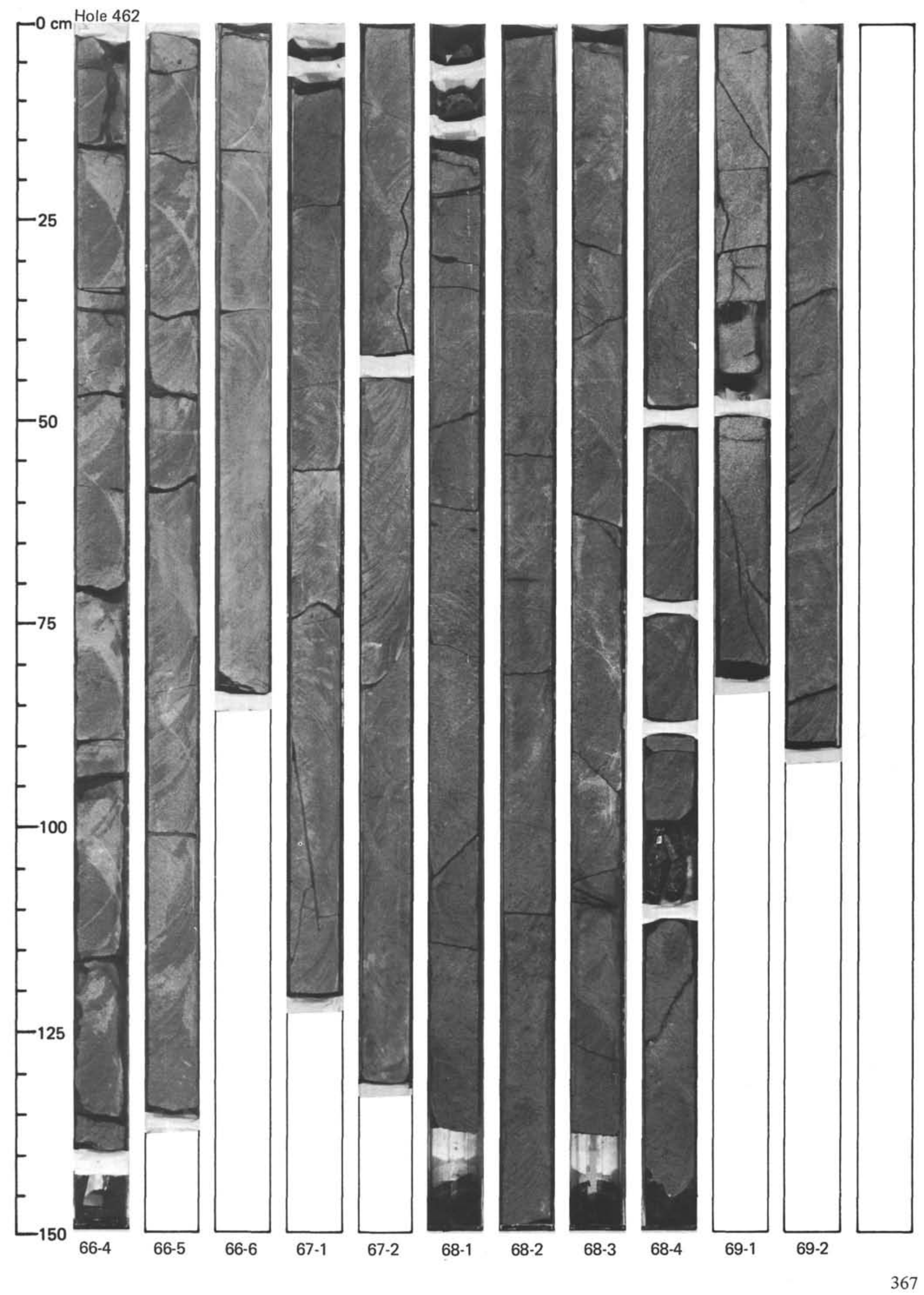




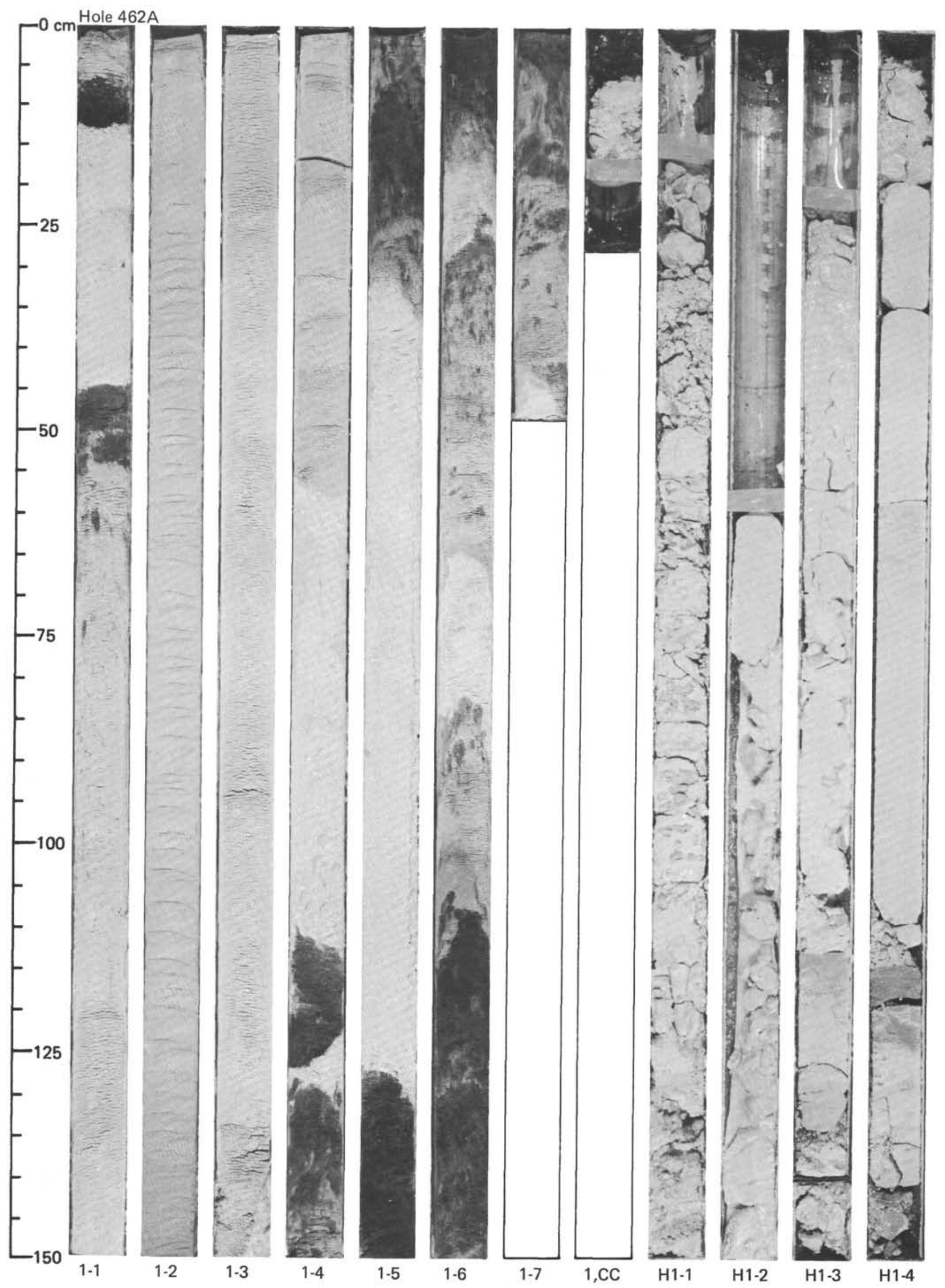



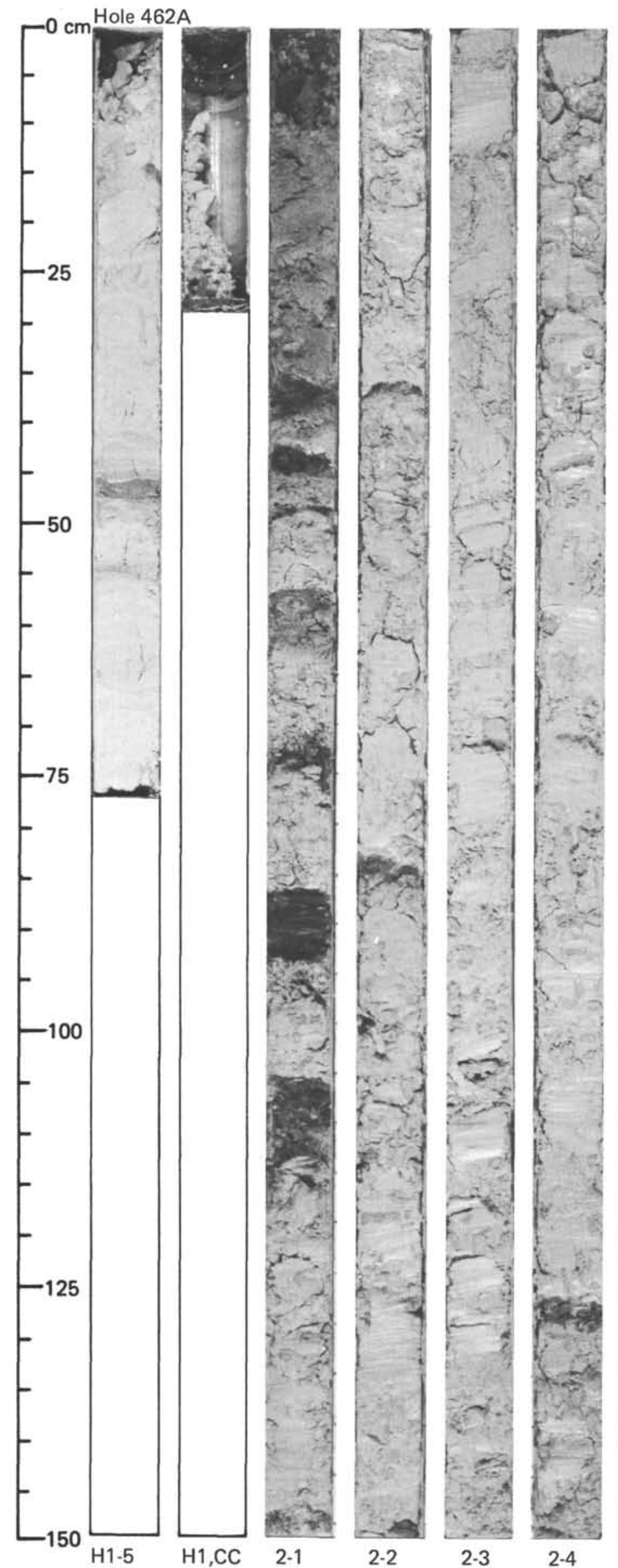
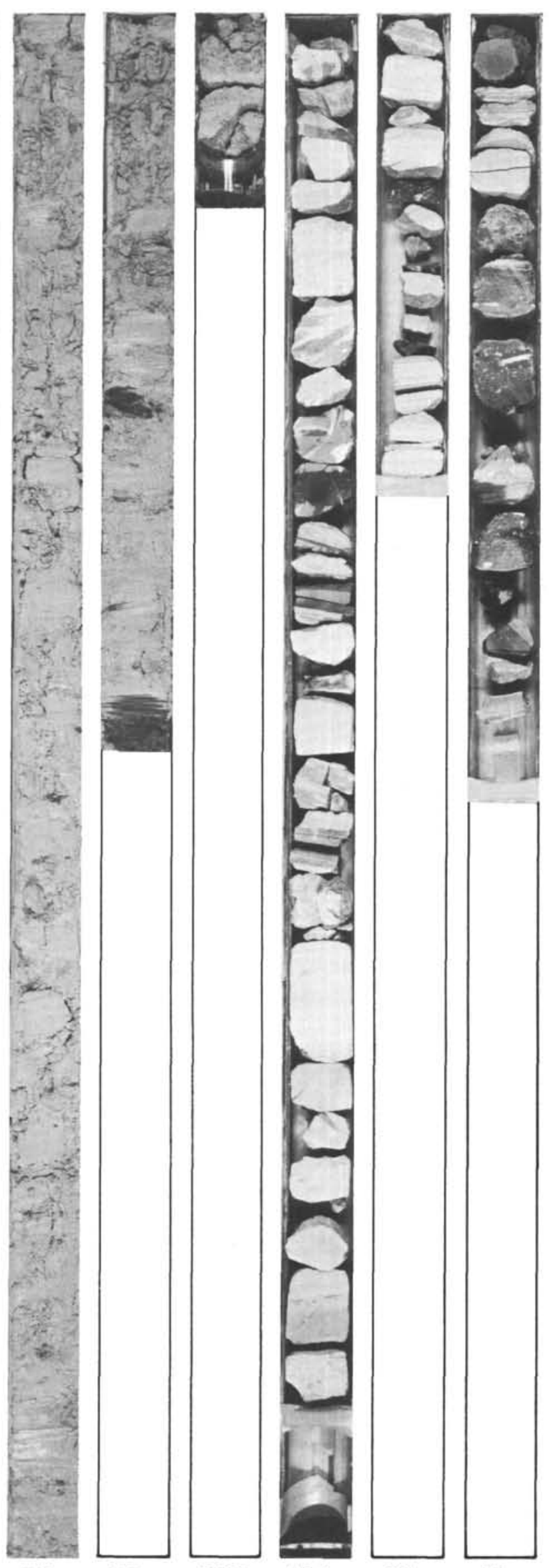

2-5
2-6

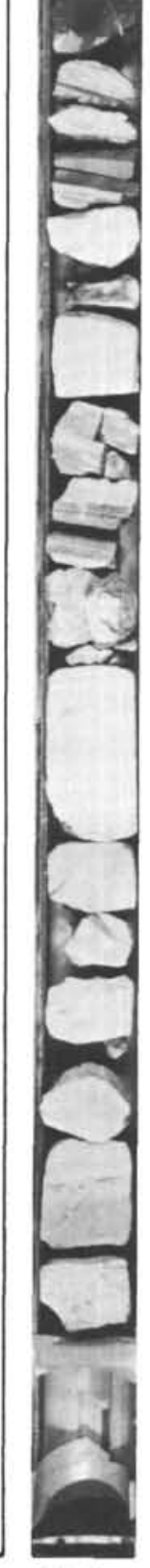

H2-1
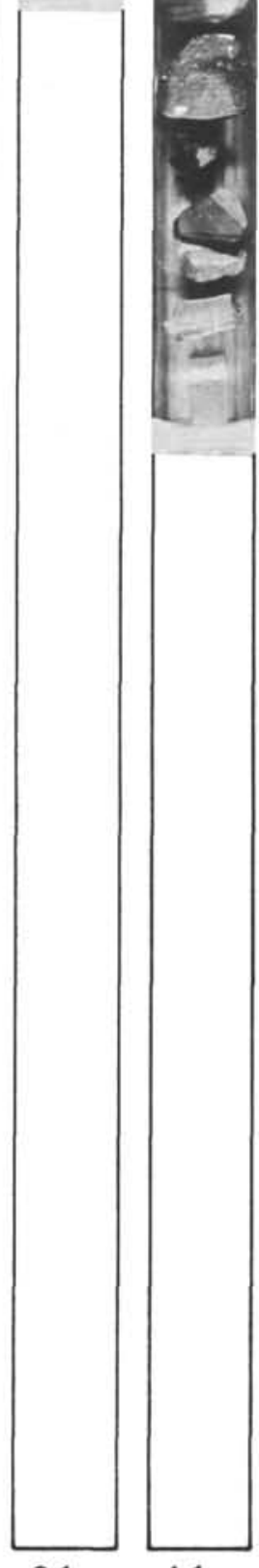

3-1 4-1 


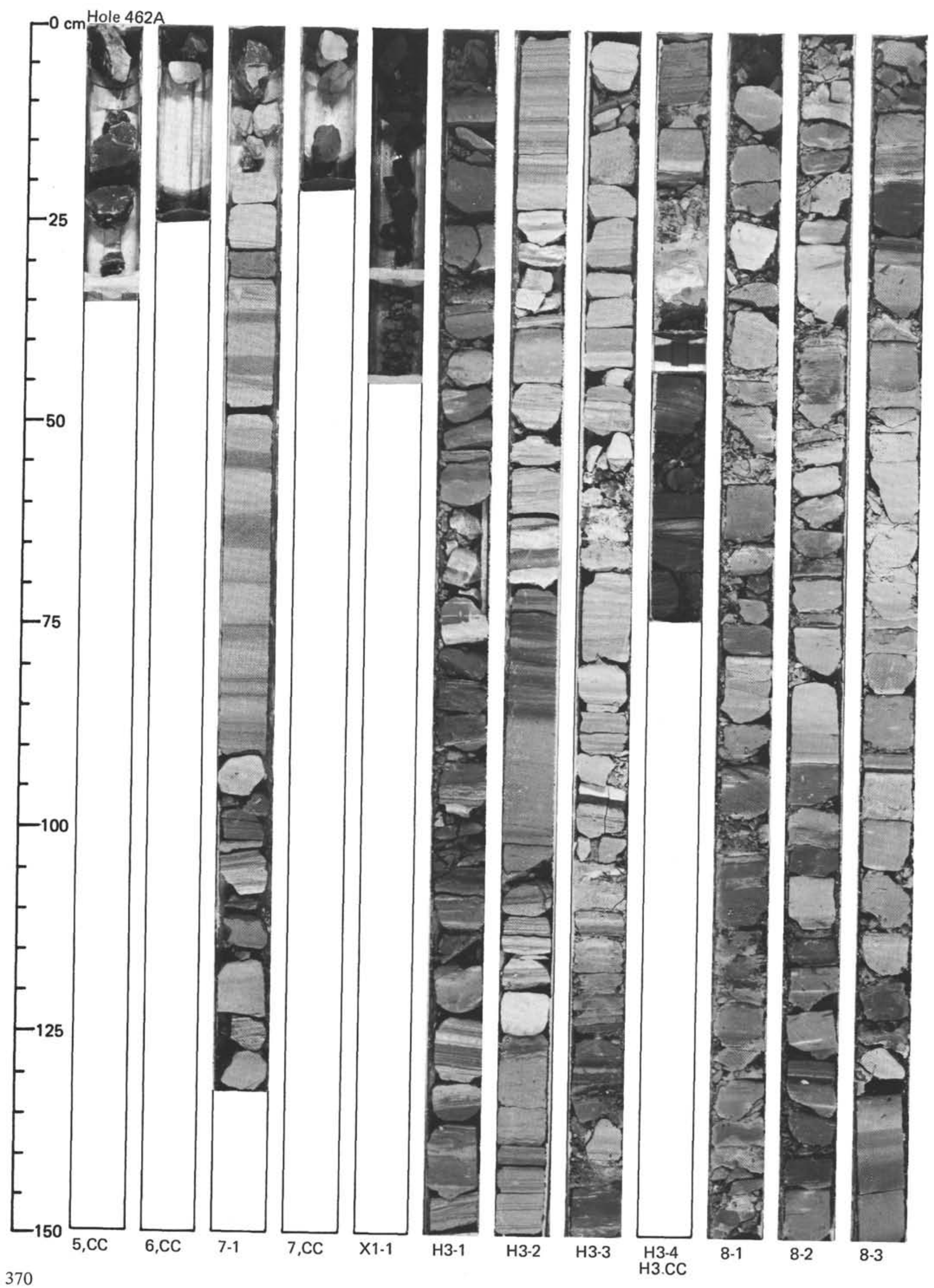




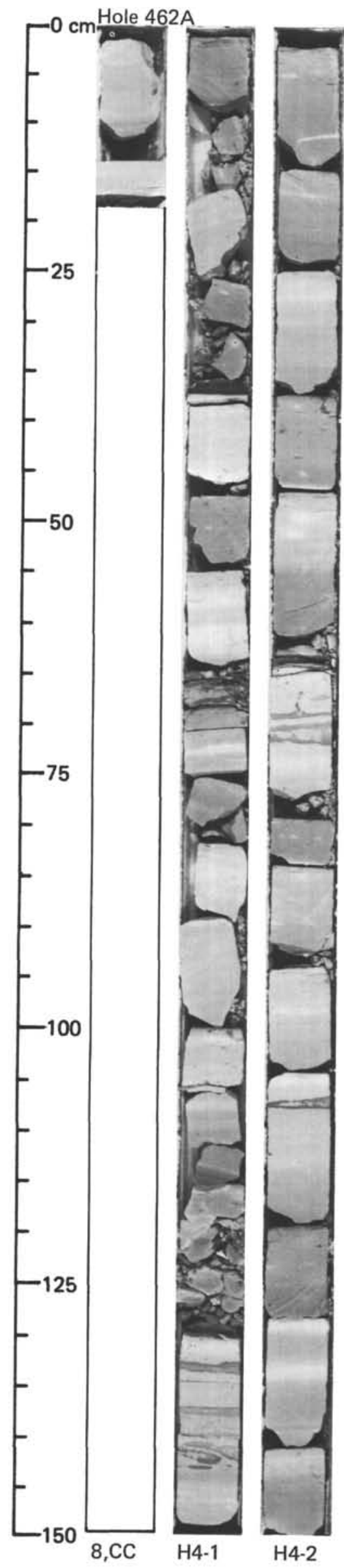

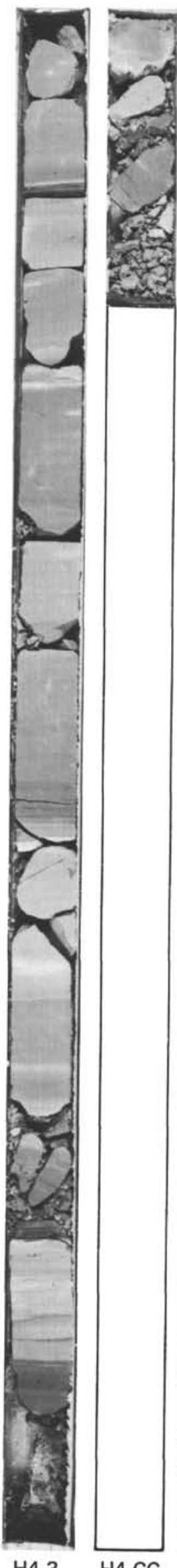

H4-3 H4,CC

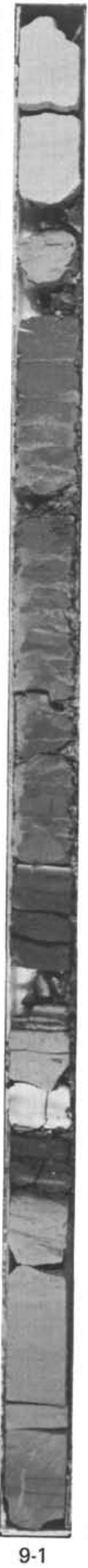

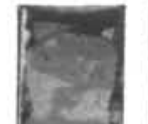
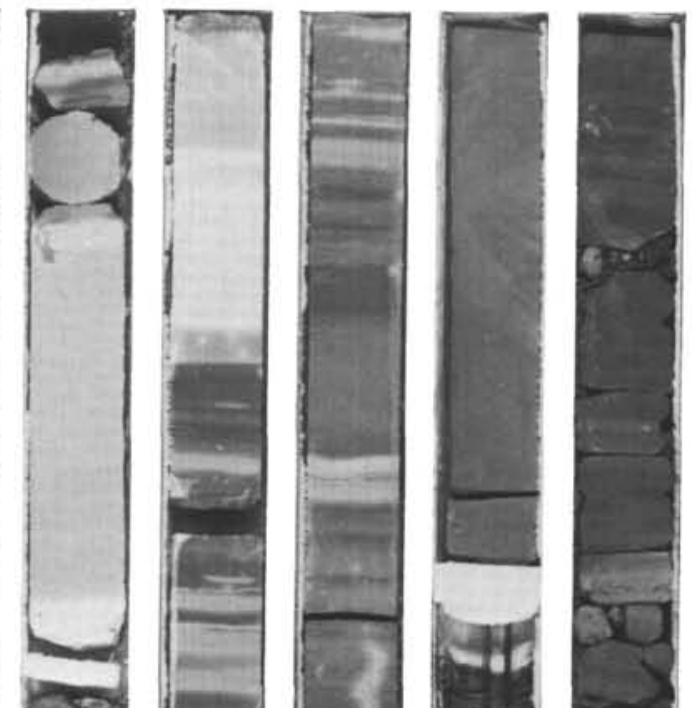

\section{$\rightarrow \infty$}
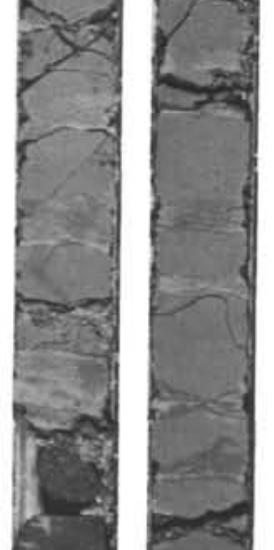

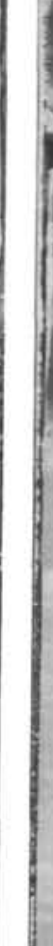
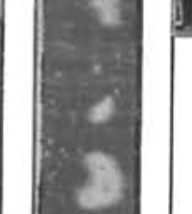

\section{(n)}

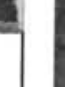




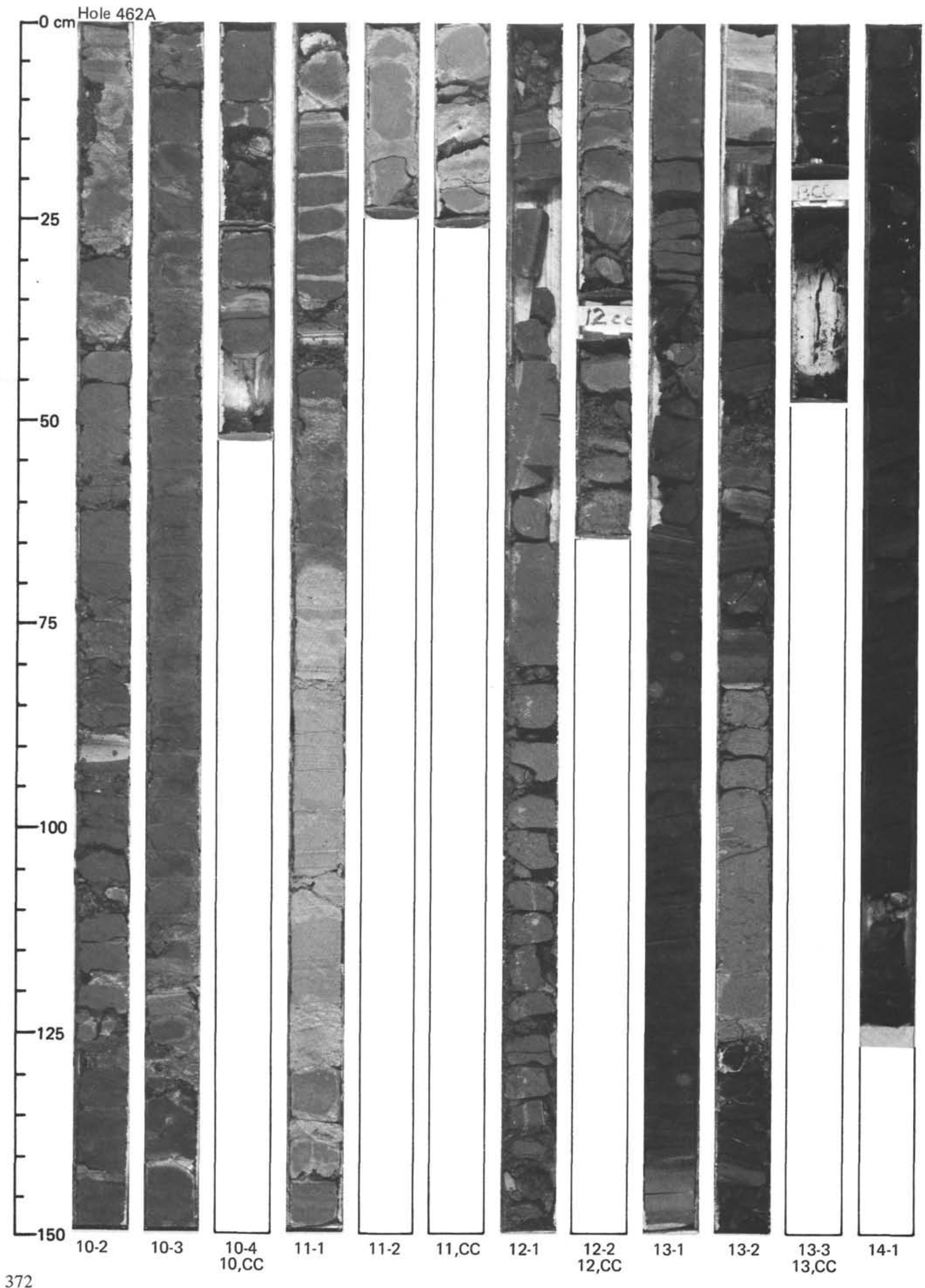



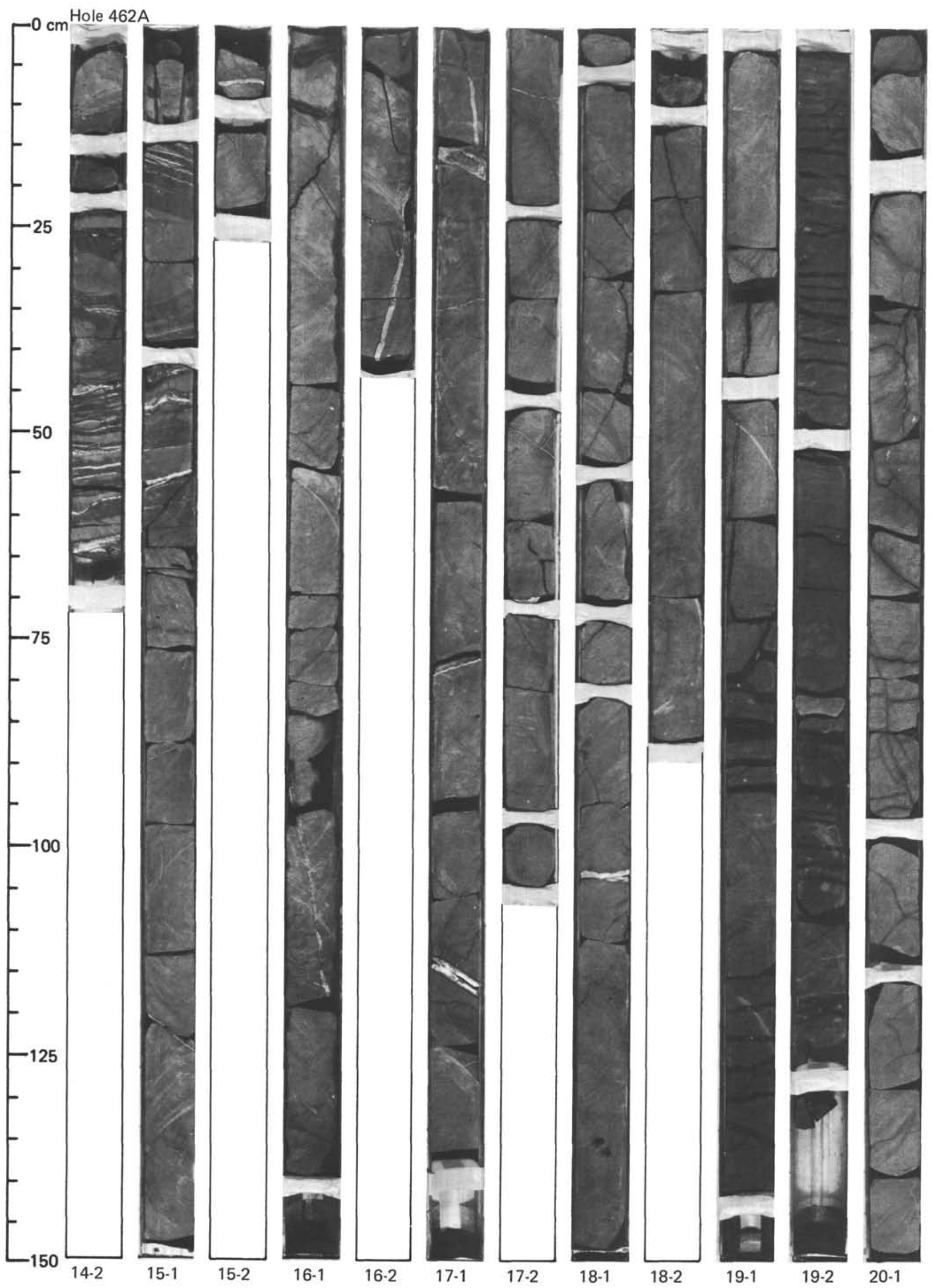


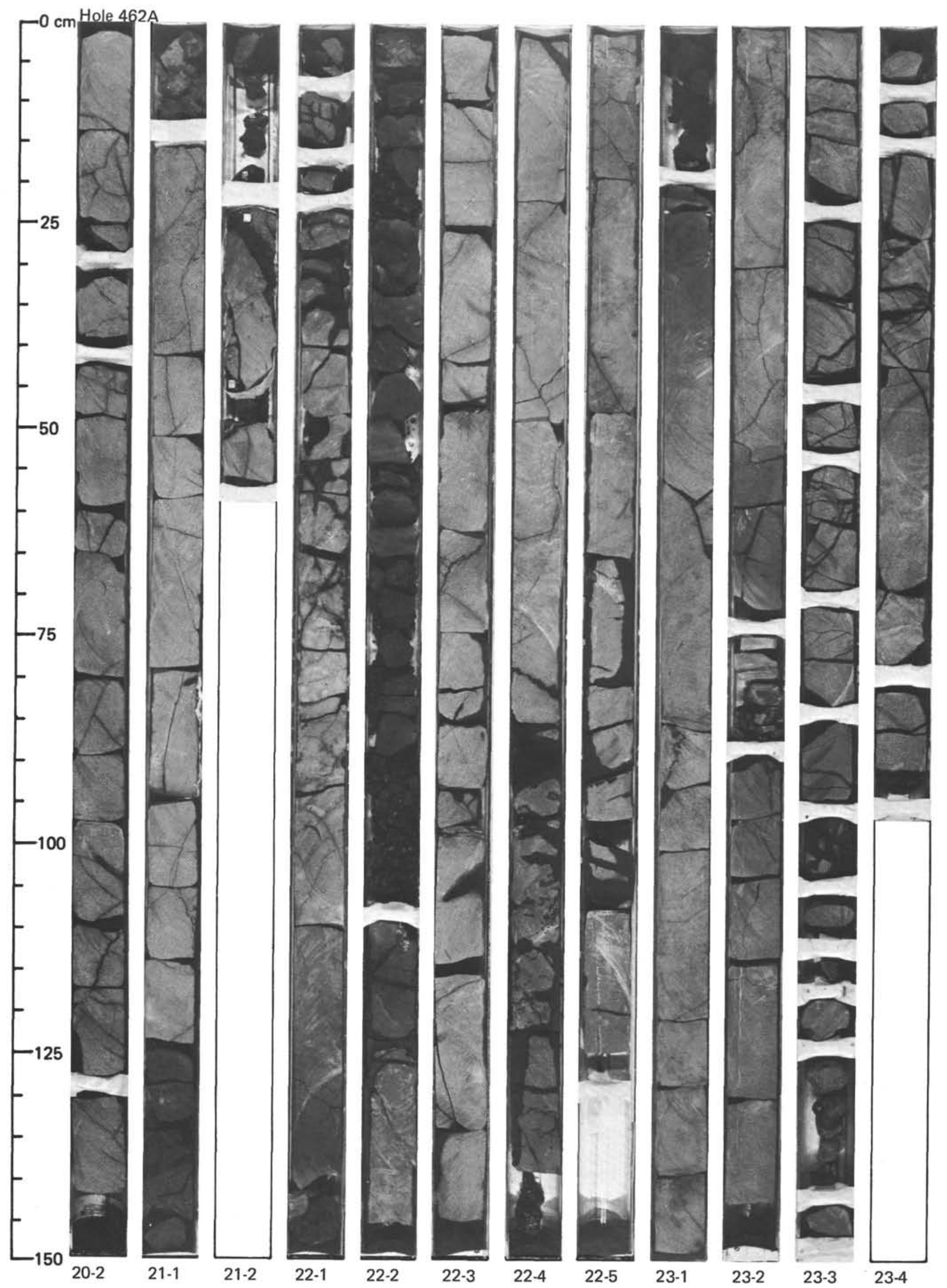




\section{- $0 \mathrm{~cm}$ Hole 462A}

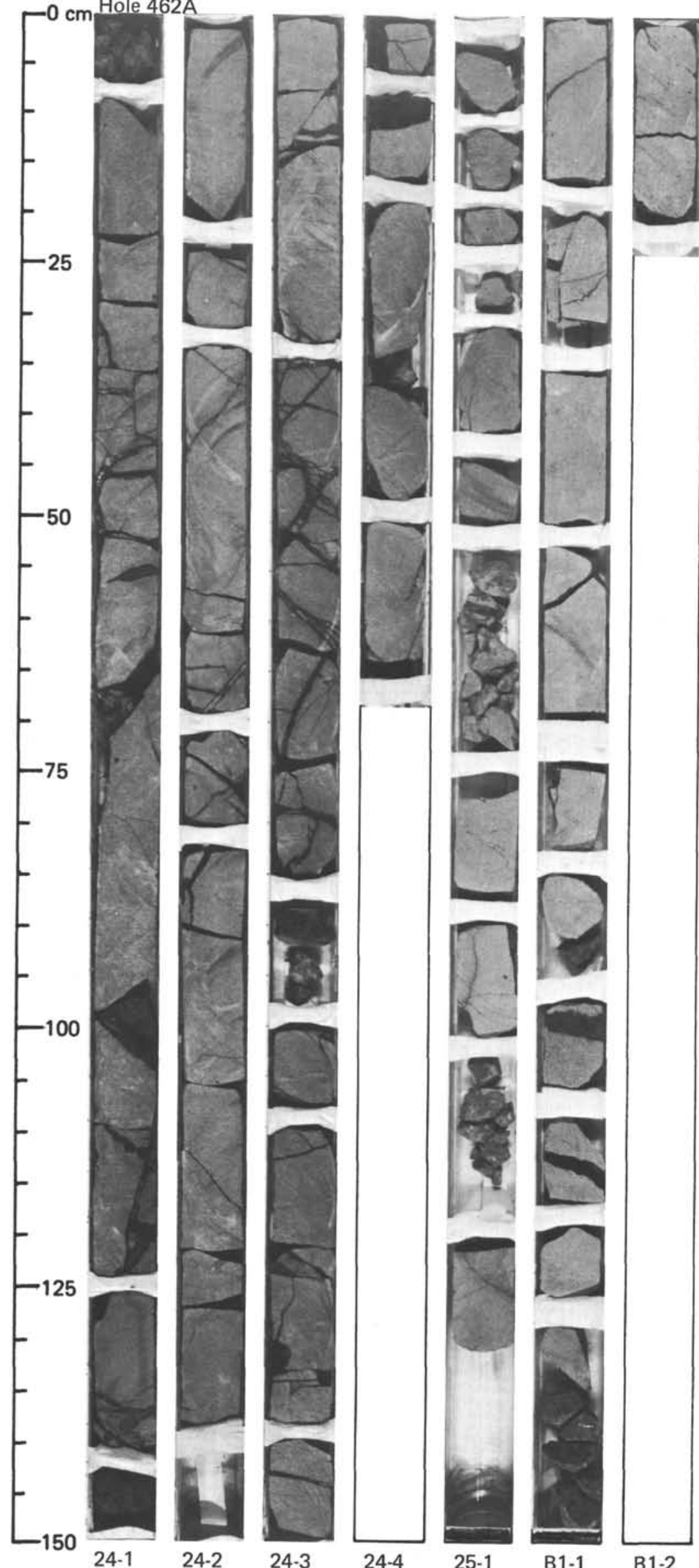

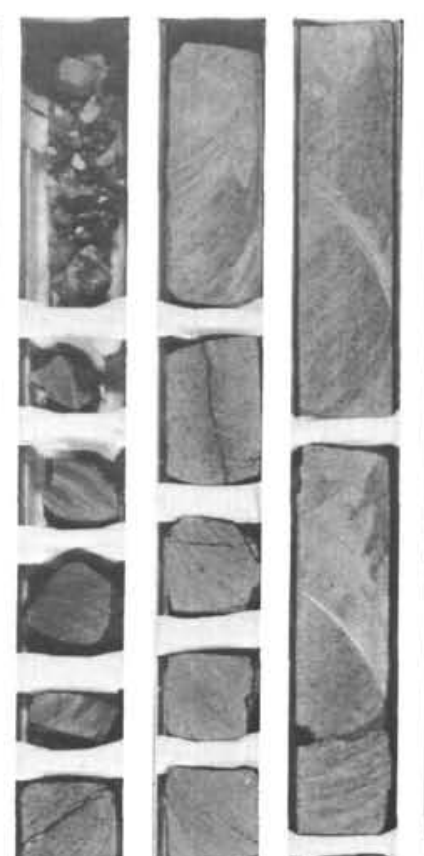
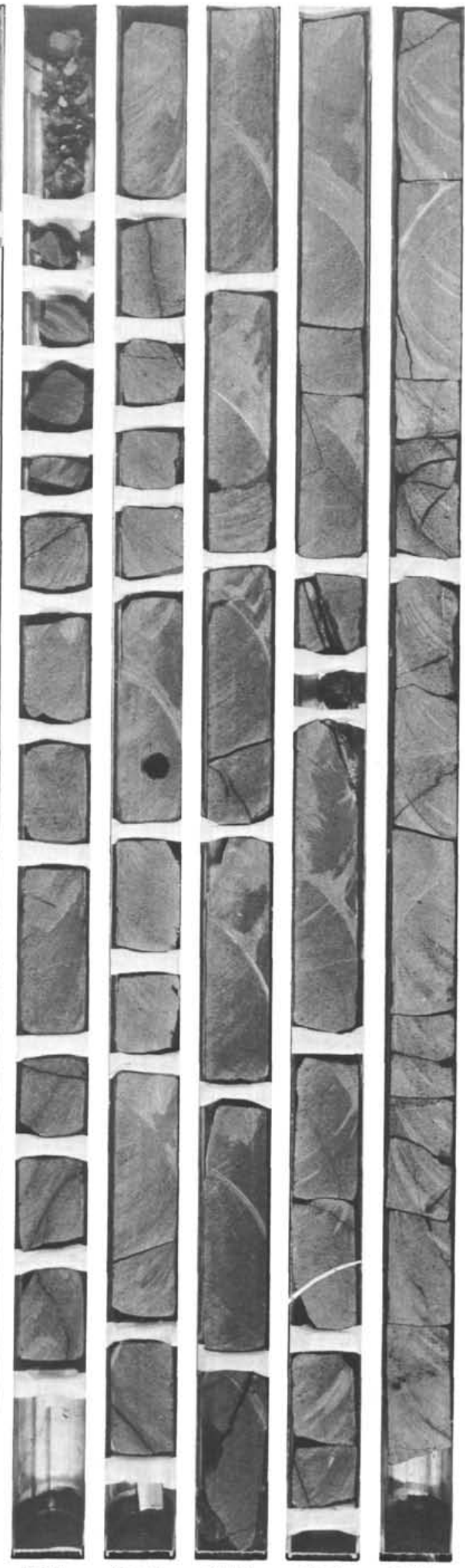
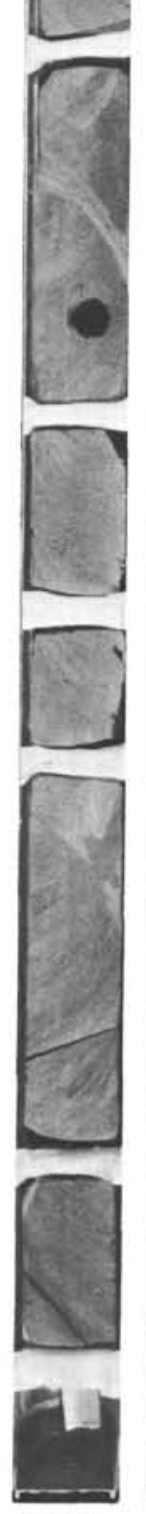


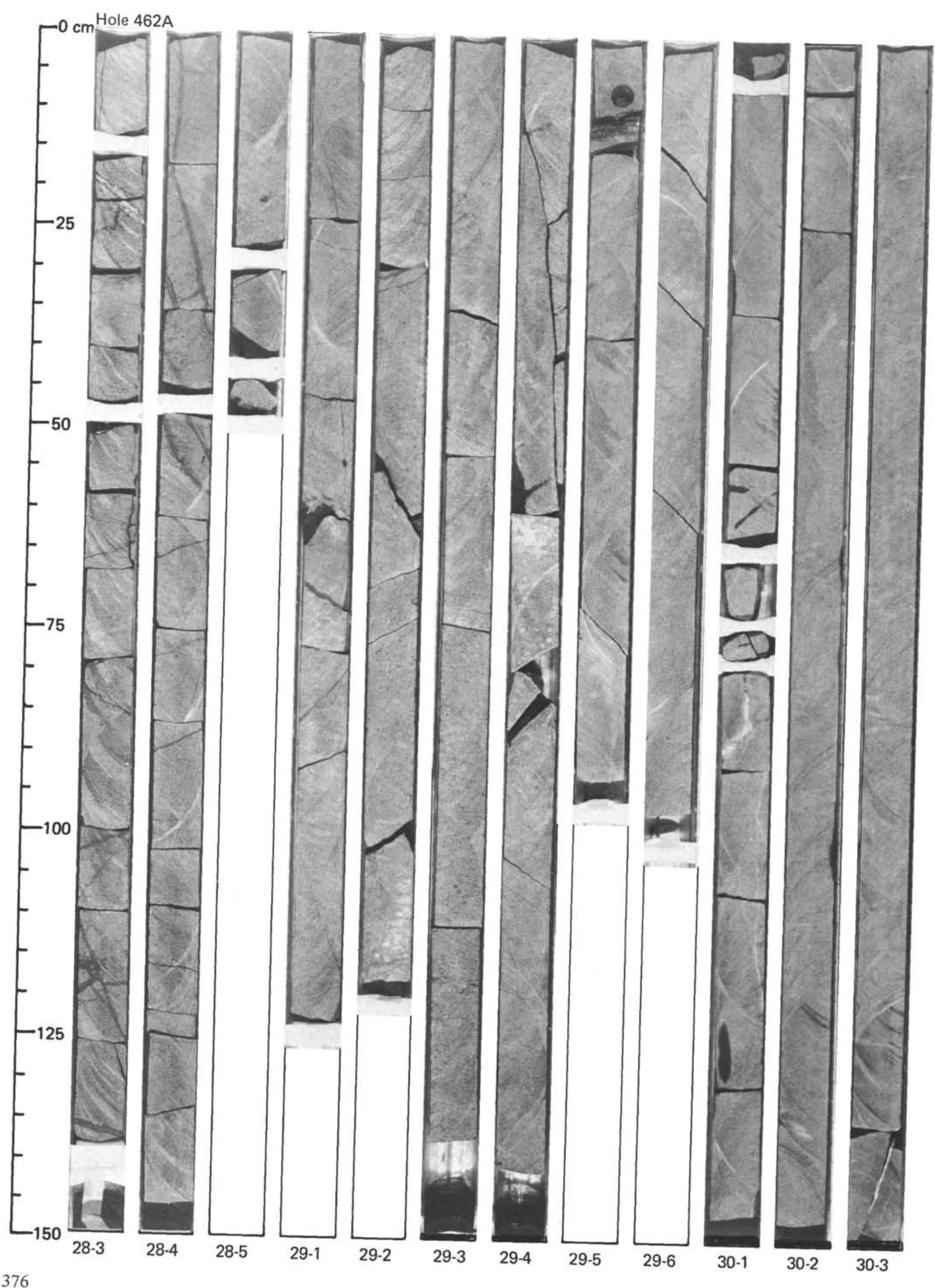




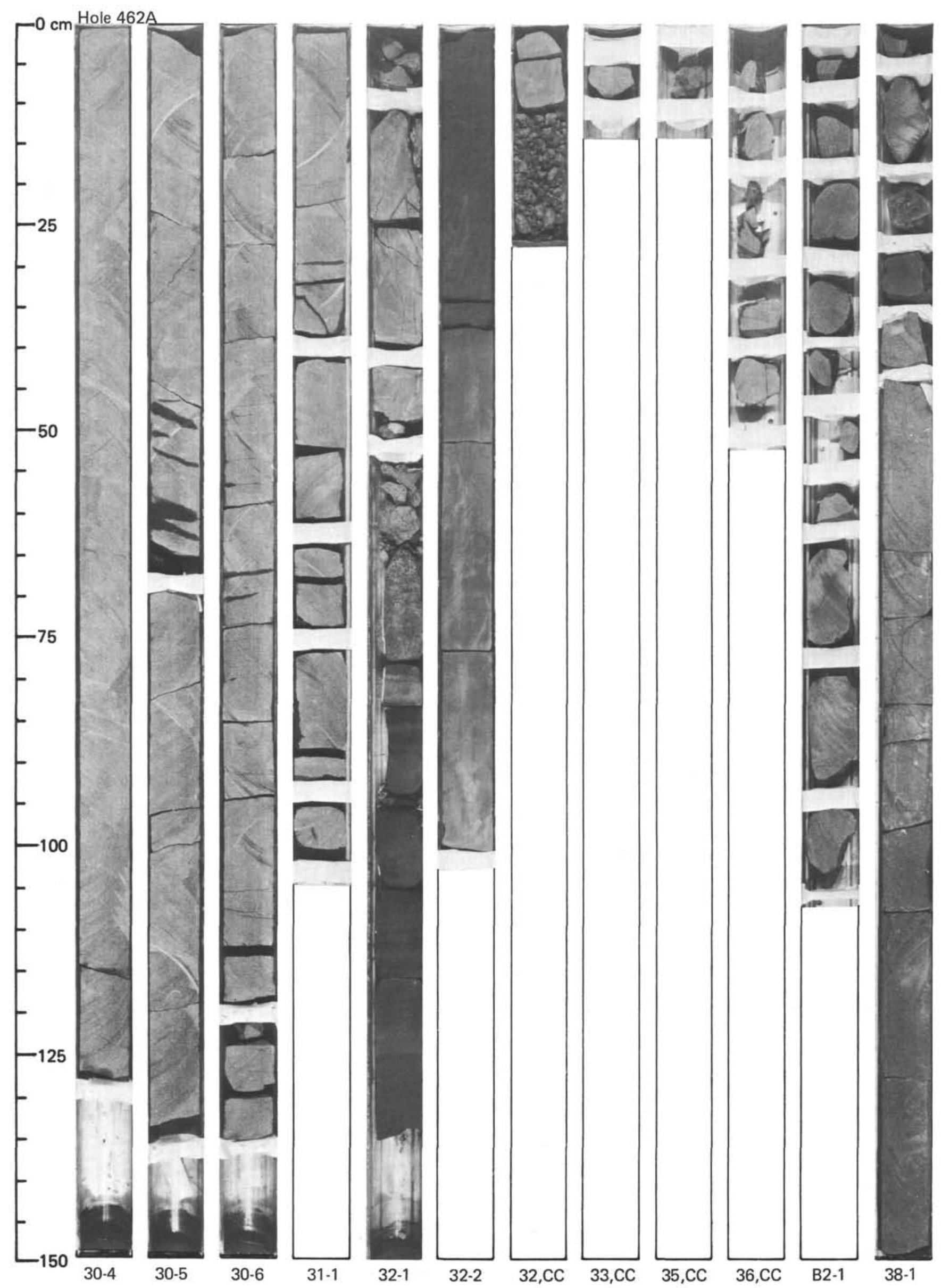




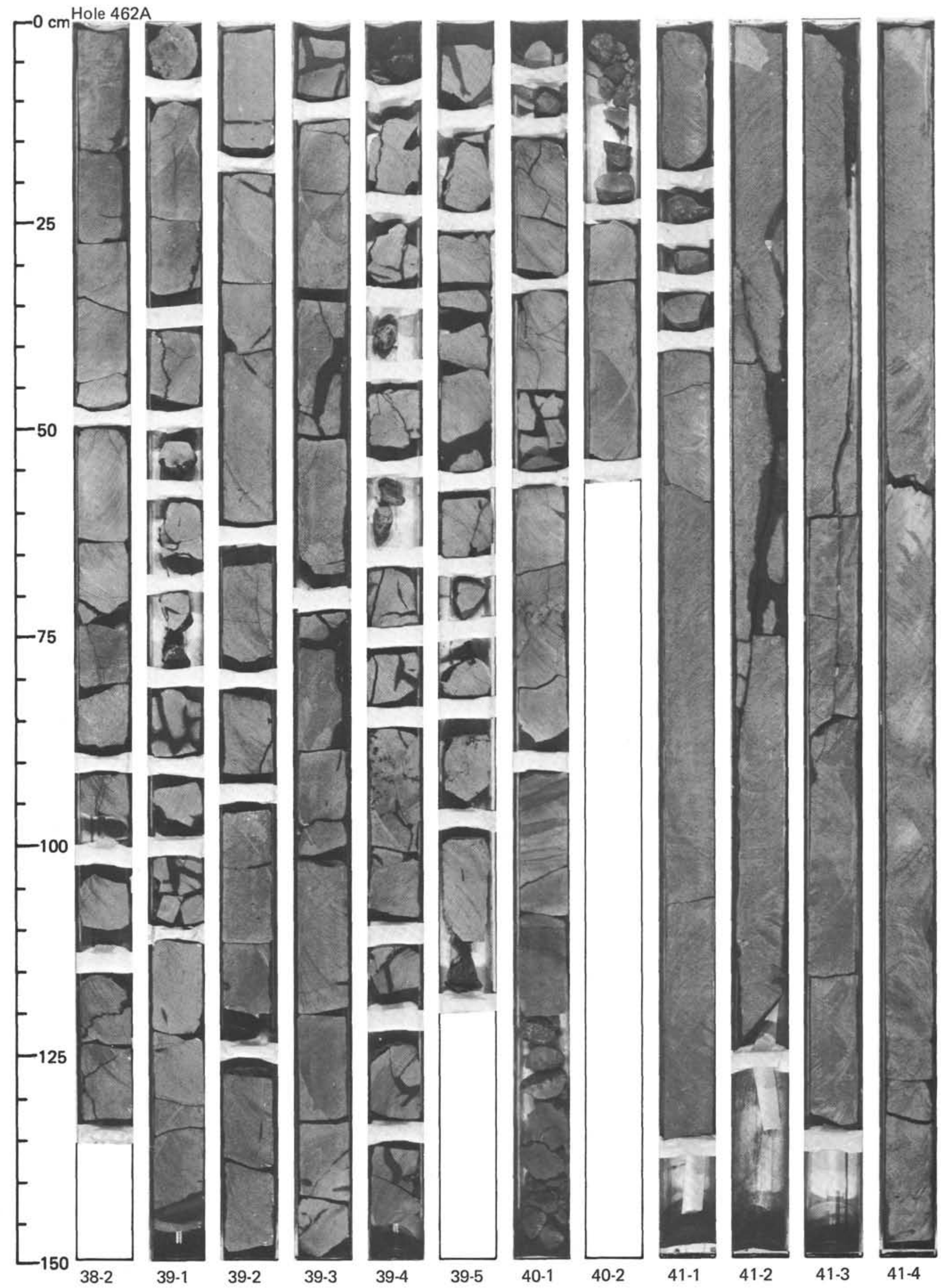




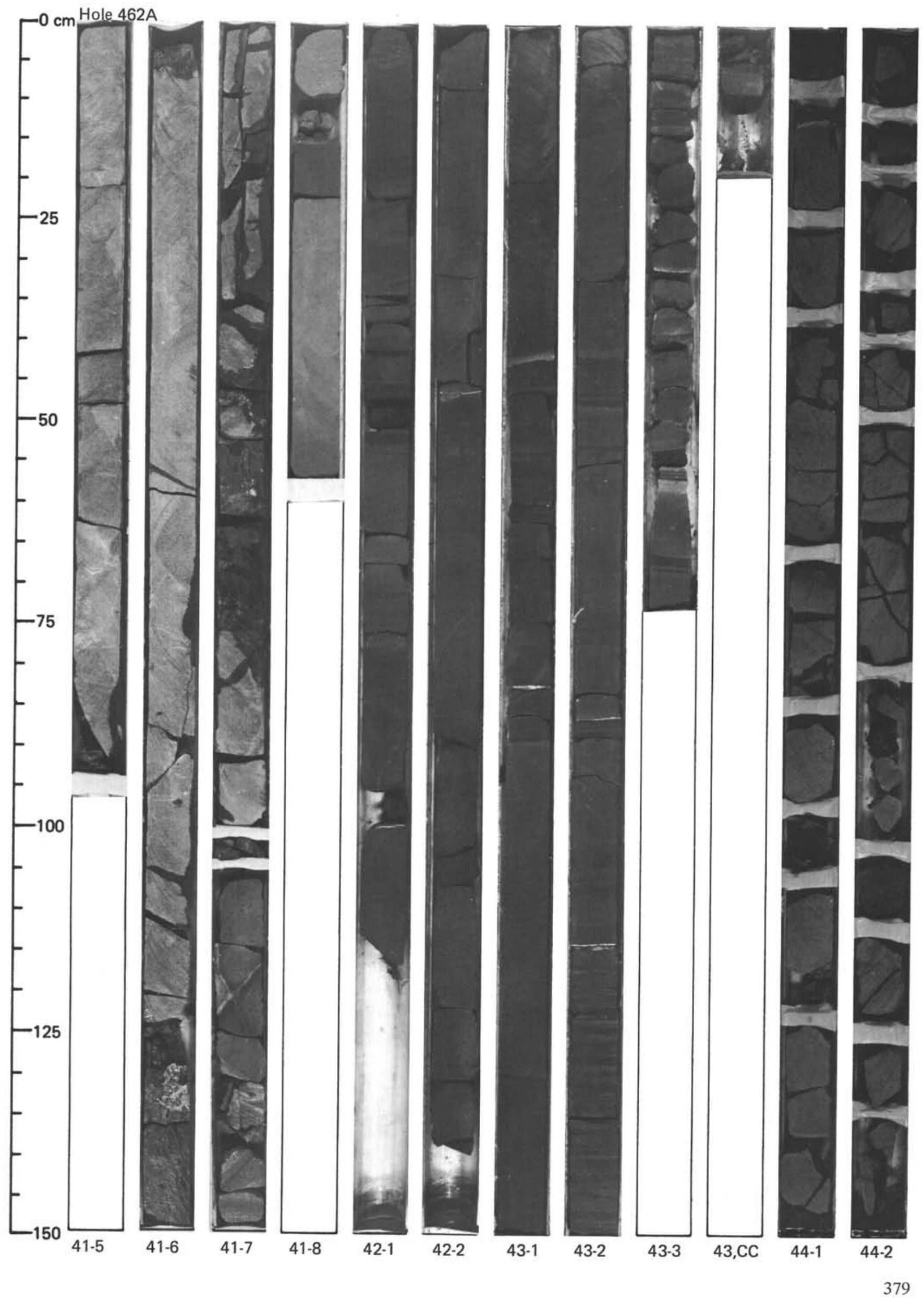


SITE 462

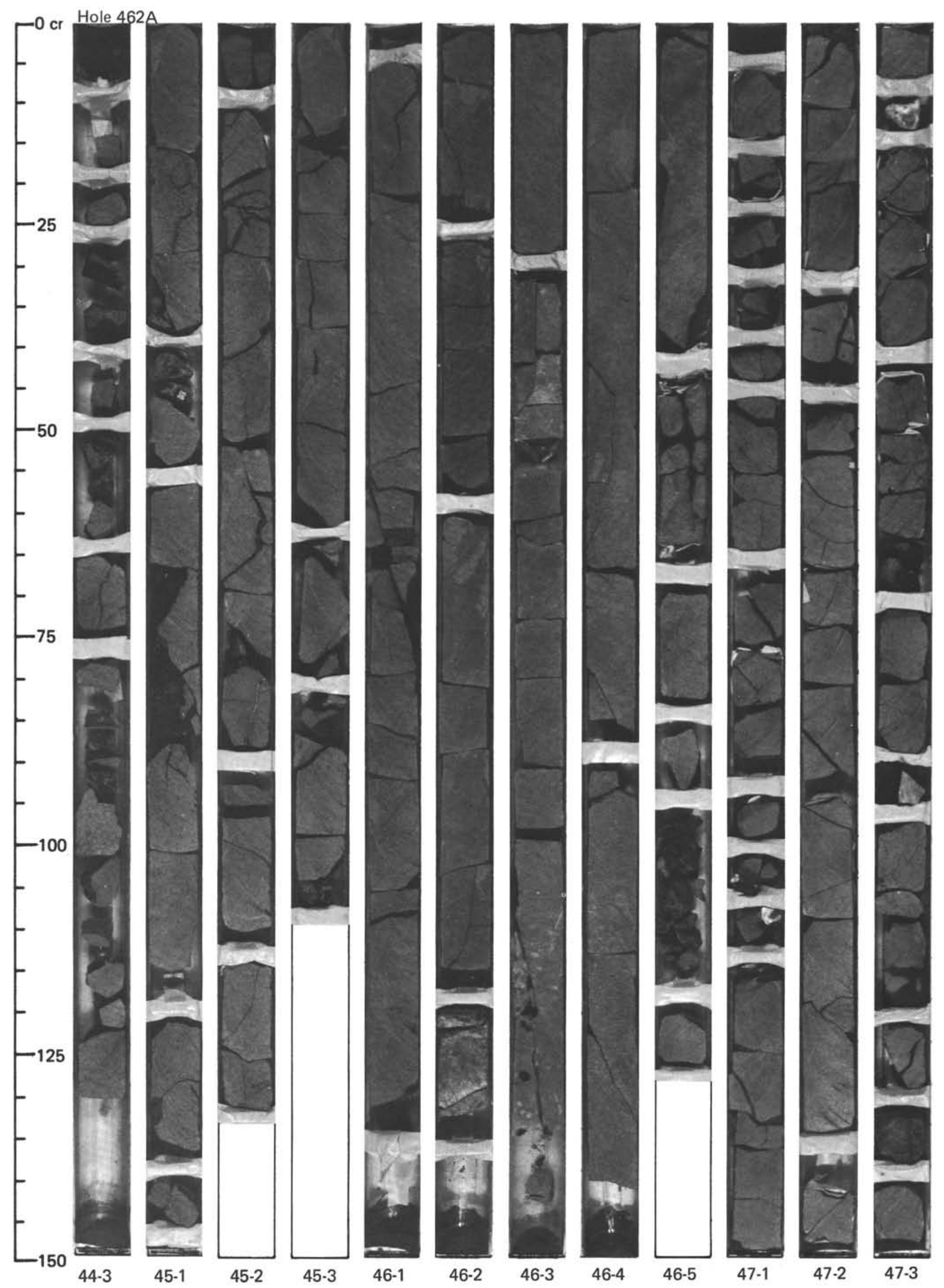




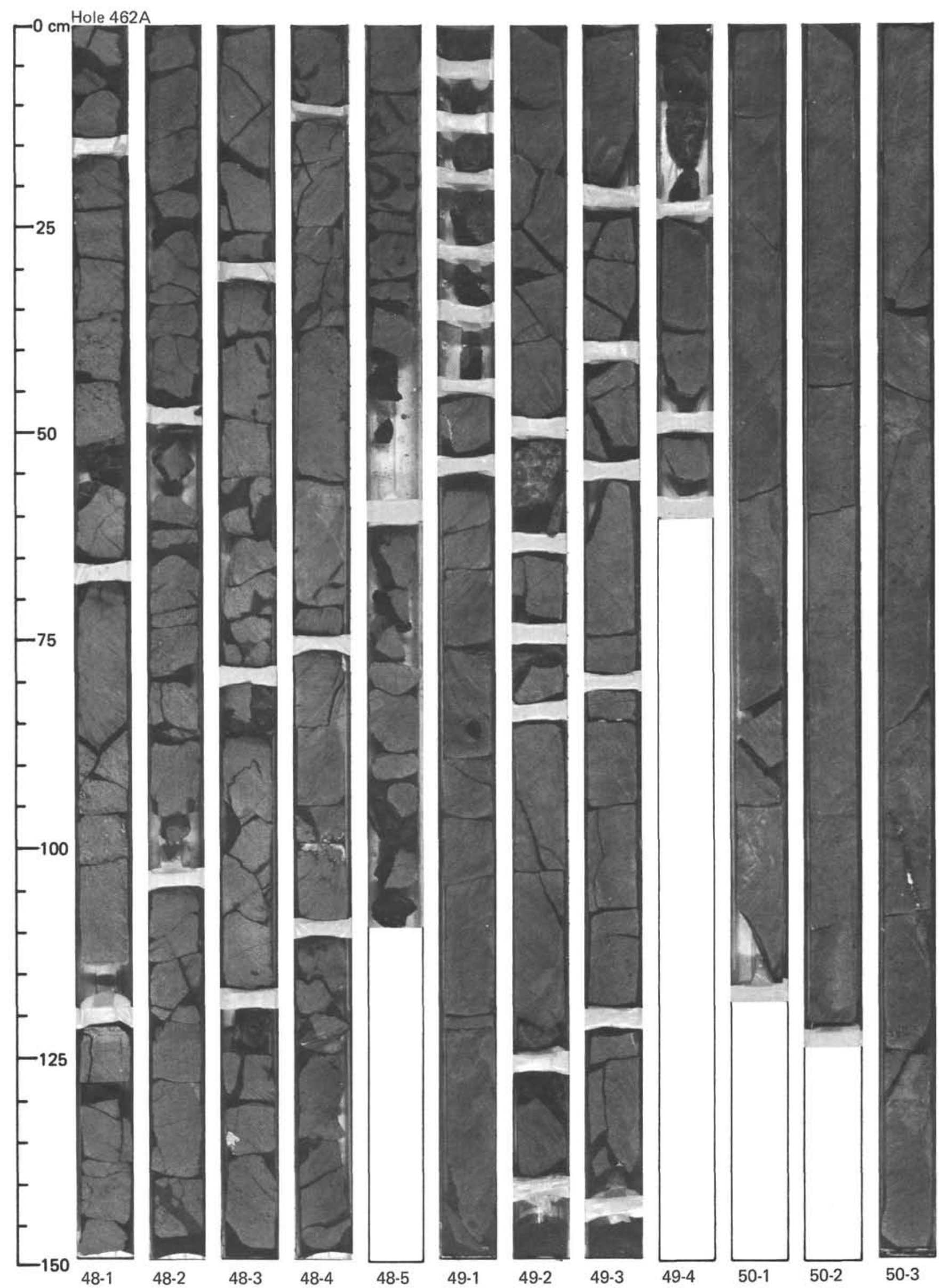




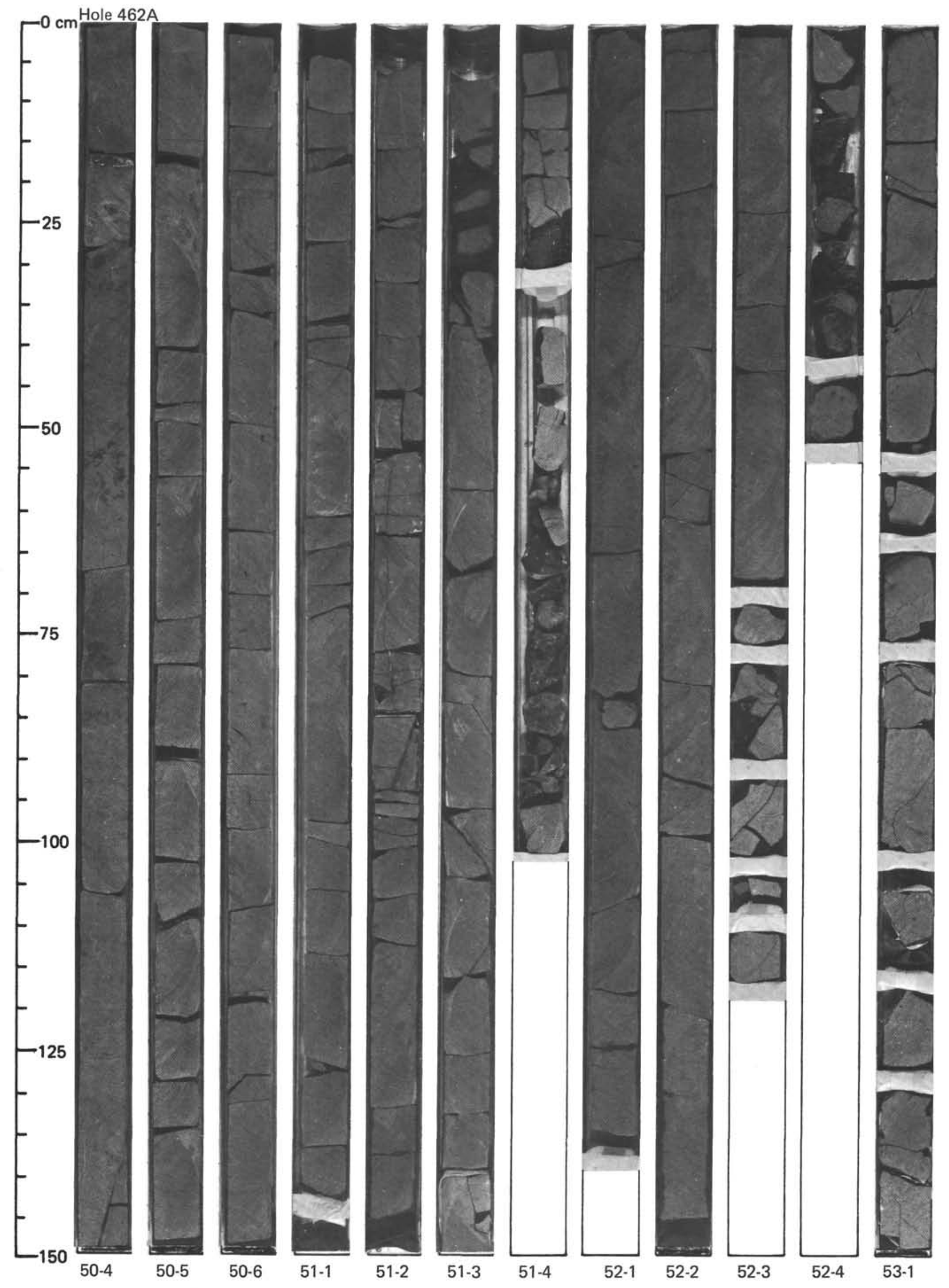



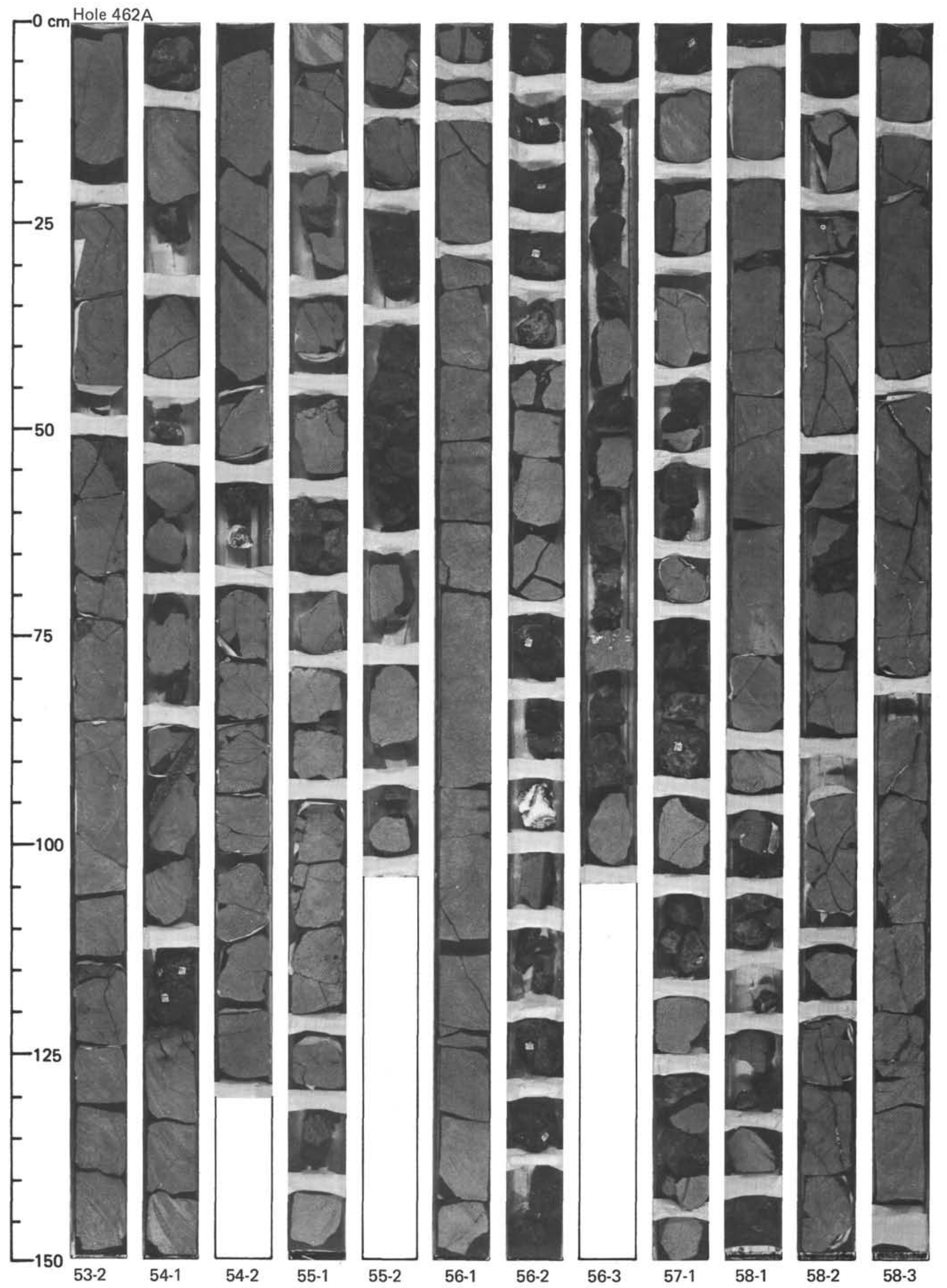


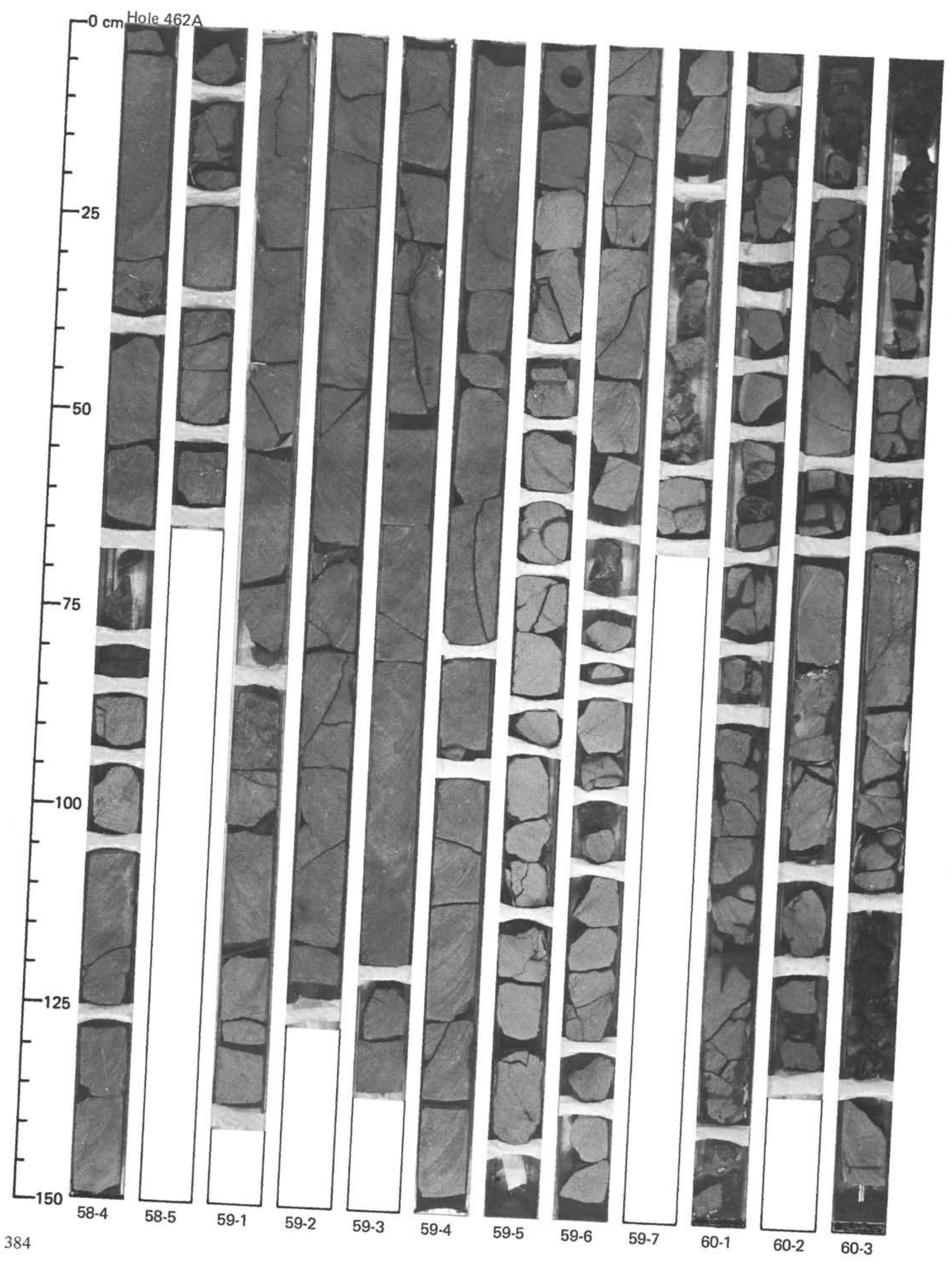




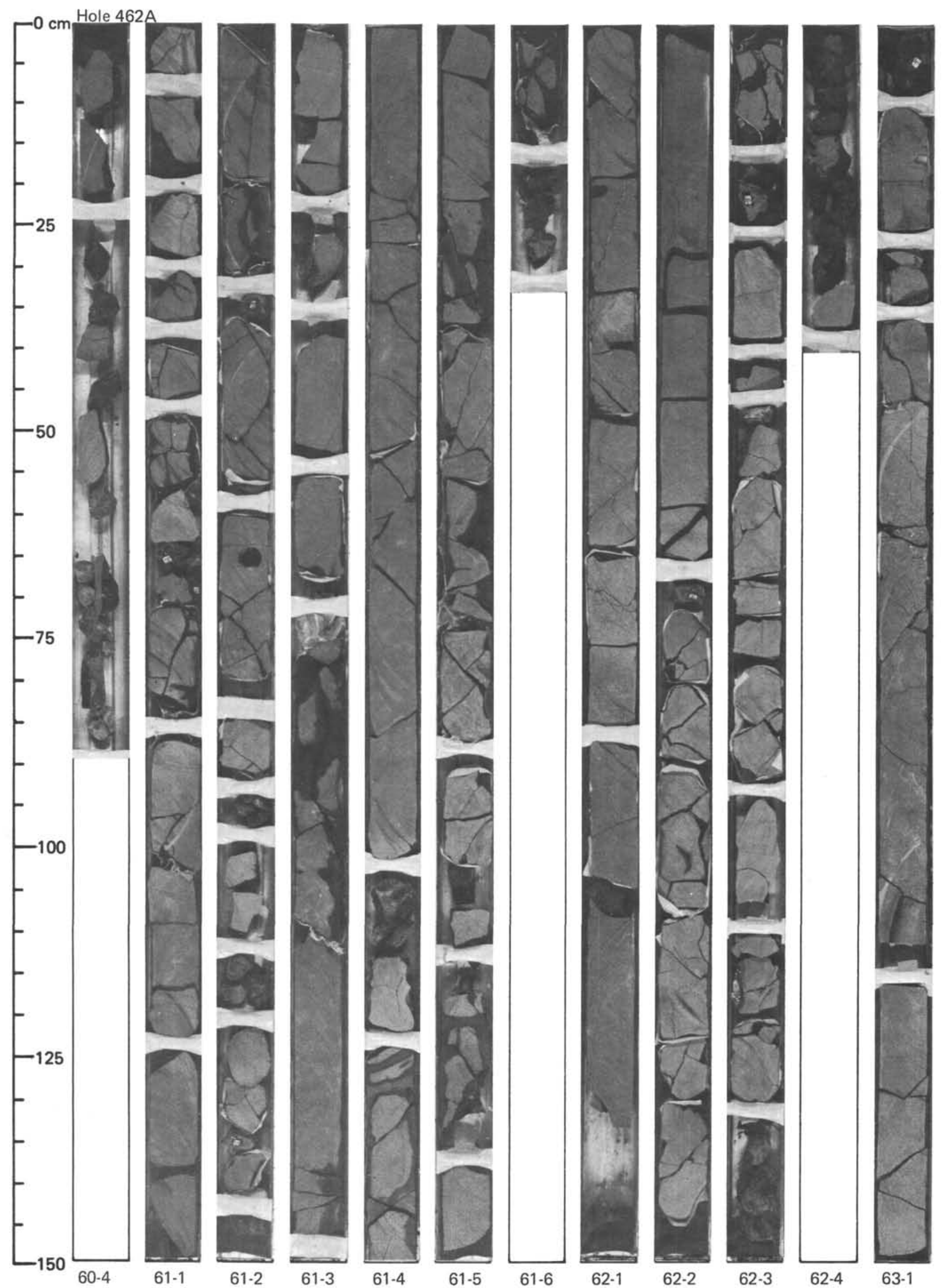




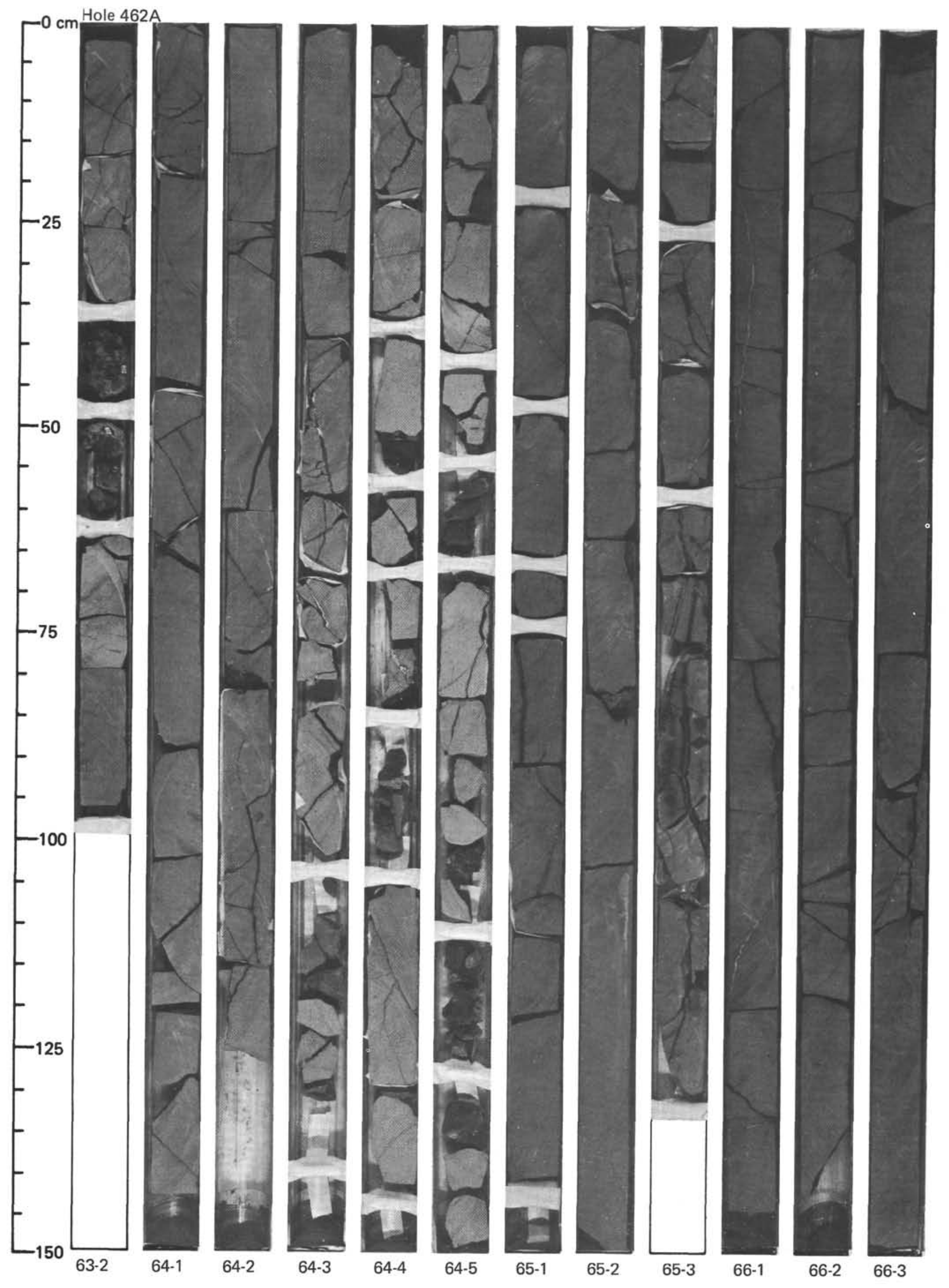




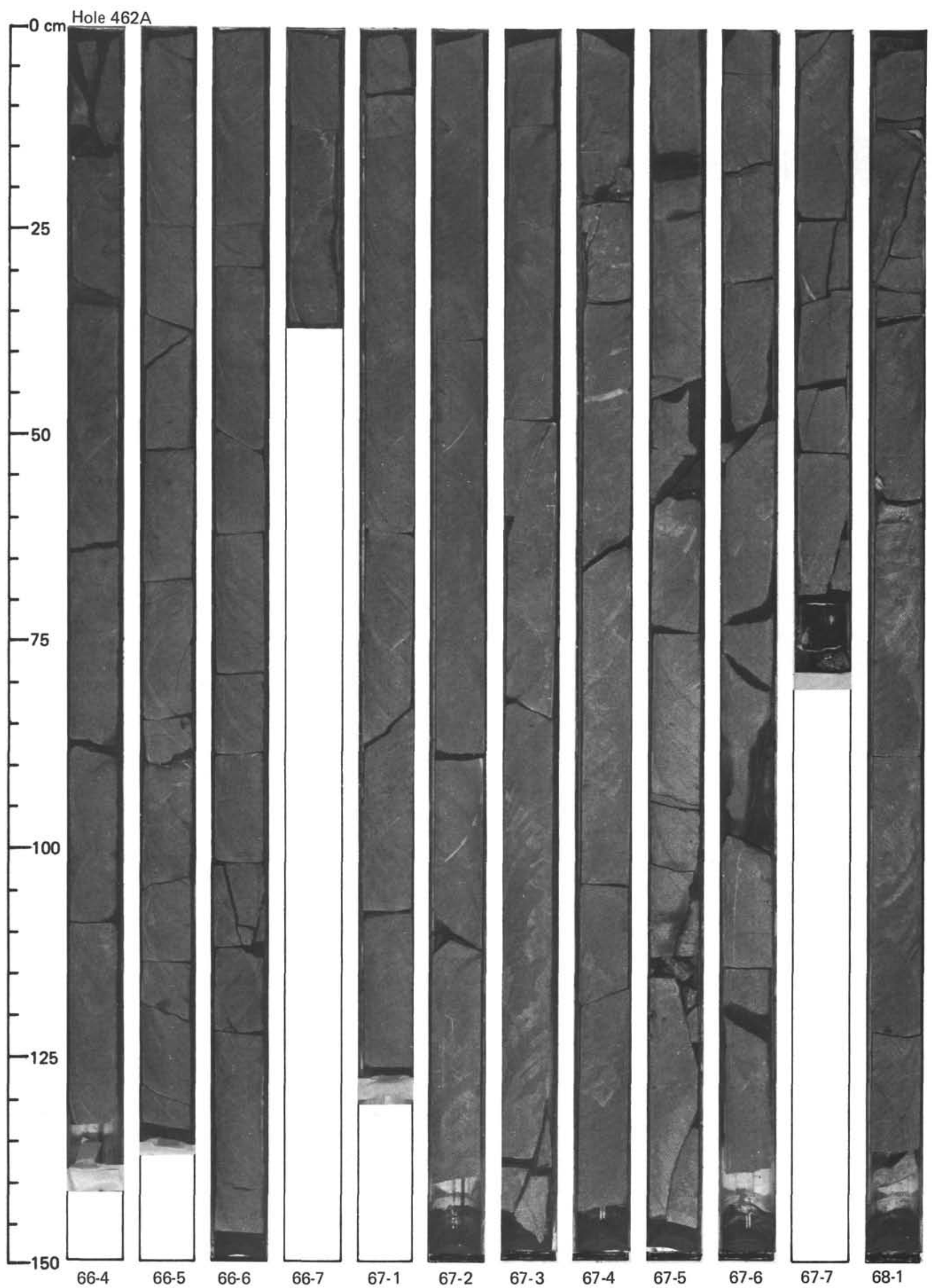




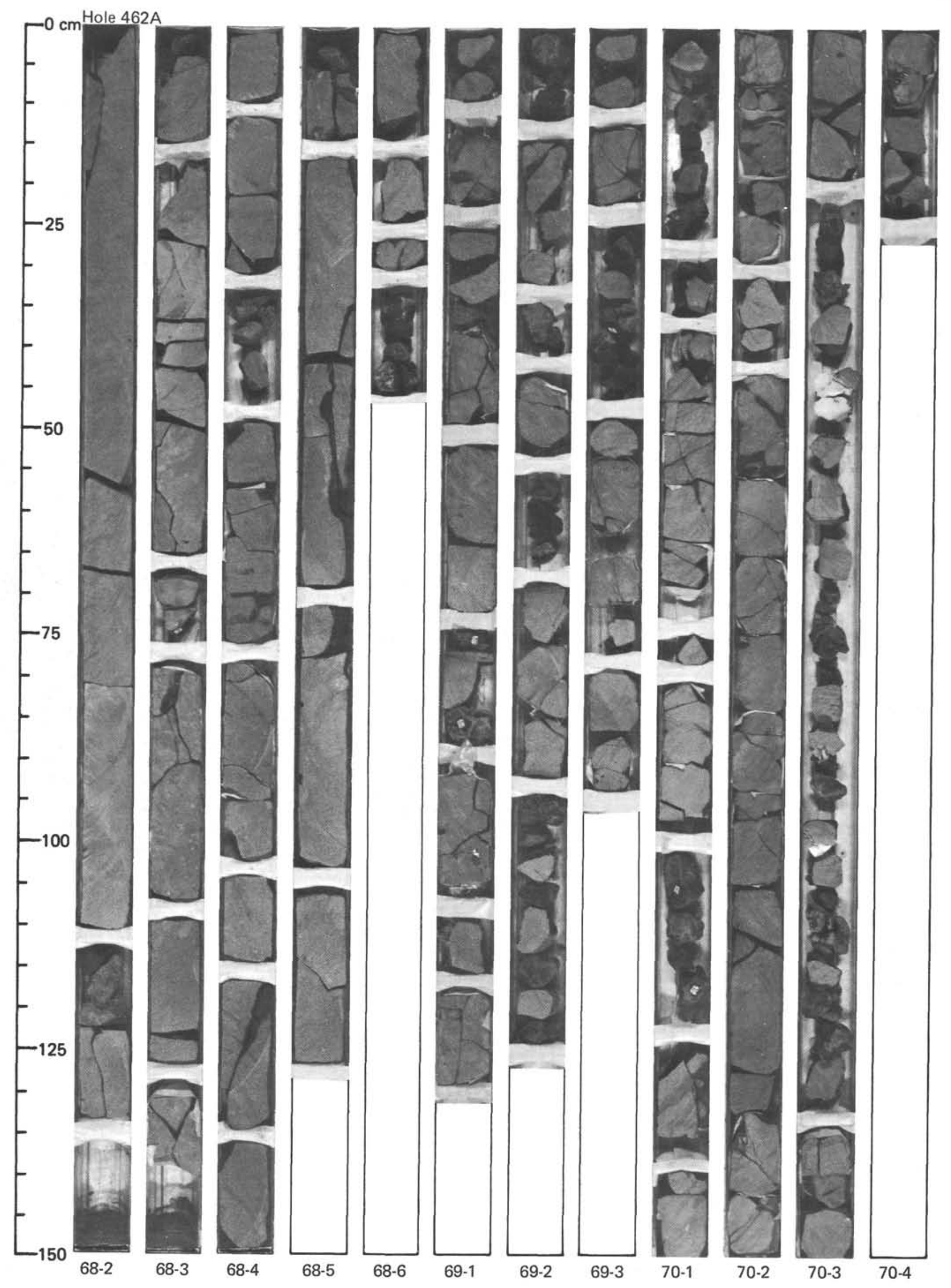



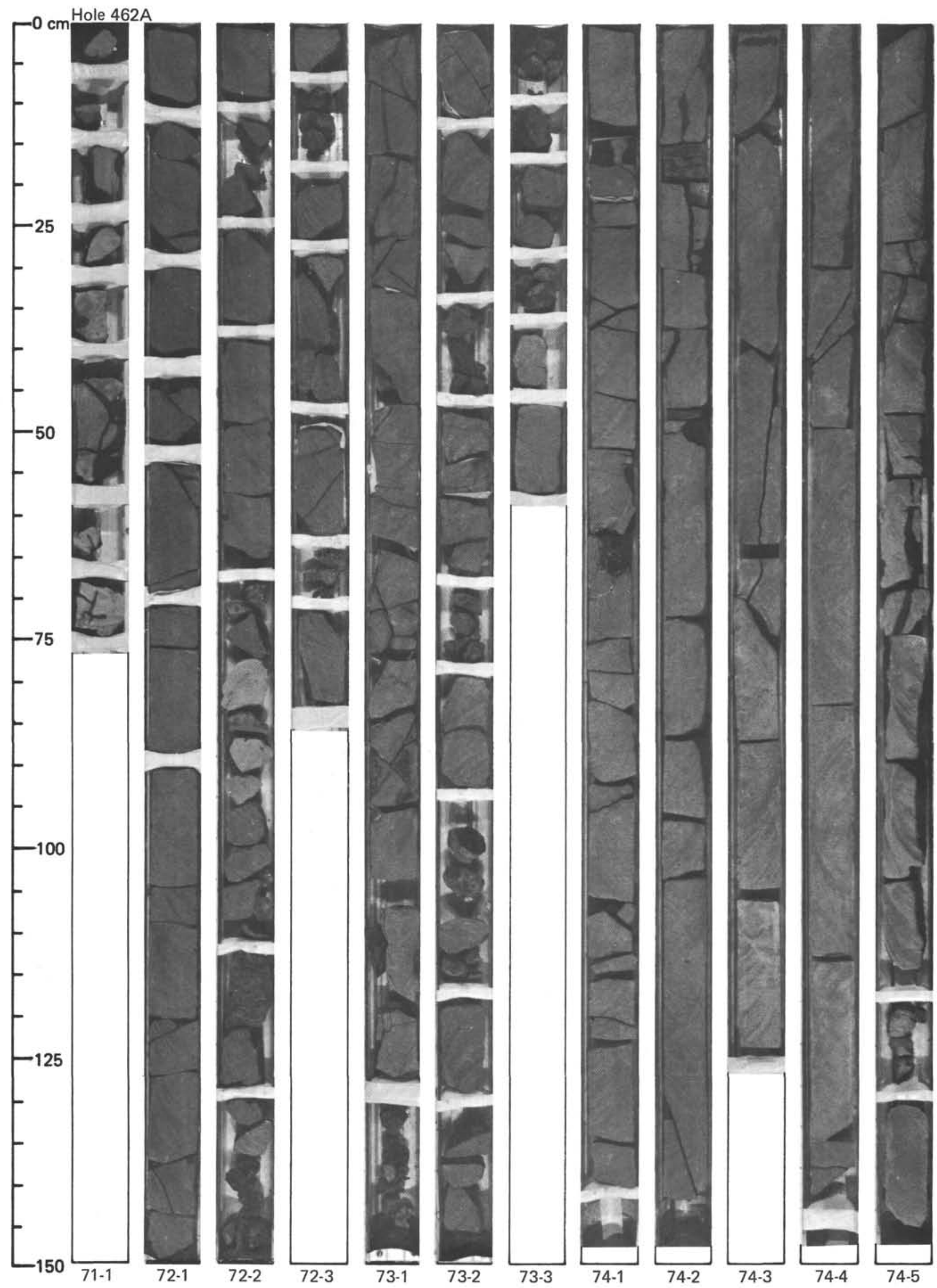


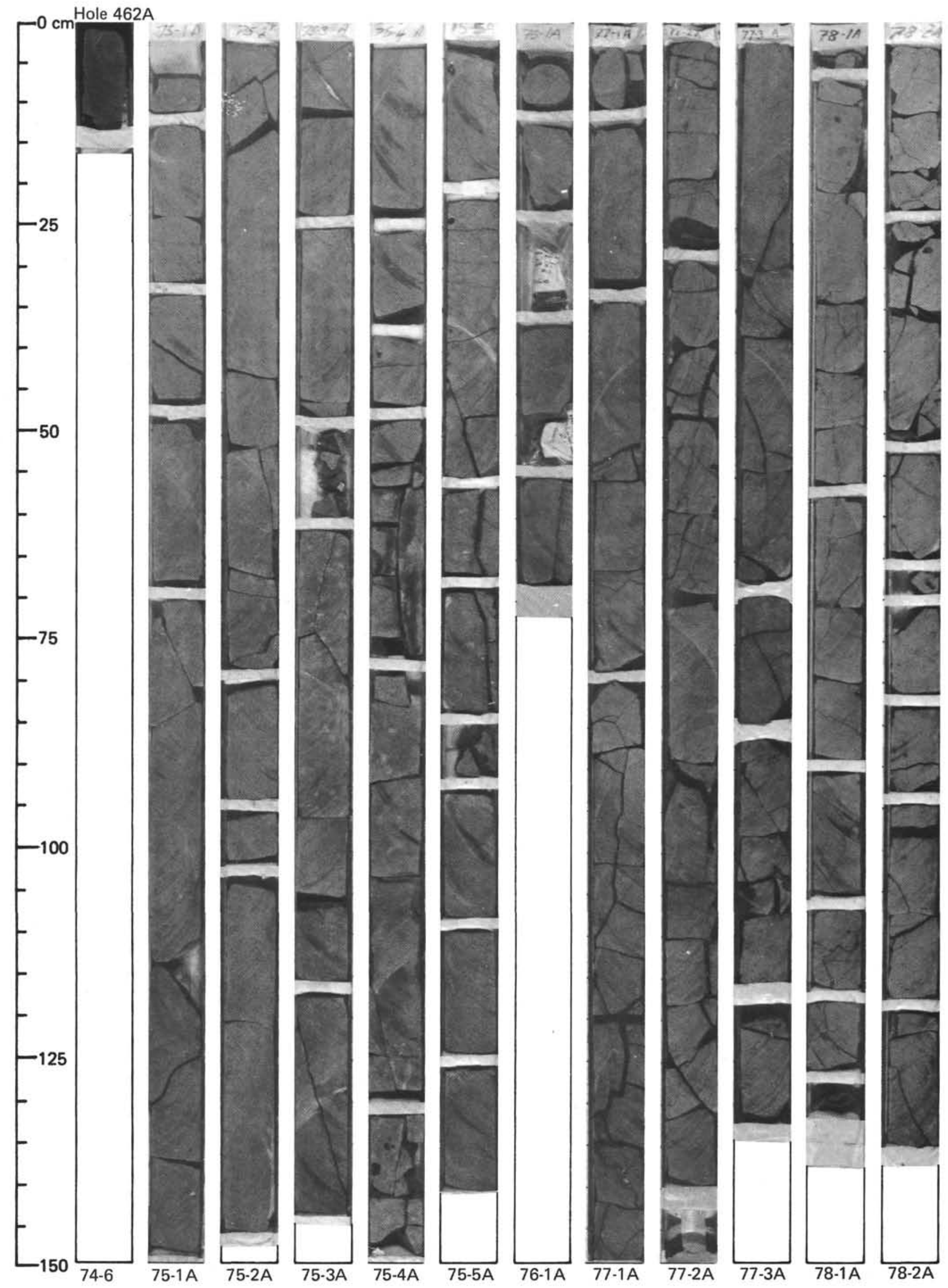


SITE 462

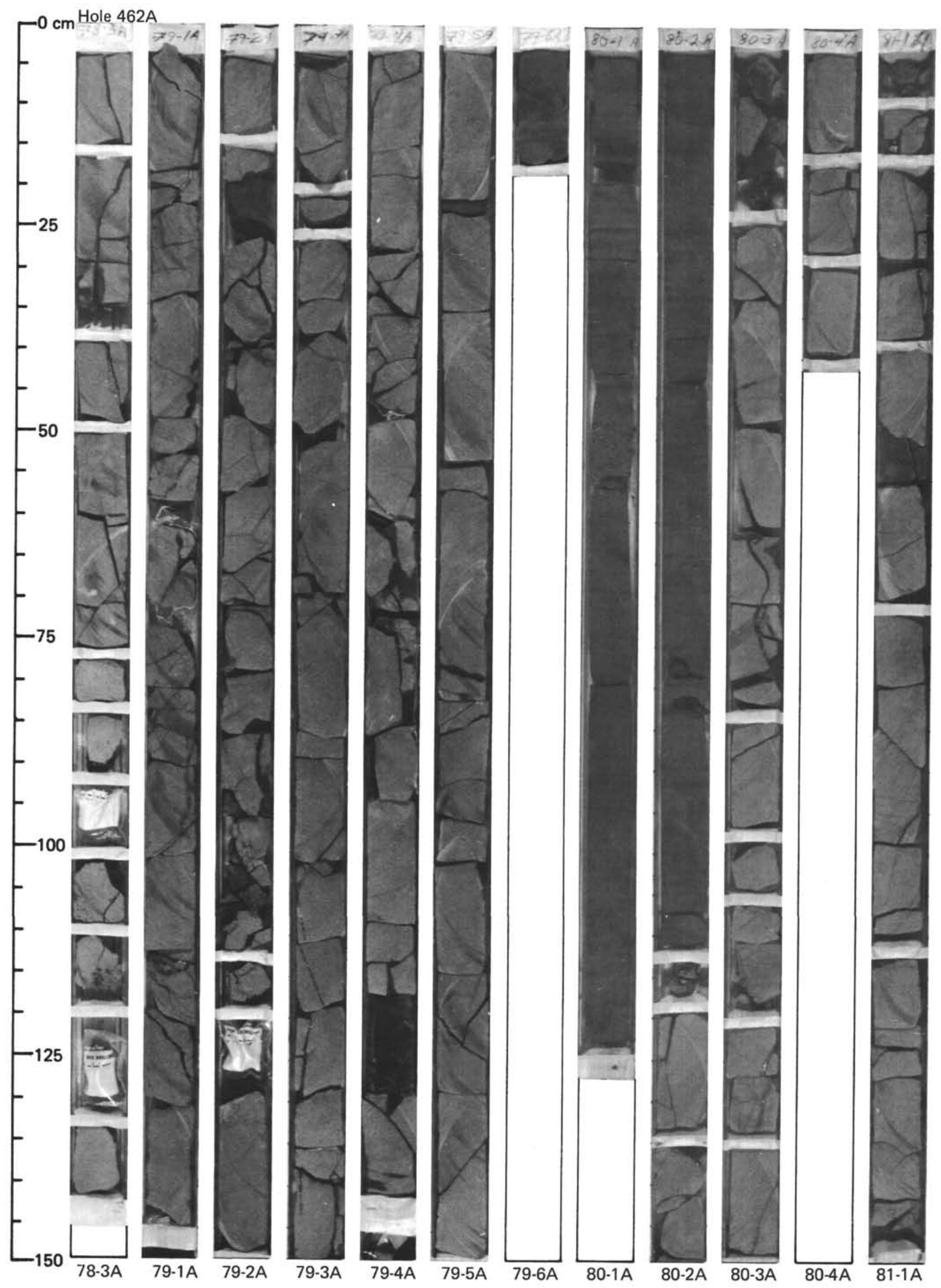




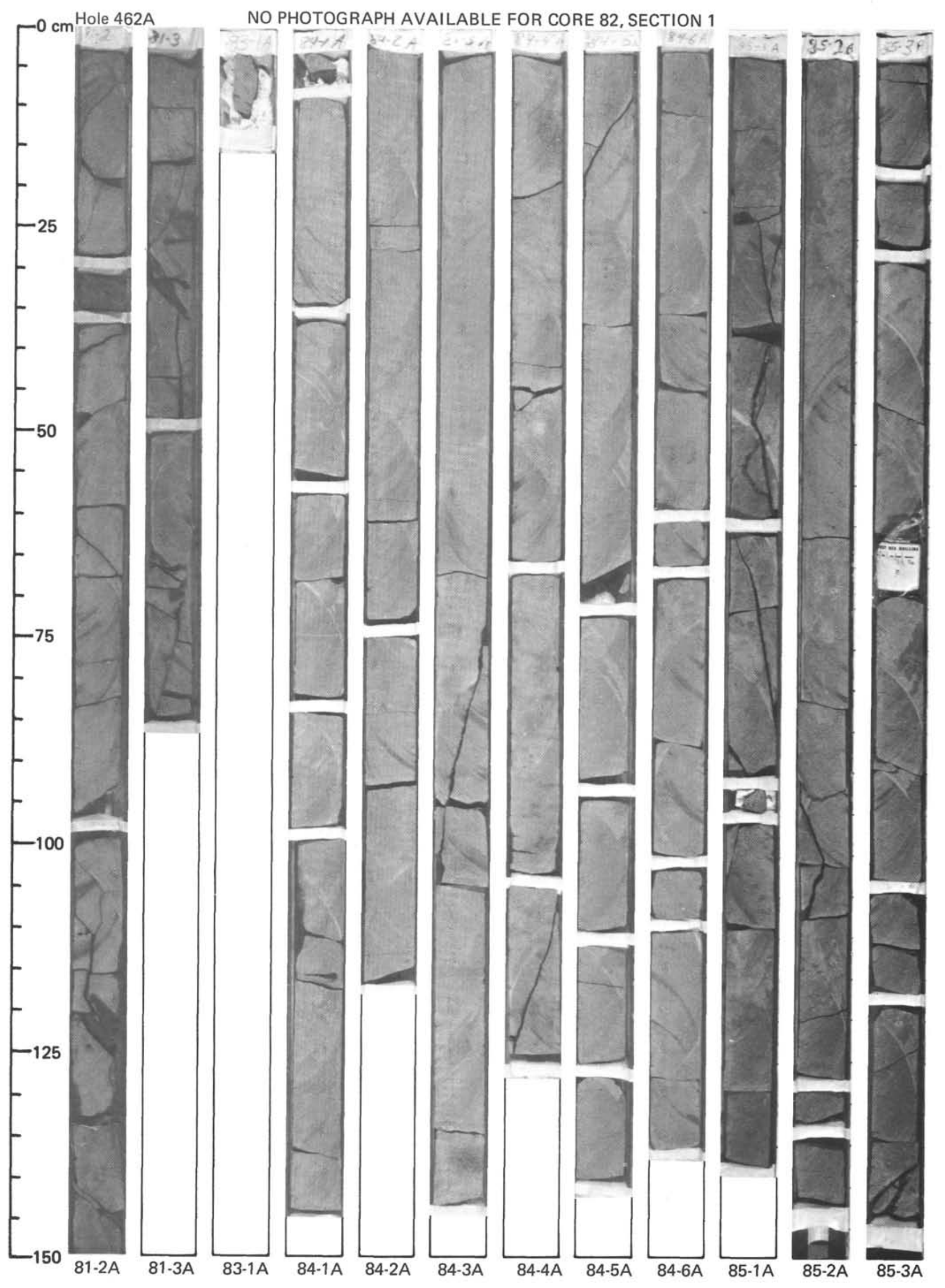




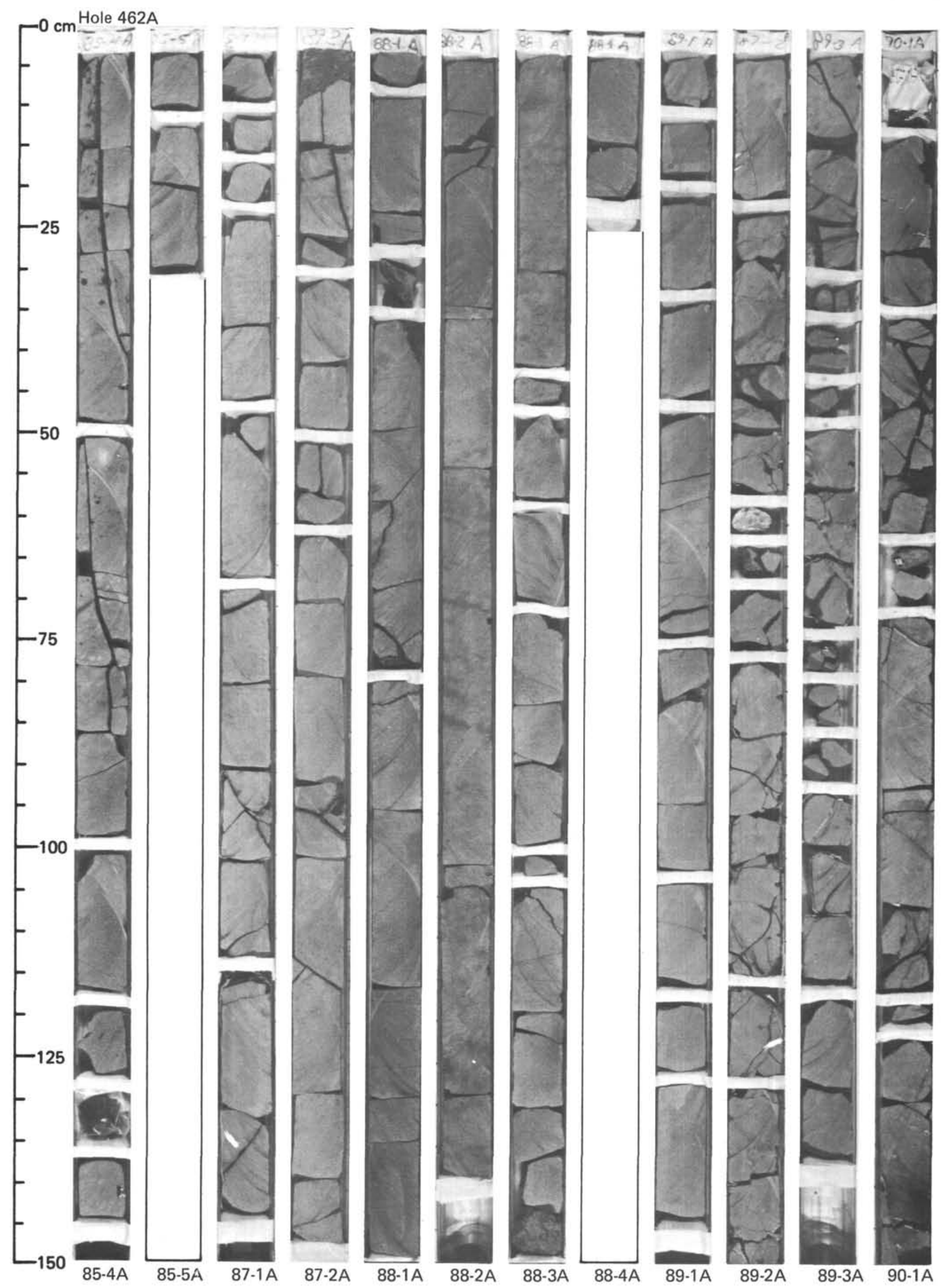




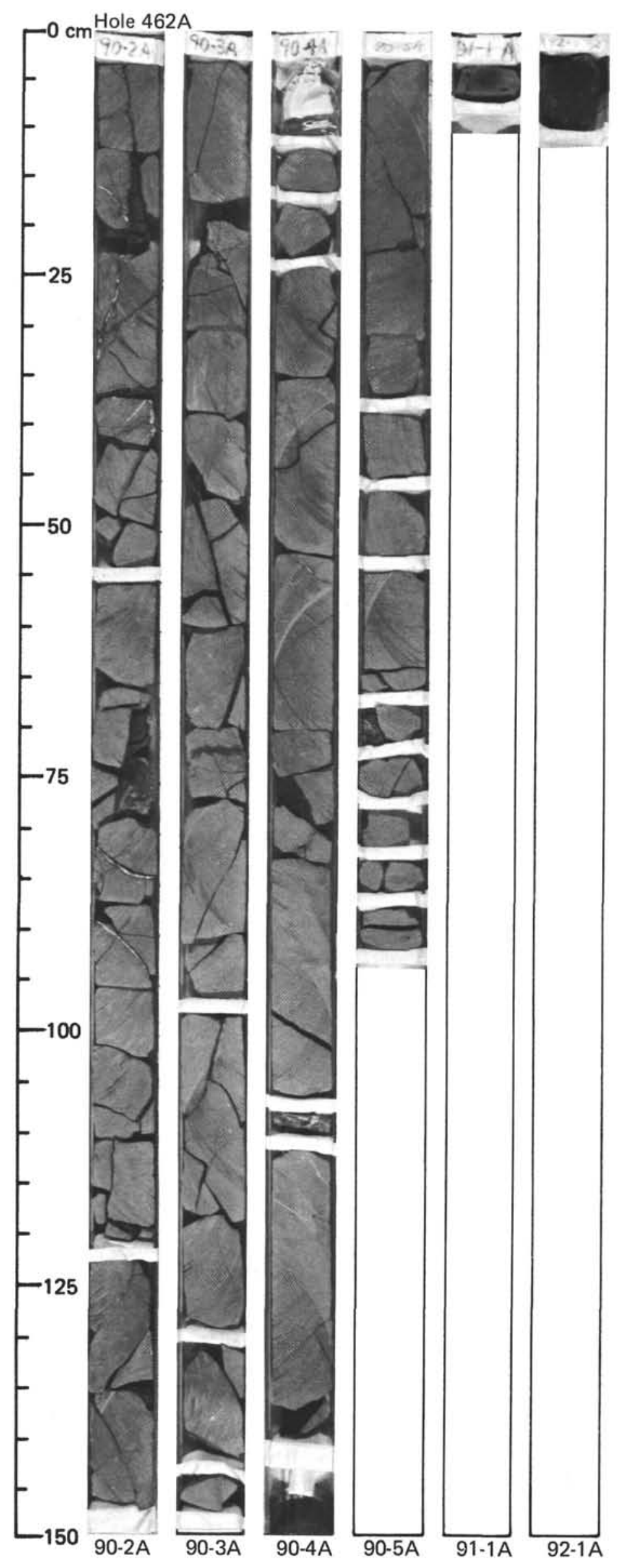

